\title{
Crystal specific constraints on subvolcanic processes preceding eruptions at Mt Taranaki, New Zealand
}

\author{
Sarah Alicia Martin
}

A thesis submitted in partial fulfilment of the requirements for the degree of Masters of Science with Honours in Geology, Victoria University of Wellington, August 2012 


\section{ABSTRACT}

Andesitic magmas are the product of a complex interplay of processes including fractional crystallisation, crystal accumulation, magma mixing and crustal assimilation. Recent studies have suggested that andesitic rocks are in many cases a complex mixture of a crystal cargo and melts with more silicic compositions than andesite. In situ glass- and mineral-specific geochemical techniques are therefore key to unravelling the processes and timescales over which andesitic magmas are produced, assembled and transported to the surface. To this end, this thesis presents a detailed in situ glass- and mineral-specific study of six Holocene eruptions (Kaupokonui, Maketawa, Inglewood a and b, and Korito) at Mt Taranaki to investigate the petrogenetic processes responsible for producing these sub-plinian eruptions at this long-lived (130 $000 \mathrm{yr}$ ) andesitic volcano. Mt Taranaki is an andesitic stratovolcano located on the west coast of New Zealand's North Island and as such it is distinct from the main subduction related volcanism. Crystal-specific major and trace element data were combined with textural analysis and quantitative modelling of intensive magmatic parameters and crystal residence times to identify distinct mineral populations and constrain the magmatic histories of the crystal populations.

Least-squares mixing modelling of glass and phenocryst compositions demonstrates that the andesitic compositions of bulk rock Mt Taranaki eruptives results from mixing of a daciticrhyolitic melt and a complex crystal cargo (plagioclase, pyroxene, amphibole) that crystallised from multiple melts under a wide range of crustal conditions. Magma mixing of compositionally similar end members that mix efficiently also occurred beneath Mt Taranaki, and as such only produced prominent disequilibrium textures in a small proportion of the minerals in the crystal cargo. The chemistry of the earliest crystallising amphibole indicates crystallisation from an andesitic-dacitic melt at depths of ca. 20-25 km, within the lower crust. Magmas then ascended through the crust relatively slowly via a complex magmatic plumbing system. However, most of the crystal cargo formed by decompression-driven crystallisation at depth so 6-10 km, as is indicated by the dominance of oscillatory zoning and the equilibrium obtained between mineral rims and the host glasses.

Taranaki magmas recharge on timescales of 1000-2000 yrs. The eruptions investigated here provide a snapshot of the end of one cycle and the beginning of another. The younger Kaupokonui and Maketawa eruptions (ca. 2890 - <1950 yr BP) are the least evolved magmas, record a stronger mixing signal in the crystal cargo, and are volumetrically smaller than the earlier Inglewood a and b and Korito eruptions (ca. 4150-3580 yr BP). The Kaupokonui and Maketawa eruptions may reflect arrival of a new pulse of magma from the lower crust, or that these are early eruptions within a recharge sequence, which have not had as much time to further differentiate and evolve as the earlier Inglewood a and $b$ and Korito eruptions that represent the end of a magma recharge cycle. One of the six investigated eruptions was identified to come from Fantham's Peak on the basis of its distinctive glass and mineral chemistry and petrology. Glass trace element data indicate that this eurption's magmatic system was distinct from that of the other main vent Holocene eruptions investigated in this study.

Crystal residence times were investigated using Fe-Mg interdiffusion in clinopyroxene and indicate that magma bodies stall in upper crustal storage chambers for timescales of a few months to years. The younger eruptions of the least evolved magmas with the strongest mixing signal return the shortest residence times, which may indicate that magma mixing events occurring a few months before eruption may have been the trigger for these eruptions at Mt Taranaki. Amphibole geospeedometry for these eruptives reveal rapid magma transport from depths of 6-10 km to the surface on timescales of $<1$ week. 


\section{ACKNOWLEDGEMENTS}

Firstly, thank you to my supervisor, Prof. Joel Baker for his time and patience throughout this thesis and for believing in me in the first place. Also thank you Dr. Marc-Alban Millet for being my unofficial secondary supervisor. Your encouragement and feedback were greatly appreciated, as well as your help in the lab.

Dan Morgan is thanked for his invaluable help with diffusion modelling and Kate Saunders for help at the beginning of this project.

The following people are thanked for their assistance during this project: Richard Wysoczanski, Sophie Barton, Alex McCoy-West and Nicole Semple for their help with fieldwork, I would have been lost and lonely without you; John Creech for his patience in setting up the EMPA techniques and answering my frantic messages even when he was off the clock; Stewart Bush for preparing thin sections; Monica Handler for help in the Geochemistry Lab; Colin Wilson, Brent Alloway, Julie Vry and Richard Wysoczanski for helpful conversations that got me thinking 'outside the box'; Colin Wilson, Alexa Van Eaton, Aidan Allan, Jess Orsman and Melissa Rotella for editing various parts of this thesis, which no doubt greatly improved its quality.

Thank you to my office mates over the years, Sophie, Chelsea, Kate, Chris, Melissa and Kirsty for the productive (and often unproductive) chats and encouragement and to Alexa, Julene and Netty, who have tried to keep me sane over the last few months. Your encouragements, distractions and the constant supply of sugar and coffee are very much appreciated.

To Jess, Sophie and Chelsea, it was a pleasure sharing this experience with you. Thank you for your friendship, the coffee breaks and sympathic ears. Also, Lucy who now knows far more geochemistry than any philosopher should.

A big thanks to everyone who offered feedback and support, particularly Simon, James, Aidan and Kylie.

To my parents, David and Anne and brothers, Matthew, Michael and Daniel, thank you for the moral and financial support. You will no longer have to feign interest in geochemical techniques and magmatic processes over dinner.

Finally, to George, I could not have done this without you. Your constant love and support has been what has kept me going through out this. 
Front matter

0.1 Title page i

0.2 Abstract ii

0.3 Acknowledgements iii

0.4 Table of contents iv

0.5 List of tables ix

0.6 List of figures $\quad \mathrm{X}$

Chapter 1 Introduction 1

1.1 Introduction 2

1.1.1 Andesite magmatism and implications for continental crust generation

1.1.2 Hazard assessment 3

1.2 Subduction zone magmatism 4

$\begin{array}{lll}1.3 & \text { Andesite petrogenesis } & 6\end{array}$

$\begin{array}{lll}1.4 & \text { Crystal forensics } & 9\end{array}$

$\begin{array}{ll}1.5 & \text { Constraining timescales of magmatic processes }\end{array}$

$\begin{array}{lll}1.6 & \text { Geological background } & 12\end{array}$

1.6.1 Regional tectonic setting $\quad 12$

1.6.2 Taupo Volcanic Zone 12

1.6.3 Taranaki setting $\quad 13$

1.6.3.1 Taranaki Basin 13

1.6.3.2 Miocene volcanism 14

1.6.3.3 Taranaki Volcanic Lineament $\quad 14$

$\begin{array}{ll}\text { 1.6.4 Mount Taranaki } & 16\end{array}$

1.6.4.1 History of Taranaki volcanism 16

1.6.4.2 Petrology 17

$\begin{array}{lll}1.7 & \text { Objectives and structure of this thesis } & 19\end{array}$

$\begin{array}{lll}\text { Chapter } 2 & \text { Fieldwork and Samples } & 22\end{array}$

$\begin{array}{llr}2.1 & \text { Fieldwork methods } & 23\end{array}$

$\begin{array}{llr}2.2 & \text { Site locations } & 24\end{array}$

2.2.1 Site 3 and 4 - Opunake Road 24

2.2.2 Site 5 - Opunake Road 24 
2.2.3 Site 6 - Pembroke Road 25

2.2.4 Site 7 - Pembroke Road 26

\subsection{Samples}

$\begin{array}{ll}\text { Chapter } 3 \text { Methods } & 30\end{array}$

3.1 Major element analysis 31

3.1.1 Sample preparation 31

3.1.2 Electron microprobe analyses 31

3.1.2.1 JEOL 733 Superprobe electron probe micro-analyser 32

3.1.2.2 JEOL JXA-8230 electron probe micro-analyser $\quad 32$

3.1.2.3 Comparison of EMPA data 35

$3.2 \quad$ Trace element analysis $\quad 39$

3.2.1 Glass trace element analysis $\quad 39$

3.2.1.1 Sample preparation $\quad 39$

3.2.1.2 Mass spectrometry $\quad 40$

3.2.2 Laser ablation ICP-MS mineral trace element analysis $\quad 45$

$\begin{array}{lll}3.3 & \text { Thermobarometry } & 49\end{array}$

3.3.1 Amphibole thermobarometry 49

3.3.1.1 Model $\quad 49$

3.3.1.2 Method 50

3.3.2 Clinopyroxene-melt thermometry 54

3.3.2.1 Model 54

3.3.2.2 Method 55

3.3.2.3 Equilibrium $\quad 57$

3.3.2.4 Other clinopyroxene thermometers 61

3.3.3 Plagioclase-melt thermometry 61

3.3.3.1 Model 61

3.3.3.2 Method 62

3.3.3.3 Equilibrium 62

3.3.3.4 Other plagioclase-melt thermometers 63

3.3.4 Comparison of results from different thermometers 65

\section{$\begin{array}{lll}3.4 & \text { Diffusion modelling } & 67\end{array}$}

3.4.1 Introduction to diffusion modelling theory 67

3.4.1.1 Diffusion in minerals $\quad 67$

3.4.1.2 Diffusion mechanisms $\quad 68$ 
3.4.1.3 Diffusion equations $\quad 69$

3.4.2 Fe-Mg interdiffusion in clinopyroxene $\quad 70$

3.4.2.1 Model parameters $\quad 70$

3.4.2.2 Model conditions $\quad 72$

3.4.3 Method 74

3.4.3.1 Minimum resolution of the model 78

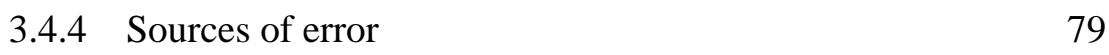

3.4.4.1 Diffusion coefficient $\quad 80$

3.4.4.2 Sectioning effects $\quad 81$

3.4.4.3 Image parameters $\quad 82$

Chapter 4 Results $\quad 84$

$\begin{array}{lll}4.1 & \text { Petrology } & 85\end{array}$

4.1.1 Plagioclase $\quad 85$

4.1.2 Clinopyroxene 88

4.1.2.1 Patchy cores and oscillatory rims $\quad 88$

4.1.2.2 Dark rim 90

$\begin{array}{lll}\text { 4.1.3 Amphibole } & 90\end{array}$

$\begin{array}{lll}\text { 4.1.4 } & \text { Fe-Ti oxides } & 92\end{array}$

4.1.5 Orthopyroxene 92

4.2 Major element chemistry 93

4.2.1 Glass major element chemistry 93

4.2.2 Melt inclusion major element chemistry 95

4.2.3 Mineral major element chemistry 95

4.2.3.1 Plagioclase $\quad 95$

4.2.3.2 Clinopyroxene $\quad 98$

4.2.3.3 Orthopyroxene 98

4.2.3.4 Amphibole 100

4.2.3.5 Fe-Ti oxides 100

$\begin{array}{lll}\text { 4. } 3 & \text { Trace element chemistry } & 103\end{array}$

4.3.1 Glass trace element chemistry 103

4.3.2 Mineral trace element chemistry 106

4.3.2.1 Plagioclase 106

4.3.2.2 Clinopyroxene 109

4.3.2.3 Amphibole 112

$\begin{array}{lll}4.4 & \text { Thermobarometry } & 115\end{array}$

$\begin{array}{lll}\text { 4.4.1 Thermometry } & 115\end{array}$ 
5.1.1 Comparison with published glass studies

5.1.2 Comparison with whole rock geochemistry

5.1.3 The relationship between glass and mineral phases

5.2.1.1 Patchy/sieved textured crystals

5.2.1.2 Oscillatory zoned crystals

5.2.1.3 Calculated plagioclase equilibrium melt

Compositions

5.2.2 Clinopyroxene 138

5.2.2.1 Clinopyroxene textures 139

5.2.2.2 Clinopyroxene chemistry 139

5.2.2.3 Inglewood a, Inglewood b and Korito processes 142

5.2.2.4 Kaupokonui, SM-6C and Maketawa processes 143

5.2.3 Amphibole 144

5.2.3.1 Physical conditions of amphibole crystallisation 145

5.2.3.2 Melt differentiation 151

5.2.3.3 Amphibole model 151

5.2.4 Fe-Ti oxides 152

5.2.4.1 SM-6C 154

5.2.5 Relationship between mineral phases $\quad 154$

5.2.5.1 Crystal cores 155

5.2.5.2 Zoning and rims 155

$\begin{array}{lll}5.3 & \text { Temporal variability } & 159\end{array}$

$\begin{array}{lll}5.4 & \text { Timescales of magmatic processes } & 163\end{array}$

5.4.1 Clinopyroxene residence times 163

5.4.1.1 Magma storage 163

5.4.1.2 Mixing 164

5.4.2 Comparisons with other studies 166

5.4.2.1 Previous work using Fe-Ti diffusion in oxides 168

5.4.3 Relationship between the older three samples 171

$\begin{array}{lll}5.5 & \text { Andesite petrogenesis at Mt Taranaki } & 172\end{array}$ 
Chapter 6 Conclusions and Future work

6.1 Conclusions

179

6.2 Suggestions for future work

180

References

182

Appendix 1 Sample List

A.2

Appendix 2 Major Element Data

A.4

Appendix 3 Trace Element Data

A.210

Appendix 4 Diffusion Modelling Images and Profiles

A.250 


\begin{tabular}{|c|c|c|}
\hline \multicolumn{3}{|c|}{ Chapter 1: Introduction } \\
\hline Table 1.1 & $\begin{array}{l}\text { Summary of the stratigraphic groups for Mt Taranaki lava and selected } \\
\text { tephra units }\end{array}$ & 17 \\
\hline \multicolumn{3}{|c|}{ Chapter 3: Methods } \\
\hline Table 3.1 & $\begin{array}{l}\text { JEOL } 733 \text { Superprobe Electron Probe Micro-Analyser standard data } \\
\text { precision and accuracy }\end{array}$ & 33 \\
\hline Table 3.2 & $\begin{array}{l}\text { Analytical conditions during analytical sessions with the JEOL JXA- } \\
8230 \text { EMPA. }\end{array}$ & 34 \\
\hline Table 3.3 & $\begin{array}{l}\text { JEOL JXA-8230 EMPA precision and accuracy of major element } \\
\text { mineral analyses }\end{array}$ & 36 \\
\hline Table 3.4 & ICP-MS instrumental and analysis conditions & 42 \\
\hline Table 3.5 & Precision and accuracy of solution ICP-MS data & 43 \\
\hline Table 3.6 & Reproducibility of duplicate samples analysed by solution ICP-MS & 44 \\
\hline Table 3.7 & $\begin{array}{l}\text { LA-ICP-MS instrumental and analytical conditions for in situ } \\
\text { clinopyroxene, amphibole and plagioclase trace element analyses }\end{array}$ & 47 \\
\hline Table 3.8 & $\begin{array}{l}\text { Precision and accuracy of LA-ICP-MS data based on multiple repeat } \\
\text { analyses of BHVO-2G }\end{array}$ & 48 \\
\hline Table 3.9 & Amphibole analyses used for thermobarometry & 52 \\
\hline Table 3.10 & $\begin{array}{l}\text { Temperature }\left({ }^{\circ} \mathrm{C}\right) \text { calculated using clinopyroxene-melt thermometry } \\
\text { using variable pressure and water content inputs. }\end{array}$ & 56 \\
\hline Table 3.11 & $\begin{array}{l}\text { Melt inclusion/glass and clinopyroxene pairs used for thermometry and } \\
\text { the associated results }\end{array}$ & 59 \\
\hline Table 3.12 & $\begin{array}{l}\text { Melt and plagioclase pairs used for thermometry and the associated } \\
\text { results }\end{array}$ & 64 \\
\hline Table 3.13 & Summary of mineral thermometry results & 66 \\
\hline \multicolumn{3}{|c|}{ Chapter 4: Results } \\
\hline Table 4.1 & $\begin{array}{l}\text { Summary of the petrographic variation observed within Taranaki eruptives investigated } \\
\text { in this study. Mineral proportions estimated visually under a petrographic microscope. }\end{array}$ & 85 \\
\hline \multicolumn{3}{|c|}{ Chapter 5: Discussion } \\
\hline Table 5.1 & Least squares mixing modelling results for selected samples. & 124 \\
\hline Table 5.2 & Plagioclase-melt partition coefficients used in this study. & 133 \\
\hline
\end{tabular}




\begin{tabular}{|l|l|l|}
\hline & & \\
\hline Table 5.3 & $\begin{array}{l}\text { The starting composition, partition coefficients }\left(\mathrm{k}_{\mathrm{D}}\right) \text { and the fractionating assemblage } \\
\text { used to model fractional crystallisation in this study. }\end{array}$ & 136 \\
\hline Table 5.4 & Clinopyroxene-melt (andesite to dacite) partition coefficients used in this study. & 142 \\
\hline Table 5.5 & Amphibole-melt (andesite-dacite) partition coefficients used in this study. & 151 \\
\hline Table 5.6 & Summary of previous studies applying diffusion modelling to volcanic systems & 167 \\
\hline
\end{tabular}

\section{List of Illustrations}

page

\begin{tabular}{|c|c|c|}
\hline \multicolumn{3}{|c|}{ Chapter 1: Introduction } \\
\hline Figure 1.1 & Schematic cross section of a subduction zone & 4 \\
\hline Figure 1.2 & Primitive mantle normalised multi-element diagram & 6 \\
\hline Figure 1.3 & Map illustrating the distribution of selected North Island Miocene-Present volcanism & 15 \\
\hline Figure 1.4 & N-MORB normalised multi-element diagram of selected Taranaki lavas & 18 \\
\hline \multicolumn{3}{|c|}{ Chapter 2: Fieldwork and Samples } \\
\hline Figure 2.1 & Map of the field area for this study showing sample locations & 24 \\
\hline Figure 2.2 & Annotated photograph of Site 6 with sampled tephra units identified & 25 \\
\hline Figure 2.3 & Annotated photograph of Site 7 with sampled tephra units identified & 27 \\
\hline Figure 2.4 & Stratigraphic locations of the samples investigated in this study & 29 \\
\hline \multicolumn{3}{|c|}{ Chapter 3: Methods } \\
\hline Figure 3.1 & $\begin{array}{l}\text { Comparison between the JEOL } 733 \text { Superprobe and JEOL JXA-8230 Electron Probe } \\
\text { Micro-Analysers }\end{array}$ & 39 \\
\hline Figure 3.2 & Comparison of two clinopyroxene-liquid barometers from Putirka (2008) & 56 \\
\hline Figure 3.3 & $\begin{array}{l}\text { Predicted clinopyroxene components based on the melt composition vs the observed } \\
\text { clinopyroxene components }\end{array}$ & 58 \\
\hline Figure 3.4 & $\begin{array}{l}\text { Schematic representation of the history of a crystal and how diffusion modelling of } \\
\text { crystal zoning represents magmatic events }\end{array}$ & 68 \\
\hline Figure 3.5 & $\begin{array}{l}\text { Schematic representation of the different types of diffusion mechanisms in minerals. } \\
\text { Figure taken from Watson \& Baxter (2007). }\end{array}$ & 69 \\
\hline Figure 3.6 & Nature of an erf curve and how it can be used for diffusion modelling & 71 \\
\hline Figure 3.7 & Examples of how diffusion profiles are obtained from BSE images. & 75 \\
\hline Figure 3.8 & Graphs illustrating the relationship between greyscale and selected major elements & 77 \\
\hline Figure 3.9 & $\begin{array}{l}\text { Graph illustrating the power function relationship between magnification of BSE image } \\
\text { and minimum temporal resolution of the diffusion model as determined by EQ } 3.20\end{array}$ & 79 \\
\hline Figure 3.10 & $\begin{array}{l}\text { Schematic representation of the effect of oblique sectioning on the 2-dimensional view } \\
\text { of the crystal. }\end{array}$ & 82 \\
\hline
\end{tabular}




\begin{tabular}{|c|c|c|}
\hline Figure 3.11 & $\begin{array}{l}\text { Calculated diffusion ages on the same zone in the same crystal using variable image } \\
\text { parameters }\end{array}$ & 83 \\
\hline \multicolumn{3}{|c|}{ Chapter 4: Results } \\
\hline Figure 4.1 & Backscattered electron images of representative plagioclase crystals & 86 \\
\hline Figure 4.2 & Backscattered electron images of representative clinopyroxene crystals. & 89 \\
\hline Figure 4.3 & Backscattered electron images of representative amphibole crystals. & 91 \\
\hline Figure 4.4 & Backscattered electron images of titanomagnetite & 92 \\
\hline Figure 4.5 & Backscattered electron images of orthopyroxene crystals. & 93 \\
\hline Figure 4.6 & Major element glass analyses & 94 \\
\hline Figure 4.7 & Total alkali-silica diagram of glass and melt inclusion data & 96 \\
\hline Figure 4.8 & Histograms of plagioclase anorthite content & 97 \\
\hline Figure 4.9 & Histograms of clinopyroxene Mg\# & 99 \\
\hline Figure 4.10 & Histograms of amphibole $\mathrm{Mg} \#$ and $\mathrm{Al}_{2} \mathrm{O}_{3}$ & 101 \\
\hline Figure 4.11 & Bivariate diagrams of Fe-Ti oxide major element chemistry & 102 \\
\hline Figure 4.12 & Representative glass trace element data plotted versus $\mathrm{SiO}_{2}$ & 104 \\
\hline Figure 4.13 & REE and multi-element diagrams of glass trace element chemistry & 105 \\
\hline Figure 4.14 & Selected trace elements versus anorthite content of plagioclase & 107 \\
\hline Figure 4.15 & Multi-element diagrams of plagioclase trace element chemistry & 108 \\
\hline Figure 4.16 & Selected trace elements versus Mg\# of clinopyroxene & 110 \\
\hline Figure 4.17 & Multi-element diagrams of clinopyroxene trace element chemistry & 111 \\
\hline Figure 4.18 & Selected trace elements plotted versus Mg\# of amphibole & 113 \\
\hline Figure 4.19 & Multi-element diagrams of amphibole trace element chemistry & 114 \\
\hline Figure 4.20 & Summary of thermobarometry models & 115 \\
\hline Figure 4.21 & Amphibole thermobarometry results & 117 \\
\hline Figure 4.22 & Amphibole hygrometry results & 118 \\
\hline Figure 4.23 & Amphibole oxybarometry results & 119 \\
\hline \multicolumn{3}{|c|}{ Chapter 5: Discussion } \\
\hline Figure 5.1 & $\begin{array}{l}\text { Comparison of glass data from this study and selected published data using selected } \\
\text { major elements. }\end{array}$ & 122 \\
\hline Figure 5.2 & $\begin{array}{l}\text { Total alkalis-silica plot of Taranaki eruptives. Whole rock data as compared with glass } \\
\text { data from this study. }\end{array}$ & 123 \\
\hline Figure 5.3 & Examples of plagioclase crystals with sieved/patchy core and mantle from Kaupokonui & 130 \\
\hline
\end{tabular}




\begin{tabular}{|c|c|c|}
\hline Figure 5.4 & $\begin{array}{l}\text { An example of a plagioclase transect showing the anti-correlation between } \mathrm{MgO} \text { and } \\
\text { anorthite content indicating that the } \mathrm{Sr} \text { and } \mathrm{Ba} \text { trace element composition of plagioclase } \\
\text { crystals have not been modified by diffusion. }\end{array}$ & 134 \\
\hline Figure 5.5 & Trace element concentrations of plagioclase equilibrium melt. & 137 \\
\hline Figure 5.6 & $\begin{array}{l}\mathrm{Mg} \# \text { vs } \mathrm{Al}_{2} \mathrm{O}_{3} \text { content of clinopyroxene cores, rims and zoning in each of the samples } \\
\text { investigated in this study. }\end{array}$ & 140 \\
\hline Figure 5.7 & $\mathrm{Mg} \#$ and $\mathrm{Al}_{2} \mathrm{O}_{3}$ plotted against a representative trace element (Sc) & 141 \\
\hline Figure 5.8 & $\begin{array}{l}\text { Selected trace element ratios vs Ce of melt various zones within clinopyroxene } \\
\text { crystallised from. }\end{array}$ & 143 \\
\hline Figure 5.9 & $\begin{array}{l}\text { Graphs of amphibole crystallisation pressure versus Ce and } \mathrm{Sr} \text { concentrations of the melt } \\
\text { in equilibrium with the amphibole. }\end{array}$ & 146 \\
\hline Figure 5.10 & Amphibole thermobarometry & 148 \\
\hline Figure 5.11 & Selected trace elements concentrations of amphibole equilibrium melt. & 150 \\
\hline Figure 5.12 & Selected major element chemistry of Fe-Ti oxides. & 153 \\
\hline Figure 5.13 & $\begin{array}{l}\text { Trace element concentrations of melt in equilibrium with the plagioclase, clinopyroxene } \\
\text { and amphibole. With the modelled fractional crystallisation shown }\end{array}$ & 157 \\
\hline Figure 5.14 & $\begin{array}{l}\text { Summary of the mineral textures observed in the Taranaki eruptives and the associated } \\
\text { interpretation. }\end{array}$ & 158 \\
\hline Figure 5.15 & $\begin{array}{l}\text { Multi-element diagrams of mineral trace element analyses for samples Inglewood a and } \\
\text { b and Korito. }\end{array}$ & 160 \\
\hline Figure 5.16 & $\begin{array}{l}\text { Probability density functions showing the results of diffusion modelling for the rims of } \\
\text { each sample. }\end{array}$ & 164 \\
\hline Figure 5.17 & $\begin{array}{l}\text { Probability density functions of representative samples showing the results of diffusion } \\
\text { modelling zones that are not the outermost rim }\end{array}$ & 165 \\
\hline Figure 5.18 & Schematic diagram of the sub-volcanic system at Mt Taranaki & 173 \\
\hline
\end{tabular}




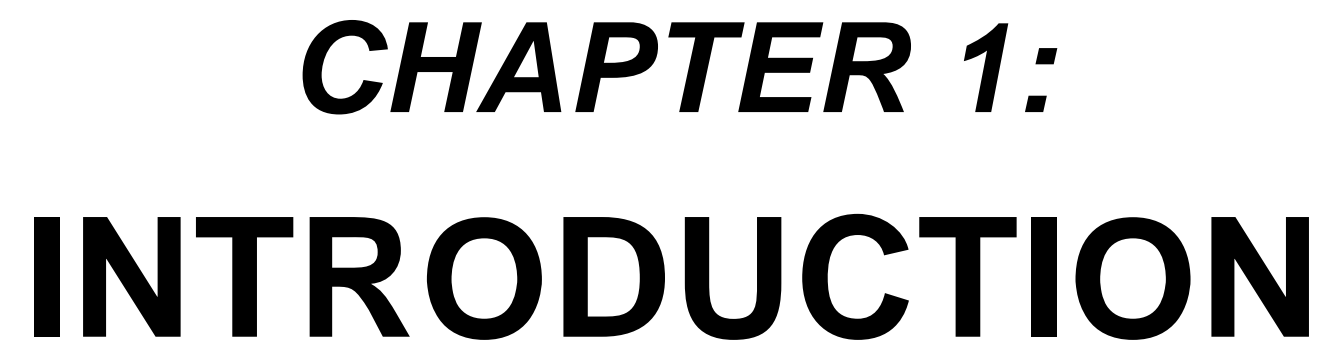




\subsection{INTRODUCTION}

\section{$\begin{array}{lllll}\text { 1.1.1 ANDESITE } & \text { MAGMATISM AND IMPLICATIONS FOR }\end{array}$}

CONTINENTAL CRUST GENERATION

The origin of andesitic (intermediate) volcanism is a contentious and important problem in the Earth Sciences. The bulk continental crust, which covers $c a .40 \%$ of Earth's surface area, has an intermediate composition $\left(55-65 \mathrm{wt} \% \mathrm{SiO}_{2}\right)$ with a similar geochemistry to that of andesite (Figure 1.2) (Rudnick, 1995; Rudnick \& Gao, 2003; Hawkesworth \& Kemp, 2006). Convergent margins where andesites are most commonly erupted, are thus considered to be the site of continental crust growth (e.g. Kay, 1980; Tatsumi \& Eggins, 1995; Taylor \& McLennan, 1995; Plank, 2005). However, primary arc magmas are typically mantle-derived basalts that are geochemically distinct from the continental crust (45-55 wt\% $\mathrm{SiO}_{2}$ ) (Kay, 1980; Anderson, 1982; Rudnick, 1995; Tatsumi \& Eggins, 1995; Taylor \& McLennan, 1995; Plank, 2005). Thus investigating the generation of andesitic melts aids in the understanding of generation of the continental crust.

Intermediate magmas such as andesites are thought to form through various processes including: 1) crystallisation of mafic magmas within the crust or upper mantle (e.g. Sisson \& Grove, 1993; Grove et al., 1997; 2003; Annen \& Sparks, 2002; Prouteau \& Scaillet, 2003; Larocque \& Canil, 2010); 2) partial melting of older crustal rocks by intrusion or underplating of mantle-derived basaltic magma (e.g. Hildreth \& Moorbath, 1988; Petford \& Atherton, 1996; Petford \& Gallagher, 2001; Annen \& Sparks, 2002); 3) Mixing between basaltic and silicic magmas (e.g. Eichelberger, 1978; Heiken \& Eichelberger, 1980; Tatsumi \& Takahashi, 2006).

In reality, a likely scenario is some combination of these processes where crystallisation of hydrous basalt produces silicic melt in the lower crust and the heat supplied by this basalt enables partial melting of lower crustal rocks (Annen et al., 2006). These two melt types mix and are further modified during ascent of the crust by processes such as fractional crystallisation, crustal assimilation and magma mixing. 
Detailed petrological and geochemical investigation of intermediate arc magmas can constrain the processes which generate andesitic magmas. This thesis study aims to add to this discussion by investigating the processes that generated recent andesitic magmas at $\mathrm{Mt}$ Taranaki, New Zealand.

\subsubsection{HAZARD ASSESSMENT}

Andesitic magmatism is also a significant hazard around the world as this type of volcanism is widespread and often explosive. The deadliness and unpredictability of andesite volcanism has been illustrated multiple times during the $20^{\text {th }}$ century by events such the 1902 eruption at Mt Pelee which killed 29000 people (Witham, 2005). The renewal of volcanic activity at Mt St. Helens was closely monitored, yet even so, 57 people died when it suddenly erupted explosively in 1980(Foxworthy \& Hill, 1982).

Mt Taranaki (New Zealand) is an andesitic stratovolcano that last erupted in AD 1854 (Platz, 2007). The tephrostratigraphic record shows that sub-plinian eruptions $\left(0.1-2 \mathrm{~km}^{3}\right)$ occurred on average every $232 \mathrm{yr}$, with smaller eruptions occurring every ca. 16 yr (Alloway et al., 1995; Turner, 2008). The probability of another Taranaki eruption occurring in the next 50 yr is estimated as 0.37-0.59 (Turner, 2008; Turner et al., 2009).

This study aims to contribute to the understanding of past hazardous events at Taranaki by looking at the timescales of pre-eruptive magma processes and storage in the past ca. $4000 \mathrm{yr}$. This will yield models for the pre-eruptive timescales that are of direct value in assessing the time scales between future unrest and possible eruption at Mt Taranaki. In particular, the information on magma depths and rise rates should be directly relevant to interpreting geophysical signals from future events. 


\subsection{SUBDUCTION ZONE MAGMATISM}

Andesite magmatism typically occurs at convergent plate boundaries, where one tectonic plate is subducted beneath another. The interaction between the down going slab and associated sediment package with the overlying mantle wedge produces magma within the mantle wedge (e.g. Kay, 1980; Gill, 1981; McCulloch \& Gamble, 1991; Elliot et al., 1997; Hawkesworth et al., 1997; Kogiso et al., 2009; Kimura et al., 2010) (Figure 1.1).

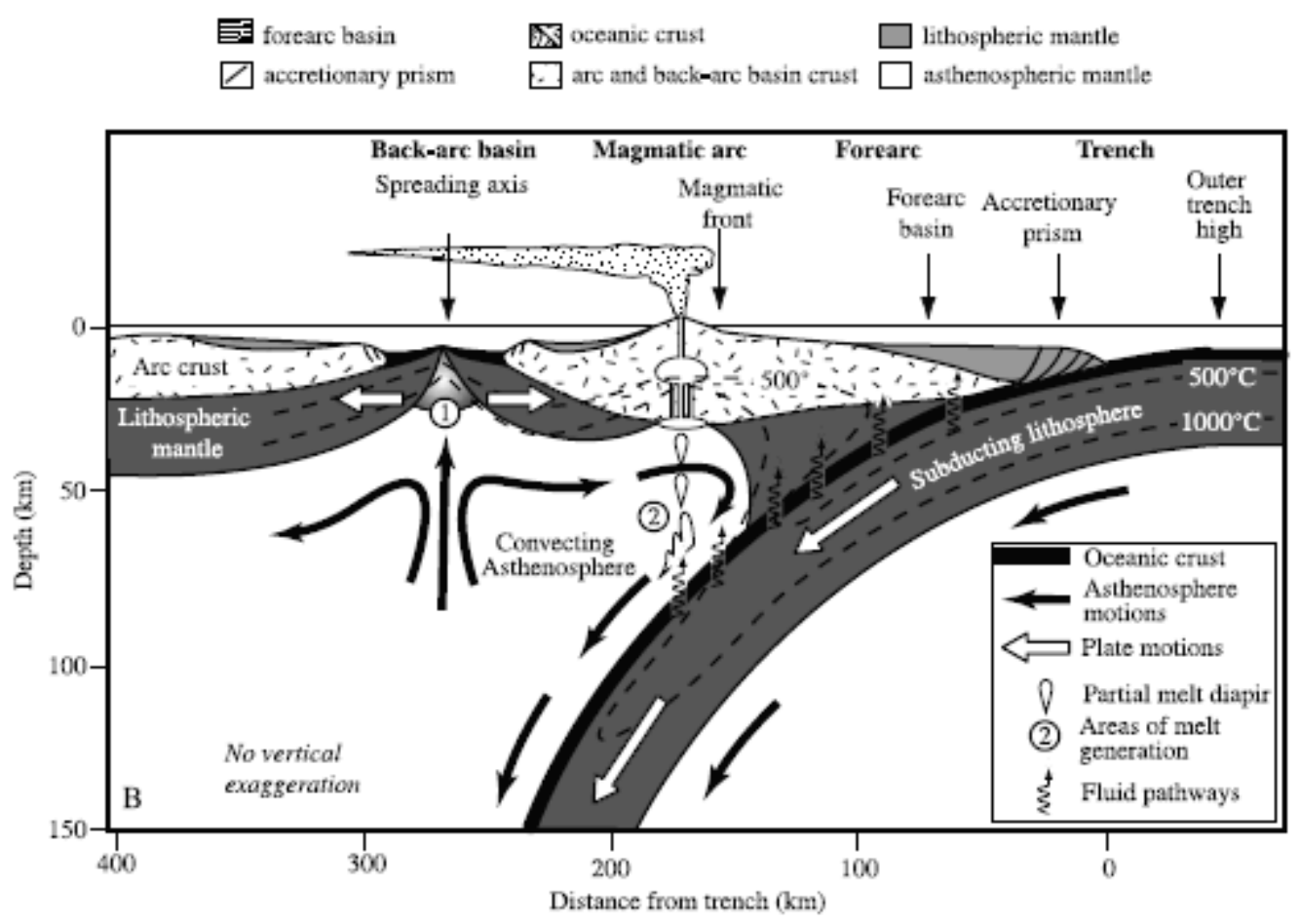

Figure 1.1 Schematic cross section of a subduction zone. Figure taken from Stern (2002).

As the oceanic plate and sediment package are subducted, these components undergo dehydration reactions as a result of prograde metamorphism (e.g. Gill, 1981; Tatsumi \& Eggins, 1995; Schmidt \& Poli, 1998; Hermann et al., 2006; Kimura et al., 2010). This release of fluids metasomatises the overlying mantle wedge, lowers the solidus of the peridotite by several hundred degrees and induces partial melting (e.g. Gill, 1981; Plank \& Langmuir, 1988; Schmidt \& Poli, 1998; Kessel et al., 2005). These fluids also carry a trace element cargo that imparts a distinct chemistry to subduction derived magma. It is generally accepted that in most subduction 
zones, the down going slab does not itself partially melt because temperatures are not sufficiently high (e.g. Peacock et al., 1994). The exception to this may be adakites which have been interpreted to form by melting of a garnet source or direct melting of the subducted slab when the slab is relatively young $(<25 \mathrm{Ma})$ and hot (Defant \& Drummond, 1990; Martin et al., 2005). It is currently unclear whether the sediment melts, as petrological and geochemical studies such as Johnson \& Plank (1999), Elliot et al. (1997) and Hawkesworth et al. (1997) require melting in order to transport fluid immobile elements such $\mathrm{Be}$ and $\mathrm{Th}$, which are observed in significant concentrations in arc lavas, to the mantle wedge. Thermal models, however, predict temperatures that are in general too low for sediment melting (e.g. Peacock et al., 1994). Either way, the result is mass transfer from the sediment to the mantle wedge, resulting in some of the enrichment in large ion lithophile elements (LILEs) and Th (Gill, 1981).

Primary magmas derived from the mantle wedge are generally basaltic with a distinctive trace element geochemistry showing depletion in high field strength elements (HFSEs) (e.g. Ta, $\mathrm{Nb}, \mathrm{Zr}, \mathrm{Hf}, \mathrm{Ti}$ ) and enrichment in LILEs (e.g. Cs, Rb, K, Ba, Pb, Sr) (e.g. Pearce \& Cann, 1973; Gill, 1981; Hawkesworth et al., 1997; Figure 1.2). Much of the enrichment in LILEs occurs because many of these are fluid mobile and so are transported by the aqueous fluids from the subducted slab and associated sediment into the mantle wedge. The origin of HFSE depletion is more controversial with two hypotheses proposed. (1) The mantle wedge may be depleted due to a previous melting event at the back arc that produced back arc basalts. This would have the effect of depleting the mantle wedge of incompatible elements and those elements that are fluid immobile would not be replenished by subduction processes, resulting in an overall depletion of HFSEs in arc magmas (McCulloch \& Gamble, 1991; Woodhead et al., 1993). (2) Melting within the mantle wedge could occur in the presence of Ti-rich accessory minerals (e.g. rutile) which retain HFSEs, resulting in an HFSE depletion in arc magmas (e.g. Green, 1981; Stern, 2002). The subduction zone signature would become more pronounced with time as the mantle wedge becomes progressively more altered by slab-derived fluids (Murphy, 2007).

The volcanic front where arc volcanism typically occurs is globally located $c a .100 \mathrm{~km}$ above the top surface of the down going slab (Gill, 1981). This is thought to be controlled by 
the flow and thermal regime of the mantle wedge (Kogiso et al., 2009), where the dehydration reactions occur (Tatsumi \& Eggins, 1995) and where the permeability of the mantle increases (Mibe et al., 1999). The volcanic front forms where the wet peridotite of the mantle wedge becomes hot enough to melt (Kushiro, 1983).

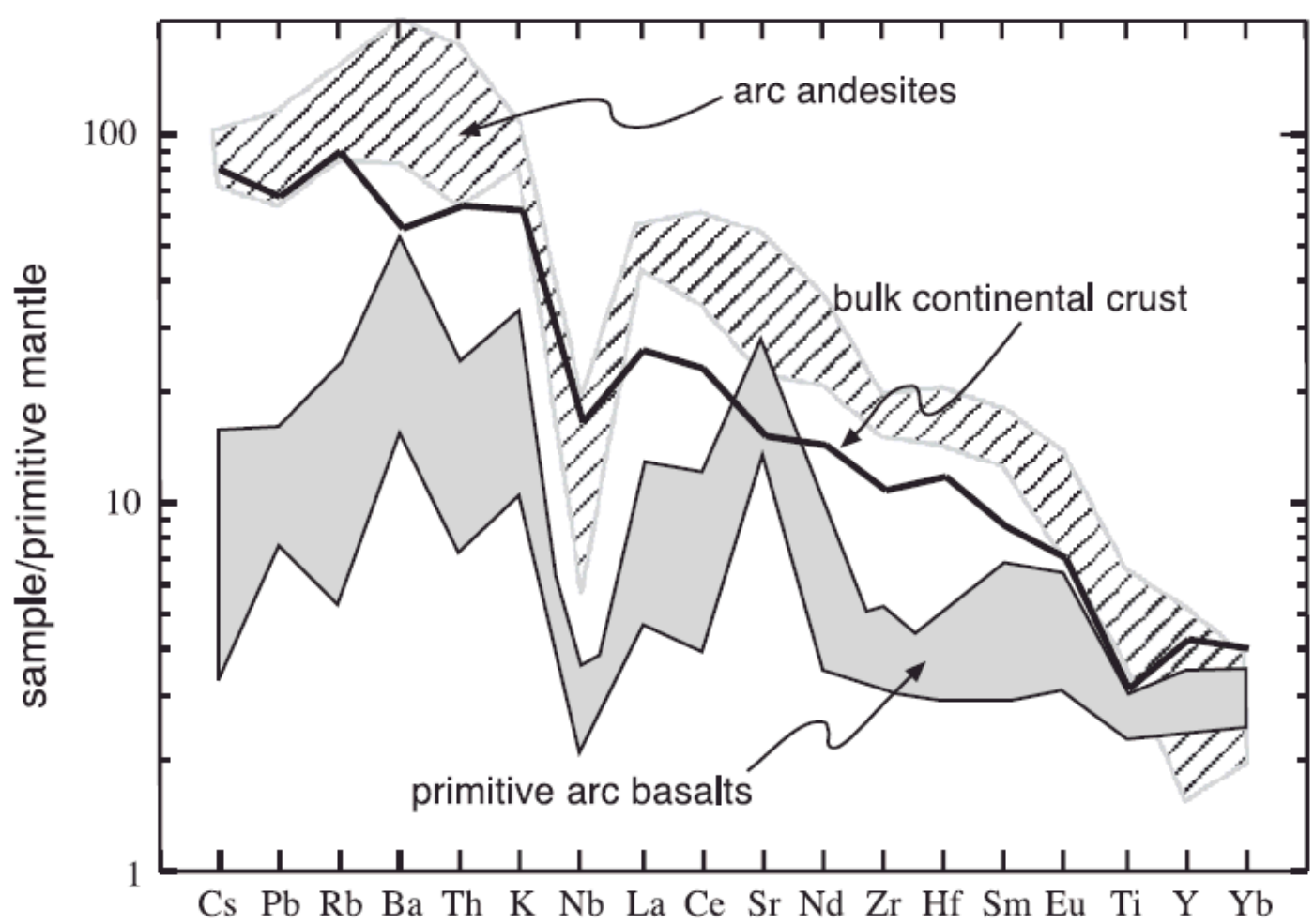

Figure 1.2 Primitive mantle normalised multi-element diagram illustrating the relative enrichment in LILEs and depletion in HFSEs of primitive arc basalts typical of subduction related magmas. Also note the broad similarities in composition between arc andesites and bulk continental crust. Figure taken from Davidson et al. (2005).

\subsection{ANDESITE PETROGENESIS}

The dominant magma type erupted at convergent margins is andesitic in composition so there is much interest in determining how these form given that primary, mantle wedge-derived magmas are generally basaltic in composition (Gill, 1981; Tatsumi \& Eggins, 1995). These primary magmas must travel through the crust, and undergo intracrustal processes and density filtering (Annen et al., 2006). Magma differentiation may occur at depth by partial melting of mafic source rocks or incomplete crystallisation of basalt with further modification occurring in upper 
crustal magma chambers (Hildreth \& Moorbath, 1988-MASH; Annen et al., 2006-Deep Crustal Hot Zone; Reubi \& Blundy, 2009). Alternatively, differentiation may occur at shallow crustal levels by fractional crystallisation and/or crustal assimilation (e.g. Grove \& Kinzler, 1986; Pichavant et al., 2002). To account for the complexity and diversity observed at andesite volcanoes, a range of processes have been proposed including fractional crystallisation, crustal assimilation, mafic recharge and magma mixing (DePaolo, 1981; Hildreth \& Moorbath, 1988; Murphy et al., 2000; Annen et al., 2006). It is difficult to explain the features of andesites by any single mechanism and in most cases these different processes are interdependent (Gill, 1981).

Assimilation of crustal material is expected to some degree whenever basaltic magma is stored in the continental crust (Hildreth \& Moorbath, 1988). Geochemical variability has been attributed to this process at a number of volcanic centres (e.g. Andes of Central Chile, Hildreth \& Moorbath, 1988; San Vincenzo Italy, Ferrara et al., 1989; Mt Ruapehu, New Zealand, Graham \& Hackett, 1987, Price et al., 1999, 2005). This can occur as either bulk assimilation where crustal rocks are incorporated and subsequently melt, or selective assimilation where partial melts extracted from the country rock are incorporated (Streck, 2008). Crustal assimilation can occur simultaneously with fractional crystallisation (AFC) as this latter process provides the necessary heat for assimilation (DePaolo, 1981; Bohrson \& Spera, 2001).

Fractional crystallisation has long been considered key in the formation of silicic magmas as the continued growth and removal of crystals from the melt evolves the composition of the magma along the liquid line of descent to more silicic compositions (Grove \& Kinzler, 1986). The crystallising phases form a crystal mush, from which a high silica melt may be extracted (Hildreth, 2004; Bachmann \& Bergantz, 2004). Alternatively, this can be remobilised by mafic recharge where the injection of a hotter magma reheats and partially melts the crystalline body (e.g. Sparks et al., 1977; Murphy et al., 2000; Bachmann et al., 2002; Dungan \& Davidson, 2004; Fowler \& Spera, 2010). The hotter, more mafic magma mixes with the silicic magma and remobilised crystal mush (Murphy et al., 2000; Dungan \& Davidson, 2004). This interaction has 
often been proposed to trigger eruptions on a timescale of days to months after the mafic recharge event (Sparks et al., 1977; Martin et al., 2008; Kent et al., 2010).

The mixing/mingling of different magma bodies, which may or may not be genetically related, is a common process. Disequilibrium features include: sieved mineral textures; disequilibrium mineral assemblages or those that crystallise over an implausibly wide range of temperatures (e.g. quartz and magnesian olivine, Ca-plagioclase and Na-plagioclase); disequilibrium between glass and mineral compositions; heterogeneous glass; Si-rich melt inclusions in andesitic eruptive products; and the presence of mafic enclaves. These have been interpreted as evidence for magma mixing (e.g. Anderson, 1976; Sparks et al., 1977; Sakuyama, 1979; Pallister et al., 1992; Murphy et al., 2000).

With micro-analytical analysis, it is now apparent that andesitic magmas are not generally intermediate in composition when the individual components of the eruptives are analysed, but are comprised of a liquid and a crystal cargo, which are not necessarily cogenetic (e.g. Eichelberger, 1975; Reubi \& Blundy, 2009). Andesitic magmas typically have a daciticrhyolitic melt which is leveraged to intermediate whole-rock compositions by their more mafic crystal cargo (e.g. Eichelberger, 1975; Davidson et al., 2005; Annen et al., 2006; Reubi \& Blundy, 2009). In fact, despite the dominance of andesitic magmas, there is an 'andesite gap' in melt compositions (Reubi \& Blundy, 2009). This suggests, that while a range of compositions are created at depth, those with an intermediate composition (59-66 wt $\% \mathrm{SiO}_{2}$ ) are less likely to be erupted due to the large compositional changes over this range that occur with a small change in temperature (Reubi \& Blundy, 2009). The abundance of andesites erupted at the surface is therefore a product of magma mixing between silicic and mafic end member magmas at shallow crustal depths (Anderson, 1976; Eichelberger, 1978; Reubi \& Blundy, 2009). The mixture of these two products is preferentially erupted as the combination of the two minimises the physical barriers to eruption (Kent et al., 2010). Basaltic magmas are dense and rhyolitic magmas are viscous, both of which hinder eruption. When these factors combine, the resulting magma is less dense and less viscous and therefore can erupt (Kent et al., 2010). 


\subsection{CRYSTAL FORENSICS}

Due to the complexity observed in andesites, in situ crystal specific studies are required to unravel the processes which formed these magmas. These studies make it possible for us to track magmatic processes such as crystallisation, crustal assimilation, magma mixing, decompression and convection (Berlo et al., 2007; Ginibre et al., 2007; Jerram \& Martin, 2008). Whole rock analyses average out and hide complexities, as they do not correspond to liquid compositions, or liquid lines of descent, resulting in whole rock data that is an overly simplistic interpretation of petrogenetic processes (Stewart et al., 1996; Streck et al., 2005; Davidson et al., 2005; 2007a; Eichelberger et al., 2006; Berlo et al., 2007; Jerram \& Martin, 2008; Reubi \& Blundy, 2009).

Crystals represent an archive of magmatic conditions as crystal texture and zoning both record changes in the physical and chemical conditions in the magma (Ginibre et al., 2002a). The progressive zones from core to rim within a crystal represent a time sequence, therefore the changing composition represents changing conditions through time (Davidson et al., 2007b). Dissolution surfaces and major compositional changes correspond to periods where the crystal was partially dissolved and no growth occurred (Davidson et al., 2007b).

Textural analysis can be combined with micro-geochemical techniques to further resolve magmatic processes. Micron scale major element analyses can be obtained by electron microprobe traverses, and trace element analyses at spot sizes of $c a .20-35 \mu \mathrm{m}$ by laser ablation inductively coupled plasma mass spectrometry. The crystal composition is dependent on the crystallising conditions, and thus the host magma at the time of crystallisation (Ginibre et al., 2007). The major element composition can vary as a function of pressure, temperature, melt composition and water content (e.g. Ginibre et al., 2002a). Trace element analyses may further constrain which of these processes is occurring, as many trace elements are primarily sensitive to changes in melt composition (e.g. Cr in clinopyroxene - Streck et al., 2002). Therefore, a change in major element chemistry, without a corresponding change in trace element chemistry, 
can indicate variation in the physical processes in the magma chamber - such as a decompression or degassing - rather than a compositional change (Ginibre et al., 2007).

Andesitic magmas typically contain multiple populations of crystals that have different histories (Jerram \& Martin, 2008). These have been broadly classified into phenocrysts, antecryts and xenocrysts based on the relationship of a crystal to the host melt (Jerram \& Martin, 2008; Streck, 2008). Phenocrysts grow in situ from a magma and constrain the evolution of the erupted magma. Antecrysts are crystals which grew from a melt genetically related to that erupted and preserve information about the magmatic system as a whole. These crystals are older, and may have crystallised from the host melt prior to a mixing event for example. Xenocrysts, which are not genetically related to the host magma, indicate interaction of the magmatic system with foreign material such as wall rocks. An individual crystal may fall into all of these categories depending on the zone of interest. Differentiating between these various crystal-melt relationships is challenging and generally requires the use of microanalytical geochemical techniques in conjunction with textural analysis. This is highlighted by cases where phenocrysts and the crystals within xenoliths are texturally and chemically similar (e.g. Price et al., 2005).

Volcanic glass represents the composition of the residual melt and can be used to investigate the relationship of the crystal cargo to the magma in which it is found (Streck, 2008). Glass analyses provide further constraints on the processes and history of the magma chamber and indicate the degree of chemical heterogeneity within the erupted melt body. Furthermore, melt inclusion analyses can provide information on the co-existing melt at the time of melt inclusion closure, assuming no post-entrapment modification and therefore can provide a relative time series of magma composition. 


\subsection{CONSTRAINING TIMESCALES OF MAGMATIC PROCESSES}

Quantifying the timescales of magmatic processes aids in our understanding of andesite petrogenesis and the evaluation of volcanic hazards (Turner \& Costa, 2007). Uranium-series isotopes have traditionally been used to constrain the timescales of magmatic systems by dating bulk samples or mineral separates (e.g. Cooper et al., 2001; Cooper \& Reid, 2003; Turner et al., 2003; Hawkesworth et al., 2004). This gave an average age of a crystal that can be misleading, especially where crystal cores are significantly older than rims. Recent advances in understanding of diffusion in solid silicates have enabled the in situ determination of timescales on a variety of mineral phases. This enables a chronology to be linked to the textural and chemical features of individual minerals and the processes these elucidate (Hawkesworth et al., 2004; Turner \& Costa, 2007). Further, multiple ages can be obtained from a number of crystals to provide a statistically robust model, and/or investigate different crystal populations and compare the processes affecting them (Chakraborty, 2008). Numerous zones within a single crystal can also be modelled enabling multiple events recorded within crystal zoning to be studied.

Diffusion modelling quantifies the time a mineral zone remained at magmatic temperatures and so dates the time between a magmatic process and eruption. Mineral zoning begins to reequilibrate immediately after formation, but this process is infinitely slow at surface temperatures (Morgan et al., 2004). Measuring the degree of compositional 'smoothing' that has occurred can therefore be used to quantify the time between the event that formed the mineral zoning and eruption (Morgan et al., 2004). As diffusion effectively terminates once the rock is erupted, the timescales of these processes can be measured independent of sample age even when they are orders of magnitude smaller than the age of the sample (Morgan et al., 2004; Chakraborty, 2008). All timescales of geological interest can be investigated using diffusion modelling as different elements diffuse at different rates within different minerals (Chakraborty, 2008; Costa et al., 2008). 
A range of different processes have been investigated using diffusion modelling of various mineral-element pairs. For example, Morgan \& Blake (2006) calculated that magma differentiation occurred on a timescale of $100000 \mathrm{yr}$ before the Bishop Tuff eruption based on $\mathrm{Ba}$ and Sr zoning in sanidine. Timescales of the order of days to weeks have been calculated for mafic recharge events, which are interpreted to be the eruption triggering process, using a range of element and mineral species (e.g. Fe-Mg in olivine-Martin et al., 2008; Ti in titanomagnetiteTurner et al., 2008; Mg in plagioclase-Kent et al., 2010).

\subsection{GEOLOGICAL BACKGROUND}

\subsubsection{REGIONAL TECTONIC SETTING}

New Zealand sits astride the plate boundary between the Pacific and Australian plates, which are converging obliquely at a rate of $42 \mathrm{~mm} / \mathrm{yr}$ at the latitude of Taranaki (De Mets et al., 1994). Offshore of the North Island, the Pacific Plate is being subducted to the west beneath the Australian Plate at the Hikurangi Trough. The subducted Pacific lithosphere initially dips shallowly at around 20 and gradually increases to a dip of $55^{\circ}$ at $100 \mathrm{~km}$ depth under the central North Island (Anderson \& Webb, 1994). The slab continues to dip more steeply to a depth of around $200 \mathrm{~km}$ beyond which it is near vertical (Anderson \& Webb, 1994; Reyners et al., 2006). Beneath the Taranaki region, the Wadati-Benioff zone is around $250 \mathrm{~km}$ deep (Adams \& Ware, 1977; Anderson \& Webb, 1994; Reyners et al., 2006). Very deep earthquakes at $600 \mathrm{~km}$ depth suggest that there is also a small detached piece of the slab at this depth beneath Taranaki (Boddington et al., 2004). There is also evidence that the subducted slab is segmented by lateral tears trending in a northwest direction (Reyners, 1983).

\subsubsection{TAUPO VOLCANIC ZONE}

The Taupo Volcanic Zone (TVZ) in the central North Island is the main expression of subduction-related volcanism in the North Island (Fig. 1.3A). It is a region of active rifting, characterised by extremely high heat flow of $\sim 700 \mathrm{~mW} / \mathrm{m}^{3}$ (e.g. Stern, 1985; Stern et al., 1987; Bibby et al., 1995; Wallace et al. 2004). The brittle upper crust is around $16 \mathrm{~km}$ thick; below 
this is either low velocity mantle (Stratford \& Stern, 2004) or extensively intruded or underplated lower crust (Harrison \& White, 2004). This is one of the most productive magmatic systems on Earth, erupting an average of $0.28 \mathrm{~m}^{3} \mathrm{~s}^{-1}$ of magma in the last $340 \mathrm{Kyrs}$ and is overwhelmingly rhyolitic in composition (Houghton et al., 1995; Wilson et al., 1995). Basaltic volcanism is evenly distributed throughout the TVZ, however rhyolitic volcanism is confined to the central portion and andesitic to dacitic volcanism is dominant only in the northern and southern segments of the TVZ (Wilson et al., 1995). The Tongariro Volcanic Centre (TgVC) is located at the southern end of the TVZ and includes the active cones of Ruapehu and Mt Ngauruhoe (Figure 1.3A). These volcanoes are dominated by medium-K, plagioclase and twopyroxene andesites (Graham \& Hackett, 1987). While the TgVC has the largest and most active andesitic volcanoes associated with this arc, volcanism in Taranaki has been present for ca. 2 Ma in a back arc setting sensu lato (e.g. Price et al., 1992, 1999, 2005). This distinct tectonic location can provide important insights into cross arc variation and the behaviour of subduction related volcanism in general.

\subsubsection{TARANAKI SETTING}

\subsubsection{Taranaki Basin}

Mt Taranaki, also known as Egmont Volcano, is an andesitic stratovolcano located on the western side of New Zealand's North Island within the Taranaki Basin (Figure 1.3). This basin opened during the Mid-Late Cretaceous as a result of rifting associated with the break-up of the paleo-Pacific margin of Gondwana and the opening of the Tasman Sea (King \& Thrasher, 1996; Muir et al., 2000). The tectonically active region of the Taranaki Basin is bound to the west by the Cape Egmont Fault Zone and to the east by the Taranaki Fault - a crustal scale fault that is thought to be a major terrane boundary (King \& Thrasher, 1996; Stagpoole \& Nicol, 2008; Giba et al., 2010). The crust in the Taranaki Basin is $25-35 \mathrm{~km}$ thick, thickening from west to east (Stern \& Davey, 1987; 1990). The basement is comprised of plutonic rocks of the Median Tectonic Zone, dominated by subduction-related calc-alkaline diorites and granites (Challis et 
al., 1994; Mortimer et al., 1997; Rattenbury et al., 1998). The basement has been overlain by ca. $6 \mathrm{~km}$ of Cretaceous to Cenozoic sediment (King \& Thrasher, 1996; Kamp et al., 2004).

The brittle-ductile transition is shallow at $10 \mathrm{~km}$ depth below Mt Taranaki and is thought to be due to the high geothermal gradient associated with this volcanism via mid-crustal intrusion and/or crustal underplating (Allis et al., 1995; Sherburn \& White, 2005). The andesitic roots of Taranaki Quaternary volcanoes intrude this crust at least as far as the basement rock on the basis of 3-dimensional gravity and magnetic anomalies (Locke et al., 1993; 1994; Locke \& Cassidy, 1997). A structure $5 \mathrm{~km}$ in diameter and extending to a depth of at least $10 \mathrm{~km}$ under $\mathrm{Mt}$ Taranaki is interpreted as the roots of the volcano and is also likely to be the focus of future magmatic intrusions (Sherburn et al., 2006).

\subsubsection{Miocene Volcanism}

The Mohakatino Volcanic Centre (Figure 1.3A) is a region of andesitic volcanism in the northern Taranaki Basin that was active during Miocene times ( 18-7 Ma) (King \& Thrasher, 1996). There is an overall NNE trend and volcanism generally becomes progressively younger towards the south (Stagpoole and Funnel, 2001; Mortimer et al., 2010). These andesitic volcanoes are thought to have a subduction-related origin, and are the southernmost expression of Miocene arc volcanism associated with the contemporaneous Pacific-Australian plate boundary. The Mohakatino Volcanic Centre is interpreted to be a part of the same volcanic arc as the Coromandel Volcanic Zone, Colville Ridge and Lau Islands that were active from 17-5 Ma (Herzer, 1995; Mortimer et al., 2010). The Coromandel Volcanic Zone and the Mohakatino Volcanics are thought to be the southern, continental propagation of the oceanic arc (Herzer, 1995).

\subsubsection{Taranaki Volcanic Lineament}

Mt Taranaki defines the youngest focus of a northwest to southeast trending lineament of Quaternary volcanic centres, along which volcanism has migrated southeast with time over $c a$. 1-2 Ma (Neall et al., 1986). The other three volcanic edifices in this progression are Paritutu and 


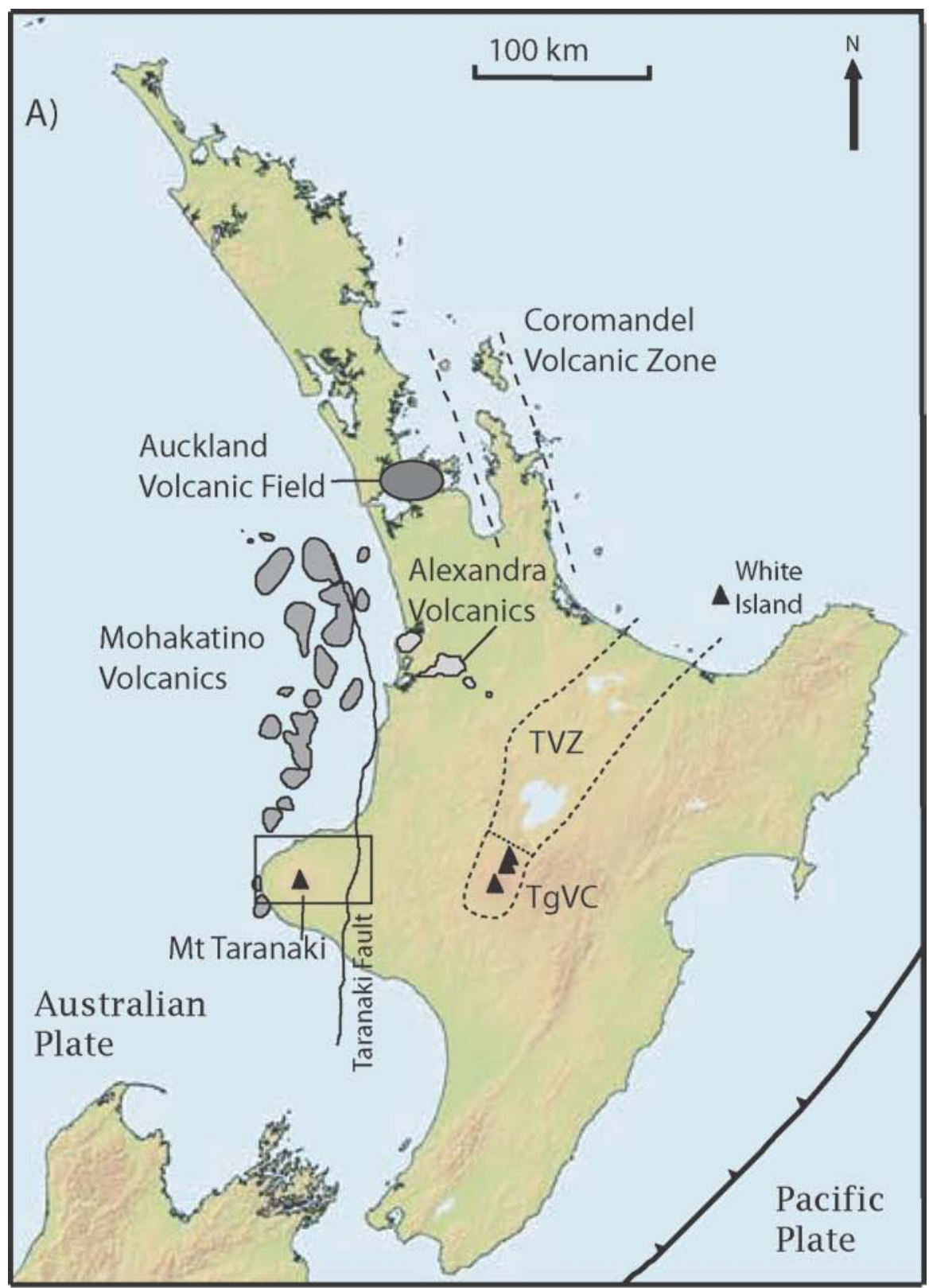

B)

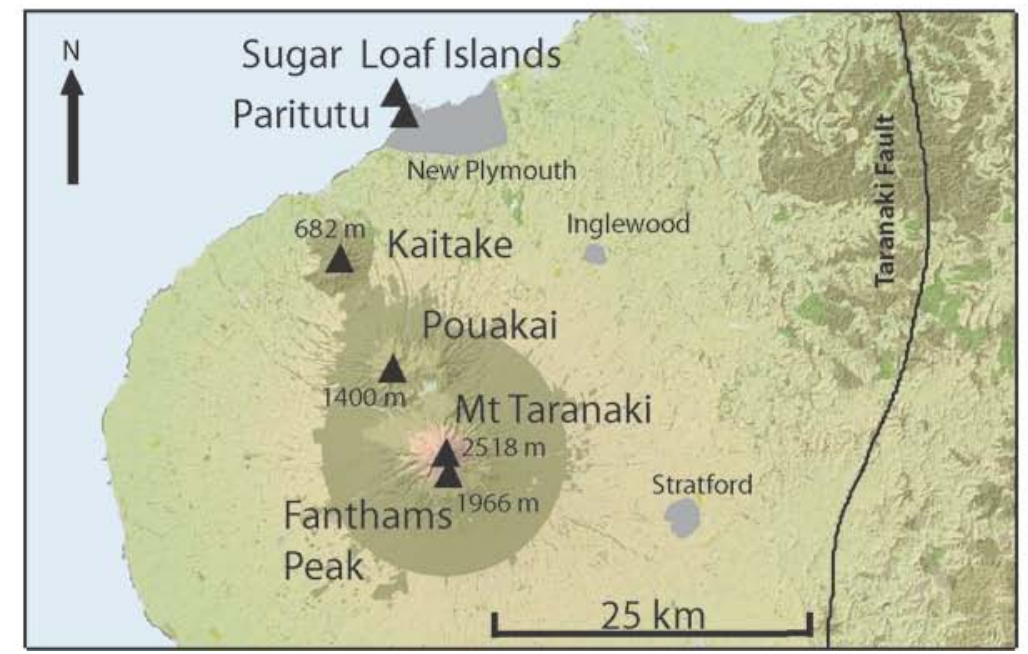

Figure 1.3 A) Map illustrating the distribution of selected North Island Miocene-Recent volcanism. Figure is based on diagrams from King \& Thrasher (1996), Stagpoole \& Funnel (2001) and Allan (2008). B) Map showing the location of Quaternary volcanism on the Taranaki Peninsula. Backgrounds courtesy of GeographX. 
the Sugar Loaf Islands (1.74 Ma), Kaitake (0.5 Ma) and Pouakai (0.25 Ma) (Figure 1.3B) (Neall, 1979). These are comprised of hornblende andesite and minor dacite (Neall, 1979; Neall et al., 1986; Locke et al., 1994). The older volcanoes are all extinct and either highly altered by hydrothermal activity and weathering, or covered in dense bush, or both. The presence of this volcanic lineament could be related to: 1) edge effects of mantle flow; or 2) tears in the subducting slab (Price et al., 1992). There may be thermal up-welling of the asthenosphere around the edge of the slab inducing a low degree of melting in a previously metasomatised mantle wedge (Price et al., 1992). The tears in the subducting slab are roughly parallel to this lineament and could localise fluid and/or melt loss from the slab forming linear zones of magma generation that are expressed as lines of volcanism (Reyners, 1983; Price et al., 1992, 1999).

\subsubsection{MT TARANAKI}

\subsubsection{History of Taranaki Volcanism}

Volcanic activity has occurred at Mt Taranaki for at least $130 \mathrm{Kyr}$ and the most recent eruption occurred in AD 1854. During this period, Mt Taranaki has undergone a minimum of 13 sector collapses and subsequent cone building phases, with five of these occurring in the last 30 Kyr (Zernack et al., 2009). The most recent sector collapse occurred 7000 yr ago and these collapses have constructed a substantial ring plain. Much of the Holocene evolution of Mt Taranaki has been described by Neall et al. (1986).

The present cone is mostly comprised of material $<10000 \mathrm{yr}$ old. It consists of detrital fragments of the remnants of older cones overlain by the younger lava flows of the most recent cone. Fanthams Peak is a parasitic cone on the southern slopes of Mt Taranaki that has been active for ca. 7000 yr. Downey et al. (1994) grouped the lava flows of the current cone into four categories on the basis of field relationships and paleomagnetic data (Table 1.1). These can be correlated with the tephro-stratigraphic record (e.g. Stewart et al., 1996). Until recently the youngest eruptive event was believed to be the Tahurangi Ash, which occurred in AD 1755 (Neall et al., 1986). It is now thought that two dome collapse events occurred in AD 1800 and 1854 (Platz, 2007). 
There is an average eruption periodicity of around 232-330 $\mathrm{yr}$ for sub-plinian eruptions (Alloway et al., 1995; Turner, 2008). There are also more frequent, smaller scale eruptions (dome- and block and ash-forming events) that tephro-stratigraphic evidence suggests generally occurs on a decadal basis (Turner, 2008; Turner et al., 2009.).

\begin{tabular}{lll}
\hline $\begin{array}{l}\text { Stratigraphic } \\
\text { group }\end{array}$ & Age (BP) & Correlative tephras \\
\hline Summit & $>0.7 \mathrm{ka}$ & $\begin{array}{l}\text { Newall Ash and lapilli (AD 1604); Burrell Lapilli (AD 1655); } \\
\text { Tahurangi Ash (AD 1755) }\end{array}$ \\
Staircase & $0.7-2 \mathrm{ka}$ & $\begin{array}{l}\text { Kaupokonui Tephra (1.4 ka BP) } \\
\text { Fanthams Peak }\end{array}$ \\
$\begin{array}{l}\text { Warwicks } \\
\text { Castle }\end{array}$ & $8-3 \mathrm{ka}$ & $\begin{array}{l}\text { Manganui Tephra (3.3 ka BP) } \\
\text { Korito Tephra (4.1 ka BP); Inglewood Tephras (3.6 ka BP); } \\
\text { Maketawa Tephra (2.9 ka BP) }\end{array}$ \\
\hline
\end{tabular}

Table 1.1 Summary of the stratigraphic groupings for Mt Taranaki lava and selected tephra units. After Price et al. (1999) using data from Neall et al. (1986), Downey et al. (1994), Alloway et al. (1995) and Stewart et al. (1996).

\subsubsection{Petrology \& Geochemistry}

Mt. Taranaki eruptives are classified as high-K basalts, basaltic andesites and andesites based on whole rock data (Neall et al., 1986; Price et al., 1992; Stewart et al., 1996; Price et al., 1999, 2005). The mineral assemblage typically consists of plagioclase, clinopyroxene, hornblende and titanomagnetite with minor amounts of olivine, orthopyroxene and ilmenite (Gow, 1968; Neall et al., 1986; Stewart et al., 1996). Fanthams Peak eruptives are similar to those of the main vent but are generally more basaltic (basalt-basaltic andesite whole rock compositions) and contain a larger proportion of olivine and less amphibole $(<5 \%)$ (Price et al., 1992). Glass specific analyses show that the composition of the melt phase immediately prior to eruption is considerably more silicic than the whole rock data suggests and that these are andesitic, dacitic and rhyolitic in composition (Price et al., 2005; Platz et al., 2007a). Trace element chemistry is typical of subduction related magmas exhibiting enrichment in LILE and depletion of HFSE (Figure 1.4; Price et al., 1992, 1999, 2005). The magmas are also relatively evolved with very low concentrations of $\mathrm{Ni}$ and $\mathrm{Cr}$ (Price et al., 1992, 1999; Stewart et al., 1996). ${ }^{87} \mathrm{Sr} /{ }^{86} \mathrm{Sr}$ and ${ }^{143} \mathrm{Nd} /{ }^{144} \mathrm{Nd}$ isotope data from Price et al. $(1992,1999)$ define narrow ranges $\left({ }^{87} \mathrm{Sr} /{ }^{86} \mathrm{Sr}=0.70378-0.70504 ;{ }^{143} \mathrm{Nd} /{ }^{144} \mathrm{Nd}=0.51276-0.51281\right)$ and suggest limited involvement of continental crustal material. 


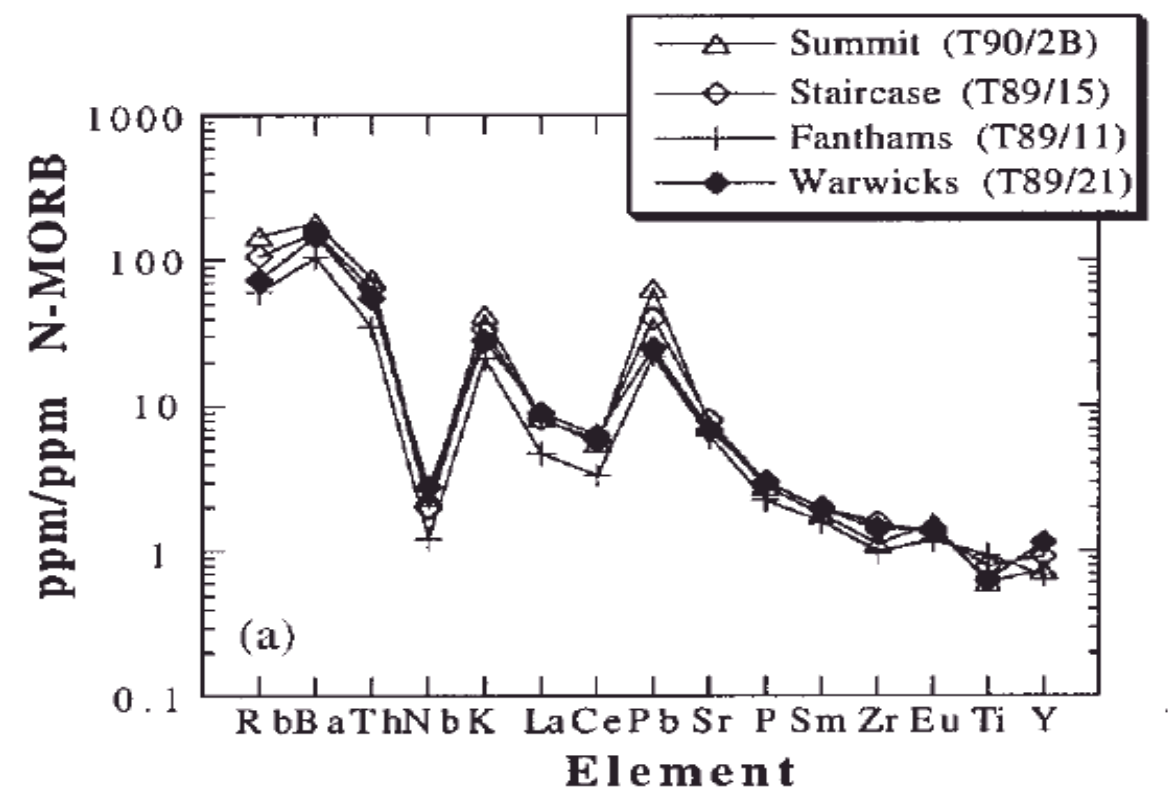

Figure 1.4 N-MORB normalised multi-element diagram of selected Taranaki lavas to illustrate the 'subduction signature' typical of Taranaki lavas. Figure taken from Price et al. (1999).

The primary magmas associated with Taranaki eruptives are thought to be hydrous, high$\mathrm{Mg}$ basalts, which are relatively under-saturated with respect to $\mathrm{SiO}_{2}$ and were formed by low degrees of partial melting of a relatively depleted, metasomatised mantle wedge (Price et al., 1992, 1999; Stewart et al, 1996). The high-Mg basalts evolved to high-Al basalts and basaltic andesites by fractionation of mafic minerals, inferred to be now represented by pyroxenite and amphibolite cumulates at the base of the crust (Stewart et al., 1996; Price et al., 1999). Assimilation and fractional crystallisation processes further modified the magma compositions (Price et al., 1992, 1999, 2005), with slight compositional and physical differences between magma batches (Price et al., 2005; Turner et al., 2008). These magma batches are inferred to have mixed at upper crustal depths on a timescale of days to weeks prior to the onset of an eruption (Turner et al., 2008). The physical similarities (i.e. temperature and viscosity) between the different magmas enable efficient mixing to occur (Turner et al., 2008).

\section{$\underline{\text { Temporal variability }}$}

Taranaki eruptives have become increasingly enriched in $\mathrm{SiO}_{2}$ and $\mathrm{K}_{2} \mathrm{O}$ over the past ca. $115000 \mathrm{yr}$ (Price et al., 1999). This temporal variation may be related to changes at the magma source such as declining degrees of partial melting, changing fluid flux and/or mantle source 
heterogeneity (Price et al., 1999). Alternatively, partial anatexis of the amphibolitic cumulates in the lower crust may occur due to a rising geothermal gradient (Stewart et al., 1996; Price et al., 1999). This would produce a high-K melt that would then interact with the high-Al basalt producing progressively more K-rich magmas with time (Stewart et al., 1996; Price et al., 1999).

\section{Cross arc variation}

Taranaki has been used in conjunction with the $\mathrm{TgVC}$, especially Ruapehu, to examine cross arc variation (e.g. Price et al., 1992, 1999, 2005). These studies show that Taranaki overlies a more depleted mantle wedge that has undergone a lower degree of partial melting than the TgVC as indicated by higher abundances of LILE and HFSE in the Taranaki eruptives (Price et al., 1992, 1999). The fluids involved at each volcanic centre are geochemically different as there is a declining influence of sediment at deeper levels of the subduction system and subduction is deeper below Mt Taranaki (Price et al., 1999). The nature of the crust at the two centres has further differentiated the magma suites by influencing the degree of interaction and the material magmas have interacted with (Price et al., 1992, 1999, 2005). Taranaki eruptives have less involvement with the crust than the andesites of the $\mathrm{TgVC}$ on the basis of lower $\delta^{18} \mathrm{O}$ values, a lack of correlation between $\mathrm{SiO}_{2}$ and ${ }^{87} \mathrm{Sr} /{ }^{86} \mathrm{Sr}$ as well as less radiogenic $\mathrm{Pb}$ isotopes when compared with Ruapehu (Price et al., 1992, 1999).

\subsection{OBJECTIVES AND STRUCTURE OF THIS THESIS}

The overall objective of this thesis is to improve understanding of explosive andesitic eruptions through investigations of the shallow crustal processes responsible for producing recent sub-plinian eruptions at Mt Taranaki. This objective is pursued through a series of mineral-specific and micro-analytical studies including:

(a) petrography and characterisation of the mineral phases present in Taranaki eruptives; 
(b) detailed in situ major and trace element analyses of these minerals using electron microprobe (EMPA) and laser ablation inductively coupled plasma mass spectrometry (LA-ICP-MS) analyses;

(c) major and trace element analyses of glass separates using EMPA and solution ICP-MS;

(d) calculation of pre-eruptive conditions including magmatic temperature, pressure, water content and oxygen fugacity calculated using amphibole geothermobarometry, clinopyroxene-melt thermometry and plagioclase-melt thermometry; and

(e) magmatic residence times of clinopyroxene crystals from diffusion modelling.

Specifically this study aims to:

(a) Compare and contrast whole-rock and glass chemistry as a guide to fractionation pathways within Taranaki.

(b) Use crystal chemistry and texture to constrain the magmatic systems and the processes operating within them.

(c) Investigate the evolution of the Taranaki magmatic system by exploring the temporal variability in the eruptive products across six samples, representing a ca. 2700 year period of eruptions from $\sim 1400$ to 4100 years before present (B.P.).

(d) Quantify the timescales of the shallow crustal processes that may trigger eruptions.

This thesis is comprised of six chapters and four appendices with the following structure:

Chapter 1: Introduction - An overview of andesitic magmatism including the importance of understanding these systems, how these magmas form and how they are modified by crustal processes as well as a summary of some of the techniques that can be used to resolve these processes. A background of the Taranaki region and volcanism including a summary of previous geochemical studies is also given.

Chapter 2: Fieldwork - A chapter showing the locations and details of sample collection. 
Chapter 3: Methods - A description of the methods used to collect the geochemical data for this thesis including an evaluation of the data quality and the standards used. The thermobarometry and diffusion modelling techniques applied in this study are also described and evaluated.

Chapter 4: Results - Presents the key geochemical and modelling results from this study.

Chapter 5: Discussion - An interpretation of the results, relating them to various magmatic processes and comparing this work with previous studies on Mt Taranaki as well as key global examples of andesitic magmatism.

Chapter 6: Conclusions - A summary of the key findings of this research and suggestions for future work.

Appendices 1-4: A list of the samples, geochemical data and diffusion modelling profiles used in this study. 


\section{CHAPTER 2:}

\section{FIELDWORK AND SAMPLES}




\subsection{FIELDWORK METHODS}

Tephra samples were collected in February 2008 from road cuttings on the eastern slopes of Mt Taranaki. The prevailing westerly winds carry eruptive products to the east and therefore this is the location of the most comprehensive tephrostratigraphic record. Field sites were selected to best represent the recent stratigraphic record and avoid areas of reworking.

Four sites were selected that collectively covered the tephrostratigraphic record of Mt Taranaki using the work of Alloway et al. (1995). In total 152 samples were collected from these sites, covering the time period of $<2000$ to $23000 \mathrm{yr}$ B.P. with the last $10000 \mathrm{yr}$ sampled continuously.

At each site, the section was cleared off with a spade so the weathered surface was removed. The sites were then measured and photographed. Every layer was sampled and described including those thought to be paleosols. Sampling began at the top of each section, working down through the stratigraphy. Where necessary, multiple sections of an outcrop were sampled to cover the entire tephrostratigraphic sequence present at an outcrop. 


\subsection{SITE LOCATIONS}

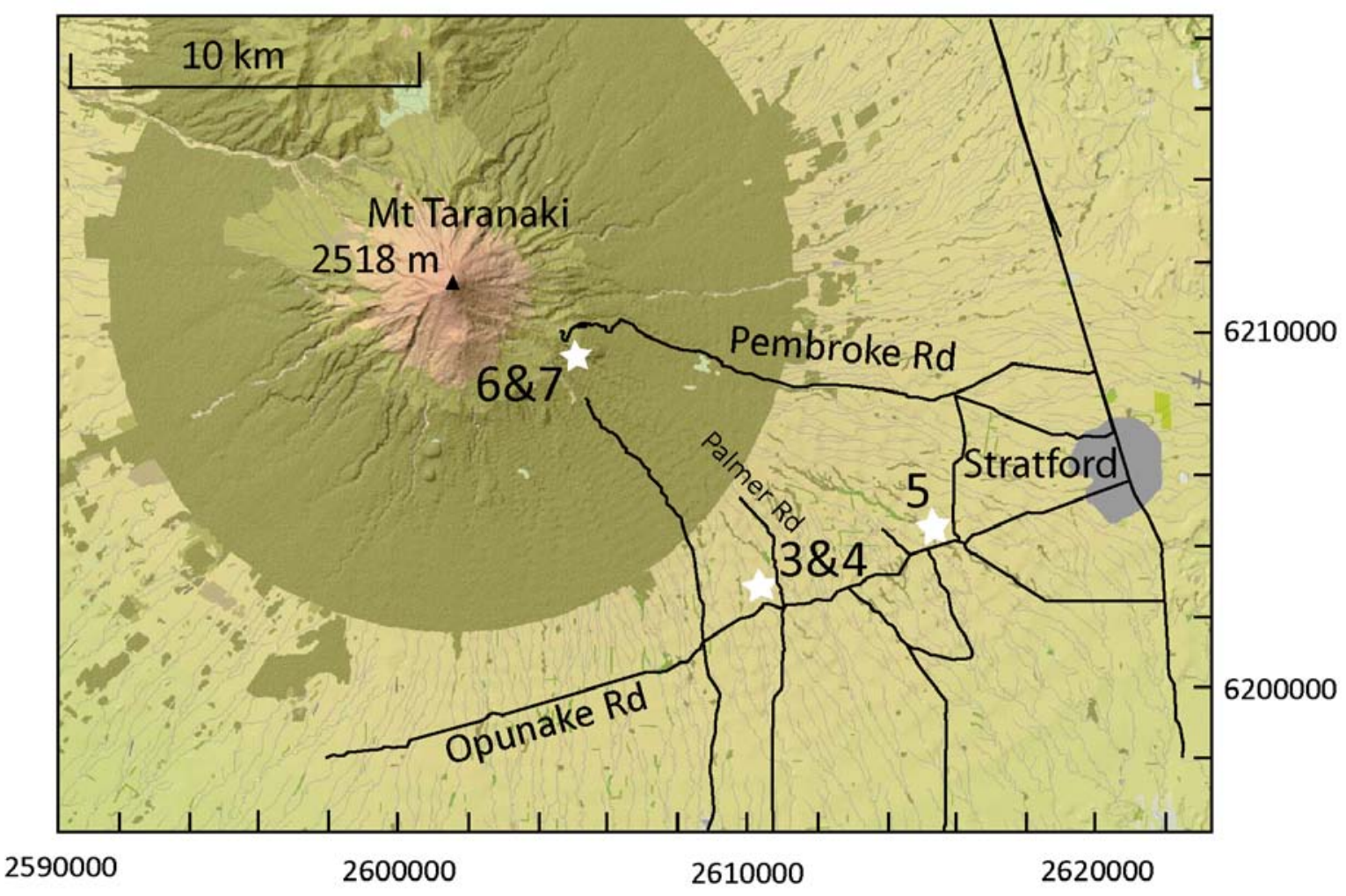

Figure 2.1 Map of the field area for this study showing the location of sampling sites. Main roads and those roads referred to in the text are also shown. Co-ordinates are New Zealand Map Grid (NZMG).

\subsubsection{SITE 3 AND 4-OPUNAKE ROAD}

Sites 3 and 4 are a north facing road cutting located on Opunake Road west of the intersection with Palmer Road (NZMG E2605134 N6202446) (Figure 2.1). The outcrop was approximately 20 metres in length and had a maximum height of around five metres. Sampling took place in six sections to cover the entire timespan represented in this outcrop. In total, 57 samples were collected covering the Maketawa to the Kaponga Tephra. Areas of this outcrop showed evidence for reworking, particularly towards the base. The six sections were carefully selected to avoid these areas where possible. Stratigraphy is unclear for the bottom three sections and may be affected by reworking.

\subsubsection{SITE 5 - OPUNAKE RD}

Site 5 is a north facing road cutting located on Opunake Road opposite Cardiff Walkway Carpark (NZMG E2615707 N6204236). This road cutting is largely covered in scrub therefore in order to sample as much of the tephrostratigraphy at this site as possible six sections of 0.5 to 
$2 \mathrm{~m}$ in height were sampled over a length of $c a .20 \mathrm{~m}$. The easternmost of these sections are located 2 m east of location 7 from Alloway et al. (1995). Sampling began at the eastern end of the outcrop and progressed up the road, with each section stratigraphically above the previous, with sampling beginning at the top of each section. In total, 53 samples were taken spanning from the Poto c to Kaihouri tephra units with some possible breaks within this sequence.

\subsubsection{SITE 6 - PEMBROKE RD}

Site 6 is a north facing road cutting on Pembroke Road within Egmont National Park (NZMG E2605134 N6210266) where 13 samples were collected. This section is ca. $1.5 \mathrm{~m}$ in height and covers the youngest samples collected for this study (Kaupokonui Tephra to the Manganui Tephra; Figure 2.2).

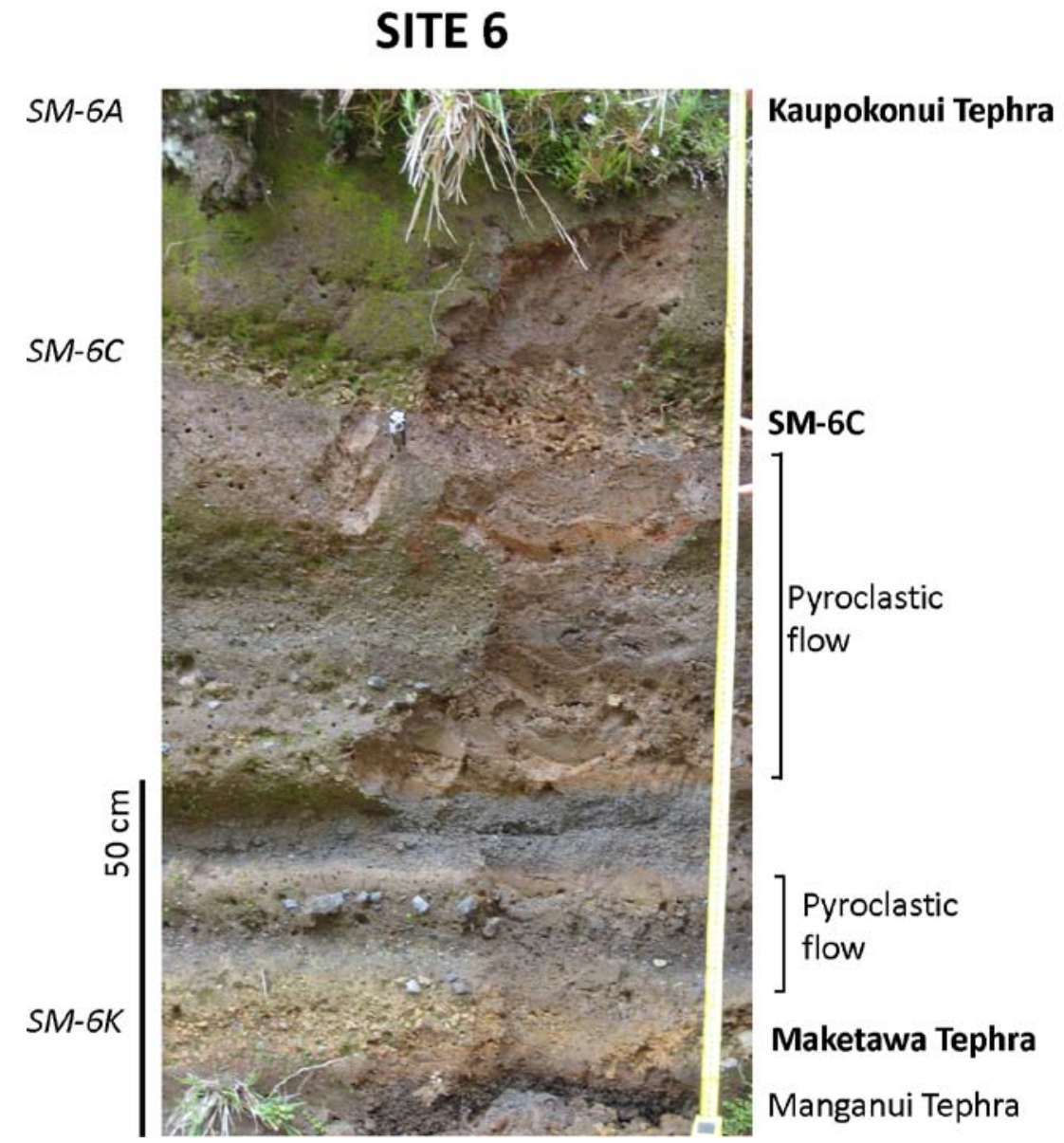

Figure 2.2 Annotated photograph of Site 6. Samples investigated in this study are identified by the sample ID (italics) and the corresponding tephra unit (bold). Other tephra units and key features are also highlighted. Note the Kaupokonui tephra (unit SM-6A) is obscured by vegetation in this image. 


\subsubsection{SITE 7 - PEMBROKE RD}

Site 7 is a south facing road cutting on Pembroke Road within Egmont National Park across the road from Site 6 (NZMG E2605134 N6210266). Much of this section overlaps that of Site 6, but this site extends to encompass older units. Sampling began at the Maketawa Tephra, rather than the top of this section to slightly overlap this site with Site 6 to ensure a continuous record. Twenty-one samples were collected from this site encompassing from the Maketawa Tephra to the Korito Tephra. Samples were collected where the tephrostratigraphy was clearest within this site and as a result, three sections were sampled, progressing down hill (Figure 2.3). 


\section{SITE 7}

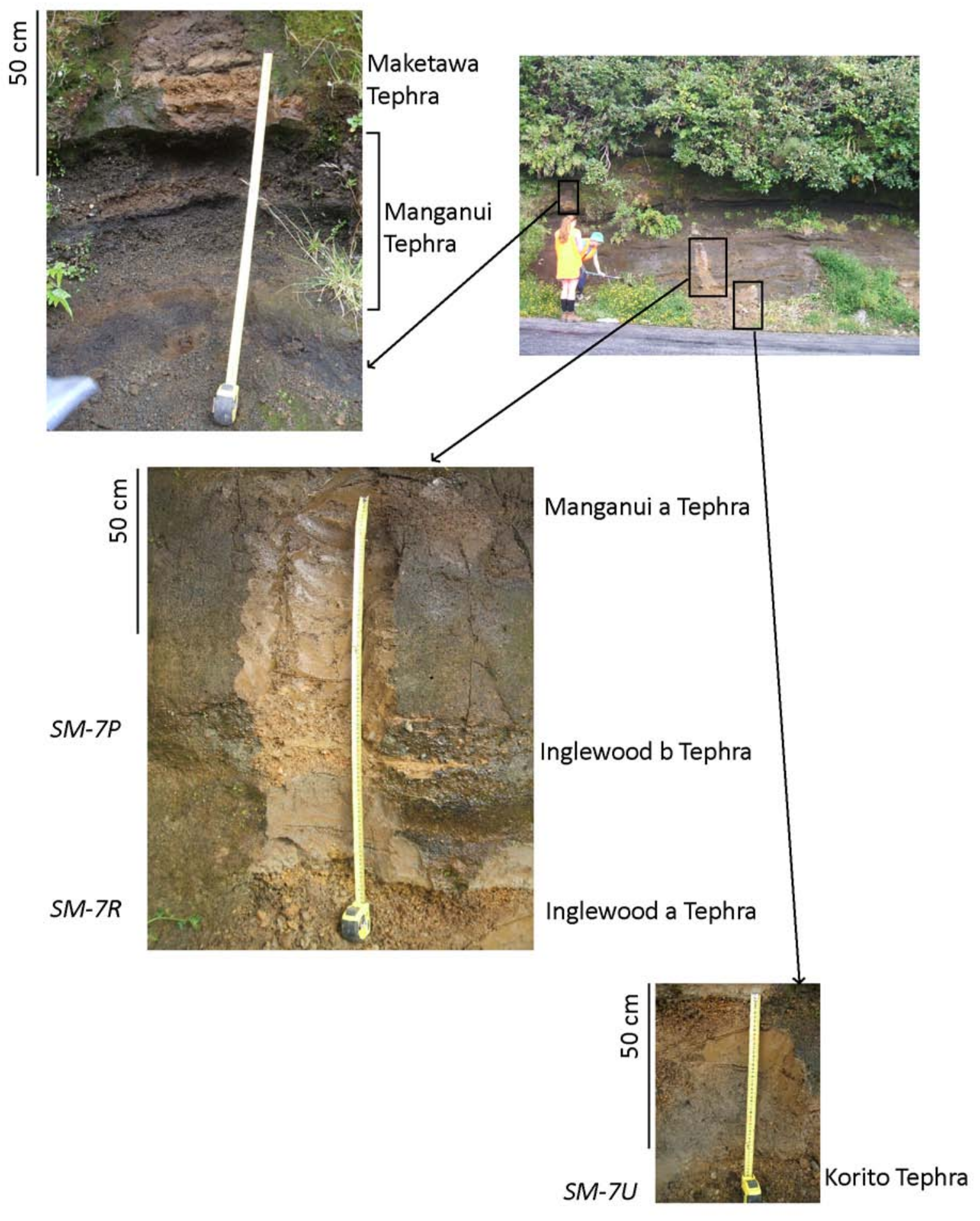

Figure 2.3 Annotated photographs of Site 7. The tephra units identified in this sample are identified. Samples worked on for this study are also labelled with the sample ID (italics). 


\subsection{SAMPLES}

In total 152 samples were collected, of which six samples from Sites 6 and 7 were selected for this study as identified in Figure 2.4. These six samples are the youngest pumiceous samples collected and are considered to characterise Holocene sub-plinian eruptions from Mt Taranaki. Younger samples have better age constraints and are less likely to be affected by secondary processes such as reworking of material and weathering. Pumiceous samples were used as these represent the magma composition at the time of eruption. Glass and mineral phases are also easier to work with in pumice as there is ample glass available for analysis and mineral phases can be easily separated without fragmenting the crystals.

Tephra units were identified and correlated to the existing tephrostratigraphic record using the tephrachronology of Alloway et al. (1995) and Turner et al. (2008) (Figure 2.4. Age constraints for these samples are based on the stratigraphic position of the tephra units in relation to radiocarbon dates of peats and woods from Neall (1979), Neall \& Alloway (1986), Hogg et al. (1987), Lowe (1988), McGlone et al. (1988) and Alloway (1989).

Sample SM-6C was unable to be correlated with a named unit from these workers. The only named unit stratigraphically between the Maketawa and Kaupokonui Tephras is the Curtis Ridge Episode from Turner et al. (2008) (Figure 2.4). The low lithic proportion of SM-6C ( $20 \%$ ) compared with that of the Curtis Ridge Episode (60\% grading to $30 \%$ of Unit 1 ; all of Unit 2) indicates that these are different units. Comparison of the mineral textures and chemistry for SM-6C from this study and the Curtis Ridge Episode from Turner et al. (2008) further indicate that these are different units. For example, the Turner et al. (2008) describe clinopyroxene crystals as having a patchy textured core and oscillatory zoned rim. This is a common feature of Taranaki clinopyroxene, but is notably absent from SM-6C. Confirmation that these units are not the same would require the comparison of glass chemical data, which is not available for the Curtis Ridge Episode. SM-6C directly overlies a series of pyroclastic flow deposits (Figure 2.2), therefore this may be the unnamed pumiceous fall deposit identified by Turner et al. (2008) (Figure 2.4). 


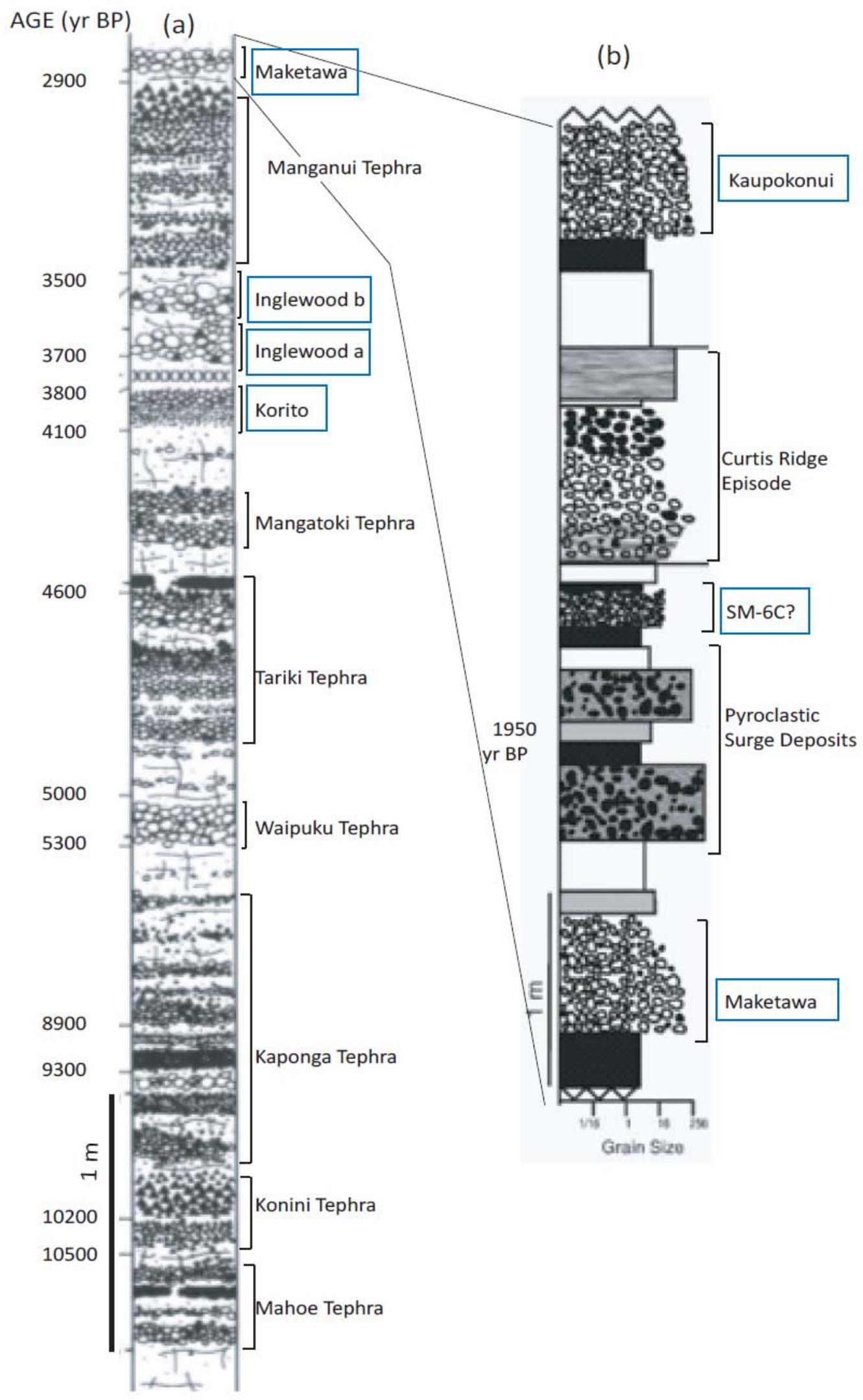

Figure 2.4 The stratigraphic locations of the samples investigated in this study. (a) after Alloway et al. (1995); (b) after Turner et al. (2008). 


\section{CHAPTER 3: METHODS}




\subsection{MAJOR ELEMENT ANALYSIS}

\subsubsection{SAMPLE PREPARATION}

Six samples were prepared for in situ geochemical analyses of mineral phases and glass. Initially all samples were rinsed with water to remove external contaminants and soaked in an ultrasonic tank for up to 20 cycles until the water remained clear. Clean samples were then dried in an oven at $25-40{ }^{\circ} \mathrm{C}$ for $1-3$ days. Pumice clasts $2-3 \mathrm{~cm}$ in size from the six samples of interest were mounted in epoxy resin blocks and sequentially with 400, 600, 2000 and 4000 grit silicon carbide paper followed by 3 and $1 \mu \mathrm{m}$ diamond suspension. Remaining pumice clasts were crushed in a mortar and pestle or, for more delicate clasts, crushed with a pestle in multiple sealed plastic bags to minimise crystal breakage. Glass was separated from the crystals using the hydrodynamic settling method. The resulting crystal concentrate was dried in a $40{ }^{\circ} \mathrm{C}$ oven for $12-48 \mathrm{hr}$ and sieved into $>1 \mathrm{~mm}, 1 \mathrm{~mm}-500 \mu \mathrm{m}, 500-250 \mu \mathrm{m}$ and $<250 \mu \mathrm{m}$ fractions. Clinopyroxene crystals were handpicked from the most crystal-rich fractions under a binocular microscope and mounted on their b-axis (exposing the (010) plane) in epoxy resin blocks to view zone boundaries dipping as closely as possible to vertical (Morgan et al., 2004). Crystals were exposed half way through using 600 and 2000 grit silicon carbide paper, and subsequently polished on 3, 1 and $0.25 \mu \mathrm{m}$ diamond suspension and finally with colloidal silica to eliminate scratches. Each mount was covered in a $25 \mathrm{~nm}$ carbon coat prior to electron microprobe analysis (EMPA) analysis and imaging.

\subsubsection{ELECTRON MICROPROBE ANALYSES}

Major element mineral and glass analyses were obtained at Victoria University of Wellington's (VUW) Geochemistry Laboratory in Wellington, New Zealand, using two different instruments. The differences between these instruments and compatibility of data are addressed in the following sections. 


\subsubsection{JEOL 733 Superprobe Electron Probe Micro-Analyser}

Glass, clinopyroxene, amphibole and plagioclase analyses of samples SM-6C, SM-6K and SM7P were determined using a JEOL 733 Superprobe equipped with three wavelength dispersive spectrometers. Major element concentrations were determined using the ZAF correction method. An accelerating voltage of $15 \mathrm{kV}$, beam current of $12 \mathrm{nA}$ and a focused beam were employed for mineral analyses. For glass, an accelerating voltage of $15 \mathrm{kV}$, beam current of 8 $\mathrm{nA}$ and a $10 \mu \mathrm{m}$ defocused beam were used. Count times were $30 \mathrm{~s}$ with $10 \mathrm{~s}$ of background for each element except $\mathrm{Na}$ and $\mathrm{K}$, which were analysed first and with shorter count times of $10 \mathrm{~s}$ and $5 \mathrm{~s}$ background to minimise alkali loss. Instrumental calibration was carried out daily using synthetic standards for $\mathrm{Al}, \mathrm{Cr}, \mathrm{Fe}, \mathrm{Mg}, \mathrm{Mn}$, and $\mathrm{Ti}$ and natural samples for $\mathrm{Cl}$ (sodalite), $\mathrm{K}$ (orthoclase), $\mathrm{Na}$ (jadeite), $\mathrm{Si}$ and $\mathrm{Ca}$ (wollastonite). Secondary standards were run at the start and end of each day to monitor spectrometer drift during the analysis and evaluate machine precision and accuracy. The secondary standards used were basaltic glass VG-A99 (USNM 113498/1) for volcanic glass and plagioclase, Kakanui augite (USNM 122142) for clinopyroxene and hornblende P.S.U. 4-190 for amphibole analyses. The precision and accuracy of these measurements are listed in Table A2.1. All standard values were accurate to $\leq$ $7 \%$ except for $\mathrm{MnO}, \mathrm{Cr}_{2} \mathrm{O}_{3}$ and $\mathrm{Cl}$ which are always present at levels $<0.5$ wt $\%$ in these standards resulting in significantly higher errors.

Backscattered electron (BSE) imaging of clinopyroxene crystals for diffusion modelling was carried out on this instrument at an accelerating voltage of $15 \mathrm{kV}$ and beam current of $12 \mathrm{nA}$. The magnification and contrast settings were optimised for each image to highlight mineral zoning.

\subsubsection{JEOL JXA-8230 Electron Probe Micro-Analyser}

Glass, clinopyroxene, amphibole, plagioclase and Fe-Ti oxide analyses for all samples were determined on a JEOL JXA-8230 Electron Probe Micro-Analyser with five wavelength dispersive spectrometers (WDS), two containing large crystals to measure minor elements present at relatively low concentrations. Mineral phases were analysed under a static electron 
Table 3.1 JEOL 733 Superprobe Electron Probe Micro-Analyser standard data precision and accuracy.

Recommended values: VG-A99-Jarosweich et al. (1980); Kakanui Augite-Klugel et al. (2005); Hornblende 4-190Ingamells (1983)

\begin{tabular}{|c|c|c|c|c|c|}
\hline \multicolumn{6}{|c|}{ VG-A99 Basaltic Glass (USNM 113498/1) } \\
\hline & Mean $^{1}$ & $\begin{array}{r}\text { Recommended } \\
\text { values }\end{array}$ & 2 SD & $\begin{array}{r}\% 2 \mathbf{S D}^{2} \\
\text { (precision) }\end{array}$ & $\begin{array}{r}\text { \% Difference } \\
\text { (accuracy) }\end{array}$ \\
\hline $\mathrm{SiO}_{2}$ (wt \%) & 50.72 & 50.94 & 0.93 & 1.8 & -0.4 \\
\hline $\mathrm{TiO}_{2}$ & 4.14 & 4.06 & 0.24 & 5.9 & 1.9 \\
\hline $\mathrm{Al}_{2} \mathbf{O}_{3}$ & 12.63 & 12.49 & 0.30 & 2.4 & 1.1 \\
\hline $\mathrm{FeO}$ & 13.31 & 13.3 & 0.43 & 3.2 & 0.1 \\
\hline MnO & 0.25 & 0.15 & 0.08 & 32.5 & 66.0 \\
\hline MgO & 5.24 & 5.08 & 0.21 & 4.1 & 3.2 \\
\hline $\mathrm{CaO}$ & 9.16 & 9.3 & 0.21 & 2.3 & -1.5 \\
\hline $\mathrm{Na}_{2} \mathrm{O}$ & 2.73 & 2.66 & 0.10 & 3.6 & 2.7 \\
\hline $\mathbf{K}_{2} \mathbf{O}$ & 0.84 & 0.82 & 0.04 & 5.1 & 2.3 \\
\hline TOTAL & 98.81 & 98.80 & & & \\
\hline n & 59 & & & & \\
\hline \multicolumn{6}{|c|}{ Kakanui augite (USNM 122142) } \\
\hline & $\operatorname{Mean}^{1}$ & $\begin{array}{r}\text { Recommended } \\
\text { values }\end{array}$ & $2 \mathrm{SD}$ & $\begin{array}{r}\% 2 \mathrm{SD}^{2} \\
\text { (precision) }\end{array}$ & $\begin{array}{r}\text { \% Difference } \\
\text { (accuracy) }\end{array}$ \\
\hline $\mathrm{SiO}_{2}$ & 50.69 & 50.39 & 0.82 & 1.6 & 0.6 \\
\hline $\mathrm{TiO}_{2}$ & 0.85 & 0.78 & 0.06 & 7.1 & 9.5 \\
\hline $\mathrm{Al}_{2} \mathbf{O}_{3}$ & 8.76 & 8.72 & 0.39 & 4.5 & 0.5 \\
\hline $\mathrm{Cr}_{2} \mathrm{O}_{3}$ & 0.21 & 0.15 & 0.07 & 31.2 & 39.3 \\
\hline FeO & 6.38 & 6.31 & 0.14 & 2.2 & 1.1 \\
\hline MnO & 0.17 & 0.14 & 0.05 & 26.7 & 22.6 \\
\hline MgO & 16.72 & 16.45 & 0.29 & 1.8 & 1.6 \\
\hline $\mathrm{CaO}$ & 15.97 & 15.89 & 0.24 & 1.5 & 0.5 \\
\hline $\mathrm{Na}_{2} \mathrm{O}$ & 1.36 & 1.25 & 0.05 & 3.7 & 8.7 \\
\hline TOTAL & 101.07 & 100.08 & & & \\
\hline $\mathbf{n}$ & 39 & & & & \\
\hline \multicolumn{6}{|c|}{ Hornblende 4-190 } \\
\hline & Mean $^{1}$ & $\begin{array}{r}\begin{array}{r}\text { Recommended } \\
\text { values }\end{array} \\
\end{array}$ & $2 \mathrm{SD}$ & $\begin{array}{r}\% 2 \mathrm{SD}^{2} \\
\text { (precision) }\end{array}$ & $\begin{array}{r}\text { \% Difference } \\
\text { (accuracy) }\end{array}$ \\
\hline $\mathrm{SiO}_{2}$ & 40.04 & 39.54 & 1.49 & 3.7 & 1.3 \\
\hline $\mathrm{TiO}_{2}$ & 2.69 & 2.88 & 0.14 & 5.2 & -6.5 \\
\hline $\mathrm{Al}_{2} \mathbf{O}_{3}$ & 10.58 & 10.00 & 0.32 & 3.0 & 5.8 \\
\hline FeO & 26.00 & 26.15 & 0.68 & 2.6 & -0.6 \\
\hline MnO & 0.47 & 0.41 & 0.09 & 19.8 & 14.5 \\
\hline MgO & 4.58 & 4.38 & 0.03 & 0.6 & 4.6 \\
\hline $\mathrm{CaO}$ & 10.74 & 10.79 & 0.15 & 1.4 & -0.5 \\
\hline $\mathrm{Na}_{2} \mathrm{O}$ & 2.09 & 2.02 & 0.01 & 0.4 & 3.3 \\
\hline $\mathbf{K}_{2} \mathbf{O}$ & 1.47 & 1.47 & 0.04 & 3.0 & 0.2 \\
\hline Cl & 0.19 & 0.18 & 0.05 & 28.2 & 7.4 \\
\hline Total & 98.85 & 97.82 & & & \\
\hline n & 20 & & & & \\
\hline
\end{tabular}


beam of $15 \mathrm{kV}$ accelerating voltage and a current of $12 \mathrm{nA}$, whilst glass analyses used a $10 \mu \mathrm{m}$ defocused beam with an accelerating voltage of $15 \mathrm{kV}$ and beam current of $8 \mathrm{nA}$. Each element had a count time of $30 \mathrm{~s}$ and a background count time of $15 \mathrm{~s}$ per analysis. Alkali monitoring detected no measureable $\mathrm{Na}$ or $\mathrm{K}$ loss using these count times. Table 3.2 shows the conditions for each analysis type. Calibrations were carried out daily on well characterised reference materials (primary standards), listed in Table 3.2. The primary standard choosen for each set of analyses was compositionally similar to the phase being analysed in order to minimise matrix effects. Where element concentrations in the standard materials were not sufficient to produce accurate calibrations $(<0.5 \mathrm{wt} \%)$, oxides were used for calibration. These same primary standards were analysed as secondary standards immediately after instrument calibration and after every 10-20 sample analyses. This allowed monitoring of any instrumental drift and correction for variation in analytical conditions. Mineral and glass analyses were corrected to this secondary standard. If secondary standard values were inaccurate, the calibration was redone.

Table 3.2: Analytical conditions during analytical sessions with the JEOL JXA-8230 EMPA. Crystal used in noted in brackets.

\begin{tabular}{|c|c|c|c|c|}
\hline \multicolumn{5}{|c|}{ Glass: Primary/Secondary Standard-VG-A99; Additional Standard-VG568 } \\
\hline Channel 1 & Channel 2 & Channel 3 & Channel 4 & Channel 5 \\
\hline Ti $(\mathrm{PET})$ & Si (TAP) & $\mathrm{Na}$ (TAP) & $\mathrm{K}(\mathrm{PET})$ & $\mathrm{Ca}(\mathrm{PET})$ \\
\hline $\mathrm{Mn}^{*}(\mathrm{LIF})$ & $\mathrm{Mg}(\mathrm{TAP})$ & $\mathrm{Al}(\mathrm{TAP})$ & $\mathrm{Fe}(\mathrm{LIF})$ & \\
\hline \multicolumn{5}{|c|}{ Clinopyroxene: Primary/Secondary Standard-Kakanui augite; Additional Standard-PX-1 } \\
\hline Channel 1 & Channel 2 & Channel 3 & Channel 4 & Channel 5 \\
\hline $\mathrm{Mn}^{*}(\mathrm{LIF})$ & $\mathrm{Si}$ (TAP) & $\mathrm{Mg}(\mathrm{TAP})$ & $\mathrm{Ca}(\mathrm{PET})$ & Fe (LIF) \\
\hline & $\mathrm{Al}(\mathrm{TAP})$ & $\mathrm{Na}(\mathrm{TAP})$ & & $\mathrm{Ti}(\mathrm{PET})$ \\
\hline \multicolumn{5}{|c|}{ Amphibole: Primary/Secondary Standard-Hornblende 4-190; Additional Standard- Engles amphibole } \\
\hline Channel 1 & Channel 2 & Channel 3 & Channel 4 & Channel 5 \\
\hline $\mathrm{Ti}(\mathrm{PET})$ & $\mathrm{Na}$ (TAP) & Si (TAP) & Fe (LIF) & $\mathrm{K} *$ (PET) \\
\hline & $\mathrm{Mg}(\mathrm{TAP})$ & $\mathrm{Al}(\mathrm{TAP})$ & $\mathrm{Ca}(\mathrm{PET})$ & $\mathrm{Mn}^{*}(\mathrm{PET})$ \\
\hline \multicolumn{5}{|c|}{ Plagioclase: Primary/Secondary Standard-Plagioclase NMNH 96189; Additional Standard- Or-1A } \\
\hline Channel 1 & Channel 2 & Channel 3 & Channel 4 & Channel 5 \\
\hline $\mathrm{Sr}^{*}$ (PET) & $\mathrm{Na}$ (TAP) & Si (TAP) & $\mathrm{Ca}(\mathrm{PET})$ & $\mathrm{K}^{\#}(\mathrm{PET})$ \\
\hline $\mathrm{Sr}^{*}(\mathrm{PET})$ & $\mathrm{Mg}^{*}$ (TAP) & $\mathrm{Al}$ (TAP) & $\mathrm{Fe}^{*}(\mathrm{LIF})$ & $\mathrm{Ti}^{*}(\mathrm{PET})$ \\
\hline \multicolumn{5}{|c|}{ Oxides: Primary/Secondary Standard-IImenite NMNH 96189; Additional Standard- Magnetite NMNH 96189} \\
\hline Channel 1 & Channel 2 & Channel 3 & Channel 4 & Channel 5 \\
\hline $\mathrm{Ca}^{+}(\mathrm{PET})$ & $\mathrm{Mg}^{*}$ (TAP) & $\mathrm{Si}^{+}$(TAP) & $\mathrm{Fe}$ (LIF) & $\mathrm{Mn}$ (LIF) \\
\hline Ti (PET) & & $\mathrm{Al}^{*}$ (TAP) & & $\mathrm{Cr}^{*}$ (PET) \\
\hline
\end{tabular}

Unless otherwise stated calibration for each element was on the primary standard.

*element standardized on oxide

\# element standardized on Or-1

+ element standardized on Wollastonite. 
This procedure also gives an indication of analytical precision and accuracy and enables correction for instrument drift and any changes in analytical conditions. However, it underestimates true analytical error by neglecting to account for the matrix effects of slight compositional differences between standards and sample mineral analyses. To better quantify these uncertainties, additional reference materials were analysed with a similar composition to the sample and primary/secondary standards. These additional standards, specified in Tables 3.2 and 3.3, were analysed immediately after instrument calibration. These showed reduced precision and accuracy compared to the primary/secondary standard. For elements present in moderate to high concentrations in the primary/secondary standards $(\geq 0.5 \mathrm{wt} \%)$ the precision was typically $< \pm 5 \%$ and always $< \pm 7 \%$, and accuracy for these elements was always $<5 \%$ (except for $\mathrm{TiO}_{2}$ in Kakanui augite). The additional standards have precisions of $< \pm 15 \%$ except for $\mathrm{MnO}$ in Engles amphibole and $\mathrm{Na}_{2} \mathrm{O}$ in orthoclase. The accuracy for these additional standards is $\leq 11 \%$ except for $\mathrm{Na}_{2} \mathrm{O}$ in orthoclase. Errors increase significantly when concentrations are $<0.5 \mathrm{wt} \%$ with precisions typically $\pm 20-30 \%$ up to $\pm 300-400 \%$ for $\mathrm{K}_{2} \mathrm{O}$ and $\mathrm{SrO}$ in plagioclase and accuracy around $\pm 16-75 \%$. These elements (except $\mathrm{K}_{2} \mathrm{O}$ ) were analysed using LA-ICP-MS to a much greater precision and accuracy. In most cases (except for glass) the errors for sample analyses are much closer to those of the primary/secondary standards because these are closer in composition than the additional standards.

Backscattered electron imaging was again carried out using an accelerating voltage of $15 \mathrm{kV}$ and a current of $12 \mathrm{nA}$.

\subsubsection{Comparison of EMPA data}

The majority of major element data used in this study were obtained from the JEOL JXA 8230 EMPA. The data between the two instruments is comparable as the precision and accuracy of elements in concentrations of $>0.5 \mathrm{wt} \%$ is $<5-7 \%$ for both instruments (Figure 3.1). However, at lower concentrations the JEOL JXA-8230 has significantly lower errors. The standardising procedure is also much more robust for this instrument as standardising was 


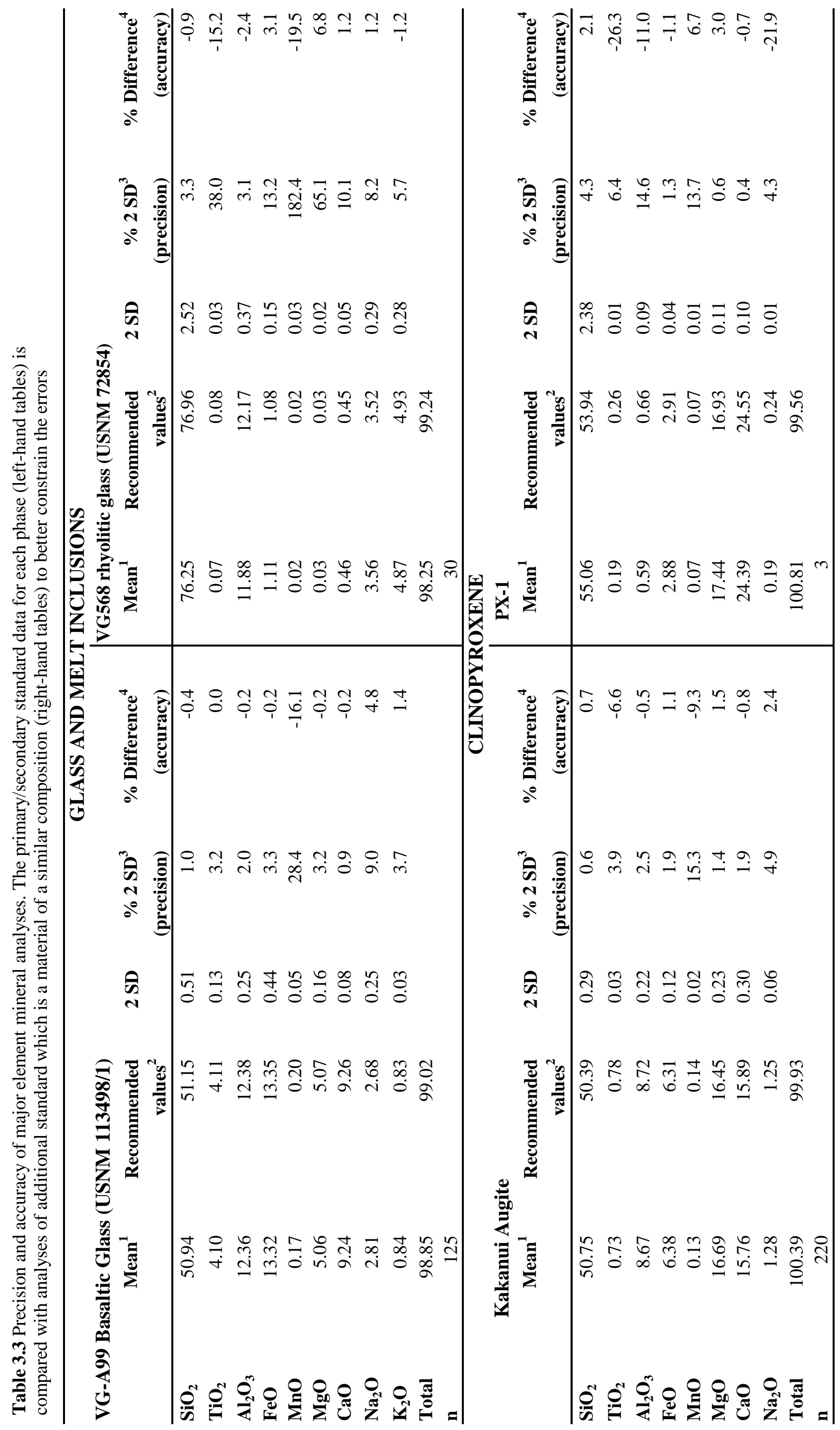




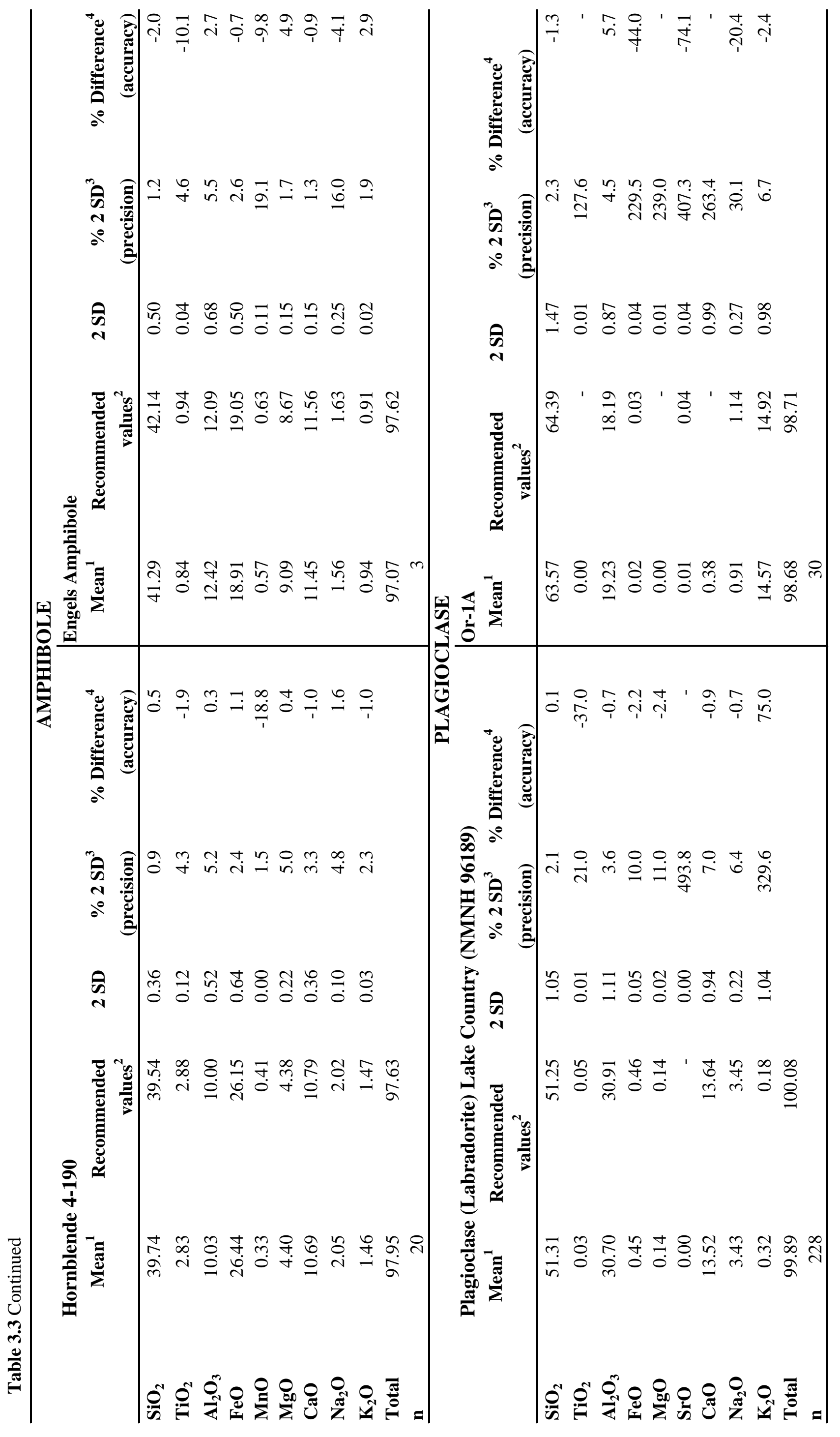




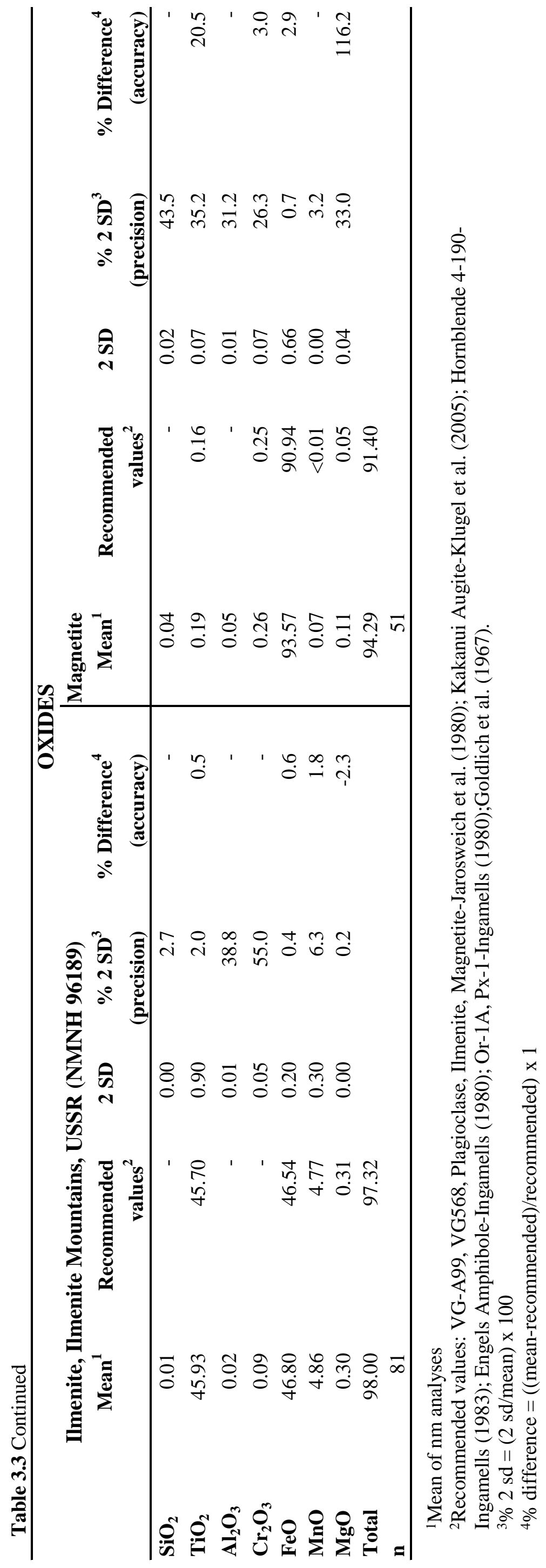


performed on mineral standards of a similar composition to the unknown rather than oxides and two standards were run to more completely assess the errors involved in these analyses.

Figure 3.1 A graphical comparison between the JEOL 733 Superprobe (dashed line) and JEOL JXA-8230 (solid line) Electron Probe Micro-Analysers evaluated by comparing how closely the average measured values of standards reproduces the reference values. Grey area represents $\pm 5 \%$ accuracy.

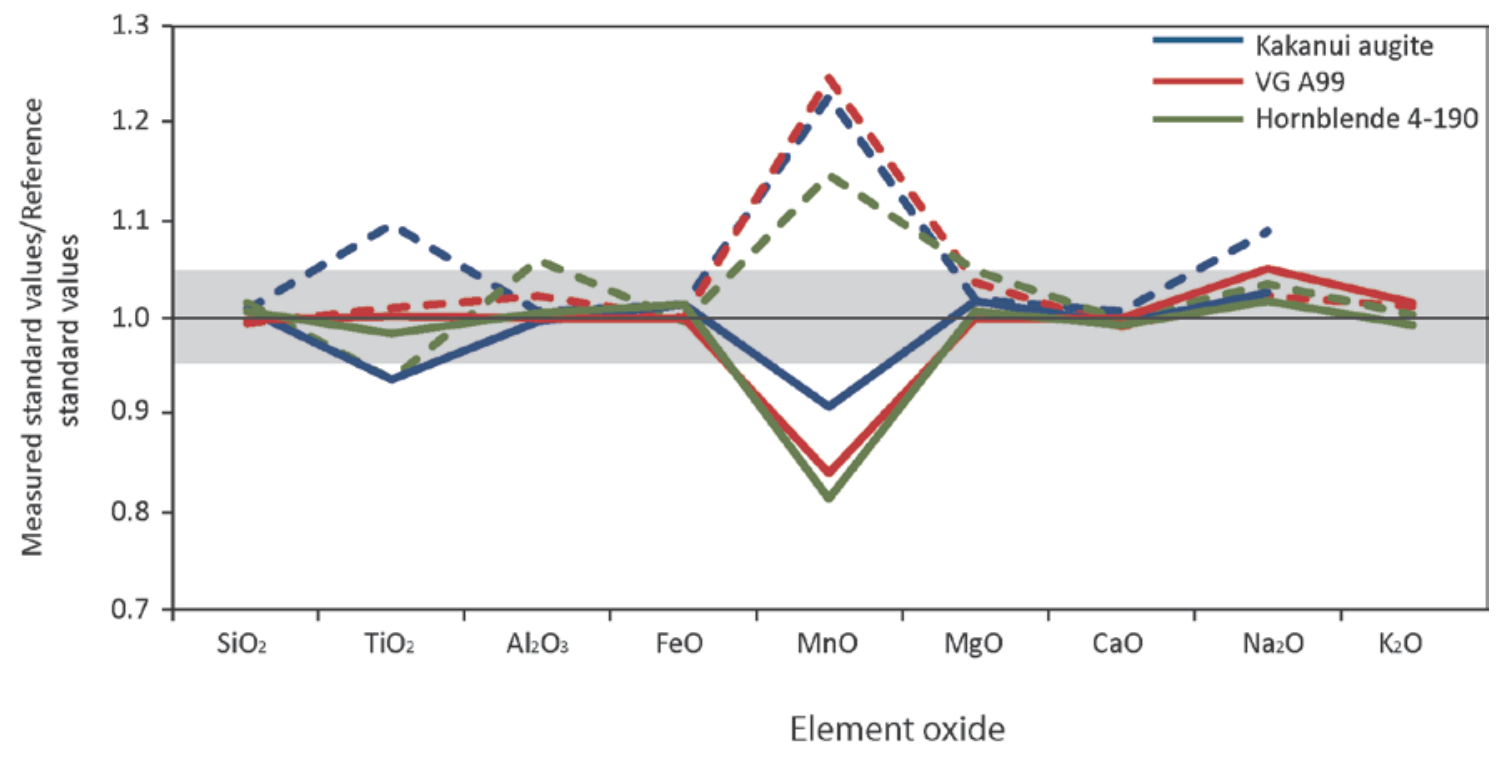

\subsection{TRACE ELEMENT ANALYSIS}

\subsubsection{GLASS TRACE ELEMENT ANALYSIS}

\subsubsection{Sample Preparation}

Glass trace element chemistry was obtained by solution inductively coupled plasma mass spectrometry (ICP-MS). Crushed pumice, which was earlier separated from crystals, was rinsed in methanol to separate the glass fraction for each sample. These were then dried at $40^{\circ} \mathrm{C}$ in an oven and inspected under a binocular microscope to check the purity of the glass was satisfactory. The samples were then rinsed three times in $>18.2 \mathrm{M} \Omega$ ultra clean water (MQ $\mathrm{H}_{2} \mathrm{O}$ ) and again dried at $40^{\circ} \mathrm{C}$ in an oven.

A total of 12 analyses were carried out: three samples were run in duplicate, three samples were run once and BHVO-2 and BCR-2 basaltic rock standards were run as primary and secondary standards, respectively. A blank was also analysed to check that the digestion process did not 
introduce any contamination. Care was taken at each step to ensure that no material was lost during digestion, as this would invalidate the dilution factors. Savillex ${ }^{\odot}$ teflon beakers $(23 \mathrm{~mL})$ were acid cleaned in $6 \mathrm{M}$ AR grade $\mathrm{HCl}, 6 \mathrm{M} \mathrm{AR}$ grade $\mathrm{HNO}_{3}, 7 \mathrm{M}$ sub-boiled (sb) $\mathrm{HNO}_{3}$ and Seastar (ss) $1 \mathrm{~mL} 7 \mathrm{M} \mathrm{HNO}_{3}$ with $0.2 \mathrm{~mL}$ ss HF. Beakers were capped and heated at $120^{\circ} \mathrm{C}$ on a hotplate during each acid step for at least $24 \mathrm{hr}$. Between cleaning steps, beakers were rinsed thoroughly three times with $\mathrm{MQ} \mathrm{H}_{2} \mathrm{O}$. Glass digestion was carried out using the following steps: 1) between 50 and $80 \mathrm{mg}$ of glass from each sample was weighed into acid cleaned beakers using a high precision balance ( $\pm 0.0001 \mathrm{~g}) .2$ ) approximately $0.2 \mathrm{~mL}$ of ss $16 \mathrm{M} \mathrm{HNO}_{3}$ and $1 \mathrm{~mL}$ of concentrated ss HF were added to the glass and capped and left on a hotplate at $120^{\circ} \mathrm{C}$ for two days. 3) samples were then evaporated at $120^{\circ} \mathrm{C}$ for ca. $5 \mathrm{hr}$ until they were incipiently dry (dry, but not yet cracking). 4) $1 \mathrm{~mL}$ of $16 \mathrm{M}$ ss $\mathrm{HNO}_{3}$ was added, left uncapped on the hotplate overnight to nitrify the sample, and then capped on the hotplate in $5 \mathrm{~mL}$ of $6 \mathrm{M}$ ss $\mathrm{HCl}$ for $3 \mathrm{hr}$ until it was fully in solution. 5) the sample was then uncapped and dried overnight. 6) approximately $1 \mathrm{~mL}$ of $16 \mathrm{M}$ ss $\mathrm{HNO}_{3}$ was then added to each sample for nitrification and immediately evaporated. Step 6 was repeated followed by the addition of $9 \mathrm{~mL}$ of $1 \mathrm{M} \mathrm{HNO}_{3}$ to the samples, which were then capped and put on the hotplate until analysis.

Thirty $10 \mathrm{~mL}$ centrifuge tubes were rinsed three times with $\mathrm{MQ} \mathrm{H}_{2} \mathrm{O}$, soaked in dilute $\mathrm{ss}^{\mathrm{HNO}_{3}}$ for three weeks and rinsed three more times in $\mathrm{MQ} \mathrm{H}_{2} \mathrm{O}$. These were then weighed using the high precision balance so that the mass of samples transferred to the centrifuge tube could be determined. Each sample solution was transferred to centrifuge tubes, weighed and centrifuged at $2000 \mathrm{rpm}$ for $5 \mathrm{~min}$. These were inspected for sedimentation to ensure all material had been digested. $60 \mu \mathrm{L}$ of each sample was transferred into another centrifuge tube and diluted with 6 $\mathrm{mL} 1 \% \mathrm{HNO}_{3}$ and reweighed. Sample weights recorded at each of these steps were used to precisely calculate the dilution factors.

\subsubsection{Mass Spectrometry}

Trace element concentrations of glass were analysed using the Agilent 7500CS ICP-MS at VUW, Wellington, New Zealand. Each analysis comprised $90 \mathrm{~s}$ of background measurement 
whilst aspirating $1 \% \mathrm{ss} \mathrm{HNO}_{3}$, a total count time of $180 \mathrm{~s}$ and then $180 \mathrm{~s}$ of washout involving $30 \mathrm{~s}$ of $\mathrm{MQ} \mathrm{H}_{2} \mathrm{O}$ and $150 \mathrm{~s}$ of $1 \% \mathrm{HNO}_{3}$. Analyses were bracketed by the primary standard (BHVO-2) and regular analyses of the secondary standard (BCR-2). ICP-MS tuning was carried out on a Agilent $1 \mathrm{ppb}$ tuning solution which contains $\mathrm{Li}, \mathrm{Co}, \mathrm{Y}, \mathrm{Ce}$ and $\mathrm{Tl}$ to maximise signal stability resulting in RSD values of $<4 \%$ for all monitored elements and oxide interferences as determined by $\mathrm{CeO}^{+} / \mathrm{Ce}^{+}$of $<1.5 \%$. This tuning resulted in $\mathrm{RSD}$ values of $<4 \%$ for all monitored elements when running BHVO-2. Analysis conditions are shown in Table 3.4.

$\mathrm{CaO}$ values from the ICP-MS analysis were compared with $\mathrm{CaO}$ values obtained from EMPA analysis as an internal calibration to correct for instrument drift and sample loss. After background counts were subtracted, the trace element concentrations were calculated by:

$$
\begin{gathered}
C_{\text {sample }}^{\text {CaO,ICP-MS }}=C_{\text {std }}^{\text {CaO }} \times\left(\frac{C P S_{\text {Sample }}^{\text {Ca }}}{C P S_{\text {std }}^{\text {Ca }}}\right) \\
C_{\text {sample }}^{x, I C P-M S}=C_{\text {std }}^{x} \times\left(\frac{C_{\text {sample }}^{\text {CaO,EMPA }}}{C_{\text {sample }}^{\text {CaO,ICP-MS }}}\right) \times\left(\frac{C P S_{\text {sample }}^{x}}{C P S_{\text {std }}^{x}}\right)
\end{gathered}
$$

$C_{\text {sample }}^{\text {CaO,ICP-MS }} C_{\text {sample }}^{\text {CaO,EMPA }}=$ concentration of Ca determined by ICP-MS or EMPA

$C_{s t d}^{C a O}=$ reference $\mathrm{CaO}$ concentration of the primary standard BHVO-2

$C P S_{\text {sample }}^{C a}, C P S_{\text {std }}^{C a}=$ counts per second obtained on ${ }^{43} \mathrm{Ca}$ during the analysis of the dilution of the sample or standard

$C a_{\text {sample }}^{x, I C P-M S}=$ concentration of element $\mathrm{x}$ determined by ICP-MS

$C_{s t d}^{x}=$ reference concentration of element $\mathrm{x}$ in the standard BHVO-2 from the Georem database (http://georem.mpch-mainz.gwdg.de/)

$C P S_{\text {sample }}^{x}, C P S_{\text {std }}^{x}=$ counts per second obtained on an isotope of element $\mathrm{x}$ in the dilution of the sample or standard 
Table 3.4 ICP-MS instrumental and analysis conditions

\section{ICP-MS}

ICP-MS system

Acquisition mode

Detection mode

\section{Standards and Calibration}

Calibration standard

Secondary standard

Internal standard

\section{Method}

Background acquisition

Sample/standard acquisition

Washout time

Measured isotopes and integration times

\section{Tuning}

Tuning standard

Monitored isotopes during tuning

Calibration standard

Monitored isotopes during tuning

Background

Oxides

Carrier gas (Ar)

Makeup gas (Ar)

RF power

RF matching

Sample depth (z)
Agilent 7500CS

Peak hopping

Pulse and analogue

BHVO-2

BCR-2

${ }^{43} \mathrm{Ca}$
Agilent $1 \mathrm{ppb}$ solution ( $\mathrm{Li}, \mathrm{Co}, \mathrm{Y}, \mathrm{Ce}, \mathrm{Tl})$

${ }^{7} \mathrm{Li},{ }^{59} \mathrm{Co},{ }^{89} \mathrm{Y},{ }^{140} \mathrm{Ce},{ }^{205} \mathrm{Tl}$ (RSD $<4 \%$ for each isotope) BHVO-2

${ }^{7} \mathrm{Li},{ }^{25} \mathrm{Mg},{ }^{43} \mathrm{Ca},{ }^{47} \mathrm{Ti},{ }^{51} \mathrm{~V},{ }^{53} \mathrm{Cr},{ }^{60} \mathrm{Ni},{ }^{86} \mathrm{Sr},{ }^{90} \mathrm{Zr},{ }^{137} \mathrm{Ba}$, ${ }^{140} \mathrm{Ce},{ }^{208} \mathrm{~Pb}$

${ }^{43}$ Ca typically $<5000$ cps always $<7000$ cps $($ ca. $<1 \%$ BHVO-2 signal, $<10 \%$ sample signal)

$\mathrm{CeO}+/ \mathrm{Ce}+: 1$ ppb solution $<1.5 \%$

$1.11 \mathrm{~L} / \mathrm{min}$

$0 \mathrm{~L} / \mathrm{min}$

$1500 \mathrm{~W}$

$1.74 \mathrm{~V}$

$7 \mathrm{~mm}$

The precision and accuracy of glass trace element analyses were determined by twice analysing BCR-2 as a secondary standard during the analyses (Table 3.5). Most elements have a precision $<5 \%$ except $\mathrm{Cr}, \mathrm{Zn}, \mathrm{Sr}(<10 \%)$ and $\mathrm{Cu}(22 \%)$. The BCR-2 analyses have an accuracy of $<10 \%$ for most elements except $\mathrm{Mo}, \mathrm{Pb}$ and $\mathrm{U}(<20 \%)$ and $\mathrm{Cr}, \mathrm{Cu}(<30 \%)$. The reproducibility of the analyses were assessed by running duplicates of three of the six samples, which also show that most elements reproducible to $< \pm 5 \%$ (exceptions to this are ${ }^{45} \mathrm{Sc},{ }^{66} \mathrm{Zn},{ }^{208} \mathrm{~Pb},{ }^{232} \mathrm{Th}$; Table 3.6). 
Table 3.5 Precision and accuracy of ICP-MS trace element data

\begin{tabular}{|c|c|c|c|c|c|c|c|}
\hline $\mathrm{CaO}=7.12$ & $\begin{array}{l}\text { average } \\
\text { BCR-2 a }\end{array}$ & $\begin{array}{l}\text { average } \\
\text { BCR-2 b } \\
\end{array}$ & Mean & $\begin{array}{l}\text { recommended } \\
\text { values }^{1}\end{array}$ & $2 \mathrm{SD}$ & $\begin{array}{l}\% 2 \mathrm{SD}^{2} \\
\text { (precision) }\end{array}$ & $\begin{array}{l}\% \text { difference } \\
\text { (accuracy) }\end{array}$ \\
\hline TiO2 (wt\%) & 2.16 & 2.17 & 2.17 & 2.26 & 0.02 & 0.70 & -4.04 \\
\hline MgO & 3.50 & 3.55 & 3.52 & 3.59 & 0.07 & 2.06 & -1.91 \\
\hline $\mathrm{CaO}$ & 7.12 & 7.12 & 7.12 & 7.12 & 0.00 & 0.00 & 0.00 \\
\hline \multicolumn{8}{|l|}{ ppm } \\
\hline $\mathbf{L i}$ & 9.64 & 9.71 & 9.67 & 9 & 0.09 & 0.94 & 7.48 \\
\hline Sc & 31.8 & 32.7 & 32.3 & 33 & 1.25 & 3.88 & -2.27 \\
\hline V & 398 & 399 & 398 & 416 & 1.30 & 0.33 & -4.24 \\
\hline $\mathrm{Cr}$ & 12.6 & 13.2 & 12.9 & 18 & 0.78 & 6.05 & -28.29 \\
\hline Co & 35.7 & 35.9 & 35.8 & 37 & 0.29 & 0.82 & -3.20 \\
\hline $\mathbf{N i}$ & 4.05 & 8.44 & 6.25 & 18 & 6.21 & 99.43 & -65.29 \\
\hline $\mathrm{Cu}$ & 13.6 & 15.9 & 14.7 & 21 & 3.27 & 22.17 & -29.86 \\
\hline $\mathbf{Z n}$ & 124 & 131 & 127 & 127 & 10.24 & 8.05 & 0.15 \\
\hline $\mathbf{G a}$ & 21.5 & 22.1 & 21.8 & 23 & 0.90 & 4.13 & -5.15 \\
\hline $\mathbf{R b}$ & 45.8 & 46.5 & 46.2 & 46.9 & 1.06 & 2.29 & -1.55 \\
\hline $\mathrm{Sr}$ & 326 & 340 & 333 & 340 & 19.58 & 5.87 & -1.97 \\
\hline $\mathbf{Y}$ & 35.0 & 35.6 & 35.3 & 37 & 0.91 & 2.57 & -4.67 \\
\hline${ }^{90} \mathrm{Zr}$ & 175 & 179 & 177 & 184 & 5.31 & 3.00 & -3.82 \\
\hline${ }^{91} \mathrm{Zr}$ & 174 & 178 & 176 & 184 & 6.00 & 3.41 & -4.31 \\
\hline $\mathrm{Nb}$ & 11.6 & 11.9 & 11.8 & 12.6 & 0.39 & 3.34 & -6.52 \\
\hline Mo & 282 & 287 & 285 & 250 & 7.25 & 2.55 & 13.91 \\
\hline Cs & 1.15 & 1.14 & 1.14 & 1.1 & 0.00 & 0.16 & 4.05 \\
\hline Ba & 668 & 684 & 676 & 677 & 22.78 & 3.37 & -0.17 \\
\hline La & 24.5 & 24.9 & 24.7 & 24.9 & 0.57 & 2.33 & -0.71 \\
\hline $\mathrm{Ce}$ & 50.5 & 51.1 & 50.8 & 52.9 & 0.90 & 1.76 & -4.02 \\
\hline Pr & 6.71 & 6.78 & 6.74 & 6.7 & 0.09 & 1.34 & 0.67 \\
\hline Nd & 28.5 & 28.8 & 28.6 & 28.7 & 0.42 & 1.47 & -0.31 \\
\hline Sm & 6.50 & 6.47 & 6.49 & 6.58 & 0.03 & 0.50 & -1.43 \\
\hline${ }^{151} \mathbf{E u}$ & 2.00 & 1.99 & 2.00 & 1.96 & 0.00 & 0.08 & 1.81 \\
\hline${ }^{153} \mathbf{E u}$ & 2.06 & 2.06 & 2.06 & 1.96 & 0.00 & 0.24 & 5.18 \\
\hline Gd & 6.85 & 6.78 & 6.82 & 6.75 & 0.10 & 1.40 & 1.00 \\
\hline Tb & 1.03 & 1.03 & 1.03 & 1.07 & 0.01 & 0.70 & -3.90 \\
\hline Dy & 6.36 & 6.35 & 6.35 & 6.41 & 0.02 & 0.31 & -0.86 \\
\hline Ho & 1.28 & 1.28 & 1.28 & 1.28 & 0.01 & 0.39 & 0.24 \\
\hline $\mathbf{E r}$ & 3.61 & 3.58 & 3.60 & 3.66 & 0.05 & 1.26 & -1.71 \\
\hline $\mathbf{T m}$ & 0.506 & 0.518 & 0.512 & 0.54 & 0.02 & 3.28 & -5.17 \\
\hline $\mathbf{Y b}$ & 3.30 & 3.31 & 3.31 & 3.38 & 0.02 & 0.55 & -2.17 \\
\hline Lu & 0.480 & 0.486 & 0.483 & 0.503 & 0.01 & 1.64 & -3.98 \\
\hline Hf & 4.56 & 4.55 & 4.55 & 4.9 & 0.02 & 0.47 & -7.06 \\
\hline Ta & 0.739 & 0.746 & 0.742 & 0.74 & 0.01 & 1.33 & 0.32 \\
\hline $\mathbf{W}$ & 0.330 & 0.326 & 0.328 & - & 0.01 & 1.66 & - \\
\hline $\mathbf{P b}$ & 12.9 & 13.2 & 13.1 & 11 & 0.44 & 3.38 & 18.89 \\
\hline Th & 5.64 & 5.47 & 5.55 & 5.7 & 0.23 & 4.13 & -2.55 \\
\hline $\mathbf{U}$ & 1.48 & 1.51 & 1.49 & 1.69 & 0.04 & 2.95 & -11.58 \\
\hline
\end{tabular}

${ }^{1}$ Recommended values: Georem preferred values

$2 \% 2 \mathrm{sd}=(2 \mathrm{sd} / \mathrm{mean}) \times 100$

$3 \%$ difference $=(($ mean-recommended $) /$ recommended $) \times 100$ 
Table 3.6 Reproducibility of duplicate sample analyses

\begin{tabular}{|c|c|c|c|c|c|c|c|c|c|}
\hline wt\% & 6a-1 & $6 a-2$ & $\%$ difference $^{1}$ & $6 c-1$ & $6 c-2$ & $\%$ difference $^{1}$ & $7 r-1$ & $7 r-2$ & $\%$ difference $^{1}$ \\
\hline & & & $6 \mathbf{a}$ & & & $6 c$ & & & $7 r$ \\
\hline TiO2 & 0.392 & 0.405 & -3.3 & 0.900 & 0.882 & 2.0 & 0.219 & 0.215 & 2.1 \\
\hline MgO & 0.852 & 0.896 & -4.9 & 1.743 & 1.700 & 2.6 & 0.263 & 0.260 & 0.9 \\
\hline $\mathrm{CaO}$ & 2.72 & 2.72 & 0.0 & 5.09 & 5.09 & 0.0 & 1.41 & 1.41 & 0.0 \\
\hline ppm & & & & & & & & & \\
\hline $\mathbf{L i}$ & 29.9 & 30.0 & -0.4 & 30.4 & 29.7 & 2.1 & 21.0 & 20.2 & 4.1 \\
\hline Sc & 3.10 & 3.46 & -10.3 & 9.72 & 9.19 & 5.7 & 0.981 & 1.13 & -13.3 \\
\hline $\mathbf{V}$ & 55.4 & 56.9 & -2.6 & 129 & 127 & 2.0 & 12.3 & 12.2 & 0.2 \\
\hline $\mathrm{Cr}$ & $\mathrm{BDL}^{1}$ & $\mathrm{BDL}^{1}$ & - & $\mathrm{BDL}^{1}$ & $\mathrm{BDL}^{1}$ & - & $\mathrm{BDL}^{1}$ & $\mathrm{BDL}^{1}$ & - \\
\hline Co & 5.01 & 5.17 & -3.1 & 10.6 & 10.3 & 2.4 & 1.11 & 1.12 & -0.4 \\
\hline $\mathbf{N i}$ & $\mathrm{BDL}^{1}$ & $\mathrm{BDL}^{1}$ & - & $\mathrm{BDL}^{1}$ & $\mathrm{BDL}^{1}$ & - & $\mathrm{BDL}^{1}$ & $\mathrm{BDL}^{1}$ & - \\
\hline $\mathbf{C u}$ & 77.7 & 74.4 & 4.4 & 150 & 145 & 3.1 & 14.1 & 15.5 & -8.6 \\
\hline Zn & 56.1 & 45.9 & 22.2 & 78.9 & 82.1 & -3.9 & 27.1 & 28.8 & -5.9 \\
\hline Ga & 17.1 & 17.4 & -1.9 & 27.0 & 26.3 & 2.5 & 11.6 & 11.3 & 2.7 \\
\hline $\mathbf{R b}$ & 107 & 108 & -1.1 & 103 & 100 & 2.1 & 69.8 & 64.0 & 9.0 \\
\hline $\mathbf{S r}$ & 320 & 327 & -1.9 & 537 & 526 & 2.2 & 176 & 176 & -0.2 \\
\hline $\mathbf{Y}$ & 14.3 & 14.9 & -3.5 & 27.3 & 26.3 & 3.7 & 12.3 & 12.0 & 2.4 \\
\hline${ }^{90} \mathrm{Zr}$ & 187 & 191 & -1.9 & 259 & 251 & 3.4 & 154 & 152 & 1.6 \\
\hline${ }^{91} \mathrm{Zr}$ & 187 & 195 & -4.1 & 259 & 252 & 3.1 & 157 & 154 & 2.3 \\
\hline $\mathrm{Nb}$ & 6.16 & 6.24 & -1.3 & 10.1 & 9.81 & 2.7 & 4.84 & 4.77 & 1.5 \\
\hline Mo & 2.34 & 2.45 & -4.3 & 2.86 & 2.89 & -1.0 & 1.82 & 1.77 & 3.0 \\
\hline Cs & 6.69 & 6.59 & 1.5 & 6.41 & 6.35 & 0.9 & 4.49 & 4.40 & 2.2 \\
\hline Ba & 1162 & 1180 & -1.5 & 1296 & 1279 & 1.3 & 760 & 743 & 2.3 \\
\hline La & 21.6 & 21.6 & 0.0 & 26.1 & 25.7 & 1.6 & 14.6 & 14.3 & 1.8 \\
\hline $\mathrm{Ce}$ & 40.5 & 41.0 & -1.1 & 55.7 & 54.5 & 2.2 & 29.3 & 28.8 & 1.6 \\
\hline Pr & 4.56 & 4.55 & 0.2 & 6.91 & 6.71 & 3.0 & 3.33 & 3.30 & 0.7 \\
\hline Nd & 16.6 & 16.7 & -0.8 & 28.2 & 27.1 & 3.9 & 12.6 & 12.4 & 1.4 \\
\hline Sm & 3.05 & 3.04 & 0.4 & 5.97 & 5.83 & 2.4 & 2.37 & 2.36 & 0.7 \\
\hline${ }^{151} \mathbf{E u}$ & 0.877 & 0.869 & 0.9 & 1.652 & 1.607 & 2.8 & 0.622 & 0.624 & -0.3 \\
\hline${ }^{153} \mathbf{E u}$ & 1.00 & 0.976 & 2.8 & 1.76 & 1.74 & 1.0 & 0.701 & 0.688 & 1.9 \\
\hline Gd & 2.88 & 2.91 & -1.2 & 5.70 & 5.74 & -0.6 & 2.19 & 2.20 & -0.3 \\
\hline $\mathbf{T b}$ & 0.395 & 0.393 & 0.5 & 0.811 & 0.808 & 0.3 & 0.314 & 0.319 & -1.5 \\
\hline Dy & 2.36 & 2.34 & 1.0 & 4.79 & 4.85 & -1.3 & 1.91 & 1.95 & -2.0 \\
\hline Ho & 0.484 & 0.484 & 0.1 & 0.962 & 0.983 & -2.2 & 0.397 & 0.405 & -2.0 \\
\hline $\mathbf{E r}$ & 1.52 & 1.46 & 4.5 & 2.82 & 2.89 & -2.3 & 1.22 & 1.23 & -0.9 \\
\hline $\mathbf{T m}$ & 0.232 & 0.234 & -0.8 & 0.404 & 0.424 & -4.6 & 0.192 & 0.194 & -1.1 \\
\hline $\mathbf{Y b}$ & 1.65 & 1.59 & 3.8 & 2.82 & 2.87 & -1.6 & 1.43 & 1.43 & -0.2 \\
\hline Lu & 0.257 & 0.249 & 3.1 & 0.427 & 0.431 & -0.7 & 0.222 & 0.224 & -1.1 \\
\hline Hf & 4.69 & 4.60 & 2.0 & 6.78 & 6.78 & 0.1 & 3.81 & 3.89 & -2.0 \\
\hline Ta & 0.434 & 0.429 & 1.2 & 0.647 & 0.659 & -1.8 & 0.327 & 0.332 & -1.4 \\
\hline $\mathbf{W}$ & 1.10 & 1.09 & 1.3 & 1.22 & 1.25 & -1.9 & 0.650 & 0.661 & -1.6 \\
\hline $\mathbf{P b}$ & 33.5 & 30.4 & 10.0 & 40.3 & 41.9 & -3.8 & 23.2 & 23.7 & -2.5 \\
\hline Th & 11.8 & 10.8 & 9.4 & 13.1 & 13.7 & -4.5 & 7.98 & 8.26 & -3.4 \\
\hline $\mathbf{U}$ & 2.99 & 2.90 & 2.9 & 3.04 & 3.13 & -2.7 & 2.01 & 2.04 & -1.1 \\
\hline
\end{tabular}

$1 \%$ difference $=(($ sample 1 -sample 2$) /$ sample 2$) \times 100$

${ }^{2} \mathrm{BDL}=$ below detection limit 


\subsubsection{LASER ABLATION ICP-MS MINERAL TRACE ELEMENT ANALYSIS}

In situ trace element analyses of plagioclase, clinopyroxene and amphibole crystals were carried out at VUW using a New Wave deep ultraviolet $(193 \mathrm{~nm})$ solid state laser ablation system coupled to an Agilent 7500CS ICP-MS. The circular mounts were halved using a slow diamond saw and the carbon coat necessary for EPMA analysis was removed from each epoxy block using AR grade methanol. The mounts were rinsed in $\mathrm{MQ} \mathrm{H}_{2} \mathrm{O}$ and dried overnight at $40^{\circ} \mathrm{C}$ in an oven.

Individual spots ranging in diameter from 20 to $35 \mu \mathrm{m}$ were analysed. Each analysis was preceded by $60 \mathrm{~s}$ of background acquisition and had a dwell time of $60 \mathrm{~s}$, followed by 20-30 s of washout time. Helium was used as the ablation gas. Tuning was carried out on BCR-2G where gas flow and torch conditions were optimised to obtain RSD values of $<10 \%$ for monitored elements $(\mathrm{Li}, \mathrm{Ca}, \mathrm{Y}, \mathrm{La}, \mathrm{Ce}, \mathrm{Pb})$ in most cases and a $\mathrm{ThO}^{+} / \mathrm{Th}^{+}$ratio of $<1.5 \%$ to minimise oxide interferences. Pulse/analogue (P/A) factors were measured daily prior to analysis for elements that may be present in sufficient concentrations ( $>1000000 \mathrm{cps})$ that analysis mode would switch from pulse to analogue. Details of analytical conditions are given in Table 3.7.

Primary standards were measured after every 5-10 sample spot analyses to monitor drift in machine conditions and immediately after changing samples. The primary standards used were those which best matched the composition of the mineral being analysed to minimise matrix effects. BCR-2G was used as a standard for clinopyroxene and amphibole analyses and NIST612 was used for plagioclase. Internal standardisation was carried out using a minor isotope $\left({ }^{43} \mathrm{Ca}\right)$ of an element measured previously by EMPA as this corrects for machine drift and the specific analytical conditions for that day. All data have been individually screened to ensure that data associated with inclusions were excluded and only the phase of interest was assessed. After background corrections the concentration of each element at each point is determined by the relationships: 


$$
\begin{gathered}
C_{\text {sample }}^{\text {CaO,ICP-MS }}=C_{\text {std }}^{\text {CaO }} \times\left(\frac{C P S_{\text {Sample }}^{\text {Ca }}}{C P S_{\text {std }}^{\text {Ca }}}\right) \\
C_{\text {sample }}^{x, I C P-M S}=C_{\text {std }}^{x} \times\left(\frac{C_{\text {sample }}^{\text {CaO,EMPA }}}{C_{\text {sample }}^{\text {CaO }, I C P-M S}}\right) \times\left(\frac{C P S_{\text {sample }}^{x}}{C P S_{\text {std }}^{x}}\right)
\end{gathered}
$$

$C_{\text {sample }}^{\text {CaO,ICP-MS }} C_{\text {sample }}^{\text {CaO,EMPA }}=$ concentration of Ca determined by LA-ICP-MS or EMPA

$C_{\text {std }}^{\mathrm{CaO}}=$ reference $\mathrm{CaO}$ concentration of the primary standard (BCR-2 or NIST 612)

$C P S_{\text {sample }}^{C a}, C P S_{\text {std }}^{C a}=$ counts per second obtained on ${ }^{43} \mathrm{Ca}$ whilst ablating the sample or standard

$C a_{\text {sample }}^{x, I C P-M S}=$ concentration of element $\mathrm{x}$ determined by LA-ICP-MS

$C_{\text {std }}^{x}=$ reference concentration of element $\mathrm{x}$ in the standard (BCR-2 or NIST 612)

$C P S_{\text {sample }}^{x}, C P S_{\text {std }}^{x}=$ counts per second obtained on an isotope of element $\mathrm{x}$ whilst ablating the sample or standard

BHVO-2G was run as a secondary standard for the clinopyroxene and amphibole analyses (Table 3.8). The precision of these analyses is typically $<15 \%$ for those elements with atomic weights $<166$ and 15-30\% for heavier elements. B and Cs were less reproducible, with \%2 SD values of 60 and 51 respectively. Most elements are within $\pm 15 \%$ of the reference values except for $\mathrm{Ni}(18 \%), \mathrm{Pb}$ and $\mathrm{Cr}(21-22 \%)$ and $\mathrm{Cu}(32 \%)$ probably due to poorly constrained reference values or a low abundance in the standard $(\mathrm{Pb})$. No secondary standards were analysed for the plagioclase method. However, a detailed study was undertaken at VUW by Allan et al. (2008) which quantified the precision and accuracy of the LA-ICP-MS method used here, finding that the mean $(n=91)$ abundances of 29 elements analysed in the rhyolitic glass standard ATHO-G were within ca. $\pm 5 \%$ of the certified values from Jochum et al. (2006). Cs was ca. 15-20\% lower than reference values and $\mathrm{Mg}$ higher by ca. $15 \%$ 
Table 3.7 LA-ICP-MS instrumental and analytical conditions for in situ clinopyroxene, amphibole and plagioclase trace element analyses

\begin{tabular}{|c|c|c|}
\hline & Clinopyroxene and amphibole & Plagioclase \\
\hline \multicolumn{3}{|l|}{ LA-ICP-MS } \\
\hline Laser ablation system & $\begin{array}{l}\text { New Wave } 193 \mathrm{~nm} \text { (deep UV) solid } \\
\text { state }\end{array}$ & $\begin{array}{l}\text { New Wave } 193 \mathrm{~nm} \text { (deep UV) } \\
\text { solid state }\end{array}$ \\
\hline Ablation mode & Static spot analyses & Static spot analyses \\
\hline Spot size & 20,25 or $35 \mu \mathrm{m}$ & 20,25 or $35 \mu \mathrm{m}$ \\
\hline Repetition rate & $5 \mathrm{~Hz}$ & $5 \mathrm{~Hz}$ \\
\hline Laser power & $65 \%$ & $65 \%$ \\
\hline \multicolumn{3}{|l|}{ ICP-MS } \\
\hline ICP-MS system & Agilent $7500 \mathrm{CS}$ octopole & Agilent $7500 \mathrm{CS}$ octopole \\
\hline Acquisition mode & Peak hopping & Peak hopping \\
\hline Detection mode & Pulse and analogue & Pulse and analogue \\
\hline \multicolumn{3}{|l|}{ Standards and Calibration } \\
\hline Calibration standard & BCR-2G & NIST612 \\
\hline Secondary standard & BHVO-2G & - \\
\hline Internal standard & ${ }^{43} \mathrm{Ca}$ & ${ }^{43} \mathrm{Ca}$ \\
\hline \multicolumn{3}{|l|}{ Method } \\
\hline Background acquisition & $60 \mathrm{~s}$ & $60 \mathrm{~s}$ \\
\hline Sample/standard acquisition & $60 \mathrm{~s}$ & $60 \mathrm{~s}$ \\
\hline Washout time & $15-30 \mathrm{~s}$ & $25-30 \mathrm{~s}$ \\
\hline Measured isotopes and integration times & 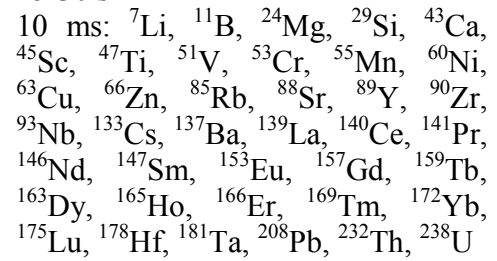 & $\begin{array}{l}10 \mathrm{~ms}:{ }^{29} \mathrm{Si},{ }^{43} \mathrm{Ca},{ }^{88} \mathrm{Sr},{ }^{137} \mathrm{Ba} \text {, } \\
20 \mathrm{~ms}:{ }^{7} \mathrm{Li},{ }^{24} \mathrm{Mg},{ }^{25} \mathrm{Mg},{ }^{139} \mathrm{La} \text {, } \\
{ }^{140} \mathrm{Ce} \\
{ }^{50 \mathrm{~ms}:}{ }^{145} \mathrm{Rb},{ }^{89} \mathrm{Y},{ }^{133} \mathrm{Cs},{ }^{141} \mathrm{Pr}, \\
{ }^{143} \mathrm{Eu},{ }^{157} \mathrm{Gd},{ }^{208} \mathrm{~Pb}\end{array}$ \\
\hline
\end{tabular}

\section{Tuning}

Tuning standard

BCR-2G

NIST612

Ablation mode

Rastering $2 \mu \mathrm{m} / \mathrm{s}$ beneath a 35 or 50 $\mu \mathrm{m}$ spot

Monitored isotopes during tuning ${ }^{7} \mathrm{Li},{ }^{43} \mathrm{Ca},{ }^{89} \mathrm{Y},{ }^{138} \mathrm{Ba},{ }^{140} \mathrm{Ce},{ }^{208} \mathrm{~Pb}$ (RSD for each isotope typically $<10 \%$ )

Rastering $2 \mu \mathrm{m} / \mathrm{s}$ beneath a 50 ${ }^{4} \mathrm{Li}$ spot ${ }^{24} \mathrm{Mg},{ }^{25} \mathrm{Mg},{ }^{29} \mathrm{Si},{ }^{43} \mathrm{Ca},{ }^{85} \mathrm{Rb}$, ${ }^{88} \mathrm{Sr},{ }^{89} \mathrm{Y},{ }^{137} \mathrm{Ba}, \quad{ }^{138} \mathrm{Ba},{ }^{208} \mathrm{~Pb}$ (RSD for each isotope typically $<10 \%$ )

Background

${ }^{43}$ Ca typically $<200 \mathrm{cps}$, always $<400$

${ }^{43} \mathrm{Ca}$ typically $<200 \mathrm{cps}$, always cps (ca. 1\% of BCR-2G and sample signal)

Oxides

$\mathrm{ThO}^{+} / \mathrm{Th}^{+}<1 \%$

$<400 \mathrm{cps}$ (ca. 1\% of NIST612

and $10 \%$ sample signal)

Carrier gas (Ar)

$0.85-0.9 \mathrm{~L} / \mathrm{min}$

$0.85-0.89 \mathrm{~L} / \mathrm{min}$

Ablation gas (He)

$80-90.5 \%$

$80-89 \%$

$1500 \mathrm{~W} \quad 1500 \mathrm{~W}$

RF matching

$1.69-1.78 \mathrm{~V}$

$1.76 \mathrm{~V}$

Sample depth (z)

$3.5-4 \mathrm{~mm}$ 


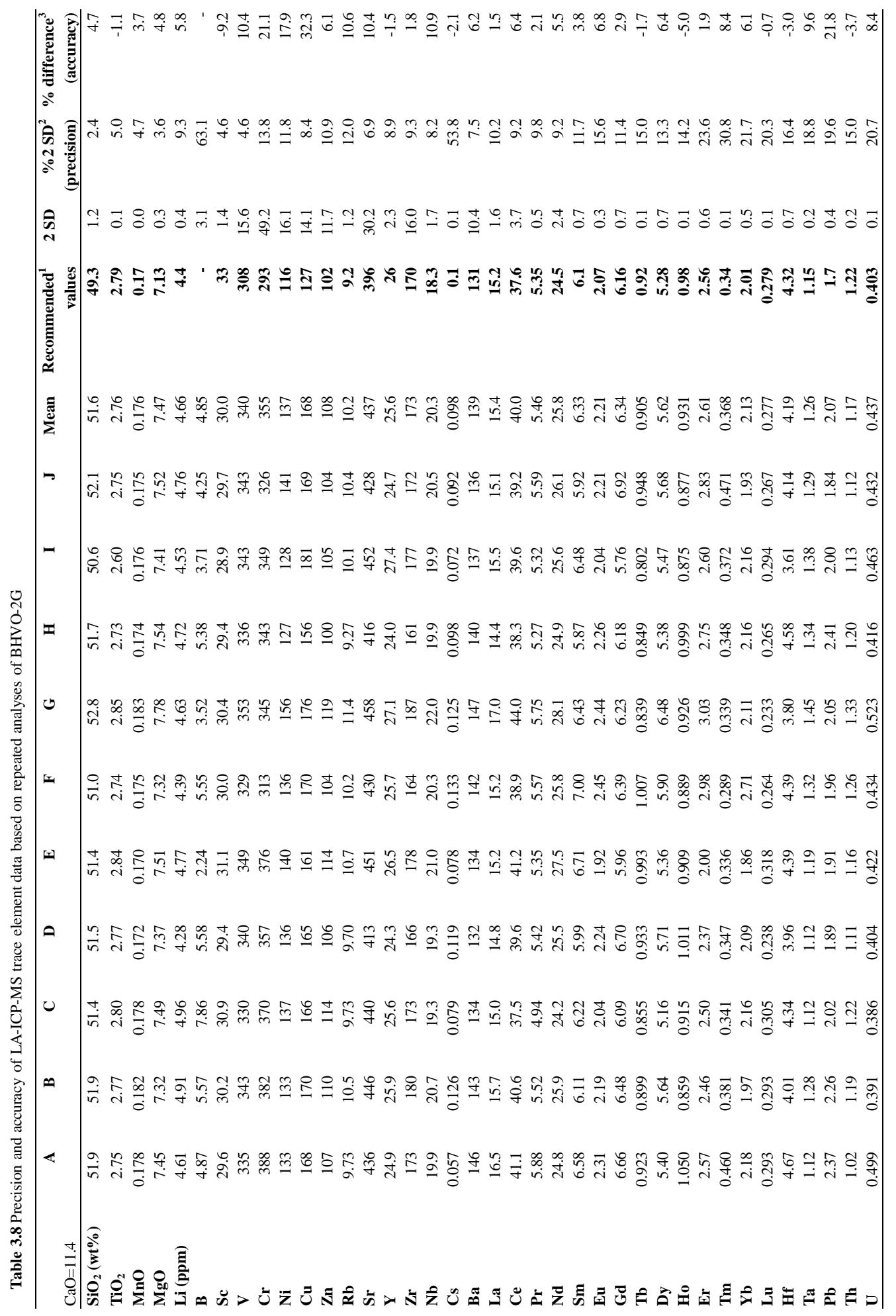




\subsection{THERMOBAROMETRY}

Estimating the physical conditions of a magmatic system can provide important insights into the behaviour and state of these systems during their evolution and immediately prior to eruption. Accurate thermometry is particularly important in this study due to the strong temperature dependence of the diffusion modelling applied in this study. Thermometry was carried out using phenocryst rims and coexisting glass to constrain the pre-eruptive magmatic conditions. In addition, amphibole barometry, hygrometry and oxybarometry were utilised. The models presented here use phases that are present in all of the samples analysed and were calibrated for silicic, hydrous, volcanic systems. Each model is discussed and evaluated for applicability to this volcanic system. The multiple thermometers are compared as tools for determining whether the different mineral phases all shared a similar history immediately prior to eruption.

\subsubsection{AMPHIBOLE THERMOBAROMETRY}

\subsubsection{Model}

The amphibole thermobarometry of Ridolfi et al. (2010) provides a means of calculating the magma temperature, pressure, water content and oxygen fugacity from amphibole major element analysis. This thermobarometric system is based on the narrow physico-chemical range that amphibole in equilibrium with calc-alkaline melts crystallises. This provides a low variance system that enables the formulation of many pre-eruptive conditions of magmatic systems based on a single phase (amphibole). This model was calibrated using empirical data for calcic amphiboles of basaltic to rhyolitic magmas, specifically for subduction-related magmatism. Amphiboles must have a composition where aluminium number $\left(\mathrm{Al} \#={ }^{[6]} \mathrm{Al} / \mathrm{Al}_{\mathrm{T}}\right) \leq 0.21$ and magnesium number $\left(\mathrm{Mg} \#=\mathrm{Mg} / \mathrm{Mg}+\mathrm{Fe}^{2+}\right)>0.5$. However, this model does not require the amphibole to be in equilibrium with coexisting melt or mineral phases as only the composition of the amphibole is used for the model. For this reason, it is especially useful for hybrid melts such as andesites. 
For this study, all amphibole analyses that fitted the model requirements stated above were put through the amphibole thermobarometric model. These were divided into rims, cores and other zoning (any zones within the mantle of the crystal), with the rim and core analyses further investigated to determine whether there were multiple populations. In the case of rim analyses, there was one dominant, low pressure population that was considered to be in equilibrium with the melt. This was compared to temperatures modelled from the rims of other phenocryst phases. In samples SM-7P and SM-7R, two core populations ( $\mathrm{C} 1$ and $\mathrm{C} 2$ ) were identified based on pressure and temperature.

\subsubsection{Method}

The amphibole thermometer is based on the silicon index $\left(\mathrm{Si}^{*}\right)$ by the formula:

$$
\mathrm{T}=-151.487 \mathrm{Si}^{*}+2041 \pm 22{ }^{\circ} \mathrm{C}
$$

Where $S i^{*}=S i+\frac{[4]_{A l}}{15}-2^{[4]} T i-\frac{[6]_{A l}}{2}-\frac{[6]_{T i}}{1.8}+\frac{F e^{3+}}{9}+\frac{F e^{2+}}{3.3}+\frac{M g}{26}+\frac{B_{C a}}{5}+\frac{B_{N a}}{1.3}-\frac{A_{N a}}{15}+$ $\frac{A_{[]}}{2.3}$

${ }^{[4]} \mathrm{Al}=$ tetrahedral $\mathrm{Al} ;{ }^{[4]} \mathrm{Ti}=$ tetrahedral $\mathrm{Ti} ;{ }^{[6]} \mathrm{Al}=$ octahedral $\mathrm{Al} ;{ }^{\left[{ }^{[6]}\right.} \mathrm{Ti}=$ octahedral $\mathrm{Ti} ;{ }^{\mathrm{B}} \mathrm{Ca}=\mathrm{Ca}$ in the $\mathrm{B}$ site; ${ }^{\mathrm{B}} \mathrm{Na}=\mathrm{Na}$ in the $\mathrm{B}$ site; ${ }^{\mathrm{A}} \mathrm{Na}=\mathrm{Na}$ in the $\mathrm{A}$ site; ${ }^{\mathrm{A}}[]=$ any other cations in the A site not yet accounted for. All cations are calculated on the basis of 13 cations using the method of Leake et al. (1997).

The barometric formulation is based on total $\mathrm{Al}$ content $\left(\mathrm{Al}_{\mathrm{T}}\right)$ by the equation:

$$
P=19.209 e^{\left(1.438 A l_{T}\right)} \pm 39 \mathrm{MPa}
$$

Where $\mathrm{Al}_{\mathrm{T}}=$ the total $\mathrm{Al}$ in amphibole calculated on the basis of 13 cations using the method of Leake et al. (1997).

The standard error of estimate $\left(\sigma_{\text {est }}\right)$ is $54 \mathrm{MPa}$, but decreases to $39 \mathrm{MPa}( \pm 14 \%$ average relative error) where pressures $(\mathrm{P})$ are $<450 \mathrm{MPa}$. The magnitude of the errors associated with the pressure calculations is also related to how close to the amphibole stability curve the 
amphibole analyses plot. The amphiboles modelled here all plot near the amphibole stability curve reducing pressure errors further to $< \pm 11 \%$ average relative error.

Other amphibole barometers (eg. Hammarstrom \& Zen, 1986; Hollister et al., 1987; Johnson \& Rutherford, 1989; Schmidt, 1992) were calibrated for a very specific mineral assemblage, including the presence of quartz, making them unsuitable for use in this system.

The water content of the melt $\left(\mathrm{H}_{2} \mathrm{O}_{\text {melt }}\right)$ is strongly correlated with octahedral $\mathrm{Al}\left({ }^{[6]} \mathrm{Al}\right)$ and this relationship is improved upon by using an octahedral aluminium index $\left({ }^{[6]} \mathrm{Al}\right.$ ) which is related to $\mathrm{H}_{2} \mathrm{O}_{\text {melt }}$ by the equation:

$$
\mathrm{H}_{2} \mathrm{O}_{\text {melt }}=5.215^{[6]} A l^{*}+12.28 \pm 0.41 \mathrm{wt} \%
$$

Where ${ }^{[6]} \mathrm{Al}^{*}={ }^{[6]} \mathrm{A} 1+\frac{[4]_{A l}}{13.9}-\frac{S i+[6]_{T i}}{5}-\frac{{ }_{C F e} e^{2+}}{3}-\frac{M g}{1.7}+\frac{B_{C a}+A_{\square}}{1.2}+\frac{A_{N a}}{2.7}-1.56 K-\frac{F e \# t}{1.6}$

${ }^{[6]} \mathrm{Al}=$ octahedral $\mathrm{Al} ;{ }^{[4]} \mathrm{Al}=$ tetrahedral $\mathrm{Al} ;{ }^{[6]} \mathrm{Ti}=$ octahedral $\mathrm{Ti} ;{ }^{\mathrm{C}} \mathrm{Fe}^{2+}=\mathrm{Fe}^{2+}$ in the $\mathrm{C}$ site; ${ }^{\mathrm{B}} \mathrm{Ca}=\mathrm{Ca}$ in $\mathrm{B}$ site; ${ }^{\mathrm{A}}[]=$ any cations in the A site not already accounted for; ${ }^{\mathrm{A}} \mathrm{Na}=\mathrm{Na}$ in the A site; $\mathrm{Fe} \#=\mathrm{Fe}^{3+} /\left(\mathrm{Fe}^{3+}+\mathrm{Mg}+\mathrm{Fe}^{2+}+\mathrm{Mn}\right)$. All cations were calculated on the basis of 13 cations using the method of Leake et al. (1997).

As magnesiohastingsite was not included in the calibration data, and this is the dominant species at Mt Taranaki, the true errors are likely to be at the upper end of those stated above. This is comparable to the plagioclase-melt hygrometer of Lange et al. (2009) and is an improvement on those of Putirka $(2005 ; 2008)$.

Oxygen fugacity is best correlated to $\mathrm{Mg}$ content in amphibole and the use of a Mg index $\left(\mathrm{Mg}^{*}\right)$ improves this relationship $\left(\mathrm{R}^{2}=0.84\right.$ to 0.89$)$ and is described by the equation 2 :

$$
\Delta N N O=1.644 M^{*}-4.01 \pm 0.22 \log \text { unit }
$$

Where $M g^{*}=M g+\frac{S i}{47}+\frac{[6] A l}{9}-1.3^{[6]} T i+\frac{F e^{3+}}{3.7}+\frac{F e^{2+}}{5.2}-\frac{B_{C a}}{20}-\frac{A_{N a}}{2.8}+\frac{A_{[]}}{9.5}$ 
Table 3.9 Amphibole analyses used for thermobarometry. Core analyses are divided into two populations (C1 and C2) where there are two distinct groups of amphibole cores.

\begin{tabular}{|c|c|c|c|c|c|c|c|c|c|c|c|}
\hline $\begin{array}{l}\text { Analysis } \\
\text { SM-6A }\end{array}$ & Zone $^{1}$ & $\begin{array}{r}\text { Temp } \\
{ }^{\circ} \mathrm{C}\end{array}$ & $\begin{array}{r}\text { Pressure } \\
\text { MPa }\end{array}$ & $\begin{array}{r}\mathbf{H}_{2} \mathbf{O}_{\text {melt }} \\
\text { wt } \%\end{array}$ & $\operatorname{logfO} O_{2}$ & $\begin{array}{l}\text { Analysis } \\
\text { SM-6C }\end{array}$ & Zone $^{1}$ & $\begin{array}{r}\text { Temp } \\
{ }^{\circ} \mathrm{C}\end{array}$ & $\begin{array}{r}\text { Pressure } \\
\text { MPa }\end{array}$ & $\begin{array}{r}\mathbf{H}_{2} \mathbf{O}_{\text {melt }} \\
\text { wt \% }\end{array}$ & $\operatorname{logfO} O_{2}$ \\
\hline 6aA10_3 & $\mathrm{C}$ & 961 & 286 & 3.73 & -9.87 & $6 c A 5 \_5$ & $\mathrm{C}$ & 1035 & 684 & 6.84 & -9.67 \\
\hline 6aA7_1 & C & 966 & 318 & 4.19 & -9.92 & 6cA9_4 & C & 1012 & 539 & 6.71 & -9.71 \\
\hline 6aA1_4 & $\mathrm{C}$ & 1011 & 447 & 5.99 & -9.05 & $6 c \mathrm{cA} 4 \_7$ & C & 1011 & 514 & 5.61 & -9.19 \\
\hline 6aA11_4 & $\mathrm{C}$ & 1011 & 530 & 5.90 & -8.97 & 6cA6_3 & C & 1008 & 505 & 5.68 & -9.23 \\
\hline 6aA3_3 & $\mathrm{C}$ & 1009 & 487 & 5.37 & -8.90 & 6cA7_6 & C & 1021 & 571 & 6.14 & -9.18 \\
\hline 6aA7_4 & C & 948 & 295 & 3.66 & -10.64 & 6cA8_2 & C & 1008 & 502 & 5.69 & -9.11 \\
\hline 6aA9_6 & C & 978 & 386 & 4.95 & -10.13 & 6cA5_2 & $\mathrm{R}^{*}$ & 1028 & 631 & 6.78 & -9.55 \\
\hline 6aA5_3 & $\mathrm{C}$ & 971 & 389 & 5.12 & -10.15 & 6cA9_1 & $\mathrm{R}^{*}$ & 1032 & 646 & 6.97 & -9.54 \\
\hline 6aA11_5 & C & 992 & 411 & 4.71 & -9.68 & 6cA6_1 & $\mathrm{R}$ & 1002 & 469 & 5.45 & -9.24 \\
\hline 6aA3_5 & $\mathrm{C}$ & 1011 & 527 & 5.59 & -9.24 & 6cA7_1 & $\mathrm{R}$ & 1010 & 501 & 5.60 & -9.17 \\
\hline 6aA1_1 & $\mathrm{R}$ & 928 & 262 & 4.12 & -10.35 & 6cA8_1 & $\mathrm{R}$ & 1006 & 522 & 5.83 & -9.23 \\
\hline 6aA10_1 & $\mathrm{R}$ & 976 & 330 & 4.12 & -9.78 & $6 c \mathrm{cA} 4 \_2$ & Z & 1016 & 530 & 5.66 & -9.08 \\
\hline 6aA11_1 & $\mathrm{R}$ & 975 & 356 & 4.60 & -9.81 & $6 c \mathrm{cA} 4 \_3$ & Z & 1017 & 539 & 5.73 & -9.00 \\
\hline 6aA3_1 & $\mathrm{R}$ & 970 & 329 & 4.18 & -9.72 & 6cA4_4 & Z & 988 & 394 & 4.93 & -9.20 \\
\hline 6aA4_2 & $\mathrm{R}$ & 953 & 335 & 4.66 & -10.32 & 6cA4_5 & Z & 1010 & 510 & 5.62 & -9.22 \\
\hline 6aA5_1 & $\mathrm{R}^{*}$ & 974 & 405 & 5.53 & -10.28 & 6cA6_2 & Z & 1004 & 456 & 5.36 & -9.11 \\
\hline 6aA7_2 & $\mathrm{R}^{*}$ & 1008 & 503 & 5.54 & -9.57 & 6cA6_4 & Z & 1006 & 491 & 5.69 & -9.21 \\
\hline 6aA9_3 & $\mathrm{R}^{*}$ & 1012 & 549 & 5.63 & -9.40 & $6 c A 7 \_2$ & Z & 1002 & 478 & 5.48 & -9.18 \\
\hline 6aA4_7 & $\mathrm{Z}$ & 985 & 501 & 6.06 & -9.80 & $6 c A 7 \_3$ & Z & 998 & 453 & 5.32 & -9.09 \\
\hline 6aA1_2 & $\mathrm{Z}$ & 983 & 432 & 5.65 & -9.37 & 6cA7_4 & Z & 1012 & 530 & 5.81 & -9.33 \\
\hline 6aA10_2 & $\mathrm{Z}$ & 964 & 290 & 3.71 & -10.04 & 6cA7_5 & Z & 960 & 303 & 4.27 & -9.85 \\
\hline 6aA10_4 & $\mathrm{Z}$ & 973 & 335 & 4.47 & -9.75 & 6cA9_2 & $\mathrm{Z}$ & 1032 & 659 & 6.89 & -9.51 \\
\hline 6aA11_2 & $\mathrm{Z}$ & 979 & 353 & 4.40 & -9.75 & 6cA9_3 & $\mathrm{Z}$ & 1027 & 637 & 6.91 & -9.59 \\
\hline 6aA11_3 & $\mathrm{Z}$ & 1007 & 478 & 5.49 & -9.28 & & & & & & \\
\hline 6aA3_2 & $\mathrm{Z}$ & 1002 & 455 & 5.25 & -9.51 & & & & & & \\
\hline 6aA9_4 & $\mathrm{Z}$ & 962 & 349 & 4.05 & -10.62 & & & & & & \\
\hline 6aA9_5 & $\mathrm{Z}$ & 998 & 481 & 5.43 & -9.96 & & & & & & \\
\hline 6aA7_3 & $\mathrm{Z}$ & 980 & 438 & 5.04 & -10.29 & & & & & & \\
\hline Mean & $\mathbf{C}$ & 986 & 408 & 4.92 & -9.65 & Mean & $\mathbf{C}$ & 1016 & 552 & 6.11 & -9.35 \\
\hline Mean & $\mathbf{R}$ & 960 & 323 & 4.34 & -10.00 & Mean & $\mathbf{R}$ & 1006 & 498 & 5.63 & -9.21 \\
\hline Mean & $\mathbf{Z}$ & 983 & 411 & 4.96 & -9.84 & Mean & $\mathbf{Z}$ & 1006 & 498 & 5.64 & -9.28 \\
\hline Mean & all & 982 & 402 & 4.90 & -9.79 & Mean & all & 1011 & 524 & 5.87 & -9.31 \\
\hline Analysis & Zone $^{1}$ & Temp & Pressure & $\mathrm{H}_{2} \mathrm{O}_{\text {melt }}$ & $\operatorname{logfO}_{2}$ & Analysis & Zone $^{1}$ & Temp & Pressure & $\mathrm{H}_{2} \mathrm{O}_{\text {melt }}$ & $\operatorname{logfO} O_{2}$ \\
\hline SM-6K & & ${ }^{\circ} \mathrm{C}$ & MPa & wt $\%$ & & SM-7P & & ${ }^{\circ} \mathrm{C}$ & MPa & wt $\%$ & \\
\hline$\overline{\text { 6kA1_3 }}$ & $\mathrm{C}$ & 981 & 387 & 5.14 & -9.90 & $7 \mathrm{pA} 2 \_6$ & C1 & 1003 & 612 & 7.35 & -10.08 \\
\hline 6kA10_6 & $\mathrm{C}$ & 996 & 457 & 5.57 & -9.32 & 7pA1_5 & $\mathrm{C} 1$ & 924 & 228 & 3.97 & -10.65 \\
\hline 6kA12_2 & C & 994 & 426 & 5.37 & -9.84 & 7pA3_5 & C1 & 915 & 214 & 3.95 & -10.89 \\
\hline 6kA13_2 & $\mathrm{C}$ & 935 & 290 & 4.04 & -11.07 & 7pA4_2 & C1 & 921 & 212 & 3.80 & -10.73 \\
\hline 6kA14_6 & $\mathrm{C}$ & 1028 & 589 & 5.53 & -8.75 & 7pA5_3 & $\mathrm{C} 1$ & 914 & 219 & 4.20 & -10.85 \\
\hline 6kA17_2 & $\mathrm{C}$ & 1017 & 574 & 6.11 & -9.55 & 7pA7_4 & C1 & 917 & 218 & 3.78 & -11.02 \\
\hline 6kA4_1 & $\mathrm{C}$ & 970 & 371 & 5.29 & -10.07 & 7pA8_3 & $\mathrm{C} 1$ & 922 & 215 & 3.72 & -10.70 \\
\hline 6kA5_1 & $\mathrm{C}$ & 1001 & 457 & 5.17 & -8.93 & 7pA11_3 & C1 & 921 & 216 & 3.71 & -10.78 \\
\hline 6kA6_1 & $\mathrm{C}$ & 938 & 270 & 4.18 & -10.36 & 7pA6_2 & C2 & 985 & 436 & 6.15 & -10.05 \\
\hline 6kA7_1 & $\mathrm{C}$ & 985 & 407 & 5.30 & -9.73 & 7pA1_6 & C2 & 984 & 436 & 5.93 & -9.93 \\
\hline 6kA9_1 & $\mathrm{C}$ & 1010 & 567 & 6.49 & -9.69 & $7 \mathrm{pA} 3 \_2$ & $\mathrm{C} 2$ & 987 & 441 & 5.95 & -10.09 \\
\hline 6kA11_1 & $\mathrm{C}$ & 936 & 250 & 3.94 & -10.35 & $7 \mathrm{pA} 5 \_4$ & C2 & 986 & 442 & 5.81 & -10.12 \\
\hline 6kA11_2 & $\mathrm{C}$ & 1012 & 558 & 6.32 & -9.52 & 7pA7_3 & C2 & 991 & 469 & 6.08 & -10.30 \\
\hline 6kA14_4 & $\mathrm{R}^{*}$ & 1020 & 580 & 5.94 & -9.29 & 7pA8_2 & C2 & 1008 & 542 & 6.27 & -10.00 \\
\hline 6kA2_1 & $\mathrm{R}^{*}$ & 1000 & 492 & 6.00 & -9.52 & 7pA11_2 & C2 & 979 & 392 & 5.46 & -10.09 \\
\hline 6kA1_1 & $\mathrm{R}$ & 939 & 299 & 4.04 & -11.01 & 7pA4_3 & $\mathrm{C} 2$ & 969 & 405 & 5.96 & -10.24 \\
\hline 6kA13_1 & $\mathrm{R}$ & 970 & 329 & 4.22 & -10.10 & 7pA1_1 & $\mathrm{R}$ & 929 & 221 & 3.68 & -10.64 \\
\hline 6kA17_1 & $\mathrm{R}$ & 967 & 308 & 4.04 & -9.99 & 7pA3_1 & $\mathrm{R}$ & 913 & 207 & 3.96 & -10.88 \\
\hline 6kA5_4 & $\mathrm{R}$ & 936 & 255 & 4.06 & -10.08 & 7pA4_1 & $\mathrm{R}$ & 927 & 227 & 3.99 & -10.76 \\
\hline 6kA7_2 & $\mathrm{R}$ & 945 & 262 & 4.02 & -10.11 & 7pA5_1 & $\mathrm{R}$ & 923 & 226 & 3.94 & -10.61 \\
\hline 6kA11_3 & $\mathrm{Z}$ & 952 & 281 & 3.87 & -10.38 & 7pA6_1 & $\mathrm{R}$ & 912 & 215 & 3.92 & -10.99 \\
\hline 6kA11_4 & $\mathrm{Z}$ & 987 & 416 & 5.30 & -9.96 & 7pA2_3 & $\mathrm{R}$ & 910 & 210 & 4.11 & -10.98 \\
\hline 6kA11_6 & $\mathrm{Z}$ & 954 & 303 & 4.40 & -10.28 & 7pA8_1 & $\mathrm{R}$ & 918 & 207 & 3.76 & -10.77 \\
\hline 6kA14_5 & $\mathrm{Z}$ & 1016 & 578 & 5.88 & -9.34 & 7pA11_1 & $\mathrm{R}$ & 919 & 215 & 3.93 & -10.83 \\
\hline 6kA2_2 & $\mathrm{Z}$ & 965 & 327 & 4.32 & -10.15 & 7pA1_2 & Z & 962 & 343 & 5.11 & -10.48 \\
\hline 6kA4_2 & $\mathrm{Z}$ & 998 & 452 & 5.57 & -9.20 & |7pA1_3 & Z & 915 & 204 & 3.83 & -10.72 \\
\hline 6kA4_3 & $\mathrm{Z}$ & 947 & 274 & 4.25 & -10.12 & 7pA2_2 & Z & 978 & 435 & 6.38 & -10.24 \\
\hline 6kA5_2 & $\mathrm{Z}$ & 1008 & 558 & 5.91 & -8.97 & 7pA2_5 & Z & 990 & 545 & 7.13 & -10.18 \\
\hline 6kA5_3 & $\mathrm{Z}$ & 1008 & 488 & 5.52 & -9.00 & 7pA7_2 & Z & 1009 & 522 & 6.22 & -9.86 \\
\hline 6kA6_2 & $\mathrm{Z}$ & 930 & 243 & 3.82 & -10.58 & 7pA5_2 & $\mathrm{Z}$ & 928 & 241 & 4.37 & -10.57 \\
\hline 6kA1_2 & $\mathrm{Z}$ & 936 & 254 & 4.00 & -10.85 & & & & & & \\
\hline \multirow[t]{2}{*}{ Mean } & $\mathbf{C}$ & 985 & 431 & 5.27 & -9.78 & Mean & C1 & 930 & 267 & 4 & -11 \\
\hline & & & & & & Mean & C2 & 986 & 445 & 6 & -10 \\
\hline Mean & $\mathbf{R}$ & 951 & 291 & 4.07 & -10.26 & Mean & $\mathbf{R}$ & 919 & 216 & 3.91 & -10.81 \\
\hline Mean & $\mathbf{Z}$ & 973 & 379 & 4.80 & -9.89 & Mean & $\mathbf{Z}$ & 964 & 382 & 5.51 & -10.34 \\
\hline Mean & all & 977 & 397 & 4.95 & -9.87 & Mean & all & 949 & 324 & 4.88 & -10.50 \\
\hline
\end{tabular}




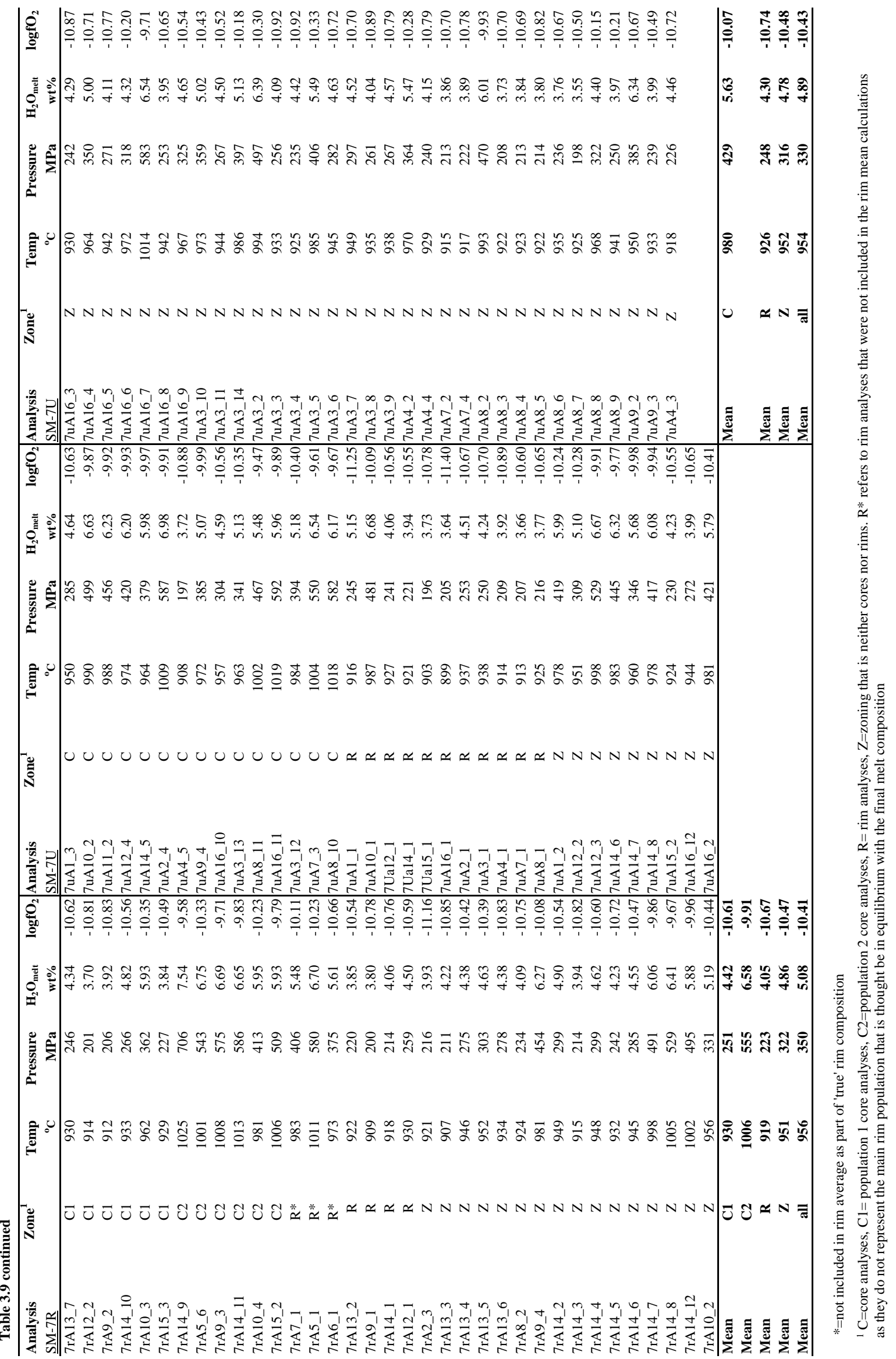


${ }^{[6]} \mathrm{Al}=$ octahedral $\mathrm{Al} ;{ }^{[6]} \mathrm{Ti}=$ octahedral $\mathrm{Ti} ;{ }^{\mathrm{B}} \mathrm{Ca}=\mathrm{Ca}$ in the $\mathrm{B}$ site; ${ }^{\mathrm{A}} \mathrm{Na}=\mathrm{Na}$ in the A site; ${ }^{A}[]=$ any cations in the A site not accounted for. All cations were calculated on the basis of 13 cations using the method of Leake et al. (1997).

The absence of ilmenite in the Taranaki samples precludes the use of ilmenite-magnetite oxybarometry, making the amphibole thermobarometer the only suitable quantification of oxygen fugacity conditions.

\subsubsection{CLINOPYROXENE-MELT THERMOMETRY}

\subsubsection{Model}

Clinopyroxene-melt thermometry was carried out using the jadeite (Jd; $\mathrm{NaAlSi}_{2} \mathrm{O}_{6}$ )diopside/hedenbergite (DiHd; $\mathrm{Ca}(\mathrm{Mg}, \mathrm{Fe}) \mathrm{Si}_{2} \mathrm{O}_{6}$ ) exchange thermometer of Putirka (2008).

$$
\begin{aligned}
T(K)= & 7.53-0.14 \ln \left(\frac{X_{J d}^{c p x} X_{C a O}^{l i q} X_{F m}^{l i q}}{X_{D i H d}^{c p x} X_{N a}^{l i q} X_{A l}^{l i q}}\right)+0.07\left(H_{2} O^{l i q}\right)-14.9\left(X_{C a O}^{l i q} X_{S i O_{2}}^{l i q}\right)- \\
& 0.08 \ln \left(X_{\text {TiO }_{2}}^{l i q}\right)-3.62\left(X_{N a O_{0.5}}^{l i q}+X_{K O_{0.5}}^{l i q}\right)-1.1\left(M_{g} \#^{l i q}\right)-0.18 \ln \left(X_{E n F S}^{c p x}\right)- \\
& 0.027 P(k b a r) \pm 42{ }^{\circ} \mathrm{C}
\end{aligned}
$$

$$
\begin{aligned}
& P(k b a r)=-48.7+271 \frac{T(K)}{10^{4}}+32 \frac{T(K)}{10^{4}} \ln \left[\frac{X_{N a A l S i_{2} O_{6}}^{c p x}}{X_{N a O_{0.5}}^{l i q} X_{A l O_{1.5}}^{l i q}\left(x_{\mathrm{SiO}_{2}}^{l i q}\right) X_{\mathrm{NaO}_{0.5}}^{l i q} X_{\mathrm{AlO}_{1.5}}^{l i q}\left(X_{\mathrm{SiO}_{2}}^{l i q}\right)^{2}}\right]- \\
& 8.2 \ln \left(X_{F e O}^{l i q}\right)+4.6 \ln \left(X_{M g O}^{l i q}\right)-0.96 \ln \left(X_{K O_{0.5}}^{l i q}\right)-2.2 \ln \left(X_{D i H d}^{c p x}\right)- \\
& 31\left(M g \#^{l i q}\right)+56\left(X_{N a O_{0.5}}^{l i q}+X_{\mathrm{KO}_{0.5}}^{l i q}\right)+0.76\left(\mathrm{H}_{2} \mathrm{O}^{l i q}\right) \pm 3.6 \mathrm{kbar}
\end{aligned}
$$

Where $X_{\text {component }}^{\text {liq }}=$ the liquid component calculated as cation fractions on an anhydrous basis, not renormalized to $100 ; X_{\text {component }}^{c p x}=$ the clinopyroxene component calculated as cations per formula unit on an anhydrous basis not renormalized to 100 .

$X_{J d}^{c p x}=X_{A l(V I)}^{c p x}$ or $X_{N a}^{c p x}$ whichever is less where $X_{A l(V I)}^{c p x}=X_{A l}^{c p x}-X_{A l(I V)}^{c p x}$ and $X_{A l(I V)}^{c p x}=2-$ $X_{S i}^{c p x} X_{F m}^{l i q}=X_{F e}^{l i q}+X_{M g}^{l i q}$ 
$X_{D i H d}^{c p x}=X_{C a}^{c p x}-X_{C a T s}^{c p x}-X_{C r C a T s}^{c p x}$ where $X_{C a T s}^{c p x}=X_{A l(V I)}^{c p x}-X_{J d}^{c p x}$ and $X_{C r C a T s}^{c p x}=X_{C r}^{c p x} / 2$

$\mathrm{H}_{2} \mathrm{O}^{\text {liq }}=$ the water content of the melt in wt $\%$

$\mathrm{Mg} \#^{\mathrm{liq}}=\left(\mathrm{Mg}^{\mathrm{liq}} /\left(\mathrm{Mg}^{\mathrm{liq}} / \mathrm{Fe}^{\mathrm{liq}}\right)\right.$ calculated as a mole fraction basis

$X_{E n F S}^{c p x}=\left[X_{F e}^{c p x}+X_{M g}^{c p x}-X_{D i H d}^{c p x}\right] / 2$

This model is based on the Jd-DiHd exchange thermometers of Putirka et al. (1996; 2003), but with reduced uncertainties due to global calibrations of experimental data conducted at pressures of $<70$ kbars. This resulted in an overall error reduction of $10-20{ }^{\circ} \mathrm{C}$ to $\pm 42{ }^{\circ} \mathrm{C}$. This model has been calibrated for hydrous systems with $\mathrm{SiO}_{2}$ up to $71.3 \mathrm{wt} \%$ (Putirka, 2008; Putirka et al., 2003).

\subsubsection{Method}

Equation 3.8 (eq 30, Putirka, 2008) was solved with Equation 3.7 as this thermometer requires a pressure input and was designed to be solved simultaneously to give the best results. Equation 3.8 was used as the pressure input because it best reproduces the hydrous data at $\mathrm{P}<$ 10 kbars, although Eq. 31 of Putirka (2008) has better overall statistics (Figure 3.2). The model error associated with the clinopyroxene-liquid barometers are on the order of \pm 3 kbar and have $2 \mathrm{sd}$ of up to $5 \mathrm{kbar}$ when applied to these samples.

Equation 3.7 is only slightly pressure dependent so varying the pressure input from 0 to 10 kbar (extremes likely to be outside of this system) reduces the resulting temperature calculation by around $40{ }^{\circ} \mathrm{C}$ (Table 3.10), which is within the model error. Clinopyroxene-liquid barometry was used in conjunction with the thermometry, rather than inputting the pressures obtained from the amphibole barometry as it cannot be certain that the amphibole rims crystallised at the same pressures as the clinopyroxene rims. Therefore, although the clinopyroxene-liquid barometry has large errors associated with it, it is more appropriate to solve the clinopyroxene thermometry and barometry simultaneously as was intended by Putirka (2008). The $\mathrm{H}_{2} \mathrm{O}_{\text {melt }}$ 
input was obtained from the Ridolfi et al. (2010) hygrometer as this is the most reliable constraint on $\mathrm{H}_{2} \mathrm{O}_{\text {melt }}$.

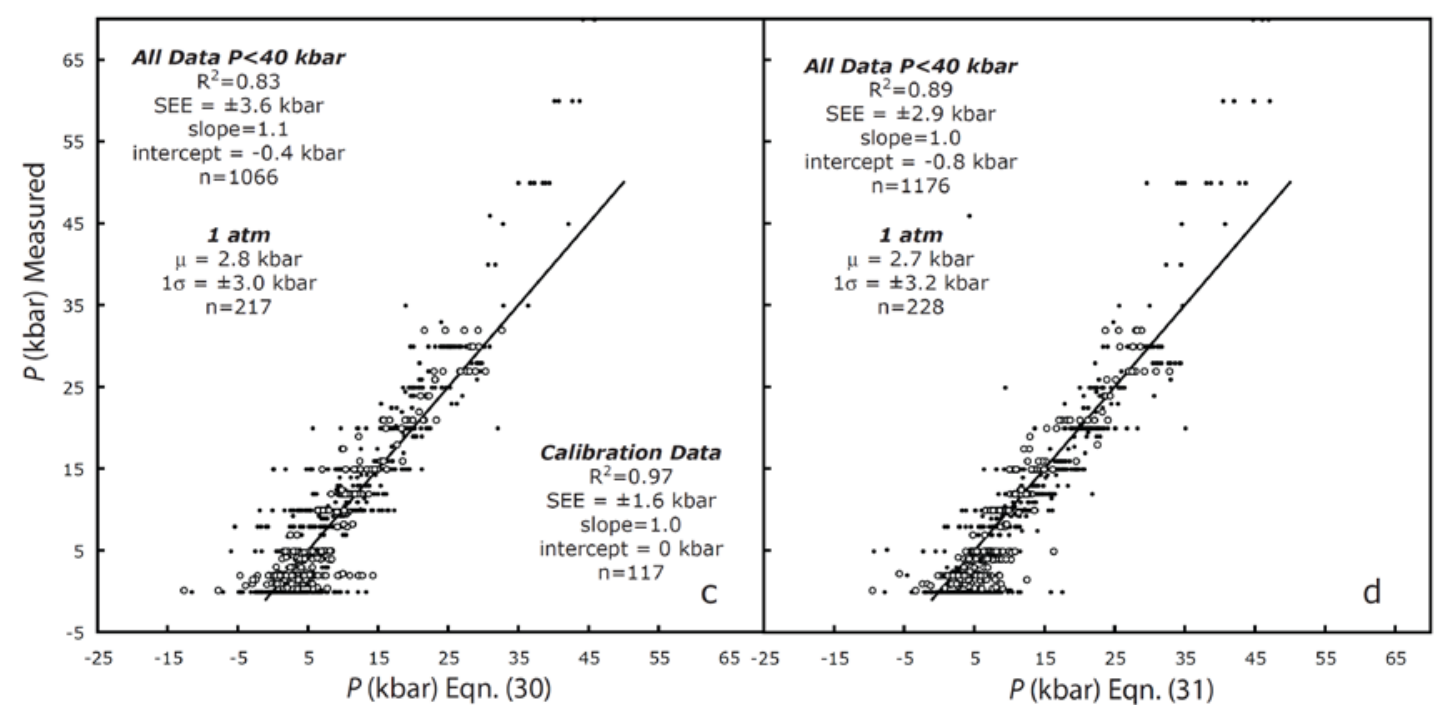

Figure 3.2 Comparison of two clinopyroxene-liquid barometers from Putirka (2008) shows that Eqn. 30 (equation 6) better reproduces the low pressure, hydrous data, although Eqn. 31 has better overall statistics. From Putirka (2008).

Table 3.10 Temperature $\left({ }^{\circ} \mathrm{C}\right)$ calculated from equation 5 using variable pressure and water content inputs. These variables are not well constrained, but within the variation expected in this system and the calculated temperature is within or very close to the model error $\left( \pm 42^{\circ} \mathrm{C}\right)$

\begin{tabular}{|c|c|c|c|c|}
\hline \multirow{2}{*}{$\begin{array}{l}\text { Pressure } \\
\text { kbars }\end{array}$} & \multicolumn{4}{|c|}{ Water content } \\
\hline & $0 \%$ & $1 \%$ & $4 \%$ & $2 \mathrm{SD}$ \\
\hline Eq $6^{1}$ & 959 & 951 & 925 & 35.15 \\
\hline $\mathbf{0}$ & 953 & 943 & 912 & 42.29 \\
\hline 5 & 973 & 962 & 931 & 43.65 \\
\hline 10 & 993 & 982 & 950 & 45.07 \\
\hline 2 SD & 36 & 35 & 31 & \\
\hline
\end{tabular}

${ }^{1}$ Using equation 6 as the pressure input and solving pressure simultaneously with equation 5

EMPA analyses of glass adhered to clinopyroxene crystals and clinopyroxene-hosted melt inclusions $>10 \mu \mathrm{m}$ were paired with adjacent clinopyroxene analyses in order to ensure that glass and clinopyroxene compositions are in equilibrium if the crystal cargo was in equilibrium with the melt at the time of eruption. It also preserves any heterogeneities within each sample and allows for easy identification of pairs that do not represent chemical equilibrium. The glass analyses compared well with those of the matrix glass for each sample except SM-6C. These showed depletion in $\mathrm{CaO}, \mathrm{Al}_{2} \mathrm{O}_{3}$ and $\mathrm{MgO}$ and enrichment in alkalis. For this reason, the average matrix glass was used for this sample. 


\subsubsection{Equilibrium}

The use of clinopyroxene-melt thermometry requires the melt and clinopyroxene to be in equilibrium with one another. Putirka (2008) provides numerous methods to test this criteria as no single method is conclusive.

\section{Fe-Mg exchange coefficients}

If the clinopyroxene and liquid compositions are in equilibrium (at least in terms of $\mathrm{Fe}$ and $\mathrm{Mg})$ then the $(\mathrm{Fe} / \mathrm{Mg})^{\mathrm{cpx}} /(\mathrm{Fe} / \mathrm{Mg})^{\text {liq }}=\mathrm{K}_{\mathrm{D}}(\mathrm{Fe}-\mathrm{Mg})^{\text {cpx-liq }}$. The Fe-Mg exchange coefficient is 0.28 \pm 0.08 with a range of 0.04-0.68 and a slight temperature dependence which can be accounted for by:

$$
\ln K_{D}(F e-M g)^{c p x-l i q}=-0.107-\frac{1719}{T(K)} \pm 0.08
$$

Although with a $\mathrm{R}^{2}=0.12$ this poorly reproduces $\mathrm{K}_{\mathrm{D}}(\mathrm{Fe}-\mathrm{Mg})^{\mathrm{cpx}-\mathrm{liq}}$. Most of the $\mathrm{K}_{\mathrm{D}}$ values calculated from these samples were much lower than 0.28 and the temperature dependent $K_{D}$ value (0.193-0.233) (Table 3.11). Half of the samples could be considered to be in equilibrium if the temperature dependent $\mathrm{K}_{\mathrm{D}} \pm 0.08$ is used. However, Fe-Mg exchange between melt and clinopyroxene is dependent on many factors including pressure, oxygen fugacity and melt composition, rather than just temperature as is assumed in this model (Bedard, 2010). Therefore both constant and temperature dependent $\mathrm{K}_{\mathrm{D}}(\mathrm{Fe}-\mathrm{Mg})^{\mathrm{cpx}-\mathrm{liq}}$ used by Putirka (2008), are a rough approximation and failure to meet this condition does not rule out equilibrium between the liquid and crystal phases.

\section{Clinopyroxene components}

Equilibrium can also be determined on the basis of predicted clinopyroxene components (e.g. CaTs, EnFs, DiHd) based on the melt composition compared with the observed clinopyroxene components. This is a more robust test of clinopyroxene-melt equilibrium as it examines whether the individual clinopyroxene components are in equilibrium rather than assuming that these are in equilibrium if Fe-Mg are. Figure 3.3 indicates how well this data fits the criteria. 
Melt inclusion/host data appears to be close to equilibrium, but the glass/rim pairs are less conclusive.
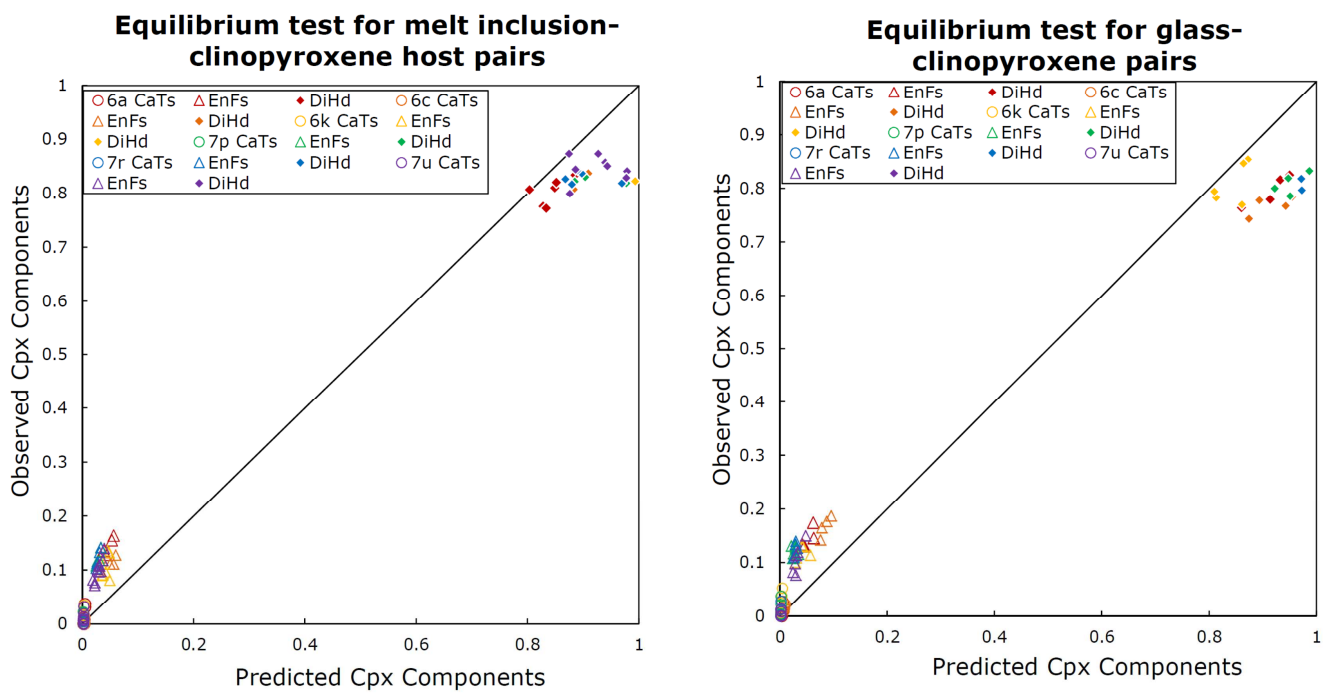

Figure 3.3 Predicted clinopyroxene components based on the melt composition vs the observed clinopyroxene components calculated from clinopyroxene analyses for glass-clinopyroxene pairs and melt inclusion-clinopyroxene host pairs. Modified after Putirka (2008).

\section{Clinopyroxene saturation}

Equation 3.10 is used as a test of the temperatures obtained from equation 3.7 as this gives the clinopyroxene saturation temperature of a melt at a given pressure. Therefore the result from this model should agree with that of equation 3.7 if the two phases are in equilibrium. The results were considered in agreement if they were within $\pm 45^{\circ} \mathrm{C}$ of each other.

$$
\begin{aligned}
& \frac{10^{4}}{T(K)}=6.39+0.076\left(\mathrm{H}_{2} \mathrm{O}^{l i q}\right)-5.55\left(X_{\mathrm{CaO}^{l i q}}^{l i q} X_{\mathrm{SiO}_{2}}^{l i q}\right)-0.386 \ln \left(X_{M g O}^{l i q}\right)-0.046 P(k b a r)+ \\
& 2.2 \times 10^{-4}[P(\text { kbar })]^{2} \quad \pm 45^{\circ} \mathrm{C}
\end{aligned}
$$

Where $\mathrm{H}_{2} \mathrm{O}^{\mathrm{liq}}=$ the water content of the melt in wt $\%$ and $X_{\text {component }}^{\text {liq }}=$ the liquid component calculated as cation fractions on an anhydrous basis, but not renormalized to 100 .

Any clinopyroxene-melt pairs that did not fit the clinopyroxene saturation equilibrium requirement were not considered to be in equilibrium and removed. Other equilibrium conditions are satisfied as indicated in Table 3.11. 


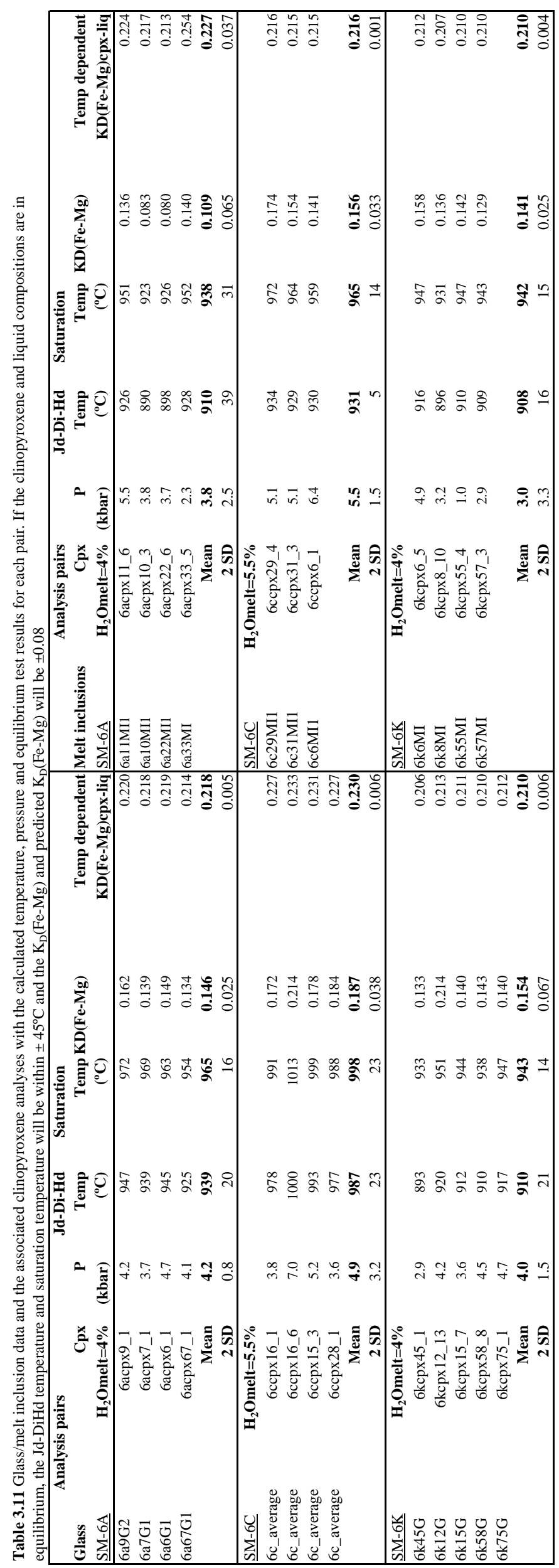




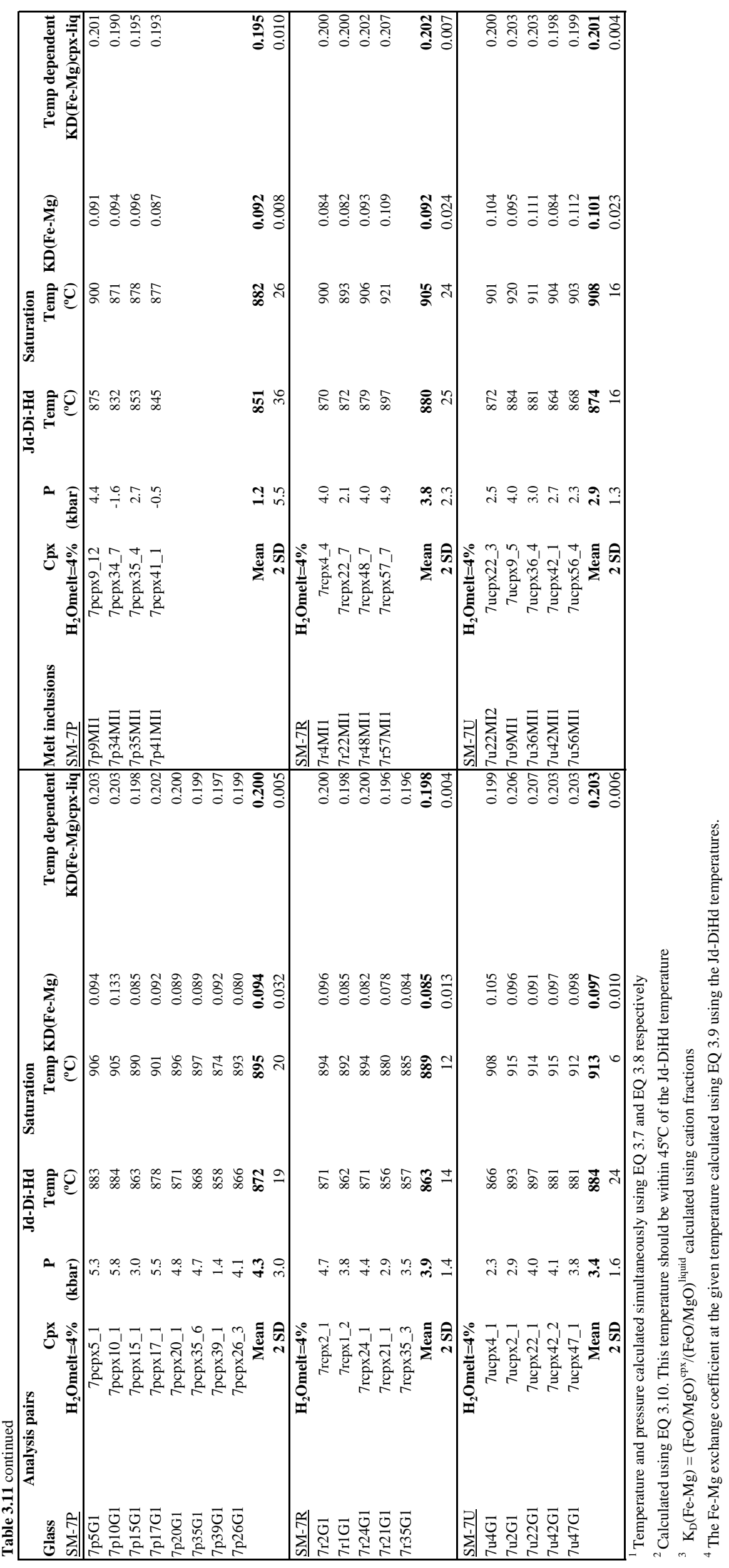




\subsubsection{Other clinopyroxene thermometers}

Clinopyroxene thermobarometry was reviewed and updated by Putirka (2008). The Jd-DiHd thermometer was used as this best fits the global calibration data for hydrous systems with the highest $\mathrm{R}^{2}$ of 0.86 and the lowest $\sigma_{\text {est }} \pm 42{ }^{\circ} \mathrm{C}$. This model accurately reproduced hydrous calibration data from $800-1200{ }^{\circ} \mathrm{C}$.

Clinopyroxene-melt thermometry requires the extra criteria of equilibrium between the melt and clinopyroxene phases be satisfied. This is not necessary for clinopyroxene-only thermometry, but these models are much less reliable with $\mathrm{R}^{2}=0.22-0.36$ and $\sigma_{\text {est }} \pm 95$ and 87 for Nimis \& Taylor (2000) and Putirka (2008) respectively.

\subsubsection{PLAGIOCLASE-MELT THERMOMETERY}

\subsubsection{Model}

The exchange of anorthite and albite between plagioclase and the coexisting melt is strongly dependent on both temperature and the water content of the melt. Multiple models have been devised to exploit this relationship by formulating thermometers and hygrometers (e.g. Sugawara, 2001; Ghiorso et al., 2002; Putirka, 2005; 2008; Lange et al., 2009)

The plagioclase-melt thermometer of Putirka (2008) was used to calculate magmatic temperatures using EMPA analyses of plagioclase rims and matrix glass. This model is based on plagioclase-melt equilibria, specifically the relationship between anorthite/albite content and temperature.

$$
\begin{aligned}
& \frac{10^{4}}{T(K)}=6.4706+0.3128 \ln \left(\frac{X_{A n}^{p l}}{X_{C a O}^{l i q}\left(X_{A l O_{1.5}}^{l i q}\right)^{2}\left(X_{S i O_{2}}^{l i q}\right)^{2}}\right)-8.103\left(X_{S i O_{2}}^{l i q}\right)+4.872\left(X_{K O_{0.5}}^{l i q}\right)+ \\
& 1.5346\left(X_{A b}^{p l}\right)^{2}+8.661\left(X_{S i O_{2}}^{l i q}\right)^{2}-3.341 \times 10^{-2}(P(k b a r))+0.18047\left(H_{2} O^{l i q}\right) \\
& \pm 36^{\circ} \mathrm{C} \\
& \text { EQ } 3.11
\end{aligned}
$$


Where $X_{\text {component }}^{l i q}=$ the melt component calculated as cation fractions on an anhydrous basis, not renormalized to 100 and $X_{\text {component }}^{p l}$ plagioclase components calculated as cation fractions on an anhydrous basis without renormalisation of weight percent values.

$$
\begin{aligned}
& X_{A n}^{p l}=X_{C a O}^{p l} /\left(X_{C a O}^{p l}+X_{N a O_{0.5}}^{p l} X_{K O_{0.5}}^{p l}\right) \\
& X_{A b}^{p l}=X_{N a O_{0.5}}^{p l} /\left(X_{C a O}^{p l}+X_{N a O_{0.5}}^{p l} X_{K O_{0.5}}^{p l}\right) \\
& \mathrm{H}_{2} \mathrm{O}^{\text {liq }}=\text { the water content of the melt in wt } \%
\end{aligned}
$$

\subsubsection{Method}

The matrix glass for each sample was averaged as it was homogeneous. This was paired with plagioclase rim analyses that appeared to be in equilibrium with the surrounding glass based on crystal texture and anorthite content. Only compositions which were in the dominant rim population were included.

This model requires both a pressure and $\mathrm{H}_{2} \mathrm{O}_{\text {melt }}$ input. The pressure and $\mathrm{H}_{2} \mathrm{O}_{\text {melt }}$ from the amphibole thermobarometry were used as this is the best constraint on these parameters. Plagioclase-liquid thermometry is very $\mathrm{H}_{2} \mathrm{O}_{\text {melt }}$ sensitive and varying this parameter by $4 \mathrm{wt} \%$ can change the resulting temperature by $>100^{\circ} \mathrm{C}$.

\subsubsection{Equilibrium}

As this is a two phase model, it is essential that the two phases of interest are in equilibrium. Putirka (2008) provides two such tests, one is based on the anorthite-albite exchange constant (Equation 3.12) while the other calculates the temperature a melt will become plagioclase saturated at a given pressure (Equation 3.13)

$$
K_{D}(A n-A b)^{p l-l i q}=\frac{X_{A b}^{p l} X_{A l o_{1.5}}^{l i q} X_{C a O}^{l i q}}{X_{A n}^{p l} X_{N a O_{0.5}}^{l i q} X_{S i O_{2}}^{l i q}}=0.10 \pm 0.05 \text { at } T<1050 \stackrel{\circ}{ } C
$$




$$
\begin{aligned}
\frac{10^{4}}{T(K)}= & 10.86-9.7654\left(X_{\text {SiO }_{2}}^{l i q}\right)+4.241\left(X_{C a O}^{l i q}\right)-55.56\left(X_{C a O}^{l i q} X_{A l O_{1.5}}^{l i q}\right)+ \\
& 37.50\left(X_{K_{0.5}}^{l i q} X_{A l O_{1.5}}^{l i q}\right)+ \\
& 11.206\left(X_{\text {SiO }_{2}}^{l i q}\right)^{3}-3.151 \times \\
& 10^{-2}(P(k b a r))+0.1709\left(H_{2} O^{l i q}\right) \pm 37^{\circ} \mathrm{C}
\end{aligned}
$$

Where $X_{\text {component }}^{l i q}=$ the liquid component calculated as cation fractions on an anhydrous basis, not renormalized to 100 and $X_{\text {component }}^{p l}=$ plagioclase components calculated as cation fractions on an anhydrous basis without renormalisation of weight percent values

$$
\begin{aligned}
& X_{A n}^{p l}=X_{C a O}^{p l} /\left(X_{C a O}^{p l}+X_{N a O_{0.5}}^{p l} X_{K O_{0.5}}^{p l}\right) \\
& X_{A b}^{p l}=X_{N a O_{0.5}}^{p l} /\left(X_{C a O}^{p l}+X_{N a O_{0.5}}^{p l} X_{K O_{0.5}}^{p l}\right) \\
& \mathrm{H}_{2} \mathrm{O}^{\mathrm{liq}}=\text { the water content of the melt in wt } \%
\end{aligned}
$$

The temperatures obtained from equations 3.11 and 3.13 are in agreement with one another to $\leq 15{ }^{\circ} \mathrm{C}$ which is well within the model error of $\pm 37{ }^{\circ} \mathrm{C}$. All samples except SM-6C were in equilibrium using the $\mathrm{K}_{\mathrm{D}} \mathrm{An}-\mathrm{Ab}$ exchange.

\subsubsection{Other plagioclase-melt thermometers}

The Putirka (2008) model was used as this is calibrated for hydrous and anhydrous systems with a temperature range of greater than $800-1300{ }^{\circ} \mathrm{C}$, while earlier models such as Sugawara (2001) and Ghiorso et al. (2002) only proved accurate for temperatures $>1100{ }^{\circ} \mathrm{C}$ (Putirka, 2005).

Lange et al. (2009) also present a thermometer and hygrometer based on the plagioclaseliquid exchange reaction between anorthite and albite. This model is calibrated as a hygrometer that requires temperature as an input. Where water content is used as an input, temperature can be calculated (Lange et al., 2009). This thermometer is comparable to that of Putirka (2005; 2008). 


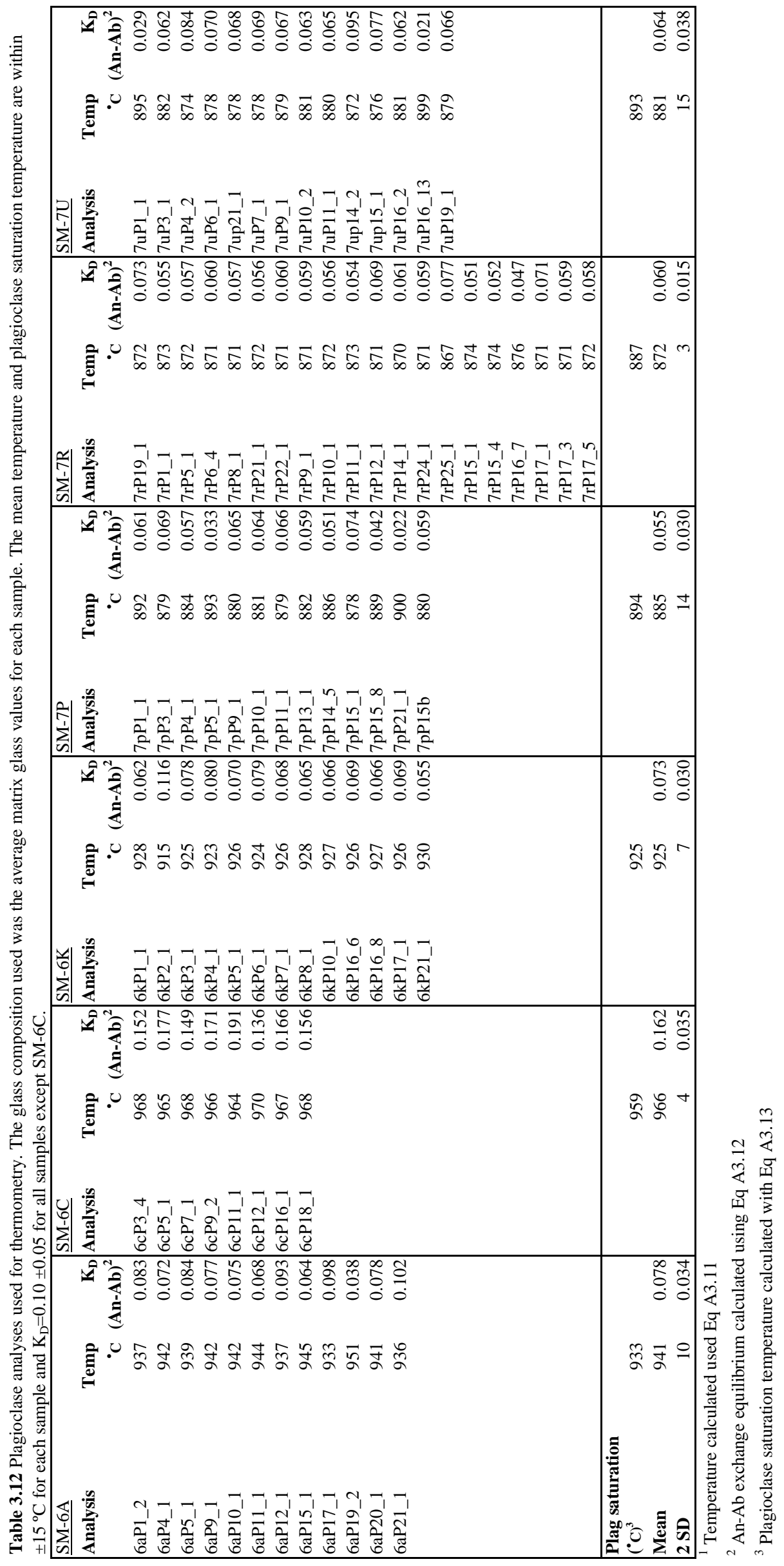




\subsubsection{COMPARISON OF RESULTS FROM DIFFERENT}

\section{THERMOMETERS}

Amphibole thermobarometry is the most reliable for the Taranaki eruptive system as all the model conditions are met and there is no requirement for equilibrium conditions so long as the host melt is calc-alkalic. The clinopyroxene-liquid thermometry, although not satisfying all equilibrium conditions stated by the model, appears to be in equilibrium. The melt inclusion/host and glass/rim clinopyroxene pairs give the same temperatures $\left( \pm 30^{\circ} \mathrm{C}\right)$ except for sample SM-6C, which further confirms the reproducibility of this method. This combined with the fact that these temperatures are in agreement with those of amphibole gives confidence that these temperatures are accurate. The plagioclase-liquid thermometer, while also giving consistent results, is less trustworthy due to the $\mathrm{H}_{2} \mathrm{O}_{\text {melt }}$ dependence. As melt water content is not a well constrained parameter, the errors associated with this model are much larger than those stated. However, these results are also in agreement with the temperatures obtained from amphibole and clinopyroxene-liquid thermometry adding confidence to these temperatures. The rim temperatures of three mineral phases all returned the same temperatures, suggesting these rims were all formed at the same melt at the same magmatic conditions and therefore had a common final history (Table 3.13). Amphibole-plagioclase thermometry is not considered appropriate for this study. As model requirements were not met by all samples and this thermometer is only appropriate for temperatures $<900{ }^{\circ} \mathrm{C}$. It is therefore not suitable for samples SM-6A, SM-6C or SM-6K and the significantly lower temperatures obtained from this model are indicative of this. This model also gives consistently lower temperatures for samples SM-7P, SM-7R and SM-7U which generally give temperatures of $<900{ }^{\circ} \mathrm{C}$ using the other thermometers assessed here. As both the phases used in this model were also used in other models evaluated here, the temperatures should correspond with one or both of these if the model is effective. Therefore, this model is not considered appropriate for this study. The results of the clinopyroxene-liquid thermometry are used in diffusion modelling, while the results of the amphibole thermobarometry are also reported in the results section of this thesis. 
Table 3.13 Summary of thermometry results. For more details see Tables 3.9 3.11, 3.12

\begin{tabular}{|c|c|c|c|c|c|c|}
\hline Inputs $^{1}$ & Sample & & Amphibole & Cpx-melt & $\begin{array}{r}\text { Cpx-melt- } \\
\text { MI }\end{array}$ & $\begin{array}{r}\text { Plag- } \\
\text { melt }\end{array}$ \\
\hline $4 \% \mathrm{H}_{2} \mathrm{O}$ & $\underline{\text { SM-6A }}$ & Mean & 960 & 939 & 910 & 941 \\
\hline 3 kbars & & $2 \mathrm{SD}$ & 41 & 20 & 39 & 10 \\
\hline $5.5 \% \mathrm{H}_{2} \mathrm{O}$ & $\underline{\text { SM-6C }}$ & Mean & 1006 & 987 & 931 & 966 \\
\hline 5 kbars & & $2 \mathrm{SD}$ & 8 & 23 & 5 & 4 \\
\hline $4 \% \mathrm{H}_{2} \mathrm{O}$ & $\underline{\text { SM-6K }}$ & Mean & 951 & 910 & 908 & 925 \\
\hline 3 kbars & & $2 \mathrm{SD}$ & 32 & 21 & 16 & 7 \\
\hline $4 \% \mathrm{H}_{2} \mathrm{O}$ & $\underline{\text { SM-7P }}$ & Mean & 919 & 872 & 851 & 885 \\
\hline 2 kbars & & $2 \mathrm{SD}$ & 14 & 19 & 36 & 14 \\
\hline $4 \% \mathrm{H}_{2} \mathrm{O}$ & $\underline{\text { SM-7R }}$ & Mean & 919 & 863 & 880 & 872 \\
\hline 2 kbars & & $2 \mathrm{SD}$ & 18 & 14 & 25 & 3 \\
\hline $4 \% \mathrm{H}_{2} \mathrm{O}$ & SM-7U & Mean & 919 & 884 & 873 & 881 \\
\hline 2 kbars & & $2 \mathrm{SD}$ & 26 & 24 & 16 & 15 \\
\hline & $\begin{array}{l}\text { Model } \\
\text { error }\end{array}$ & ${ }^{\circ} \mathrm{C}$ & \pm 22 & \pm 42 & \pm 42 & \pm 36 \\
\hline
\end{tabular}




\subsection{DIFFUSION MODELLING}

\subsubsection{INTRODUCTION TO DIFFUSION MODELLING THEORY}

\subsubsection{DIFFUSION IN MINERALS}

Diffusion can be defined as "the relative motion of one or more particles of a system relative to other particles of the same system" (Onsager, 1945). Diffusion in solid silicates is a powerful tool for tracking timescales of subvolcanic processes, some of which occur in the lead up to an eruption (e.g. Zellmer et al., 2003; Morgan et al., 2004; Martin et al., 2008). The diffusion rates of commonly measured elements vary considerably for different mineral species, so depending on the mineral-element pair that is being studied, a range of processes can be investigated on timescales ranging from hours to millennia (Chakraborty, 2008).

When the magmatic system surrounding a crystal experiences a change in melt chemistry, temperature, pressure and/or oxygen fugacity, a new crystal zone in equilibrium with the new conditions may grow (Figure 3.4a). The boundary between the new zone and crystal interior is, in effect, a disequilibrium feature that immediately begins to re-equilibrate by diffusion (Figure 3.4). Due to the exponential temperature dependence of elemental diffusion rates, diffusion effectively ceases on eruption for most elements applied to volcanic systems. If eruption occurs before complete diffusive re-equilibration can be attained, a snapshot of the incomplete element exchange occurring over that boundary is preserved. Therefore, calculating the length of time during which diffusion occurred between mineral zones provides valuable constraints on the timescales of pre-eruptive magmatic conditions independent of sample age. 


\subsubsection{DIFFUSION MECHANISMS}

Diffusion is ubiquitous, occurring randomly as the movement of atoms is driven by their thermal energy (Costa et al., 2008). Atoms migrate away from their starting position given a driving force such as a concentration gradient (or more strictly, chemical potential), resulting in an initially heterogeneous phase becoming homogeneous. Given its random nature, the process is defined statistically, averaging the movement of a large number of atoms using a Gaussian function (Chakraborty, 2008).

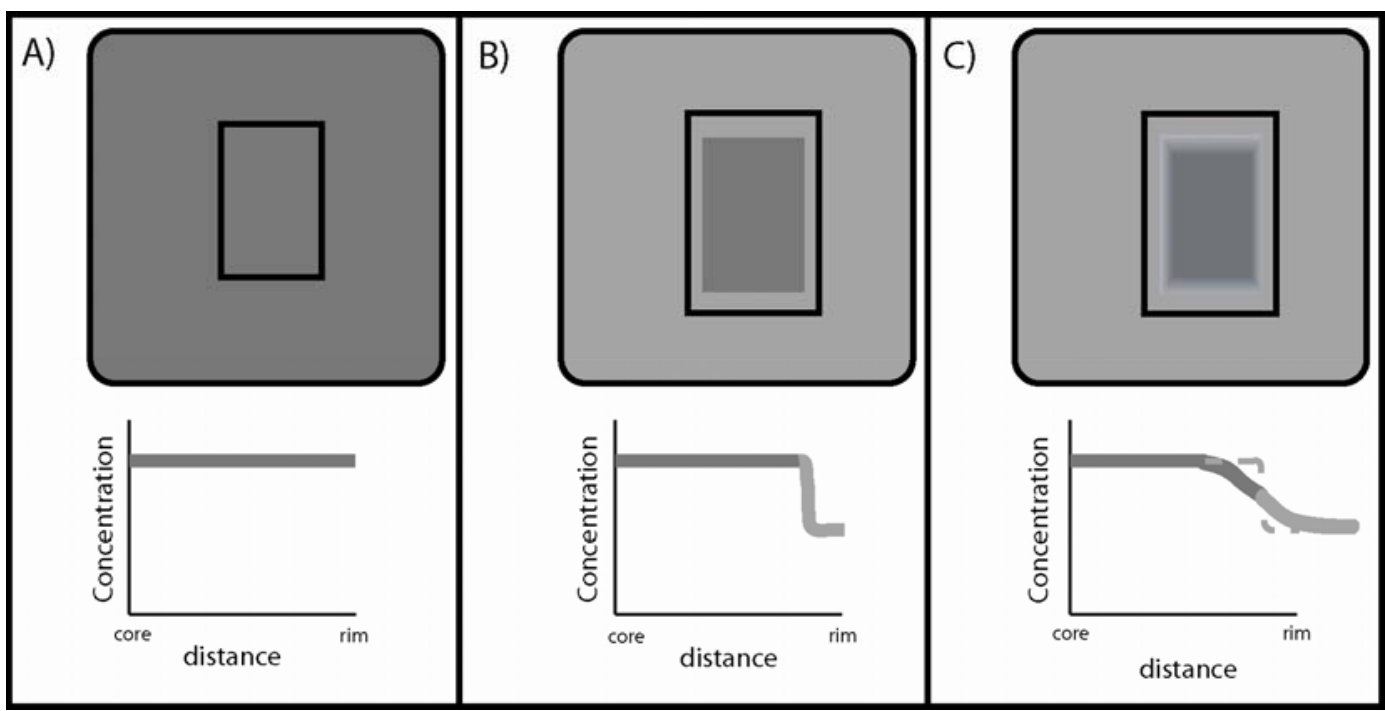

Figure 3.4 Schematicrepresentation of the history of a crystal and how diffusion modelling of crystal zoning represents magmatic events. A) The crystal has grown in a melt at a specific set of conditions resulting in a homogeneous crystal. B) The conditions of the melt have changed resulting in the growth of a new zone with a different composition and a sharp compositional boundary. C) With time this initially sharp zone boundary is smoothed as a result of diffusion. By constraining the shape of the diffusion modified boundary, and with knowledge of the temperature and diffusion coefficient of the element of interest in the mineral, one can constrain the time between event B and eruption. Modified after Costa et al. (2008).

There are four main processes by which atoms migrate within a crystal lattice: (1) vacancy diffusion, whereby an atom jumps to a vacancy; (2) interstitial, when atoms are small enough to fit into interstitial sites within the crystal lattice; (3) exchange, during which atoms swap places; and (4) ring exchange, when more than two atoms exchange places in a circuit (Figure 3.5; Watson \& Baxter, 2007; Costa et al., 2008). The most common of these is vacancy diffusion (Dimanov \& Wiedenbeck, 2006; Chakraborty, 2008; Costa et al., 2008). Vacancies form when ions are forced out of their site, which requires energy. Energy is also required to allow the atoms to make the 'jump' to fill the vacancy. Therefore, temperature is a pivotal factor in determining the diffusion rate (Chakraborty, 2008). 


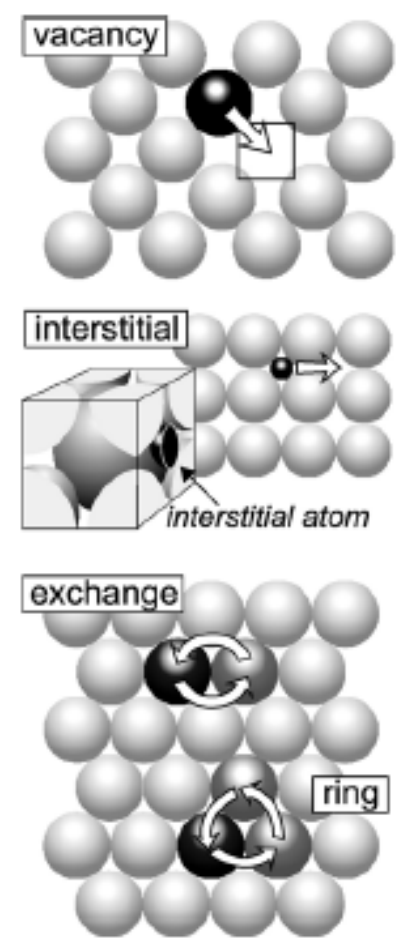

Figure 3.5 Schematic representation of the different types of diffusion mechanisms in minerals. Figure taken from Watson \& Baxter (2007).

\subsubsection{DIFFUSION EQUATIONS}

The evolution of the concentration gradient due to diffusion is governed by Fick's First Law:

$$
J_{i}=-D_{i} \frac{\partial C_{i}}{\partial x}
$$

Where $\quad J_{i}=$ flux of diffusing component $i$

$D_{i}=$ diffusion coefficient of component $i$

$\frac{\partial \mathrm{C}_{i}}{\partial x}=$ concentration gradient

To determine timescales Fick's Second Law is applied, which introduces changes in concentration with time:

$$
\frac{\partial C_{x, t}}{\partial t}=D_{i} \frac{\partial^{2} C_{x, t}}{\partial x^{2}}
$$


Where

$$
\begin{aligned}
& \mathrm{C}_{x, t}=\text { the concentration at point } x \text { and time } t \\
& t=\text { time } \\
& \mathrm{D}_{i}=\text { diffusion coefficient of component } i \\
& x=\text { position within the system }
\end{aligned}
$$

There are many analytical solutions to this equation and selection of an appropriate solution is dependent on the nature of the system being modelled including variables such as the dimensions, geometry, amount of diffusion that has occurred, boundary and initial conditions of the system (Crank, 1975). Appropriate models can be found in Crank (1975) and Carslaw \& Jaeger (1986).

\subsubsection{FE-MG INTERDIFFUSION IN CLINOPYROXENE}

\subsubsection{MODEL PARAMETERS}

Interdiffusion of $\mathrm{Fe}$ and $\mathrm{Mg}$ in clinopyroxene crystals is modelled using the method of Morgan et al. (2004) to calculate the timescales between the growth of a mineral zone and eruption. The basis of this model and its application are briefly discussed here.

This is a simple 1-dimensional model that assumes a stepwise initial concentration gradient between mineral zones (Figure 3.6A). While the crystal is at magmatic temperatures, this gradient is progressively smoothed over time by diffusion in a manner that can be mathematically modelled in the form of a progressively modified error function (erf) or complementary error function (erfc) curve (Figure 3.6). Therefore a solution to Fick's Second Law from Crank (1975) is used.

$$
\frac{\left(C-C_{0}\right)}{\left(C_{1}-C_{0}\right)}=1-\left[0.5 \operatorname{erfc}\left(\frac{h}{2 \sqrt{D t}}\right)\right]
$$

Where $\quad C_{1}$ and $\mathrm{C}_{0}=$ the end member concentrations

$$
\begin{aligned}
& C=\text { composition at point } h \text { and time } t \\
& h=\text { extent of diffusion from the half width }
\end{aligned}
$$




$$
\begin{aligned}
& D=\text { diffusion coefficient } \\
& t=\text { time }
\end{aligned}
$$

A)

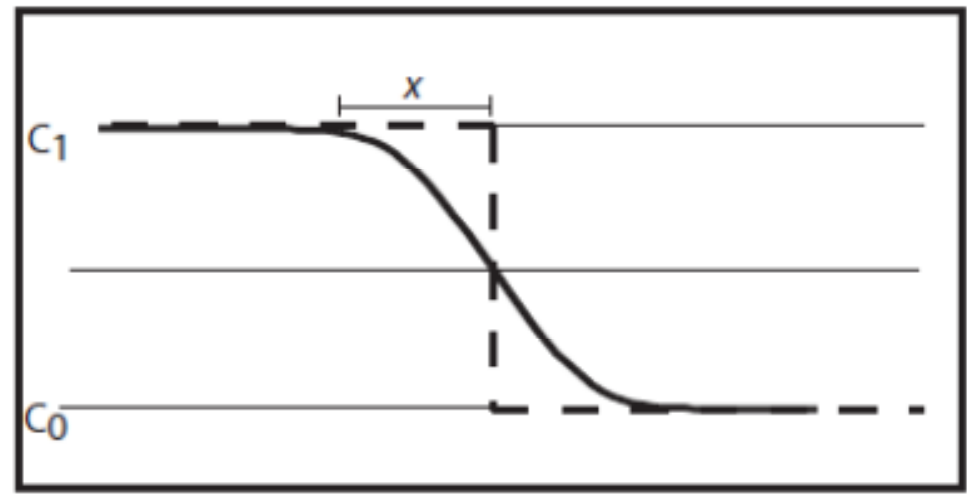

B)

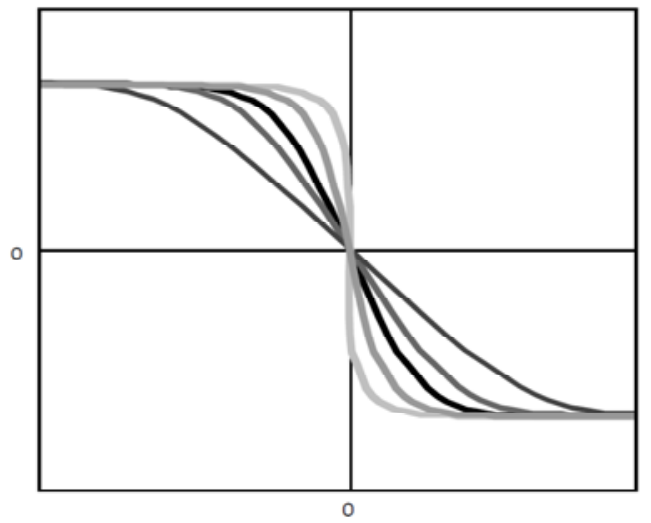

Figure 3.6 A) The dashed line represents an initial sharp chemical boundary in a mineral as is assumed in this model and the solid line illustrates how this profile looks some time later once partially smoothed to an erfe function. The parameters of EQA4.4 are identified. Figures modified after Morgan et al. (2004) and Costa et al. (2008). B) Shows the geometry of various erfc curves. Each of these could be the diffusion profile across a zone at various points in time, starting with the steepest profile and becoming progressively wider with time.

The erf function is uniquely defined because any point on the curve other than the origin has a single solution (Figure 3.6B). This enables the better constrained central $80 \%$ of the curve to be modelled and reduces the errors associated with defining the full width of the diffusion curve, as the tails of the profile are often lost to compositional noise (Morgan et al., 2004). Equation 3.17 is modified to account for this and for the limited spatial resolution resulting from the pixellated nature of the data. Therefore the diffusion equation used is:

$$
C_{x, t}=\frac{n}{2(n+1)}=1-\left[0.5 \operatorname{erfc}\left(\frac{x}{2 \sqrt{D t}}\right)\right]
$$

Where $\quad C_{x, t}=$ concentration at point $x$ and time $t$

$$
C=\text { compositional contrast on a scale of } 0-0.5
$$




$$
\begin{aligned}
& x=\text { half-width } \\
& D=\text { diffusion coefficient } \\
& t=\text { time since zone formed } \\
& n=\text { number of grades of contrast over the diffusion profile }
\end{aligned}
$$

\subsubsection{MODEL CONDITIONS}

\section{$\underline{\text { Initial conditions }}$}

A step-like initial condition was selected because the diffusion widths being modelled are generally narrow $(\leq 5 \mu \mathrm{m})$ and the renewal of crystal growth with a different composition is assumed to be abrupt and sharp. Any smoothing of this profile is attributed to diffusion which results in the calculation of a maximum age. A 1-dimensional model is justified as the lengths of the modelled diffusion profiles are very small in comparison to the size of the crystals (Costa et al., 2008).

An additional factor to consider in the diffusion process is how crystal growth affects calculated timescales. Magma evolution in response to fractionation during crystal growth can also produce smooth concentration profiles between crystal zones (Costa et al., 2008). In this case the assumption of an initially sharp, step-like profile is not valid, and could result in overestimating calculated timescales. For this reason, only zones that could reliably be inferred to have originally had sharp boundaries were modelled. Wherever possible, this was verified by observations of incongruent and congruent portions of individual boundaries. Incongruent boundaries, where there is a mismatch of the crystal lattice, diffuse at a much slower rate than congruent boundaries and therefore the curved sections of zones appear to remain sharp when straight sections have diffused (Morgan, 2003). This property was used to confirm the initial boundary sharpness by checking that the incongruent section of a modelled zone appeared crisp in backscatter electron (BSE) images. Only zones that met this criterion were modelled. 


\section{$\underline{\text { Boundary Conditions }}$}

Simple boundary conditions were used in the models assuming an isothermal, closed system. Thermometry results from both mineral rim and internal zones consistently returned the same temperature within the model error $\left( \pm 42^{\circ} \mathrm{C}\right)$ suggesting there was no overall heating or cooling trend affecting the zones of interest, justifying the use of an isothermal model. A closed system was assumed, as the growth rate appears to be relatively fast $\left(\sim 10^{-12} \mathrm{~ms}^{-1}\right)$, which has the effect of isolating newly formed zones from the surrounding melt ca. $1000 \mathrm{~s}$ after formation (D. Morgan, pers. comm.). This time period is significantly shorter than the resolution of the model and will therefore have no impact on the calculated timescales (see discussion of model resolution below).

\section{Diffusion Coefficient}

The diffusion coefficient is calculated from an Arrhenius type equation (Equation 3.19). This is mainly related to the temperature-controlled concentration of vacancies. Other variables such as pressure, oxygen fugacity, composition and crystallographic orientation can also affect the diffusion coefficient depending on the mineral and element of interest (e.g. Costa \& Dungan, 2005). The pre-exponential factor $\left(\mathrm{D}_{0}\right)$ and activation energy $(\mathrm{Q})$ have been previously determined experimentally for each element-mineral pair. The temperature is determined separately.

Dimanov \& Sautter (2000) experimentally investigated Fe-Mg interdiffusion in clinopyroxene and calculated a $\mathrm{D}_{0}$ value of $9.55 \times 10^{-5} \mathrm{~m}^{2} \mathrm{~s}^{-1}$ and $\mathrm{Q}$ of $406 \mathrm{~kJ}$. During these original experiments the oxygen fugacity spanned five orders of magnitude, from $10^{-18}$ to $10^{-13}$. Earlier studies had shown that the activation energy varies depending on whether the oxygen fugacity is fixed or buffered (e.g. Chakraborty \& Ganguly, 1992). Dimanov \& Sautter (2000) postulated that their activation energy of $406 \mathrm{~kJ} / \mathrm{mol}$ was an overestimate and Dimanov \& Wiedenbeck (2006) confirmed this by calculating an activation energy $\sim 25 \%$ lower of $297 \pm 31$ $\mathrm{kJ} / \mathrm{mol}$. The revised activation energy is in better agreement with other published studies of divalent cation diffusion in Fe-Mg silicates, which typically give values between 200-300 
kJ/mol (e.g. Fe self-diffusion in clinopyroxene, Azough \& Freer, 2000; Pb in clinoproxene, Cherniak, 2001; Dimanov \& Wiedenbeck, 2006).

The Fe-Mg interdiffusion coefficient for clinopyroxene used here is calculated using the Dimanov \& Wiedenbeck (2006) equation:

$$
D=D_{0}\left(\frac{p O_{2}}{p O_{2}^{r e f}}\right)^{n} \exp \left(-\frac{Q}{R T}\right)
$$

Where $D=$ the diffusion coefficient $\left(\mathrm{cm}^{2} / \mathrm{s}\right)$

$D_{0}=$ the pre-exponential factor $\left(7.68 \times 10^{-2}\right)$

$p \mathrm{O}_{2}=$ oxygen partial pressure

$p O_{2}^{\text {ref }}=$ a reference oxygen partial pressure $(0.21 \mathrm{~atm})$

$n=$ the oxygen fugacity exponent $(0.22 \pm 0.02)$

$Q=$ the activation energy $(297 \pm 31 \mathrm{~kJ} / \mathrm{mol})$

$R=$ the gas constant $(8.314 \mathrm{~J} / \mathrm{mol} / \mathrm{K})$

$T=$ temperature $\left({ }^{\circ} \mathrm{K}\right)$

Dimanov \& Wiedenbeck (2006) investigated Fe-Mg interdiffusion in clinopyroxene along the [001] axis assuming compositional independence. A strong sensitivity to oxygen fugacity was found, which was quantified and incorporated as a separate factor into the above model.

\subsubsection{METHOD}

Greyscale values from BSE images are used as a proxy for Fe and $\mathrm{Mg}$ concentrations and allow the shape of the diffusion profile to be defined and modelled. These images were imported into the image manipulation program Image ${ }^{\circledR}$ and rotated so that the boundary of interest was vertical (Figure 3.7). Greyscale values were calculated using an area of between 100 and 300 pixels along the length of the zone to calculate average values and reduce the amount of noise. Care was taken to minimise interference from imaging imperfections that may affect the greyscale such as polishing scratches, grease marks and light interactions (Figure 3.7). 
A)
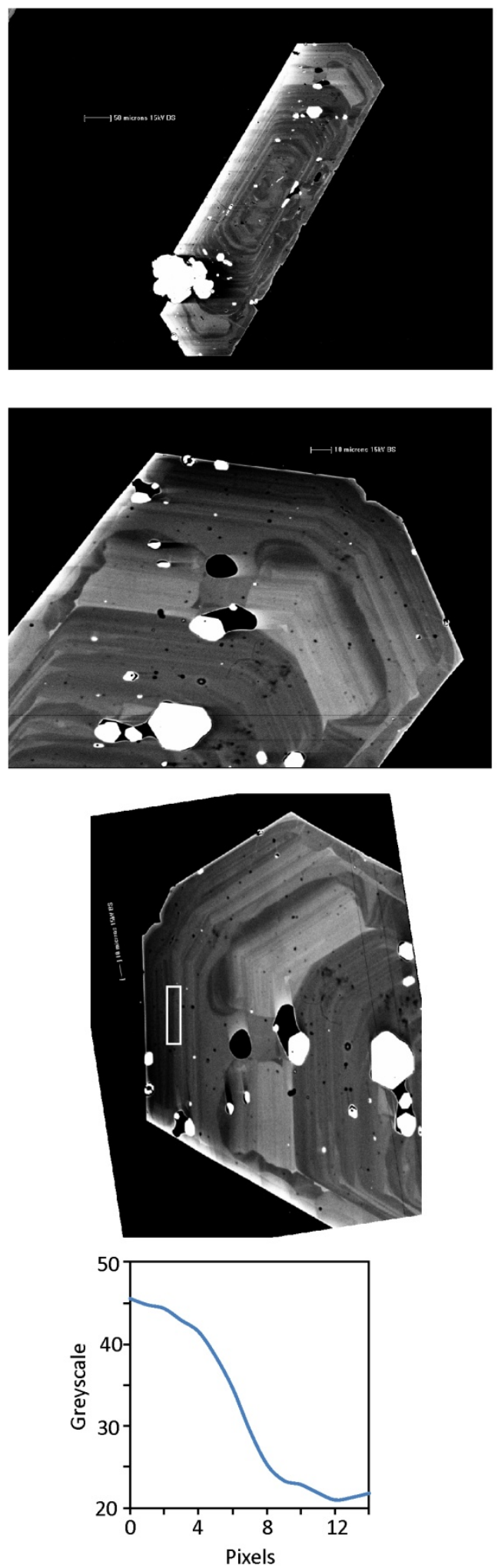

B)
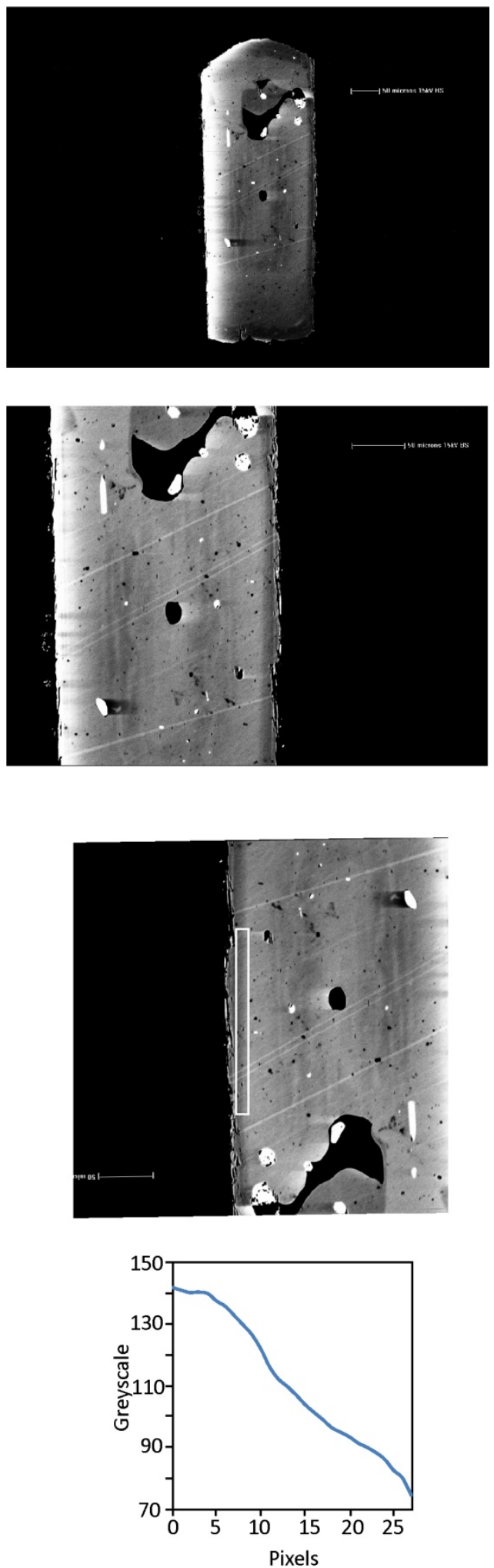

Figure 3.7 Examples of how diffusion profiles are obtained from BSE images. From top to bottom- an overview of the entire crystal is shown; an expanded image of the zones of interest; the image is rotated so the boundary of interest is vertical; the resulting profile across the modelled zone. A) an example of a good zone to model and the resulting smooth curve. B) an example of an inappropriate zone to model. 
BSE images were obtained using a JEOL 733 Superprobe Electron Probe MicroAnalyser (EMPA) at Victoria University of Wellington (VUW). The greyscale intensity of these images was used as a proxy for concentration rather than compositional traverses as images provide better resolution with submicron as compared with micron resolution. The intensity of backscattering is related to the mean atomic number of the mineral beneath the rastered electron beam (Reed, 1975). Fe has the highest atomic number (56) of the major elements in clinopyroxene so it has the strongest influence on the BSE image greyscale (Figure 3.8). BSE imaging does not strongly differentiate between $\mathrm{Mg}, \mathrm{Al}$ and $\mathrm{Si}$ as they have similar atomic numbers (24, 27 and 28 respectively) (Reed, 1975; Figure 3.8). Therefore the contrast observed in BSE images of clinopyroxene largely reflects variations in Fe making it an effective proxy for tracking $\mathrm{Fe}$ and $\mathrm{Mg}$ variation within clinopyroxene crystals (Morgan et al., 2004). BSE images provide a 2-dimensional map of the distribution of Fe-Mg zoning which more completely characterises the nature and distribution of the zoning than can be achieved by point analyses, enabling multiple zones in a crystal to be modelled (Ginibre et al., 2002b).

Energy dispersive spectrometry (EDS) mapping shows Al is the only other major element that shows zoning on the scale of $\mathrm{Fe}$ and $\mathrm{Mg}$ and therefore may affect the greyscale variations within BSE images. The affects of $\mathrm{Al}$ are however negligible as it has a similar atomic number to $\mathrm{Mg}$ and $\mathrm{Si}$. In addition, its tetrahedral coordination within the crystal lattice results in a high activation energy that means it diffuses three orders of magnitude slower than Fe-Mg interdiffusion (Sautter et al., 1988; Dimanov \& Sautter, 2000). This makes Al diffusion in pyroxenes negligible on geologic timescales at temperatures of $<1000{ }^{\circ} \mathrm{C}$ (Sautter et al., 1988). The overall affect of $\mathrm{Al}$ on the greyscale values is that it introduces some noise but has a minimal affect on the calculated timescale (D. Morgan, pers. comm.). 


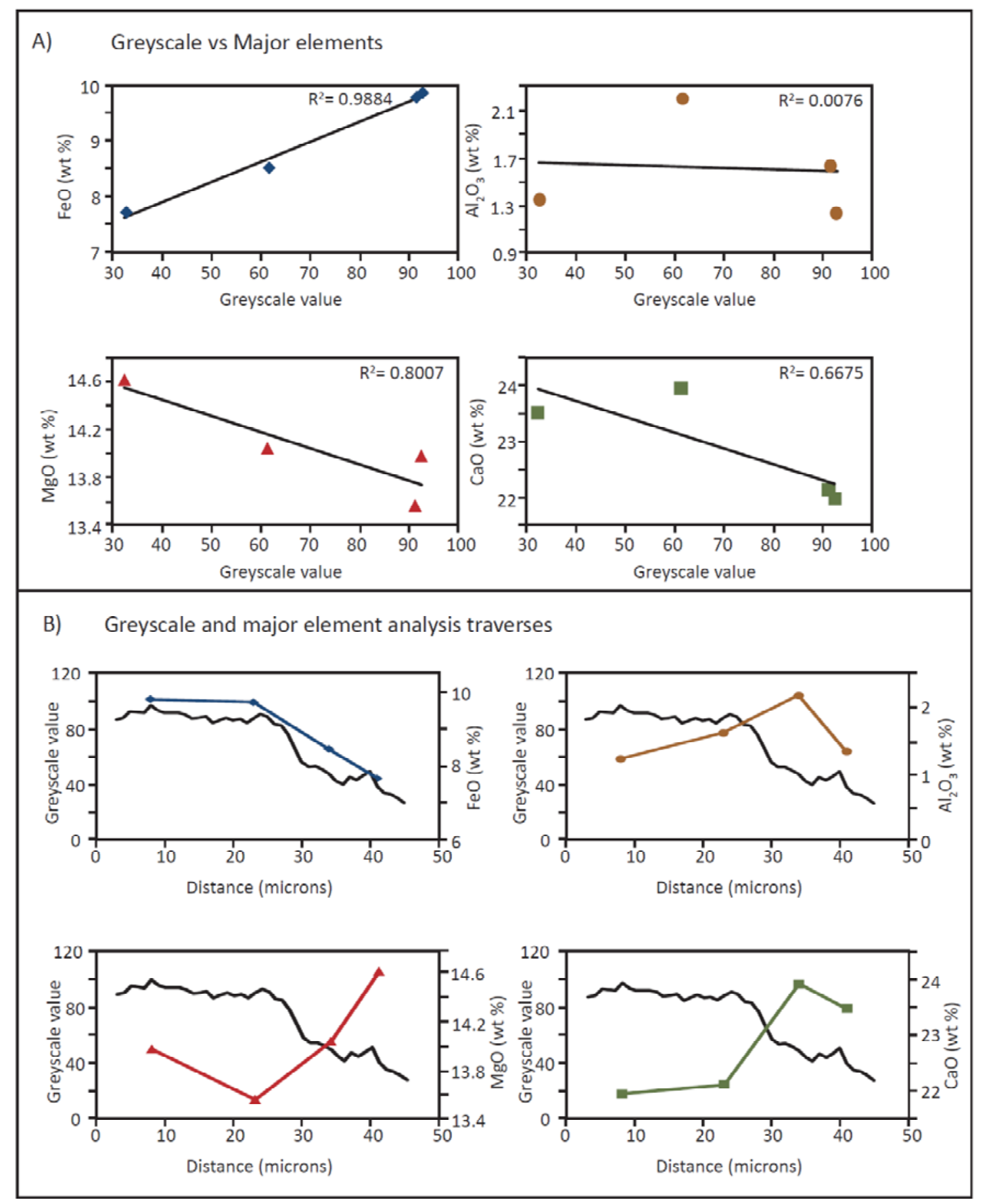

Figure 3.8 Graphs illustrating the relationship between greyscale and selected major elements. A) Greyscale plotted against selected major elements. Linear trend lines have been fitted to each graph and the regression value shown. Greyscale most closely correlates with $\mathrm{FeO}$ and $\mathrm{Mg} \#$ and has a very poor correlation with $\mathrm{Al}_{2} \mathrm{O}_{3}$ and $\mathrm{CaO}$. This indicates that the greyscale value of clinopyroxene is primarily controlled by the Fe content. B) A transect across a clinopyroxene zone comparing greyscale values (black line) and major element analyses (coloured lines). Also note the much better resolution provided by greyscale than EMPA analyses. 


\subsubsection{MINIMUM RESOLUTION OF THE MODEL}

The spatial resolution of the data is dependent on pixel size and therefore the magnification of the image. The minimum resolution of the model with regards to timescale was calculated by modelling a perfectly sharp boundary, that is, a boundary that has undergone no diffusion and should therefore represent a diffusion timescale of zero. This was carried out on cracks and the edge of crystals (where the crystal meets epoxy) as these are discrete boundaries. This was done at a range of magnifications for each sample as each sample has a different diffusion coefficient due to their different temperatures. A numerical relationship was determined to calculate the minimum resolution for any given magnification and diffusion coefficient (Equation 3.20) and the results from these calculations are shown in figure 3.9.

$$
y=a x^{-1.598}
$$

Where $y=$ the minimum resolution of the model in years

$x=$ the magnification of the image

$a=$ the pre-exponential factor which is determined by the diffusion coefficient

These times represent the error related to the resolution of the data and are assumed to be the minimum temporal resolution of the model. Any zones that return timescales at or below this threshold cannot be resolved using this model and are considered to represent boundaries not significantly modified by diffusion and therefore with diffusion timescales of zero age. Each calculated age was checked against its specific minimum resolution (dependent on image magnification and diffusion coefficient). No crystal zones modelled in this study returned ages at or near this threshold. 


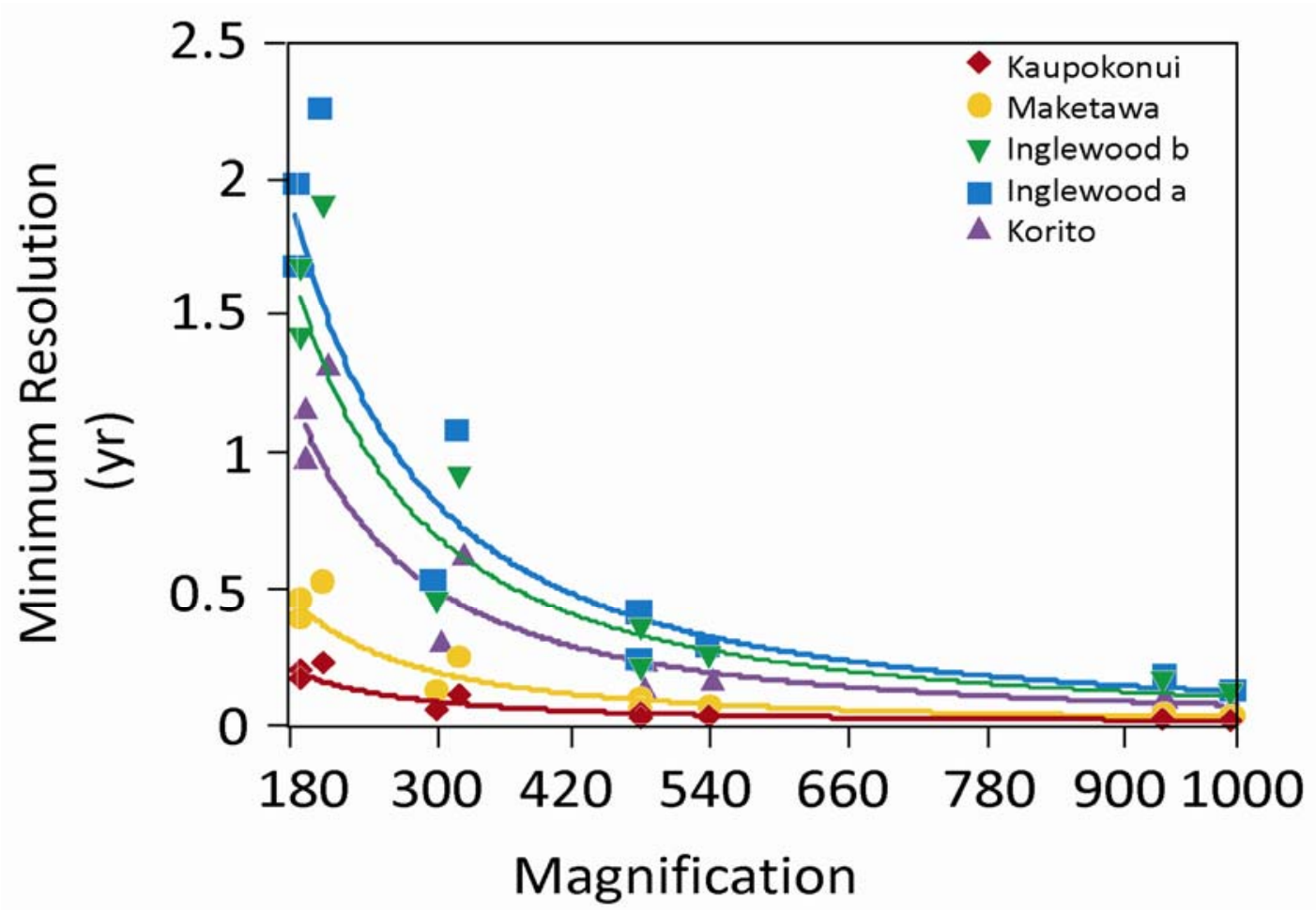

Figure 3.9 Graph illustrating the power function relationship between magnification of BSE image and minimum temporal resolution of the diffusion model as determined by EQ 3.20. This is calculated for each sample as the diffusion coefficient is different for each sample due to differences in temperature and oxygen fugacity. Image magnifications used in modelling range from $180 \mathrm{x}-1000 \mathrm{x}$, but most $(\sim 75 \%)$ modelled images were taken at a magnification of $400 x-800 x$.

\subsubsection{SOURCES OF ERROR}

There are a number of simplifications made in this model that will result in the propagation of errors and these effects must be considered. It is important to note that the same values of $\mathrm{D}_{0}$ and $\mathrm{Q}$ were used for all calculations. Therefore the errors associated with $\mathrm{D}_{0}$ and $\mathrm{Q}$ will affect the absolute ages, but not the relative ages. Temperature is the greatest source of error as the diffusion coefficient is exponentially dependent on temperature. It is therefore the only error quantified and factored into the age calculations. This is considered to be the total error as the other sources of error would fall within the range already defined by the temperature uncertainty. Other sources of error such as those associated with the simplifications necessary for the model have been reduced where possible and are assumed to be minimal. 


\subsubsection{DIFFUSION COEFFICIENT}

The diffusion coefficient used from Dimanov \& Wiedenbeck (2006) is a simplistic model as it does not take into account anisotropy or compositional dependence, as these variables are either currently not constrained or considered insignificant for clinopyroxene (Dimanov \& Sautter, 2000; Dimanov \& Wiedenbeck, 2006). However, these factors are both significant in the diffusivity within other mineral phases, specifically Fe-Mg interdiffusion in olivine (e.g. Costa \& Dungan, 2005; Martin et al., 2008) and orthopyroxene (e.g. Ganguly \& Tazzoli, 1994; Cherniak, 2001). It could therefore be expected to affect the Fe-Mg interdiffusion coefficient of clinopyroxene.

\section{Anisotropy}

The diffusion coefficient of Dimanov \& Wiedenbeck (2006) was calculated for the plane parallel to the [001] axis (c-axis). However, the zoning in this direction was generally too narrow to model. To minimise any affects of anisotropy, clinopyroxene crystals were orientated during sample preparation and the [101] plane was primarily modelled. Therefore any error associated with this will affect only the absolute ages and not the relative ages. In addition, where possible, zones parallel to the [001] axis were modelled and these returned the same timescales within the error of the model.

\section{Composition}

Dimanov \& Wiedenbeck (2006) assumed the rate of Fe-Mg interdiffusion in clinopyroxene was composition independent. This is justified by the previous work on interdiffusion rates in clinopyroxenes as the rates are very similar regardless of whether the clinopyroxene has a Ferich or Mg-rich composition (Dimanov \& Sautter, 2000; Dimanov \& Wiedenbeck, 2006). However, diffusivity is thought to be more sensitive to composition at higher oxygen fugacities (Dimanov \& Wiedenbeck, 2006). The oxygen fugacity of the samples modelled here are above the QFM buffer in the range where composition may have a larger effect (Dimanov \& Wiedenbeck, 2006). The diffusion coefficient was determined for $\mathrm{Mg}_{87}$ which is more 
magnesium rich than the majority of clinopyroxene crystals modelled here. Any affect this has should be minimised as the $\mathrm{Mg} \#\left(\mathrm{Mg} / \mathrm{Mg}+\mathrm{Fe}^{2+}\right)$ for these samples is restricted to 75-90 with the bulk of compositions clustering around $\mathrm{Mg} \#=80-85$.

\section{$\underline{\text { Temperature }}$}

The largest source of error in diffusion modelling is related to temperature. Temperature is the key energy input into the system, so it therefore determines the number of vacancies formed and whether atoms have enough energy to 'jump' into vacancies. The temperatures used here were calculated using the clinopyroxene-liquid thermometer of Putirka (2008) as discussed above in the thermobarometry section. The error associated with this thermometry is $\pm 42{ }^{\circ} \mathrm{C}$ (standard error of estimate). Two other thermometers were applied to these samples (amphibole - Ridolfi et al., 2010; plagioclase-melt - Putirka, 2008) which returned temperatures within error of those used here. This adds further confidence to the thermometry results and suggests the model error of $\pm 42^{\circ} \mathrm{C}$ is a maximum uncertainty.

\subsubsection{SECTIONING EFFECTS}

Sampling a three dimensional crystal in two dimensions can result in some geometric complexities whereby the crystal is not sectioned perpendicular to the zones of interest (Costa \& Morgan, in press). This has the effect of blurring the boundaries, making them appear more diffuse than they actually are and modelling of these boundaries will overestimate timescales (Figure 3.10; Ganguly et al., 2000). To reduce this effect, crystals were orientated on the [010] axis in epoxy blocks and polished approximately half way through the crystal. Sectioning in this way also enables the 'real' texture to be viewed and therefore the context of the diffusion ages may be better understood. When the crystal is sectioned obliquely, the same zone will appear more diffuse on one side of the crystal as compared to the other. Where this occurred, the narrowest zone was modelled as this is less affected by the sectioning and therefore more closely reflects the true diffusion length and therefore timescale (Ganguly et al., 2000). Rim zones are the least affected by sectioning, and this effect becomes more pronounced towards the cores, meaning the rim zones in general give more accurate timescales than the cores (D. 
Morgan, pers. comm.). The majority of zones modelled in this study were crystal rims, or within the outer $\sim 50 \mu \mathrm{m}$ of the crystals so this affect is minimised.

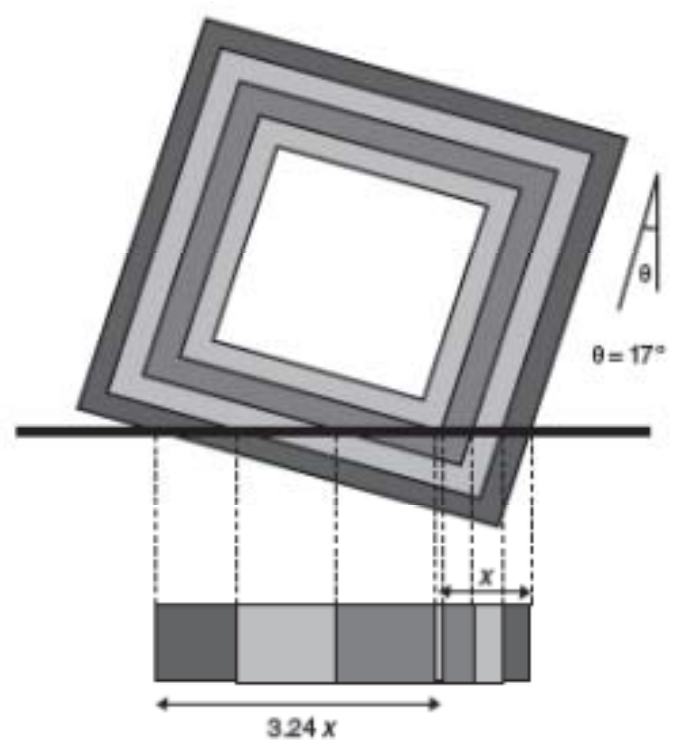

Figure 3.10 Schematic representation of the effect of oblique sectioning on the 2-dimensional view of the crystal. Note the smearing out affect of the crystal zones and therefore boundaries and hence the calculated timescales. From Costa \& Morgan (2010).

\subsubsection{IMAGE PARAMETERS}

The effects of image parameters on calculated timescales were investigated. In particular whether there was any variation in the timescales calculated using variable resolution, magnification, contrast or brightness settings. It was found that there was no change in the timescale calculated using these variable parameters (Figure 3.11). The only affect these had was the minimum resolution of the images, which increased with increasing magnification as discussed previously. 


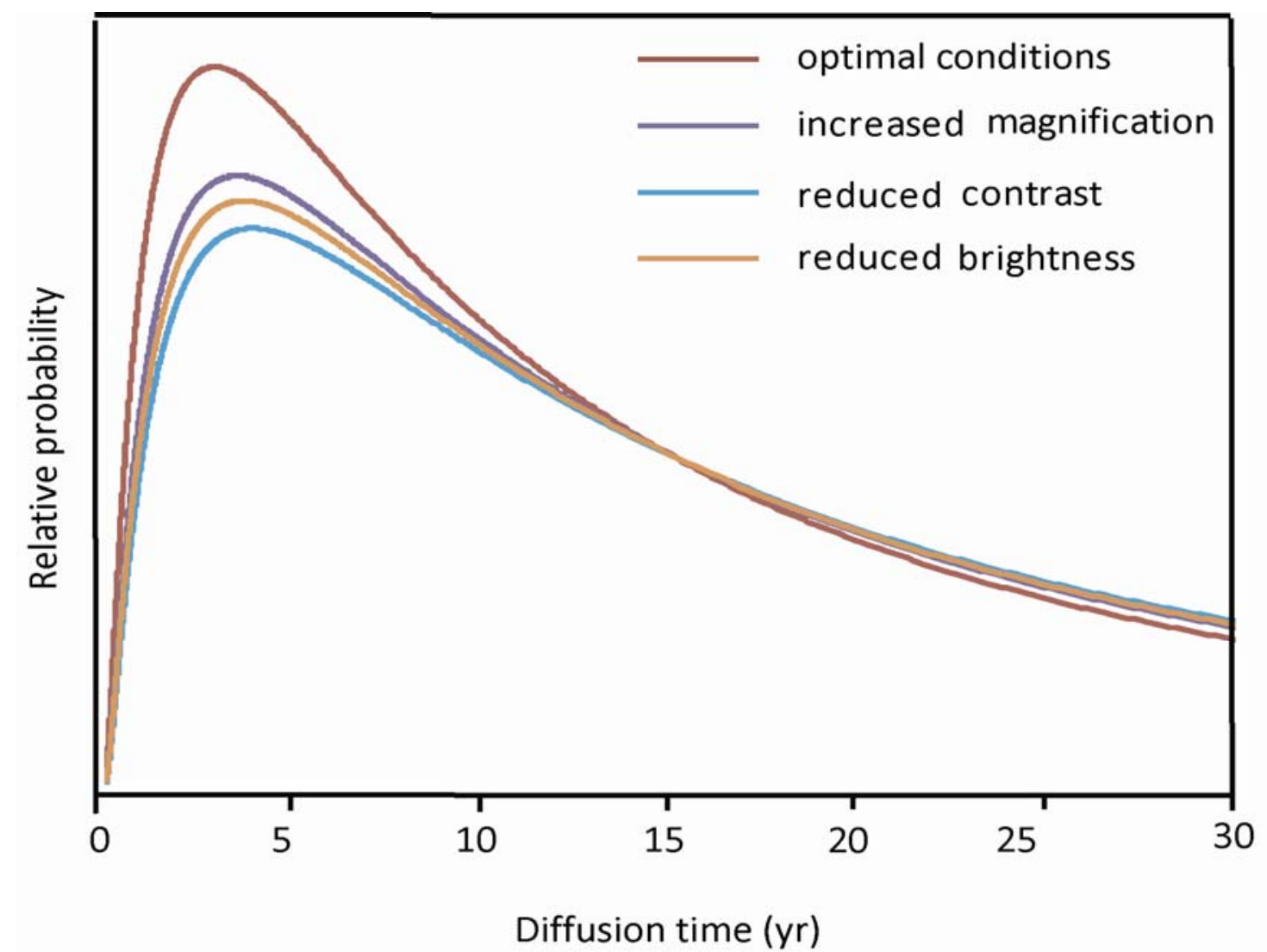

Figure 3.11 Calculated diffusion ages on the same zone in the same crystal using variable image parameters 


\section{CHAPTER 4: RESULTS}




\subsection{PETROLOGY}

The six samples investigated in this study are pumice-lithic lapillis and classified as andesite-basaltic andesite based on whole rock compositions (Neall et al., 1986; Price et al., 1992; Stewart et al., 1996; Price et al., 1999, 2005). The pumice clasts are vesicular ( 30-55 vol. \% vesicles) and crystal rich ( $20-30 \%)$. Mineral phases range from microlites $(\sim 10 \mu \mathrm{m})$ to $2 \mathrm{~mm}$ in length and include plagioclase, clinopyroxene, amphibole and Fe-Ti oxides with rare olivine and orthopyroxene. Glomerocrysts are common and include clinopyroxene and Fe-Ti oxides with occasional plagioclase, amphibole, olivine and orthopyroxene. Xenoliths are present in SM-6C and contain plagioclase, orthopyroxene and amphibole. A summary of the petrology of each sample is given in Table 4.1 .

Table 4.1 Summary of the petrographic variation observed within Taranaki eruptives investigated in this study. Mineral proportions were estimated visually under a petrographic microscope.

\begin{tabular}{|c|c|c|c|c|c|c|c|c|c|c|}
\hline ID & Sample & $\begin{array}{l}\text { Vesicle } \\
\text { content }\end{array}$ & $\begin{array}{l}\text { Glass } \\
\text { content }^{1}\end{array}$ & $\begin{array}{l}\text { Phenocryst } \\
\text { content }^{1}\end{array}$ & Plag $^{1}$ & $C p x^{1}$ & $\operatorname{Amph}^{1}$ & Oxides $^{1}$ & Olivine $^{1}$ & Opx ${ }^{1}$ \\
\hline $\begin{array}{l}\text { SM- } \\
6 \mathrm{~A}\end{array}$ & Kaupokonui & $\sim 40 \%$ & $\sim 50 \%$ & $\sim 50 \%$ & $\sim 25 \%$ & $\sim 10 \%$ & $\sim 15 \%$ & $<2 \%$ & - & - \\
\hline $\begin{array}{l}\text { SM- } \\
6 \mathrm{C}\end{array}$ & SM-6C & $\sim 40 \%$ & $\sim 65 \%$ & $\sim 35 \%$ & $\sim 25 \%$ & $\sim 10 \%$ & $<<5 \%$ & $<5 \%$ & $<<1 \%$ & $<1 \%$ \\
\hline $\begin{array}{l}\text { SM- } \\
6 \mathrm{~K}\end{array}$ & Maketawa & $\geq 50 \%$ & $\sim 40 \%$ & $\sim 60 \%$ & $\sim 40 \%$ & $\sim 10 \%$ & $\sim 10 \%$ & $<10 \%$ & - & - \\
\hline $\begin{array}{l}\text { SM- } \\
7 \mathrm{P}\end{array}$ & $\begin{array}{l}\text { Inglewood } \\
\mathrm{b}\end{array}$ & $\sim 30 \%$ & $\sim 60 \%$ & $\sim 40 \%$ & $\sim 20 \%$ & $\sim 15 \%$ & $\sim 5 \%$ & $<5 \%$ & - & - \\
\hline $\begin{array}{l}\text { SM- } \\
7 \mathrm{R}\end{array}$ & $\begin{array}{l}\text { Inglewood } \\
\text { a }\end{array}$ & $\sim 55 \%$ & $\sim 35 \%$ & $\sim 65 \%$ & $45 \%$ & $\sim 10 \%$ & $\sim 10 \%$ & $<5 \%$ & - & - \\
\hline $\begin{array}{l}\text { SM- } \\
7 \mathrm{U}\end{array}$ & Korito & $\sim 55 \%$ & $\sim 35 \%$ & $\sim 65 \%$ & $\sim 55 \%$ & $<5 \%$ & $\sim 10 \%$ & $<1 \%$ & - & - \\
\hline
\end{tabular}

${ }^{1}$ Proportions of glass and minerals calculated on a vesicle free basis.

\subsubsection{PLAGIOCLASE}

Plagioclase is the most common mineral phase within Taranaki eruptives and is present in all samples. Crystals are generally euhedral to subhedral and range in size from $\sim 20 \mu \mathrm{m}$ to 2 mm. Plagioclase crystals are typically individual crystals, but occasionally form glomerocrysts with other plagioclase crystals as well as amphibole and Fe-Ti oxides. On the basis of mineral texture, three different types of plagioclase have been identified, although there is overlap 

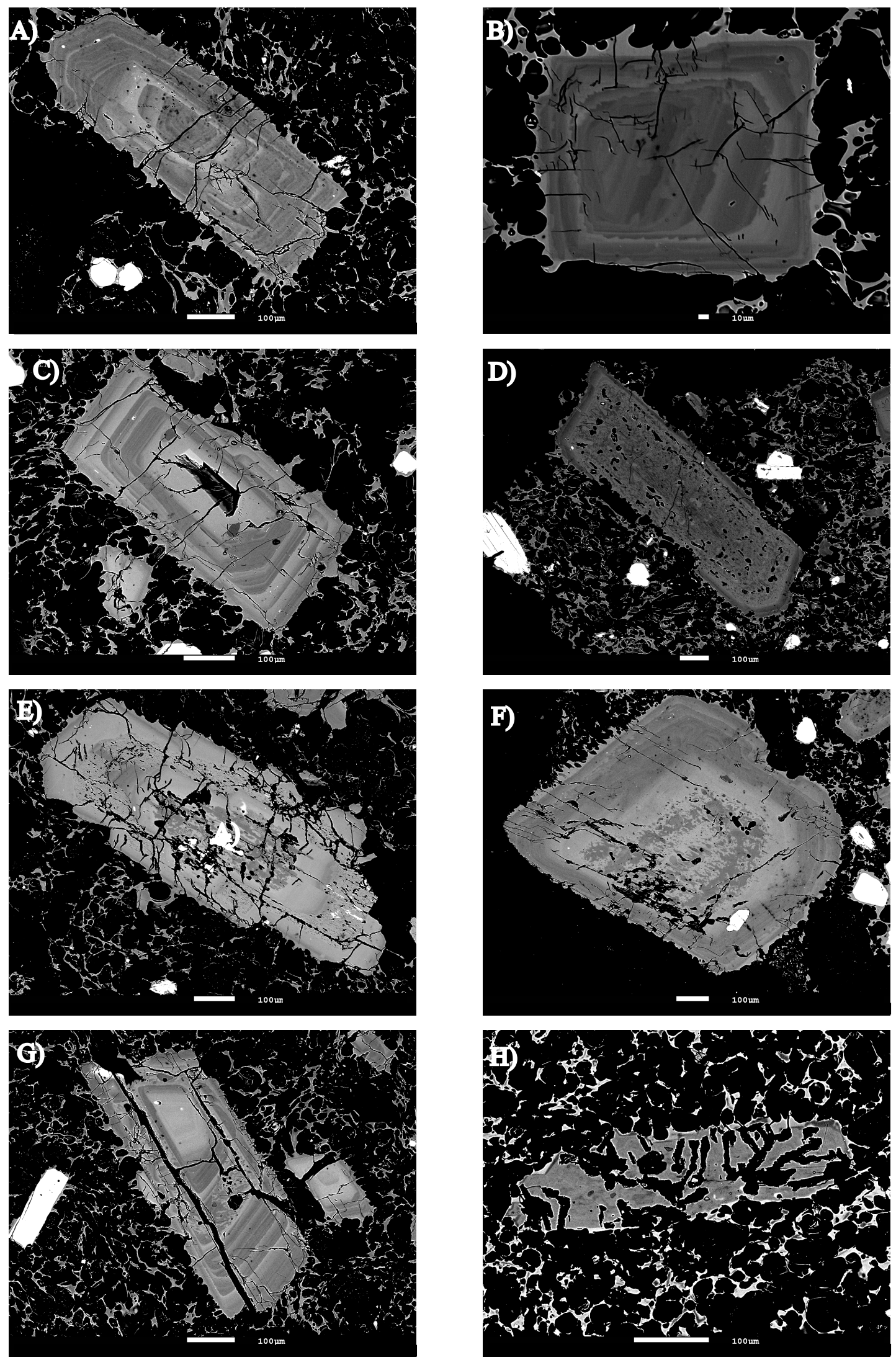

Figure 4.1 Backscattered electron images of representative plagioclase crystals. A) and B) Oscillatory zoned; C) Homogeneous high anorthite core with oscillatory rim; D) Sieved core with a thin rim; E) Patchy textured core and sieved zone; F) Patchy textured core with an oscillatory zoned rim; G) Patchy textured zone within oscillatory texture; H) Partially dissolved crystal. 
between these. Plagioclase textures are: (1) oscillatory zoned; (2) patchy zoned and sieve textured; (3) dissolved textures (Figure 4.1).

Oscillatory zoned plagioclase crystals are the most common population and compæise $50 \%$ of plagioclase crystals in each sample except SM-6C $(<20 \%)$. The oscillatory zoning spans most of the compositional range of plagioclase $\left(\mathrm{An}_{36-84}\right)$ and usually extends from crystal rim to core (Figure 4.1a and b). About 50\% of the older three samples have near homogeneous anorthite-rich cores $\left(\mathrm{An}_{67-82}\right)$ which, in some cases started to resorb (Figure 4.1c). Oscillations occur on a range of scales from $<5$ to 60 microns. The finest scale oscillations do not appear to have any resorption associated with them, but larger scale zones occur with minor and major resorption zones with changes of up to $20 \mathrm{~mol} \%$ in anorthite content. Despite the wide range in compositions, the rims are consistently low anorthite for any given sample $\left(\mathrm{An}_{36-60}\right)$.

Plagioclase exhibits sieved and/or patchy textures in 30-50\% ( $90 \%$ for SM-6C) of crystals in each sample. This generally affects the crystal core, which in some cases is surrounded by only a thin rim (Figure 4.1d), although specific zones in oscillatory crystals may be affected and both the crystal core as well as a distinct zone can be sieved or patchy (Figure 4.1e). Sieved and patchy textured crystals have low anorthite, oscillatory zoned rims which are compositionally the same as those of the oscillatory population rims. In some cases, the crystals appear identical to those of the oscillatory zoned population, but have a patchy texture in the core (Figure 4.1f). Sieved areas of crystals generally have a high anorthite content $\left(\mathrm{An}_{66-92}\right)$ and patchy areas display a bimodal composition with the high anorthite peak corresponding to sieved zones and the low anorthite composition corresponding to the oscillatory rims. It is therefore interpreted that the calcic composition is the original core/zone, which underwent partial resorption. Sieved and patchy textures differ in that areas with a patchy texture underwent recrystallisation.

Partially dissolved crystals that have undergone extensive resorption account for $<10 \%$ of the plagioclase crystals and are mostly found in sample SM-6C. These have undergone almost entire resorption and no or very little recrystallisation has occurred (Figure 4.1h). These crystals have very high anorthite contents $\left(\mathrm{An}_{86-92}\right)$. 


\subsubsection{CLINOPYROXENE}

Clinopyroxene crystals range in size from microlites $10 \mu \mathrm{m}$ to $1.5 \mathrm{~mm}$ in length and occur as isolated crystals with abundant $\mathrm{Fe}-\mathrm{Ti}$ oxide and melt inclusions, but also commonly form glomerocrysts with Fe-Ti oxides and rare plagioclase and amphibole. Clinopyroxene crystals are primarily euhedral and compositionally have $\mathrm{Mg} \#_{70-92}$ with $\sim 80 \%$ restricted to $\mathrm{Mg} \#_{76-86}$. Clinopyroxene crystals exhibit a wide range of textures, with most of this variability evident in the younger three samples. These samples contain crystals with patchy cores and oscillatory rims (all samples), patchy cores with Mg-rich rims (Maketawa, SM-6C, Kaupokonui) and multiply zoned crystals (Figure 4.2a; Maketawa and SM-6C). The two most abundant textural types are described in more detail below.

\subsubsection{Patchy core and oscillatory rims}

This is the dominant population within the samples investigated here and is the only clinopyroxene texture observed in Inglewood $\mathrm{a}$ and $\mathrm{b}$ and Korito, where the form of this texture in these three samples is near identical. The patchy cores contain abundant melt inclusions associated with the optically dark areas, indicating that the optically light areas represent the original core that underwent resorption and recrystallised as optically dark clinopyroxene (Figure 4.2c). Occasionally, the 'original' core exhibits oscillatory zoning (in the older 3 samples) (Figure 4.2d). A small population $(<10 \%)$ within Maketawa has a distinct high-Mg resorption core $\left(\mathrm{Mg} \#_{87-94}\right)$ (Figure 4.2e). Oscillatory zoning ranges in size from $\sim 20 \mu \mathrm{m}$ to comprising the entire crystal (Figure 4.2b). Oscillations occur on multiple scales with fine zoning $(\leq 10 \mu \mathrm{m})$ superimposed on coarser zoning $(10-60 \mu \mathrm{m})$. These are commonly straight, asymmetric boundaries and various degrees of resorption is common. In some cases resorption is extensive and results in a zone or series of oscillatory zones more closely resembling a patchy texture. SM-6C contains a distinct population of oscillatory zoned crystals where oscillations are very fine $(<10 \mu \mathrm{m})$ and are more like fine lamellae (Figure $4.2 \mathrm{f})$. 

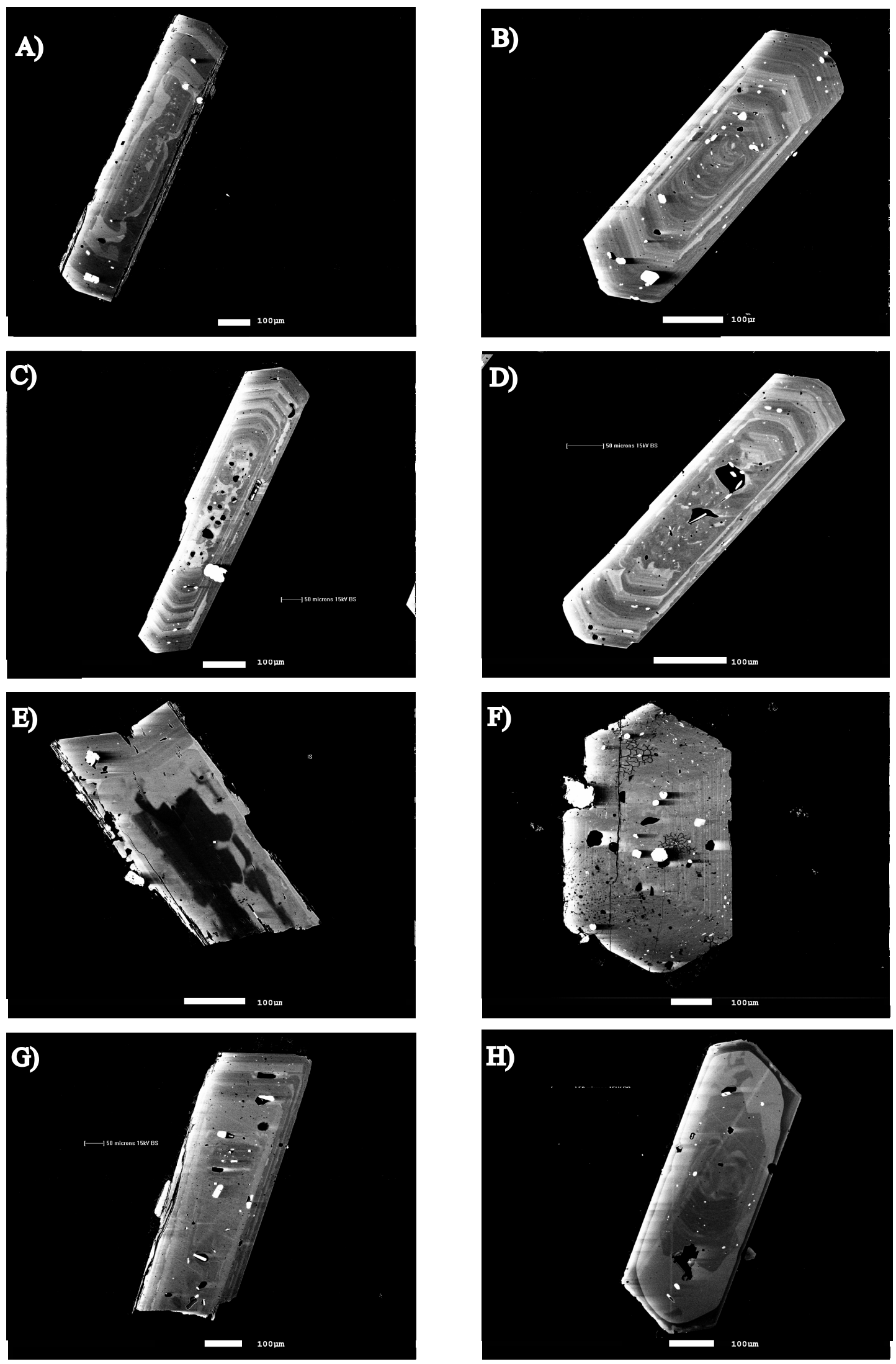

Figure 4.2 Backscattered electron images of representative clinopyroxene crystals. A)Multiple zoned; B) Oscillatory zoned; C) Patchy textured core with melt inclusions associated with the optically darker patches surrounded by an oscillatory rim; D) Resorbed oscillatory zoning; E) High-Mg resorbed core; F) Fine laminar zoning; G) Dark rim from Maketawa; H) Dark rim from Kaupokonui 


\subsubsection{Dark rim}

A dark rim is present in the younger 3 samples as a final coarse oscillatory or multiple zone (Figure $4.2 \mathrm{~g}$ ), or the rim on a Fe-rich patchy textured core with abundant, large melt inclusions (Figure 4.2h). This dark rim is most pronounced in Kaupokonui where it is commonly associated with a large degree of resorption and can have a thin overgrowth of more Fe-rich clinopyroxene.

\subsubsection{AMPHIBOLE}

Amphibole is most abundant as euhedral to subhedral individual crystals $20 \mu \mathrm{m}$ to $1 \mathrm{~mm}$ in size and can contain small Fe-Ti oxides and occasional melt inclusions. Occasionally amphibole is found in glomerocrysts with clinopyroxene \pm plagioclase $\pm \mathrm{Fe}-\mathrm{Ti}$ oxides. Amphibole compositions are magnesio-hastingsite and range in composition from $\mathrm{Mg} \#_{60-92}$ with a shift to higher values in younger samples. A range of textures is observed across the sample suite including patchy zoning $(\sim 50 \%)$, simple zoning $(\sim 20 \%)$, multiple zoning $(\sim 15 \%)$, unzoned $(\sim 10 \%)$ and oscillatory zoning $(\sim 5 \%)$.

Patchy zoning occurs in all samples and is typically limited to the core which is then overgrown with an optically dark rim. Specifically there is a distinct population where a low $\mathrm{Mg}$ and high $\mathrm{Al}\left(\mathrm{Mg \#}{ }_{68-78} ; \mathrm{Al}_{2} \mathrm{O}_{3}=12-15 \mathrm{wt} \%\right)$ resorption core is recrystallised with a high $\mathrm{Mg}$ and low $\mathrm{Al}$ rim $\left(\mathrm{Mg}_{74-82} ; \mathrm{Al}_{2} \mathrm{O}_{3}=9.5-11 \mathrm{wt} \%\right)$ (Figure 4.3a). In some cases, this rim has oscillatory zoning (Figure 4.3b). This population is the sole amphibole type in Inglewood $b$ and is dominant $(\sim 50 \%)$ in Inglewood a and Korito and typically restricted to the smaller size fraction $(<150 \mu \mathrm{m}, 20 \mu \mathrm{m}$ in Maketawa). Simple zoning is most common in the younger three samples and typically comprises an optically light core with a dark rim (Figure 4.3c), although the reverse is also observed (Figure 4.3d). Multiple zoning occurs in the Korito, Inglewood a, Maketawa and Kaupokonui sample amphiboles (Figure 4.3e). Unzoned amphibole is present in all samples but Inglewood $b$ and is observed only as microlite $30(\mu \mathrm{m})$ (Figure. 4.3f).

Oscillatory zoning occurs in Korito, Inglewood a and SM-6C and is always present in only the largest amphibole size fraction ( $\geq 500 \mu \mathrm{m}$ ) or as part of a glomerocryst (Figure $4.3 \mathrm{~g}$ and $\mathrm{h}$ ). 

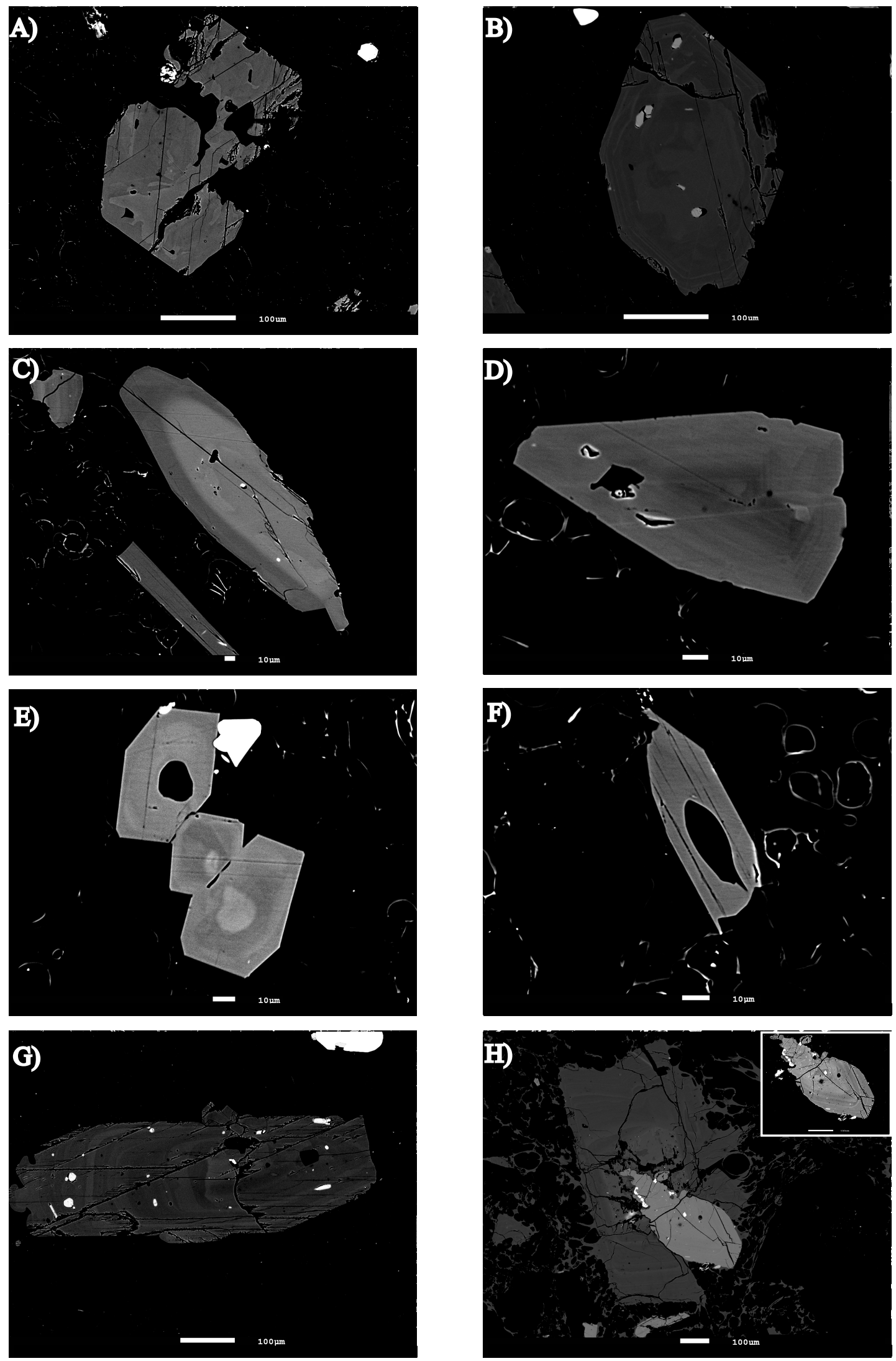

Figure 4.3 Backscattered electron images of representative amphibole crystals. A) Patchy textured core; B) Patchy core with oscillatory rim; C) Simple zoning with a light core and dark rim; D) Simple zoning with a dark core and light rim; E) Multiple zoning; F) Oscillatory zoning; G) Plagioclase and amphibole glomerocryst-inset highlights the oscillatory zoning of the amphibole 


\subsubsection{FE-TI OXIDES}

The main Fe-Ti oxide phase is titanomagnetite, although rare ilmenite is also present. Titanomagnetite occurs as individual crystals, clusters of crystals and as inclusions in clinopyroxene and amphibole. These range in composition from $\mathrm{X}_{\mathrm{Usp}} \sim 0.1-0.3$. There are two populations of single crystal titanomagnetites based on morphology. (1) Large (50-300 $\mu \mathrm{m})$ subhedral to anhedral crystals which appear to be resorbed and contain abundant apatite inclusions $(\sim 70 \%)$. In sample SM-6C, a small amount of these are very large ( $\sim 200$ $300 \mu \mathrm{m}$ ) and fragmented (Figure 4.4a). (2) Small euhedral to subhedral crystals 10-50 $\mu \mathrm{m}$ in size $(\sim 30 \%)$ (Figure $4.4 \mathrm{~b})$. Titanomagnetite also occurs as inclusions in, or forms glomerocrysts with, clinopyroxene and amphibole crystals ranging in size from $<10$ to 200 $\mu \mathrm{m}$ and are typically subhedral to anhedral in shape.
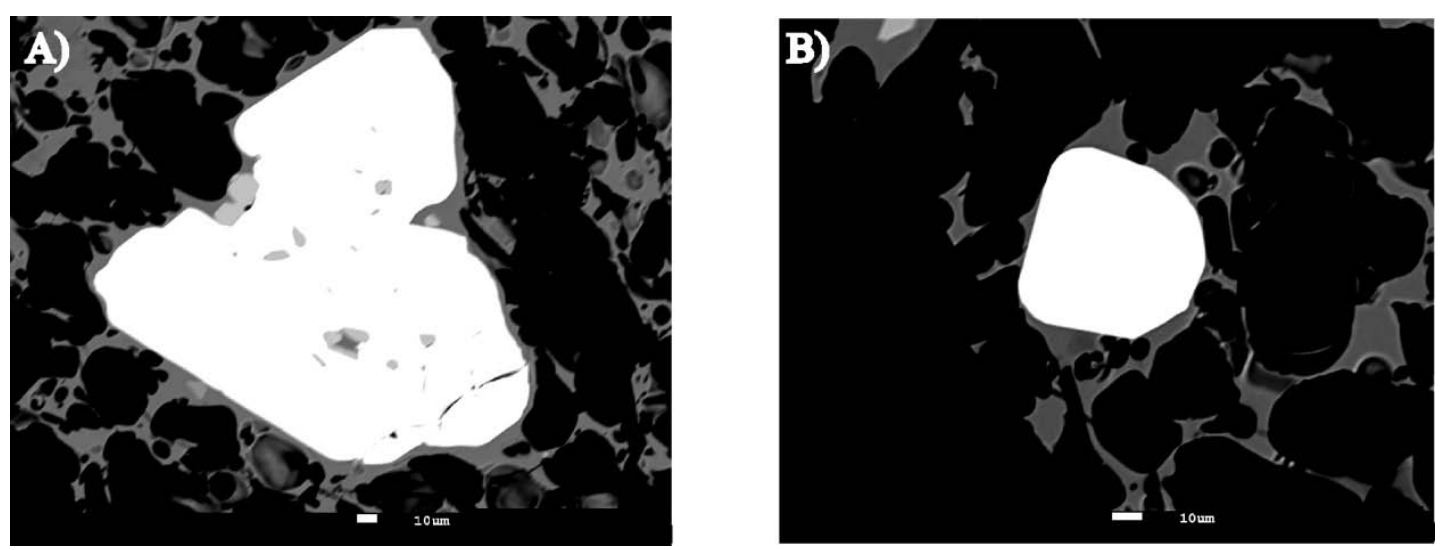

Figure 4.4 Backscattered electron images of titanomagnetite. A) Large, resorbed crystal; B) small euhedral crystal.

\subsubsection{ORTHOPYROXENE}

Orthopyroxene crystals are only present in sample SM-6C where they form euhedral to anhedral crystals $100-400 \mu \mathrm{m}$ in size (Figure $4.5 \mathrm{a}$ ). There is little compositional variation $(\mathrm{Mg} \#=70-81)$ and weak zoning. Orthopyroxene crystals contain abundant melt and Fe-Ti oxide inclusions and rare crystals have an olivine core (Figure 4.5b). 

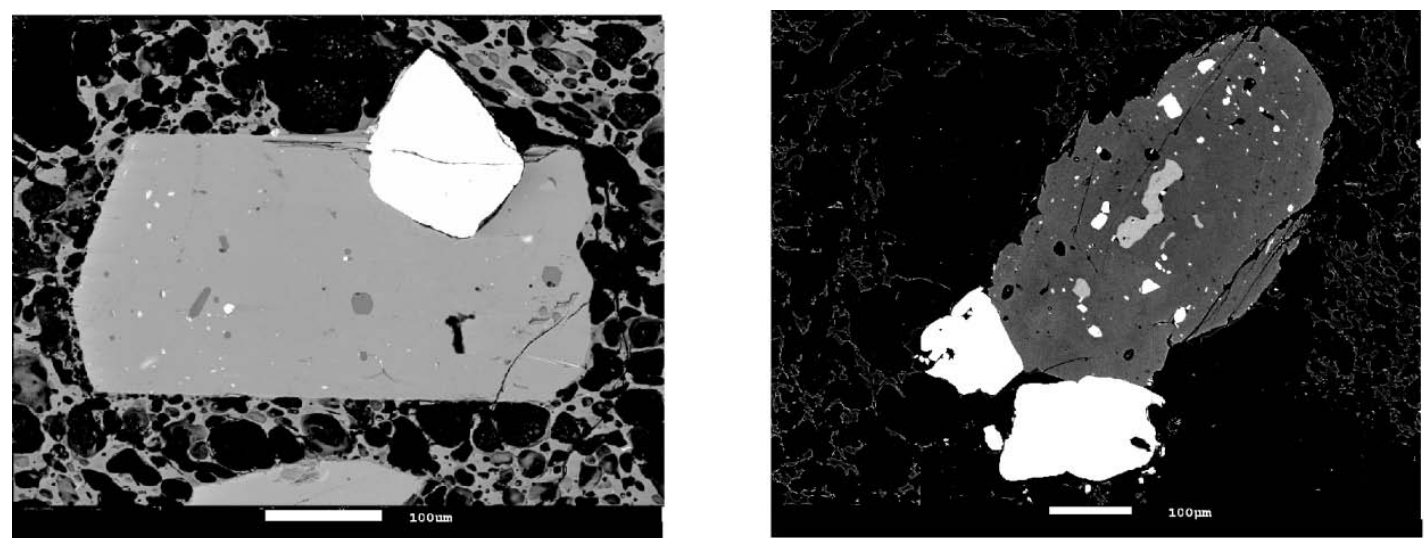

Figure 4.5 Backscattered electron images of orthopyroxene crystals. Left: weakly zoned euhedral crystal; Right: olivine cored orthopyroxene crystal.

\subsection{MAJOR ELEMENT CHEMISTRY}

\subsubsection{GLASS MAJOR ELEMENT CHEMISTY}

Taranaki eruptives are classified as high $\mathrm{K}_{2} \mathrm{O}$ andesites on the basis of whole rock data, however, glass data compositions have been shown to be dacitic (e.g. Price et al., 2005; Platz et al., 2007a). The glass major element data from this study are in agreement with this, but extend the range of glass compositions from andesite with slightly elevated $\mathrm{K}_{2} \mathrm{O}$ content to high $\mathrm{K}_{2} \mathrm{O}$ rhyolite (Figure 4.6). The overall trend of the glass major element chemistry is that of fractional crystallisation as $\mathrm{FeO}, \mathrm{MgO}$ and $\mathrm{CaO}$ all decrease as $\mathrm{SiO}_{2}$ increases (Figure 4.6). Five of the six samples form a continuous trend from dacitic to rhyolitic glass compositions that broadly corresponds to the chronologic order of these eruptions from youngest to oldest (Figure 4.6). Inglewood $\mathrm{a}$ and $\mathrm{b}$ and Korito are the most evolved samples and cluster at the rhyolite end of the spectrum. Maketawa and Kaupokonui are less evolved being dacitic in composition. Sample SM-6C falls on the same geochemical trend but is distinct because it is significantly less evolved than the other samples with lower $\mathrm{SiO}_{2}$ and $\mathrm{K}_{2} \mathrm{O}$ and higher $\mathrm{Al}_{2} \mathrm{O}_{3}, \mathrm{FeO}, \mathrm{MgO}, \mathrm{CaO}$ and $\mathrm{TiO}_{2}$. There is limited scatter within each sample, indicating that the glass composition is relatively homogeneous. 

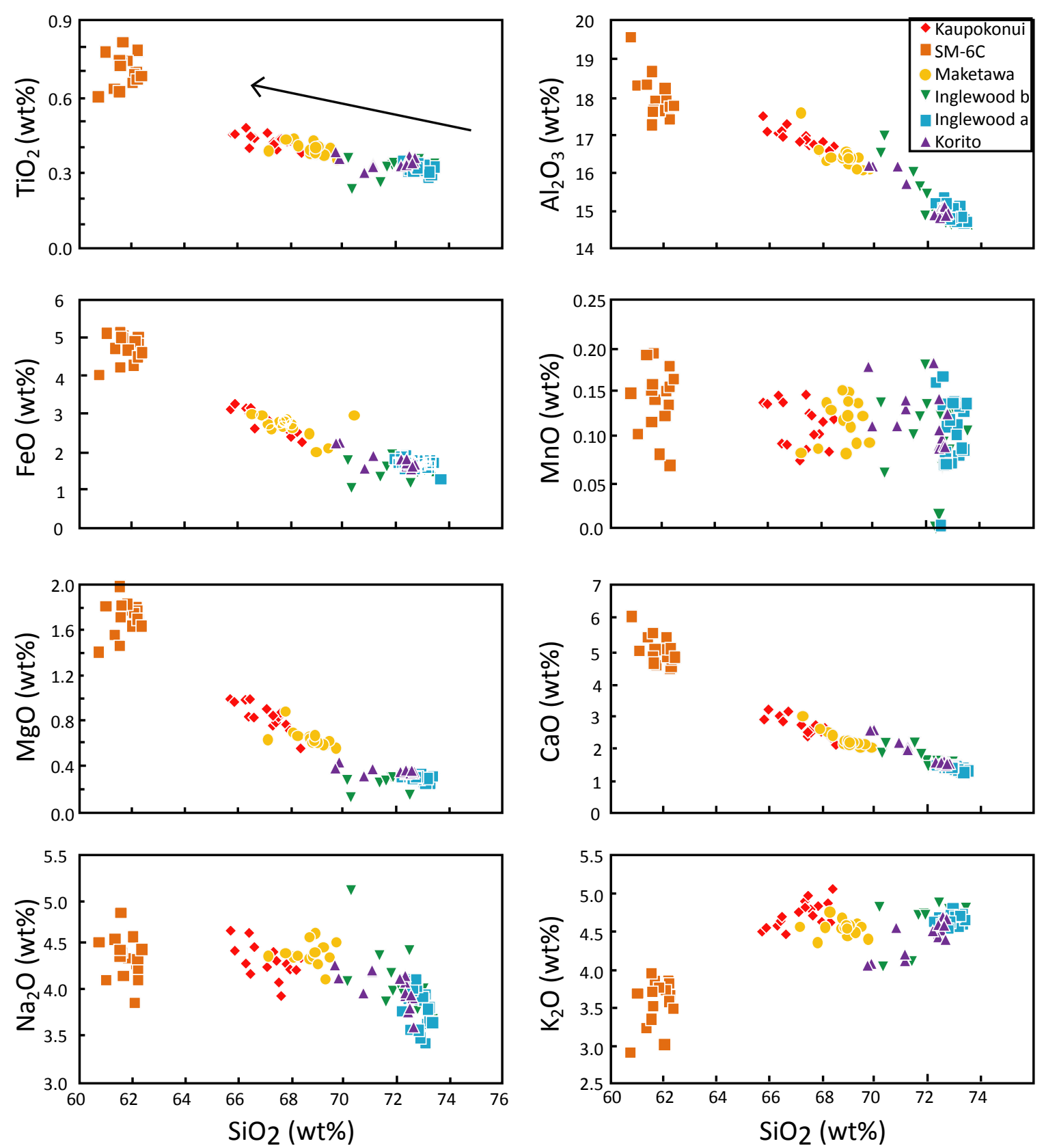

Figure 4.6 Major element analyses of glass determined by EMPA plotted versus $\mathrm{SiO}_{2}$. A broad trend is evident from least to more evolved compositions with decreasing eruption age as indicated by the arrow. SM-6C is falls off this trend. 


\subsubsection{MELT INCLUSION MAJOR ELEMENT CHEMISTRY}

The melt inclusion data shows the same general trend as the groundmass glass data, but with more scatter (Figure 4.7). The amphibole-hosted melt inclusions correspond most clearly to the glass compositions. Clinopyroxene-hosted melt inclusions are consistently 1-2 wt $\%$ lower in total alkalis (Figure 4.7c). The plagioclase melt inclusions from Inglewood a and b are less evolved than the glass compositions.

SM-6C however, has much more evolved melt inclusions compared with the glass data with the exception of the single amphibole-hosted melt inclusion analysed which overlaps with the glass field (Figure 4.7d).

\subsubsection{MINERAL MAJOR ELEMENT CHEMISTRY}

\subsubsection{Plagioclase}

Plagioclase compositions range from anorthite $(\mathrm{An}) 34-94(\mathrm{An}=100 \times(\mathrm{Ca} /(\mathrm{Ca}+\mathrm{Na}+\mathrm{K}))$ (Figure 4.8). The peak in anorthite content for each sample is at the sodic end of this range with Inglewood $\mathrm{a}$ and $\mathrm{b}$ and Korito exhibiting almost identical patterns where the dominant composition is ca. $\mathrm{An}_{45}$. Kaupokonui, SM-6C and Maketawa generally contain more calcic plagioclase crystals with a mode of around $\mathrm{An}_{55-60}$, and $\mathrm{SM}-6 \mathrm{C}$ has some plagioclase crystals with the highest anorthite contents.

Most samples show a bimodal distribution with the high anorthite population $\left(\mathrm{An}_{70-80}\right)$ consisting primarily of core analyses and the low anorthite $\left(\mathrm{An}_{45-55}\right)$ population comprising both cores and rims. SM-6C and Maketawa consist of one main peak which has an anorthite content intermediate between the two populations of the other samples. The cores of these samples also have higher overall anorthite content than the rims.

Each sample contains oscillatory zoned and sieve textured crystals. Where recrytallisation has occurred within the sieved crystals a patchy texture is evident. As both the initial zone undergoing dissolution and the recrystallising composition were analysed and classified as 

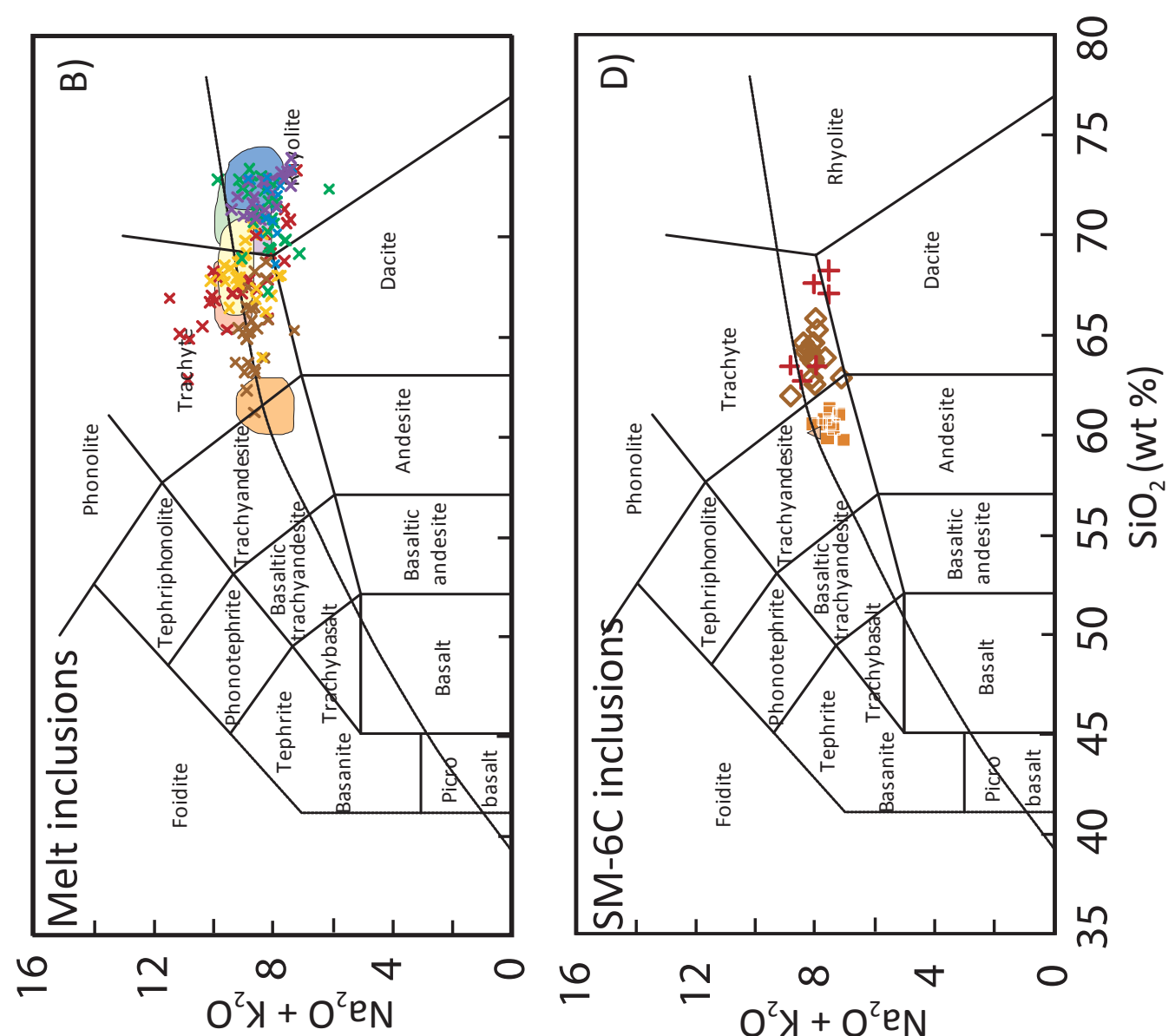

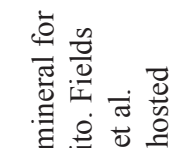

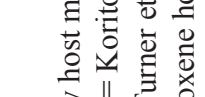
它 응

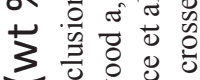
N. 的要

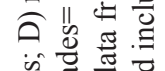
के 픔

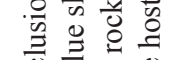
글

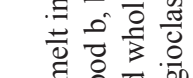

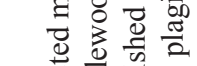
额 굴

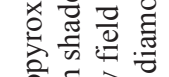

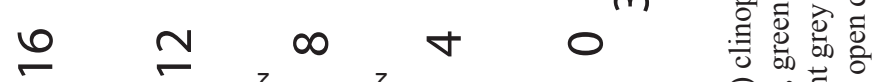

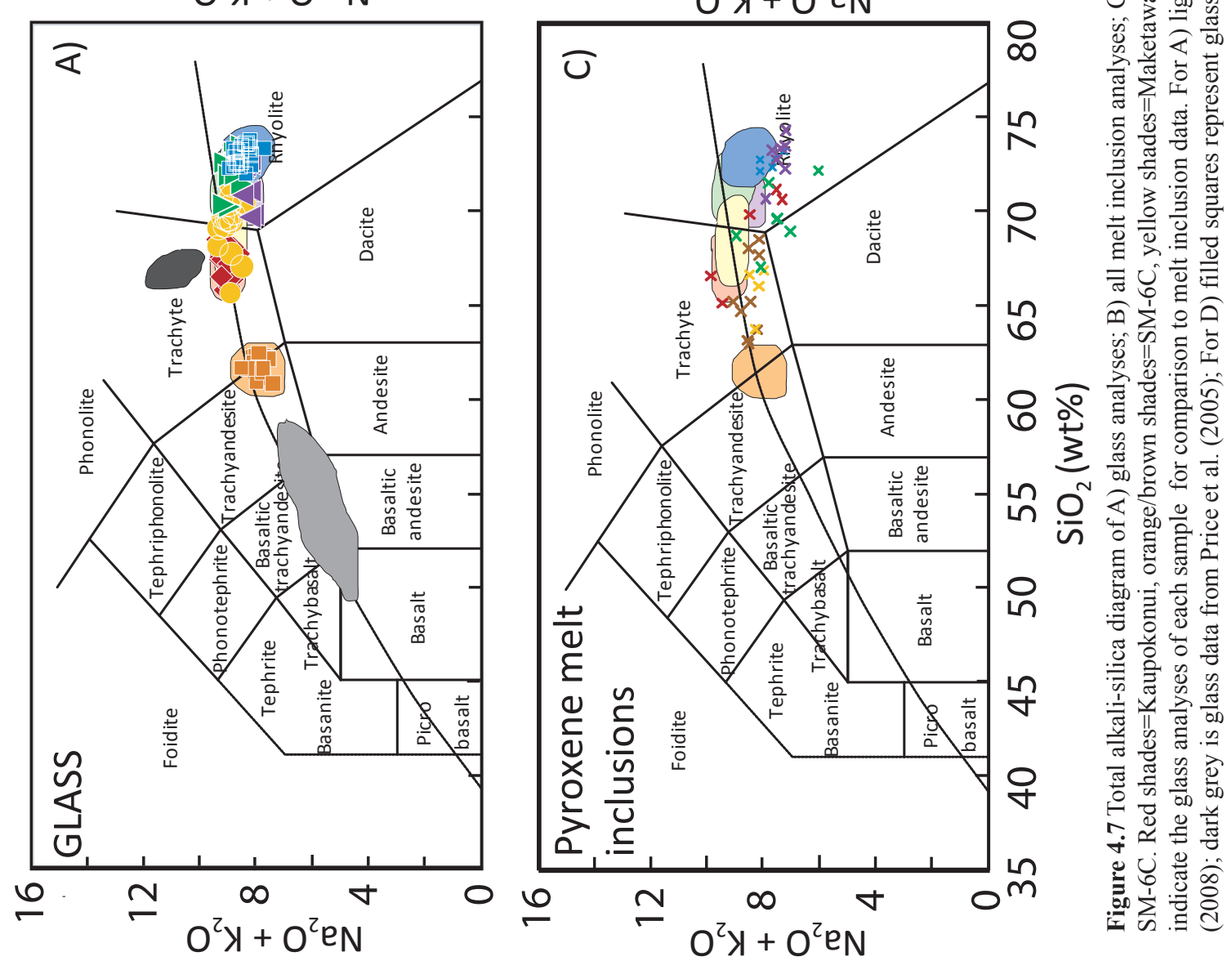



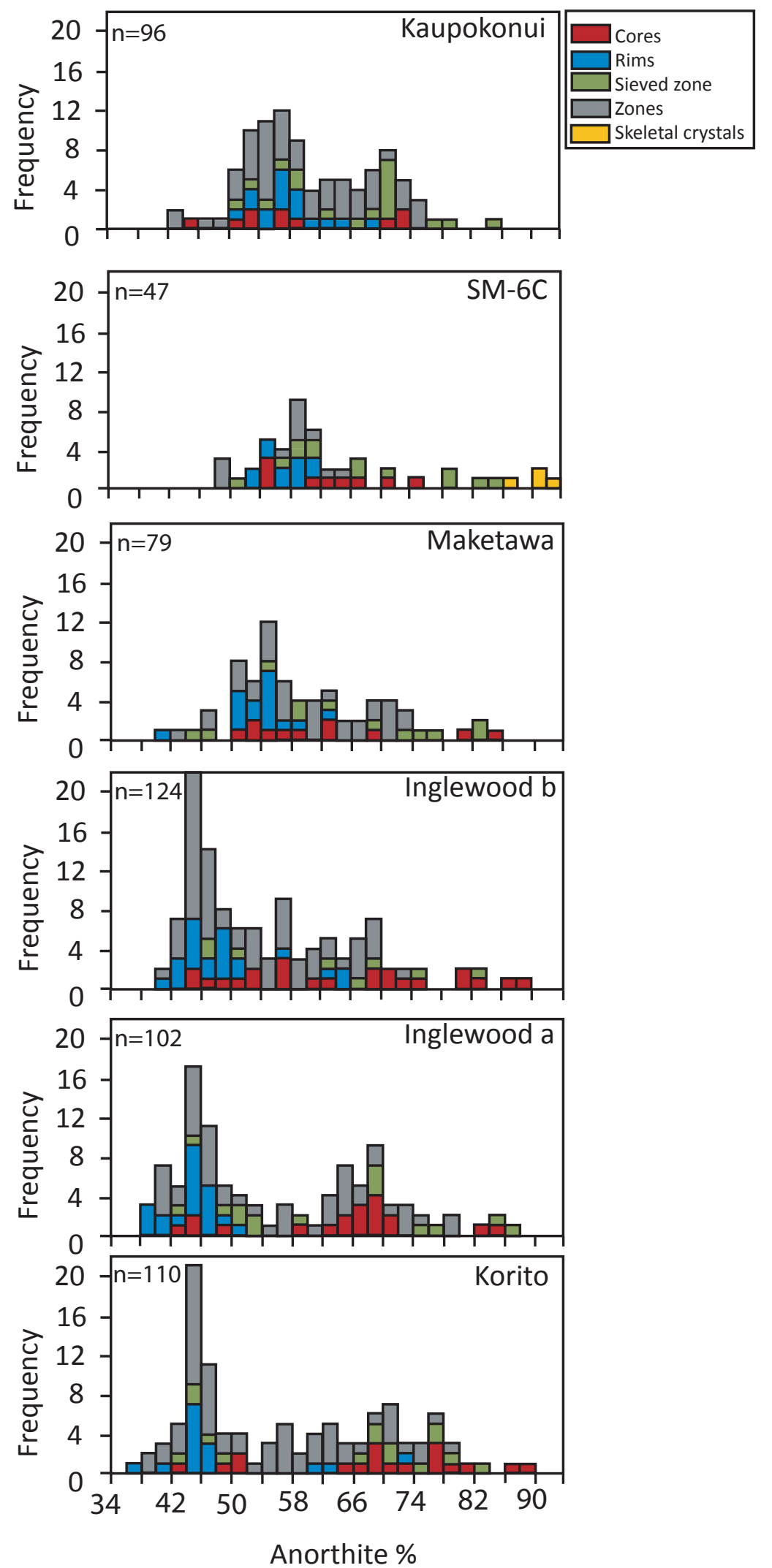

Figure 4.8 Anorthite content of plagioclase by crystal zone in each sample. Zoning refers to oscillatory zoning that is not a distinct core or rim zone. Sieved zoning occurs in both crystal cores and mantles. Core values span most of the range of each sample but rim compositions typically form a low anorthite peak. 
sieved/patchy, a bimodal compositional pattern is observed for these zones. This gives the composition of the disequilibrium zone and the plagioclase composition that is in equilibrium with the new magmatic conditions. Sample SM-6C contains an additional crystal population referred to here as skeletal, where most of the crystal has been dissolved away. This population represents the most calcic plagioclase crystals $\left(\mathrm{An}_{86-92}\right)$.

\subsubsection{Clinopyroxene}

Clinopyroxene crystals from this study have diopside and augite compositions and show limited variation in major element chemistry. $\mathrm{Mg} \#\left(\mathrm{Mg} \#=100 \times\left(\mathrm{Mg} /\left(\mathrm{Mg}+\mathrm{Fe}^{2+}\right)\right.\right.$ for all six samples fall within the range of $\mathrm{Mg}_{75-90}$ with a peak at 80-85 (Figure 4.9). Sample SM-6C exhibits slightly lower $\mathrm{Mg \#}$ values on average and Kaupokonui has slightly elevated $\mathrm{Mg} \#$

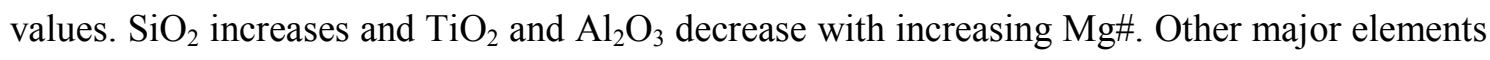
show no clear trend.

Most clinopyroxene crystals have a patchy textured core with an oscillatory zoned rim. Kaupokonui also contains crystals with a distinct high-Mg rim or zone near the rim. In SM-6C and Korito a Fe-rich zone can be identified in some crystal populations. This zone is the mantle for SM-6C (between a Mg rich core and rim) and between the patchy core and oscillatory zoned rim for Korito. As a population, the clinopyroxene cores and rims are not distinguishable on the basis of major element data and aside from the distinctive zones already identified, no other pattern can be recognized on the basis of crystal zoning or texture.

\subsubsection{Orthopyroxene}

Orthopyroxene is a minor phase in the eruptives of Mt. Taranaki. It was detected only in SM-6C where it was present in cumulates and in reaction rims that mantled olivine cores. The orthopyroxene generally contain Fe-Ti oxides and melt inclusions. There is no clear distinction between cores and rims as these overlap with a $\mathrm{Mg} \#_{75-80}$. Crystals associated with cumulates had a lower $\mathrm{Mg \#}\left(\mathrm{Mg \#}_{66-70}\right)$. 

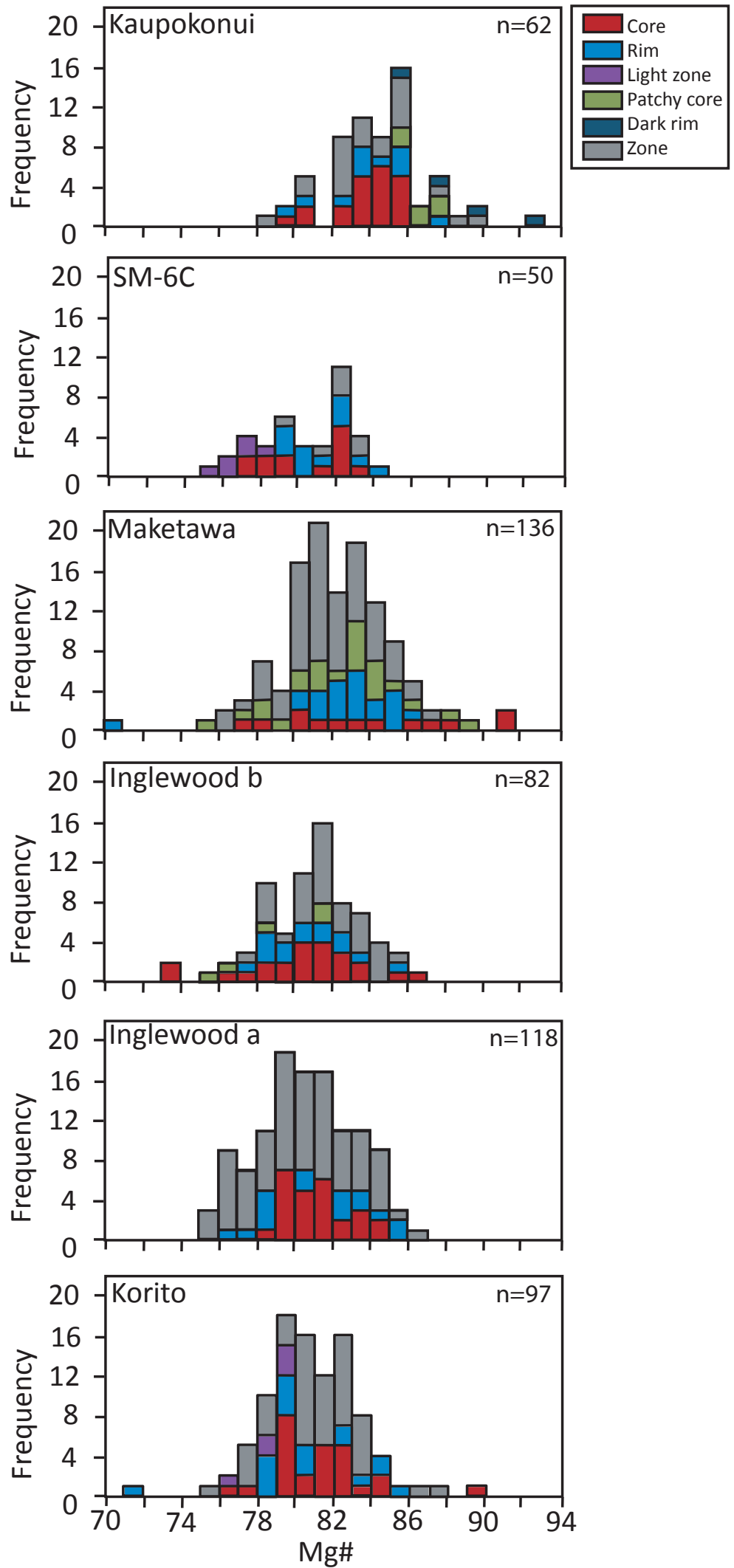

Figure 4.9 Histograms of clinopyroxene zones by Mg\#. Analyses are divided into cores and rims. Light zones are a distinctive zone that appears to be correlated between crystals within a particular sample. Patchy textured cores that appear to have two compositions are plotted as 'patchy cores'. Dark rims refer to a Mg-rich rim population present only in Kaupokonui. Zones adjacent to the rim with similar characteristics are also in this group. Zoning that is not distinct is classified as 'zones'. There is no clear distinction between core and rim composition on the basis of $\mathrm{Mg \#}$. 


\subsubsection{Amphibole}

Amphibole $\mathrm{Mg} \#(\mathrm{Mg} \#=\mathrm{Mg} /(\mathrm{Mg}+\mathrm{Fe}))$ varies from 0.6-0.9 with a dominant population of 0.7-0.8. This peak shifts to slightly higher Mg\# values with time. Cores and rims overlap for each sample with core compositions spanning the entire $\mathrm{Mg \#}$ range for each sample. There is a high Mg\# population of rims in each sample $(\mathrm{Mg} \#=0.76-0.8)$ and a population of low $\mathrm{Mg}$ rims in some samples (Maketawa and Inglewood a) which clusters around 0.66-0.7. In most cases the higher Mg rim population overlaps a peak in the core composition. This is especially well illustrated in Inglewood b where two core populations are distinguished on the basis of crystal texture as well as chemistry and the rim compositions overlap with the high $\mathrm{Mg}$, 'dark core' population.

SM-6C does not follow most of the trends discussed above. This sample shows a bimodal distribution that falls on either side of the peak Mg\# of all other samples (Figure 4.10a). The core compositions fall within a discrete peak and the rim compositions are bimodal with one population overlapping with the cores and the other coinciding with the low Mg\# rim population observed in other samples.

The $\mathrm{Al}$ content $\left(\mathrm{Al}_{2} \mathrm{O}_{3} \mathrm{wt} \%\right)$ of amphibole crystals distinguishes cores and rims more effectively than $\mathrm{Mg \#}$ for Inglewood a and b and Korito (Figure 4.10b). Core compositions again span the entire range but there is a dominant low $\mathrm{Al}$ rim population common to these three samples. The same pattern is observed in the $\mathrm{Al}$ data as has been identified in the $\mathrm{Mg}$ values for Kaupokonui, SM-6C and Maketawa.

\subsubsection{Fe-Ti oxides}

Titanomagnetite is the dominant Fe-Ti oxide phase found in these eruptives at Mt Taranaki. It is present in the groundmass as euhedral to subhedral crystals ranging in size from $<10$ to 200 $\mu \mathrm{m}$. Titanomagnetite is commonly found associated with, or as inclusions in, clinopyroxene, orthopyroxene, amphibole and rare plagioclase crystals. Fe-Ti oxides are particularly common 

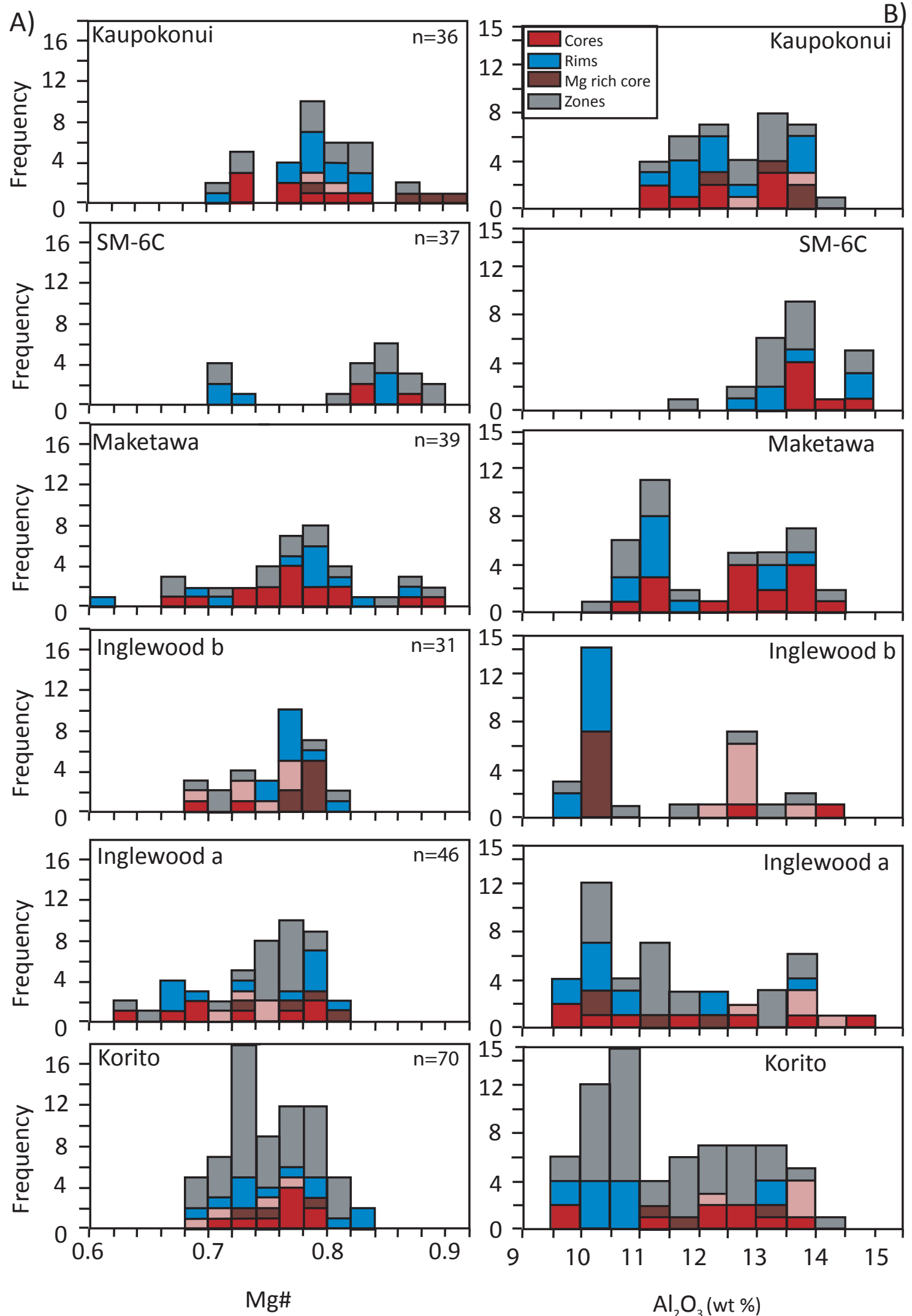

Figure 4.10 Histograms of amphibole composition by (A) $\mathrm{Mg} \#$ and (B) $\mathrm{Al}_{2} \mathrm{O}_{3}$. Analyses have been divided into cores, rims and zoning that is not distinct. In some crystals there are different populations of cores on the basis of texture and these have been categorised separately as light or dark cores. Core values generally span the entire compositional range whereas rim concentrations are often clustered at low $\mathrm{Al}_{2} \mathrm{O}_{3}$, high $\mathrm{Mg} \#$ values or bimodal in nature. 
in clinopyroxene where smaller, anhedral to subhedral inclusions are present in the core and larger subhedral crystals form with the rim.

The samples can be divided into 4 groups on the basis of titanomagnetite major element chemistry (Figure 4.11): (1) A low ulvospinel population ( $\mathrm{X}^{\prime} \mathrm{usp}_{0.15-0.19}$ ) with moderate $\mathrm{Al}_{2} \mathrm{O}_{3}$ and $\mathrm{MnO}$, and high $\mathrm{MgO}$ and $\mathrm{Fe}_{2} \mathrm{O}_{3}$ that encompasses samples Kaupokonui and Maketawa. (2) Inglewood $\mathrm{a}$ and $\mathrm{b}$ and Korito are enriched in $\mathrm{MnO}$ with low concentrations of $\mathrm{MgO}$ and $\mathrm{Al}_{2} \mathrm{O}_{3}$ at an ulvospinel content of 0.16-0.21. (3) Amphibole hosted and broken groundmass crystals from SM-6C have a low ulvospinel content that overlaps with group 1. (4) Groundmass and clinopyroxene hosted oxides from sample SM-6C which have a high ulvospinel content $\left(\mathrm{X}^{\prime} \mathrm{usp}_{0.23-0.27}\right)$. Groups 3 and 4 broadly overlap in other major elements and are relatively enriched in $\mathrm{Al}_{2} \mathrm{O}_{3}$ and $\mathrm{MgO}$ and depleted in $\mathrm{MnO}, \mathrm{FeO}$ and $\mathrm{Fe}_{2} \mathrm{O}_{3}$.

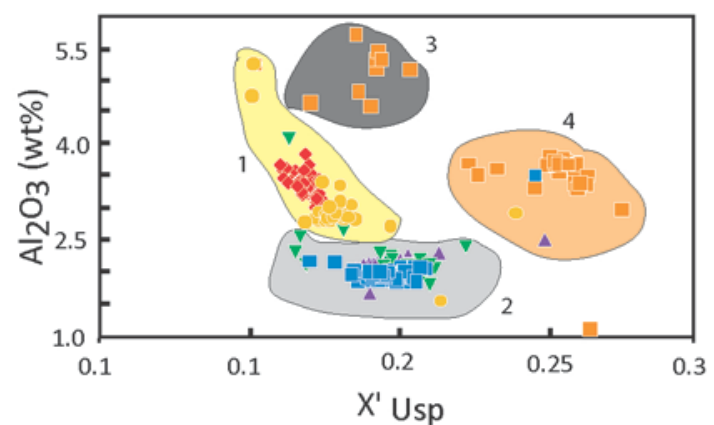

$$
\begin{array}{|l|}
\hline \text { Kaupokonui } \\
\text { SM-6C } \\
\text { Maketawa } \\
\nabla \text { Inglewood b } \\
\text { Inglewood a } \\
\text {. Korito } \\
\hline
\end{array}
$$
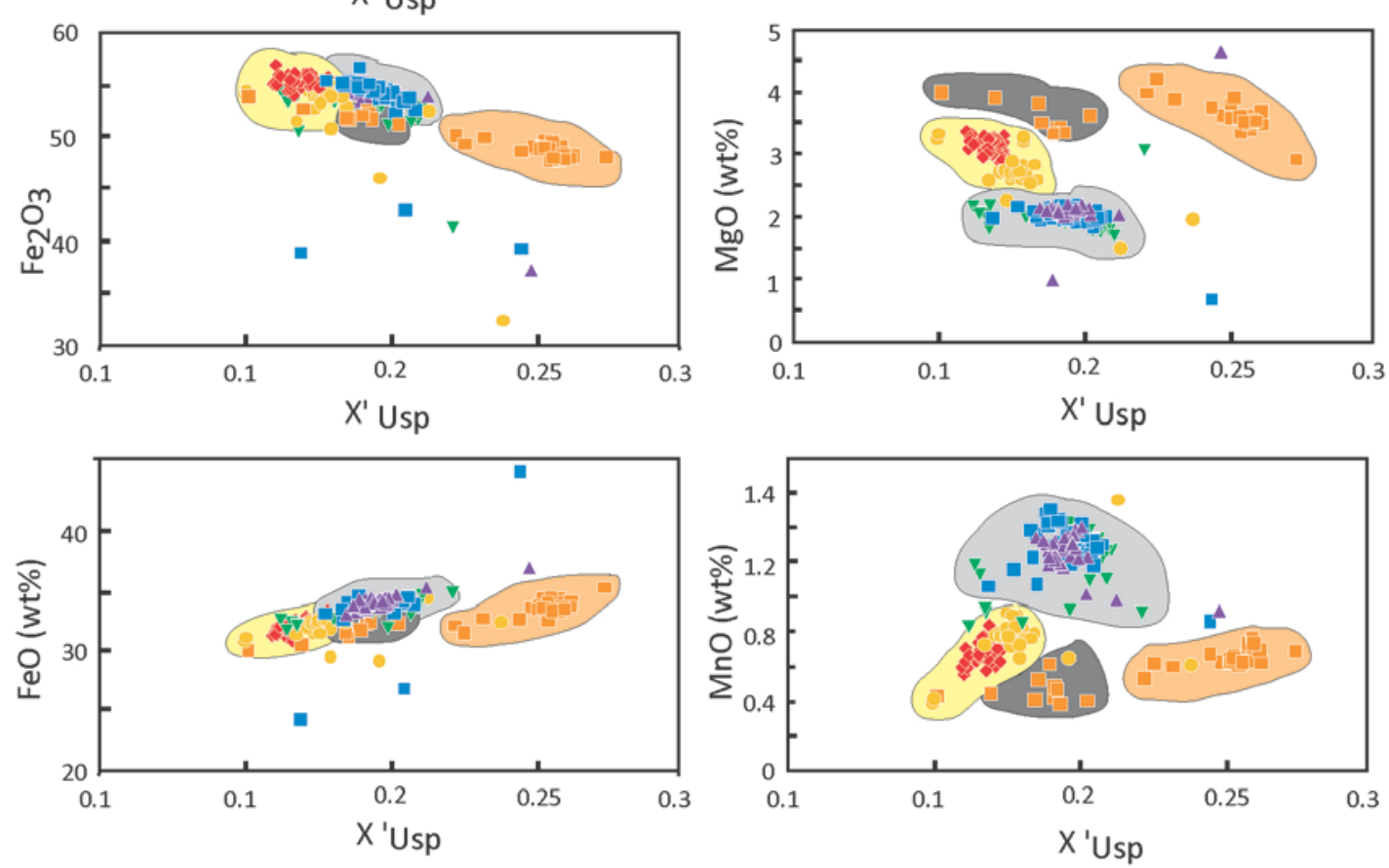

Figure 4.11 Bivariate diagrams of ulvospinel versus selected element oxides. Ulvospinel (X'Usp) was calculated using the method of Stormer (1983). Four groups of titanomagnetite can be identified and this is particularly well illustrated in a plot of X'Usp vs $\mathrm{Al}_{2} \mathrm{O}_{3}$ 


\subsection{TRACE ELEMENT CHEMISTRY}

\subsubsection{GLASS TRACE ELEMENT CHEMISTRY}

Most trace elements show a negative relationship with $\mathrm{SiO}_{2}$ as illustrated in Figure 4.12. Compatible elements such as $\mathrm{Co}, \mathrm{Sc}, \mathrm{V}$ and $\mathrm{Sr}$ form a linear trend with $\mathrm{SM}-6 \mathrm{C}$ sometimes plotting above this line. Other trace elements show less variation and the negative correlation is less pronounced. Inglewood $b$ is enriched in these elements and therefore plots off the trend for incompatible elements. Fluid mobile elements, in particular the LILEs are enriched in Kaupokonui and Inglewood b. SM-6C, Maketawa, Inglewood a and Korito all show similar trends for all trace elements. SM-6C is enriched in all elements with the most significant enrichments in compatible elements.

The rare earth element (REE) diagram shows enrichment in the light REEs (LREE) and depletion in the middle REEs (MREE) for each of the six samples (Figure 4.13a). Maketawa, Inglewood $\mathrm{b}$ and Korito have similar chondrite normalised REE concentrations. Inglewood a and SM-6C have relative depletion and enrichment in REEs respectively, with SM-6C exhibiting the larger offset. Each of the samples also exhibits a marked negative Eu anomaly (Eu/Eu*). Most samples have similar $\mathrm{Eu} / \mathrm{Eu}^{*}$ of around 0.8 but Kaupokonui and Maketawa have smaller Eu anomalies. Maketawa has a slight negative europium anomaly with $\mathrm{Eu} / \mathrm{Eu}$ * of 0.94 .

A multi-element diagram (Figure 4.13b) shows a typical subduction signature when normalised to N-MORB. There is an enrichment in the LILEs such as $\mathrm{Cs}, \mathrm{Rb}$ and $\mathrm{Ba}$ and other fluid mobile elements like $\mathrm{Pb}$. There is also a depletion in high field strength elements (HFSE) especially $\mathrm{Nb}$ and $\mathrm{Ta}$ as well as $\mathrm{Sr}$ and $\mathrm{Ti}$ which are strongly compatible in commonly crystallising phases of these eruptives. The variation between the samples is similar to that illustrated by the REE diagram where SM-6C is relatively enriched in these elements and Inglewood a is slightly depleted compared with the other samples. This offset is similar for each element except $\mathrm{Li}$ which is homogeneous across all samples. Inglewood b has a slight enrichment in $\mathrm{Zr}$ and $\mathrm{Hf}$. 

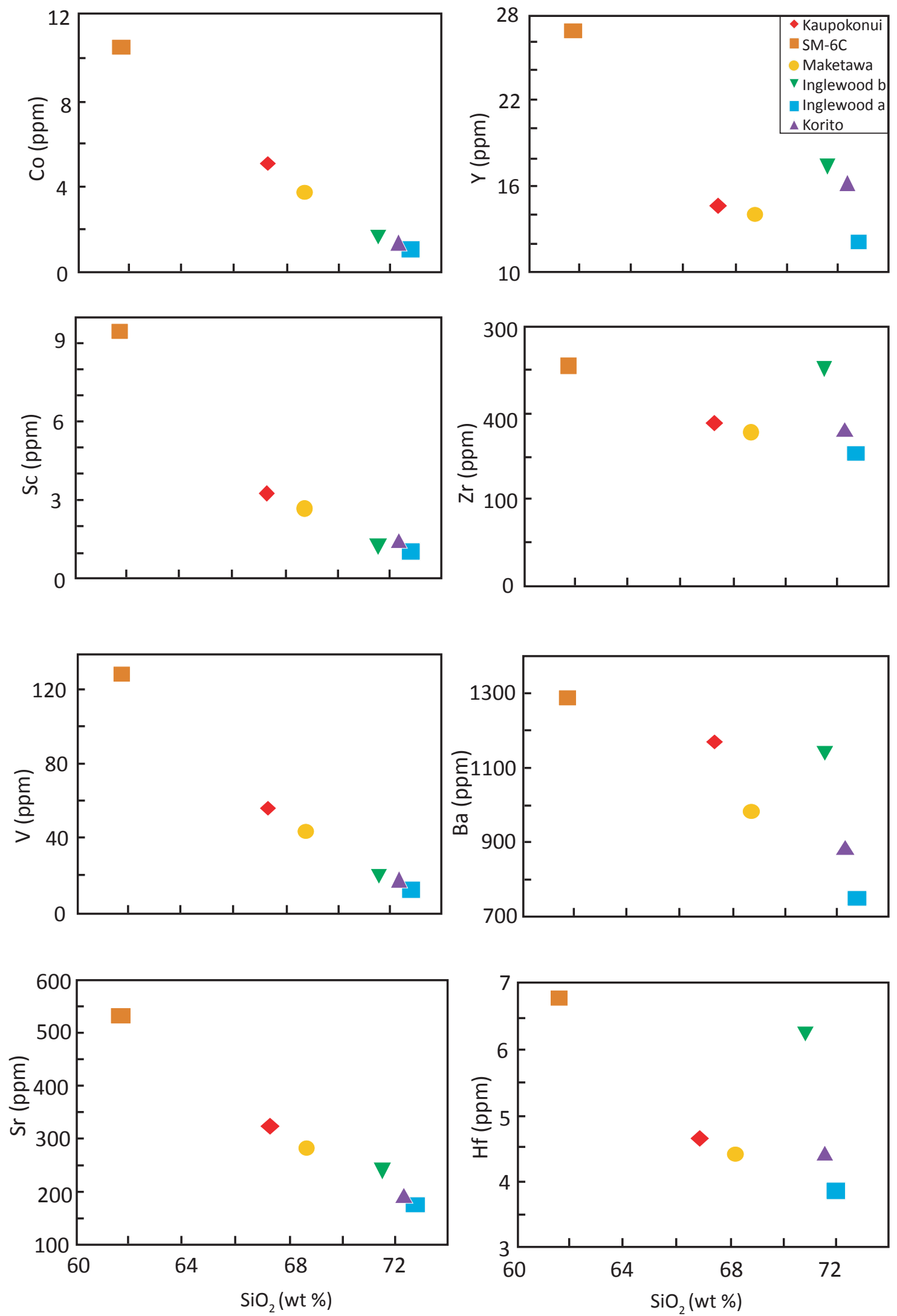

Figure 4.12 Representative trace elements plotted versus $\mathrm{SiO}_{2}$ of the glass compositions of Taranaki eruptives. Compatible elements such as $\mathrm{Co}, \mathrm{Sc}, \mathrm{V}$ and $\mathrm{Sr}$ show a negative linear trend with $\mathrm{SiO}_{2}$. Less variability is observed with other trace element concentrations ( $\mathrm{Y}, \mathrm{Nb}, \mathrm{Ba}$ and $\mathrm{Hf}$ ). $2 \mathrm{SD}$ errors are smaller than graph symbols 

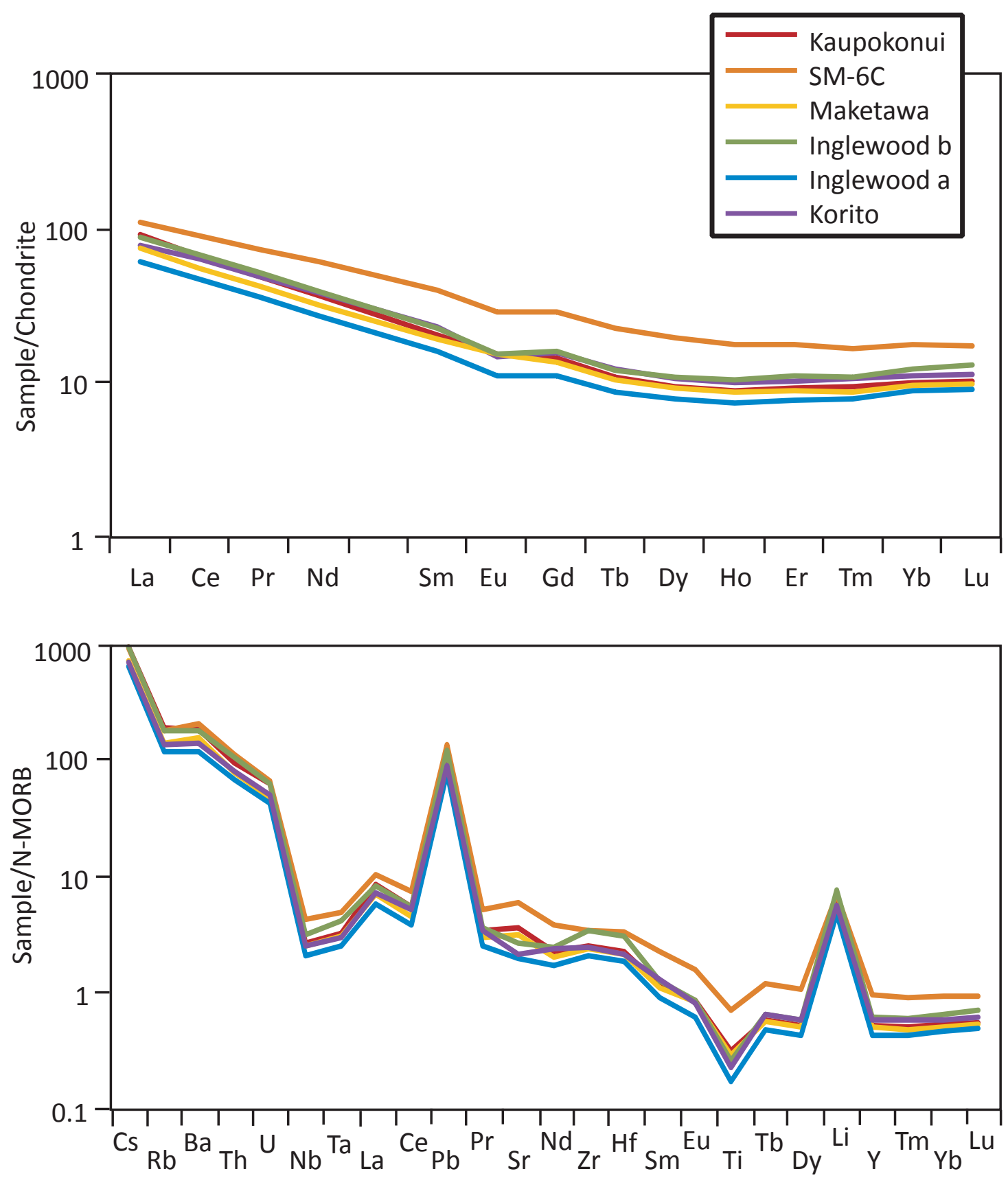

Figure 4.13 Diagrams of glass compositions illustrating the pattern and variation of Taranaki eruptives. All samples show the same broad trends. SM-6C is relatively enriched and Inglewood a is relatively depleted in trace elements. Normalising values for N-MORB were taken from Sun \& McDonough (1989). (A) chondritenormalised rare earth element diagram. All samples show enrichment in light REEs, a negative Eu anomaly characteritic of plaigoclase fractionation and a trough in the MREEs attributed to amphibole fractionation. (B) Multi-element diagram normalised to N-MORB. All samples show an enrichment in LILE, Pb and Li and depletion in HFSE and compatible elements. 


\subsubsection{MINERAL TRACE ELEMENT CHEMISTRY}

Trace element concentrations generally correlate with the major element data as positive correlations are observed for compatible elements and negative relationships for incompatible elements (Figures 4.14, 4.16 and 4.18). However, a large degree of variability is also evident within this trace element data set.

The overall patterns of the mineral specific multi-element plots are controlled by the partition coefficients of the mineral phase of interest and the composition of the equilibrium melt as discussed above (Figures 4.15, 4.17 and 4.19). There is a slight distinction between core and rim analyses with one population containing a greater number of relatively enriched compositions than the other. These two populations overlap substantially so the core/rim distinction identified in the major element data is generally less evident, in part because of the logarithmic scale of these plots. The variation within a sample is greater than the variation between samples.

\subsubsection{Plagioclase}

The trace elements measured in plagioclase show negative correlations with anorthite content with the exception of Sr. (Figure 4.14). There is a large degree of variability as concentrations range by a factor of 2-10 at a given anorthite content and by up to an order of magnitude for the entire sample suite. The deviations from this trend include an anomalous enrichment of $\mathrm{Li}$ in the rims of Kaupokonui and Maketawa plagioclase and a change in the trend of $\mathrm{Sr}$ and $\mathrm{Ba}$ correlations at $\mathrm{An}>70$ for Inglewood a and $\mathrm{b}$ and Korito plagioclase. Sr changes from a positive to a negative relationship with An content and the Ba contents of these analyses decreases at a slower rate as anorthite content increases.

The same multi-element pattern is observed in all plagioclase analyses and the range of values for each sample overlaps (Figure 4.15). The variation within each sample is up to an order of magnitude and this largely reflects the variation in the core compositions whereas the rim compositions are consistent between and within samples. Crystal rims are relatively more 


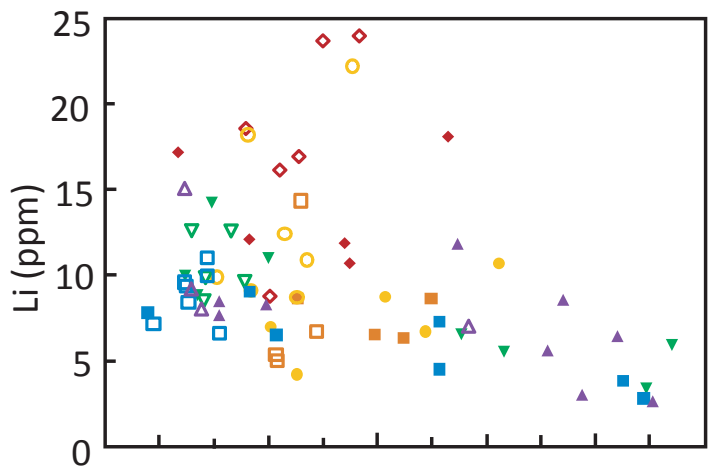

Kaupokonui

SM-6C

Maketawa

$\checkmark$ Inglewood b

- Inglewood a

$\Delta$ Korito
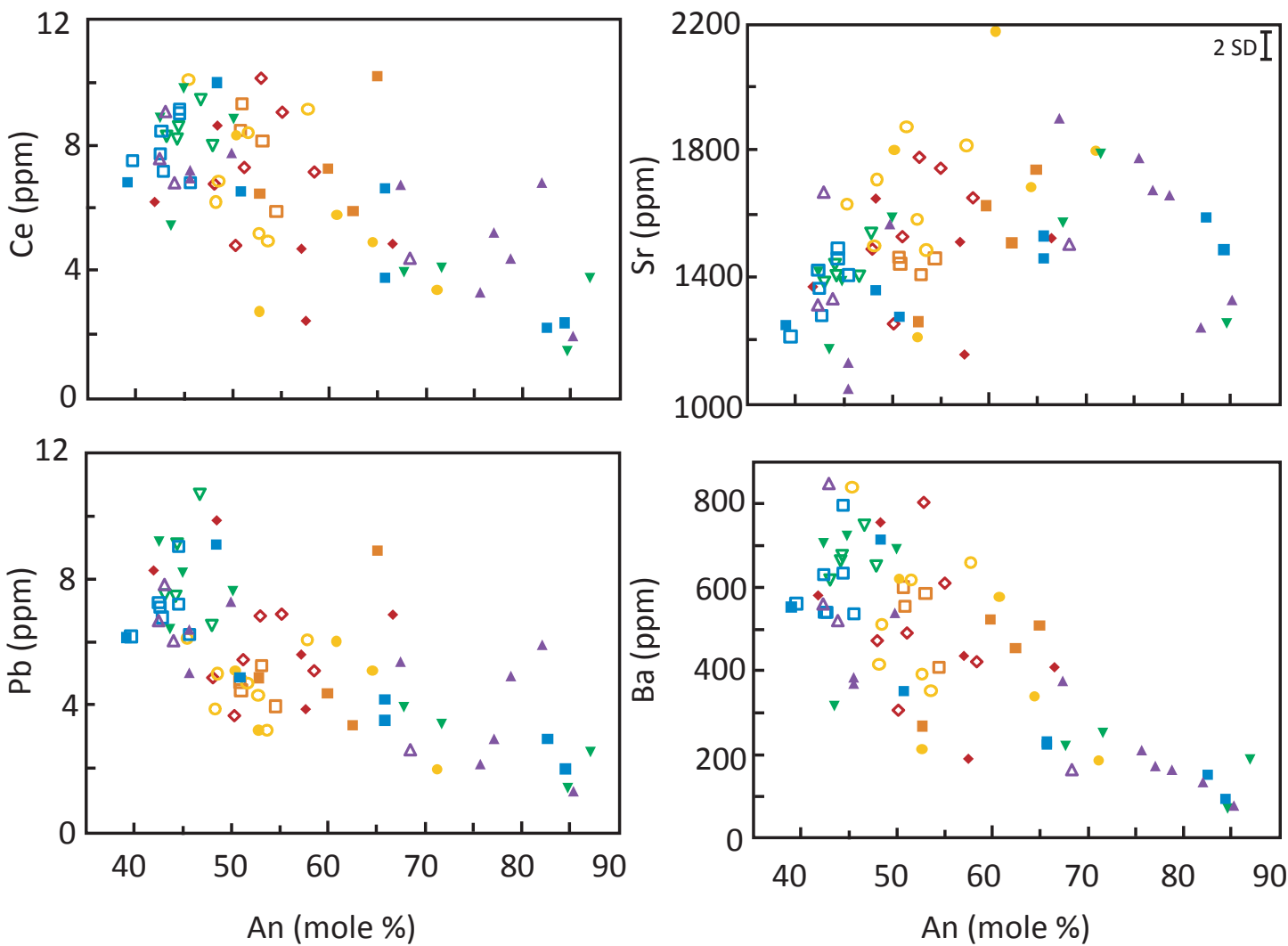

Figure 4.14 Selected trace elements plotted versus anorthite content of plagioclase crystals. Open symbols represent rim compositions and filled symbols indicate core analyses. Each of the trace elements except Sr show a negative correlation with anorthite content. Sr has a positive correlation with anorthite content except at the high anorthite end member where Sr values decrease. Kaupokonui and Maketawa show relative enrichments in Li and Sr. Errors as stated or smaller than symbol. 


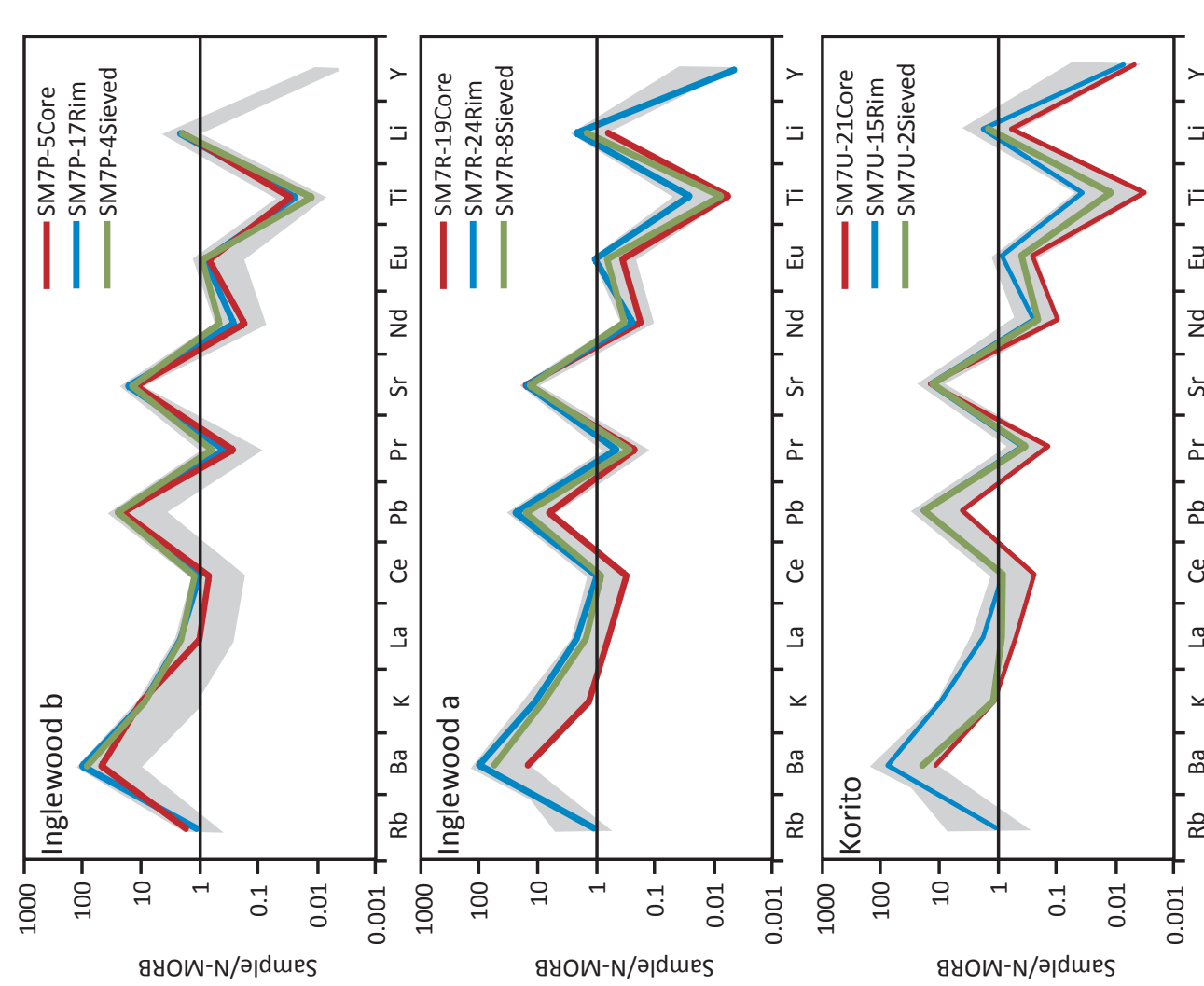

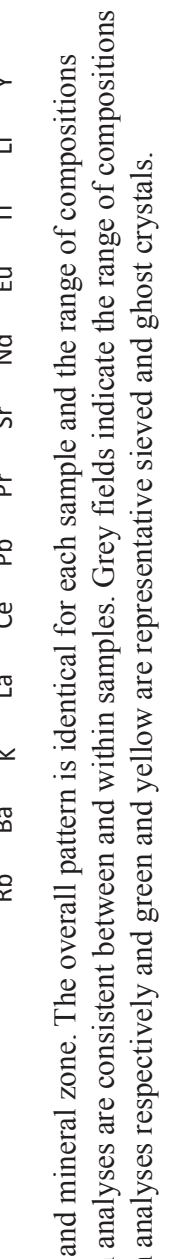

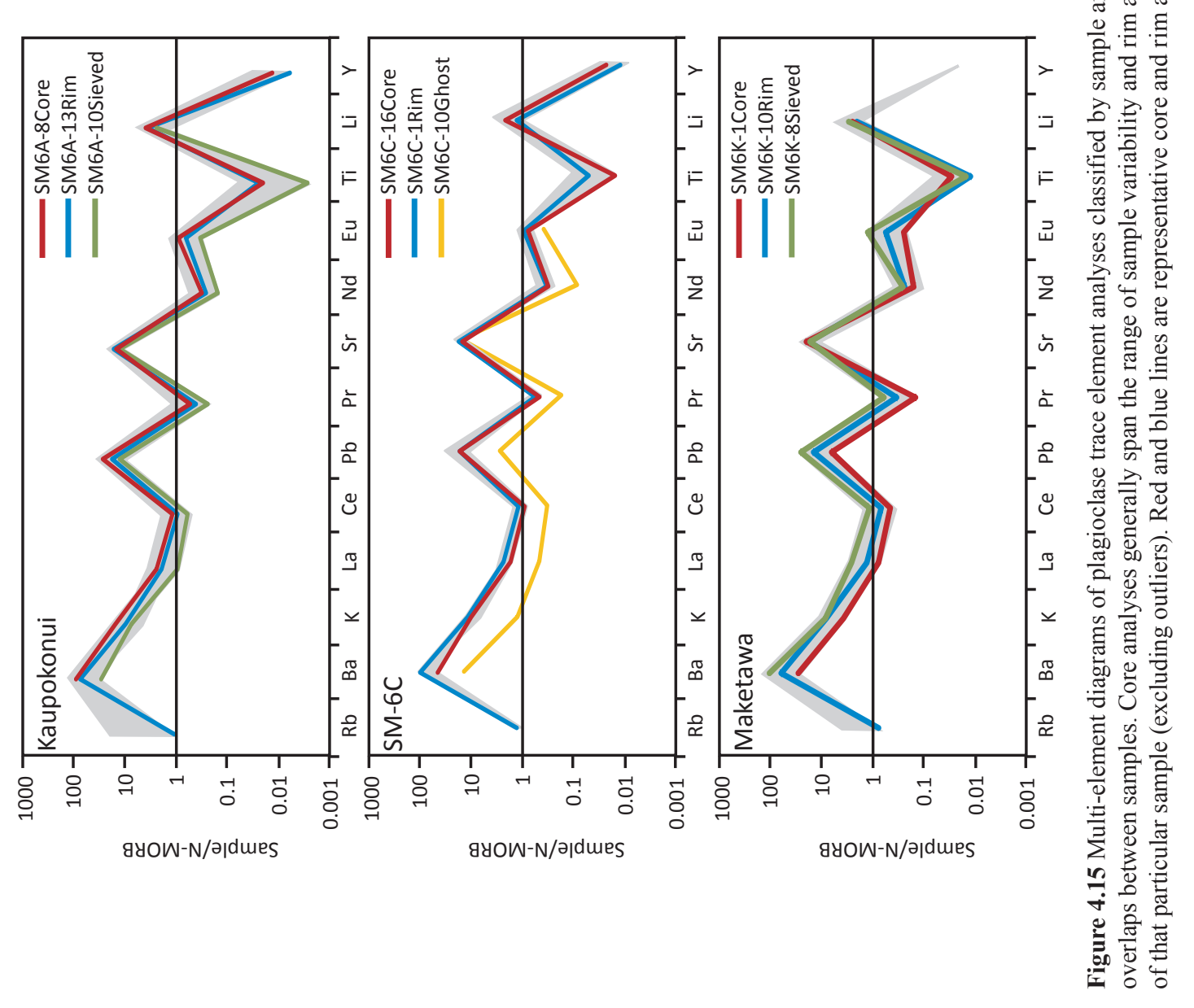


evolved than cores in Inglewood a and b, Korito and SM-6C but the core analyses are enriched in Kaupokonui and Maketawa. The sieved zone compositions generally overlap the rims but extend to lower values. The ghost crystals present in SM-6C are around 7 times lower in trace element concentration than the dominant population. Sr values are the most consistent with a total variation of less than $2 \mathrm{ppm}$.

\subsubsection{Clinopyroxene}

There is a large range in the trace element chemistry of clinopyroxene crystals from Taranaki eruptives on the order of a factor of two to five (Figure 4.16). There is a slight positive correlation between $\mathrm{Mg} \#$ and elements compatible in clinopyroxene such as $\mathrm{Sc}, \mathrm{V}$ and $\mathrm{Ni}$ and elements that are compatible in other major mineral phases such as Sr. Negative correlations are evident in the incompatible elements at $\mathrm{Mg} \#>85$ which primarily relates to the rims of Kaupokonui. Kaupokonui, SM-6C and Maketawa are enriched in compatible trace elements and depleted in incompatible elements compared with Inglewood a and b and Korito. There is no widespread differentiation between core and rim analyses although the rims of the two most primitive samples appear to contain higher abundance of compatible trace elements.

The overall trend observed in the multi-element diagrams (Figure 4.17) show little variability between samples and the dominant population of each sample is coincident in most cases. The exception is Maketawa, which is relatively depleted. In detail there are also fluctuations in the REEs and $\mathrm{Li}$ on the order of less than a factor of three.

Within the main population in each sample a distinction between the core and rim analyses can be identified. The trace element concentrations of cores are generally higher for SM-6C, Maketawa, Inglewood a and b but the rims are relatively enriched in Kaupokonui and Korito. This distinction is weak and the two groups overlap each other.

The high Mg\#, dark rim population present in Kaupokonui displays a different trace element pattern. These are depleted in most elements with some present in concentrations of up to a factor of seven lower than the main population. Crystal 4 in Korito exhibits a different 

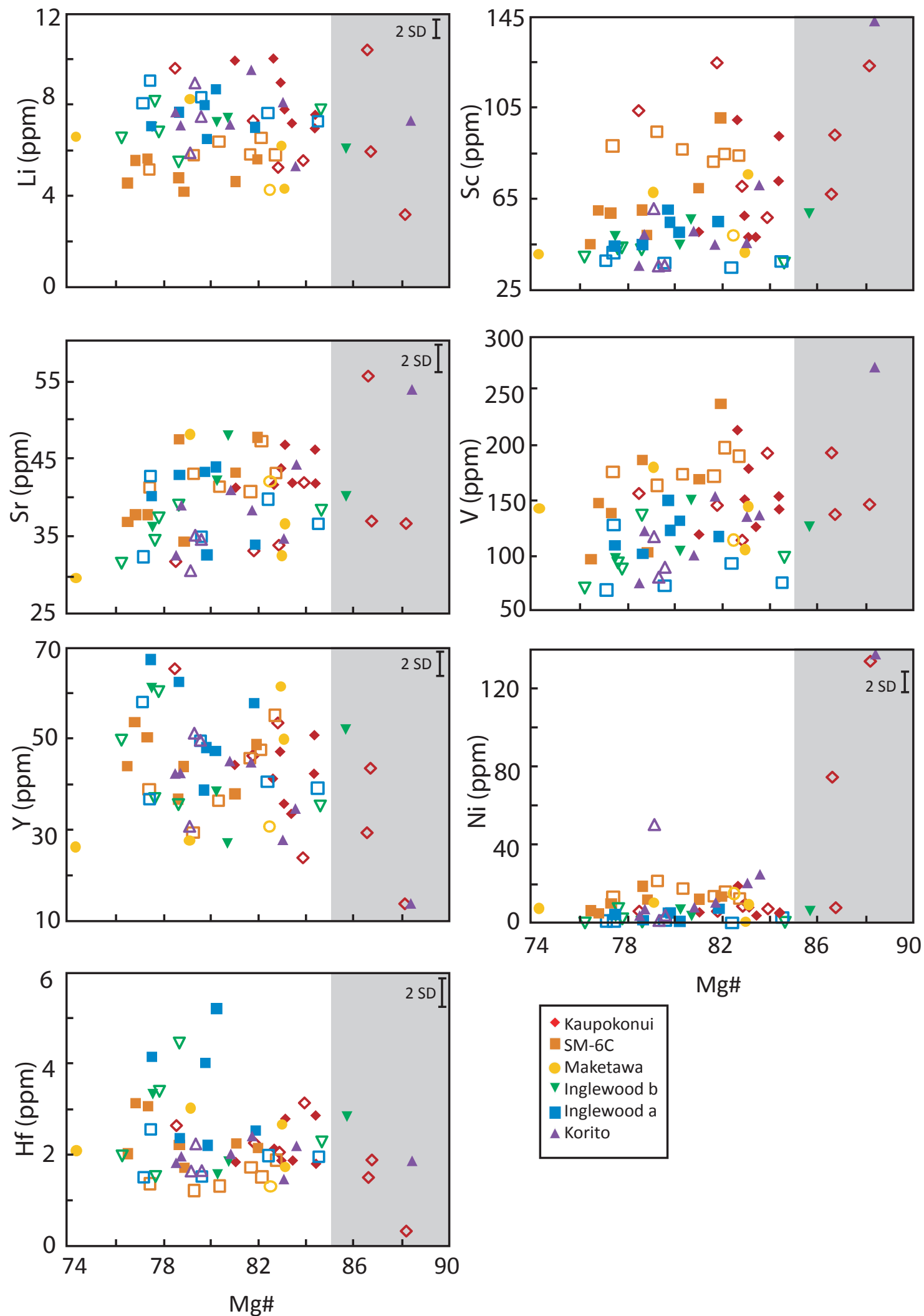

- Kaupokonui

SM-6C

- Maketawa

$\nabla$ Inglewood b

Inglewood a

Korito

Figure 4.16 Selected trace elements plotted versus Mg\# of clinopyroxene crystals. Open symbols represent rim compositions and filled symbols indicate core analyses. Kaupokonui, SM-6C and Maketawa show relative enrichments in compatible elements ( $\mathrm{Sc}, \mathrm{V}, \mathrm{Ni}$ ) compared to Inglewood a and b and Korito. Shaded area highlights $\mathrm{Mg} \#>$ 85. Error bars as stated or smaller than symbol. 

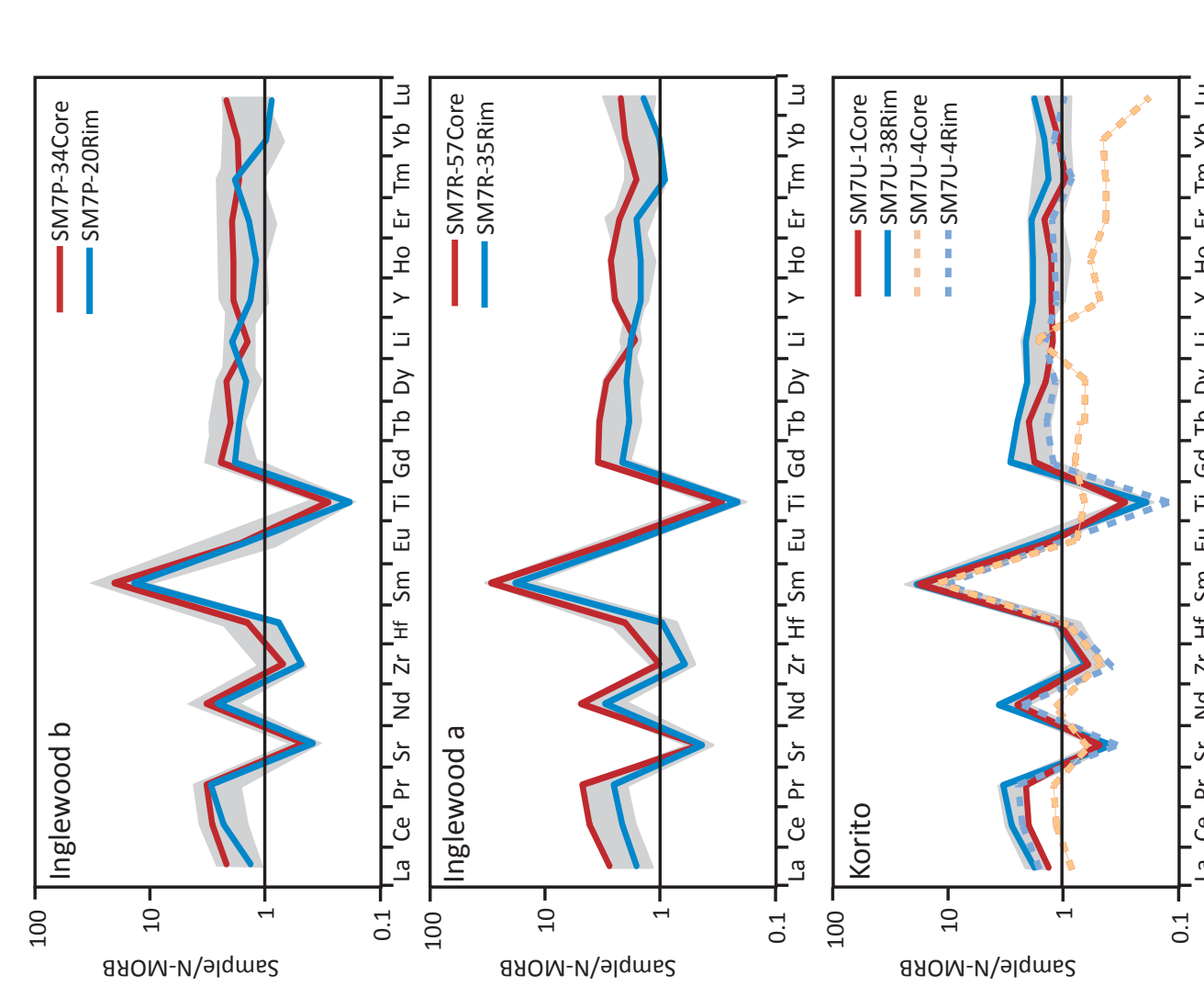

$\rightleftarrows$

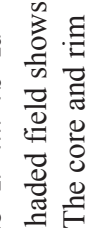

오 핸

$>$ 矛䓂

公吾寻寻

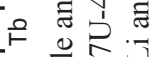

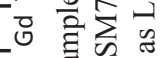

iF

E 8

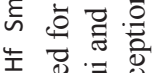

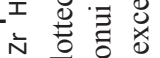

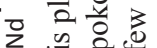

的要

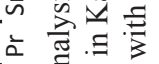

ช ส है च

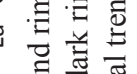

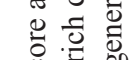

¿

可

可

产 들

४
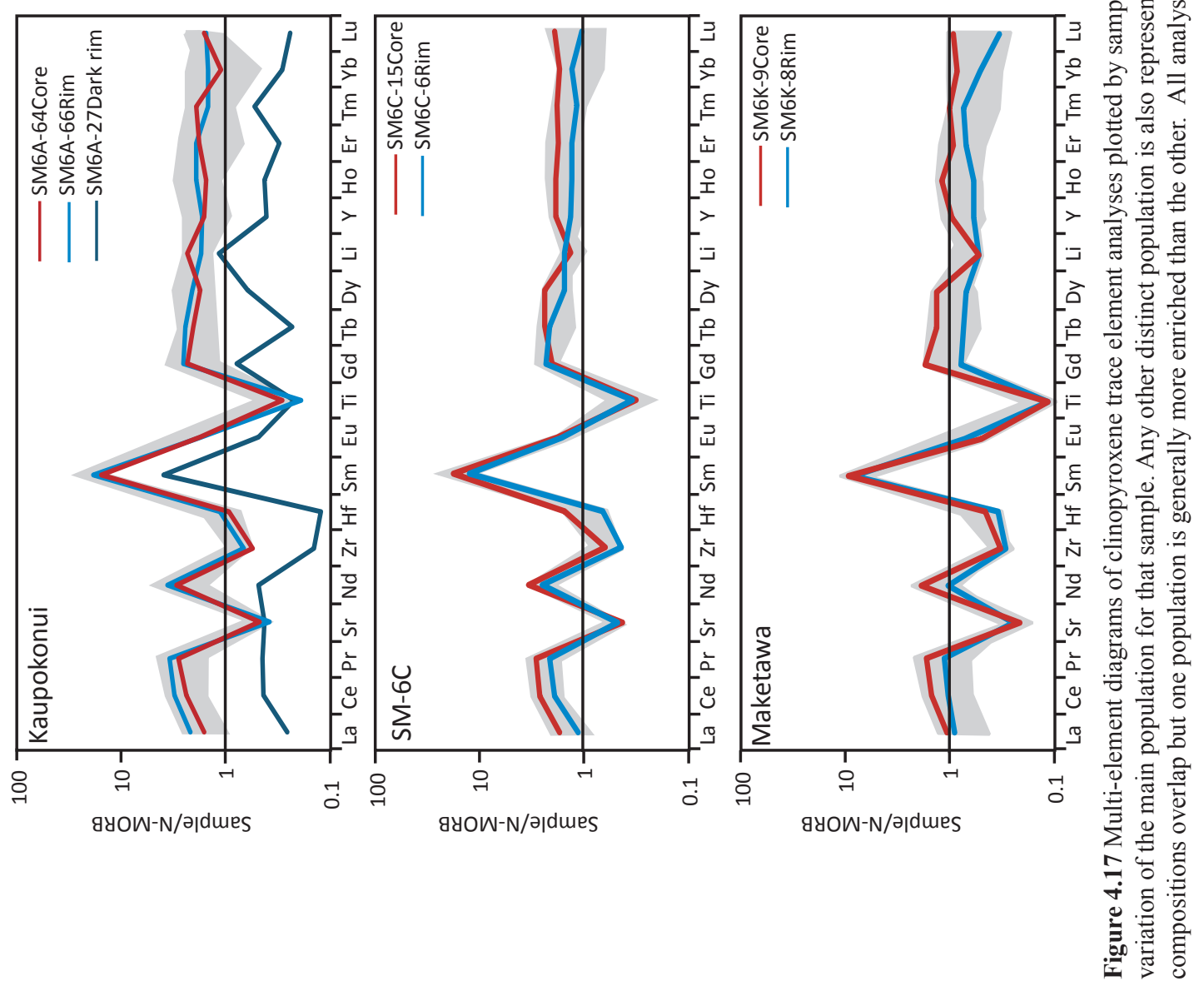
chemistry, especially in its core. This is depleted in trace elements with a peak in Li and a lack of a negative anomaly at Ti. This unusual chemistry can also be identified as an outlier in Figure 4.16.

\subsubsection{Amphibole}

There is a large amount of variability in amphibole trace element concentrations with most elements varying by a factor of four (Figure 4.18). Most of this variability is at low Mg\# values $(\mathrm{Mg} \#<80)$. There is a weak correlation between $\mathrm{Mg} \#$ and trace element concentrations. Compatible elements such as $\mathrm{Sc}, \mathrm{V}$ and Ni have a slight positive correlation with $\mathrm{Mg \#}$. All other trace elements except $\mathrm{Sr}$ have a slight negative trend. The trace element data more clearly distinguish between samples, with Kaupokonui and SM-6C showing the least evolved chemistry (higher compatible and lower incompatible element concentrations), followed by Maketawa and Inglewood $a$ and $b$ displaying the most evolved chemistry in a trend which mimics that of the glass chemistry. Korito breaks this pattern, because although it is one of the evolved samples, it has $\mathrm{Sr}$ and incompatible trace element concentrations that overlap those of the less evolved samples.

The overall range of trace element compositions for each sample is broadly the same. There are two populations within each sample: Population 1 which is relatively depleted in trace elements and Population 2 which has a relatively enriched chemistry with negative anomalies at Th, U, Pb, Sr, Hf, Zr and Li (Figure 4.19). One population typically dominates a sample with $\sim 10-20 \%$ of analyses comprising the minor group. This minor group is typically a population of amphibole core analyses except for Korito where this is rim analyses. Population 1 dominates in Kaupokonui, SM-6C and Korito samples, while Population 2 is the major group for the other 3 samples. 

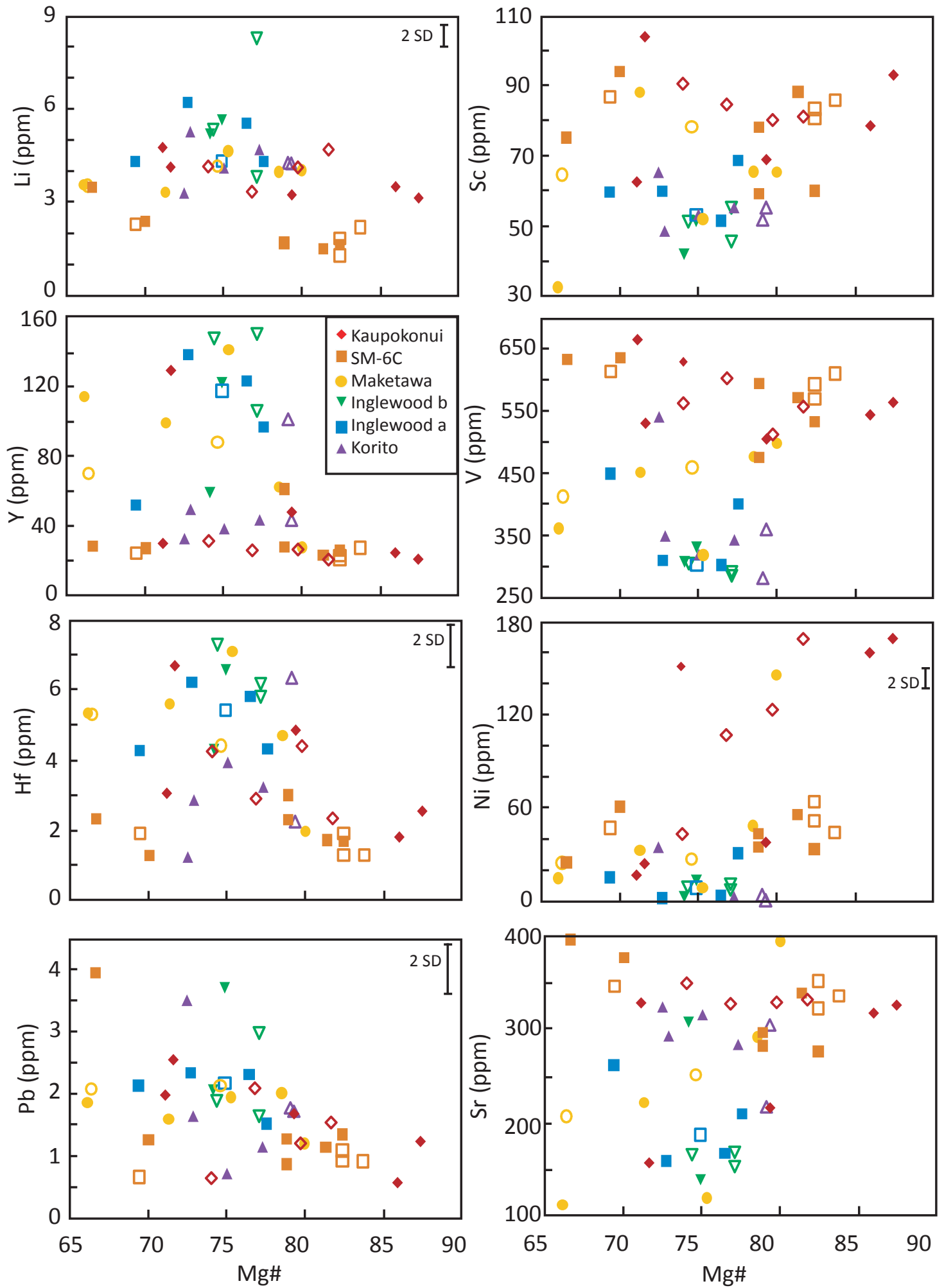

Figure 4.18 Selected trace elements versus $\mathrm{Mg} \#$ for amphibole crystals. Open symbols represent rim compositions and filled symbols indicate core analyses. Kaupokonui, SM-6C and Maketawa have more primative compositions with higher concentrations of compatible elements ( $\mathrm{Sc}, \mathrm{V}, \mathrm{Ni}$ and $\mathrm{Sr}$ ) and lower concentrations of incompatible elements $(\mathrm{Li}, \mathrm{Y}, \mathrm{Hf}$ and $\mathrm{Pb}$ ). There is a large variation in trace elements concentration of a factor of 4 to 10 at a given $\mathrm{Mg} \#$ where $\mathrm{Mg} \#<80$. Error bars as stated or smaller than the symbol size. 


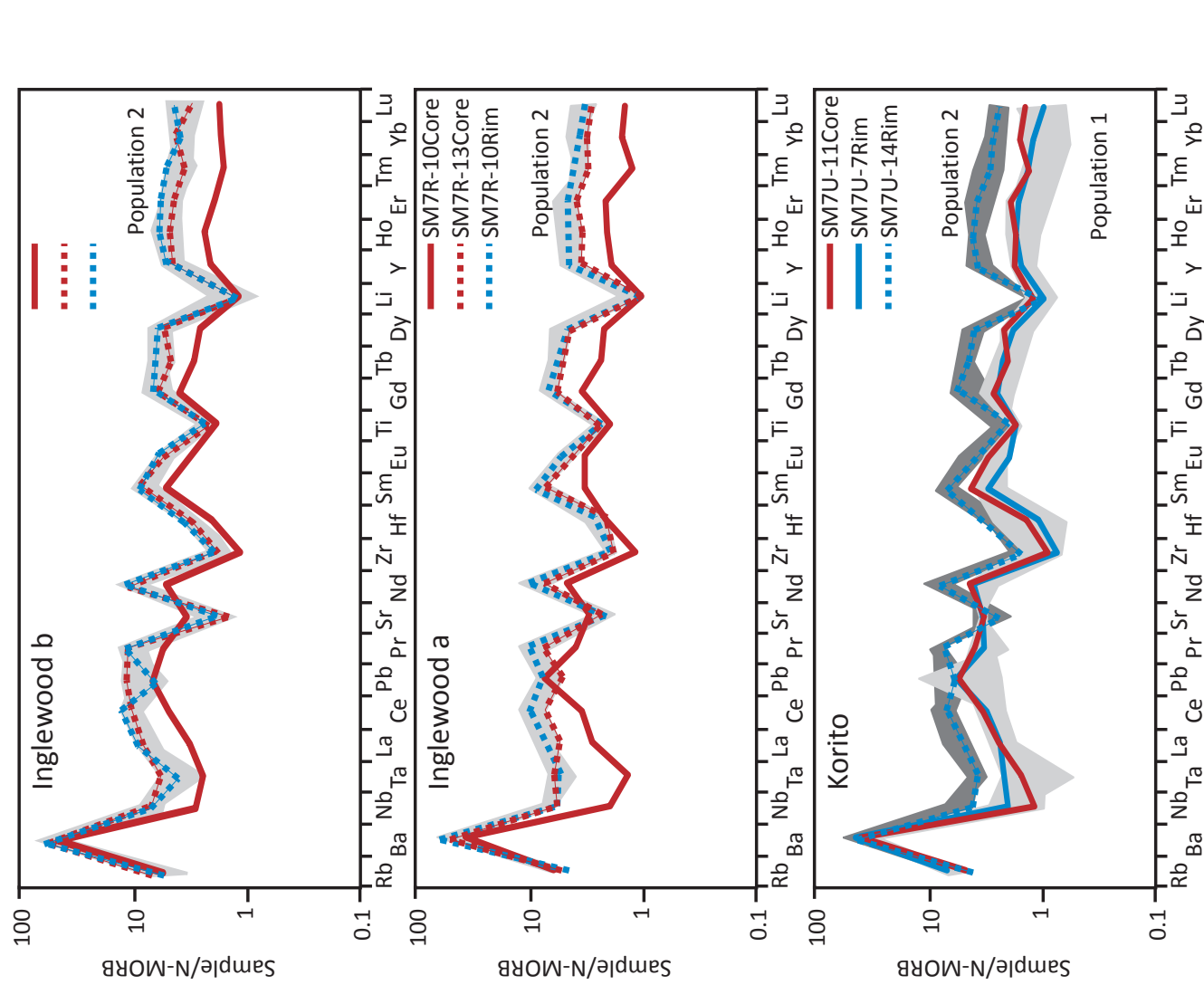

峁 


\subsection{THERMOBAROMETRY}

\subsubsection{THERMOMETRY}

All four thermometers applied to the sample suite returned the same temperature for each sample within the $\pm 42{ }^{\circ} \mathrm{C}$ model error (Figure 4.20). All six samples are also within model error of one another, however Inglewood a and b and Korito consistently return lower temperatures of $\sim 860-920{ }^{\circ} \mathrm{C}$ compared with Kaupokonui, SM-6C and Maketawa, which have temperatures $\sim 910-1000{ }^{\circ} \mathrm{C}$. Sample SM-6C is the hottest sample. These temperatures are broadly consistent with the $\mathrm{SiO}_{2}$ content of the samples with those highest in $\mathrm{SiO}_{2}$ recording the coolest temperatures and vice versa.

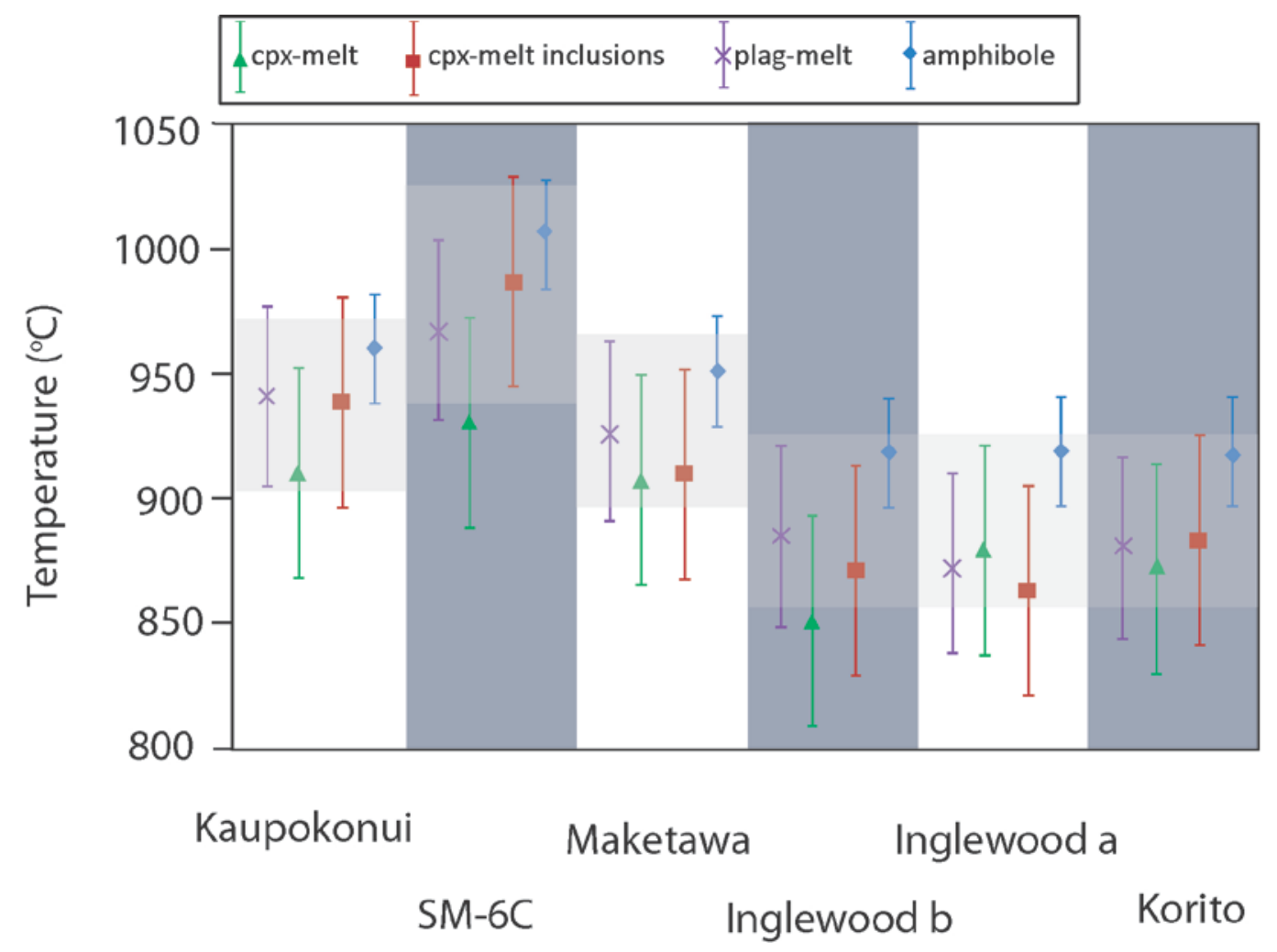

Figure 4.20 Summary of thermobarometry models. Symbols represent sample averages and error bars indicate the model error. 


\subsubsection{AMPHIBOLE THERMOBAROMETRY}

Each sample spans a similar range of temperature, pressure, melt water content $\left(\mathrm{H}_{2} \mathrm{O}_{\text {melt }}\right)$ and oxygen fugacity (Figures 4.21, 4.22, 4.23). Amphibole core values generally extend the range of observed values (temperature $\sim 1050$ to $900{ }^{\circ} \mathrm{C}$; pressure $\sim 200$ to $600 \mathrm{MPa}$; $\mathrm{H}_{2} \mathrm{O}_{\text {melt }} \sim 4$ to $7 \mathrm{wt} \%$; $\log \mathrm{fO}_{2} \sim-11$ to -9 ) but rims are typically clustered at low end member values, with a minor rim population overlapping the high core values. This is especially well illustrated by Inglewood b where there are two distinct amphibole populations. One is hotter, deeper as well as more hydrous and oxidised, and is comprised entirely of cores and zoning. The low temperature population is tightly constrained and contains amphibole rim values and the remaining cores and zones. This core-rim distinction is not present in Kaupokonui and SM6C as cores and rims overlap the range observed in these samples. These samples also do not extend to values as low as most others and SM-6C exhibits the highest values for each variable. The older three samples have the lowest temperature, pressure, water content and oxygen fugacity. 

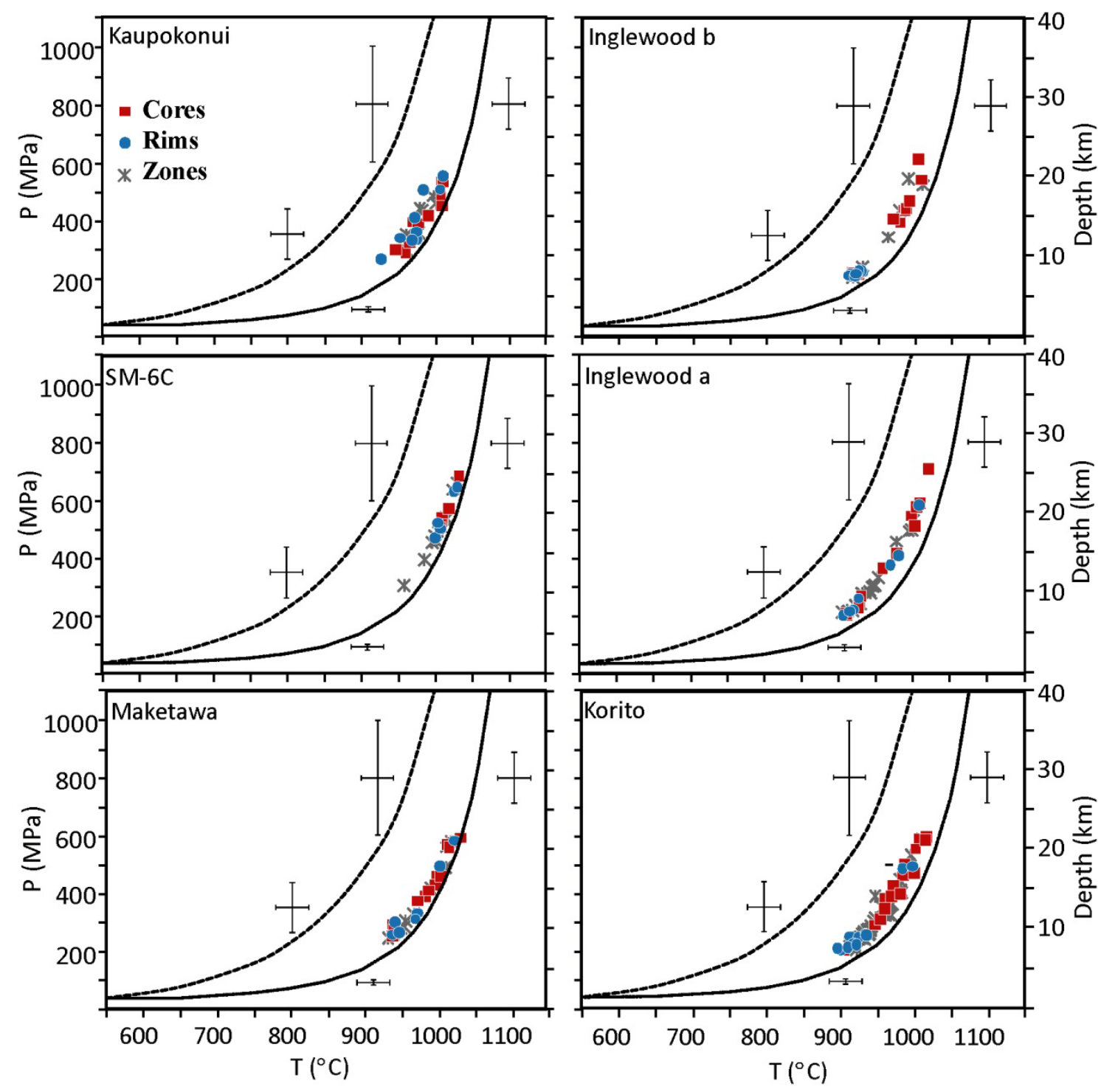

Figure 4.21 Amphibole thermobarometry results. Black curves outline the range of amphiboles this model is appropriate for, the base of which is determined by the amphibole stability curve. Temperature errors are constant $\pm 22^{\circ} \mathrm{C}$, pressure errors range from $11 \%$ near the amphibole stability curve to $25 \%$ at the upper limit of appropriate amphibole values. The errors for these values are closer to $11 \%$ as they plot near the amphibole stability curve. Depth is calculated based on average specific weights of $2.7 \mathrm{~g} / \mathrm{cm}^{3}$ 

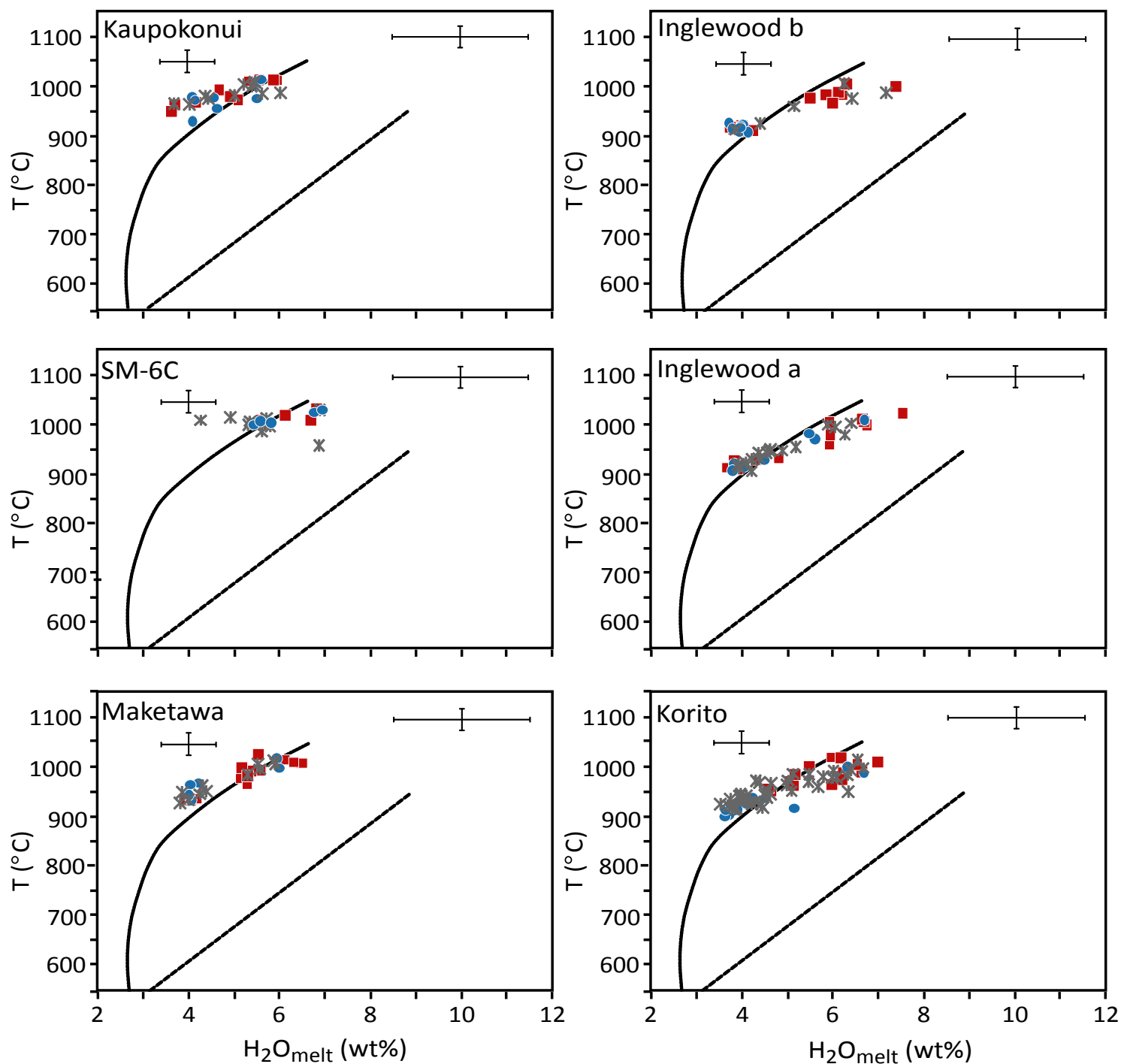

Figure 4.22 $\mathrm{H}_{2} \mathrm{O}_{\text {melt }}$ vs temperature from amphibole thermometry and hygrometry models. Errors for temperature are constant at $\pm 22^{\circ} \mathrm{C}$ and $\mathrm{H}_{2} \mathrm{O}_{\text {melt }}$ errors are $15 \%$. Black curves outline the range of amphiboles which are suitable for this model. The extended stability of some of these amphiboles is also evident in the Ridolfi et al. (2010) magnesiohastingite data set and attributed to large amounts of $\mathrm{CO}_{2}$ in the system at relatively high temperatures and low $\mathrm{H}_{2} \mathrm{O}_{\text {melt }}$ stabilising magnesiohastingsite compositions. Symbols as for Figure 4.21. 

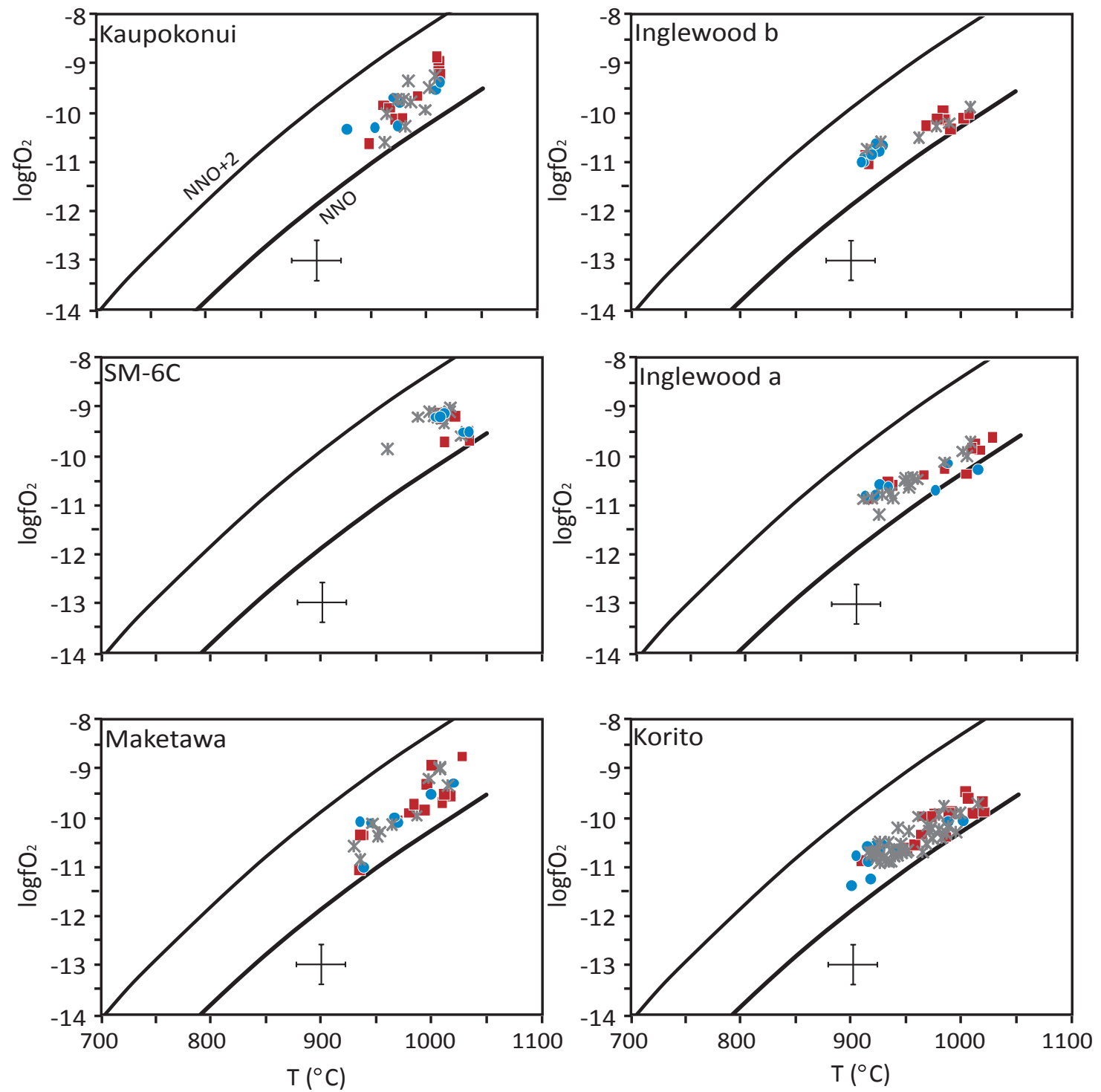

Figure 4.23 Temperature-oxygen fugacity results from amphibole thermometry and oxybarometry. Black curves represent Nickel-nickel oxide buffer (NNO) and $\mathrm{NNO}+2$. Errors are constant at $\pm 22 \mathrm{C}$ for themometry and 0.4 $\log$ unit for oxygen fugacity. Symbols as for Figure 4.21. 


\section{CHAPTER 5:}

DISCUSSION 


\subsection{GLASS CHEMISTRY}

Most of the previous geochemical studies of Mt Taranaki eruptives analysed whole rock samples (Price et al., 1992, 1999; Turner et al., 2008). Whole rock data is the weighted average of the heterogeneous crystal cargo and host melt (Davidson et al., 2007a). Glass represents the residual melt phase of the magma, which may or may not be related to the crystal cargo. Therefore these represent two different aspects of the magma system which provide different information about andesite petrogenesis. Whole rock information provides an overview of the system and detects broad scale processes and inputs into the system, whereas glass gives a snapshot of melt evolution and can be used in conjunction with mineral chemistry to unravel the complexities of the sub-volcanic magmatic system.

\subsubsection{COMPARISON WITH PUBLISHED GLASS STUDIES}

Much of the published glass analyses are from distal sites and have been investigated from a tephrostratigraphic perspective. Tephra layers originating at Taranaki have been identified distally in sediment cores from lakes (e.g. Lowe, 1988; Shane, 2005). These tephra records are better constrained chronologically than lava flow sequences. For example, the lava flow sequences are grouped into units encompassing $700 \mathrm{yr}$ to $5000 \mathrm{yr}$ and those eruptions that predate major sector collapse events are broadly grouped into Young Egmont Ring Plain and Old Egmont Ring Plain, which encompass thousands of years and tens of thousands of years, respectively (Stewart et al., 1996; Price et al., 1999). The tephrostratigraphic record provides a higher resolution, temporally constrained record that extends back as far as 70,000 yr (Shane, 2005). However, correlating between these units is challenging due to the typically heterogeneous nature of andesitic glass (Shane, 2005; Platz et al., 2007b).

The major element results from this study are consistent with published glass data from distal sites (Lowe, 1988; Shane, 2005) and proximal sites (Platz et al., 2007b; Figure 5.1). The groundmass glass compositions of Price et al. (2005) fall off this trend, most likely due to microlite crystallisation during and after lava emplacement. Published data from distal tephras from the past 70,000 yr show the same degree of major element variability as the $\sim 3000 \mathrm{yr}$ 
record represented by the six samples investigated in this thesis. Unit Eg-2 from Lowe (1988) represents Inglewood a (Alloway et al., 1995). These values overlap when the $\mathrm{SiO}_{2}$ errors of Eg-2 are considered ( $\pm 0.99 \mathrm{wt} \%)$.
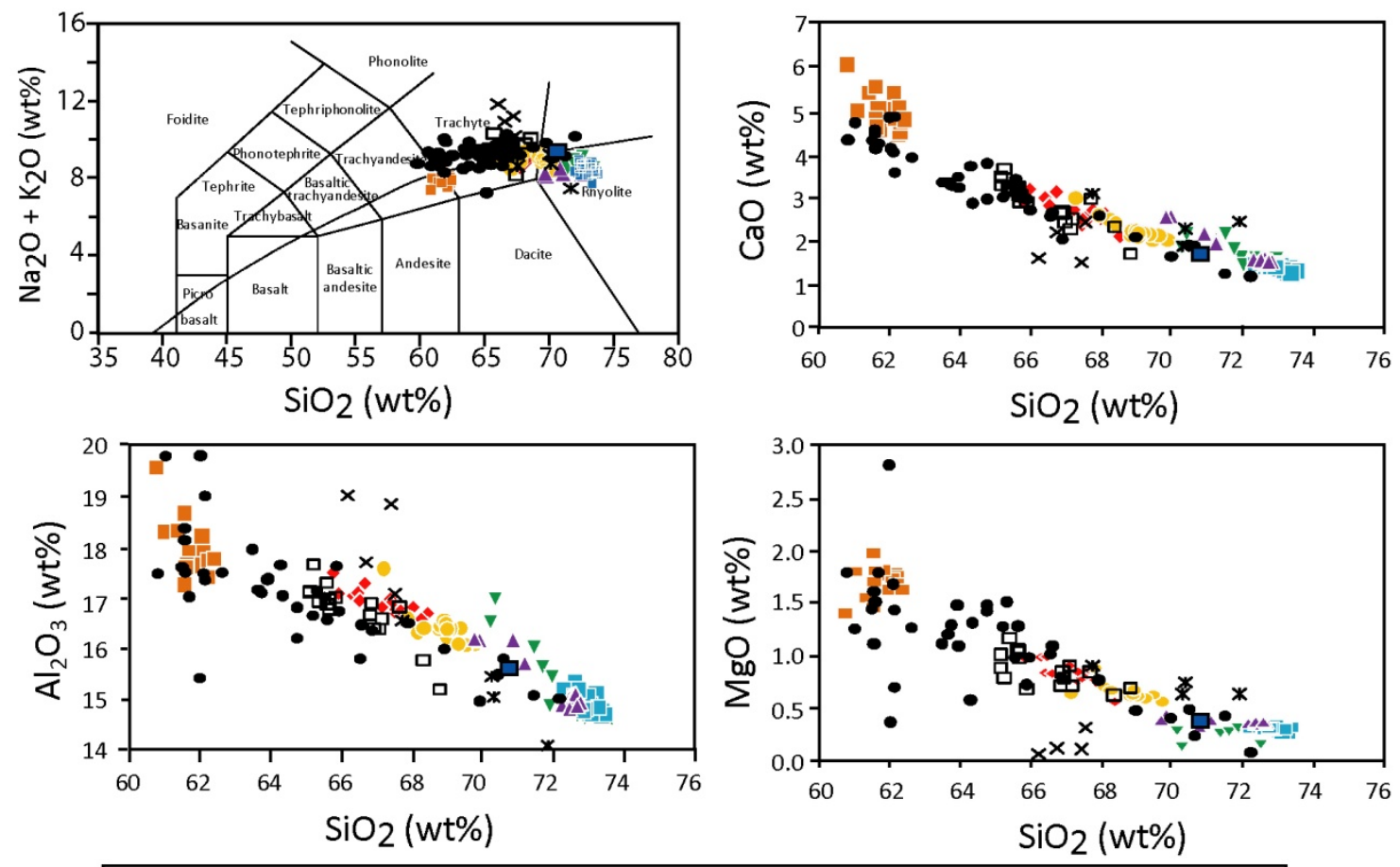

KEY

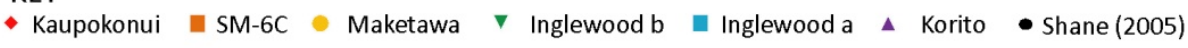

口 Platz et al. (2007) $\quad \times$ Price et al. (2005) $\quad *$ Lowe (1988)

ㅁ Eg-2 from Lowe (1988)

Figure 5.1 Comparison of glass data from this study and selected published data using selected major elements. Analyses are recalculated to $100 \%$ on a volatile free basis. Published data are mean analyses for a specific unit where 1 sd range from: $\mathrm{SiO}_{2}=0.45-3.83 \mathrm{wt} \% ; \mathrm{CaO}=0.1-1.49 ; \mathrm{MgO}=0.06-0.76 ; \mathrm{Na}_{2} \mathrm{O}=0.12-1.38 ; \mathrm{K}_{2} \mathrm{O}=0.18-1.38$ (except Platz et al., 2007a which are representative EMP analyses).

\subsubsection{COMPARISON WITH WHOLE ROCK GEOCHEMISTRY}

Taranaki major element glass data (this study; Price et al., 2005; Platz et al., 2007a) are more evolved than the associated whole rock data: the $\mathrm{SiO}_{2}$ content of the glass $\sim 60-75 \mathrm{wt} \%$ compared with $~ 53-57 \mathrm{wt} \%$ for the associated whole rock. Glass is also relatively depleted in most other major elements (except $\mathrm{K}_{2} \mathrm{O}$ and $\mathrm{Na}_{2} \mathrm{O}$ ) when compared with whole rock analyses (Figure 5.2; Price et al., 1992, 1999; Stewart et al., 1996; Turner et al., 2008). The discrepancy between the two data types is due to the incorporation of mineral phases in the whole rock analyses, rather than different chemistries of the eruptives. This is illustrated by the major element data which show that whole rock and glass values are related by crystal accumulation 
of plagioclase, clinopyroxene and amphibole. This has been quantified using least squares mixing modelling, which confirms that the whole rock chemistry of contemporaneous lava flows can be reproduced using a realistic mixture of phenocryst mineral assemblages and glass (Table 5.1). The modal mineral abundances used in this modelling broadly agree (i.e. $r^{2}<1$ ) with those estimated for lava flow sequences from Stewart et al. (1996), Price et al. (1999) and Turner et al. (2008) (Table 5.1). The plagioclase modal proportion model input is up to $10 \%$ higher than the published estimates probably due to the high abundance of plagioclase microlites in the whole rocks which were not included in these published estimates. The major element data from this study are in agreement with that of previous studies once the least squares mixing modelling has accounted for the comparison of glass and whole rock data.

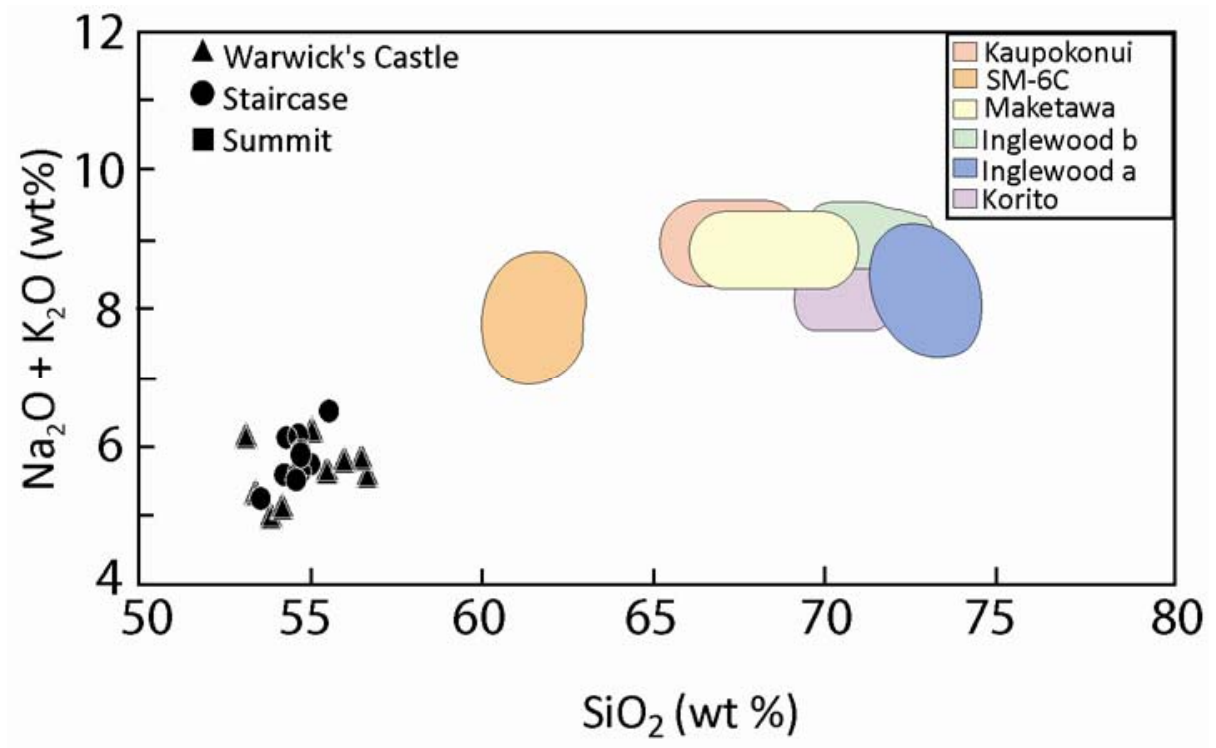

Figure 5.2 Total alkalis-silica plot of Taranaki eruptives. Whole rock data as compared with glass data from this study (coloured fields). Filled symbols represent published whole rock data and open symbols represent temporally associated published glass data. Published data taken from Stewart et al. (1996), Price et al. (1999; 2005), Platz et al. (2007a) and Turner et al. (2008).

Representative glass samples from this study were paired up with the average whole rock values for the contemporaneous lava flow sequences and used for least squares mixing modelling. However, the eruptions investigated in this study are unlikely to be directly represented in the lava flow sequences, but were paired up with the lava flow sequence which temporally coincides with the age of the associated tephra unit. The whole rock major element values for the Warwick's Castle and Staircase group lavas overlap and exhibit limited compositional variability (Figure 


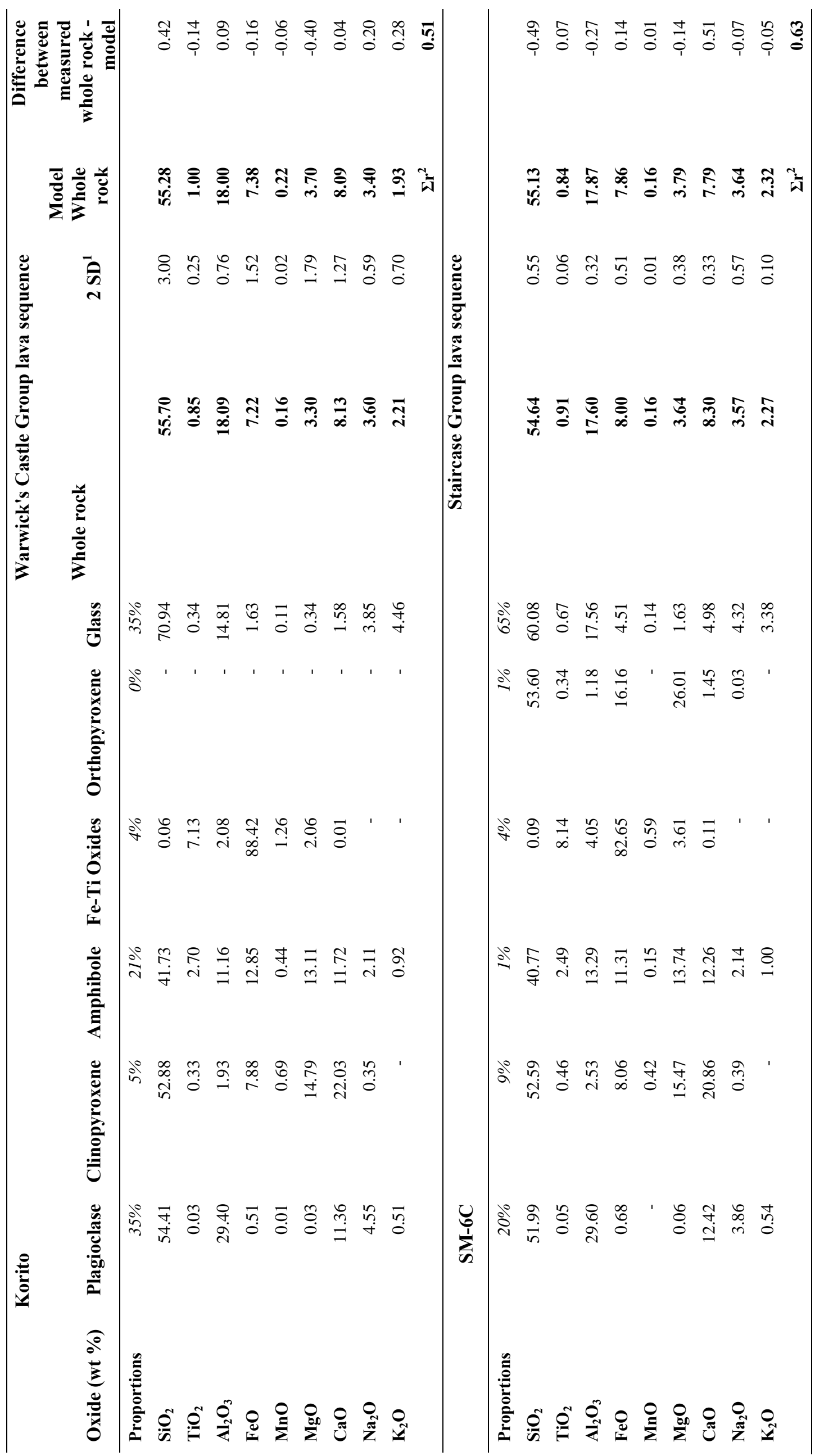




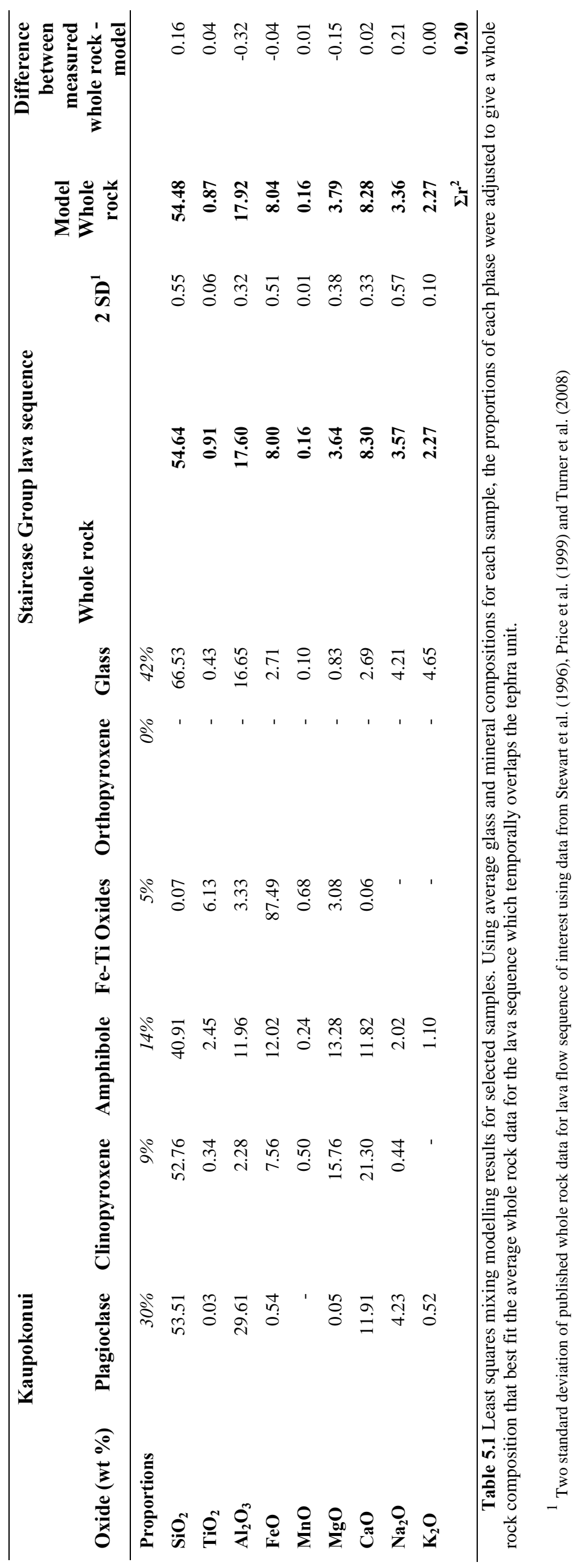


5.2; Stewart et al., 1996; Price et al., 1999; Turner et al., 2008). The close fit of each sample to this limited whole rock range may point to some of the samples having approximately the same major element whole rock compositions with the observed variations in major element glass chemistry due to late stage crystallisation. Price et al. (2005) came to a similar conclusion when comparing modal groundmass abundance with whole rock compositions for flow groups of Ruapehu eruptives, postulating that $20-30 \%$ of the crystal populations could have formed during closed system crystallisation.

Xenoliths are common in Taranaki eruptives and are dominated by plagioclase-hornblendeclinopyroxene-glass assemblages that have similar crystal textures and compositions to the phenocrysts in Taranaki andesites (Stewart et al., 1996; Price et al., 2005; Gruender et al., 2010). Therefore many of the phenocrysts in andesites such as the Ruapehu and Taranaki eruptives may be xenocrysts derived from the disaggregation of microxenoliths (Price et al., 2005). The close match produced by the least squares mixing model supports this as whole rock analyses would have included any xenoliths, which were not included as inputs into the model. Therefore it is possible that xenocrysts were analysed as a population of the mineral phases and therefore incorporated into the average mineral compositions input into the model, or alternatively, not analysed but having a similar composition to the phenocrysts and therefore not altering whole rock geochemistry.

\subsubsection{THE RELATIONSHIP BETWEEN GLASS AND MINERAL PHASES}

The relationship between the glass and mineral phases can be addressed by considering two end-member scenarios: 1) where they are directly related by closed system processes such as crystallisation and; 2) where the crystals have no genetic relationship to the melt in which they are found but were mixed immediately prior to eruption. Closed system processes would result in phenocryst assemblages in equilibrium with the glass and crystallisation that would drive the composition of the magma to more evolved compositions. Where the melt and crystals have evolved separately, they are unlikely to be in equilibrium and features such as sieve textured crystals, may be apparent. 
A combination of these processes appears to be occurring at Taranaki as there is both a phenocryst population of plagioclase, clinopyroxene and amphibole that are in equilibrium with the host melt (see Section 3.3 for equations used to calculate equilibrium and associated discussion) as well as other mineral populations of these phases with more complex zoning and crystallisation histories. The cores of these complex crystals display a range of major and trace element compositions suggesting these crystals are from multiple magma sources (maybe including xenoliths) and were incorporated into the host magma at a later stage. The rim compositions of these complex crystals have little variability and generally coincide with that of the phenocryst population so also likely grew from the host melt. This rim is absent in a small population of crystals which display less evolved major and trace element chemistry and are therefore probably a final addition to this magma

These findings are consistent with recently proposed concepts of intermediate magmas as a mixture of silicic melt and assorted minerals derived from various sources (e.g. Eichelberger, 1978; Davidson et al., 2005; Price et al., 2005; Reubi \& Blundy, 2009). Silicic melts appear to be formed in the lower crust by processes such as crystallisation of hydrous basalts, melting of mafic source rocks (Hildreth and Moorbath, 1988; Annen et al., 2006) and/or interaction of a mantle-derived melt with the lower crust (Price et al., 2005). Melt differentiation at depth is favoured as melt inclusions are consistently silicic regardless of the location within the host crystal (Price et al., 2005; Annen et al., 2006; Reubi \& Blundy, 2009). Although melt inclusion compositions are more variable than the groundmass glass, the average $\mathrm{SiO}_{2}$ content overlaps that of the glass for each sample and Gruender et al. (2010) found the glass composition of xenoliths also coincides with that of the Taranaki glass. The dominance of type II xenoliths comprising mostly cumulates and granulites suggest a large degree of involvement with the lower crust (Stewart et al., 1996; Gruender et al., 2010).

These silicic lower crustal melts incorporate minerals from various sources as they traverse the crust resulting in a complex crystal cargo containing xenocrysts, antecrysts and phenocrysts with a range of textures and chemistries. Xenoliths are incorporated largely in the lower crust and silicic melts migrate through the crust as crystal and lithic rich magmas to recharge the 
shallow magmatic system (Stewart et al., 1996; Price et al., 2005; Turner et al., 2008). As these magmas migrate to the surface, the crystal cargo is further modified by incorporation of antecrysts due to interaction with the shallow magmatic system and crystallisation of phenocrysts and growth of equilibrium rims on xenocrysts and antecrysts. The complex interplay of magma storage, recharge and subsequent mixing in the shallow magmatic system results in a mixture of crystal cargo that has originated from different parts of this system and therefore may have little or no relationship to the host magma. The following section will explore the nature of the mineral cargo using a detailed examination of mineral chemistry to decipher the history of the various mineral populations.

\subsection{MINERAL CHEMISTRY}

Unravelling the history of mineral populations requires detailed examination of both chemical and textural evidence. In particular, the use of in situ techniques to construct a crystal stratigraphy enables the investigation of magmatic evolution through time. Mineral phases can form at different stages of magmatic evolution prior to eruption and are sensitive to different processes. Therefore each phase provides distinct insights into the sub-volcanic magmatic system, and populations within these phases can identify complex open system processes. The chemistry and textures of plagioclase, clinopyroxene and amphibole crystals in this section will be discussed individually in the context of magmatic processes operating beneath Mt Taranaki.

\subsubsection{PLAGIOCLASE}

Plagioclase is a particularly useful mineral for investigating magmatic processes. The major element chemistry recorded during crystallisation is preserved due to the slow rate of NaSiCaAl interdiffusion, hence preserving the mineral zoning (Morse, 1984; Grove et al., 1984). Plagioclase crystallises over a range of magmatic conditions and is sensitive to changes in magmatic parameters and composition. However, distinguishing uniquely between these factors is not always straightforward. Melt composition and temperature are the most important variables in influencing plagioclase anorthite content, with a small change in either of these parameters producing a large effect (Zellmer et al., 2003; Humphreys et al., 2006). Pressure and 
$p \mathrm{H}_{2} \mathrm{O}$ also affect plagioclase crystallisation and chemistry, with decreasing pressure of a water undersaturated system inducing resorption. Decompression of a water saturated system is also able to produce crystallisation of more sodic plagioclase (Vance, 1965; Nelson \& Montana, 1992). Given these basic relationships, the range of plagioclase textures and populations observed in the Taranaki eruptives provide evidence for different crystallisation histories.

Plagioclase crystals in the Taranaki eruptives typically display one or all of the following textures: sieved or patchy textures $(\sim 30-50 \%)$ and oscillatory zoning (> 50\%). Oscillatory zoning is the dominant texture, particularly in crystal rims. Sieved and patchy textures are usually features of plagioclase phenocryst cores but can also occur outside the core in isolated zones that interrupt oscillatory zoning.

\subsubsection{Patchy/sieved textured crystals}

As patchy textures simply represent crystallisation of the melt within the sieved regions (Streck, 2008), there is no clear distinction between patchy and sieved textures and they will be discussed together. Sieve texturing is limited to the high anorthite zones (An > 60) of crystals and the nature of the patchy zoning indicates sodic plagioclase crystallised within calcic plagioclase. This is further supported by the association of melt inclusions with the sodic plagioclase (e.g. Humphreys et al., 2006). In previous work, this texture has been interpreted to result from either rapid growth or resorption (Streck, 2008). In this case, the rounded nature of the sieving favours a resorption origin as rapid, skeletal growth would likely form a boxy cellular texture with square melt inclusions (Figure 5.3; Streck, 2008).

Formation of calcic cores with sodic rims requires that the cores crystallised from either a magma which was hotter, more mafic or at considerably higher $p \mathrm{H}_{2} \mathrm{O}$, and these textures are generally attributed to crystal cumulates which were then resorbed during water undersaturated decompression (Zellmer et al., 2003; Humphreys et al., 2006; Berlo et al., 2007; Turner et al., 2008). The patchy and sieved textures which are found in cores and mantles appear similar (Figure 5.3) and are interpreted to be formed by the same process. The effects of decompression 

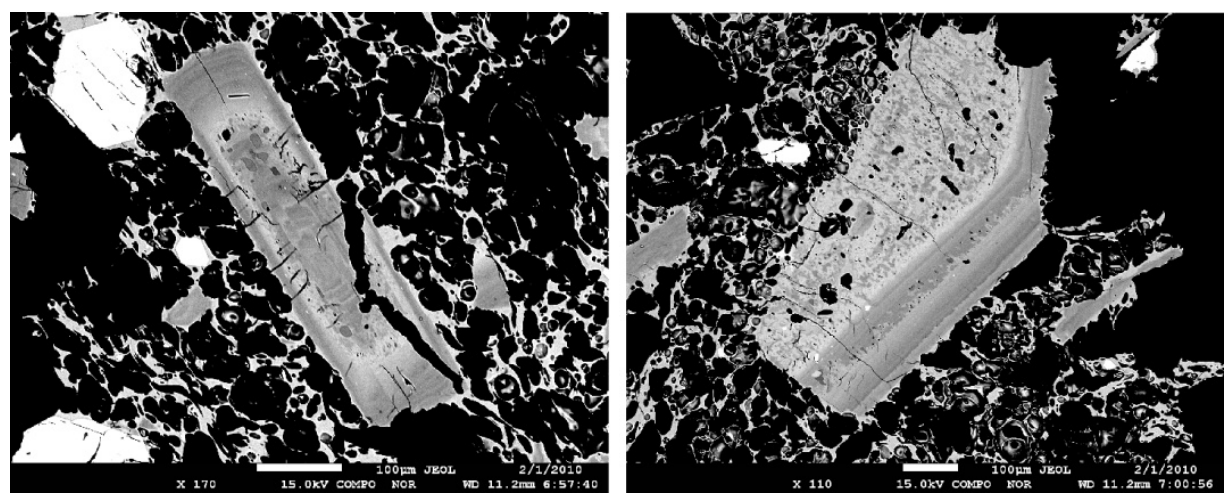

Figure 5.3 Examples of plagioclase crystals with sieved/patchy core and mantle from Kaupokonui (crystals= left: 6a_P9, right: 6a_P10). Note the similarity of the patchy/sieved texture in the core and mantle and the rounded nature of the melt inclusions. These patchy/sieved zones appear to be partially crystallised highlighting the continuum between the patchy and sieved textures.

could account for indiscriminate sieving of an entire core, but not the isolated bands of sieving which interrupt oscillatory zoning (Figure 5.3). The sieved zoning is therefore more likely to be the result of changing melt composition and temperature, possibly due to the intrusion of a hotter and/or more mafic magma into the magmatic system/magma chamber.

Browne et al. (2006) observed a similar feature in the eruptive products of Mt Unzen, where a population of oscillatory zoned crystals contained a resorbed zone. This was attributed to being locally engulfed by a basaltic injection, which resorbed the oscillatory zoning and crystallised higher anorthite plagioclase. Afterwards, the basalt may have dispersed into the silicic body and oscillatory zoning resumed. These authors correlated the increase in anorthite content with increased $\mathrm{Sr} / \mathrm{Ba}$ ratios, an indicator of more mafic magma. The heterogeneous and melt inclusion-rich nature of the patchy/sieved zones in this study generally precluded LA-ICPMS analysis of the high anorthite patches of the zones. Therefore it was difficult to distinguish between mixing of mafic magma and reheating of the system by a hotter magma on the basis of geochemical data. Interaction with a less evolved magma is favoured because the dissolution penetrated the crystal, rather than exhibiting a simple smoothing of crystal edges which may have been attributed to magma heating (Tsuchiyama, 1985; Singer et al., 1995). 


\section{Dissolved crystals}

Dissolved crystals are mostly confined to sample SM-6C and are characterised by very high anorthite (An> 86), and REE concentrations that are almost an order of magnitude lower than other plagioclase crystals from this sample. These are therefore interpreted to be plagioclase crystals from a more primitive melt that were incorporated into the host melt or, alternatively, may represent the remnants of disaggregated xenoliths.

\subsubsection{Oscillatory zoned crystals}

Oscillatory zoning has been attributed to a number of processes including kinetic effects (e.g. Pearce \& Kolisnik, 1990; Ginibre et al., 2002b), convection (Pearce \& Kolisnik, 1990; Singer et al., 1995), decompression-heating cycles (Blundy et al., 2006) and magma recharge (e.g. Sparks \& Marshall, 1986; Singer et al., 1995; Davidson \& Tepley, 1997; Ginibre et al., 2002a). There are multiple scales of oscillatory zoning observed in the Taranaki samples, and these were likely produced by different mechanisms. Different scales of zoning are superimposed on one another. The finest scale zoning occurs on a scale of $<5 \mu \mathrm{m}$, exhibits very minor changes in anorthite content and do not appear to have any resorption associated with them. These are similar to the Low Amplitude Oscillatory (LAO-type) zoning of Ginibre et al. (2002b), which are thought to form at near equilibrium conditions by kinetic effects (e.g. Bottinga et al., 1966; Sibley et al., 1976; Haase et al., 1980; Allegre et al., 1981; Anderson, 1984). These conditions occur where a super-saturated liquid forms a local boundary layer as element diffusion is too slow to replenish the melt at the interface (Bottinga et al., 1966). The interface is periodically destroyed by a pulse of new melt with slightly different composition and possibly also different temperature, resulting in a minor, but sudden change in anorthite composition (Ginibre et al., 2002b).

The more common, broader scale oscillatory zoning ranges in scale from 5 to $60 \mu \mathrm{m}$ with changes in anorthite content of $\sim 10$ to $20 \mathrm{~mol} \%$. These are saw-tooth shaped with sharp increases in anorthite content following resorption surfaces which then trend to lower anorthite values until truncation by another resorption surface. These resorption-associated oscillations 
resemble a range of documented textures including the saw-tooth pattern with resorption zoning (STR-type) of Ginibre et al. (2002b) and the Type II of Pearce \& Kolisnik (1990). The smaller oscillations can be repeated tens to hundreds of times, while the larger features may occur only twice. Turner et al. (2008) attributed all oscillatory zoning in plagioclase and clinopyroxene to kinetic effects operating in a shallow magma chamber. While this process may be responsible for the finest scale zoning, most oscillatory zoning in the Taranaki eruptives from the present study is likely due to other mechanisms, as kinetic effects are unlikely to produce the observed resorption and the compositional variation observed is difficult to produce with kinetic effects (Ginibre et al., 2002a; Humphreys et al., 2006).

Oscillatory zoning has been attributed by Blundy et al. (2006) to the complex interplay between decompression, crystallisation and heating. In this model, decompression of a hydrous magma crystallises plagioclase with decreasing anorthite content. However, this crystallisation releases latent heat which slightly resorbs the sodic plagioclase and crystallises more calcic plagioclase. This would produce many oscillations and may be a mechanism for producing the finer scale of the resorption related oscillations. Similarly, rhythmic oscillatory zoning associated with resorption has also been related to growth during convection within the magma chamber as a response to a weak thermal gradient (Singer et al., 1995). In this model, dissolution occurs as the crystals descend, interact with hotter magma, and crystallisation renews on ascent into cooler magma. A combination of these factors likely account for the small scale, rhythmic oscillatory zoning observed in some crystals. In contrast, the larger scale oscillatory zones are interpreted to result from repeated mafic recharge. The heat from these intrusions resorbs the outside of the equilibrium plagioclase before crystallising the higher anorthite, higher temperature plagioclase. As the heat dissipates, progressively lower anorthite plagioclase crystallises (Singer et al., 1995). All of these processes are a function of intensive and extensive parameters operating on a shallow magma chamber. Equilibrium calculations based on major element concentrations indicate that the rims of plagioclase crystals are in equilibrium with the host glass. Therefore, in general, the oscillatory zoning is considered to have formed in the host silicic magma. 


\subsubsection{Calculated plagioclase equilibrium melt compositions}

The trace element chemistry of plagioclase crystals reflects that of the melt from which it crystallised, and is controlled by partition coefficients. The trace element concentrations of the equilibrium melts were calculated using the partition coefficients of Blundy \& Wood (1991) and Bindeman et al. (1998), using temperatures obtained from plagioclase-melt thermometry (Putirka, 2008) (Table 5.2). Calculation of the melt composition as opposed to directly interpreting the plagioclase trace element concentrations is important because temperature and anorthite content affect the partitioning of most trace elements (Blundy \& Wood, 1991; Bindeman et al., 1998). As variation in anorthite content can be caused by a number of factors, reconstructing the trace element composition of the plagioclase melt provides useful constraints on changes in the melt composition. This information can be used to distinguish between changing melt composition and changes in physical parameters.

\begin{tabular}{|cccc|}
\hline \multicolumn{3}{|c}{ Plagioclase } & $925^{\circ} \mathbf{C}$ \\
\hline Element & $\mathbf{a}$ & $\mathbf{b}$ & $\mathrm{An}_{45}$ \\
$\mathbf{~ L i}$ & -6900 & -12100 & 0.22 \\
$\mathbf{~ M g}$ & -26100 & -25700 & 0.02 \\
$\mathbf{R b}$ & -40000 & -15100 & 0.04 \\
$\mathbf{S r}$ & -26700 & 26800 & 4.37 \\
$\mathbf{B a}$ & -38200 & 10200 & 0.49 \\
$\mathbf{L a}$ & -10800 & -12400 & 0.18 \\
$\mathbf{C e}$ & -17500 & -12400 & 0.13 \\
$\mathbf{P r}$ & -22500 & -9300 & 0.14 \\
$\mathbf{N d}$ & -19900 & -9400 & 0.16 \\
$\mathbf{S m}$ & -25700 & -7700 & 0.14 \\
$\mathbf{E u}$ & -16100 & -14200 & 0.12 \\
$\mathbf{P b}$ & -60500 & 25300 & 0.81 \\
\hline
\end{tabular}

Table 5.2 Plagioclase-melt partition coefficients used in this study. These partition coefficients are strongly dependent on anorthite content and temperature so have been calculated for each analysis using the equation: $\mathrm{RT} \ln \mathrm{D}_{\text {element }}=\mathrm{b}-\mathrm{a} * \mathrm{X}_{\mathrm{An}}$ where $\mathrm{R}$ is the gas constant $\left(8.314 \mathrm{JK}^{-1}\right)$ and $\mathrm{T}$ is temperature in Kelvin. A representative set of partition coefficients are given using $\mathrm{An}_{45}$ and $\mathrm{T}=925^{\circ} \mathrm{C}\left(=1198^{\circ} \mathrm{K}\right)$. a and $\mathrm{b}$ values are from Bindeman et al. (1998), except Sr and Ba which are from Blundy \& Wood (1991).

\section{$\underline{\text { Diffusion effects }}$}

Trace element compositions of plagioclase can be modified by diffusion. Strontium in particular diffuses within plagioclase on timescales of decades to centuries which are relevant to 
magmatic processes operating at andesitic volcanoes (e.g. Zellmer et al., 1999; 2003; Saunders et al., 2010). Following the example of Smith et al. (2009) it will be shown that Sr and Ba diffusion has not significantly altered the trace element concentrations of plagioclase from this study and therefore the trends observed do indeed reflect melt compositions.

The effect of diffusion on trace elements cannot be assessed directly because these measurements are point analyses on a scale of 25-35 $\mu \mathrm{m}$. Therefore the behaviour of $\mathrm{Mg}$, a minor element in plagioclase, which has been analysed by EMPA transects, is used to qualitatively determine the effects of diffusion on these samples. The rate of diffusion for these elements in plagioclase with an anorthite content of $\sim 30-58$ at $850^{\circ} \mathrm{C}$ fall within the following ranges: $\mathrm{Mg}-3.4 \times 10^{-6}$ to $5.8 \times 10^{-5} \mathrm{~mm}^{2} / \mathrm{s}$ (Costa et al., 2003); $\mathrm{Sr}-2.1 \times 10^{-8}$ to $5.4 \times 10^{-7}$ $\mathrm{mm}^{2} / \mathrm{s}$ (Giletti \& Casserly, 1994); and Ba $-1.5 \times 10^{-11}$ to $1.4 \times 10^{-9} \mathrm{~mm}^{2} / \mathrm{s}$ (Cherniak, 2002). As Mg diffuses 100 times more quickly than $\mathrm{Sr}$ and 10000 times quickly than $\mathrm{Ba}$, if the $\mathrm{Mg}$ profile has not been heavily modified by diffusion, Sr and Ba will not have been affected on the scale of interest here.

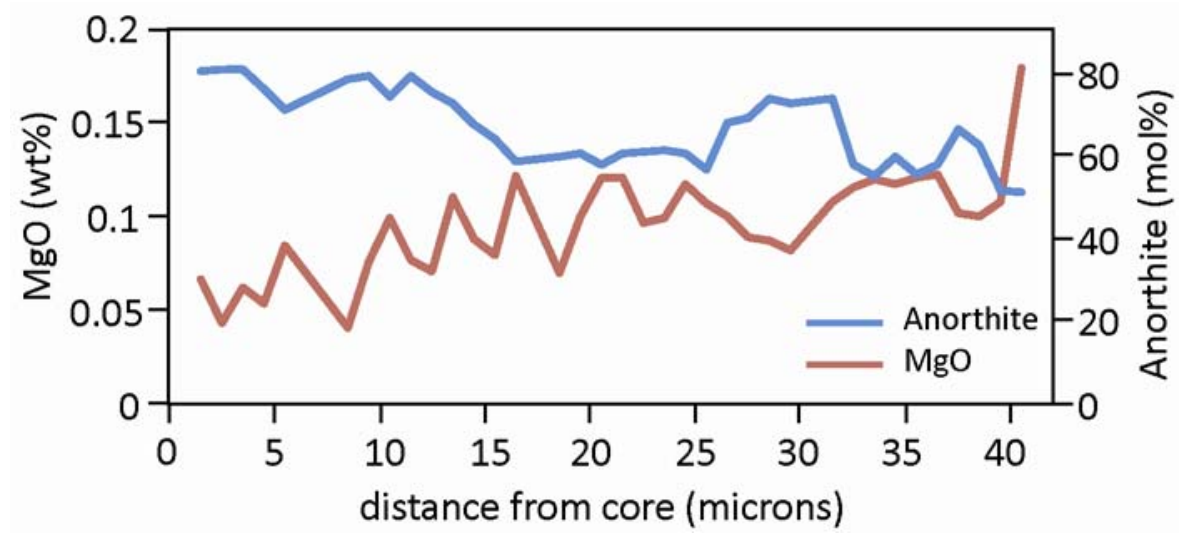

Figure 5.4 An example of a plagioclase transect (crystal SM-6C Pg) showing the anti-correlation between MgO and anorthite content indicating that the $\mathrm{Sr}$ and $\mathrm{Ba}$ trace element composition of plagioclase crystals have not been modified by diffusion.

There is a weak compositional sensitivity of Mg partitioning into plagioclase - it is slightly more compatible at lower anorthite content (Bindeman et al., 1998). Based on this relationship, Mg would initially vary inversely with anorthite content, and diffusion would act to smooth the Mg profile to a near flat equilibrium profile. As illustrated by Figure 5.4, An and Mg vary 
inversely in plagioclase. Therefore, $\mathrm{Mg}$ is not considered to have diffused significantly and diffusion of Sr and Ba has not modified plagioclase trace element compositions.

The overall trend of each sample shows decreasing $\mathrm{Sr}$ and $\mathrm{Ba}$ trending towards the measured matrix glass value for that sample (Figure 5.5). The close agreement of many of the rim-calculated melt values with the measured matrix glass concentrations verifies the use of these partition coefficients and further supports the hypothesis that the oscillatory rims are hostderived. Inglewood a and b and Korito samples contain two distinct groups: the melts in equilibrium with the anorthite-rich cores and sieved cores and zones ('core melt') and those calculated from the oscillatory zoning, rims and infilling plagioclase ('rim melt') (Figure 5.5). The 'core melt' was a less evolved composition, relatively enriched in $\mathrm{Sr}$ and depleted in La compared with the 'rim melt'. The calcic and sieved cores may be a restite of partial melting of the lower crust with resorption related to decompression in a water undersaturated system (Zellmer et al., 2003; Humphreys et al., 2006; Berlo et al., 2007). Alternatively, these may be remnants of an earlier phase of crystallisation or introduced by mixing with a mafic magma (Zellmer et al., 2003). Calcic cores that do not exhibit resorption may be an artefact of crystal orientation during sectioning, so that the core was not exposed in the observed two-dimensional plane. Alternatively, these crystals may have experienced continuous or episodic crystallisation (Berlo et al., 2007). The sieving may also be feasibly attributed to disequilibrium conditions during which calcic plagioclase entered the silicic melt before its rim crystallised. Given the available data it is not immediately clear whether these cores crystallised from the same melt, but the plagioclase assemblages imply that there were mafic additions to a shallow, silicic magma chamber, occurring as a single, or episodic, injection of more mafic magma.

The 'rim melt' forms a distinct group in Ba-Sr space, suggesting these are linked by a common process (Figure 5.5). The decrease in Sr may be a crystallisation trend as $\mathrm{Sr}$ is compatible in plagioclase. However, the crystallising assemblage does not account for the decreasing $\mathrm{Ba}$ due to its incompatible behaviour in the fractionating assemblage of plagioclase, clinopyroxene and amphibole. Published partition coefficients for Ba in these 


\begin{tabular}{|c|c|c|c|c|}
\hline & $\begin{array}{l}\text { Starting } \\
\text { composition }\end{array}$ & $\begin{array}{l}k_{\mathrm{D}} \\
\text { plag }\end{array}$ & cpx & amph \\
\hline $\mathrm{Sr}$ & 663.0 & 4 & 0.101 & 0.49 \\
\hline $\mathrm{Nd}$ & 21.4 & 0.15 & 0.38 & 1.24 \\
\hline $\mathrm{Ce}$ & 37.8 & 0.12 & 0.25 & 0.63 \\
\hline \multicolumn{5}{|c|}{ fractionating assemblage } \\
\hline & Kaupokonui & 0.4 & 0.1 & 0.15 \\
\hline & SM-6C & 0.5 & 0.1 & 0.05 \\
\hline & Maketawa & 0.4 & 0.05 & 0.05 \\
\hline & Inglewood b & 0.35 & 0.1 & 0.1 \\
\hline & Inglewood a & 0.4 & 0.1 & 0.1 \\
\hline & Korito & 0.4 & 0.05 & 0.1 \\
\hline
\end{tabular}

Table 5.3 The starting composition, partition coefficients $\left(\mathrm{k}_{\mathrm{D}}\right)$ and the fractionating assemblage used to model fractional crystallisation in this study.

mineral phases are all < 1 (e.g. Rollinson, 1993 and references therein; Ewart \& Griffin, 1994; Blundy \& Wood, 1991; Severs et al., 2009). This is consistent with the trace element data from this study because the Ba concentrations of the host melt are higher than the equilibrium rims of the dominant mineral assemblage. For example, in Inglewood b, the glass Ba concentration is 1140 ppm compared with $\sim 600-700$ ppm in plagioclase rims and $\sim 300-400 \mathrm{ppm}$ in amphibole rims (values are below the detection limit in clinopyroxene). Therefore crystallisation of this assemblage will concentrate $\mathrm{Ba}$ in the melt producing the opposite trend to that observed in Figure 5.5. Quantitative modelling of fractional crystallisation also shows that the plagioclase compositions cannot be reproduced by fractional crystallisation.

Humphreys et al. (2006) identified a similar trend of decreasing $\mathrm{Sr}$ and Ba which was interpreted as melt evolution during fractional crystallisation. However, these authors invoked the presence of phlogopite in the crystallising cumulate body, in which Ba is compatible. This is an unlikely solution for the Taranaki eruptives due to the absence of phlogopite, and because the anomalous trend appears to be recorded in the shallow magma chamber, host melt or some parent thereof. The decreasing Sr-Ba trend must therefore reflect open system processes, with the linear nature of this trend further indicating possible mixing with a melt high in $\mathrm{Sr}$ and $\mathrm{Ba}$. 

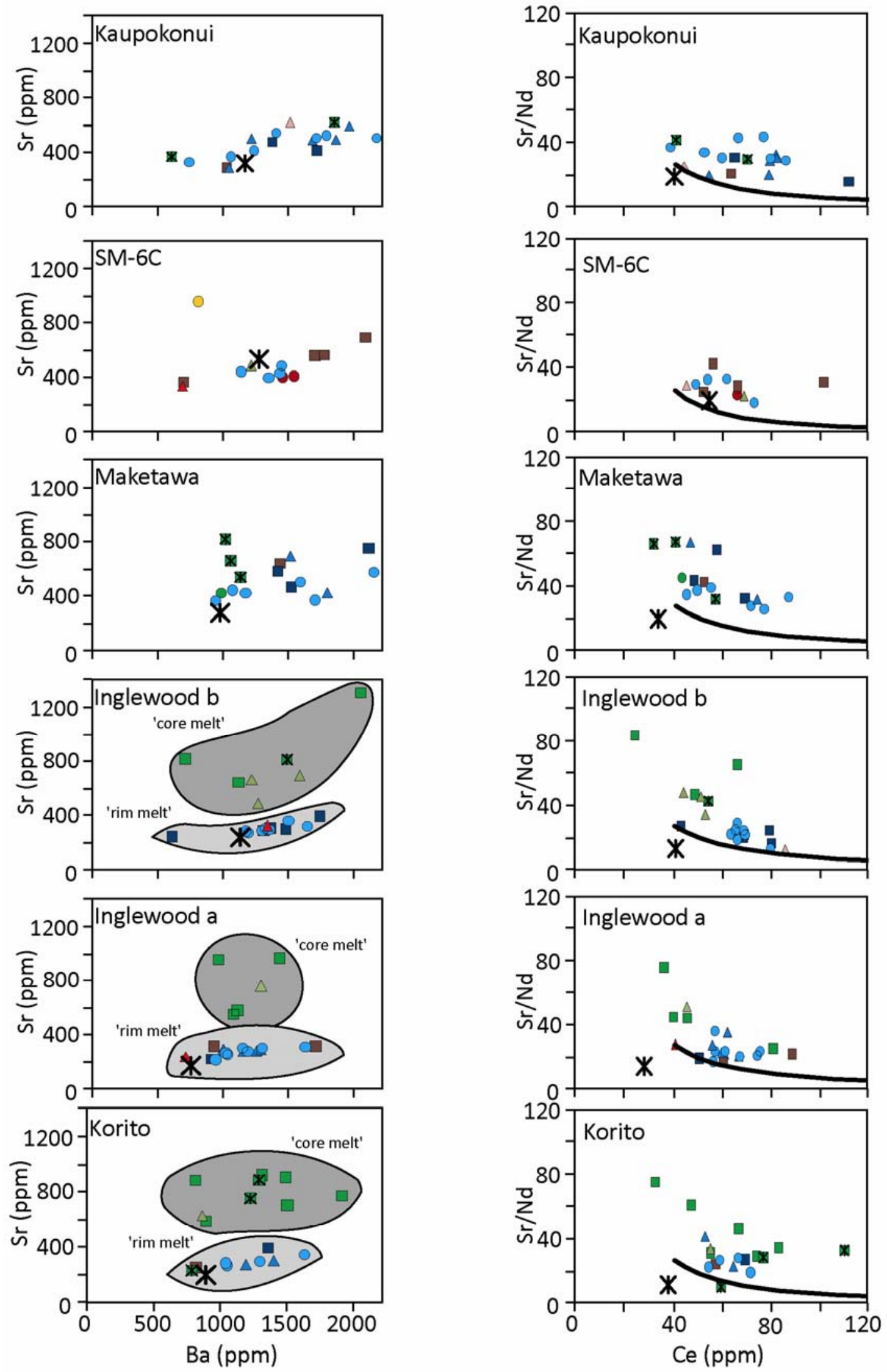

\footnotetext{
KEY

a calcic core $\boldsymbol{W}$ patchy-sieved core $\Delta$ calcic zone $\mathbf{a}$ oscillatory core $\Delta$ oscillatory zone oscillatory rim sodic core $\boldsymbol{\Delta}$ sodic patchy zone sodic rim $\boldsymbol{X}$ average matrix glass

fractional crystallisation model
}

Figure 5.5 Trace element concentrations of plagioclase equilibrium melt. Fractional crystallisation was modelled using the parameters in Table 5.3. 
The melt compositions from which the plagioclase cores crystallised in sample SM-6C fall on a linear trend with those of the rims and matrix glass, and generally trend toward lower values. The single point representing dissolved crystals is separate from this trend as it is significantly enriched in $\mathrm{Sr}$ and depleted in Ba. Therefore it appears to have crystallised from a distinct, less evolved, higher Sr and more mafic melt.

The trace element data for Kaupokonui and Maketawa indicate a more complex relationship between plagioclase crystals. The overall trend of decreasing Sr and Ba of the oscillatory zoning is evident, but exhibits more scatter and the oscillatory zoning appears to fall into distinct groups. The greater degree of variability of the oscillatory zoning may indicate that these crystallised from two different magma bodies that were mixed prior to eruption or crystallised within a single magma chamber that was compositionally variable. Determining the history of the plagioclase crystals is further complicated by the lack of trace element data for anorthiterich, sieved/patchy zoning for these crystals, limiting interpretation of the host melt of disequilibrium cores.

\subsubsection{CLINOPYROXENE}

The major element chemistry of clinopyroxene responds to changes in magmatic conditions primarily by variations in $\mathrm{Mg} \#\left(=\mathrm{Mg} /\left(\mathrm{Mg}+\mathrm{Fe}^{2+}\right)\right)$. This value is illustrated in backscattered electron imaging with higher Mg\# portions appearing darker. Clinopyroxene textures in conjunction with major and trace element data therefore provide important information related to the processes which have formed these crystals. Fe-Mg interdiffusion is significant over the timescales of magmatic processes $\left(1.17 \times 10^{-22} \mathrm{~m}^{2} / \mathrm{s}\right.$ at $\left.900^{\circ} \mathrm{C}\right)$, and are not necessarily an accurate representation of the original zoning. As a result, clinopyroxene crystals give a clearer picture of later stage processes such as those occurring in the shallow crust and in the lead up to eruption. 


\subsubsection{Clinopyroxene textures}

Simple and multiple zoning forms from one or more changes in magmatic conditions such as melt composition, temperature and oxygen fugacity. Patchy textured cores are indicative of disequilibrium conditions and can form by both partial dissolution of the pre-existing core followed by recrystallisation of equilibrium clinopyroxene (Simonetti et al., 1996), and by diffusion from melt inclusions formed during partial dissolution of the core (Tomiya \& Takahashi, 2005; Streck et al., 2007). Most crystal cores are melt inclusion-rich and major element analyses of these melt inclusions show that these compositions overlap with that of the host glass for any particular sample. Therefore it is interpreted that melt inclusions were open until a later stage of crystallisation in the host melt (or similar melt), and so cores may reequilibrate to rim compositions.

Oscillatory zoning is found in all the samples investigated here and shows cyclical changes in $\left.\mathrm{Mg \#} \mathrm{(Mg \#}{ }_{75-85}\right)$ with varying amounts of resorption associated with the changes in composition. As with plagioclase, oscillatory zoning in clinopyroxene crystals has been attributed to a range of processes including kinetic effects (e.g. Turner et al., 2008), cyclical changes within a shallow magma chamber such as convection (e.g. Morgan et al., 2004) and multiple replenishment events (Nakagawa et al., 1999). Clinopyroxene oscillatory zoning occurs on a number of scales and may not be clearly attributable to any single process. As this textural feature is similar to that of plagioclase, it is assumed to be produced by similar processes within a shallow magma chamber.

\subsubsection{Clinopyroxene chemistry}

Mg\# is typically used as an index of crystallising conditions, with increasing Mg\# attributed to crystallisation from a more mafic and/or hotter melt (e.g. Nakagawa et al., 1999; Turner et al., 2008). However, there is little correlation between $\mathrm{Mg \#}$ and other major and trace elements in the samples investigated here (Figure 5.7). The exception to this is clinopyroxene with Mg\# > 85, showing a positive relationship between $\mathrm{Mg} \#, \mathrm{Al}_{2} \mathrm{O}_{3}$ and compatible trace elements (e.g. $\mathrm{Ni}$, 

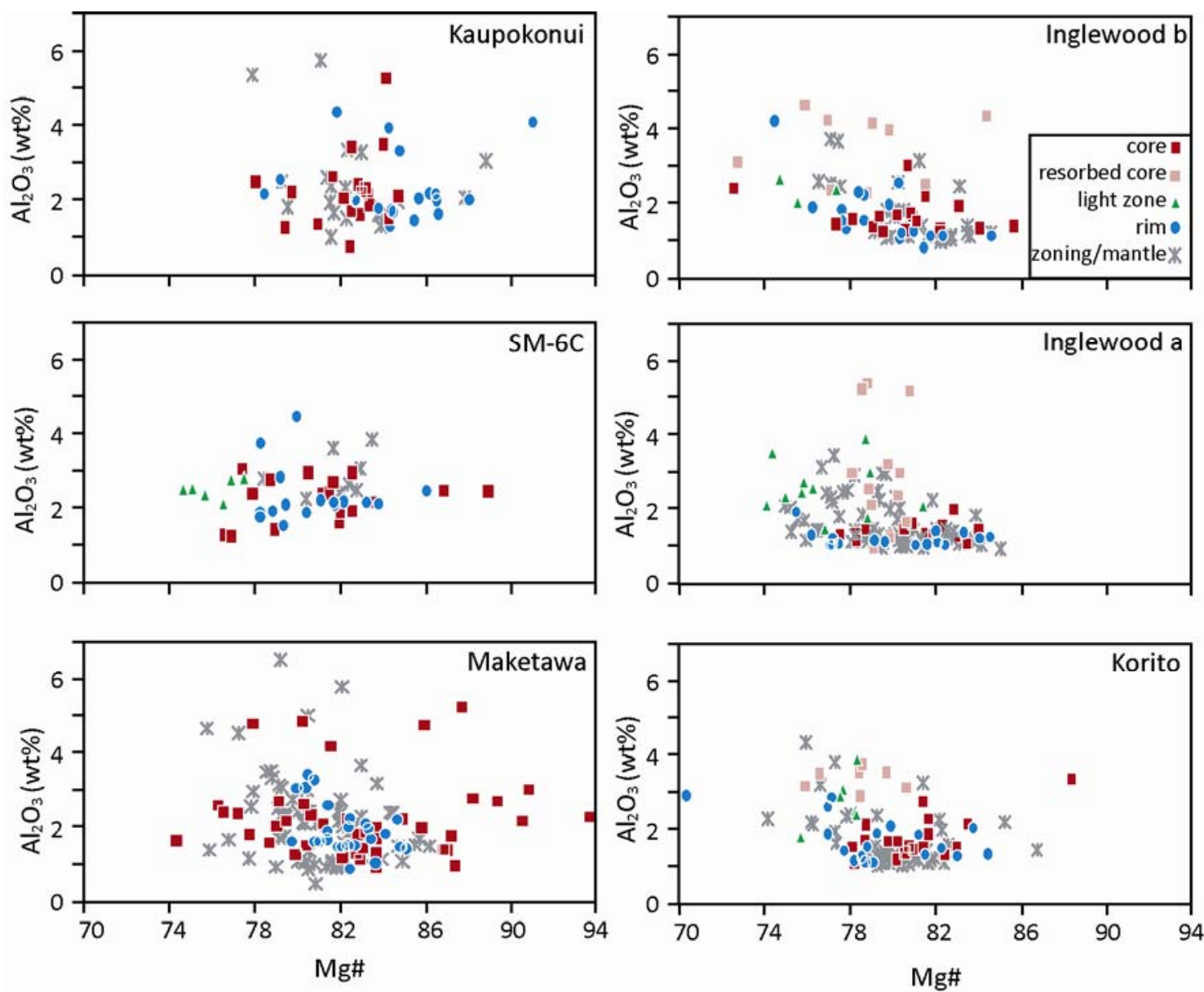

Figure 5.6 Mg\# vs Al2O3 content of clinopyroxene cores, rims and zoning in each of the samples investigated in this study

Cr, V, Sc) and a negative relationship with incompatible trace elements (e.g. Hf, Ce). Therefore this clinopyroxene population may be recording melt evolution. Streck (2008) stated that Mg\# does not necessarily record melt evolution in pyroxene which crystallised from felsic melts, so the observed termination of the Mg\#-trace element correlations may reflect the transition from crystallisation of mafic-intermediate melts to more silicic melts. Where Mg\# $<85$ cores, rims and mantles/zoning can be differentiated on the basis of $\mathrm{Al}_{2} \mathrm{O}_{3}$ for all samples (with the exception of SM-6C), and Mg\# for the younger three samples (Figure 5.6). Variation in

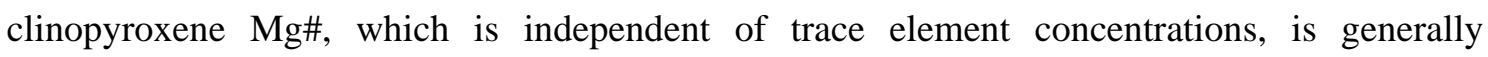
attributed to changes in physical parameters such as temperature and oxygen fugacity (Nakagawa et al., 2002). 

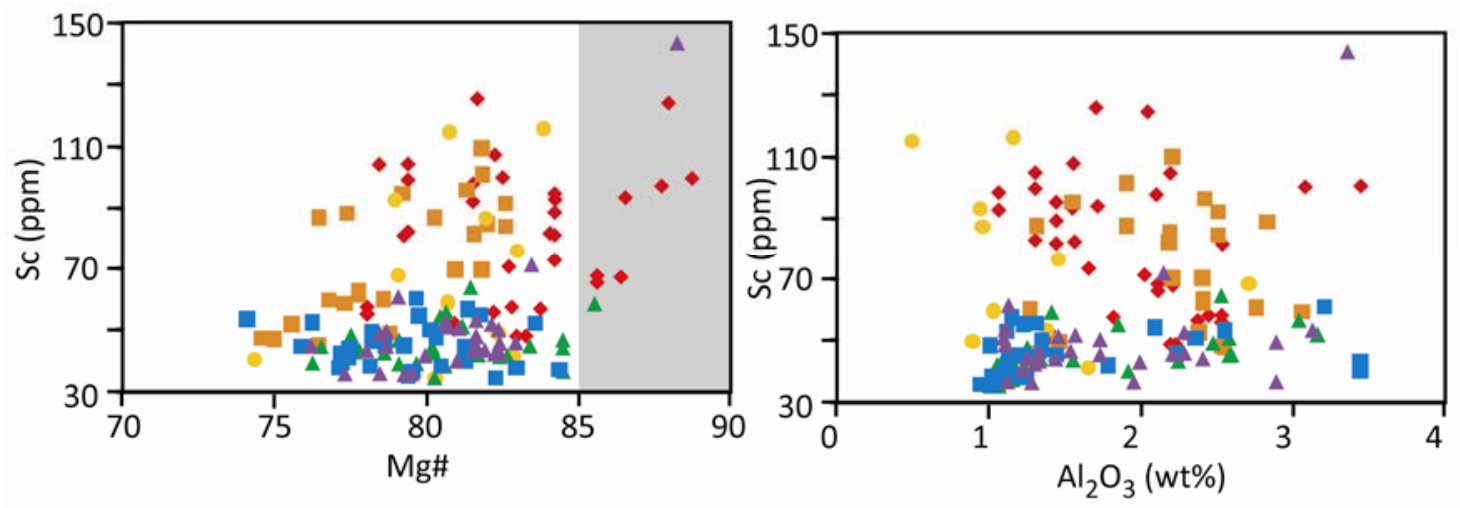

Figure 5.7 Mg\# and $\mathrm{Al}_{2} \mathrm{O}_{3}$ plotted against a representative trace element (Sc) to illustrate the lack of correlation between major element indices and trace element chemistry. The grey shaded area highlights $\mathrm{Mg}>85$ where a positive correlation is observed in a relatively small number of crystals. Symbols relate to samples as in Figure 4.6.

Variations in $\mathrm{Al}$ concentrations within clinopyroxene have also been related to changes in melt composition, pressure and temperature (e.g. Umino \& Horio, 1998; Streck et al., 2005; Turner et al., 2008; Putirka, 2008). Melt composition is an unlikely cause of the observed variation in clinopyroxene composition as $\mathrm{Al}_{2} \mathrm{O}_{3}$ does not correlate with major or trace element compositions (Figure 5.7). Streck et al. (2005) and Turner et al. (2008) attribute high Al/low Mg\# clinopyroxene to crystallisation from a melt which has undergone extensive crystallisation of mafic phases such as olivine and pyroxene, but limited plagioclase crystallisation. However, this too would be reflected in trace element chemistry as this melt is implied to be less evolved due to limited plagioclase crystallisation resulting in a high Sr melt. Also the disequilibrium textures associated with the high-Al zones indicate a sudden change in conditions, implying either different melt or a change in physical parameters.

Al contents in clinopyroxene have been used as a barometer (e.g. Nimis, 1995; 1999; Putirka et al., 1996; Putirka, 2005; 2008). The errors associated with these quantitative models are large ( $\pm 2-5$ kbars), therefore these models are not applied to these samples. However, the general relationship of increasing $\mathrm{Al}$ incorporation into clinopyroxene at greater pressures can potentially be used as a qualitative indicator of pressure (e.g. Simonetti et al., 1996).

Umino \& Horio (1998) also observed variations in $\mathrm{Al}_{2} \mathrm{O}_{3}$ rather than $\mathrm{Mg} \#$ between clinopyroxene populations. The authors attributed this to mixing between a low temperature rhyolitic melt with a higher temperature dacite, where low Al clinopyroxene crystallised from 
the more silicic melt. They also did not observe dissolution of the low-Al core due to nearhomogeneous Mg\# amongst the different clinopyroxene populations.

\section{Melt Chemistry}

To gain further insights into the magmatic conditions as recorded by clinopyroxene, the trace element composition of the equilibrium melt was calculated using partition coefficients from Bacon \& Druitt (1988), Rollinson (1993) and Severs et al. (2009) (Table 5.4). This shows that while the trace element concentrations are variable, the clinopyroxene appear to be related primarily by fractional crystallisation processes in most samples (Figure 5.8). Therefore crystals have formed from a genetically related suite of melts.

\begin{tabular}{|cc|cc|cc|}
\hline \multicolumn{6}{|c|}{ Clinopyroxene } \\
\hline Element & $\mathbf{K}_{\mathbf{D}}$ & Element & $\mathbf{K}_{\mathbf{D}}$ & Element & $\mathbf{K}_{\mathbf{D}}$ \\
$\mathbf{S C}$ & 3.306 & $\mathbf{S r}$ & 0.101 & $\mathbf{G d}$ & 0.907 \\
$\mathbf{T i}$ & 0.412 & $\mathbf{Y}$ & 0.949 & $\mathbf{T b}$ & $1.1^{b}$ \\
$\mathbf{V}$ & 1.532 & $\mathbf{Z r}$ & 0.097 & $\mathbf{D y}$ & 0.926 \\
$\mathbf{C r}$ & $30^{a}$ & $\mathbf{L a}$ & 0.082 & $\mathbf{H o}$ & 1.009 \\
$\mathbf{M n}$ & 2.877 & $\mathbf{C e}$ & $0.25^{b}$ & $\mathbf{E r}$ & $1.33^{b}$ \\
$\mathbf{N i}$ & $6^{b}$ & $\mathbf{N d}$ & 0.38 & $\mathbf{Y b}$ & 0.973 \\
$\mathbf{C u}$ & $0.66^{b}$ & $\mathbf{S m}$ & 0.61 & $\mathbf{L u}$ & $0.665^{b}$ \\
$\mathbf{Z n}$ & $2^{a}$ & $\mathbf{E u}$ & 0.626 & $\mathbf{H f}$ & 0.171 \\
\hline
\end{tabular}

Table 5.4 Clinopyroxene-melt (andesite to dacite) partition coefficients used in this study. Values are from

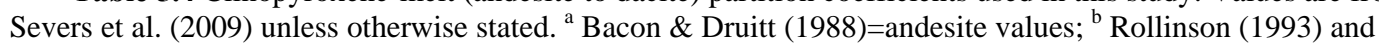
references therein=dacite values.

\subsubsection{Inglewood a, Inglewood $b$ and Korito Processes}

The three older samples are dominated by two clinopyroxene populations. One contains patchy textured cores and oscillatory rims and the other is comprised entirely of oscillatory zoning. Patchy textured cores have resorbed, high-Al clinopyroxene that is replaced by low-Al clinopyroxene. Oscillatory rims are primarily comprised of low Al clinopyroxene which is periodically interrupted by low Al/low Mg\# bands (indicated by a light zone in BSE images). High Al cores may originate from a greater depth and be resorbed by decompression. However, this cannot also explain the light zones which are more likely to result from changes in temperature or oxygen fugacity of the magma, possibly as a result of repeated recharge of the shallow magma chamber. 


\subsubsection{Kaupokonui, SM-6C and Maketawa Processes}

Clinopyroxene in the three younger samples are distinguished primarily on the basis of Mg\#. As the variation in Mg\# is not associated with changes in trace elements, this is likely due to changes in temperature and/or oxygen fugacity (Nakagawa et al., 2002; Turner et al., 2008). Additionally, there is a high- $\mathrm{Al}_{2} \mathrm{O}_{3}$ population, which is assumed to have the same origin as those in the older three samples. The variation of $\mathrm{Mg}$ rather than $\mathrm{Al}$ in these samples may be because they are recording different processes or the same processes in a different way. These younger samples also contain two populations of clinopyroxene crystals, each providing evidence for open system processes such as magma mixing.
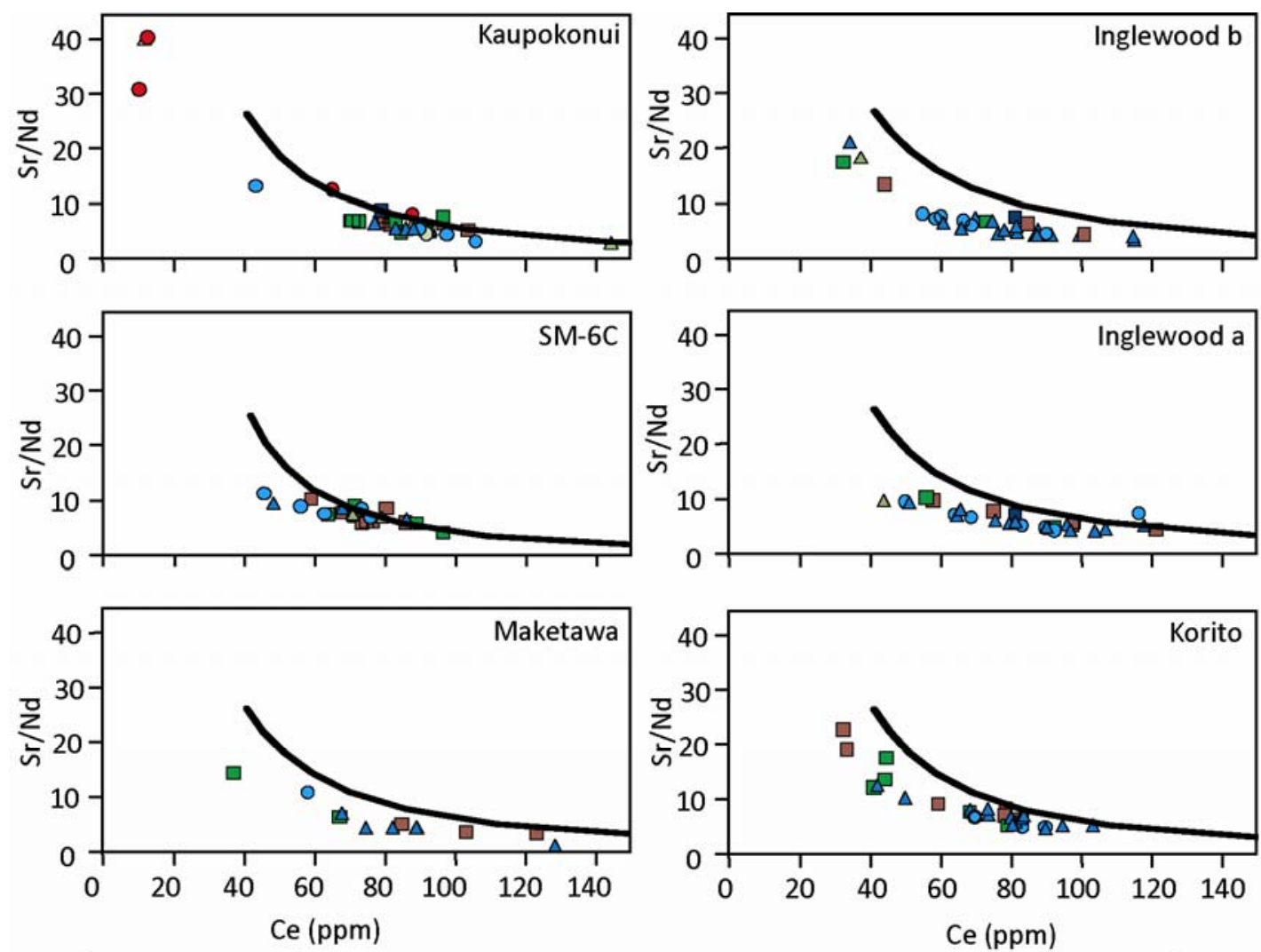

\begin{tabular}{|l}
\hline KEY \\
$\square$ Fe-rich/Al-rich core $\Delta$ Fe-rich/Al-rich zone Oscillatory core $\Delta$ Oscillatory zone $\bigcirc$ Oscillatory rim \\
$\square$ Mg-rich core $\Delta$ Mg-rich zone $\quad$ Mg-rich zone $\quad$ Modelled fractional crystallisation
\end{tabular}

Figure 5.8 Ce vs $\mathrm{Sr} / \mathrm{Nd}$ of the clinopyroxene equilibrium melt. Fractional crystallisation was modelled using the parameters defined in Table 5.3

Some crystals in Kaupokonui and Maketawa contain highly resorbed, high Mg\# cores which appear to be from a more mafic magma. These cores were likely later incorporated into a 
more silicic melt by magma mixing or incorporation of cumulates. Most crystals in these samples have a variable but high-Mg rim, implying there was an increase in the temperature and/or oxygen fugacity of the magma chamber shortly before eruption. However, the influence on individual crystals differed. Some crystals within the Kaupokonui sample have extremely zoned rims, where $\mathrm{Mg \#} \mathrm{>} 85$ and compatible elements such as $\mathrm{Cr}$ and $\mathrm{Ni}$ are enriched, and incompatible elements are depleted. These are interpreted as crystallising from a less evolved melt. The high Mg\# rims and the variability observed within these rims can be explained by a model based on that of Nakagawa et al. (2002), where an invading high temperature melt can displace the host melt and engulf some crystals, resulting in extremely zoned rims. This melt then mixes with the more silicic host melt. The subsequent rim compositions reflect that of the corresponding ratio of the melt components, producing progressively less extreme zonation. As a small proportion of crystals ( 15\%) record the higher compatible element signature, the intruding magma is volumetrically small compared with the host silicic melt and so it is efficiently mixed and the host melt remains silicic. It is after this magma mixing, or during ascent and cooling, that the thin Fe-rich overgrowths form. The low $\mathrm{Cr}(\sim 385 \mathrm{ppm})$ and $\mathrm{Ni}$ ( 130 ppm) content of the extremely zoned rims indicates that the intruding magma had already undergone extensive differentiation and so was probably at least intermediate in composition.

The multiple zoning observed in Maketawa may reflect a similar process whereby a more chemically similar, but hotter, melt was injected into the host. This would produce Mg-rich rims without a strong trace element signature. In sample SM-6C, homogeneous and laminar crystals have a similar Mg\# to the rims of the simple and multiple zoned crystals of this sample. Those crystals with more Fe-rich cores were therefore incorporated into a hotter, possibly more mafic melt which hosted the laminar and homogeneous crystals via mixing or incorporation of cumulate material.

\subsubsection{AMPHIBOLE}

Amphiboles are compositionally complex and record changes in melt composition, pressure, temperature, melt water content $\left(\mathrm{H}_{2} \mathrm{O}_{\text {melt }}\right)$ and oxygen fugacity $\left(\mathrm{fO}_{2}\right)$. 
Thermobarometric models (e.g. Ridolfi et al., 2010) have enabled quantification of physicalchemical conditions in equilibrium, with individual zones resulting in a less ambiguous interpretation of amphibole chemistry. This can enable pathways of magma ascent to be reconstructured.

\subsubsection{Physical Conditions of Amphibole Crystallisation}

The pressure-temperature- $\mathrm{H}_{2} \mathrm{O}_{\text {melt }}-\mathrm{fO}_{2}$ values are consistent with some amphibole crystallisation occurring at depth in a hotter, water-rich magma before ascending through the crust and cooling with time. The highest pressure population of amphiboles indicate crystallisation depths of $\sim 20$ $25 \mathrm{~km}$. Given that the crust in the Taranaki region is 25-35 km thick (Stern \& Davey, 1987; 1990), these high pressure amphibole crystals represent mid- to lower crustal conditions. There is also a dominant low pressure, temperature, $\mathrm{H}_{2} \mathrm{O}_{\text {melt }}$ and $\mathrm{fO}_{2}$ population in most samples, which indicates a shallow magma chamber at $\sim 8-10 \mathrm{~km}$ depth. This is in agreement with 3dimensional tomographic imaging indicating a high- $V p$ low $V p / V s$ structure that extends to at least $10 \mathrm{~km}$ depth (Sherburn et al., 2006). The authors interpreted this as the 'roots' of Mt Taranaki. Amphibole trace element concentrations indicate crystallisation from two different melts, where the less evolved melt corresponds to the higher pressure amphibole (Figure 5.9). However, other high pressure amphiboles have trace element concentrations similar to those that crystallised at cooler, shallower conditions. This may indicate two crystallising conditions from distinct melts that mix in the mid-crust, or alternatively, that an evolved melt ascended and both crystallised amphibole and entrained cumulates. It is difficult to distinguish between these two options on the basis of trace element data due to the limited analyses of amphibole that crystallised at higher pressures. The exception to this is Kaupokonui sample where there is a clear trend between the high pressure, less evolved trace element amphiboles (Population 1) and the more evolved, low pressure amphiboles (Population 2). In some samples, most notably Inglewood b, textural evidence supports a cumulate origin. Thornber et al. (2008) proposed that those amphibole crystals with patchy-resorbed cores and subhedral overgrowths reflect xenocryst assimilation at depth. The temperatures calculated from the low pressure population are in agreement with those calculated from other mineral phases, and this likely represents 

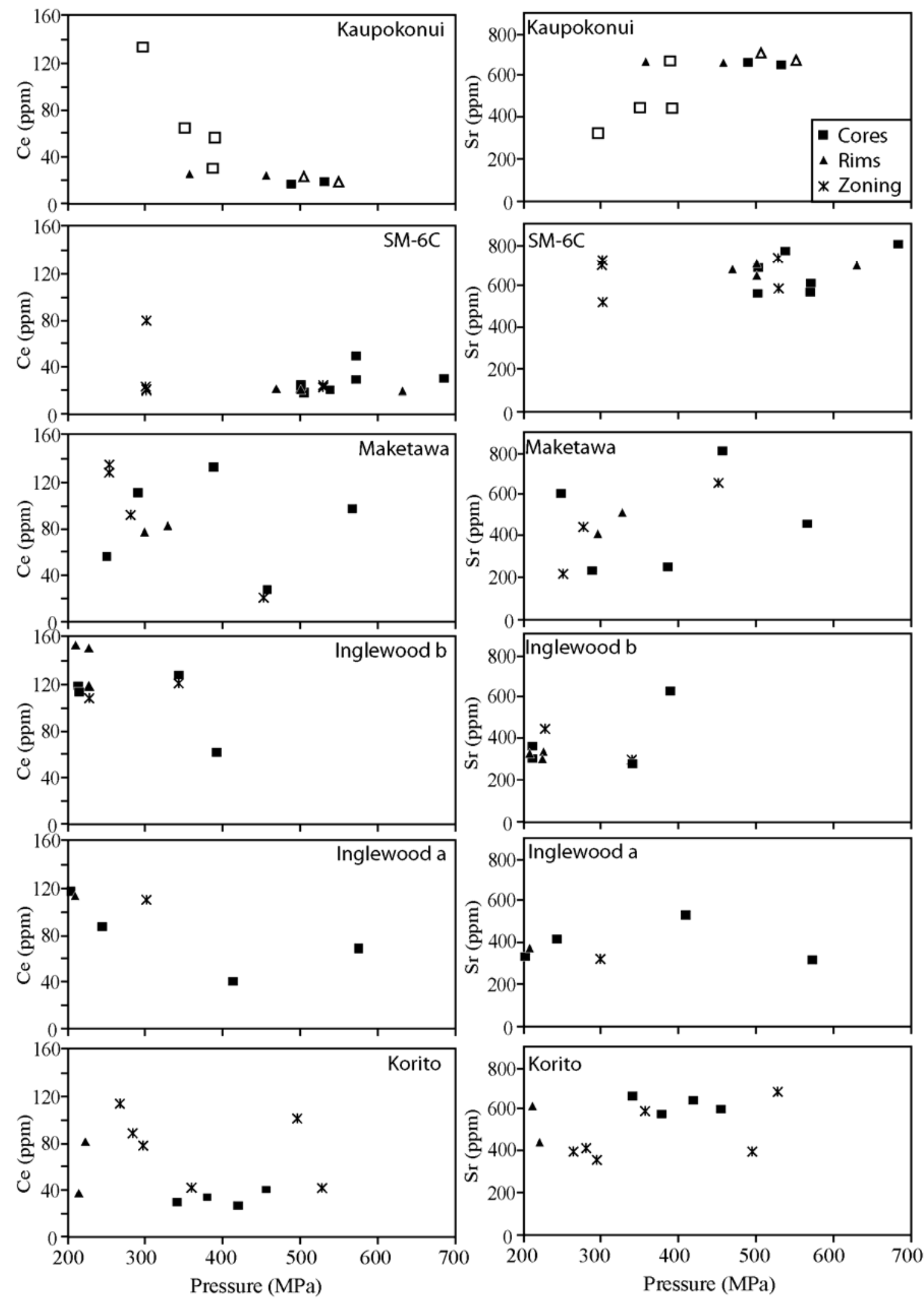

Figure 5.9 Graphs of amphibole crystallisation pressure versus Ce and Sr concentrations of the melt in equilibrium with the amphibole. Amphibole analyses are classified as cores, rims and other zoning for each sample except Kaupokonui, where there are two populations of amphibole (filled and open symbols). Equilibrium melts were calculated using partition coefficients from the GERM database as given in Table 5.5. 
crystallisation in a shallow magma chamber from which the eruption originated. Major and trace element data are consistent with most amphibole rims crystallising in this shallow magma chamber and some crystals growing entirely from this melt (phenocrysts). Therefore the majority of amphibole crystals either grew from, or stalled at, this shallow magma chamber. The exception to this is a small population of crystals which only record lower crustal conditions.

Most crystals exhibit sharp changes between zones, indicating that the amphibole experienced large scale changes in parameters consistent with periods of rapid ascent between each zone. Most amphibole crystals from this study display simple or multiple zoning, so melts likely stalled once or twice in the mid- to upper crust. The near continuous range of magmatic conditions apparent in some samples is most likely a function of multiple magma batches which stalled at various levels within the crust before finally intruding into the shallow magma chamber (Figure 5.10).

Amphibole begins to breakdown and be replaced by anhydrous minerals such as pyroxene, plagioclase and Fe-Ti oxides during magma ascent, forming reaction rims which are a common feature of amphibole in many arc magmas (Rutherford \& Devine, 1988; Rutherford \& Hill, 1993). Amphibole is unstable at low pressures due to the decreasing $\mathrm{H}_{2} \mathrm{O}_{\text {melt }}$ and at Mt Taranaki this upper limit of amphibole stability is at $\sim 5.2 \mathrm{~km}$ depth (Platz et al., 2007a). The amphibole crystals from this study do not have reaction rims, which provides important constraints on the minimum magma ascent rate. Amphibole begins to break down after $\sim 6$ days outside of the stability field (Rutherford \& Hill, 1993; Rutherford \& Devine, 2003; Browne \& Gardner, 2006). Therefore, the ascent rate for magmas stored in the shallow magma chamber is $>1.3 \mathrm{~km} / \mathrm{day}$. Those samples which do not show evidence for accumulation in a shallow magma chamber may have ascent rates twice this. The shallow magma chamber values are in agreement with the ascent rates of fresh amphibole from other arc volcanoes such as Mt St Helens (>1.6 km/day; Rutherford \& Hill, 1993; >1.2 km/day; Thornber et al., 2008) and Soufriere Hills ( >1.6 km/day; Rutherford \& Devine, 2003). 

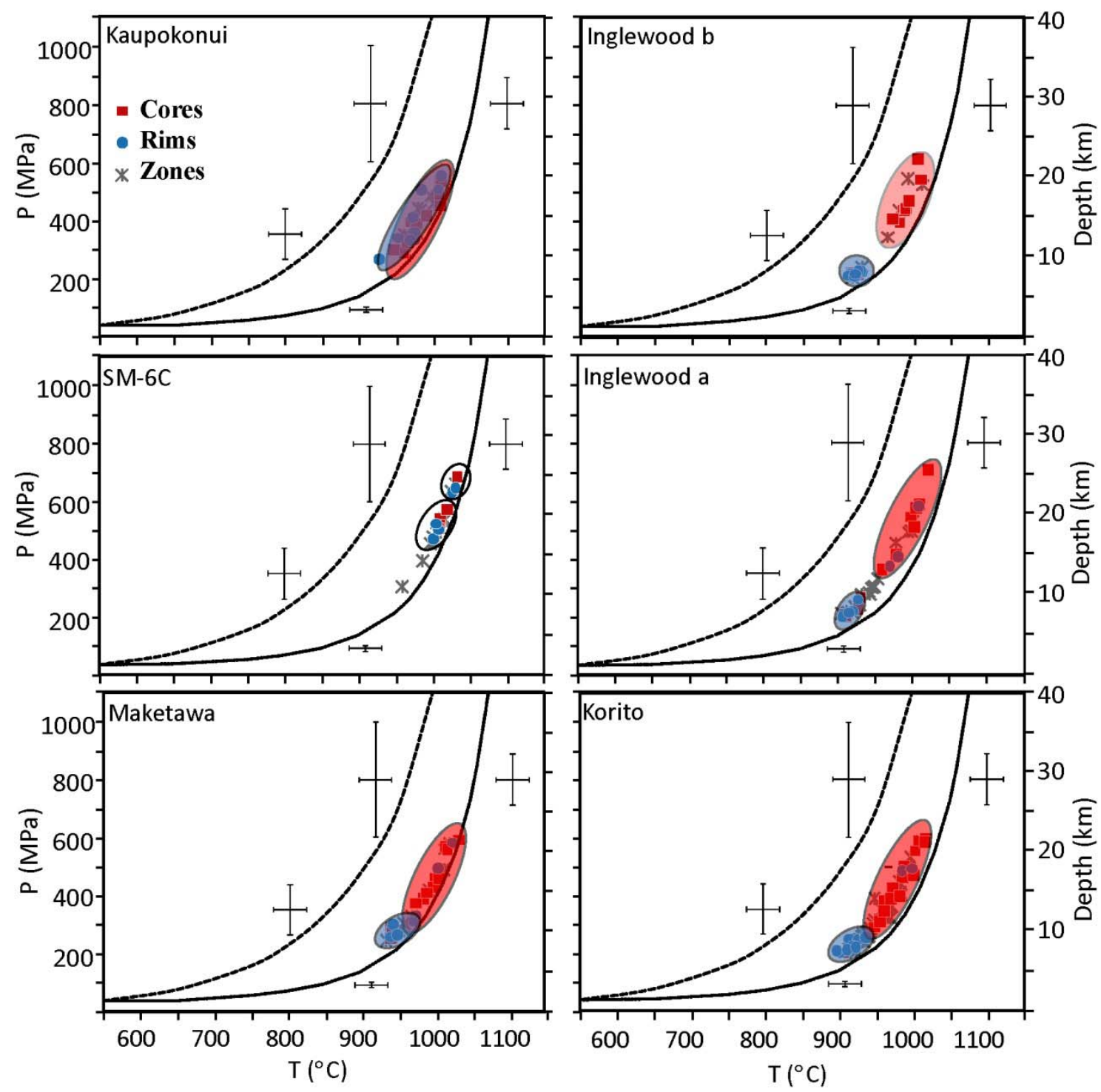

Figure 5.10 Amphibole thermobarometry results. The key populations are identified where red and blue fields represent populations that are dominated by cores and rims respectively. SM-6Ccontains two populations which appear to be independent of cores/rims.

A distinct amphibole population within the Kaupokonui sample records higher pressure, temperature, $\mathrm{H}_{2} \mathrm{O}_{\text {melt }}$ and $\mathrm{fO}_{2}$ within the crystal rims when compared with the cores. These rims record the highest values for this sample, overlapping with cores of other crystal populations. The required increase in pressure during crystallisation of these crystals is 100-200 MPa ( 3-7 $\mathrm{km})$. As this is limited to, and consistent within, a specific amphibole population it is probably not analytical error, however, it is difficult to reconcile with geological processes. Rutherford \& Devine (2008) explained cyclically zoned amphibole with a Fe- and Al-rich central zone by convection within the storage chamber. As crystallisation does not occur in the sinking magma, there is a sharp chemical transition between the cores and rims. However, the cores from the 

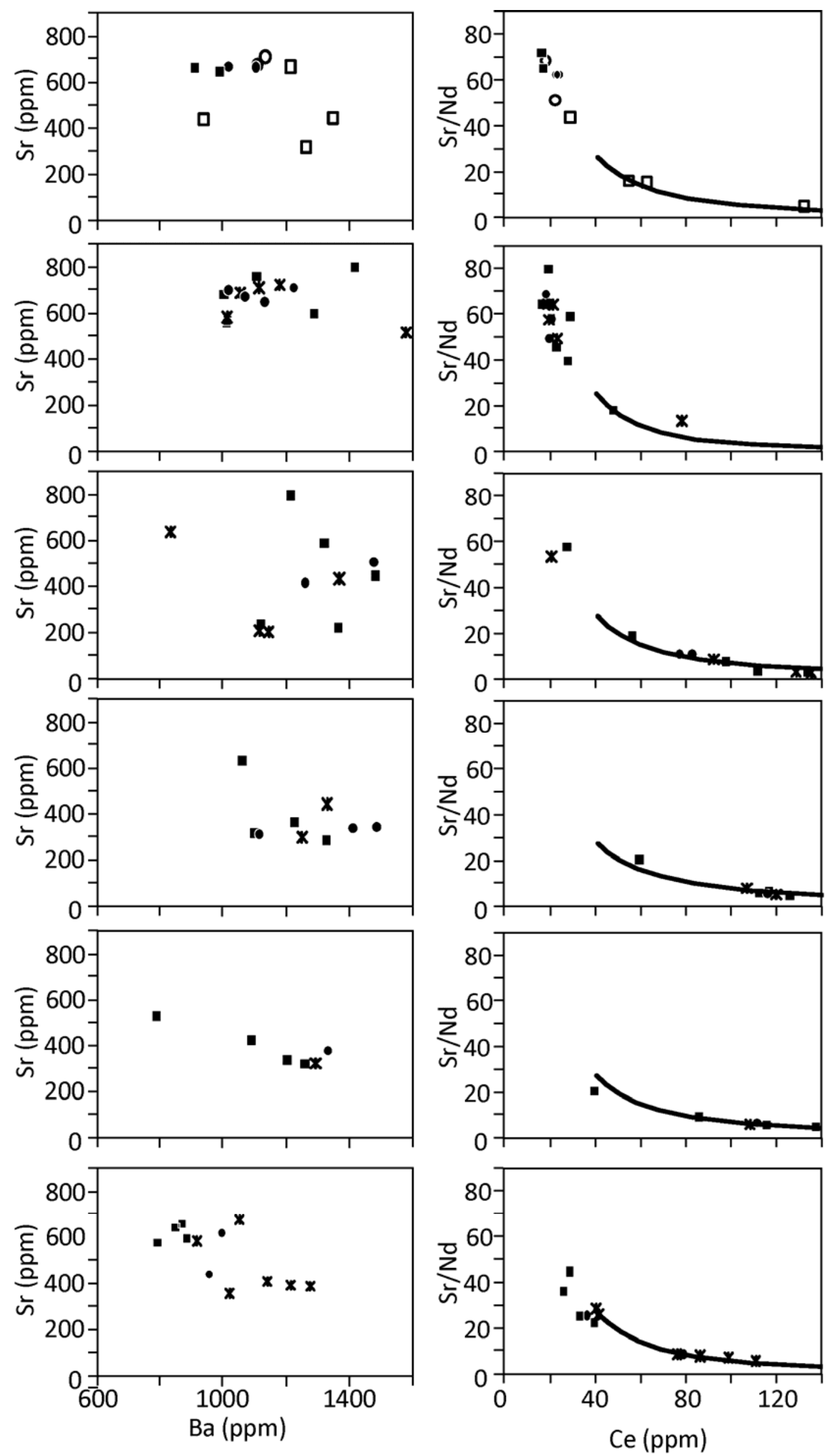
Figure 5.11 Selected trace elements concentrations of amphibole equilibrium melt. Fractional crystallisation was modelled using the parameters in Table 5.3

reversely zoned amphibole population from Taranaki contain enriched trace element chemistries (2 to 9 times higher REE concentrations). This requires the cores and rims to have grown from different melts at different conditions. Mixing with a hotter, more mafic magma can account for the increased temperature and more primitive trace element concentrations of the rims, but not the recorded increase in pressure. The same is true if the cores were xenocrysts incorporated into the host magma. There may be a combination of processes operating where intrusion of a hotter, more mafic magma causes convection or the convecting magma incorporates xenocrysts.

There are two populations of amphibole present in sample SM-6C which differ primarily in pressure, $\mathrm{H}_{2} \mathrm{O}_{\text {melt }}$ and $\mathrm{fO}_{2}$ and only slightly in temperature (Figure 5.10). These samples overlap the high pressure, less evolved end members of the other samples, but do not display the trend to lower values present in all other samples. Amphibole is a minor phase in this sample $(<5 \%)$. This may be related to the lack of amphibole crystallisation at shallower levels (where the dominant amphibole populations of other samples crystallised) due to rapid ascent from the 15 km depth recorded by rim compositions or, alternatively, due to magma stalling at conditions outside of the amphibole stability field.

Browne \& Gardner (2006) found that amphibole dissolution does not necessarily result in the formation of reaction rims, but can round crystal edges and reduce the modal abundance of amphibole. This typically occurs at $\sim 75-90 \mathrm{MPa}$, which is the pressure range where amphibole dissolution is greatest (Browne \& Gardner, 2006). The subhedral to euhedral nature of amphibole crystals from this sample in conjunction with the low modal abundance suggests that magma stalled at $\sim 2-3 \mathrm{~km}$ depth during ascent. Thornber et al. (2008) came to a similar conclusion for a small population of resorbed amphibole crystals from the 2004-6 Mt St Helens dacite. 


\subsubsection{Melt Differentiation}

Trace element compositions of the melt in equilibrium with various amphibole zones were calculated using the amphibole-dacite partition coefficients from the GERM database (Table 5.5). The Sr content of the back calculated melts were used to estimate the $\mathrm{SiO}_{2}$ content of amphibole equilibrium melts using the relationship between $\mathrm{SiO}_{2}$ and $\mathrm{Sr}$ in the measured matrix glass. The amphibole cores that record crystallisation depths of $\sim 25 \mathrm{~km}$ crystallised from melts with 530-800 ppm Sr for Population 1 and 250-650 ppm for Population 2, which are inferred to have $\mathrm{SiO}_{2}$ contents of $\sim 52-62 \mathrm{wt} \%$ and $57-70 \mathrm{wt} \% \mathrm{SiO}_{2}$ (basaltic andesite to rhyolite). Early melt differentiation is also supported by the low compatible trace element concentrations recorded by other mineral phases, most notably Cr levels below detection, and low V and Sc in clinopyroxene. This is in agreement with models where melt differentiation occured in the lower crust (Price et al., 2005; Annen et al., 2006). The Price et al. (2005) model states that dacitic to rhyolitic compositions are generated in the lower crust, whereas Annen et al. (2006) propose that a range of compositions from basaltic andesite to rhyolite can be generated depending on both how evolved the deep crustal hot zone is and the depth within the hot zone.

\begin{tabular}{|c|c|c|c|c|c|c|c|}
\hline \multicolumn{8}{|c|}{ Amphibole } \\
\hline Element & $K_{D}$ & Element & $K_{D}$ & Element & $K_{D}$ & Element & $K_{D}$ \\
\hline $\mathbf{L i}$ & 0.18 & $\mathrm{Cu}$ & 1.2 & Ba & 0.28 & Tb & 3.08 \\
\hline Sc & 35 & $\mathbf{Z n}$ & 10.7 & La & 0.26 & Er & 2.34 \\
\hline $\mathbf{T i}$ & 3.66 & $\mathbf{R b}$ & 0.18 & $\mathrm{Ce}$ & 0.63 & Yb & 1.31 \\
\hline $\mathbf{v}$ & 4.92 & Sr & 0.49 & Nd & 1.24 & Lu & 1.75 \\
\hline $\mathrm{Cr}$ & 21 & $\mathbf{Y}$ & 2.46 & Sm & 2.38 & $\mathbf{P b}$ & 0.53 \\
\hline Mn & 15.7 & $\mathbf{Z r}$ & 0.34 & Eu & 5.9 & & \\
\hline $\mathbf{N i}$ & 9.3 & Nb & 2.5 & Gd & 2 & & \\
\hline
\end{tabular}

Table 5.5 Amphibole-melt (andesite-dacite) partition coefficients used in this study. All values are from the GERM database (http://earthref.org/GERM/)

\subsubsection{Amphibole Model}

The amphibole data from most samples are consistent with a model where amphibole crystallises in the lower crust at depths of $\sim 20 \mathrm{~km}$ from a differentiated hydrous, oxidised melt. The amphibole and the associated melt migrates through the crust possibly through a series of 
sills and dykes similar to that described by Price et al. (1997) and Gamble et al. (1999). As the melt moves through the crust, cumulates may be incorporated and amphibole continues to crystallise. This melt stalls at a depth of $\sim 8 \mathrm{~km}$ for the older three samples and $\sim 10 \mathrm{~km}$ for Maketawa and Kaupokonui samples, where a large proportion of amphibole crystallises. Many of the deeper-sourced amphibole crystals grow a rim in this shallow magma chamber. However, a small population do not, suggesting these spent a very limited time at these conditions before eruption. Magma ascent from the storage zone to the surface was rapid, as indicated by a lack of break down textures in amphibole crystals.

Sample SM-6C records a different history where amphibole crystallises at $\sim 25 \mathrm{~km}$ depth before migrating to a depth of $\sim 15-20 \mathrm{~km}$ in association with an increase in melt $\mathrm{fO}_{2}$. Melt ascent from this depth was rapid, stalling briefly at $~ 2-3 \mathrm{~km}$ depth before eruption.

\subsubsection{FE-TI OXIDES}

The chemistry of Fe-Ti oxides reflect temperature, oxygen fugacity and melt composition of the magmatic system immediately prior to eruption because they equilibrate rapidly (on the order of a few years at $900^{\circ}$ C; Freer \& Hauptman, 1978; Frost \& Lindsley, 1991; Devine et al., 2003; Tomiya \& Takahashi, 2005). This is reflected in the restricted chemistry of oxides within each sample. The chemical variations between samples can be used to further investigate the differences in the pre-eruptive magmatic conditions among samples.

Four compositionally distinct groups of Fe-Ti oxides have been identified and are differentiated primarily by $\mathrm{Ti}$ content ( $\mathrm{X}_{\text {Usp }}^{\prime}$ ), $\mathrm{Al}_{2} \mathrm{O}_{3}, \mathrm{MnO}$ and $\mathrm{MgO}$ (Figure 5.12). The Ti content of magnetite records changes in temperature or oxygen fugacity and has been widely used to infer magma mixing and reheating events (e.g. Nakamura, 1995; Devine et al., 2003; Chertkoff \& Gardner, 2004; Turner et al., 2008). The $\mathrm{Al}_{2} \mathrm{O}_{3}$ content of magnetite reflects that of the melt and therefore reflects melt evolution (Chertkoff \& Gardner, 2004; Tomiya \& Takahashi, 2005) and the $\mathrm{Mg} / \mathrm{Mn}$ ratio is indicative of magmatic temperature (Bacon \& Hirschmann, 1988). There is a strong relationship between $\mathrm{Al}_{2} \mathrm{O}_{3}$ and $\mathrm{Mg} / \mathrm{Mn}$ indicating that these parameters are reflecting melt evolution where high $\mathrm{Al}_{2} \mathrm{O}_{3}$ and $\mathrm{Mg} / \mathrm{Mn}$ oxides crystallised 
from a hotter melt that has experienced less plagioclase crystallisation. This is consistent with the glass analyses and thermometry results for these samples as Inglewood a and b and Korito are the most evolved, lowest temperature samples and Kaupokonui, SM-6C and Maketawa are the less evolved and hottest magmas. The $\mathrm{X}_{\text {Usp }}$ content does not correspond with the relative magmatic temperatures calculated or the $\mathrm{Mg} / \mathrm{Mn}$ ratio and is therefore most likely recording changes in $\mathrm{fO}_{2}$.
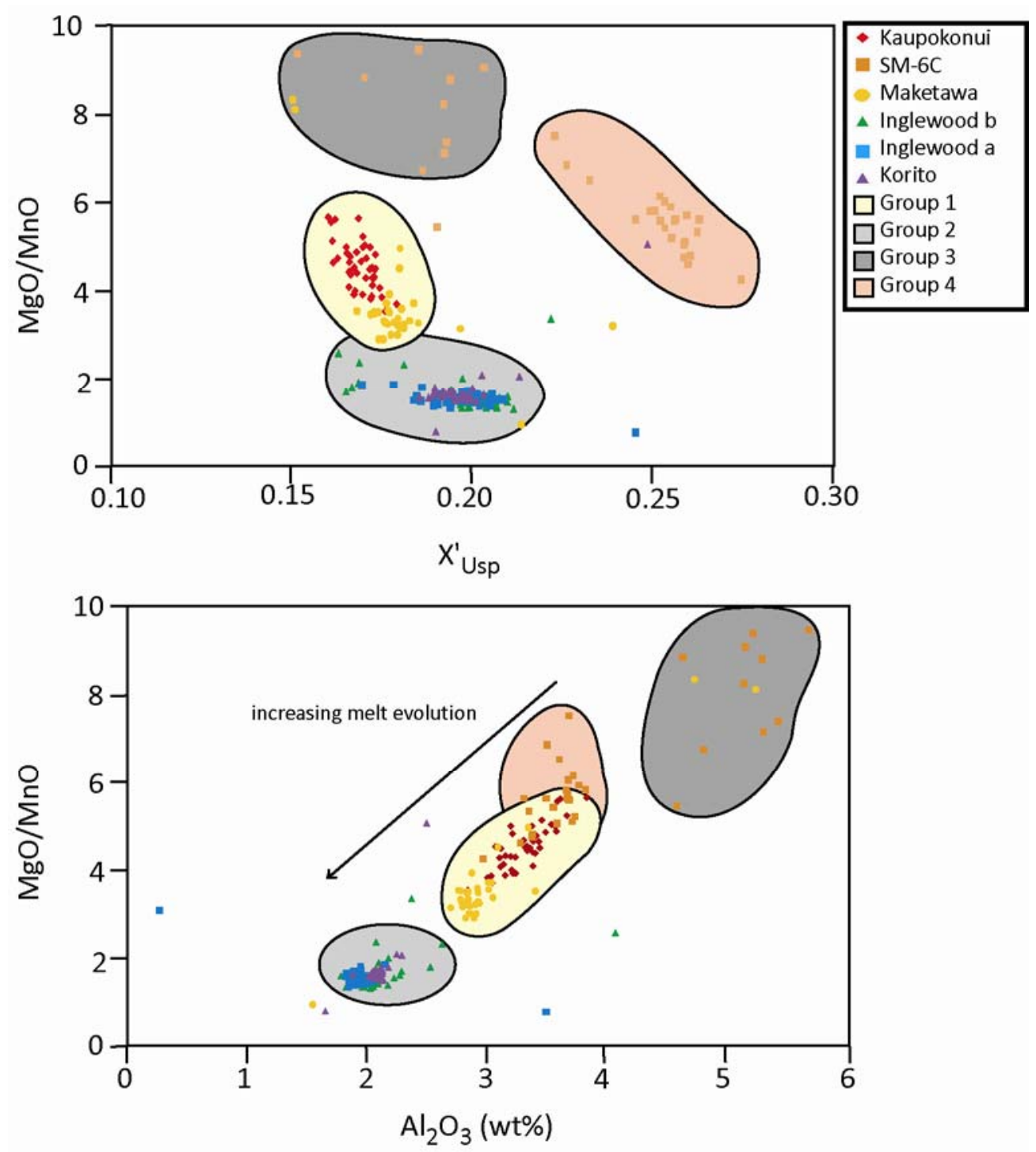

Figure 5.12 Selected major element chemistry of Fe-Ti oxides. 


\subsubsection{SM-6C}

SM-6C has two populations of Fe-Ti oxides, recording two different magmatic conditions and that have crystallised from two different melts. Other studies (e.g. Nakamura, 1995; Venezky \& Rutherford, 1999; Devine et al., 2003; Turner et al., 2008) have used the presence of two oxide populations to infer that magma mixing must have occurred shortly before eruption. However, most of the oxides which record the least evolved magmatic compositions are amphibole hosted and thus have been isolated from the new melt conditions. The few groundmass oxides which also fall into this population are broken up so these may have formed part of a cumulate which was later disaggregated. Therefore the presence of these two populations cannot constrain the timescales of any mixing event, but does demonstrate that incorporation of xenoliths or antecrystic material occurred.

Amphibole oxybarometry results show two populations of amphibole crystals within SM6C on the basis of $\mathrm{fO}_{2}$. Qualitatively, groundmass oxides would relate to the higher pressure amphibole population (the groundmass population and the high pressure population have the lower $\mathrm{fO}_{2}$ of the two groups). This may mean that lower pressure amphibole population from SM-6C are cumulates or xenoliths which were incorporated into the host magma during ascent.

\subsubsection{RELATIONSHIP BETWEEN MINERAL PHASES}

There are a number of common textures within the dominant mineral assemblage that are most likely formed by the same set of processes (e.g. Humphreys et al., 2006). Most notably plagioclase and clinopyroxene exhibit similar textural and chemical features that indicate a similar history. However, various mineral phases can respond differently to magmatic processes. The interpretations of mineral textures in this study are strongly influenced by the nature of BSE imaging as this was the basis of mineral characterisation. Zoning highlighted by BSE imaging for plagioclase and clinopyroxene minerals are those chemical variations which are particularly sensitive to magmatic conditions (anorthite content and Mg\#). Zoning in amphibole also primarily reflects variations in Mg\# which in turn is most strongly controlled by oxygen fugacity (Ridolfi et al., 2010). 


\subsubsection{Crystal cores}

Trace element data show that those plagioclase cores which are high in anorthite and/or patchy did not form in conjunction with high pressure amphibole (Figure 5.13). This is consistent with suppression of plagioclase crystallisation at high $\mathrm{H}_{2} \mathrm{O}_{\text {melt }}$ (Gaetani et al., 1993) such as those recorded by the high pressure amphibole cores. The high $\mathrm{Al}$ clinopyroxene cores may have formed with either the high anorthite and sieved plagioclase cores or the high pressure amphibole cores. The clinopyroxene major element data and textures are consistent with both crystallisation at high pressure with amphibole, or a less evolved and/or hotter melt with the plagioclase cores. Distinguishing between these is difficult due to the limited trace element analyses of the high $\mathrm{Al}$ cores and the ambiguous interpretation of clinopyroxene major element data. As plagioclase and clinopyroxene share many other common textural and chemical features, it is considered more likely that these have a similar origin.

\subsubsection{Zoning and rims}

Magma mixing where a hotter and/or less evolved melt is injected into the shallow magma body will be recorded differently by individual crystals depending on the proximity to the site of the intrusion (Murphy et al., 2000). Those with the strongest disequilibrium features such as sieved zones in plagioclase and distinctive, strongly resorbed zones in clinopyroxene crystals, were formed when these crystals were engulfed by a hotter magma (Nakagawa et al., 2002; Browne et al., 2006). Other crystals primarily recorded heating of the system and are most likely represented by the multiple zoning within clinopyroxene and the larger scale oscillatory zoning in plagioclase ( $\sim 50 \mathrm{~m}, 15-20 \mathrm{~mol} \%$ change in anorthite). These textures are evidence for disequilibrium conditions, but do not record large changes in melt chemistry. Other crystals appear to be unaffected, and the overall result is a wide range of textures within each sample.

Plagioclase and clinopyroxene crystals as well as some amphibole rims are comprised of oscillatory zoning. These textures are probably formed by a combination of processes including kinetic effects, convection and recharge which results in slightly different morphologies and scales of oscillatory zoning. 

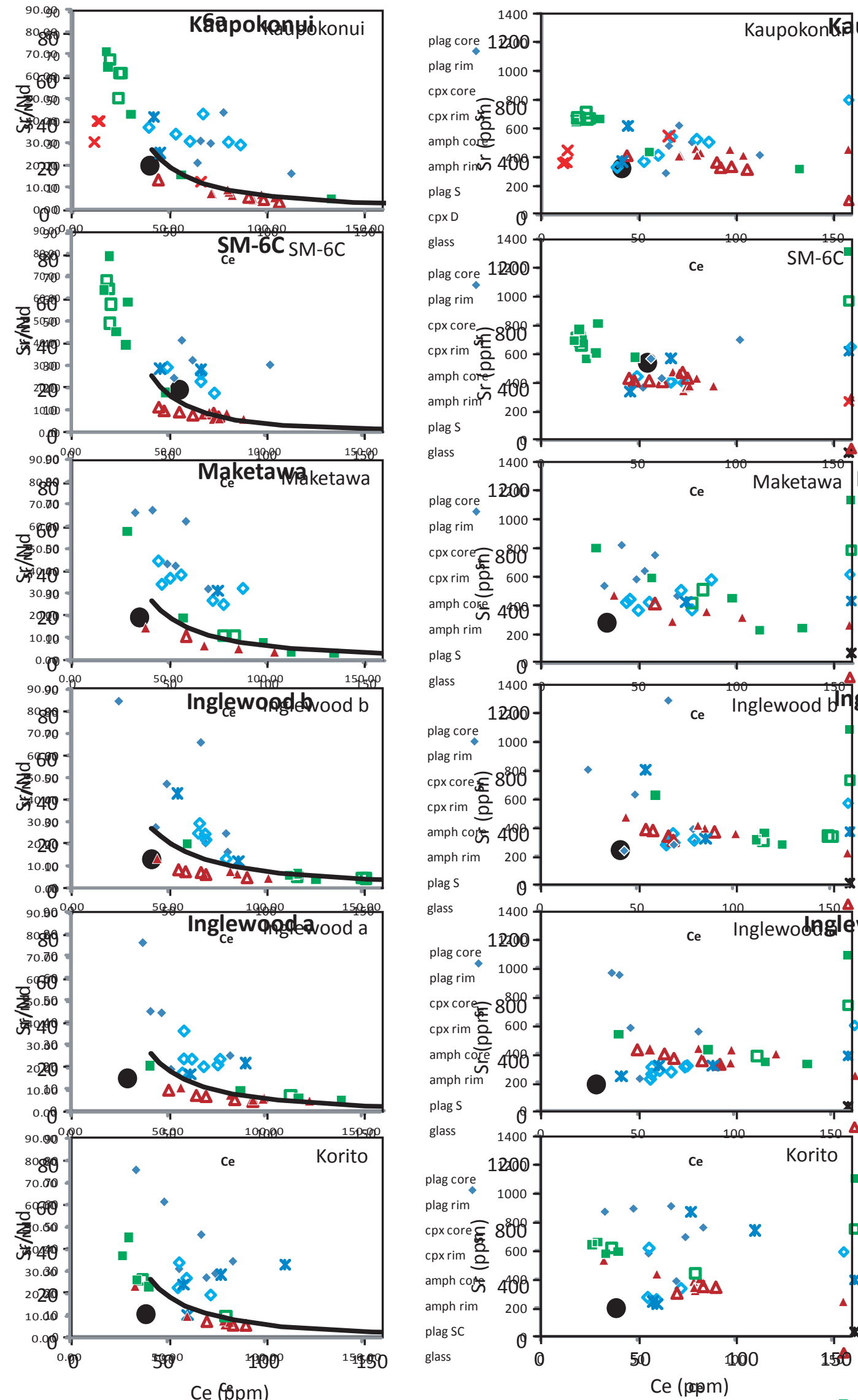

- plagioclase $\boldsymbol{\Delta}$ clinopyroxene amphibole $\boldsymbol{X}$ sieved-patchy plagioclase $\boldsymbol{X}$ extremely zoned

matrix glass fractional crystallisation model Mg-rich cpx rims 
Figure 5.13 Trace element concentrations of melt in equilibrium with the plagioclase, clinopyroxene and amphibole. Ce vs $\mathrm{Sr} / \mathrm{Nd}$ is used as an index of fractional crystallisation and the composition of the equilibrium melts is compared with the modelled evolution of the melt as driven by fractionation of plagioclase, clinopyroxene and amphibole using the parameters from Table 5.3. Ce vs $\mathrm{Sr}$ is also shown as Nd is present in low concentrations in plagioclase (1-4 ppm) so the consistent offset apparent in the Ce vs $\mathrm{Sr} / \mathrm{Nd}$ of the plagioclase data is most likely related to the low accuracy of the Nd data which is then amplified by the affect of modelling melt composition values using partition coefficients.

Amphibole crystallisation primarily reflects the evolution of the host melt as it ascends the crust because the trace element compositions of both the high and low amphibole population follows a fractional crystallisation trend (Figure 5.13). Plagioclase and clinopyroxene oscillatory zoning coincide with this fractional crystallisation trend marked by the low pressure amphibole. This trend is particularly dominant in the older three samples. The younger three samples display more variability within the trace element chemistry (e.g. Sr values for this 'equilibrium assemblage' vary by up to $400 \mathrm{ppm}$ at a fixed Ce concentration). This may relate to a stronger mixing signature in these younger samples shortly before eruption that is apparent in the mineral textures. 


\begin{tabular}{|c|c|c|c|}
\hline & Mineral Texture & Observation & Interpretation \\
\hline $\begin{array}{l}\text { ஸे } \\
\frac{0}{0} \\
\frac{0}{0} \\
\frac{0}{2}\end{array}$ & & $\begin{array}{l}\text { Oscillatory zoning } \\
\text { Calcic and sieved cores } \\
\text { Sieved zone } \\
\text { Dissolved crystals }\end{array}$ & $\begin{array}{l}\text { Crystallisation in a shallow magma } \\
\text { chamber } \\
\text { Crystallisation from a hotter more mafic } \\
\text { magma } \\
\text { Engulfed by hotter and/or mafic magma } \\
\text { which is then mixed into the host } \\
\text { Xenoliths or crystals from a much more } \\
\text { mafic magma }\end{array}$ \\
\hline 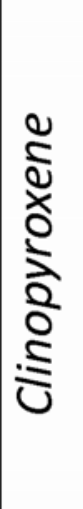 & & $\begin{array}{l}\text { Oscillatory zoning } \\
\text { Multiple zoning } \\
\text { Resorbed zone } \\
\text { Patchy core } \\
\text { Extreme Mg-rich rim }\end{array}$ & $\begin{array}{l}\text { Crystallisation in a shallow magma } \\
\text { chamber } \\
\text { Records perturbations to a shallow } \\
\text { magma chamber e.g. heating } \\
\text { Heated, possibly by interaction with a } \\
\text { hotter magma } \\
\text { Crystallisation at depth or in a hotter } \\
\text { and/or mafic magma } \\
\text { Engulfed by an andesitic magma which } \\
\text { is then mixed into the dacitic host }\end{array}$ \\
\hline 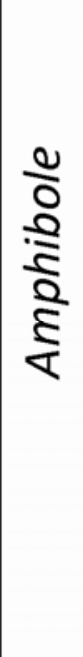 & & $\begin{array}{l}\text { Unzoned } \\
\text { Simple zoning } \\
\text { Oscillatory rim } \\
\text { Patchy-resorbed core } \\
\text { Multiple zoning }\end{array}$ & $\begin{array}{l}\text { Equilibrium crystallised in a shallow } \\
\text { magma chamber from the host melt } \\
\text { Cores crystallise at depth, rims } \\
\text { crystallised in shallow storage chamber } \\
\text { Cores crystallise at depth, rims } \\
\text { crystallised in shallow storage chamber, } \\
\text { probably for a longer period of time } \\
\text { than simple zoning } \\
\text { Cumulate origin? } \\
\text { Records multiple periods of magma } \\
\text { stalling during ascent of the crust }\end{array}$ \\
\hline
\end{tabular}

Figure 5.14 Summary of the mineral textures observed in the Holocene Taranaki eruptives and the associated interpretation. 


\subsection{TEMPORAL VARIABILITY}

The long term temporal variability at Mt Taranaki shows that these eruptives are becoming more potassic with time (Price et al., 1999). Over shorter time periods (100's to 1000's of years), the degree of variability is much greater, a trend that has been noted at other andesitic volcanoes such as Mt Ruapehu (Gamble et al., 1999), Tongariro (Hobden et al., 1999) and Tatara San Pedro (Dungan et al., 2001). Long term geochemical variability is controlled by broad scale processes such as variations in the mantle source, slab flux and subducted sediment as well as crustal processes related to the evolution of the magmatic system including crustal assimilation and fractional crystallisation (Graham \& Hackett, 1987; Stewart et al., 1996). In contrast, short term variability is related to the complexity of andesitic plumbing systems and is controlled by magma system processes such as magma recharge, mixing and mingling as well as which parts of the system are tapped (Gamble et al., 1999; Stewart 2010).

The six samples investigated here span a time frame from 4000 years to 2000 years ago. This is not a complete record of the volcanic history during this period, but represents the larger sub-plinian eruptions. The geochemistry results indicate that Taranaki eruptives over this time period became less silicic with time. It has been emphasised in the discussion thus far that the samples investigated fall into three populations on the basis of petrology and chemistry: 1) The older three samples, Inglewood a and b and Korito; 2) Maketawa and Kaupokonui; and 3) SM6C. The short-term variations in petrology and chemistry of these eruptions may in part be related to complexities in the sub-volcanic system.

The older three samples have the most evolved glass $\left(\mathrm{SiO}_{2}=70-74 \mathrm{wt} \%\right)$, and are the lowest temperature (850-900 $\mathrm{C}$ ) and largest eruptive units in the suite. These samples are almost indistinguishable on the basis of petrology and chemistry (except Group 1 amphibole in Korito) (Figure 5.15). Amphibole thermobarometry data indicate that each of these magmas ascended through the crust in a similar way, stalling and crystallising from $\sim 20 \mathrm{~km}$ depth to the shallow storage system at $\sim 6 \mathrm{~km}$ depth. 

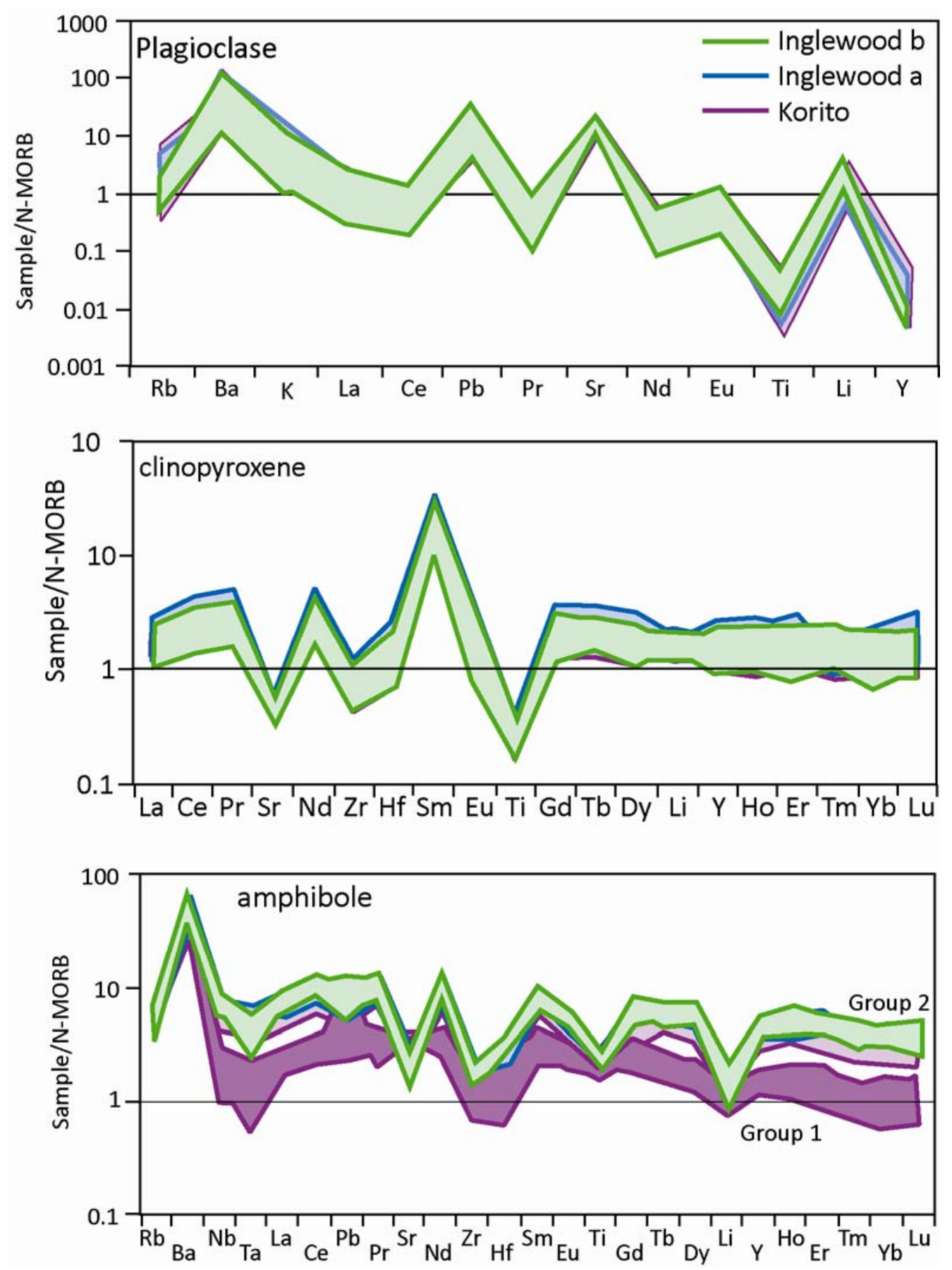

Figure 5.15 Multi-element diagrams of mineral trace element analyses for samples Inglewood a and b and Korito. The trace element chemistry for each mineral phase is very similar between these samples with the exception of Group 1 amphibole in Korito.

In contrast, the Maketawa and Kaupokonui are hotter (900-950 $\mathrm{C})$, less evolved samples with dacitic glass compositions $\left(\mathrm{SiO}_{2}=66-69 \mathrm{wt} \%\right)$. Trace element chemistry of both glass and mineral phases indicates that these formed from similar magmas. Thermobarometry modelling also implicates a similar history of ascent through the crust, with crystallisation occurring continuously from $\sim 20 \mathrm{~km}$ to $\sim 8 \mathrm{~km}$. 
SM-6C is consistently identified as a distinctly different sample within this suite. SM-6C is the least evolved sample as indicated by major element glass chemistry $\left(\mathrm{SiO}_{2}=60-62 \mathrm{wt} \%\right.$ $\mathrm{K}_{2} \mathrm{O}=3-4 \mathrm{wt} \%$ ). It is also petrographically distinct due to the presence of orthopyroxene and olivine, which are notably absent from the other samples. The plagioclase, clinopyroxene, amphibole and titanomagnetite from this sample exhibit a range of textures that are not observed in the other samples from this study.

The origin of geochemical distinctions between different groups of eruptions has been examined at many andesitic volcanic systems (e.g. Tatara-San Pedro Complex, Dungan et al., 2001; Ngauruhoe, Price et al., 2010). These variations have been related to factors including variability of the parental magma composition, changes in the magma supply rate and reorganisation of the sub-volcanic magmatic system (Dungan et al., 2001). Geochemically similar groups of lava flows at Taranaki can erupt for periods of 1000 to 2000 years (Downey et al., 1994). This relates to broader-scale replenishment of the magmatic system, while localised interactions within the storage region give rise to shorter period events (Stewart, 2010). The older three Taranaki samples span a time range of $\sim 500$ years $(4150-3580$ years B.P.) and Maketawa and Kaupokonui are 1000 yrs apart from each other. Gross differences between the older samples and the Maketawa/Kaupokonui are therefore likely related to large scale replenishment.

These two groups of eruptions relate to different pulses of magma from the lower crust. Therefore they will have started with slightly different magmatic compositions that were further modified during ascent and storage in the crust. Additionally, there appears to be shift in the nature of the magmatic plumbing system between these two groups of eruptions based on amphibole thermobarometry data. The older three samples appear to have stalled in a shallow magma chamber at 6-8 km depth, whereas Kaupokonui and Maketawa stalled at 8-10 km depth. This reorganisation of the sub-volcanic reservoir system may have resulted in changes in the degree and style of mixing and the contamination components (Dungan et al., 2001). The deeper, less evolved and volumetrically smaller nature of the Kaupokonui and Maketawa eruptions may have caused the stronger apparent mixing signal in these samples. Additionally, 
the nature of the mixing component is likely to have also changed as a result of this larger scale replenishment to a less evolved composition (e.g. Gardner et al., 1995). In comparison, the three older samples have a stronger fractional crystallisation signature, possibly as a result of a longer residence time in a shallower storage system.

SM-6C is interpreted to be an eruption from the satellite vent of Fanthams Peak. The reported petrology of eruptions from Fanthams Peak more closely fits that observed in this sample than the summit vent eruptions. Fanthams Peak eruptions are less evolved, with basaltic to basaltic andesite whole rock compositions (e.g. Neall et al., 1986; Stewart et al., 1996). They are significantly lower in $\mathrm{K}_{2} \mathrm{O}$ and contain orthopyroxene and rare olivine, which is consistent with the mineralogy of SM-6C. The limited published major element mineral data for Fanthams Peak eruptives (Stewart et al., 1996; Turner et al., 2008) show a general agreement with that of SM-6C. Plagioclase anorthite content is significantly higher in those units sourced from Fanthams peak $\left(\mathrm{An}_{80-90}\right.$ compared with $\left.\mathrm{An}_{45-75}\right)$ and SM-6C plagioclase compositions extend to higher anorthite values than the other samples from this study, overlapping the reported values from Fanthams Peak. Amphibole $\mathrm{Al}_{2} \mathrm{O}_{3}$ content is $12.5-15$ wt\% in Fanthams Peak eruptives, which is higher than the $10-11 \mathrm{wt} \%$ published for the corresponding summit vent eruptions from these same studies. The high $\mathrm{Al}$ content has been attributed to amphibole crystallisation from a greater depth. Both the higher $\mathrm{Al}_{2} \mathrm{O}_{3}$ and deeper crystallisation pressures are features of SM-6C. Clinopyroxene data is less conclusive, as the published core values correspond to most of the samples in this study (including SM-6C) but the rim values do not. Glass trace element chemistry shows that the five samples assumed to be from the summit vent form a straight line trend in $\mathrm{SiO}_{2}$-compatible trace element space. This is interpreted as a mixing trend and indicates that these samples may be related. SM-6C plots off this trend, showing that it has not interacted with the magmatic systems of the other samples. 


\subsection{TIMESCALES OF MAGMATIC PROCESSES}

Modelling of Fe-Mg interdiffusion in clinopyroxene was applied to quantify the timescales of magma storage and mixing. The model of Morgan et al. (2004) was applied using the diffusion coefficient of Dimanov \& Wiedenbeck (2006) (Chapter 3). Clinopyroxene from all samples were modelled except those from SM-6C, which did not contain zoning characteristics appropriate for this model. The outermost zone from a number texturally diverse crystals was modelled in each sample. Where possible, zones closer to the core were also modelled to better constrain residence times.

\subsubsection{CLINOPYROXENE RESIDENCE TIMES}

The minimum residence times (ages) of clinopyroxene crystals in the host magma are of the order of months to years as recorded by the outermost rims of these crystals (Figure 5.16). The total range of ages for these outermost crystal rims range from ca. 0.3-3 yr for Korito, Maketawa and Kaupokonui and ca. 1-10 yr for Inglewood a and b, with the distribution skewed towards younger ages (Figure 5.15). A range of zones within the oscillatory zoning bands of individual crystals were also modelled for Kaupokonui, Inglewood a and b and Korito samples. These give residence times of 2-5 yr for Inglewood a and b and Korito, 0.5 to 2 yr for Maketawa and months (indistinguishable from the outermost rims) for Kaupokonui (Figure 5.17).

\subsubsection{Magma storage}

Oscillatory zoning has been attributed to crystallisation conditions within the main storage magma chamber (e.g. Browne et al., 2006; Humphreys et al., 2006). The boundary between clinopyroxene cores and oscillatory zoning is generally resorbed and not appropriate for diffusion modelling. Therefore, the 'inner oscillatory zone' population provides the best estimate for crystal residence times within this storage chamber. These ages indicate that clinopyroxene crystals were stored in a shallow level magma chamber at least $5 \mathrm{yr}$ prior to eruption for Inglewood a and b and Korito, and 1 yr prior to the eruption of the Kaupokonui and Maketawa samples. The variability in the range of ages calculated for a population of zones 
increases towards the core of the crystal. This relates to the nature of oscillatory zoning because the zones cannot be correlated between crystals (Ginibre et al., 2002b). The older three samples are the most silicic, containing rhyolitic glass compositions $\left(\mathrm{SiO}_{2}=70-74 \mathrm{wt} \%\right)$. These also record the longest residence times in the storage chamber. Therefore these samples may have undergone more fractional crystallisation and subsequently more evolution of the melt phase.
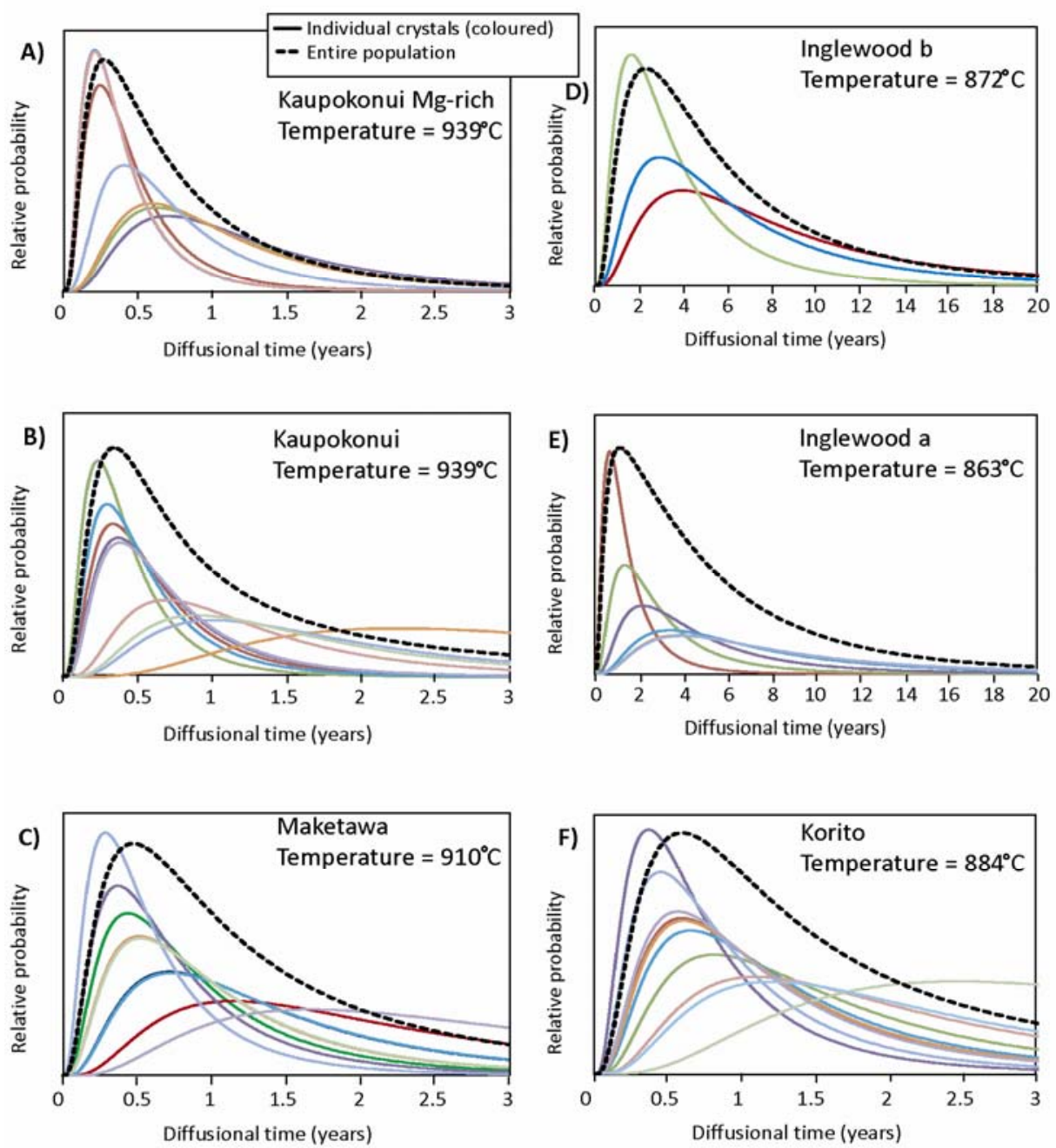

Figure 5.16 Probability density functions showing the results of diffusion modelling for the rims of each sample. The high-Mg rims from Kaupokonui are presented separately from the oscillatory rims from this sample. Temperatures shown are those used in the modelling.

\subsubsection{Mixing}

Diffusion modelling of the Mg-rich rims from Kaupokonui, which are proposed to record the intrusion of a hotter, intermediate (andesitic-dacitic) magma, also returned residence times of months. This short time between magma mixing and eruption suggests it may have been the eruption triggering event. In comparison it is more difficult to decipher whether mixing 
events triggered the other eruptions investigated in this study because the mixing is between magmas of similar composition. Some of the broader scale oscillatory and multiple zoning may record perturbations to the magma chamber induced by magma mixing. Addition of clinopyroxene to the shallow magma chamber may have occurred as a consequence of a mixing event. In this case, the residence times of the oscillatory zoning provides a minimum timescale for magma mixing.
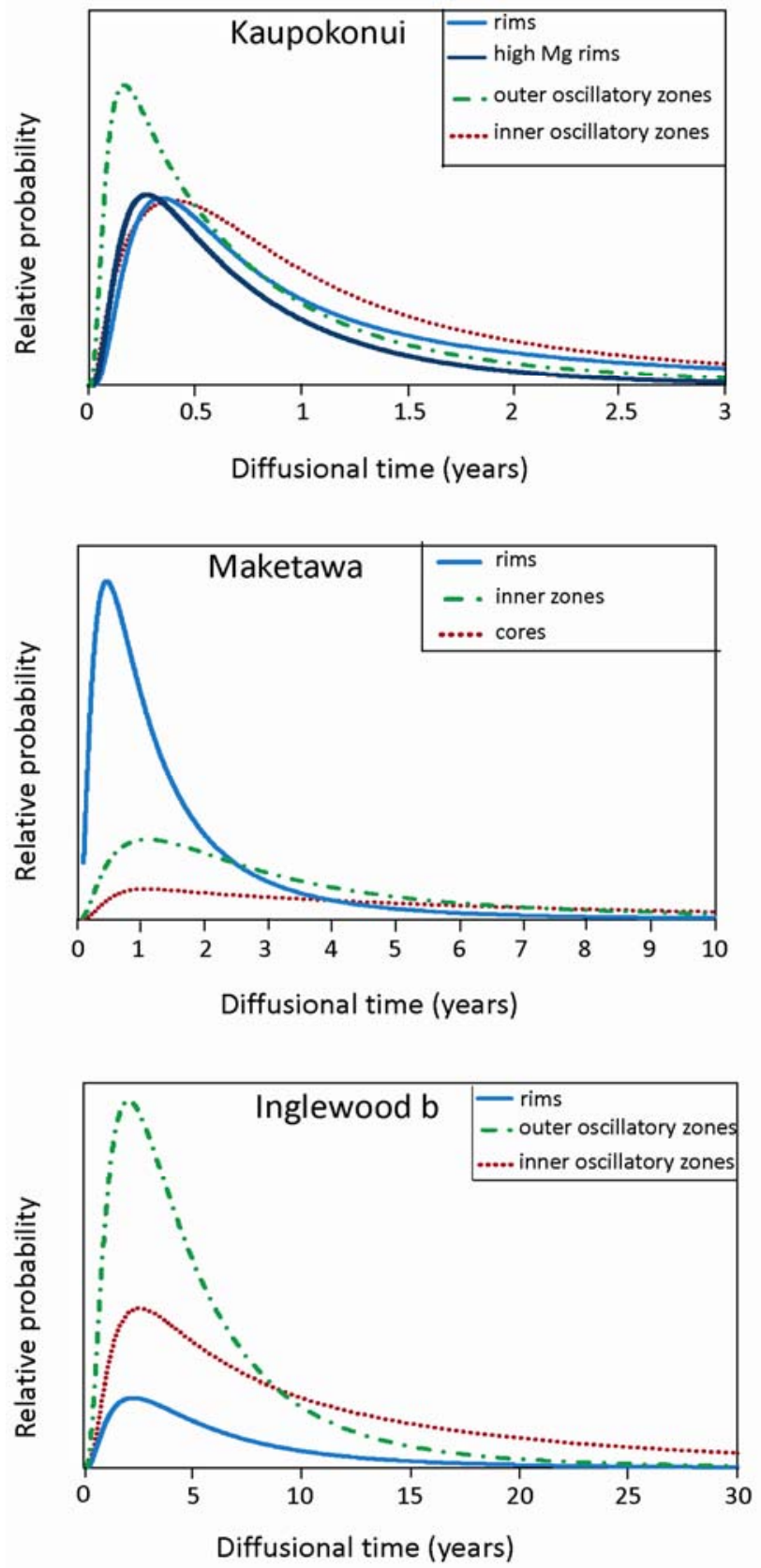

Figure 5.17 Probability density functions of representative samples showing the results of diffusion modelling zones that are not the outermost rim (shown in Figure 5.16). 


\subsubsection{COMPARISON WITH OTHER STUDIES}

The timescales obtained from these Taranaki samples are similar to those found in other studies of andesitic volcanoes. Timescales of the order of months to years fall within the intermediate range for magma mixing in general, and are relatively short for crystal residence times in shallow magma chambers. The same diffusion model was applied by Morgan et al. (2004), who used Fe-Mg interdiffusion in clinopyroxene to constrain the open system processes occurring during the 1944 eruption at Vesuvius. The authors calculated a range of residence times of Fe-rich rims from 4.5 months to $9 \mathrm{yr}$, with the shorter ages predominant. This was interpreted to be related to recharge of the magma chamber, and concluded that the bulk of the magma was intruded $<6$ months prior to the eruption. A population with no measurable diffusion was also identified, signifying the final input into the system and triggering of the eruption. The diffusion coefficient used by Morgan et al. (2004) was $1.7979 \times 10^{-20}$ at a temperature of $1077^{\circ} \mathrm{C}$ from Dimanov \& Sautter (2000). For comparison, the residence times of Morgan et al. (2004) were recalculated applying a diffusion coefficient determined using the method of Dimanov \& Wiedenbeck (2006) (6.35 x 10 $\left.0^{-21}\right)$. This increased the timescales by a factor of 2.72, resulting in residence times of 1 to $25 \mathrm{yr}$. The recalculated values are on a scale of years to decades compared with the months to years presented in this thesis for Taranaki.

Other published studies that investigated crystal residence times typically return ages that are longer than those calculated in this study (Table 5.6). In general, the studies that use crystal residence times to infer timescales of crystallisation and crustal residence times (e.g. Zellmer et al., 1999; Morgan \& Blake, 2006) are measuring a longer lived process than the shallow magma chamber residence times constrained in this study.

The timescales of magma mixing have been investigated using diffusion modelling at a number of volcanoes returning timescales ranging from days to centuries (Table 5.6). Much of the focus on magma mixing has been on systems where basaltic magma intrudes into a silicic reservoir (e.g. Martin et al., 2008; Kent et al., 2010; Costa \& Chakraborty, 2004). Martin et al. 
(2008) used Fe-Mg interdiffusion in olivine to constrain a basaltic magma injection on a timescale of $c a$. 1 month at Santorini, making this intrusion the probable triggering event.

Table 5.6 Summary of previous studies applying diffusion modelling to volcanic systems. Modified from Costa \& Chakraborty (2004).

\begin{tabular}{|c|c|c|c|c|}
\hline Case Study & Method & $\begin{array}{l}\text { Time (prior } \\
\text { to eruption) }\end{array}$ & Process & Reference \\
\hline $\begin{array}{l}\text { Curtis Ridge episode, } \\
\text { Mt Taranaki (New } \\
\text { Zealand) }\end{array}$ & Fe-Ti oxide zoning & $\begin{array}{l}\text { Hours to } \\
\text { weeks }\end{array}$ & Andesite-andesite mixing & $\begin{array}{l}\text { Turner et al. } \\
\text { (2008) }\end{array}$ \\
\hline $\begin{array}{l}\text { Montserrat (Lesser } \\
\text { Antilles) }\end{array}$ & Fe-Ti oxide zoning & $\begin{array}{l}\text { Days to } \\
\text { weeks }\end{array}$ & $\begin{array}{l}\text { Andesite remobilisation by } \\
\text { mafic intrusions }\end{array}$ & $\begin{array}{l}\text { Devine et al. } \\
\text { (2003) }\end{array}$ \\
\hline Usu (Japan) & Fe-Ti oxide zoning & $\begin{array}{l}\text { Days to } \\
\text { weeks }\end{array}$ & $\begin{array}{l}\text { Basalt-rhyolite-andesite; } \\
\text { dacite-rhyolite; dacite-dacite } \\
\text { mixing }\end{array}$ & $\begin{array}{l}\text { Tomiya \& } \\
\text { Takahashi } \\
(2005)\end{array}$ \\
\hline Ceboruco (Mexico) & Fe-Ti oxide zoning & $\begin{array}{l}\text { Days to } 6 \\
\text { months }\end{array}$ & $\begin{array}{l}\text { Rhyodacite-dacite-mafic } \\
\text { mixing }\end{array}$ & $\begin{array}{l}\text { Chertkoff \& } \\
\text { Gardner (2004) }\end{array}$ \\
\hline Unzen (Japan) & Fe-Ti oxide zoning & $\begin{array}{l}\text { Weeks to } \\
\text { months }\end{array}$ & Dacite-dacite mixing & $\begin{array}{l}\text { Venezky \& } \\
\text { Rutherford } \\
\text { (1999) }\end{array}$ \\
\hline Unzen (Japan) & Fe-Ti oxide zoning & $\begin{array}{l}\text { Weeks to } \\
\text { months }\end{array}$ & Dacite-dacite mixing & $\begin{array}{l}\text { Nakamura } \\
\text { (1995) }\end{array}$ \\
\hline Trident (Alaska) & $\begin{array}{l}\text { Fe-Ti oxide zoning } \\
\text { and Fe-Mg olivine } \\
\text { zoning }\end{array}$ & $\begin{array}{l}\text { Days to } 2 \\
\text { years }\end{array}$ & Dacite-andesite mixing & $\begin{array}{l}\text { Coombs et al. } \\
(2000)\end{array}$ \\
\hline $\begin{array}{l}1944 \text { eruption - } \\
\text { Vesuvius (Italy) }\end{array}$ & $\begin{array}{l}\text { Fe-Mg zoning in } \\
\text { clinopyroxene }\end{array}$ & $\begin{array}{l}\text { Months to } \\
\text { years }\end{array}$ & Magma recharge & $\begin{array}{l}\text { Morgan et al. } \\
\text { (2004) }\end{array}$ \\
\hline Santorini (Greece) & $\begin{array}{l}\text { Fe-Mg olivine } \\
\text { zoning }\end{array}$ & 1 month & Basaltic -andesite mixing & $\begin{array}{l}\text { Martin et al. } \\
\text { (2008) }\end{array}$ \\
\hline $\begin{array}{l}\text { Tatara-San Pedro } \\
\text { (Chile) }\end{array}$ & $\begin{array}{l}\text { Fe-Mg, Mn, Ni } \\
\text { zoning in olivine }\end{array}$ & $\begin{array}{l}\text { Months to } 10 \\
\text { years }\end{array}$ & $\begin{array}{l}\text { Magmatic assimilation of } \\
\text { hydrous mafic to ultramafic } \\
\text { cumulates by ascending basalts }\end{array}$ & $\begin{array}{l}\text { Costa \& } \\
\text { Dungan (2005) }\end{array}$ \\
\hline San Pedro (Chile) & $\begin{array}{l}\text { Fe-Mg olivine } \\
\text { zoning }\end{array}$ & $\begin{array}{l}\text { Year to } \\
\text { decades }\end{array}$ & $\begin{array}{l}\text { Basaltic andesite-dacite mixing } \\
\text { at depth }\end{array}$ & $\begin{array}{l}\text { Costa \& } \\
\text { Chakraborty } \\
(2004)\end{array}$ \\
\hline $\begin{array}{l}\text { Mt St. Helens } \\
\text { (Washington) }\end{array}$ & $\mathrm{Li}$ in plagioclase & $<1$ year & $\begin{array}{l}\text { Vapour transfer and } \\
\text { accumulation at the top of the } \\
\text { magma reservoir }\end{array}$ & $\begin{array}{l}\text { Kent et al. } \\
\text { (2007) }\end{array}$ \\
\hline Mt Hood (Oregon) & $\begin{array}{l}\text { Mg zoning in } \\
\text { plagioclase }\end{array}$ & Days & Mafic-silicic mixing & $\begin{array}{l}\text { Kent et al. } \\
(2010)\end{array}$ \\
\hline San Pedro (Chile) & $\begin{array}{l}\text { Mg zoning in } \\
\text { plagioclase }\end{array}$ & $\begin{array}{l}\text { Decades to } \\
100 \text { years }\end{array}$ & Metasomatism of xenoliths & $\begin{array}{l}\text { Costa et al. } \\
\text { (2003) }\end{array}$ \\
\hline $\begin{array}{l}\text { Santorini (Greece); } \\
\text { Montserrat (Lesser } \\
\text { Antilles) }\end{array}$ & $\begin{array}{l}\text { Sr zoning in } \\
\text { plagioclase }\end{array}$ & $\begin{array}{l}100-450 \\
\text { years }\end{array}$ & Crystal residence time & $\begin{array}{l}\text { Zellmer et al. } \\
\text { (1999) }\end{array}$ \\
\hline $\begin{array}{l}\text { Montserrat (Lesser } \\
\text { Antilles) }\end{array}$ & $\begin{array}{l}\text { Sr and Ba zoning in } \\
\text { plagioclase }\end{array}$ & $\begin{array}{l}10-1200 \\
\text { years }\end{array}$ & $\begin{array}{l}\text { Andesite remobilisation by } \\
\text { mafic intrusions }\end{array}$ & $\begin{array}{l}\text { Zellmer et al. } \\
\text { (2003) }\end{array}$ \\
\hline $\begin{array}{l}\text { A.D. } 79 \text { eruption- } \\
\text { Vesuvius (Italy) }\end{array}$ & Ba zoning in sanidine & Decades & Episodic recharge & $\begin{array}{l}\text { Morgan et al. } \\
\text { (2006) }\end{array}$ \\
\hline $\begin{array}{l}\text { Bishop Tuff } \\
\text { (Calfornia) }\end{array}$ & $\begin{array}{l}\text { Sr and Ba zoning in } \\
\text { sanidine }\end{array}$ & $\begin{array}{l}114000 \\
\text { years }\end{array}$ & Crystal residence time & $\begin{array}{l}\text { Morgan \& } \\
\text { Blake (2006) }\end{array}$ \\
\hline $\begin{array}{l}\text { Mt Taranaki (New } \\
\text { Zealand) }\end{array}$ & $\begin{array}{l}\mathrm{Fe}-\mathrm{Mg} \text { zoning in } \\
\text { clinopyroxene }\end{array}$ & $\begin{array}{l}\text { Months to } \\
\text { years }\end{array}$ & $\begin{array}{l}\text { Intermediate-silicic mixing; } \\
\text { residence in a shallow storage } \\
\text { chamber }\end{array}$ & This work \\
\hline
\end{tabular}


However, Costa \& Chakraborty (2004) calculated timescales of years to decades at San Pedro, Chile, meaning the basaltic input did not necessarily trigger the eruption. Rather, it was induced by collapse of the eastern flank of the volcano. These authors also proposed that the mixing occurred at depths of $\sim 6 \mathrm{~km}$ (Costa et al., 2004), so there would be a longer time span between mixing and eruption than if this mixing occurred in the conduit.

\subsubsection{Previous work using Fe-Ti diffusion in oxides}

Ti diffusion in Fe-Ti oxides is the most frequently applied diffusion technique for investigating andesite petrogenesis, including processes such as magma recharge, mixing and reheating on a short timescale (e.g. Nakamura, 1995; Devine et al., 2003; Tomiya \& Takahashi, 2005; Turner et al., 2008). This method was outside the scope of the present study as the Fe-Ti oxides did not show compositional variability appropriate for diffusion modelling. The samples did not contain Fe-Ti oxides with zoning and all but SM-6C contained only one population. Although SM-6C did contain two oxide populations, one of these was considered to be isolated from the melt and therefore not record magmatic perturbations. As such, this section discusses previous work employing this technique in andesitic complexes and identifies the conclusions relevant to an understanding of the Taranaki magma system.

Ti diffuses so rapidly in Fe-Ti oxides that the Ti distribution homogenises within a few years (at $900^{\circ}$ C) (Freer \& Hauptman, 1978). Therefore Ti disequilibrium within these minerals indicates a perturbation to the magmatic system on a timescale shorter than a few years. The presence of Fe-Ti oxides preserving the unaffected 'original' composition, when independent evidence indicates a late stage perturbation, may suggest shorter timescales still (Devine et al., 2003). However, these minerals reset so quickly that they only record the final reheating event before eruption, thereby provide different information about pre-eruptive processes than silicate minerals (Turner \& Costa, 2007). This can lead to the calculation of conflicting timescales. For example, Zellmer et al. (2003) and Devine et al. (2003) both investigated the shallow magmatic processes at Soufriere Hills, Montserrat. Zellmer et al. (1999) obtained residence times from Ba and Sr zoning in plagioclase crystals of 10-1200 yr which they interpreted as multiple pulses of 
magma into the shallow crust over this period of time. Devine et al. (2003) used Ti zoning within Fe-Ti oxides to infer that reheating and subsequent remobilisation of the andesite body by a hotter, mafic magma occurred days to weeks before eruption and continued throughout this eruption. At Soufriere Hills, the plagioclase crystals recorded the intrusion of the various andesitic pulses into the upper crust and the formation of the magma body which was eventually erupted. The Fe-Ti oxides recorded the remobilisation of this andesite and therefore constrained the triggering events of these eruptions and quantified the timescales between eruption triggering and the subsequent eruption.

Turner et al. (2008) used Ti diffusion in titanomagnetite to identify a recharge triggering event hours to weeks prior to the eruption of the Curtis Ridge episode from Mt Taranaki on the basis of two distinct Fe-Ti oxide populations present in the groundmass of the eruptives. There was no Ti compositional gradient in these oxides and therefore no Ti diffusion. This led the authors to conclude that one population was part of a triggering injection which cryptically mixed with the resident magma hours to weeks prior to eruption. The clinopyroxene crystals from the Turner et al. (2008) study are similar to those of the oscillatory rim population found in Korito and Inglewood a and b presented here. Turner et al. (2008) attribute the change from patchy cores to oscillatory rims of the clinopyroxene crystals in the Curtis Ridge sample to the same triggering event - results which are inconsistent with the work of this thesis. However, separate eruptions are investigated and therefore different processes and/or slightly different timescales may be expected to occur. Also, Fe-Ti oxides generally record separate events to silicate minerals, and the interpretation of Turner et al. that the recharge event introduced both the high Ti magnetite population and a population of clinopyroxene crystals, which then crystallised an oscillatory zoned rim, may not be valid. Clinopyroxene crystals (along with plagioclase and amphibole) may have been introduced into the magma chamber months to years prior to eruption before a final injection of magma triggering the eruption as is observed at Montserrat and Vesuvius (Devine et al., 2003; Zellmer et al., 2003; Morgan et al., 2004). Most of the samples investigated here appear to have been cryptically mixed by the injection of a compositionally similar magma as discussed by Turner et al. (2008). This is most evident in the 
Kaupokonui sample where the extreme high-Mg rims are clear evidence for interaction with a hotter, more mafic magma.

The long relative timescales for magma mixing calculated in this study when compared with the results of other diffusion modelling used to constrain the timescales of mixing between intermediate to silicic end members may be related to the use of magnetite rather than silicate minerals. Diffusion modelling in silicate minerals has primarily been applied to mixing between more extreme end members (basalt and silicic melt). This may be because mixing between intermediate and silicic end-members as has been proposed at Taranaki is not clearly recorded in silicate minerals.

Magma mixing and recharge has been strongly linked to eruption triggering by a number of studies (e.g. Sparks et al., 1977; Eichelberger \& Izbekov, 2000; Murphy et al., 2000; Martin et al., 2008; Kent et al., 2010). However, magma mixing does not necessarily trigger eruptions (Costa \& Chakraborty, 2004). This is supported by the results of this thesis, which establish that clinopyroxene disequilibrium features related to mixing events are present in older parts of the crystals formed prior to the mixing event constrained by diffusion modelling.

The range in timescales inferred by diffusion modelling for magma mixing processes has been linked to the end member compositions involved in the mixing (Turner \& Costa, 2007) and the mode of andesite formation (Costa \& Chakraborty, 2004). The summary of previous work presented in Table 5.6 does not support the idea that timescales of magma mixing are controlled by the end member compositions. Mixing between basalt-dacite and dacite-dacite have both been estimated to occur on short timescales (days to weeks) at various volcanoes. However, the mode of andesite formation is likely to be a more important control on the timescales of magmatic processes. Diffusion modelling timescales is most strongly related to the nature of the formative process, and this is in turn dependent on the mineral-element pair being modelled. Other factors such as the magma composition(s) may play a minor role. 


\subsubsection{RELATIONSHIPS BETWEEN THE OLDER THREE ERUPTIONS}

Diffusion modelling can be used to test two hypotheses about the geochemically and petrographically similar, older three samples: (1) they represent three separate magma batches formed by the same petrogenetic processes, producing similar eruptives over a period of time; or (2) they are from the same magma batch, which is periodically remobilised and erupted. The diffusion ages for these three samples get progressively older as the eruptions get younger, by ca. six months to a year. However, these timescales are too small to infer that the eruptions are from a single magma batch, as Inglewood a and b erupted ca. 50 yr apart (Alloway et al., 1995 and references therein). The Korito is around 100-400 yr older than the Inglewood Tephras (Alloway et al., 1995 and references therein) and is therefore even more difficult to reconcile with the diffusion ages assuming a single magma batch (Alloway et al., 1995 and references therein). These timescales can be reconciled if the diffusion process is slowed down to a near negligible rate by cooling of the magma to temperatures around $700^{\circ} \mathrm{C}$ (D. Morgan, pers comm.). This requires a cooling of the magma body by ca. $150^{\circ} \mathrm{C}$, followed by subsequent reheating within 6 months to a year. Cooling on this timescale is unlikely in context of other magmatic systems. For example, Ngauruhoe erupted in 1975, and eight years later Giggenbach (1982) recorded a gas temperature of $650^{\circ}$ C. Magmatic systems do not typically cool on the timescale of months required for these eruptions to represent progressive eruptions from a single host magma. This is in agreement with Hildreth \& Moorbath (1988), who favour the repeated input of new magma preferentially following established conduits, rather than the continuous evolution of a single magma batch.

In summary, these three samples represent three separate magma batches which record a similar ascent through the crust and were formed by very similar petrogenetic processes. Amphibole barometry indicates that the Inglewood a and Korito continuously record crystallisation between the $20 \mathrm{~km}$ initial depth and $6 \mathrm{~km}$ storage depth. However, Inglewood b does not record crystallisation between $\sim 12$ and $8 \mathrm{~km}$ depth, suggesting that it used the magmatic plumbing system established by the previous eruptions and therefore ascended more rapidly. 


\subsection{ANDESITE PETROGENESIS AT MT TARANAKI}

The petrogenesis of the Taranaki andesites investigated in this study is described within the context of previous work using a four-stage model in which: (i) Melt is differentiated at depth (> ca. $25 \mathrm{~km}$ ) to an intermediate - silicic composition; (ii) The melt migrates through the crust via a complex plumbing system, possibly consisting of interconnected sills and dykes; (iii) Magma stalls in the upper crust, where decompression crystallisation and magma mixing between compositionally similar end members occurs during ascent and storage; and (iv) Fractional crystallisation takes place in the shallow magma chamber, imprinting a dominant signature on these magmas (Figure 5.18). Geochemical and textural evidence for each of these stages will be discussed in detail in the following sections.

\section{i. Differentiation of melt at depth}

Melt differentiation occurring at depth of greater than ca. $20 \mathrm{~km}$ as indicated by the evolved nature of the glass and mineral trace element chemistry, including the earliest crystallising phases. There is little evidence for basaltic melt in the upper crust due to the evolved nature of mixing end-members and the notable absence of erupted basaltic melt. The Annen et al. (2006) model is favoured for melt differentiation, in which evolved melts are produced in a deep crustal hot zone. Partial crystallisation of hydrous basalt and partial melting of the surrounding crust is induced by heat and volatiles provided by the intruding hydrous basalt. This provides a mechanism for producing crystal-poor, differentiated melts with a range of compositions from andesite to rhyolite. The mineral chemistry data do not suggest that large quantities of crystals originated from the lower crust (25-35 km; Stern \& Davey, 1987, 1990), as was proposed by Price et al. (2005). Rather, the earliest crystallising amphiboles record pressures that equate to depths of around 20-25 km. Trace element chemistry of these amphibole crystals indicates that those crystals crystallised directly from the evolving host melt, and do not represent xenocrystic material. 


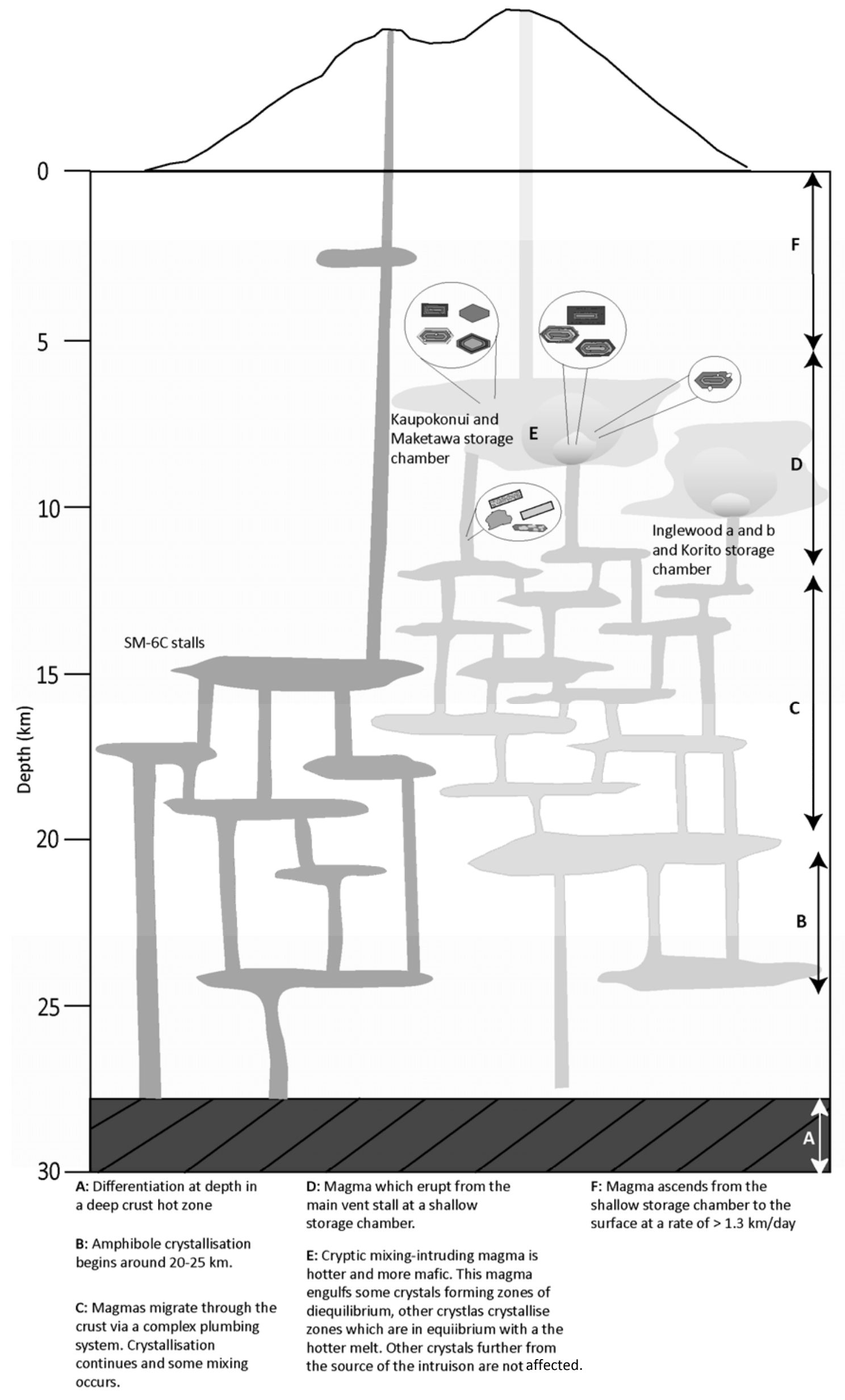

Figure 5.18 Schematic diagram of the petrogenetic processes operating at Mt Taranaki during the Holocene. 


\section{ii. Magma ascent through the crust}

Magma ascent from a deep origin is inferred from amphibole barometry. The pressure records indicate near-continuous crystallisation between the onset of deep-seated crystallisation, and storage in a shallow magma chamber (ca. 6-10 km). Magmatic ascent is therefore relatively slow and suggests a complex plumbing system such as a series of sills and dykes that would have impeded ascent (Price et al., 1997; Gamble et al., 1999). As the system developed, evidence for increased interaction with the crust is provided by the long term geochemical trends at Taranaki, including increasing $\mathrm{K}_{2} \mathrm{O}$ and ${ }^{87} \mathrm{Sr} /{ }^{86} \mathrm{Sr}$ ratios (Price et al., 1999). This is in contrast to the style of ascent proposed by Annen et al. (2006), invoking rapid ascent of melt through the crust via a series of dykes due to the low viscosity and density of the crystal poor, water-rich melts. The slower ascent occurring at Taranaki may be related to a range of extensive parameters such as the nature of the crust at this site and the mass flux rate.

\section{iii. Stagnation of magma in the upper crust}

Magmas stall in the shallow crust as a result of decompression crystallisation (Blundy \& Cashman, 2001). For example, Blundy \& Cashman (2001) calculated an isothermal crystallisation rate of $0.23 \%$ per MPa for a water-saturated andesitic magma at $900^{\circ} \mathrm{C}$. The combined effect of increased crystal content and decreased melt water content causes stagnation at this point for a period of months to years as calculated from clinopyroxene residence times. The abundant crystal growth occurring at this depth is reflected in the dominance of oscillatory zoning in plagioclase and clinopyroxene, as well as a strong fractional crystallisation signature evident in the least squares mixing modelling. There is a significant correlation between the silica content of the melt, the depth of the storage magma chamber and the residence time within this chamber, and a number of feedbacks are possible. For example, a shallow emplacement depth would favour higher rates of crystallisation (Blundy \& Cashman, 2001), which would in turn evolve the melt to a more silicic composition.

In contrast to the other samples investigated in this study, SM-6C magma likely ascended from a slightly shallower depth of $c a .15 \mathrm{~km}$, stalling briefly in the upper crust (ca. 2-3 km) for 
a few days. It did not therefore experience the same degree of decompression crystallisation as the others, as reflected by a lower silica and crystal content.

\section{iv. Magma mixing}

Magma mixing is a key process occurring at Mt Taranaki and is a primary source of variability within these eruptives. The magma mixing at Taranaki is not occurring in the traditional manner where a basaltic magma injects a shallow silicic body, often triggering an eruption. Rather, the mixing is between compositionally similar end-members, which enables efficient mixing. This process leaves behind little evidence, except within mineral phases where disequilibrium features and variable trace element chemistry indicate open system processes. The mixing is likely occurring in both the plumbing system and the shallow storage chamber as magmas traverse the crust using existing pathways (Hildreth \& Moorbath, 1988; Gamble et al., 1999, 2003).

'Cryptic' magma mixing reflects repeated, efficient mixing of small batches of magma with similar compositions (Humphreys et al., 2006). Such efficient mixing is attributed to similar physical properties and the small volume of the intruding magma (Sparks \& Marshall, 1986). This has a variable effect on the magma chamber-hosted minerals depending on the spatial distribution of the intrusion and crystal assemblage. Therefore, individual crystals will record the event differently. Humphreys et al. (2006) noted little overlap in the mineral textures of Shiveluch Volcano, which was attributed to spatial and temporal isolation of the mineral populations. Crystals near the intrusion may be incorporated into the intruding melt, inducing extreme disequilibrium features such as sieving and resorption of zones. Crystals that are nearby, but not close enough to be engulfed, may just record hotter conditions, while other crystals will not record this intrusion at all. This makes the correlation of such disequilibrium features challenging, and has been used to account for disequilibrium textures in plagioclase at Unzen, Japan (Browne et al., 2006), and clinopyroxene at Ruapehu, New Zealand (Nakagawa et al., 2002). 
This work dominantly discusses the intrusion of hotter melts, but occurrence of magma mixing and recharge may also occur by intrusion of a more silicic melt into a relatively mafic host. Identifying the latter style is challenging, as calcic cores are more resistant to dissolution when immersed in a more felsic melt (Nakamura \& Shimakita, 1998; Larsen, 2005); the textural record is therefore less conclusive. Also, the dominant textures apparent from magma mixing will be induced by the cooler, more felsic-hosted minerals interacting with a hotter, more mafic melt. This does not necessarily indicate which magma was the host.

Magma mixing appears to be occurring in all the samples investigated here. However, it appears more dominant in the younger three samples as evident in the mineral textures, major element and trace element chemistry. Mineral textures illustrate more variability and more disequilibrium textures. Major element chemistry shows that there is less of a distinction between cores and rims, a feature also apparent in the amphibole thermobarometry results. Trace element chemistry shows that minerals from the younger three samples have chemistries typical of a less evolved melt and show more variability in compatible trace elements (e.g. V in clinopyroxene).

The shorter term variability noted in the Taranaki eruptives are thought to be related to pulses of magma from the lower crust that then migrate through the crust. The samples investigated in this study appear to cover the transition from one magma pulse to another. The older three samples are more evolved, stalled for longer in the shallow storage chamber and appear to be following established magmatic pathways through the crust. Kaupokonui and Maketawa may represent the initial stages of the next pulse of melt. The chemistry is different, and magma has not had time to accumulate large quantities of magma and therefore the mixing signature is stronger because the host magma batches are smaller. The more basaltic nature of the later samples may be inherent to the new magma pulse, or may be related to the fact that this is the early stages of a magma pulse which has therefore not evolved and differentiated via intra-crustal processes. 
Overall, variations in these processes, including magma ascent path, degree of fractional crystallisation, and the nature and extent of magma mixing, contribute to short term (100's to 1000’s yr) variability at the Mt Taranaki system. Signatures from these processes are therefore superimposed on the longer term magmatic evolution, and resulting geochemical characteristics. 


\section{CHAPTER 6:}

\section{CONCLUSIONS}




\subsection{CONCLUSIONS}

This thesis has presented detailed crystal specific and glass geochemical data for six subplinian eruptions from Mt Taranaki. Intensive magmatic parameters and crystal residence times were quantified. This investigation has resulted in the following conclusions:

1) These 'andesites' are the product of a complex set of processes including magma mixing and fractional crystallisation. This results in a large degree of geochemical variability on a timescale of 100's to 1000's yr that is superimposed on the longer term evolution of the magmatic system.

2) In situ crystal specific studies of plagioclase, clinopyroxene and amphibole record magmatic evolution and provide evidence for processes such as cryptic magma mixing and reheating of the magma chamber. Combining petrographic techniques with major and trace element analyses enables petrogenetic processes to be better constrained.

3) Magma mixing is cryptic, occurring between evolved and compositionally similar endmembers. This mixing is most prominent when it occurs in the shallow storage chamber (6-10 km depth). However, it is most likely also occurring throughout the magmatic plumbing system. The volumetrically small nature of the intruding magma results in a heterogeneous effect on the host magma, imprinting a range of textural and chemical features on the resident crystal population. This means correlating zoning between individual minerals is often not possible.

4) Melt differentiates at depth (ca. $30 \mathrm{~km})$ to an andesitic - silicic composition and ascends the crust gradually via a complex plumbing system.

5) Most crystallisation occurs in the shallow crust within a storage magma chamber as shown by mineral textures and thermobarometry modelling. This is due to decompression driven crystallisation and results in a dominant fractional crystallisation signature. The fractional crystallisation signature is further evident by the relationship between glass data from this study and published whole rock data as quantified by the least squares mixing modelling. 
6) Residence times obtained from diffusion modelling show that magma mixing does not always trigger eruptions. Clinopyroxene residence times obtained from Fe-Mg interdiffusion modelling indicates that magmas are resident in a shallow storage chamber for months to years prior to eruption. Magma mixing is implicated as a triggering event for the Kaupokonui Tephra, however other samples do not show such conclusive evidence for magma mixing as a triggering event.

\subsection{SUGGESTIONS FOR FUTURE WORK}

The data acquired and ideas proposed in this thesis lend themselves to further study to be properly tested. Some recommendations for further study are summarised below:

1) Much of the ambiguity relating to the cause of disequilibrium textures and the origins of non-host derived cores is related to the lack of trace element data for these zones due to the spot size required for LA-ICP-MS analysis. The use of Secondary Ion Mass Spectrometry (SIMS) which obtains trace element analyses on a scale of $1 \mu \mathrm{m}$ would enable the trace element composition of these features to be obtained and therefore better constrain the origin.

2) It is suggested that the sample SM-6C represents an unknown eruption from the satellite vent of Fantham's Peak. In order to test this, glass analyses from an eruption known to have been sourced from Fantham's Peak (such as the Manganui Tephra) could be compared with the glass from SM-6C. The same could be done for the Curtis Ridge Episode, which is the other eruption this unit may relate to.

3) Sample SM-6C could be further constrained by detailed investigation of the nature of the deposits. Mapping and the construction of isopachs would also aid in determining whether this sample is sourced from Fantham's Peak and whether this sample represents the Curtis Ridge Episode investigated by Turner et al. (2008).

4) Residence times of clinopyroxene crystals were modelled using Fe-Mg interdiffusion. Modelling of additional mineral phased such as Mg and Sr diffusion in plagioclase and Fe-Ti diffusion in titanomagnetite may constrain different magmatic processes that 
occur on a different timescales from the months to years that are accessible by clinopyroxene diffusion modelling.

5) Open system processes could be further investigated by using $\mathrm{Sr}-\mathrm{Nd}-\mathrm{Hf}-\mathrm{Pb}$ isotopic data for specific mineral phases. Whole rock isotopic analyses have been published by Price et al. (1992, 1999) which provides constraints on the overall degree of crustal contamination. In situ isotopic analyses of individual mineral phases would enable the isotopic evolution of the magma system to be resolved and the various open system inputs to the system such as magma mixing and crustal contamination to be further constrained. 


\section{REFERENCES}

Adams, R. D. \& Ware, D. E. (1977). Subcrustal earthquakes beneath New Zealand: locations determined with a laterally inhomogeneous velocity model. New Zealand Journal of Geology and Geophysics 20, 59-83.

Allan, A. S. R. (2008). An elemental and isotopic investigation of Quaternary silicic Taupo Volcanic Zone tephras from ODP Site 1123: Chronostratigraphic and petrogenetic applications. M.Sc. Dissertation, Victoria University of Wellington, $210 \mathrm{pp}$.

Allan, A. S. R., Baker, J. A., Carter, L. \& Wysoczanksi, R. J. (2008). Reconstructing the Quaternary evolution of the world's most active silicic volcanic system: insights from an similar to 1.65 Ma deep ocean tephra record sourced from Taupo Volcanic Zone, New Zealand. Quaternary Science Reviews 27, 2341-2360.

Allegre, C. J., Provost, A. \& Jaupart, C. (1981). Oscillatory zoning - a pathological case of crystal-growth. Nature 294, 223-228.

Allis, R. G., Armstrong, P. A. \& Funnell, R. H. (1995). Implications for a high heat-flow anomaly around New Plymouth, North Island, New Zealand. New Zealand Journal of Geology and Geophysics 38, 121-130.

Alloway, B. (1989). Late Quaternary cover-bed stratigraphy and tephra-chronology of north-eastern and central Taranaki region, New Zealand. Ph.D Dissertation, Massey University.

Alloway, B., Neall, V. E. \& Vucetich, C. G. (1995). Late Quaternary (post 28,000 year BP) tephrostratigraphy of northeast and central Taranaki, New Zealand. Journal of the Royal Society of New Zealand 25, 385-458.

Anderson, A. T. (1976). Magma mixing [mdash] petrological process and volcanological tool. Journal of Volcanology and Geothermal Research 1, 3-33.

Anderson, D. L. (1982). Isotopic evolution of the mantle - The role of magma mixing. Earth and Planetary Science Letters 57, 1-12.

Anderson, A. T. (1984). Probable relations between plagioclase zoning and magma dynamics, Fuego Volcano, Guatemala. American Mineralogist 69, 660-676.

Anderson, H. \& Webb, T. (1994). New Zealand Seismicity: Patterns revealed by the upgraded National Seismic Network. New Zealand Journal of Geology and Geophysics 37, 477-493.

Annen, C. \& Sparks, R. S. J. (2002). Effects of repetitive emplacement of basaltic intrusions on thermal evolution and melt generation in the crust. Earth and Planetary Science Letters 203, 937-955. 
Annen, C., Blundy, J. D. \& Sparks, R. S. J. (2006). The genesis of intermediate and silicic magmas in deep crustal hot zones. Journal of Petrology 47, 505-539.

Azough, F. \& Freer, R. (2000). Iron diffusion in single-crystal diopside. Physics and Chemistry of Minerals 27, $732-740$

Bachmann, O. \& Bergantz, G. W. (2004). On the origin of crystal-poor rhyolites: Extracted from batholithic crystal mushes. Journal of Petrology 45, 1565-1582.

Bachmann, O., Dungan, M. A. \& Lipman, P. W. (2002). The Fish Canyon magma body, San Juan volcanic field, Colorado: Rejuvenation and eruption of an upper-crustal batholith. Journal of Petrology 43, 1469-1503.

Bacon, C. R. \& Druitt, T. H. (1988). Compositional evolution of the zoned calcalkaline magma chamber of Mount Mazama, Crater Lake, Oregon. Contributions to Mineralogy and Petrology 98, 224-256.

Bedard, J. H. (2010). Parameterization of the $\mathrm{Fe}=\mathrm{Mg}$ exchange coefficient (kd) between clinopyroxene and silicate melts. Chemical Geology 274, 169-176.

Berlo, K., Blundy, J., Turner, S. \& Hawkesworth, C. (2007). Textural and chemical variation in plagioclase phenocrysts from the 1980 eruptions of Mount St. Helens, USA. Contributions to Mineralogy and Petrology 154, 291-308.

Bibby, H. M., Caldwell, T. G., Davey, F. J. \& Webb, T. H. (1995). Geophysical evidence on the structure of the Taupo Volcanic Zone and its hydrothermal circulation. Journal of Volcanology and Geothermal Research 68, 29-58.

Bindeman, I. N., Davis, A. M. \& Drake, M. J. (1998). Ion microprobe study of plagioclase-basalt partition experiments at natural concentration levels of trace elements. Geochimica et Cosmochimica Acta 62, 1175-1193.

Blundy, J. D. \& Wood, B. (1991). Crystal-chemical controls on the partitioning of Sr and Ba between plagioclase feldspar, silicate melts, and hydrothermal solutions. Geochimica et Cosmochimica Acta 55, 193-209.

Blundy, J. \& Cashman, K. (2001). Ascent-driven crystallisation of dacite magmas at Mount St Helens, 19801986. Contributions to Mineralogy and Petrology 140, 631-650.

Blundy, J., Cashman, K. \& Humphreys, M. C. S. (2006). Magma heating by decompression-driven crystallisation beneath andesite volcanoes. Nature 443, 76-80.

Boddington, T., Parkin, C. J. \& Gubbins, D. (2004). Isolated deep earthquakes beneath the North Island of New Zealand. Geophysical Journal International 158, 972-982. 
Bohrson, W. A. \& Spera, F. J. (2001). Energy-constrained open-system magmatic processes II: Application of energy-constrained assimilation-fractional crystallization (EC-AFC) model to magmatic systems. Journal of Petrology 42, 1019-1041.

Bottinga, Y., Kudo, A. \& Weill, D. (1966). Some observations on oscillatory zoning and crystallization of magmatic plagioclase. American Mineralogist 51, 792-806.

Browne, B. L. \& Gardner, J. E. (2006). The influence of magma ascent path on the texture, mineralogy, and formation of hornblende reaction rims. Earth and Planetary Science Letters 246, 161-176.

Browne, B. L., Eichelberger, J. C., Patino, L. C., Vogel, T. A., Uto, K. \& Hoshizumi, H. (2006). Magma mingling as indicated by texture and $\mathrm{Sr} / \mathrm{Ba}$ ratios of plagioclase phenocrysts from Unzen volcano, SW Japan. Journal of Volcanology and Geothermal Research 154, 103-116.

Carslaw, H. S. \& Jaeger, J. C. (1986). Conduction of Heat in Solids. New York: Oxford University Press.

Chakraborty, S. (2008). Diffusion in solid silicates: A tool to track timescales of processes comes of age. Annual Review of Earth and Planetary Sciences 36, 153-190.

Chakraborty, S. \& Ganguly, J. (1992). Cation diffusion in aluminosilicate garnets - experimental-determination in spessartine-almandine diffusion couples, evaluation of effective binary diffusion-coefficients, and applications. Contributions to Mineralogy and Petrology 111, 74-86.

Challis, G. A., Johnston, M. R., Lauder, W. R. \& Suggate, R. P. (1994). Geology of the Lake Rotoroa area, Nelson. Institute of Geological and Nuclear Sciences geological map 8. 1 sheet + 32 . Lower Hutt, New Zealand: Institute of Geological and Nuclear Sciences Limited.

Cherniak, D. J. (2001). Pb diffusion in Cr diopside, augite, and enstatite, and consideration of the dependence of cation diffusion in pyroxene on oxygen fugacity. Chemical Geology 177, 381-397.

Cherniak, D. J. (2002). Ba diffusion in feldspar. Geochimica et Cosmochimica Acta 66, 1641-1650.

Chertkoff, D. G. \& Gardner, J. E. (2004). Nature and timing of magma interactions before, during, and after the caldera-forming eruption of Volcan Ceboruco, Mexico. Contributions to Mineralogy and Petrology 146, 715-735.

Coombs, M. L., Eichelberger, J. C. \& Rutherford, M. J. (2000). Magma storage and mixing conditions for the 1953-1974 eruptions of Southwest Trident volcano, Katmai National Park, Alaska. Contributions to Mineralogy and Petrology 140, 99-118. 
Cooper, K. M. \& Reid, M. R. (2003). Re-examination of crystal ages in recent Mount St. Helens lavas: implications for magma reservoir processes. Earth and Planetary Science Letters 213, 149-167.

Cooper, K. M., Reid, M. R., Murrell, M. T. \& Clague, D. A. (2001). Crystal and magma residence at Kilauea Volcano, Hawaii: Th-230-Ra-226 dating of the 1955 east rift eruption. Earth and Planetary Science Letters 184, 703718.

Costa, F. \& Chakraborty, S. (2004). Decadal time gaps between mafic intrusion and silicic eruption obtained from chemical zoning patterns in olivine. Earth and Planetary Science Letters 227, 517-530.

Costa, F. \& Dungan, M. (2005). Short time scales of magmatic assimilation from diffusion modeling of multiple elements in olivine. Geology 33, 837-840.

Costa, F., Chakraborty, S. \& Dohmen, R. (2003). Diffusion coupling between trace and major elements and a model for calculation of magma residence times using plagioclase. Geochimica et Cosmochimica Acta 67, 21892200 .

Costa, F., Scaillet, B. \& Pichavant, M. (2004). Petrologic and experimental constraints on the pre-eruption conditions of Holocene dacite from Volcan San Pedro (36 $\mathrm{S}$, Chilean Andes) and the importance of sulfur in silicic subduction-related magmas. Journal of Petrology 45, 855-881.

Costa, F., Dohmen, R. \& Chakraborty, S. (2008). Time Scales of Magmatic Processes from Modeling the Zoning Patterns of Crystals. In: Putirka, K. D. \& Tepley, F. J. (eds.) Minerals, Inclusions and Volcanic Processes, 545-594.

Costa, F. \& Morgan, D. J. (2010). Time constraints from chemical equilibrium in magmatic crystals. In: Dosseto, A., Turner, S. \& Van Orman, J. A. (eds.) Timescales of Magmatic Processes: From core to atmosphere: Blackwell Publishing Limited.

Crank, J. (1975). The mathematics of diffusion. London: Oxford Press.

Davidson, J. P. \& Tepley, F. J. (1997). Recharge in volcanic systems: Evidence from isotope profiles of phenocrysts. Science $\mathbf{2 7 5}$, 826-829.

Davidson, J. P., Hora, J. M., Garrison, J. M. \& Dungan, M. A. (2005). Crustal forensics in arc magmas. Journal of Volcanology and Geothermal Research 140, 157-170.

Davidson, J. P., Morgan, D. J. \& Charlier, B. L. A. (2007a). Isotopic microsampling of magmatic rocks. Elements 3, 253-259. 
Davidson, J. P., Morgan, D. J., Charlier, B. L. A., Harlou, R. \& Hora, J. M. (2007b). Microsampling and isotopic analysis of igneous rocks: Implications for the study of magmatic systems. Annual Review of Earth and Planetary Sciences 35, 273-311.

Defant, M. J. \& Drummond, M. S. (1990). Derivation of some modern arc magmas by melting of young subducted lithosphere. Nature 347, 662-665.

Demets, C., Gordon, R. G., Argus, D. F. \& Stein, S. (1994). Effect of recent revisions to the geomagnetic reversal time-scale on estimates of current plate motions. Geophysical Research Letters 21, 2191-2194.

DePaolo, D. J. (1981). Trace element and isotopic effects of combined wallrock assimilation and fractional crystallization. Earth and Planetary Science Letters 53, 189-202.

Devine, J. D., Rutherford, M. J., Norton, G. E. \& Young, S. R. (2003). Magma storage region processes inferred from geochemistry of Fe-Ti oxides in andesitic magma, Soufriere Hills Volcano, Montserrat, W.I.. Journal of Petrology 44, 1375-1400.

Dimanov, A. \& Sautter, V. (2000). "Average" interdiffusion of (Fe,Mn)-Mg in natural diopside. European Journal of Mineralogy 12, 749-760.

Dimanov, A. \& Wiedenbeck, M. (2006). (Fe,Mn)-Mg interdiffusion in natural diopside: effect of pO2. European Journal of Mineralogy 18, 705-718.

Downey, W. S., Kellett, R. J., Smith, I. E. M., Price, R. C. \& Stewart, R. B. (1994). New palaeomagnetic evidence for the recent eruptive activity of Mt. Taranaki, New Zealand. Journal of Volcanology and Geothermal Research 60, 15-27.

Dungan, M. A. \& Davidson, J. (2004). Partial assimilative recycling of the mafic plutonic roots of arc volcanoes: an example from the Chilean Andes. Geology 32, 773-776.

Dungan, M. A., Wulff, A. \& Thompson, R. (2001). Eruptive stratigraphy of the Tatara-San Pedro complex, 36 degrees S, southern volcanic zone, Chilean Andes: Reconstruction method and implications for magma evolution at long-lived arc volcanic centers. Journal of Petrology 42, 555-626.

Eichelberger, J. C. (1975). Origin of andesite and dacite - evidence of mixing at Glass Mountain in California and at other circum-Pacific volcanos. Geological Society of America Bulletin 86, 1381-1391.

Eichelberger, J. C. (1978). Andesitic volcanism and crustal evolution. Nature 275, 21-27. 
Eichelberger, J. C. \& Izbekov, P. E. (2000). Eruption of andesite triggered by dyke injection: contrasting cases at Karymsky Volcano, Kamchatka and Mt Katmai, Alaska. Philosophical Transactions of the Royal Society of London. Series A: Mathematical, Physical and Engineering Sciences 358, 1465-1485.

Eichelberger, J. C., Izbekov, P. E. \& Browne, B. L. (2006). Bulk chemical trends at arc volcanoes are not liquid lines of descent. Lithos 87, 135-154.

Elliott, T., Plank, T., Zindler, A., White, W. \& Bourdon, B. (1997). Element transport from slab to volcanic front at the Mariana arc. Journal of Geophysical Research 102, 14,991-15,019.

Ewart, A. \& Griffin, W. L. (1994). Application of proton-microprobe data to trace-element partitioning in volcanic rocks. Chemical Geology 117, 251-284.

Ferrara, G., Petrini, R., Serri, G. \& Tonarini, S. (1989). Petrology and isotope-geochemistry of San Vincenzo rhyolites (Tuscany, Italy). Bulletin of Volcanology 51, 379-388.

Fowler, S. J. \& Spera, F. J. (2010). A metamodel for crustal magmatism: Phase equilibria of giant ignimbrites. Journal of Petrology 51, 1783-1830.

Foxworthy, B. L. \& Hill, M. (1982). Volcanic Eruptions of 1980 at Mount St. Helens: The First 100 Days. Washington: United States Government Printing Office.

Freer, R. \& Hauptman, Z. (1978). An experimental study of magnetite-titanomagetite interdiffusion. Physics of the Earth and Planetary Interiors 16, 223-231.

Frost, B. R. \& Lindsley, D. H. (1991). Occurrence of iron-titanium oxides in igneous rocks. Reviews in Mineralogy and Petrology 25, 433-468.

Gaetani, G. A., Grove, T. L. \& Bryan, W. B. (1993). The influence of water on the petrogenesis of subductionrelated igneous rocks. Nature $\mathbf{3 6 5}, 332-334$.

Gamble, J. A., Wood, C. P., Price, R. C., Smith, I. E. M., Stewart, R. B. \& Waight, T. (1999). A fifty year perspective of magmatic evolution on Ruapehu Volcano, New Zealand: verification of open system behaviour in an arc volcano. Earth and Planetary Science Letters 170, 301-314.

Gamble, J. A., Price, R. C., Smith, I. E. M., McIntosh, W. C. \& Dunbar, N. W. (2003). Ar-40/Ar-39 geochronology of magmatic activity, magma flux and hazards at Ruapehu volcano, Taupo Volcanic Zone, New Zealand. Journal of Volcanology and Geothermal Research 120, 271-287. 
Ganguly, J. \& Tazzoli, V. (1994). Fe2+-Mg interdiffusion in ortho-pyroxene - retrieval from the data on intracrystalline exchange-reaction. American Mineralogist 79, 930-937.

Ganguly, J., Dasgupta, S., Cheng, W. J. \& Neogi, S. (2000). Exhumation history of a section of the Sikkim Himalayas, India: records in the metamorphic mineral equilibria and compositional zoning of garnet. Earth and Planetary Science Letters 183, 471-486.

Gardner, J. E., Carey, S., Rutherford, M. J. \& Sigurdsson, H. (1995). Petrologic diversity in Mount St. Helens dacites during the last 4,000 years: implications for magma mixing. Contributions to Mineralogy and Petrology 119, 224-238.

Ghiorso, M. S., Hirschmann, M. M., Reiners, P. W. \& Kress, V. C. I. (2002). The pMELTS: a revision of MELTS for improved calculation of phase relations and major element partitioning related to partial melting of the mantle to $3 \mathrm{GPa}$. Geochemistry, Geophysics, Geosystems 3, 1-36.

Giba, M., Nicol, A. \& Walsh, J. J. (2010). Evolution of faulting and volcanism in a back-arc basin and its implications for subduction processes. Tectonics 29, TC4020.

Giggenbach, W. (1982). The chemical and isotopic composition of gas discharges from New Zealand andesitic volcanoes. Bulletin of Volcanology 45, 253-255.

Giletti, B. J. \& Casserly, J. E. D. (1994). Strontium diffusion kinetics in plagioclase feldspars. Geochimica et Cosmochimica Acta 58, 3785-3793.

Gill, J. B. (1981). Orogenic Andesites and Plate Tectonics. New York: Springer-Verlag.

Ginibre, C., Worner, G. \& Kronz, A. (2002a). Minor- and trace-element zoning in plagioclase: implications for magma chamber processes at Parinacota volcano, northern Chile. Contributions to Mineralogy and Petrology 143, $300-315$.

Ginibre, C., Kronz, A. \& Worner, G. (2002b). High-resolution quantitative imaging of plagioclase composition using accumulated backscattered electron images: new constraints on oscillatory zoning. Contributions to Mineralogy and Petrology 142, 436-448.

Ginibre, C., Worner, G. \& Kronz, A. (2007). Crystal zoning as an archive for magmatic evolution. Elements 3, $261-266$

Goldlich, M. S., Ingamells, C. O., Suhr, N. H. \& Anderson, D. T. (1967). Analyses of silicate rock and mineral standards. Canadian Journal of Earth Sciences 4, 747-755. 
Gow, A. J. (1968). Petrographic and petrochemical studies of Mt Egmont andesites. New Zealand Journal of Geology and Geophysics 11, 166-190.

Graham, I. J. \& Hackett, W. R. (1987). Petrology of calc-alkaline lavas from Ruapehu volcano and related vents, Taupo Volcanic Zone, New Zealand. Journal of Petrology 28, 531-567.

Green, T. H. (1981). Experimental evidence for the role of accessory phases in magma genesis. Journal of Volcanology and Geothermal Research 10, 405-422.

Grove, T. L. \& Kinzler, R. J. (1986). Petrogenesis of Andesites. Annual Review of Earth and Planetary Sciences 14, $417-454$

Grove, T. L., Baker, M. B. \& Kinzler, R. J. (1984). Coupled CaAl-NaSi diffusion in plagioclase feldspar experiments and applications to cooling rate speedometry. Geochimica et Cosmochimica Acta 48, 2113-2121.

Grove, T. L., Donnelly-Nolan, J. M. \& Housh, T. (1997). Magmatic processes that generated the rhyolite of Glass Mountain, Medicine Lake volcano, N. California. Contributions to Mineralogy and Petrology 127, 205-223.

Grove, T. L., Elkins-Tanton, L. T., Parman, S. W., Chatterjee, N., Muntener, O. \& Gaetani, G. A. (2003). Fractional crystallisation and mantle-melting controls on calc-alkaline differentiation trends. Contributions to Mineralogy and Petrology 145, 515-533.

Gruender, K., Stewart, R. B. \& Foley, S. (2010). Xenoliths from the sub-volcanic lithosphere of Mt Taranaki, New Zealand. Journal of Volcanology and Geothermal Research 190, 192-202.

Jochum, K. P., Stoll, B., Herwig, K., Willbold, M., Hofmann, A. W., Amini, M., Aarburg, S., Abouchami, W., Hellebrand, E., Mocek, B., Raczek, I., Stracke, A., Alard, O., Bouman, C., Becker, S., Ducking, M., Bratz, H., Klemd, R., de Bruin, D., Canil, D., Cornell, D., de Hoog, C. J., Dalpe, C., Danyushevsky, L., Eisenhauer, A., Gao, Y. J., Snow, J. E., Goschopf, N., Gunther, D., Latkoczy, C., Guillong, M., Hauri, E. H., Hofer, H. E., Lahaye, Y., Horz, K., Jacob, D. E., Kassemann, S. A., Kent, A. J. R., Ludwig, T., Zack, T., Mason, P. R. D., Meixner, A., Rosner, M., Misawa, K. J., Nash, B. P., Pfander, J., Premo, W. R., Sun, W. D., Tiepolo, M., Vannucci, R., Vennemann, T., Wayne, D. \& Woodhead, J. D. (2006). MPI-DING reference glasses for in situ microanalysis: New reference values for element concentrations and isotope ratios. Geochemistry Geophysics Geosystems 7.Q02008, doi:10.1029/2005GC001060.

Haase, C. S., Chadam, J., Feinn, D. \& Ortoleva, P. (1980). Oscillatory zoning in plagioclase feldspar. Science 209, 272-274. 
Hammarstrom, J. M. \& Zen, E. A. (1986). Aluminium in hornblende - An empirical igneous geobarometer. American Mineralogist 71, 1297-1313.

Harrison, A. J. \& White, R. S. (2004). Crustal structure of the Taupo Volcanic Zone, New Zealand: Stretching and igneous intrusion. Geophysical Research Letters 31, L13615.

Hawkesworth, C. J. \& Kemp, A. I. S. (2006). Evolution of the continental crust. Nature 443, 811-817.

Hawkesworth, C. J., Turner, S. P., McDermott, F., Peate, D. W. \& van Calstern, P. (1997). U-Th isotopes in arc magmas: Implications for element transfer from the subducted crust. Science 276, 551-555.

Hawkesworth, C., George, R., Turner, S. \& Zellmer, G. (2004). Time scales of magmatic processes. Earth and Planetary Science Letters 218, 1-16.

Heiken, G. \& Eichelberger, J. C. (1980). Eruptions at Chaos Crags, Lassen Volcanic National Park, California. Journal of Volcanology and Geothermal Research 7, 443-481.

Hermann, J., Spandler, C., Hack, A. \& Korsakov, A. V. (2006). Aqueous fluids and hydrous melts in highpressure and ultra-high pressure rocks: Implications for element transfer in subduction zones. Lithos 92, 399-417.

Herzer, R. H. (1995). Seismic stratigraphy of a buried volcanic arc, Northland, New Zealand and implications for Neogene subduction. Marine and Petroleum Geology 12, 511-531.

Hildreth, W. (2004). Volcanological perspectives on Long Valley, Mammoth Mountain, and Mono Craters: several contiguous but discrete systems. Journal of Volcanology and Geothermal Research 136, 169-198.

Hildreth, W. \& Moorbath, S. (1988). Crustal contributions to arc magmatism in the Andes of Central Chile. Contributions to Mineralogy and Petrology 98, 455-489.

Hobden, B. J., Houghton, B. F., Davidson, J. P. \& Weaver, S. D. (1999). Small and short-lived magma batches at composite volcanoes: time windows at Tongariro volcano, New Zealand. Journal of the Geological Society 156, 865-868.

Hogg, A. G., Lowe, D. J. \& Hendey, C. H. (1987). University of Waikato radiocarbon dates I. Radiocarbon 29, 263-301.

Hollister, L. S., Grissom, G. C., Peters, E. K., Stowell, H. H. \& Sisson, V. B. (1987). Confirmation of the empirical correlation of $\mathrm{Al}$ in hornblende with pressure of solidification of calc-alkaline plutons. American Mineralogist 72, 231-239. 
Houghton, B. F., Wilson, C. J. N., McWilliams, M. O., Lanphere, M. A., Weaver, S. D., Briggs, R. M. \& Pringle, M. S. (1995). Chronology and dynamics of a large silicic magmatic system: Central Taupo Volcanic Zone, New Zealand. Geology 23, 13-16.

Humphreys, M. C. S., Blundy, J. D. \& Sparks, R. S. J. (2006). Magma evolution and open-system processes at Shiveluch Volcano: insights from phenocryst zoning. Journal of Petrology 47, 2303-2334.

Ingamells, C. O. (1980). Analyzed minerals for electron microprobe standards. Geostandards Newsletter 2, 115.

Ingamells, C. O. (1983). Microprobe Column. Geostandards Newsletter 7, 243-244.

Jarosweich, E., Nelen, J. A. \& Norber, J. A. (1980). Reference samples for electron microprobe analysis. Geostandards Newsletter 4, 43-47.

Jerram, D. A. \& Martin, V. M. (2008). Understanding crystal populations and their significance through the magma plumbing system. Geological Society, London, Special Publications 304, 133-148.

Johnson, M. C. \& Plank, T. (1999). Dehydration and melting experiments constrain the fate of subducted sediments. Geochemistry, Geophysics, Geosystems 1, 1-26.

Johnson, M. C. \& Rutherford, M. J. (1989). Experimental calibration of the aluminium-in-hornblende geobarometer with application to Long-Valley Caldera (California) volcanic-rocks. Geology 17, 837-841.

Kamp, P. J. J., Vonk, A. J., Bland, K. J., Hansen, R. J., Hendy, A. J. W., McIntyre, A. P., Ngatai, M., Cartwright, S. J., Hayton, S. \& Nelson, C. S. (2004). Neogene stratigraphic architecture and tectonic evolution of Wanganui, King Country, and eastern Taranaki Basins, New Zealand. New Zealand Journal of Geology and Geophysics 47, 625-644.

Kay, R. W. (1978). Aleutian magnesian andesites - melts from subducted Pacific Ocean crust. Journal of Volcanology and Geothermal Research 4, 117-132.

Kay, R. W. (1980). Volcanic arc magmas - Implications of a melting-mixing model for element recycling in the crust-upper mantle system. Geology $\mathbf{8 8}, 497-522$.

Kent, A. J. R., Blundy, J., Cashman, K. V., Cooper, K. M., Donnelly, C., Pallister, J. S., Reagan, M., Rowe, M. C. \& Thornber, C. R. (2007). Vapor transfer prior to the October 2004 eruption of Mount St. Helens, Washington. Geology 35, 231-234.

Kent, A. J. R., Darr, C., Koleszar, A. M., Salisbury, M. J. \& Cooper, K. M. (2010). Preferential eruption of andesitic magmas through recharge filtering. Nature Geoscience 3, 631-636. 
Kessel, R., Schmidt, M. W., Ulmer, P. \& Pettke, T. (2005). Trace element signature of subduction-zone fluids, melts and supercritical liquids at 120-180 km depth. Nature 437, 724-727.

Kimura, J.-I., Kent, A. J. R., Rowe, M. C., Katakuse, M., Nakano, F., Hacker, B. R., van Keken, P. E., Kawabata, H. \& Stern, R. J. (2010). Origin of cross-chain geochemical variation in Quaternary lavas from the northern Izu arc: Using a quantitative mass balance approach to identify mantle sources and mantle wedge processes. Geochemistry, Geophysics Geosystems 11, Q10011.

King, P. R. \& Thrasher, G. P. (1996). Cretaceous-Cenozoic Geology and Petroleum Systems of the Taranaki Basin, New Zealand. Institute of Geological and Nuclear Sciences Monograph 13, 243 pp.

Klugel, A., Hansteen, T. H. \& Galipp, K. (2005). Magma storage and underplating beneath Cumbre Vieja volcano, La Palma (Canary Islands). Earth and Planetary Science Letters 236, 211-226.

Kogiso, T., Omori, S. \& Maruyama, S. (2009). Magma genesis beneath Northeast Japan arc: A new perspective on subduction zone magmatism. Gondwana Research 16, 446-457.

Kushiro, I. (1983). On the lateral variation in chemical composition and volume of Quaternary volcanic rocks across Japan arc. Journal of Volcanology and Geothermal Research 18, 435-447.

Lange, R. A., Frey, H. M. \& Hector, J. (2009). A thermodynamic model for the plagioclase-liquid hygrometer/thermometer. American Mineralogist 94, 494-506.

Larocque, J. \& Canil, D. (2010). The role of amphibole in the evolution of arc magmas and crust: the case from the Jurassic Bonanza arc section, Vancouver Island, Canada. Contributions to Mineralogy and Petrology 159, 475492.

Larsen, J. F. (2005). Experimental study of plagioclase rim growth around anorthite seed crystals in rhyodacitic melt. American Mineralogist 90, 417-427.

Leake, B. E., Woolley, A. R., Arps, C. E. S., Birch, W. D., Gilbert, M. C., Grice, J. D., Hawthorne, F. C., Kato, A., Kisch, H. J., Krivovichev, V. G., Linthout, K., Laird, J., Mandarino, J., Maresch, W. V., Nickel, E. H., Rock, N. M. S., Schumacher, J. C., Smith, D. C., Stephenson, N. C. N., Ungaretti, L., Whittaker, E. J. W. \& Youzhi, G. (1997). Nomenclature of amphiboles: Report of the Subcommittee on Amphiboles of the International Mineralogical Association Commission on New Minerals and Mineral Names. Mineralogical Magazine 61, 295-321.

Lepage, L. D. (2003). ILMAT: an Excel worksheet for ilmenite-magnetite geothermometry and geobarometry. Computers \& Geosciences 29, 673-678. 
Locke, C. A. \& Cassidy, J. (1997). Egmont Volcano, New Zealand: three-dimensional structure and its implications for evolution. Journal of Volcanology and Geothermal Research 76, 149-161.

Locke, C. A., Cassidy, J. \& MacDonald, A. (1993). Three-dimensional structure of relict stratovolcanoes in Taranaki, New Zealand: evidence from gravity data. Journal of Volcanology and Geothermal Research 59, 121-130.

Locke, C. A., Cassidy, J. \& MacDonald, A. (1994). Constraints on the evolution of the Taranaki volcanoes, New Zealand, based on aeromagnetic data. Bulletin of Volcanology 56, 552-560.

Lowe, D. J. (1988). Stratigraphy, age, composition, and correlation of late Quaternary tephras interbedded with organic sediments in Waikato lakes, North Island, New Zealand. New Zealand Journal of Geology and Geophysics 31, 125-165.

Martin, H. (1999). Adakitic magmas: Modern analogues of Archaean granitoids. Lithos 46, 411-429.

Martin, H., Smithies, R. H., Rapp, R., Moyen, J. F. \& Champion, D. (2005). An overview of adakite, tonalitetrondhjemite-granodiorite (TTG), and sanukitoid: relationships and some implications for crustal evolution. Lithos 79, $1-24$

Martin, V. M., Morgan, D. J., Jerram, D. A., Caddick, M. J., Prior, D. J. \& Davidson, J. P. (2008). Bang! Monthscale eruption triggering at Santorini Volcano. Science 321, 1178.

McCulloch, M. T. \& Gamble, J. A. (1991). Geochemical and geodynamical constraints on subduction zone magmatism. Earth and Planetary Science Letters 102, 358-374.

McGlone, M. S., Neall, V. E. \& Clarkson, B. D. (1988). The effect of recent volcanic events and climatic changes on the vegetation of Mt Egmont (Mt Taranaki ), New Zealand. New Zealand Journal of Botany 26, 123-144.

Mibe, K., Fujii, T. \& Yasuda, A. (1999). Control of the location of the volcanic front in island arcs by aqueous fluid connectivity in the mantle wedge. Nature 401, 259-262.

Morgan, D. J. (2003). Timescales of crystal residence and magmatic differentiation: Vesuvius. Ph.D. Dissertation, University of Durham

Morgan, D. J. \& Blake, S. (2006). Magmatic residence times of zoned phenocrysts: introduction and application of the binary element diffusion modelling (BEDM) technique. Contributions to Mineralogy and Petrology 151, 5870. 
Morgan, D. J., Blake, S., Rogers, N. W., DeVivo, B., Rolandi, G., Macdonald, R. \& Hawkesworth, C. J. (2004). Time scales of crystal residence and magma chamber volume from modelling of diffusion profiles in phenocrysts: Vesuvius 1944. Earth and Planetary Science Letters 222, 933-946.

Morgan, D. J., Blake, S., Rogers, N. W., De Vivo, B., Rolandi, G. \& Davidson, J. P. (2006). Magma chamber recharge at Vesuvius in the century prior to the eruption of A.D. 79. Geology 34, 845-848.

Morse, S. A. (1984). Cation diffusion in plagioclase feldspar. Science 225, 504-505.

Mortimer, N., Tulloch, A. J. \& Ireland, T. R. (1997). Basement geology of Taranaki and Wanganui Basins, New Zealand. New Zealand Journal of Geology and Geophysics 40, 223-236.

Mortimer, N., Gans, P. B., Palin, J. M., Meffre, S., Herzer, R. H. \& Skinner, D. N. B. (2010). Location and migration of Miocene-Quaternary volcanic arcs in the SW Pacific region. Journal of Volcanology and Geothermal Research 190, 1-10.

Muir, R. J., Bradshaw, J. D., Weaver, S. D. \& Laird, M. G. (2000). The influence of basement structure on the evolution of the Taranaki Basin, New Zealand. Journal of the Geological Society 157, 1179-1185.

Murphy, J. B. (2007). Arc Magmatism II: Geochemical and Isotopic Characteristics. Geoscience Canada 34, 735.

Murphy, M. D., Sparks, R. S. J., Barclay, J., Carroll, M. R. \& Brewer, T. S. (2000). Remobilisation of andesite magma by intrusion of mafic magma at Soufriere Hills Volcano, Montserrat, West Indies. Journal of Petrology 41, $21-42$.

Nakagawa, M., Wada, K., Thordarson, T., Wood, C. P. \& Gamble, J. A. (1999). Petrologic investigations of the 1995 and 1996 eruptions of Ruapehu volcano, New Zealand: formation of discrete and small magma pockets and their intermittent discharge. Bulletin of Volcanology 61, 15-31.

Nakagawa, M., Wada, K. \& Wood, C. P. (2002). Mixed magmas, mush chambers and eruption triggers: Evidence from zoned clinopyroxene phenocrysts in andesitic scoria from the 1995 eruptions of Ruapehu volcano, New Zealand. Journal of Petrology 43, 2279-2303.

Nakamura, M. (1995). Continuous mixing of crystal mush and replenished magma in the ongoing Unzen eruption. Geology 23, 807-810.

Nakamura, M. \& Shimakita, S. (1998). Dissolution origin and syn-entrapment compositional change of melt inclusion in plagioclase. Earth and Planetary Science Letters 161, 119-133. 
Neall, V. E. (1979). Sheets P19, P20 \& P21 New Plymouth, Egmont and Mania. Geological Map of New Zealand 1:50 000. Wellington: New Zealand Geological Survey Department of Scientific and Industrial Research, 3 maps and notes, 36p.

Neall, V. E. \& Alloway, B. A. (1986). Quaternary volcaniclastics and volcanic hazards of Taranaki. New Zealand Geological Survey Report 12, 101-137.

Neall, V. E., Stewart, R. B. \& Smith, I. E. M. (1986). History and Petrology of the Taranaki Volcanoes. The Royal Society of New Zealand Bulletin 23, 251-263.

Nelson, S. T. \& Montana, A. (1992). Sieve-textured plagioclase in volcanic rocks produced by rapid decompression. American Mineralogist 77, 1242-1249.

Nimis, P. (1995). A clinopyroxene geobarometer for basaltic systems based on crystal-structure modeling. Contributions to Mineralogy and Petrology 121, 115-125.

Nimis, P. (1999). Clinopyroxene geobarometry of magmatic rocks. Part 2. Structural geobarometers for basic to acid, tholeiitic and mildly alkaline magmatic systems. Contributions to Mineralogy and Petrology 135, 62-74.

Nimis, P. \& Taylor, W. R. (2000). Single clinopyroxene thermobarometry for garnet peridotites. Part I. Calibration and testing of a Cr-in-Cpx barometer and an enstatite-in-Cpx thermometer. Contributions to Mineralogy and Petrology 139, 541-554.

Onsager, L. (1945). Theories and problems of liquid diffusion. Annuals of the New York Academy of Sciences 46, 241-265.

Pallister, J. S., Hoblitt, R. P. \& Reyes, A. G. (1992). A Basalt Trigger for the 1991 Eruptions of Pinatubo Volcano? Nature 356, 426-428.

Peacock, S. M., Rushmer, T. \& Thompson, A. B. (1994). Partial melting of subducting oceanic crust. Earth and Planetary Science Letters 121, 227-244.

Pearce, J. A. \& Cann, J. R. (1973). Tectonic setting of basic volcanic rocks determined using trace element analyses. Earth and Planetary Science Letters 19, 290-300.

Pearce, T. H. \& Kolisnik, A. M. (1990). Observations of plagioclase zoning using interference imaging. Earth Science Reviews 29, 9-26.

Petford, N. \& Atherton, M. (1996). Na-rich partial melts from newly underplated basaltic crust: the Cordillera Blanca Batholith, Peru. Journal of Petrology 37, 1491-1521. 
Petford, N. \& Gallagher, K. (2001). Partial melting of mafic (amphibolitic) lower crust by periodic influx of basaltic magma. Earth and Planetary Science Letters 193, 483-499.

Pichavant, M., Martel, C., Bourdier, J.-L. \& Scaillet, B. (2002). Physical conditions, structure, and dynamics of a zoned magma chamber: Mount Pelée (Martinique, Lesser Antilles Arc). Journal of Geophysical Research 107, (B5)2093.

Plank, T. (2005). Constraints from thorium/lanthanum on sediment recycling at subduction zones and the evolution of the continents. Journal of Petrology 46, 921-944.

Plank, T. \& Langmuir, C. H. (1988). An evaluation of the global variations in the major element chemistry of arc basalts. Earth and Planetary Science Letters 90, 349-370.

Platz, T. (2007). Understanding aspects of andesitic dome-forming eruptions through the last $1000 \mathrm{yrs}$ of volcanism at Mt Taranaki, New Zealand. Ph.D. Dissertation, Massey University, 264 pp.

Platz, T., Cronin, S. J., Cashman, K., Stewart, R. B. \& Smith, I. E. M. (2007a). Transition from effusive to explosive phases in andesite eruptions- A case-study from the AD1655 eruption of Mt. Taranaki, New Zealand. Journal of Volcanology and Geothermal Research 161, 15-34.

Platz, T., Cronin, S. J., Smith, I. E. M., Turner, M. P. \& Steward, R. P. (2007b). Improving the reliability of microprobe-based analyses of andesitic glasses for tephra correlation. Holocene 17, 573-583.

Price, R. C., McCulloch, M. T., Smith, I. E. M. \& Stewart, R. B. (1992). Pb-Nd-Sr isotopic compositions and trace element characteristics of young volcanic rocks from Egmont Volcano and comparisons with basalts and andesites from the Taupo Volcanic Zone, New Zealand. Geochimica et Cosmochimica Acta 56, 941-953.

Price, R. C., Waight, T. E., Chapman, J. R., Beyer, E. E., Smith, I. E. M. \& Stewart, R. B. (1997). The geochemical evolution of arc magmas in a continental setting: evidence from detailed chemo-stratigraphy at Ruapehu, New Zealand. Geological Society of Australia Abstracts 45, 79-81.

Price, R. C., Stewart, R. B., Woodhead, J. D. \& Smith, I. E. M. (1999). Petrogenesis of high-K arc magmas: evidence from Egmont Volcano, North Island, New Zealand. Journal of Petrology 40, 167-197.

Price, R. C., Gamble, J. A., Smith, I. E. M., Stewart, R. B., Eggins, S. \& Wright, I. C. (2005). An integrated model for the temporal evolution of andesites and rhyolites and crustal development in New Zealand's North Island. Journal of Volcanology and Geothermal Research 140, 1-24. 
Price, R. C., Turner, S., Cook, C., Hobden, B., Smith, I. E. M., Gamble, J. A., Handley, H., Maas, R. \& Möbis, A. (2010). Crustal and mantle influences and U-Th-Ra disequilibrium in andesitic lavas of Ngauruhoe volcano, New Zealand. Chemical Geology 277, 355-373.

Prouteau, G. \& Scaillet, B. (2003). Experimental constraints on the origin of the 1991 Pinatubo dacite. Journal of Petrology 44, 2203-2241.

Putirka, K. A. (2005). Igneous thermometers and barometers based on plagioclase plus liquid equilibria: Tests of some existing models and new calibrations. American Mineralogist 90, 336-346.

Putirka, K. D. (2008). Thermometers and Barometers for Volcanic Systems. In: Putirka, K. D. \& Tepley, F. J. (eds.) Minerals, Inclusions and Volcanic Processes, 61-120.

Putirka, K., Johnson, M., Kinzler, R., Longhi, J. \& Walker, D. (1996). Thermobarometry of mafic igneous rocks based on clinopyroxene-liquid equilibria, 0-30 kbar. Contributions to Mineralogy and Petrology 123, 92-108.

Putirka, K. D., Mikaelian, H., Ryerson, F. \& Shaw, H. (2003). New clinopyroxene-liquid thermobarometers for mafic, evolved, and volatile-bearing lava compositions, with applications to lavas from Tibet and the Snake River Plain, Idaho. American Mineralogist 88, 1542-1554.

Rattenbury, M. S., Cooper, R. A. \& Johnston, M. R. (1998). Geology of the Nelson area. Institute of Geological and Nuclear Sciences 1:250 000 geological map 9.1 sheet +67 p. Lower Hutt, New Zealand: Institute of Geological and Nuclear Sciences Limited.

Reed. (1975). Electron Microprobe Analysis. Cambridge: Cambridge University Press.

Reubi, O. \& Blundy, J. (2009). A dearth of intermediate melts at subduction zone volcanoes and the petrogenesis of arc andesites. Nature 461, 1269-1273.

Reyners, M. (1983). Lateral Segmentation of the Subducted Plate at the Hikurangi Margin, New Zealand: Seismological Evidence. Tectonophysics 96, 203-223.

Reyners, M., Eberhart-Phillips, D., Stuart, G. \& Nishimura, Y. (2006). Imaging subduction from the trench to $300 \mathrm{~km}$ depth beneath the central North Island, New Zealand, with Vp and Vp/Vs. Geophysical Journal International $165,565-583$.

Ridolfi, F., Renzulli, A. \& Puerini, M. (2010). Stability and chemical equilibrium of amphibole in calc-alkaline magmas: an overview, new thermobarometric formulations and application to subduction-related volcanoes.

Contributions to Mineralogy and Petrology 160, 45-66. 
Rollinson, H. (1993). Using Geochemical Data: Evaluation, Presentation, Interpretation. London: Longman Group Limited.

Rudnick, R. L. (1995). Making continental crust. Nature 378, 571-578.

Rudnick, R. L. \& Gao, S. (2003). Composition of the Continental Crust. In: Heinrich, D. H. \& Karl, K. T. (eds.) Treatise on Geochemistry. Oxford: Pergamon, 1-64.

Rutherford, M. J. \& Devine, J. D. (1988). The May 18, 1980, eurption of Mount St Helens. 3. Stability and chemistry of amphibole in the magma chamber. Journal of Geophysical Research-Solid Earth and Planets 93, 1194911959.

Rutherford, M. J. \& Hill, P. M. (1993). Magma ascent rates from amphibole breakdown - An experimental study applied to the 1980-1986 Mount St-Helens eruptions. Journal of Geophysical Research 98, 19667-19685.

Rutherford, M. J. \& Devine, J. D. (2003). Magmatic conditions and magma ascent as indicated by hornblende phase equilibria and reactions in the 1995-2002 Soufriere Hills magma. Journal of Petrology 44, 1433-1454.

Rutherford, M. J. \& Devine, J. D. (eds.) (2008). Magmatic conditions and processes in the storage zone of the 2004-2006 Mount St. Helens eruption: The record in amphibole and plagioclast phenocrysts. In: Sherrod, D. R., Scott, W. E. and Stauffer, P. H. (eds.) A volcano rekindled: the first year of renewed eruption at Mount St. Helens, 2004-2006. US Geological Survey Professional Paper 1750, ch 31.

Sakuyama, M. (1979). Evidence of magma mixing: Petrological study of Shirouma-Oike calc-alkaline andesite volcano, Japan. Journal of Volcanology and Geothermal Research 5, 179-208.

Saunders, K. E., Morgan, D. J., Baker, J. A. \& Wysoczanski, R. J. (2010). The magmatic evolution of the Whakamaru supereruption, New Zealand, constrained by a microanalytical study of plagioclase and quartz. Journal of Petrology 51, 2465-2488.

Sautter, V., Jaoul, O. \& Abel, F. (1988). Aluminium diffusion in diopside using the Al-27(P, gamma) Si-28 nuclear-reaction - preliminary results. Earth and Planetary Science Letters 89, 109-114.

Schmidt, M. W. (1992). Amphibole composition in tonalite as a function of pressure - An experimental calibration of the Al-in-hornblende barometer. Contributions to Mineralogy and Petrology 110, 304-310.

Schmidt, M. W. \& Poli, S. (1998). Experimentally based water budgets for dehydrating slabs and consequences for arc magma generation. Earth and Planetary Science Letters 163, 361-379. 
Severs, M. J., Beard, J. S., Fedele, L., Hanchar, J. M., Mutchler, S. R. \& Bodnar, R. J. (2009). Partitioning behaviour of trace elements between dacitic melt and plagioclase, orthopyroxene, and clinopyroxene based on laser ablation ICPMS analysis of silicate melt inclusions. Geochimica et Cosmochimica Acta 73, 2123-2141.

Shane, P. (2005). Towards a comprehensive distal andesitic tephrostratigraphic framework for New Zealand based on eruptions from Egmont volcano. Journal of Quaternary Science 20, 45-57.

Sherburn, S. \& White, R. S. (2005). Crustal seismicity in Taranaki, New Zealand using accurate hypocentres from a dense network. Geophysical Journal International 162, 494-506.

Sherburn, S., White, R. S. \& Chadwick, M. (2006). Three-dimensional tomographic imaging of the Taranaki volcanoes, New Zealand. Geophysical Journal International 166, 957-969.

Sibley, D. F., Vogel, T. A., Walker, B. M. \& Byerly, G. (1976). Origin of oscillatory zoning in plagioclase diffusion and growth controlled model. American Journal of Science 276, 275-284.

Simonetti, A., Shore, M. \& Bell, K. (1996). Diopside phenocrysts from a nephelinite lavas, Napak Volcano, Eastern Uganda: Evidence for magma mixing. The Canadian Mineralogist 34, 411-421.

Singer, B. S., Dungan, M. A. \& Layne, G. D. (1995). Textures and Sr, Ba, Mg, K and Ti compositional profiles in volcanic plagioclase - Clues to the dynamics of calc-alkaline magma chambers. American Mineralogist 80, 776798.

Sisson, T. W. \& Grove, T. L. (1993). Experimental investigations of the role of H2O in calc-alkaline differentiation and subduction zone magmatism. Contributions to Mineralogy and Petrology 113, 143-166.

Smith, V. C., Blundy, J. D. \& Arce, J. L. (2009). A temporal record of magma accumulation and evolution beneath Nevado de Toluca, Mexico, preserved in plagioclase phenocrysts. Journal of Petrology 50, 405-426.

Sparks, R. S. J. \& Marshall, L. A. (1986). Thermal and mechanical constraints on mixing between mafic and silicic magmas. Journal of Volcanology and Geothermal Research 29, 99-124.

Sparks, R. S. J., Sigurdsson, H. \& Wilson, L. (1977). Magma mixing: a mechanism for triggering acid explosive eruptions. Nature 267, 315-318.

Stagpoole, V. \& Funnell, R. (2001). Arc magmatism and hydrocarbon generation in the northern Taranaki Basin, New Zealand. Petroleum Geoscience 7, 255-267.

Stagpoole, V. \& Nicol, A. (2008). Regional structure and kinematic history of a large subduction back thrust: Taranaki Fault, New Zealand. Journal of Geophysical Research 113, B01403. 
Stern, R. J. (2002). Subduction zones. Reviews of Geophysics 40, 3-1.

Stern, T. A. (1985). A back-arc basin formed within the continental lithosphere - The Central Volcanic Region of New Zealand. Tectonophysics 112, 385-409.

Stern, T. A. \& Davey, F. J. (1987). A seismic investigation of the crustal and upper mantle structure within the Central Volcanic Region of New Zealand. New Zealand Journal of Geology and Geophysics 30, 217-231.

Stern, T. A. \& Davey, F. J. (1990). Deep seismic expression of a foreland basin - Taranaki Basin, New Zealand. Geology 18, 979-982.

Stern, T., Smith, E. G. C., Davey, F. J. \& Muirhead, K. J. (1987). Crustal and upper mantle structure of the Northwestern North Island, New Zealand, from seismic refraction data. Geophysical Journal of the Royal Astronomical Society 91, 913-936.

Stewart, R. B. (2010). Andesites as magmatic liquids or liquid-crystal mixtures; Insights from Egmont and Ruapehu Volcanoes, New Zealand. Central European Journal of Geosciences 2, 329-338.

Stewart, R. B., Price, R. C. \& Smith, I. E. M. (1996). Petrogenesis of high-K arc magmas: Evidence from Egmont Volcano, North Island, New Zealand. Journal of Volcanology and Geothermal Research 74, 275-295.

Stormer, J. C. J. (1983). The effects of recalculation on estimates of temperature and oxygen fugacity from analyses of multi-component iron-titanium oxides. American Mineralogist 68, 589-594.

Stratford, W. R. \& Stern, T. A. (2004). Strong seismic reflections and melts in the mantle of a continental backarc basin. Geophysical Research Letters 31, L06622.

Streck, M. J. (2008). Mineral textures and zoning as evidence for open system processes. Reviews in Mineralogy and Geochemistry 69, 595-622.

Streck, M. J., Dungan, M. A., Malavassi, E., Reagan, M. \& Bussy, F. (2002). The role of basalt replenishment in the generation of basaltic andesites of the ongoing activity at Arenal volcano, Costa Rica: evidence from clinopyroxene and spinel. Bulletin of Volcanology 64, 316-327.

Streck, M. J., Dungan, M. A., Bussy, F. \& Malavassi, E. (2005). Mineral inventory of continuously erupting basaltic andesites at Arenal volcano, Costa Rica: implications for interpreting monotonous, crystal-rich, mafic arc stratigraphies. Journal of Volcanology and Geothermal Research 140, 133-155.

Streck, M. J., Leeman, W. P. \& Chesley, J. (2007). High-magnesian andesite from Mount Shasta: A product of magma mixing and contamination, not a primitive mantle melt. Geology 35, 351-354. 
Sugawara, T. (2001). Ferric iron partitioning between plagioclase and silicate liquid: thermodynamics and petrological applications. Contributions to Mineralogy and Petrology 141, 659-686.

Sun, S.-s. \& McDonough, W. F. (1989). Chemical and isotopic systematics of oceanic basalts: implications for mantle composition and processes. Geological Society, London, Special Publications 42, 313-345.

Tatsumi, Y. \& Eggins, S. (1995). Subduction Zone Magmatism. Oxford: Blackwell Scientific.

Tatsumi, Y. \& Takahashi, T. (2006). Operation of subduction factory and production of andesite. Journal of Mineralogical and Petrological Sciences 101, 145-153.

Taylor, S. R. \& McLennan, S. M. (1995). The geochemical evolution of the continental crust. Reviews in Geophysics 33, 241-265.

Thornber, C. R., Pallister, J. S., Lowers, H. A., Rowe, M. C., Mandeville, C. W. \& Meeker, G. P. (eds.) (2008). Chemistry, mineralogy, and petrology of amphibole in Mount St. Helens 2004-2006 dacite In: Sherrod, D.R., Scott, W.E., and Stauffer, P.H., (eds.) A volcano rekindled; the renewed eruption of Mount St. Helens, 2004-2006. U.S. Geological Survey Professional Paper 1750, ch 32.

Tomiya, A. \& Takahashi, E. (2005). Evolution of the magma chamber beneath Usu volcano since 1663: A natural laboratory for observing changing phenocryst compositions and textures. Journal of Petrology 46, 2395-2426.

Tsuchiyama, A. (1985). Dissolution kinetics of plagioclase in the melt of the system diopside-albite-anorthite, and origin of dusty plagioclase in andesites. Contributions to Mineralogy and Petrology 89, 1-16.

Turner, M. B. (2008). Eruption Cycles and Magmatic Processes at a Reawakening Volcano, Mt Taranaki, New Zealand. Ph.D. Dissertation, Massey University, 409 pp.

Turner, S. \& Costa, F. (2007). Measuring timescales of magmatic evolution. Elements 3, 267-272.

Turner, S., George, R., Jerram, D. A., Carpenter, N. \& Hawkesworth, C. (2003). Case studies of plagioclase growth and residence times in island arc lavas from Tonga and the Lesser Antilles, and a model to reconcile discordant age information. Earth and Planetary Science Letters 214, 279-294.

Turner, M. B., Cronin, S. J., Smith, I. E. M., Stewart, R. B. \& Neall, V. E. (2008). Eruption episodes and magma recharge events in andesitic systems: Mt Taranaki, New Zealand. Journal of Volcanology and Geothermal Research 177, 1063-1076.

Turner, M. B., Bebbington, M., Cronin, S. J. \& Stewart, R. B. (2009). Merging eruption datasets: building an integrated Holocene eruptive record for Mt Taranaki, New Zealand. Bulletin of Volcanology 71, 903-918. 
Umino, S. \& Horio, A. (1998). Multistage Magma Mixing Revealed in Phenocryst Zoning of the Yunokuchi Pumice Akagi Volcano, Japan. Journal of Petrology 39, 101-124.

Vance, J. A. (1965). Zoning in igneous plagioclase: patchy zoning. Geology 73, 636-651.

Venezky, M. J. \& Rutherford, M. J. (1999). Petrology and Fe-Ti oxide reequilibration of the 1991 Mount Unzen mixed magma. Journal of Volcanology and Geothermal Research 89, 213-230.

Wallace, L. M., Beavan, J., McCaffrey, R. \& Darby, D. (2004). Subduction zone coupling and tectonic block rotations in the North Island, New Zealand. Journal of Geophysical Research 109, B12406.

Watson, E. B. \& Baxter, E. F. (2007). Diffusion in solid-Earth systems. Earth and Planetary Science Letters 253, 307-327.

Wilson, C. J. N., Houghton, B. F., McWilliams, M. O., Lanphere, M. A., Weaver, S. D. \& Briggs, R. M. (1995). Volcanic and structural evolution of Taupo Volcanic Zone, New Zealand - A review. Journal of Volcanology and Geothermal Research 68, 1-28.

Witham, C. S. (2005). Volcanic disasters and incidents: A new database. Journal of Volcanology and Geothermal Research 148, 191-233.

Woodhead, J., Eggins, S. \& Gamble, J. (1993). High field strength and transition element systematics in island arc and back-arc basin basalts: Evidence for multi-phase melt extraction and a depleted mantle wedge. Earth and Planetary Science Letters 114, 491-504.

Zellmer, G. F., Blake, S., Vance, D., Hawkesworth, C. \& Turner, S. (1999). Plagioclase residence times at two island arc volcanoes (Kameni Islands, Santorini, and Soufriere, St. Vincent) determined by Sr diffusion systematics. Contributions to Mineralogy and Petrology 136, 345-357.

Zellmer, G. F., Sparks, R. S. J., Hawkesworth, C. J. \& Wiedenbeck, M. (2003). Magma emplacement and remobilization timescales beneath Montserrat: Insights from $\mathrm{Sr}$ and Ba zonation in plagioclase phenocrysts. Journal of Petrology 44, 1413-1431.

Zernack, A. V., Procter, J. N. \& Cronin, S. J. (2009). Sedimentary signatures of cyclic growth and destruction of stratovolcanoes: A case study from Mt. Taranaki, New Zealand. Sedimentary Geology 220, 288-305. 


\section{APPENDICES:}

Appendix 1: Sample list

Appendix 2: Major element data

Appendix 3: Trace element data

Appendix 4: Diffusion modelling images and profiles 
APPENDIX 1:

Table A1.1 SAMPLE LIST 
Table A1.1 List of tephra samples used in this thesis.

\begin{tabular}{|c|c|c|c|}
\hline Sample ID & Inferred Unit / ID & Age (yr BP) & Description \\
\hline SM-6A & Kaupokonui & $<1950 \pm 90$ & $\begin{array}{l}\text { Pumice lapilli; dark brown; friable; clast } \\
\text { supported; maximum clast diameter }=50 \mathrm{~mm} \text {, } \\
\text { mean clast diameter }=3 \mathrm{~mm} \text {. }\end{array}$ \\
\hline SM-6C & SM-6C & $<1950 \pm 90$ & $\begin{array}{l}\text { Pumice lapilli; } 80 \% \text { pumice, } 20 \% \text { lithics; } \\
\text { dark brown, matrix supported, maximum } \\
\text { clast }=40 \mathrm{~mm} \text {, mean clast }=5 \mathrm{~mm} \text {, reverse } \\
\text { graded. }\end{array}$ \\
\hline SM-6K & Maketawa & $<2890 \pm 100$ & $\begin{array}{l}\text { Pumice lapilli; } 80 \% \text { pumice, } 20 \% \text { lithics; } \\
\text { reddish brown, maximum clast }=20 \mathrm{~mm} \text {, } \\
\text { mean clast }=5 \mathrm{~mm} .\end{array}$ \\
\hline SM-7P & Inglewood b & $>3610 \pm 60$ & $\begin{array}{l}\text { Pumice lapilli; } 90 \% \text { pumice, } 10 \% \text { lithics, } \\
\text { reddish brown, maximum clast }=30 \mathrm{~mm} \text {, } \\
\text { mean clast }=2 \mathrm{~mm}\end{array}$ \\
\hline SM-7R & Inglewood a & $<3870 \pm 110$ & $\begin{array}{l}\text { Pumice lapilli; } 90 \% \text { pumice, } 10 \% \\
\text { lithics;reddish brown; friable; maximum clast } \\
=50 \mathrm{~mm} \text {, mean clast }=4 \mathrm{~mm} \text {; reverse graded. }\end{array}$ \\
\hline SM-7U & Korito & $4150-3580$ & $\begin{array}{l}\text { Pumice lapilli; yellowish brown; friable; } \\
\text { moderately sorted; maximum clast }=50 \mathrm{~mm} \text {, } \\
\text { mean clast }=4 \mathrm{~mm} \text {; slight reverse grading. }\end{array}$ \\
\hline
\end{tabular}

Age estimates from Alloway et al. (1995) and references therein, and are based on radiocarbon ages of peat and wood between tephra units.Maximum or minimum ages are indicated, based on dated material found stratigraphically below or above the tephra unit. A range of values is given where ages are available directly above and below the unit. 


\section{APPENDIX 2: \\ MAJOR ELEMENT DATA}

Table A2.1 Glass major element data

Table A2.2 Melt inclusion major element data

Table A2.3 Plagioclase major element data

Table A2.4 Clinopyroxene major element data

Table A2.5 Orthopyroxene major element data

Table A2.6 Amphibole major element data

Table A2.7 Oxides major element data 


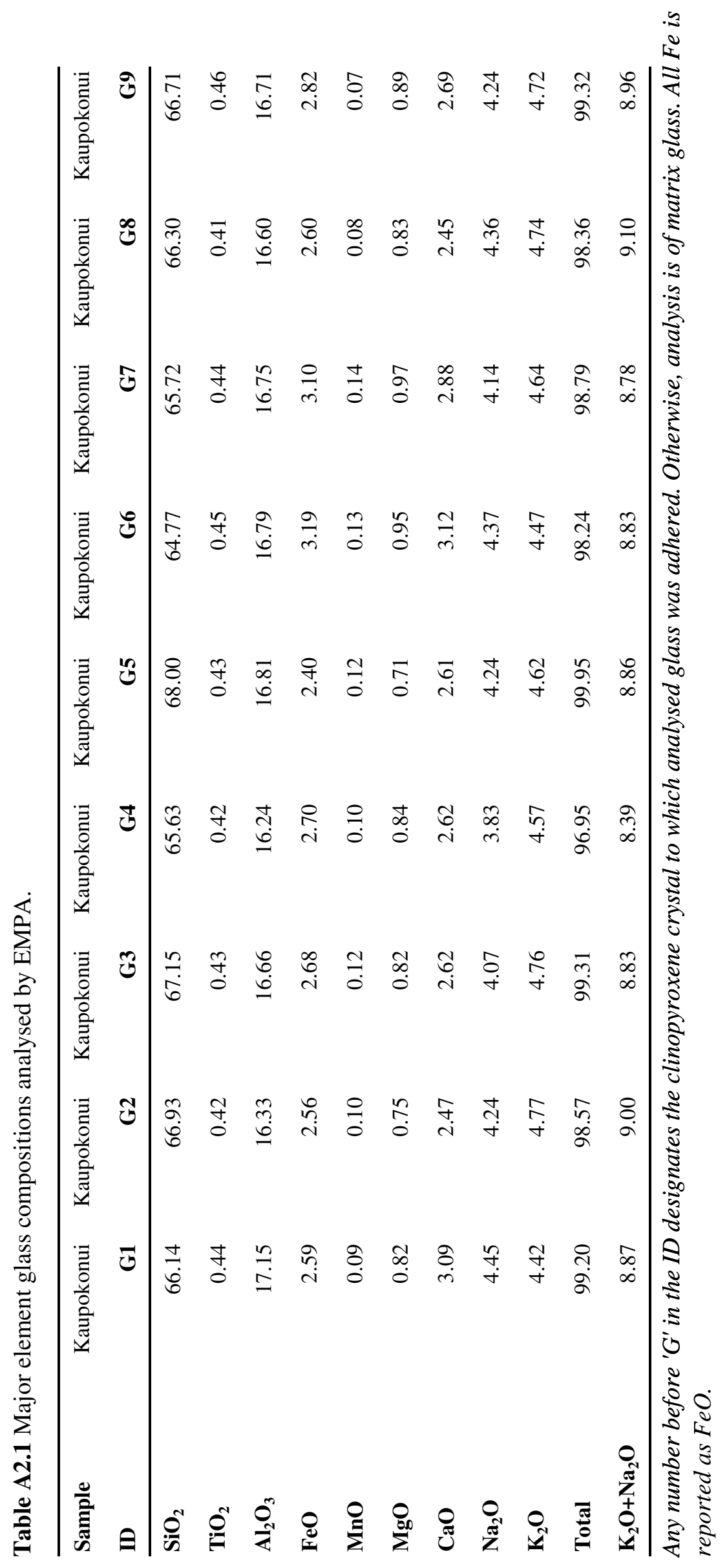




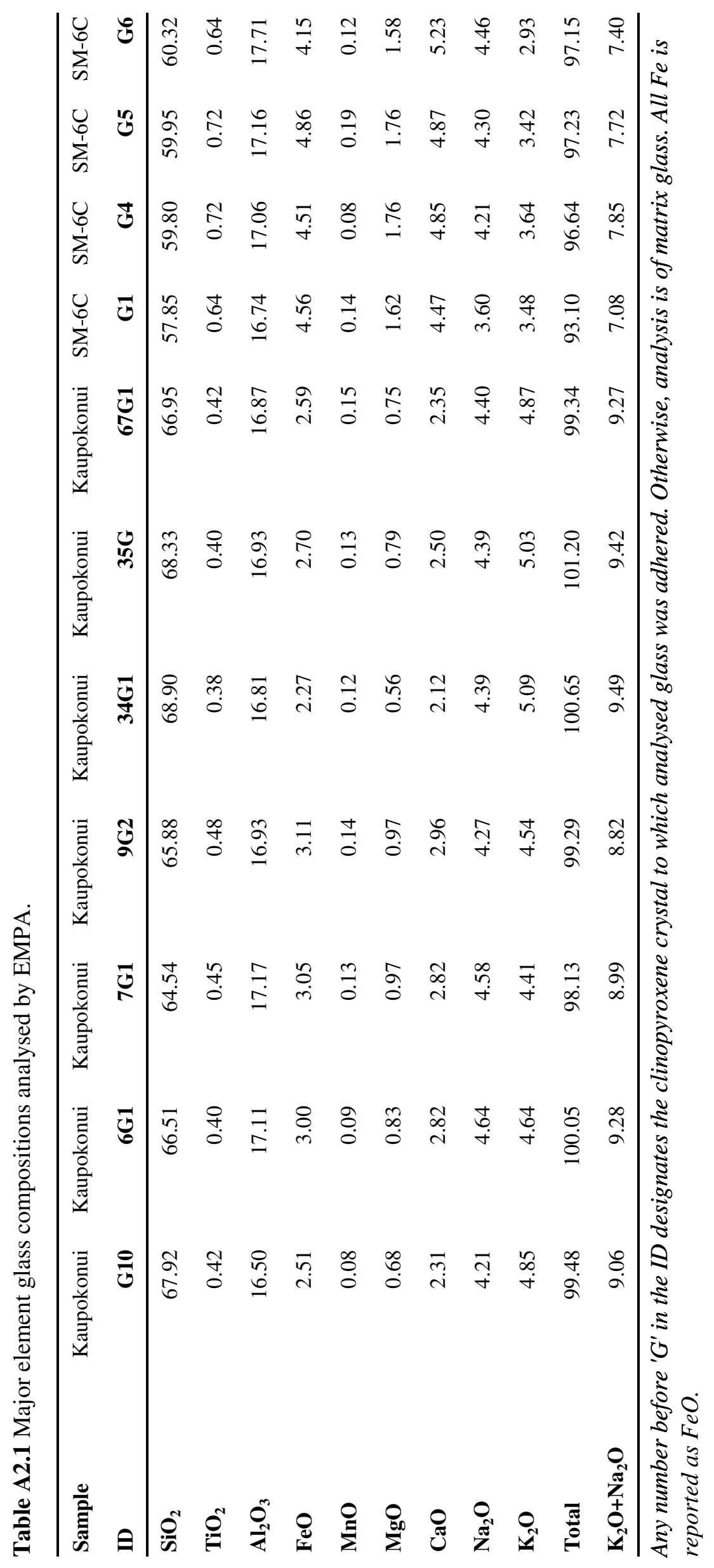




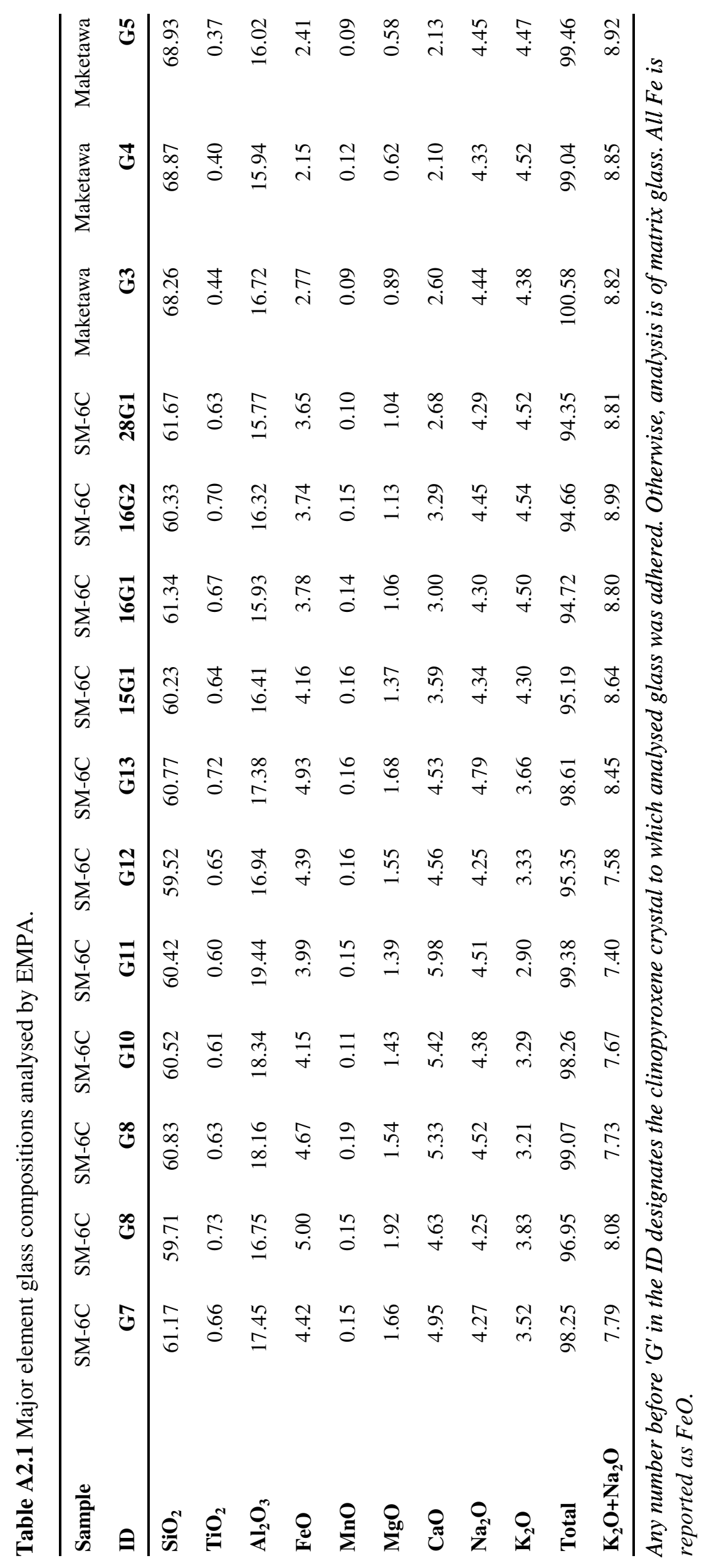




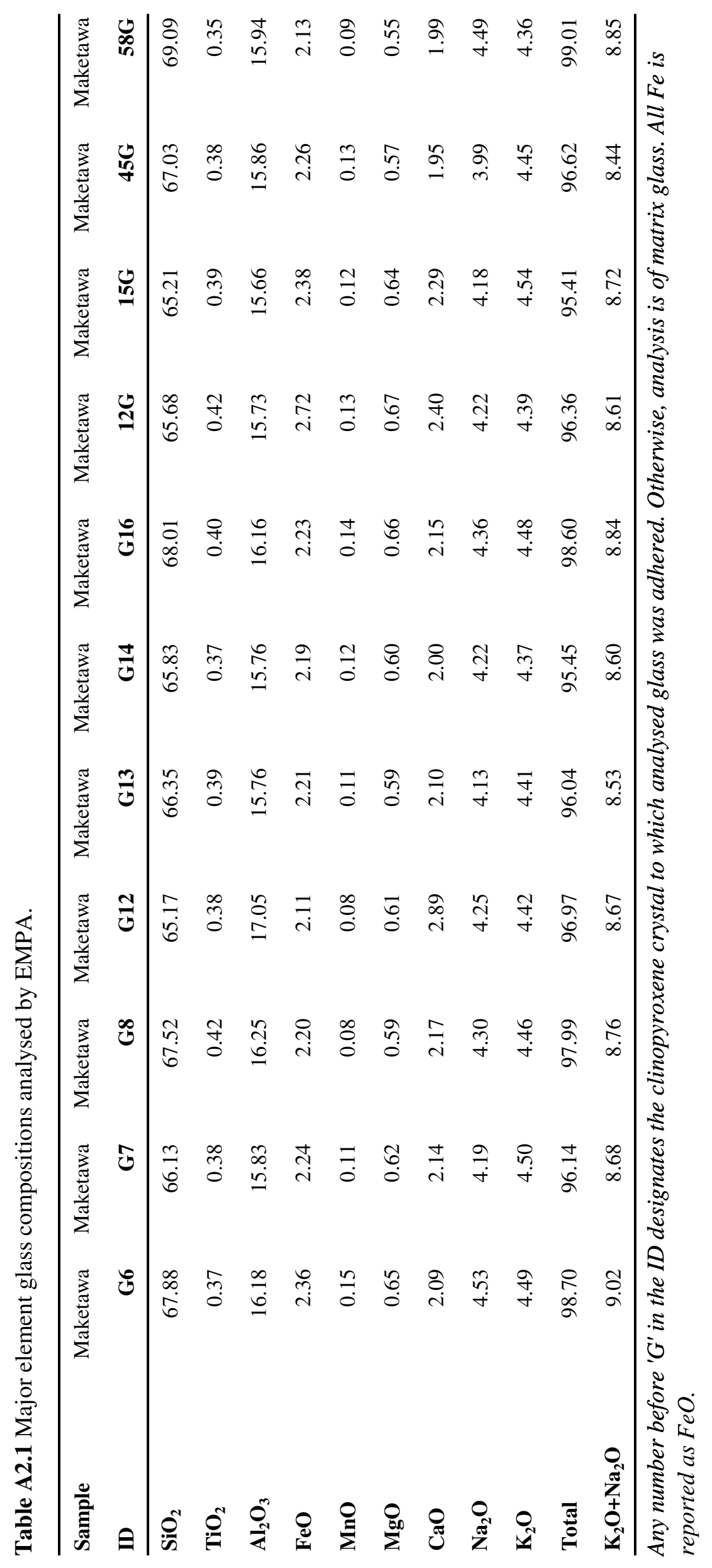




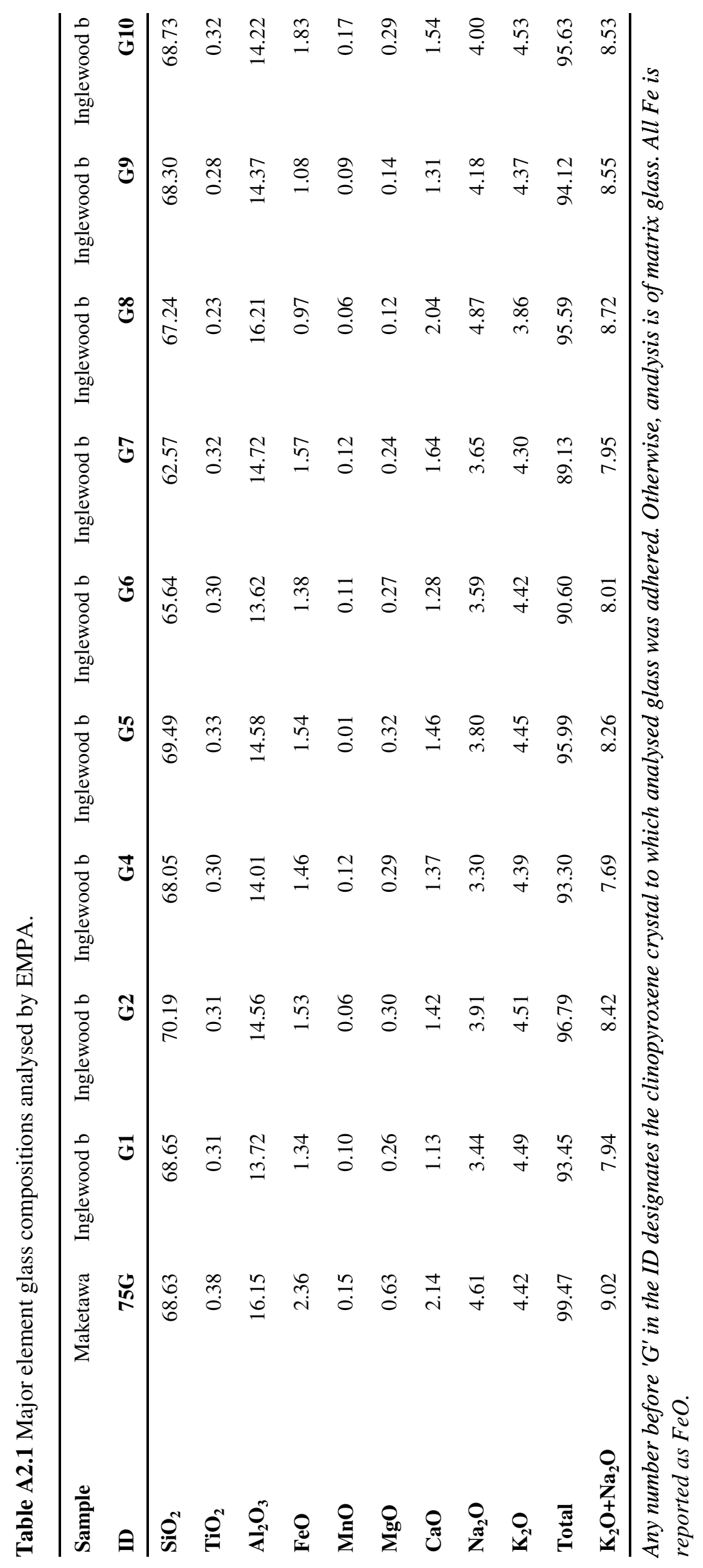




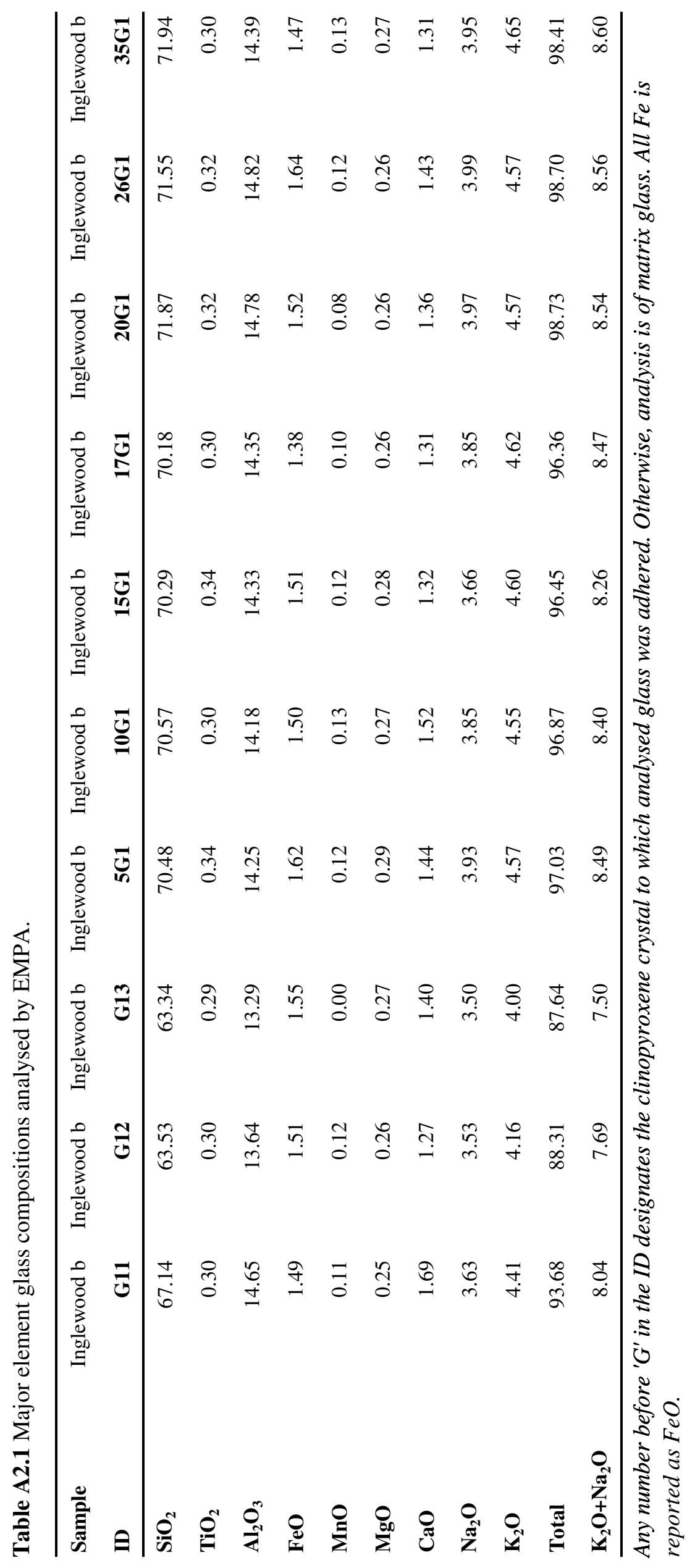

A. 10 


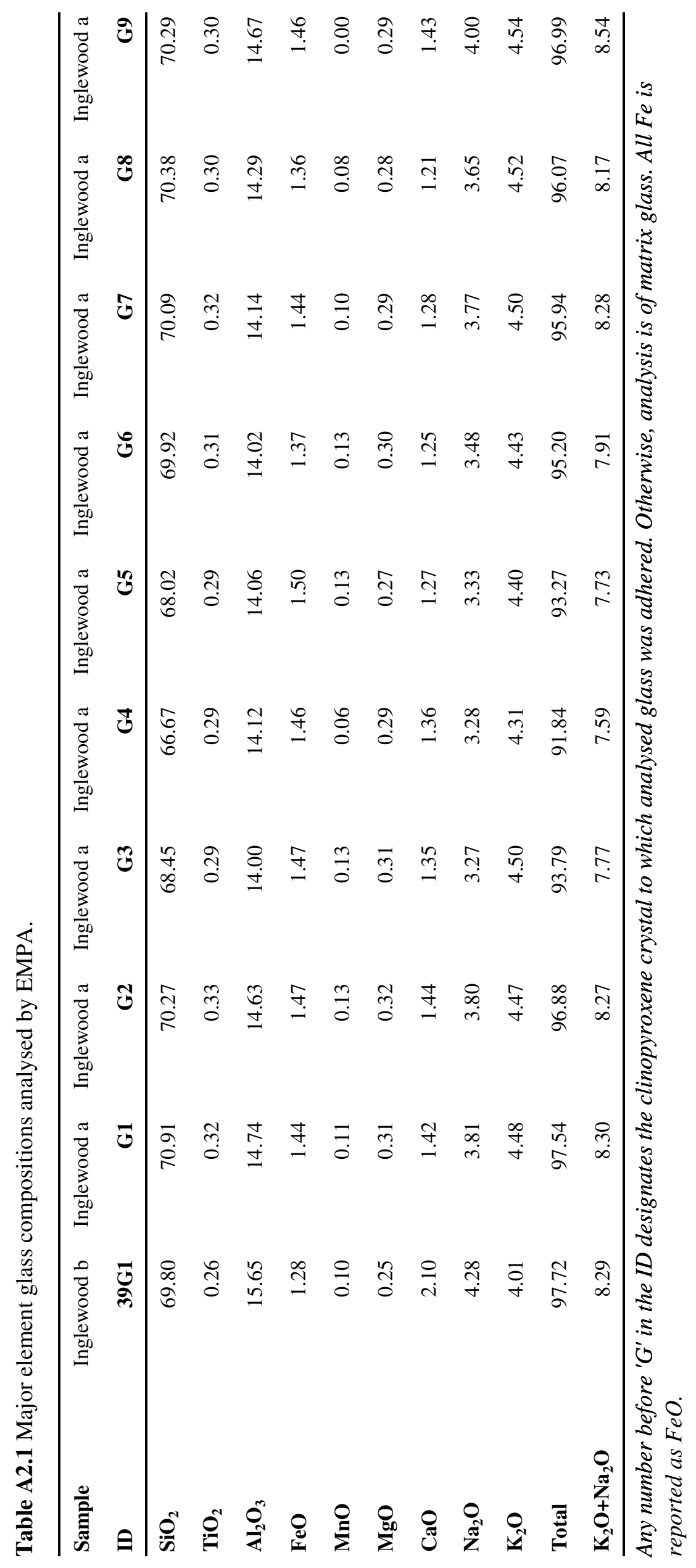




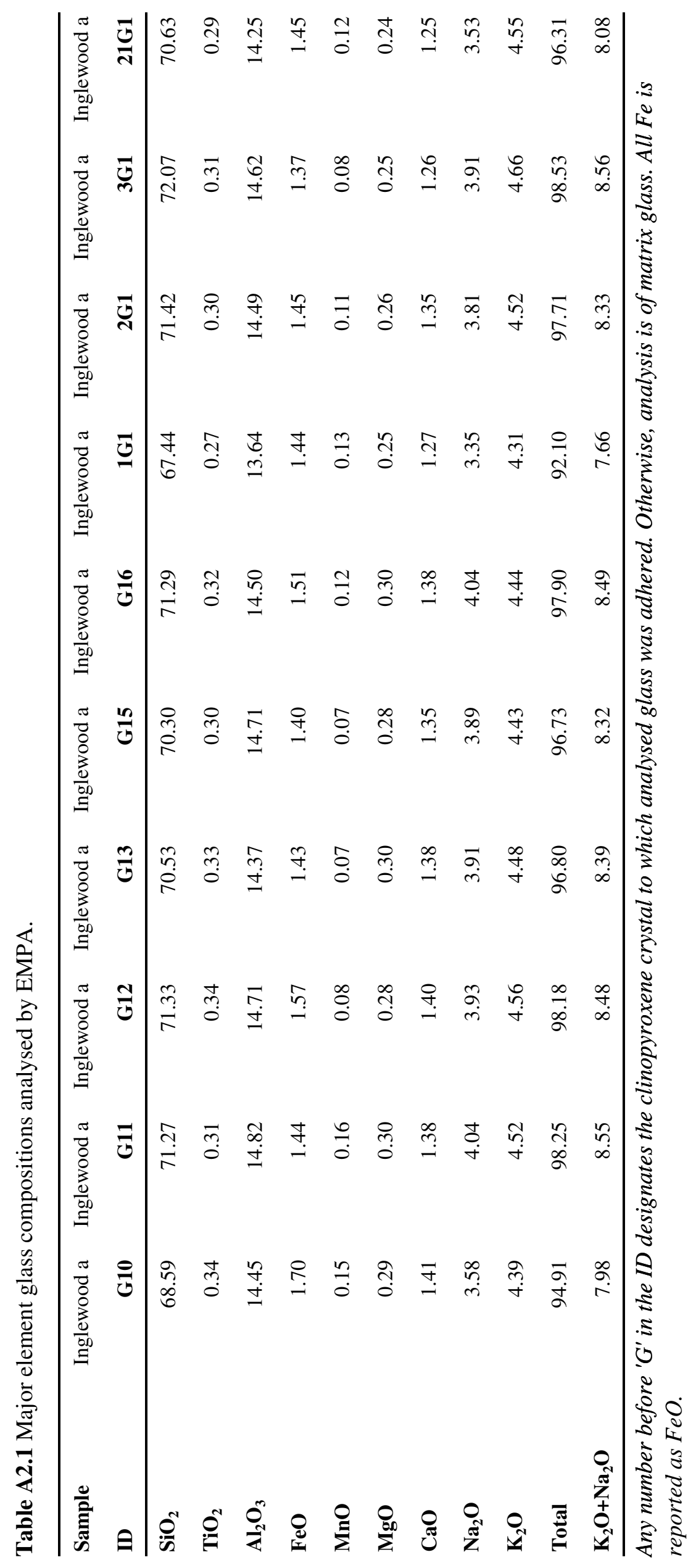

A. 12 


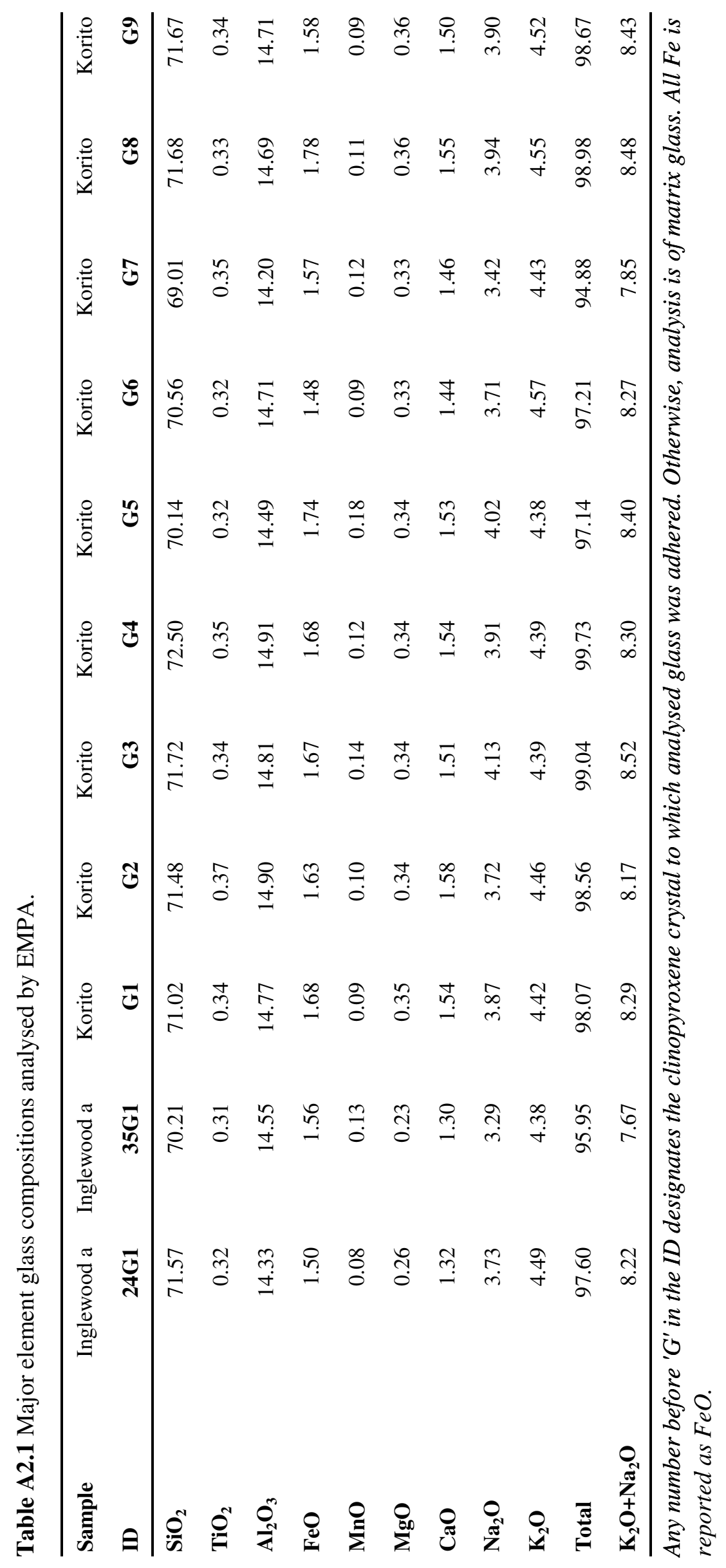

A. 13 


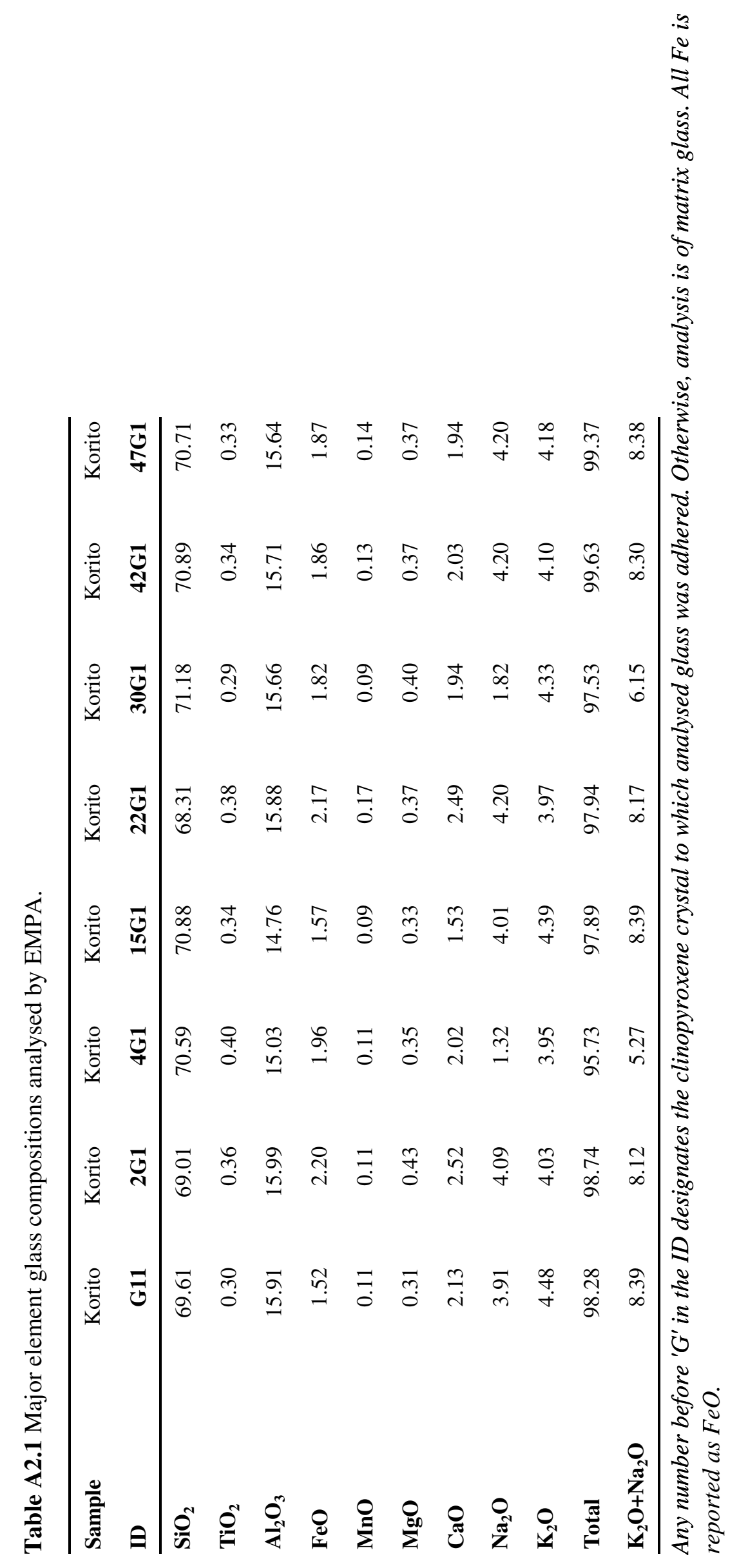

A. 14 


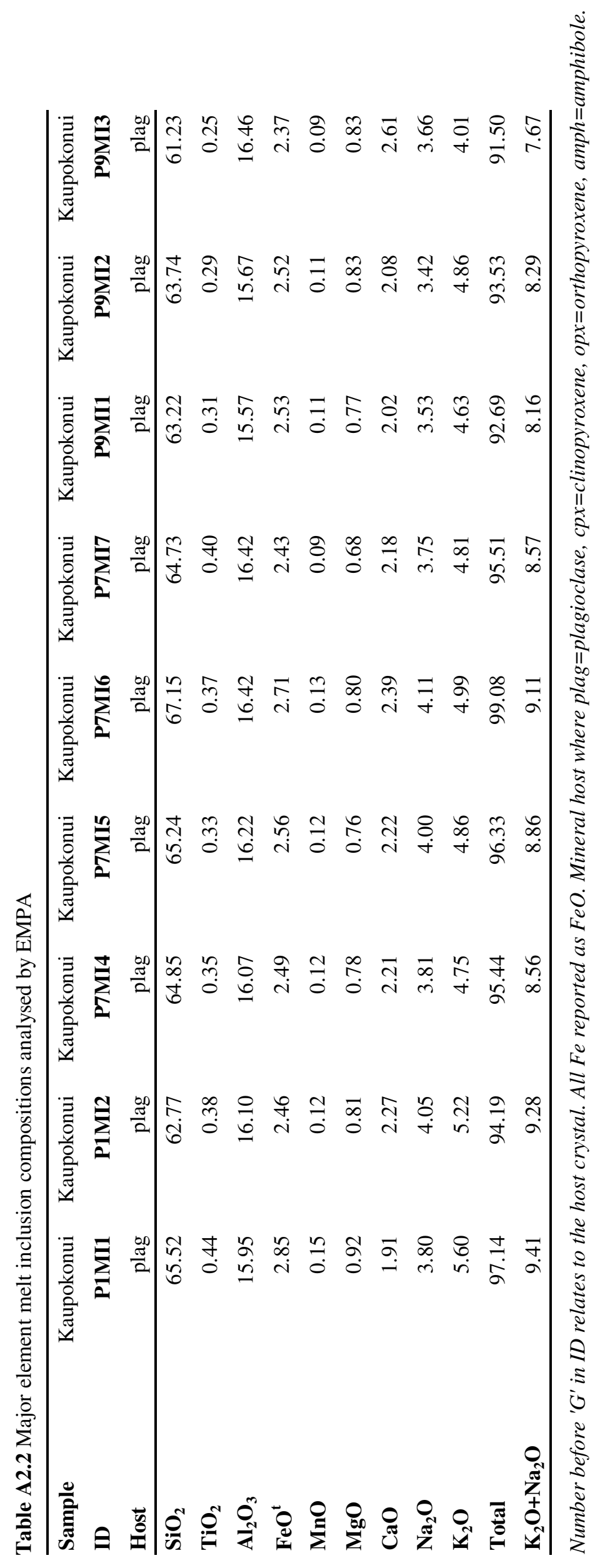

A. 15 


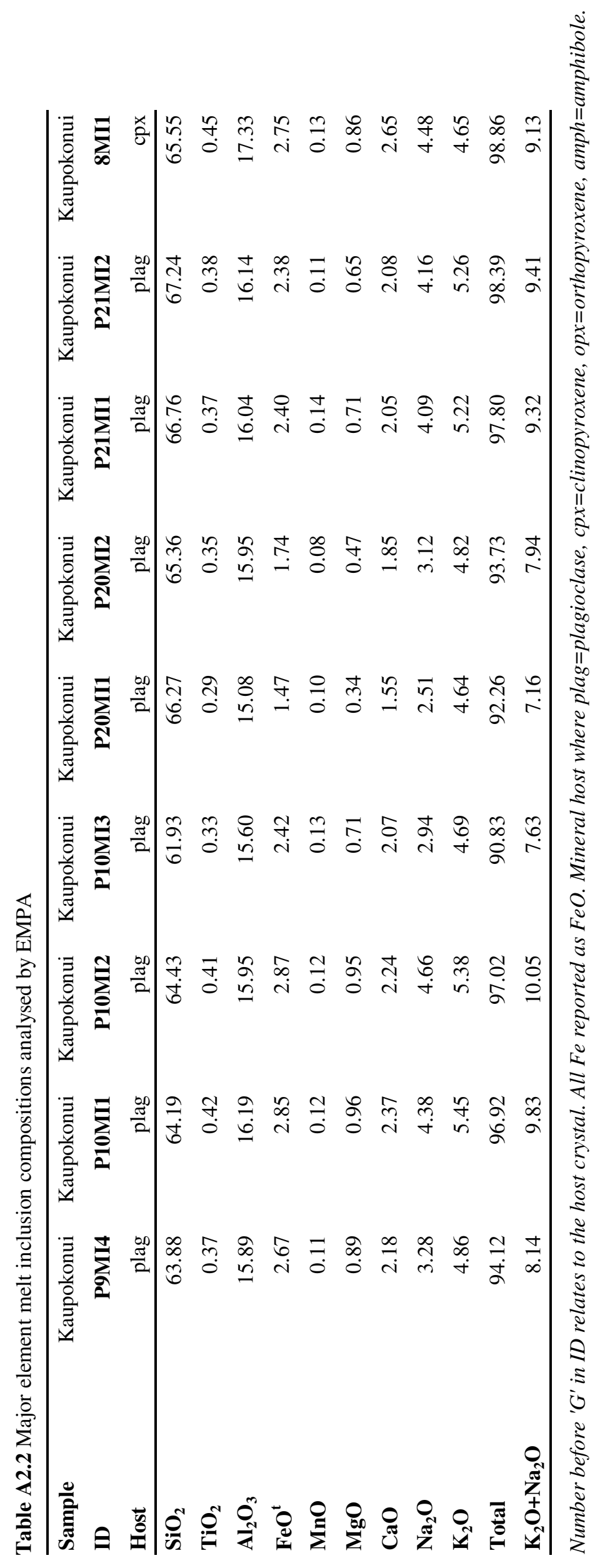

A. 16 


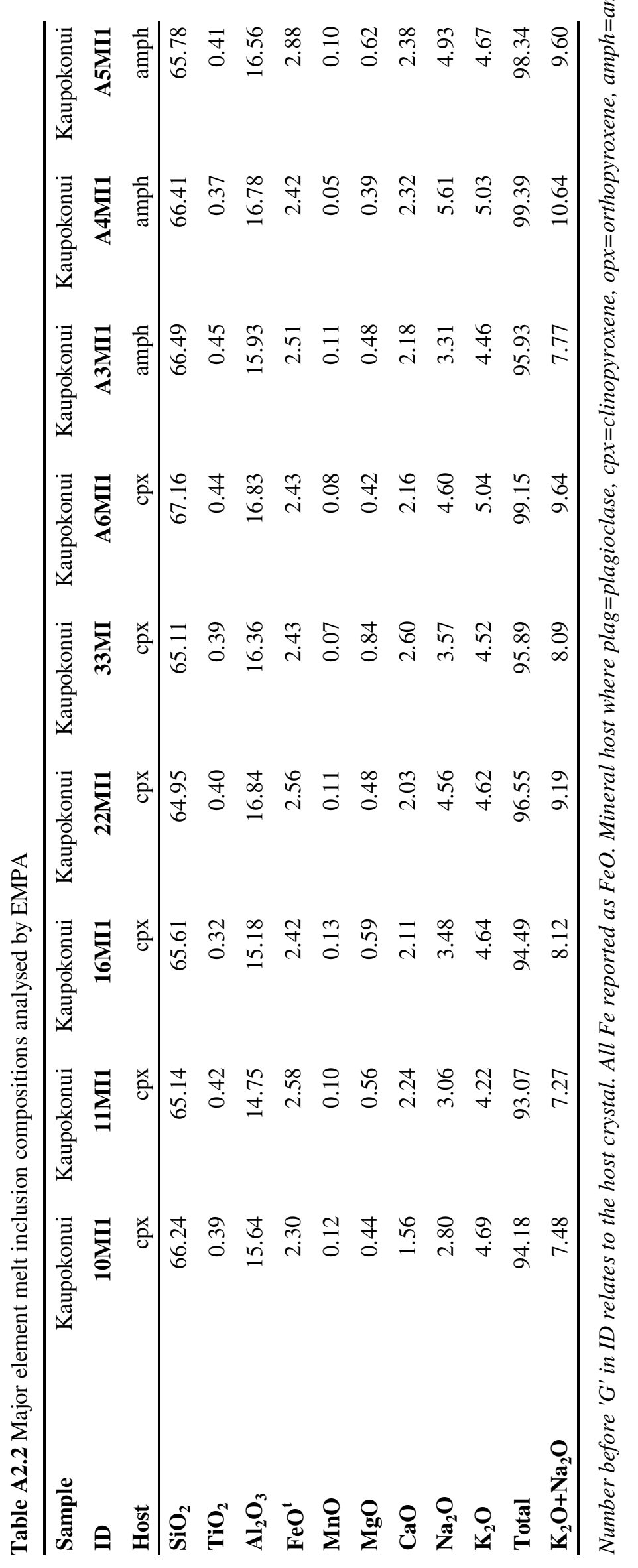




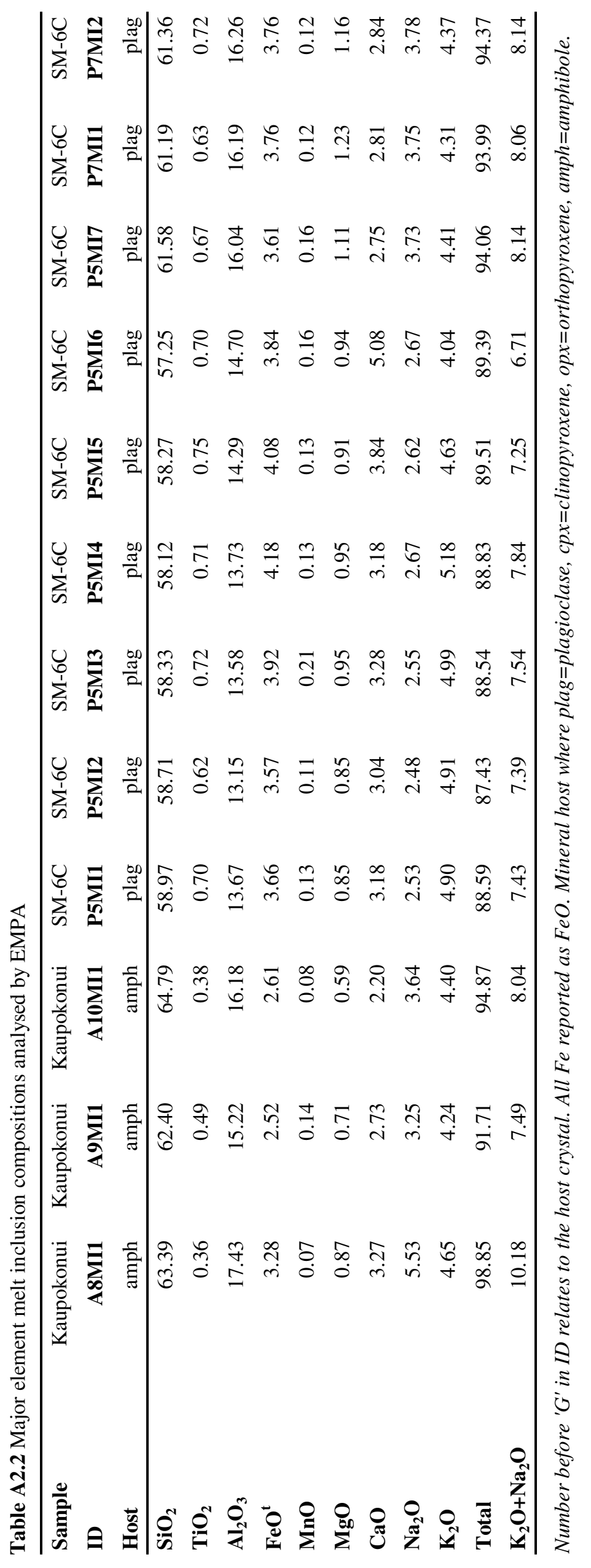




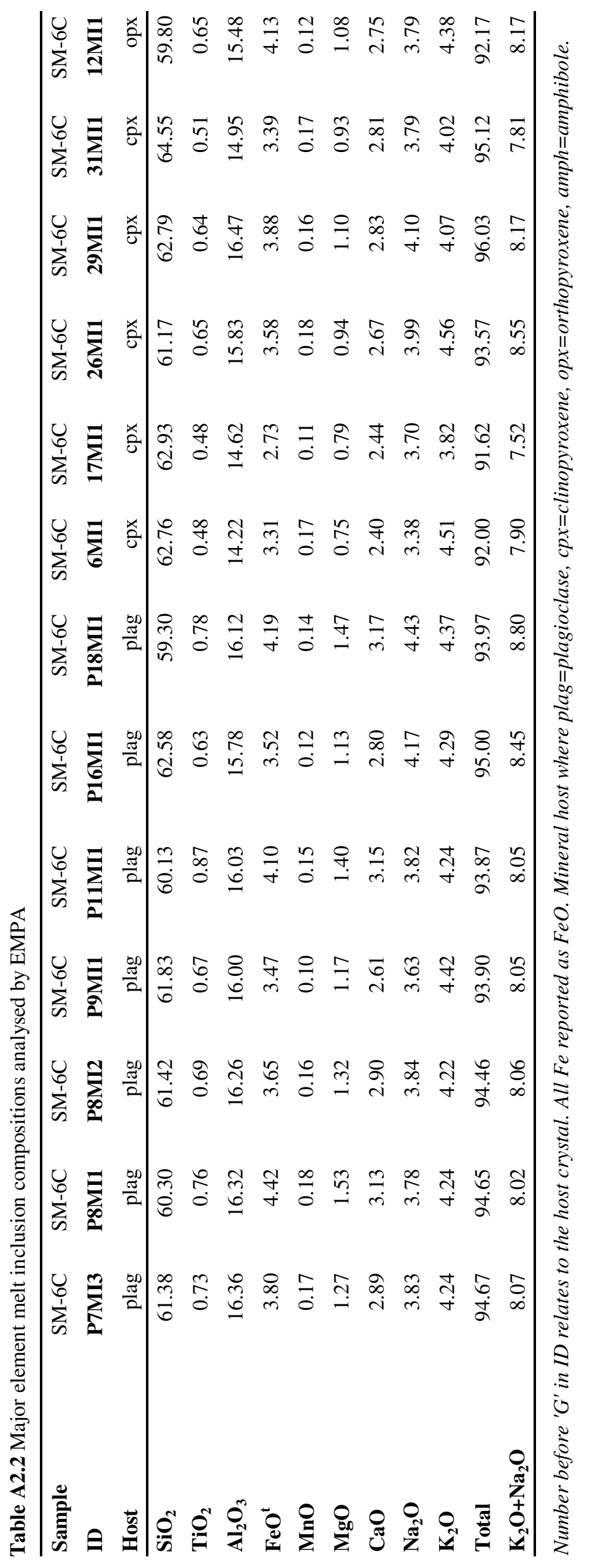




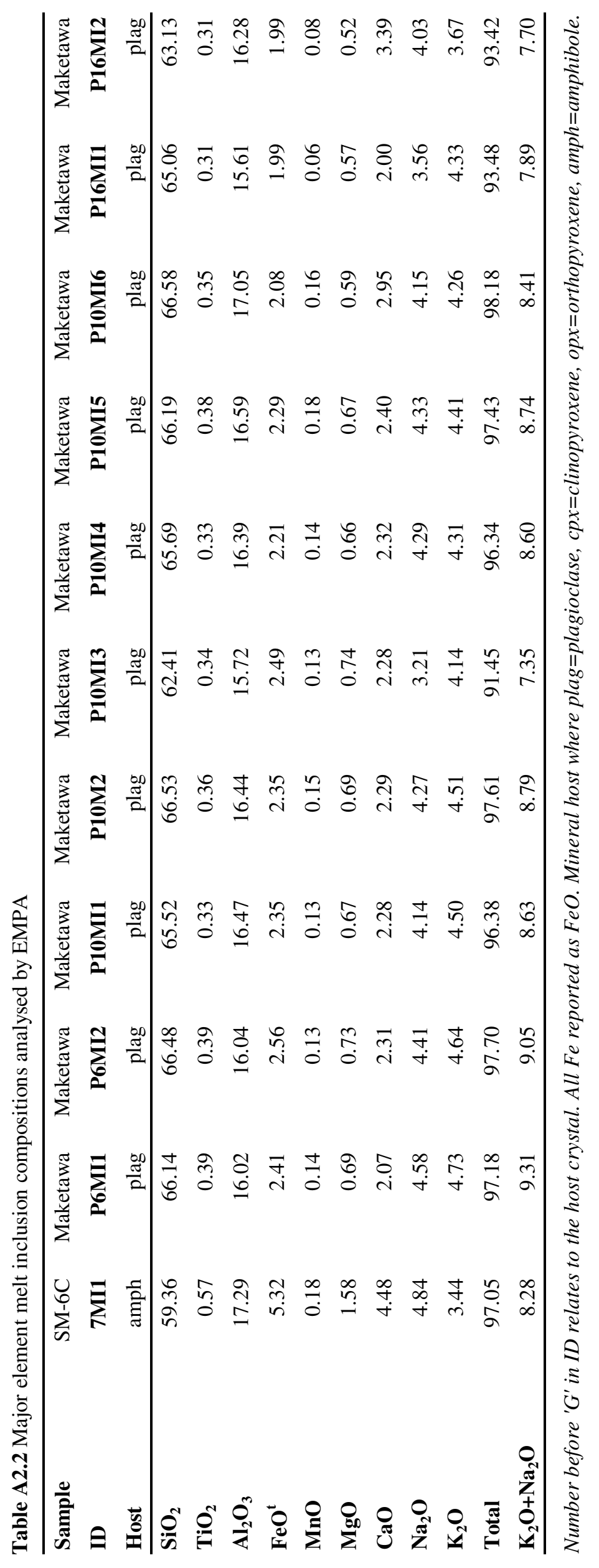




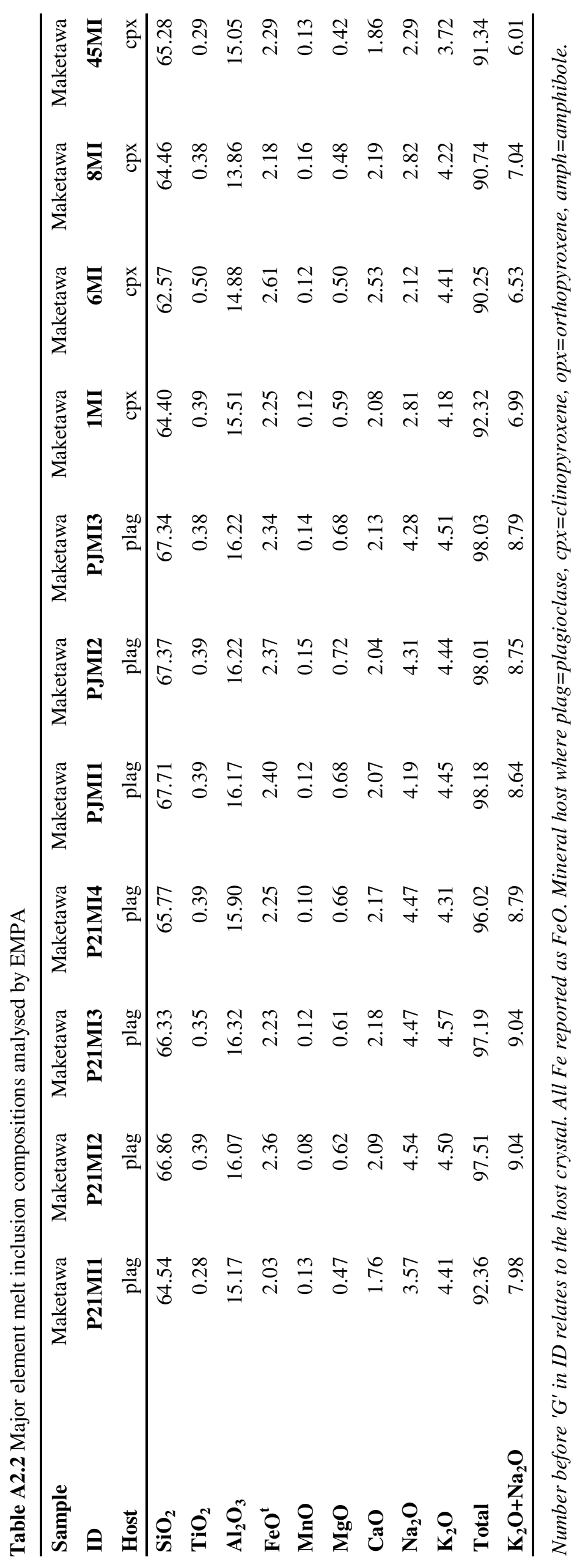




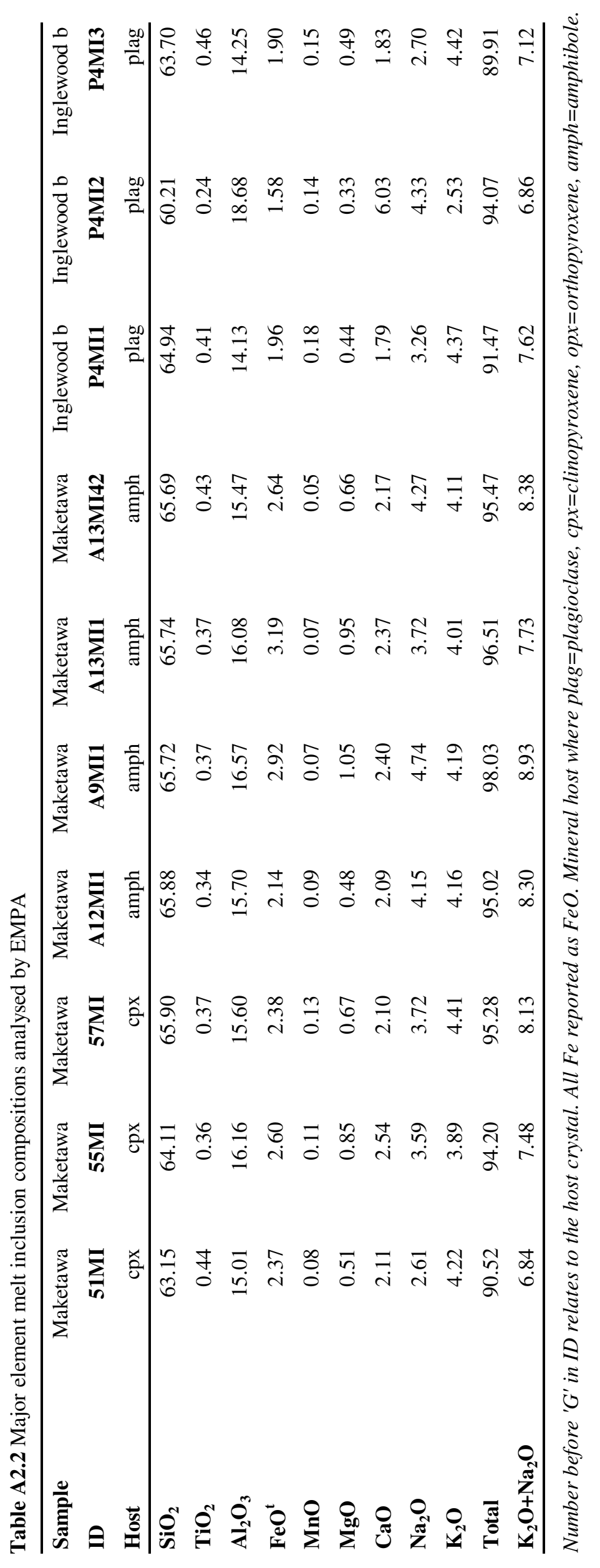




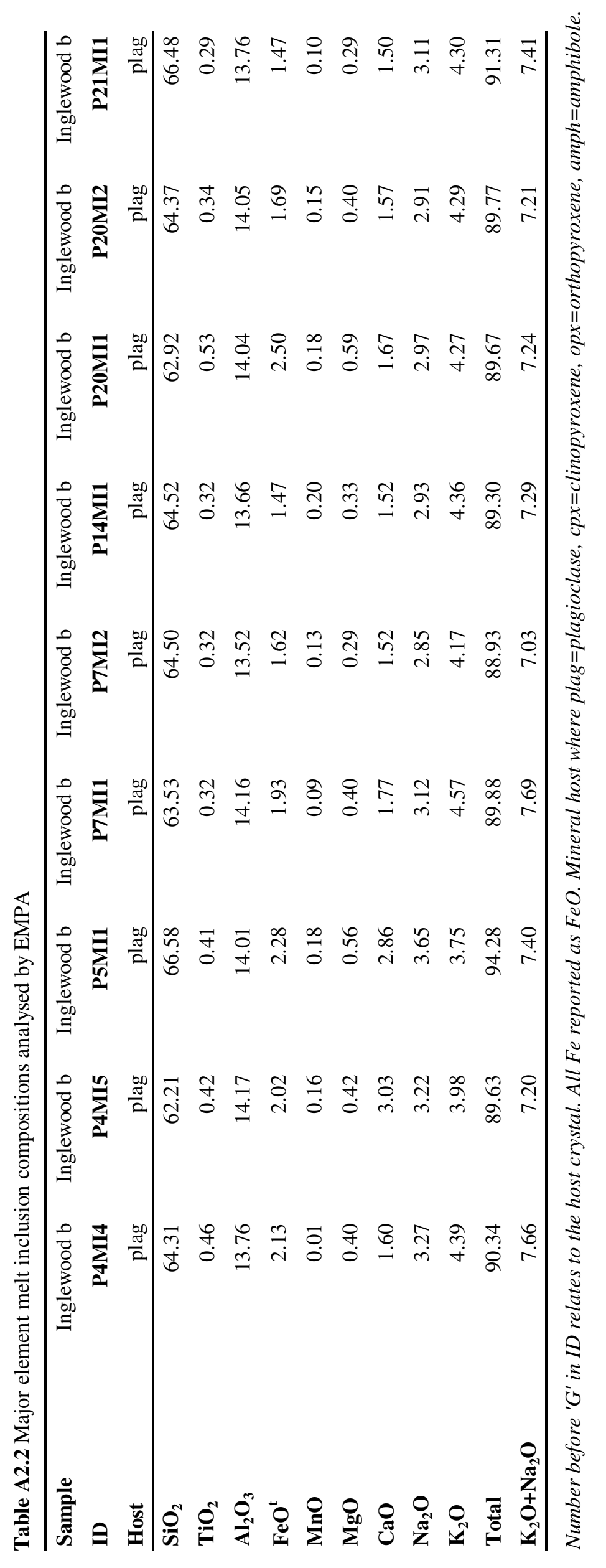




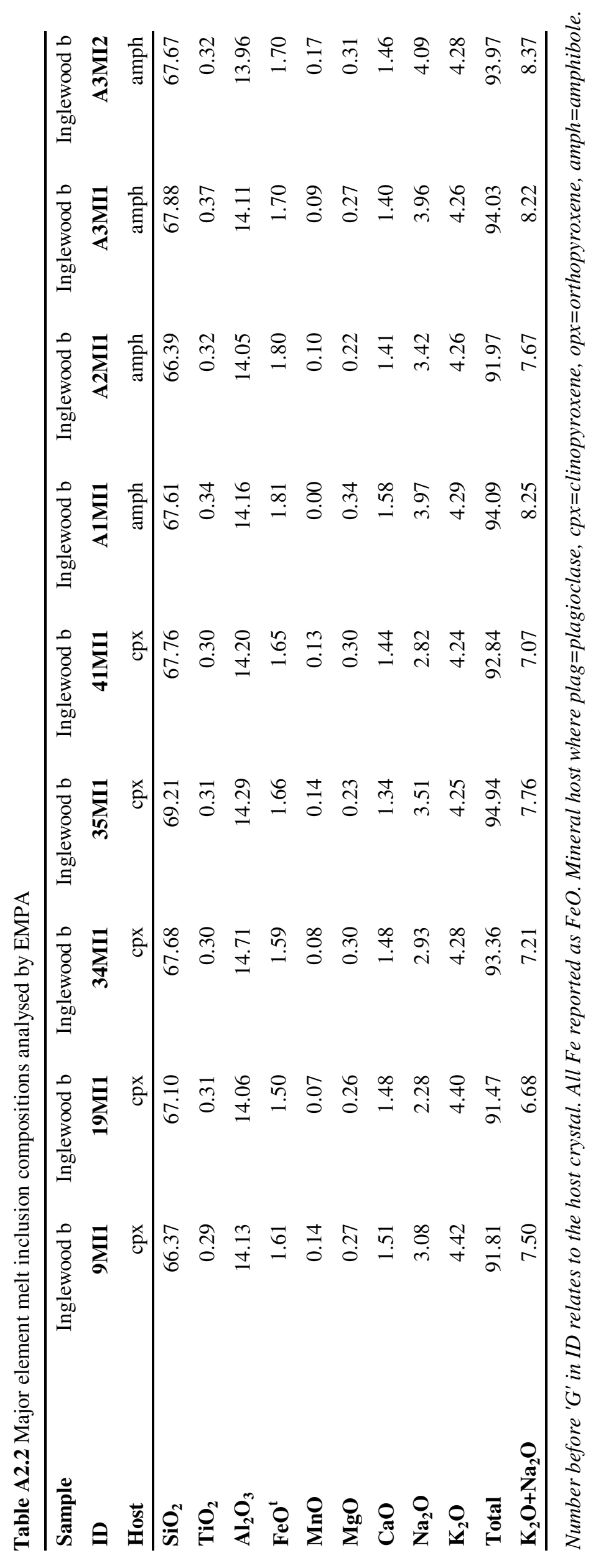




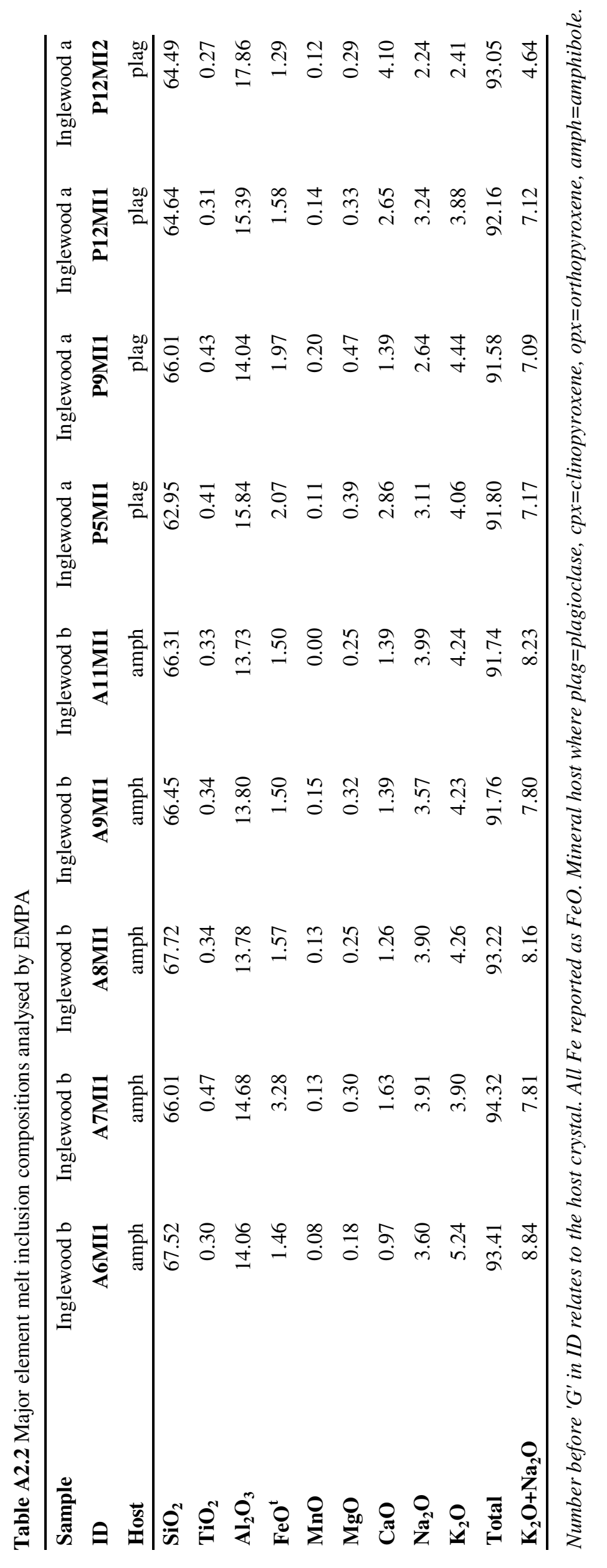




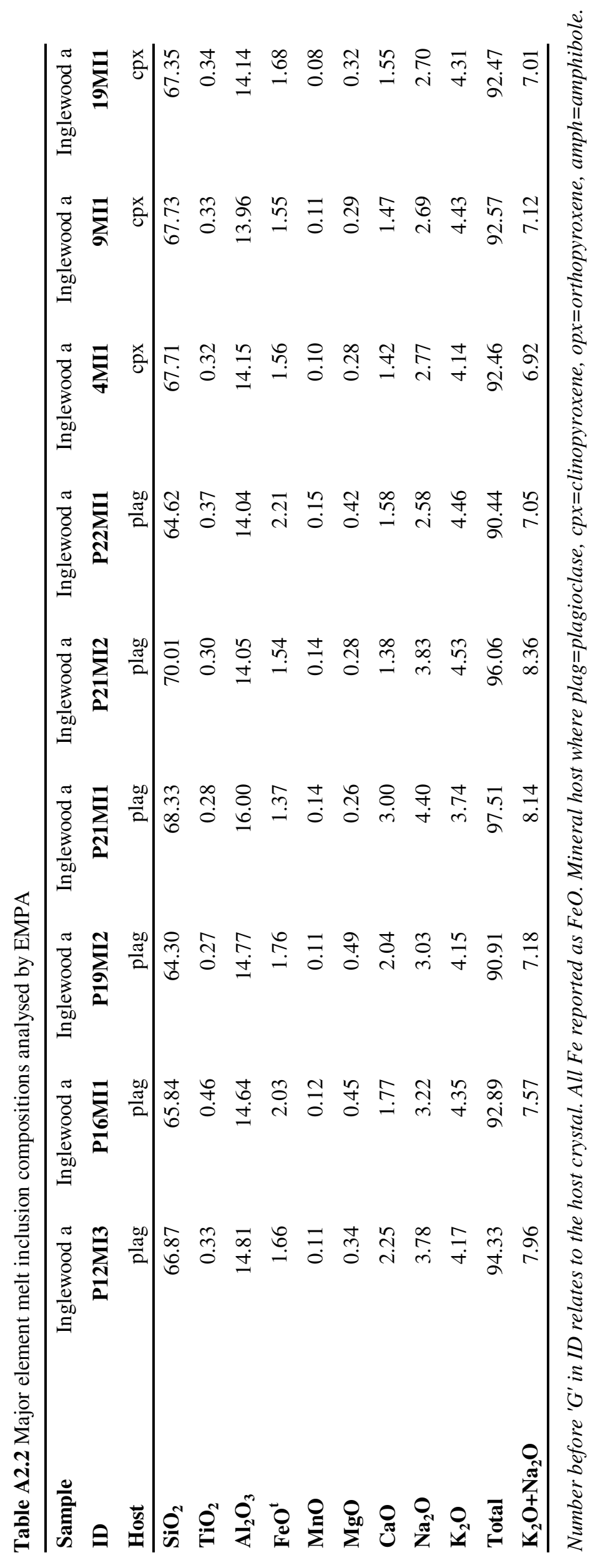




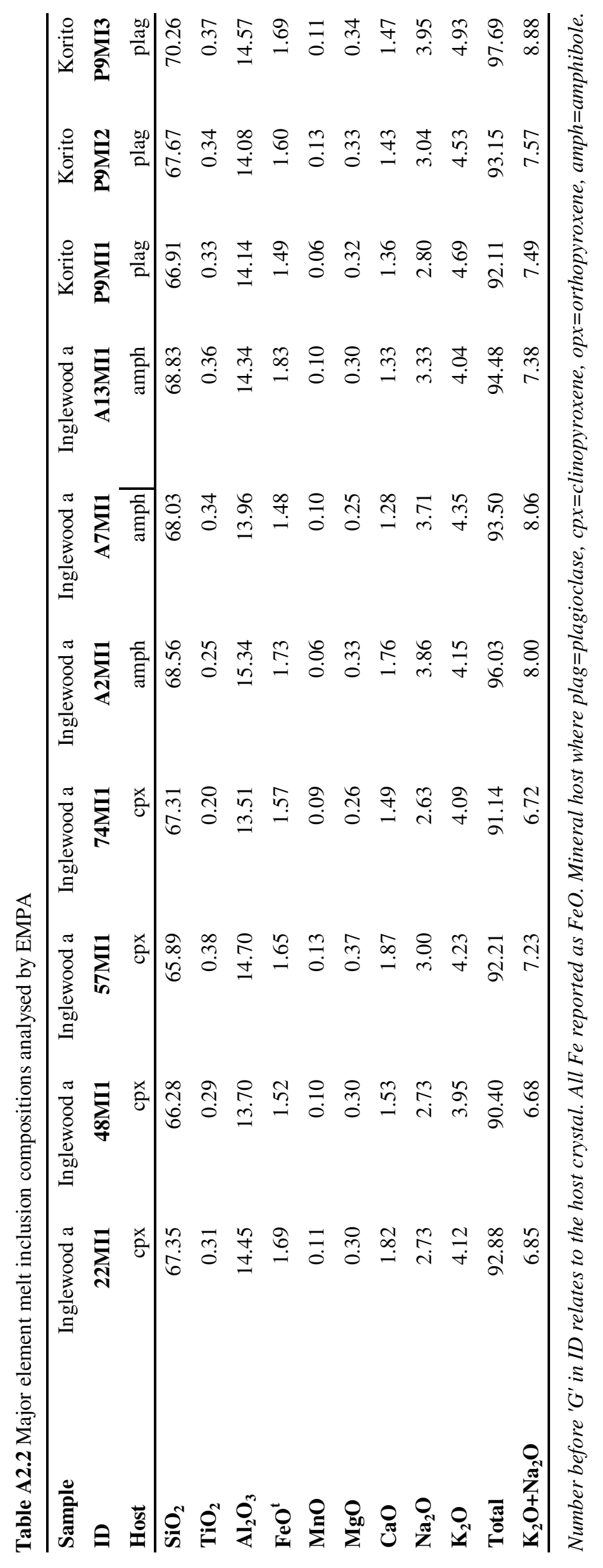




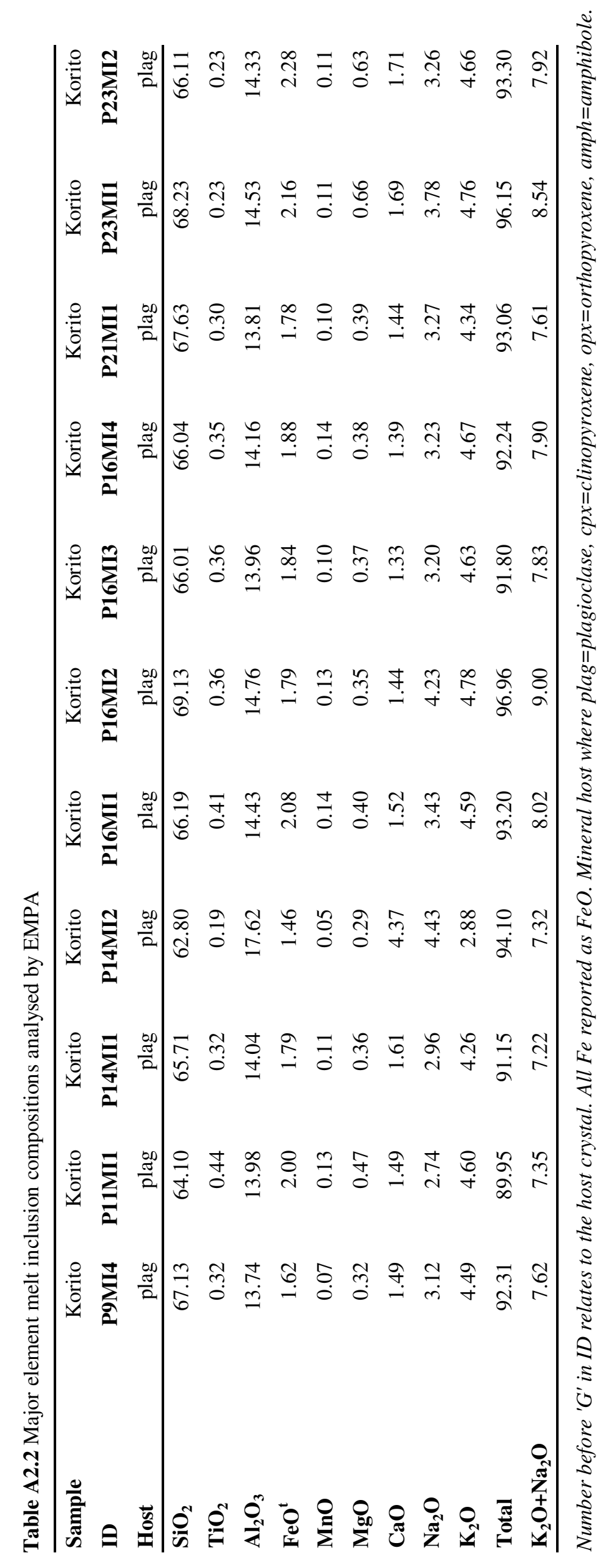




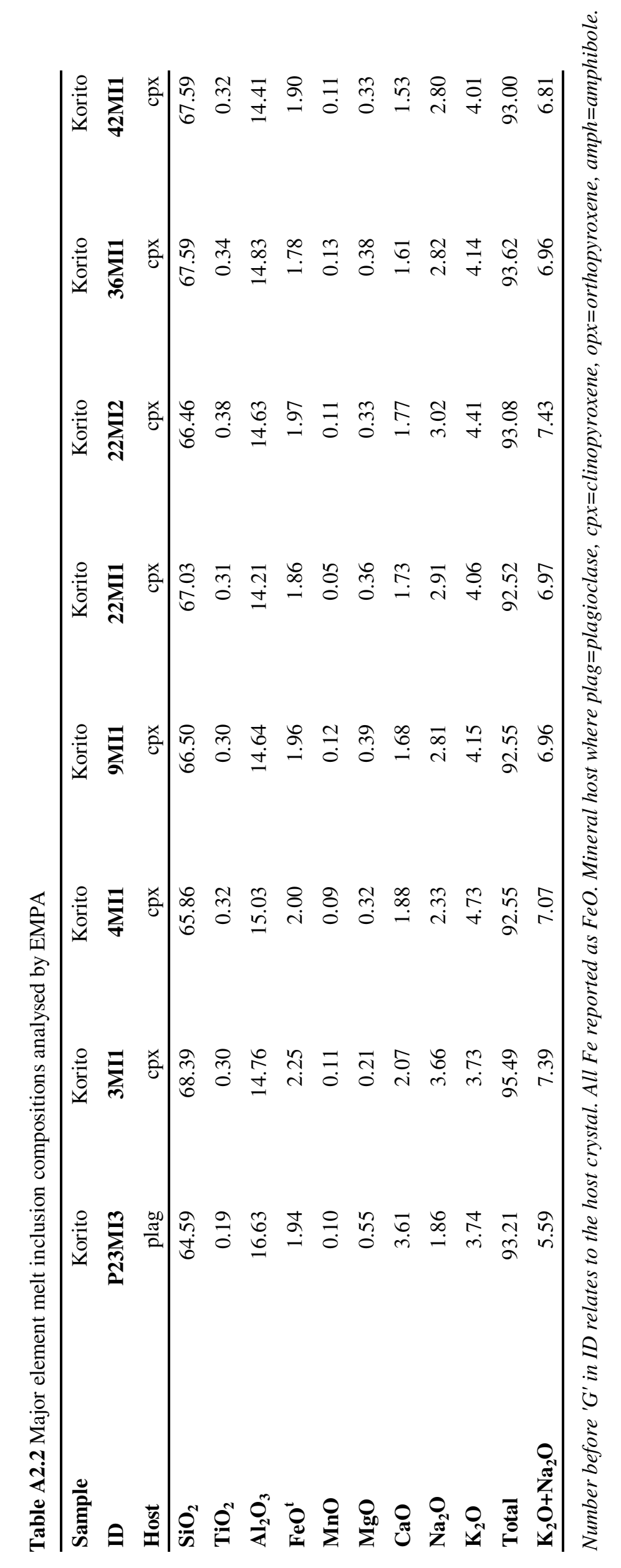




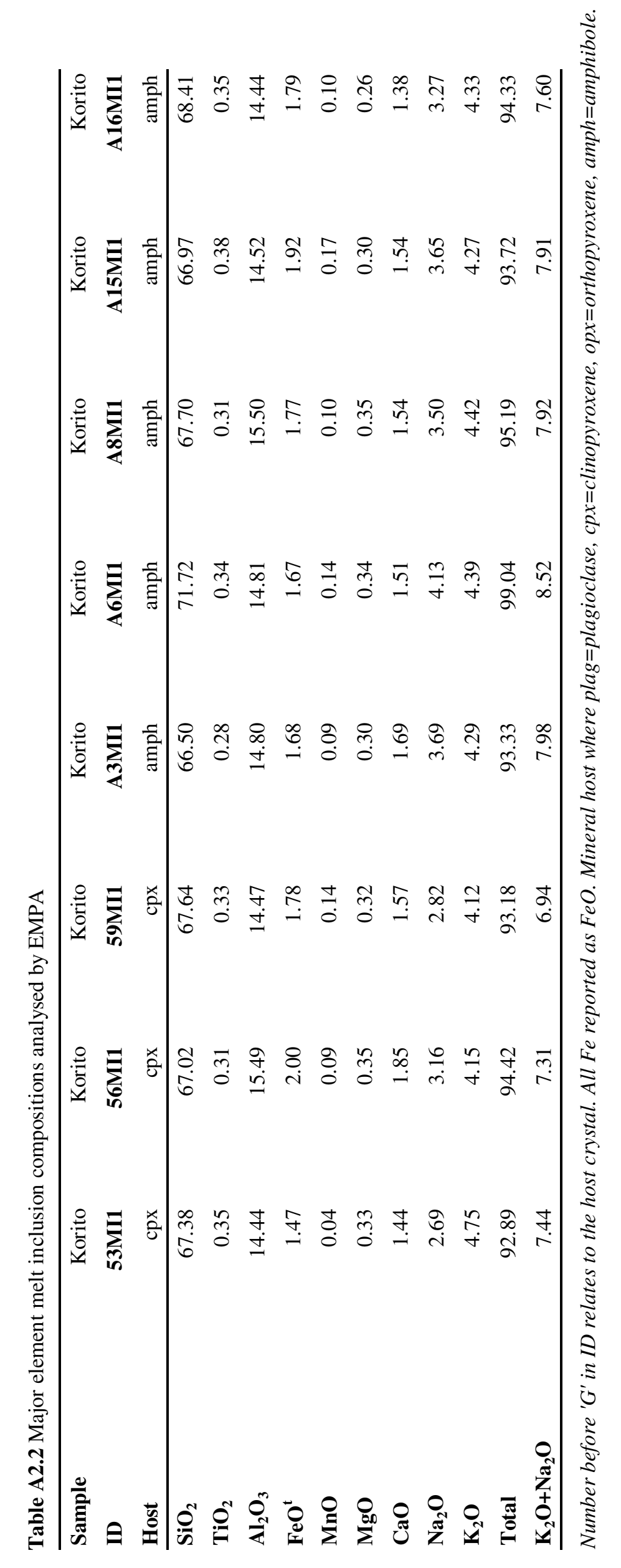




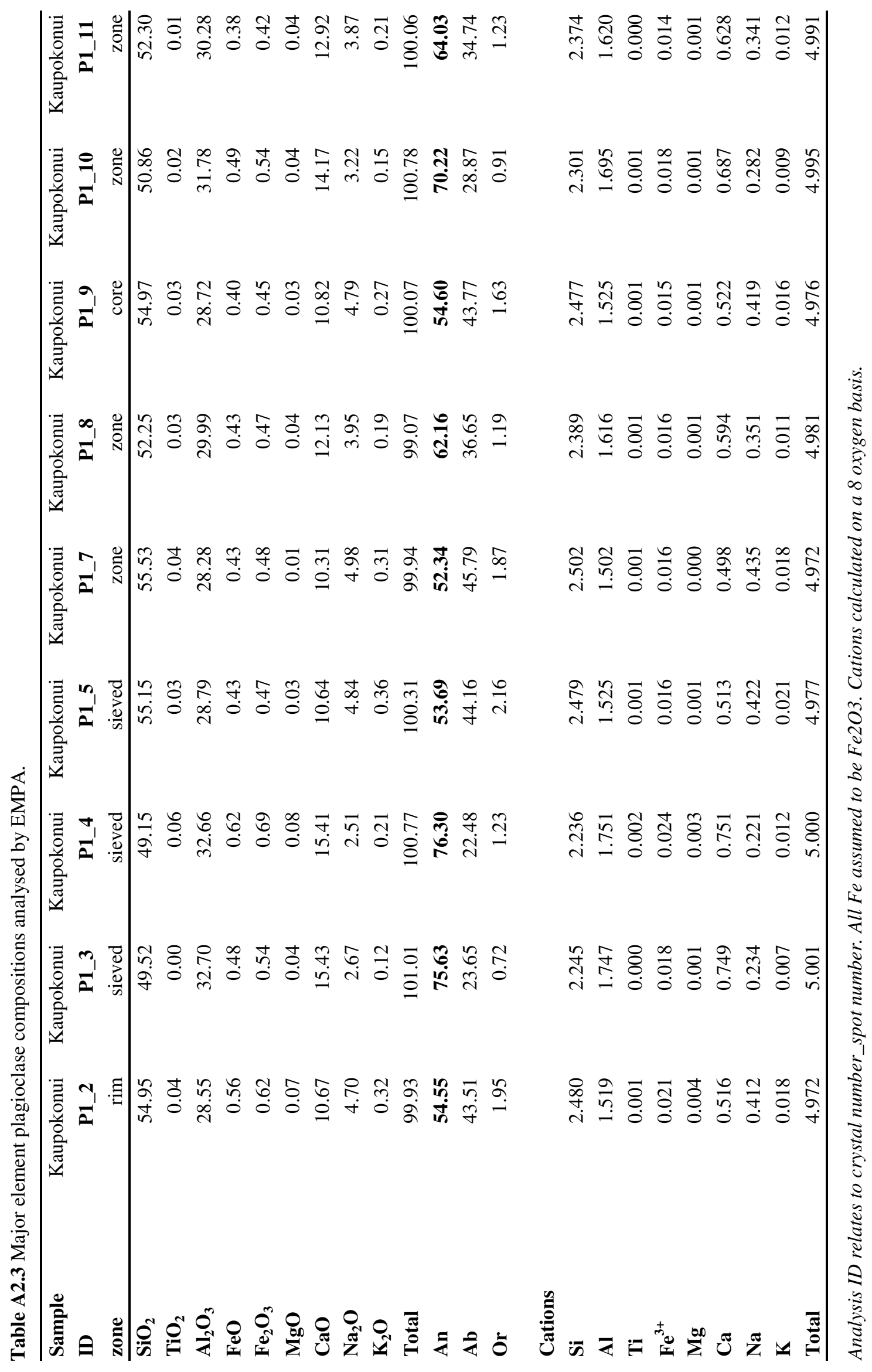




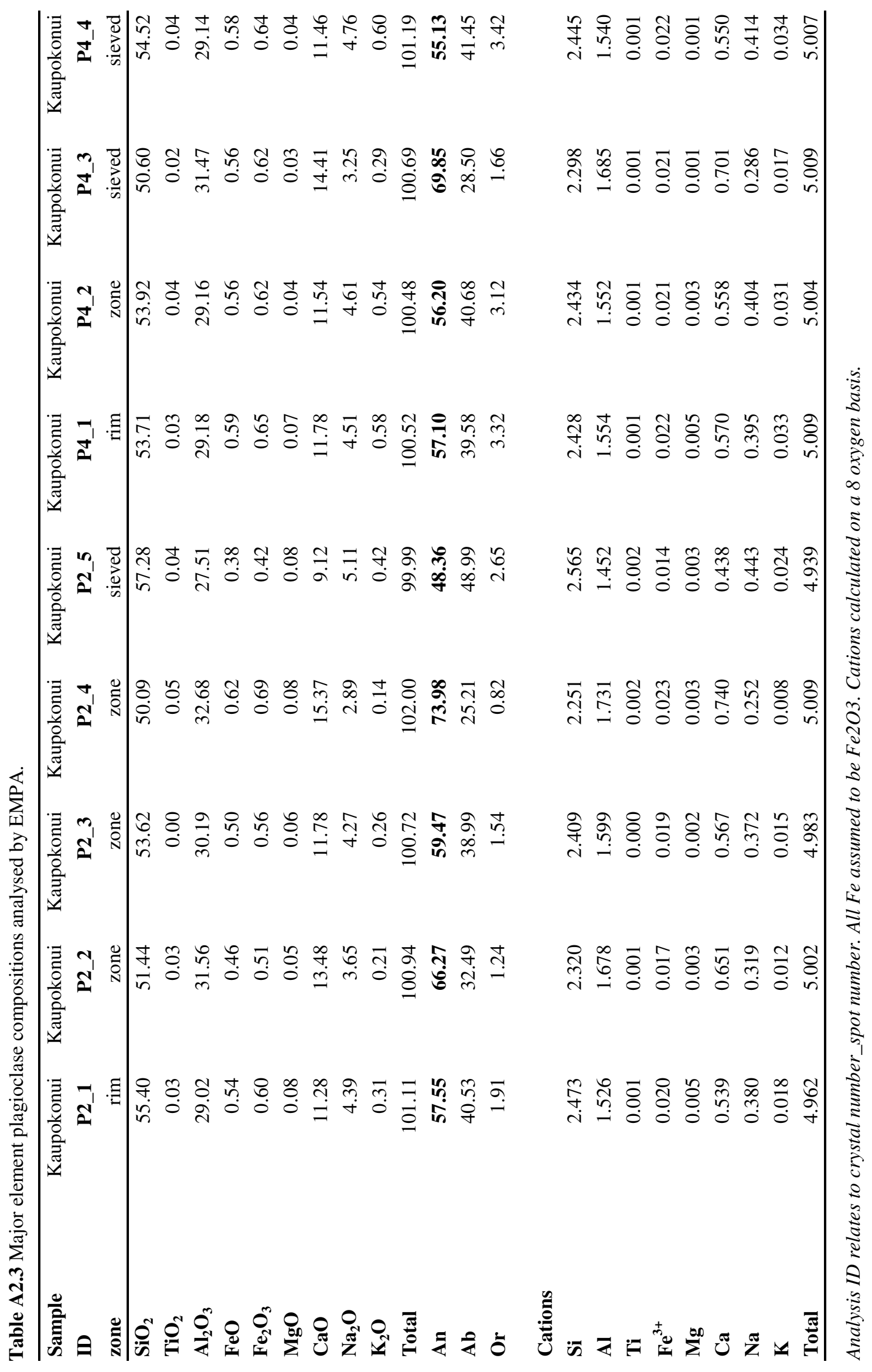




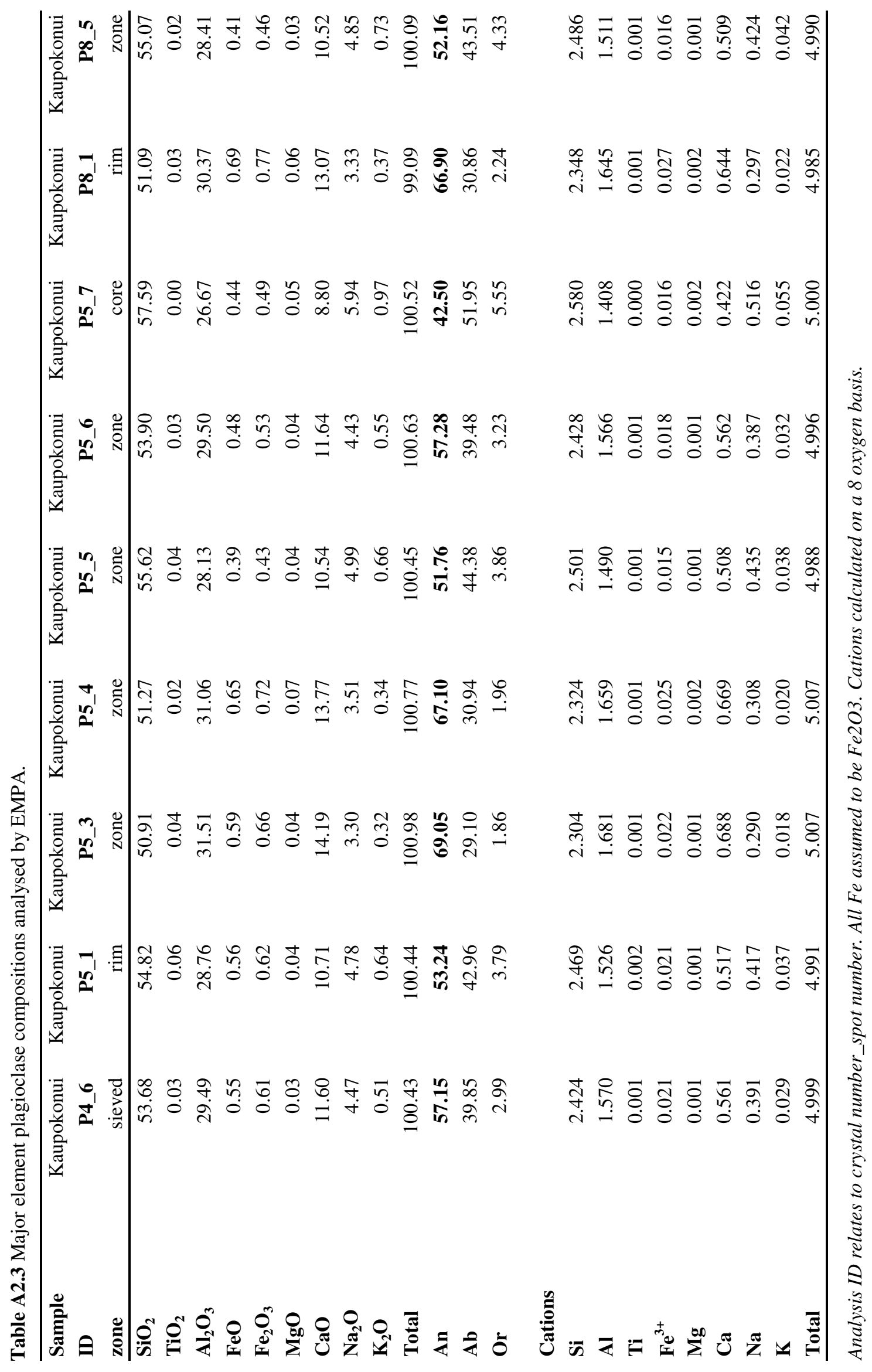




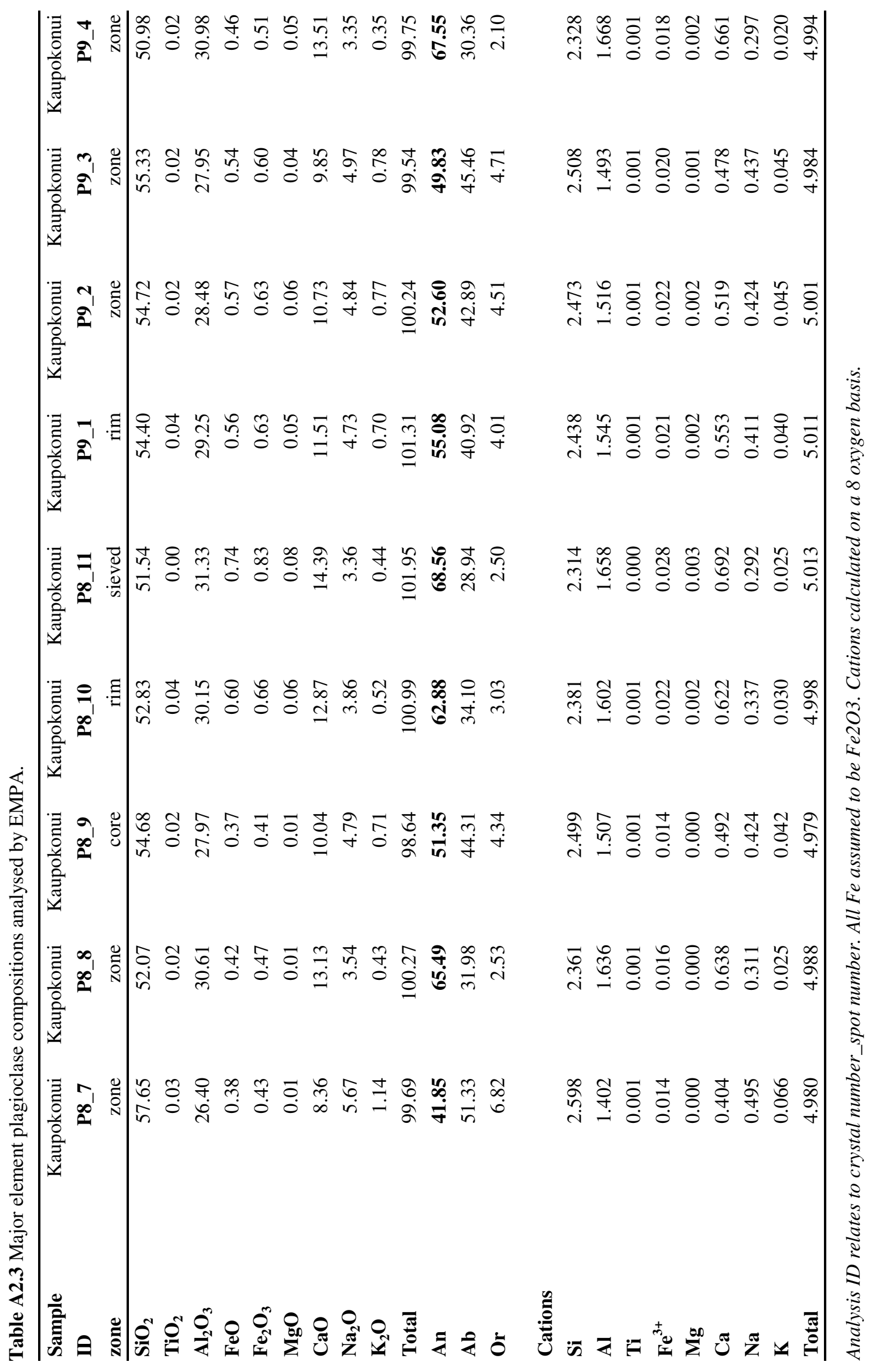




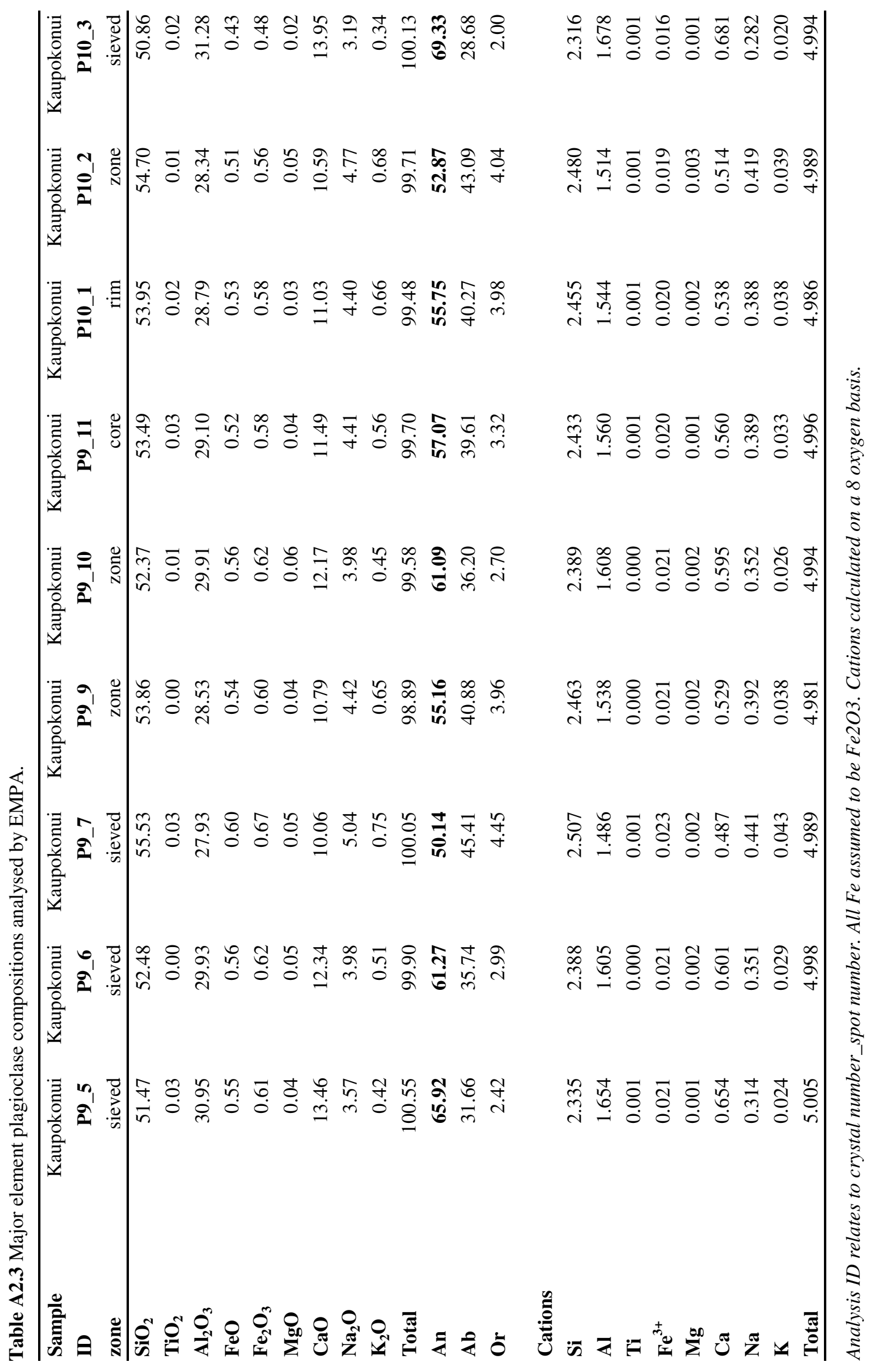




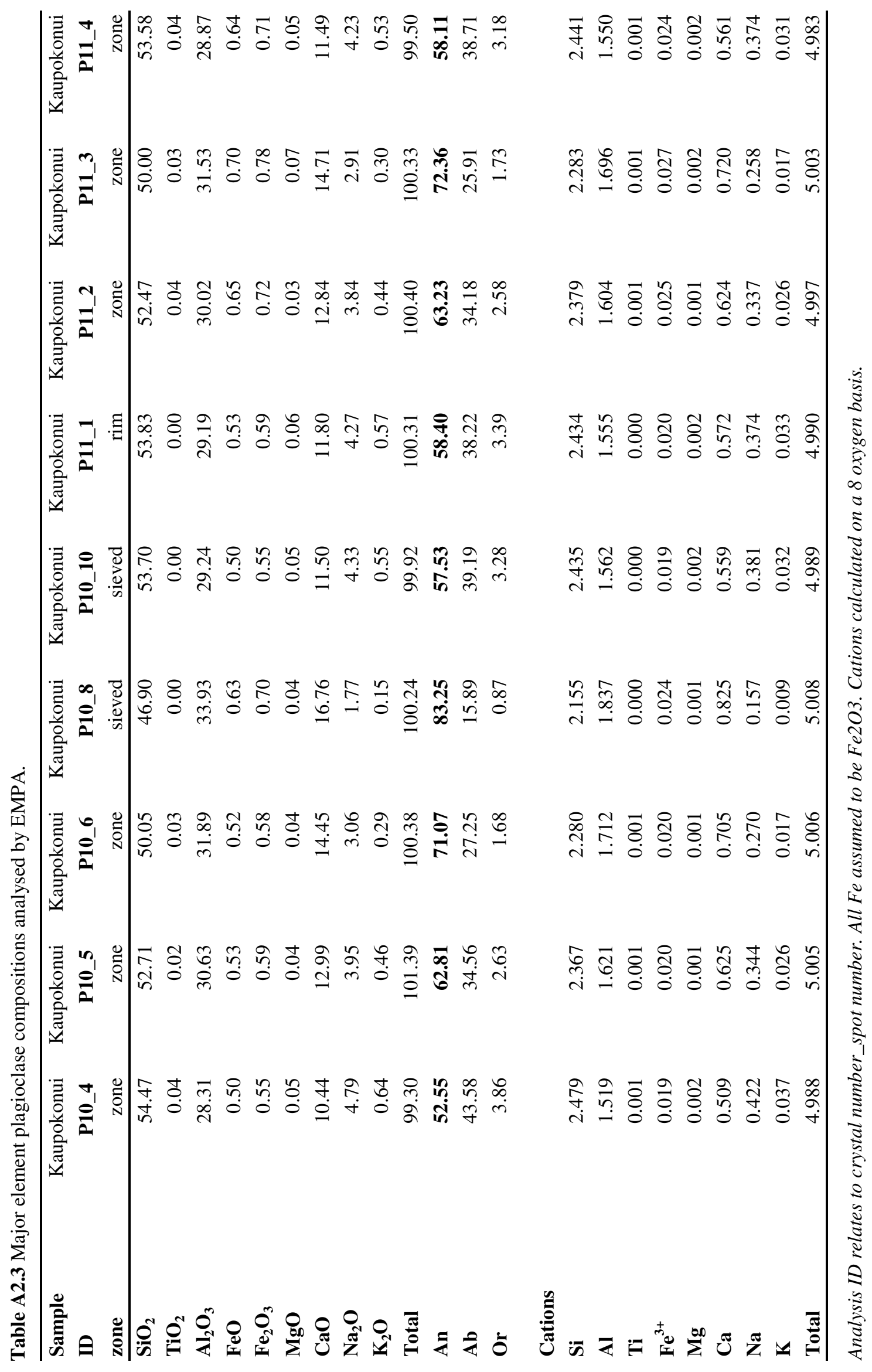




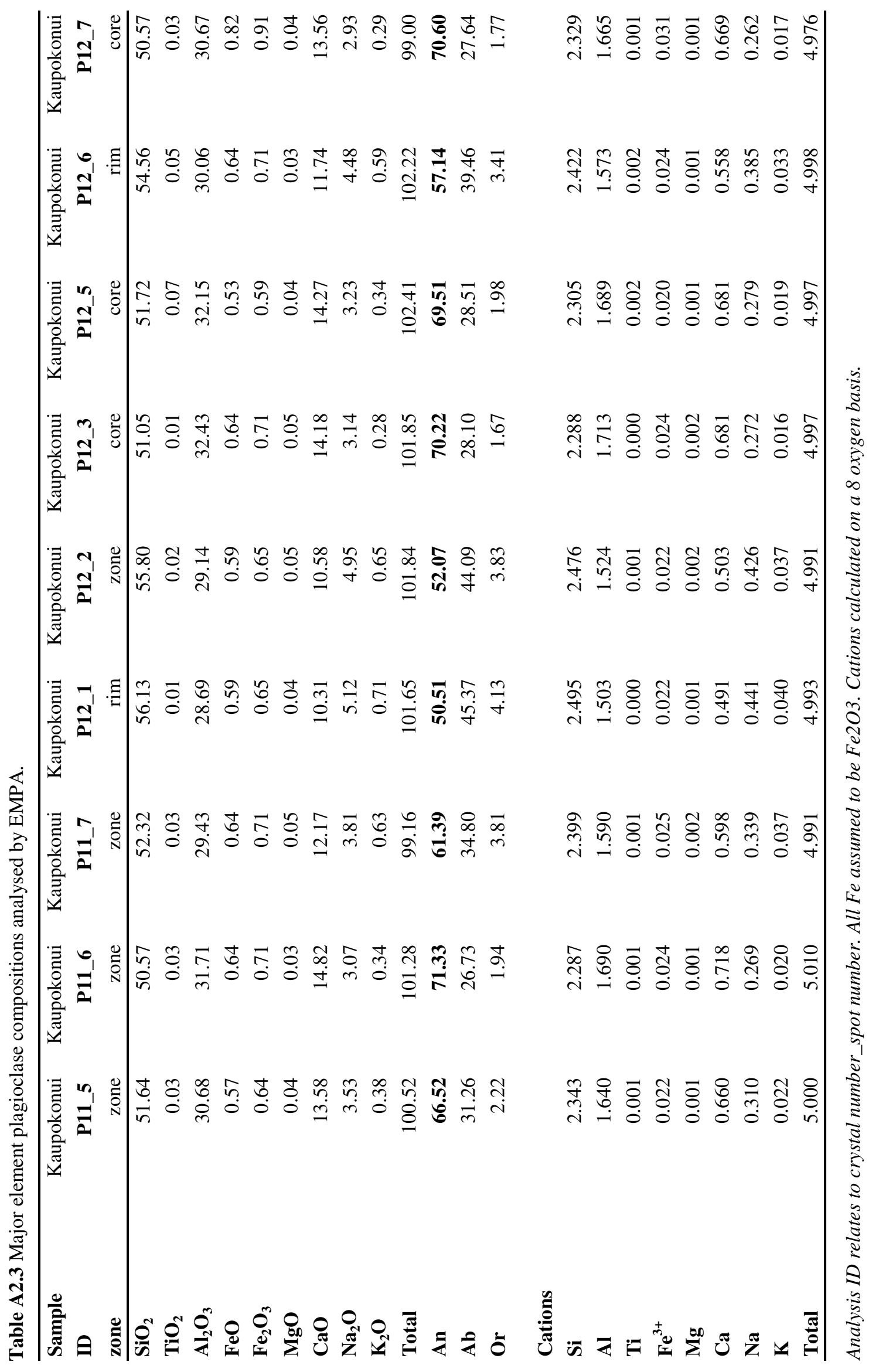




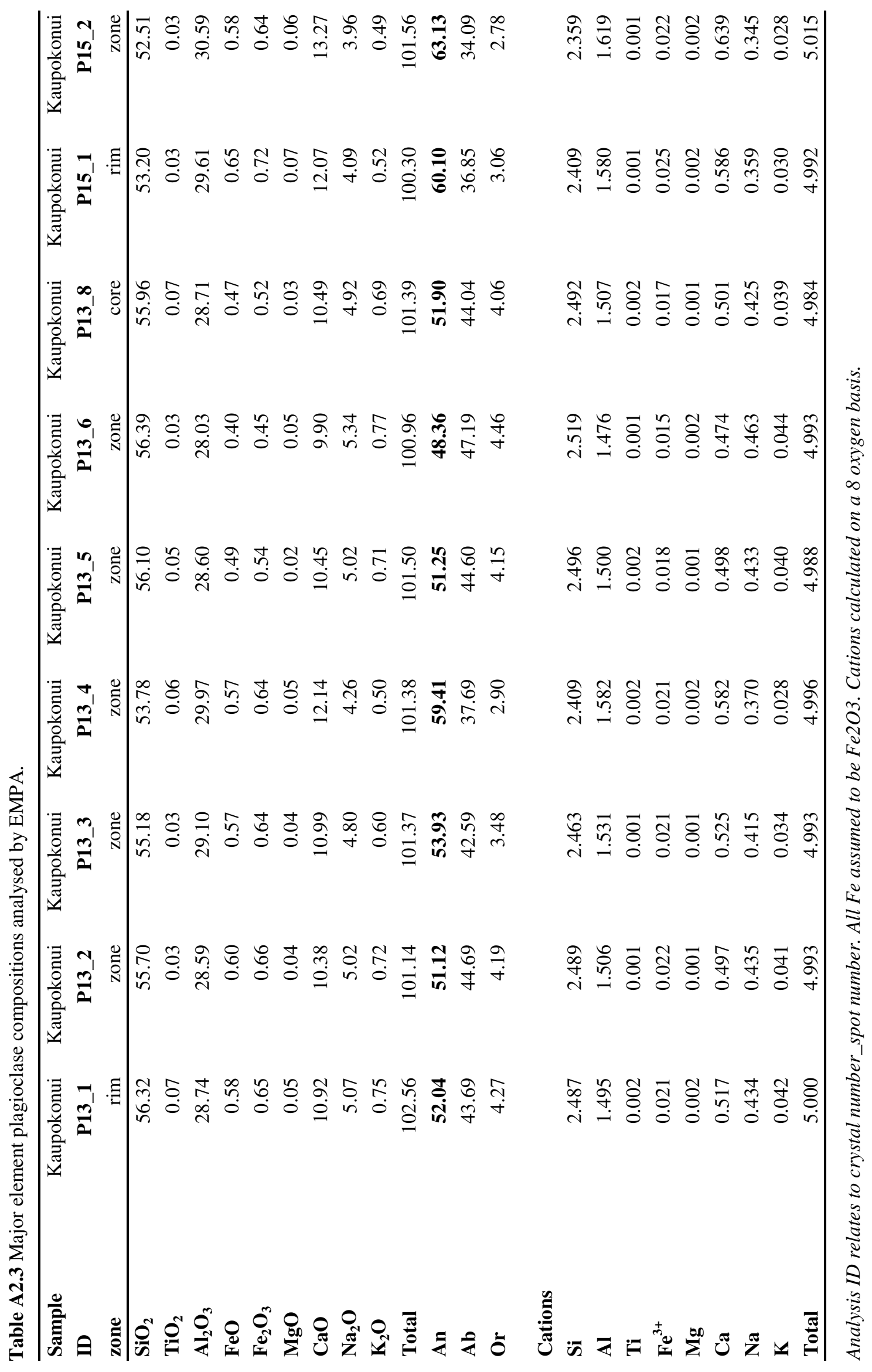




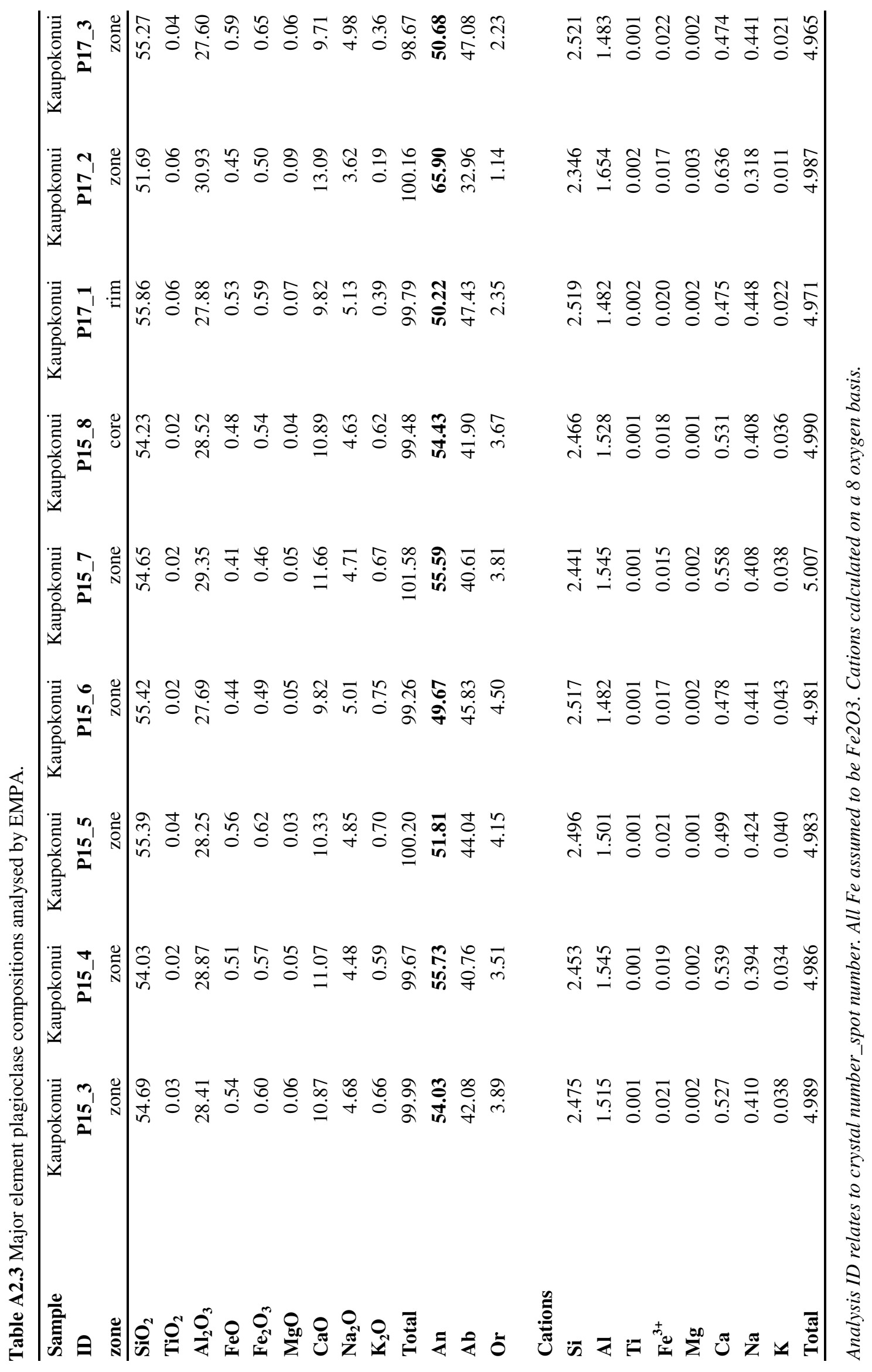




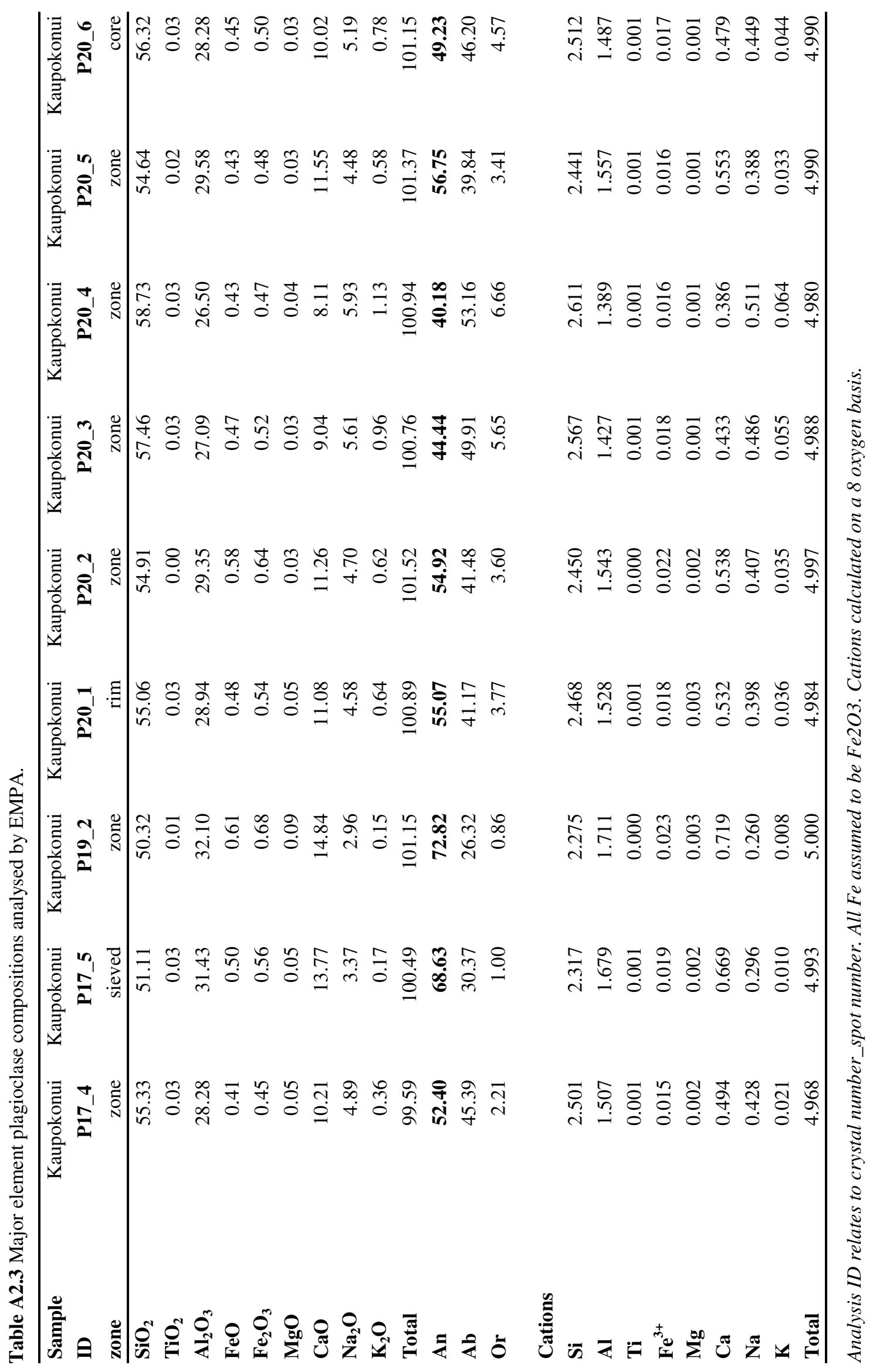




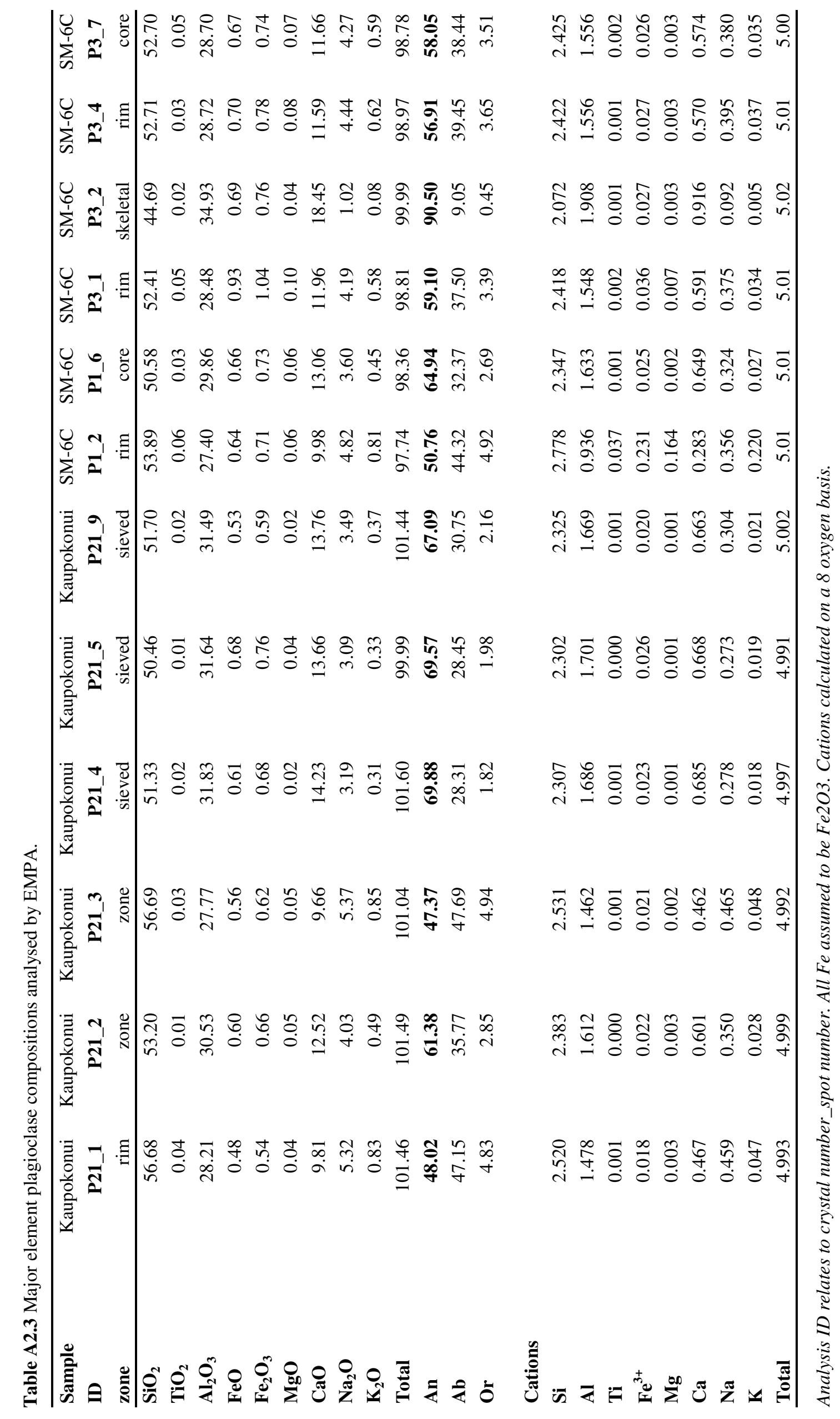




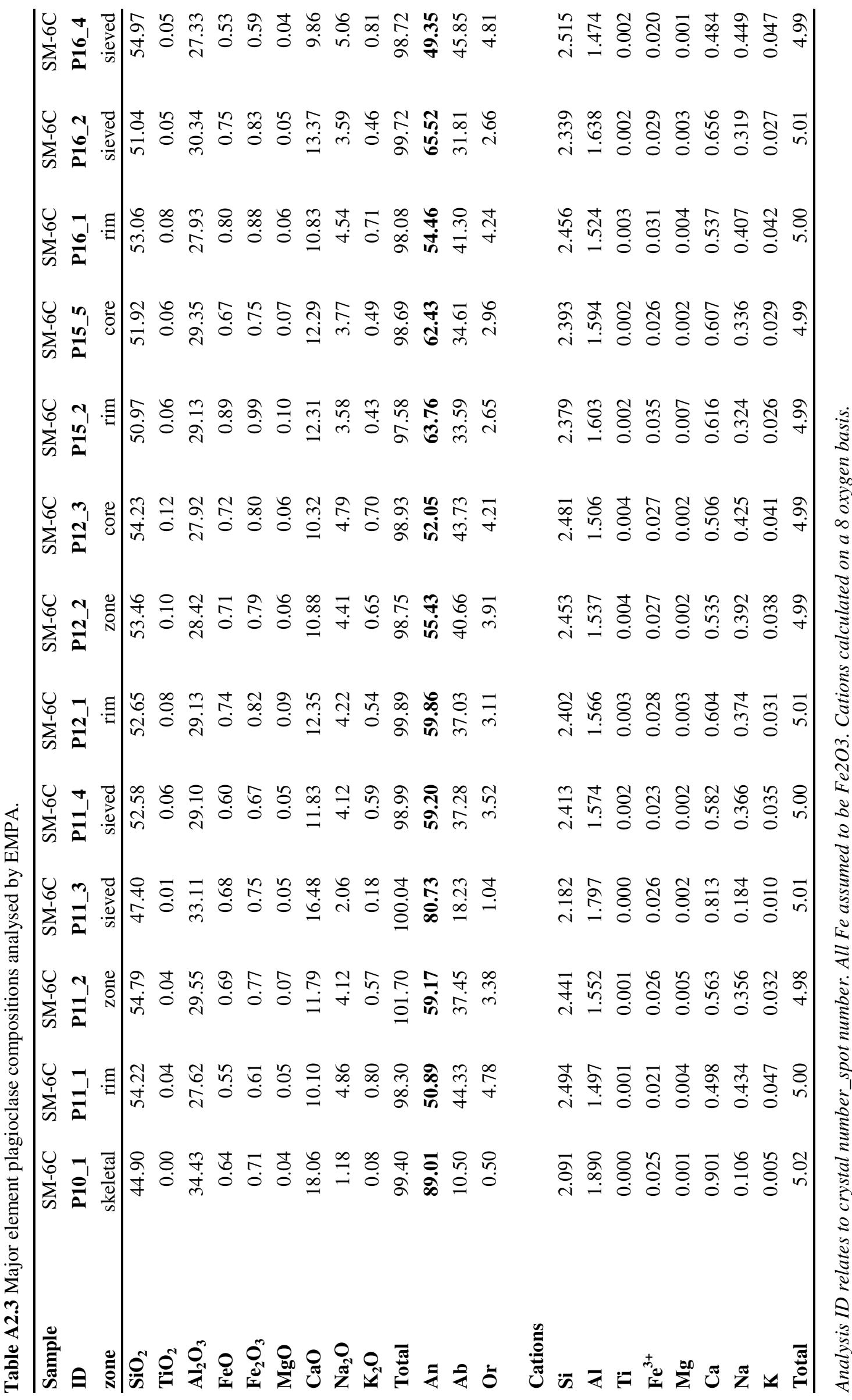




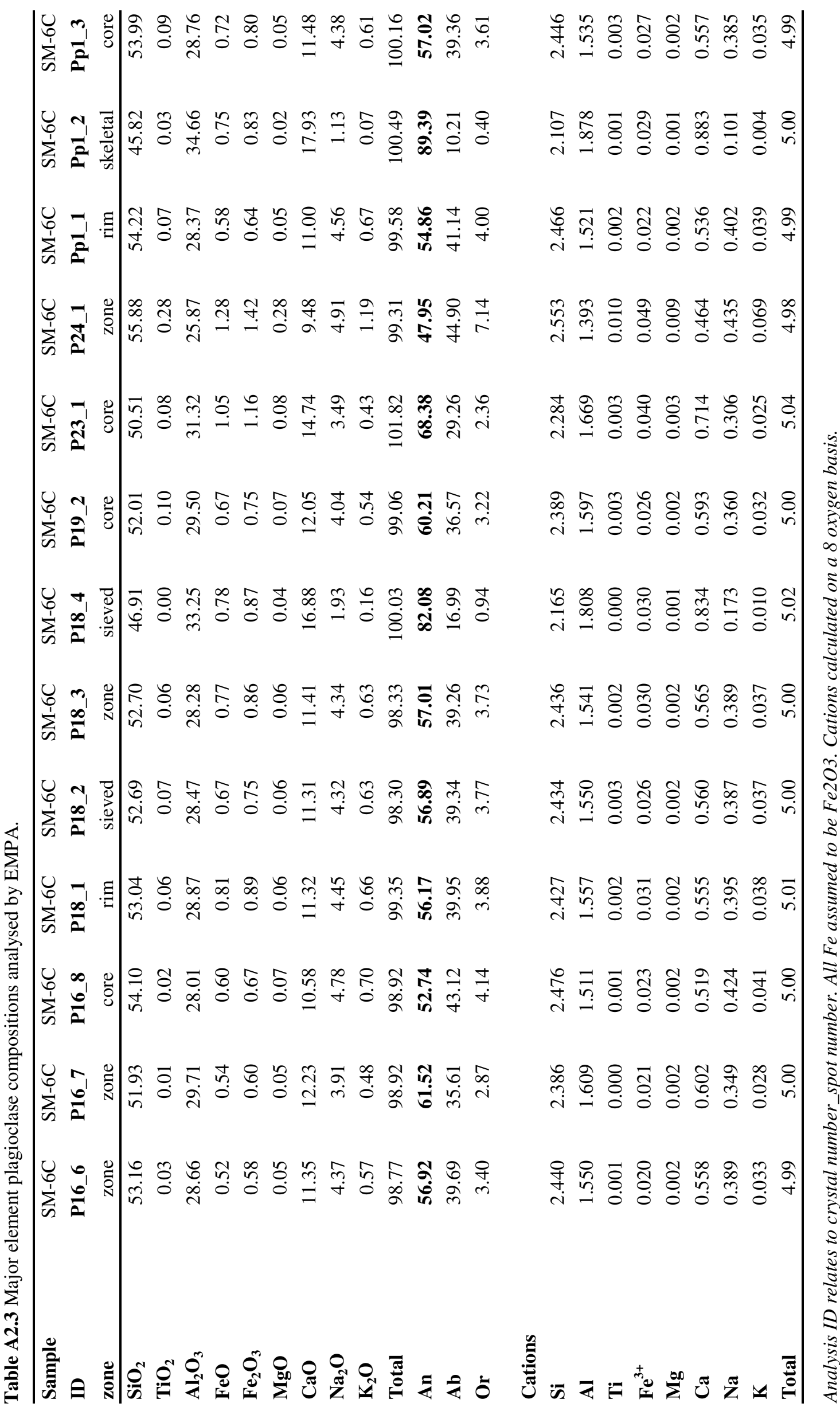




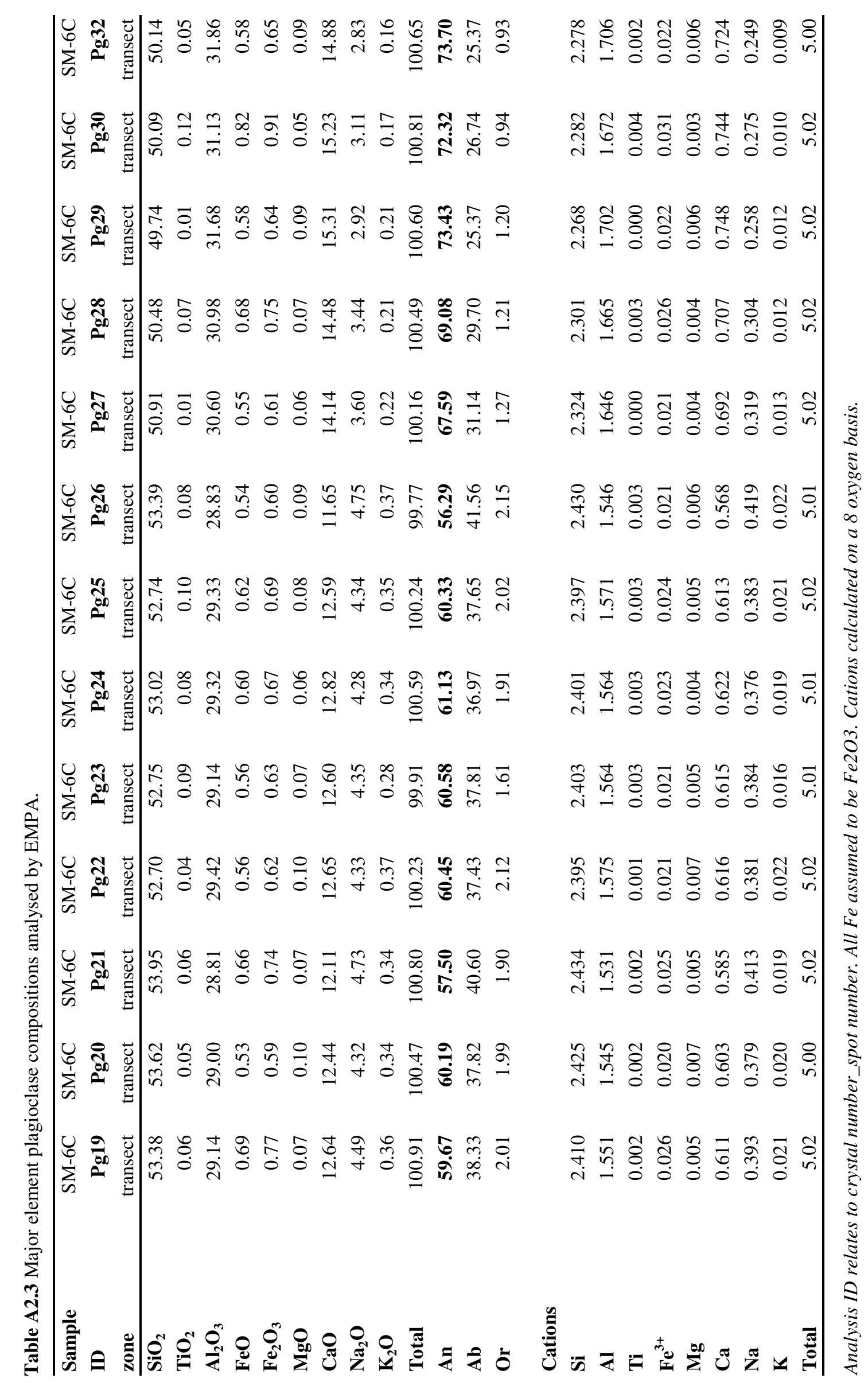




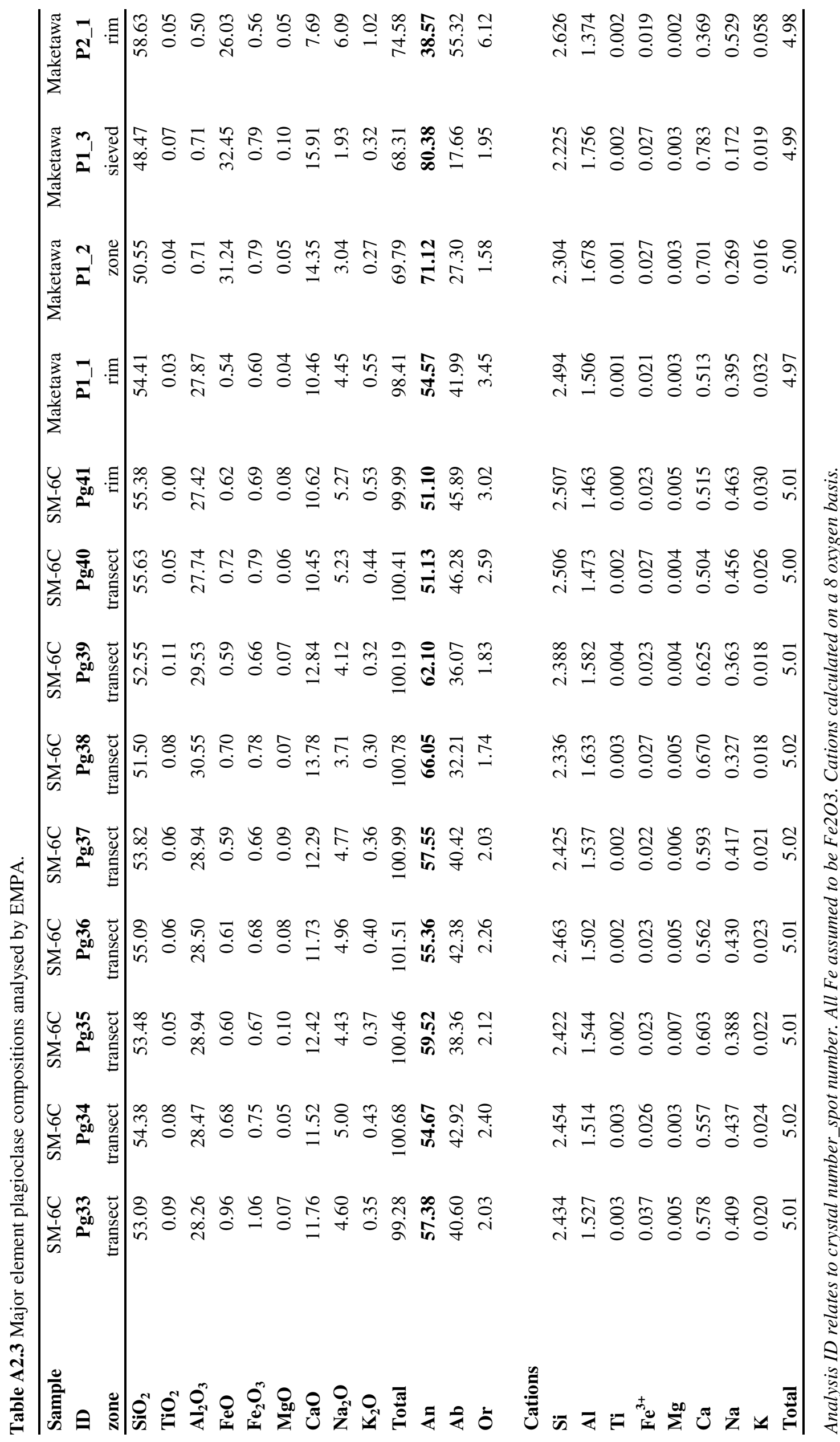




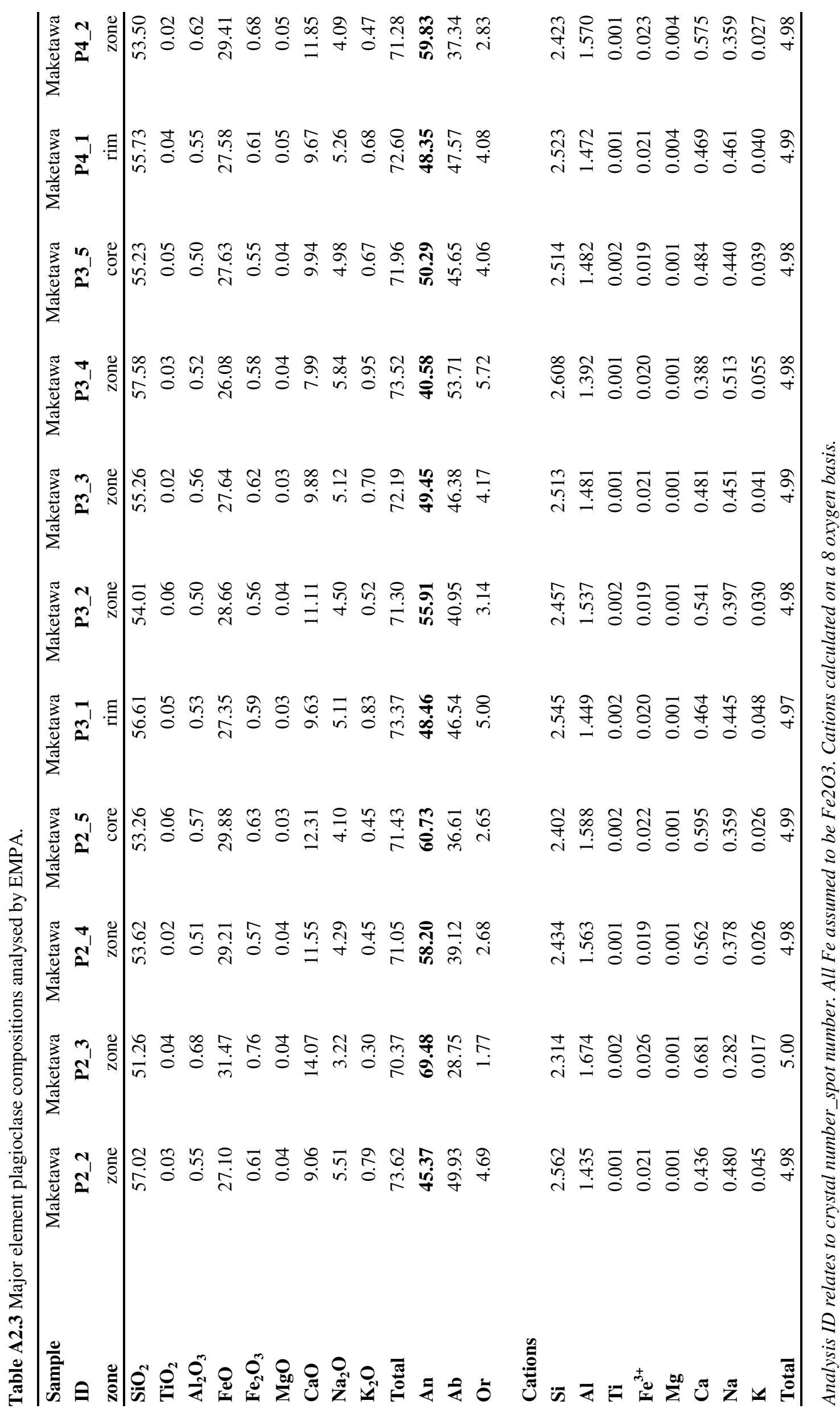




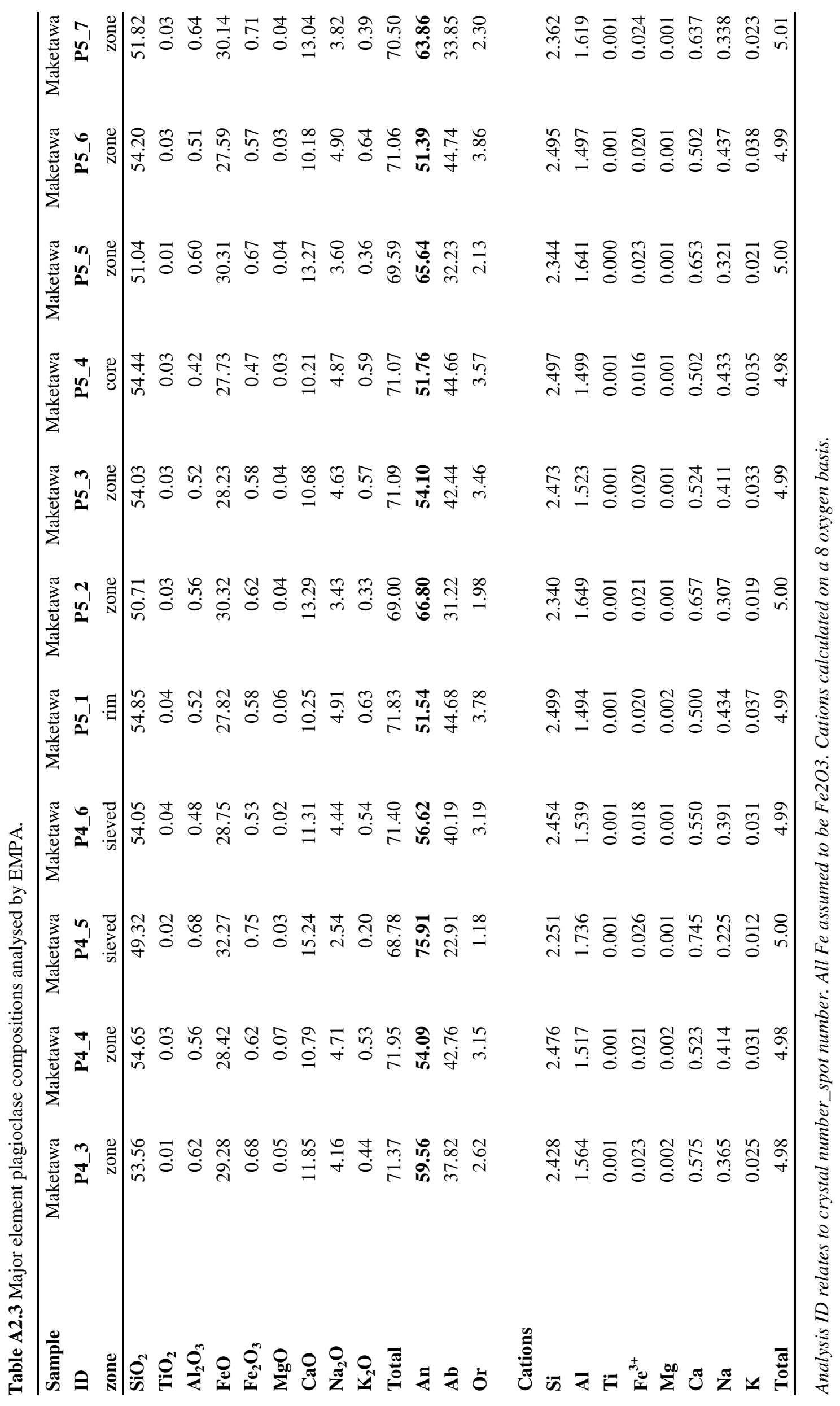




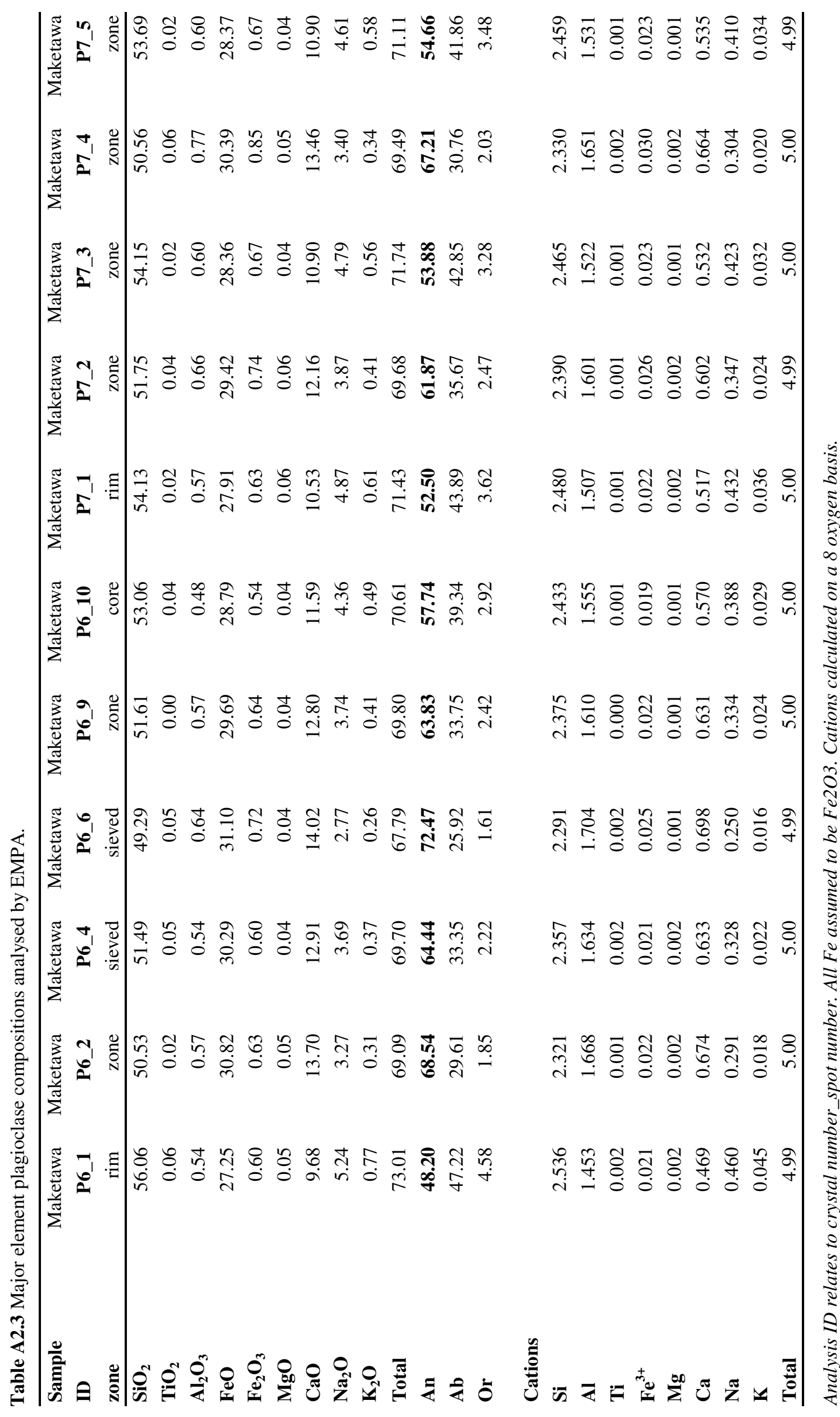




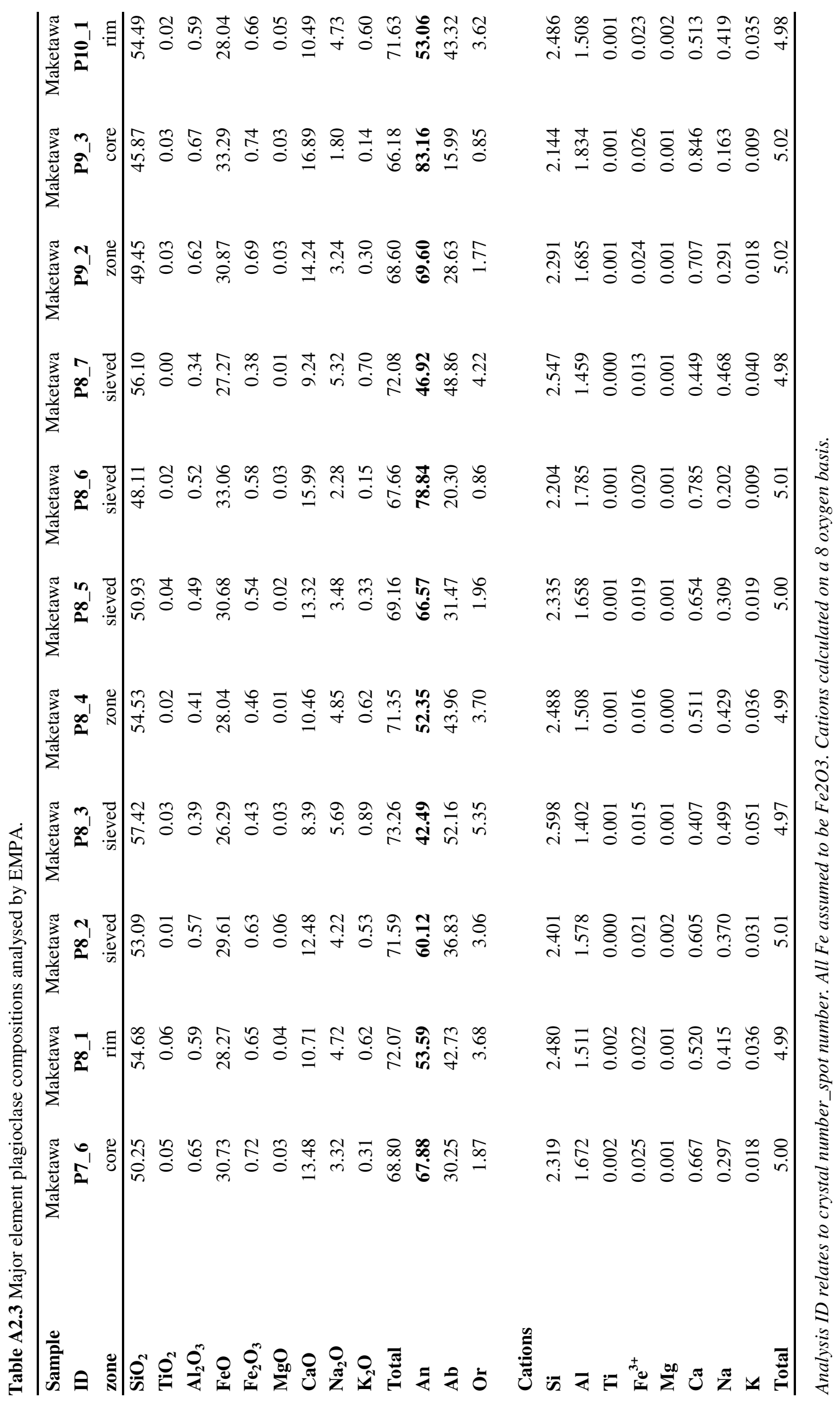




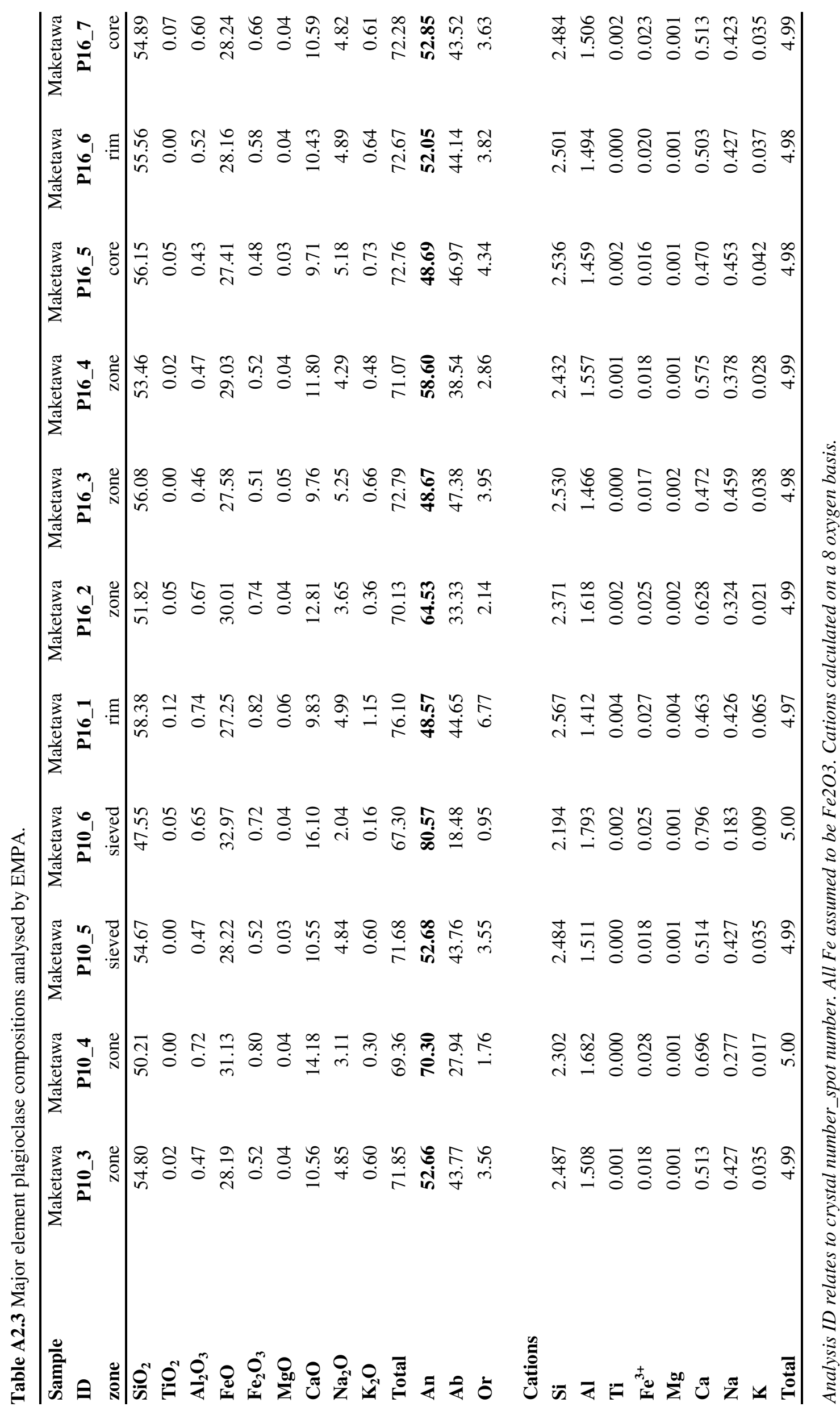




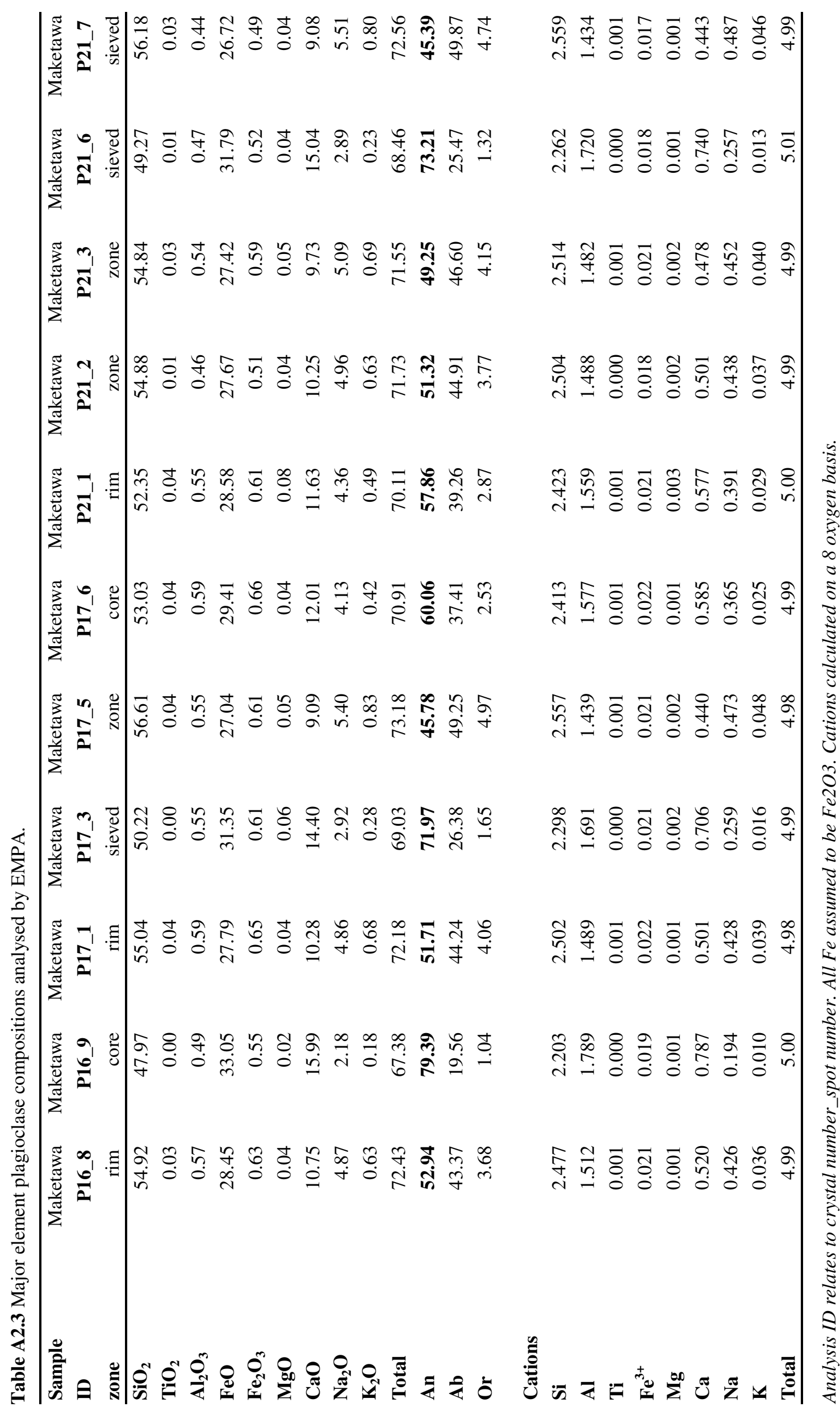




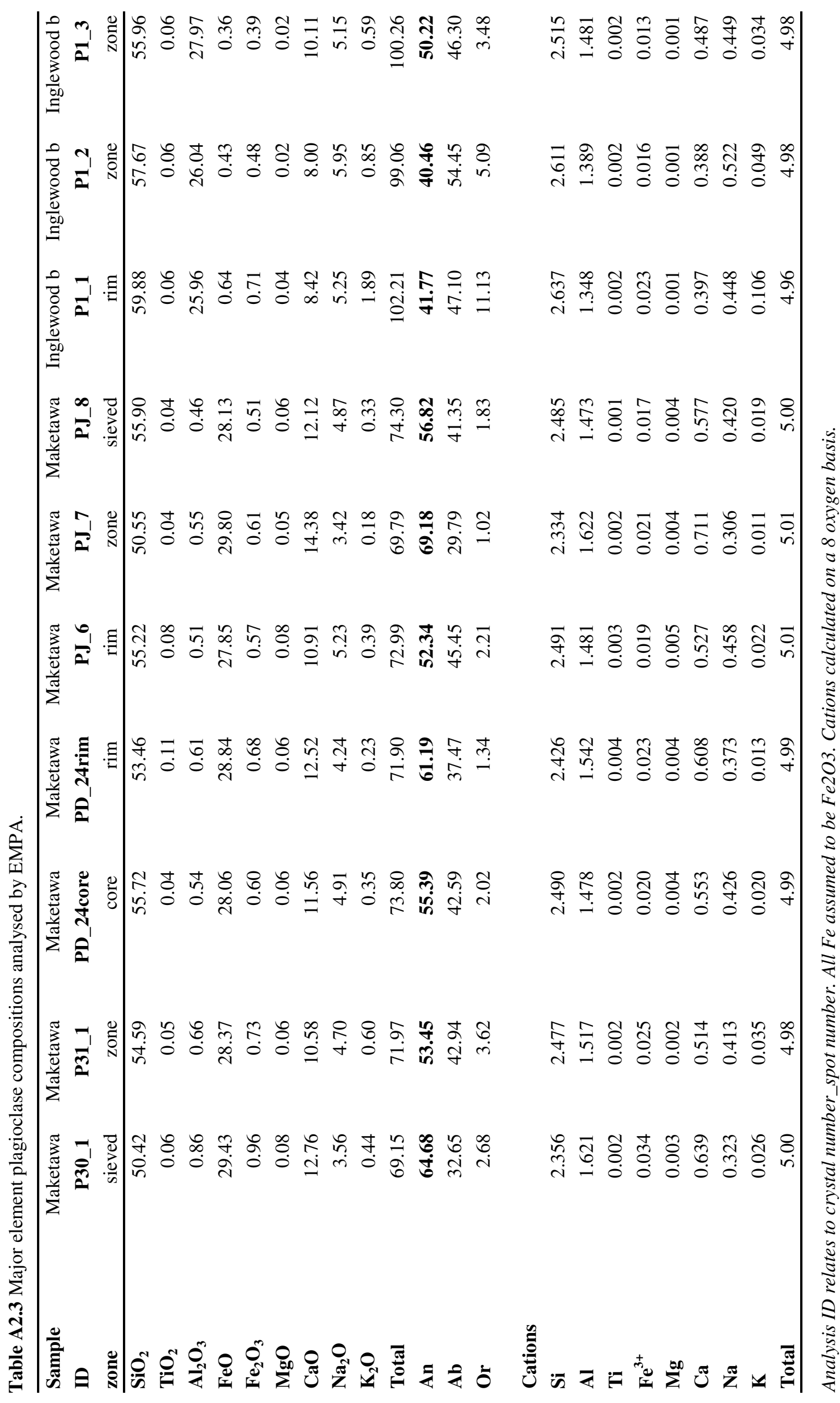




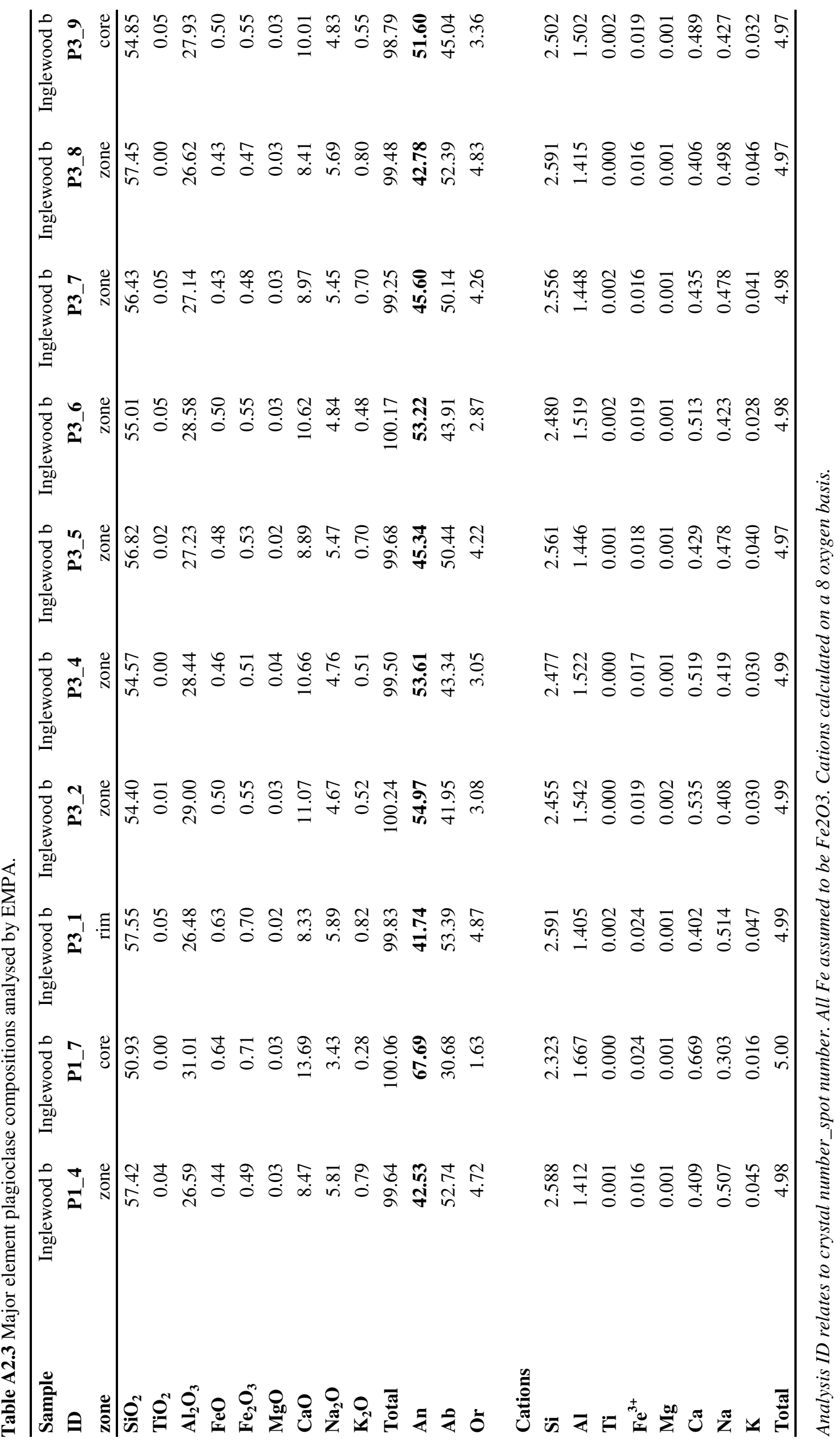




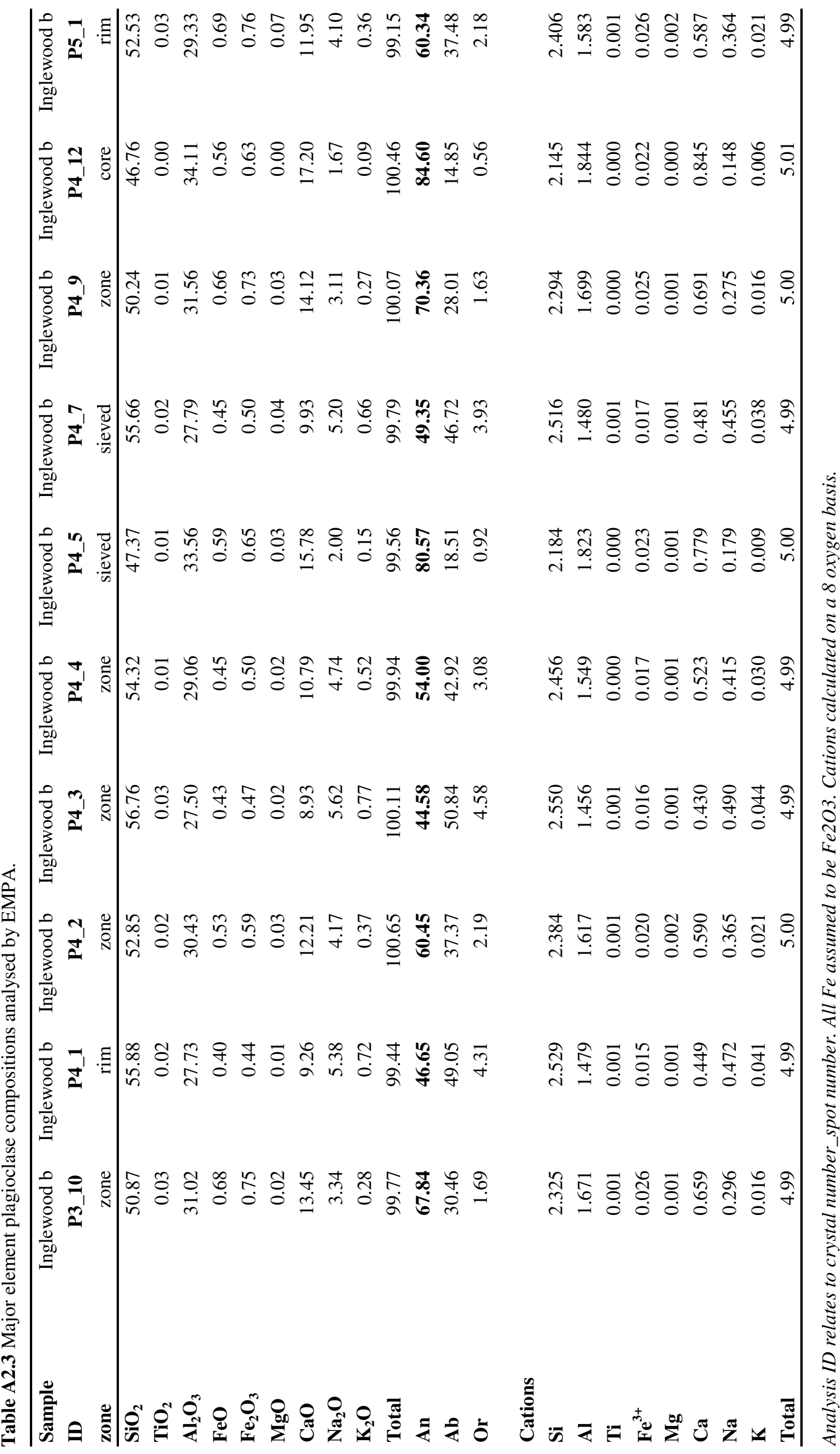




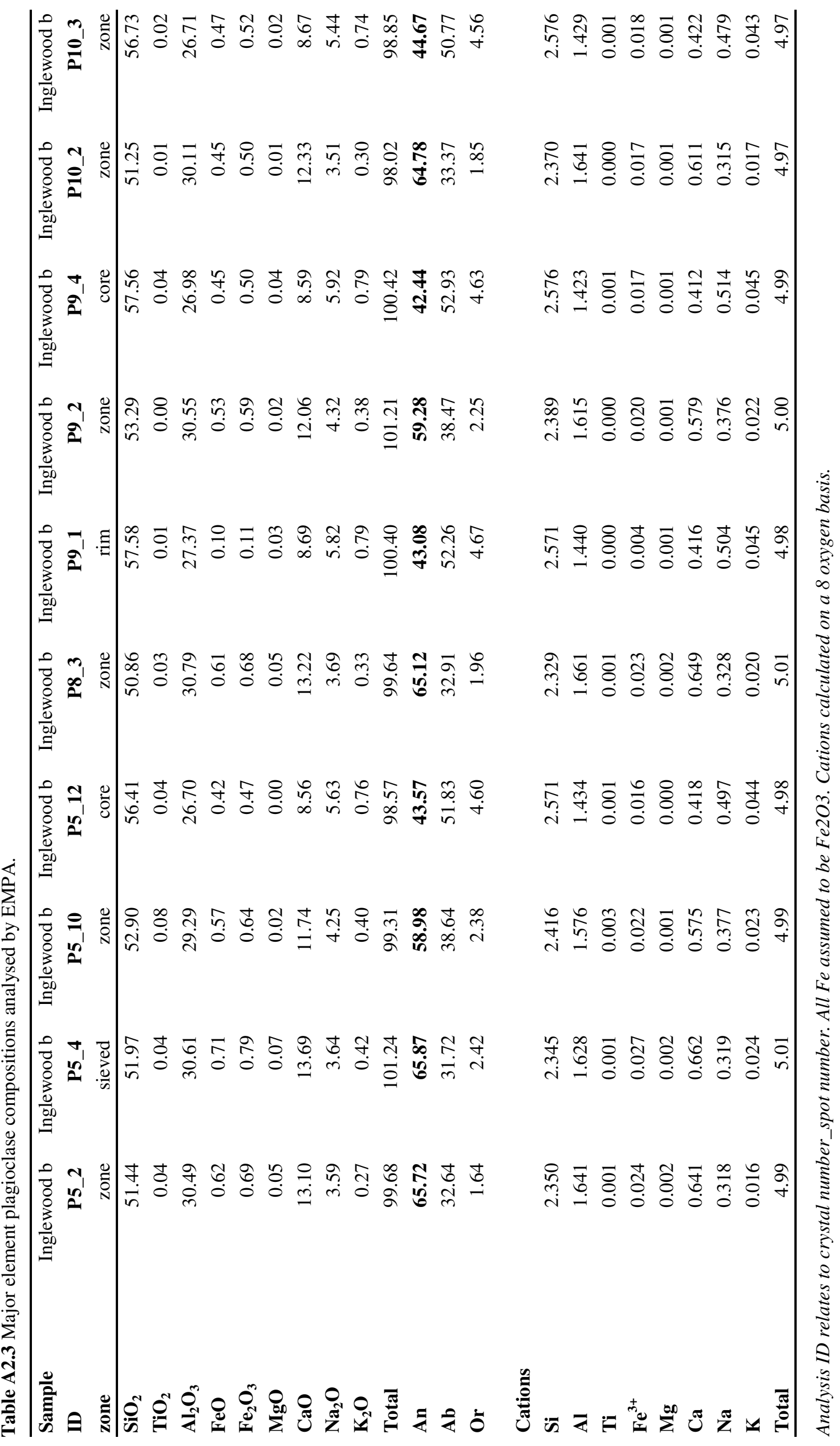




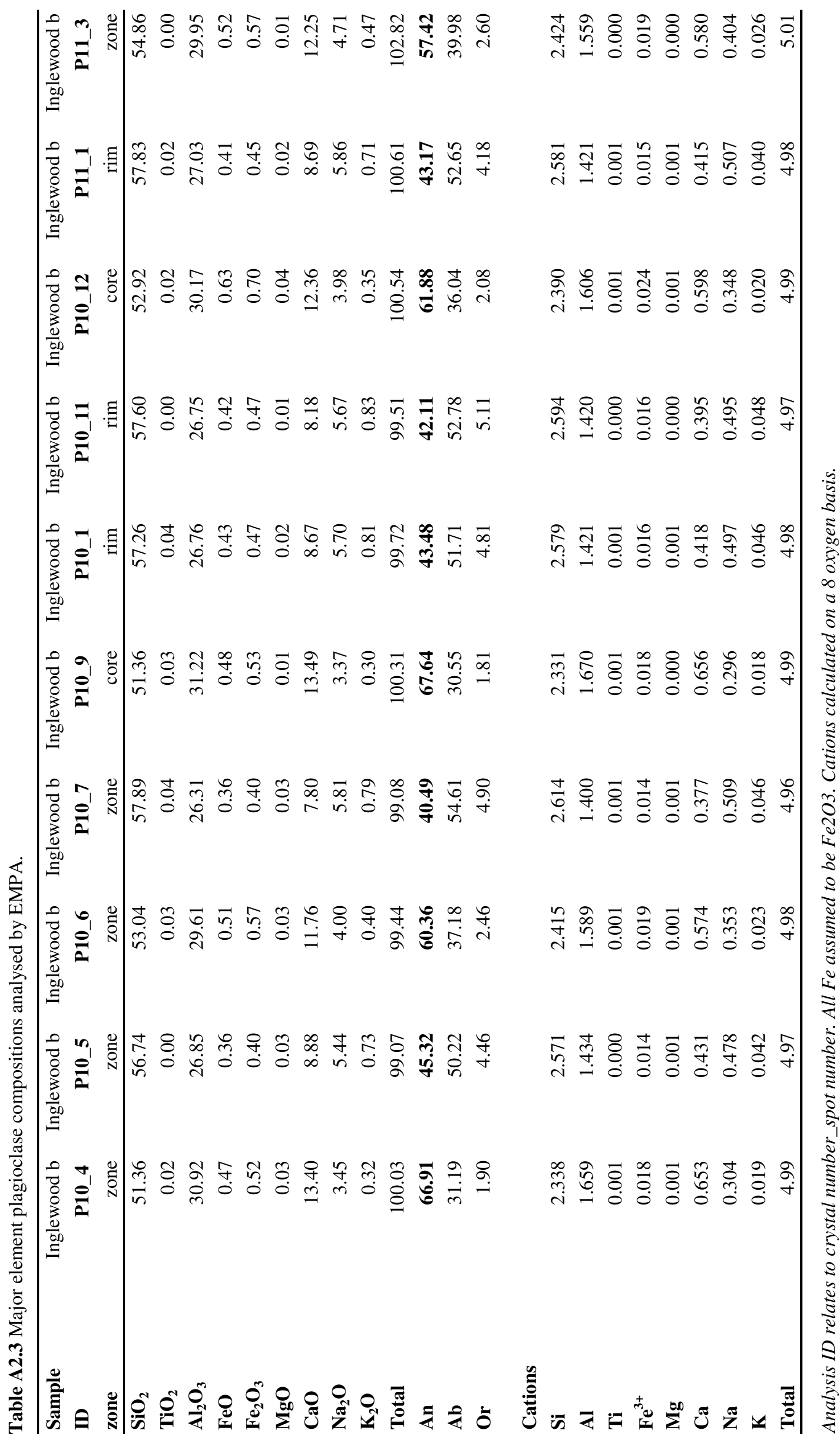




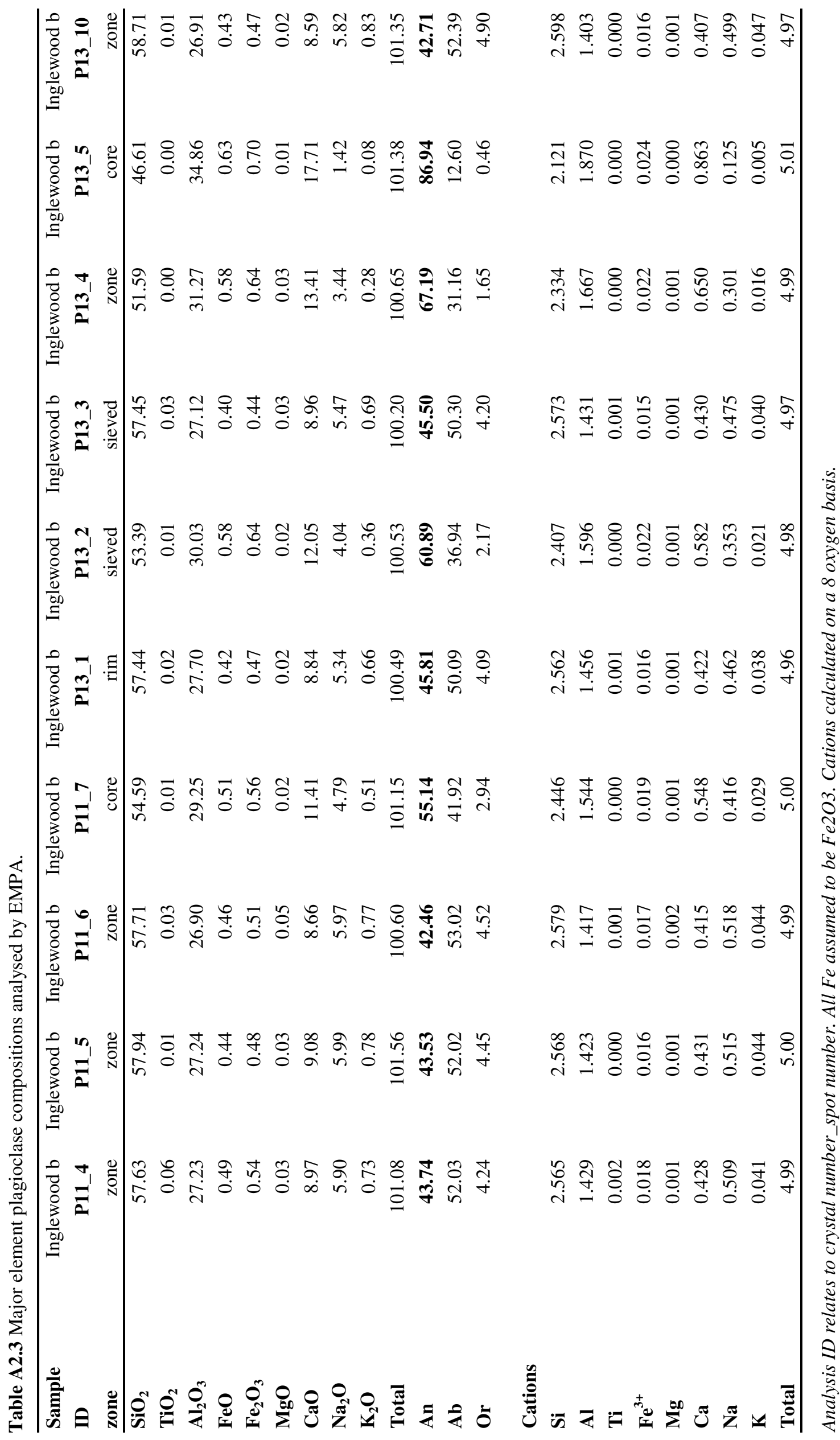




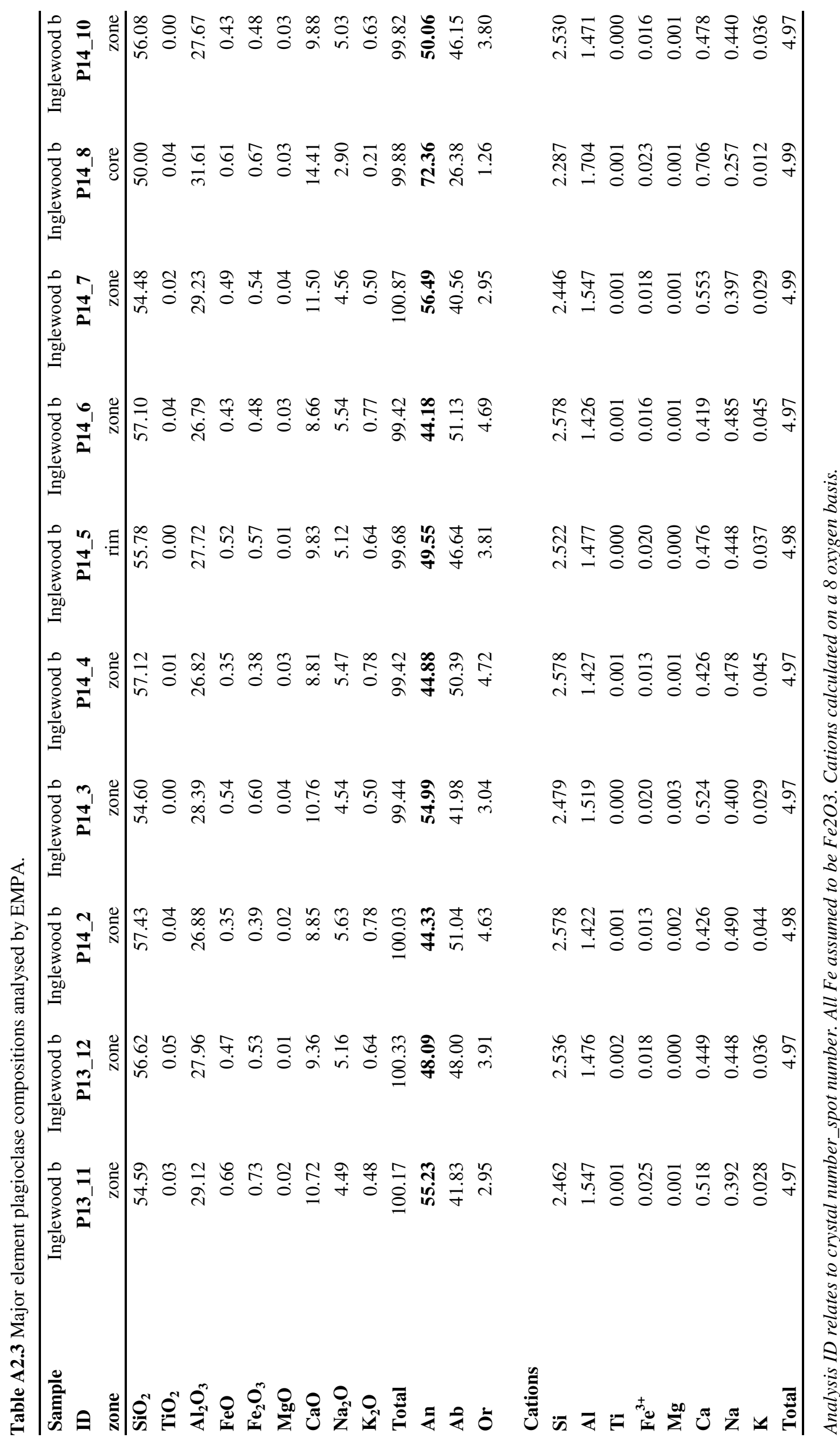




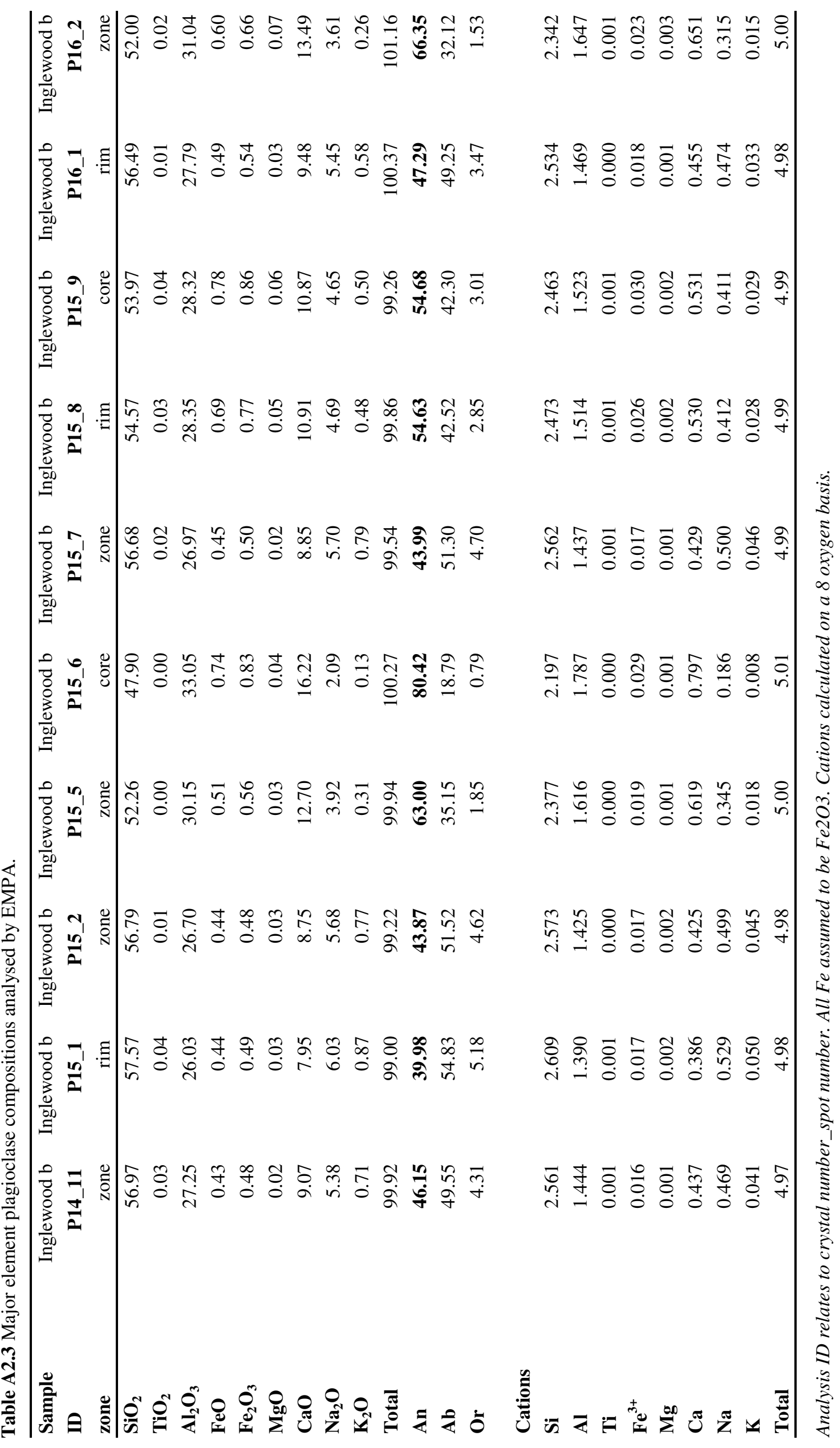




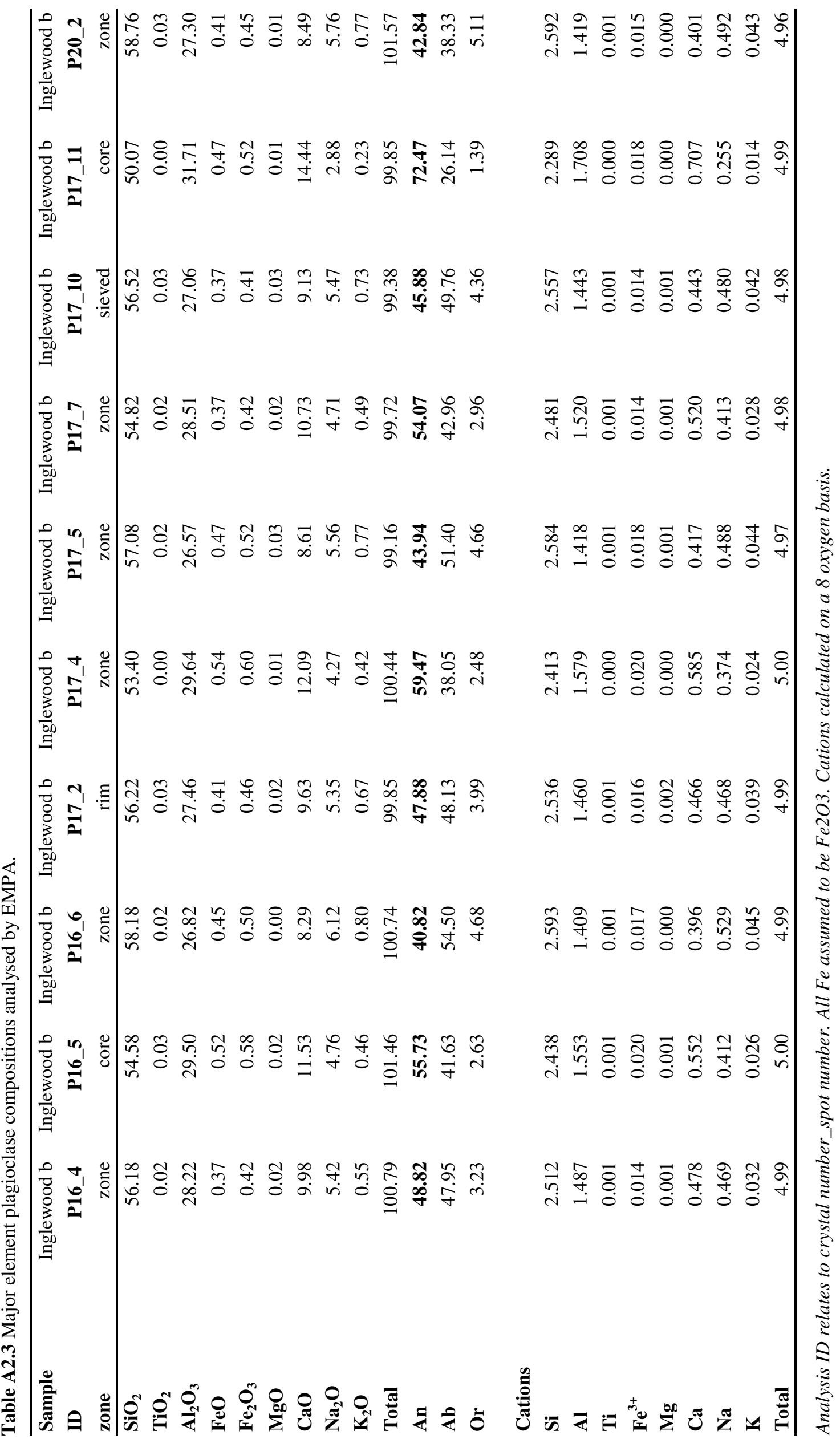




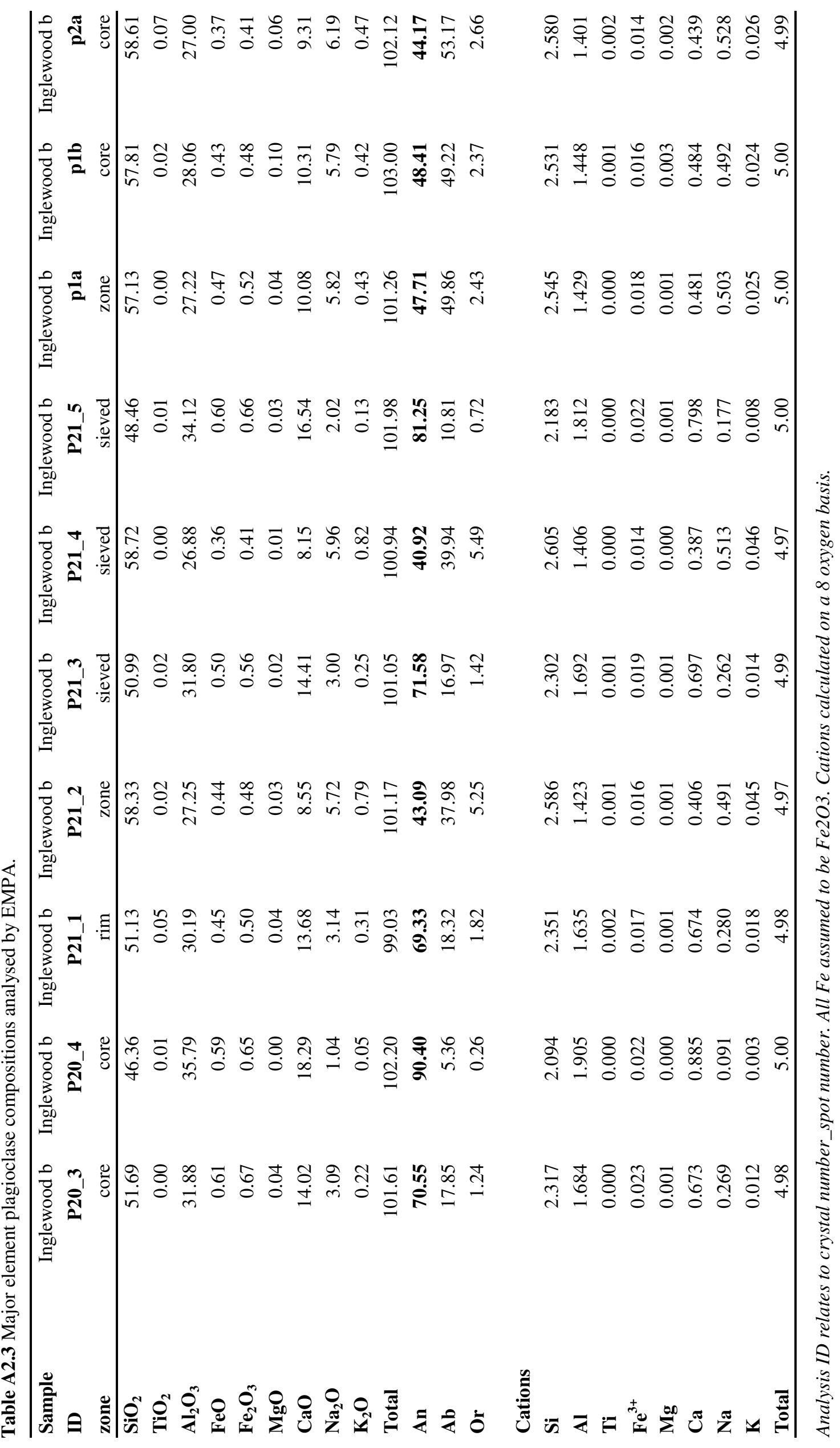




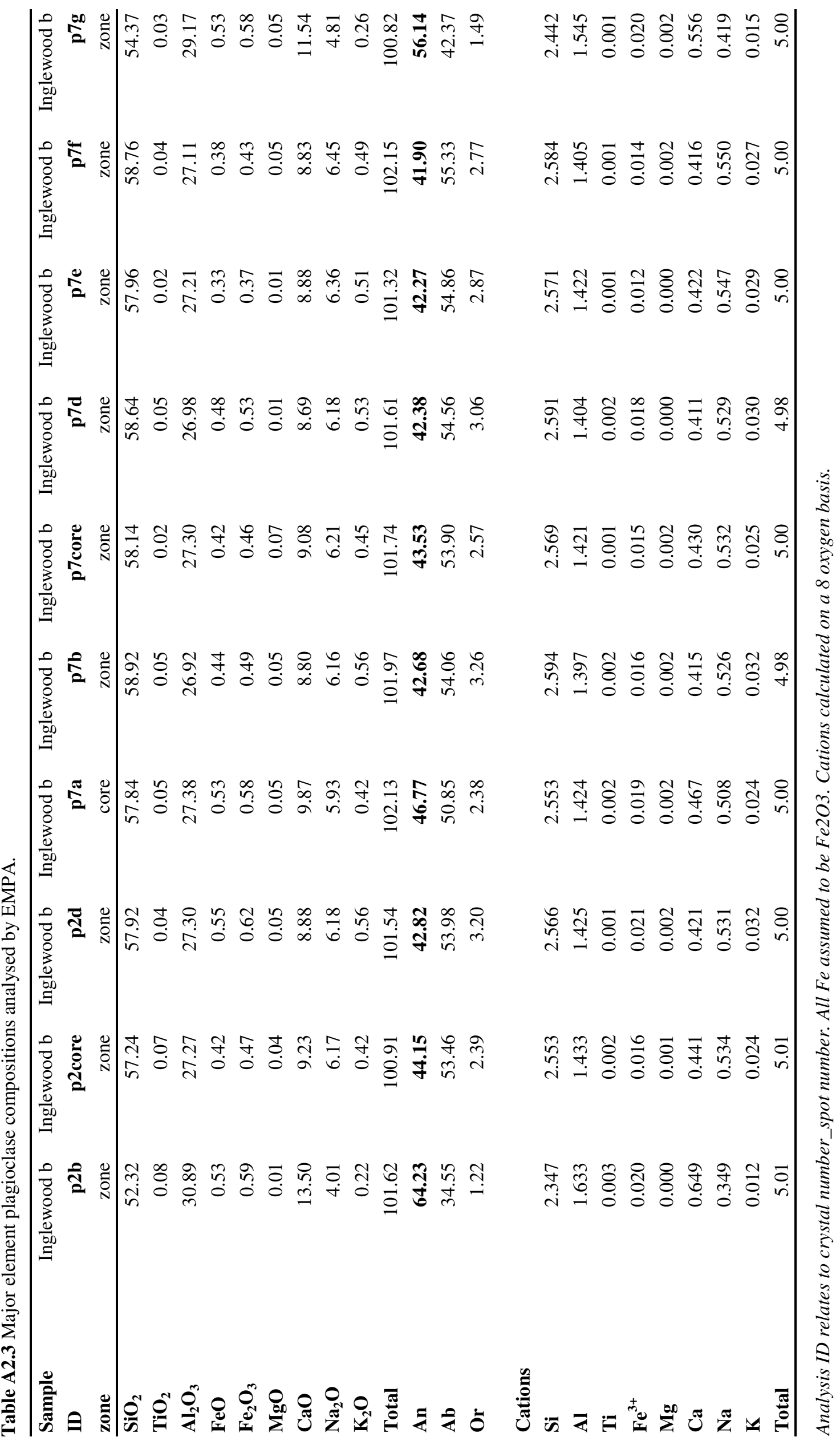




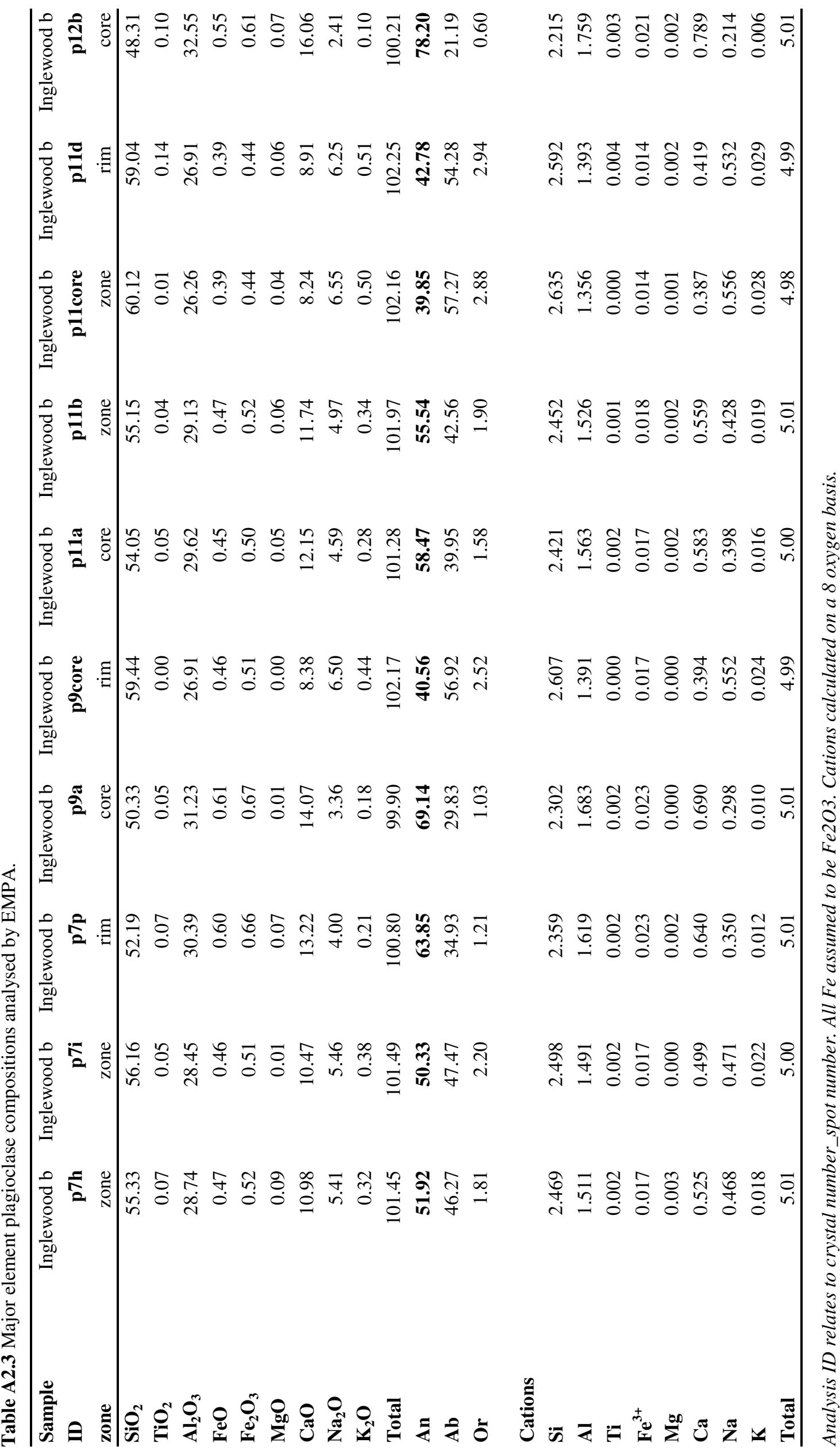




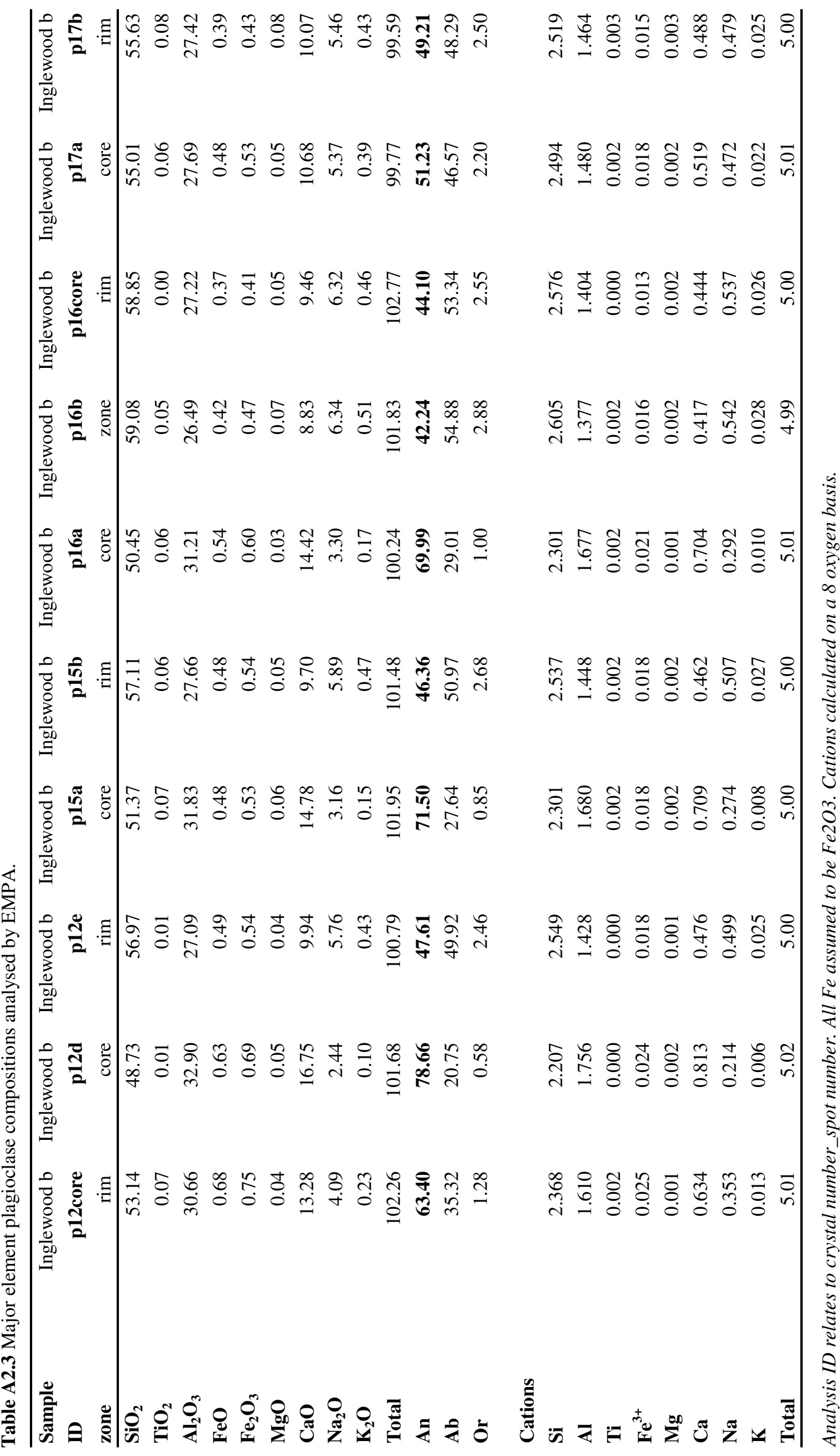




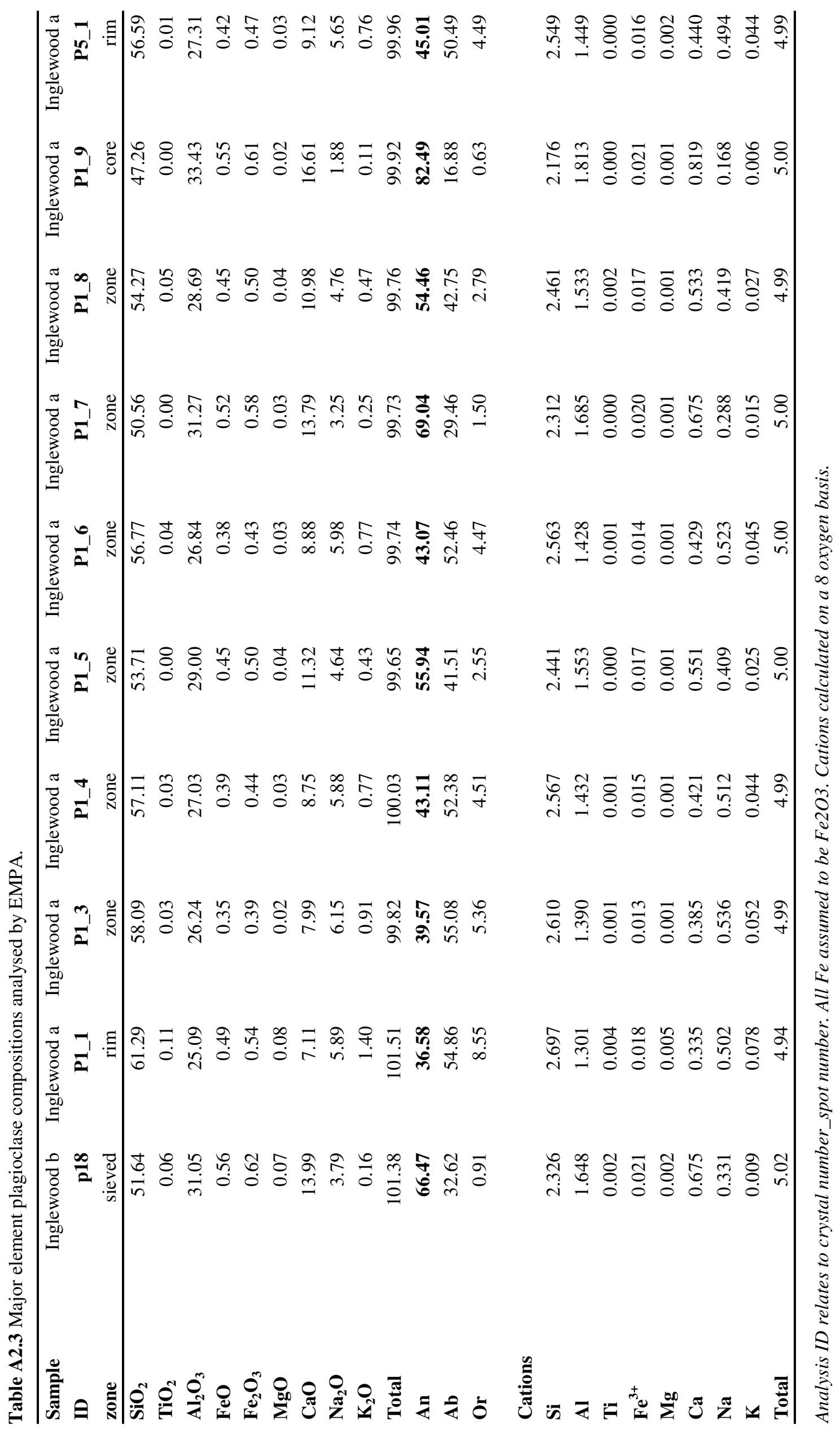




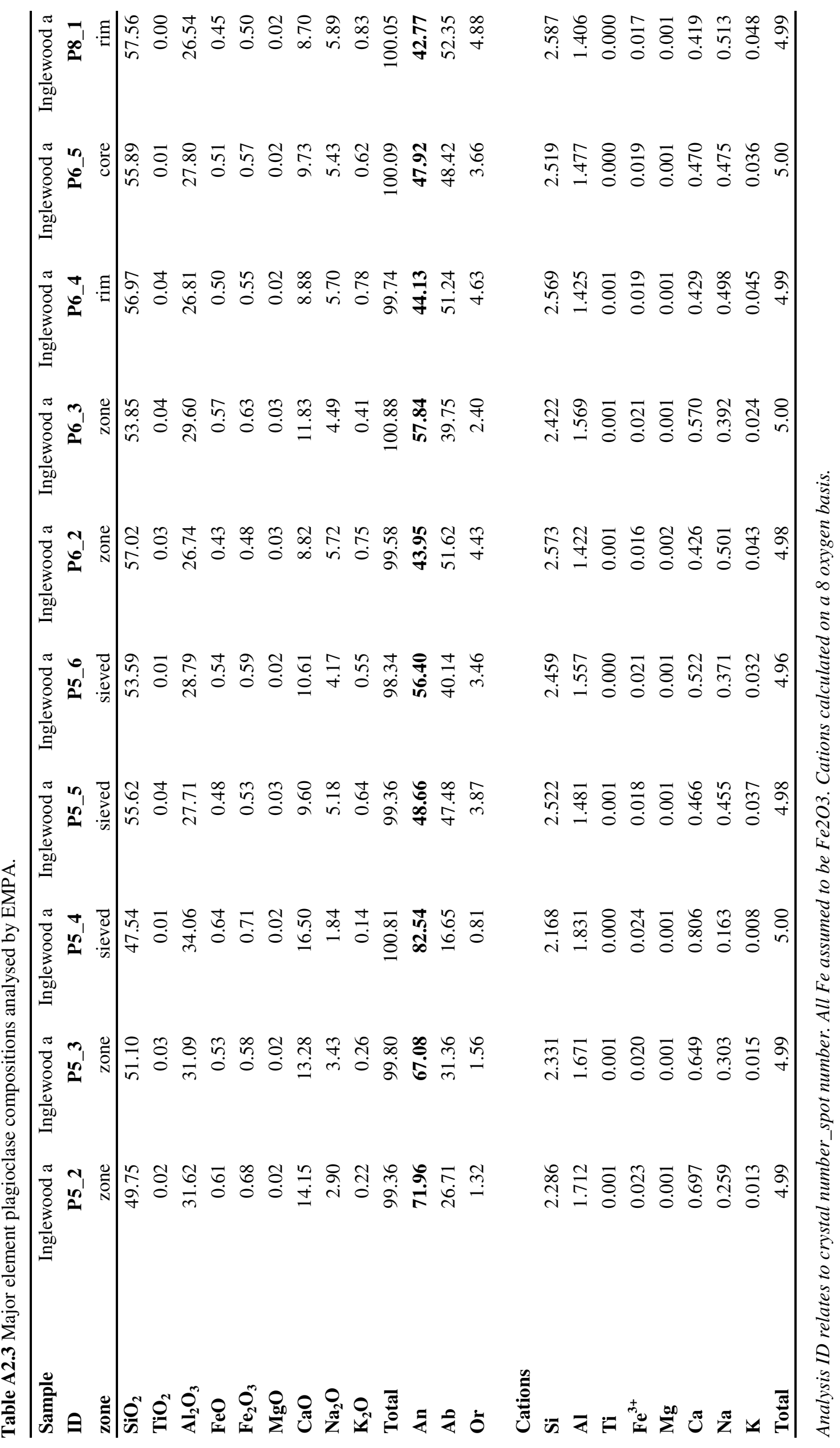




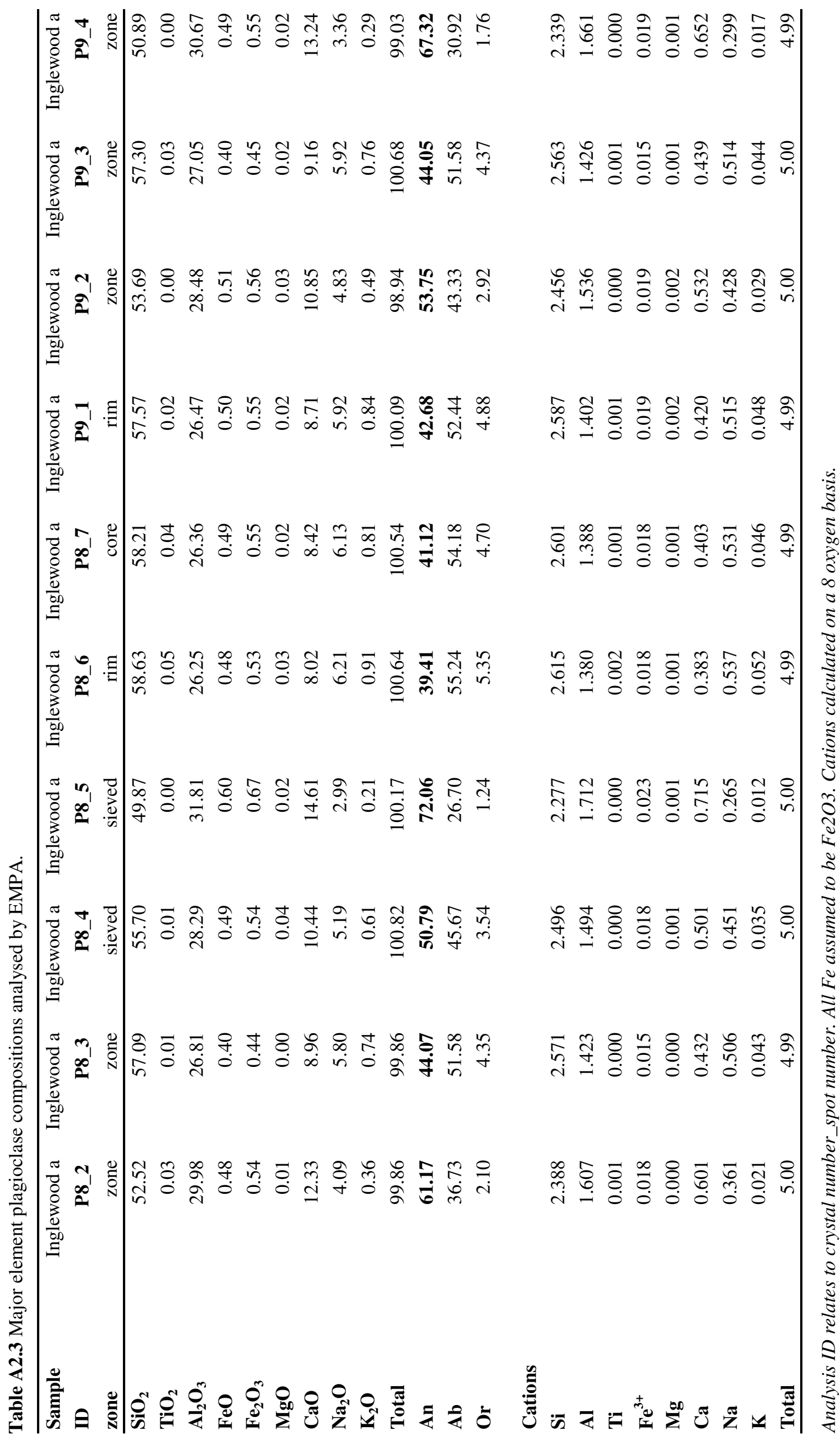




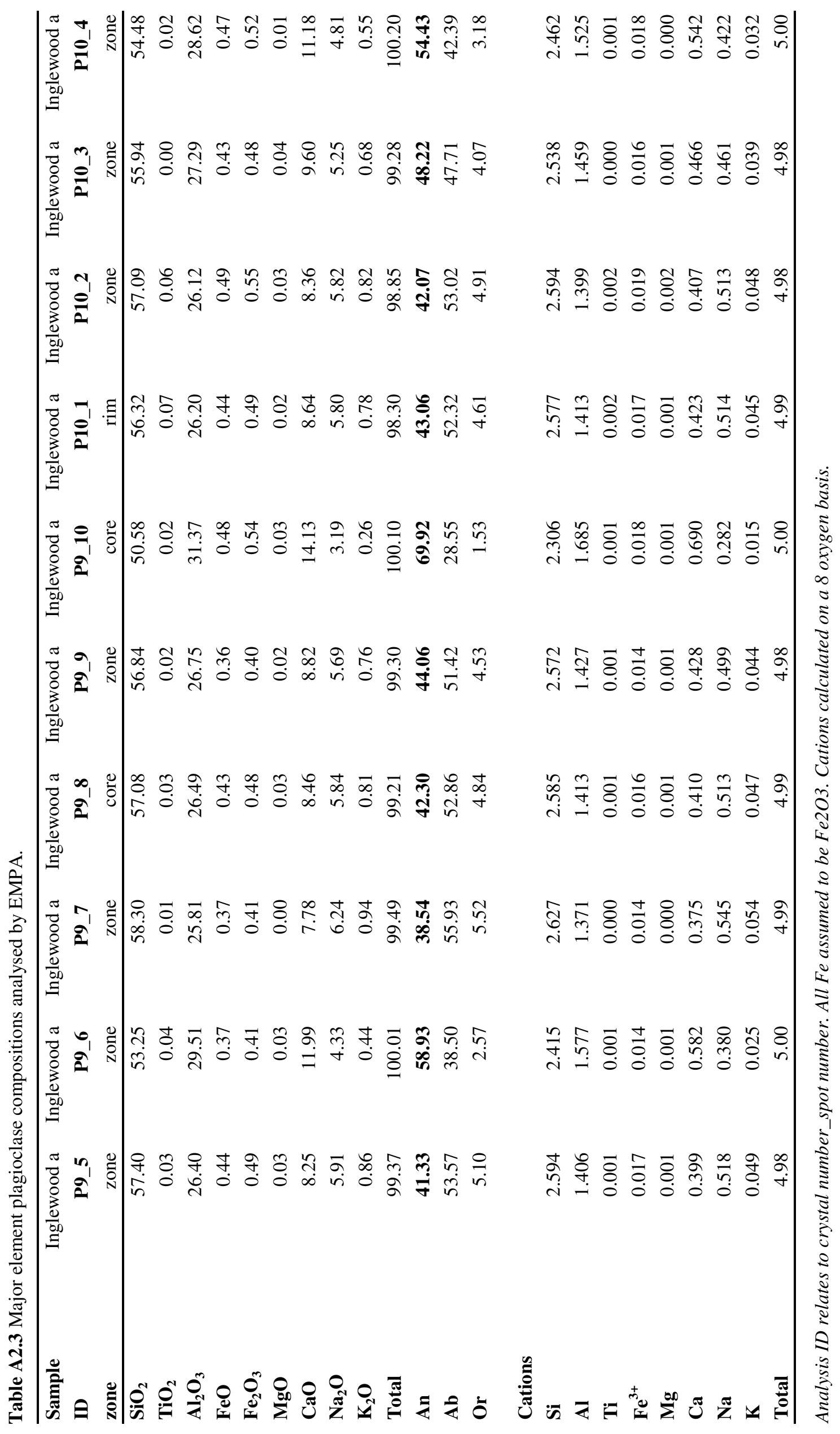




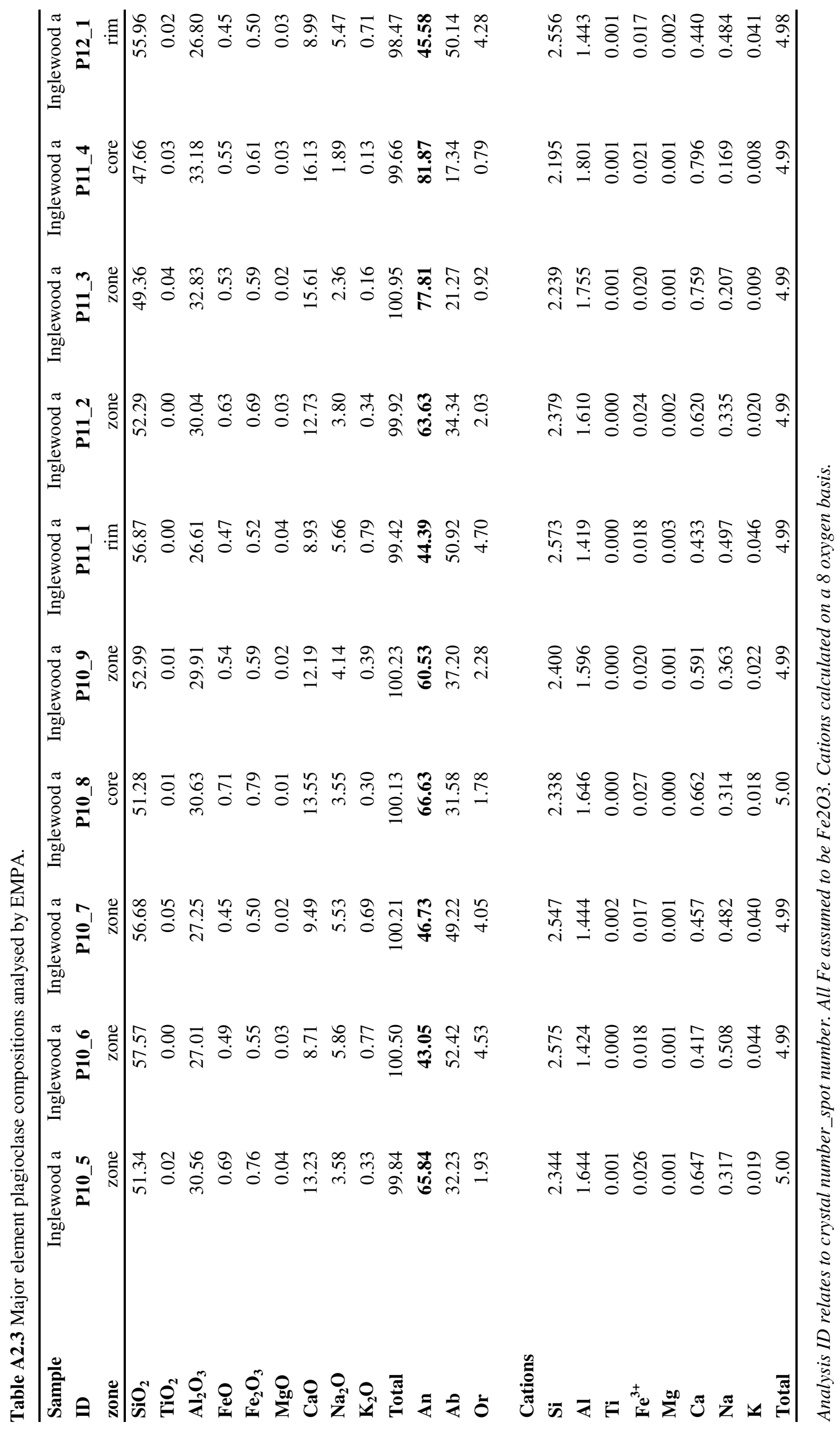




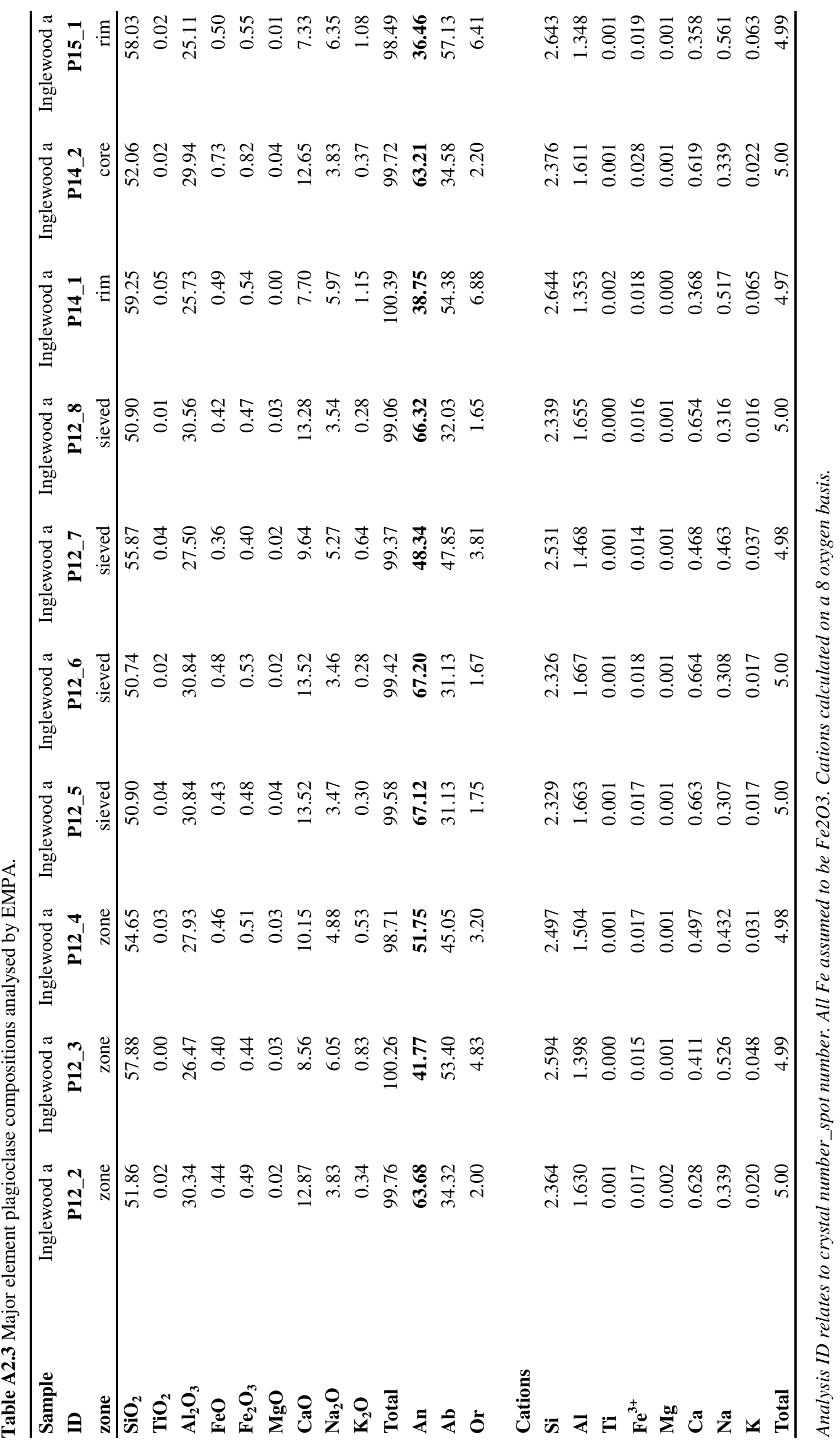




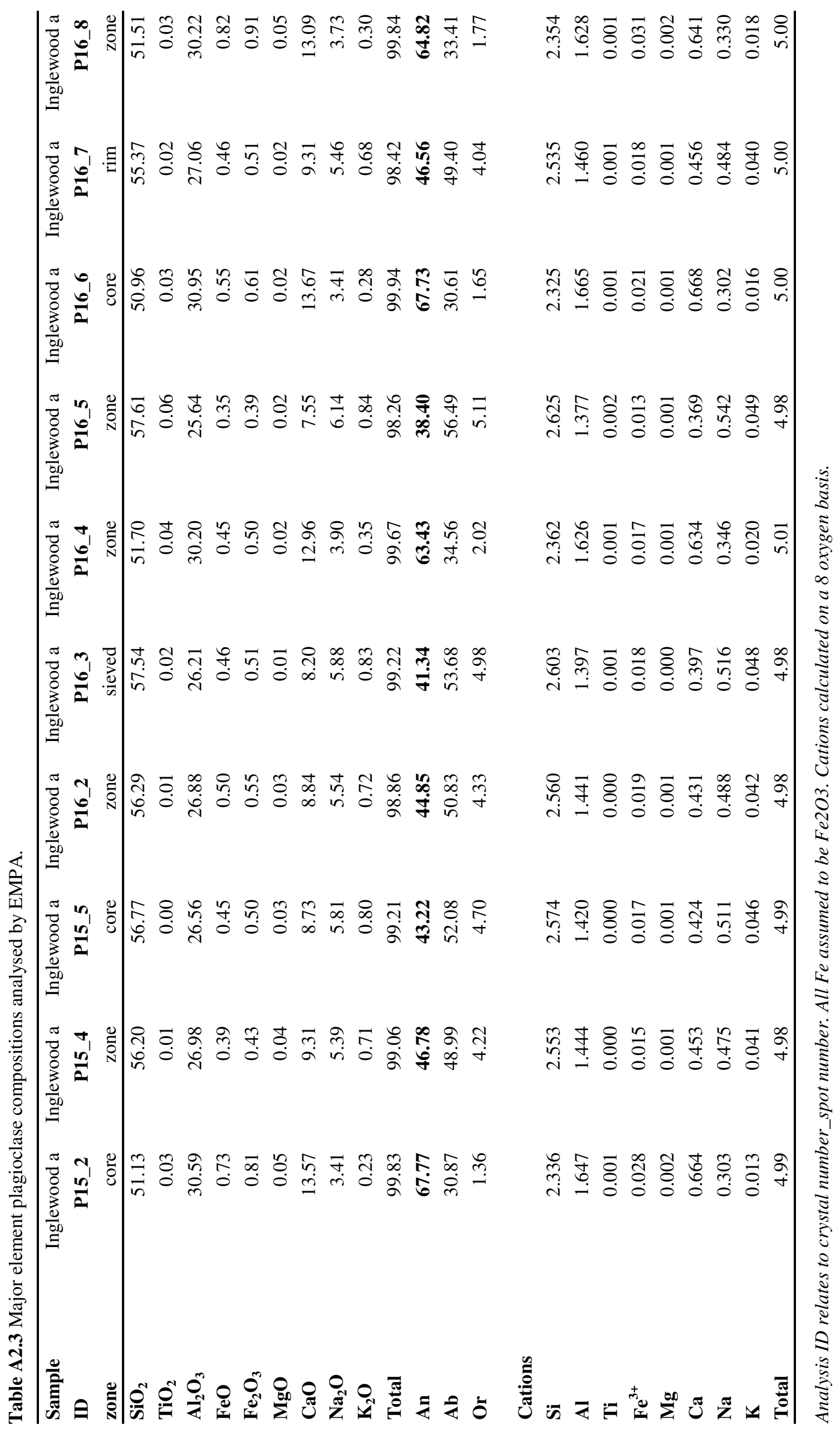




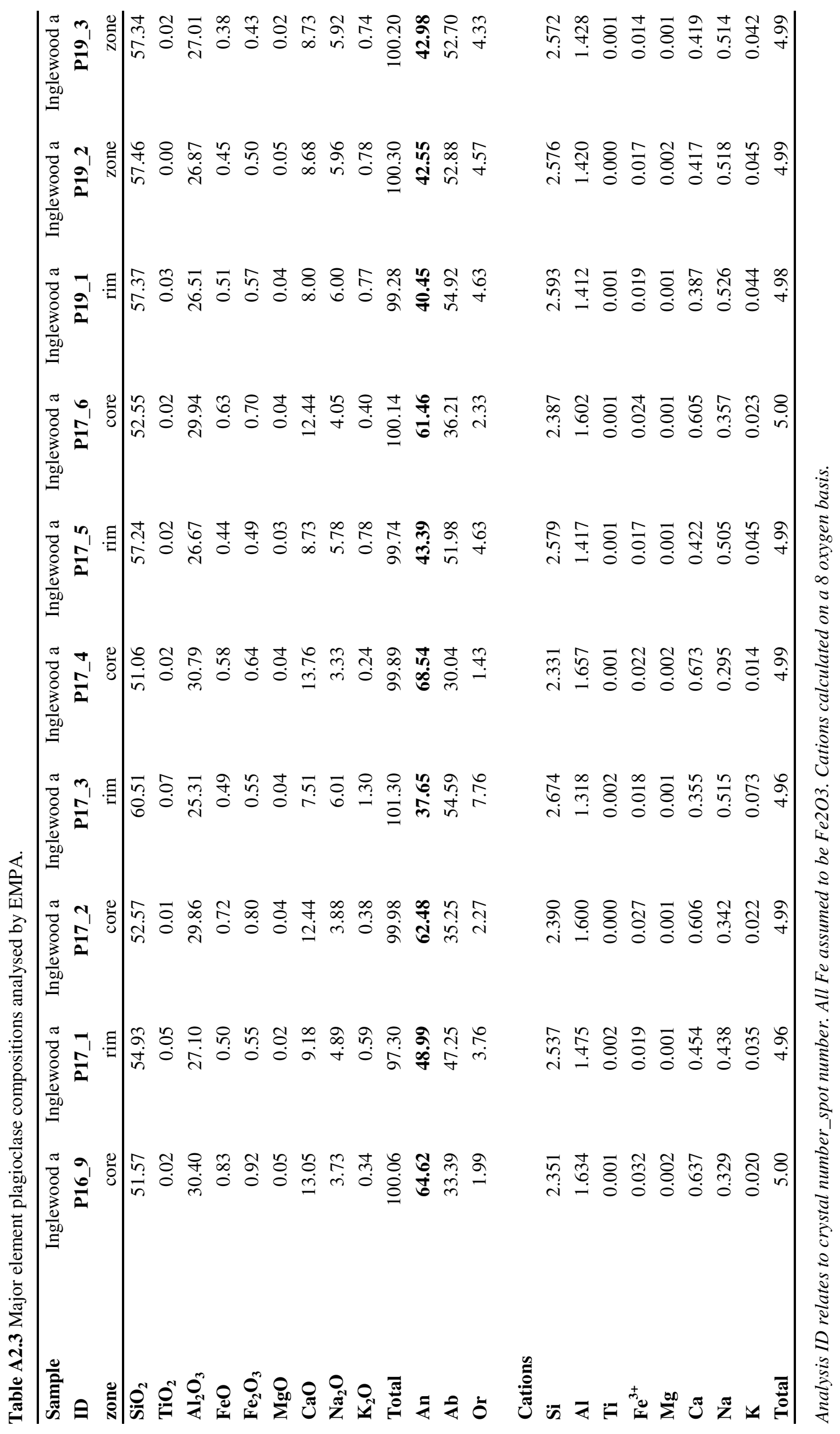




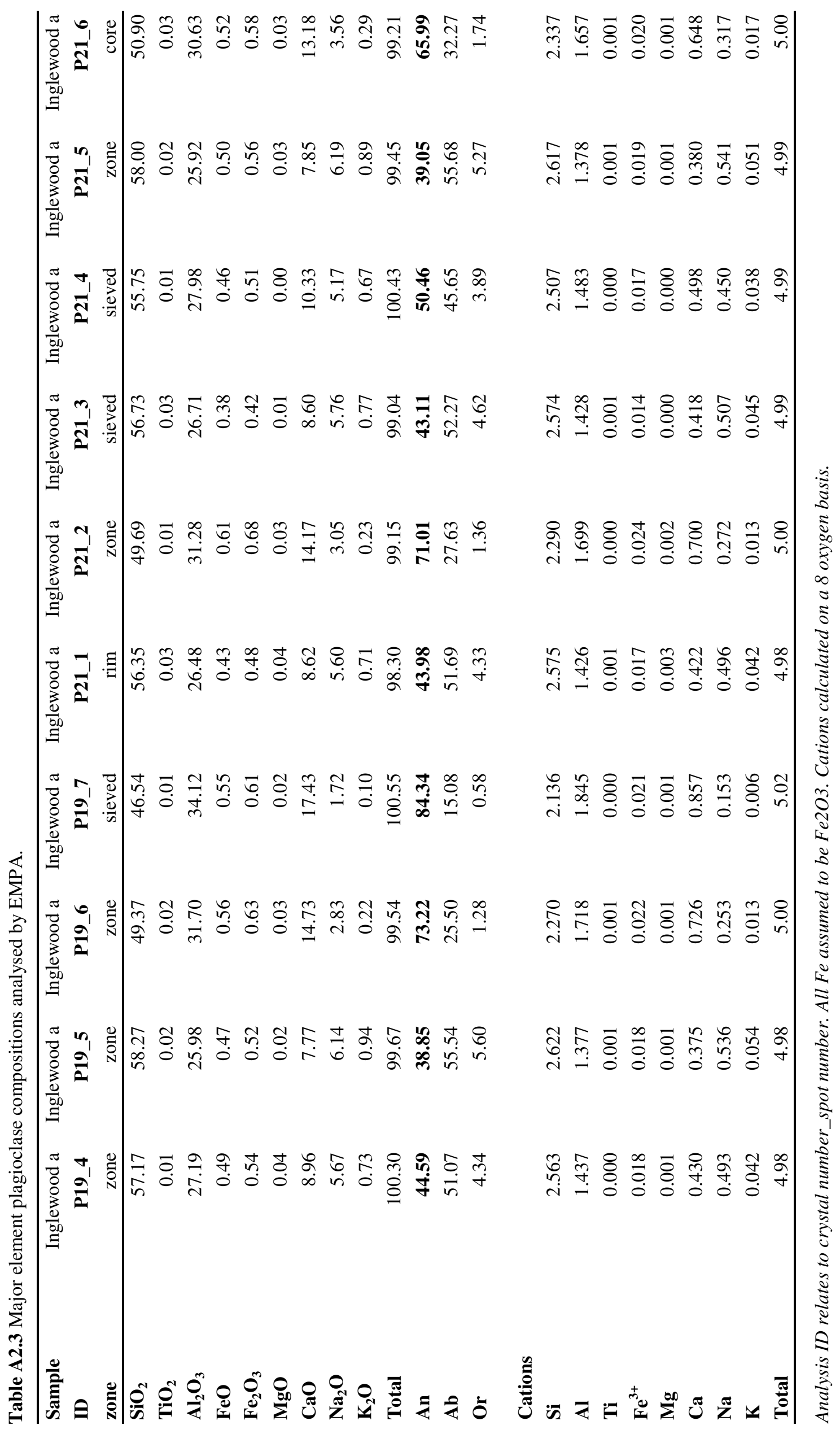




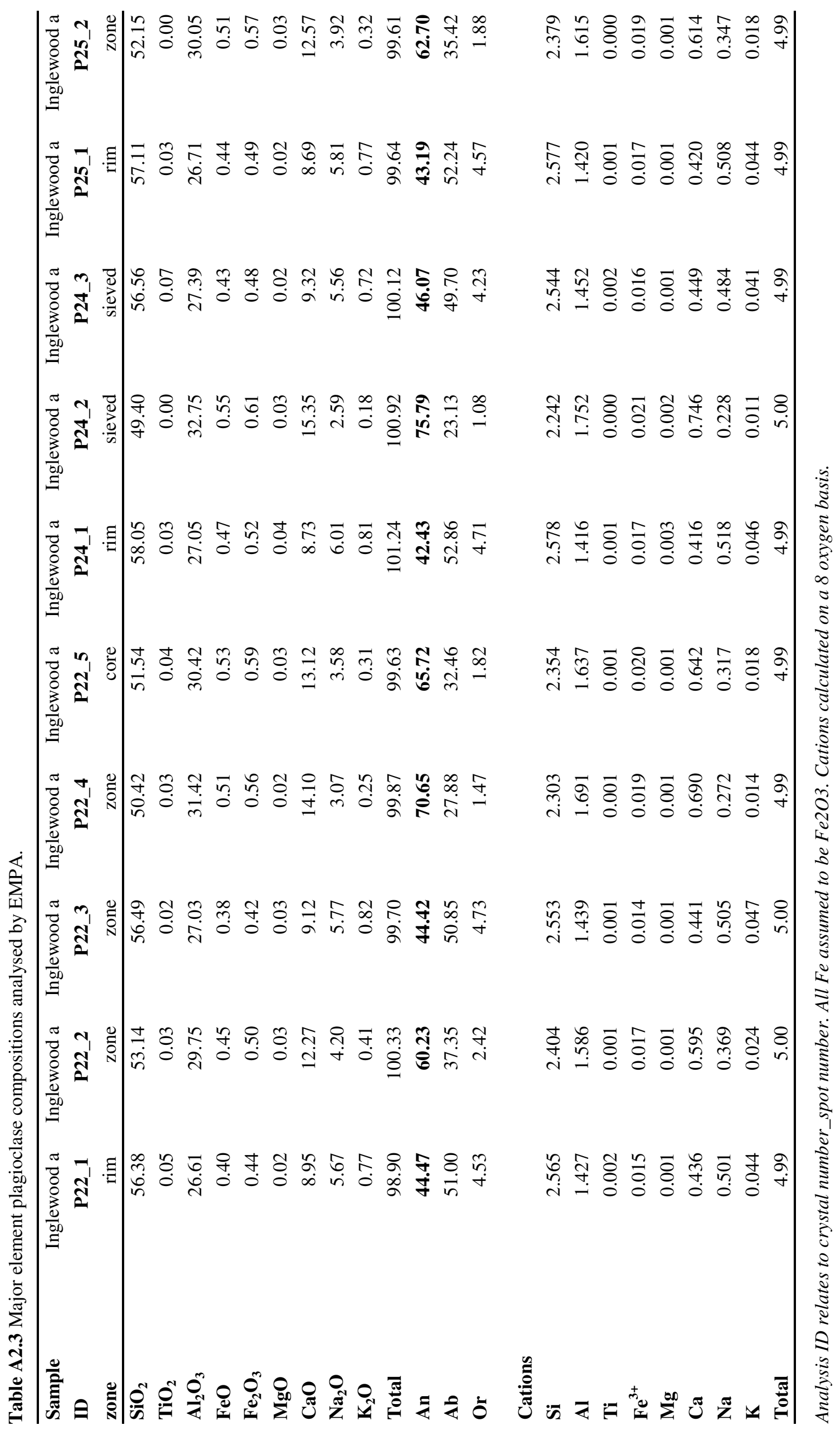




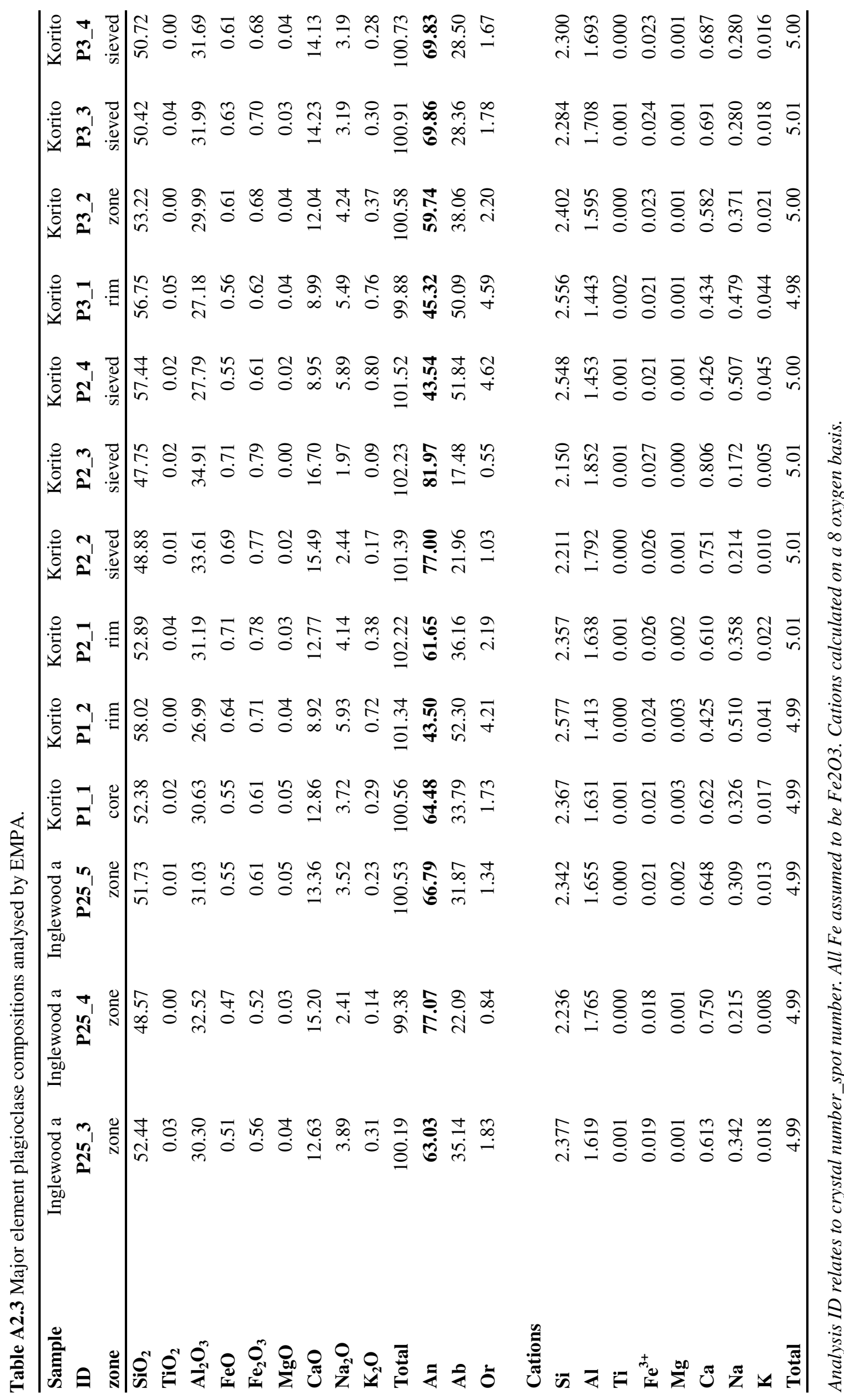




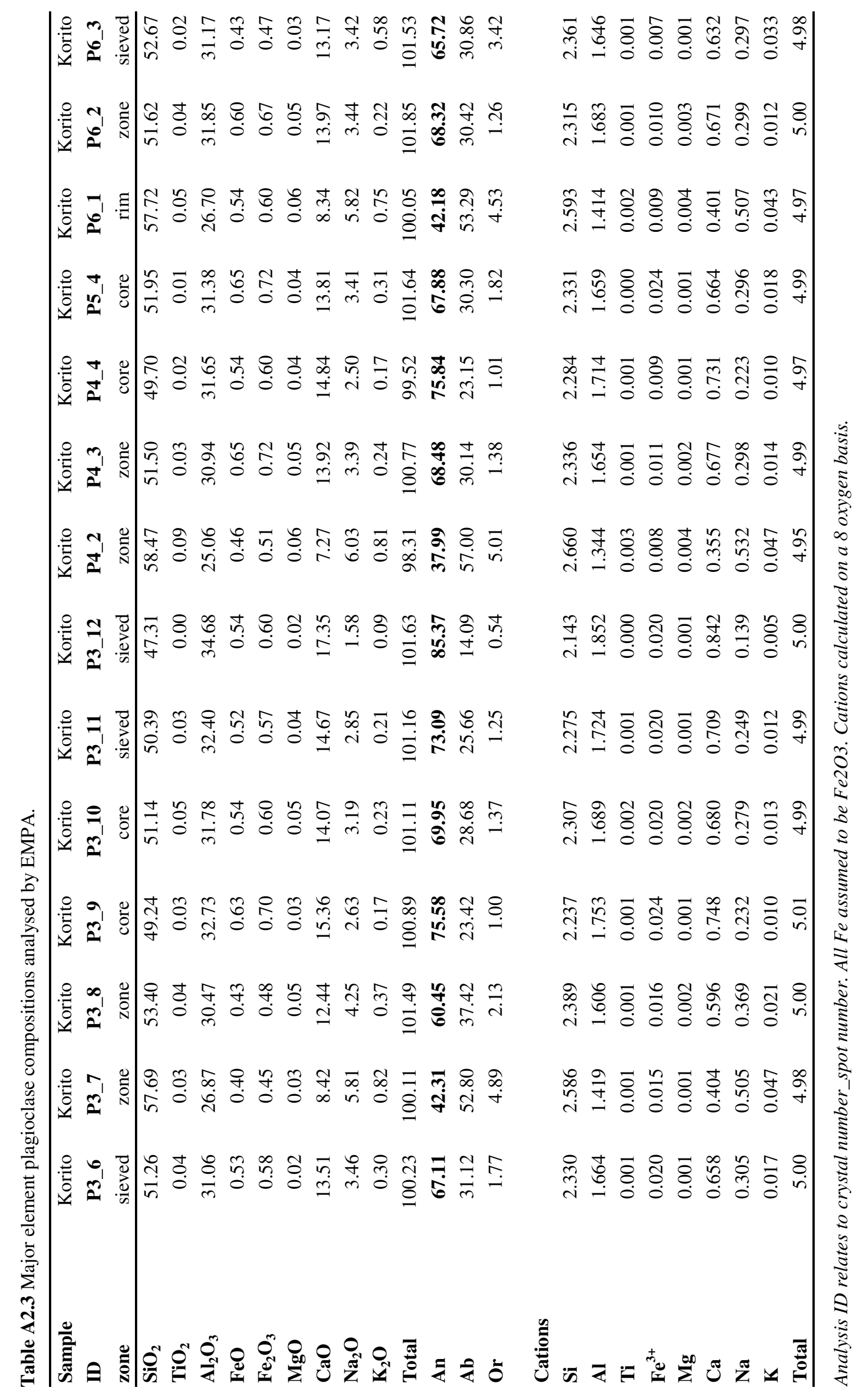




\begin{tabular}{|c|c|}
\hline 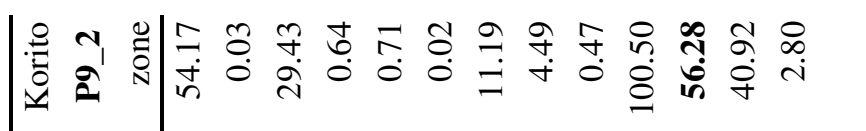 & 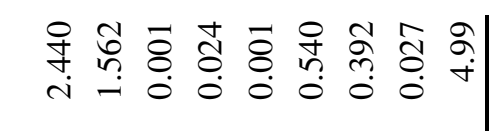 \\
\hline 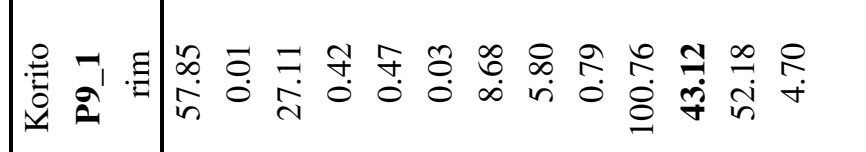 & 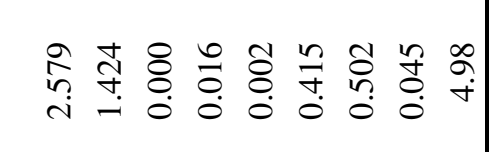 \\
\hline 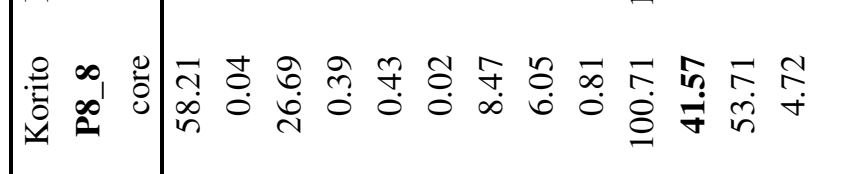 & 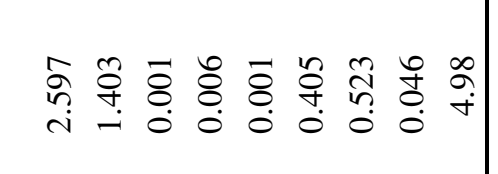 \\
\hline 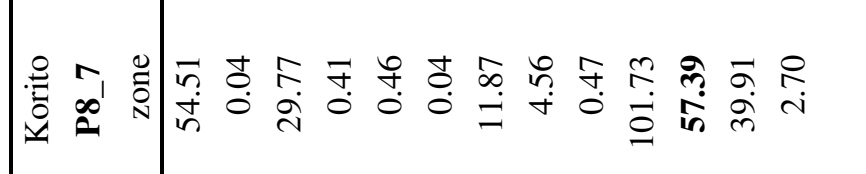 & 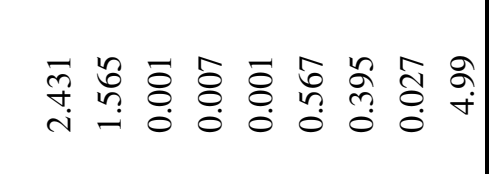 \\
\hline 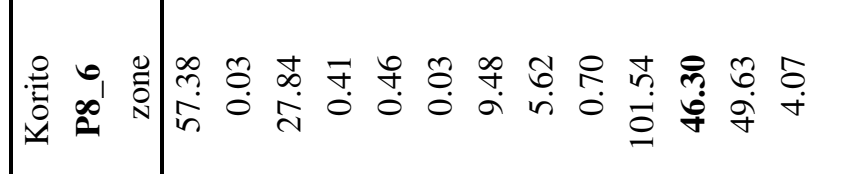 & 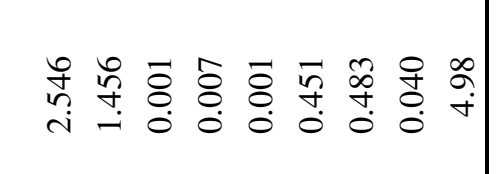 \\
\hline 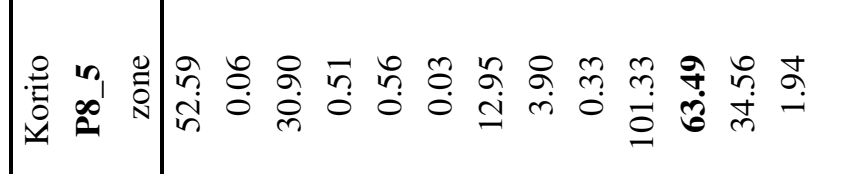 & 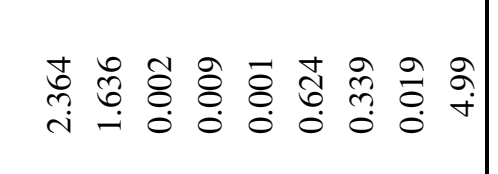 \\
\hline 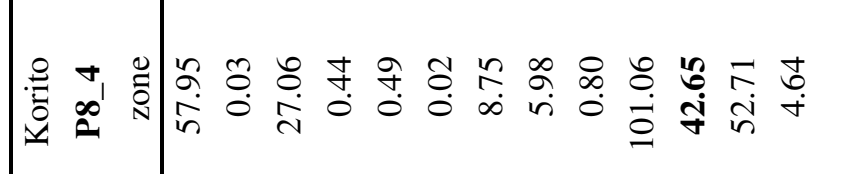 & 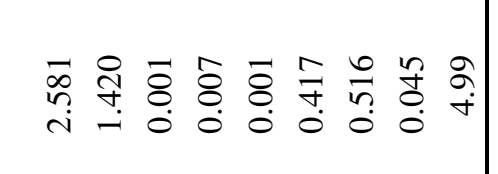 \\
\hline 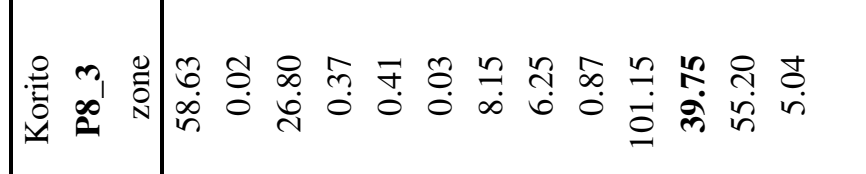 & 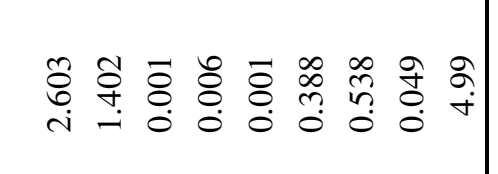 \\
\hline 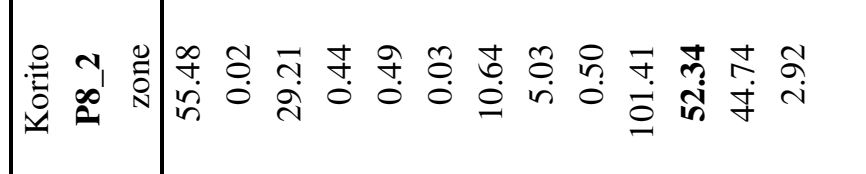 & 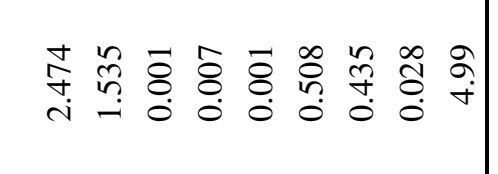 \\
\hline 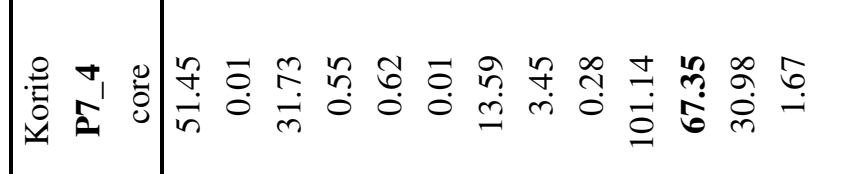 & 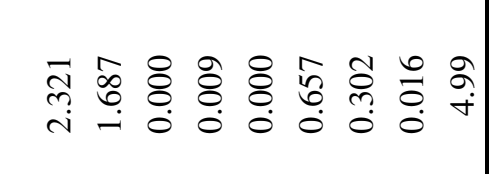 \\
\hline 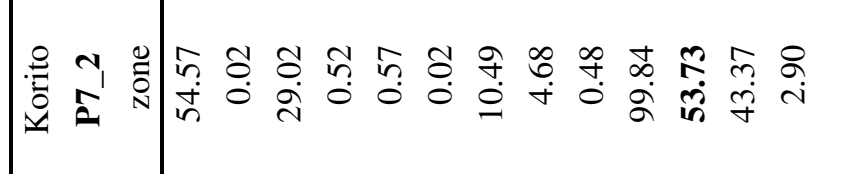 & 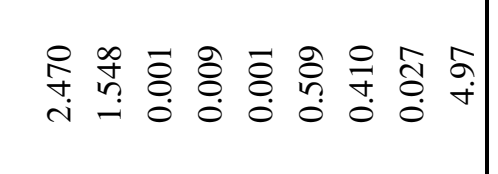 \\
\hline 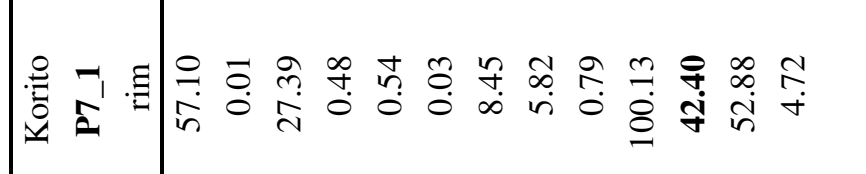 & 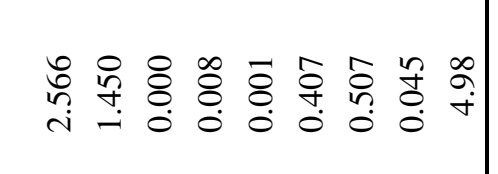 \\
\hline 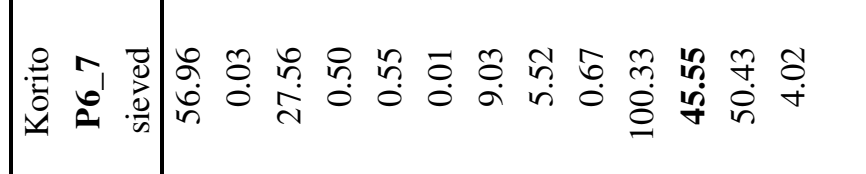 & 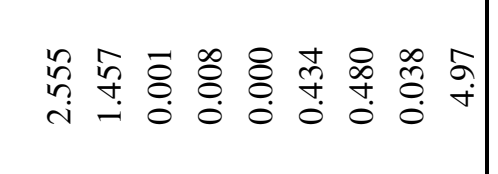 \\
\hline 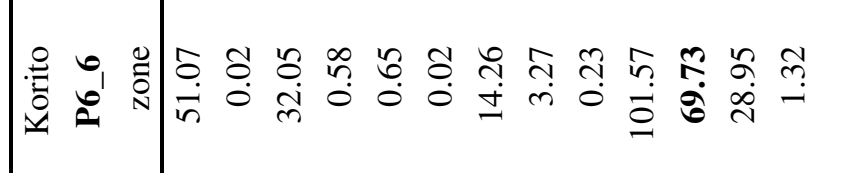 & 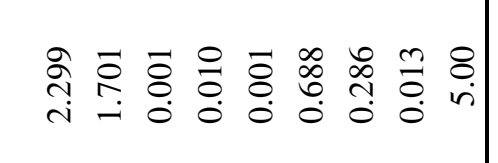 \\
\hline 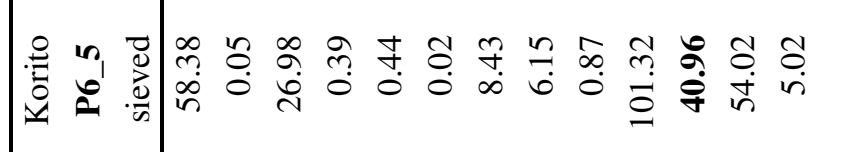 & 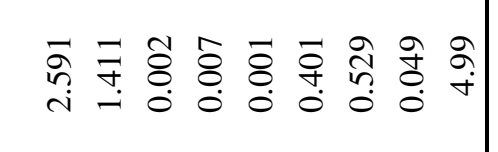 \\
\hline
\end{tabular}




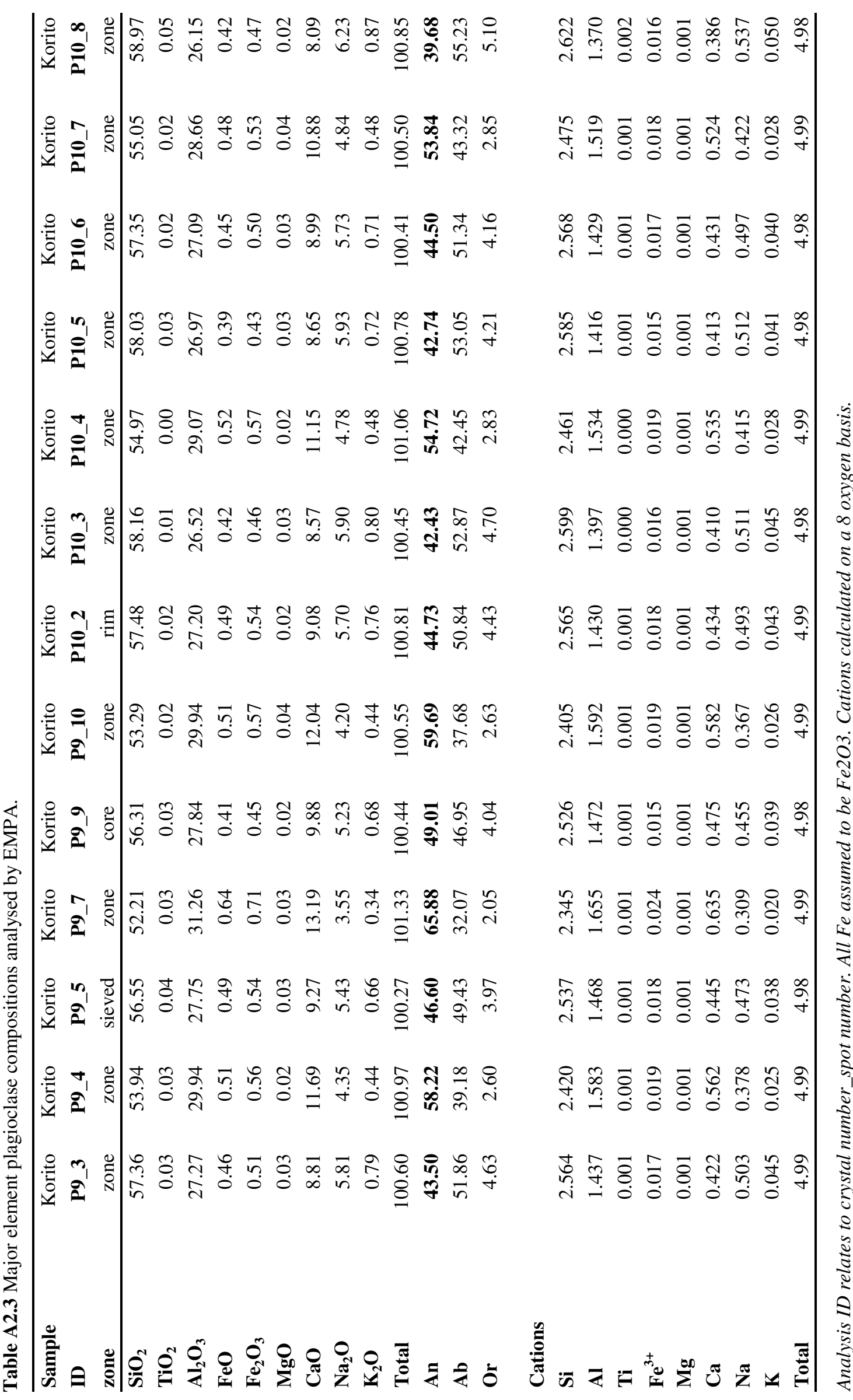




\begin{tabular}{|c|c|}
\hline 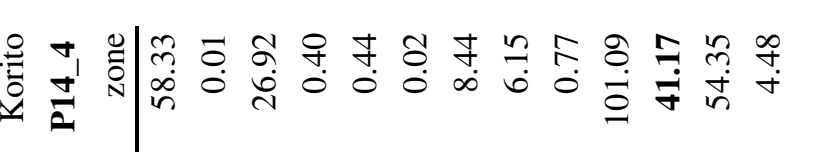 & 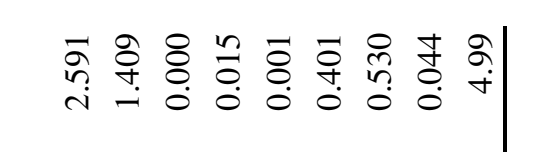 \\
\hline 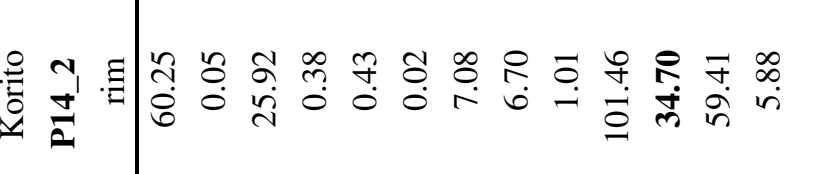 & 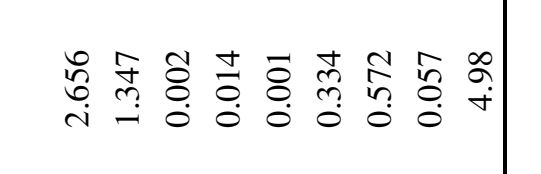 \\
\hline 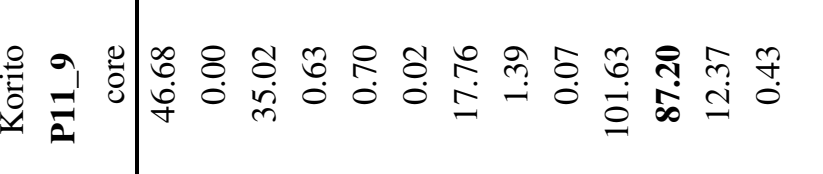 & 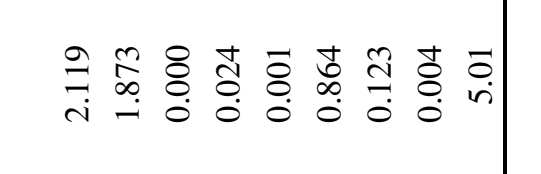 \\
\hline 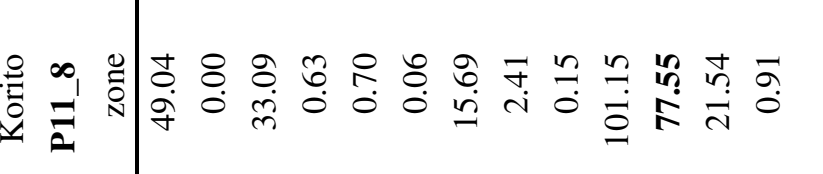 & 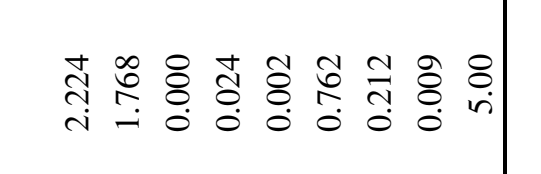 \\
\hline 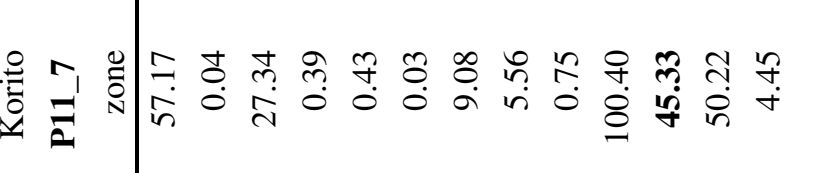 & 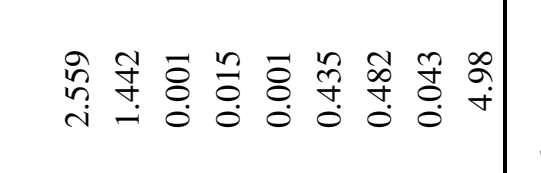 \\
\hline 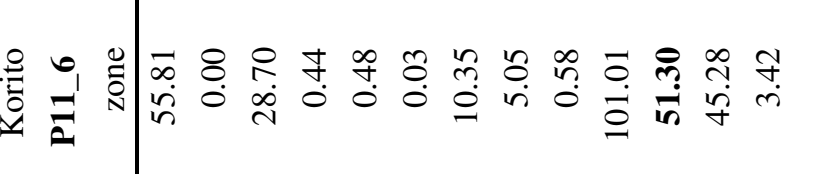 & 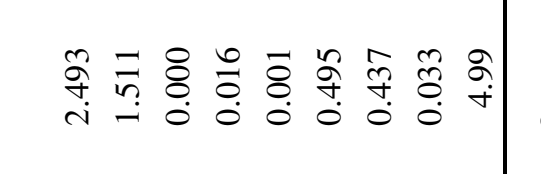 \\
\hline 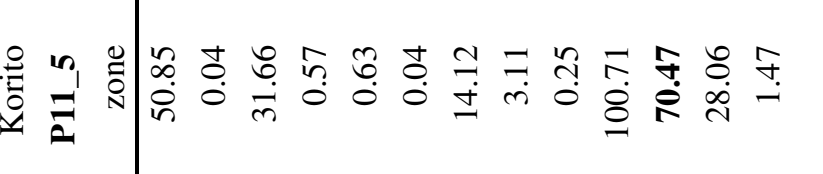 & 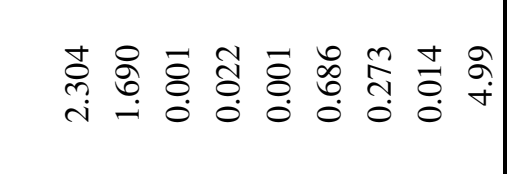 \\
\hline 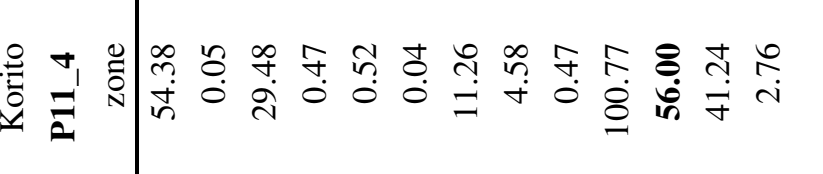 & 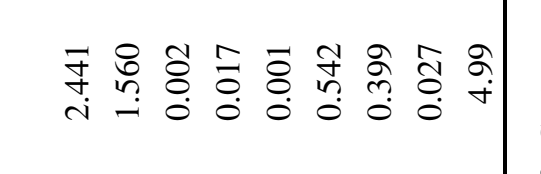 \\
\hline 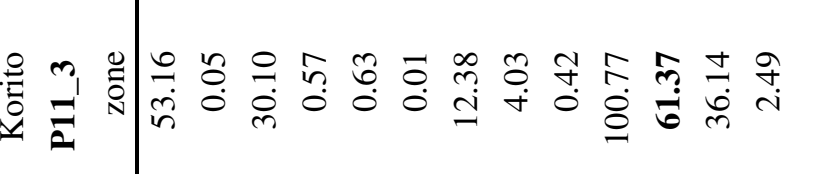 & 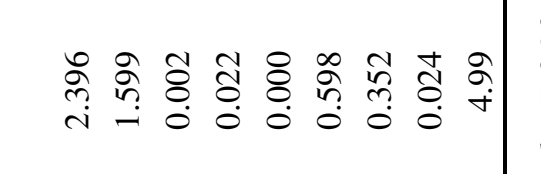 \\
\hline 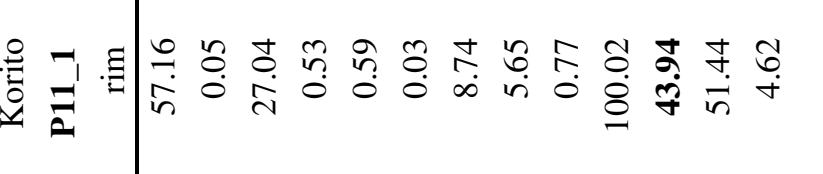 & 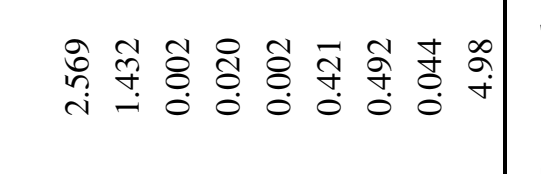 \\
\hline 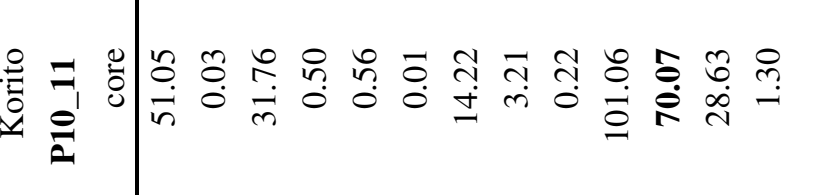 & 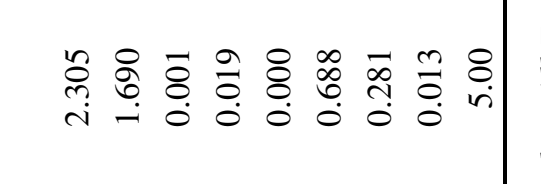 \\
\hline 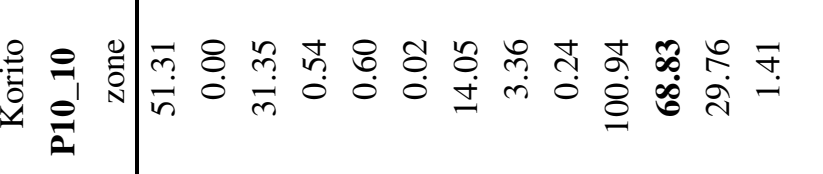 & 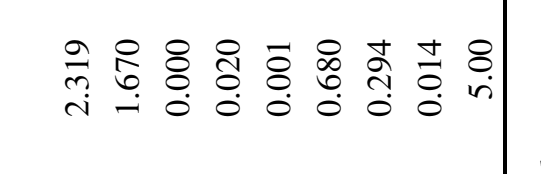 \\
\hline 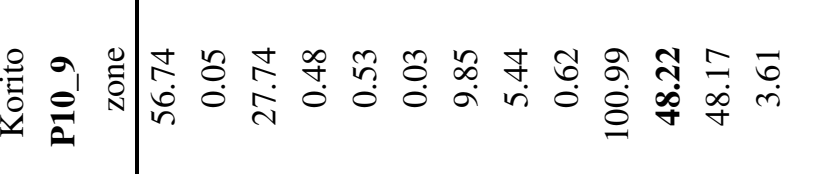 & 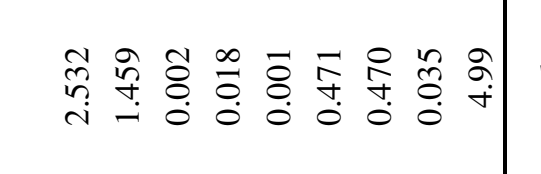 \\
\hline
\end{tabular}




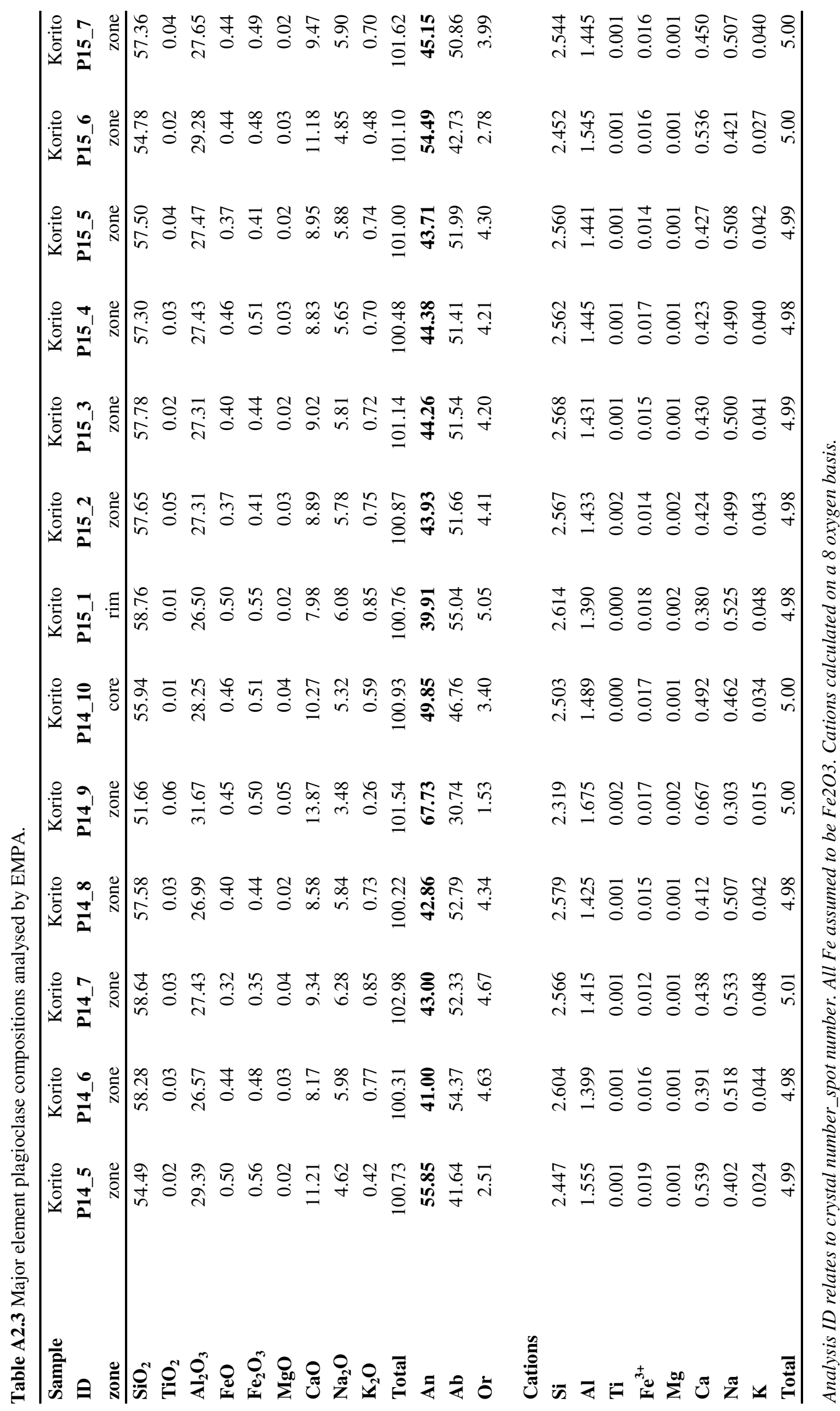




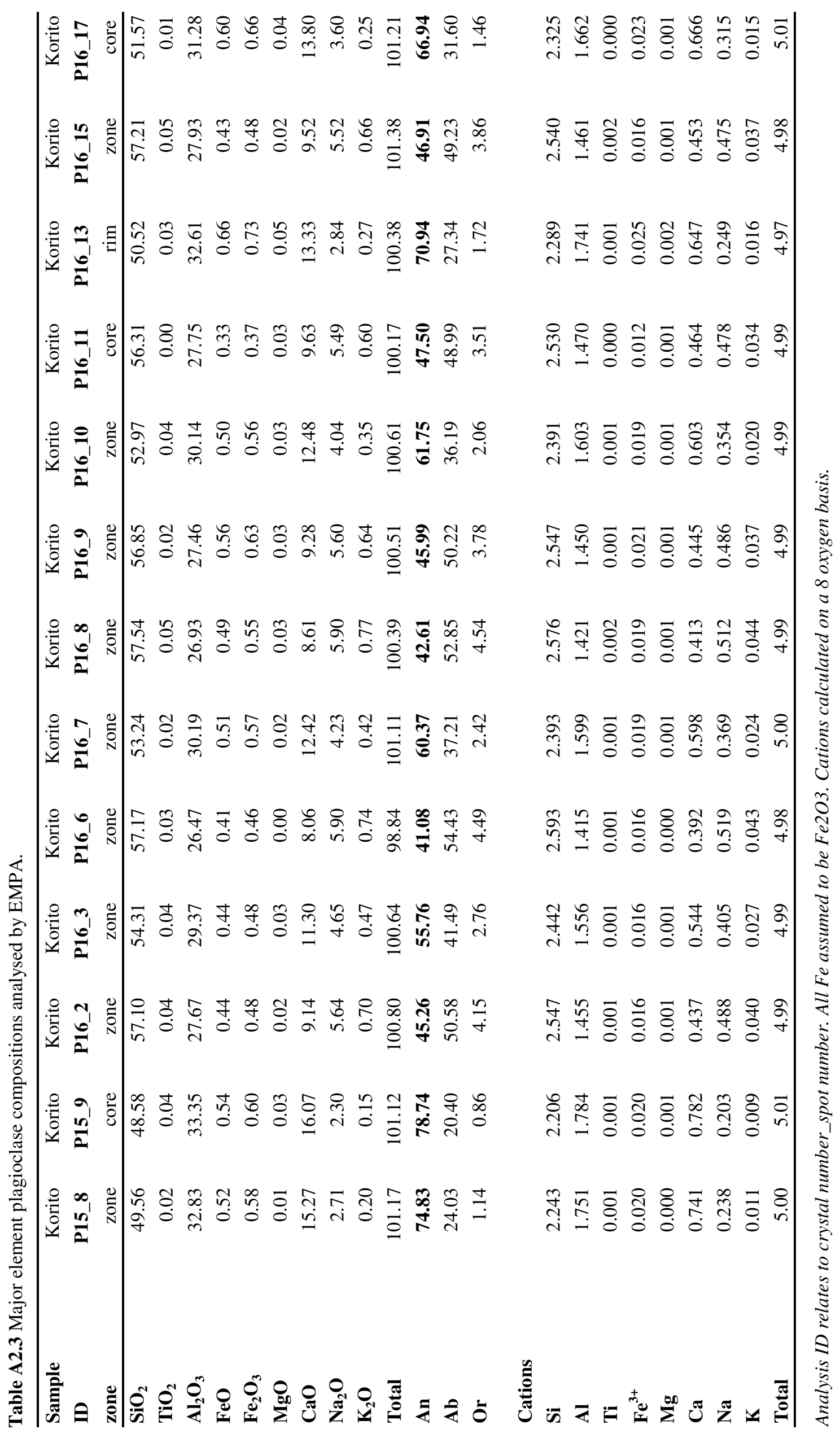




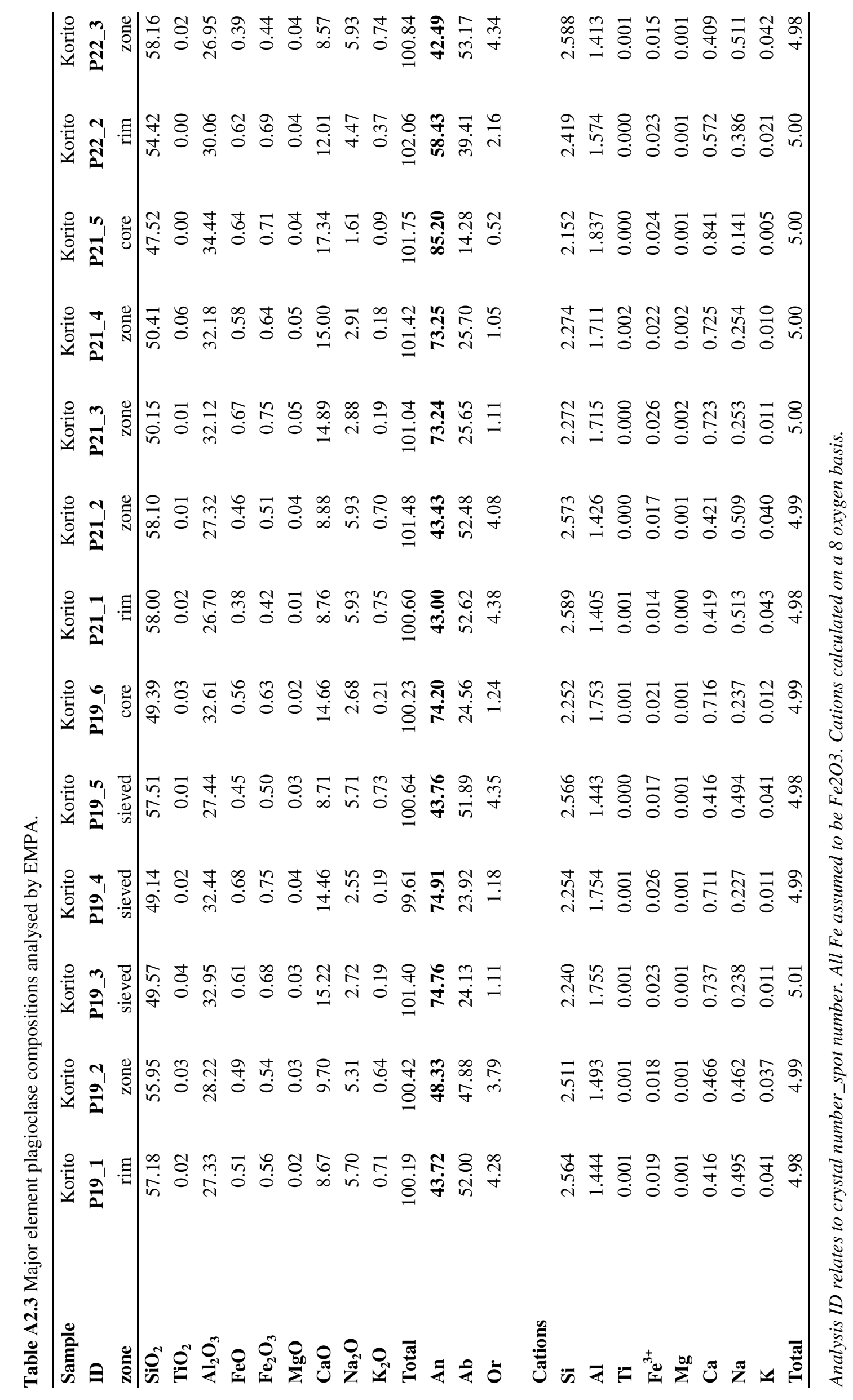




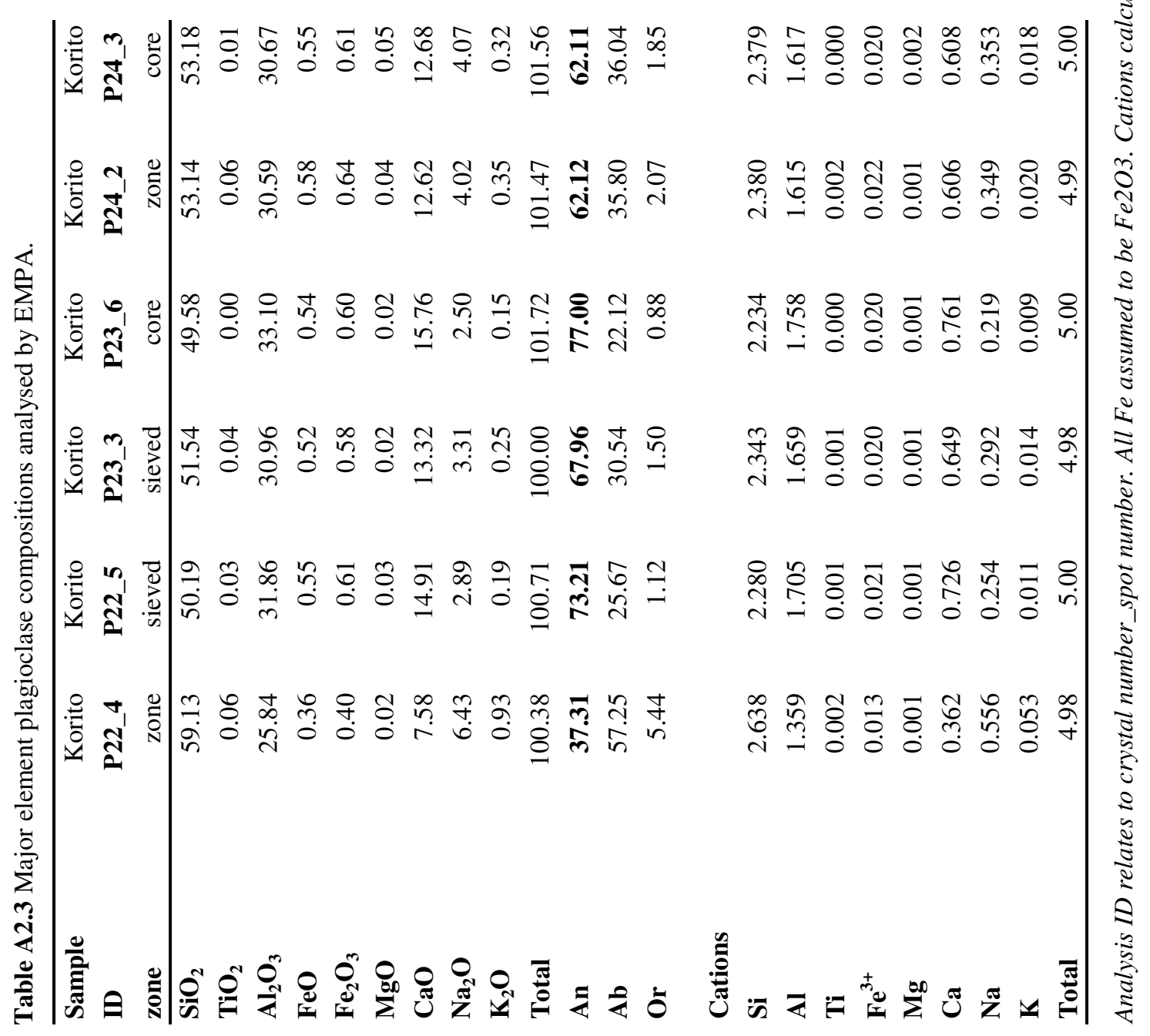




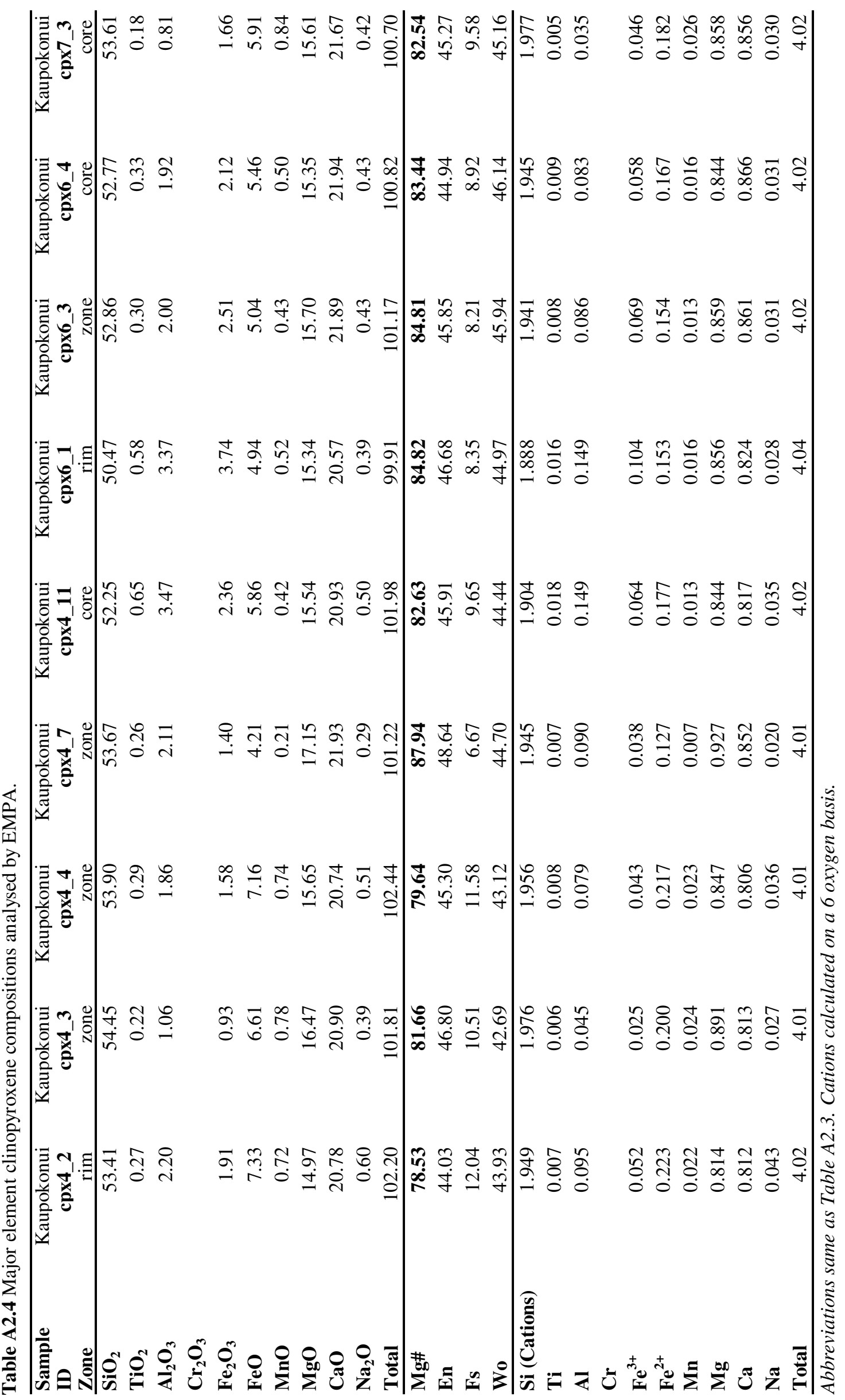




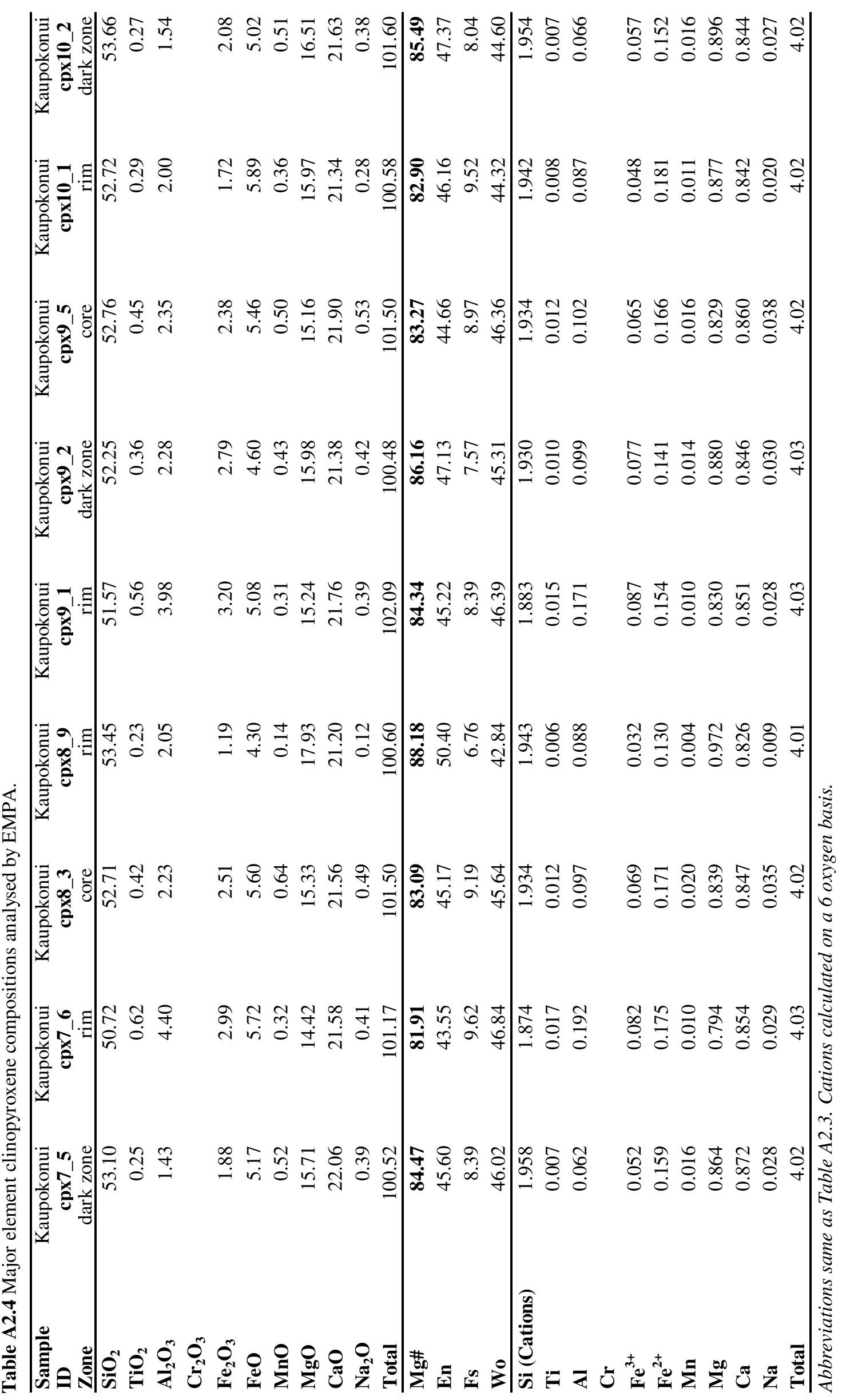




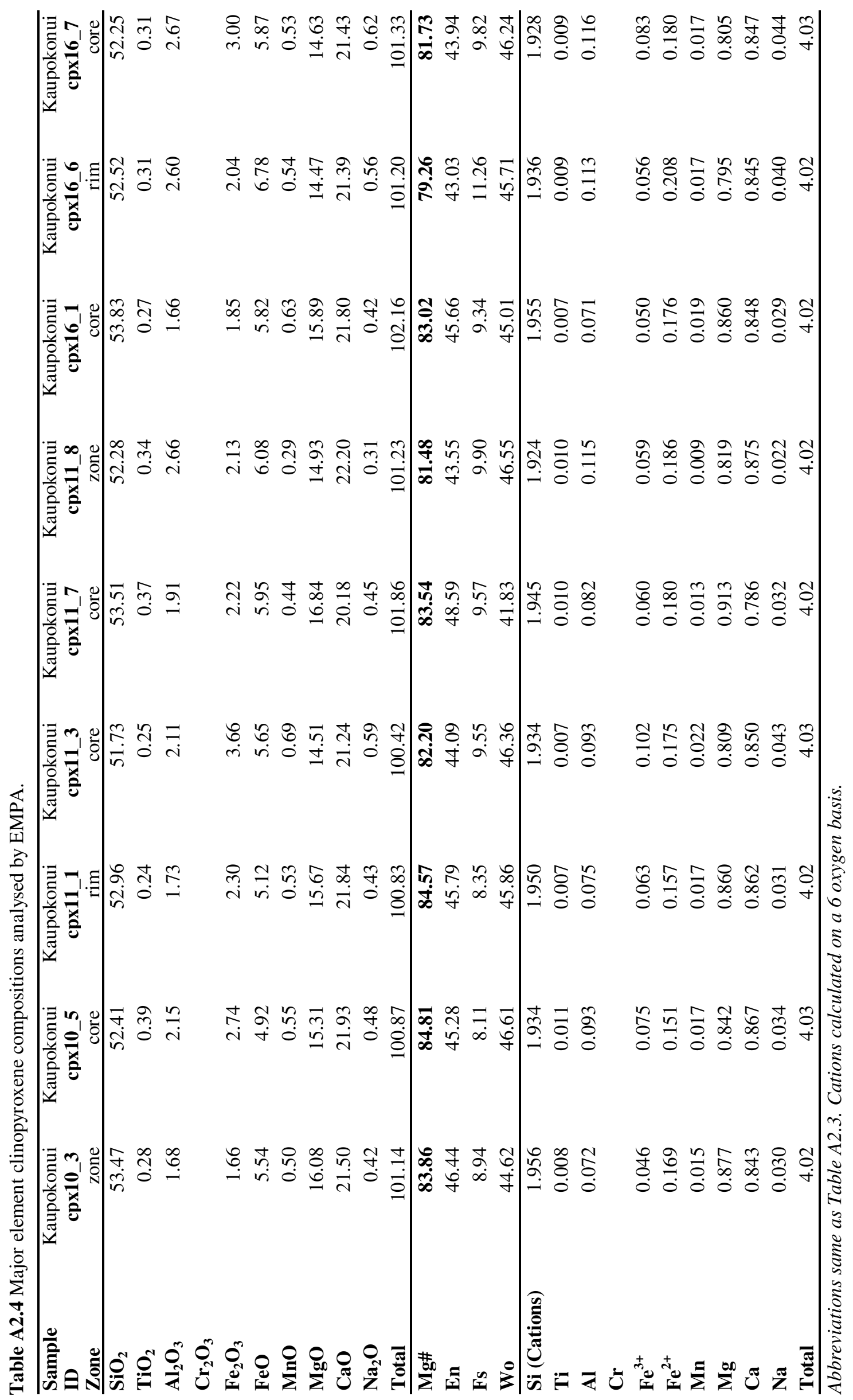




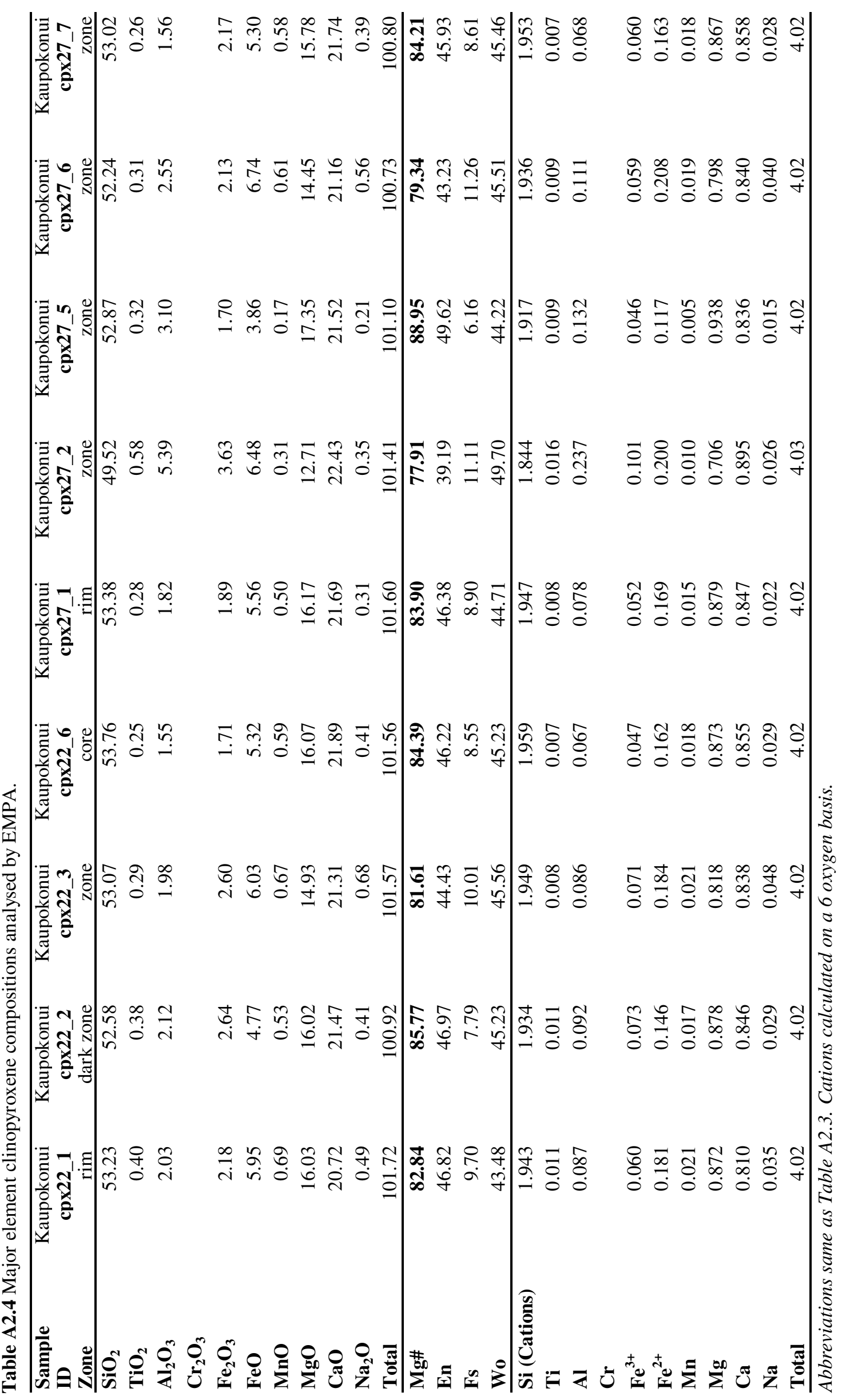




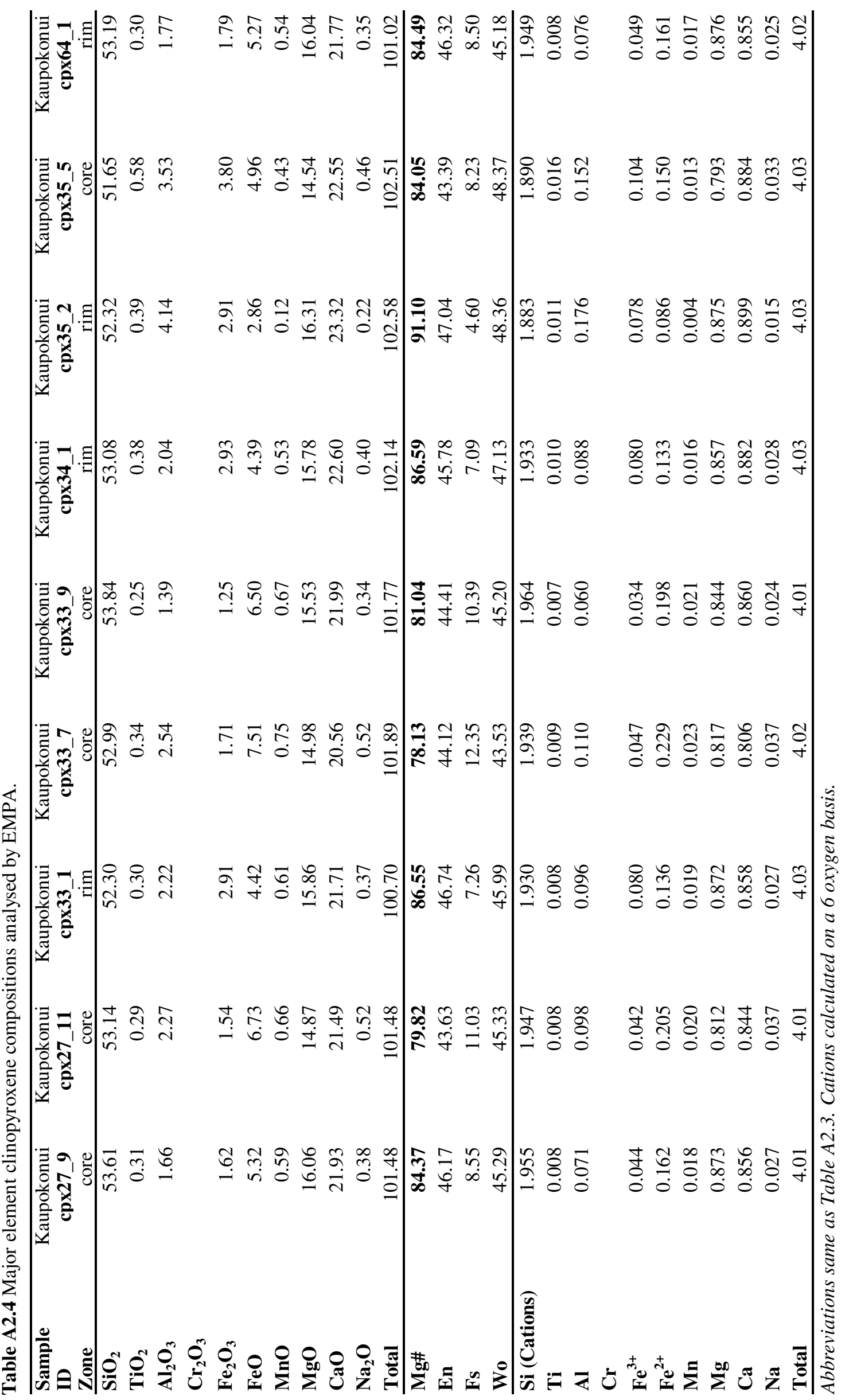




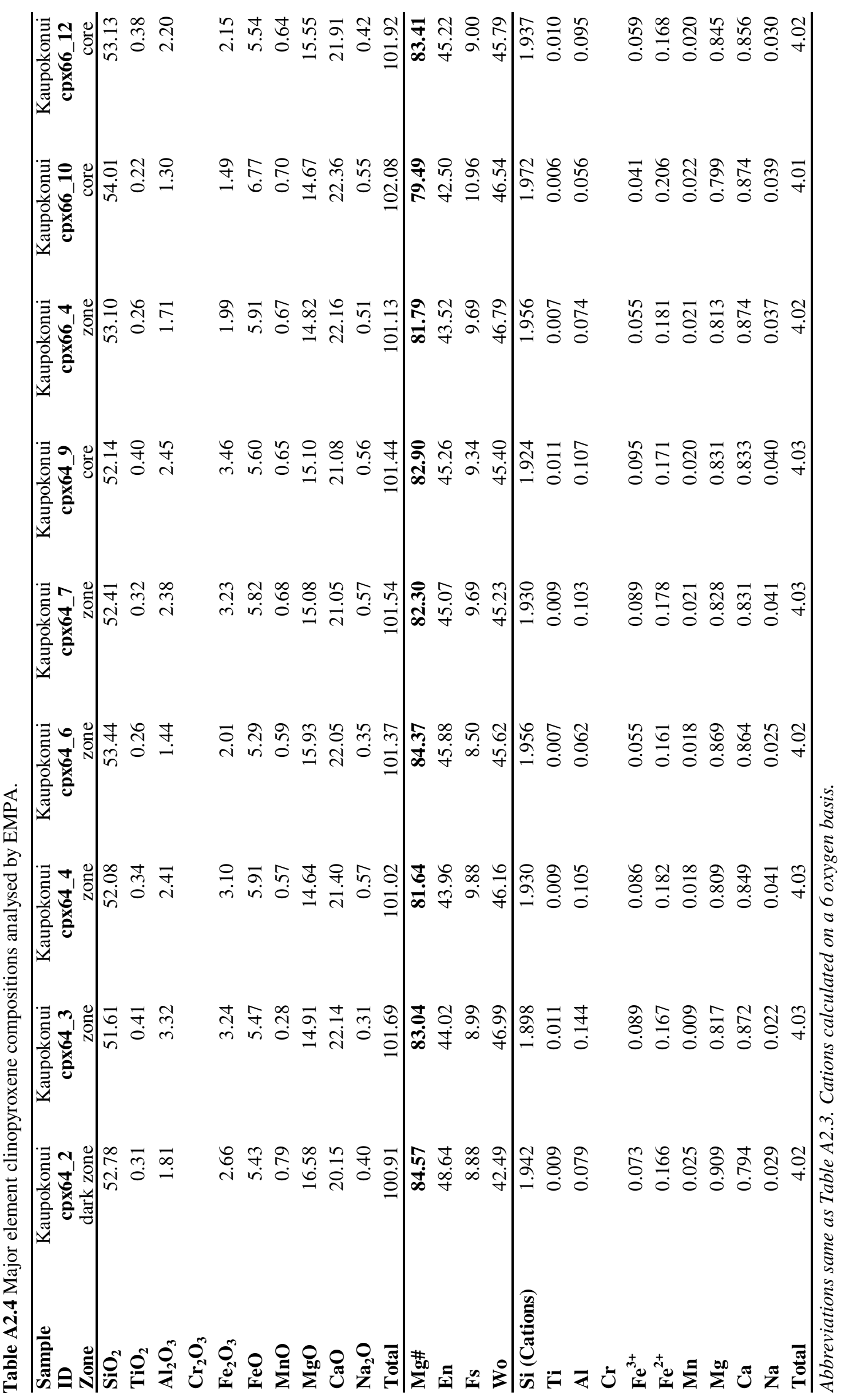




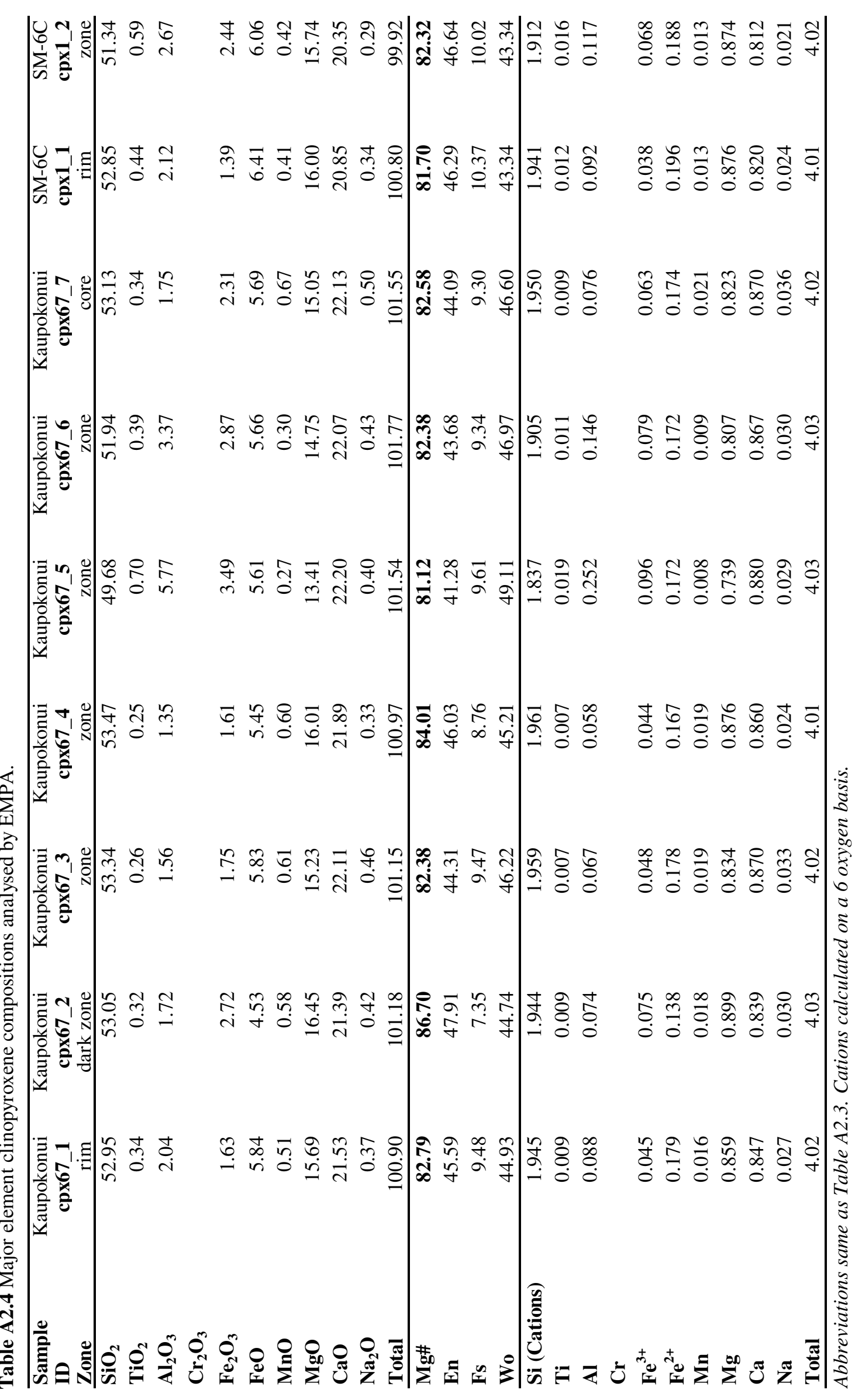




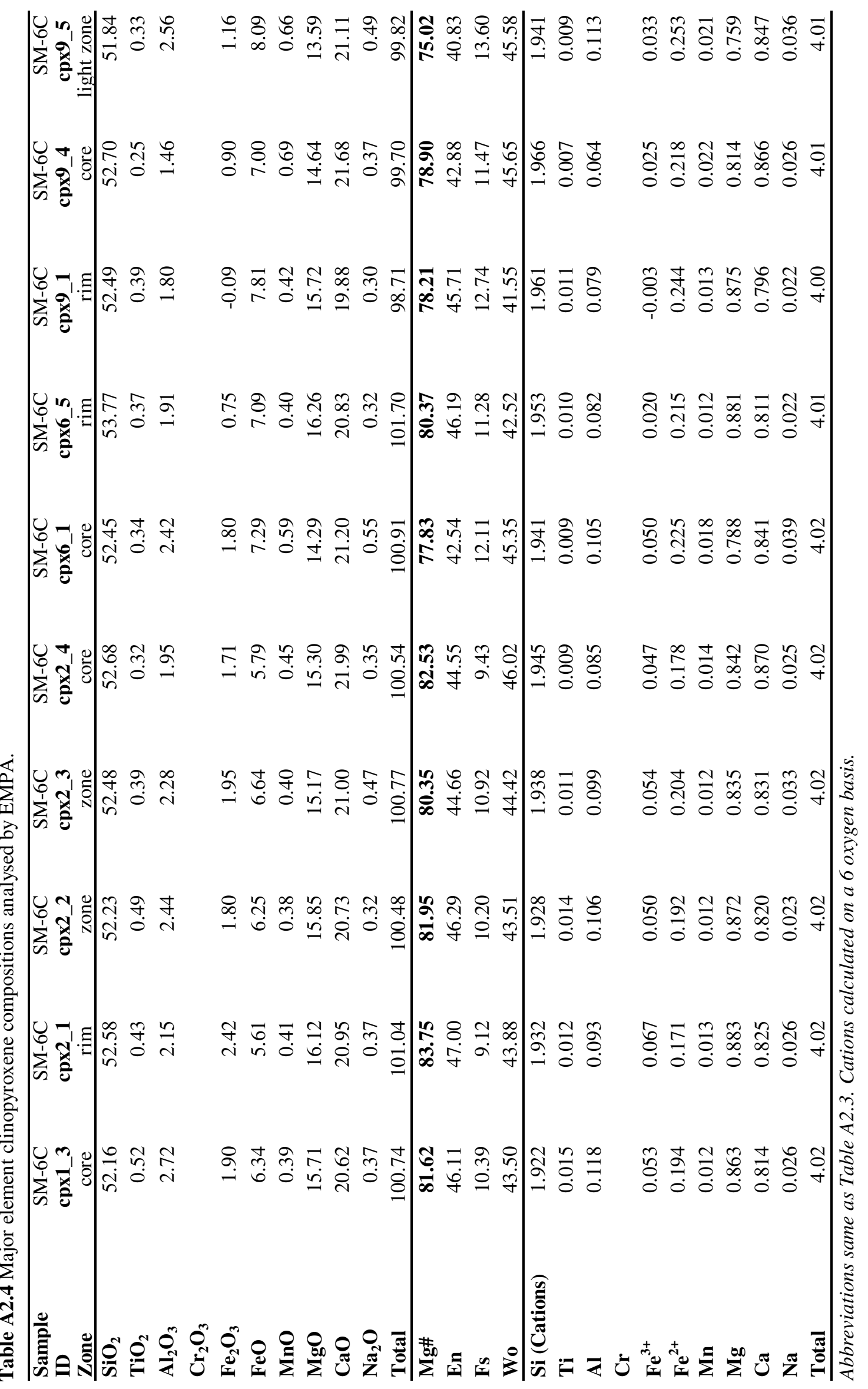




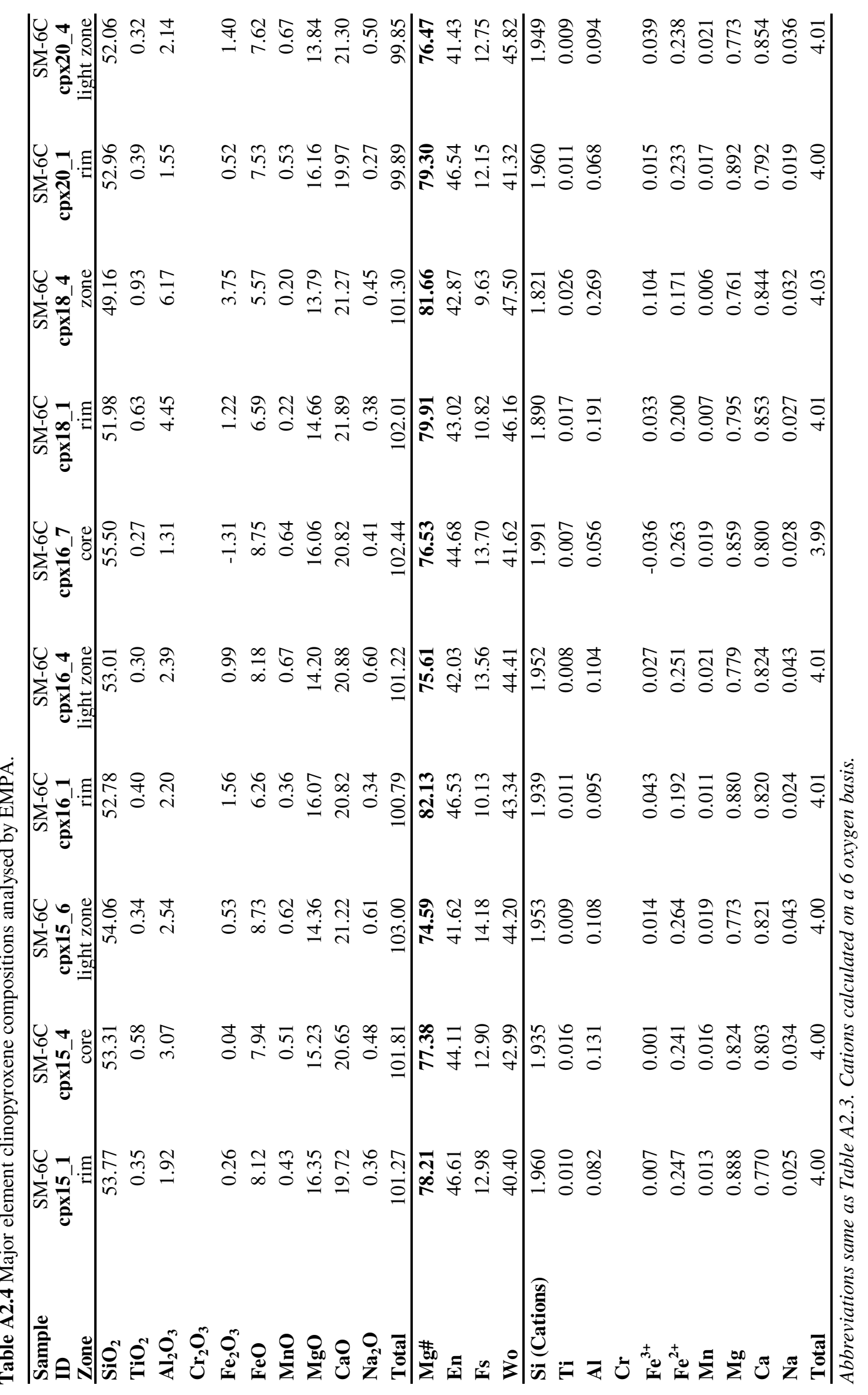




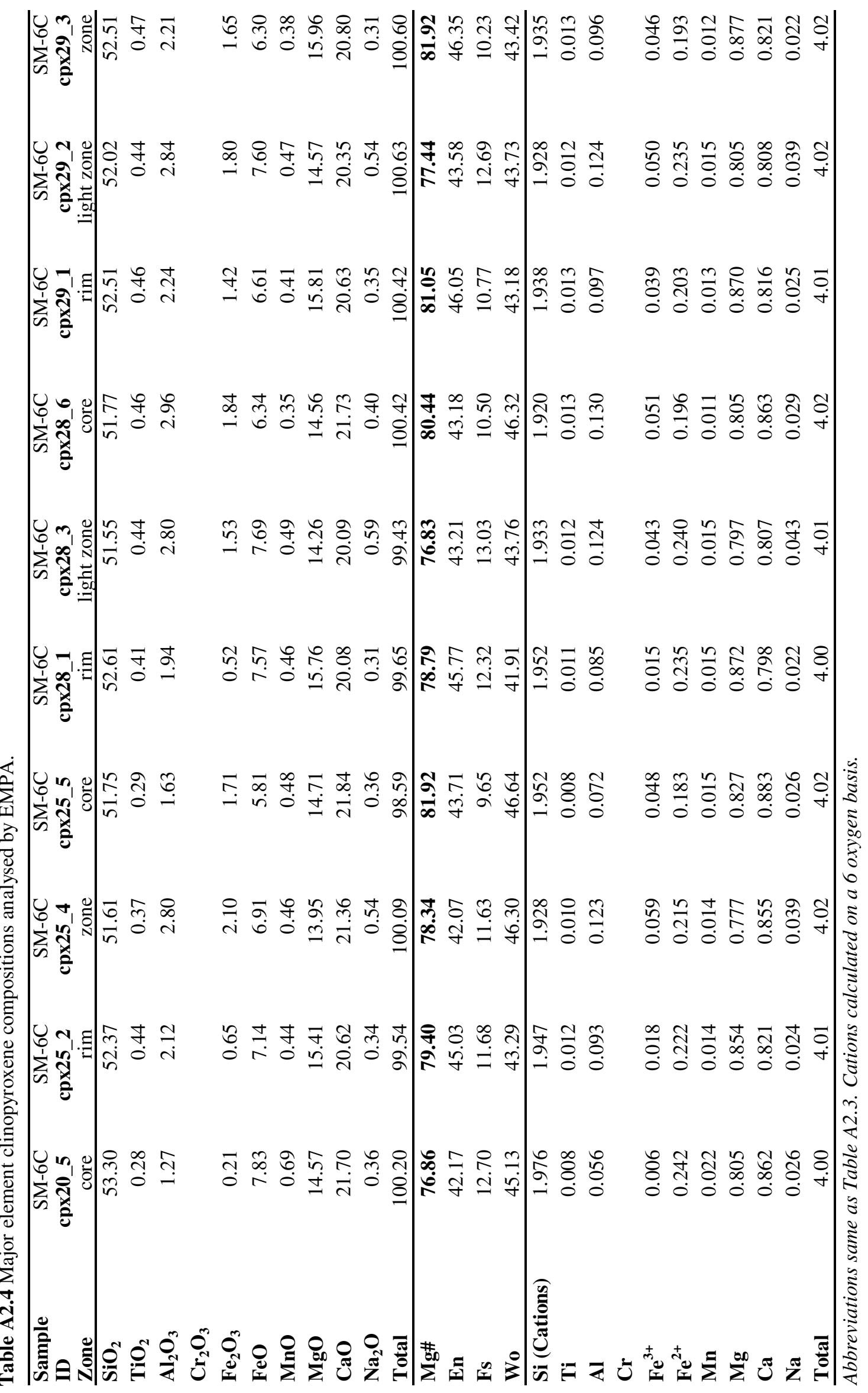




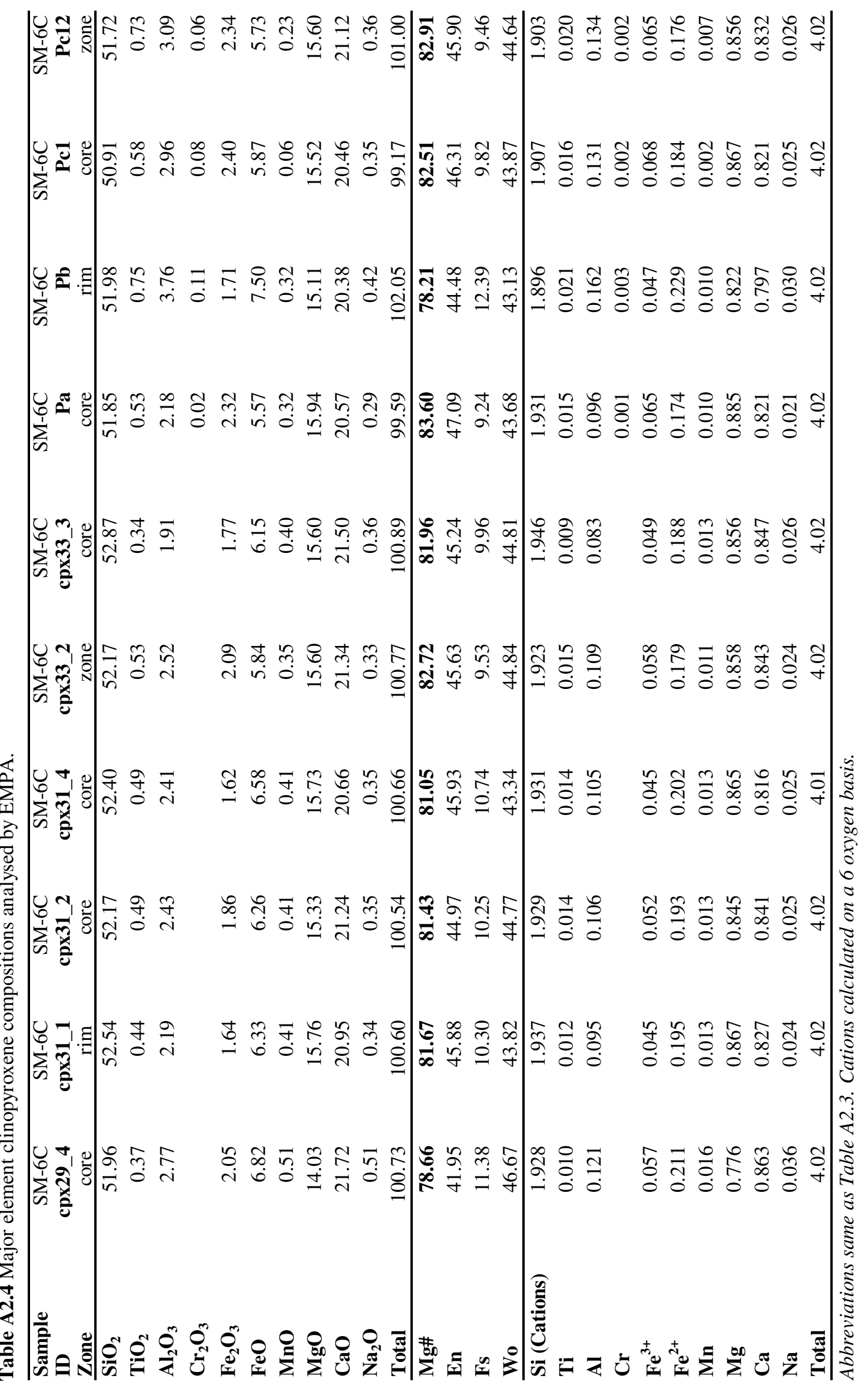




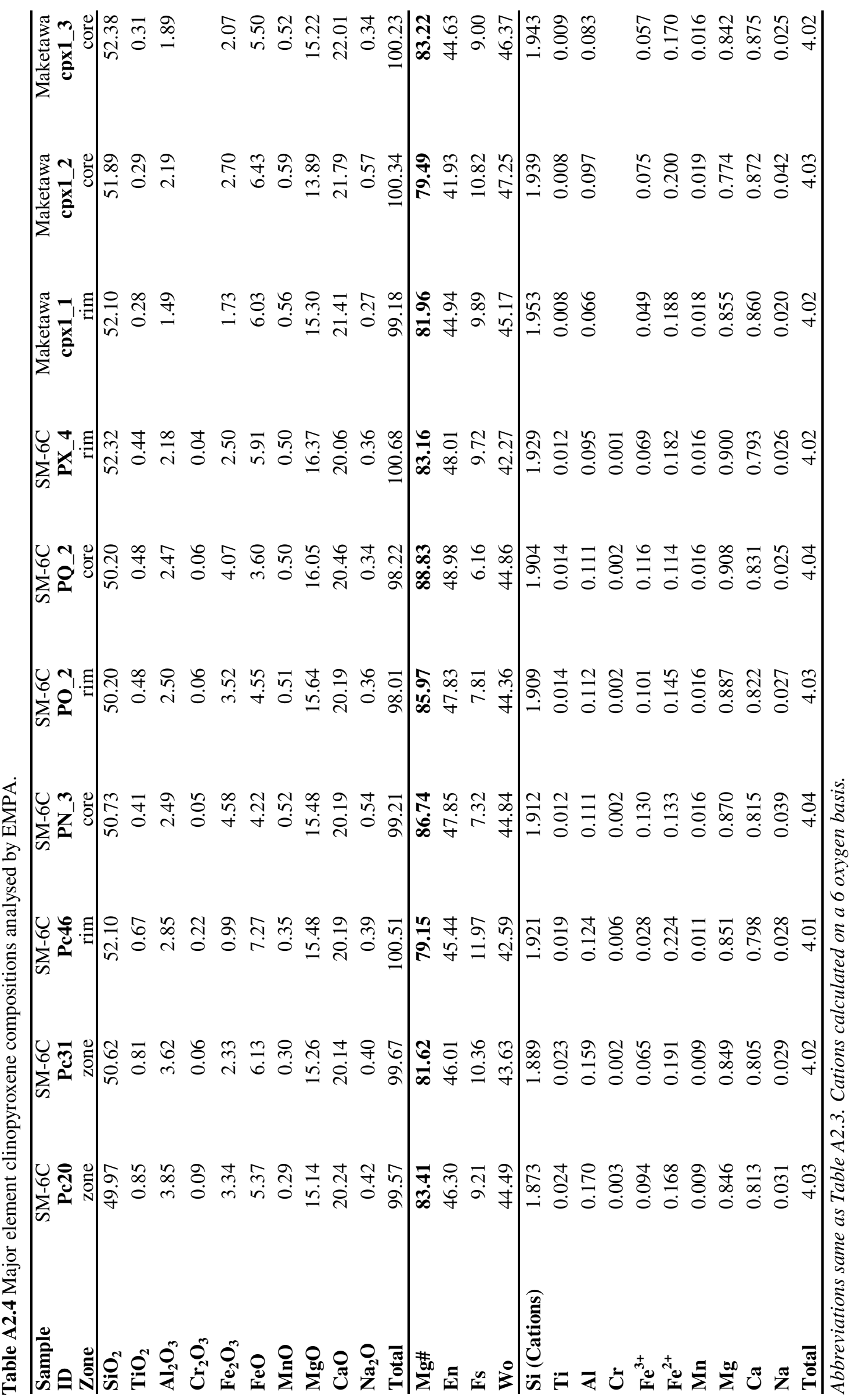




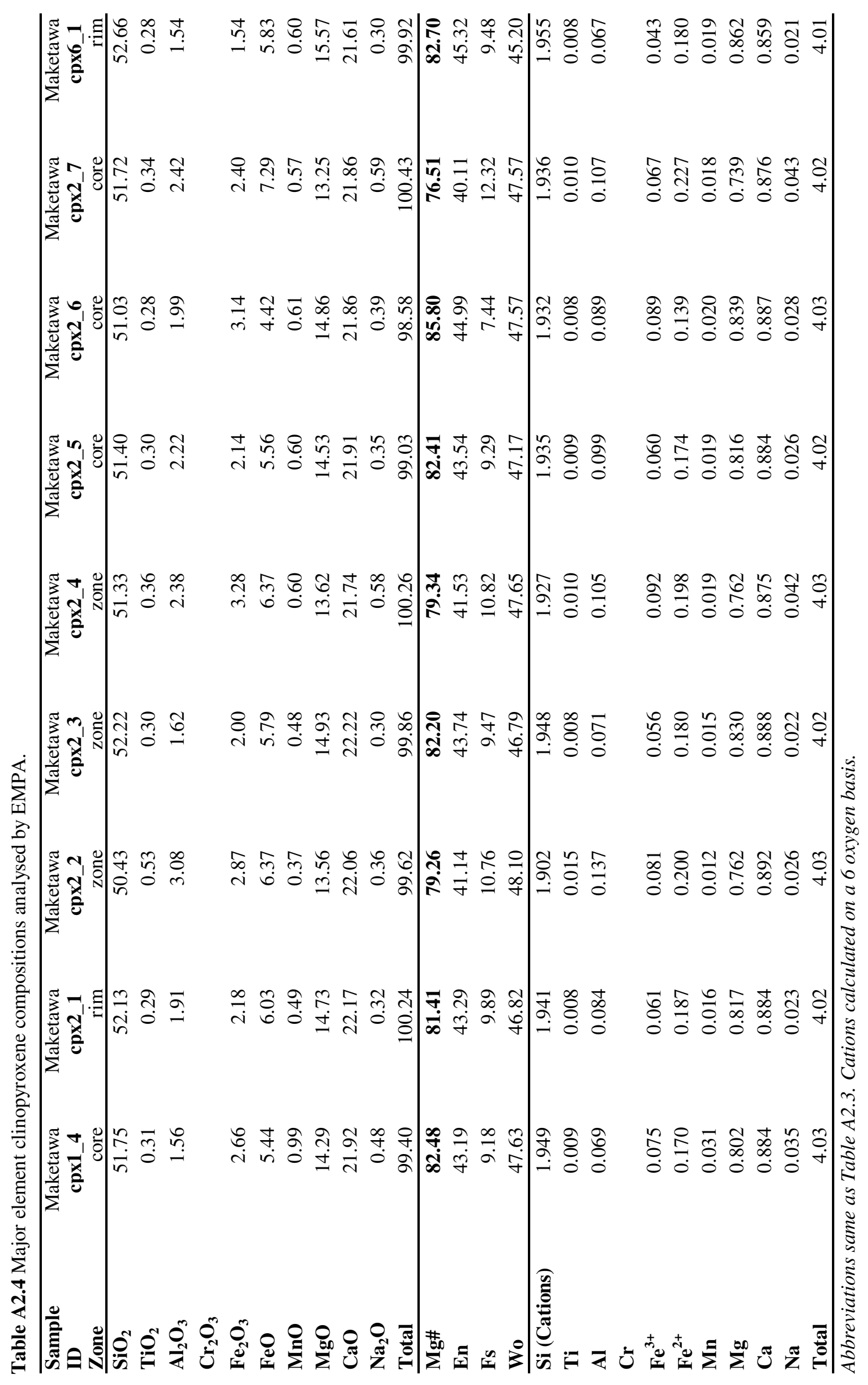




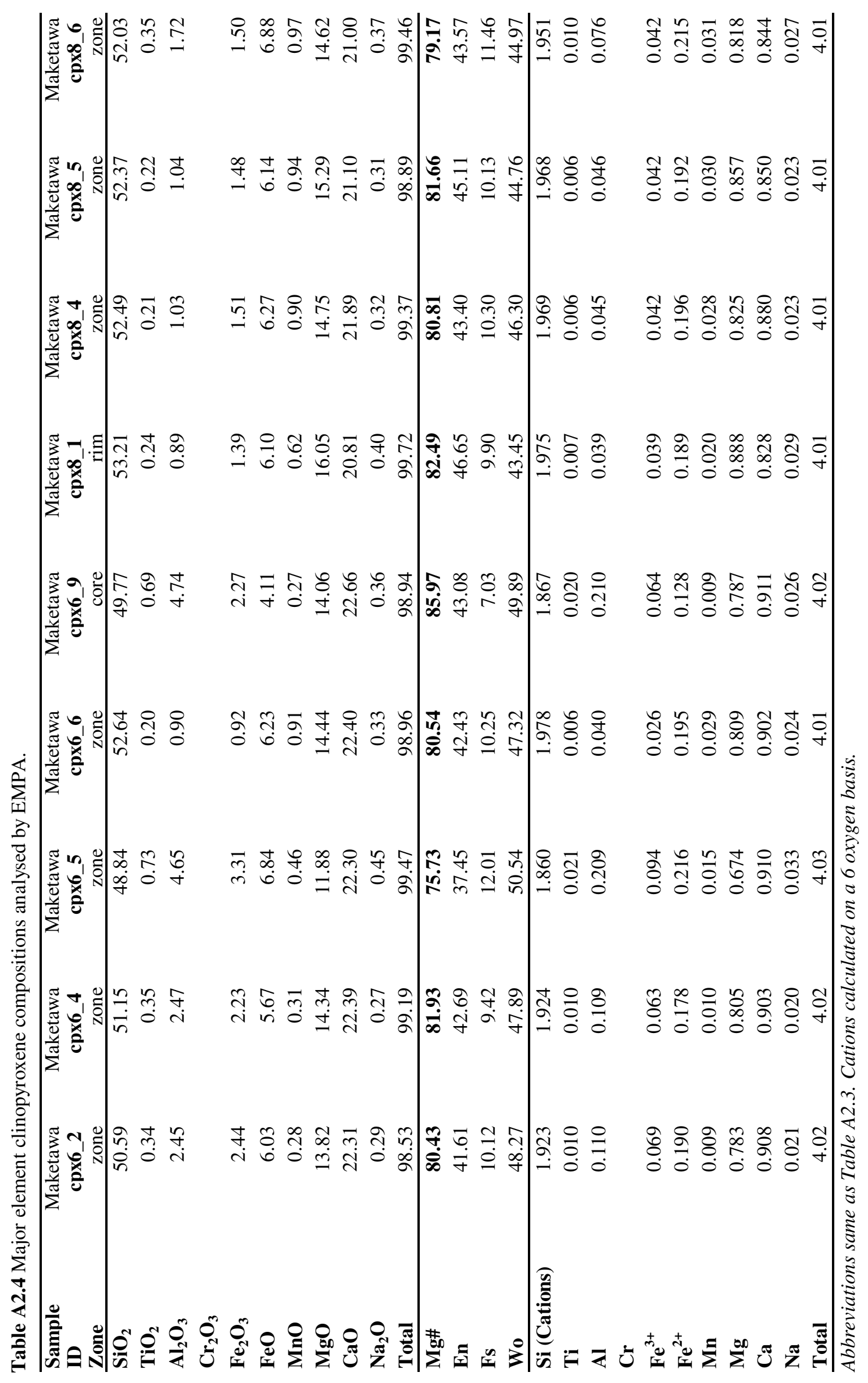




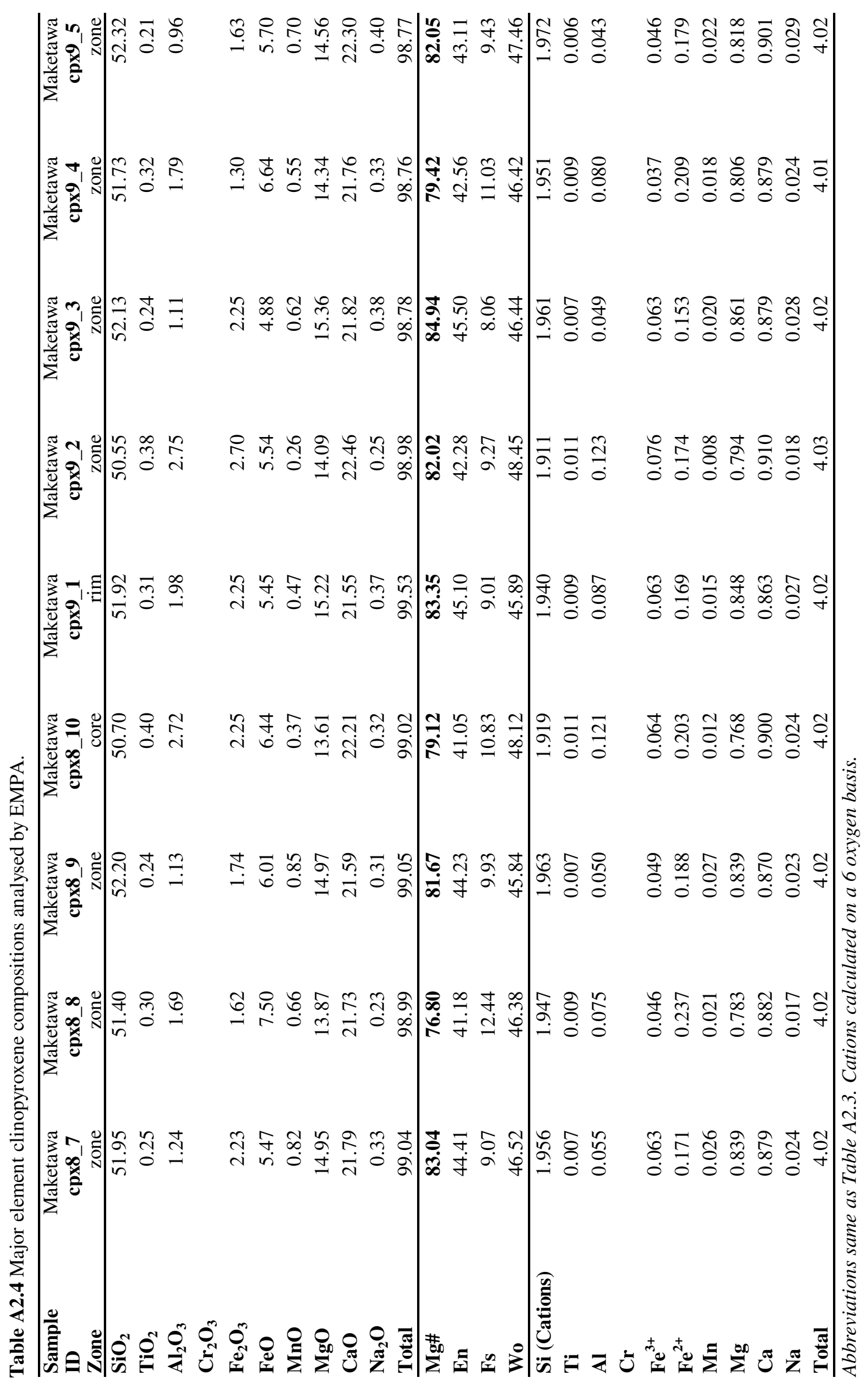




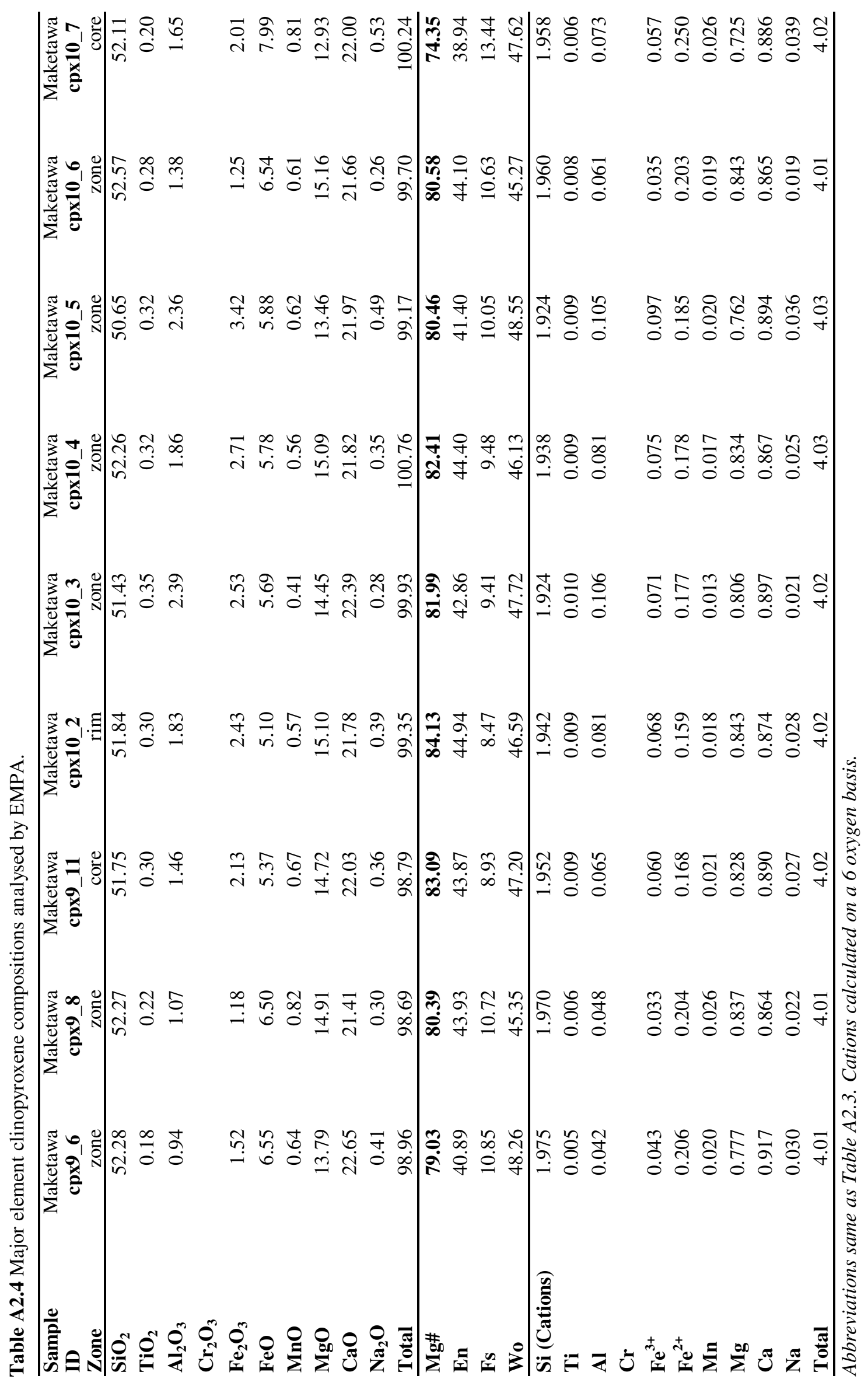




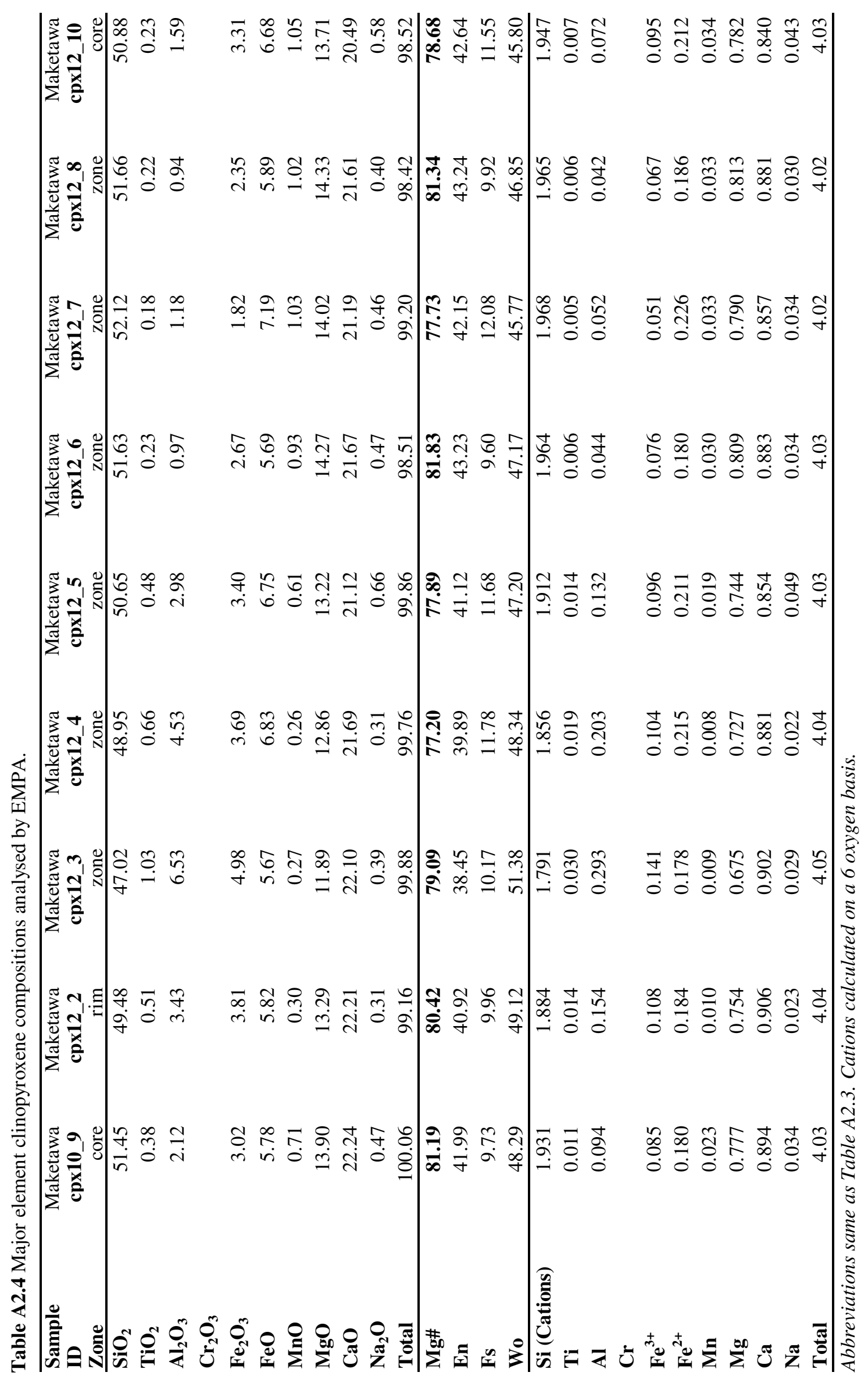




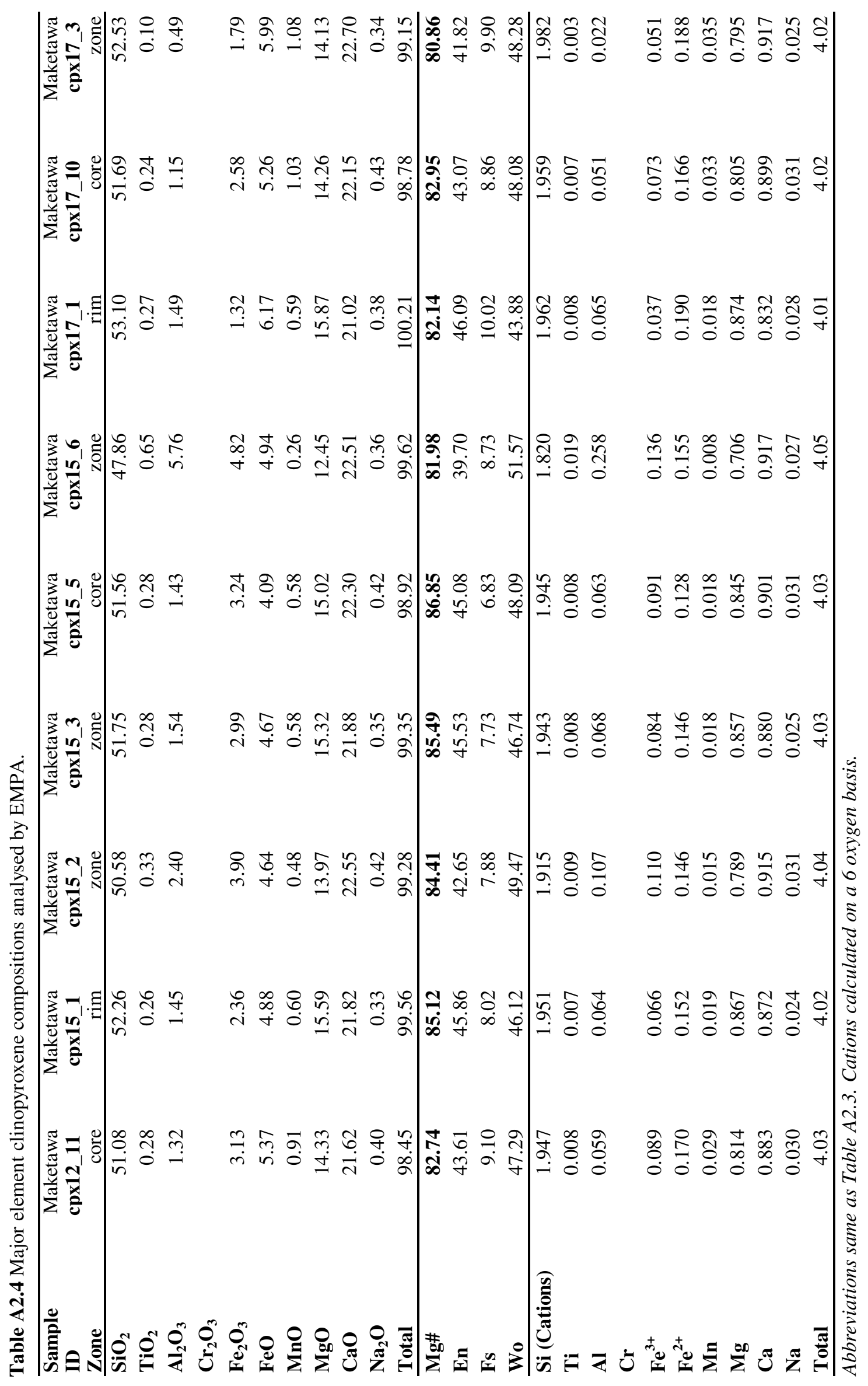




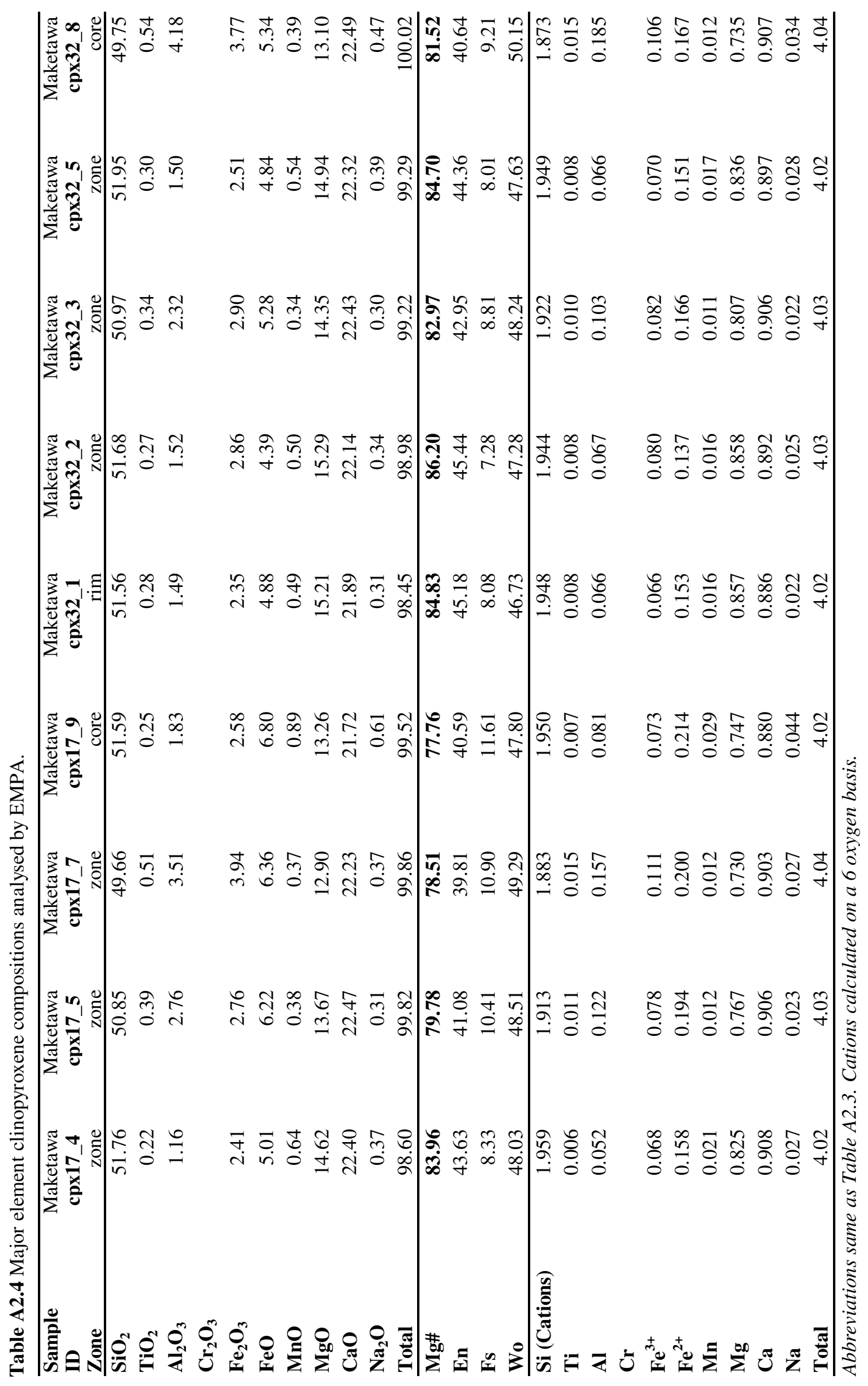




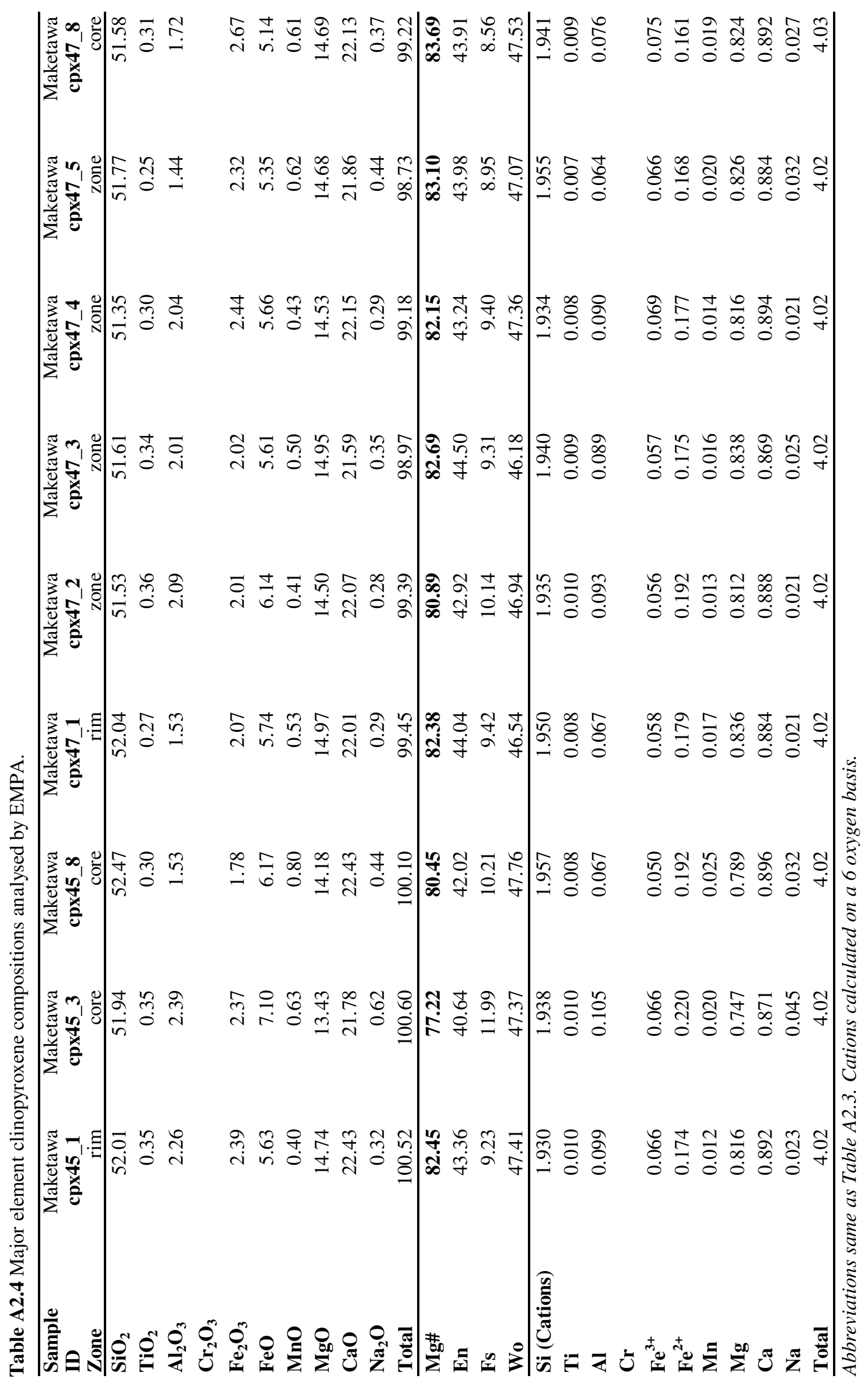




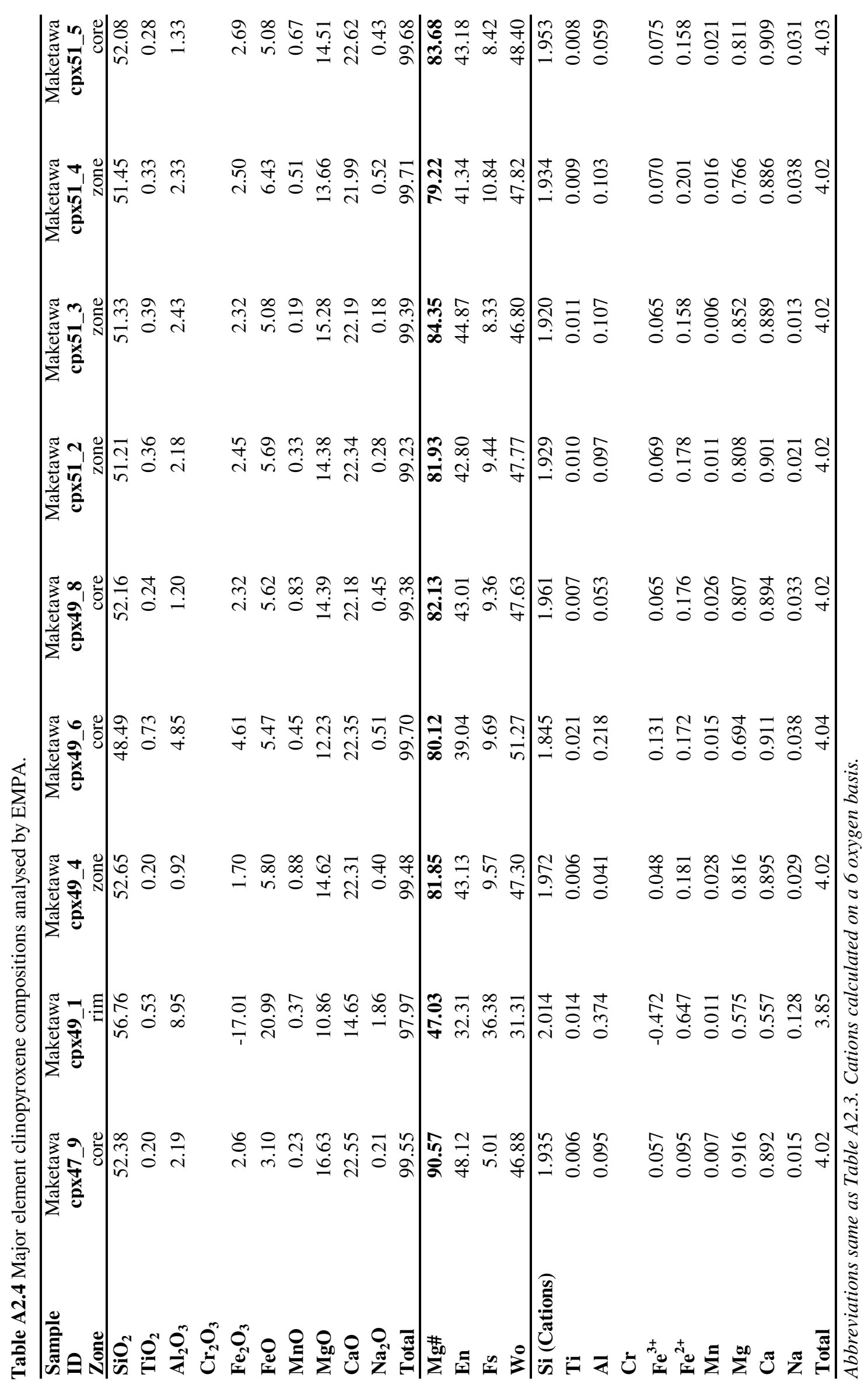




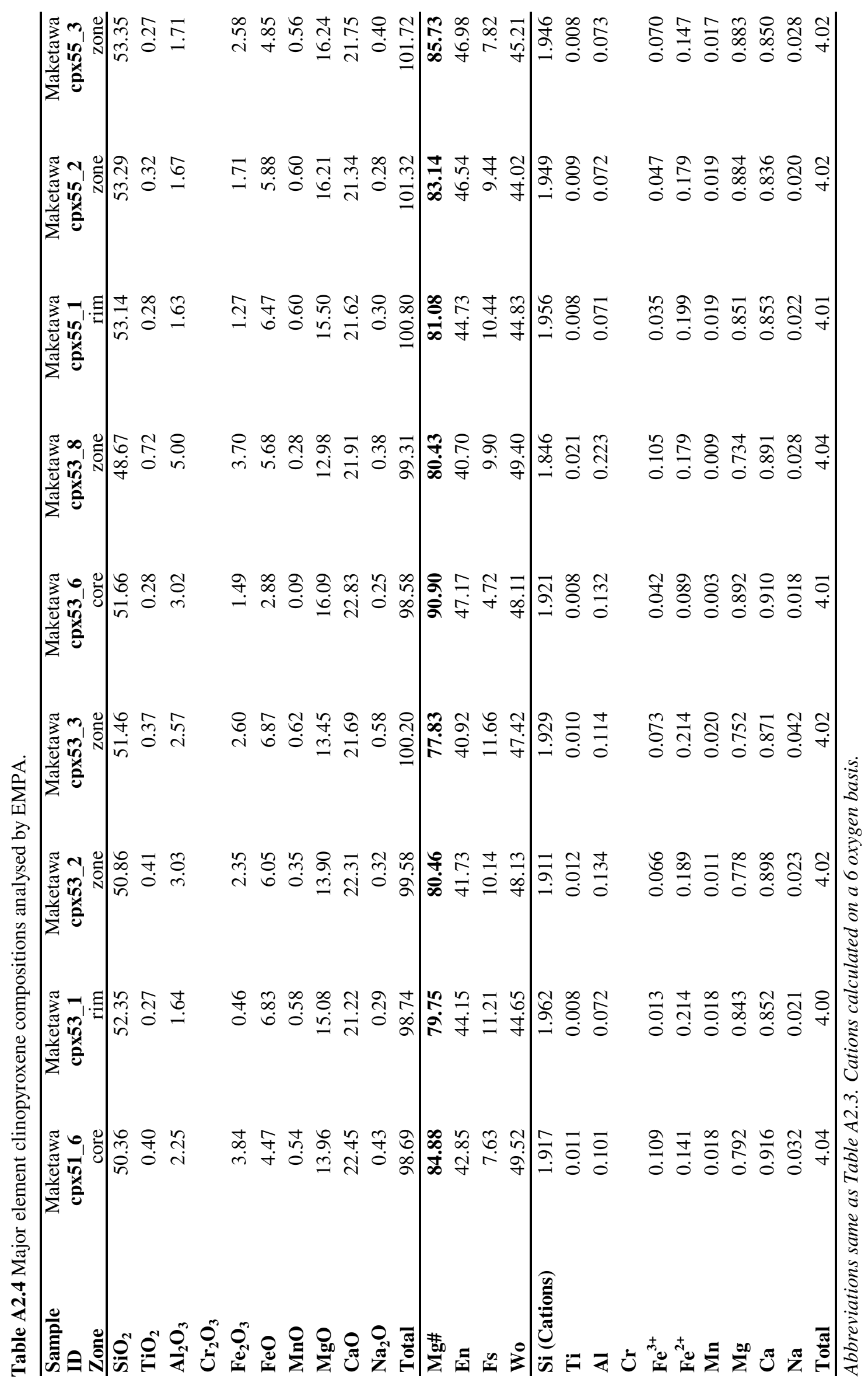




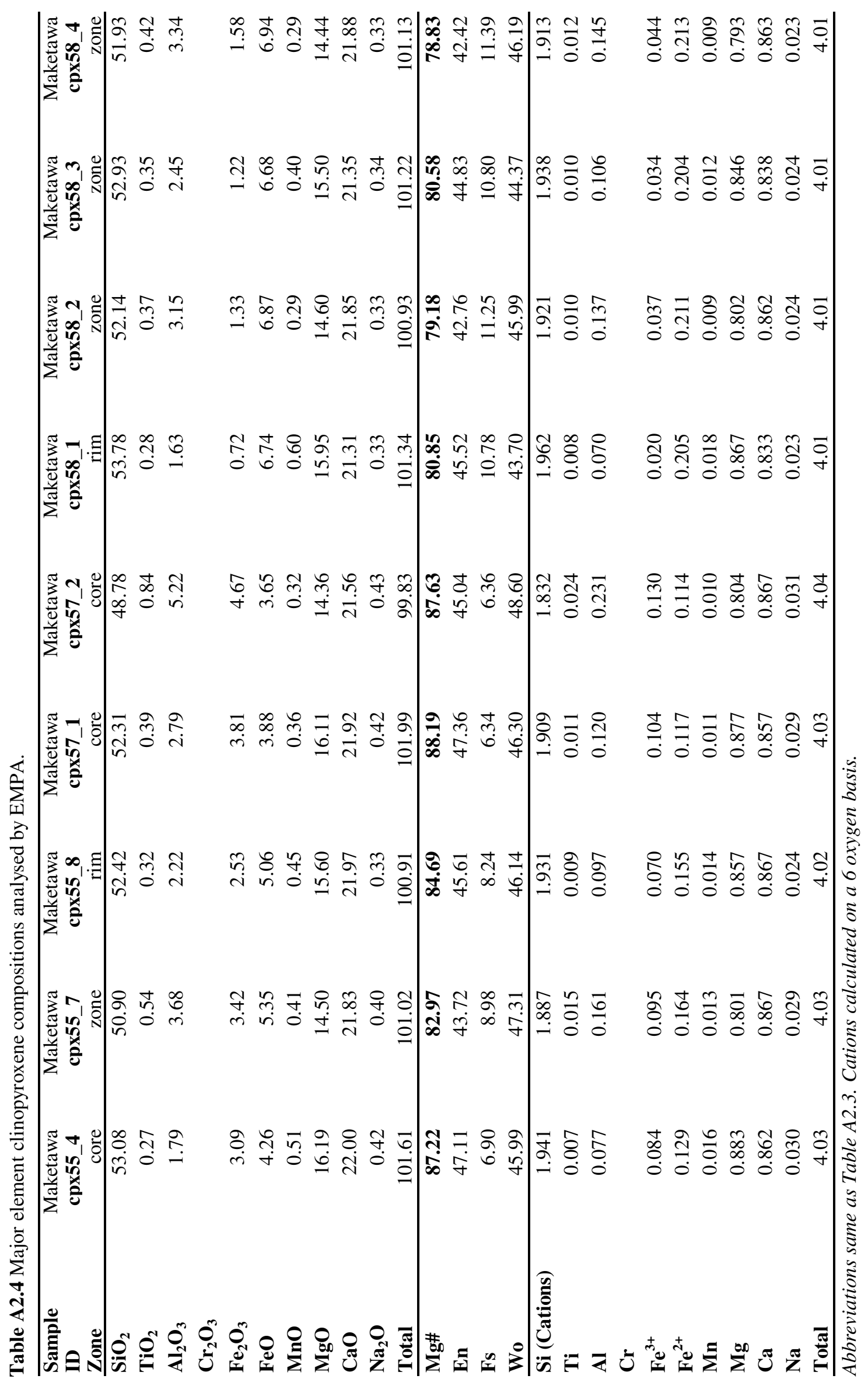




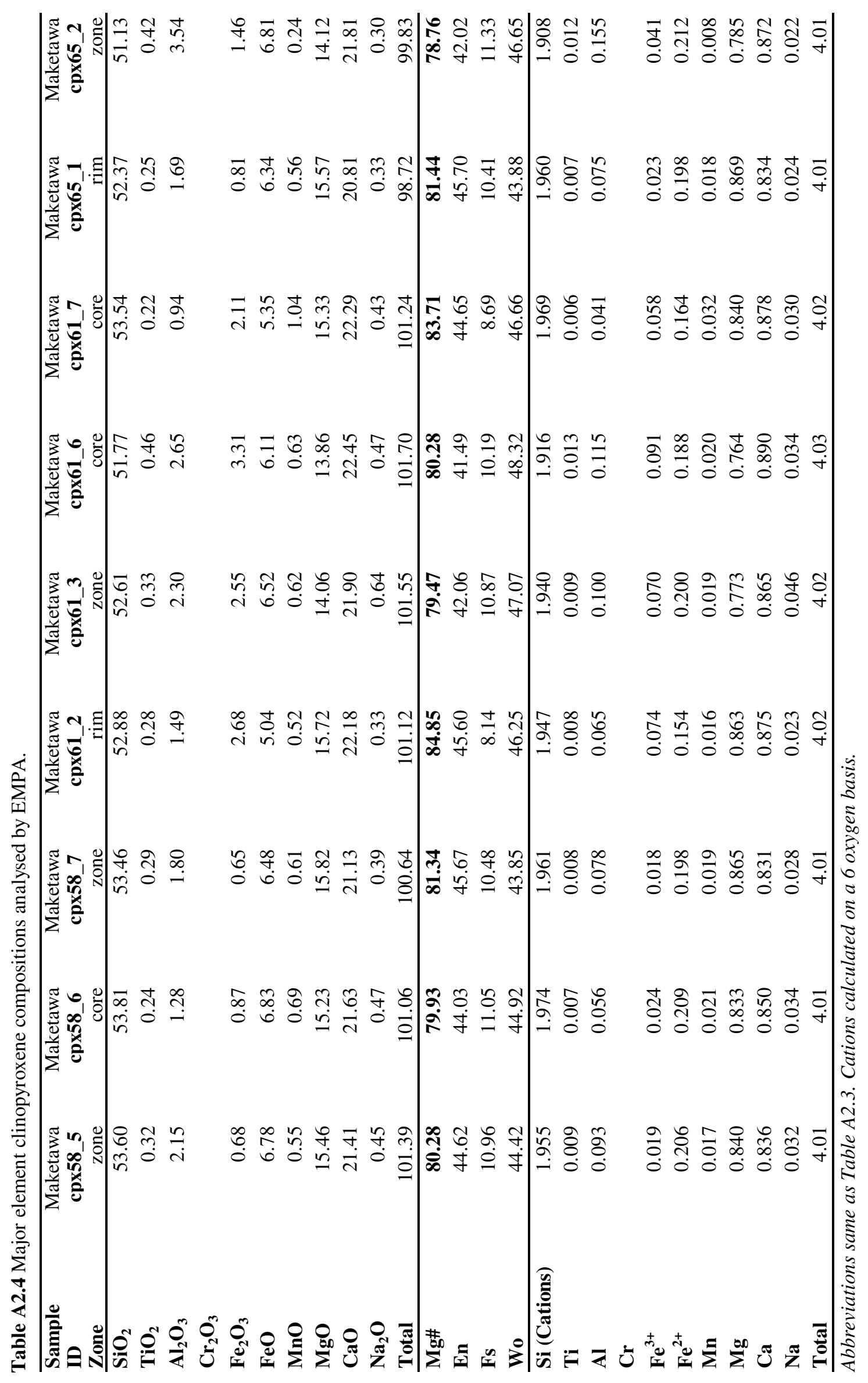




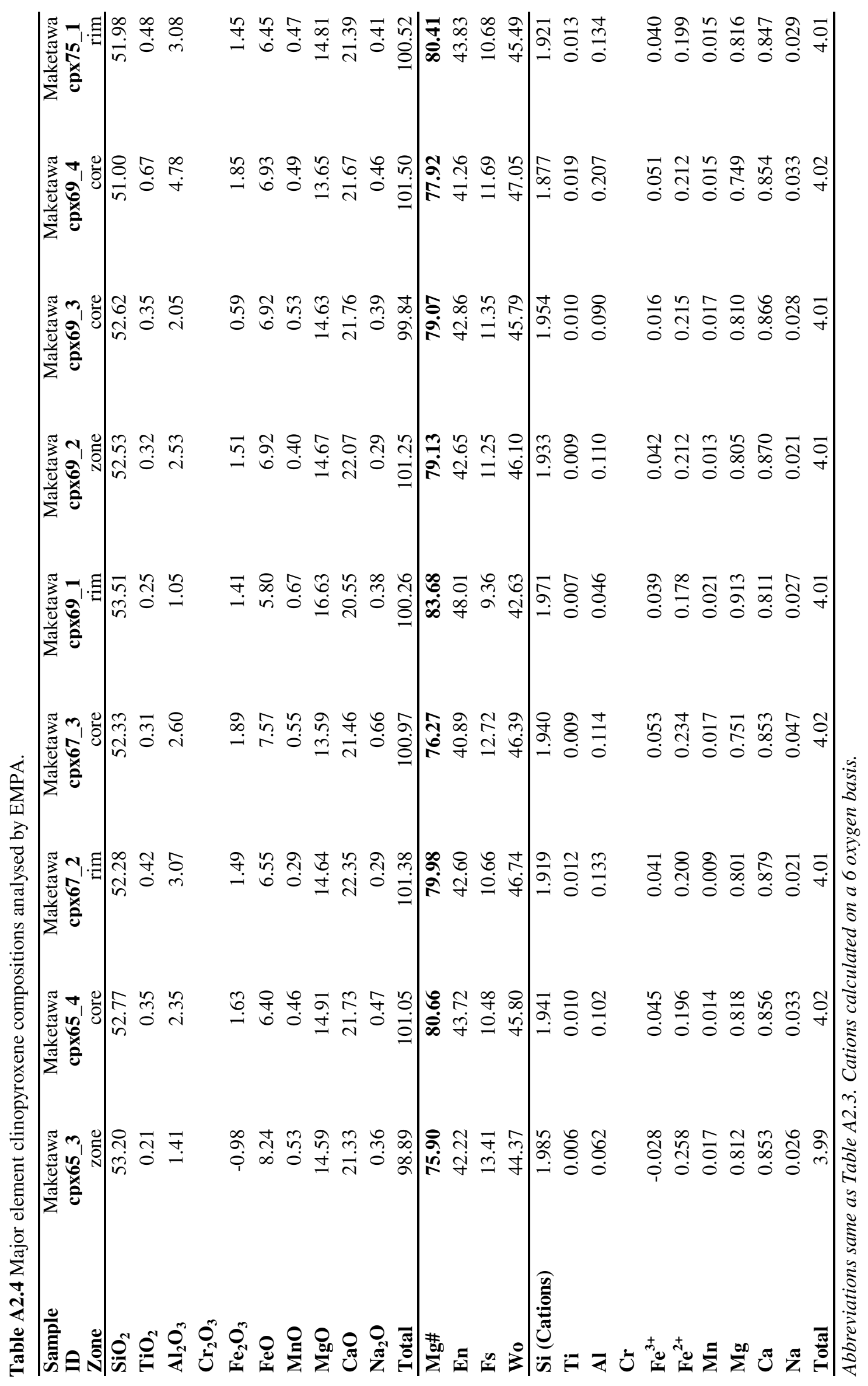




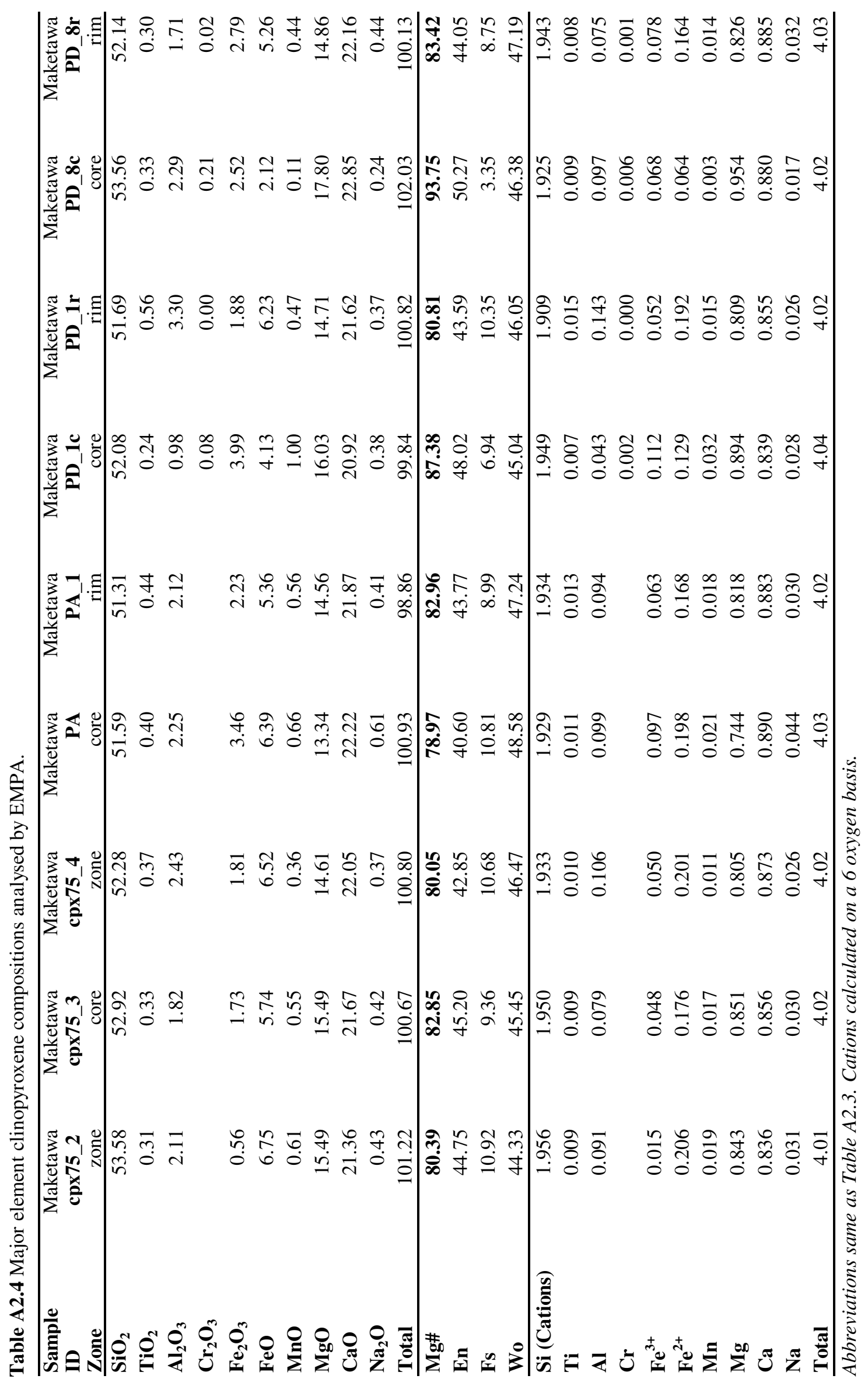




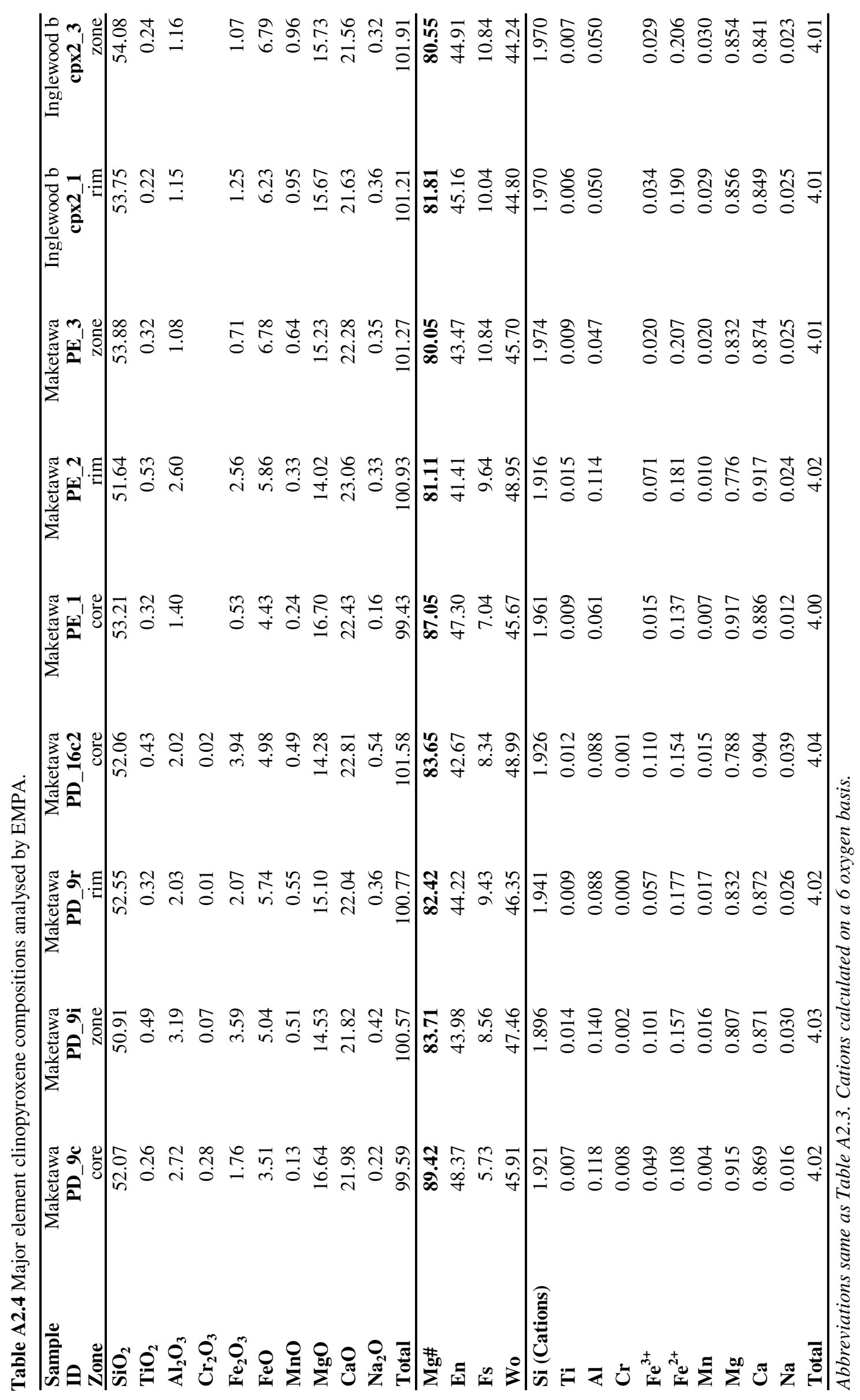




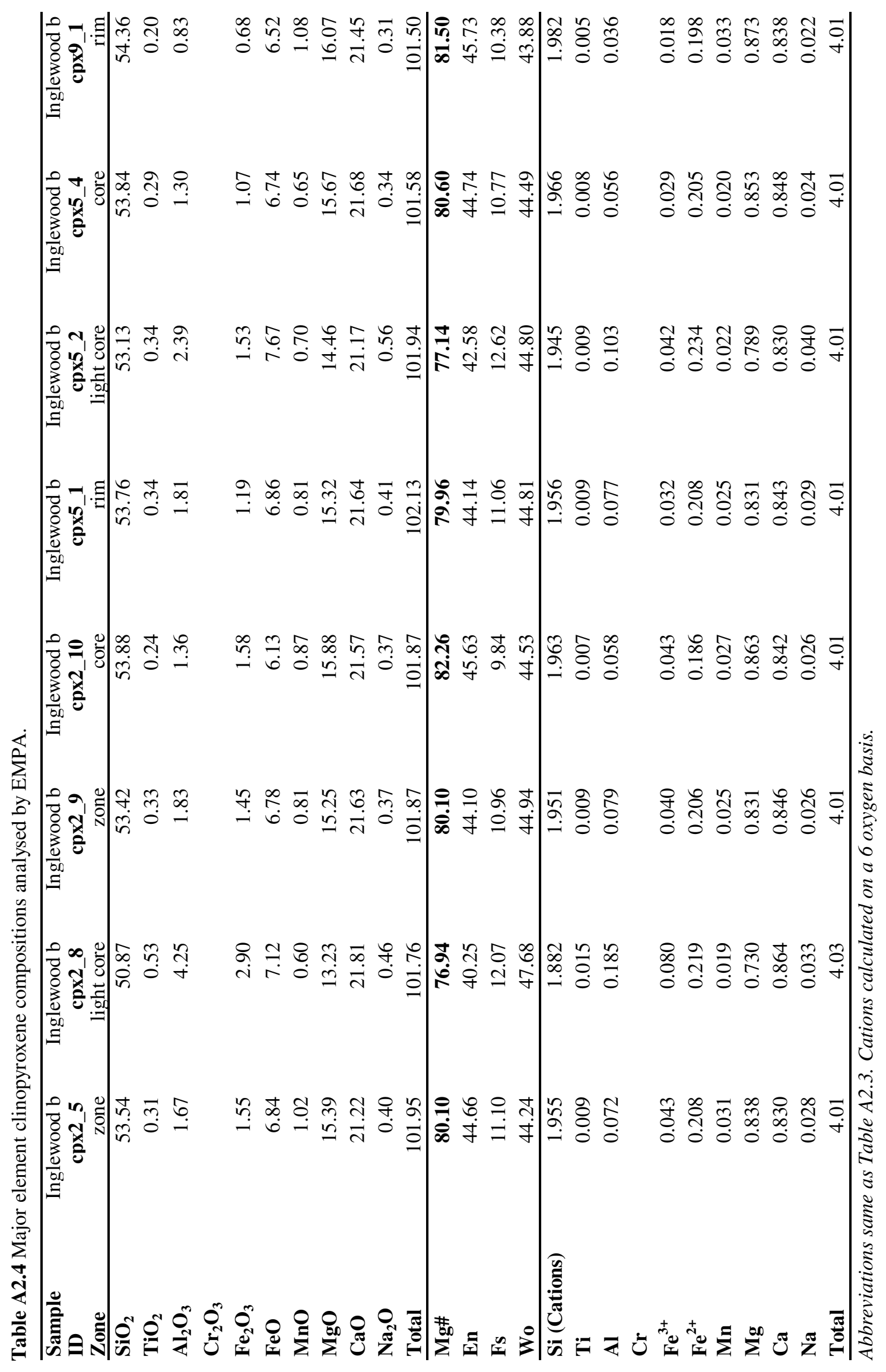




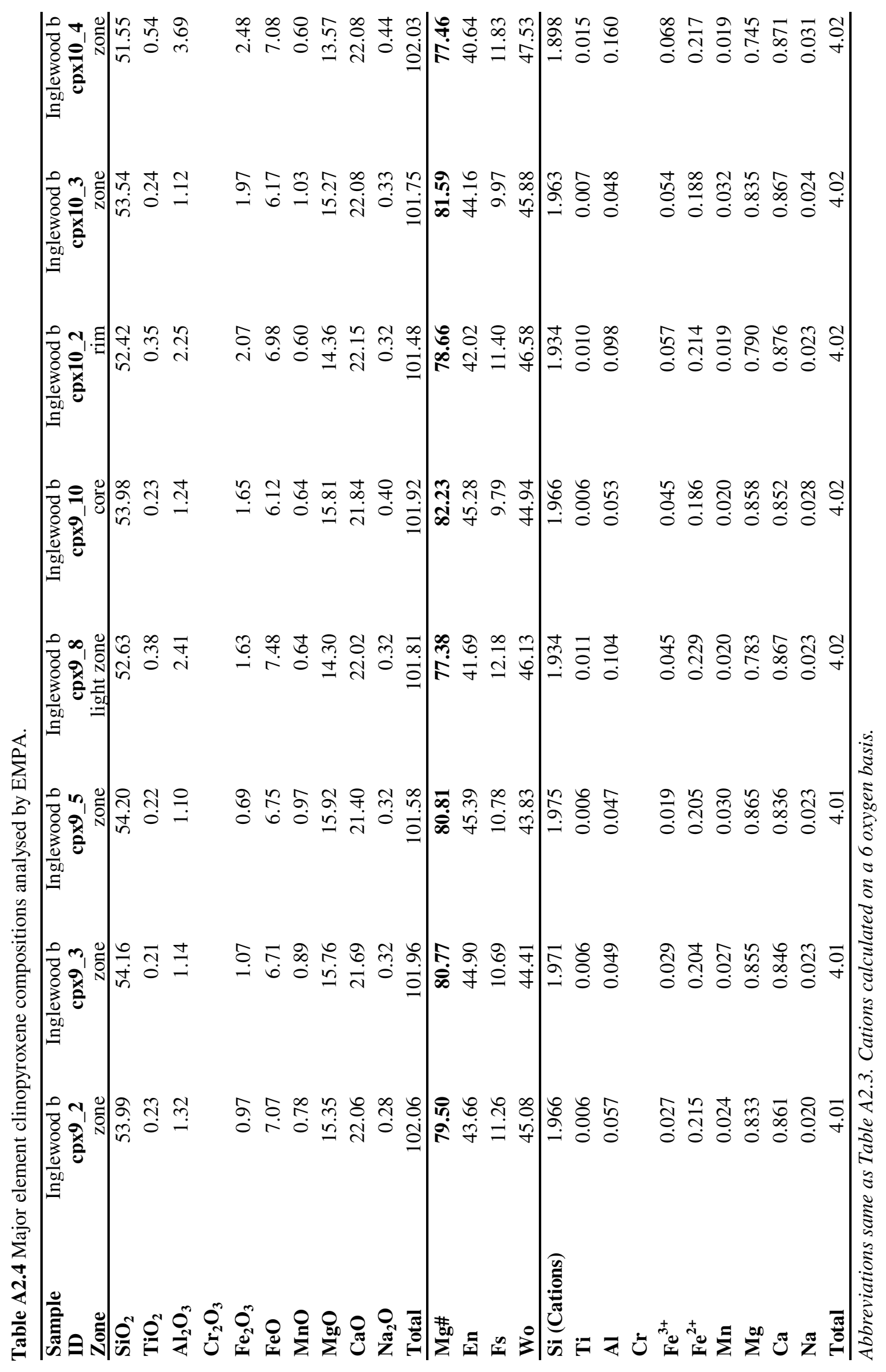




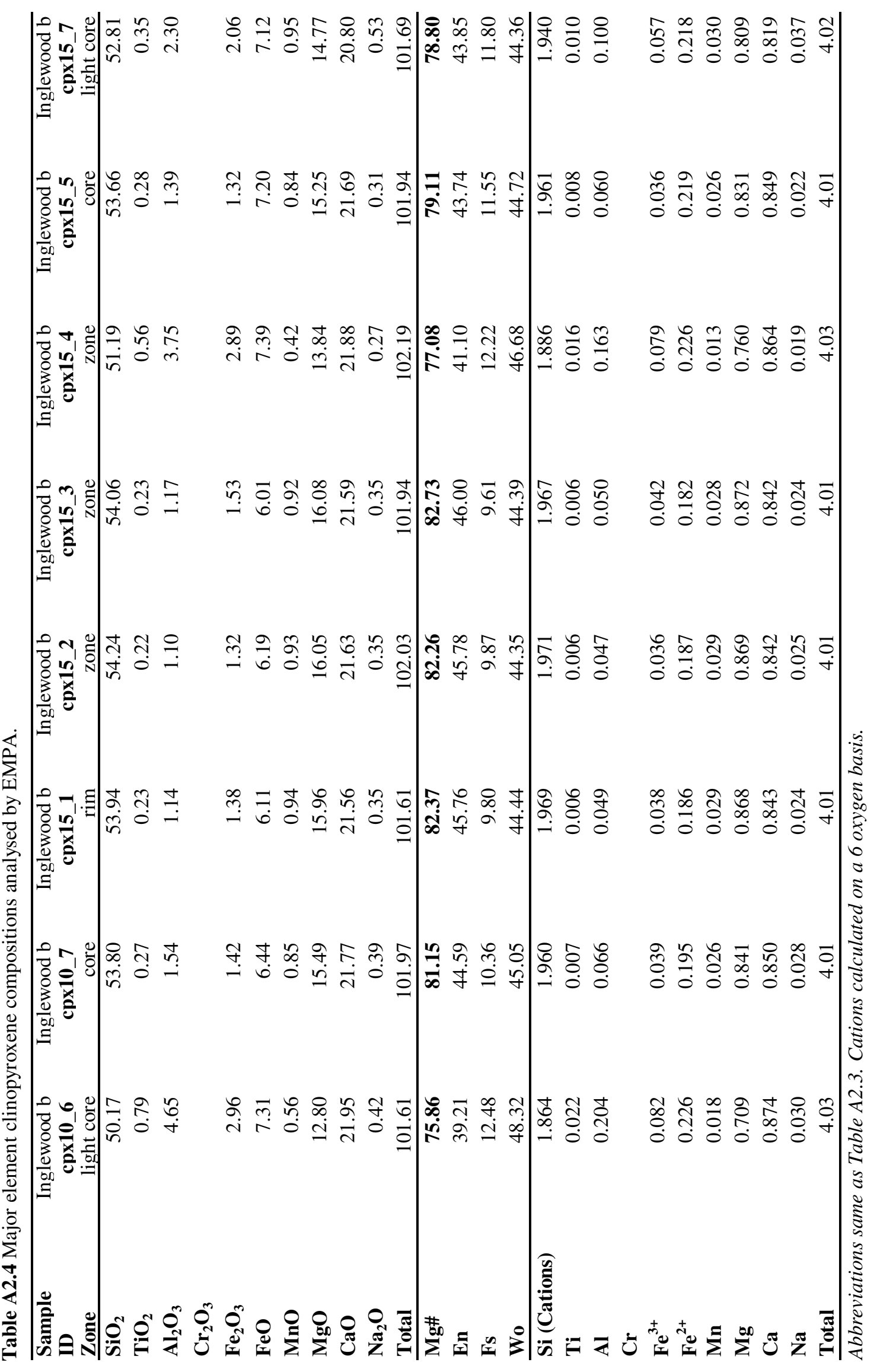




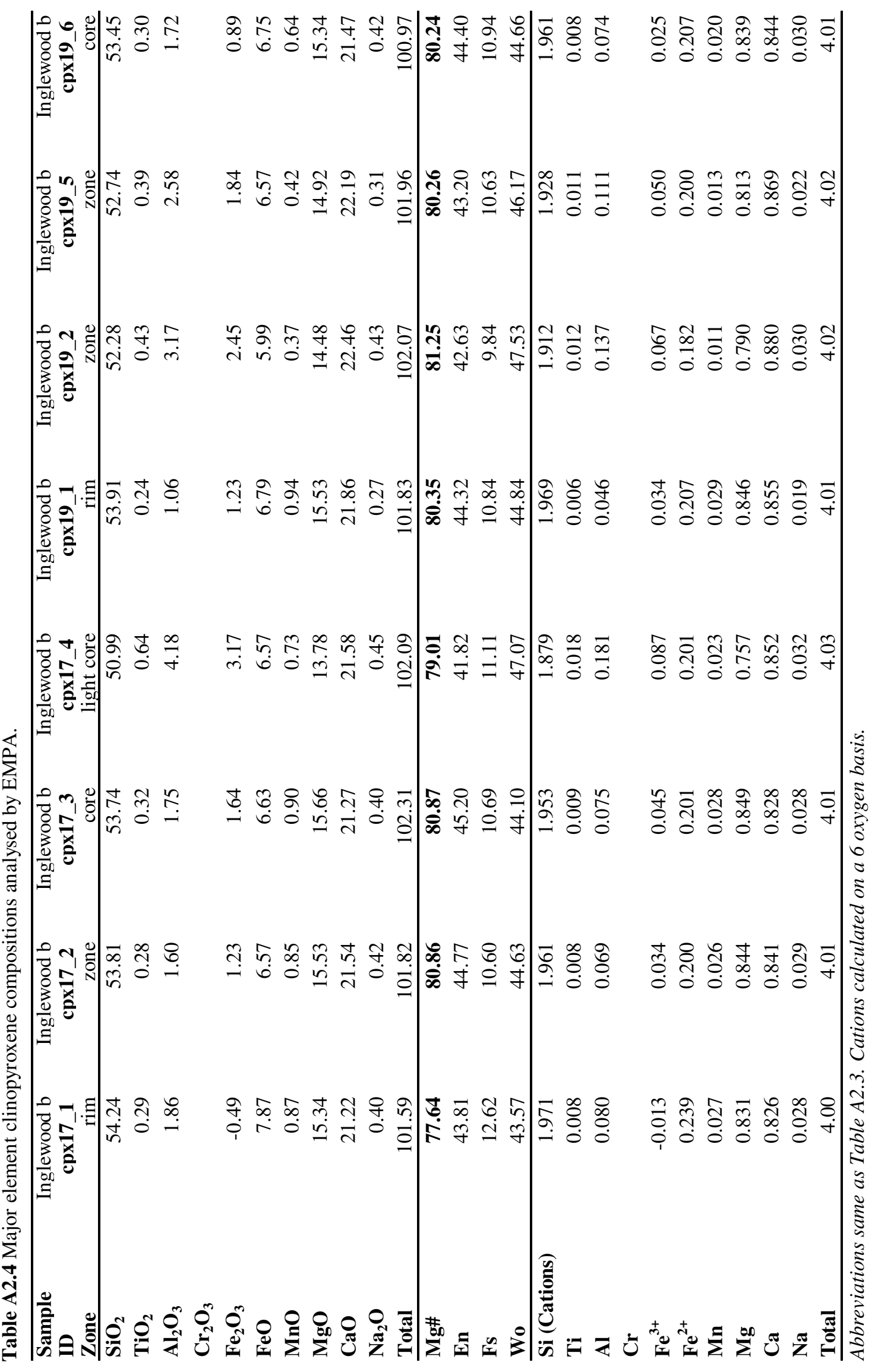




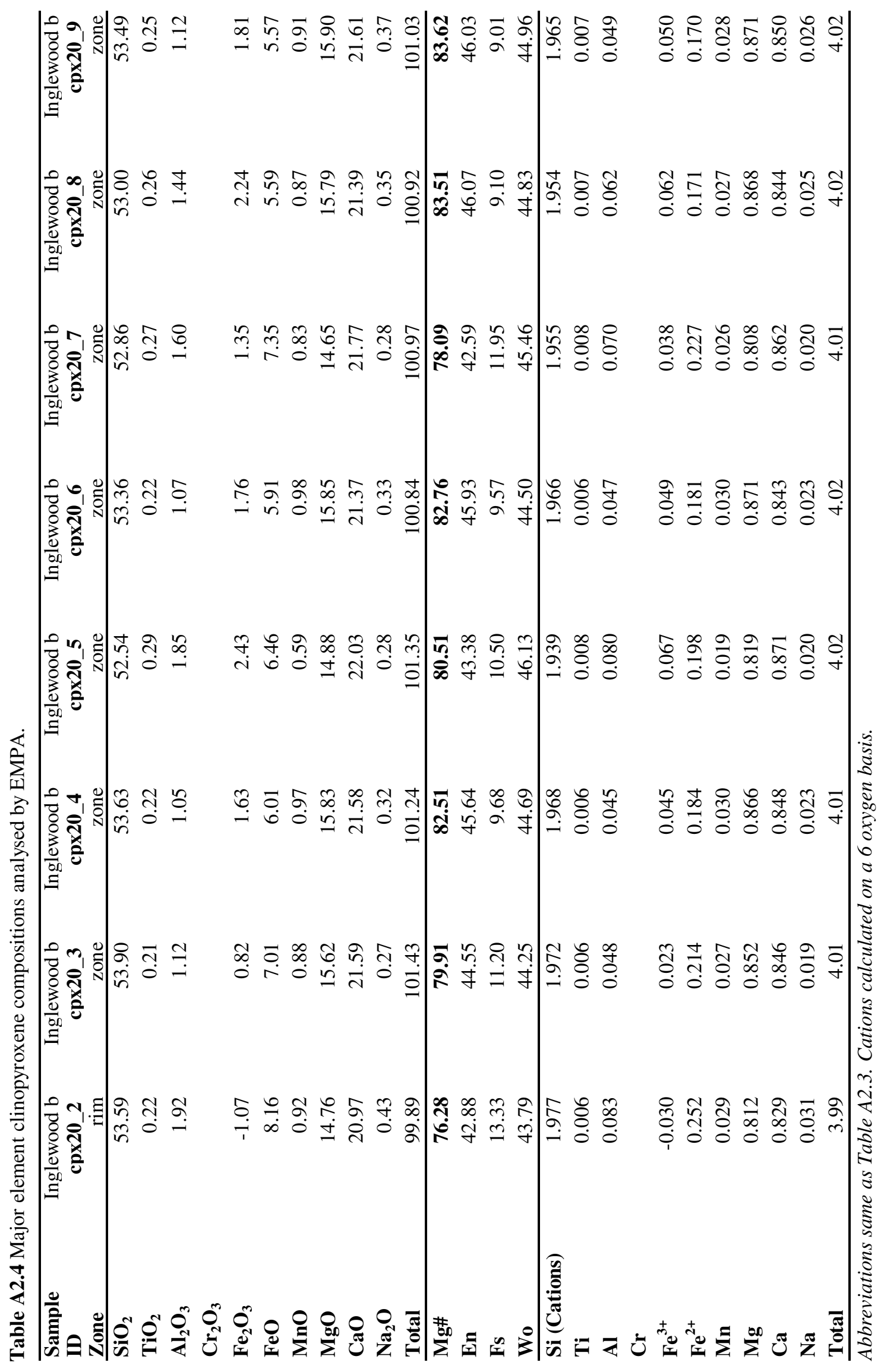




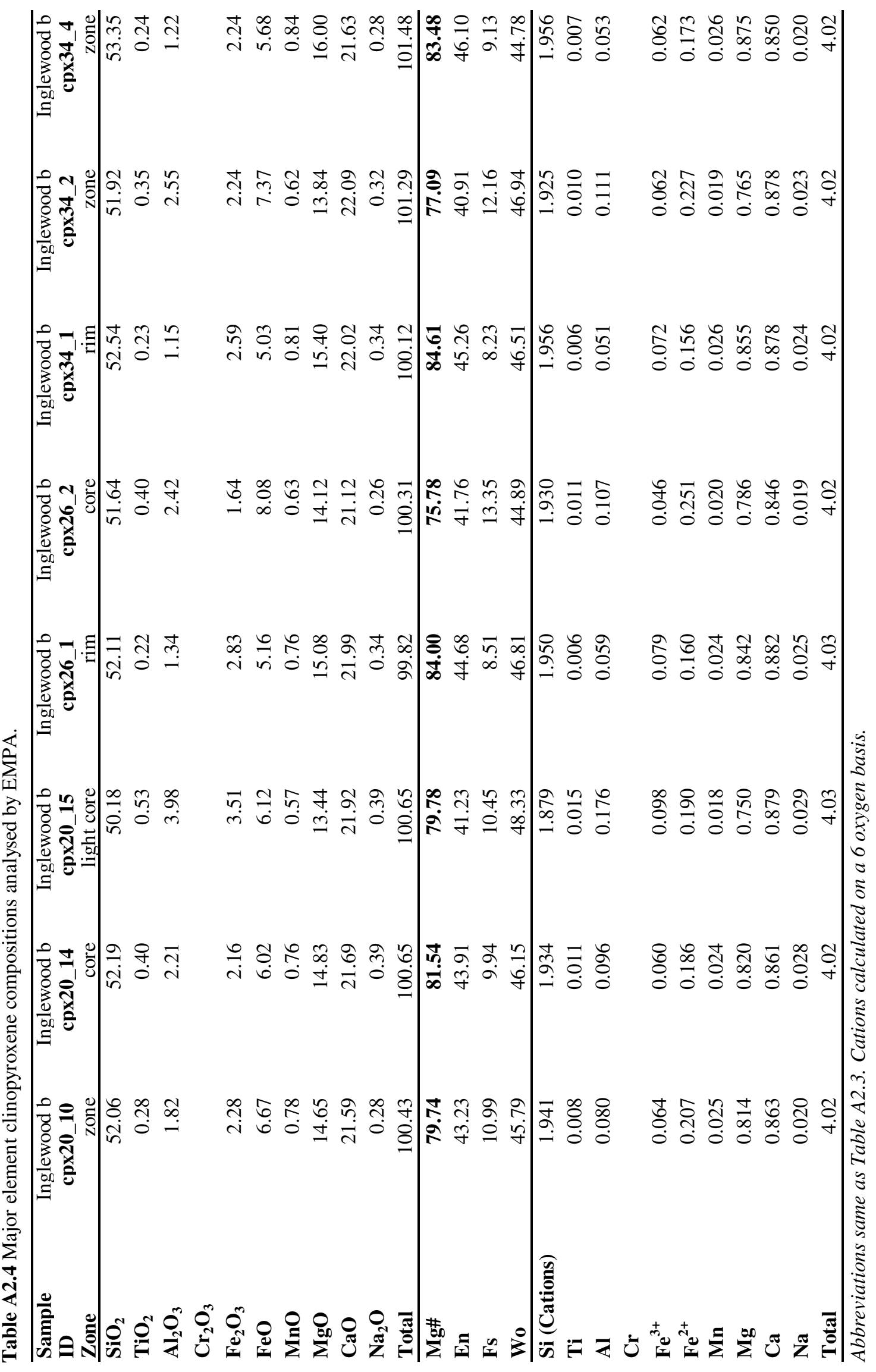




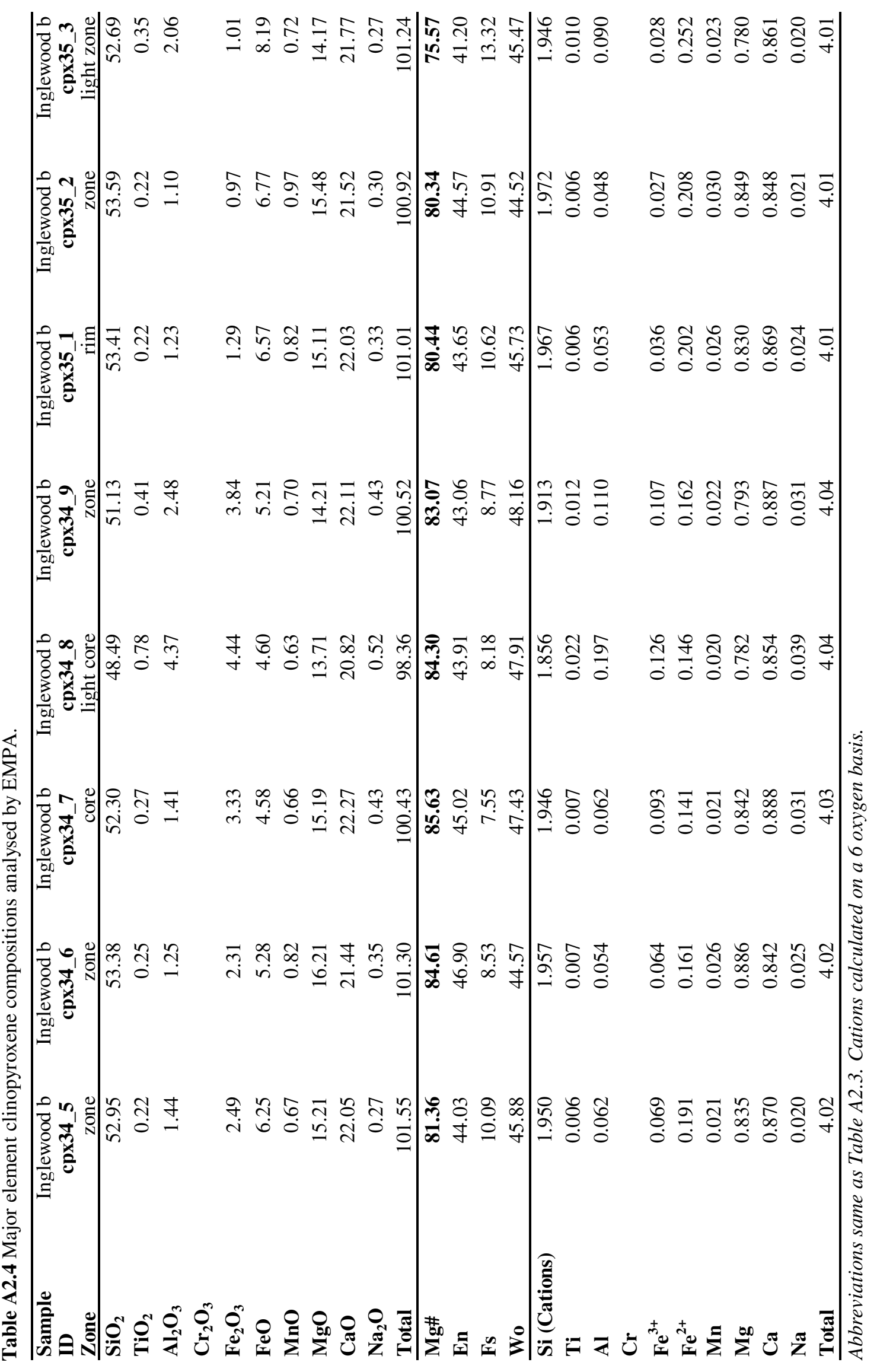




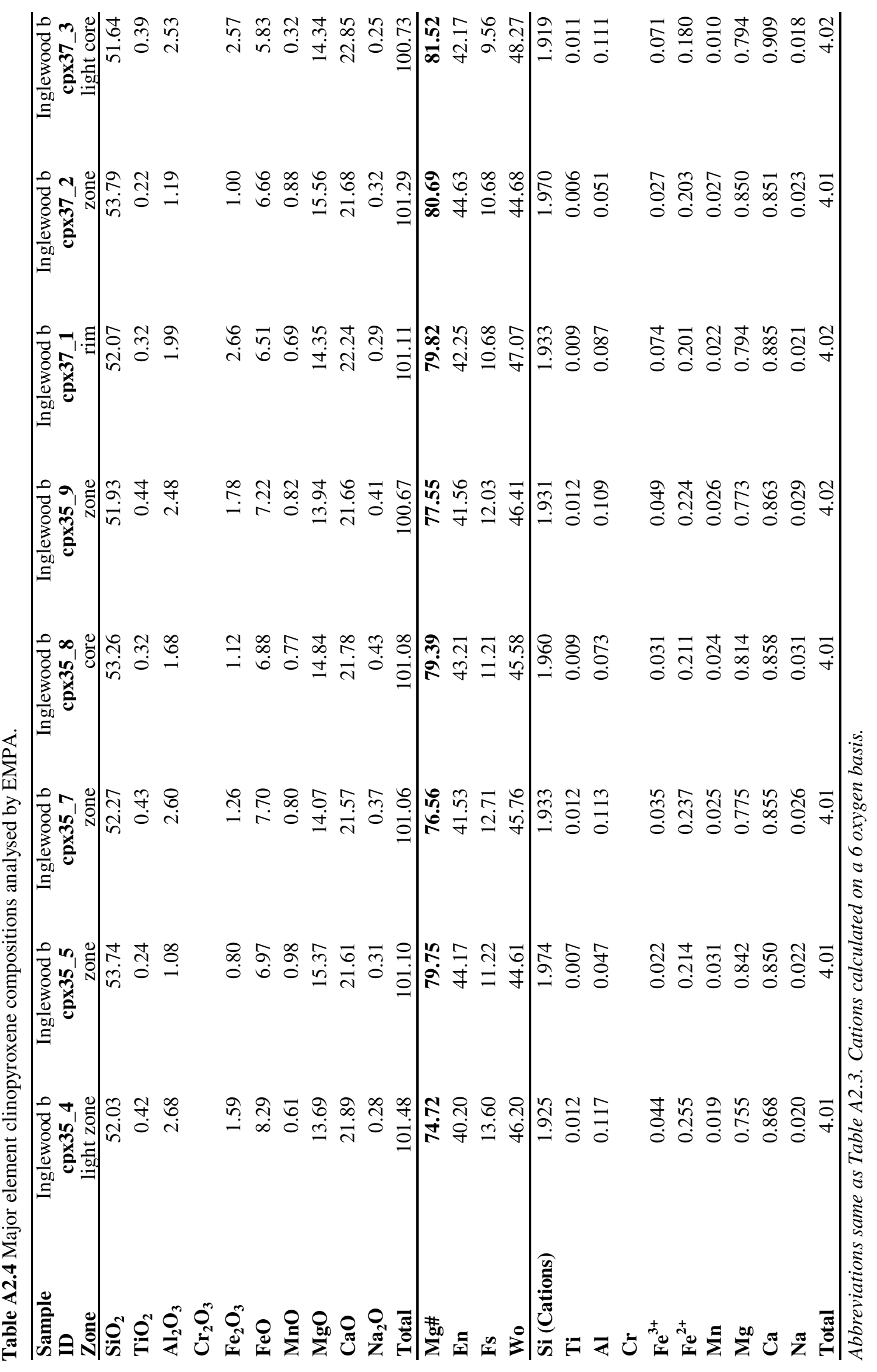




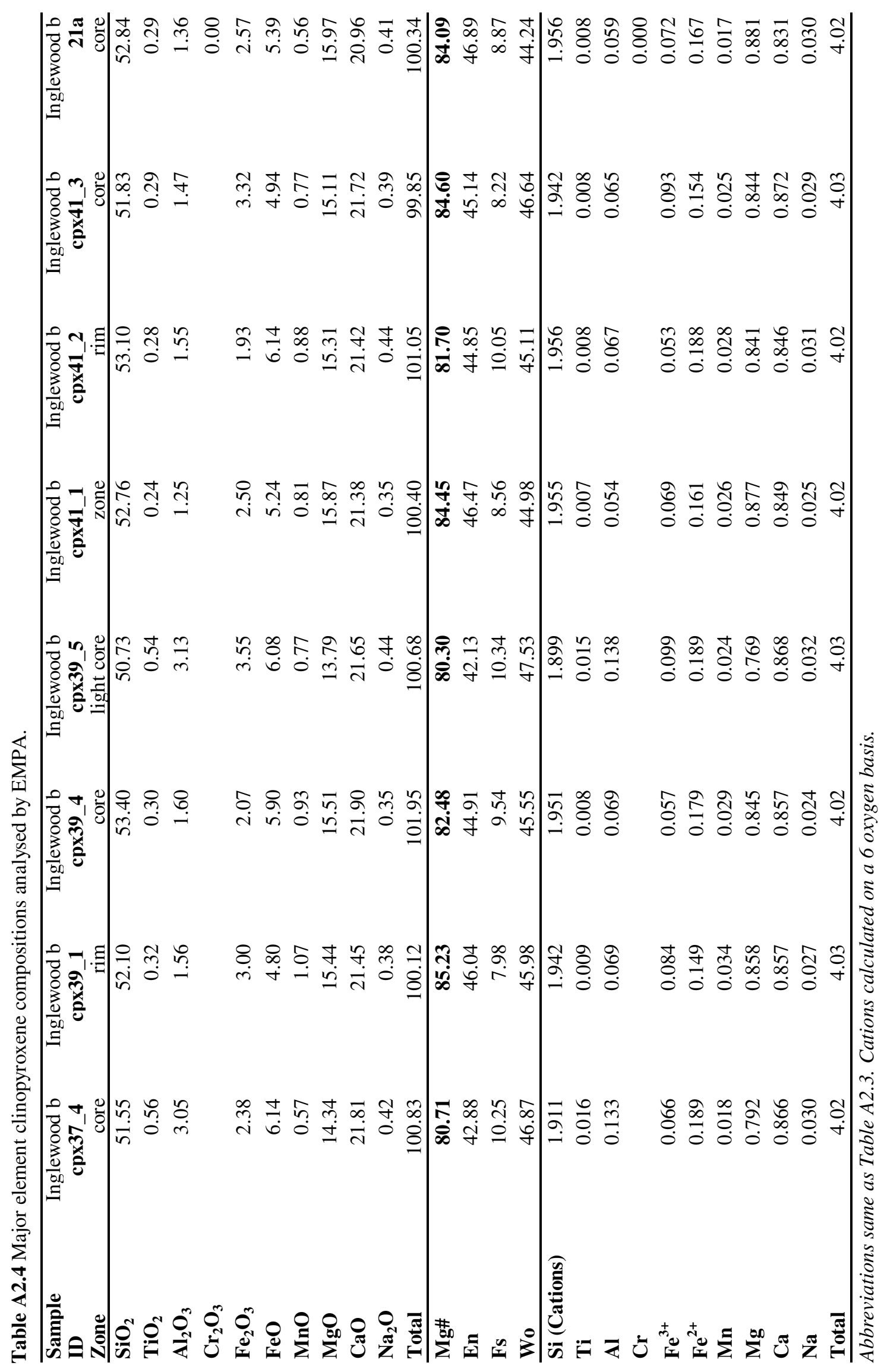




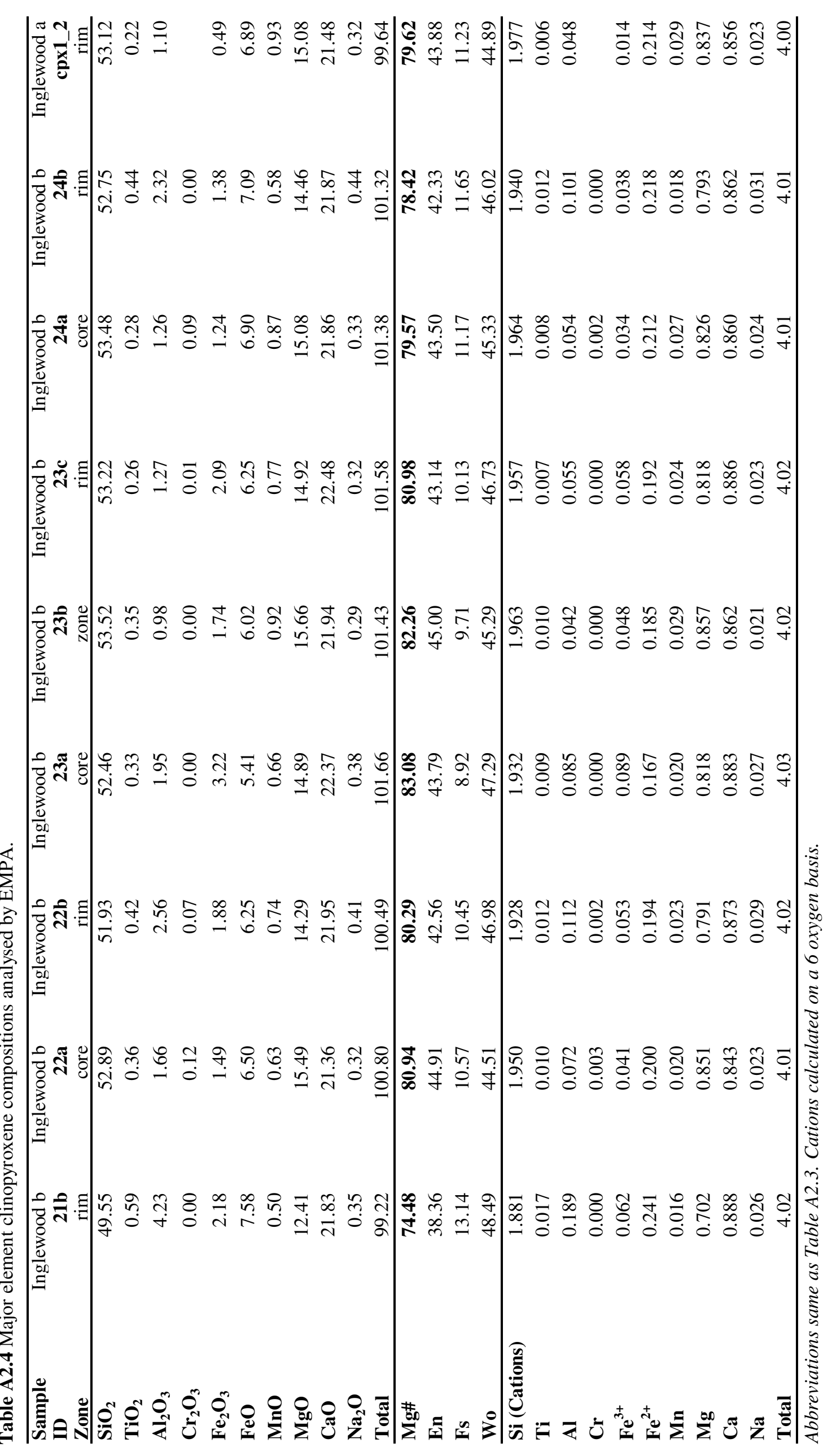




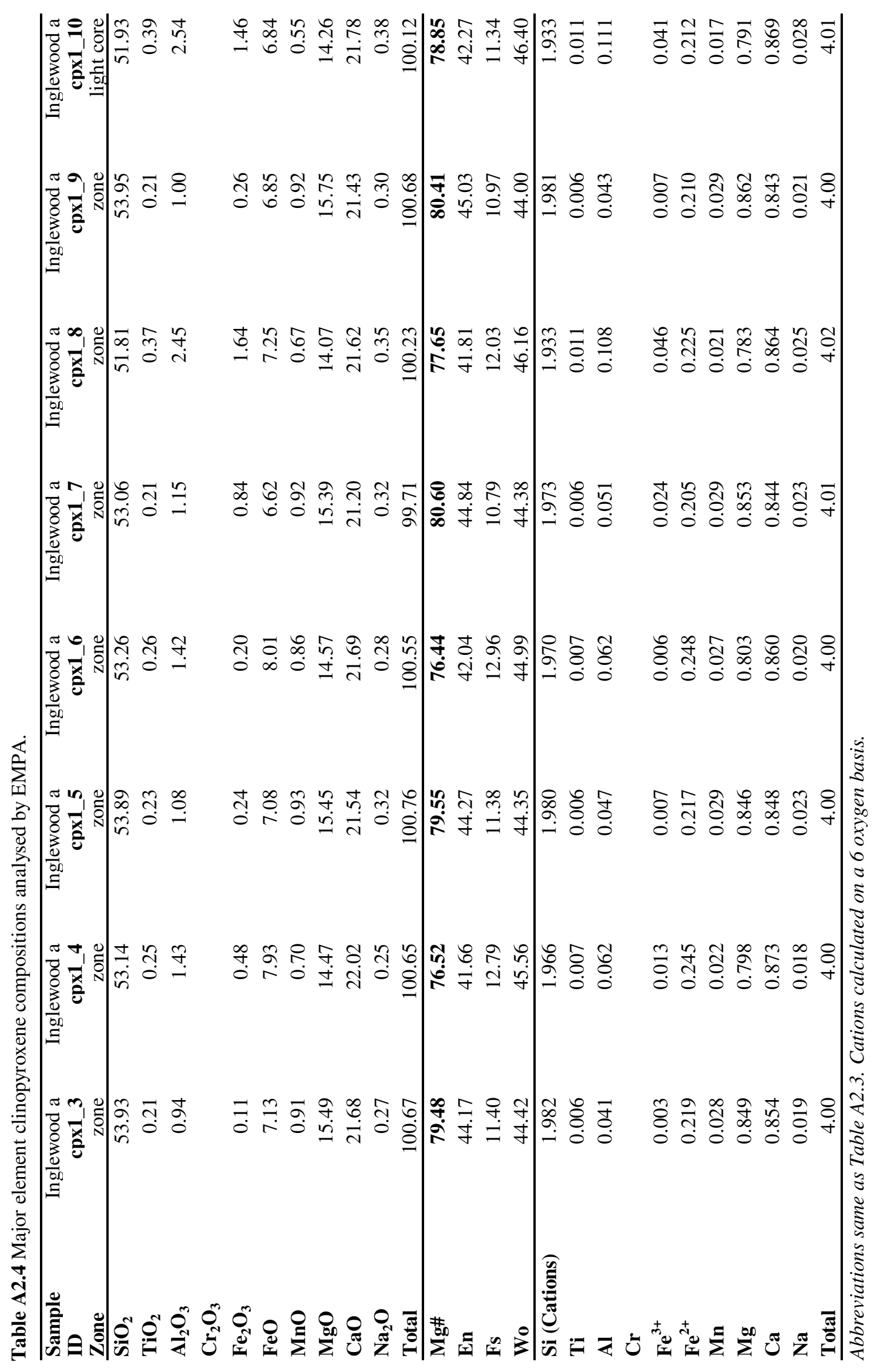




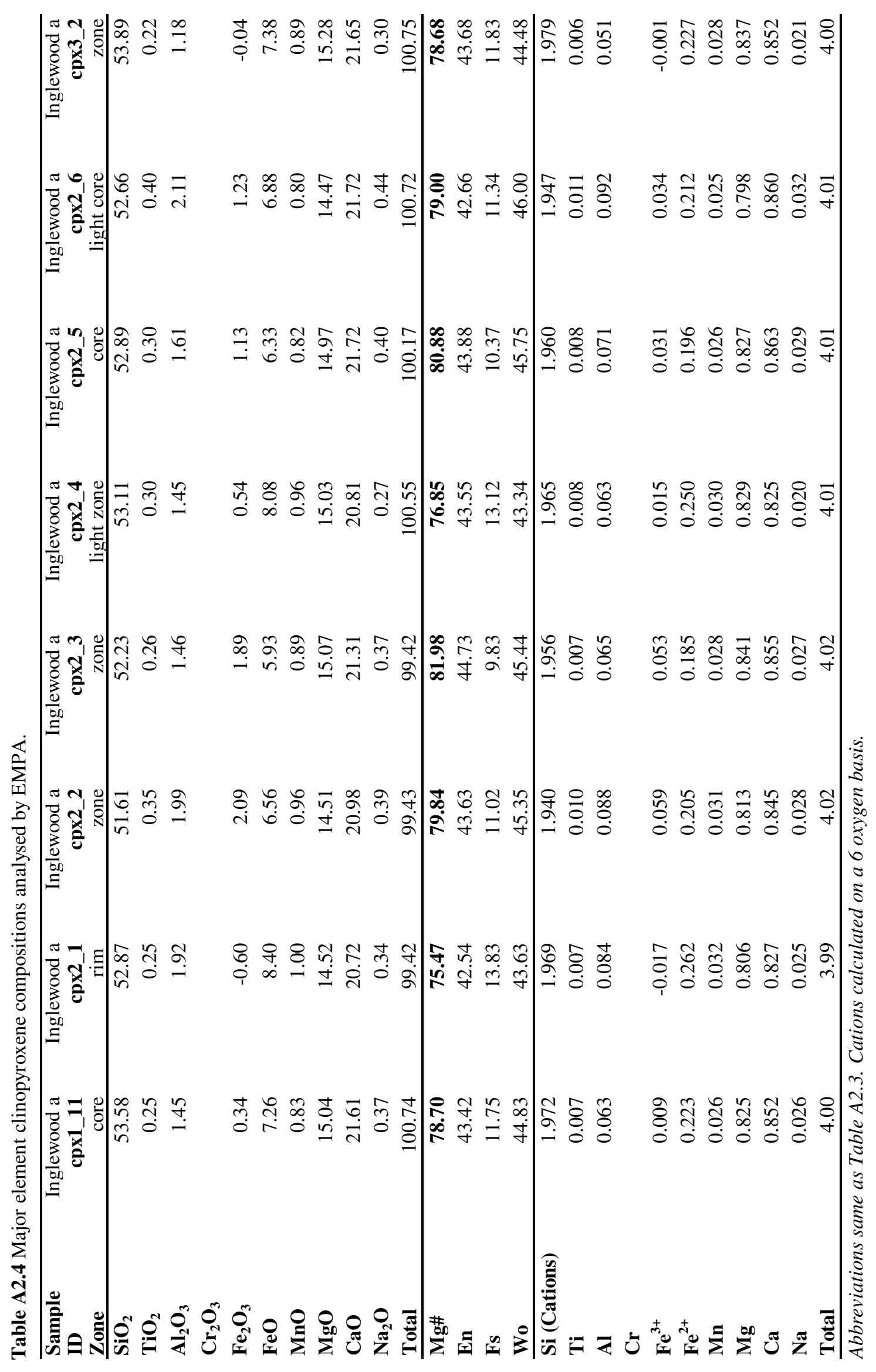




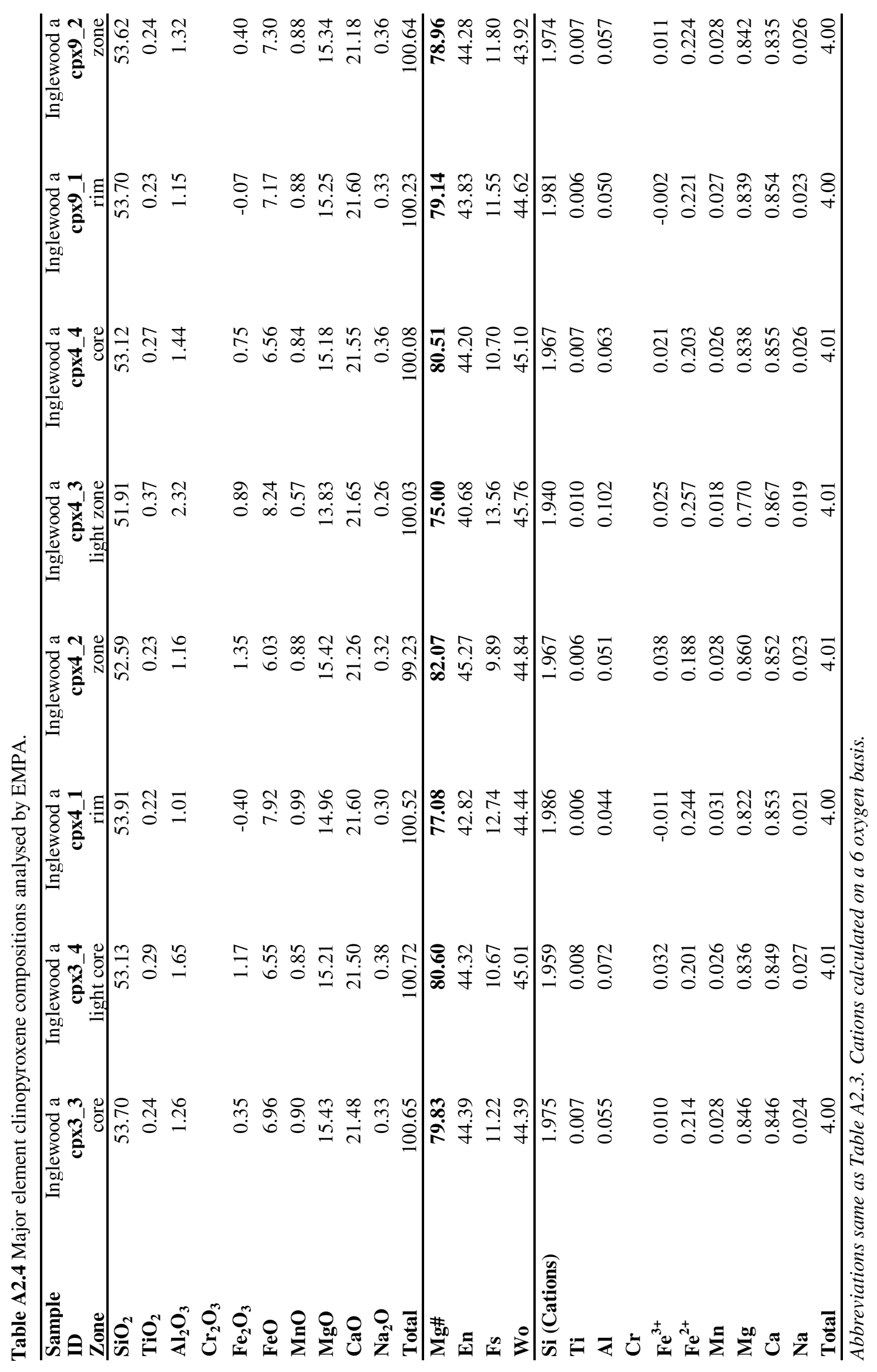




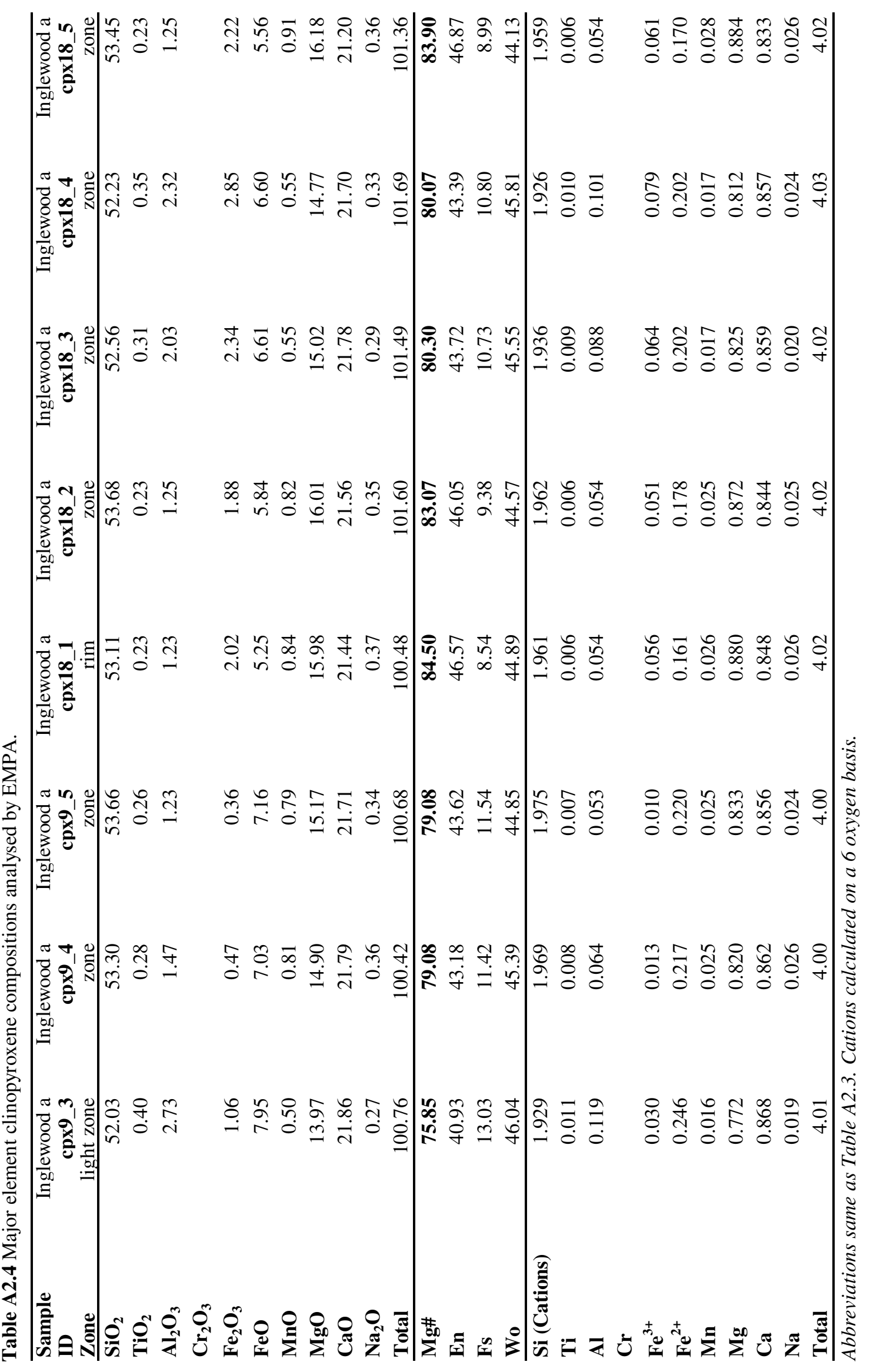




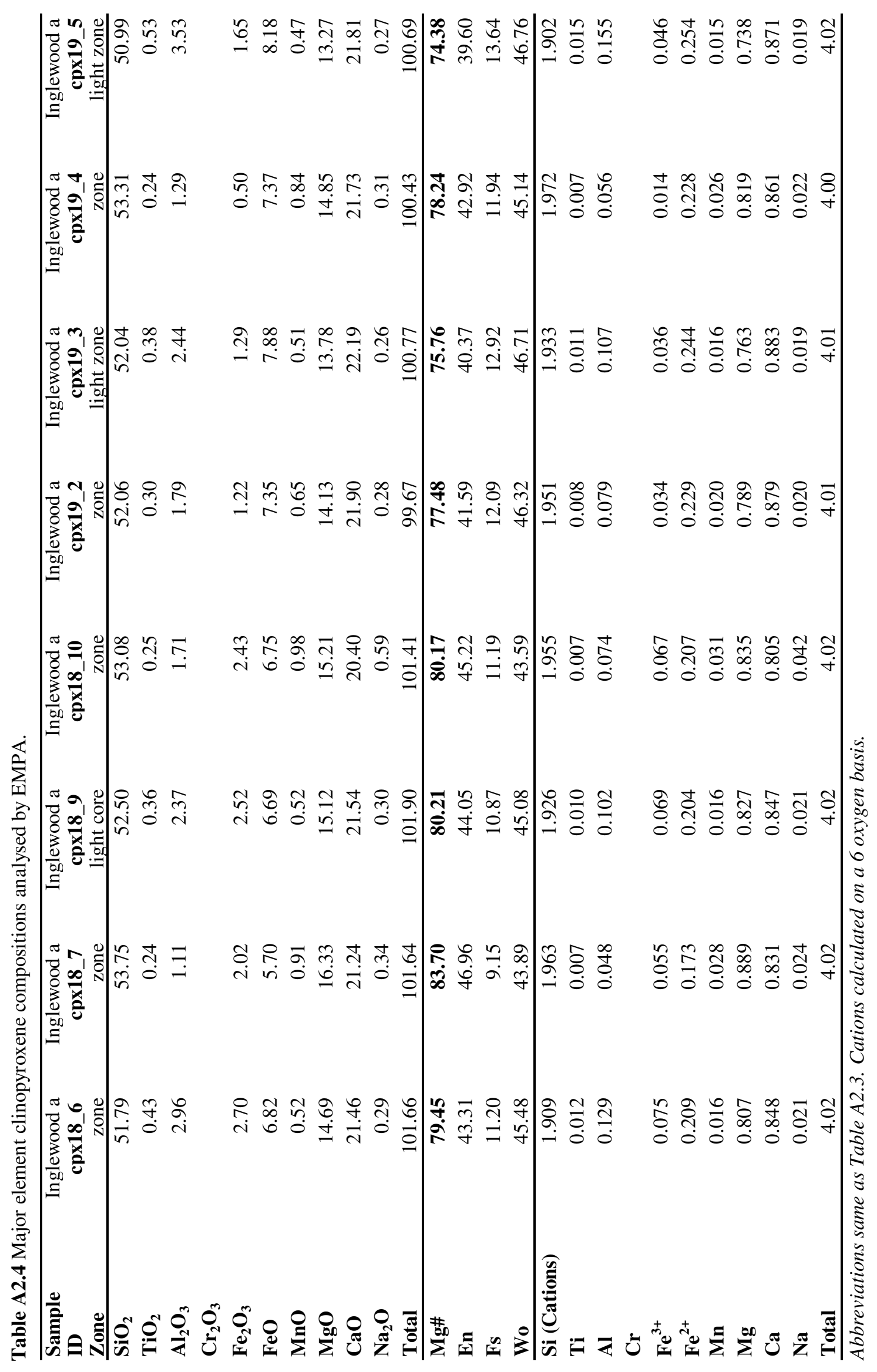




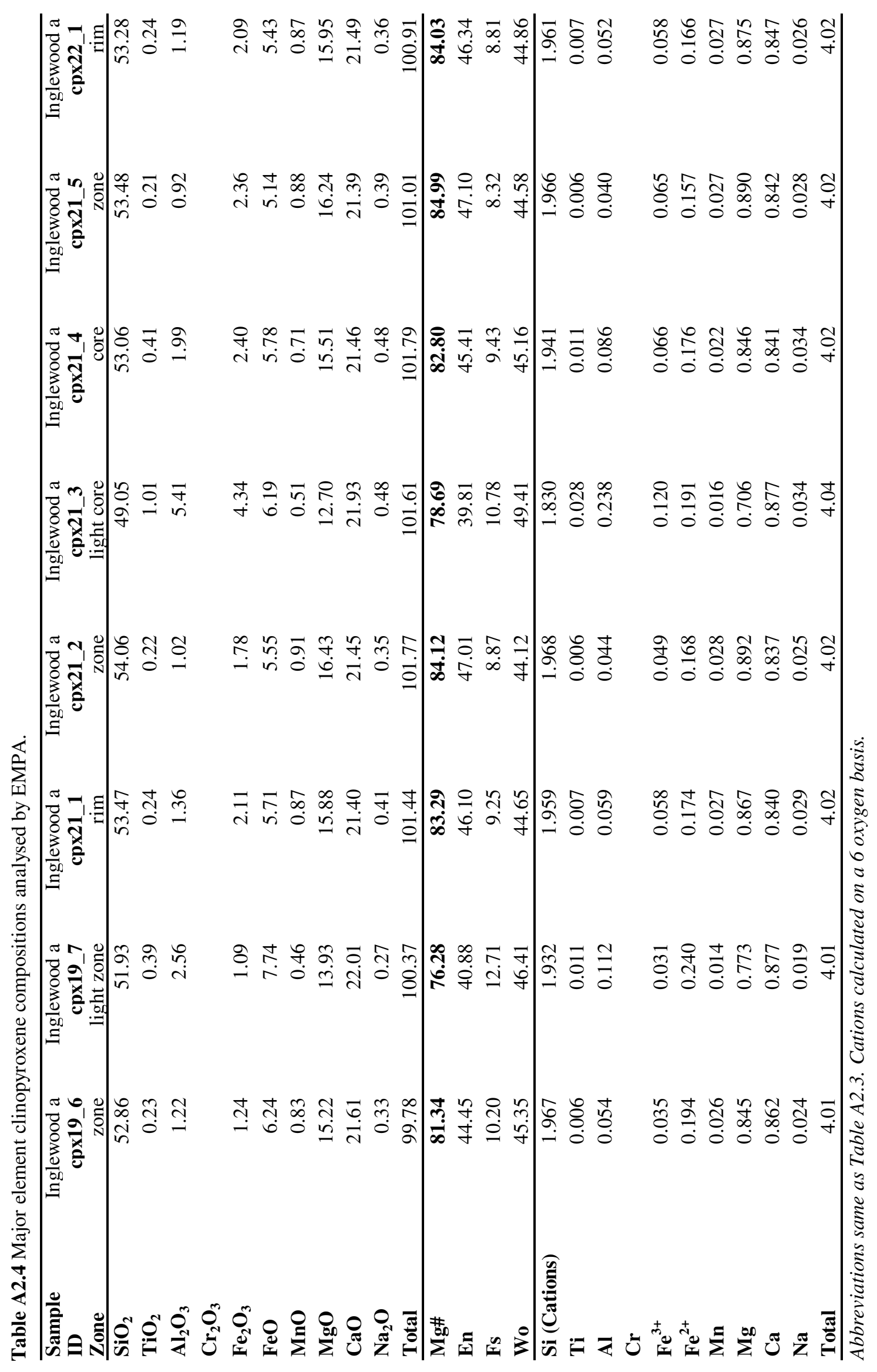




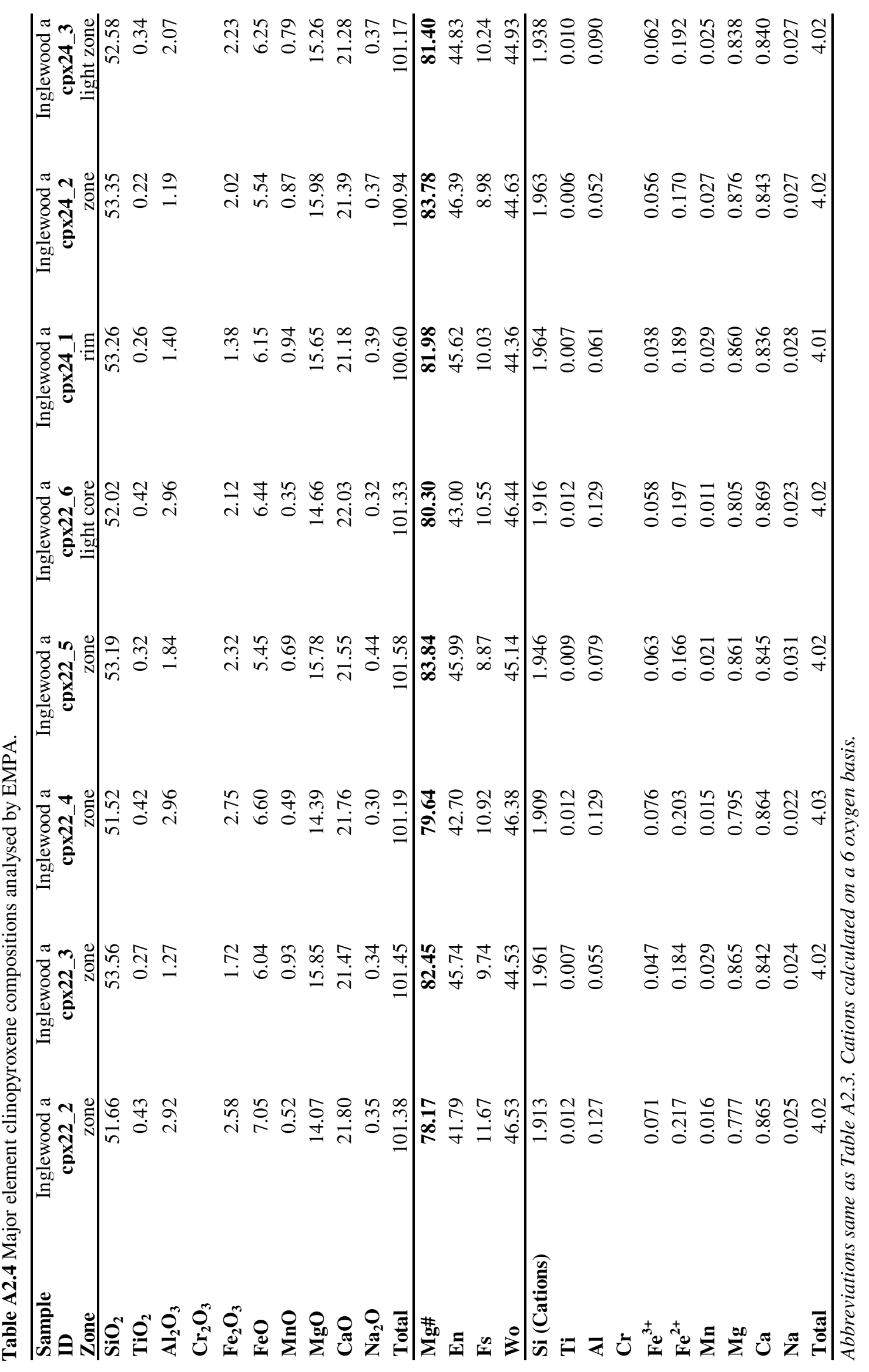




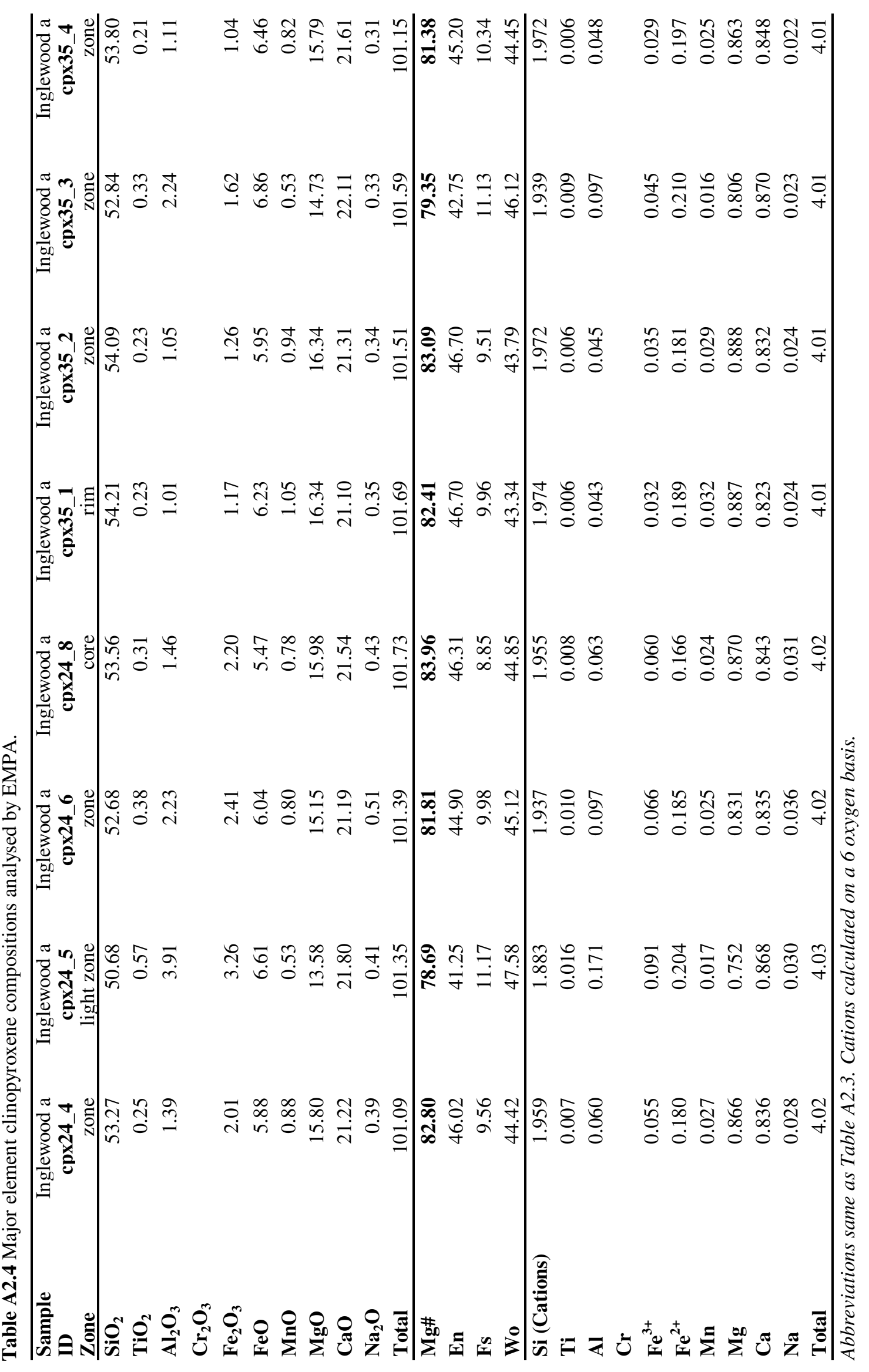




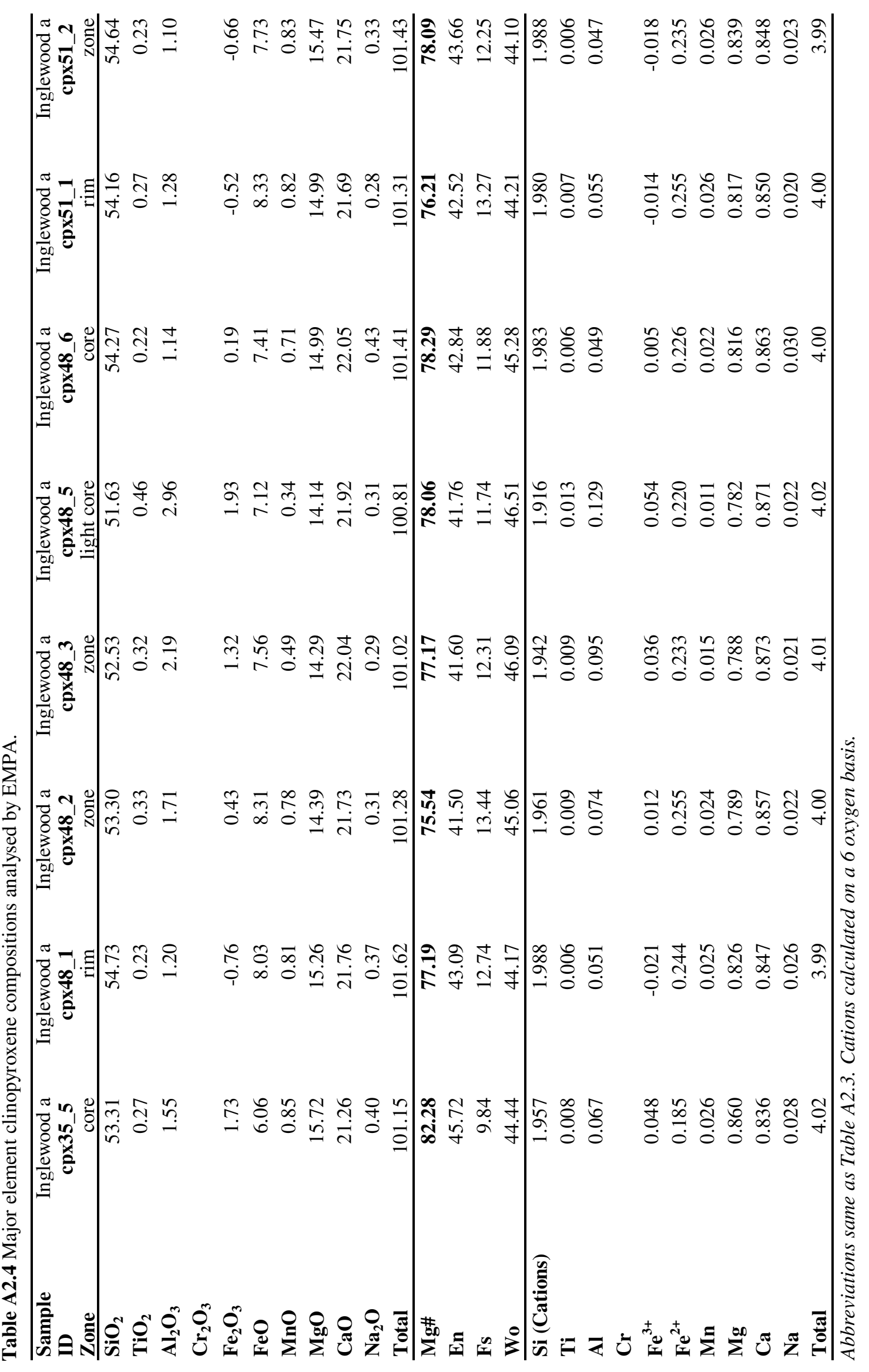

A.131 


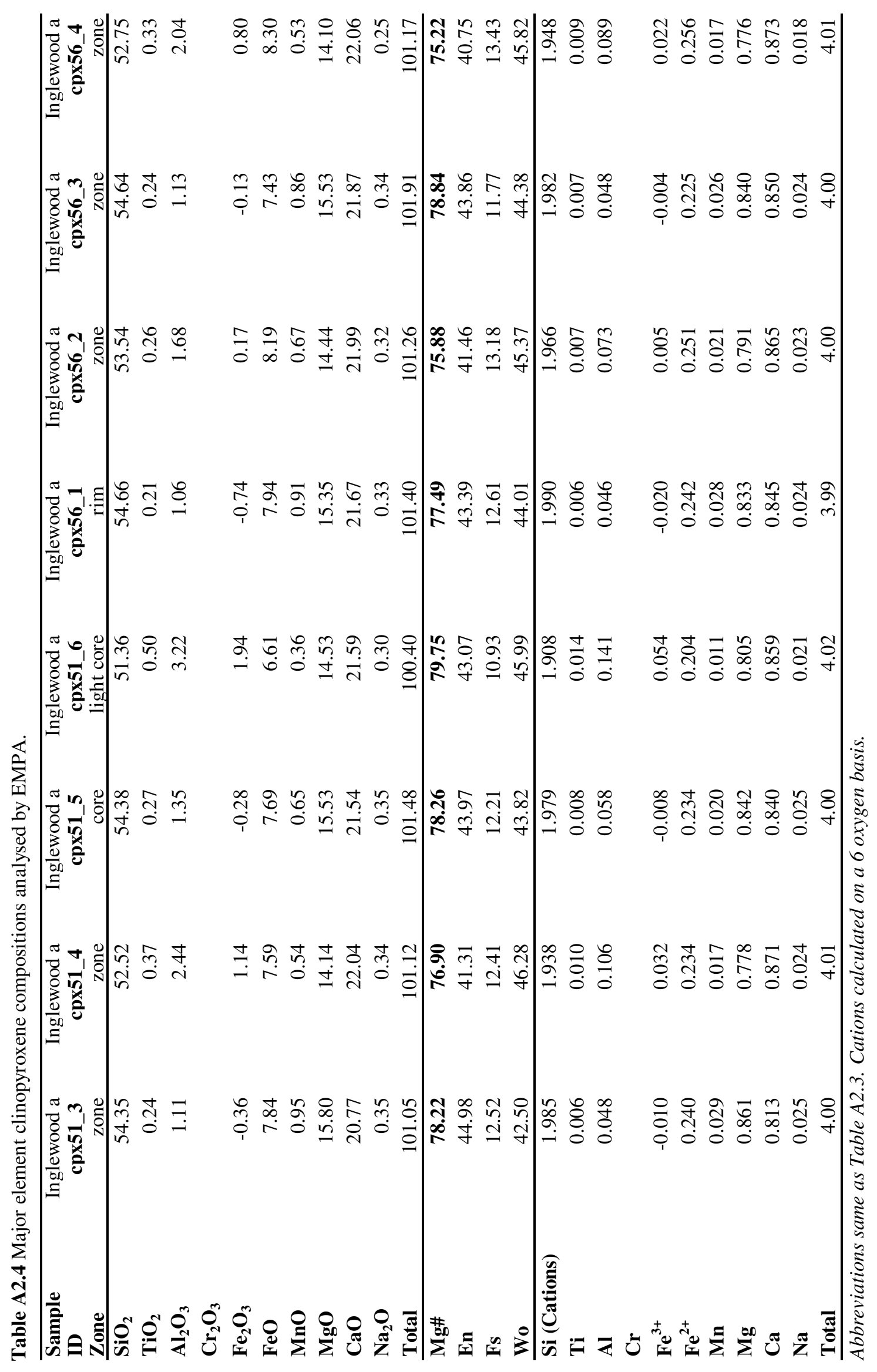

A. 132 


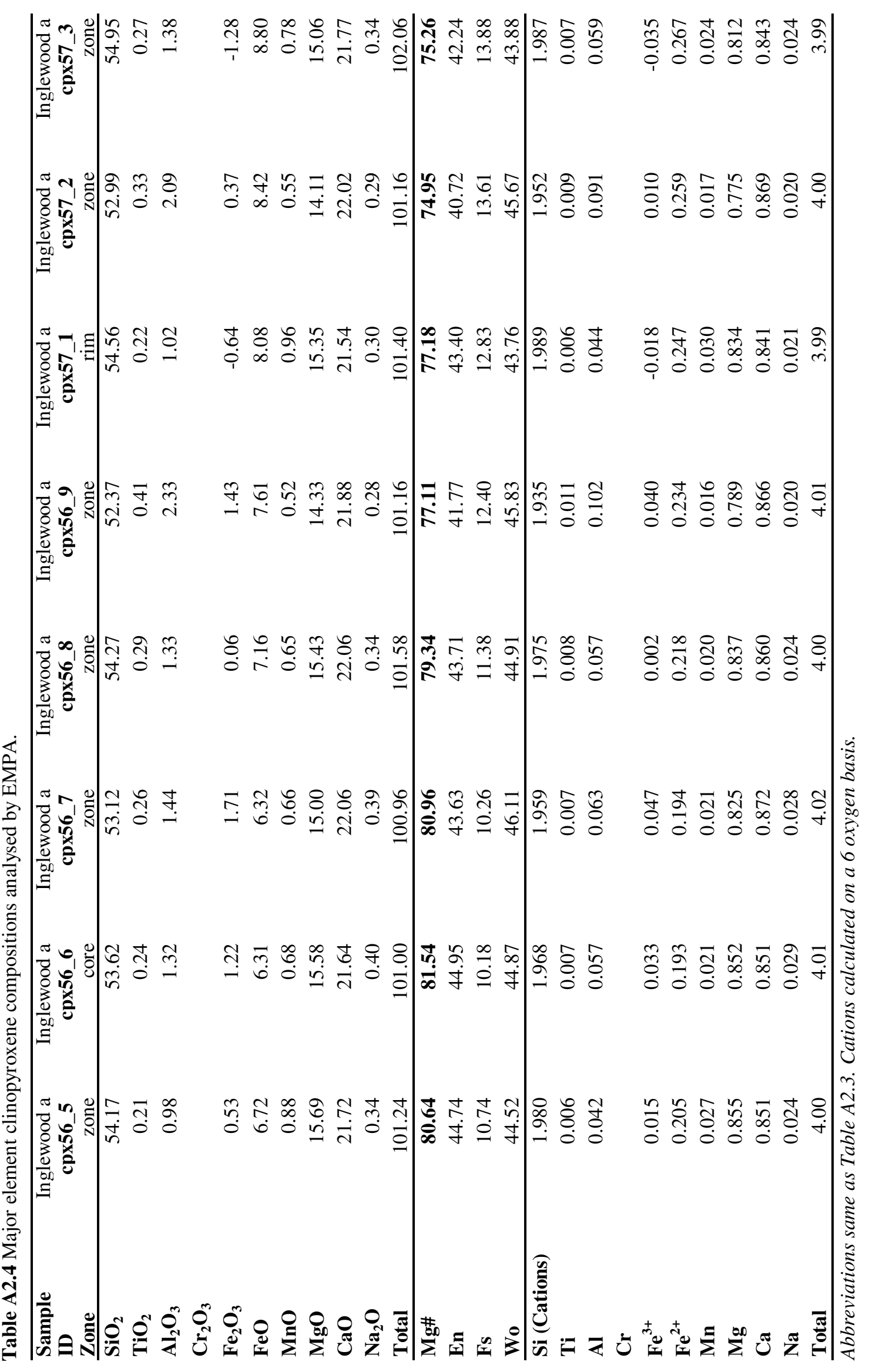




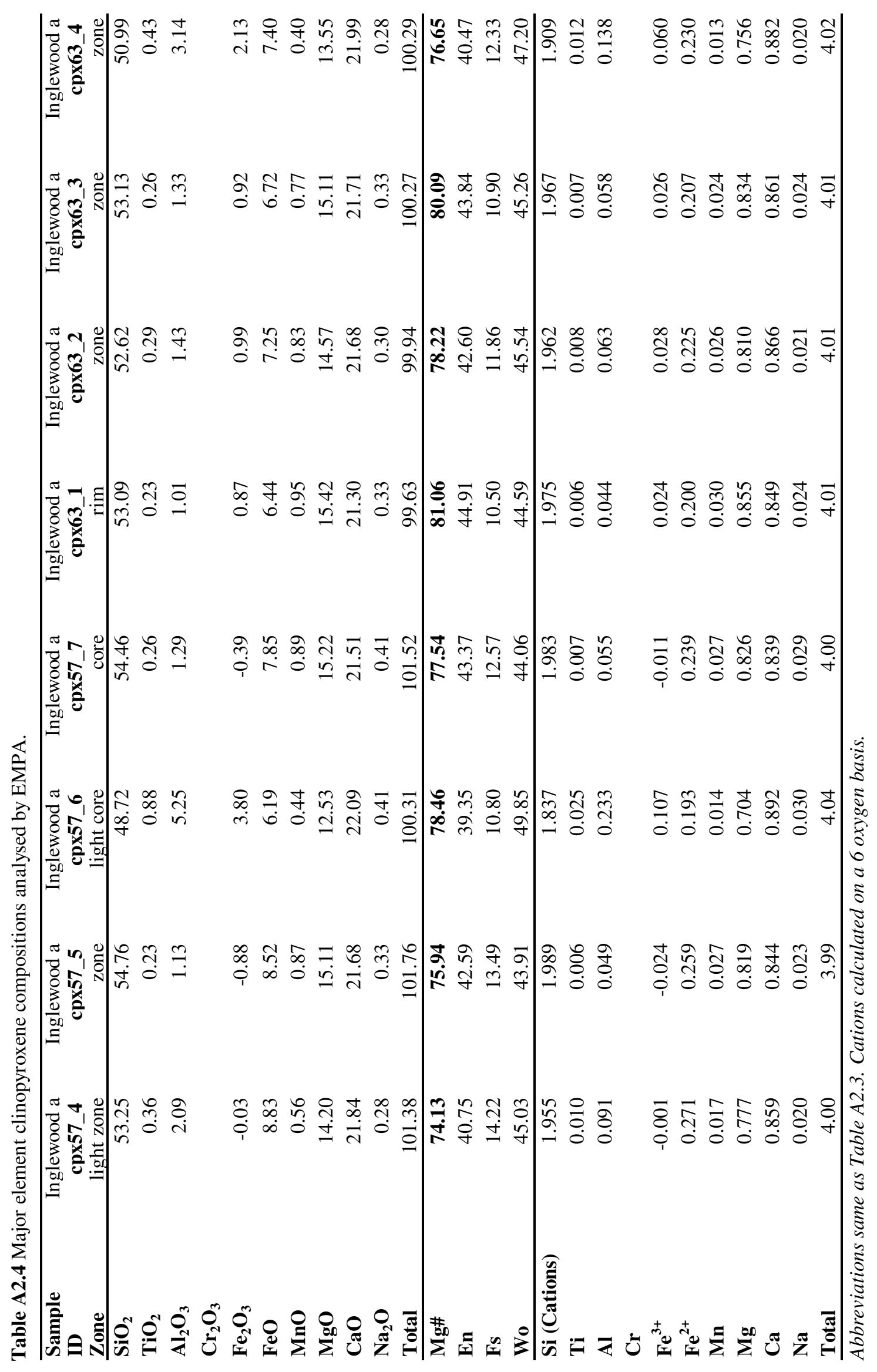




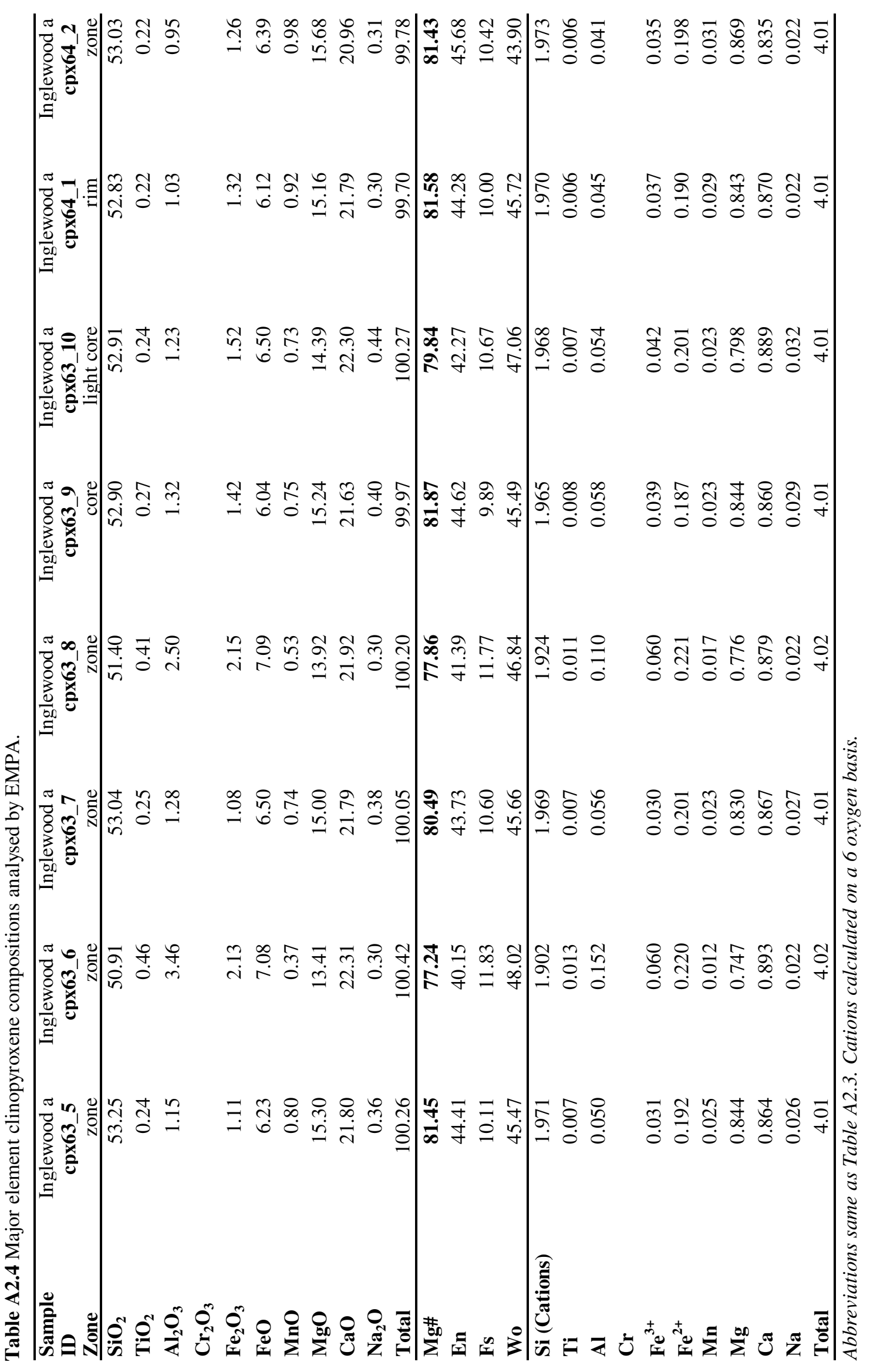




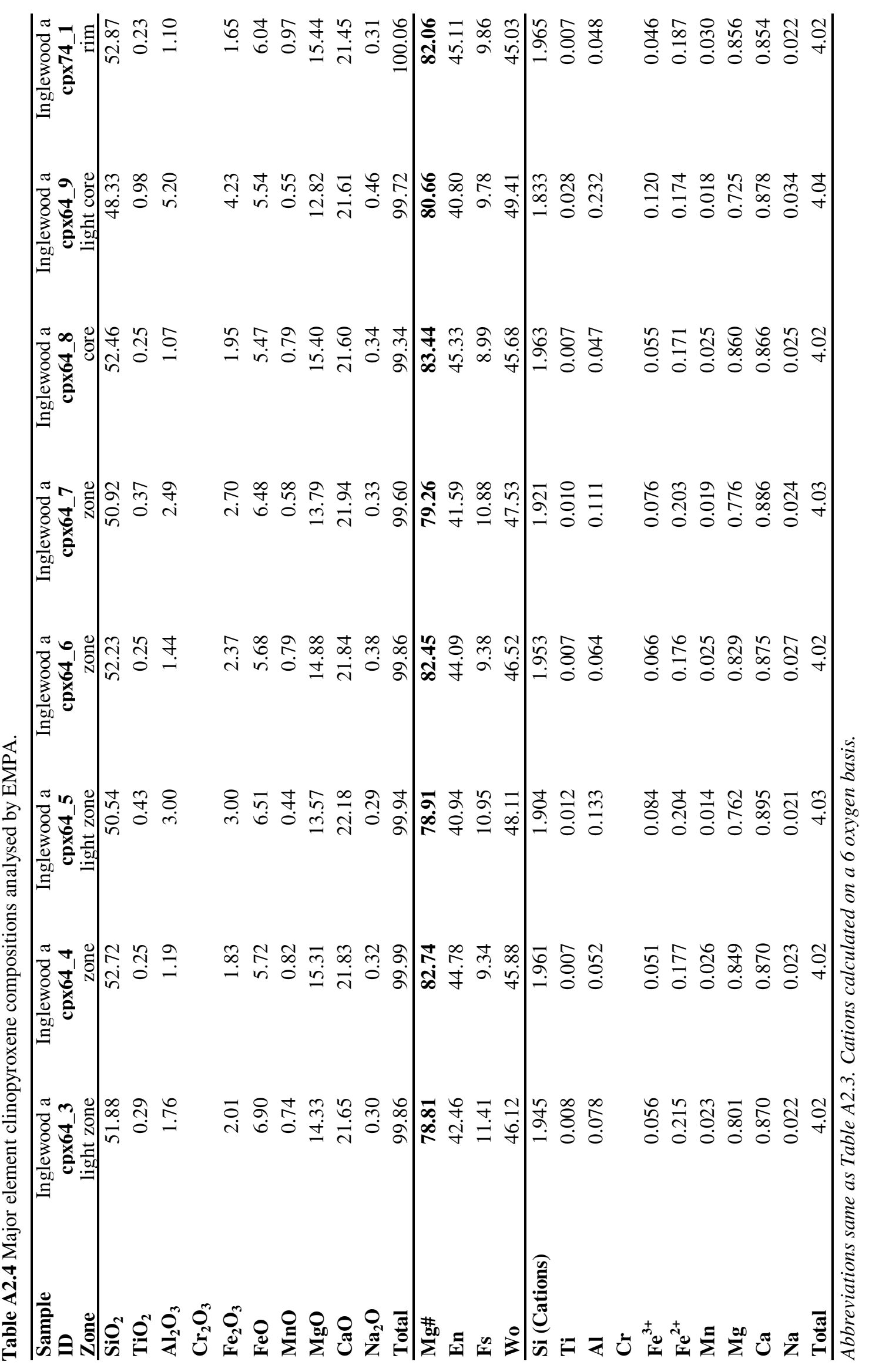




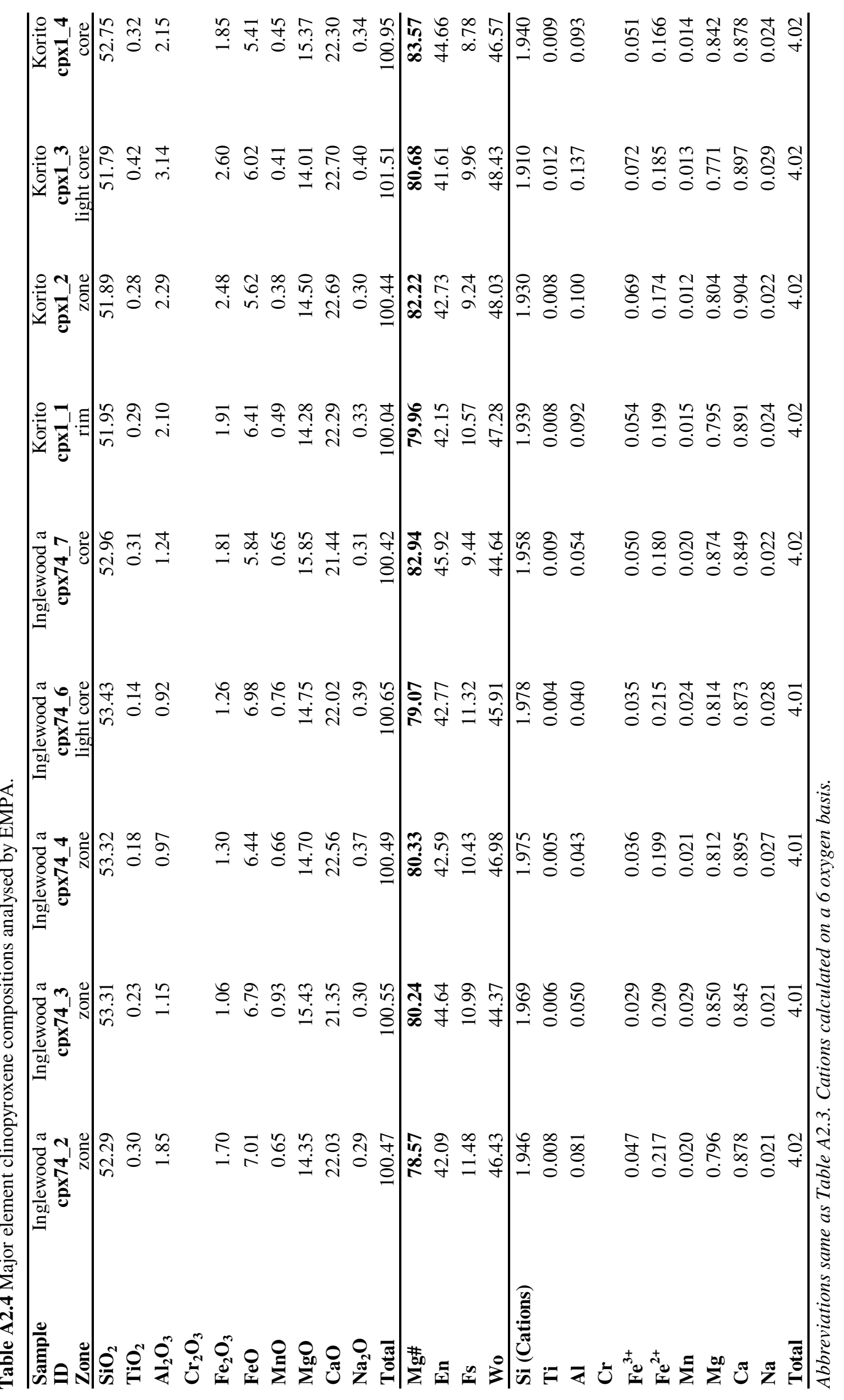




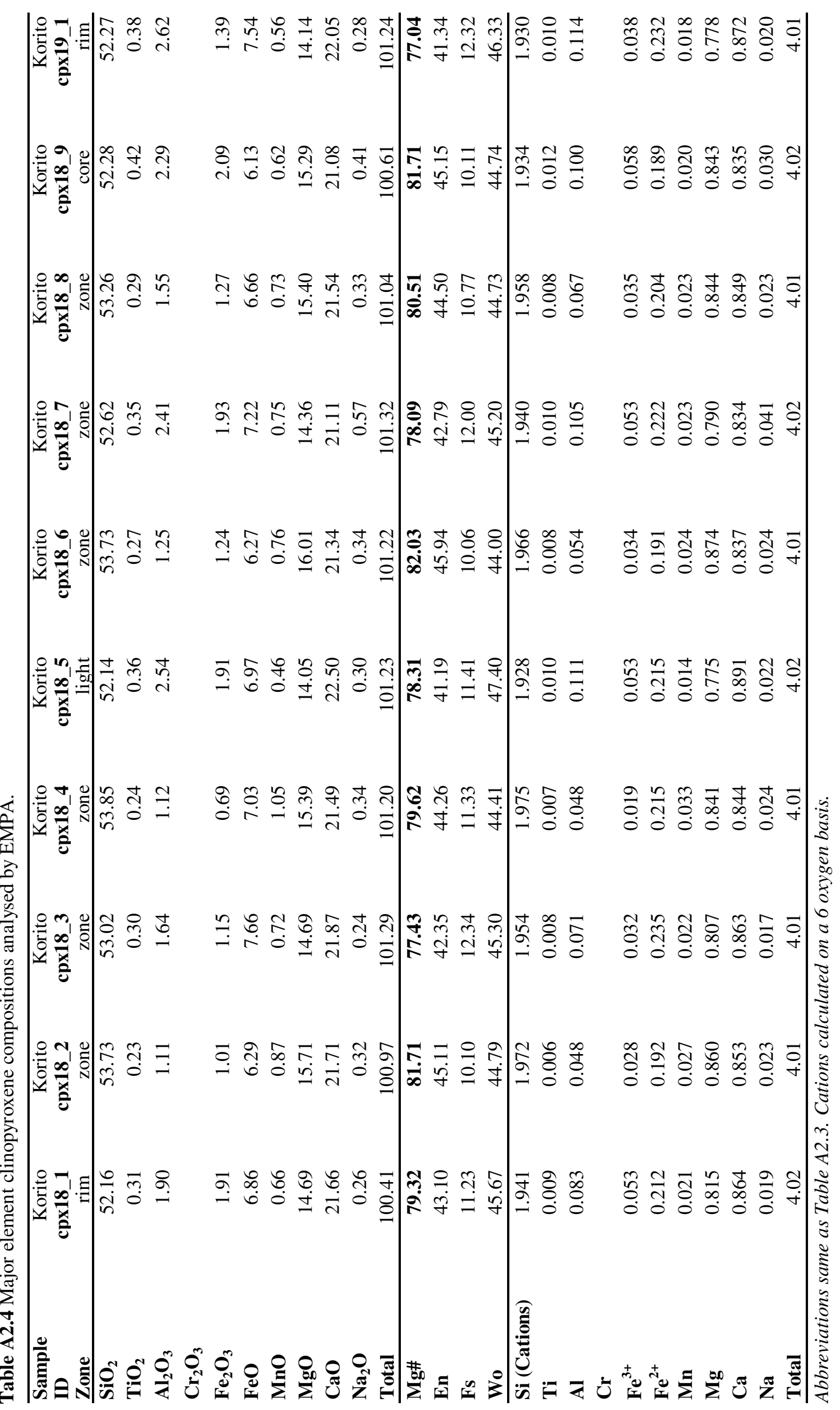




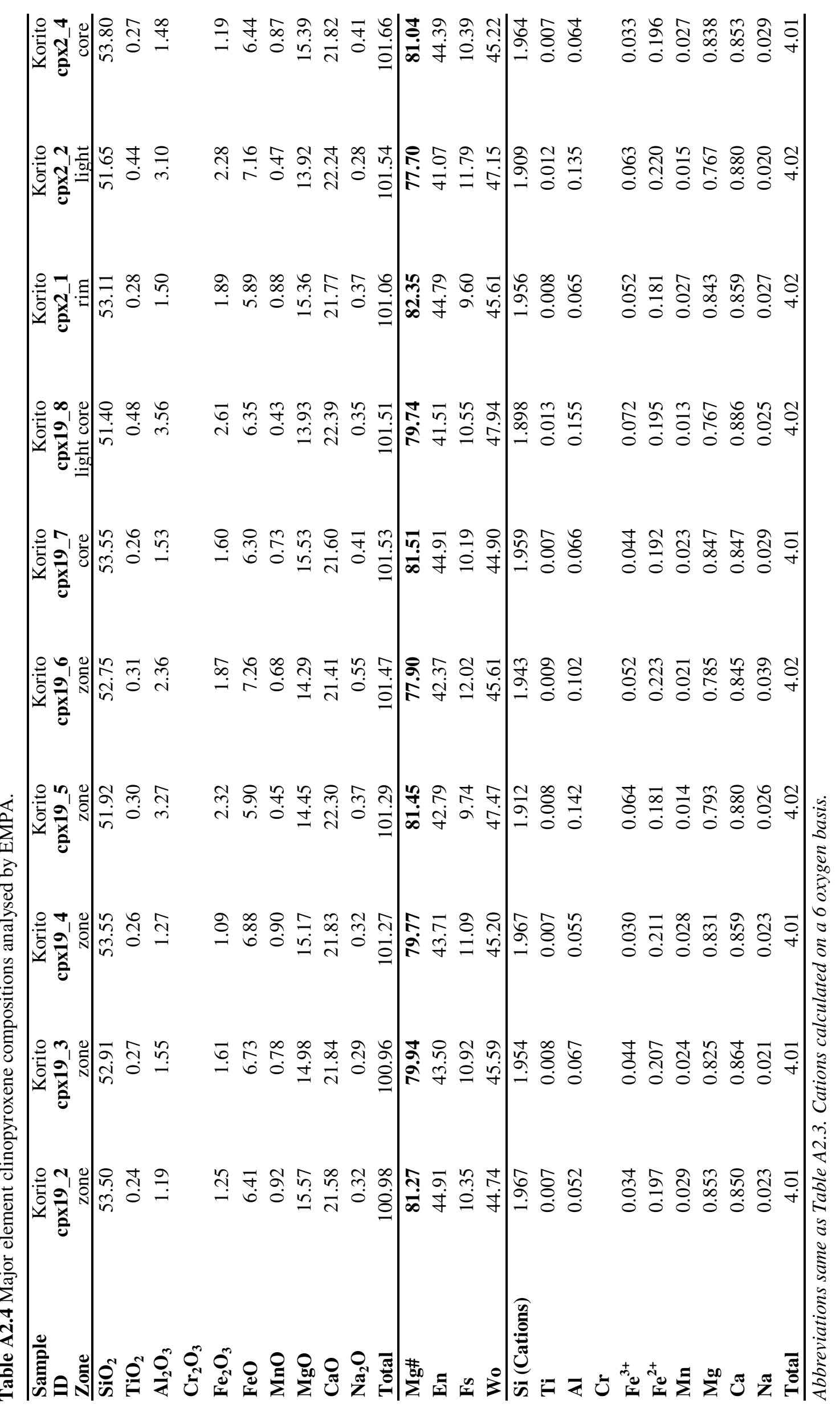




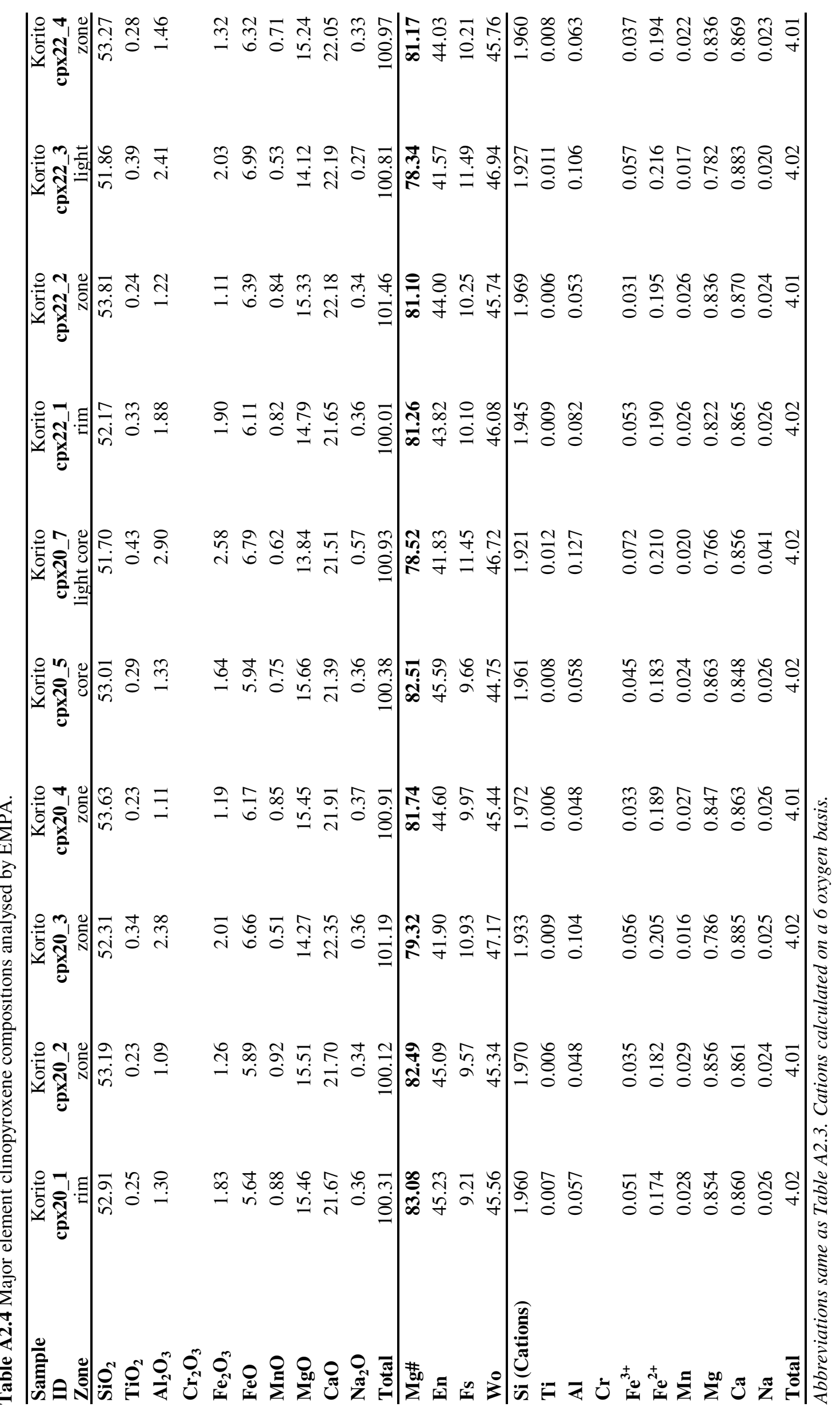




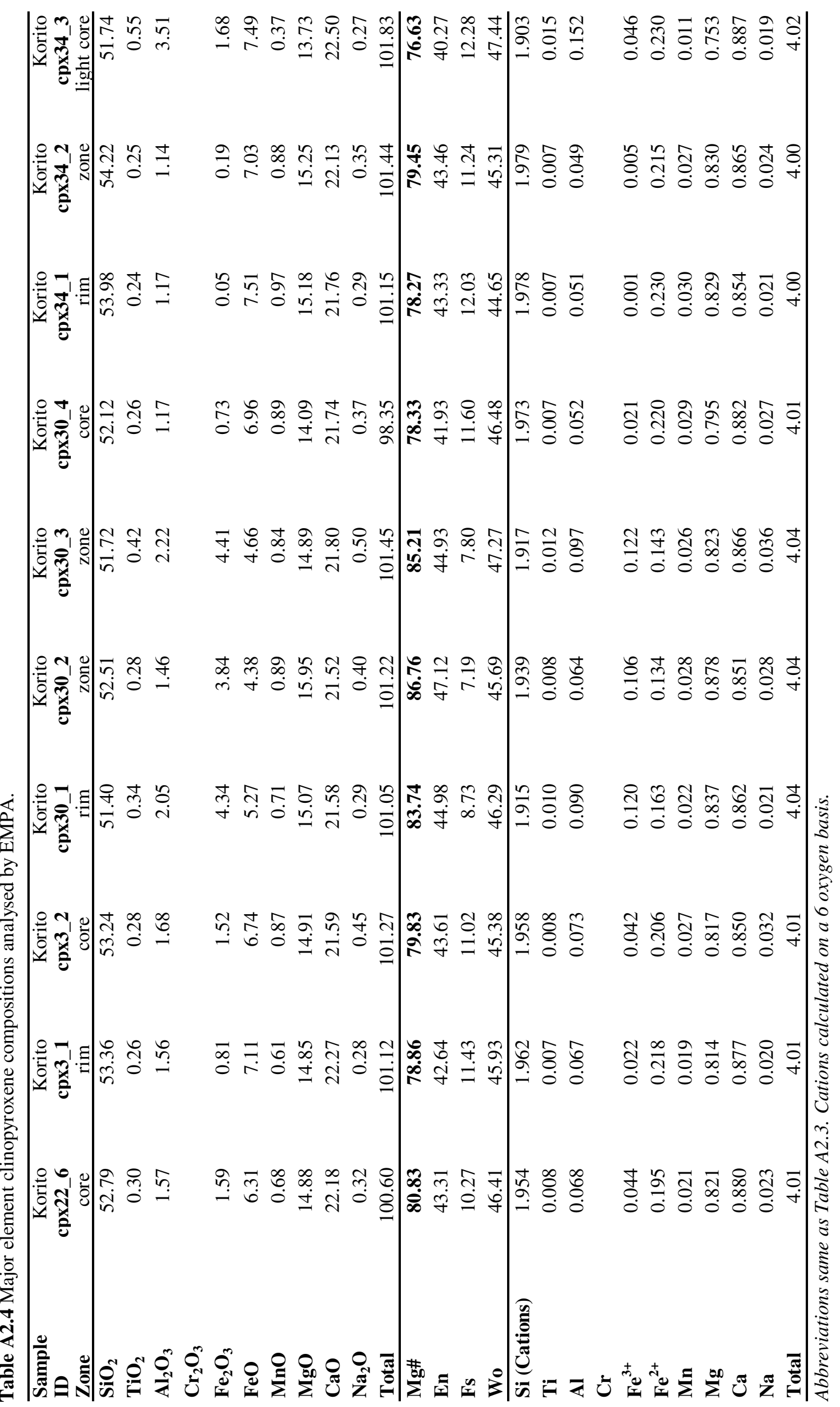




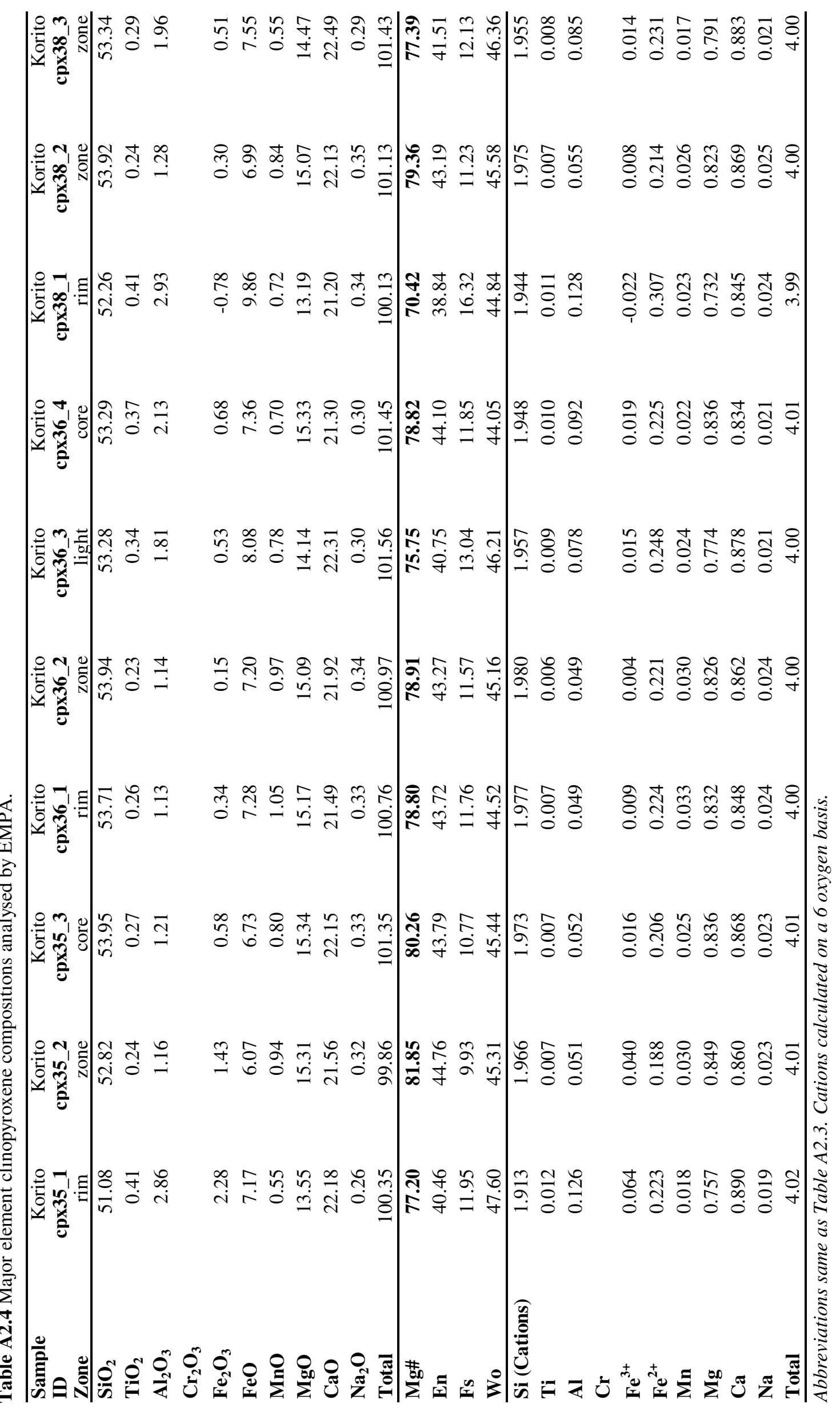




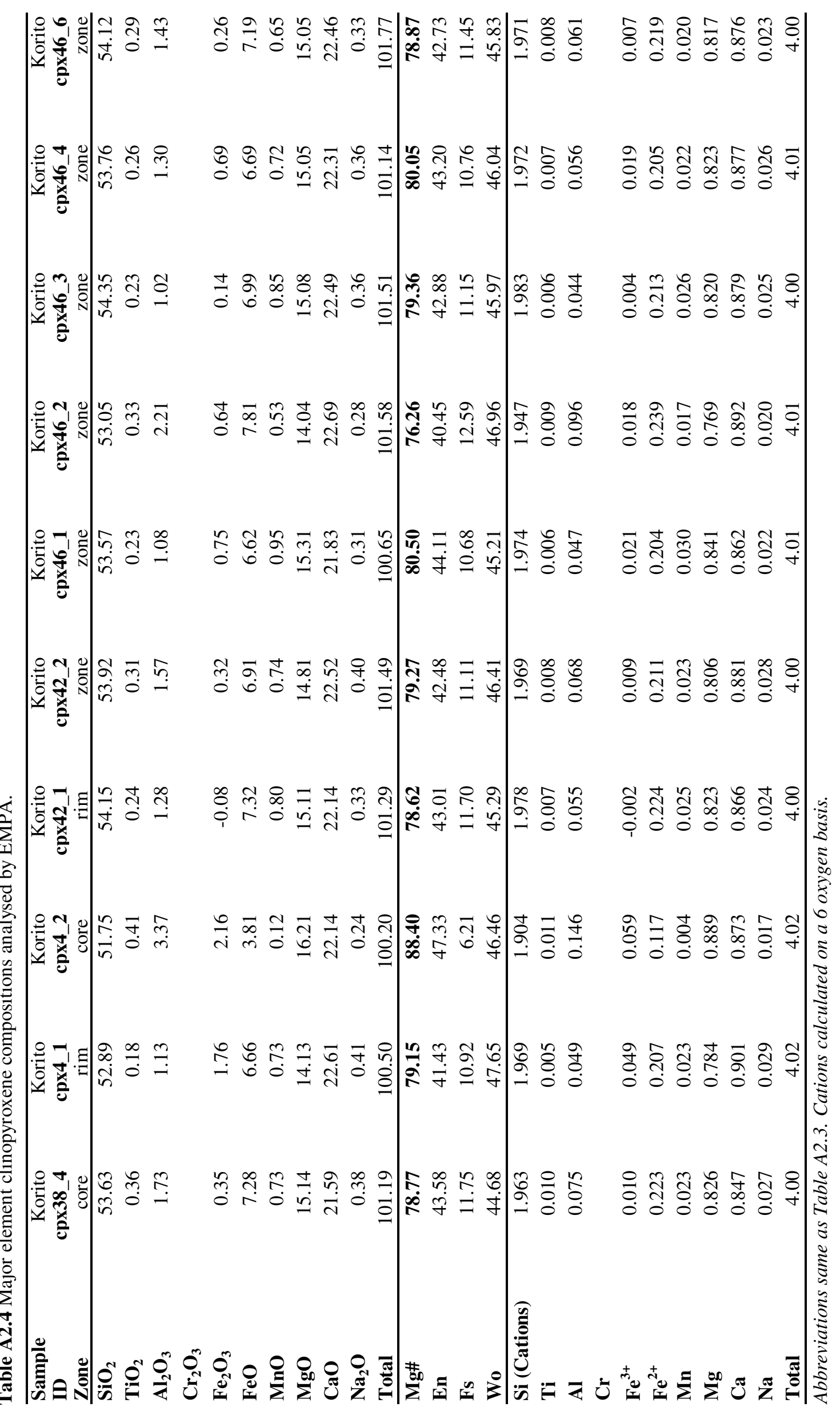




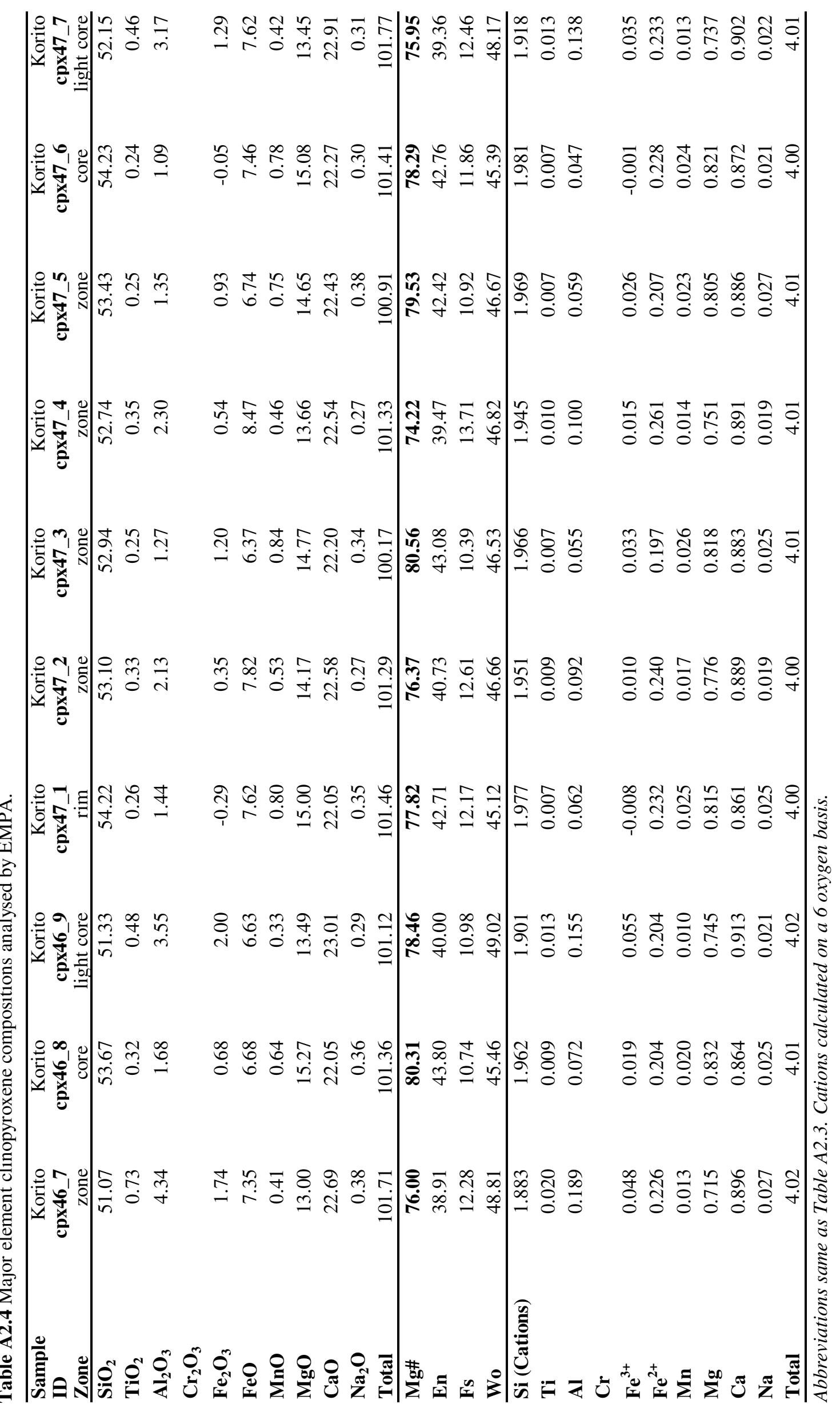




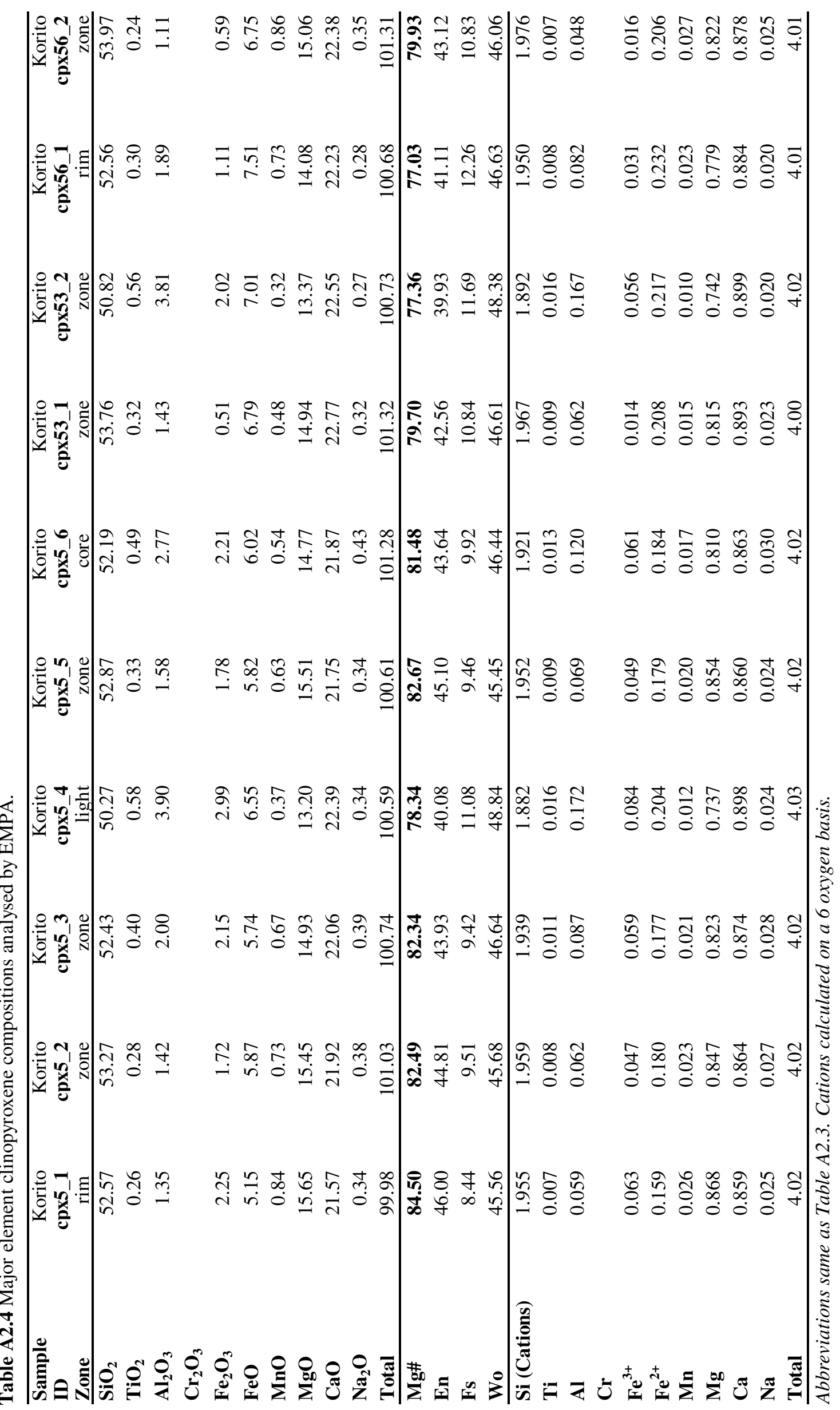




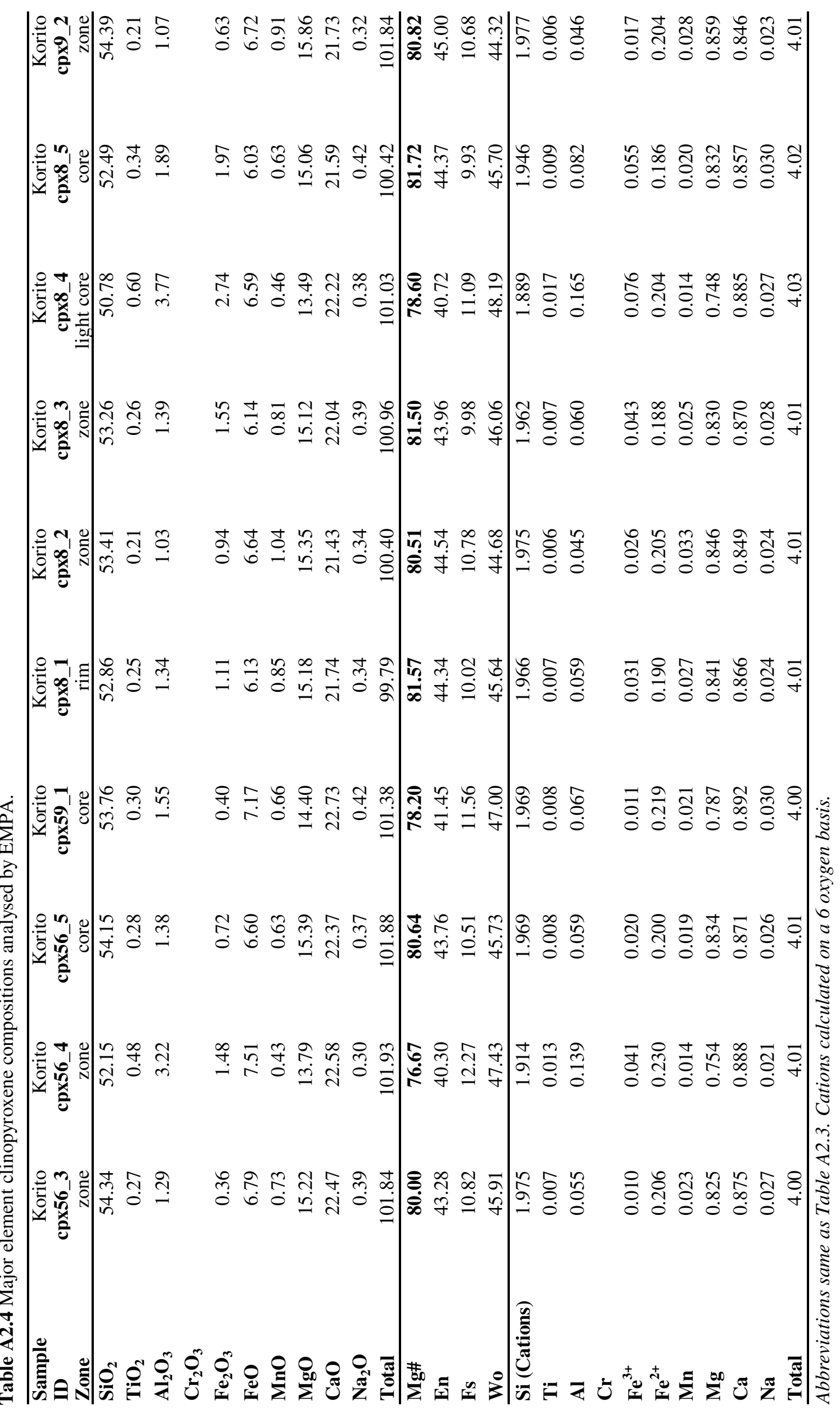




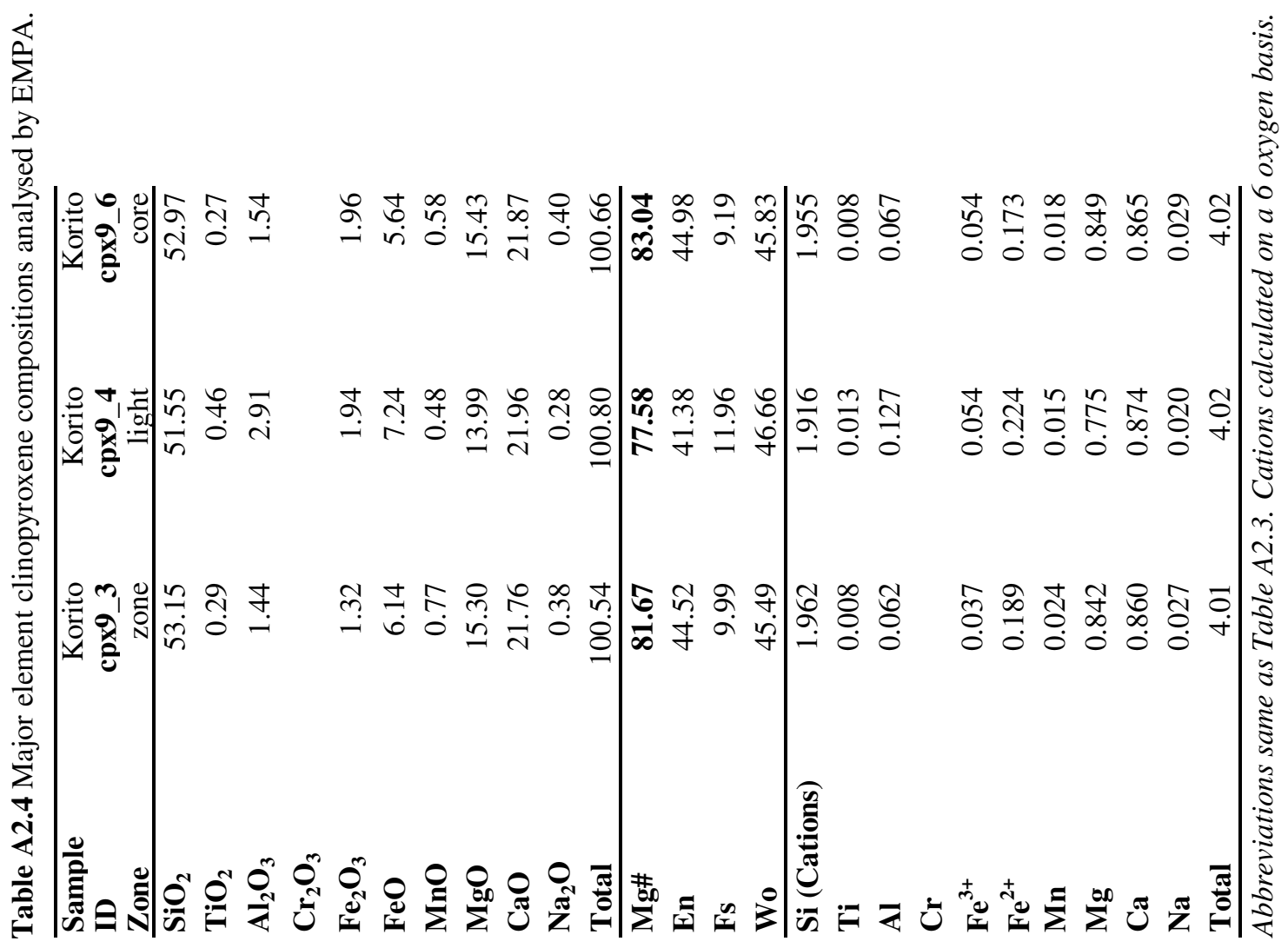




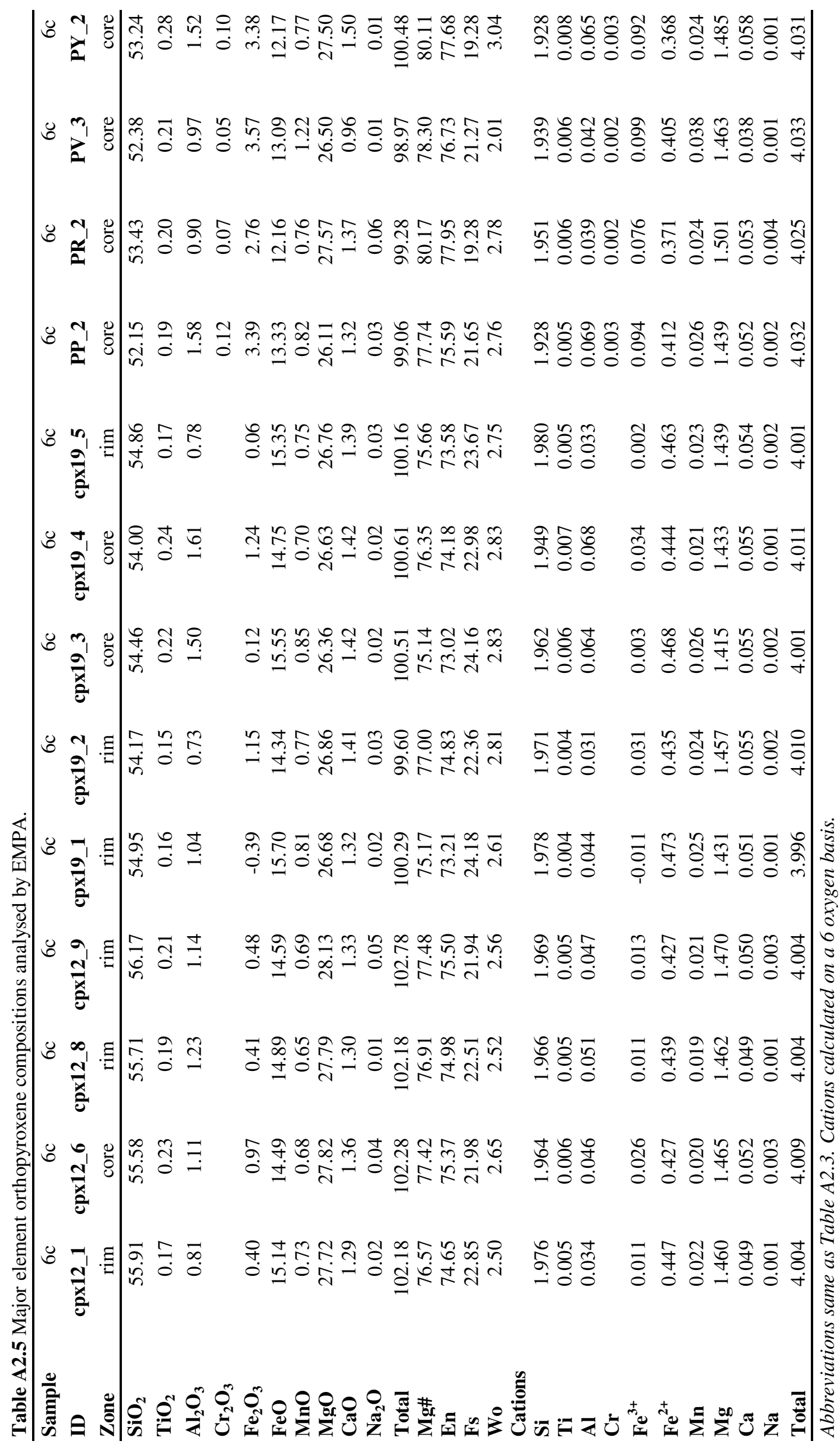


Table A2.6 Major element amphibole compositions analysed by EMPA.

\begin{tabular}{|c|c|c|c|c|c|}
\hline $\begin{array}{l}\text { Sample } \\
\text { ID } \\
\text { Zone }\end{array}$ & $\begin{array}{c}\text { Kaupokonui } \\
\text { A1_1 } \\
\text { rim }\end{array}$ & $\begin{array}{r}\text { Kaupokonui } \\
\text { A1_2 } \\
\text { zone }\end{array}$ & $\begin{array}{r}\text { Kaupokonui } \\
\text { A1_4 } \\
\text { core }\end{array}$ & $\begin{array}{r}\text { Kaupokonui } \\
\text { A3_1 } \\
\text { rim }\end{array}$ & $\begin{array}{r}\text { Kaupokonui } \\
\text { A3_2 } \\
\text { zone }\end{array}$ \\
\hline$\overline{\mathrm{SiO}_{2}}$ & 43.37 & 41.15 & 41.77 & 41.67 & 40.33 \\
\hline $\mathrm{TiO}_{2}$ & 2.51 & 2.06 & 1.84 & 2.63 & 2.53 \\
\hline $\mathrm{Al}_{2} \mathbf{O}_{3}$ & 10.52 & 12.50 & 12.70 & 11.38 & 12.59 \\
\hline $\mathrm{Fe}_{2} \mathrm{O}_{3}$ & 5.49 & 7.95 & 2.62 & 6.08 & 5.68 \\
\hline $\mathrm{FeO}$ & 6.04 & 4.44 & 7.79 & 5.87 & 7.26 \\
\hline MnO & 0.30 & 0.16 & 0.15 & 0.27 & 0.17 \\
\hline MgO & 14.48 & 14.21 & 14.90 & 14.42 & 13.49 \\
\hline $\mathrm{CaO}$ & 11.23 & 11.67 & 13.37 & 11.76 & 12.12 \\
\hline $\mathrm{Na}_{2} \mathrm{O}$ & 2.03 & 1.93 & 1.98 & 2.02 & 2.06 \\
\hline $\mathbf{K}_{2} \mathbf{O}$ & 1.08 & 0.94 & 0.86 & 1.11 & 1.06 \\
\hline $\mathbf{H}_{2} \mathbf{O}_{\text {calc }}$ & 1.90 & 1.89 & 1.92 & 1.89 & 1.88 \\
\hline Total & 98.97 & 98.90 & 99.89 & 99.10 & 99.16 \\
\hline Mg\# & 81.03 & 85.09 & 77.33 & 81.40 & 76.81 \\
\hline \multicolumn{6}{|l|}{ Cations } \\
\hline $\mathbf{S i}$ & 6.357 & 6.048 & 6.106 & 6.137 & 5.980 \\
\hline $\mathbf{T i}$ & 0.276 & 0.228 & 0.202 & 0.291 & 0.282 \\
\hline Al & 1.818 & 2.165 & 2.188 & 1.975 & 2.201 \\
\hline $\mathrm{Fe}^{3+}$ & 0.606 & 0.880 & 0.288 & 0.674 & 0.634 \\
\hline $\mathrm{Fe}^{2+}$ & 0.741 & 0.546 & 0.952 & 0.723 & 0.900 \\
\hline Mn & 0.037 & 0.019 & 0.018 & 0.033 & 0.021 \\
\hline Mg & 3.164 & 3.114 & 3.246 & 3.167 & 2.981 \\
\hline $\mathbf{C a}$ & 1.764 & 1.839 & 2.094 & 1.855 & 1.925 \\
\hline $\mathbf{N a}$ & 0.578 & 0.551 & 0.560 & 0.578 & 0.591 \\
\hline $\mathbf{K}$ & 0.203 & 0.176 & 0.160 & 0.208 & 0.200 \\
\hline Total & 15.54 & 15.57 & 15.81 & 15.64 & 15.72 \\
\hline \multicolumn{6}{|l|}{ P-C conditions } \\
\hline $\mathbf{T}\left({ }^{\circ} \mathbf{C}\right)$ & 928 & 983 & 1011 & 970 & 1002 \\
\hline Uncertanty & 22 & 22 & 22 & 22 & 22 \\
\hline P (MPa) & 262 & 432 & 447 & 329 & 455 \\
\hline Uncertanty & 29 & 48 & 49 & 36 & 50 \\
\hline $\begin{array}{l}\text { Equivalent depth } \\
(\mathbf{k m})\end{array}$ & 9.9 & 16.3 & 16.9 & 12.4 & 17.2 \\
\hline$\triangle \mathbf{N N O}$ & 1.03 & 1.05 & 0.96 & 0.95 & 0.62 \\
\hline $\log \mathrm{fO}_{2}$ & -10.35 & -9.37 & -9.05 & -9.72 & -9.51 \\
\hline Uncertanty & 0.4 & 0.4 & 0.4 & 0.4 & 0.4 \\
\hline $\mathrm{H}_{2} \mathrm{O}_{\text {melt }}$ (wt.\%) & 4.1 & 5.7 & 6.0 & 4.2 & 5.3 \\
\hline Uncertanty & 0.6 & 0.8 & 0.9 & 0.6 & 0.8 \\
\hline
\end{tabular}

Cation proportions calculated using Leake et al. (1997) on the basis of 13 cations. $P-C=$ Physicalchemical conditions, calculated using the method of Ridolfi et al. (2010). 
Table A2.6 Major element amphibole compositions analysed by EMPA.

\begin{tabular}{|c|c|c|c|c|c|}
\hline $\begin{array}{l}\text { Sample } \\
\text { ID } \\
\text { Zone }\end{array}$ & $\begin{array}{r}\text { Kaupokonui } \\
\text { A3_3 } \\
\text { core }\end{array}$ & $\begin{array}{r}\text { Kaupokonui } \\
\text { A3_5 } \\
\text { core }\end{array}$ & $\begin{array}{c}\text { Kaupokonui } \\
\text { A4__2 } \\
\text { rim }\end{array}$ & $\begin{array}{c}\text { Kaupokonui } \\
\text { A4_7 } \\
\text { zone }\end{array}$ & $\begin{array}{r}\text { Kaupokonui } \\
\text { A5_1 } \\
\text { rim }\end{array}$ \\
\hline$\overline{\mathrm{SiO}_{2}}$ & 40.74 & 40.01 & 42.71 & 41.21 & 40.38 \\
\hline $\mathrm{TiO}_{2}$ & 2.10 & 2.07 & 2.88 & 2.34 & 2.31 \\
\hline $\mathrm{Al}_{2} \mathbf{O}_{3}$ & 13.07 & 13.16 & 11.53 & 13.04 & 11.90 \\
\hline $\mathrm{Fe}_{2} \mathrm{O}_{3}$ & 7.94 & 6.41 & 4.21 & 5.50 & 4.52 \\
\hline $\mathrm{FeO}$ & 3.80 & 6.37 & 7.67 & 6.93 & 9.75 \\
\hline $\mathrm{MnO}$ & 0.13 & 0.23 & 0.27 & 0.22 & 0.30 \\
\hline MgO & 14.80 & 13.51 & 13.78 & 13.17 & 12.09 \\
\hline $\mathrm{CaO}$ & 11.92 & 11.98 & 11.45 & 11.52 & 11.88 \\
\hline $\mathrm{Na}_{2} \mathrm{O}$ & 2.17 & 2.16 & 2.13 & 2.06 & 1.94 \\
\hline $\mathrm{K}_{2} \mathrm{O}$ & 0.96 & 1.09 & 1.14 & 1.10 & 1.09 \\
\hline $\mathbf{H}_{2} \mathbf{O}_{\text {calc }}$ & 1.90 & 1.88 & 1.91 & 1.89 & 1.85 \\
\hline Total & 99.55 & 98.88 & 99.70 & 98.98 & 98.03 \\
\hline Mg\# & 87.40 & 79.07 & 76.20 & 77.20 & 68.86 \\
\hline \multicolumn{6}{|l|}{ Cations } \\
\hline $\mathbf{S i}$ & 5.947 & 5.940 & 6.252 & 6.081 & 6.105 \\
\hline $\mathbf{T i}$ & 0.230 & 0.231 & 0.317 & 0.260 & 0.263 \\
\hline Al & 2.248 & 2.303 & 1.988 & 2.267 & 2.120 \\
\hline $\mathrm{Fe}^{3+}$ & 0.873 & 0.717 & 0.464 & 0.611 & 0.514 \\
\hline $\mathrm{Fe}^{2+}$ & 0.464 & 0.791 & 0.939 & 0.856 & 1.233 \\
\hline Mn & 0.016 & 0.029 & 0.034 & 0.028 & 0.039 \\
\hline Mg & 3.221 & 2.990 & 3.006 & 2.898 & 2.726 \\
\hline $\mathbf{C a}$ & 1.865 & 1.906 & 1.796 & 1.822 & 1.925 \\
\hline $\mathbf{N a}$ & 0.615 & 0.622 & 0.605 & 0.589 & 0.568 \\
\hline $\mathbf{K}$ & 0.179 & 0.207 & 0.213 & 0.207 & 0.211 \\
\hline Total & 15.66 & 15.73 & 15.61 & 15.62 & 15.70 \\
\hline \multicolumn{6}{|l|}{ P-C conditions } \\
\hline $\mathbf{T}\left({ }^{\circ} \mathbf{C}\right)$ & 1009 & 1011 & 953 & 985 & 974 \\
\hline Uncertanty & 22 & 22 & 22 & 22 & 22 \\
\hline P (MPa) & 487 & 527 & 335 & 501 & 405 \\
\hline Uncertanty & 54 & 58 & 37 & 55 & 45 \\
\hline $\begin{array}{l}\text { Equivalent depth } \\
(\mathbf{k m})\end{array}$ & 18.4 & 19.9 & 12.7 & 18.9 & 15.3 \\
\hline$\triangle \mathbf{N N O}$ & 1.12 & 0.72 & 0.62 & 0.56 & 0.30 \\
\hline $\log \mathrm{fO}_{2}$ & -8.90 & -9.24 & -10.32 & -9.80 & -10.28 \\
\hline Uncertanty & 0.4 & 0.4 & 0.4 & 0.4 & 0.4 \\
\hline $\mathrm{H}_{2} \mathrm{O}_{\text {melt }}$ (wt.\%) & 5.4 & 5.6 & 4.7 & 6.1 & 5.5 \\
\hline Uncertanty & 0.8 & 0.8 & 0.7 & 0.9 & 0.8 \\
\hline
\end{tabular}

Cation proportions calculated using Leake et al. (1997) on the basis of 13 cations. $P-C=$ Physicalchemical conditions, calculated using the method of Ridolfi et al. (2010). 
Table A2.6 Major element amphibole compositions analysed by EMPA.

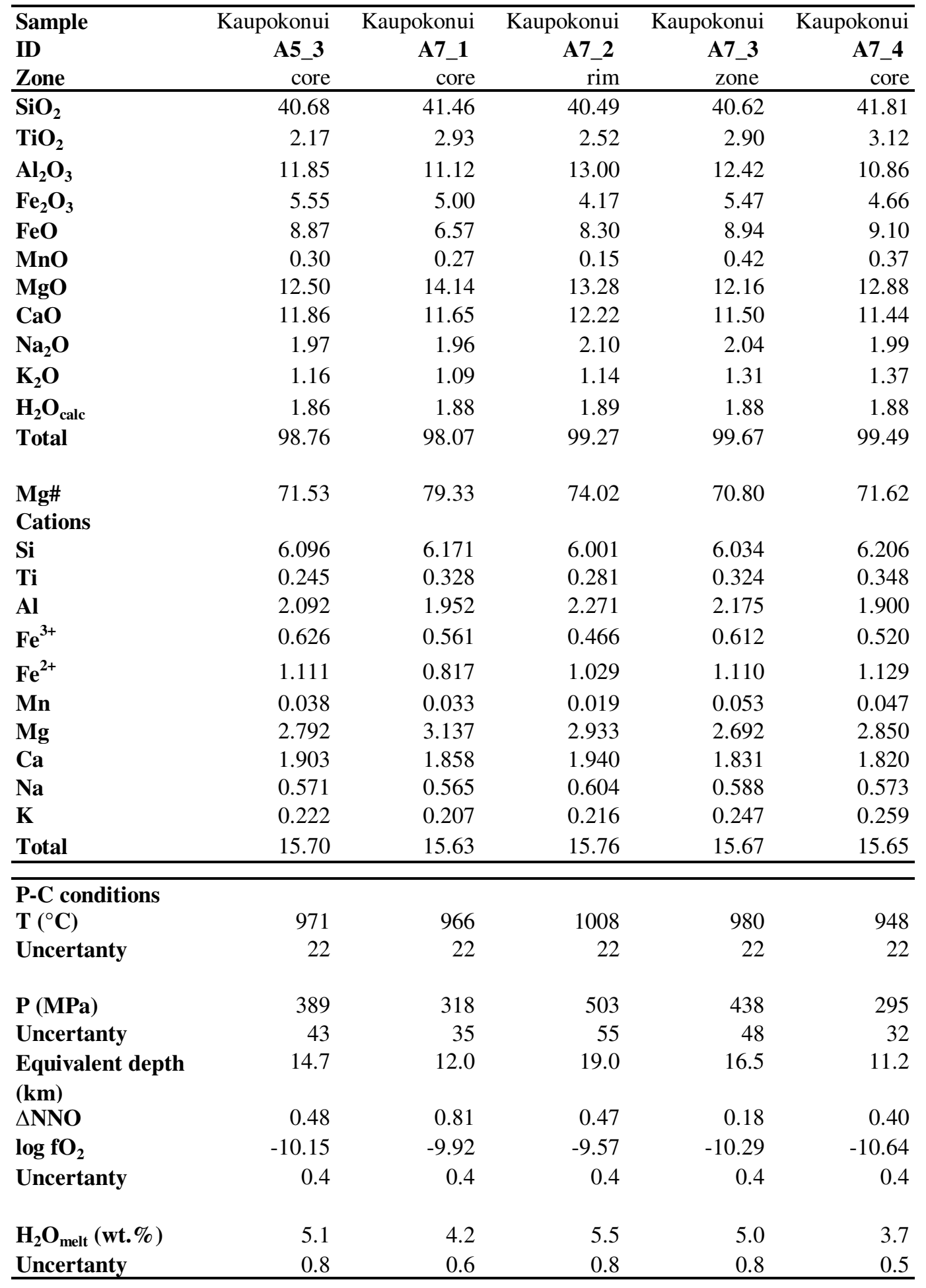

Cation proportions calculated using Leake et al. (1997) on the basis of 13 cations. $P-C=$ Physicalchemical conditions, calculated using the method of Ridolfi et al. (2010). 
Table A2.6 Major element amphibole compositions analysed by EMPA.

\begin{tabular}{|c|c|c|c|c|c|}
\hline Sample & Kaupokonui & Kaupokonui & Kaupokonui & Kaupokonui & Kaupokonui \\
\hline $\begin{array}{l}\text { ID } \\
\text { Zone }\end{array}$ & $\begin{array}{r}\text { A9_3 } \\
\text { rim }\end{array}$ & $\begin{array}{r}\text { A9_4 } \\
\text { zone }\end{array}$ & $\begin{array}{r}\text { A9_5 } \\
\text { zone }\end{array}$ & $\begin{array}{r}\text { A9_6 } \\
\text { core }\end{array}$ & $\underset{\text { rim }}{\text { A10_1 }}$ \\
\hline$\overline{\mathrm{SiO}_{2}}$ & 39.81 & 40.47 & 39.66 & 40.50 & 41.06 \\
\hline $\mathrm{TiO}_{2}$ & 2.41 & 3.01 & 2.66 & 2.54 & 2.94 \\
\hline $\mathrm{Al}_{2} \mathbf{O}_{3}$ & 13.26 & 11.31 & 12.62 & 11.75 & 11.28 \\
\hline $\mathrm{Fe}_{2} \mathrm{O}_{3}$ & 5.81 & 4.55 & 5.16 & 4.19 & 5.37 \\
\hline $\mathrm{FeO}$ & 6.93 & 9.81 & 8.95 & 9.19 & 6.46 \\
\hline MnO & 0.16 & 0.41 & 0.32 & 0.26 & 0.31 \\
\hline MgO & 13.15 & 11.99 & 12.20 & 12.69 & 14.11 \\
\hline $\mathrm{CaO}$ & 11.85 & 11.33 & 11.75 & 11.83 & 11.74 \\
\hline $\mathrm{Na}_{2} \mathrm{O}$ & 2.04 & 2.00 & 2.16 & 2.12 & 2.02 \\
\hline $\mathbf{K}_{2} \mathbf{O}$ & 1.18 & 1.41 & 1.12 & 1.10 & 1.09 \\
\hline $\mathrm{H}_{2} \mathrm{O}_{\text {calc }}$ & 1.87 & 1.85 & 1.86 & 1.86 & 1.88 \\
\hline Total & 98.49 & 98.14 & 98.45 & 98.04 & 98.26 \\
\hline Mg\# & 77.18 & 68.55 & 70.86 & 71.11 & 79.58 \\
\hline \multicolumn{6}{|l|}{ Cations } \\
\hline $\mathbf{S i}$ & 5.937 & 6.123 & 5.969 & 6.105 & 6.113 \\
\hline $\mathbf{T i}$ & 0.270 & 0.343 & 0.301 & 0.288 & 0.330 \\
\hline Al & 2.331 & 2.017 & 2.240 & 2.087 & 1.979 \\
\hline $\mathrm{Fe}^{3+}$ & 0.653 & 0.518 & 0.585 & 0.475 & 0.602 \\
\hline $\mathrm{Fe}^{2+}$ & 0.864 & 1.241 & 1.126 & 1.159 & 0.804 \\
\hline Mn & 0.021 & 0.053 & 0.041 & 0.034 & 0.040 \\
\hline Mg & 2.924 & 2.704 & 2.739 & 2.853 & 3.133 \\
\hline $\mathbf{C a}$ & 1.893 & 1.836 & 1.895 & 1.911 & 1.872 \\
\hline $\mathbf{N a}$ & 0.590 & 0.587 & 0.630 & 0.620 & 0.582 \\
\hline $\mathbf{K}$ & 0.225 & 0.272 & 0.216 & 0.211 & 0.207 \\
\hline Total & 15.71 & 15.70 & 15.74 & 15.74 & 15.66 \\
\hline \multicolumn{6}{|l|}{ P-C conditions } \\
\hline $\mathbf{T}\left({ }^{\circ} \mathbf{C}\right)$ & 1012 & 962 & 998 & 978 & 976 \\
\hline Uncertanty & 22 & 22 & 22 & 22 & 22 \\
\hline P (MPa) & 549 & 349 & 481 & 386 & 330 \\
\hline Uncertanty & 60 & 38 & 53 & 42 & 36 \\
\hline Equivalent depth & 20.7 & 13.2 & 18.2 & 14.6 & 12.5 \\
\hline$(\mathbf{k m})$ & & & & & \\
\hline$\triangle \mathbf{N N O}$ & 0.55 & 0.17 & 0.22 & 0.40 & 0.79 \\
\hline $\log \mathrm{fO}_{2}$ & -9.40 & -10.62 & -9.96 & -10.13 & -9.78 \\
\hline Uncertanty & 0.4 & 0.4 & 0.4 & 0.4 & 0.4 \\
\hline $\mathrm{H}_{2} \mathrm{O}_{\text {melt }}(\mathrm{wt} . \%)$ & 5.6 & 4.1 & 5.4 & 5.0 & 4.1 \\
\hline Uncertanty & 0.8 & 0.6 & 0.8 & 0.7 & 0.6 \\
\hline
\end{tabular}

Cation proportions calculated using Leake et al. (1997) on the basis of 13 cations. $P-C=$ Physicalchemical conditions, calculated using the method of Ridolfi et al. (2010). 
Table A2.6 Major element amphibole compositions analysed by EMPA.

\begin{tabular}{|c|c|c|c|c|c|}
\hline $\begin{array}{l}\text { Sample } \\
\text { ID } \\
\text { Zone }\end{array}$ & $\begin{array}{r}\text { Kaupokonui } \\
\text { A10_2 } \\
\text { zone }\end{array}$ & $\begin{array}{r}\text { Kaupokonui } \\
\text { A10_3 } \\
\text { core }\end{array}$ & $\begin{array}{r}\text { Kaupokonui } \\
\text { A10_4 } \\
\text { zone }\end{array}$ & $\begin{array}{c}\text { Kaupokonui } \\
\text { A11_1 } \\
\text { rim }\end{array}$ & $\begin{array}{r}\text { Kaupokonui } \\
\text { A11_2 } \\
\text { zone }\end{array}$ \\
\hline $\mathrm{SiO}_{2}$ & 41.62 & 41.89 & 41.24 & 41.38 & 41.06 \\
\hline $\mathrm{TiO}_{2}$ & 3.09 & 2.74 & 2.65 & 2.85 & 2.85 \\
\hline $\mathbf{A l}_{2} \mathbf{O}_{3}$ & 10.79 & 10.79 & 11.33 & 11.66 & 11.56 \\
\hline $\mathrm{Fe}_{2} \mathrm{O}_{3}$ & 4.82 & 5.57 & 5.34 & 5.64 & 5.54 \\
\hline $\mathrm{FeO}$ & 7.18 & 6.29 & 6.36 & 6.35 & 6.38 \\
\hline MnO & 0.32 & 0.30 & 0.33 & 0.31 & 0.31 \\
\hline MgO & 14.13 & 14.53 & 14.15 & 14.02 & 14.04 \\
\hline $\mathrm{CaO}$ & 11.74 & 11.76 & 11.79 & 11.70 & 11.71 \\
\hline $\mathrm{Na}_{2} \mathrm{O}$ & 2.08 & 2.10 & 2.01 & 2.01 & 2.05 \\
\hline $\mathbf{K}_{2} \mathbf{O}$ & 1.09 & 1.07 & 1.03 & 1.06 & 1.07 \\
\hline $\mathbf{H}_{2} \mathbf{O}_{\text {calc }}$ & 1.89 & 1.89 & 1.88 & 1.89 & 1.88 \\
\hline Total & 98.76 & 98.92 & 98.10 & 98.88 & 98.46 \\
\hline Mg\# & 77.82 & 80.45 & 79.86 & 79.74 & 79.69 \\
\hline \multicolumn{6}{|l|}{ Cations } \\
\hline $\mathbf{S i}$ & 6.174 & 6.186 & 6.141 & 6.114 & 6.099 \\
\hline $\mathbf{T i}$ & 0.345 & 0.304 & 0.297 & 0.317 & 0.319 \\
\hline Al & 1.887 & 1.878 & 1.988 & 2.030 & 2.024 \\
\hline $\mathrm{Fe}^{3+}$ & 0.538 & 0.620 & 0.598 & 0.627 & 0.620 \\
\hline $\mathrm{Fe}^{2+}$ & 0.891 & 0.777 & 0.792 & 0.785 & 0.792 \\
\hline Mn & 0.040 & 0.038 & 0.042 & 0.039 & 0.040 \\
\hline Mg & 3.126 & 3.198 & 3.142 & 3.089 & 3.108 \\
\hline $\mathbf{C a}$ & 1.866 & 1.860 & 1.881 & 1.852 & 1.864 \\
\hline $\mathrm{Na}$ & 0.599 & 0.602 & 0.581 & 0.576 & 0.591 \\
\hline $\mathbf{K}$ & 0.207 & 0.201 & 0.195 & 0.200 & 0.203 \\
\hline Total & 15.67 & 15.66 & 15.66 & 15.63 & 15.66 \\
\hline \multicolumn{6}{|l|}{ P-C conditions } \\
\hline $\mathbf{T}\left({ }^{\circ} \mathbf{C}\right)$ & 964 & 961 & 973 & 975 & 979 \\
\hline Uncertanty & 22 & 22 & 22 & 22 & 22 \\
\hline P (MPa) & 290 & 286 & 335 & 356 & 353 \\
\hline Uncertanty & 32 & 31 & 37 & 39 & 39 \\
\hline $\begin{array}{l}\text { Equivalent depth } \\
(\mathbf{k m})\end{array}$ & 10.9 & 10.8 & 12.7 & 13.4 & 13.3 \\
\hline$\Delta \mathbf{N N O}$ & 0.75 & 0.96 & 0.86 & 0.76 & 0.77 \\
\hline $\log \mathrm{fO}_{2}$ & -10.04 & -9.87 & -9.75 & -9.81 & -9.75 \\
\hline Uncertanty & 0.4 & 0.4 & 0.4 & 0.4 & 0.4 \\
\hline $\mathbf{H}_{2} \mathbf{O}_{\text {melt }}(w t . \%)$ & 3.7 & 3.7 & 4.5 & 4.6 & 4.4 \\
\hline Uncertanty & 0.6 & 0.6 & 0.7 & 0.7 & 0.7 \\
\hline
\end{tabular}

Cation proportions calculated using Leake et al. (1997) on the basis of 13 cations. $P-C=$ Physicalchemical conditions, calculated using the method of Ridolfi et al. (2010). 
Table A2.6 Major element amphibole compositions analysed by EMPA.

\begin{tabular}{|c|c|c|c|c|c|c|}
\hline Sample & Kaupokonui & Kaupokonui & Kaupokonui & $\begin{array}{l}\text { SM-6C } \\
\text { A4 } 2\end{array}$ & $\begin{array}{c}\text { SM-6C } \\
\text { A4 3 }\end{array}$ & $\begin{array}{r}\text { SM-6C } \\
\text { A4 } 4\end{array}$ \\
\hline Zone & $\begin{array}{r}\text { A11_5 } \\
\text { zone }\end{array}$ & $\begin{array}{r}\text { A11_4 } \\
\text { core }\end{array}$ & $\begin{array}{r}\text { A1__J } \\
\text { core }\end{array}$ & $\begin{array}{l}\text { A4_2 } \\
\text { zone }\end{array}$ & $\begin{array}{l}\text { A4_5 } \\
\text { zone }\end{array}$ & $\begin{array}{r}\text { A4_4 } \\
\text { zone }\end{array}$ \\
\hline$\overline{\mathrm{SiO}_{2}}$ & 40.26 & 40.67 & 40.69 & 39.99 & 39.68 & 40.99 \\
\hline $\mathrm{TiO}_{2}$ & 2.56 & 2.14 & 2.72 & 2.33 & 2.38 & 2.14 \\
\hline $\mathrm{Al}_{2} \mathbf{O}_{3}$ & 12.84 & 13.37 & 12.15 & 13.25 & 13.30 & 12.09 \\
\hline $\mathrm{Fe}_{2} \mathrm{O}_{3}$ & 6.76 & 7.33 & 4.89 & 7.06 & 8.15 & 7.67 \\
\hline $\mathrm{FeO}$ & 5.67 & 4.22 & 7.41 & 5.31 & 4.35 & 4.26 \\
\hline MnO & 0.18 & 0.14 & 0.24 & 0.14 & 0.13 & 0.11 \\
\hline MgO & 13.91 & 14.48 & 13.60 & 13.93 & 13.97 & 14.72 \\
\hline $\mathrm{CaO}$ & 11.98 & 11.93 & 11.95 & 11.97 & 11.81 & 11.83 \\
\hline $\mathrm{Na}_{2} \mathrm{O}$ & 2.03 & 2.03 & 2.00 & 2.09 & 1.99 & 2.03 \\
\hline $\mathbf{K}_{2} \mathbf{O}$ & 0.97 & 0.98 & 1.19 & 1.00 & 0.99 & 0.95 \\
\hline $\mathbf{H}_{2} \mathbf{O}_{\text {calc }}$ & 1.88 & 1.90 & 1.88 & 1.88 & 1.87 & 1.88 \\
\hline Total & 99.03 & 99.19 & 98.72 & 98.97 & 98.61 & 98.67 \\
\hline Mg\# & 81.39 & 85.94 & 76.59 & 82.38 & 85.12 & 86.03 \\
\hline \multicolumn{7}{|l|}{ Cations } \\
\hline $\mathbf{S i}$ & 5.946 & 5.955 & 6.051 & 5.907 & 5.872 & 6.040 \\
\hline $\mathbf{T i}$ & 0.284 & 0.236 & 0.305 & 0.259 & 0.264 & 0.237 \\
\hline Al & 2.235 & 2.307 & 2.130 & 2.307 & 2.319 & 2.100 \\
\hline $\mathrm{Fe}^{3+}$ & 0.752 & 0.808 & 0.547 & 0.785 & 0.908 & 0.850 \\
\hline $\mathrm{Fe}^{2+}$ & 0.700 & 0.517 & 0.922 & 0.656 & 0.539 & 0.525 \\
\hline Mn & 0.022 & 0.017 & 0.030 & 0.018 & 0.016 & 0.014 \\
\hline Mg & 3.062 & 3.160 & 3.016 & 3.068 & 3.082 & 3.234 \\
\hline $\mathrm{Ca}$ & 1.896 & 1.872 & 1.904 & 1.895 & 1.872 & 1.869 \\
\hline $\mathbf{N a}$ & 0.580 & 0.575 & 0.578 & 0.598 & 0.570 & 0.581 \\
\hline $\mathbf{K}$ & 0.183 & 0.183 & 0.226 & 0.189 & 0.186 & 0.178 \\
\hline Total & 15.66 & 15.63 & 15.71 & 15.68 & 15.63 & 15.63 \\
\hline \multicolumn{7}{|l|}{$\overline{P-C}$ conditions } \\
\hline $\mathbf{T}\left({ }^{\circ} \mathbf{C}\right)$ & 1007 & 1011 & 992 & 1016 & 1017 & 988 \\
\hline Uncertanty & 22 & 22 & 22 & 22 & 22 & 22 \\
\hline P (MPa) & 478 & 530 & 411 & 530 & 539 & 394 \\
\hline Uncertanty & 53 & 58 & 45 & 58 & 59 & 43 \\
\hline Equivalent depth & 18.1 & 20.0 & 15.5 & 20.0 & 20.4 & 14.9 \\
\hline$(\mathbf{k m})$ & & & & & & \\
\hline$\Delta$ NNO & 0.77 & 1.01 & 0.62 & 0.82 & 0.89 & 1.18 \\
\hline $\log \mathrm{fO}_{2}$ & -9.28 & -8.97 & -9.68 & -9.08 & -9.00 & -9.20 \\
\hline Uncertanty & 0.4 & 0.4 & 0.4 & 0.4 & 0.4 & 0.4 \\
\hline $\mathrm{H}_{2} \mathrm{O}_{\text {melt }}$ (wt.\%) & 5.5 & 5.9 & 4.7 & 5.7 & 5.7 & 4.9 \\
\hline Uncertanty & 0.8 & 0.9 & 0.7 & 0.8 & 0.9 & 0.7 \\
\hline
\end{tabular}

Cation proportions calculated using Leake et al. (1997) on the basis of 13 cations. P-C = Physicalchemical conditions, calculated using the method of Ridolfi et al. (2010). 
Table A2.6 Major element amphibole compositions analysed by EMPA.

\begin{tabular}{|c|c|c|c|c|c|c|}
\hline Sample & SM-6C & SM-6C & SM-6C & SM-6C & SM-6C & SM-6C \\
\hline ID & A4_5 & A4_7 & A5_2 & A5_5 & A6_1 & A6_2 \\
\hline Zone & zone & core & rim & core & rim & zone \\
\hline $\mathrm{SiO}_{2}$ & 40.10 & 40.17 & 41.80 & 40.97 & 40.41 & 40.63 \\
\hline $\mathrm{TiO}_{2}$ & 2.33 & 2.29 & 2.73 & 2.90 & 2.45 & 2.27 \\
\hline $\mathrm{Al}_{2} \mathrm{O}_{3}$ & 13.07 & 13.08 & 14.22 & 14.44 & 12.77 & 12.70 \\
\hline $\mathrm{Fe}_{2} \mathrm{O}_{3}$ & 6.90 & 6.30 & 0.00 & 0.33 & 7.25 & 7.00 \\
\hline $\mathrm{FeO}$ & 5.62 & 5.78 & 10.60 & 11.37 & 4.89 & 4.96 \\
\hline MnO & 0.17 & 0.13 & 0.14 & 0.17 & 0.18 & 0.14 \\
\hline MgO & 13.77 & 13.89 & 13.49 & 12.73 & 14.12 & 14.45 \\
\hline $\mathrm{CaO}$ & 11.90 & 11.91 & 13.03 & 12.85 & 11.75 & 12.06 \\
\hline $\mathrm{Na}_{2} \mathrm{O}$ & 2.07 & 2.16 & 2.21 & 2.31 & 2.08 & 2.08 \\
\hline $\mathbf{K}_{2} \mathbf{O}$ & 1.01 & 1.00 & 1.10 & 1.12 & 0.95 & 0.94 \\
\hline $\mathrm{H}_{2} \mathrm{O}_{\text {calc }}$ & 1.88 & 1.88 & 1.95 & 1.94 & 1.88 & 1.89 \\
\hline Total & 98.83 & 98.60 & 101.27 & 101.13 & 98.74 & 99.11 \\
\hline Mg\# & 81.38 & 81.08 & 69.41 & 66.63 & 83.71 & 83.85 \\
\hline \multicolumn{7}{|l|}{ Cations } \\
\hline Si & 5.935 & 5.954 & 6.058 & 5.981 & 5.967 & 5.976 \\
\hline $\mathbf{T i}$ & 0.260 & 0.256 & 0.298 & 0.318 & 0.271 & 0.252 \\
\hline Al & 2.280 & 2.285 & 2.428 & 2.485 & 2.222 & 2.202 \\
\hline $\mathrm{Fe}^{3+}$ & 0.769 & 0.702 & 0.000 & 0.036 & 0.806 & 0.774 \\
\hline $\mathrm{Fe}^{2+}$ & 0.695 & 0.716 & 1.284 & 1.388 & 0.604 & 0.610 \\
\hline Mn & 0.022 & 0.016 & 0.018 & 0.022 & 0.022 & 0.018 \\
\hline Mg & 3.039 & 3.070 & 2.914 & 2.771 & 3.107 & 3.168 \\
\hline $\mathrm{Ca}$ & 1.888 & 1.892 & 2.023 & 2.009 & 1.859 & 1.900 \\
\hline $\mathbf{N a}$ & 0.594 & 0.619 & 0.622 & 0.654 & 0.597 & 0.592 \\
\hline $\mathbf{K}$ & 0.192 & 0.190 & 0.204 & 0.208 & 0.180 & 0.176 \\
\hline Total & 15.67 & 15.70 & 15.85 & 15.87 & 15.64 & 15.67 \\
\hline \multicolumn{7}{|l|}{ P-C conditions } \\
\hline $\mathbf{T}\left({ }^{\circ} \mathbf{C}\right)$ & 1010 & 1011 & 1028 & 1035 & 1002 & 1004 \\
\hline Uncertanty & 22 & 22 & 22 & 22 & 22 & 22 \\
\hline P (MPa) & 510 & 514 & 631 & 684 & 469 & 456 \\
\hline Uncertanty & 56 & 56 & 69 & 75 & 52 & 50 \\
\hline $\begin{array}{l}\text { Equivalent depth } \\
(\mathbf{k m})\end{array}$ & 19.2 & 19.4 & 23.8 & 25.8 & 17.7 & 17.2 \\
\hline$\triangle \mathbf{N N O}$ & 0.78 & 0.79 & 0.15 & -0.09 & 0.88 & 0.99 \\
\hline $\log \mathrm{fO}_{2}$ & -9.22 & -9.19 & -9.55 & -9.67 & -9.24 & -9.11 \\
\hline Uncertanty & 0.4 & 0.4 & 0.4 & 0.4 & 0.4 & 0.4 \\
\hline $\mathrm{H}_{2} \mathrm{O}_{\text {melt }}($ wt. \%) & 5.6 & 5.6 & 6.8 & 6.8 & 5.4 & 5.4 \\
\hline Uncertanty & 0.8 & 0.8 & 1.0 & 1.0 & 0.8 & 0.9 \\
\hline
\end{tabular}

Cation proportions calculated using Leake et al. (1997) on the basis of 13 cations. $P-C=$ Physicalchemical conditions, calculated using the method of Ridolfi et al. (2010). 
Table A2.6 Major element amphibole compositions analysed by EMPA.

\begin{tabular}{|c|c|c|c|c|c|c|}
\hline Sample & SM-6C & SM-6C & SM-6C & SM-6C & SM-6C & SM-6C \\
\hline ID & A6_3 & A6_4 & A7_1 & A7_2 & A7_3 & A7_4 \\
\hline Zone & core & zone & rim & zone & zone & zone \\
\hline $\mathrm{SiO}_{2}$ & 40.31 & 40.41 & 40.16 & 40.63 & 40.81 & 40.11 \\
\hline $\mathrm{TiO}_{2}$ & 2.35 & 2.28 & 2.35 & 2.25 & 2.05 & 2.44 \\
\hline $\mathrm{Al}_{2} \mathrm{O}_{3}$ & 13.03 & 12.93 & 13.00 & 12.92 & 12.71 & 13.19 \\
\hline $\mathrm{Fe}_{2} \mathrm{O}_{3}$ & 6.34 & 6.56 & 6.80 & 7.51 & 7.88 & 5.80 \\
\hline $\mathrm{FeO}$ & 5.69 & 5.53 & 5.33 & 4.80 & 4.20 & 6.46 \\
\hline MnO & 0.14 & 0.18 & 0.15 & 0.10 & 0.16 & 0.17 \\
\hline MgO & 13.92 & 14.00 & 14.00 & 14.23 & 14.54 & 13.54 \\
\hline $\mathrm{CaO}$ & 11.93 & 11.99 & 11.90 & 11.85 & 11.83 & 11.92 \\
\hline $\mathrm{Na}_{2} \mathrm{O}$ & 2.08 & 2.03 & 2.09 & 2.05 & 2.10 & 2.13 \\
\hline $\mathbf{K}_{2} \mathbf{O}$ & 1.00 & 0.98 & 0.97 & 1.00 & 0.97 & 1.01 \\
\hline $\mathrm{H}_{2} \mathrm{O}_{\text {calc }}$ & 1.88 & 1.88 & 1.88 & 1.89 & 1.89 & 1.88 \\
\hline Total & 98.68 & 98.77 & 98.64 & 99.23 & 99.14 & 98.66 \\
\hline Mg\# & 81.34 & 81.87 & 82.40 & 84.08 & 86.05 & 78.88 \\
\hline \multicolumn{7}{|l|}{ Cations } \\
\hline Si & 5.966 & 5.973 & 5.946 & 5.968 & 5.990 & 5.953 \\
\hline $\mathbf{T i}$ & 0.262 & 0.254 & 0.262 & 0.248 & 0.226 & 0.272 \\
\hline Al & 2.273 & 2.253 & 2.268 & 2.236 & 2.198 & 2.306 \\
\hline $\mathrm{Fe}^{3+}$ & 0.706 & 0.729 & 0.758 & 0.830 & 0.870 & 0.648 \\
\hline $\mathrm{Fe}^{2+}$ & 0.704 & 0.683 & 0.660 & 0.590 & 0.516 & 0.802 \\
\hline Mn & 0.018 & 0.023 & 0.019 & 0.013 & 0.019 & 0.022 \\
\hline Mg & 3.071 & 3.085 & 3.089 & 3.115 & 3.181 & 2.996 \\
\hline $\mathrm{Ca}$ & 1.891 & 1.899 & 1.887 & 1.865 & 1.861 & 1.895 \\
\hline $\mathbf{N a}$ & 0.596 & 0.582 & 0.600 & 0.585 & 0.598 & 0.614 \\
\hline $\mathbf{K}$ & 0.188 & 0.184 & 0.184 & 0.187 & 0.181 & 0.192 \\
\hline Total & 15.67 & 15.67 & 15.67 & 15.64 & 15.64 & 15.70 \\
\hline \multicolumn{7}{|l|}{ P-C conditions } \\
\hline $\mathbf{T}\left({ }^{\circ} \mathbf{C}\right)$ & 1008 & 1006 & 1010 & 1002 & 998 & 1012 \\
\hline Uncertanty & 22 & 22 & 22 & 22 & 22 & 22 \\
\hline P (MPa) & 505 & 491 & 501 & 478 & 453 & 530 \\
\hline Uncertanty & 56 & 54 & 55 & 53 & 50 & 58 \\
\hline $\begin{array}{l}\text { Equivalent depth } \\
(\mathbf{k m})\end{array}$ & 19.1 & 18.5 & 18.9 & 18.1 & 17.1 & 20.0 \\
\hline$\triangle \mathbf{N N O}$ & 0.80 & 0.85 & 0.84 & 0.95 & 1.10 & 0.63 \\
\hline $\log \mathrm{fO}_{2}$ & -9.23 & -9.21 & -9.17 & -9.18 & -9.09 & -9.33 \\
\hline Uncertanty & 0.4 & 0.4 & 0.4 & 0.4 & 0.4 & 0.4 \\
\hline $\mathrm{H}_{2} \mathrm{O}_{\text {melt }}($ wt. \%) & 5.7 & 5.7 & 5.6 & 5.5 & 5.3 & 5.8 \\
\hline Uncertanty & 0.9 & 0.8 & 0.8 & 0.9 & 0.8 & 0.8 \\
\hline
\end{tabular}

Cation proportions calculated using Leake et al. (1997) on the basis of 13 cations. $P-C=$ Physicalchemical conditions, calculated using the method of Ridolfi et al. (2010). 
Table A2.6 Major element amphibole compositions analysed by EMPA.

\begin{tabular}{|c|c|c|c|c|c|c|}
\hline Sample & SM-6C & SM-6C & SM-6C & SM-6C & SM-6C & SM-6C \\
\hline ID & A7_5 & A7_6 & A8_1 & A8_2 & A9_1 & A9_2 \\
\hline Zone & zone & core & rim & core & rim & zone \\
\hline $\mathrm{SiO}_{2}$ & 41.87 & 39.51 & 40.73 & 40.48 & 41.58 & 41.34 \\
\hline $\mathbf{T i O}_{2}$ & 2.70 & 2.19 & 2.35 & 2.36 & 2.76 & 2.81 \\
\hline $\mathrm{Al}_{2} \mathrm{O}_{3}$ & 11.03 & 13.45 & 13.31 & 13.12 & 14.27 & 14.35 \\
\hline $\mathrm{Fe}_{2} \mathrm{O}_{3}$ & 6.33 & 6.66 & 6.98 & 7.62 & 0.00 & 0.61 \\
\hline $\mathrm{FeO}$ & 5.56 & 6.36 & 5.20 & 4.55 & 10.71 & 10.34 \\
\hline MnO & 0.25 & 0.20 & 0.15 & 0.15 & 0.13 & 0.14 \\
\hline MgO & 14.49 & 13.30 & 14.02 & 14.23 & 13.33 & 13.33 \\
\hline $\mathrm{CaO}$ & 11.56 & 12.04 & 11.81 & 11.89 & 13.09 & 12.86 \\
\hline $\mathrm{Na}_{2} \mathrm{O}$ & 2.09 & 2.18 & 2.12 & 1.99 & 2.24 & 2.32 \\
\hline $\mathrm{K}_{2} \mathrm{O}$ & 0.95 & 0.92 & 1.00 & 0.98 & 1.06 & 1.02 \\
\hline $\mathbf{H}_{2} \mathbf{O}_{\text {calc }}$ & 1.89 & 1.87 & 1.90 & 1.89 & 1.95 & 1.94 \\
\hline Total & 98.72 & 98.68 & 99.56 & 99.26 & 101.11 & 101.05 \\
\hline Mg\# & 82.30 & 78.85 & 82.79 & 84.80 & 68.94 & 69.69 \\
\hline \multicolumn{7}{|l|}{ Cations } \\
\hline $\mathbf{S i}$ & 6.175 & 5.881 & 5.962 & 5.939 & 6.045 & 6.008 \\
\hline $\mathbf{T i}$ & 0.300 & 0.245 & 0.259 & 0.261 & 0.302 & 0.307 \\
\hline Al & 1.918 & 2.359 & 2.297 & 2.270 & 2.445 & 2.458 \\
\hline $\mathrm{Fe}^{3+}$ & 0.703 & 0.746 & 0.769 & 0.841 & 0.000 & 0.067 \\
\hline $\mathrm{Fe}^{2+}$ & 0.686 & 0.792 & 0.636 & 0.558 & 1.302 & 1.256 \\
\hline Mn & 0.032 & 0.025 & 0.018 & 0.018 & 0.016 & 0.017 \\
\hline Mg & 3.187 & 2.952 & 3.060 & 3.113 & 2.889 & 2.888 \\
\hline $\mathrm{Ca}$ & 1.827 & 1.920 & 1.853 & 1.869 & 2.040 & 2.002 \\
\hline $\mathbf{N a}$ & 0.596 & 0.628 & 0.602 & 0.567 & 0.632 & 0.653 \\
\hline $\mathbf{K}$ & 0.178 & 0.176 & 0.186 & 0.183 & 0.196 & 0.188 \\
\hline Total & 15.60 & 15.72 & 15.64 & 15.62 & 15.87 & 15.84 \\
\hline \multicolumn{7}{|l|}{ P-C conditions } \\
\hline $\mathbf{T}\left({ }^{\circ} \mathbf{C}\right)$ & 960 & 1021 & 1006 & 1008 & 1032 & 1032 \\
\hline Uncertanty & 22 & 22 & 22 & 22 & 22 & 22 \\
\hline $\mathbf{P}$ (MPa) & 303 & 571 & 522 & 502 & 646 & 659 \\
\hline Uncertanty & 33 & 63 & 57 & 55 & 71 & 72 \\
\hline $\begin{array}{l}\text { Equivalent depth } \\
(\mathrm{km})\end{array}$ & 11.4 & 21.6 & 19.7 & 19.0 & 24.4 & 24.9 \\
\hline$\Delta \mathbf{N N O}$ & 0.99 & 0.63 & 0.81 & 0.93 & 0.09 & 0.11 \\
\hline $\log \mathrm{fO}_{2}$ & -9.85 & -9.18 & -9.23 & -9.11 & -9.54 & -9.51 \\
\hline Uncertanty & 0.4 & 0.4 & 0.4 & 0.4 & 0.4 & 0.4 \\
\hline $\mathrm{H}_{2} \mathrm{O}_{\text {melt }}$ (wt.\%) & 4.3 & 6.1 & 5.8 & 5.7 & 7.0 & 6.9 \\
\hline Uncertanty & 0.9 & 0.9 & 0.6 & 0.9 & 1.0 & 1.0 \\
\hline
\end{tabular}

Cation proportions calculated using Leake et al. (1997) on the basis of 13 cations. $P-C=$ Physicalchemical conditions, calculated using the method of Ridolfi et al. (2010). 
Table A2.6 Major element amphibole compositions analysed by EMPA.

\begin{tabular}{|c|c|c|c|c|c|c|}
\hline Sample & SM-6C & SM-6C & Maketawa & Maketawa & Maketawa & Maketawa \\
\hline ID & A9_3 & A9_4 & A1_1 & A1_2 & A1_3 & A2_1 \\
\hline Zone & zone & core & rim & zone & core & rim \\
\hline $\mathrm{SiO}_{2}$ & 41.71 & 42.64 & 41.30 & 42.16 & 40.73 & 40.52 \\
\hline $\mathrm{TiO}_{2}$ & 2.72 & 2.63 & 2.74 & 2.90 & 2.57 & 2.38 \\
\hline $\mathrm{Al}_{2} \mathbf{O}_{3}$ & 14.24 & 13.62 & 10.79 & 10.23 & 11.85 & 12.91 \\
\hline $\mathrm{Fe}_{2} \mathrm{O}_{3}$ & 0.09 & 0.00 & 5.19 & 4.18 & 4.96 & 5.70 \\
\hline $\mathrm{FeO}$ & 10.76 & 10.48 & 10.53 & 9.84 & 7.77 & 6.80 \\
\hline MnO & 0.12 & 0.12 & 0.58 & 0.62 & 0.28 & 0.17 \\
\hline MgO & 13.35 & 13.74 & 11.64 & 12.78 & 13.28 & 13.45 \\
\hline $\mathrm{CaO}$ & 12.97 & 13.08 & 11.41 & 11.72 & 11.82 & 11.90 \\
\hline $\mathrm{Na}_{2} \mathrm{O}$ & 2.26 & 2.25 & 1.92 & 2.08 & 2.10 & 2.14 \\
\hline $\mathbf{K}_{2} \mathbf{O}$ & 1.04 & 1.00 & 1.40 & 1.09 & 0.98 & 0.91 \\
\hline $\mathbf{H}_{2} \mathbf{O}_{\text {calc }}$ & 1.95 & 1.96 & 1.86 & 1.88 & 1.87 & 1.88 \\
\hline Total & 101.22 & 101.53 & 99.37 & 99.47 & 98.19 & 98.78 \\
\hline Mg\# & 68.87 & 70.02 & 66.35 & 69.84 & 75.30 & 77.90 \\
\hline \multicolumn{7}{|l|}{ Cations } \\
\hline $\mathbf{S i}$ & 6.050 & 6.157 & 6.196 & 6.274 & 6.094 & 6.005 \\
\hline $\mathbf{T i}$ & 0.297 & 0.285 & 0.309 & 0.324 & 0.289 & 0.266 \\
\hline Al & 2.435 & 2.318 & 1.908 & 1.794 & 2.089 & 2.255 \\
\hline $\mathrm{Fe}^{3+}$ & 0.010 & 0.000 & 0.586 & 0.468 & 0.559 & 0.636 \\
\hline $\mathrm{Fe}^{2+}$ & 1.306 & 1.266 & 1.321 & 1.225 & 0.972 & 0.843 \\
\hline Mn & 0.014 & 0.015 & 0.074 & 0.079 & 0.035 & 0.022 \\
\hline Mg & 2.888 & 2.958 & 2.605 & 2.836 & 2.962 & 2.973 \\
\hline $\mathbf{C a}$ & 2.016 & 2.024 & 1.834 & 1.868 & 1.895 & 1.890 \\
\hline $\mathbf{N a}$ & 0.635 & 0.630 & 0.560 & 0.599 & 0.608 & 0.616 \\
\hline $\mathbf{K}$ & 0.193 & 0.185 & 0.267 & 0.206 & 0.187 & 0.171 \\
\hline Total & 15.84 & 15.84 & 15.66 & 15.67 & 15.69 & 15.68 \\
\hline \multicolumn{7}{|l|}{ P-C conditions } \\
\hline $\mathbf{T}\left({ }^{\circ} \mathbf{C}\right)$ & 1027 & 1012 & 939 & 936 & 981 & 1000 \\
\hline Uncertanty & 22 & 22 & 22 & 22 & 22 & 22 \\
\hline P (MPa) & 637 & 539 & 299 & 254 & 387 & 492 \\
\hline Uncertanty & 70 & 59 & 33 & 28 & 43 & 54 \\
\hline $\begin{array}{l}\text { Equivalent depth } \\
(\mathbf{k m})\end{array}$ & 24.0 & 20.3 & 11.3 & 9.6 & 14.6 & 18.6 \\
\hline$\triangle \mathbf{N N O}$ & 0.12 & 0.25 & 0.16 & 0.39 & 0.58 & 0.62 \\
\hline $\log \mathrm{fO}_{2}$ & -9.59 & -9.71 & -11.01 & -10.85 & -9.90 & -9.52 \\
\hline Uncertanty & 0.4 & 0.4 & 0.4 & 0.4 & 0.4 & 0.4 \\
\hline $\mathrm{H}_{2} \mathrm{O}_{\text {melt }}$ (wt.\%) & 6.9 & 6.7 & 4.0 & 4.0 & 5.1 & 6.0 \\
\hline Uncertanty & 1.0 & 1.0 & 0.6 & 0.6 & 0.8 & 0.9 \\
\hline
\end{tabular}

Cation proportions calculated using Leake et al. (1997) on the basis of 13 cations. $P-C=$ Physicalchemical conditions, calculated using the method of Ridolfi et al. (2010). 
Table A2.6 Major element amphibole compositions analysed by EMPA.

\begin{tabular}{|c|c|c|c|c|c|c|}
\hline $\begin{array}{l}\text { Sample } \\
\text { ID } \\
\text { Zone }\end{array}$ & $\begin{array}{c}\text { Maketawa } \\
\text { A2_2 } \\
\text { zone }\end{array}$ & $\begin{array}{r}\text { Maketawa } \\
\text { A4_1 } \\
\text { core }\end{array}$ & $\begin{array}{r}\text { Maketawa } \\
\text { A4_2 } \\
\text { zone }\end{array}$ & $\begin{array}{r}\text { Maketawa } \\
\text { A4_3 } \\
\text { zone }\end{array}$ & $\begin{array}{r}\text { Maketawa } \\
\text { A5_1 } \\
\text { core }\end{array}$ & $\begin{array}{r}\text { Maketawa } \\
\text { A5_2 } \\
\text { zone }\end{array}$ \\
\hline$\overline{\mathrm{SiO}_{2}}$ & 41.41 & 42.26 & 41.94 & 43.83 & 42.02 & 41.07 \\
\hline $\mathrm{TiO}_{2}$ & 2.81 & 2.41 & 2.08 & 2.60 & 2.08 & 1.84 \\
\hline $\mathrm{Al}_{2} \mathrm{O}_{3}$ & 11.27 & 12.08 & 12.96 & 10.98 & 13.08 & 13.82 \\
\hline $\mathrm{Fe}_{2} \mathrm{O}_{3}$ & 5.32 & 6.04 & 6.52 & 5.64 & 7.54 & 9.13 \\
\hline FeO & 7.71 & 7.99 & 5.49 & 6.97 & 3.90 & 3.97 \\
\hline MnO & 0.32 & 0.35 & 0.14 & 0.33 & 0.10 & 0.14 \\
\hline MgO & 13.48 & 13.44 & 14.75 & 14.77 & 15.35 & 14.29 \\
\hline $\mathrm{CaO}$ & 11.60 & 12.04 & 12.29 & 12.11 & 12.27 & 11.96 \\
\hline $\mathrm{Na}_{2} \mathrm{O}$ & 2.19 & 2.24 & 2.25 & 2.19 & 2.02 & 2.01 \\
\hline $\mathrm{K}_{2} \mathrm{O}$ & 1.06 & 0.94 & 0.91 & 0.95 & 1.09 & 1.11 \\
\hline $\mathbf{H}_{2} \mathbf{O}_{\text {calc }}$ & 1.88 & 1.93 & 1.94 & 1.96 & 1.94 & 1.92 \\
\hline Total & 99.06 & 101.71 & 101.27 & 102.33 & 101.40 & 101.25 \\
\hline Mg\# & 75.71 & 74.99 & 82.74 & 79.07 & 87.51 & 86.52 \\
\hline \multicolumn{7}{|l|}{ Cations } \\
\hline $\mathbf{S i}$ & 6.144 & 6.113 & 6.032 & 6.254 & 6.009 & 5.910 \\
\hline $\mathbf{T i}$ & 0.313 & 0.262 & 0.225 & 0.278 & 0.224 & 0.199 \\
\hline Al & 1.971 & 2.060 & 2.196 & 1.847 & 2.204 & 2.343 \\
\hline $\mathrm{Fe}^{3+}$ & 0.594 & 0.658 & 0.705 & 0.606 & 0.811 & 0.988 \\
\hline $\mathrm{Fe}^{2+}$ & 0.956 & 0.967 & 0.660 & 0.832 & 0.467 & 0.478 \\
\hline Mn & 0.040 & 0.043 & 0.018 & 0.040 & 0.013 & 0.017 \\
\hline Mg & 2.981 & 2.898 & 3.164 & 3.142 & 3.272 & 3.066 \\
\hline $\mathbf{C a}$ & 1.844 & 1.866 & 1.895 & 1.851 & 1.879 & 1.844 \\
\hline $\mathbf{N a}$ & 0.630 & 0.628 & 0.629 & 0.606 & 0.560 & 0.560 \\
\hline $\mathbf{K}$ & 0.201 & 0.174 & 0.166 & 0.174 & 0.200 & 0.204 \\
\hline Total & 15.68 & 15.67 & 15.69 & 15.63 & 15.64 & 15.61 \\
\hline \multicolumn{7}{|l|}{ P-C conditions } \\
\hline $\mathbf{T}\left({ }^{\circ} \mathbf{C}\right)$ & 965 & 970 & 998 & 947 & 1001 & 1008 \\
\hline Uncertanty & 22 & 22 & 22 & 22 & 22 & 22 \\
\hline $\mathbf{P}$ (MPa) & 327 & 371 & 452 & 274 & 457 & 558 \\
\hline Uncertanty & 36 & 41 & 50 & 30 & 50 & 61 \\
\hline $\begin{array}{l}\text { Equivalent depth } \\
(\mathrm{km})\end{array}$ & 12.4 & 14.0 & 17.1 & 10.3 & 17.3 & 21.1 \\
\hline$\Delta$ NNO & 0.61 & 0.59 & 0.99 & 0.94 & 1.22 & 1.03 \\
\hline $\log \mathrm{fO}_{2}$ & -10.15 & -10.07 & -9.20 & -10.12 & -8.93 & -8.97 \\
\hline Uncertanty & 0.4 & 0.4 & 0.4 & 0.4 & 0.4 & 0.4 \\
\hline $\mathrm{H}_{2} \mathrm{O}_{\text {melt }}$ (wt.\%) & 4.3 & 5.3 & 5.6 & 4.3 & 5.2 & 5.9 \\
\hline Uncertanty & 0.6 & 0.8 & 0.8 & 0.6 & 0.8 & 0.9 \\
\hline
\end{tabular}

Cation proportions calculated using Leake et al. (1997) on the basis of 13 cations. P-C = Physicalchemical conditions, calculated using the method of Ridolfi et al. (2010). 
Table A2.6 Major element amphibole compositions analysed by EMPA.

\begin{tabular}{|c|c|c|c|c|c|c|}
\hline $\begin{array}{l}\text { Sample } \\
\text { ID } \\
\text { Zone }\end{array}$ & $\begin{array}{r}\text { Maketawa } \\
\text { A5_3 } \\
\text { zone }\end{array}$ & $\begin{array}{r}\text { Maketawa } \\
\text { A5_4 } \\
\text { rim }\end{array}$ & $\begin{array}{r}\text { Maketawa } \\
\text { A6_1 } \\
\text { core }\end{array}$ & $\begin{array}{c}\text { Maketawa } \\
\text { A6_2 } \\
\text { zone }\end{array}$ & $\begin{array}{c}\text { Maketawa } \\
\text { A7_1 } \\
\text { core }\end{array}$ & $\begin{array}{r}\text { Maketawa } \\
\text { A7_2 } \\
\text { rim }\end{array}$ \\
\hline$\overline{\mathrm{SiO}_{2}}$ & 41.59 & 43.87 & 43.91 & 43.74 & 40.67 & 42.35 \\
\hline $\mathrm{TiO}_{2}$ & 2.22 & 2.59 & 2.42 & 2.52 & 2.39 & 2.64 \\
\hline $\mathrm{Al}_{2} \mathrm{O}_{3}$ & 13.25 & 10.63 & 10.82 & 10.36 & 12.12 & 10.47 \\
\hline $\mathrm{Fe}_{2} \mathrm{O}_{3}$ & 6.50 & 6.88 & 4.22 & 4.84 & 6.18 & 6.14 \\
\hline FeO & 4.95 & 4.90 & 8.20 & 8.62 & 6.95 & 6.28 \\
\hline MnO & 0.14 & 0.38 & 0.32 & 0.43 & 0.29 & 0.33 \\
\hline MgO & 14.90 & 15.21 & 14.34 & 13.98 & 13.40 & 14.38 \\
\hline $\mathrm{CaO}$ & 12.39 & 11.48 & 11.99 & 11.94 & 11.86 & 11.66 \\
\hline $\mathrm{Na}_{2} \mathrm{O}$ & 2.00 & 2.23 & 2.19 & 2.16 & 2.06 & 2.06 \\
\hline $\mathrm{K}_{2} \mathrm{O}$ & 1.06 & 0.89 & 1.09 & 1.11 & 0.97 & 0.94 \\
\hline $\mathbf{H}_{2} \mathbf{O}_{\text {calc }}$ & 1.93 & 1.94 & 1.94 & 1.93 & 1.87 & 1.89 \\
\hline Total & 100.93 & 101.01 & 101.46 & 101.63 & 98.76 & 99.14 \\
\hline Mg\# & 84.30 & 84.71 & 75.71 & 74.31 & 77.47 & 80.32 \\
\hline \multicolumn{7}{|l|}{ Cations } \\
\hline $\mathbf{S i}$ & 5.993 & 6.293 & 6.330 & 6.325 & 6.047 & 6.237 \\
\hline $\mathbf{T i}$ & 0.240 & 0.280 & 0.263 & 0.274 & 0.268 & 0.293 \\
\hline Al & 2.250 & 1.798 & 1.839 & 1.766 & 2.123 & 1.817 \\
\hline $\mathrm{Fe}^{3+}$ & 0.705 & 0.743 & 0.458 & 0.527 & 0.691 & 0.681 \\
\hline $\mathrm{Fe}^{2+}$ & 0.596 & 0.587 & 0.989 & 1.042 & 0.864 & 0.774 \\
\hline Mn & 0.017 & 0.046 & 0.039 & 0.053 & 0.037 & 0.041 \\
\hline Mg & 3.200 & 3.253 & 3.083 & 3.013 & 2.970 & 3.158 \\
\hline $\mathbf{C a}$ & 1.913 & 1.765 & 1.852 & 1.850 & 1.889 & 1.839 \\
\hline $\mathbf{N a}$ & 0.558 & 0.621 & 0.613 & 0.605 & 0.595 & 0.589 \\
\hline $\mathbf{K}$ & 0.195 & 0.164 & 0.201 & 0.204 & 0.184 & 0.176 \\
\hline Total & 15.67 & 15.55 & 15.67 & 15.66 & 15.67 & 15.60 \\
\hline \multicolumn{7}{|l|}{ P-C conditions } \\
\hline $\mathbf{T}\left({ }^{\circ} \mathbf{C}\right)$ & 1008 & 936 & 938 & 930 & 985 & 945 \\
\hline Uncertanty & 22 & 22 & 22 & 22 & 22 & 22 \\
\hline $\mathbf{P}$ (MPa) & 488 & 255 & 270 & 243 & 407 & 262 \\
\hline Uncertanty & 54 & 28 & 30 & 27 & 45 & 29 \\
\hline $\begin{array}{l}\text { Equivalent depth } \\
(\mathrm{km})\end{array}$ & 18.4 & 9.6 & 10.2 & 9.2 & 15.4 & 9.9 \\
\hline$\Delta$ NNO & 1.03 & 1.17 & 0.84 & 0.77 & 0.68 & 0.98 \\
\hline $\log \mathrm{fO}_{2}$ & -9.00 & -10.08 & -10.36 & -10.58 & -9.73 & -10.11 \\
\hline Uncertanty & 0.4 & 0.4 & 0.4 & 0.4 & 0.4 & 0.4 \\
\hline $\mathrm{H}_{2} \mathrm{O}_{\text {melt }}$ (wt.\%) & 5.5 & 4.1 & 4.2 & 3.8 & 5.3 & 4.0 \\
\hline Uncertanty & 0.8 & 0.6 & 0.6 & 0.6 & 0.8 & 0.6 \\
\hline
\end{tabular}

Cation proportions calculated using Leake et al. (1997) on the basis of 13 cations. P-C = Physicalchemical conditions, calculated using the method of Ridolfi et al. (2010). 
Table A2.6 Major element amphibole compositions analysed by EMPA.

\begin{tabular}{|c|c|c|c|c|c|c|}
\hline $\begin{array}{l}\text { Sample } \\
\text { ID } \\
\text { Zone }\end{array}$ & $\begin{array}{c}\text { Maketawa } \\
\text { A9_1 } \\
\text { core }\end{array}$ & $\begin{array}{c}\text { Maketawa } \\
\text { A10_6 } \\
\text { core }\end{array}$ & $\begin{array}{c}\text { Maketawa } \\
\text { A11_1 } \\
\text { core }\end{array}$ & $\begin{array}{c}\text { Maketawa } \\
\text { A11_2 } \\
\text { core }\end{array}$ & $\begin{array}{c}\text { Maketawa } \\
\text { A11_3 } \\
\text { zone }\end{array}$ & $\begin{array}{r}\text { Maketawa } \\
\text { A11_4 } \\
\text { zone }\end{array}$ \\
\hline$\overline{\mathrm{SiO}_{2}}$ & 39.57 & 41.31 & 42.53 & 39.73 & 41.76 & 40.61 \\
\hline $\mathrm{TiO}_{2}$ & 2.29 & 1.94 & 2.70 & 2.43 & 2.84 & 2.73 \\
\hline $\mathrm{Al}_{2} \mathrm{O}_{3}$ & 13.28 & 12.77 & 10.23 & 13.33 & 10.62 & 12.23 \\
\hline $\mathrm{Fe}_{2} \mathrm{O}_{3}$ & 4.79 & 5.87 & 5.48 & 5.99 & 4.34 & 5.47 \\
\hline FeO & 8.83 & 6.33 & 6.89 & 7.16 & 8.60 & 8.16 \\
\hline MnO & 0.16 & 0.15 & 0.39 & 0.29 & 0.37 & 0.35 \\
\hline MgO & 12.32 & 14.19 & 14.12 & 12.85 & 13.44 & 12.92 \\
\hline $\mathrm{CaO}$ & 12.06 & 12.18 & 11.52 & 11.82 & 11.75 & 11.85 \\
\hline $\mathrm{Na}_{2} \mathrm{O}$ & 2.09 & 2.21 & 2.05 & 2.22 & 2.05 & 2.18 \\
\hline $\mathrm{K}_{2} \mathrm{O}$ & 0.97 & 0.97 & 0.98 & 0.90 & 1.15 & 0.98 \\
\hline $\mathbf{H}_{2} \mathbf{O}_{\text {calc }}$ & 1.86 & 1.91 & 1.89 & 1.87 & 1.88 & 1.88 \\
\hline Total & 98.22 & 99.82 & 98.78 & 98.59 & 98.79 & 99.35 \\
\hline Mg\# & 71.31 & 79.98 & 78.51 & 76.19 & 73.59 & 73.83 \\
\hline \multicolumn{7}{|l|}{ Cations } \\
\hline $\mathbf{S i}$ & 5.952 & 6.047 & 6.291 & 5.925 & 6.224 & 6.029 \\
\hline $\mathbf{T i}$ & 0.259 & 0.213 & 0.301 & 0.273 & 0.319 & 0.305 \\
\hline Al & 2.354 & 2.204 & 1.783 & 2.343 & 1.866 & 2.139 \\
\hline $\mathrm{Fe}^{3+}$ & 0.542 & 0.646 & 0.610 & 0.672 & 0.486 & 0.612 \\
\hline $\mathrm{Fe}^{2+}$ & 1.111 & 0.775 & 0.852 & 0.893 & 1.072 & 1.013 \\
\hline Mn & 0.020 & 0.018 & 0.049 & 0.037 & 0.047 & 0.044 \\
\hline Mg & 2.762 & 3.096 & 3.114 & 2.858 & 2.986 & 2.859 \\
\hline Ca & 1.943 & 1.911 & 1.825 & 1.889 & 1.876 & 1.884 \\
\hline $\mathbf{N a}$ & 0.610 & 0.627 & 0.588 & 0.641 & 0.593 & 0.627 \\
\hline $\mathbf{K}$ & 0.187 & 0.181 & 0.185 & 0.171 & 0.218 & 0.186 \\
\hline Total & 15.74 & 15.72 & 15.60 & 15.70 & 15.69 & 15.70 \\
\hline \multicolumn{7}{|l|}{ P-C conditions } \\
\hline $\mathbf{T}\left({ }^{\circ} \mathbf{C}\right)$ & 1010 & 996 & 936 & 1012 & 952 & 987 \\
\hline Uncertanty & 22 & 22 & 22 & 22 & 22 & 22 \\
\hline $\mathbf{P}$ (MPa) & 567 & 457 & 250 & 558 & 281 & 416 \\
\hline Uncertanty & 62 & 50 & 27 & 61 & 31 & 46 \\
\hline $\begin{array}{l}\text { Equivalent depth } \\
(\mathrm{km})\end{array}$ & 21.4 & 17.3 & 9.4 & 21.1 & 10.6 & 15.7 \\
\hline$\Delta$ NNO & 0.28 & 0.90 & 0.89 & 0.43 & 0.60 & 0.41 \\
\hline $\log \mathrm{fO}_{2}$ & -9.69 & -9.32 & -10.35 & -9.52 & -10.38 & -9.96 \\
\hline Uncertanty & 0.4 & 0.4 & 0.4 & 0.4 & 0.4 & 0.4 \\
\hline $\mathrm{H}_{2} \mathrm{O}_{\text {melt }}$ (wt.\%) & 6.5 & 5.6 & 3.9 & 6.3 & 3.9 & 5.3 \\
\hline Uncertanty & 1.0 & 0.8 & 0.6 & 0.9 & 0.6 & 0.8 \\
\hline
\end{tabular}

Cation proportions calculated using Leake et al. (1997) on the basis of 13 cations. P-C = Physicalchemical conditions, calculated using the method of Ridolfi et al. (2010). 
Table A2.6 Major element amphibole compositions analysed by EMPA.

\begin{tabular}{|c|c|c|c|c|c|c|}
\hline $\begin{array}{l}\text { Sample } \\
\text { ID } \\
\text { Zone } \\
\end{array}$ & $\begin{array}{c}\text { Maketawa } \\
\text { A11_6 } \\
\text { zone } \\
\end{array}$ & $\begin{array}{c}\text { Maketawa } \\
\text { A12_2 } \\
\text { core }\end{array}$ & $\begin{array}{r}\text { Maketawa } \\
\text { A13_1 } \\
\text { rim }\end{array}$ & $\begin{array}{c}\text { Maketawa } \\
\text { A13_2 } \\
\text { core }\end{array}$ & $\begin{array}{r}\text { Maketawa } \\
\text { A14_4 } \\
\text { rim }\end{array}$ & $\begin{array}{r}\text { Maketawa } \\
\text { A14_5 } \\
\text { zone }\end{array}$ \\
\hline$\overline{\mathrm{SiO}_{2}}$ & 41.76 & 40.10 & 41.22 & 41.27 & 39.60 & 39.72 \\
\hline $\mathrm{TiO}_{2}$ & 2.83 & 2.41 & 2.84 & 2.69 & 2.27 & 2.30 \\
\hline $\mathrm{Al}_{2} \mathrm{O}_{3}$ & 10.97 & 12.17 & 11.22 & 10.62 & 13.44 & 13.43 \\
\hline $\mathrm{Fe}_{2} \mathrm{O}_{3}$ & 5.41 & 4.53 & 4.10 & 4.85 & 5.21 & 5.49 \\
\hline FeO & 7.60 & 9.00 & 8.22 & 10.62 & 7.26 & 6.97 \\
\hline MnO & 0.32 & 0.25 & 0.33 & 0.63 & 0.15 & 0.14 \\
\hline MgO & 13.52 & 12.80 & 13.54 & 11.61 & 13.16 & 13.14 \\
\hline $\mathrm{CaO}$ & 11.56 & 12.12 & 11.70 & 11.35 & 12.00 & 11.83 \\
\hline $\mathrm{Na}_{2} \mathrm{O}$ & 2.07 & 2.22 & 2.25 & 1.93 & 2.18 & 2.11 \\
\hline $\mathrm{K}_{2} \mathrm{O}$ & 1.02 & 0.95 & 1.07 & 1.38 & 1.07 & 1.14 \\
\hline $\mathbf{H}_{2} \mathbf{O}_{\text {calc }}$ & 1.88 & 1.86 & 1.87 & 1.85 & 1.87 & 1.87 \\
\hline Total & 98.94 & 98.41 & 98.36 & 98.81 & 98.22 & 98.15 \\
\hline Mg\# & 76.03 & 71.72 & 74.60 & 66.10 & 76.37 & 77.08 \\
\hline \multicolumn{7}{|l|}{ Cations } \\
\hline $\mathbf{S i}$ & 6.192 & 6.027 & 6.160 & 6.226 & 5.925 & 5.938 \\
\hline $\mathbf{T i}$ & 0.315 & 0.272 & 0.319 & 0.305 & 0.255 & 0.259 \\
\hline Al & 1.918 & 2.156 & 1.975 & 1.888 & 2.370 & 2.367 \\
\hline $\mathrm{Fe}^{3+}$ & 0.604 & 0.513 & 0.461 & 0.551 & 0.587 & 0.618 \\
\hline $\mathrm{Fe}^{2+}$ & 0.942 & 1.131 & 1.027 & 1.339 & 0.909 & 0.871 \\
\hline Mn & 0.040 & 0.032 & 0.041 & 0.080 & 0.020 & 0.018 \\
\hline Mg & 2.988 & 2.869 & 3.016 & 2.611 & 2.936 & 2.929 \\
\hline Ca & 1.837 & 1.952 & 1.874 & 1.835 & 1.924 & 1.896 \\
\hline $\mathbf{N a}$ & 0.596 & 0.646 & 0.652 & 0.565 & 0.632 & 0.612 \\
\hline $\mathbf{K}$ & 0.192 & 0.183 & 0.204 & 0.265 & 0.205 & 0.217 \\
\hline Total & 15.63 & 15.78 & 15.73 & 15.66 & 15.76 & 15.73 \\
\hline \multicolumn{7}{|l|}{ P-C conditions } \\
\hline $\mathbf{T}\left({ }^{\circ} \mathbf{C}\right)$ & 954 & 994 & 970 & 935 & 1020 & 1016 \\
\hline Uncertanty & 22 & 22 & 22 & 22 & 22 & 22 \\
\hline $\mathbf{P}$ (MPa) & 303 & 426 & 329 & 290 & 580 & 578 \\
\hline Uncertanty & 33 & 47 & 36 & 32 & 64 & 64 \\
\hline $\begin{array}{l}\text { Equivalent depth } \\
(\mathbf{k m})\end{array}$ & 11.4 & 16.1 & 12.4 & 11.0 & 21.9 & 21.8 \\
\hline$\Delta$ NNO & 0.65 & 0.41 & 0.57 & 0.17 & 0.53 & 0.55 \\
\hline $\log \mathrm{fO}_{2}$ & -10.28 & -9.84 & -10.10 & -11.07 & -9.29 & -9.34 \\
\hline Uncertanty & 0.4 & 0.4 & 0.4 & 0.4 & 0.4 & 0.4 \\
\hline $\mathrm{H}_{2} \mathrm{O}_{\text {melt }}$ (wt.\%) & 4.4 & 5.4 & 4.2 & 4.0 & 5.9 & 5.9 \\
\hline Uncertanty & 0.7 & 0.8 & 0.6 & 0.6 & 0.9 & 0.9 \\
\hline
\end{tabular}

Cation proportions calculated using Leake et al. (1997) on the basis of 13 cations. P-C = Physicalchemical conditions, calculated using the method of Ridolfi et al. (2010). 
Table A2.6 Major element amphibole compositions analysed by EMPA.

\begin{tabular}{|c|c|c|c|c|c|}
\hline $\begin{array}{l}\text { Sample } \\
\text { ID } \\
\text { Zone }\end{array}$ & $\begin{array}{c}\text { Maketawa } \\
\text { A14_6 } \\
\text { core }\end{array}$ & $\begin{array}{c}\text { Maketawa } \\
\text { A17_1 } \\
\text { rim }\end{array}$ & $\begin{array}{c}\text { Maketawa } \\
\text { A17_2 } \\
\text { core }\end{array}$ & $\begin{array}{r}\text { Inglewood b } \\
\mathbf{A 1} 1 \mathbf{1} \\
\text { rim }\end{array}$ & $\begin{array}{r}\text { Inglewood b } \\
\text { A1_2 } \\
\text { zone }\end{array}$ \\
\hline$\overline{\mathrm{SiO}_{2}}$ & 39.61 & 41.18 & 39.34 & 42.45 & 41.30 \\
\hline $\mathrm{TiO}_{2}$ & 2.07 & 2.82 & 2.38 & 2.95 & 2.78 \\
\hline $\mathrm{Al}_{2} \mathrm{O}_{3}$ & 13.60 & 10.96 & 13.33 & 9.70 & 11.45 \\
\hline $\mathrm{Fe}_{2} \mathrm{O}_{3}$ & 6.79 & 5.16 & 5.05 & 4.92 & 5.02 \\
\hline FeO & 4.62 & 7.11 & 8.30 & 8.07 & 9.15 \\
\hline MnO & 0.12 & 0.34 & 0.18 & 0.48 & 0.59 \\
\hline MgO & 14.25 & 13.88 & 12.56 & 13.74 & 12.51 \\
\hline $\mathrm{CaO}$ & 11.99 & 11.61 & 11.88 & 11.63 & 11.75 \\
\hline $\mathrm{Na}_{2} \mathrm{O}$ & 2.06 & 2.25 & 2.35 & 2.03 & 2.10 \\
\hline $\mathrm{K}_{2} \mathrm{O}$ & 1.16 & 0.99 & 0.96 & 0.94 & 0.99 \\
\hline $\mathbf{H}_{2} \mathbf{O}_{\text {calc }}$ & 1.87 & 1.87 & 1.86 & 1.88 & 1.88 \\
\hline Total & 98.14 & 98.18 & 98.20 & 98.79 & 99.52 \\
\hline Mg\# & 84.60 & 77.69 & 72.94 & 75.23 & 70.91 \\
\hline \multicolumn{6}{|l|}{ Cations } \\
\hline $\mathbf{S i}$ & 5.884 & 6.151 & 5.915 & 6.311 & 6.139 \\
\hline $\mathbf{T i}$ & 0.232 & 0.317 & 0.269 & 0.329 & 0.311 \\
\hline Al & 2.381 & 1.930 & 2.363 & 1.700 & 2.005 \\
\hline $\mathrm{Fe}^{3+}$ & 0.759 & 0.579 & 0.571 & 0.550 & 0.561 \\
\hline $\mathrm{Fe}^{2+}$ & 0.574 & 0.888 & 1.044 & 1.003 & 1.138 \\
\hline Mn & 0.015 & 0.044 & 0.023 & 0.060 & 0.075 \\
\hline Mg & 3.156 & 3.091 & 2.815 & 3.046 & 2.773 \\
\hline $\mathbf{C a}$ & 1.908 & 1.857 & 1.914 & 1.853 & 1.872 \\
\hline $\mathbf{N a}$ & 0.592 & 0.651 & 0.686 & 0.585 & 0.604 \\
\hline $\mathbf{K}$ & 0.220 & 0.189 & 0.184 & 0.179 & 0.187 \\
\hline Total & 15.72 & 15.70 & 15.78 & 15.62 & 15.66 \\
\hline \multicolumn{6}{|l|}{$\overline{\mathrm{P}-\mathrm{C} \text { conditions }}$} \\
\hline $\mathbf{T}\left({ }^{\circ} \mathbf{C}\right)$ & 1028 & 967 & 1017 & 929 & 962 \\
\hline Uncertanty & 22 & 22 & 22 & 22 & 22 \\
\hline $\mathbf{P}$ (MPa) & 589 & 308 & 574 & 221 & 343 \\
\hline Uncertanty & 65 & 34 & 63 & 24 & 38 \\
\hline $\begin{array}{l}\text { Equivalent depth } \\
(\mathbf{k m})\end{array}$ & 22.3 & 11.6 & 21.7 & 8.4 & 13.0 \\
\hline$\Delta$ NNO & 0.96 & 0.73 & 0.31 & 0.73 & 0.31 \\
\hline $\log \mathrm{fO}_{2}$ & -8.75 & -9.99 & -9.55 & -10.64 & -10.48 \\
\hline Uncertanty & 0.4 & 0.4 & 0.4 & 0.4 & 0.4 \\
\hline $\mathrm{H}_{2} \mathrm{O}_{\text {melt }}$ (wt.\%) & 5.5 & 4.0 & 6.1 & 3.7 & 5.1 \\
\hline Uncertanty & 0.8 & 0.6 & 0.9 & 0.6 & 0.8 \\
\hline
\end{tabular}

Cation proportions calculated using Leake et al. (1997) on the basis of 13 cations. $P-C=$ Physicalchemical conditions, calculated using the method of Ridolfi et al. (2010). 
Table A2.6 Major element amphibole compositions analysed by EMPA.

\begin{tabular}{|c|c|c|c|c|c|}
\hline $\begin{array}{l}\text { Sample } \\
\text { ID } \\
\text { Zone }\end{array}$ & $\begin{array}{r}\text { Inglewood b } \\
\text { A1_3 } \\
\text { zone }\end{array}$ & $\begin{array}{r}\text { Inglewood b } \\
\text { A1_5 } \\
\text { core }\end{array}$ & $\begin{array}{r}\text { Inglewood b } \\
\text { A1_6 } \\
\text { core }\end{array}$ & $\begin{array}{r}\text { Inglewood b } \\
\text { A2_2 } \\
\text { zone }\end{array}$ & $\begin{array}{r}\text { Inglewood b } \\
\text { A2_3 } \\
\text { rim }\end{array}$ \\
\hline$\overline{\mathrm{SiO}_{2}}$ & 43.11 & 42.73 & 40.13 & 40.78 & 43.03 \\
\hline $\mathrm{TiO}_{2}$ & 2.82 & 2.72 & 2.22 & 2.44 & 2.77 \\
\hline $\mathrm{Al}_{2} \mathrm{O}_{3}$ & 9.46 & 9.87 & 12.31 & 12.27 & 9.47 \\
\hline $\mathrm{Fe}_{2} \mathrm{O}_{3}$ & 6.33 & 6.00 & 6.96 & 4.02 & 4.65 \\
\hline FeO & 6.89 & 7.27 & 7.48 & 9.47 & 8.28 \\
\hline MnO & 0.58 & 0.64 & 0.46 & 0.37 & 0.57 \\
\hline MgO & 13.97 & 13.72 & 12.52 & 12.30 & 13.47 \\
\hline $\mathrm{CaO}$ & 11.38 & 11.44 & 11.69 & 11.91 & 11.40 \\
\hline $\mathrm{Na}_{2} \mathrm{O}$ & 2.00 & 2.05 & 2.15 & 2.09 & 1.94 \\
\hline $\mathbf{K}_{2} \mathbf{O}$ & 0.86 & 0.92 & 0.85 & 0.83 & 0.91 \\
\hline $\mathbf{H}_{2} \mathbf{O}_{\text {calc }}$ & 1.89 & 1.89 & 1.86 & 1.87 & 1.88 \\
\hline Total & 99.30 & 99.24 & 98.63 & 98.35 & 98.34 \\
\hline Mg\# & 78.32 & 77.09 & 74.89 & 69.84 & 74.36 \\
\hline \multicolumn{6}{|l|}{ Cations } \\
\hline $\mathbf{S i}$ & 6.352 & 6.313 & 6.006 & 6.116 & 6.412 \\
\hline $\mathbf{T i}$ & 0.312 & 0.302 & 0.250 & 0.275 & 0.310 \\
\hline Al & 1.643 & 1.719 & 2.171 & 2.169 & 1.663 \\
\hline $\mathrm{Fe}^{3+}$ & 0.702 & 0.667 & 0.784 & 0.453 & 0.521 \\
\hline $\mathrm{Fe}^{2+}$ & 0.849 & 0.898 & 0.937 & 1.188 & 1.031 \\
\hline Mn & 0.073 & 0.080 & 0.059 & 0.047 & 0.071 \\
\hline Mg & 3.068 & 3.022 & 2.794 & 2.751 & 2.991 \\
\hline $\mathbf{C a}$ & 1.796 & 1.811 & 1.874 & 1.914 & 1.820 \\
\hline $\mathbf{N a}$ & 0.572 & 0.588 & 0.624 & 0.608 & 0.560 \\
\hline $\mathbf{K}$ & 0.161 & 0.173 & 0.162 & 0.160 & 0.172 \\
\hline Total & 15.53 & 15.57 & 15.66 & 15.68 & 15.55 \\
\hline \multicolumn{6}{|l|}{$\overline{\mathrm{P}-\mathrm{C} \text { conditions }}$} \\
\hline $\mathbf{T}\left({ }^{\circ} \mathbf{C}\right)$ & 915 & 924 & 984 & 978 & 910 \\
\hline Uncertanty & 22 & 22 & 22 & 22 & 22 \\
\hline $\mathbf{P}$ (MPa) & 204 & 228 & 436 & 435 & 210 \\
\hline Uncertanty & 22 & 25 & 48 & 48 & 23 \\
\hline $\begin{array}{l}\text { Equivalent depth } \\
(\mathrm{km})\end{array}$ & 7.7 & 8.6 & 16.5 & 16.4 & 7.9 \\
\hline$\Delta$ NNO & 0.90 & 0.80 & 0.48 & 0.26 & 0.72 \\
\hline $\log \mathrm{fO}_{2}$ & -10.72 & -10.65 & -9.93 & -10.24 & -10.98 \\
\hline Uncertanty & 0.4 & 0.4 & 0.4 & 0.4 & 0.4 \\
\hline $\mathrm{H}_{2} \mathrm{O}_{\text {melt }}$ (wt.\%) & 3.8 & 4.0 & 5.9 & 6.4 & 4.1 \\
\hline Uncertanty & 0.6 & 0.6 & 0.9 & 1.0 & 0.6 \\
\hline
\end{tabular}

Cation proportions calculated using Leake et al. (1997) on the basis of 13 cations. P-C = Physicalchemical conditions, calculated using the method of Ridolfi et al. (2010). 
Table A2.6 Major element amphibole compositions analysed by EMPA.

\begin{tabular}{|c|c|c|c|c|c|}
\hline $\begin{array}{l}\text { Sample } \\
\text { ID } \\
\text { Zone }\end{array}$ & $\begin{array}{r}\text { Inglewood b } \\
\text { A2_5 } \\
\text { zone }\end{array}$ & $\begin{array}{r}\text { Inglewood b } \\
\text { A2_6 } \\
\text { core }\end{array}$ & $\begin{array}{r}\text { Inglewood b } \\
\text { A3_1 } \\
\text { rim }\end{array}$ & $\begin{array}{r}\text { Inglewood b } \\
\text { A3_2 } \\
\text { core }\end{array}$ & $\begin{array}{r}\text { Inglewood b } \\
\text { A3_5 } \\
\text { core }\end{array}$ \\
\hline$\overline{\mathrm{SiO}_{2}}$ & 40.15 & 39.21 & 42.97 & 40.02 & 42.92 \\
\hline $\mathrm{TiO}_{2}$ & 2.16 & 2.10 & 2.78 & 2.52 & 2.93 \\
\hline $\mathrm{Al}_{2} \mathrm{O}_{3}$ & 13.14 & 13.51 & 9.45 & 12.34 & 9.62 \\
\hline $\mathrm{Fe}_{2} \mathrm{O}_{3}$ & 4.82 & 5.57 & 5.26 & 6.00 & 5.82 \\
\hline $\mathrm{FeO}$ & 9.72 & 9.89 & 7.81 & 8.69 & 7.59 \\
\hline MnO & 0.34 & 0.35 & 0.57 & 0.38 & 0.57 \\
\hline MgO & 11.58 & 11.08 & 13.64 & 12.19 & 13.55 \\
\hline $\mathrm{CaO}$ & 11.81 & 11.81 & 11.42 & 11.80 & 11.31 \\
\hline $\mathrm{Na}_{2} \mathrm{O}$ & 2.12 & 2.17 & 1.96 & 2.14 & 1.98 \\
\hline $\mathrm{K}_{2} \mathrm{O}$ & 0.87 & 0.85 & 0.89 & 0.86 & 0.91 \\
\hline $\mathbf{H}_{2} \mathbf{O}_{\text {calc }}$ & 1.86 & 1.85 & 1.88 & 1.86 & 1.89 \\
\hline Total & 98.57 & 98.40 & 98.62 & 98.80 & 99.09 \\
\hline Mg\# & 67.97 & 66.63 & 75.69 & 71.42 & 76.07 \\
\hline \multicolumn{6}{|l|}{ Cations } \\
\hline $\mathbf{S i}$ & 6.030 & 5.928 & 6.384 & 5.999 & 6.350 \\
\hline $\mathbf{T i}$ & 0.244 & 0.239 & 0.310 & 0.284 & 0.326 \\
\hline Al & 2.326 & 2.408 & 1.654 & 2.180 & 1.678 \\
\hline $\mathrm{Fe}^{3+}$ & 0.545 & 0.633 & 0.588 & 0.677 & 0.648 \\
\hline $\mathrm{Fe}^{2+}$ & 1.221 & 1.251 & 0.970 & 1.090 & 0.940 \\
\hline Mn & 0.043 & 0.044 & 0.072 & 0.048 & 0.072 \\
\hline Mg & 2.591 & 2.497 & 3.021 & 2.723 & 2.987 \\
\hline $\mathrm{Ca}$ & 1.900 & 1.912 & 1.818 & 1.896 & 1.792 \\
\hline $\mathbf{N a}$ & 0.616 & 0.636 & 0.564 & 0.622 & 0.567 \\
\hline $\mathbf{K}$ & 0.166 & 0.165 & 0.168 & 0.165 & 0.172 \\
\hline Total & 15.68 & 15.71 & 15.55 & 15.68 & 15.53 \\
\hline \multicolumn{6}{|l|}{ P-C conditions } \\
\hline $\mathbf{T}\left({ }^{\circ} \mathbf{C}\right)$ & 990 & 1003 & 913 & 987 & 915 \\
\hline Uncertanty & 22 & 22 & 22 & 22 & 22 \\
\hline $\mathbf{P}(\mathbf{M P a})$ & 545 & 612 & 207 & 441 & 214 \\
\hline Uncertanty & 60 & 67 & 23 & 49 & 24 \\
\hline $\begin{array}{l}\text { Equivalent depth } \\
(\mathrm{km})\end{array}$ & 20.6 & 23.1 & 7.8 & 16.7 & 8.1 \\
\hline$\Delta$ NNO & 0.10 & -0.02 & 0.78 & 0.28 & 0.73 \\
\hline $\log \mathrm{fO}_{2}$ & -10.18 & -10.08 & -10.88 & -10.09 & -10.89 \\
\hline Uncertanty & 0.4 & 0.4 & 0.4 & 0.4 & 0.4 \\
\hline $\mathrm{H}_{2} \mathrm{O}_{\text {melt }}($ wt. \%) & 7.1 & 7.3 & 4.0 & 5.9 & 3.9 \\
\hline Uncertanty & 1.1 & 1.1 & 0.6 & 0.9 & 0.6 \\
\hline
\end{tabular}

Cation proportions calculated using Leake et al. (1997) on the basis of 13 cations. P-C = Physicalchemical conditions, calculated using the method of Ridolfi et al. (2010). 
Table A2.6 Major element amphibole compositions analysed by EMPA.

\begin{tabular}{|c|c|c|c|c|c|}
\hline $\begin{array}{l}\text { Sample } \\
\text { ID } \\
\text { Zone }\end{array}$ & $\begin{array}{r}\text { Inglewood b } \\
\text { A4_1 } \\
\text { rim }\end{array}$ & $\begin{array}{r}\text { Inglewood b } \\
\text { A4_2 } \\
\text { core }\end{array}$ & $\begin{array}{r}\text { Inglewood b } \\
\text { A4_3 } \\
\text { core }\end{array}$ & $\begin{array}{r}\text { Inglewood b } \\
\text { A5_1 } \\
\text { rim }\end{array}$ & $\begin{array}{r}\text { Inglewood b } \\
\text { A5_2 } \\
\text { zone }\end{array}$ \\
\hline $\mathrm{SiO}_{2}$ & 42.41 & 43.00 & 41.25 & 42.80 & 42.60 \\
\hline $\mathrm{TiO}_{2}$ & 2.85 & 2.89 & 2.49 & 2.80 & 2.65 \\
\hline $\mathbf{A l}_{2} \mathbf{O}_{3}$ & 9.74 & 9.58 & 12.11 & 9.87 & 10.07 \\
\hline $\mathrm{Fe}_{2} \mathrm{O}_{3}$ & 4.34 & 4.80 & 5.54 & 6.41 & 5.92 \\
\hline $\mathrm{FeO}$ & 8.50 & 7.86 & 7.91 & 6.68 & 6.99 \\
\hline $\mathrm{MnO}$ & 0.57 & 0.56 & 0.52 & 0.58 & 0.60 \\
\hline MgO & 13.45 & 13.91 & 12.70 & 13.90 & 13.76 \\
\hline $\mathrm{CaO}$ & 11.58 & 11.56 & 11.54 & 11.35 & 11.43 \\
\hline $\mathrm{Na}_{2} \mathrm{O}$ & 2.02 & 2.05 & 2.14 & 1.99 & 2.04 \\
\hline $\mathbf{K}_{2} \mathbf{O}$ & 0.93 & 0.90 & 0.88 & 0.92 & 0.84 \\
\hline $\mathrm{H}_{2} \mathrm{O}_{\text {calc }}$ & 1.87 & 1.89 & 1.88 & 1.89 & 1.88 \\
\hline Total & 98.27 & 98.99 & 98.95 & 99.20 & 98.77 \\
\hline Mg\# & 73.82 & 75.94 & 74.11 & 78.75 & 77.82 \\
\hline \multicolumn{6}{|l|}{ Cations } \\
\hline $\mathbf{S i}$ & 6.341 & 6.363 & 6.125 & 6.311 & 6.310 \\
\hline $\mathbf{T i}$ & 0.321 & 0.322 & 0.279 & 0.311 & 0.295 \\
\hline Al & 1.717 & 1.671 & 2.120 & 1.715 & 1.758 \\
\hline $\mathrm{Fe}^{3+}$ & 0.488 & 0.534 & 0.619 & 0.712 & 0.659 \\
\hline $\mathrm{Fe}^{2+}$ & 1.063 & 0.972 & 0.982 & 0.824 & 0.866 \\
\hline Mn & 0.072 & 0.070 & 0.065 & 0.072 & 0.075 \\
\hline Mg & 2.998 & 3.068 & 2.811 & 3.054 & 3.037 \\
\hline $\mathbf{C a}$ & 1.854 & 1.833 & 1.836 & 1.793 & 1.814 \\
\hline $\mathbf{N a}$ & 0.585 & 0.589 & 0.616 & 0.569 & 0.586 \\
\hline $\mathbf{K}$ & 0.178 & 0.170 & 0.166 & 0.174 & 0.159 \\
\hline Total & 15.62 & 15.59 & 15.62 & 15.54 & 15.56 \\
\hline \multicolumn{6}{|l|}{ P-C conditions } \\
\hline $\mathbf{T}\left({ }^{\circ} \mathbf{C}\right)$ & 927 & 921 & 969 & 923 & 928 \\
\hline Uncertanty & 22 & 22 & 22 & 22 & 22 \\
\hline P (MPa) & 227 & 212 & 405 & 226 & 241 \\
\hline Uncertanty & 25 & 23 & 45 & 25 & 26 \\
\hline $\begin{array}{l}\text { Equivalent depth } \\
(\mathbf{k m})\end{array}$ & 8.6 & 8.0 & 15.3 & 8.5 & 9.1 \\
\hline$\Delta \mathbf{N N O}$ & 0.65 & 0.78 & 0.42 & 0.86 & 0.82 \\
\hline $\log \mathrm{fO}_{2}$ & -10.76 & -10.73 & -10.24 & -10.61 & -10.57 \\
\hline Uncertanty & 0.4 & 0.4 & 0.4 & 0.4 & 0.4 \\
\hline $\mathrm{H}_{2} \mathrm{O}_{\text {melt }}$ (wt.\%) & 4.0 & 3.8 & 6.0 & 3.9 & 4.4 \\
\hline Uncertanty & 0.6 & 0.6 & 0.9 & 0.6 & 0.7 \\
\hline
\end{tabular}

Cation proportions calculated using Leake et al. (1997) on the basis of 13 cations. P-C = Physicalchemical conditions, calculated using the method of Ridolfi et al. (2010). 
Table A2.6 Major element amphibole compositions analysed by EMPA.

\begin{tabular}{|c|c|c|c|c|c|}
\hline $\begin{array}{l}\text { Sample } \\
\text { ID } \\
\text { Zone }\end{array}$ & $\begin{array}{r}\text { Inglewood b } \\
\text { A5_3 } \\
\text { core }\end{array}$ & $\begin{array}{r}\text { Inglewood b } \\
\text { A5_4 } \\
\text { core }\end{array}$ & $\begin{array}{c}\text { Inglewood b } \\
\text { A6_1 } \\
\text { rim }\end{array}$ & $\begin{array}{r}\text { Inglewood b } \\
\text { A6_2 } \\
\text { core }\end{array}$ & $\begin{array}{r}\text { Inglewood b } \\
\text { A7_2 } \\
\text { zone }\end{array}$ \\
\hline $\mathrm{SiO}_{2}$ & 43.35 & 40.42 & 42.98 & 40.20 & 39.26 \\
\hline $\mathrm{TiO}_{2}$ & 2.86 & 2.79 & 2.89 & 2.34 & 2.62 \\
\hline $\mathbf{A l}_{2} \mathbf{O}_{3}$ & 9.77 & 12.45 & 9.59 & 12.23 & 12.92 \\
\hline $\mathrm{Fe}_{2} \mathrm{O}_{3}$ & 5.54 & 6.00 & 5.22 & 4.87 & 5.02 \\
\hline $\mathrm{FeO}$ & 7.40 & 8.12 & 8.00 & 8.98 & 9.23 \\
\hline $\mathrm{MnO}$ & 0.54 & 0.55 & 0.65 & 0.29 & 0.25 \\
\hline MgO & 13.79 & 12.40 & 13.39 & 12.39 & 12.08 \\
\hline $\mathrm{CaO}$ & 11.36 & 11.60 & 11.25 & 11.94 & 11.97 \\
\hline $\mathrm{Na}_{2} \mathrm{O}$ & 1.98 & 2.22 & 1.99 & 2.11 & 2.25 \\
\hline $\mathbf{K}_{2} \mathbf{O}$ & 0.87 & 0.91 & 0.98 & 0.82 & 0.86 \\
\hline $\mathrm{H}_{2} \mathrm{O}_{\text {calc }}$ & 1.90 & 1.88 & 1.88 & 1.86 & 1.85 \\
\hline Total & 99.36 & 99.33 & 98.81 & 98.04 & 98.29 \\
\hline Mg\# & 76.87 & 73.14 & 74.90 & 71.09 & 70.00 \\
\hline \multicolumn{6}{|l|}{ Cations } \\
\hline $\mathbf{S i}$ & 6.376 & 6.009 & 6.380 & 6.057 & 5.923 \\
\hline $\mathbf{T i}$ & 0.316 & 0.312 & 0.323 & 0.265 & 0.297 \\
\hline Al & 1.693 & 2.181 & 1.679 & 2.172 & 2.297 \\
\hline $\mathrm{Fe}^{3+}$ & 0.613 & 0.671 & 0.583 & 0.553 & 0.571 \\
\hline $\mathrm{Fe}^{2+}$ & 0.910 & 1.009 & 0.992 & 1.132 & 1.164 \\
\hline Mn & 0.068 & 0.069 & 0.082 & 0.037 & 0.032 \\
\hline Mg & 3.024 & 2.748 & 2.962 & 2.783 & 2.717 \\
\hline $\mathbf{C a}$ & 1.790 & 1.847 & 1.789 & 1.928 & 1.935 \\
\hline $\mathbf{N a}$ & 0.565 & 0.640 & 0.572 & 0.616 & 0.658 \\
\hline $\mathbf{K}$ & 0.164 & 0.172 & 0.185 & 0.157 & 0.165 \\
\hline Total & 15.52 & 15.66 & 15.55 & 15.70 & 15.76 \\
\hline \multicolumn{6}{|l|}{ P-C conditions } \\
\hline $\mathbf{T}\left({ }^{\circ} \mathbf{C}\right)$ & 914 & 986 & 912 & 985 & 1009 \\
\hline Uncertanty & 22 & 22 & 22 & 22 & 22 \\
\hline P (MPa) & 219 & 442 & 215 & 436 & 522 \\
\hline Uncertanty & 24 & 49 & 24 & 48 & 57 \\
\hline $\begin{array}{l}\text { Equivalent depth } \\
(\mathbf{k m})\end{array}$ & 8.3 & 16.7 & 8.1 & 16.5 & 19.7 \\
\hline$\Delta \mathbf{N N O}$ & 0.78 & 0.26 & 0.68 & 0.35 & 0.15 \\
\hline $\log \mathrm{fO}_{2}$ & -10.85 & -10.12 & -10.99 & -10.05 & -9.86 \\
\hline Uncertanty & 0.4 & 0.4 & 0.4 & 0.4 & 0.4 \\
\hline $\mathrm{H}_{2} \mathrm{O}_{\text {melt }}$ (wt.\%) & 4.2 & 5.8 & 3.9 & 6.2 & 6.2 \\
\hline Uncertanty & 0.6 & 0.9 & 0.6 & 0.9 & 0.9 \\
\hline
\end{tabular}

Cation proportions calculated using Leake et al. (1997) on the basis of 13 cations. P-C = Physicalchemical conditions, calculated using the method of Ridolfi et al. (2010). 
Table A2.6 Major element amphibole compositions analysed by EMPA.

\begin{tabular}{|c|c|c|c|c|c|}
\hline Sample & Inglewood b & Inglewood b & Inglewood b & Inglewood b & $\begin{array}{c}\text { Inglewood b } \\
\end{array}$ \\
\hline ID & A7_3 & A7_4 & A8_1 & A8_2 & A8_3 \\
\hline Zone & core & core & rim & core & core \\
\hline $\mathrm{SiO}_{2}$ & 39.75 & 42.55 & 43.15 & 39.38 & 43.13 \\
\hline $\mathrm{TiO}_{2}$ & 2.67 & 3.12 & 3.10 & 3.16 & 3.11 \\
\hline $\mathbf{A l}_{2} \mathbf{O}_{3}$ & 12.50 & 9.64 & 9.53 & 13.16 & 9.72 \\
\hline $\mathrm{Fe}_{2} \mathrm{O}_{3}$ & 4.55 & 5.59 & 5.60 & 5.83 & 5.92 \\
\hline $\mathrm{FeO}$ & 10.48 & 8.18 & 7.36 & 8.38 & 7.19 \\
\hline MnO & 0.32 & 0.64 & 0.49 & 0.45 & 0.55 \\
\hline MgO & 11.57 & 13.15 & 14.00 & 11.93 & 14.00 \\
\hline $\mathrm{CaO}$ & 11.88 & 11.15 & 11.48 & 11.53 & 11.44 \\
\hline $\mathrm{Na}_{2} \mathrm{O}$ & 2.22 & 2.09 & 1.98 & 2.24 & 2.05 \\
\hline $\mathbf{K}_{2} \mathbf{O}$ & 0.90 & 0.95 & 0.87 & 0.89 & 0.91 \\
\hline $\mathrm{H}_{2} \mathrm{O}_{\text {calc }}$ & 1.85 & 1.88 & 1.90 & 1.86 & 1.90 \\
\hline Total & 98.69 & 98.92 & 99.44 & 98.82 & 99.91 \\
\hline Mg\# & 66.32 & 74.14 & 77.22 & 71.74 & 77.64 \\
\hline \multicolumn{6}{|l|}{ Cations } \\
\hline $\mathbf{S i}$ & 5.996 & 6.327 & 6.349 & 5.896 & 6.320 \\
\hline $\mathbf{T i}$ & 0.303 & 0.349 & 0.343 & 0.355 & 0.342 \\
\hline Al & 2.221 & 1.689 & 1.652 & 2.322 & 1.679 \\
\hline $\mathrm{Fe}^{3+}$ & 0.516 & 0.625 & 0.620 & 0.657 & 0.652 \\
\hline $\mathrm{Fe}^{2+}$ & 1.321 & 1.016 & 0.906 & 1.049 & 0.881 \\
\hline Mn & 0.040 & 0.081 & 0.062 & 0.058 & 0.068 \\
\hline Mg & 2.602 & 2.914 & 3.070 & 2.663 & 3.058 \\
\hline $\mathbf{C a}$ & 1.920 & 1.776 & 1.809 & 1.850 & 1.796 \\
\hline $\mathbf{N a}$ & 0.651 & 0.601 & 0.564 & 0.649 & 0.583 \\
\hline $\mathbf{K}$ & 0.174 & 0.181 & 0.164 & 0.169 & 0.169 \\
\hline Total & 15.74 & 15.56 & 15.54 & 15.67 & 15.55 \\
\hline \multicolumn{6}{|l|}{ P-C conditions } \\
\hline $\mathbf{T}\left({ }^{\circ} \mathbf{C}\right)$ & 991 & 917 & 918 & 1008 & 922 \\
\hline Uncertanty & 22 & 22 & 22 & 22 & 22 \\
\hline P (MPa) & 469 & 218 & 207 & 542 & 215 \\
\hline Uncertanty & 52 & 24 & 23 & 60 & 24 \\
\hline $\begin{array}{l}\text { Equivalent depth } \\
(\mathbf{k m})\end{array}$ & 17.7 & 8.2 & 7.8 & 20.5 & 8.1 \\
\hline$\Delta \mathbf{N N O}$ & -0.01 & 0.56 & 0.80 & 0.01 & 0.79 \\
\hline $\log \mathrm{fO}_{2}$ & -10.30 & -11.02 & -10.77 & -10.00 & -10.70 \\
\hline Uncertanty & 0.4 & 0.4 & 0.4 & 0.4 & 0.4 \\
\hline $\mathrm{H}_{2} \mathrm{O}_{\text {melt }}$ (wt.\%) & 6.1 & 3.8 & 3.8 & 6.3 & 3.7 \\
\hline Uncertanty & 0.9 & 0.6 & 0.6 & 0.9 & 0.6 \\
\hline
\end{tabular}

Cation proportions calculated using Leake et al. (1997) on the basis of 13 cations. P-C = Physicalchemical conditions, calculated using the method of Ridolfi et al. (2010). 
Table A2.6 Major element amphibole compositions analysed by EMPA.

\begin{tabular}{|c|c|c|c|c|c|}
\hline $\begin{array}{l}\text { Sample } \\
\text { ID } \\
\text { Zone }\end{array}$ & $\begin{array}{r}\text { Inglewood b } \\
\text { A11_1 } \\
\text { rim }\end{array}$ & $\begin{array}{r}\text { Inglewood b } \\
\text { A11_2 } \\
\text { core }\end{array}$ & $\begin{array}{r}\text { Inglewood b } \\
\text { A11_3 } \\
\text { core }\end{array}$ & $\begin{array}{r}\text { Inglewood a } \\
\text { A2_3 } \\
\text { zone }\end{array}$ & $\begin{array}{r}\text { Inglewood a } \\
\text { A5_1 } \\
\text { rim }\end{array}$ \\
\hline$\overline{\mathrm{SiO}_{2}}$ & 42.62 & 40.70 & 42.53 & 42.72 & 39.21 \\
\hline $\mathrm{TiO}_{2}$ & 2.95 & 2.63 & 3.03 & 3.43 & 2.95 \\
\hline $\mathrm{Al}_{2} \mathrm{O}_{3}$ & 9.54 & 11.98 & 9.57 & 9.54 & 13.26 \\
\hline $\mathrm{Fe}_{2} \mathrm{O}_{3}$ & 4.46 & 6.01 & 5.30 & 2.36 & 3.07 \\
\hline FeO & 8.14 & 7.94 & 7.54 & 10.04 & 11.24 \\
\hline MnO & 0.53 & 0.55 & 0.55 & 0.50 & 0.24 \\
\hline MgO & 13.59 & 12.77 & 13.66 & 13.17 & 11.26 \\
\hline $\mathrm{CaO}$ & 11.44 & 11.69 & 11.29 & 11.40 & 11.84 \\
\hline $\mathrm{Na}_{2} \mathrm{O}$ & 1.97 & 2.28 & 2.02 & 2.25 & 2.40 \\
\hline $\mathrm{K}_{2} \mathrm{O}$ & 0.91 & 0.85 & 0.93 & 0.86 & 0.86 \\
\hline $\mathbf{H}_{2} \mathbf{O}_{\text {calc }}$ & 1.87 & 1.88 & 1.87 & 1.88 & 1.85 \\
\hline Total & 98.01 & 99.26 & 98.30 & 98.16 & 98.18 \\
\hline Mg\# & 74.86 & 74.13 & 76.35 & 70.05 & 67.74 \\
\hline \multicolumn{6}{|l|}{ Cations } \\
\hline $\mathbf{S i}$ & 6.372 & 6.051 & 6.339 & 6.400 & 5.944 \\
\hline $\mathbf{T i}$ & 0.332 & 0.294 & 0.340 & 0.387 & 0.336 \\
\hline Al & 1.680 & 2.098 & 1.682 & 1.684 & 2.370 \\
\hline $\mathrm{Fe}^{3+}$ & 0.502 & 0.672 & 0.594 & 0.266 & 0.350 \\
\hline $\mathrm{Fe}^{2+}$ & 1.017 & 0.987 & 0.940 & 1.258 & 1.425 \\
\hline Mn & 0.067 & 0.069 & 0.069 & 0.064 & 0.030 \\
\hline Mg & 3.029 & 2.829 & 3.036 & 2.942 & 2.544 \\
\hline Ca & 1.832 & 1.862 & 1.803 & 1.830 & 1.924 \\
\hline $\mathbf{N a}$ & 0.571 & 0.656 & 0.582 & 0.653 & 0.705 \\
\hline $\mathbf{K}$ & 0.174 & 0.162 & 0.177 & 0.164 & 0.167 \\
\hline Total & 15.58 & 15.68 & 15.56 & 15.65 & 15.80 \\
\hline \multicolumn{6}{|l|}{$\overline{\mathrm{P}-\mathrm{C} \text { conditions }}$} \\
\hline $\mathbf{T}\left({ }^{\circ} \mathbf{C}\right)$ & 919 & 979 & 921 & 921 & 1011 \\
\hline Uncertanty & 22 & 22 & 22 & 22 & 22 \\
\hline $\mathbf{P}$ (MPa) & 215 & 392 & 216 & 216 & 580 \\
\hline Uncertanty & 24 & 43 & 24 & 24 & 64 \\
\hline $\begin{array}{l}\text { Equivalent depth } \\
(\mathbf{k m})\end{array}$ & 8.1 & 14.8 & 8.1 & 8.2 & 21.9 \\
\hline$\Delta$ NNO & 0.70 & 0.41 & 0.73 & 0.35 & -0.28 \\
\hline $\log \mathrm{fO}_{2}$ & -10.83 & -10.09 & -10.78 & -11.16 & -10.23 \\
\hline Uncertanty & 0.4 & 0.4 & 0.4 & 0.4 & 0.4 \\
\hline $\mathrm{H}_{2} \mathrm{O}_{\text {melt }}$ (wt.\%) & 3.9 & 5.5 & 3.7 & 3.9 & 6.7 \\
\hline Uncertanty & 0.6 & 0.8 & 0.6 & 0.6 & 1.0 \\
\hline
\end{tabular}

Cation proportions calculated using Leake et al. (1997) on the basis of 13 cations. $P-C=$ Physicalchemical conditions, calculated using the method of Ridolfi et al. (2010). 
Table A2.6 Major element amphibole compositions analysed by EMPA.

\begin{tabular}{|c|c|c|c|c|c|}
\hline $\begin{array}{l}\text { Sample } \\
\text { ID } \\
\text { Zone }\end{array}$ & $\begin{array}{r}\text { Inglewood a } \\
\text { A5_6 } \\
\text { core }\end{array}$ & $\begin{array}{r}\text { Inglewood a } \\
\text { A6_1 } \\
\text { rim }\end{array}$ & $\begin{array}{r}\text { Inglewood a } \\
\text { A13_7 } \\
\text { core }\end{array}$ & $\begin{array}{r}\text { Inglewood a } \\
\text { A7_1 } \\
\text { rim }\end{array}$ & $\begin{array}{r}\text { Inglewood a } \\
\text { A8_2 } \\
\text { zone }\end{array}$ \\
\hline$\overline{\mathrm{SiO}_{2}}$ & 39.52 & 40.81 & 42.45 & 40.02 & 42.14 \\
\hline $\mathbf{T i O}_{2}$ & 2.78 & 3.17 & 3.01 & 2.44 & 2.78 \\
\hline $\mathrm{Al}_{2} \mathrm{O}_{3}$ & 13.03 & 11.64 & 10.14 & 11.91 & 9.86 \\
\hline $\mathrm{Fe}_{2} \mathrm{O}_{3}$ & 3.53 & 2.44 & 5.72 & 4.92 & 5.68 \\
\hline $\mathrm{FeO}$ & 11.14 & 11.08 & 7.08 & 9.23 & 7.75 \\
\hline MnO & 0.27 & 0.37 & 0.39 & 0.32 & 0.50 \\
\hline MgO & 11.25 & 12.05 & 13.72 & 12.35 & 13.30 \\
\hline $\mathrm{CaO}$ & 11.81 & 11.76 & 11.27 & 11.87 & 11.30 \\
\hline $\mathrm{Na}_{2} \mathrm{O}$ & 2.39 & 2.36 & 2.08 & 2.20 & 2.00 \\
\hline $\mathbf{K}_{2} \mathbf{O}$ & 0.81 & 0.81 & 0.81 & 0.91 & 0.92 \\
\hline $\mathbf{H}_{2} \mathbf{O}_{\text {calc }}$ & 1.85 & 1.87 & 1.88 & 1.85 & 1.86 \\
\hline Total & 98.37 & 98.35 & 98.56 & 98.03 & 98.09 \\
\hline Mg\# & 61.85 & 64.28 & 65.96 & 76.79 & 75.42 \\
\hline \multicolumn{6}{|l|}{ Cations } \\
\hline $\mathbf{S i}$ & 5.979 & 6.148 & 6.294 & 6.049 & 6.307 \\
\hline $\mathbf{T i}$ & 0.316 & 0.360 & 0.336 & 0.278 & 0.313 \\
\hline Al & 2.323 & 2.066 & 1.772 & 2.122 & 1.739 \\
\hline $\mathrm{Fe}^{3+}$ & 0.402 & 0.276 & 0.638 & 0.560 & 0.640 \\
\hline $\mathrm{Fe}^{2+}$ & 1.409 & 1.396 & 0.878 & 1.166 & 0.970 \\
\hline Mn & 0.034 & 0.047 & 0.049 & 0.041 & 0.064 \\
\hline Mg & 2.536 & 2.706 & 3.033 & 2.784 & 2.967 \\
\hline $\mathrm{Ca}$ & 1.914 & 1.899 & 1.790 & 1.922 & 1.813 \\
\hline $\mathbf{N a}$ & 0.700 & 0.688 & 0.598 & 0.643 & 0.579 \\
\hline $\mathbf{K}$ & 0.156 & 0.156 & 0.153 & 0.176 & 0.177 \\
\hline Total & 15.77 & 15.74 & 15.54 & 15.74 & 15.57 \\
\hline \multicolumn{6}{|l|}{ P-C conditions } \\
\hline $\mathbf{T}\left({ }^{\circ} \mathbf{C}\right)$ & 1001 & 973 & 930 & 983 & 924 \\
\hline Uncertanty & 22 & 22 & 22 & 22 & 22 \\
\hline $\mathbf{P}$ (MPa) & 543 & 375 & 246 & 406 & 234 \\
\hline Uncertanty & 60 & 41 & 27 & 45 & 26 \\
\hline $\begin{array}{l}\text { Equivalent depth } \\
(\mathrm{km})\end{array}$ & 20.5 & 14.2 & 9.3 & 15.3 & 8.8 \\
\hline$\Delta \mathbf{N N O}$ & -0.22 & -0.05 & 0.73 & 0.33 & 0.70 \\
\hline $\log \mathrm{fO}_{2}$ & -10.33 & -10.66 & -10.62 & -10.11 & -10.75 \\
\hline Uncertanty & 0.4 & 0.4 & 0.4 & 0.4 & 0.4 \\
\hline $\mathrm{H}_{2} \mathrm{O}_{\text {melt }}$ (wt.\%) & 6.7 & 5.6 & 4.3 & 5.5 & 4.1 \\
\hline Uncertanty & 1.0 & 0.8 & 0.7 & 0.8 & 0.6 \\
\hline
\end{tabular}

Cation proportions calculated using Leake et al. (1997) on the basis of 13 cations. $P-C=$ Physicalchemical conditions, calculated using the method of Ridolfi et al. (2010). 
Table A2.6 Major element amphibole compositions analysed by EMPA.

\begin{tabular}{|c|c|c|c|c|c|}
\hline $\begin{array}{l}\text { Sample } \\
\text { ID } \\
\text { Zone } \\
\end{array}$ & $\begin{array}{r}\text { Inglewood a } \\
\text { A9_1 } \\
\text { rim } \\
\end{array}$ & $\begin{array}{r}\text { Inglewood a } \\
\text { A9_2 } \\
\text { core } \\
\end{array}$ & $\begin{array}{r}\text { Inglewood a } \\
\text { A9_3 } \\
\text { core } \\
\end{array}$ & $\begin{array}{r}\text { Inglewood a } \\
\text { A9_4 } \\
\text { zone } \\
\end{array}$ & $\begin{array}{r}\text { Inglewood a } \\
\text { A10_2 } \\
\text { zone }\end{array}$ \\
\hline$\overline{\mathrm{SiO}_{2}}$ & 43.79 & 43.53 & 40.00 & 40.92 & 41.22 \\
\hline $\mathbf{T i O}_{2}$ & 2.73 & 2.72 & 2.30 & 2.32 & 2.50 \\
\hline $\mathrm{Al}_{2} \mathrm{O}_{3}$ & 9.46 & 9.52 & 13.49 & 12.63 & 11.28 \\
\hline $\mathrm{Fe}_{2} \mathrm{O}_{3}$ & 6.16 & 5.20 & 5.52 & 6.03 & 6.27 \\
\hline $\mathrm{FeO}$ & 6.77 & 7.66 & 8.31 & 8.42 & 8.45 \\
\hline MnO & 0.61 & 0.61 & 0.25 & 0.30 & 0.53 \\
\hline MgO & 14.23 & 13.96 & 12.42 & 12.48 & 12.56 \\
\hline $\mathrm{CaO}$ & 11.42 & 11.52 & 11.94 & 11.81 & 11.64 \\
\hline $\mathrm{Na}_{2} \mathrm{O}$ & 2.00 & 2.05 & 2.23 & 2.18 & 2.11 \\
\hline $\mathbf{K}_{2} \mathbf{O}$ & 0.89 & 0.88 & 0.89 & 0.85 & 0.89 \\
\hline $\mathbf{H}_{2} \mathbf{O}_{\text {calc }}$ & 1.91 & 1.90 & 1.88 & 1.89 & 1.87 \\
\hline Total & 99.96 & 99.55 & 99.22 & 99.83 & 99.31 \\
\hline Mg\# & 78.93 & 76.45 & 72.72 & 72.55 & 72.61 \\
\hline \multicolumn{6}{|l|}{ Cations } \\
\hline $\mathbf{S i}$ & 6.395 & 6.398 & 5.945 & 6.045 & 6.135 \\
\hline $\mathbf{T i}$ & 0.300 & 0.300 & 0.257 & 0.258 & 0.279 \\
\hline Al & 1.629 & 1.649 & 2.364 & 2.200 & 1.979 \\
\hline $\mathrm{Fe}^{3+}$ & 0.677 & 0.575 & 0.618 & 0.670 & 0.702 \\
\hline $\mathrm{Fe}^{2+}$ & 0.827 & 0.942 & 1.033 & 1.040 & 1.051 \\
\hline Mn & 0.075 & 0.076 & 0.031 & 0.038 & 0.066 \\
\hline Mg & 3.098 & 3.059 & 2.752 & 2.749 & 2.787 \\
\hline $\mathrm{Ca}$ & 1.787 & 1.814 & 1.901 & 1.870 & 1.856 \\
\hline $\mathbf{N a}$ & 0.565 & 0.584 & 0.643 & 0.624 & 0.610 \\
\hline $\mathbf{K}$ & 0.166 & 0.165 & 0.169 & 0.160 & 0.169 \\
\hline Total & 15.52 & 15.56 & 15.71 & 15.65 & 15.63 \\
\hline \multicolumn{6}{|l|}{ P-C conditions } \\
\hline $\mathbf{T}\left({ }^{\circ} \mathbf{C}\right)$ & 909 & 912 & 1008 & 981 & 956 \\
\hline Uncertanty & 22 & 22 & 22 & 22 & 22 \\
\hline $\mathbf{P}$ (MPa) & 200 & 206 & 575 & 454 & 331 \\
\hline Uncertanty & 22 & 23 & 63 & 50 & 36 \\
\hline $\begin{array}{l}\text { Equivalent depth } \\
(\mathrm{km})\end{array}$ & 7.5 & 7.8 & 21.7 & 17.2 & 12.5 \\
\hline$\Delta$ NNO & 0.95 & 0.84 & 0.29 & 0.37 & 0.45 \\
\hline $\log \mathrm{fO}_{2}$ & -10.78 & -10.83 & -9.71 & -10.08 & -10.44 \\
\hline Uncertanty & 0.4 & 0.4 & 0.4 & 0.4 & 0.4 \\
\hline $\mathrm{H}_{2} \mathrm{O}_{\text {melt }}$ (wt.\%) & 3.8 & 3.9 & 6.7 & 6.3 & 5.2 \\
\hline Uncertanty & 0.6 & 0.6 & 1.0 & 0.9 & 0.8 \\
\hline
\end{tabular}

Cation proportions calculated using Leake et al. (1997) on the basis of 13 cations. P-C = Physicalchemical conditions, calculated using the method of Ridolfi et al. (2010). 
Table A2.6 Major element amphibole compositions analysed by EMPA.

\begin{tabular}{|c|c|c|c|c|c|}
\hline $\begin{array}{l}\text { Sample } \\
\text { ID } \\
\text { Zone }\end{array}$ & $\begin{array}{r}\text { Inglewood a } \\
\text { A10_3 } \\
\text { core }\end{array}$ & $\begin{array}{r}\text { Inglewood a } \\
\text { A10_4 } \\
\text { core }\end{array}$ & $\begin{array}{c}\text { Inglewood a } \\
\text { A12_1 } \\
\text { rim }\end{array}$ & $\begin{array}{r}\text { Inglewood a } \\
\text { A12_2 } \\
\text { core }\end{array}$ & $\begin{array}{r}\text { Inglewood a } \\
\mathbf{A 1 3} \_2 \\
\text { rim }\end{array}$ \\
\hline$\overline{\mathrm{SiO}_{2}}$ & 41.53 & 40.55 & 43.00 & 43.02 & 42.64 \\
\hline $\mathrm{TiO}_{2}$ & 2.32 & 2.44 & 2.61 & 2.90 & 2.43 \\
\hline $\mathrm{Al}_{2} \mathrm{O}_{3}$ & 11.70 & 12.12 & 10.48 & 9.36 & 9.69 \\
\hline $\mathrm{Fe}_{2} \mathrm{O}_{3}$ & 5.38 & 4.96 & 6.07 & 5.38 & 6.00 \\
\hline $\mathrm{FeO}$ & 8.86 & 9.63 & 7.35 & 7.55 & 7.04 \\
\hline MnO & 0.43 & 0.37 & 0.55 & 0.62 & 0.47 \\
\hline MgO & 12.67 & 12.24 & 13.63 & 13.84 & 13.95 \\
\hline $\mathrm{CaO}$ & 11.89 & 11.97 & 11.53 & 11.50 & 11.49 \\
\hline $\mathrm{Na}_{2} \mathrm{O}$ & 2.19 & 2.30 & 2.00 & 1.91 & 2.04 \\
\hline $\mathbf{K}_{2} \mathbf{O}$ & 0.74 & 0.78 & 0.95 & 0.93 & 0.91 \\
\hline $\mathbf{H}_{2} \mathbf{O}_{\text {calc }}$ & 1.89 & 1.87 & 1.91 & 1.88 & 1.88 \\
\hline Total & 99.60 & 99.23 & 100.08 & 98.89 & 98.53 \\
\hline Mg\# & 71.83 & 69.38 & 76.78 & 76.58 & 77.95 \\
\hline \multicolumn{6}{|l|}{ Cations } \\
\hline $\mathbf{S i}$ & 6.150 & 6.057 & 6.294 & 6.373 & 6.336 \\
\hline $\mathbf{T i}$ & 0.259 & 0.275 & 0.287 & 0.323 & 0.272 \\
\hline Al & 2.043 & 2.134 & 1.809 & 1.634 & 1.696 \\
\hline $\mathrm{Fe}^{3+}$ & 0.600 & 0.557 & 0.668 & 0.599 & 0.671 \\
\hline $\mathrm{Fe}^{2+}$ & 1.097 & 1.203 & 0.900 & 0.935 & 0.874 \\
\hline Mn & 0.054 & 0.047 & 0.068 & 0.078 & 0.060 \\
\hline Mg & 2.798 & 2.727 & 2.975 & 3.058 & 3.091 \\
\hline $\mathrm{Ca}$ & 1.886 & 1.915 & 1.808 & 1.825 & 1.829 \\
\hline $\mathbf{N a}$ & 0.629 & 0.665 & 0.568 & 0.549 & 0.587 \\
\hline $\mathbf{K}$ & 0.139 & 0.149 & 0.178 & 0.176 & 0.173 \\
\hline Total & 15.65 & 15.73 & 15.55 & 15.55 & 15.59 \\
\hline \multicolumn{6}{|l|}{ P-C conditions } \\
\hline $\mathbf{T}\left({ }^{\circ} \mathbf{C}\right)$ & 962 & 981 & 930 & 914 & 922 \\
\hline Uncertanty & 22 & 22 & 22 & 22 & 22 \\
\hline $\mathbf{P}(\mathbf{M P a})$ & 362 & 413 & 259 & 201 & 220 \\
\hline Uncertanty & 40 & 45 & 28 & 22 & 24 \\
\hline $\begin{array}{l}\text { Equivalent depth } \\
(\mathrm{km})\end{array}$ & 13.7 & 15.6 & 9.8 & 7.6 & 8.3 \\
\hline$\Delta \mathbf{N N O}$ & 0.43 & 0.24 & 0.76 & 0.82 & 0.96 \\
\hline $\log \mathrm{fO}_{2}$ & -10.35 & -10.23 & -10.59 & -10.81 & -10.54 \\
\hline Uncertanty & 0.4 & 0.4 & 0.4 & 0.4 & 0.4 \\
\hline $\mathrm{H}_{2} \mathrm{O}_{\text {melt }}$ (wt.\%) & 5.9 & 5.9 & 4.5 & 3.7 & 3.8 \\
\hline Uncertanty & 0.9 & 0.9 & 0.7 & 0.6 & 0.6 \\
\hline
\end{tabular}

Cation proportions calculated using Leake et al. (1997) on the basis of 13 cations. $P-C=$ Physicalchemical conditions, calculated using the method of Ridolfi et al. (2010). 
Table A2.6 Major element amphibole compositions analysed by EMPA.

\begin{tabular}{|c|c|c|c|c|c|}
\hline $\begin{array}{l}\text { Sample } \\
\text { ID } \\
\text { Zone } \\
\end{array}$ & $\begin{array}{r}\text { Inglewood a } \\
\text { A13_3 } \\
\text { zone } \\
\end{array}$ & $\begin{array}{r}\text { Inglewood a } \\
\text { A13_4 } \\
\text { zone } \\
\end{array}$ & $\begin{array}{r}\text { Inglewood a } \\
\text { A13_5 } \\
\text { zone } \\
\end{array}$ & $\begin{array}{r}\text { Inglewood a } \\
\text { A13_6 } \\
\text { zone } \\
\end{array}$ & $\begin{array}{r}\text { Inglewood a } \\
\text { A14_1 } \\
\text { rim }\end{array}$ \\
\hline$\overline{\mathrm{SiO}_{2}}$ & 43.48 & 41.54 & 41.32 & 41.79 & 43.02 \\
\hline $\mathbf{T i O}_{2}$ & 2.58 & 2.65 & 2.73 & 3.00 & 2.71 \\
\hline $\mathrm{Al}_{2} \mathrm{O}_{3}$ & 9.59 & 10.53 & 10.90 & 10.58 & 9.61 \\
\hline $\mathrm{Fe}_{2} \mathrm{O}_{3}$ & 5.78 & 6.10 & 6.10 & 6.00 & 5.29 \\
\hline $\mathrm{FeO}$ & 7.21 & 7.74 & 7.79 & 8.33 & 7.57 \\
\hline MnO & 0.46 & 0.45 & 0.40 & 0.44 & 0.64 \\
\hline MgO & 13.88 & 13.24 & 13.04 & 12.65 & 13.79 \\
\hline $\mathrm{CaO}$ & 11.37 & 11.56 & 11.48 & 11.15 & 11.47 \\
\hline $\mathrm{Na}_{2} \mathrm{O}$ & 1.92 & 2.08 & 2.09 & 2.01 & 2.06 \\
\hline $\mathbf{K}_{2} \mathbf{O}$ & 0.86 & 0.91 & 0.93 & 1.04 & 0.85 \\
\hline $\mathbf{H}_{2} \mathbf{O}_{\text {calc }}$ & 1.89 & 1.87 & 1.87 & 1.87 & 1.89 \\
\hline Total & 99.03 & 98.67 & 98.66 & 98.87 & 98.89 \\
\hline Mg\# & 77.44 & 75.30 & 74.90 & 73.04 & 77.54 \\
\hline \multicolumn{6}{|l|}{ Cations } \\
\hline $\mathbf{S i}$ & 6.410 & 6.198 & 6.166 & 6.228 & 6.369 \\
\hline $\mathbf{T i}$ & 0.286 & 0.298 & 0.306 & 0.337 & 0.301 \\
\hline Al & 1.666 & 1.851 & 1.918 & 1.859 & 1.678 \\
\hline $\mathrm{Fe}^{3+}$ & 0.641 & 0.685 & 0.685 & 0.673 & 0.590 \\
\hline $\mathrm{Fe}^{2+}$ & 0.889 & 0.966 & 0.973 & 1.038 & 0.937 \\
\hline Mn & 0.058 & 0.057 & 0.051 & 0.055 & 0.081 \\
\hline Mg & 3.051 & 2.945 & 2.902 & 2.811 & 3.044 \\
\hline $\mathrm{Ca}$ & 1.796 & 1.848 & 1.836 & 1.780 & 1.820 \\
\hline $\mathbf{N a}$ & 0.549 & 0.601 & 0.605 & 0.580 & 0.590 \\
\hline $\mathbf{K}$ & 0.162 & 0.173 & 0.176 & 0.199 & 0.160 \\
\hline Total & 15.51 & 15.62 & 15.62 & 15.56 & 15.57 \\
\hline \multicolumn{6}{|l|}{ P-C conditions } \\
\hline $\mathbf{T}\left({ }^{\circ} \mathbf{C}\right)$ & 907 & 946 & 952 & 934 & 918 \\
\hline Uncertanty & 22 & 22 & 22 & 22 & 22 \\
\hline $\mathbf{P}$ (MPa) & 211 & 275 & 303 & 278 & 214 \\
\hline Uncertanty & 23 & 30 & 33 & 31 & 24 \\
\hline $\begin{array}{l}\text { Equivalent depth } \\
(\mathrm{km})\end{array}$ & 8.0 & 10.4 & 11.4 & 10.5 & 8.1 \\
\hline$\Delta$ NNO & 0.91 & 0.66 & 0.58 & 0.44 & 0.81 \\
\hline $\log \mathrm{fO}_{2}$ & -10.85 & -10.42 & -10.39 & -10.83 & -10.76 \\
\hline Uncertanty & 0.4 & 0.4 & 0.4 & 0.4 & 0.4 \\
\hline $\mathrm{H}_{2} \mathrm{O}_{\text {melt }}$ (wt.\%) & 4.2 & 4.4 & 4.6 & 4.4 & 4.1 \\
\hline Uncertanty & 0.6 & 0.7 & 0.7 & 0.7 & 0.6 \\
\hline
\end{tabular}

Cation proportions calculated using Leake et al. (1997) on the basis of 13 cations. $P-C=$ Physicalchemical conditions, calculated using the method of Ridolfi et al. (2010). 
Table A2.6 Major element amphibole compositions analysed by EMPA.

\begin{tabular}{|c|c|c|c|c|c|}
\hline $\begin{array}{l}\text { Sample } \\
\text { ID } \\
\text { Zone }\end{array}$ & $\begin{array}{r}\text { Inglewood a } \\
\text { A14_2 } \\
\text { zone } \\
\end{array}$ & $\begin{array}{r}\text { Inglewood a } \\
\text { A14_3 } \\
\text { zone } \\
\end{array}$ & $\begin{array}{c}\text { Inglewood a } \\
\text { A14_4 } \\
\text { zone } \\
\end{array}$ & $\begin{array}{r}\text { Inglewood a } \\
\text { A14_5 } \\
\text { zone } \\
\end{array}$ & $\begin{array}{r}\text { Inglewood a } \\
\text { A14_6 } \\
\text { zone } \\
\end{array}$ \\
\hline$\overline{\mathrm{SiO}_{2}}$ & 41.66 & 43.15 & 41.82 & 42.65 & 42.05 \\
\hline $\mathrm{TiO}_{2}$ & 2.78 & 2.82 & 3.17 & 2.96 & 2.74 \\
\hline $\mathrm{Al}_{2} \mathbf{O}_{3}$ & 10.85 & 9.64 & 10.92 & 10.08 & 10.71 \\
\hline $\mathrm{Fe}_{2} \mathrm{O}_{3}$ & 4.82 & 5.58 & 5.17 & 4.24 & 5.02 \\
\hline $\mathrm{FeO}$ & 8.45 & 7.38 & 8.08 & 8.51 & 7.95 \\
\hline MnO & 0.61 & 0.61 & 0.54 & 0.54 & 0.44 \\
\hline MgO & 12.95 & 13.78 & 13.03 & 13.54 & 13.40 \\
\hline $\mathrm{CaO}$ & 11.55 & 11.34 & 11.34 & 11.58 & 11.50 \\
\hline $\mathrm{Na}_{2} \mathrm{O}$ & 2.14 & 2.02 & 2.11 & 2.14 & 2.16 \\
\hline $\mathbf{K}_{2} \mathbf{O}$ & 0.88 & 0.91 & 0.97 & 0.88 & 0.92 \\
\hline $\mathrm{H}_{2} \mathrm{O}_{\text {calc }}$ & 1.87 & 1.89 & 1.88 & 1.89 & 1.88 \\
\hline Total & 98.56 & 99.12 & 99.03 & 99.02 & 98.77 \\
\hline Mg\# & 73.74 & 78.48 & 76.45 & 75.28 & 70.91 \\
\hline Cations & & & & & \\
\hline $\mathbf{S i}$ & 6.221 & 6.370 & 6.205 & 6.322 & 6.247 \\
\hline $\mathbf{T i}$ & 0.312 & 0.313 & 0.353 & 0.330 & 0.307 \\
\hline Al & 1.909 & 1.677 & 1.910 & 1.761 & 1.875 \\
\hline $\mathrm{Fe}^{3+}$ & 0.542 & 0.619 & 0.578 & 0.473 & 0.561 \\
\hline $\mathrm{Fe}^{2+}$ & 1.055 & 0.910 & 1.002 & 1.055 & 0.988 \\
\hline Mn & 0.077 & 0.077 & 0.068 & 0.067 & 0.055 \\
\hline Mg & 2.884 & 3.033 & 2.884 & 2.991 & 2.968 \\
\hline $\mathrm{Ca}$ & 1.848 & 1.794 & 1.802 & 1.840 & 1.830 \\
\hline $\mathbf{N a}$ & 0.619 & 0.578 & 0.608 & 0.616 & 0.623 \\
\hline $\mathbf{K}$ & 0.168 & 0.172 & 0.183 & 0.166 & 0.174 \\
\hline Total & 15.63 & 15.54 & 15.59 & 15.62 & 15.63 \\
\hline \multicolumn{6}{|l|}{ P-C conditions } \\
\hline $\mathbf{T}\left({ }^{\circ} \mathbf{C}\right)$ & 949 & 915 & 948 & 932 & 945 \\
\hline Uncertanty & 22 & 22 & 22 & 22 & 22 \\
\hline P (MPa) & 299 & 214 & 299 & 242 & 285 \\
\hline Uncertanty & 33 & 24 & 33 & 27 & 31 \\
\hline $\begin{array}{l}\text { Equivalent depth } \\
(\mathbf{k m})\end{array}$ & 11.3 & 8.1 & 11.3 & 9.1 & 10.7 \\
\hline$\Delta \mathbf{N N O}$ & 0.47 & 0.80 & 0.43 & 0.60 & 0.62 \\
\hline $\log \mathrm{fO}_{2}$ & -10.54 & -10.82 & -10.60 & -10.72 & -10.47 \\
\hline Uncertanty & 0.4 & 0.4 & 0.4 & 0.4 & 0.4 \\
\hline $\mathrm{H}_{2} \mathrm{O}_{\text {melt }}($ wt. \%) & 4.9 & 3.9 & 4.6 & 4.2 & 4.6 \\
\hline Uncertanty & 0.7 & 0.6 & 0.7 & 0.6 & 0.7 \\
\hline
\end{tabular}

Cation proportions calculated using Leake et al. (1997) on the basis of 13 cations. $P-C=$ Physicalchemical conditions, calculated using the method of Ridolfi et al. (2010). 
Table A2.6 Major element amphibole compositions analysed by EMPA.

\begin{tabular}{|c|c|c|c|c|c|}
\hline $\begin{array}{l}\text { Sample } \\
\text { ID }\end{array}$ & $\begin{array}{c}\text { Inglewood a } \\
\text { A14_7 }\end{array}$ & $\begin{array}{c}\text { Inglewood a } \\
\text { A14_8 }\end{array}$ & $\begin{array}{r}\text { Inglewood a } \\
\text { A14_9 }\end{array}$ & $\begin{array}{c}\text { Inglewood a } \\
\text { A14_10 }\end{array}$ & $\begin{array}{c}\text { Inglewood a } \\
\text { A14_11 }\end{array}$ \\
\hline Zone & zone & zone & core & core & core \\
\hline $\mathrm{SiO}_{2}$ & 40.12 & 39.84 & 39.25 & 42.92 & 39.47 \\
\hline $\mathrm{TiO}_{2}$ & 2.61 & 2.30 & 2.09 & 2.42 & 2.51 \\
\hline $\mathrm{Al}_{2} \mathbf{O}_{3}$ & 12.87 & 13.07 & 14.26 & 10.55 & 13.50 \\
\hline $\mathrm{Fe}_{2} \mathrm{O}_{3}$ & 6.32 & 5.71 & 5.93 & 5.25 & 5.72 \\
\hline $\mathrm{FeO}$ & 7.60 & 7.75 & 8.57 & 7.94 & 8.71 \\
\hline MnO & 0.49 & 0.35 & 0.32 & 0.55 & 0.51 \\
\hline MgO & 12.55 & 12.63 & 11.83 & 13.56 & 11.90 \\
\hline $\mathrm{CaO}$ & 11.68 & 11.88 & 12.03 & 11.70 & 11.82 \\
\hline $\mathrm{Na}_{2} \mathrm{O}$ & 2.25 & 2.20 & 2.25 & 2.08 & 2.31 \\
\hline $\mathbf{K}_{2} \mathbf{O}$ & 0.89 & 0.86 & 0.83 & 0.87 & 0.89 \\
\hline $\mathrm{H}_{2} \mathrm{O}_{\text {calc }}$ & 1.87 & 1.86 & 1.87 & 1.90 & 1.87 \\
\hline Total & 99.25 & 98.46 & 99.25 & 99.74 & 99.21 \\
\hline Mg\# & 73.34 & 73.22 & 76.91 & 74.21 & 73.92 \\
\hline \multicolumn{6}{|l|}{ Cations } \\
\hline $\mathbf{S i}$ & 5.961 & 5.962 & 5.853 & 6.308 & 5.896 \\
\hline $\mathbf{T i}$ & 0.292 & 0.258 & 0.234 & 0.267 & 0.282 \\
\hline Al & 2.253 & 2.306 & 2.507 & 1.828 & 2.377 \\
\hline $\mathrm{Fe}^{3+}$ & 0.707 & 0.643 & 0.666 & 0.581 & 0.642 \\
\hline $\mathrm{Fe}^{2+}$ & 0.944 & 0.970 & 1.069 & 0.976 & 1.087 \\
\hline Mn & 0.062 & 0.044 & 0.040 & 0.069 & 0.064 \\
\hline Mg & 2.780 & 2.817 & 2.631 & 2.972 & 2.651 \\
\hline $\mathbf{C a}$ & 1.859 & 1.904 & 1.921 & 1.843 & 1.892 \\
\hline $\mathrm{Na}$ & 0.647 & 0.638 & 0.651 & 0.593 & 0.668 \\
\hline $\mathbf{K}$ & 0.168 & 0.165 & 0.158 & 0.162 & 0.170 \\
\hline Total & 15.67 & 15.71 & 15.73 & 15.60 & 15.73 \\
\hline \multicolumn{6}{|l|}{ P-C conditions } \\
\hline $\mathbf{T}\left({ }^{\circ} \mathbf{C}\right)$ & 998 & 1005 & 1025 & 933 & 1013 \\
\hline Uncertanty & 22 & 22 & 22 & 22 & 22 \\
\hline P (MPa) & 491 & 529 & 706 & 266 & 586 \\
\hline Uncertanty & 54 & 58 & 78 & 29 & 64 \\
\hline Equivalent depth & 18.5 & 20.0 & 26.7 & 10.1 & 22.1 \\
\hline$\Delta$ NNO & 0.33 & 0.40 & 0.14 & 0.73 & 0.09 \\
\hline $\log \mathrm{fO}_{2}$ & -9.86 & -9.67 & -9.58 & -10.56 & -9.83 \\
\hline Uncertanty & 0.4 & 0.4 & 0.4 & 0.4 & 0.4 \\
\hline $\mathrm{H}_{2} \mathrm{O}_{\text {melt }}($ wt. \% $)$ & 6.1 & 6.4 & 7.5 & 4.8 & 6.6 \\
\hline Uncertanty & 0.9 & 1.0 & 1.1 & 0.7 & 1.0 \\
\hline
\end{tabular}

Cation proportions calculated using Leake et al. (1997) on the basis of 13 cations. $P-C=$ Physicalchemical conditions, calculated using the method of Ridolfi et al. (2010). 
Table A2.6 Major element amphibole compositions analysed by EMPA.

\begin{tabular}{|c|c|c|c|c|c|c|}
\hline $\begin{array}{l}\text { Sample } \\
\text { ID } \\
\text { Zone } \\
\end{array}$ & $\begin{array}{c}\text { Inglewood a } \\
\text { A14_12 } \\
\text { zone } \\
\end{array}$ & $\begin{array}{r}\text { Inglewood a } \\
\text { A15_2 } \\
\text { core } \\
\end{array}$ & $\begin{array}{r}\text { Inglewood a } \\
\text { A15_3 } \\
\text { core } \\
\end{array}$ & $\begin{array}{c}\text { Korito } \\
\text { A1_1 } \\
\text { rim }\end{array}$ & $\begin{array}{c}\text { Korito } \\
\text { A1_2 } \\
\text { zone } \\
\end{array}$ & $\begin{array}{c}\text { Korito } \\
\text { A1_3 } \\
\text { core } \\
\end{array}$ \\
\hline$\overline{\mathrm{SiO}_{2}}$ & 39.23 & 39.74 & 42.62 & 44.54 & 40.71 & 41.58 \\
\hline $\mathrm{TiO}_{2}$ & 2.85 & 2.67 & 2.90 & 2.94 & 2.41 & 2.90 \\
\hline $\mathrm{Al}_{2} \mathrm{O}_{3}$ & 12.76 & 13.00 & 9.84 & 10.34 & 12.17 & 10.61 \\
\hline $\mathrm{Fe}_{2} \mathrm{O}_{3}$ & 6.94 & 6.46 & 5.55 & 1.49 & 4.76 & 3.64 \\
\hline FeO & 7.78 & 7.86 & 6.89 & 11.14 & 9.42 & 9.68 \\
\hline MnO & 0.56 & 0.53 & 0.49 & 0.55 & 0.44 & 0.51 \\
\hline MgO & 12.00 & 12.39 & 14.10 & 13.18 & 12.27 & 12.83 \\
\hline $\mathrm{CaO}$ & 11.48 & 11.85 & 11.54 & 12.02 & 11.91 & 11.82 \\
\hline $\mathrm{Na}_{2} \mathrm{O}$ & 2.23 & 2.17 & 1.93 & 2.05 & 2.17 & 2.09 \\
\hline $\mathbf{K}_{2} \mathbf{O}$ & 0.91 & 0.97 & 0.94 & 0.88 & 0.88 & 0.93 \\
\hline $\mathbf{H}_{2} \mathbf{O}_{\text {calc }}$ & 1.85 & 1.87 & 1.88 & 1.94 & 1.87 & 1.87 \\
\hline Total & 98.59 & 99.52 & 98.69 & 101.06 & 99.01 & 98.45 \\
\hline Mg\# & 75.03 & 74.65 & 74.40 & 67.83 & 69.89 & 70.27 \\
\hline \multicolumn{7}{|l|}{ Cations } \\
\hline $\mathbf{S i}$ & 5.895 & 5.909 & 6.312 & 6.471 & 6.084 & 6.238 \\
\hline $\mathbf{T i}$ & 0.323 & 0.299 & 0.323 & 0.321 & 0.270 & 0.328 \\
\hline Al & 2.260 & 2.279 & 1.718 & 1.770 & 2.144 & 1.876 \\
\hline $\mathrm{Fe}^{3+}$ & 0.784 & 0.723 & 0.619 & 0.162 & 0.535 & 0.411 \\
\hline $\mathrm{Fe}^{2+}$ & 0.977 & 0.978 & 0.854 & 1.354 & 1.177 & 1.214 \\
\hline Mn & 0.071 & 0.067 & 0.061 & 0.068 & 0.056 & 0.064 \\
\hline Mg & 2.689 & 2.746 & 3.113 & 2.854 & 2.733 & 2.870 \\
\hline $\mathbf{C a}$ & 1.848 & 1.887 & 1.831 & 1.871 & 1.907 & 1.899 \\
\hline $\mathbf{N a}$ & 0.649 & 0.624 & 0.553 & 0.578 & 0.629 & 0.607 \\
\hline $\mathbf{K}$ & 0.174 & 0.185 & 0.178 & 0.163 & 0.168 & 0.178 \\
\hline Total & 15.67 & 15.70 & 15.56 & 15.61 & 15.70 & 15.68 \\
\hline \multicolumn{7}{|l|}{$\overline{\mathrm{P}-\mathrm{C} \text { conditions }}$} \\
\hline $\mathbf{T}\left({ }^{\circ} \mathbf{C}\right)$ & 1002 & 1006 & 929 & 916 & 978 & 950 \\
\hline Uncertanty & 22 & 22 & 22 & 22 & 22 & 22 \\
\hline $\mathbf{P}$ (MPa) & 495 & 509 & 227 & 245 & 419 & 285 \\
\hline Uncertanty & 54 & 56 & 25 & 27 & 46 & 31 \\
\hline $\begin{array}{l}\text { Equivalent depth } \\
(\mathrm{km})\end{array}$ & 18.7 & 19.2 & 8.6 & 9.2 & 15.8 & 10.8 \\
\hline$\Delta$ NNO & 0.17 & 0.27 & 0.88 & 0.33 & 0.27 & 0.37 \\
\hline $\log \mathrm{fO}_{2}$ & -9.96 & -9.79 & -10.49 & -11.25 & -10.24 & -10.63 \\
\hline Uncertanty & 0.4 & 0.4 & 0.4 & 0.4 & 0.4 & 0.4 \\
\hline $\mathrm{H}_{2} \mathrm{O}_{\text {melt }}$ (wt.\%) & 5.9 & 5.9 & 3.8 & 5.2 & 6.0 & 4.6 \\
\hline Uncertanty & 0.9 & 0.9 & 0.6 & 0.8 & 0.9 & 0.7 \\
\hline
\end{tabular}

Cation proportions calculated using Leake et al. (1997) on the basis of 13 cations. $P-C=$ Physicalchemical conditions, calculated using the method of Ridolfi et al. (2010). 
Table A2.6 Major element amphibole compositions analysed by EMPA.

\begin{tabular}{|c|c|c|c|c|c|c|c|}
\hline Sample & Korito & Korito & Korito & Korito & Korito & Korito & Korito \\
\hline ID & A2_1 & A2 22 & A2_4 & A3_1 & A3_2 & A3_3 & A3_4 \\
\hline Zone & rim & rim & core & rim & zone & zone & zone \\
\hline $\mathrm{SiO}_{2}$ & 42.43 & 40.03 & 39.70 & 42.08 & 39.91 & 42.08 & 42.85 \\
\hline $\mathrm{TiO}_{2}$ & 2.73 & 2.75 & 2.19 & 2.97 & 2.66 & 3.16 & 2.93 \\
\hline $\mathrm{Al}_{2} \mathrm{O}_{3}$ & 10.22 & 12.78 & 13.50 & 10.09 & 12.72 & 10.26 & 9.95 \\
\hline $\mathrm{Fe}_{2} \mathrm{O}_{3}$ & 3.62 & 4.62 & 4.94 & 3.40 & 3.74 & 4.80 & 3.63 \\
\hline $\mathrm{FeO}$ & 9.25 & 9.49 & 9.80 & 9.15 & 10.44 & 9.16 & 9.40 \\
\hline MnO & 0.50 & 0.44 & 0.38 & 0.57 & 0.46 & 0.54 & 0.43 \\
\hline MgO & 13.34 & 12.13 & 11.71 & 13.25 & 11.59 & 12.76 & 13.29 \\
\hline $\mathrm{CaO}$ & 11.86 & 11.99 & 12.11 & 11.73 & 11.84 & 11.38 & 11.65 \\
\hline $\mathrm{Na}_{2} \mathrm{O}$ & 2.07 & 2.28 & 2.28 & 2.00 & 2.22 & 2.05 & 2.10 \\
\hline $\mathbf{K}_{2} \mathbf{O}$ & 0.88 & 0.80 & 0.86 & 0.96 & 0.93 & 1.04 & 0.84 \\
\hline $\mathbf{H}_{2} \mathbf{O}_{\text {calc }}$ & 1.88 & 1.87 & 1.87 & 1.87 & 1.86 & 1.88 & 1.89 \\
\hline Total & 98.78 & 99.17 & 99.34 & 98.09 & 98.37 & 99.12 & 98.96 \\
\hline Mg\# & 71.98 & 69.50 & 68.05 & 72.08 & 66.42 & 71.30 & 71.59 \\
\hline \multicolumn{8}{|l|}{ Cations } \\
\hline $\mathbf{S i}$ & 6.320 & 5.980 & 5.935 & 6.312 & 6.025 & 6.265 & 6.363 \\
\hline $\mathbf{T i}$ & 0.305 & 0.309 & 0.246 & 0.335 & 0.302 & 0.354 & 0.327 \\
\hline Al & 1.793 & 2.251 & 2.378 & 1.785 & 2.263 & 1.801 & 1.741 \\
\hline $\mathrm{Fe}^{3+}$ & 0.406 & 0.519 & 0.556 & 0.384 & 0.425 & 0.538 & 0.405 \\
\hline $\mathrm{Fe}^{2+}$ & 1.153 & 1.185 & 1.226 & 1.148 & 1.318 & 1.140 & 1.168 \\
\hline Mn & 0.063 & 0.055 & 0.048 & 0.073 & 0.059 & 0.069 & 0.054 \\
\hline Mg & 2.961 & 2.701 & 2.610 & 2.964 & 2.608 & 2.833 & 2.942 \\
\hline $\mathbf{C a}$ & 1.893 & 1.919 & 1.940 & 1.886 & 1.914 & 1.816 & 1.854 \\
\hline $\mathbf{N a}$ & 0.597 & 0.661 & 0.660 & 0.583 & 0.651 & 0.593 & 0.605 \\
\hline $\mathbf{K}$ & 0.168 & 0.153 & 0.164 & 0.184 & 0.178 & 0.198 & 0.159 \\
\hline Total & 15.66 & 15.73 & 15.76 & 15.65 & 15.74 & 15.61 & 15.62 \\
\hline \multicolumn{8}{|l|}{ P-C conditions } \\
\hline $\mathbf{T}\left({ }^{\circ} \mathbf{C}\right)$ & 937 & 1000 & 1009 & 938 & 994 & 933 & 925 \\
\hline Uncertanty & 22 & 22 & 22 & 22 & 22 & 22 & 22 \\
\hline P (MPa) & 253 & 489 & 587 & 250 & 497 & 256 & 235 \\
\hline Uncertanty & 28 & 54 & 65 & 28 & 55 & 28 & 26 \\
\hline $\begin{array}{l}\text { Equivalent depth } \\
(\mathbf{k m})\end{array}$ & 9.6 & 18.5 & 22.2 & 9.4 & 18.8 & 9.7 & 8.9 \\
\hline$\triangle \mathbf{N N O}$ & 0.57 & 0.09 & 0.07 & 0.51 & -0.05 & 0.38 & 0.52 \\
\hline $\log \mathrm{fO}_{2}$ & -10.67 & -10.06 & -9.91 & -10.70 & -10.30 & -10.92 & -10.92 \\
\hline Uncertanty & 0.4 & 0.4 & 0.4 & 0.4 & 0.4 & 0.4 & 0.4 \\
\hline $\mathrm{H}_{2} \mathrm{O}_{\text {melt }}($ wt. \%) & 4.5 & 6.3 & 7.0 & 4.2 & 6.4 & 4.1 & 4.4 \\
\hline Uncertanty & 0.7 & 0.9 & 1.0 & 0.6 & 1.0 & 0.6 & 0.7 \\
\hline
\end{tabular}

Cation proportions calculated using Leake et al. (1997) on the basis of 13 cations. $P-C=$ Physicalchemical conditions, calculated using the method of Ridolfi et al. (2010). 
Table A2.6 Major element amphibole compositions analysed by EMPA.

\begin{tabular}{|c|c|c|c|c|c|c|c|}
\hline Sample & Korito & Korito & Korito & Korito & Korito & Korito & Korito \\
\hline ID & A3_5 & A3_6 & A3_7 & A3_8 & A3_9 & A3_10 & A3_11 \\
\hline Zone & zone & zone & zone & zone & zone & zone & zone \\
\hline $\mathrm{SiO}_{2}$ & 40.49 & 41.93 & 41.63 & 42.14 & 42.27 & 40.69 & 42.13 \\
\hline $\mathrm{TiO}_{2}$ & 3.15 & 3.05 & 3.09 & 3.04 & 2.84 & 2.98 & 2.84 \\
\hline $\mathrm{Al}_{2} \mathrm{O}_{3}$ & 12.08 & 10.64 & 10.82 & 10.31 & 10.44 & 11.52 & 10.41 \\
\hline $\mathrm{Fe}_{2} \mathrm{O}_{3}$ & 4.40 & 3.94 & 4.38 & 3.91 & 3.78 & 4.19 & 3.97 \\
\hline $\mathrm{FeO}$ & 9.74 & 9.39 & 9.18 & 9.65 & 9.71 & 9.86 & 8.70 \\
\hline MnO & 0.45 & 0.49 & 0.51 & 0.54 & 0.49 & 0.44 & 0.42 \\
\hline MgO & 12.25 & 12.89 & 12.72 & 12.79 & 12.94 & 12.35 & 13.47 \\
\hline $\mathrm{CaO}$ & 11.84 & 11.66 & 11.48 & 11.52 & 11.71 & 11.81 & 11.77 \\
\hline $\mathrm{Na}_{2} \mathrm{O}$ & 2.25 & 2.08 & 2.11 & 2.04 & 2.17 & 2.19 & 2.10 \\
\hline $\mathbf{K}_{2} \mathbf{O}$ & 0.90 & 0.94 & 1.02 & 1.13 & 0.91 & 0.97 & 0.87 \\
\hline $\mathbf{H}_{2} \mathbf{O}_{\text {calc }}$ & 1.88 & 1.88 & 1.87 & 1.88 & 1.88 & 1.87 & 1.88 \\
\hline Total & 99.43 & 98.89 & 98.82 & 98.96 & 99.14 & 98.87 & 98.56 \\
\hline Mg\# & 69.15 & 71.00 & 71.17 & 70.25 & 70.37 & 69.07 & 73.40 \\
\hline \multicolumn{8}{|l|}{ Cations } \\
\hline $\mathbf{S i}$ & 6.037 & 6.250 & 6.216 & 6.288 & 6.289 & 6.102 & 6.278 \\
\hline $\mathbf{T i}$ & 0.353 & 0.342 & 0.347 & 0.342 & 0.318 & 0.336 & 0.318 \\
\hline Al & 2.122 & 1.869 & 1.904 & 1.814 & 1.830 & 2.036 & 1.829 \\
\hline $\mathrm{Fe}^{3+}$ & 0.494 & 0.442 & 0.492 & 0.439 & 0.423 & 0.473 & 0.445 \\
\hline $\mathrm{Fe}^{2+}$ & 1.215 & 1.170 & 1.146 & 1.205 & 1.208 & 1.237 & 1.084 \\
\hline Mn & 0.057 & 0.062 & 0.065 & 0.069 & 0.062 & 0.055 & 0.053 \\
\hline Mg & 2.723 & 2.864 & 2.830 & 2.845 & 2.870 & 2.761 & 2.992 \\
\hline $\mathbf{C a}$ & 1.892 & 1.863 & 1.837 & 1.842 & 1.867 & 1.897 & 1.880 \\
\hline $\mathbf{N a}$ & 0.651 & 0.600 & 0.611 & 0.590 & 0.626 & 0.637 & 0.608 \\
\hline $\mathbf{K}$ & 0.171 & 0.179 & 0.195 & 0.214 & 0.172 & 0.185 & 0.165 \\
\hline Total & 15.71 & 15.64 & 15.64 & 15.65 & 15.67 & 15.72 & 15.65 \\
\hline \multicolumn{8}{|l|}{ P-C conditions } \\
\hline $\mathbf{T}\left({ }^{\circ} \mathbf{C}\right)$ & 985 & 945 & 949 & 935 & 938 & 973 & 944 \\
\hline Uncertanty & 22 & 22 & 22 & 22 & 22 & 22 & 22 \\
\hline P (MPa) & 406 & 282 & 297 & 261 & 267 & 359 & 267 \\
\hline Uncertanty & 45 & 31 & 33 & 29 & 29 & 39 & 29 \\
\hline $\begin{array}{l}\text { Equivalent depth } \\
(\mathbf{k m})\end{array}$ & 15.3 & 10.7 & 11.2 & 9.8 & 10.1 & 13.6 & 10.1 \\
\hline$\triangle \mathbf{N N O}$ & 0.07 & 0.37 & 0.33 & 0.37 & 0.41 & 0.18 & 0.59 \\
\hline $\log \mathrm{fO}_{2}$ & -10.33 & -10.72 & -10.70 & -10.89 & -10.79 & -10.43 & -10.52 \\
\hline Uncertanty & 0.4 & 0.4 & 0.4 & 0.4 & 0.4 & 0.4 & 0.4 \\
\hline $\mathrm{H}_{2} \mathrm{O}_{\text {melt }}$ (wt. \%) & 5.5 & 4.6 & 4.5 & 4.0 & 4.6 & 5.0 & 4.5 \\
\hline Uncertanty & 0.8 & 0.7 & 0.7 & 0.6 & 0.7 & 0.8 & 0.7 \\
\hline
\end{tabular}

Cation proportions calculated using Leake et al. (1997) on the basis of 13 cations. $P-C=$ Physicalchemical conditions, calculated using the method of Ridolfi et al. (2010). 
Table A2.6 Major element amphibole compositions analysed by EMPA.

\begin{tabular}{|c|c|c|c|c|c|c|c|}
\hline Sample & Korito & Korito & Korito & Korito & Korito & Korito & Korito \\
\hline ID & A3_12 & A3_13 & A3_14 & A4_1 & A4_2 & A4_3 & A4_4 \\
\hline Zone & core & core & zone & rim & zone & zone & zone \\
\hline $\mathrm{SiO}_{2}$ & 40.28 & 41.61 & 40.47 & 43.34 & 41.15 & 43.42 & 42.76 \\
\hline $\mathbf{T i O}_{2}$ & 3.20 & 2.77 & 2.94 & 2.91 & 2.72 & 2.44 & 2.94 \\
\hline $\mathrm{Al}_{2} \mathrm{O}_{3}$ & 11.84 & 11.40 & 11.97 & 9.54 & 11.68 & 9.87 & 10.06 \\
\hline $\mathrm{Fe}_{2} \mathrm{O}_{3}$ & 3.42 & 3.91 & 4.47 & 4.68 & 5.25 & 4.76 & 4.17 \\
\hline $\mathrm{FeO}$ & 10.35 & 8.86 & 9.37 & 8.17 & 8.52 & 8.17 & 8.89 \\
\hline MnO & 0.42 & 0.38 & 0.41 & 0.59 & 0.48 & 0.41 & 0.49 \\
\hline MgO & 12.16 & 13.09 & 12.57 & 13.75 & 12.79 & 13.84 & 13.41 \\
\hline $\mathrm{CaO}$ & 11.84 & 11.75 & 11.86 & 11.58 & 11.76 & 11.78 & 11.68 \\
\hline $\mathrm{Na}_{2} \mathrm{O}$ & 2.23 & 2.19 & 2.32 & 1.93 & 2.19 & 1.95 & 1.99 \\
\hline $\mathbf{K}_{2} \mathbf{O}$ & 0.99 & 0.91 & 0.95 & 0.94 & 0.83 & 0.86 & 0.98 \\
\hline $\mathbf{H}_{2} \mathbf{O}_{\text {calc }}$ & 1.86 & 1.88 & 1.87 & 1.90 & 1.88 & 1.90 & 1.89 \\
\hline Total & 98.59 & 98.76 & 99.21 & 99.31 & 99.27 & 99.40 & 99.25 \\
\hline Mg\# & 67.69 & 72.48 & 70.50 & 75.00 & 72.79 & 75.13 & 72.89 \\
\hline \multicolumn{8}{|l|}{ Cations } \\
\hline $\mathbf{S i}$ & 6.064 & 6.195 & 6.042 & 6.394 & 6.113 & 6.393 & 6.332 \\
\hline $\mathbf{T i}$ & 0.362 & 0.310 & 0.330 & 0.322 & 0.304 & 0.270 & 0.328 \\
\hline Al & 2.101 & 1.999 & 2.107 & 1.659 & 2.045 & 1.713 & 1.755 \\
\hline $\mathrm{Fe}^{3+}$ & 0.388 & 0.439 & 0.502 & 0.520 & 0.587 & 0.528 & 0.465 \\
\hline $\mathrm{Fe}^{2+}$ & 1.302 & 1.104 & 1.170 & 1.008 & 1.059 & 1.006 & 1.101 \\
\hline Mn & 0.054 & 0.047 & 0.052 & 0.073 & 0.060 & 0.051 & 0.061 \\
\hline Mg & 2.729 & 2.906 & 2.796 & 3.024 & 2.832 & 3.039 & 2.959 \\
\hline $\mathbf{C a}$ & 1.910 & 1.873 & 1.897 & 1.830 & 1.872 & 1.858 & 1.852 \\
\hline $\mathbf{N a}$ & 0.650 & 0.632 & 0.672 & 0.552 & 0.632 & 0.555 & 0.572 \\
\hline $\mathbf{K}$ & 0.190 & 0.174 & 0.181 & 0.177 & 0.158 & 0.161 & 0.185 \\
\hline Total & 15.75 & 15.68 & 15.75 & 15.56 & 15.66 & 15.57 & 15.61 \\
\hline \multicolumn{8}{|l|}{ P-C conditions } \\
\hline $\mathbf{T}\left({ }^{\circ} \mathbf{C}\right)$ & 984 & 963 & 986 & 914 & 970 & 918 & 929 \\
\hline Uncertanty & 22 & 22 & 22 & 22 & 22 & 22 & 22 \\
\hline $\mathbf{P}(\mathbf{M P a})$ & 394 & 341 & 397 & 209 & 364 & 226 & 240 \\
\hline Uncertanty & 43 & 37 & 44 & 23 & 40 & 25 & 26 \\
\hline $\begin{array}{l}\text { Equivalent depth } \\
(\mathbf{k m})\end{array}$ & 14.9 & 12.9 & 15.0 & 7.9 & 13.7 & 8.5 & 9.1 \\
\hline$\Delta \mathbf{N N O}$ & 0.03 & 0.43 & 0.21 & 0.74 & 0.38 & 0.84 & 0.58 \\
\hline $\log \mathrm{fO}_{2}$ & -10.40 & -10.35 & -10.18 & -10.89 & -10.28 & -10.72 & -10.79 \\
\hline Uncertanty & 0.4 & 0.4 & 0.4 & 0.4 & 0.4 & 0.4 & 0.4 \\
\hline $\mathrm{H}_{2} \mathrm{O}_{\text {melt }}$ (wt.\%) & 5.2 & 5.1 & 5.1 & 3.9 & 5.5 & 4.5 & 4.2 \\
\hline Uncertanty & 0.8 & 0.8 & 0.8 & 0.6 & 0.8 & 0.7 & 0.6 \\
\hline
\end{tabular}

Cation proportions calculated using Leake et al. (1997) on the basis of 13 cations. $P-C=$ Physicalchemical conditions, calculated using the method of Ridolfi et al. (2010). 
Table A2.6 Major element amphibole compositions analysed by EMPA.

\begin{tabular}{|c|c|c|c|c|c|c|c|}
\hline $\begin{array}{l}\text { Sample } \\
\text { ID } \\
\text { Zone }\end{array}$ & $\begin{array}{l}\text { Korito } \\
\text { A4_5 } \\
\text { core }\end{array}$ & $\begin{array}{l}\text { Korito } \\
\text { A7_1 } \\
\text { rim }\end{array}$ & $\begin{array}{c}\text { Korito } \\
\text { A7_2 } \\
\text { zone }\end{array}$ & $\begin{array}{c}\text { Korito } \\
\text { A7_3 } \\
\text { core }\end{array}$ & $\begin{array}{c}\text { Korito } \\
\text { A7_4 } \\
\text { zone }\end{array}$ & $\begin{array}{l}\text { Korito } \\
\text { A8_1 } \\
\text { rim }\end{array}$ & $\begin{array}{c}\text { Korito } \\
\text { A8_2 } \\
\text { zone }\end{array}$ \\
\hline$\overline{\mathrm{SiO}_{2}}$ & 43.35 & 43.39 & 43.30 & 40.45 & 43.25 & 42.99 & 40.09 \\
\hline $\mathrm{TiO}_{2}$ & 2.80 & 2.74 & 2.80 & 2.20 & 2.82 & 3.02 & 2.47 \\
\hline $\mathrm{Al}_{2} \mathbf{O}_{3}$ & 9.29 & 9.57 & 9.66 & 13.42 & 9.83 & 9.72 & 12.63 \\
\hline $\mathrm{Fe}_{2} \mathrm{O}_{3}$ & 5.31 & 6.87 & 6.19 & 5.83 & 5.99 & 5.60 & 5.89 \\
\hline $\mathrm{FeO}$ & 7.60 & 5.79 & 6.57 & 7.81 & 7.23 & 7.33 & 8.48 \\
\hline MnO & 0.49 & 0.53 & 0.59 & 0.18 & 0.55 & 0.60 & 0.24 \\
\hline MgO & 13.94 & 14.43 & 14.11 & 12.83 & 13.81 & 13.99 & 12.41 \\
\hline $\mathrm{CaO}$ & 11.44 & 11.21 & 11.31 & 12.09 & 11.31 & 11.60 & 11.91 \\
\hline $\mathrm{Na}_{2} \mathrm{O}$ & 1.94 & 2.04 & 1.99 & 2.09 & 2.02 & 1.96 & 2.08 \\
\hline $\mathbf{K}_{2} \mathbf{O}$ & 0.91 & 0.90 & 0.92 & 0.94 & 0.97 & 0.93 & 0.92 \\
\hline $\mathbf{H}_{2} \mathbf{O}_{\text {calc }}$ & 1.89 & 1.90 & 1.90 & 1.89 & 1.90 & 1.90 & 1.87 \\
\hline Total & 98.96 & 99.37 & 99.32 & 99.73 & 99.68 & 99.64 & 99.00 \\
\hline Mg\# & 76.56 & 81.62 & 79.30 & 74.54 & 77.30 & 77.28 & 72.28 \\
\hline \multicolumn{8}{|l|}{ Cations } \\
\hline Si & 6.408 & 6.359 & 6.362 & 5.967 & 6.349 & 6.320 & 5.986 \\
\hline $\mathbf{T i}$ & 0.312 & 0.302 & 0.310 & 0.244 & 0.312 & 0.334 & 0.277 \\
\hline Al & 1.618 & 1.653 & 1.672 & 2.333 & 1.701 & 1.684 & 2.223 \\
\hline $\mathrm{Fe}^{3+}$ & 0.591 & 0.757 & 0.684 & 0.647 & 0.662 & 0.620 & 0.662 \\
\hline $\mathrm{Fe}^{2+}$ & 0.940 & 0.710 & 0.807 & 0.964 & 0.887 & 0.902 & 1.059 \\
\hline Mn & 0.061 & 0.066 & 0.073 & 0.022 & 0.068 & 0.075 & 0.030 \\
\hline Mg & 3.071 & 3.153 & 3.091 & 2.823 & 3.022 & 3.066 & 2.762 \\
\hline $\mathbf{C a}$ & 1.812 & 1.760 & 1.781 & 1.912 & 1.780 & 1.828 & 1.905 \\
\hline $\mathbf{N a}$ & 0.557 & 0.581 & 0.566 & 0.598 & 0.576 & 0.560 & 0.603 \\
\hline $\mathbf{K}$ & 0.172 & 0.167 & 0.172 & 0.177 & 0.182 & 0.174 & 0.175 \\
\hline Total & 15.54 & 15.51 & 15.52 & 15.69 & 15.54 & 15.56 & 15.68 \\
\hline \multicolumn{8}{|l|}{ P-C conditions } \\
\hline $\mathbf{T}\left({ }^{\circ} \mathbf{C}\right)$ & 908 & 913 & 915 & 1004 & 917 & 925 & 993 \\
\hline Uncertanty & 22 & 22 & 22 & 22 & 22 & 22 & 22 \\
\hline P (MPa) & 197 & 207 & 213 & 550 & 222 & 216 & 470 \\
\hline Uncertanty & 22 & 23 & 23 & 60 & 24 & 24 & 52 \\
\hline $\begin{array}{l}\text { Equivalent depth } \\
(\mathbf{k m})\end{array}$ & 7.4 & 7.8 & 8.0 & 20.8 & 8.4 & 8.2 & 17.7 \\
\hline$\triangle \mathbf{N N O}$ & 0.87 & 1.05 & 0.92 & 0.45 & 0.80 & 0.80 & 0.34 \\
\hline $\log \mathrm{fO}_{2}$ & -10.88 & -10.60 & -10.70 & -9.61 & -10.78 & -10.65 & -9.93 \\
\hline Uncertanty & 0.4 & 0.4 & 0.4 & 0.4 & 0.4 & 0.4 & 0.4 \\
\hline $\mathrm{H}_{2} \mathrm{O}_{\text {melt }}$ (wt.\%) & 3.7 & 3.7 & 3.9 & 6.5 & 3.9 & 3.8 & 6.0 \\
\hline Uncertanty & 0.6 & 0.5 & 0.6 & 1.0 & 0.6 & 0.6 & 0.9 \\
\hline
\end{tabular}

Cation proportions calculated using Leake et al. (1997) on the basis of 13 cations. $P-C=$ Physicalchemical conditions, calculated using the method of Ridolfi et al. (2010). 
Table A2.6 Major element amphibole compositions analysed by EMPA.

\begin{tabular}{|c|c|c|c|c|c|c|c|}
\hline $\begin{array}{l}\text { Sample } \\
\text { ID } \\
\text { Zone }\end{array}$ & $\begin{array}{c}\text { Korito } \\
\text { A8_3 } \\
\text { zone }\end{array}$ & $\begin{array}{c}\text { Korito } \\
\text { A8_4 } \\
\text { zone }\end{array}$ & $\begin{array}{c}\text { Korito } \\
\text { A8_5 } \\
\text { zone }\end{array}$ & $\begin{array}{c}\text { Korito } \\
\text { A8_6 } \\
\text { zone }\end{array}$ & $\begin{array}{c}\text { Korito } \\
\text { A8_7 } \\
\text { zone }\end{array}$ & $\begin{array}{c}\text { Korito } \\
\text { A8_8 } \\
\text { zone }\end{array}$ & $\begin{array}{c}\text { Korito } \\
\text { A8_9 } \\
\text { zone }\end{array}$ \\
\hline$\overline{\mathrm{SiO}_{2}}$ & 42.87 & 42.80 & 43.05 & 42.46 & 43.15 & 41.25 & 42.43 \\
\hline $\mathrm{TiO}_{2}$ & 2.97 & 2.88 & 3.01 & 3.21 & 3.08 & 3.08 & 2.71 \\
\hline $\mathrm{Al}_{2} \mathbf{O}_{3}$ & 9.49 & 9.59 & 9.63 & 10.02 & 9.36 & 11.21 & 10.24 \\
\hline $\mathrm{Fe}_{2} \mathrm{O}_{3}$ & 5.11 & 5.17 & 4.51 & 4.94 & 5.80 & 5.44 & 5.57 \\
\hline $\mathrm{FeO}$ & 7.55 & 7.78 & 8.50 & 8.28 & 6.90 & 7.66 & 6.59 \\
\hline MnO & 0.63 & 0.56 & 0.56 & 0.50 & 0.43 & 0.39 & 0.36 \\
\hline MgO & 13.93 & 13.84 & 13.70 & 13.59 & 14.31 & 13.46 & 14.36 \\
\hline $\mathrm{CaO}$ & 11.59 & 11.68 & 11.68 & 11.59 & 11.41 & 11.69 & 11.61 \\
\hline $\mathrm{Na}_{2} \mathrm{O}$ & 1.95 & 1.92 & 1.99 & 2.09 & 2.05 & 2.14 & 2.11 \\
\hline $\mathrm{K}_{2} \mathrm{O}$ & 0.92 & 0.91 & 0.95 & 0.96 & 0.88 & 0.98 & 0.90 \\
\hline $\mathbf{H}_{2} \mathbf{O}_{\text {calc }}$ & 1.89 & 1.89 & 1.90 & 1.89 & 1.90 & 1.88 & 1.89 \\
\hline Total & 98.88 & 99.02 & 99.48 & 99.54 & 99.27 & 99.18 & 98.76 \\
\hline Mg\# & 76.70 & 76.01 & 74.17 & 74.53 & 78.71 & 75.79 & 79.52 \\
\hline \multicolumn{8}{|l|}{ Cations } \\
\hline $\mathbf{S i}$ & 6.351 & 6.339 & 6.355 & 6.272 & 6.351 & 6.117 & 6.271 \\
\hline $\mathbf{T i}$ & 0.331 & 0.321 & 0.334 & 0.357 & 0.341 & 0.343 & 0.301 \\
\hline Al & 1.657 & 1.674 & 1.676 & 1.744 & 1.623 & 1.959 & 1.785 \\
\hline $\mathrm{Fe}^{3+}$ & 0.570 & 0.576 & 0.501 & 0.549 & 0.642 & 0.607 & 0.620 \\
\hline $\mathrm{Fe}^{2+}$ & 0.935 & 0.964 & 1.050 & 1.023 & 0.849 & 0.950 & 0.815 \\
\hline Mn & 0.079 & 0.070 & 0.070 & 0.062 & 0.054 & 0.050 & 0.045 \\
\hline Mg & 3.077 & 3.056 & 3.014 & 2.994 & 3.139 & 2.974 & 3.163 \\
\hline $\mathbf{C a}$ & 1.839 & 1.853 & 1.848 & 1.835 & 1.799 & 1.857 & 1.839 \\
\hline $\mathbf{N a}$ & 0.559 & 0.551 & 0.570 & 0.600 & 0.586 & 0.616 & 0.604 \\
\hline $\mathbf{K}$ & 0.173 & 0.173 & 0.179 & 0.181 & 0.166 & 0.185 & 0.169 \\
\hline Total & 15.57 & 15.58 & 15.60 & 15.62 & 15.55 & 15.66 & 15.61 \\
\hline \multicolumn{8}{|l|}{ P-C conditions } \\
\hline $\mathbf{T}\left({ }^{\circ} \mathbf{C}\right)$ & 922 & 923 & 922 & 935 & 925 & 968 & 941 \\
\hline Uncertanty & 22 & 22 & 22 & 22 & 22 & 22 & 22 \\
\hline P (MPa) & 208 & 213 & 214 & 236 & 198 & 322 & 250 \\
\hline Uncertanty & 23 & 23 & 24 & 26 & 22 & 35 & 28 \\
\hline $\begin{array}{l}\text { Equivalent depth } \\
(\mathbf{k m})\end{array}$ & 7.9 & 8.1 & 8.1 & 8.9 & 7.5 & 12.1 & 9.4 \\
\hline$\triangle \mathbf{N N O}$ & 0.80 & 0.79 & 0.67 & 0.59 & 0.95 & 0.55 & 0.94 \\
\hline $\log \mathrm{fO}_{2}$ & -10.70 & -10.69 & -10.82 & -10.67 & -10.50 & -10.15 & -10.21 \\
\hline Uncertanty & 0.4 & 0.4 & 0.4 & 0.4 & 0.4 & 0.4 & 0.4 \\
\hline $\mathrm{H}_{2} \mathrm{O}_{\text {melt }}$ (wt.\%) & 3.7 & 3.8 & 3.8 & 3.8 & 3.5 & 4.4 & 4.0 \\
\hline Uncertanty & 0.6 & 0.6 & 0.6 & 0.6 & 0.5 & 0.7 & 0.6 \\
\hline
\end{tabular}

Cation proportions calculated using Leake et al. (1997) on the basis of 13 cations. $P-C=$ Physicalchemical conditions, calculated using the method of Ridolfi et al. (2010). 
Table A2.6 Major element amphibole compositions analysed by EMPA.

\begin{tabular}{|c|c|c|c|c|c|c|c|}
\hline $\begin{array}{l}\text { Sample } \\
\text { ID } \\
\text { Zone }\end{array}$ & $\begin{array}{c}\text { Korito } \\
\text { A8_10 } \\
\text { core }\end{array}$ & $\begin{array}{l}\text { Korito } \\
\text { A8_11 } \\
\text { core }\end{array}$ & $\begin{array}{c}\text { Korito } \\
\text { A9_2 } \\
\text { zone }\end{array}$ & $\begin{array}{c}\text { Korito } \\
\text { A9_3 } \\
\text { zone }\end{array}$ & $\begin{array}{l}\text { Korito } \\
\text { A9_4 } \\
\text { core }\end{array}$ & $\begin{array}{l}\text { Korito } \\
\text { A10_1 } \\
\text { rim }\end{array}$ & $\begin{array}{c}\text { Korito } \\
\text { A10_2 } \\
\text { core }\end{array}$ \\
\hline$\overline{\mathrm{SiO}_{2}}$ & 39.30 & 40.43 & 43.60 & 42.74 & 41.32 & 40.48 & 40.26 \\
\hline $\mathrm{TiO}_{2}$ & 2.69 & 2.25 & 2.58 & 3.03 & 2.27 & 2.40 & 2.11 \\
\hline $\mathrm{Al}_{2} \mathbf{O}_{3}$ & 13.48 & 12.68 & 12.31 & 10.12 & 11.99 & 12.79 & 12.96 \\
\hline $\mathrm{Fe}_{2} \mathrm{O}_{3}$ & 5.92 & 5.44 & 3.85 & 5.92 & 6.29 & 5.81 & 7.37 \\
\hline $\mathrm{FeO}$ & 8.17 & 7.21 & 9.49 & 6.91 & 7.50 & 8.77 & 7.61 \\
\hline MnO & 0.35 & 0.21 & 0.49 & 0.42 & 0.35 & 0.30 & 0.35 \\
\hline MgO & 12.24 & 13.55 & 12.86 & 14.07 & 13.20 & 12.17 & 12.31 \\
\hline $\mathrm{CaO}$ & 11.84 & 12.06 & 11.81 & 11.48 & 11.71 & 11.93 & 11.85 \\
\hline $\mathrm{Na}_{2} \mathrm{O}$ & 2.20 & 2.26 & 2.18 & 2.08 & 2.19 & 2.04 & 2.02 \\
\hline $\mathbf{K}_{2} \mathbf{O}$ & 1.01 & 0.97 & 0.91 & 0.87 & 1.05 & 0.81 & 0.84 \\
\hline $\mathbf{H}_{2} \mathbf{O}_{\text {calc }}$ & 1.87 & 1.88 & 1.95 & 1.90 & 1.89 & 1.88 & 1.87 \\
\hline Total & 99.08 & 98.95 & 102.03 & 99.55 & 99.76 & 99.36 & 99.56 \\
\hline Mg\# & 72.77 & 77.01 & 70.73 & 78.40 & 75.81 & 71.20 & 74.24 \\
\hline \multicolumn{8}{|l|}{ Cations } \\
\hline $\mathbf{S i}$ & 5.870 & 6.001 & 6.266 & 6.277 & 6.094 & 6.017 & 5.969 \\
\hline $\mathbf{T i}$ & 0.302 & 0.251 & 0.279 & 0.335 & 0.251 & 0.268 & 0.235 \\
\hline Al & 2.373 & 2.219 & 2.085 & 1.752 & 2.084 & 2.240 & 2.265 \\
\hline $\mathrm{Fe}^{3+}$ & 0.666 & 0.608 & 0.417 & 0.654 & 0.699 & 0.650 & 0.823 \\
\hline $\mathrm{Fe}^{2+}$ & 1.020 & 0.895 & 1.140 & 0.849 & 0.926 & 1.090 & 0.944 \\
\hline Mn & 0.044 & 0.026 & 0.060 & 0.053 & 0.044 & 0.038 & 0.044 \\
\hline Mg & 2.726 & 2.999 & 2.754 & 3.081 & 2.902 & 2.697 & 2.721 \\
\hline $\mathbf{C a}$ & 1.895 & 1.917 & 1.818 & 1.807 & 1.851 & 1.900 & 1.882 \\
\hline $\mathbf{N a}$ & 0.636 & 0.650 & 0.607 & 0.593 & 0.625 & 0.587 & 0.582 \\
\hline $\mathbf{K}$ & 0.193 & 0.184 & 0.166 & 0.163 & 0.198 & 0.153 & 0.159 \\
\hline Total & 15.72 & 15.75 & 15.59 & 15.56 & 15.67 & 15.64 & 15.62 \\
\hline \multicolumn{8}{|l|}{ P-C conditions } \\
\hline $\mathbf{T}\left({ }^{\circ} \mathbf{C}\right)$ & 1018 & 1002 & 950 & 933 & 972 & 987 & 990 \\
\hline Uncertanty & 22 & 22 & 22 & 22 & 22 & 22 & 22 \\
\hline P (MPa) & 582 & 467 & 385 & 239 & 385 & 481 & 499 \\
\hline Uncertanty & 64 & 51 & 42 & 26 & 42 & 53 & 55 \\
\hline $\begin{array}{l}\text { Equivalent depth } \\
(\mathbf{k m})\end{array}$ & 22.0 & 17.6 & 14.5 & 9.0 & 14.5 & 18.2 & 18.8 \\
\hline$\triangle \mathbf{N N O}$ & 0.19 & 0.66 & 0.29 & 0.81 & 0.63 & 0.27 & 0.43 \\
\hline $\log \mathrm{fO}_{2}$ & -9.67 & -9.47 & -10.67 & -10.49 & -9.99 & -10.09 & -9.87 \\
\hline Uncertanty & 0.4 & 0.4 & 0.4 & 0.4 & 0.4 & 0.4 & 0.4 \\
\hline $\mathrm{H}_{2} \mathrm{O}_{\text {melt }}$ (wt.\%) & 6.2 & 5.5 & 6.3 & 4.0 & 5.1 & 6.7 & 6.6 \\
\hline Uncertanty & 0.9 & 0.8 & 1.0 & 0.6 & 0.8 & 1.0 & 1.0 \\
\hline
\end{tabular}

Cation proportions calculated using Leake et al. (1997) on the basis of 13 cations. $P-C=$ Physicalchemical conditions, calculated using the method of Ridolfi et al. (2010). 
Table A2.6 Major element amphibole compositions analysed by EMPA.

\begin{tabular}{|c|c|c|c|c|c|c|c|}
\hline $\begin{array}{l}\text { Sample } \\
\text { ID } \\
\text { Zone }\end{array}$ & $\begin{array}{c}\text { Korito } \\
\text { A11_2 } \\
\text { core }\end{array}$ & $\begin{array}{l}\text { Korito } \\
\text { A12_1 } \\
\text { rim }\end{array}$ & $\begin{array}{c}\text { Korito } \\
\text { A12_2 } \\
\text { zone }\end{array}$ & $\begin{array}{l}\text { Korito } \\
\text { A12_3 } \\
\text { zone }\end{array}$ & $\begin{array}{c}\text { Korito } \\
\text { A12_4 } \\
\text { core }\end{array}$ & $\begin{array}{c}\text { Korito } \\
\text { A14_1 } \\
\text { rim }\end{array}$ & $\begin{array}{c}\text { Korito } \\
\text { A14_5 } \\
\text { core }\end{array}$ \\
\hline$\overline{\mathrm{SiO}_{2}}$ & 40.27 & 42.53 & 41.95 & 40.33 & 41.09 & 43.14 & 41.51 \\
\hline $\mathrm{TiO}_{2}$ & 2.20 & 2.61 & 2.40 & 2.09 & 1.90 & 2.54 & 1.95 \\
\hline $\mathrm{Al}_{2} \mathbf{O}_{3}$ & 12.50 & 10.05 & 11.08 & 13.18 & 12.28 & 9.80 & 11.89 \\
\hline $\mathrm{Fe}_{2} \mathrm{O}_{3}$ & 5.92 & 5.96 & 5.82 & 5.42 & 6.35 & 6.08 & 6.61 \\
\hline $\mathrm{FeO}$ & 8.30 & 7.01 & 7.47 & 9.15 & 7.68 & 6.67 & 6.97 \\
\hline MnO & 0.31 & 0.59 & 0.50 & 0.31 & 0.27 & 0.61 & 0.26 \\
\hline MgO & 12.50 & 13.71 & 13.40 & 12.17 & 12.94 & 14.15 & 13.30 \\
\hline $\mathrm{CaO}$ & 11.97 & 11.38 & 11.69 & 12.07 & 11.91 & 11.47 & 11.81 \\
\hline $\mathrm{Na}_{2} \mathrm{O}$ & 2.05 & 1.99 & 2.08 & 2.25 & 2.12 & 2.05 & 2.01 \\
\hline $\mathbf{K}_{2} \mathbf{O}$ & 0.86 & 0.98 & 0.85 & 0.86 & 0.80 & 0.91 & 0.79 \\
\hline $\mathbf{H}_{2} \mathbf{O}_{\text {calc }}$ & 1.86 & 1.88 & 1.88 & 1.88 & 1.88 & 1.89 & 1.88 \\
\hline Total & 98.72 & 98.70 & 99.12 & 99.71 & 99.21 & 99.30 & 98.99 \\
\hline Mg\# & 72.87 & 77.72 & 76.19 & 70.34 & 75.02 & 79.09 & 77.28 \\
\hline \multicolumn{8}{|l|}{ Cations } \\
\hline $\mathbf{S i}$ & 6.023 & 6.309 & 6.209 & 5.986 & 6.091 & 6.347 & 6.142 \\
\hline $\mathbf{T i}$ & 0.247 & 0.292 & 0.268 & 0.234 & 0.212 & 0.281 & 0.217 \\
\hline Al & 2.202 & 1.758 & 1.932 & 2.306 & 2.145 & 1.699 & 2.074 \\
\hline $\mathrm{Fe}^{3+}$ & 0.666 & 0.666 & 0.648 & 0.606 & 0.708 & 0.673 & 0.736 \\
\hline $\mathrm{Fe}^{2+}$ & 1.037 & 0.870 & 0.924 & 1.136 & 0.952 & 0.821 & 0.863 \\
\hline Mn & 0.039 & 0.074 & 0.062 & 0.039 & 0.034 & 0.075 & 0.033 \\
\hline Mg & 2.786 & 3.033 & 2.957 & 2.694 & 2.858 & 3.104 & 2.935 \\
\hline $\mathbf{C a}$ & 1.918 & 1.809 & 1.855 & 1.919 & 1.891 & 1.809 & 1.873 \\
\hline $\mathbf{N a}$ & 0.594 & 0.573 & 0.597 & 0.646 & 0.609 & 0.584 & 0.576 \\
\hline $\mathbf{K}$ & 0.163 & 0.186 & 0.161 & 0.164 & 0.151 & 0.170 & 0.149 \\
\hline Total & 15.67 & 15.57 & 15.61 & 15.73 & 15.65 & 15.56 & 15.60 \\
\hline \multicolumn{8}{|l|}{ P-C conditions } \\
\hline $\mathbf{T}\left({ }^{\circ} \mathbf{C}\right)$ & 988 & 927 & 951 & 998 & 974 & 921 & 964 \\
\hline Uncertanty & 22 & 22 & 22 & 22 & 22 & 22 & 22 \\
\hline P (MPa) & 456 & 241 & 309 & 529 & 420 & 221 & 379 \\
\hline Uncertanty & 50 & 26 & 34 & 58 & 46 & 24 & 42 \\
\hline $\begin{array}{l}\text { Equivalent depth } \\
(\mathbf{k m})\end{array}$ & 17.2 & 9.1 & 11.7 & 20.0 & 15.9 & 8.3 & 14.3 \\
\hline$\triangle \mathbf{N N O}$ & 0.43 & 0.83 & 0.70 & 0.26 & 0.63 & 0.96 & 0.78 \\
\hline $\log \mathrm{fO}_{2}$ & -9.92 & -10.56 & -10.28 & -9.91 & -9.93 & -10.55 & -9.97 \\
\hline Uncertanty & 0.4 & 0.4 & 0.4 & 0.4 & 0.4 & 0.4 & 0.4 \\
\hline $\mathrm{H}_{2} \mathrm{O}_{\text {melt }}$ (wt.\%) & 6.2 & 4.1 & 5.1 & 6.7 & 6.2 & 3.9 & 6.0 \\
\hline Uncertanty & 0.9 & 0.6 & 0.8 & 1.0 & 0.9 & 0.6 & 0.9 \\
\hline
\end{tabular}

Cation proportions calculated using Leake et al. (1997) on the basis of 13 cations. $P-C=$ Physicalchemical conditions, calculated using the method of Ridolfi et al. (2010). 
Table A2.6 Major element amphibole compositions analysed by EMPA.

\begin{tabular}{|c|c|c|c|c|c|c|}
\hline Sample & Korito & Korito & Korito & Korito & Korito & Korito \\
\hline ID & A14_6 & A14_7 & A14_8 & A15_1 & A15_2 & A16_1 \\
\hline Zone & zone & zone & zone & rim & zone & rim \\
\hline $\mathrm{SiO}_{2}$ & 40.95 & 41.80 & 40.97 & 43.62 & 43.12 & 43.95 \\
\hline $\mathrm{TiO}_{2}$ & 1.97 & 1.98 & 2.09 & 2.52 & 2.41 & 2.89 \\
\hline $\mathrm{Al}_{2} \mathbf{O}_{3}$ & 12.53 & 11.56 & 12.22 & 9.34 & 9.93 & 9.43 \\
\hline $\mathrm{Fe}_{2} \mathrm{O}_{3}$ & 6.41 & 6.44 & 5.70 & 6.96 & 5.21 & 2.68 \\
\hline $\mathrm{FeO}$ & 7.27 & 7.01 & 7.93 & 6.18 & 7.52 & 9.93 \\
\hline MnO & 0.25 & 0.27 & 0.34 & 0.64 & 0.50 & 0.64 \\
\hline MgO & 13.12 & 13.58 & 12.96 & 14.18 & 14.01 & 13.21 \\
\hline $\mathrm{CaO}$ & 12.00 & 11.93 & 11.93 & 11.24 & 11.71 & 11.19 \\
\hline $\mathrm{Na}_{2} \mathrm{O}$ & 2.07 & 2.03 & 2.18 & 1.96 & 2.02 & 2.20 \\
\hline $\mathbf{K}_{2} \mathbf{O}$ & 0.80 & 0.76 & 0.79 & 0.92 & 0.89 & 1.13 \\
\hline $\mathbf{H}_{2} \mathbf{O}_{\text {calc }}$ & 1.88 & 1.89 & 1.88 & 1.90 & 1.89 & 1.90 \\
\hline Total & 99.25 & 99.25 & 98.98 & 99.44 & 99.21 & 99.15 \\
\hline Mg\# & 76.28 & 77.55 & 74.44 & 80.34 & 76.86 & 70.32 \\
\hline \multicolumn{7}{|l|}{ Cations } \\
\hline $\mathbf{S i}$ & 6.058 & 6.168 & 6.089 & 6.400 & 6.358 & 6.508 \\
\hline $\mathbf{T i}$ & 0.219 & 0.219 & 0.233 & 0.278 & 0.268 & 0.322 \\
\hline Al & 2.185 & 2.011 & 2.141 & 1.616 & 1.726 & 1.646 \\
\hline $\mathrm{Fe}^{3+}$ & 0.714 & 0.715 & 0.637 & 0.768 & 0.578 & 0.298 \\
\hline $\mathrm{Fe}^{2+}$ & 0.900 & 0.865 & 0.986 & 0.759 & 0.927 & 1.230 \\
\hline Mn & 0.031 & 0.034 & 0.043 & 0.079 & 0.063 & 0.080 \\
\hline Mg & 2.893 & 2.988 & 2.871 & 3.101 & 3.080 & 2.915 \\
\hline $\mathbf{C a}$ & 1.902 & 1.887 & 1.900 & 1.767 & 1.850 & 1.775 \\
\hline $\mathbf{N a}$ & 0.593 & 0.581 & 0.628 & 0.556 & 0.576 & 0.631 \\
\hline $\mathbf{K}$ & 0.150 & 0.144 & 0.150 & 0.172 & 0.167 & 0.214 \\
\hline Total & 15.64 & 15.61 & 15.68 & 15.49 & 15.59 & 15.62 \\
\hline \multicolumn{7}{|l|}{ P-C conditions } \\
\hline $\mathbf{T}\left({ }^{\circ} \mathbf{C}\right)$ & 983 & 960 & 978 & 903 & 924 & 899 \\
\hline Uncertanty & 22 & 22 & 22 & 22 & 22 & 22 \\
\hline P (MPa) & 445 & 346 & 417 & 196 & 230 & 205 \\
\hline Uncertanty & 49 & 38 & 46 & 22 & 25 & 23 \\
\hline $\begin{array}{l}\text { Equivalent depth } \\
(\mathbf{k m})\end{array}$ & 16.8 & 13.1 & 15.8 & 7.4 & 8.7 & 7.7 \\
\hline$\Delta$ NNO & 0.66 & 0.85 & 0.57 & 1.05 & 0.91 & 0.50 \\
\hline $\log \mathrm{fO}_{2}$ & -9.77 & -9.98 & -9.94 & -10.78 & -10.55 & -11.40 \\
\hline Uncertanty & 0.4 & 0.4 & 0.4 & 0.4 & 0.4 & 0.4 \\
\hline $\mathrm{H}_{2} \mathrm{O}_{\text {melt }}$ (wt. \%) & 6.3 & 5.7 & 6.1 & 3.7 & 4.2 & 3.6 \\
\hline Uncertanty & 0.9 & 0.9 & 0.9 & 0.6 & 0.6 & 0.4 \\
\hline
\end{tabular}

Cation proportions calculated using Leake et al. (1997) on the basis of 13 cations. $P-C=$ Physicalchemical conditions, calculated using the method of Ridolfi et al. (2010). 
Table A2.6 Major element amphibole compositions analysed by EMPA.

\begin{tabular}{|c|c|c|c|c|c|c|}
\hline $\begin{array}{l}\text { Sample } \\
\text { ID } \\
\text { Zone }\end{array}$ & $\begin{array}{c}\text { Korito } \\
\text { A16_2 } \\
\text { zone }\end{array}$ & $\begin{array}{c}\text { Korito } \\
\text { A16_3 } \\
\text { zone }\end{array}$ & $\begin{array}{c}\text { Korito } \\
\text { A16_4 } \\
\text { zone }\end{array}$ & $\begin{array}{c}\text { Korito } \\
\text { A16_5 } \\
\text { zone }\end{array}$ & $\begin{array}{c}\text { Korito } \\
\text { A16_6 } \\
\text { zone }\end{array}$ & $\begin{array}{c}\text { Korito } \\
\text { A16_7 } \\
\text { zone }\end{array}$ \\
\hline$\overline{\mathrm{SiO}_{2}}$ & 40.36 & 42.41 & 40.87 & 42.17 & 41.52 & 39.79 \\
\hline $\mathrm{TiO}_{2}$ & 2.77 & 2.98 & 2.99 & 3.10 & 3.50 & 2.75 \\
\hline $\mathrm{Al}_{2} \mathrm{O}_{3}$ & 12.08 & 9.98 & 11.38 & 10.49 & 11.15 & 13.52 \\
\hline $\mathrm{Fe}_{2} \mathrm{O}_{3}$ & 3.55 & 3.05 & 3.58 & 3.52 & 3.49 & 5.16 \\
\hline $\mathrm{FeO}$ & 10.53 & 9.59 & 10.59 & 9.65 & 8.21 & 8.00 \\
\hline MnO & 0.36 & 0.56 & 0.56 & 0.44 & 0.34 & 0.28 \\
\hline MgO & 11.91 & 13.14 & 11.95 & 13.01 & 13.75 & 12.52 \\
\hline $\mathrm{CaO}$ & 11.88 & 11.68 & 11.66 & 11.58 & 11.68 & 11.70 \\
\hline $\mathrm{Na}_{2} \mathrm{O}$ & 2.13 & 2.01 & 2.17 & 2.15 & 2.31 & 2.35 \\
\hline $\mathbf{K}_{2} \mathbf{O}$ & 0.97 & 0.95 & 1.06 & 1.07 & 0.92 & 0.86 \\
\hline $\mathbf{H}_{2} \mathbf{O}_{\text {calc }}$ & 1.86 & 1.87 & 1.86 & 1.88 & 1.89 & 1.88 \\
\hline Total & 98.39 & 98.23 & 98.66 & 99.07 & 98.76 & 98.80 \\
\hline Mg\# & 66.85 & 70.94 & 66.79 & 70.62 & 74.90 & 73.62 \\
\hline \multicolumn{7}{|l|}{ Cations } \\
\hline $\mathbf{S i}$ & 6.087 & 6.354 & 6.152 & 6.277 & 6.163 & 5.927 \\
\hline $\mathbf{T i}$ & 0.314 & 0.335 & 0.338 & 0.347 & 0.390 & 0.308 \\
\hline Al & 2.147 & 1.761 & 2.018 & 1.839 & 1.951 & 2.373 \\
\hline $\mathrm{Fe}^{3+}$ & 0.403 & 0.344 & 0.406 & 0.394 & 0.389 & 0.578 \\
\hline $\mathrm{Fe}^{2+}$ & 1.327 & 1.202 & 1.333 & 1.201 & 1.020 & 0.996 \\
\hline Mn & 0.045 & 0.071 & 0.071 & 0.056 & 0.043 & 0.035 \\
\hline Mg & 2.677 & 2.934 & 2.681 & 2.886 & 3.043 & 2.781 \\
\hline $\mathbf{C a}$ & 1.920 & 1.875 & 1.880 & 1.847 & 1.857 & 1.868 \\
\hline $\mathbf{N a}$ & 0.623 & 0.585 & 0.633 & 0.622 & 0.665 & 0.679 \\
\hline $\mathbf{K}$ & 0.186 & 0.182 & 0.203 & 0.203 & 0.175 & 0.163 \\
\hline Total & 15.73 & 15.64 & 15.72 & 15.67 & 15.70 & 15.71 \\
\hline \multicolumn{7}{|l|}{$\bar{P}-\mathrm{C}$ conditions } \\
\hline $\mathbf{T}\left({ }^{\circ} \mathbf{C}\right)$ & 981 & 930 & 964 & 942 & 972 & 1014 \\
\hline Uncertanty & 22 & 22 & 22 & 22 & 22 & 22 \\
\hline $\mathbf{P}$ (MPa) & 421 & 242 & 350 & 271 & 318 & 583 \\
\hline Uncertanty & 46 & 27 & 38 & 30 & 35 & 64 \\
\hline $\begin{array}{l}\text { Equivalent depth } \\
(\mathrm{km})\end{array}$ & 15.9 & 9.1 & 13.2 & 10.2 & 12.0 & 22.0 \\
\hline$\triangle$ NNO & 0.06 & 0.47 & 0.06 & 0.38 & 0.44 & 0.20 \\
\hline $\log \mathrm{fO}_{2}$ & -10.41 & -10.87 & -10.71 & -10.77 & -10.20 & -9.71 \\
\hline Uncertanty & 0.4 & 0.4 & 0.4 & 0.4 & 0.4 & 0.4 \\
\hline $\mathrm{H}_{2} \mathrm{O}_{\text {melt }}$ (wt.\%) & 5.8 & 4.3 & 5.0 & 4.1 & 4.3 & 6.5 \\
\hline Uncertanty & 0.9 & 0.6 & 0.7 & 0.6 & 0.6 & 1.0 \\
\hline
\end{tabular}

Cation proportions calculated using Leake et al. (1997) on the basis of 13 cations. $P-C=$ Physicalchemical conditions, calculated using the method of Ridolfi et al. (2010). 
Table A2.6 Major element amphibole compositions analysed by EMPA.

\begin{tabular}{|c|c|c|c|c|c|}
\hline Sample & Korito & Korito & Korito & Korito & Korito \\
\hline ID & A16_8 & A16_9 & A16_10 & A16_11 & A16_12 \\
\hline Zone & zone & zone & core & core & zone \\
\hline $\mathrm{SiO}_{2}$ & 42.45 & 41.15 & 41.79 & 39.23 & 42.00 \\
\hline $\mathrm{TiO}_{2}$ & 3.18 & 3.31 & 3.18 & 2.94 & 3.04 \\
\hline $\mathrm{Al}_{2} \mathbf{O}_{3}$ & 10.22 & 11.14 & 10.99 & 13.50 & 10.48 \\
\hline $\mathrm{Fe}_{2} \mathrm{O}_{3}$ & 2.53 & 3.03 & 3.84 & 4.66 & 3.65 \\
\hline $\mathrm{FeO}$ & 9.58 & 9.99 & 9.37 & 9.44 & 9.35 \\
\hline MnO & 0.38 & 0.43 & 0.42 & 0.38 & 0.39 \\
\hline MgO & 13.57 & 12.73 & 13.02 & 11.85 & 13.15 \\
\hline $\mathrm{CaO}$ & 11.81 & 11.74 & 11.71 & 11.77 & 11.66 \\
\hline $\mathrm{Na}_{2} \mathrm{O}$ & 2.14 & 2.26 & 2.23 & 2.32 & 2.06 \\
\hline $\mathbf{K}_{2} \mathbf{O}$ & 1.00 & 0.96 & 0.94 & 1.11 & 1.12 \\
\hline $\mathrm{H}_{2} \mathrm{O}_{\text {calc }}$ & 1.89 & 1.87 & 1.89 & 1.87 & 1.88 \\
\hline Total & 98.76 & 98.60 & 99.37 & 99.06 & 98.78 \\
\hline Mg\# & 71.64 & 69.44 & 71.25 & 69.11 & 71.48 \\
\hline \multicolumn{6}{|l|}{ Cations } \\
\hline $\mathbf{S i}$ & 6.317 & 6.167 & 6.200 & 5.880 & 6.265 \\
\hline $\mathbf{T i}$ & 0.356 & 0.373 & 0.354 & 0.331 & 0.341 \\
\hline Al & 1.792 & 1.968 & 1.921 & 2.384 & 1.843 \\
\hline $\mathrm{Fe}^{3+}$ & 0.284 & 0.342 & 0.429 & 0.526 & 0.410 \\
\hline $\mathrm{Fe}^{2+}$ & 1.192 & 1.252 & 1.162 & 1.183 & 1.167 \\
\hline Mn & 0.048 & 0.055 & 0.053 & 0.049 & 0.050 \\
\hline Mg & 3.011 & 2.844 & 2.880 & 2.647 & 2.925 \\
\hline $\mathrm{Ca}$ & 1.884 & 1.885 & 1.861 & 1.890 & 1.863 \\
\hline $\mathbf{N a}$ & 0.619 & 0.657 & 0.640 & 0.674 & 0.596 \\
\hline $\mathbf{K}$ & 0.190 & 0.183 & 0.178 & 0.212 & 0.213 \\
\hline Total & 15.69 & 15.73 & 15.68 & 15.78 & 15.67 \\
\hline \multicolumn{6}{|l|}{ P-C conditions } \\
\hline $\mathbf{T}\left({ }^{\circ} \mathbf{C}\right)$ & 942 & 967 & 957 & 1019 & 944 \\
\hline Uncertanty & 22 & 22 & 22 & 22 & 22 \\
\hline P (MPa) & 253 & 325 & 304 & 592 & 272 \\
\hline Uncertanty & 28 & 36 & 33 & 65 & 30 \\
\hline Equivalent depth & 9.5 & 12.3 & 11.5 & 22.4 & 10.3 \\
\hline$(\mathbf{k m})$ & & & & & \\
\hline$\Delta \mathbf{N N O}$ & 0.49 & 0.18 & 0.33 & -0.05 & 0.45 \\
\hline $\log \mathrm{fO}_{2}$ & -10.65 & -10.54 & -10.56 & -9.89 & -10.65 \\
\hline Uncertanty & 0.4 & 0.4 & 0.4 & 0.4 & 0.4 \\
\hline $\mathrm{H}_{2} \mathrm{O}_{\text {melt }}($ wt. \%) & 4.0 & 4.6 & 4.6 & 6.0 & 4.0 \\
\hline Uncertanty & 0.6 & 0.7 & 0.7 & 0.9 & 0.6 \\
\hline
\end{tabular}

Cation proportions calculated using Leake et al. (1997) on the basis of 13 cations. $P-C=$ Physicalchemical conditions, calculated using the method of Ridolfi et al. (2010). 


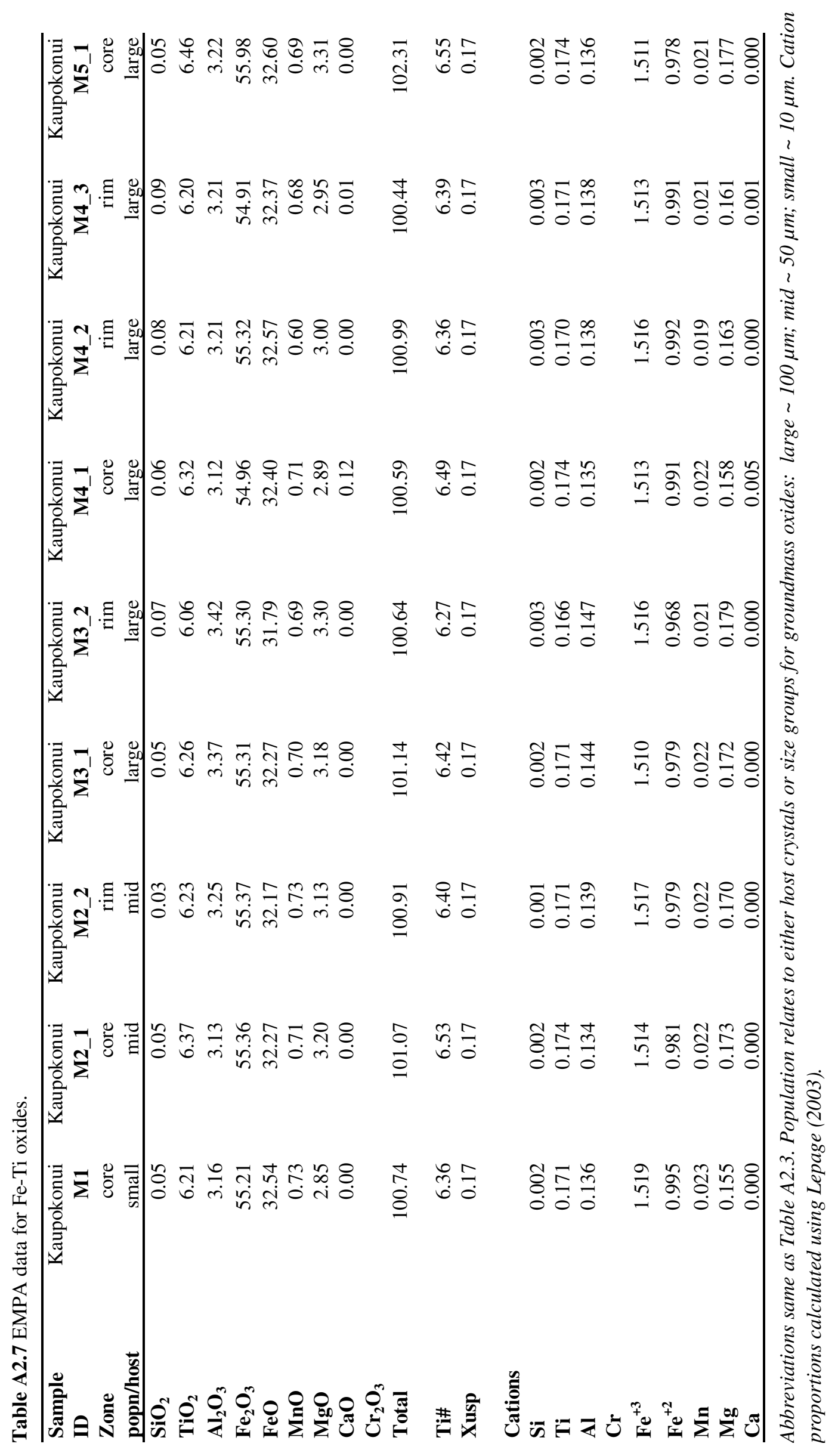




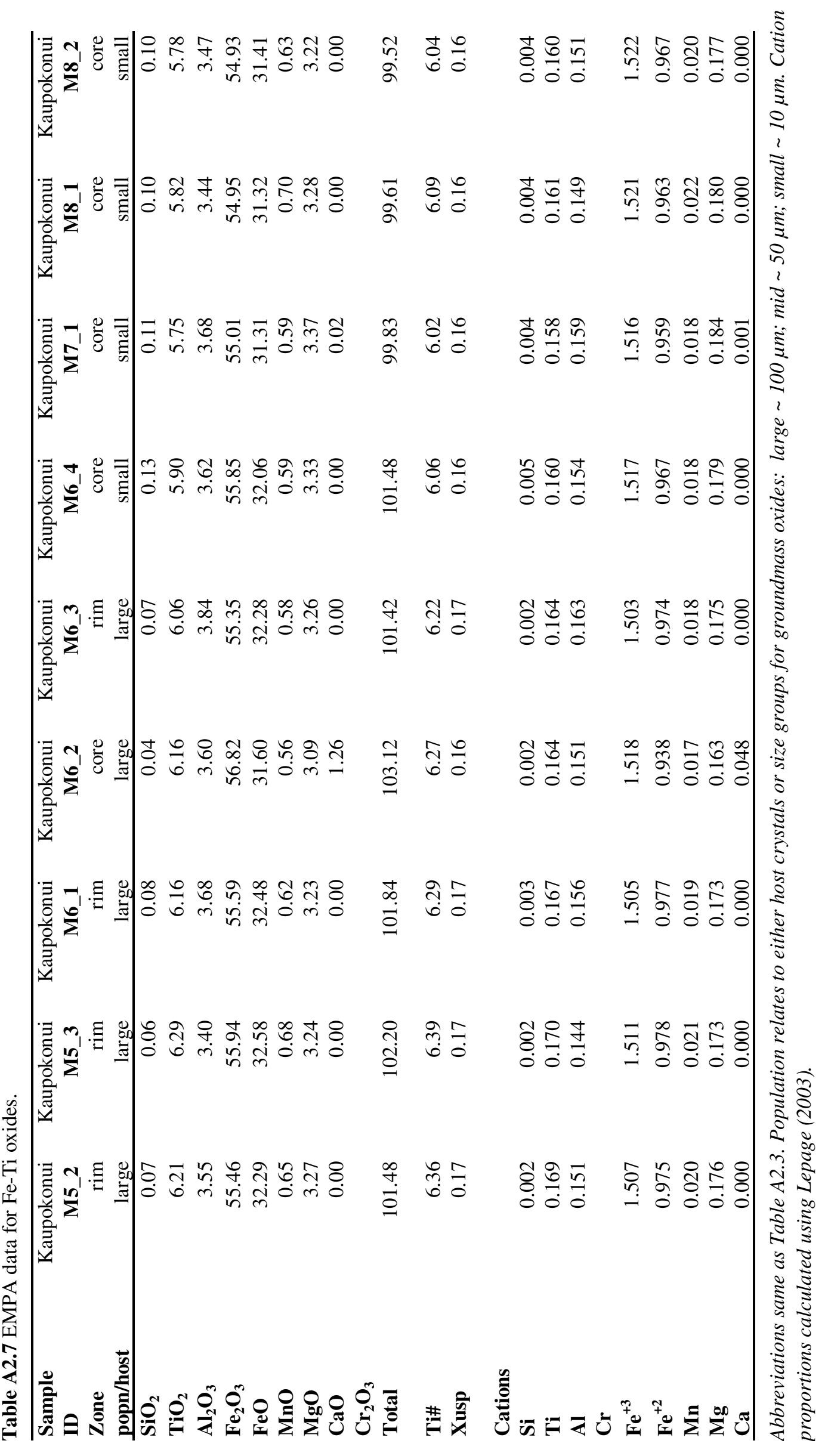




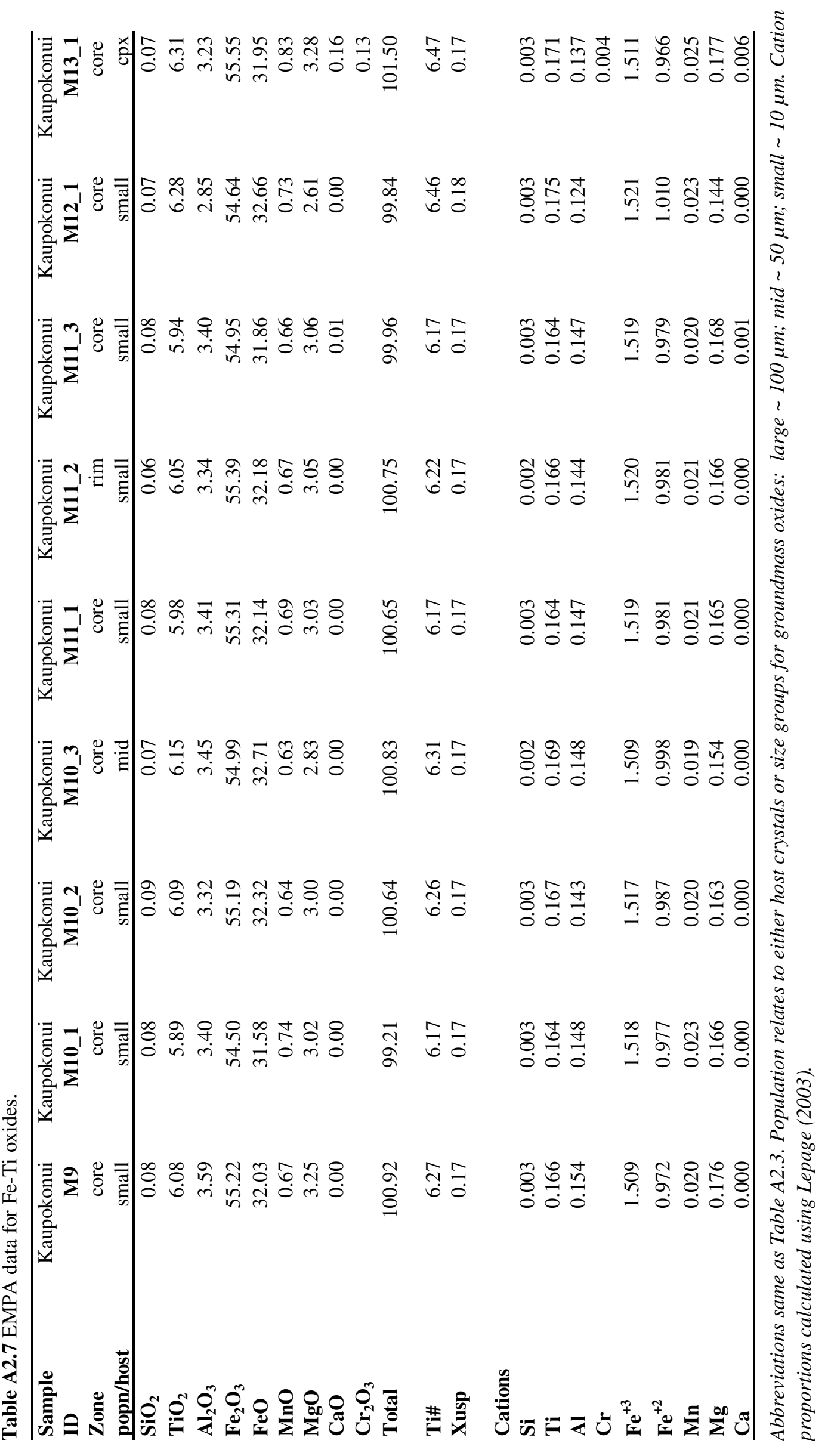




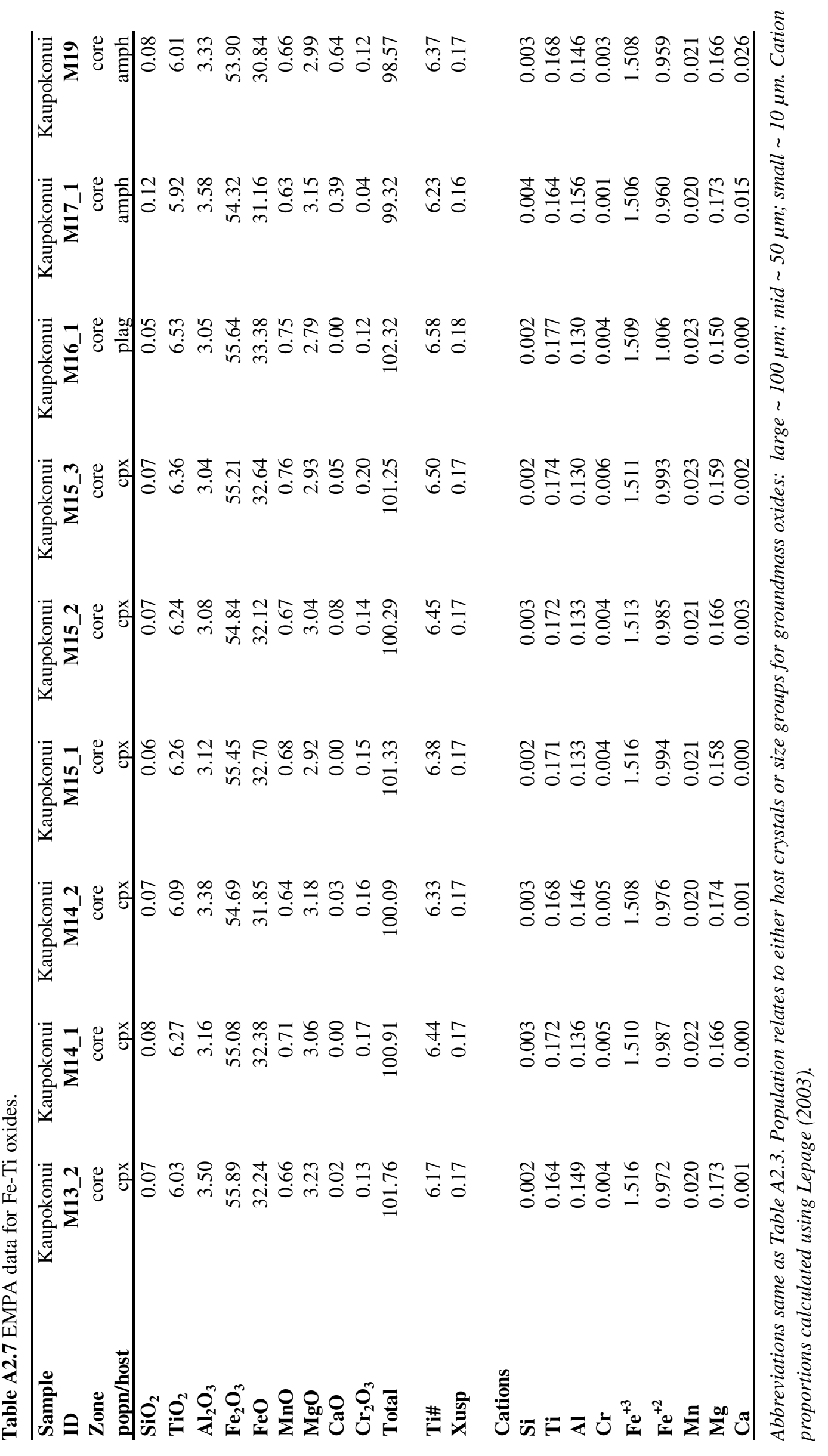




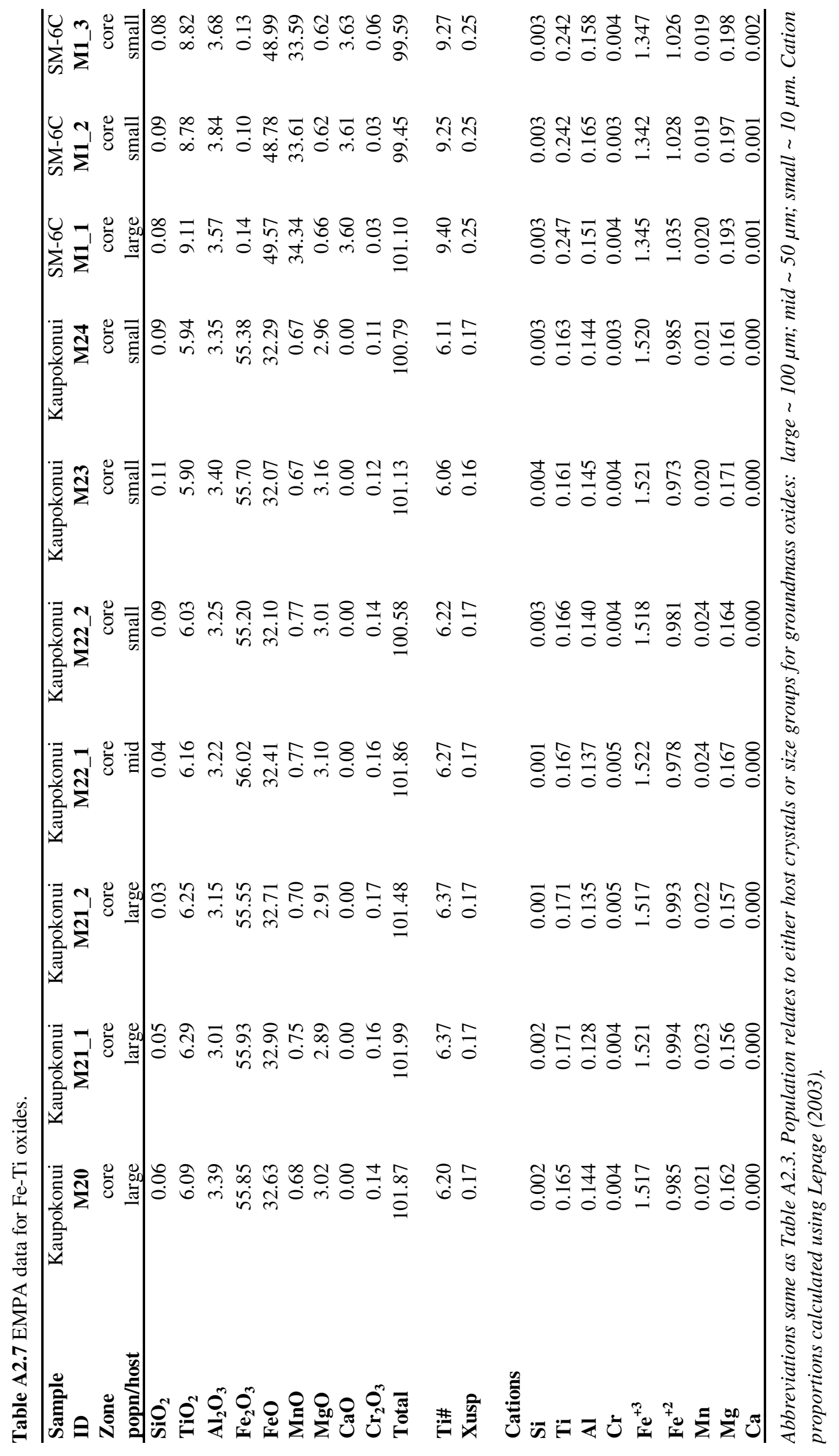




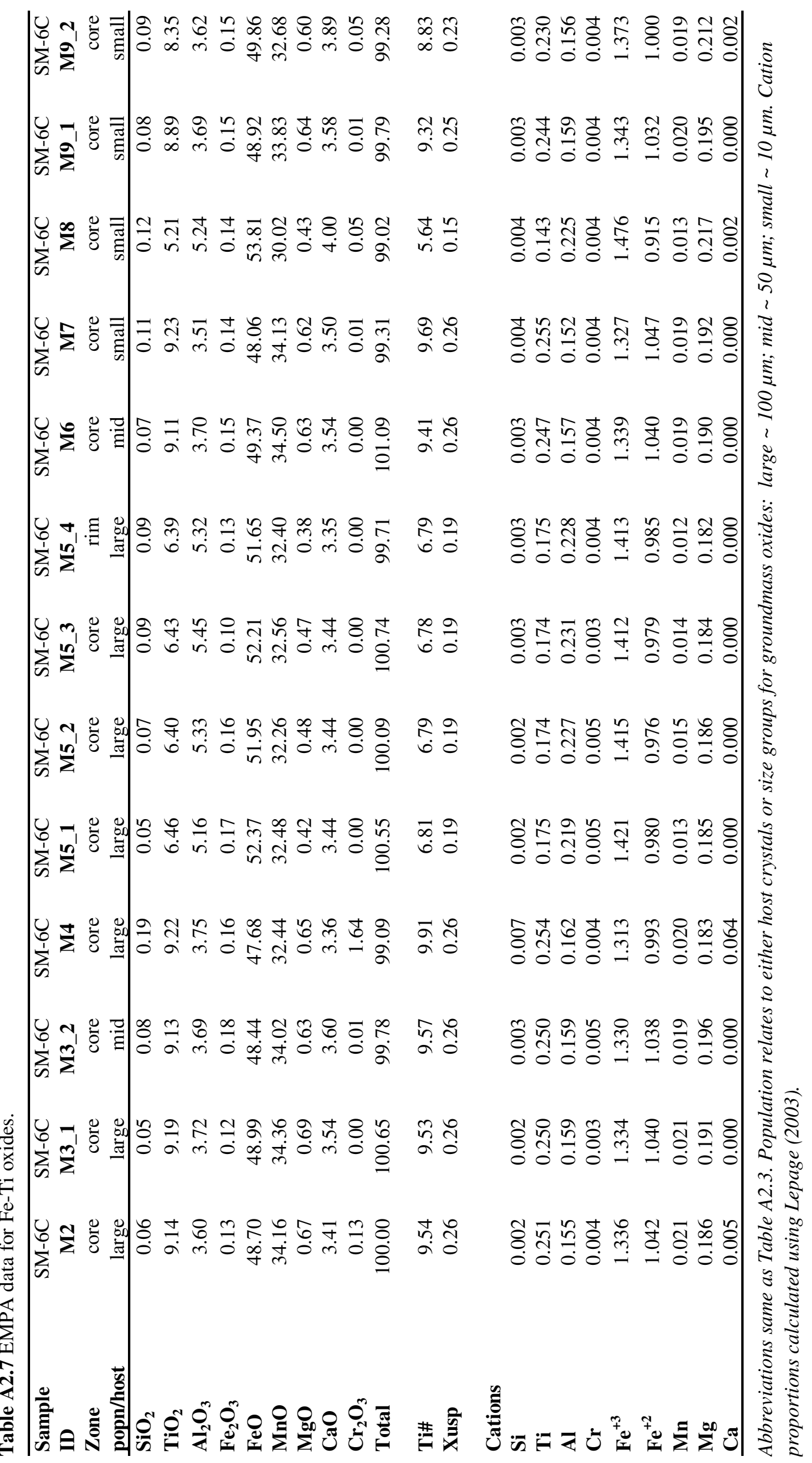




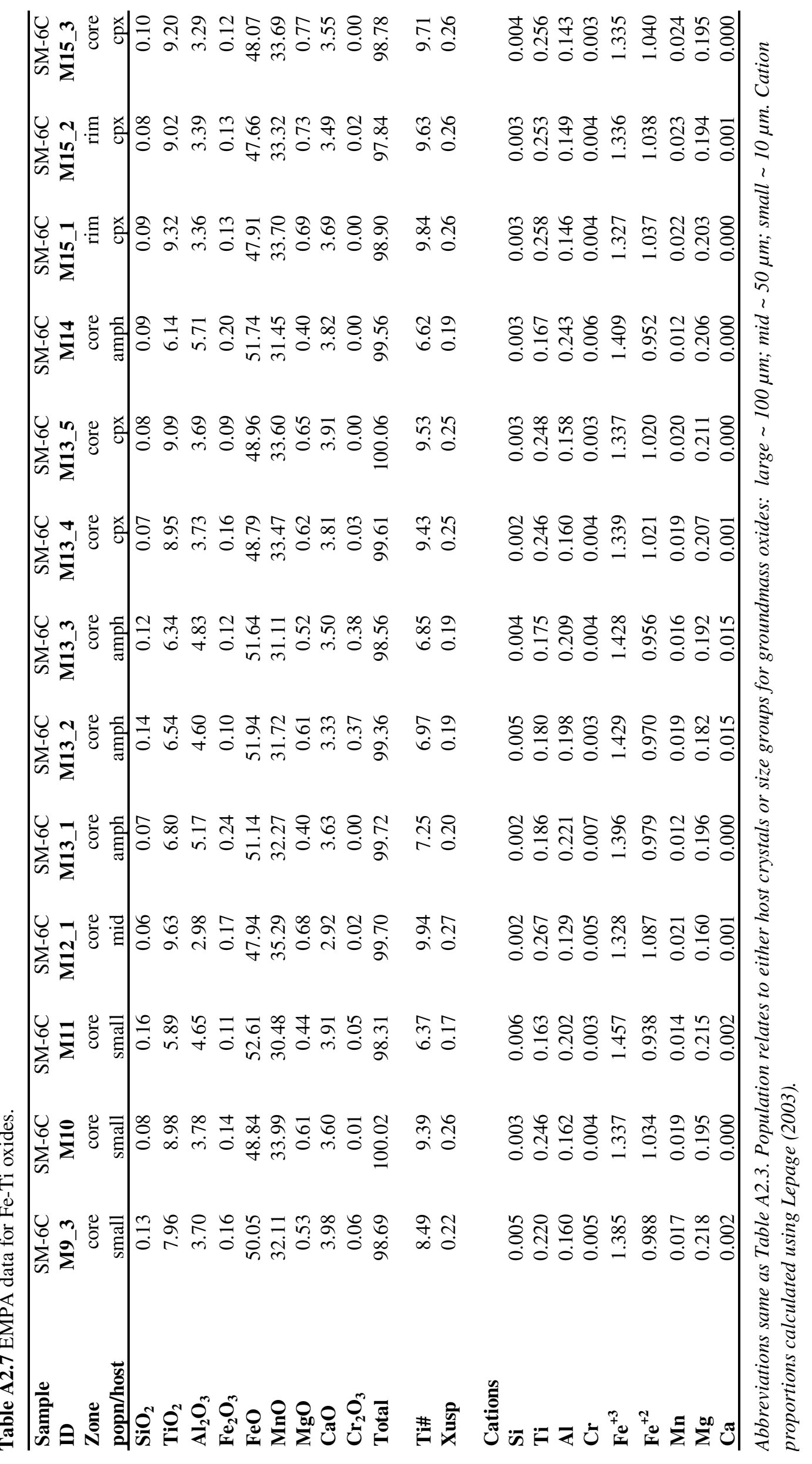




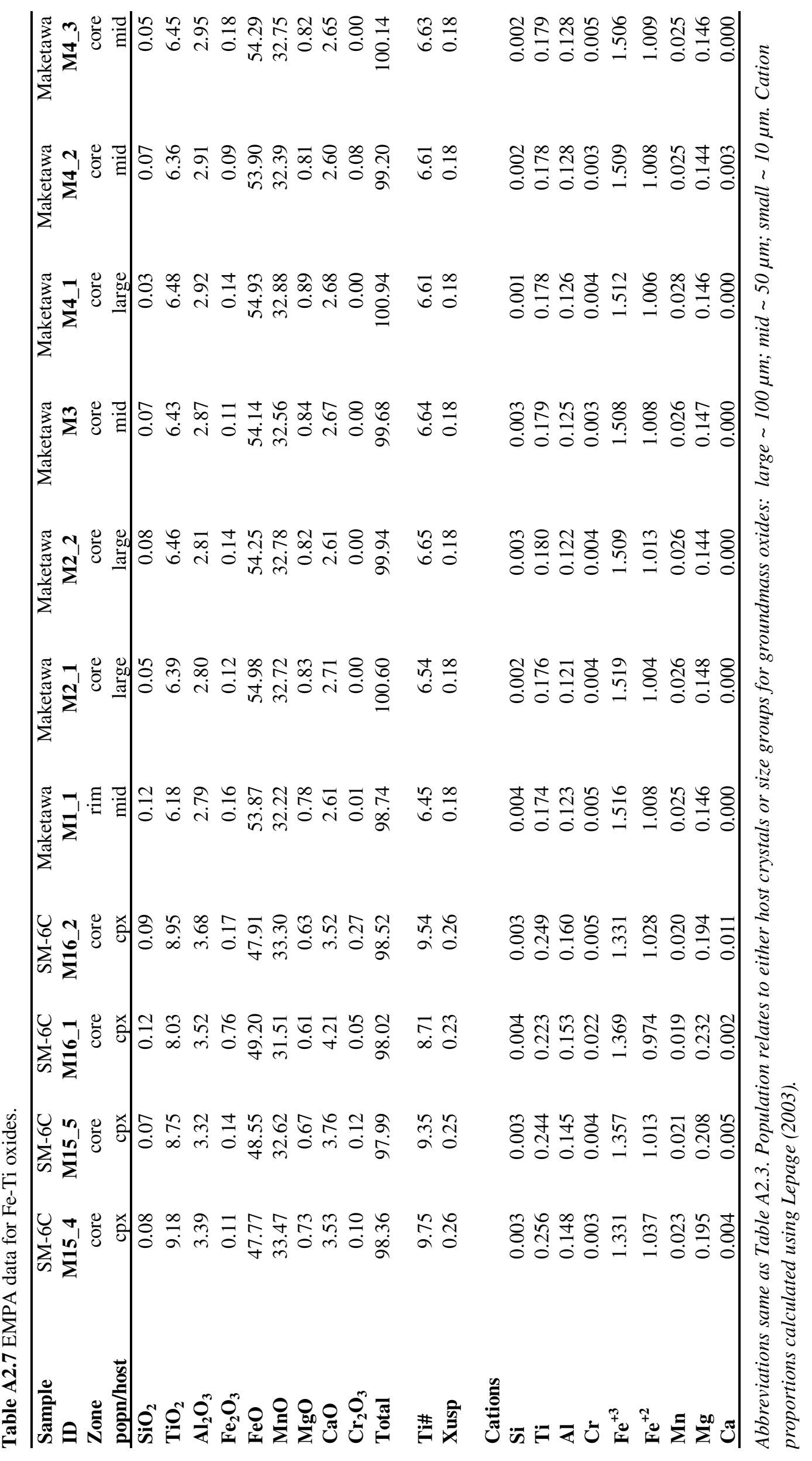




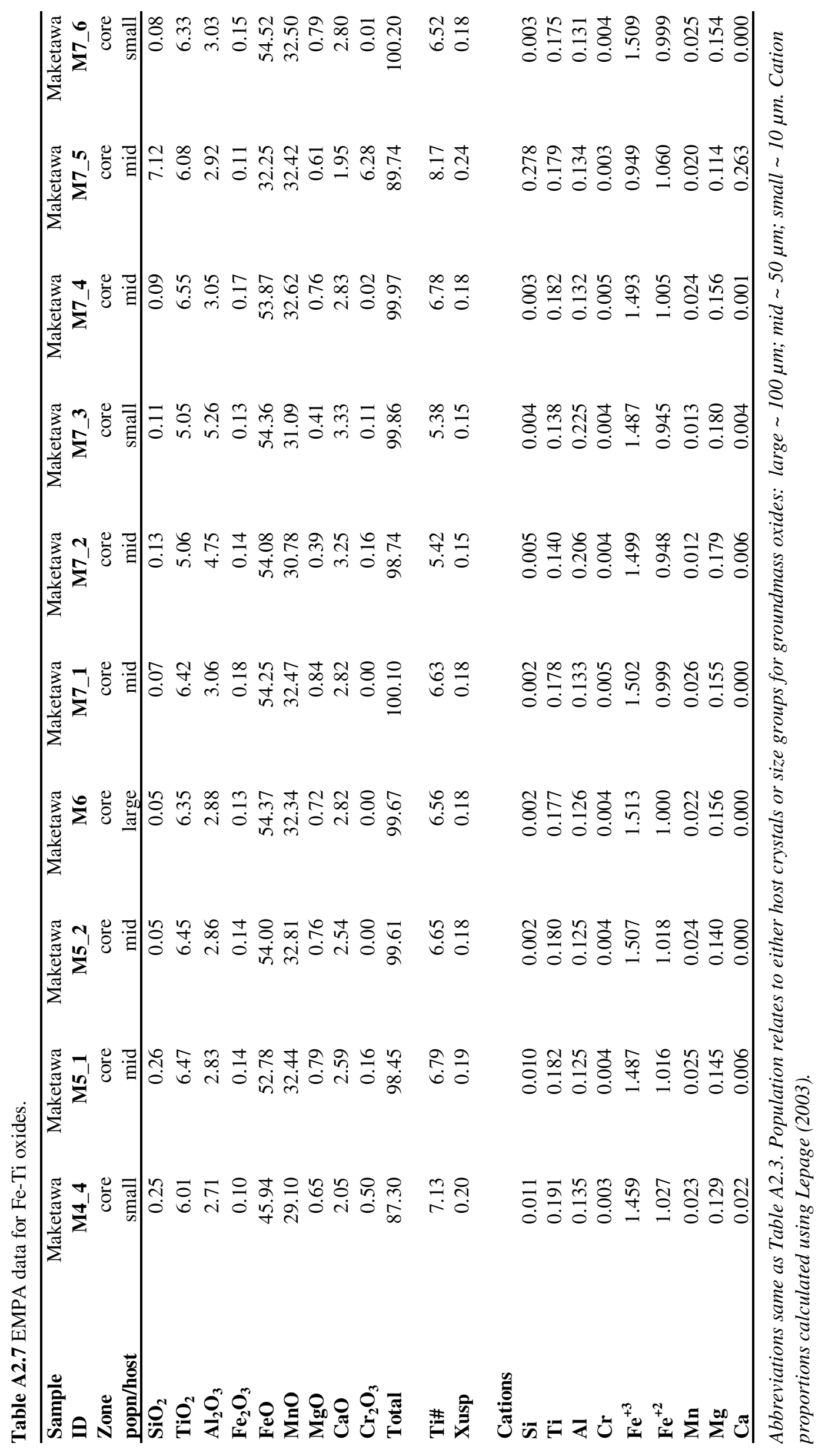




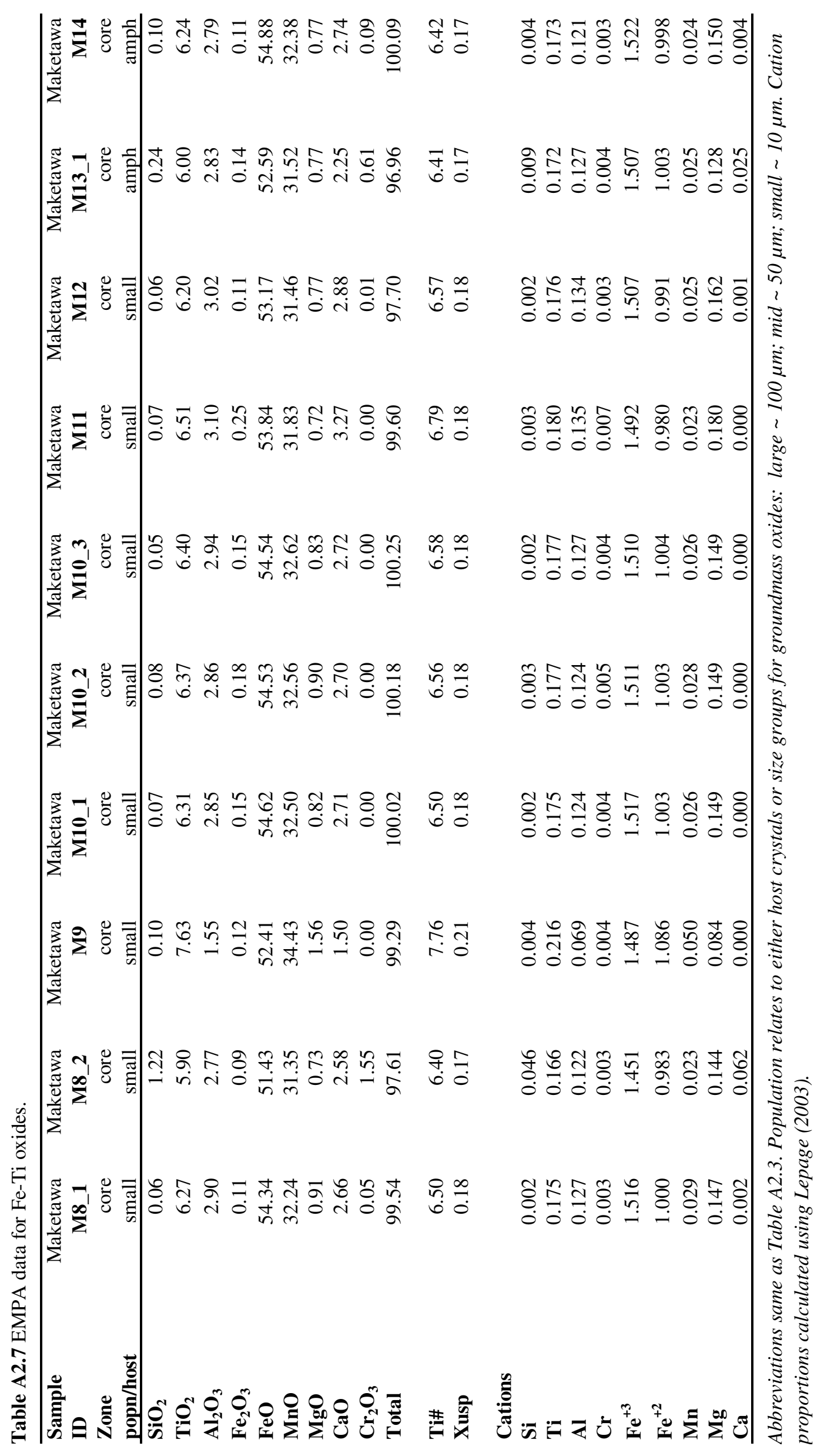




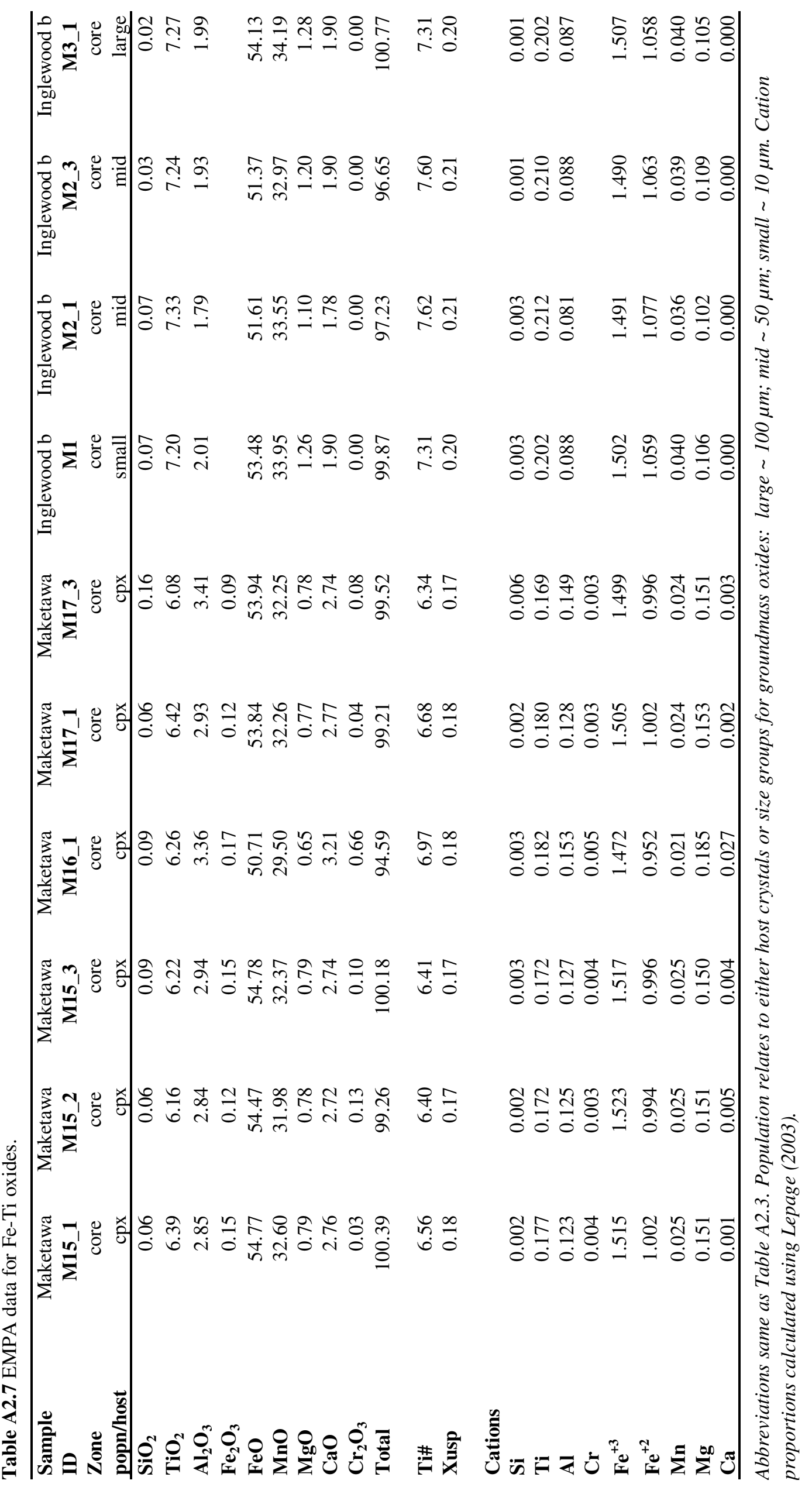




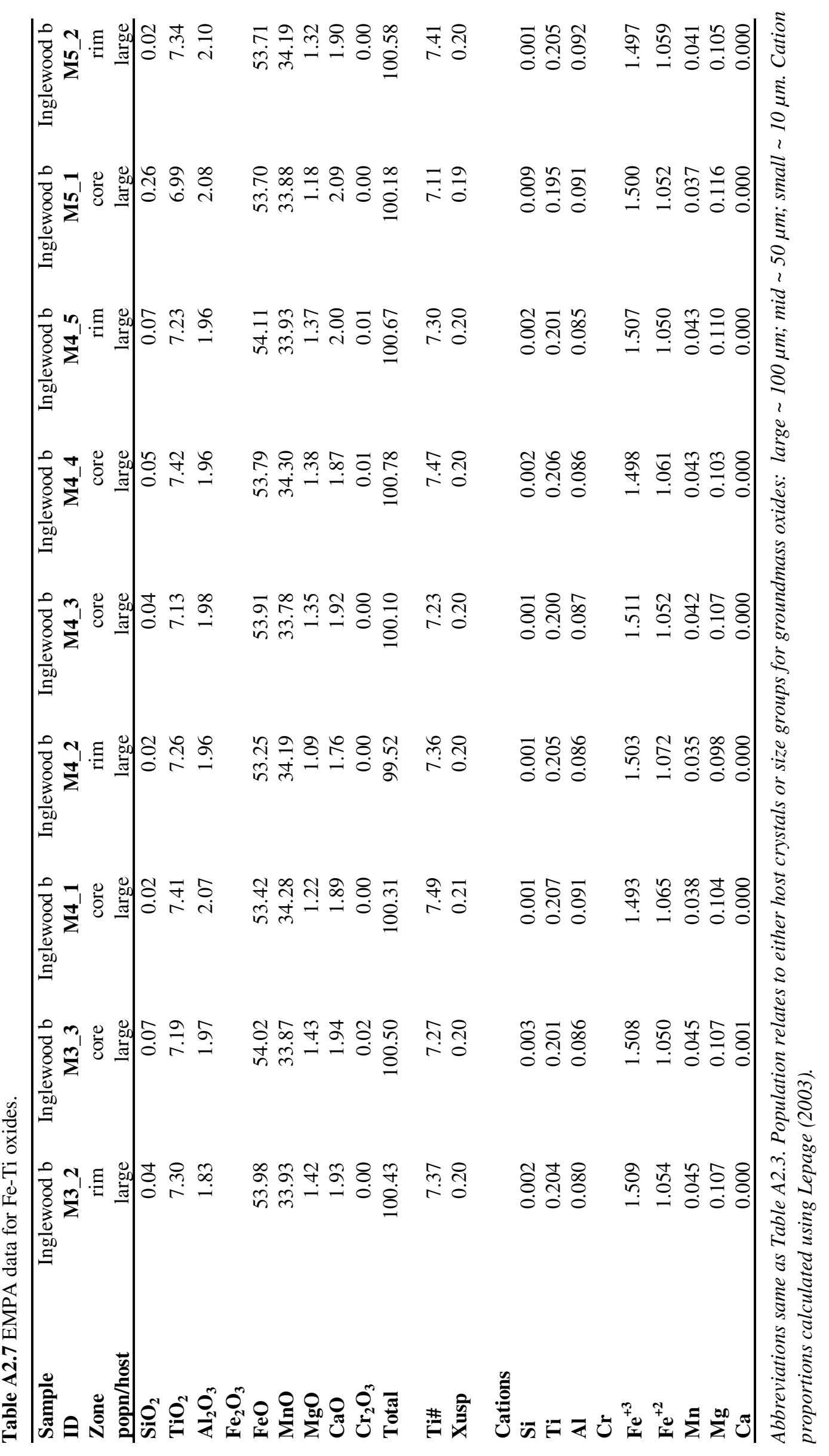




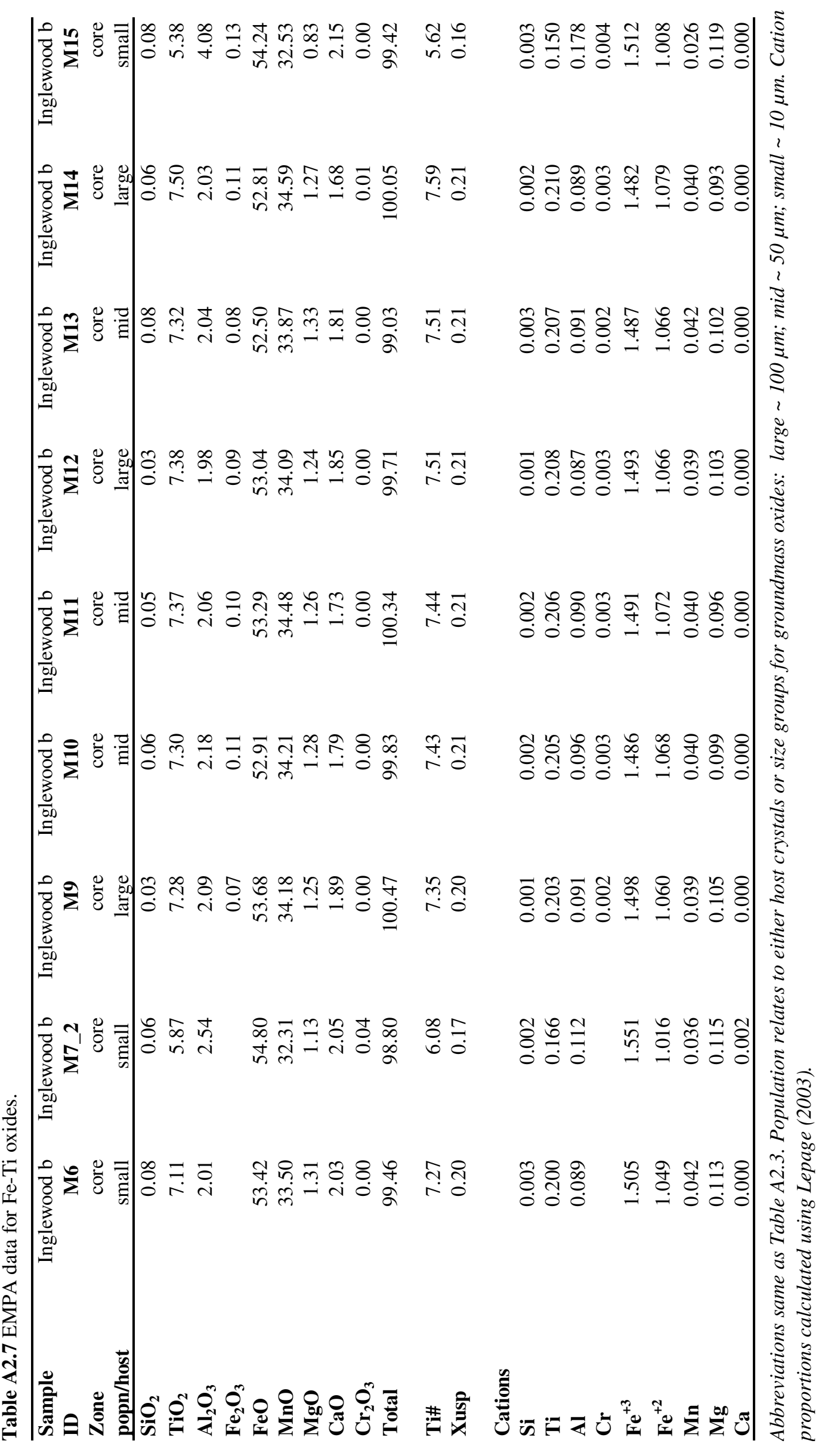




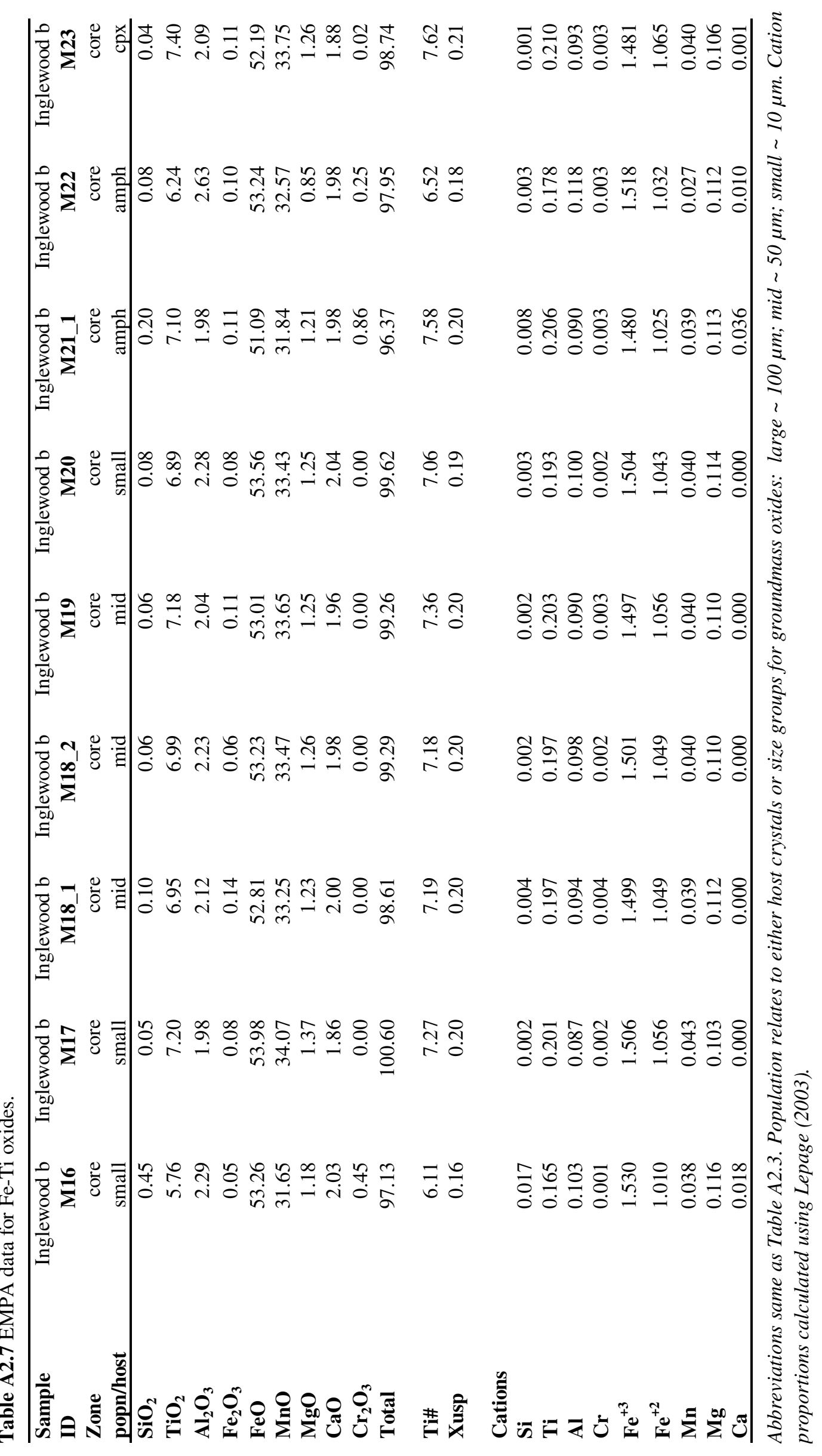




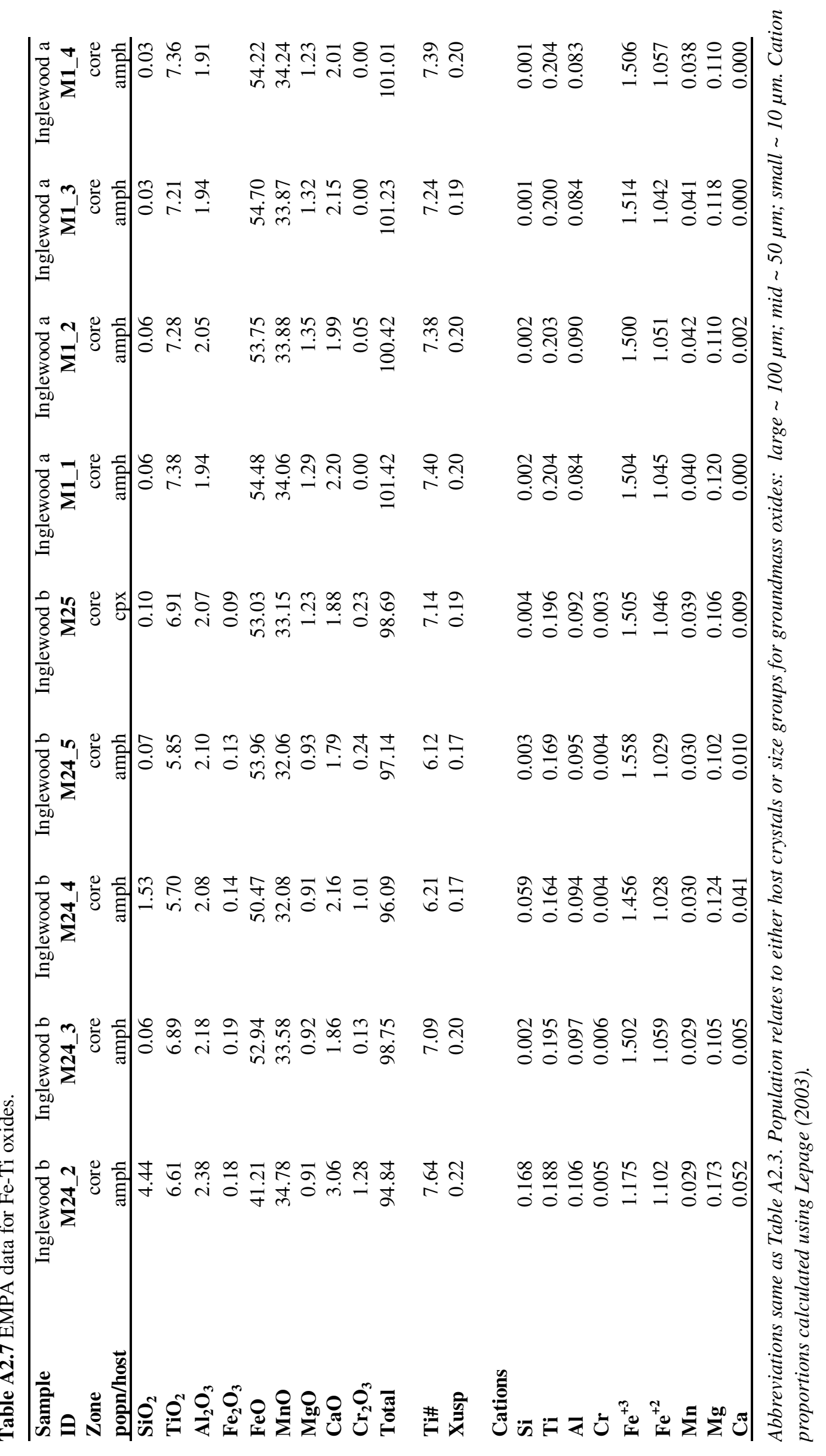




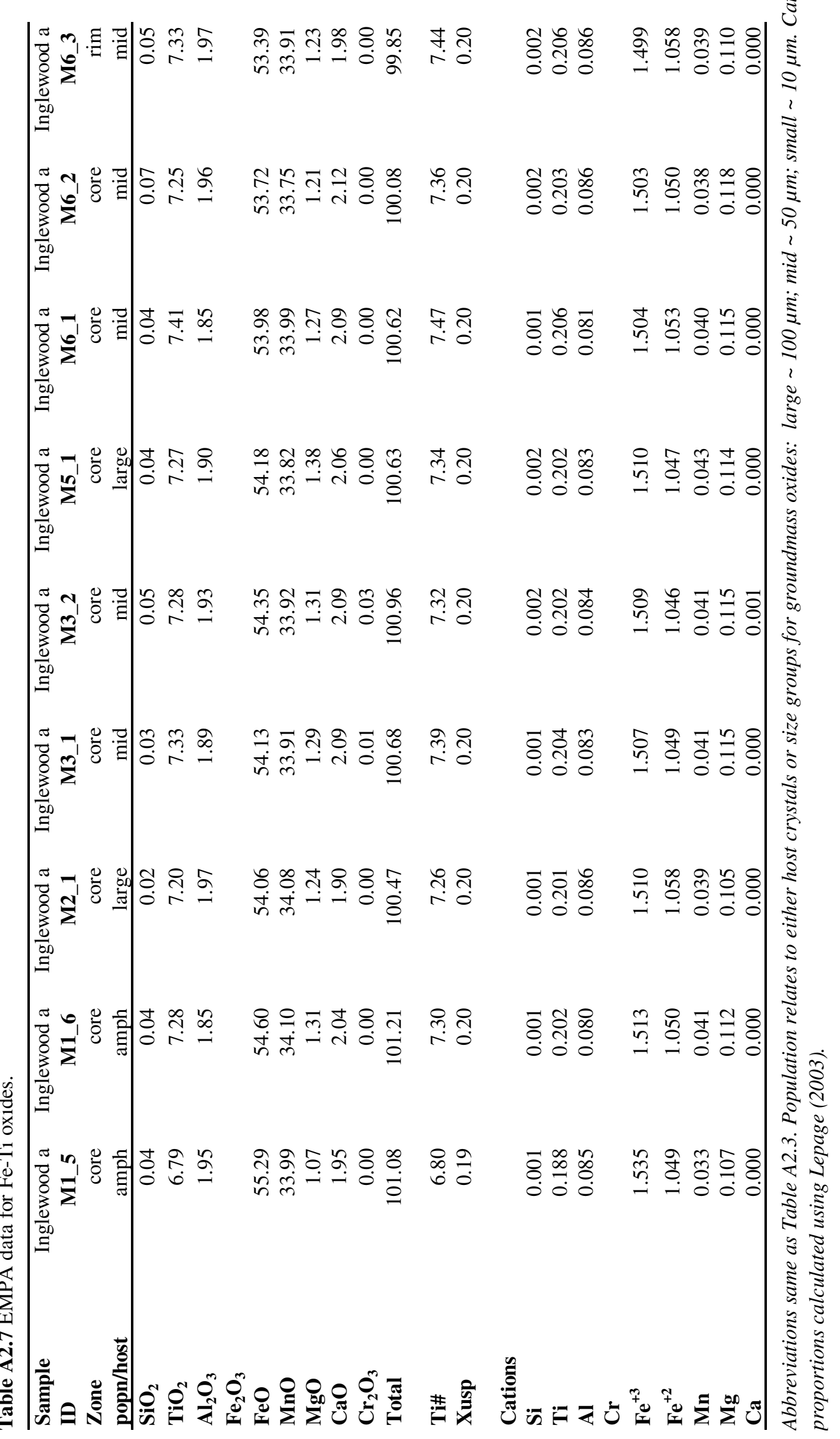




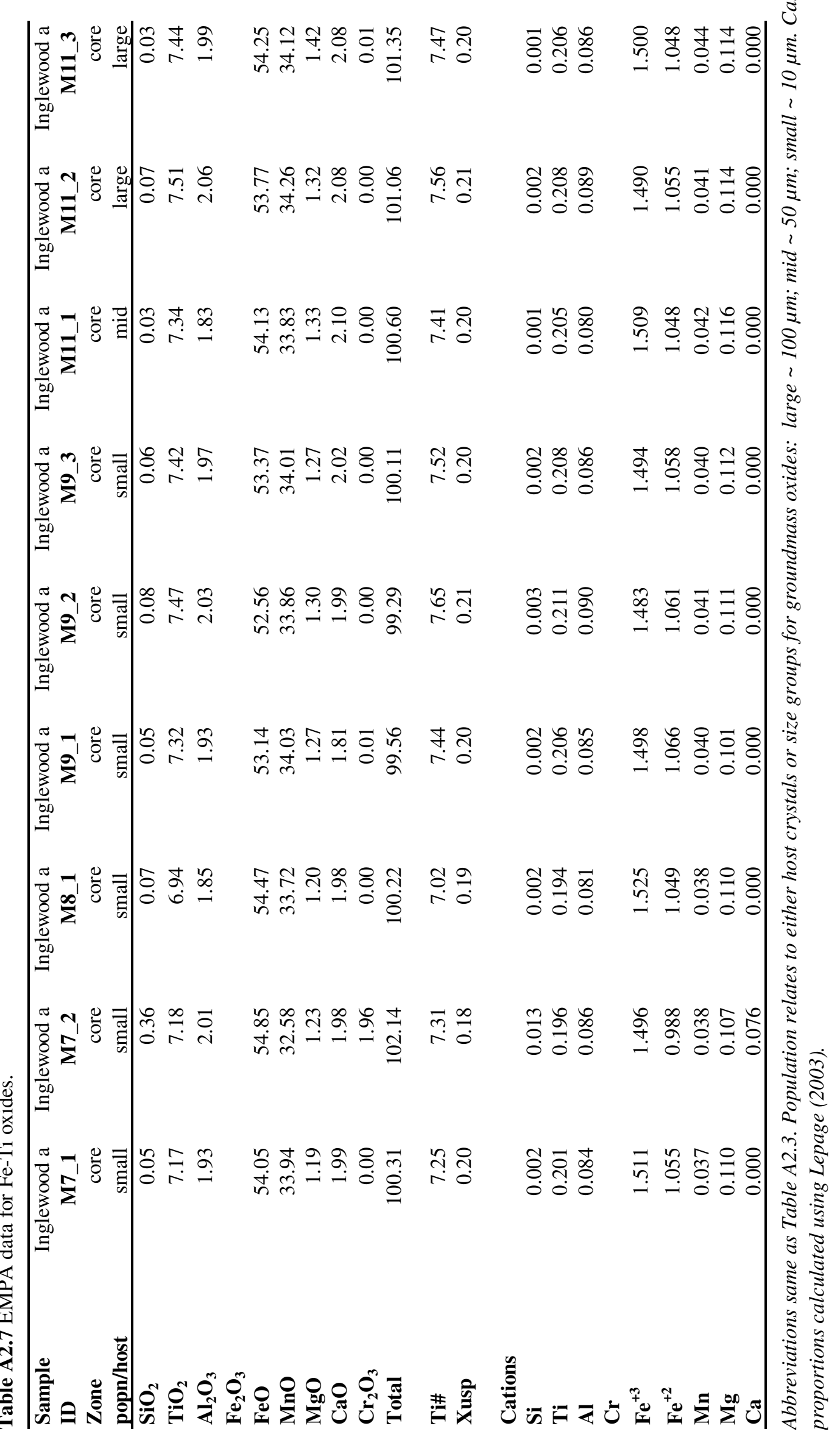




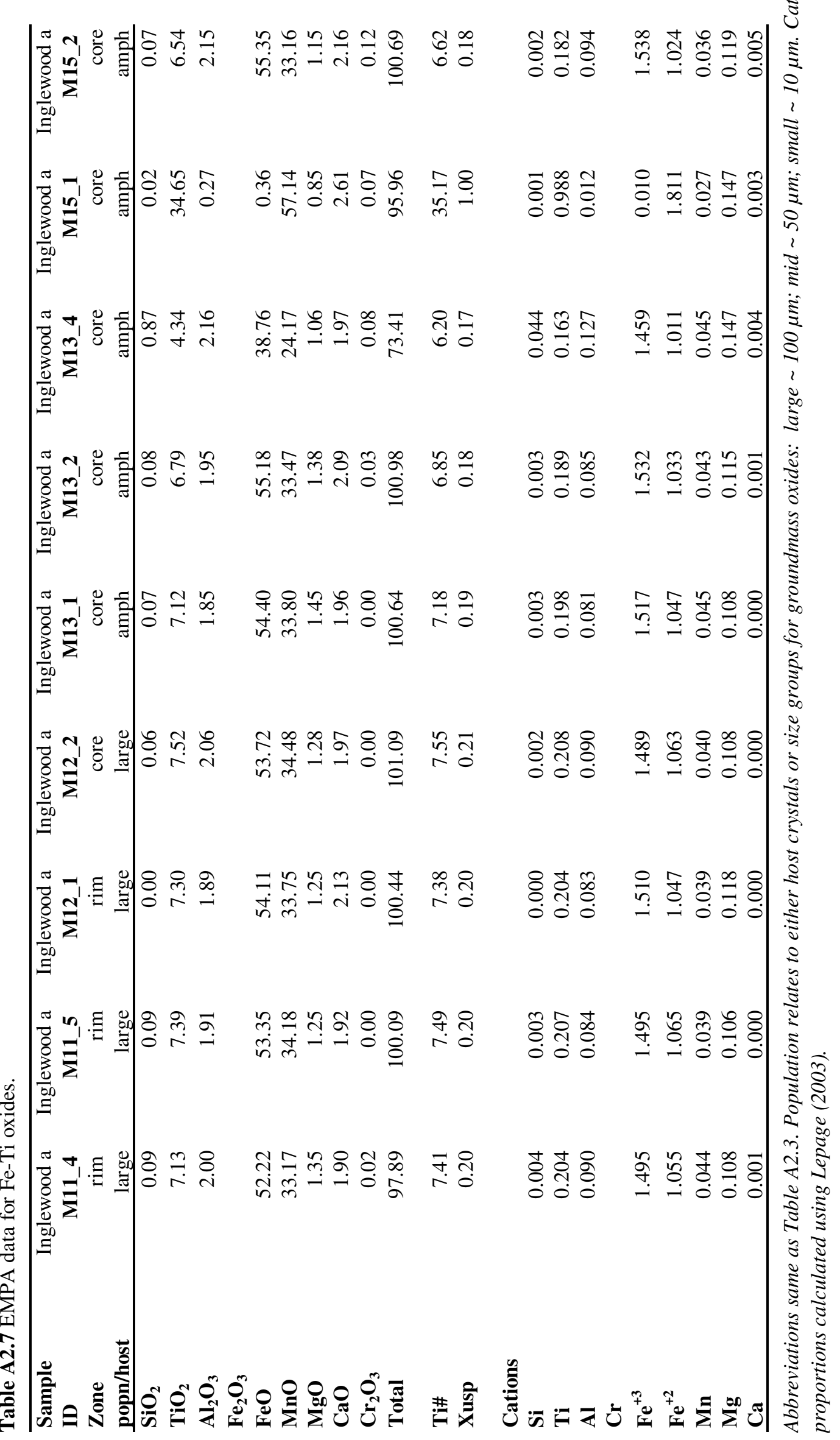




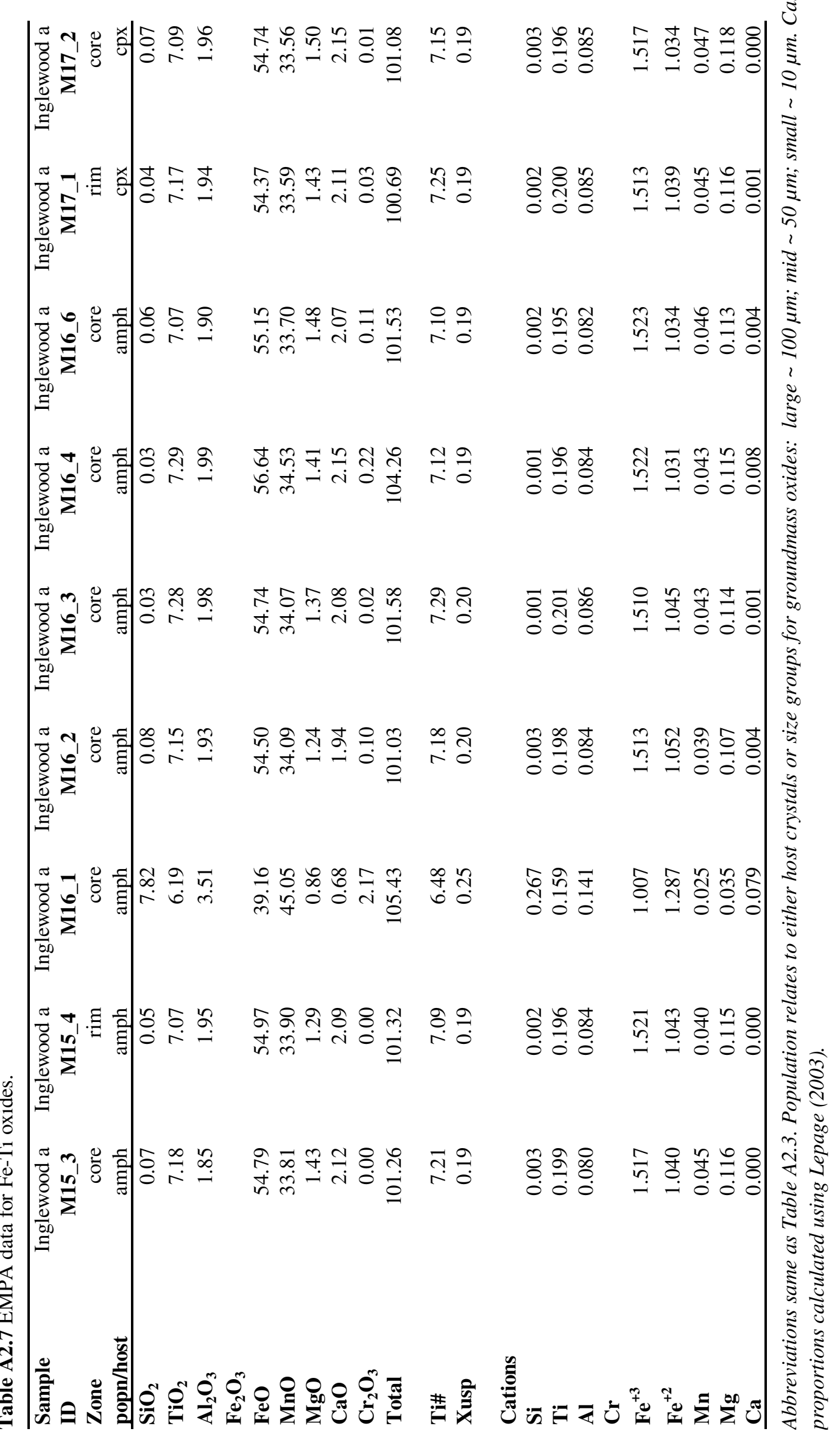




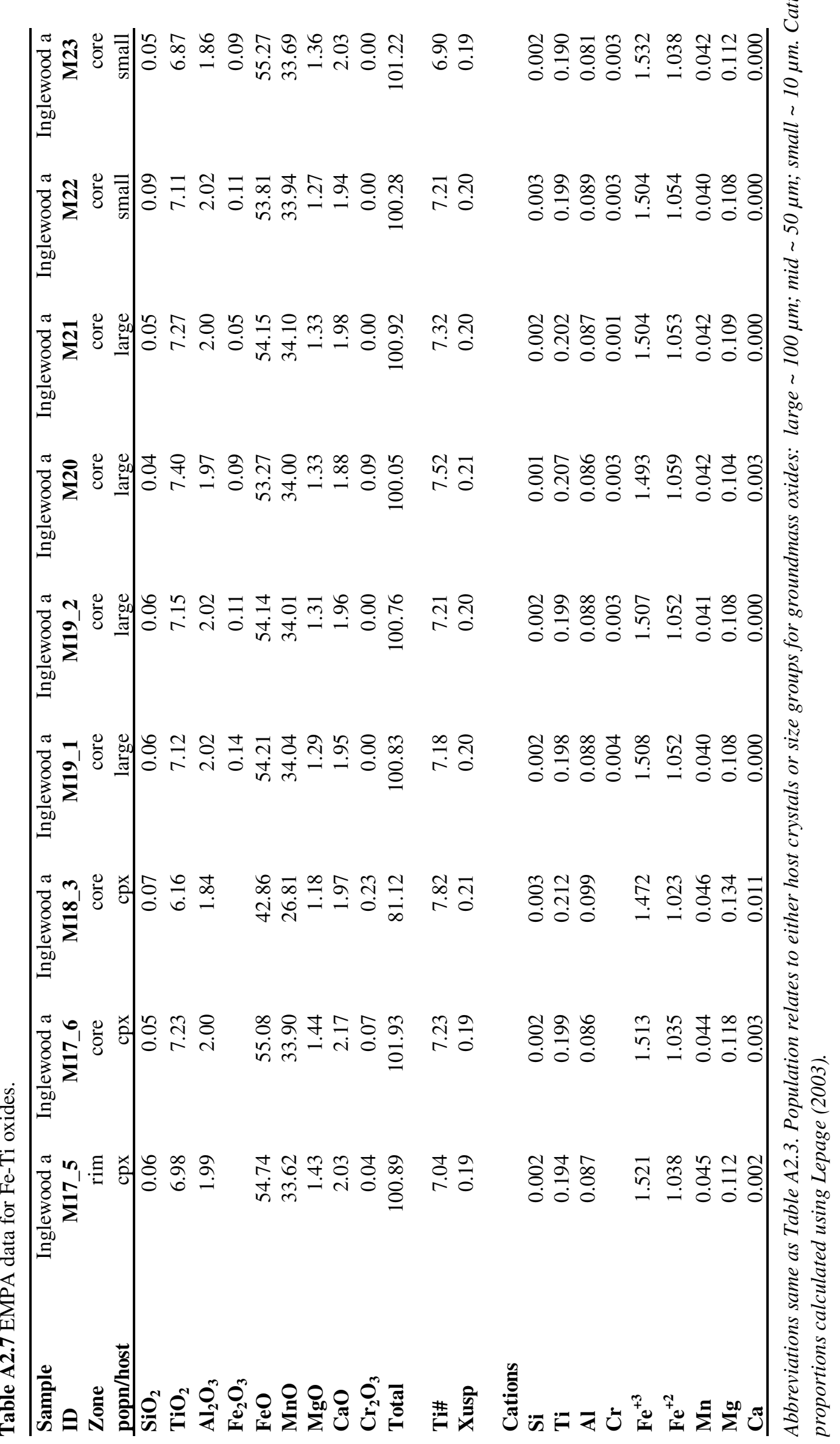




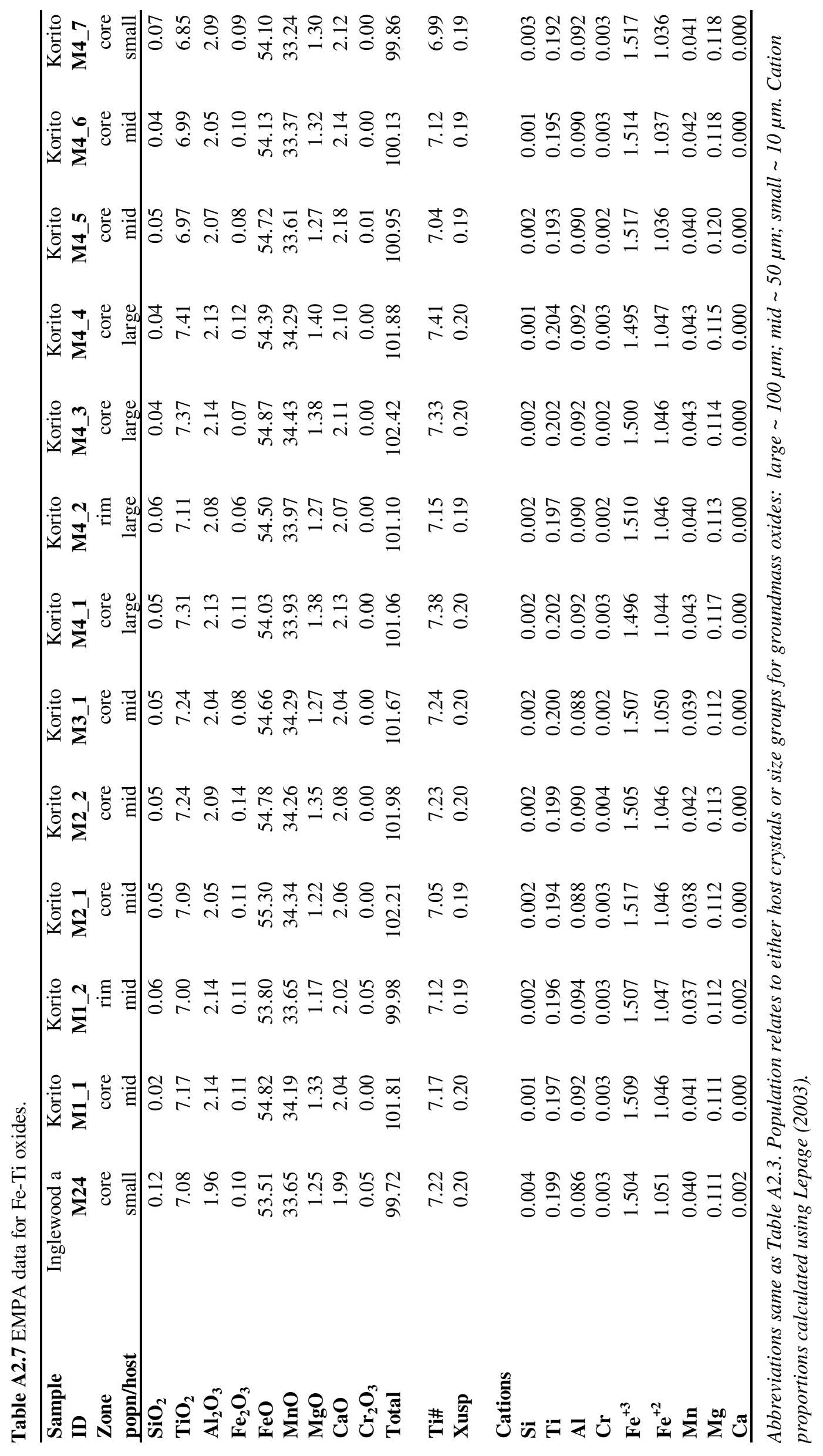




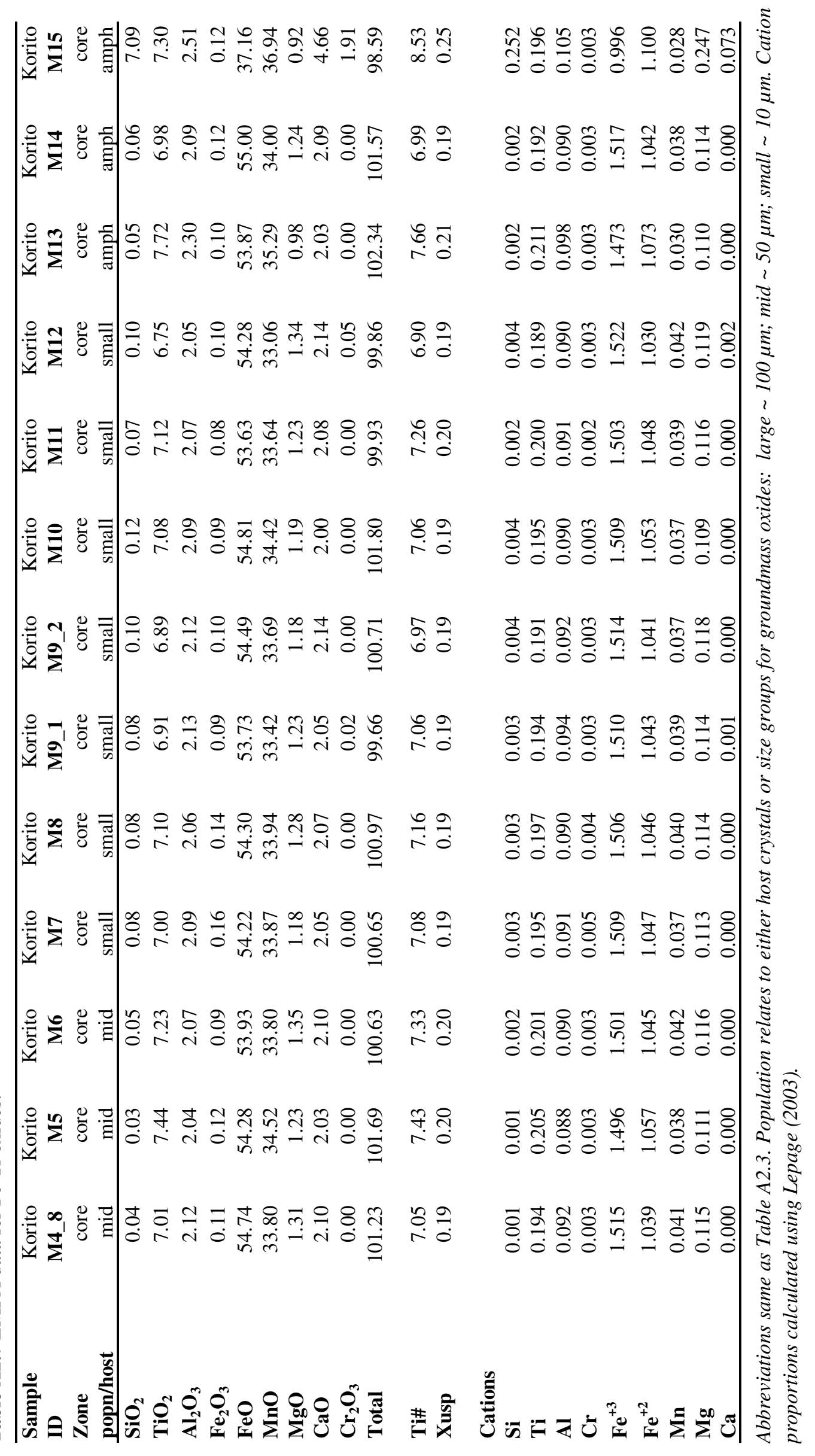




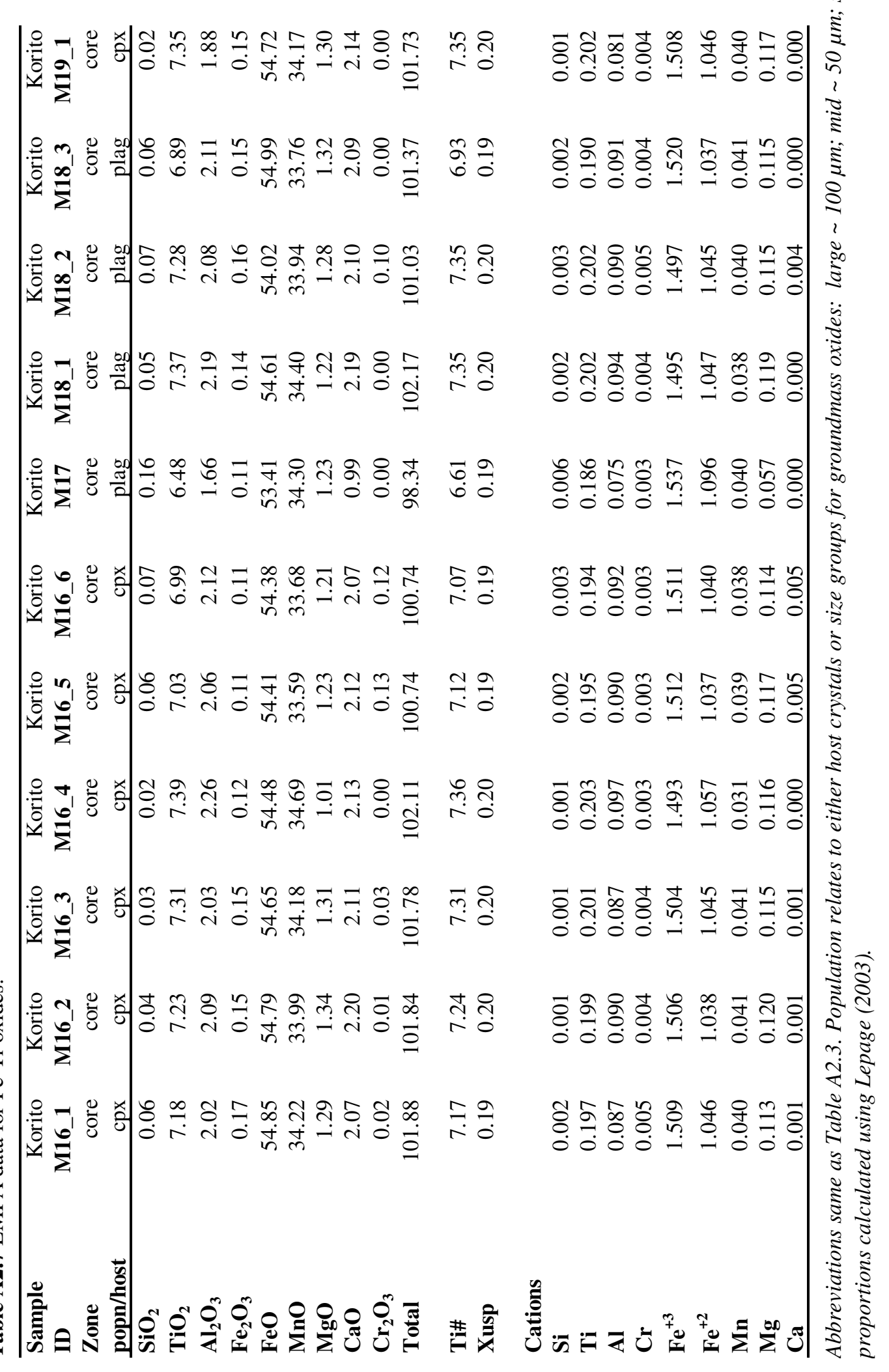




\section{APPENDIX 3: \\ TRACE ELEMENT DATA}

Table A3.1 Glass trace element data

Table A3.2 Plagioclase trace element data

Table A3.3 Clinopyroxene trace element data

Table A3.4 Amphibole trace element data 
Table A3.1 Trace element concentrations of glass analysed by solution ICP-MS.

\begin{tabular}{|c|c|c|c|c|c|c|}
\hline wt\% & Kaupokonui & SM-6C & Maketawa & Inglewood b & Inglewood a & Korito \\
\hline $\mathrm{SiO}_{2} \mathrm{EMPA}^{*}$ & 67.32 & 61.69 & 68.74 & 71.55 & 72.79 & 72.34 \\
\hline $\mathrm{CaO}$ & 2.72 & 5.09 & 2.28 & 1.84 & 1.41 & 1.61 \\
\hline \multicolumn{7}{|l|}{ ppm } \\
\hline $\mathbf{L i}$ & 30.0 & 30.0 & 24.5 & 32.9 & 20.6 & 24.2 \\
\hline Sc & 3.28 & 9.45 & 2.69 & 1.24 & 1.06 & 1.49 \\
\hline $\mathbf{T i}$ & 2378 & 5322 & 2187 & 1987 & 1296 & 1731 \\
\hline $\mathbf{V}$ & 56.2 & 128.2 & 43.8 & 19.6 & 12.3 & 18.0 \\
\hline Co & 5.09 & 10.4 & 3.73 & 1.66 & 1.12 & 1.43 \\
\hline $\mathrm{Cu}$ & 76.0 & 147.6 & 55.0 & 57.6 & 14.8 & 21.5 \\
\hline Zn & 51.0 & 80.5 & 49.6 & 26.4 & 28.0 & 21.7 \\
\hline Ga & 17.3 & 26.6 & 16.1 & 16.6 & 11.5 & 13.7 \\
\hline $\mathbf{R b}$ & 108 & 102 & 77.9 & 101 & 66.9 & 76.7 \\
\hline $\mathrm{Sr}$ & 324 & 531 & 283 & 239 & 176 & 194 \\
\hline $\mathbf{Y}$ & 14.6 & 26.8 & 14.0 & 17.3 & 12.1 & 16.2 \\
\hline $\mathrm{Zr}$ & 190 & 255 & 178 & 251 & 154 & 182 \\
\hline Nb & 6.20 & 9.94 & 5.87 & 7.43 & 4.80 & 5.87 \\
\hline Mo & 2.39 & 2.88 & 1.85 & 2.87 & 1.80 & 1.43 \\
\hline Cs & 6.64 & 6.38 & 5.05 & 6.66 & 4.44 & 4.86 \\
\hline $\mathbf{B a}$ & 1171 & 1288 & 983 & 1140 & 752 & 887 \\
\hline $\mathbf{L a}$ & 21.6 & 25.9 & 17.6 & 21.0 & 14.4 & 18.3 \\
\hline $\mathrm{Ce}$ & 40.8 & 55.1 & 34.1 & 41.4 & 29.0 & 38.6 \\
\hline Pr & 4.55 & 6.81 & 3.94 & 4.83 & 3.32 & 4.52 \\
\hline Nd & 16.6 & 27.6 & 14.7 & 17.8 & 12.5 & 17.6 \\
\hline Sm & 3.04 & 5.90 & 2.87 & 3.36 & 2.37 & 3.45 \\
\hline Eu & 0.873 & 1.63 & 0.861 & 0.869 & 0.623 & 0.838 \\
\hline Gd & 2.90 & 5.72 & 2.70 & 3.17 & 2.20 & 3.13 \\
\hline Tb & 0.394 & 0.809 & 0.380 & 0.435 & 0.317 & 0.441 \\
\hline Dy & 2.35 & 4.82 & 2.28 & 2.67 & 1.93 & 2.64 \\
\hline Но & 0.484 & 0.973 & 0.474 & 0.568 & 0.401 & 0.544 \\
\hline $\mathbf{E r}$ & 1.49 & 2.85 & 1.43 & 1.78 & 1.23 & 1.64 \\
\hline Tm & 0.233 & 0.414 & 0.216 & 0.270 & 0.193 & 0.264 \\
\hline $\mathbf{Y b}$ & 1.62 & 2.84 & 1.56 & 1.99 & 1.43 & 1.79 \\
\hline Lu & 0.253 & 0.429 & 0.243 & 0.320 & 0.223 & 0.278 \\
\hline Hf & 4.65 & 6.78 & 4.40 & 6.23 & 3.85 & 4.43 \\
\hline $\mathbf{T a}$ & 0.431 & 0.653 & 0.409 & 0.552 & 0.329 & 0.391 \\
\hline $\mathbf{W}$ & 1.10 & 1.24 & 0.81 & 1.01 & 0.655 & 0.763 \\
\hline $\mathbf{P b}$ & 32.0 & 41.1 & 25.7 & 36.1 & 23.5 & 26.8 \\
\hline Th & 11.3 & 13.4 & 9.37 & 12.7 & 8.12 & 9.58 \\
\hline $\mathbf{U}$ & 2.95 & 3.09 & 2.21 & 2.94 & 2.03 & 2.36 \\
\hline
\end{tabular}

* Average $\mathrm{SiO}_{2}$ content for each sample from EMPA. 


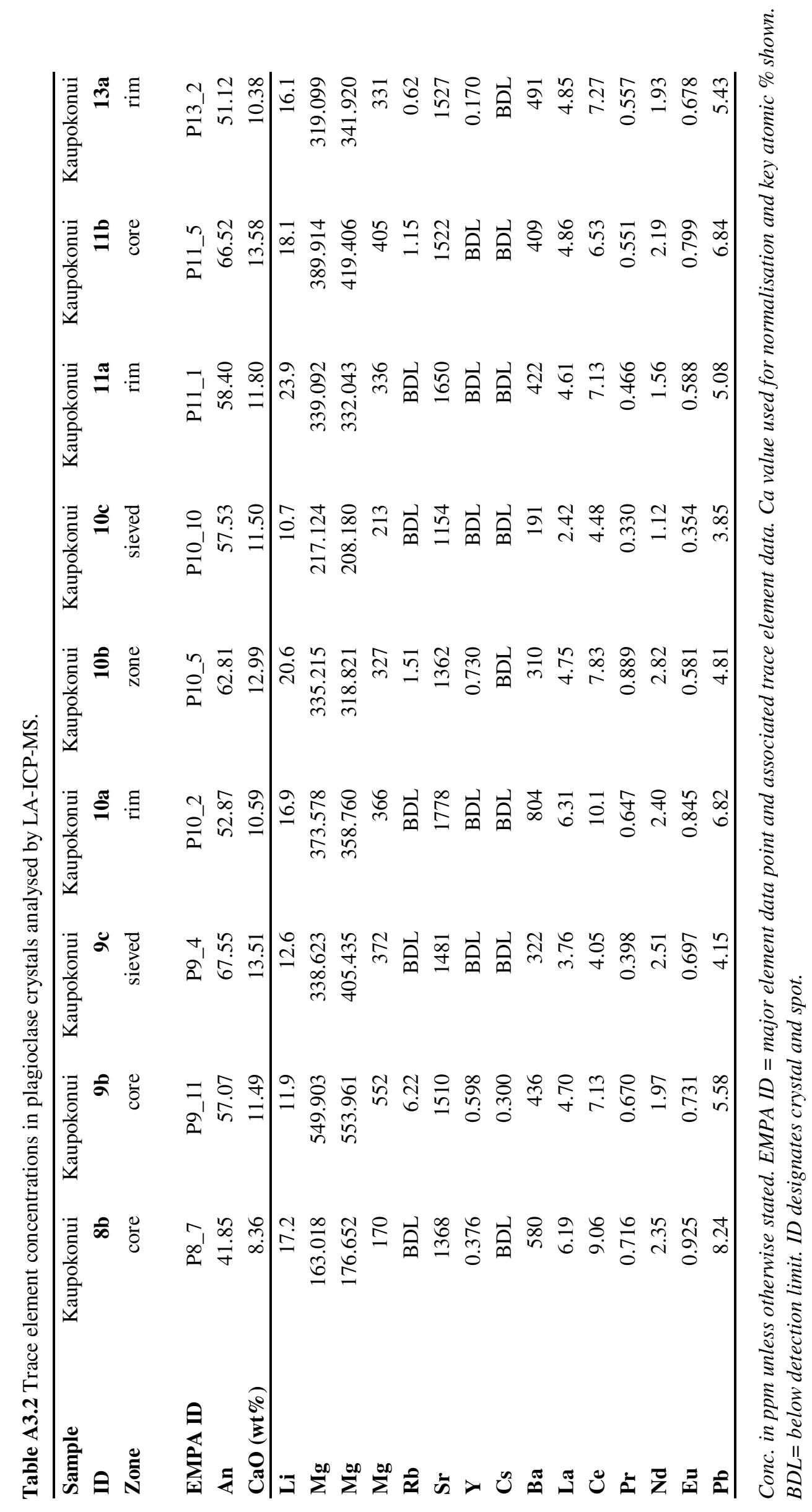




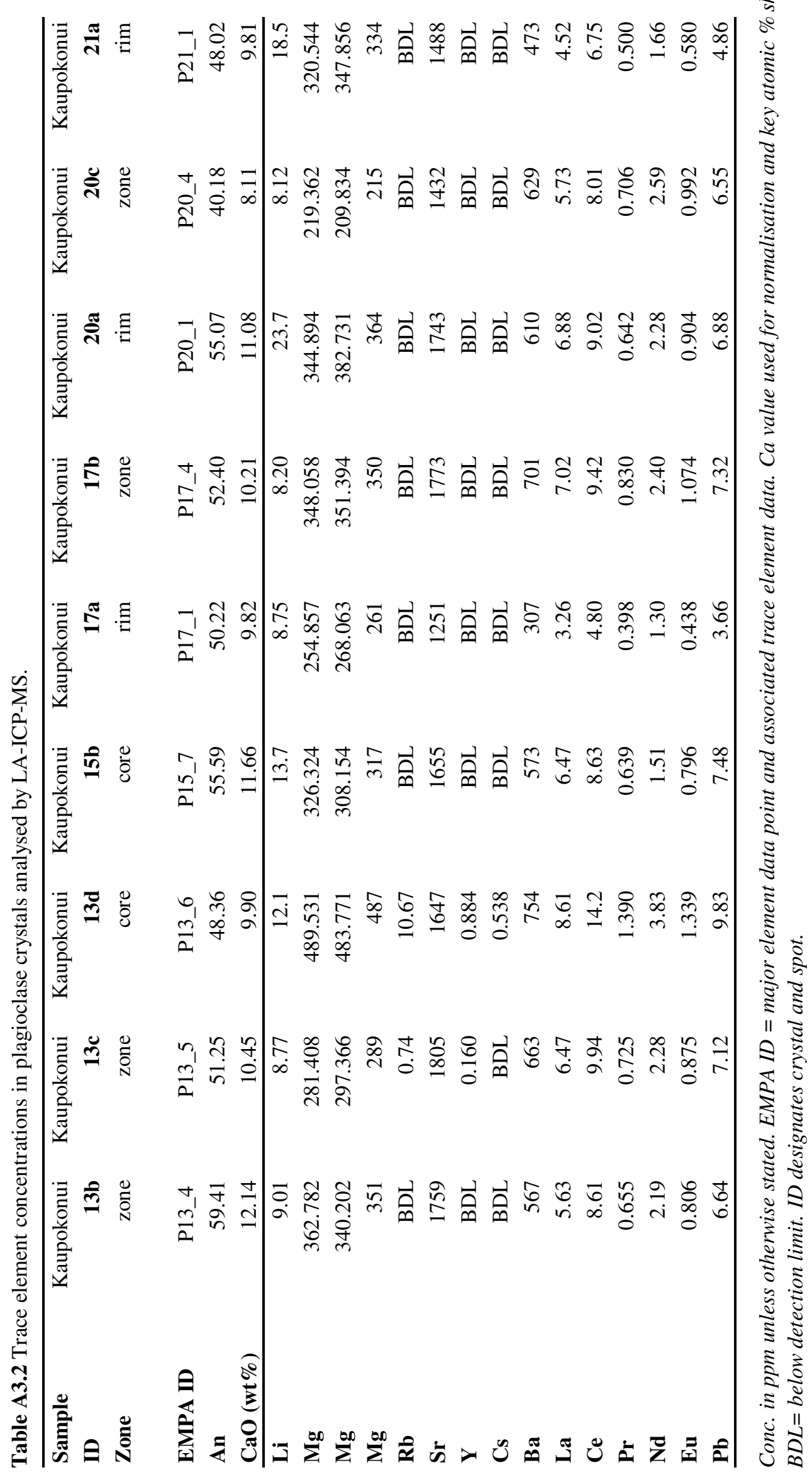




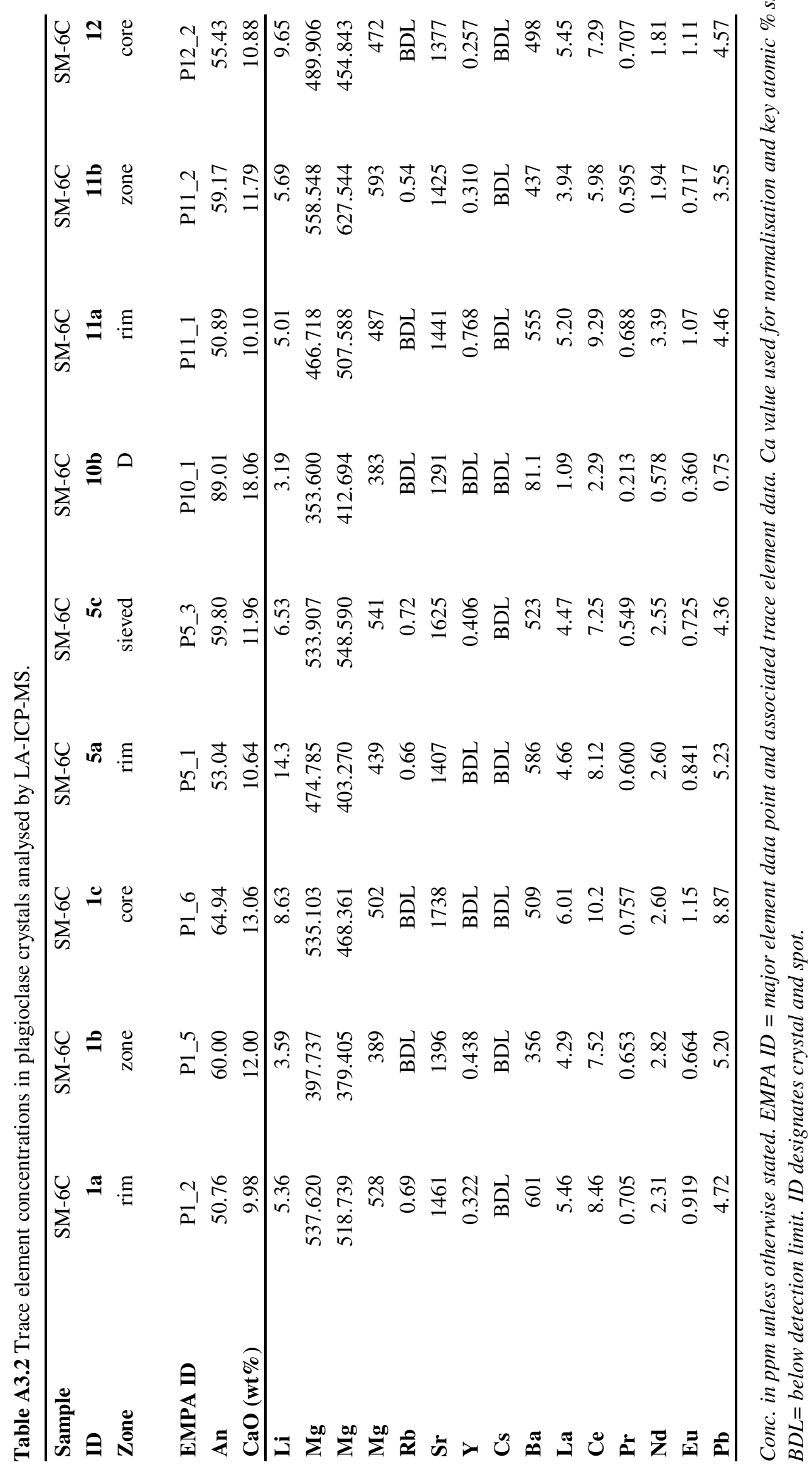




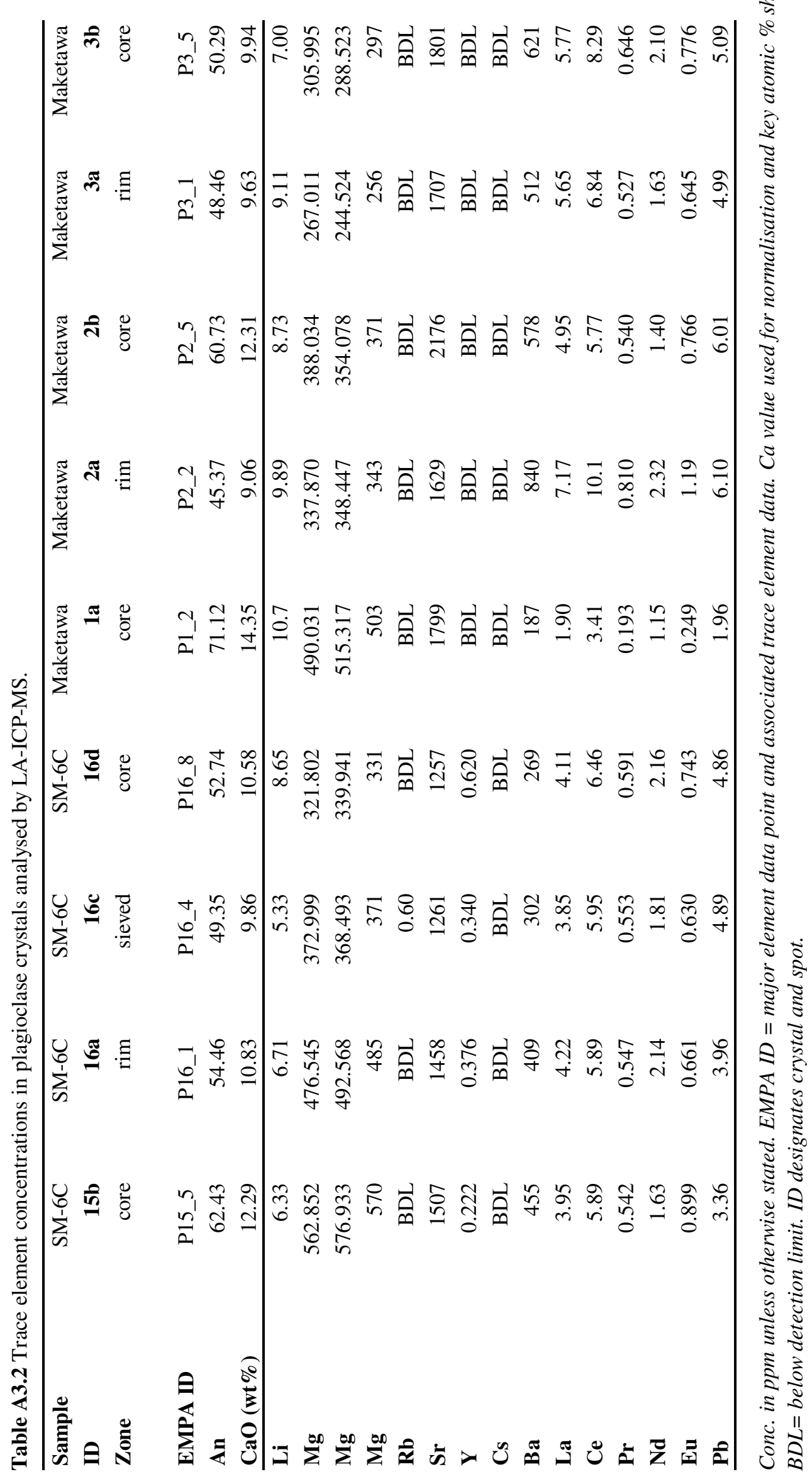




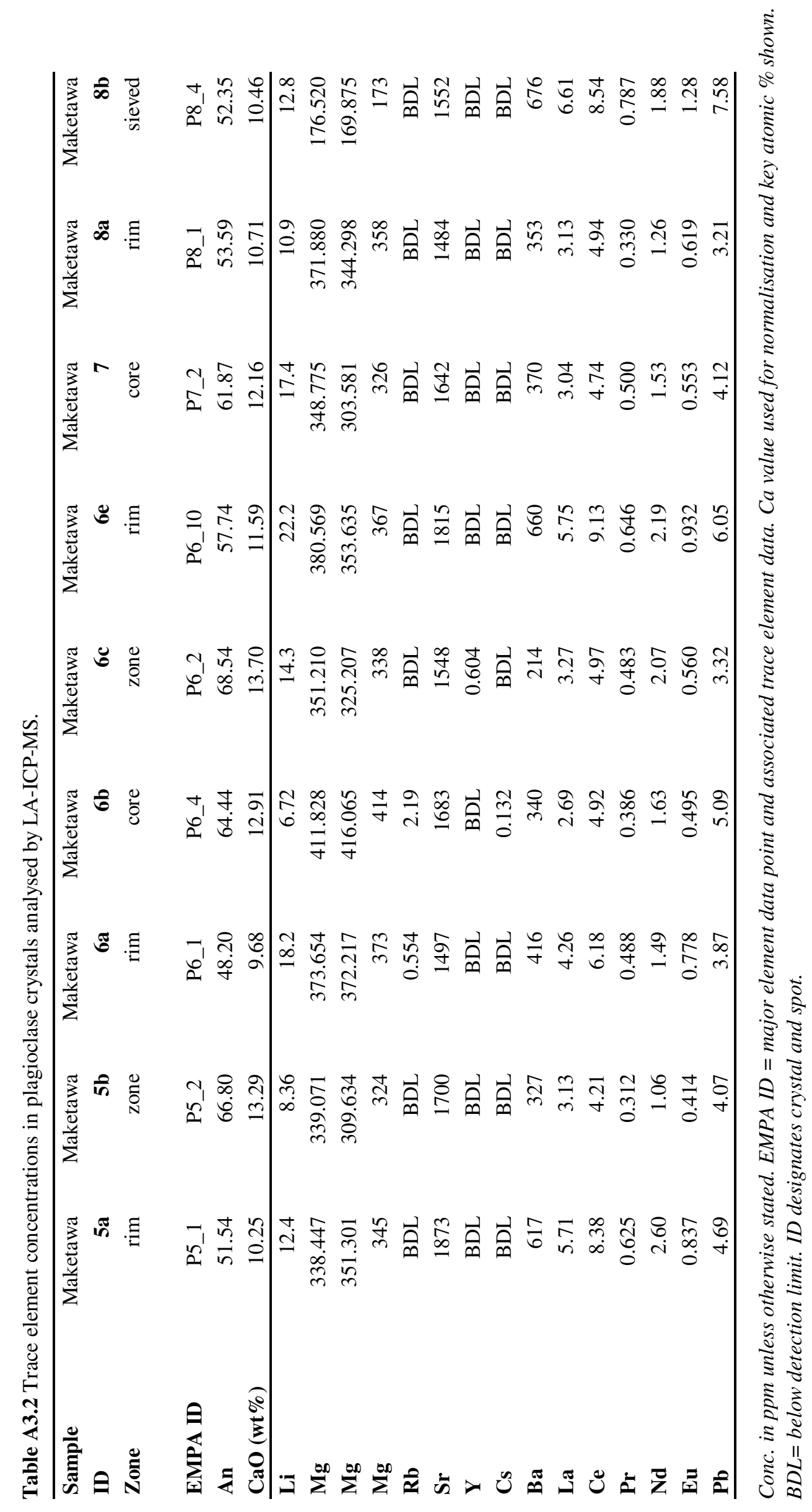




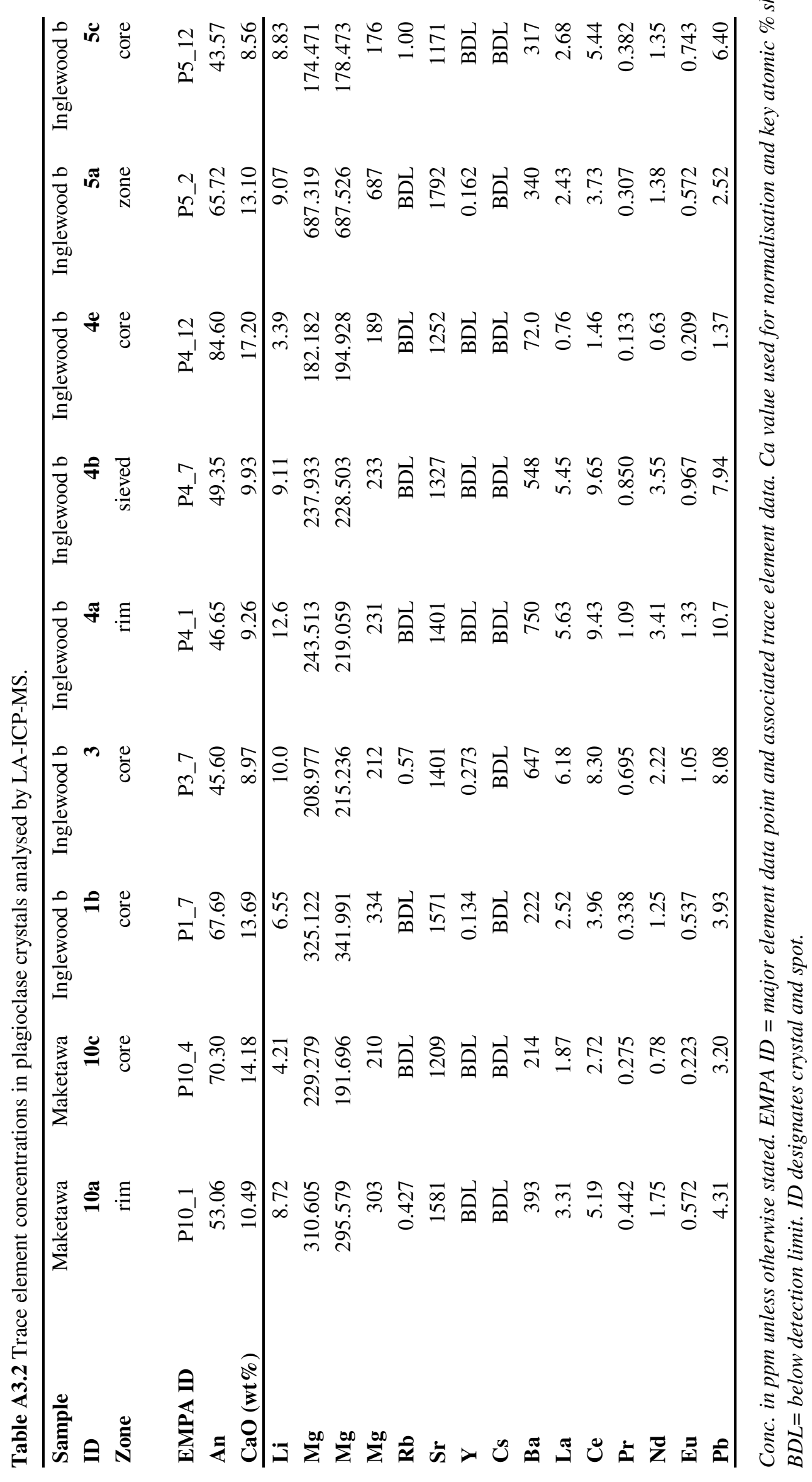




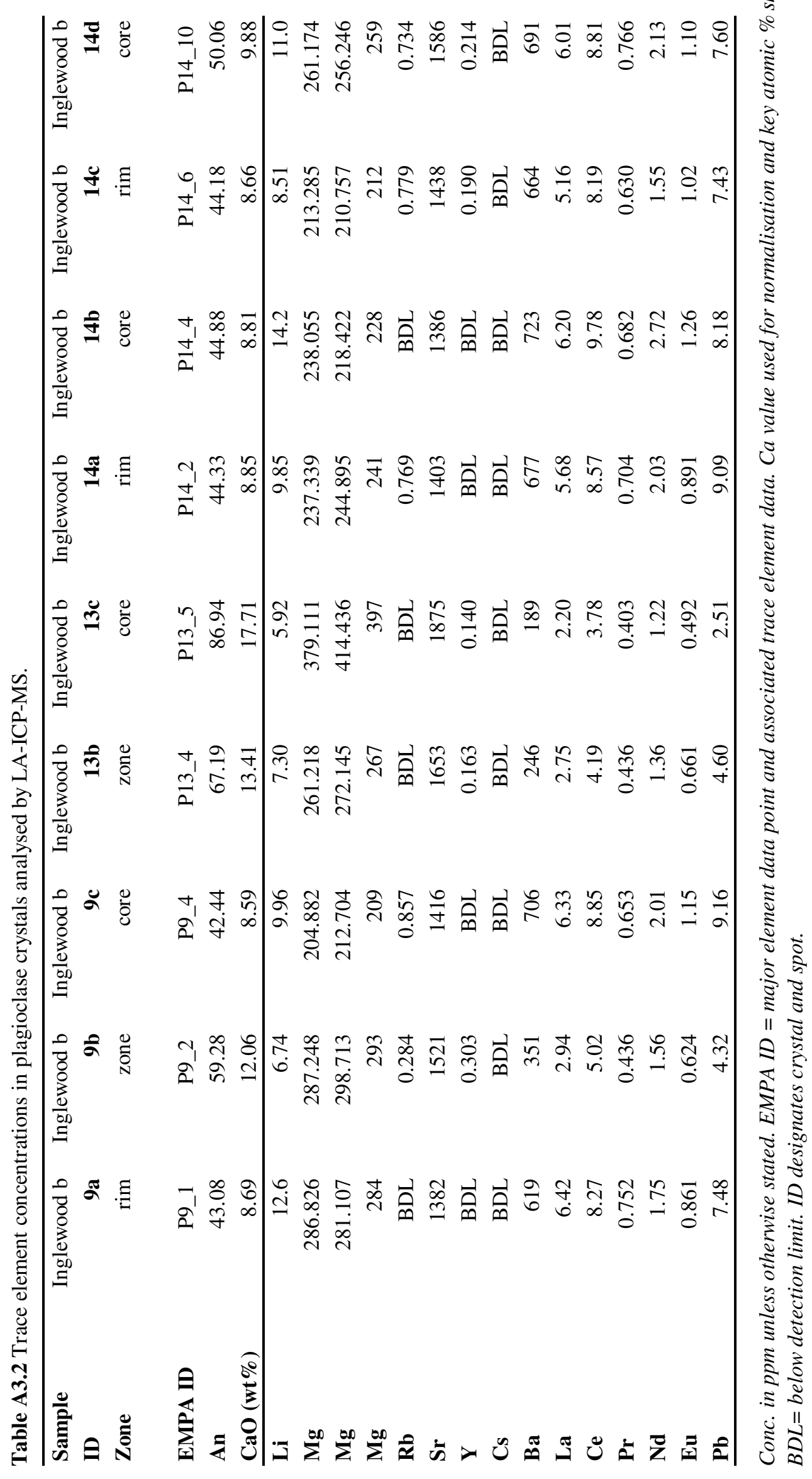




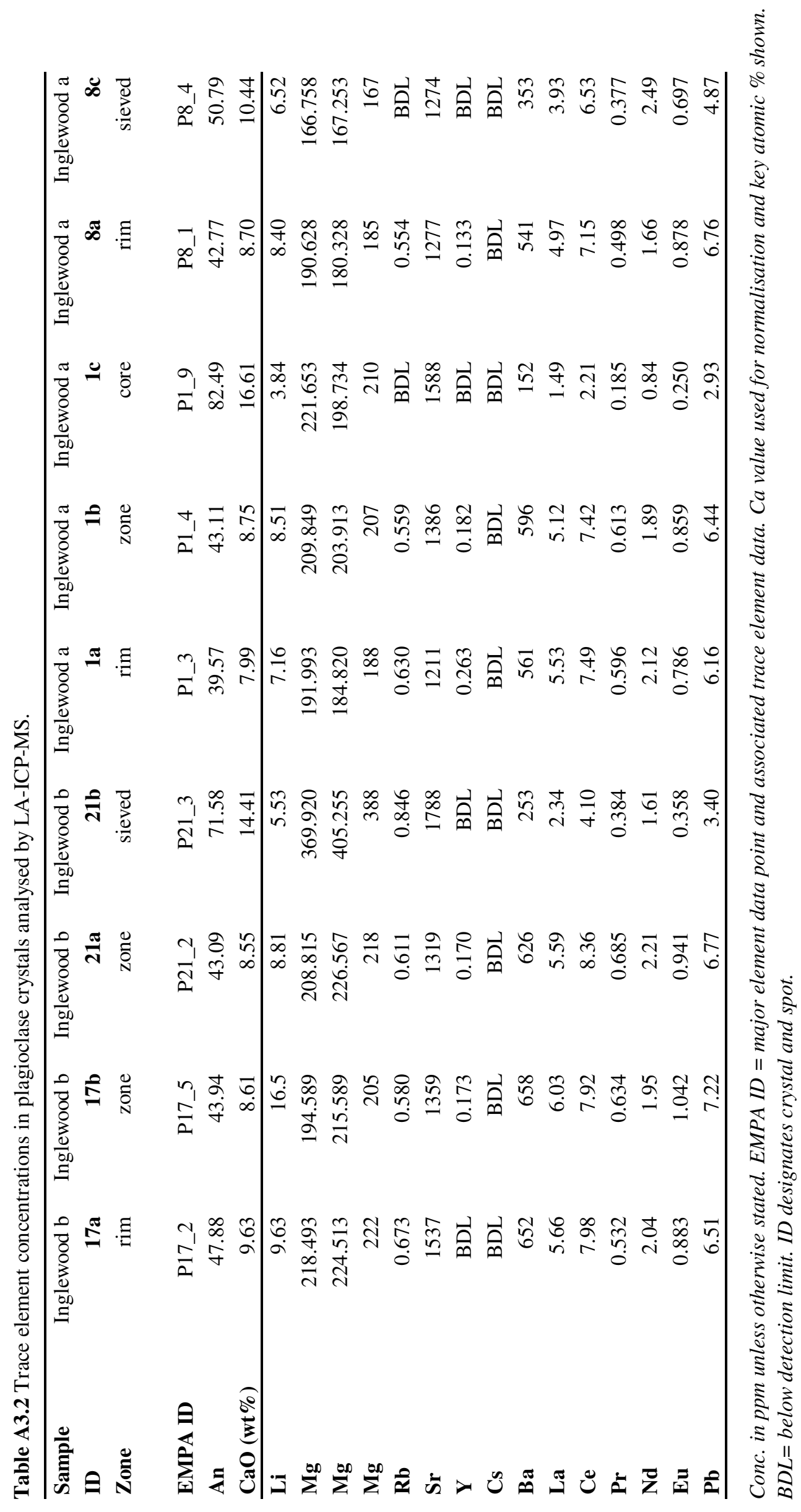




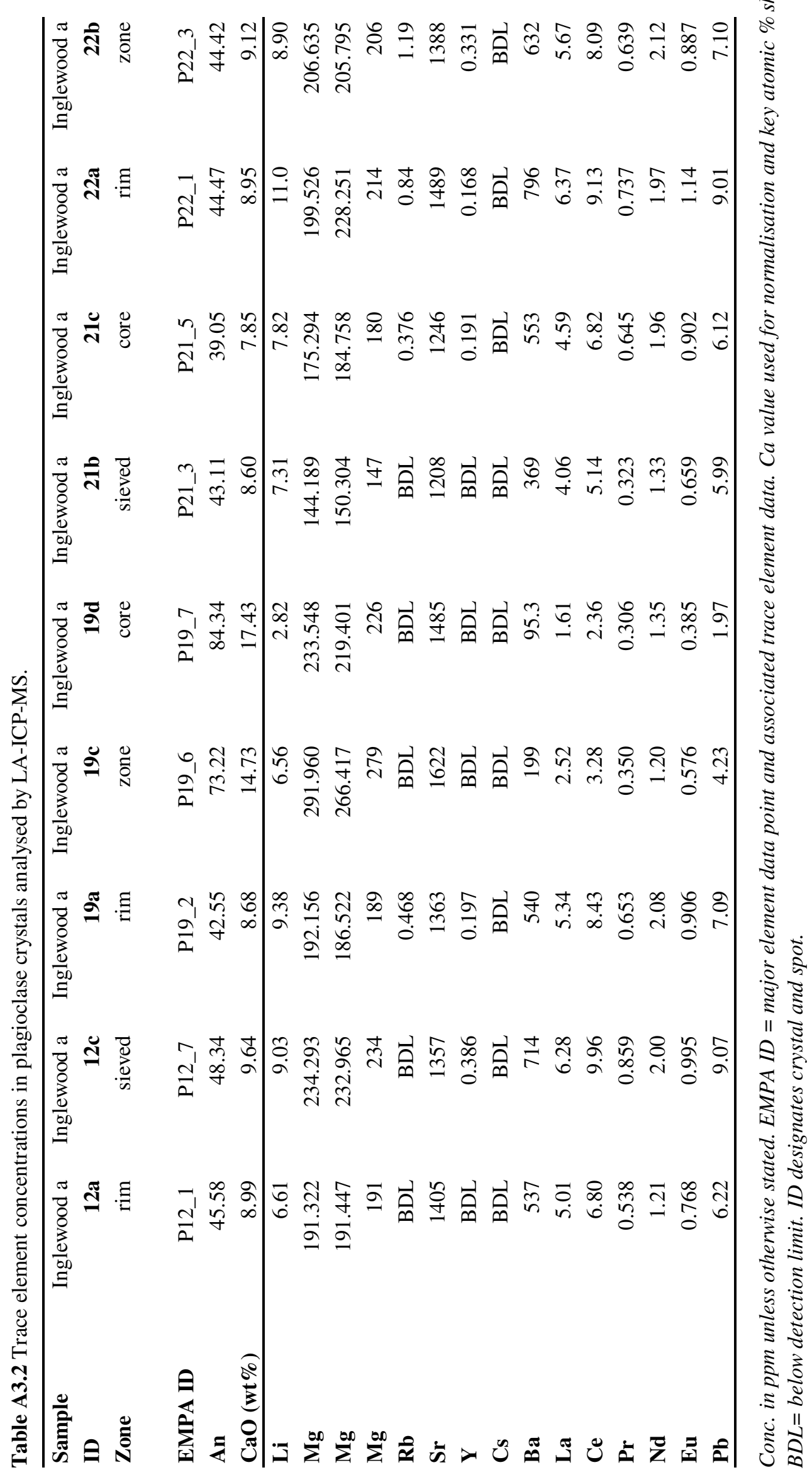




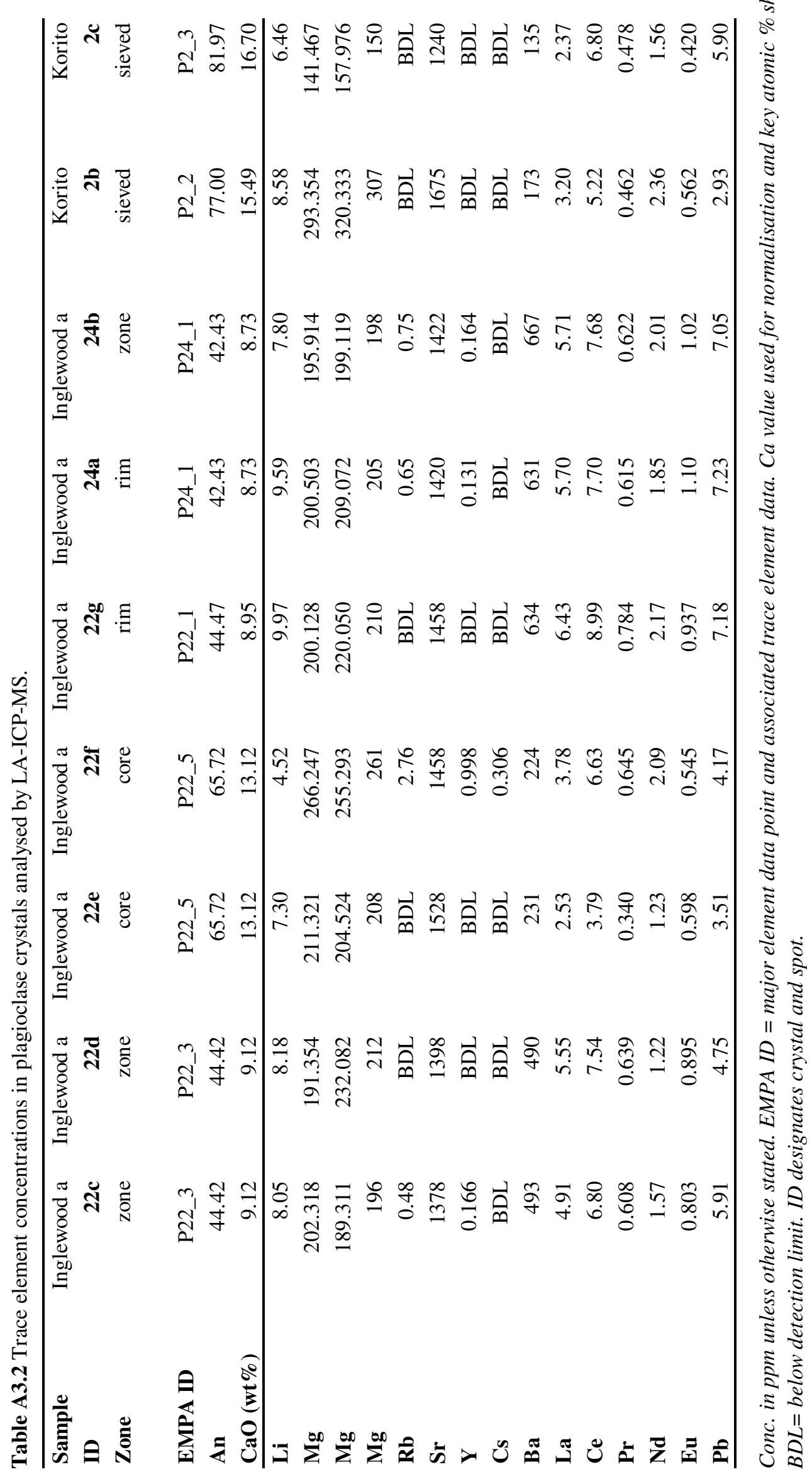




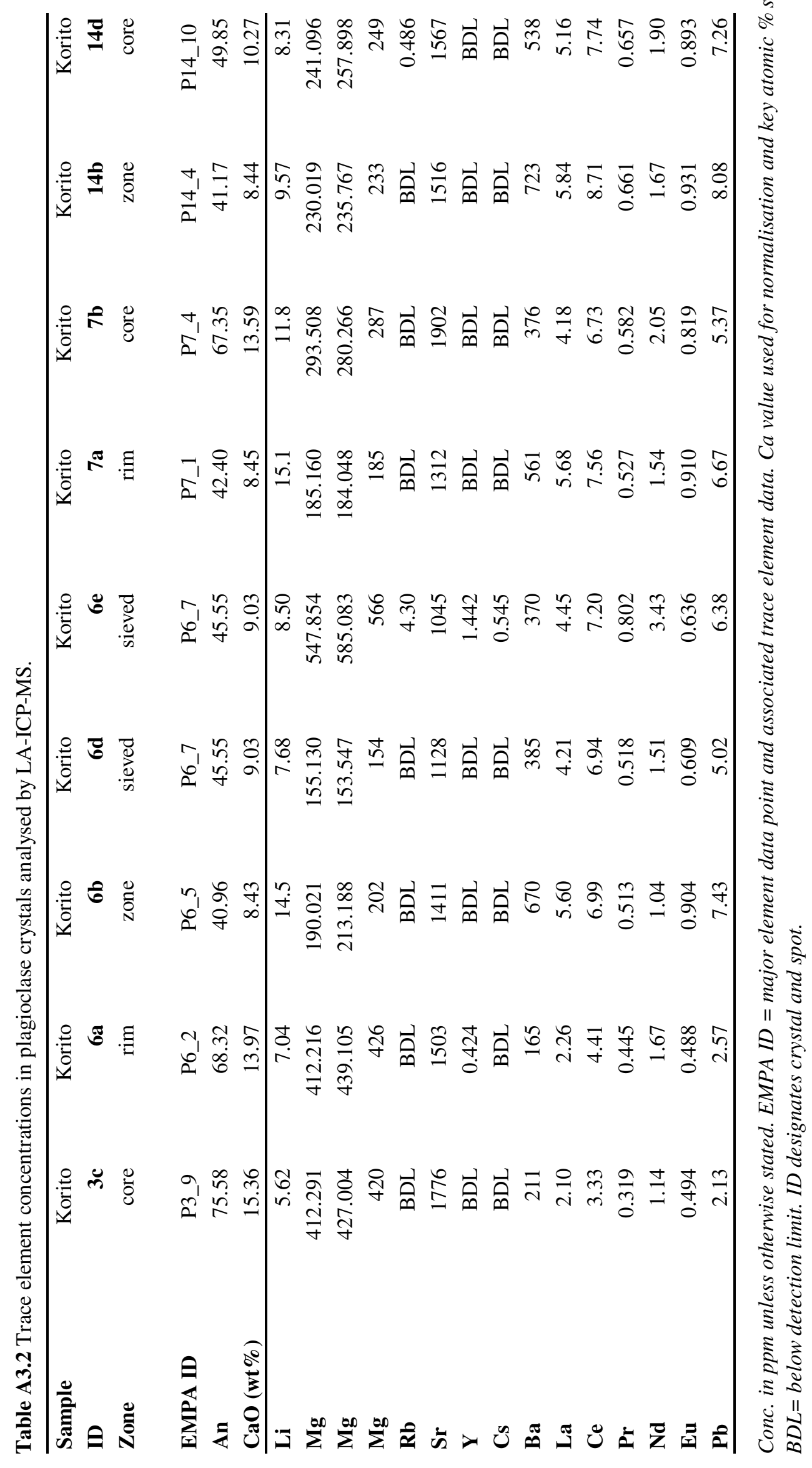




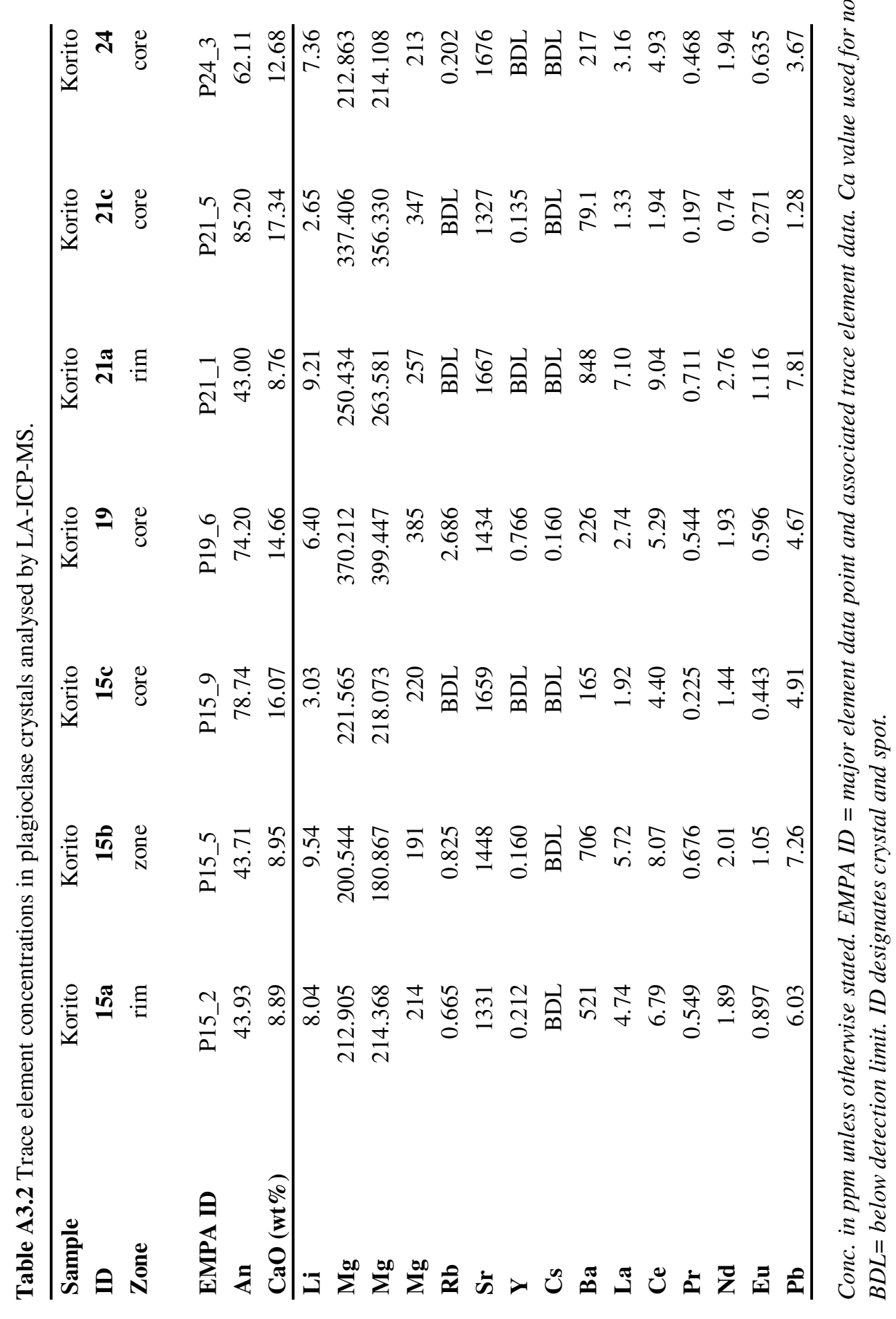




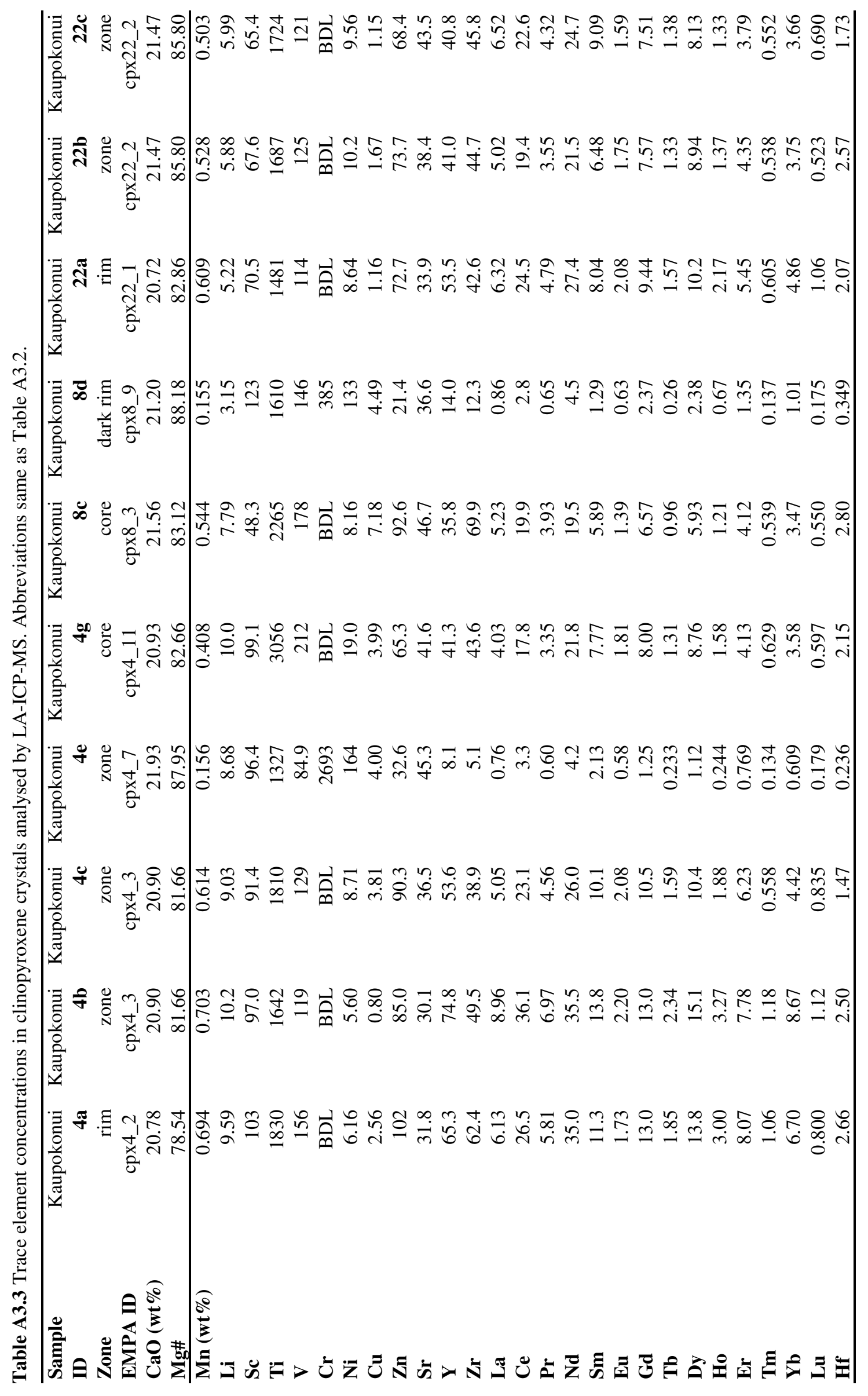




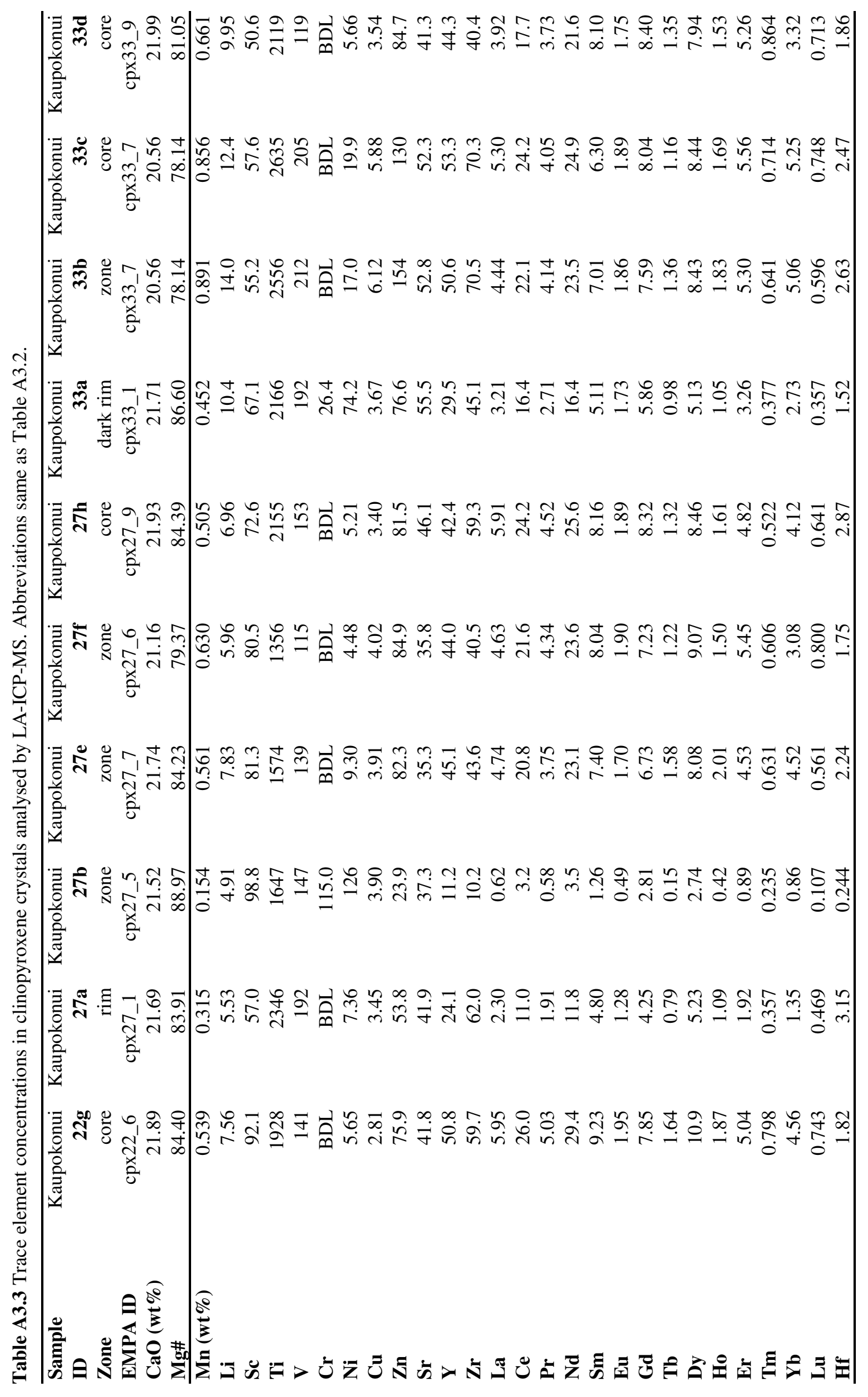




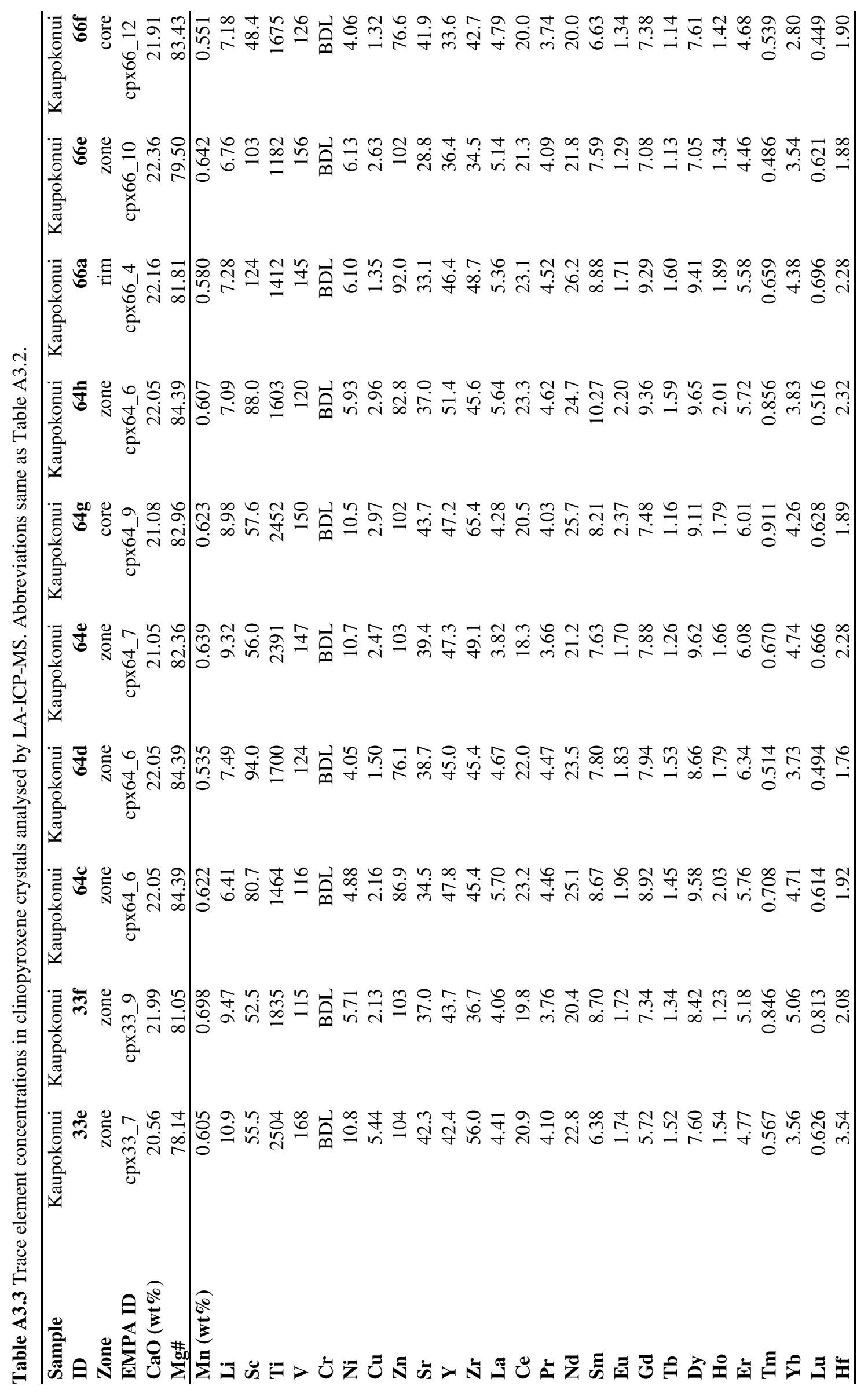




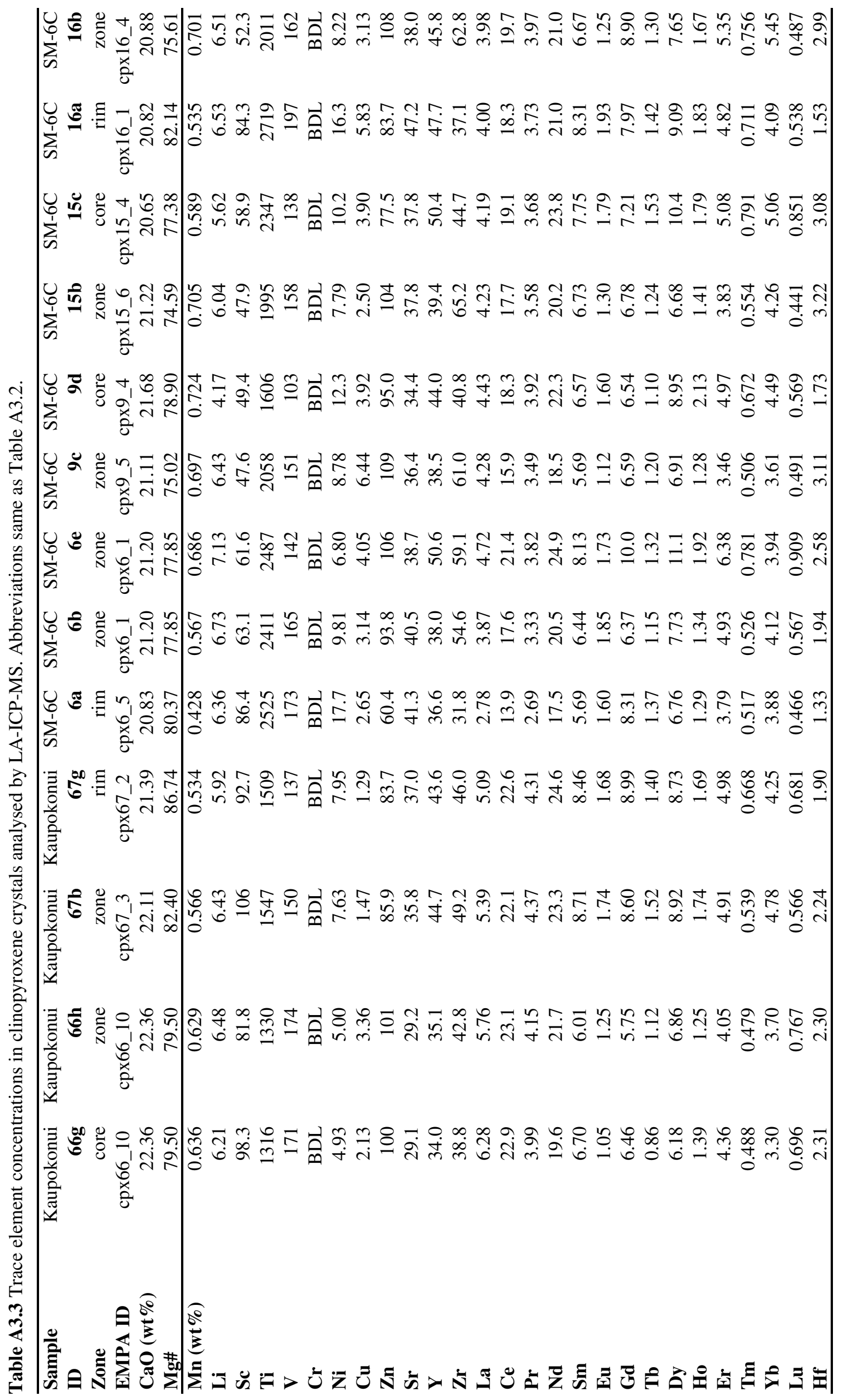




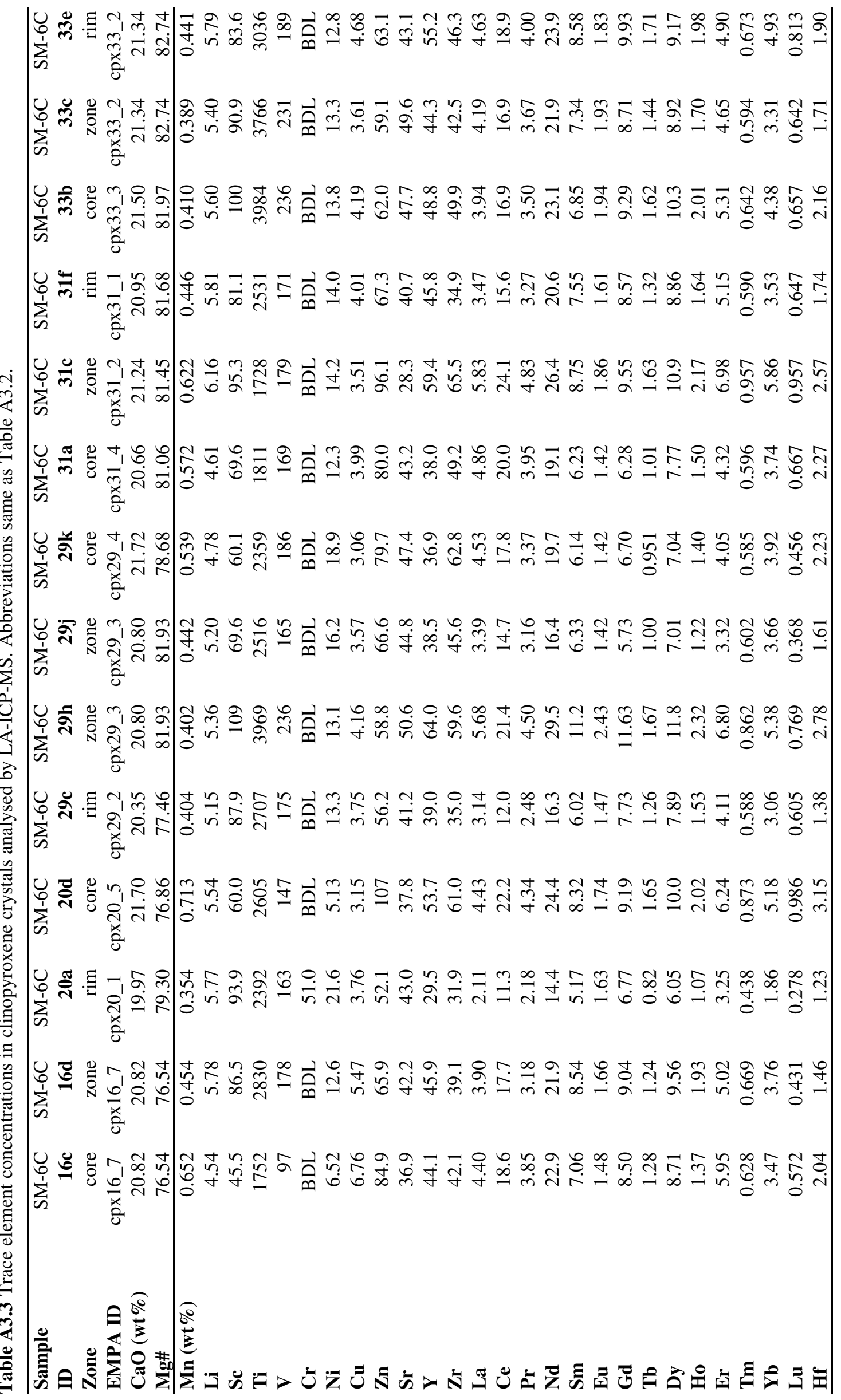




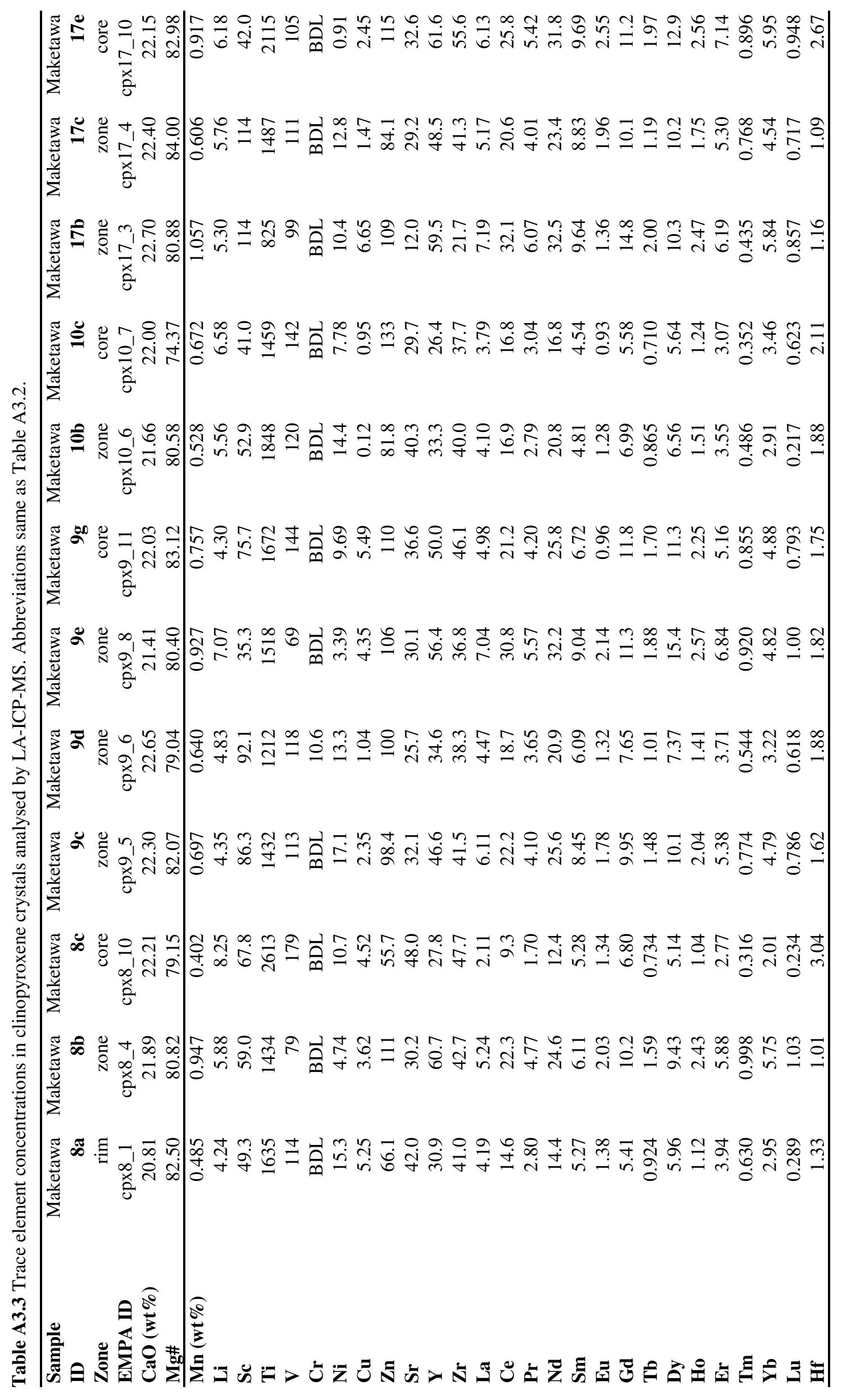




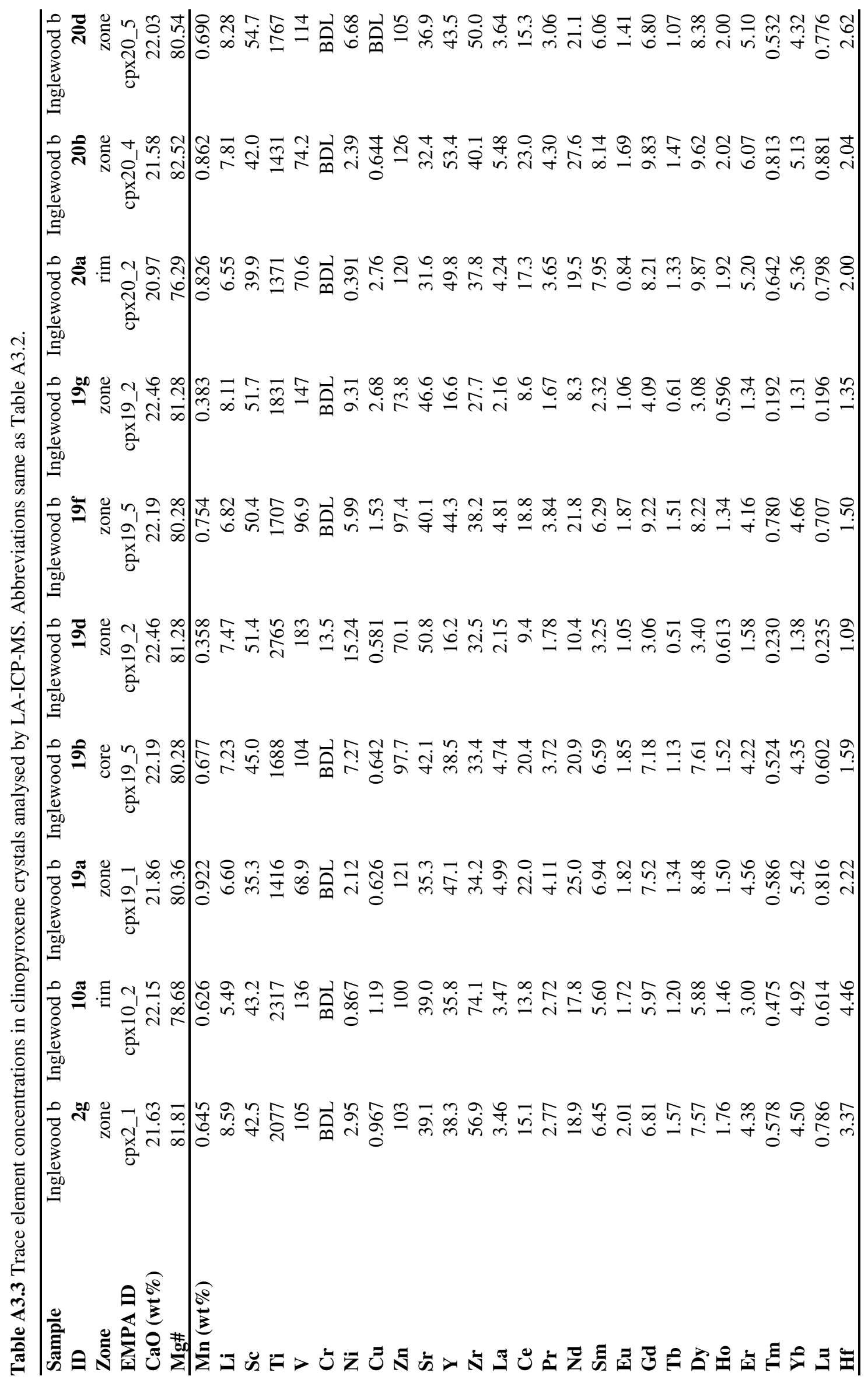




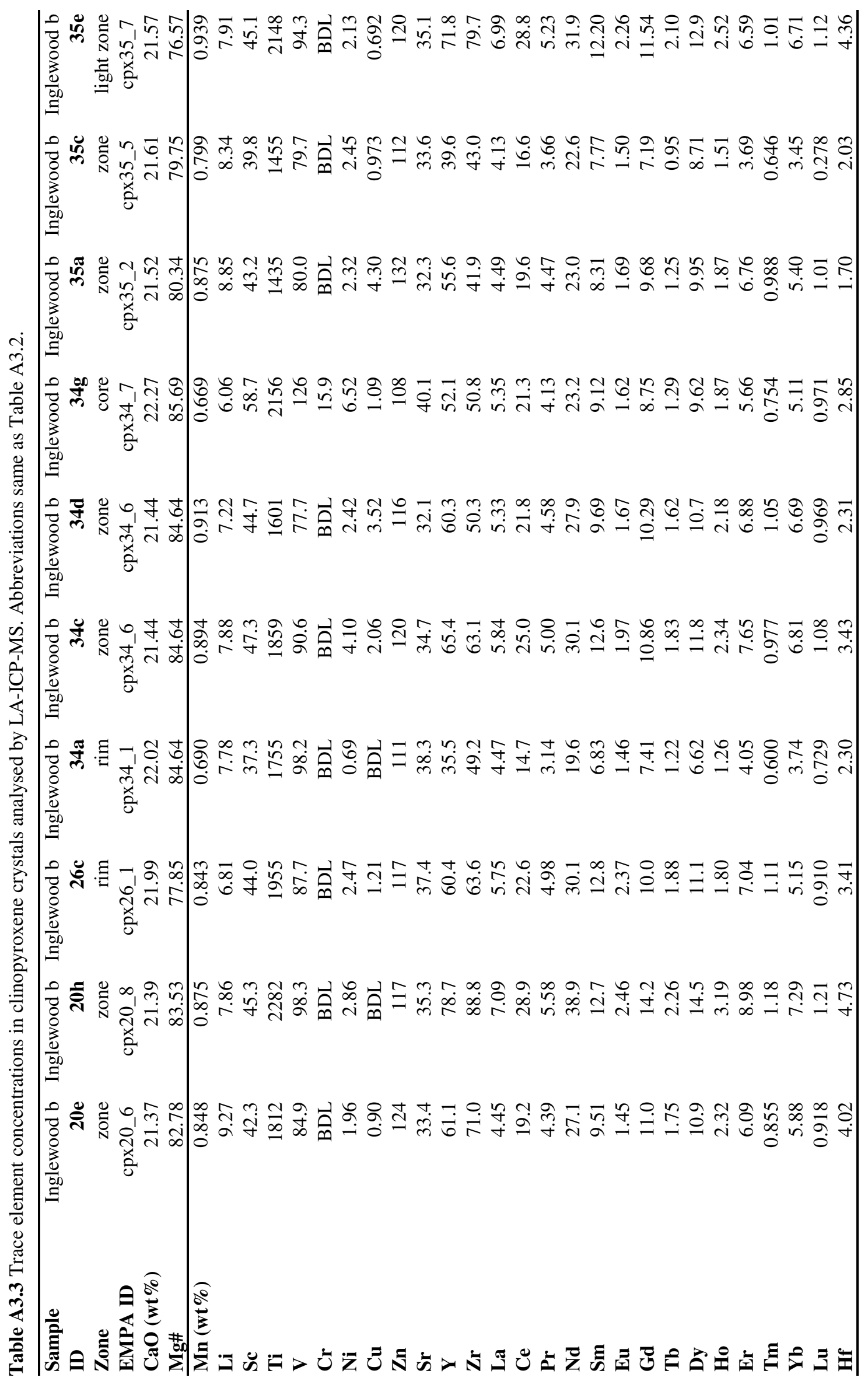




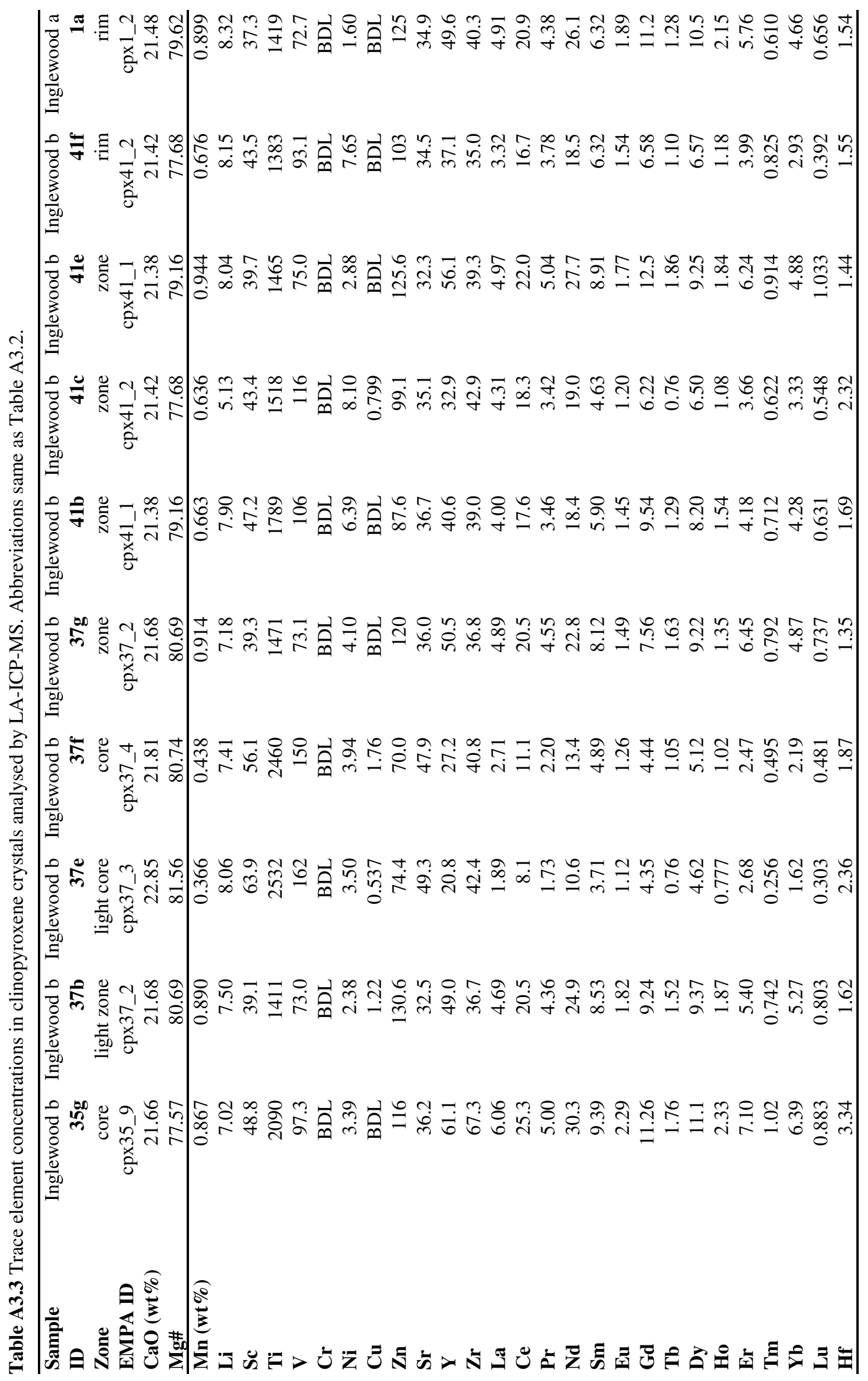




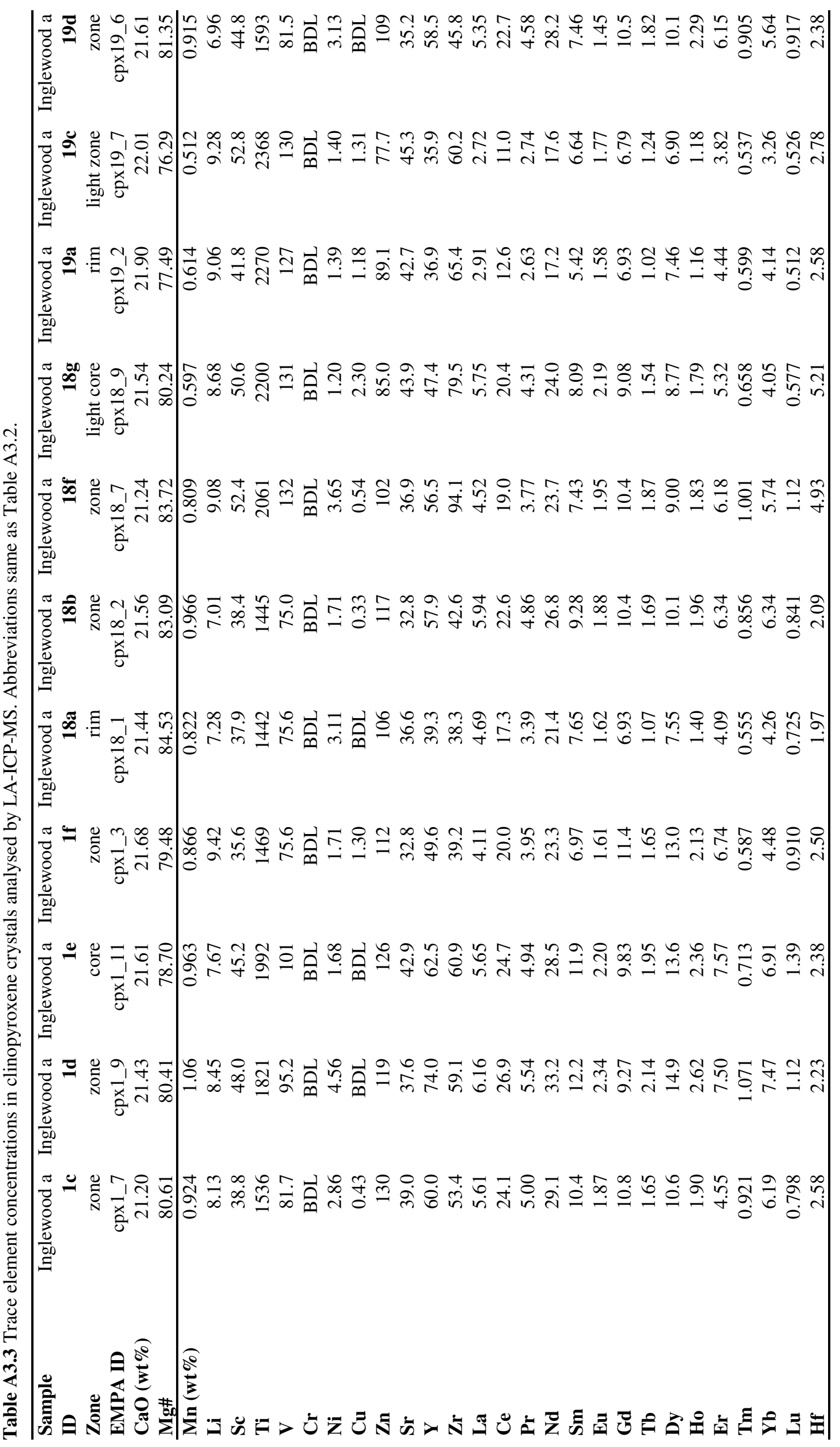




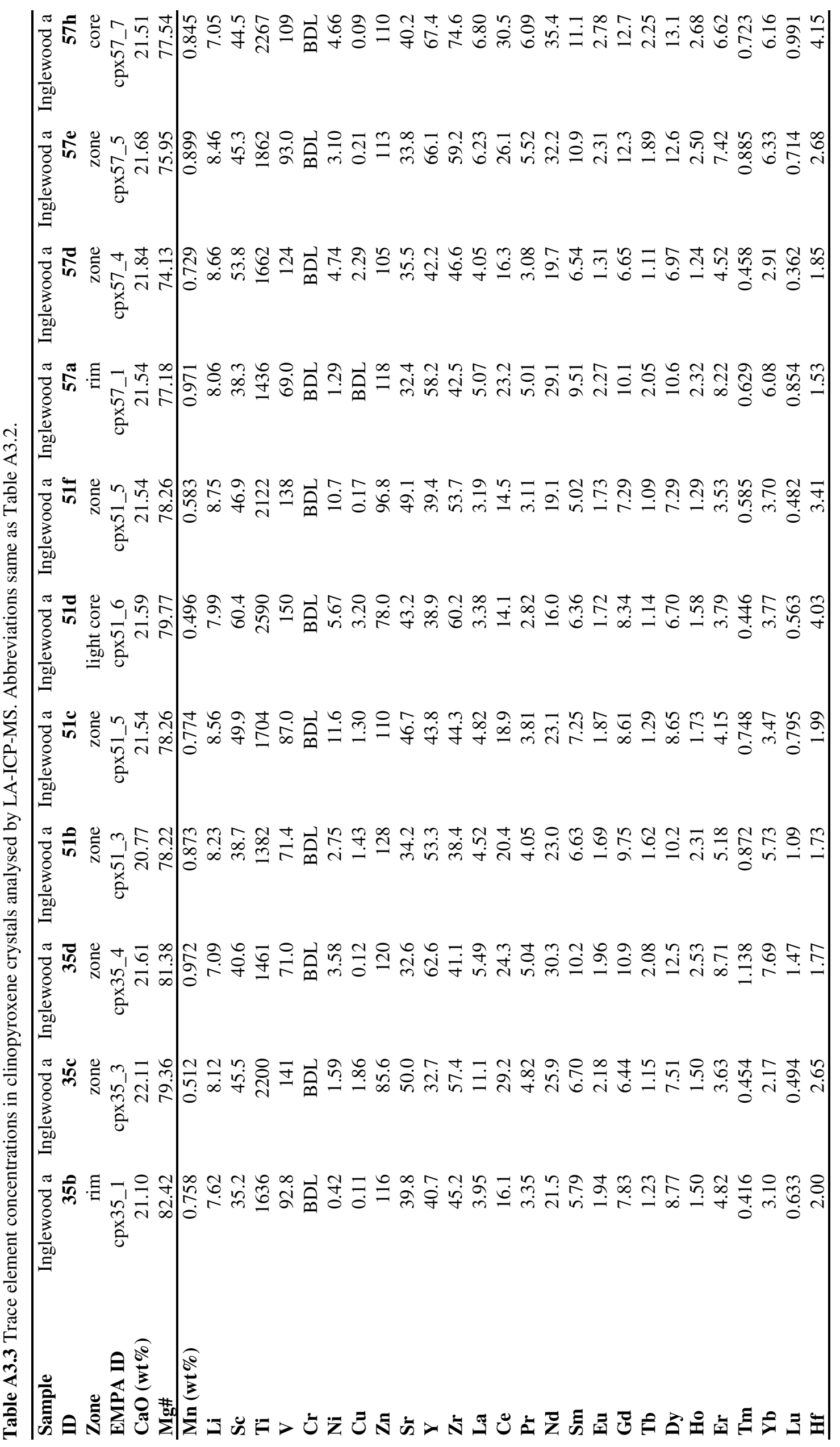




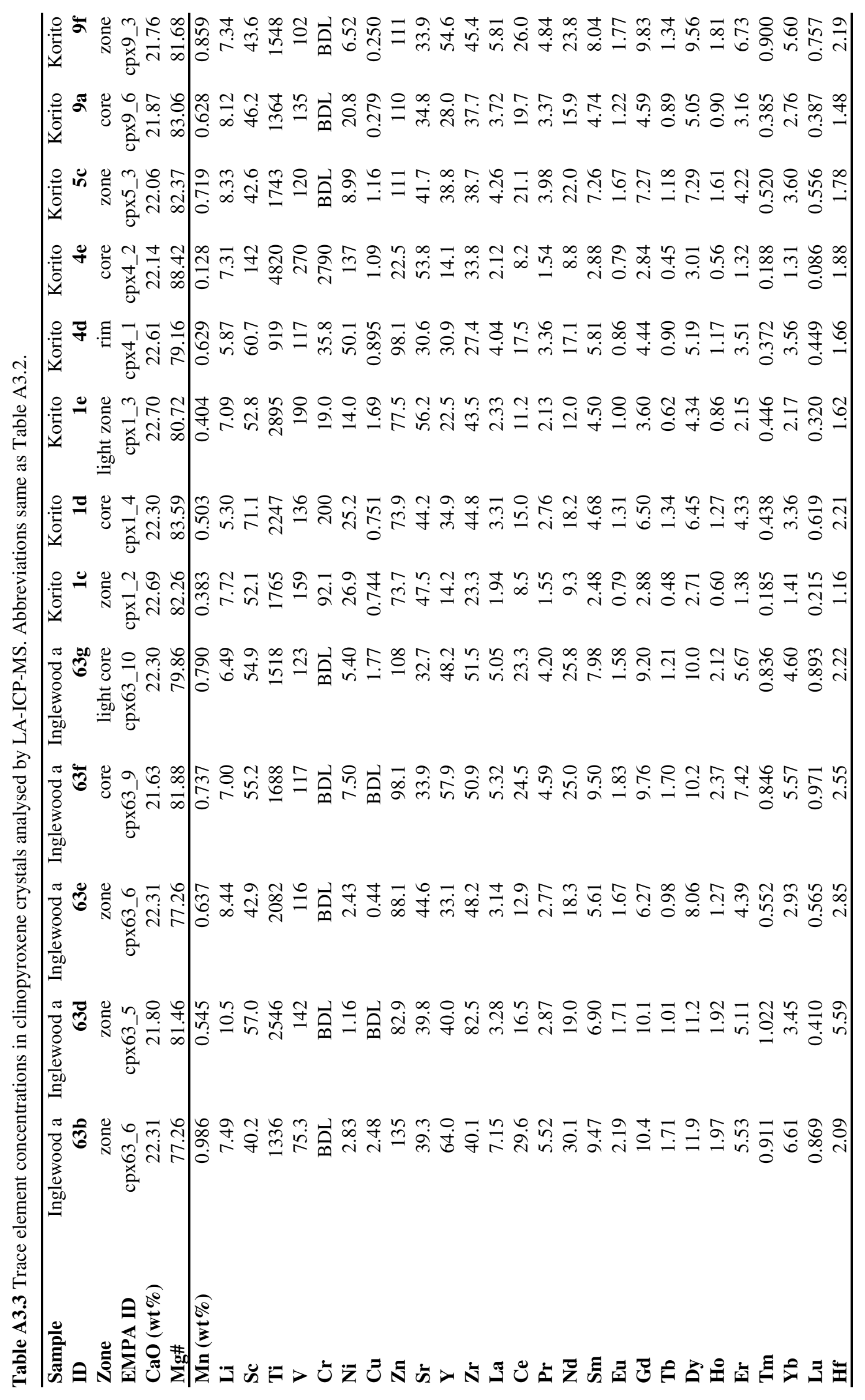




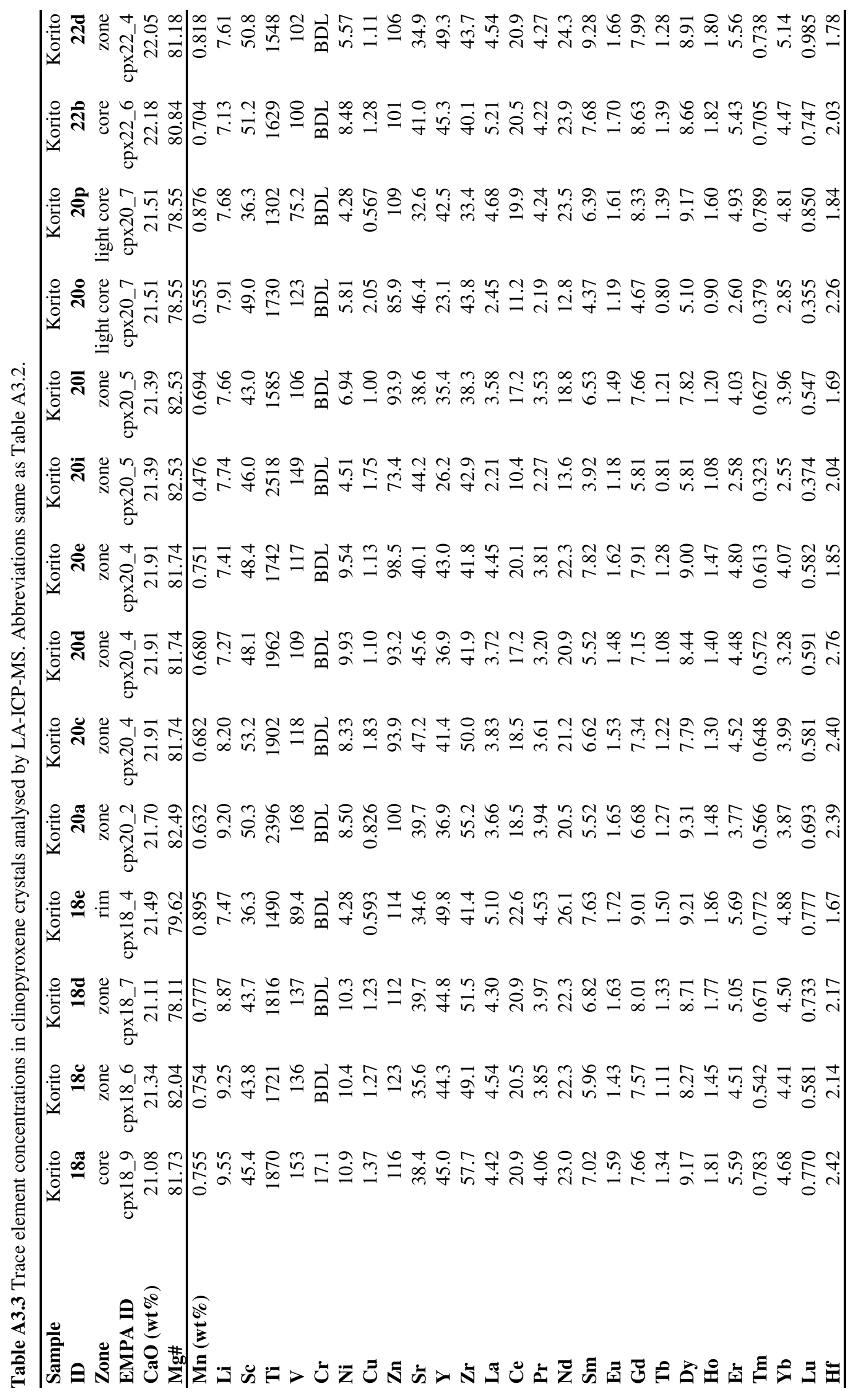




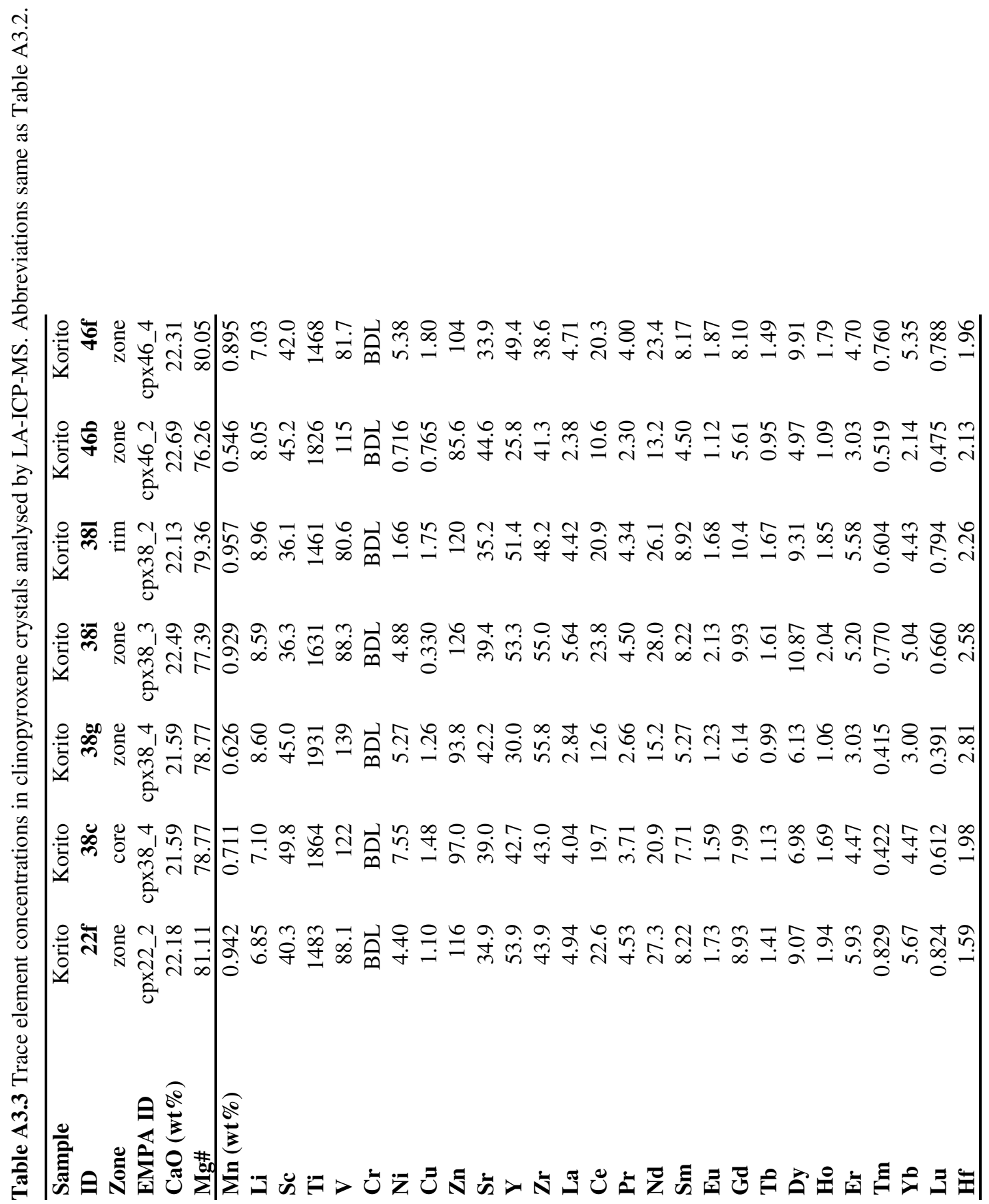


Table A3.4 Trace element concentrations in amphibole crystals analysed by LA-ICP-MS.

Abbreviations same as Table A3.2.

\begin{tabular}{|c|c|c|c|c|c|}
\hline Sample & Kaupokonui & Kaupokonui & Kaupokonui & Kaupokonui & Kaupokonui \\
\hline ID & A3a & $\mathbf{A} 3 \mathbf{b}$ & A5b & $\mathbf{A} 7 \mathbf{a}$ & A7b \\
\hline zone & rim & core & core & rim & core \\
\hline EMPA ID & A3 22 & A3_3 & A5_3 & A7_2 & A7_4 \\
\hline $\mathrm{CaO}$ & 12.12 & 11.92 & 11.86 & 12.22 & 11.44 \\
\hline Mg\# & 76.81 & 87.40 & 79.33 & 74.02 & 71.62 \\
\hline $\operatorname{Mn}(w t \%)$ & 0.161 & 0.134 & 0.254 & 0.195 & 0.417 \\
\hline $\mathbf{L i}$ & 3.33 & 3.14 & 3.24 & 4.13 & 4.13 \\
\hline Sc & 84.5 & 92.9 & 68.8 & 90.4 & 103.8 \\
\hline $\mathbf{T i}$ & 14632 & 12712 & 13394 & 14090 & 18812 \\
\hline $\mathbf{V}$ & 602 & 563 & 504 & 562 & 530 \\
\hline $\mathrm{Cr}$ & 24.1 & 65.4 & 46.6 & 7.4 & 8.6 \\
\hline $\mathbf{N i}$ & 107 & 169 & 38.3 & 43.3 & 24.7 \\
\hline $\mathbf{Z n}$ & 78.6 & 56.7 & 114 & 94.2 & 157 \\
\hline $\mathbf{R b}$ & 4.12 & 4.03 & 4.05 & 4.30 & 4.60 \\
\hline $\mathbf{S r}$ & 327 & 325 & 216 & 349 & 157 \\
\hline $\mathbf{Y}$ & 25.8 & 20.6 & 47.6 & 31.2 & 129 \\
\hline $\mathbf{Z r}$ & 62.4 & 47.4 & 118 & 82.0 & 136 \\
\hline $\mathbf{N b}$ & 3.04 & 1.86 & 5.95 & 4.12 & 16.9 \\
\hline $\mathbf{B a}$ & 308 & 254 & 262 & 316 & 353 \\
\hline La & 3.88 & 2.82 & 9.53 & 4.37 & 22.1 \\
\hline $\mathrm{Ce}$ & 14.9 & 10.8 & 35.1 & 14.6 & 83.8 \\
\hline $\mathbf{P r}$ & 2.85 & 2.34 & 6.25 & 3.24 & 15.5 \\
\hline Nd & 13.3 & 11.4 & 34.5 & 17.3 & 85.0 \\
\hline Sm & 5.20 & 3.26 & 8.57 & 5.43 & 24.5 \\
\hline $\mathbf{E u}$ & 1.35 & 1.38 & 2.45 & 1.53 & 5.73 \\
\hline Gd & 4.95 & 5.45 & 8.74 & 6.22 & 22.5 \\
\hline $\mathbf{T b}$ & 0.591 & 0.779 & 1.45 & 0.929 & 4.21 \\
\hline Dy & 6.60 & 5.11 & 9.98 & 6.07 & 25.59 \\
\hline Но & 1.19 & 0.739 & 1.48 & 1.25 & 4.95 \\
\hline Er & 2.91 & 1.88 & 4.91 & 3.85 & 12.5 \\
\hline $\mathbf{T m}$ & 0.164 & 0.374 & 0.713 & 0.432 & 1.73 \\
\hline Yb & 2.08 & 0.978 & 4.01 & 2.01 & 11.3 \\
\hline $\mathbf{L u}$ & 0.273 & 0.224 & 0.333 & 0.321 & 0.959 \\
\hline Hf & 2.89 & 2.55 & 4.85 & 4.25 & 6.67 \\
\hline $\mathbf{T a}$ & BDL & 0.145 & 0.300 & 0.213 & 0.359 \\
\hline $\mathbf{P b}$ & 2.09 & 1.22 & 1.67 & 0.631 & 2.54 \\
\hline
\end{tabular}

*Where EMPA analyses were invalid, data from a similar crystal (on the basis of texture and backscatter intensity) were substituted. 
Table A3.4 Trace element concentrations in amphibole crystals analysed by LA-ICP-MS.

Abbreviations same as Table A3.2.

\begin{tabular}{|c|c|c|c|c|c|}
\hline Sample & Kaupokonui & Kaupokonui & Kaupokonui & Kaupokonui & Kaupokonui \\
\hline ID & A9d & A9e & A9f & A11a & A11b \\
\hline zone & rim & zone & core & rim & core \\
\hline EMPA ID & A9_2 & A9_4 & A9_6 & A11_1 & A11_4 \\
\hline $\mathrm{CaO}$ & 11.89 & 11.33 & 11.83 & 11.70 & 11.93 \\
\hline Mg\# & 81.70 & 68.55 & 71.11 & 79.74 & 85.94 \\
\hline $\operatorname{Mn}(w t \%)$ & 0.125 & 0.333 & 0.216 & 0.137 & 0.133 \\
\hline $\mathbf{L i}$ & 4.67 & 3.88 & 4.76 & 4.10 & 3.50 \\
\hline $\mathrm{Sc}$ & 81.1 & 45.9 & 62.4 & 80.1 & 78.4 \\
\hline $\mathbf{T i}$ & 12764 & 15867 & 15422 & 13471 & 12538 \\
\hline $\mathbf{V}$ & 556 & 495 & 664 & 512 & 543 \\
\hline $\mathrm{Cr}$ & 216.0 & BDL & 15.6 & 13.8 & 26.9 \\
\hline $\mathbf{N i}$ & 169 & 20.3 & 17.3 & 123 & 160 \\
\hline $\mathbf{Z n}$ & 66.4 & 150 & 107 & 58.9 & 47.5 \\
\hline $\mathbf{R b}$ & 5.24 & 4.42 & 4.87 & 4.13 & 3.58 \\
\hline $\mathbf{S r}$ & 331 & 218 & 328 & 328 & 317 \\
\hline $\mathbf{Y}$ & 20.5 & 47.6 & 29.6 & 26.3 & 24.2 \\
\hline $\mathbf{Z r}$ & 46.7 & 88.0 & 65.1 & 75.9 & 52.1 \\
\hline $\mathbf{N b}$ & 1.80 & 9.99 & 3.88 & 3.31 & 2.45 \\
\hline $\mathbf{B a}$ & 309 & 376 & 339 & 284 & 276 \\
\hline La & 3.54 & 10.0 & 4.60 & 3.92 & 2.47 \\
\hline $\mathrm{Ce}$ & 11.9 & 40.0 & 18.8 & 15.6 & 11.3 \\
\hline $\mathbf{P r}$ & 2.90 & 7.04 & 3.43 & 2.61 & 2.07 \\
\hline Nd & 12.3 & 36.0 & 19.0 & 13.4 & 12.3 \\
\hline Sm & 2.95 & 10.1 & 6.80 & 3.71 & 3.08 \\
\hline $\mathbf{E u}$ & 1.46 & 2.60 & 1.52 & 1.19 & 1.80 \\
\hline Gd & 6.18 & 11.9 & 5.98 & 3.92 & 5.58 \\
\hline $\mathbf{T b}$ & 0.586 & 1.54 & 0.823 & 0.746 & 0.542 \\
\hline Dy & 4.27 & 10.0 & 6.26 & 6.06 & 3.19 \\
\hline Ho & 0.581 & 1.93 & 1.23 & 1.03 & 0.74 \\
\hline Er & 1.90 & 5.06 & 3.27 & 3.25 & 3.49 \\
\hline $\mathbf{T m}$ & 0.204 & 0.916 & 0.368 & 0.214 & 0.245 \\
\hline Yb & 1.22 & 4.74 & 2.89 & 2.12 & 2.20 \\
\hline $\mathbf{L u}$ & 0.213 & 0.635 & 0.334 & 0.205 & 0.248 \\
\hline Hf & 2.33 & 3.57 & 3.06 & 4.40 & 1.82 \\
\hline $\mathbf{T a}$ & 0.201 & 0.427 & 0.233 & 0.333 & 0.076 \\
\hline $\mathbf{P b}$ & 1.53 & 2.40 & 1.97 & 1.19 & 0.557 \\
\hline
\end{tabular}

*Where EMPA analyses were invalid, data from a similar crystal (on the basis of texture and backscatter intensity) were substituted. 
Table A3.4 Trace element concentrations in amphibole crystals analysed by LA-ICP-MS.

Abbreviations same as Table A3.2.

\begin{tabular}{|c|c|c|c|c|c|c|c|}
\hline Sample & SM-6C & SM-6C & SM-6C & SM-6C & SM-6C & SM-6C & SM-6C \\
\hline ID & A1f & A3a & A3g & A3h & A3d & $\mathbf{A} \mathbf{3} \mathbf{j}$ & A5d \\
\hline zone & core & rim & zone & zone & zone & core & rim \\
\hline EMPA ID & A7_1 ${ }^{*}$ & A7_1 ${ }^{*}$ & A7_ $5^{*}$ & A7_ $5^{*}$ & A7_4 ${ }^{*}$ & A7_6* & A5_2 \\
\hline $\mathrm{CaO}$ & 11.90 & 11.90 & 11.56 & 11.56 & 11.92 & 12.04 & 13.03 \\
\hline Mg\# & 82.40 & 82.40 & 82.30 & 82.30 & 78.88 & 78.85 & 69.41 \\
\hline $\operatorname{Mn}(w t \%)$ & 0.160 & 0.141 & 0.142 & 0.134 & 0.159 & 0.215 & 0.151 \\
\hline $\mathbf{L i}$ & 1.63 & 1.84 & 1.93 & 1.30 & 1.35 & 1.71 & 2.29 \\
\hline Sc & 60.0 & 80.6 & 79.8 & 82.7 & 72.5 & 78.1 & 86.8 \\
\hline $\mathbf{T i}$ & 14929 & 15160 & 15381 & 15322 & 15669 & 17323 & 16020 \\
\hline $\mathbf{V}$ & 532 & 570 & 610 & 584 & 579 & 475 & 613 \\
\hline $\mathrm{Cr}$ & 8.70 & 38.1 & 26.1 & 30.8 & 15.2 & 9.44 & 39.1 \\
\hline $\mathbf{N i}$ & 33.9 & 52.0 & 53.7 & 70.8 & 42.6 & 43.7 & 47.4 \\
\hline Zn & 68.3 & 68.4 & 66.5 & 63.9 & 72.0 & 93.0 & 72.8 \\
\hline $\mathbf{R b}$ & 3.15 & 3.01 & 4.02 & 4.48 & 3.64 & 3.43 & 2.61 \\
\hline $\mathbf{S r}$ & 276 & 322 & 342 & 352 & 289 & 282 & 346 \\
\hline $\mathbf{Y}$ & 25.4 & 22.4 & 20.8 & 20.0 & 25.1 & 61.0 & 23.9 \\
\hline $\mathbf{Z r}$ & 35.1 & 34.3 & 35.2 & 33.6 & 35.9 & 58.1 & 34.6 \\
\hline $\mathbf{N b}$ & 3.53 & 2.33 & 1.88 & 2.29 & 2.55 & 8.15 & 2.47 \\
\hline $\mathbf{B a}$ & 283 & 317 & 295 & 312 & 284 & 284 & 285 \\
\hline La & 3.65 & 2.91 & 2.96 & 2.53 & 3.51 & 5.93 & 3.22 \\
\hline $\mathrm{Ce}$ & 14.6 & 13.0 & 12.6 & 12.2 & 14.9 & 30.6 & 11.6 \\
\hline Pr & 2.77 & 2.41 & 2.32 & 2.06 & 2.51 & 6.06 & 1.99 \\
\hline Nd & 15.4 & 14.1 & 15.1 & 13.8 & 14.9 & 40.0 & 12.7 \\
\hline Sm & 3.38 & 4.08 & 3.82 & 4.95 & 4.35 & 8.68 & 3.81 \\
\hline $\mathbf{E u}$ & 1.30 & 1.92 & 1.37 & 1.40 & 1.92 & 2.49 & 1.34 \\
\hline Gd & 4.67 & 6.18 & 4.28 & 6.04 & 5.21 & 13.9 & 4.53 \\
\hline $\mathbf{T b}$ & 0.910 & 0.840 & 0.621 & 0.734 & 0.779 & 1.76 & 0.666 \\
\hline Dy & 3.97 & 4.45 & 2.99 & 3.49 & 5.52 & 11.3 & 5.54 \\
\hline Ho & 0.807 & 0.687 & 0.459 & 0.837 & 1.17 & 2.45 & 0.914 \\
\hline Er & 2.25 & 2.22 & 2.06 & 2.11 & 3.03 & 5.69 & 1.90 \\
\hline $\mathbf{T m}$ & 0.413 & 0.286 & 0.204 & 0.264 & 0.237 & 0.743 & 0.350 \\
\hline Yb & 2.08 & 1.80 & 1.27 & 1.55 & 1.91 & 5.32 & 1.46 \\
\hline $\mathbf{L u}$ & 0.228 & 0.220 & 0.322 & 0.219 & 0.208 & 0.703 & 0.331 \\
\hline Hf & 1.68 & 1.91 & 1.39 & 1.64 & 1.04 & 3.00 & 1.91 \\
\hline $\mathbf{T a}$ & 0.135 & 0.076 & 0.162 & 0.207 & 0.316 & 0.280 & 0.127 \\
\hline $\mathbf{P b}$ & 1.34 & 1.08 & 0.801 & 1.57 & 1.42 & 0.862 & 0.653 \\
\hline
\end{tabular}

*Where EMPA analyses were invalid, data from a similar crystal (on the basis of texture and backscatter intensity) were substituted. 
Table A3.4 Trace element concentrations in amphibole crystals analysed by LA-ICP-MS.

Abbreviations same as Table A3.2.

\begin{tabular}{|c|c|c|c|c|c|c|c|}
\hline Sample & SM-6C & SM-6C & SM-6C & SM-6C & SM-6C & SM-6C & SM-6C \\
\hline ID & A5e & A6b & A6d & $\mathbf{A} 7 \mathbf{a}$ & A7b & A7c & A7d \\
\hline zone & core & rim & core & rim & zone & zone & core \\
\hline EMPA ID & A5_5 & A6_1 & A6_3 & A7_1 & A7_4 & A7_5 & A7_6 \\
\hline $\mathrm{CaO}$ & 12.85 & 11.75 & 11.93 & 11.90 & 11.92 & 11.56 & 12.04 \\
\hline Mg\# & 66.63 & 83.71 & 81.34 & 82.40 & 78.88 & 82.30 & 78.85 \\
\hline $\operatorname{Mn}(w t \%)$ & 0.177 & 0.155 & 0.140 & 0.141 & 0.162 & 0.269 & 0.210 \\
\hline $\mathbf{L i}$ & 3.48 & 2.20 & 1.51 & 1.29 & 1.98 & 1.84 & 1.67 \\
\hline Sc & 75.1 & 85.8 & 88.1 & 83.3 & 79.0 & 83.2 & 59.2 \\
\hline $\mathbf{T i}$ & 16401 & 16051 & 14986 & 15487 & 16734 & 18577 & 14663 \\
\hline $\mathbf{V}$ & 632 & 610 & 571 & 592 & 614 & 502 & 594 \\
\hline $\mathrm{Cr}$ & 16.4 & 9.47 & 40.4 & 24.1 & 15.1 & BDL & 3.88 \\
\hline $\mathbf{N i}$ & 25.3 & 44.5 & 55.9 & 64.4 & 54.2 & 41.7 & 35.2 \\
\hline Zn & 72.2 & 59.9 & 61.4 & 70.1 & 75.1 & 100 & 91.1 \\
\hline $\mathbf{R b}$ & 8.33 & 3.19 & 2.83 & 4.58 & 4.42 & 3.38 & 3.85 \\
\hline $\mathbf{S r}$ & 396 & 336 & 338 & 351 & 359 & 256 & 296 \\
\hline $\mathbf{Y}$ & 27.9 & 27.1 & 22.8 & 20.2 & 24.7 & 68.5 & 27.5 \\
\hline $\mathbf{Z r}$ & 59.3 & 39.7 & 36.4 & 35.5 & 36.5 & 81.1 & 44.2 \\
\hline $\mathbf{N b}$ & 3.68 & 2.83 & 2.40 & 1.67 & 3.29 & 11.80 & 2.72 \\
\hline $\mathbf{B a}$ & 397 & 301 & 281 & 343 & 330 & 443 & 361 \\
\hline La & 4.78 & 3.02 & 2.21 & 2.48 & 3.32 & 11.19 & 4.49 \\
\hline $\mathrm{Ce}$ & 18.5 & 12.7 & 10.7 & 12.3 & 13.7 & 49.6 & 17.7 \\
\hline $\mathbf{P r}$ & 3.02 & 2.24 & 2.60 & 2.06 & 2.38 & 7.84 & 3.53 \\
\hline Nd & 17.0 & 17.3 & 13.3 & 13.8 & 14.2 & 48.3 & 19.0 \\
\hline Sm & 6.32 & 4.72 & 3.85 & 3.31 & 4.05 & 14.38 & 5.28 \\
\hline $\mathbf{E u}$ & 1.79 & 1.27 & 1.40 & 1.68 & 1.74 & 3.26 & 1.47 \\
\hline Gd & 5.19 & 6.58 & 5.31 & 5.77 & 5.31 & 15.17 & 5.67 \\
\hline $\mathbf{T b}$ & 0.910 & 0.925 & 1.04 & 0.743 & 1.06 & 2.25 & 0.937 \\
\hline Dy & 5.38 & 5.13 & 4.04 & 4.58 & 6.11 & 17.6 & 5.08 \\
\hline Но & 0.908 & 0.867 & 0.578 & 0.754 & 0.785 & 2.393 & 0.917 \\
\hline Er & 1.73 & 2.25 & 1.92 & 2.07 & 2.12 & 7.59 & 2.21 \\
\hline $\mathbf{T m}$ & 0.141 & 0.274 & 0.110 & 0.117 & 0.222 & 0.755 & 0.331 \\
\hline Yb & 2.26 & 1.89 & 0.79 & 1.97 & 1.37 & 5.26 & 2.06 \\
\hline $\mathbf{L u}$ & 0.491 & 0.205 & 0.237 & 0.272 & 0.280 & 0.424 & 0.270 \\
\hline Hf & 2.33 & 1.30 & 1.72 & 1.30 & 1.78 & 3.39 & 2.31 \\
\hline $\mathbf{T a}$ & 0.356 & 0.203 & 0.263 & 0.240 & 0.080 & 0.534 & 0.040 \\
\hline $\mathbf{P b}$ & 3.95 & 0.908 & 1.13 & 0.918 & 0.767 & 1.36 & 1.26 \\
\hline
\end{tabular}

*Where EMPA analyses were invalid, data from a similar crystal (on the basis of texture and backscatter intensity) were substituted. 
Table A3.4 Trace element concentrations in amphibole crystals analysed by LA-ICP-MS.

Abbreviations same as Table A3.2.

\begin{tabular}{|c|c|c|c|c|c|c|}
\hline Sample & SM-6C & Maketawa & Maketawa & Maketawa & Maketawa & Maketawa \\
\hline ID & A9a & A1a & A1c & A1d & A1f & A4a \\
\hline zone & core & rim & zone & zone & core & zone \\
\hline EMPA ID & A9_4 & $\mathrm{A} 1 \_1$ & A1_2 & A1_2 & A1_3 & A4_2 \\
\hline $\mathrm{CaO}$ & 13.08 & 11.41 & 11.72 & 11.72 & 11.82 & 12.29 \\
\hline Mg\# & 70.02 & 66.35 & 69.84 & 69.84 & 75.30 & 82.74 \\
\hline $\operatorname{Mn}(w t \%)$ & 0.161 & 0.361 & 0.584 & 0.592 & 0.569 & 0.166 \\
\hline $\mathbf{L i}$ & 2.39 & 3.53 & 6.04 & 4.97 & 4.64 & 3.37 \\
\hline Sc & 93.9 & 64.6 & 42.9 & 35.5 & 51.9 & 77.7 \\
\hline $\mathbf{T i}$ & 17139 & 16853 & 17362 & 16364 & 17509 & 13752 \\
\hline $\mathbf{V}$ & 635 & 413 & 391 & 366 & 319 & 497 \\
\hline $\mathrm{Cr}$ & 41.5 & 15.4 & $\mathrm{BDL}$ & BDL & 6.44 & 19.0 \\
\hline $\mathbf{N i}$ & 61.1 & 25.2 & 29.2 & 17.7 & 9.27 & 176 \\
\hline Zn & 69.1 & 140 & 244 & 235 & 215 & 68.8 \\
\hline $\mathbf{R b}$ & 4.37 & 3.25 & 4.09 & 4.45 & 2.82 & 4.05 \\
\hline $\mathbf{S r}$ & 377 & 207 & 105 & 103 & 119 & 316 \\
\hline $\mathbf{Y}$ & 26.8 & 69.9 & 129 & 120 & 141 & 26.9 \\
\hline $\mathbf{Z r}$ & 35.6 & 111 & 127 & 130 & 160 & 54.7 \\
\hline $\mathrm{Nb}$ & 2.72 & 11.1 & 23.6 & 23.1 & 23.1 & 2.47 \\
\hline $\mathbf{B a}$ & 310 & 353 & 312 & 320 & 313 & 234 \\
\hline $\mathbf{L a}$ & 3.03 & 13.0 & 22.6 & 19.1 & 22.4 & 3.43 \\
\hline $\mathrm{Ce}$ & 12.4 & 48.8 & 85.4 & 81.2 & 84.4 & 13.3 \\
\hline $\mathbf{P r}$ & 2.71 & 9.51 & 15.7 & 14.2 & 16.1 & 2.38 \\
\hline Nd & 12.0 & 46.2 & 78.7 & 73.1 & 87.4 & 14.9 \\
\hline Sm & 6.18 & 12.3 & 24.6 & 21.4 & 25.3 & 4.52 \\
\hline $\mathbf{E u}$ & 1.94 & 3.51 & 4.74 & 4.54 & 5.65 & 1.98 \\
\hline Gd & 5.66 & 15.8 & 23.2 & 22.0 & 30.3 & 6.44 \\
\hline $\mathbf{T b}$ & 1.09 & 2.01 & 3.71 & 3.08 & 3.87 & 0.920 \\
\hline Dy & 5.83 & 13.1 & 23.7 & 23.7 & 27.7 & 6.16 \\
\hline Ho & 0.900 & 2.82 & 4.13 & 4.37 & 5.68 & 1.17 \\
\hline Er & 2.25 & 7.16 & 12.1 & 11.2 & 14.4 & 2.78 \\
\hline $\mathbf{T m}$ & 0.288 & 0.847 & 1.74 & 1.73 & 1.90 & 0.241 \\
\hline $\mathbf{Y b}$ & 1.73 & 4.65 & 11.2 & 11.0 & 12.3 & 2.30 \\
\hline $\mathbf{L u}$ & 0.196 & 0.87 & 1.25 & 1.49 & 1.79 & 0.19 \\
\hline Hf & 1.28 & 5.29 & 5.60 & 4.70 & 7.08 & 2.70 \\
\hline $\mathbf{T a}$ & 0.255 & 0.508 & 0.726 & 0.566 & 0.691 & 0.051 \\
\hline $\mathbf{P b}$ & 1.25 & 2.07 & 2.05 & 2.52 & 1.94 & 0.662 \\
\hline
\end{tabular}

*Where EMPA analyses were invalid, data from a similar crystal (on the basis of texture and backscatter intensity) were substituted. 
Table A3.4 Trace element concentrations in amphibole crystals analysed by LA-ICP-MS. Abbreviations same as Table A3.2.

\begin{tabular}{|c|c|c|c|c|c|}
\hline Sample & Maketawa & Maketawa & Maketawa & Maketawa & Maketawa \\
\hline ID & A9a & A9b & A10a & A11c & A11d \\
\hline zone & rim & core & core & zone & core \\
\hline EMPA ID & A9_2 & A9_1 & A10_6 & A11_3 & A11_1 \\
\hline $\mathrm{CaO}$ & 11.62 & 12.06 & 12.18 & 11.75 & 11.52 \\
\hline Mg\# & 78.54 & 71.31 & 79.98 & 73.59 & 78.51 \\
\hline $\operatorname{Mn}(w t \%)$ & 0.366 & 0.384 & 0.178 & 0.408 & 0.347 \\
\hline $\mathbf{L i}$ & 3.85 & 3.32 & 4.02 & 4.00 & 3.97 \\
\hline Sc & 79.4 & 88.1 & 65.4 & 71.3 & 65.5 \\
\hline $\mathbf{T i}$ & 17617 & 18537 & 13196 & 18089 & 16360 \\
\hline $\mathbf{V}$ & 429 & 451 & 498 & 451 & 477 \\
\hline $\mathrm{Cr}$ & 2.86 & 9.64 & 9.37 & 25.5 & 22.7 \\
\hline $\mathbf{N i}$ & 28.1 & 33.2 & 145 & 43.3 & 48.8 \\
\hline Zn & 125 & 148 & 79.3 & 166 & 151 \\
\hline $\mathbf{R b}$ & 8.22 & 2.88 & 4.23 & 2.90 & 3.07 \\
\hline $\mathrm{Sr}$ & 229 & 221 & 394 & 215 & 291 \\
\hline $\mathbf{Y}$ & 94.8 & 99.0 & 27.3 & 85.1 & 62.2 \\
\hline $\mathbf{Z r}$ & 148 & 140 & 59.8 & 129 & 104 \\
\hline $\mathbf{N b}$ & 14.9 & 17.2 & 2.70 & 13.8 & 8.89 \\
\hline $\mathbf{B a}$ & 447 & 415 & 340 & 383 & 370 \\
\hline $\mathbf{L a}$ & 16.9 & 16.7 & 4.56 & 15.6 & 10.1 \\
\hline $\mathrm{Ce}$ & 55.9 & 61.7 & 17.7 & 58.3 & 35.7 \\
\hline Pr & 10.4 & 10.5 & 2.84 & 9.66 & 6.37 \\
\hline Nd & 56.2 & 68.5 & 17.3 & 59.8 & 38.4 \\
\hline Sm & 15.5 & 17.4 & 7.20 & 13.3 & 14.0 \\
\hline $\mathbf{E u}$ & 4.38 & 4.29 & 1.47 & 5.86 & 3.78 \\
\hline Gd & 18.1 & 21.2 & 6.56 & 17.6 & 14.7 \\
\hline $\mathbf{T b}$ & 3.03 & 3.19 & 0.788 & 3.26 & 1.96 \\
\hline Dy & 17.3 & 19.9 & 5.93 & 19.2 & 11.7 \\
\hline Но & 3.29 & 3.55 & 0.752 & 3.04 & 1.98 \\
\hline Er & 10.4 & 10.2 & 2.12 & 6.73 & 6.50 \\
\hline Tm & 1.65 & 1.07 & 0.448 & 1.06 & 0.595 \\
\hline $\mathbf{Y b}$ & 7.82 & 8.77 & 3.27 & 7.26 & 5.99 \\
\hline $\mathbf{L u}$ & 1.13 & 1.43 & 0.21 & 0.84 & 0.43 \\
\hline Hf & 7.09 & 5.59 & 1.96 & 4.80 & 4.69 \\
\hline $\mathbf{T a}$ & 0.735 & 0.659 & 0.028 & 0.533 & 0.345 \\
\hline $\mathbf{P b}$ & 2.74 & 1.59 & 1.19 & 2.55 & 2.01 \\
\hline
\end{tabular}

*Where EMPA analyses were invalid, data from a similar crystal (on the basis of texture and backscatter intensity) were substituted. 
Table A3.4 Trace element concentrations in amphibole crystals analysed by LA-ICP-MS.

Abbreviations same as Table A3.2.

\begin{tabular}{|c|c|c|c|c|c|}
\hline Sample & Maketawa & Maketawa & Inglewood b & Inglewood b & Inglewood b \\
\hline ID & A13a & A13d & A1b & A1c & A1d \\
\hline zone & rim & core & rim & core & zone \\
\hline EMPA ID & A13_1 & A13_2 & A1_5 & A1_6 & A1_6 \\
\hline $\mathrm{CaO}$ & 11.70 & 11.35 & 11.44 & 11.69 & 11.69 \\
\hline Mg\# & 74.60 & 66.10 & 77.09 & 74.89 & 74.89 \\
\hline $\operatorname{Mn}(w t \%)$ & 0.377 & 0.571 & 0.660 & 0.596 & 0.633 \\
\hline $\mathbf{L i}$ & 4.15 & 3.55 & 8.27 & 5.64 & 6.80 \\
\hline Sc & 78.3 & 32.5 & 55.3 & 51.3 & 49.3 \\
\hline $\mathbf{T i}$ & 19085 & 16581 & 17068 & 16121 & 16335 \\
\hline $\mathbf{V}$ & 459 & 361 & 292 & 331 & 348 \\
\hline $\mathrm{Cr}$ & 3.21 & BDL & BDL & $\mathrm{BDL}$ & 14.3 \\
\hline $\mathbf{N i}$ & 27.4 & 15.2 & 7.69 & 13.7 & 14.3 \\
\hline Zn & 141 & 211 & 226 & 210 & 209 \\
\hline $\mathbf{R b}$ & 2.76 & 3.89 & 2.91 & 3.84 & 3.16 \\
\hline $\mathbf{S r}$ & 251 & 112 & 168 & 139 & 145 \\
\hline $\mathbf{Y}$ & 87.8 & 114 & 150 & 122 & 117 \\
\hline $\mathbf{Z r}$ & 132.5 & 141 & 141 & 136 & 133 \\
\hline $\mathrm{Nb}$ & 12.6 & 19.6 & 20.4 & 16.4 & 16.6 \\
\hline $\mathbf{B a}$ & 414 & 382 & 415 & 370 & 349 \\
\hline La & 13.9 & 19.4 & 22.3 & 19.8 & 19.5 \\
\hline $\mathrm{Ce}$ & 52.3 & 70.5 & 94.1 & 79.1 & 75.3 \\
\hline Pr & 9.91 & 13.9 & 17.1 & 15.2 & 13.7 \\
\hline Nd & 56.0 & 71.2 & 95.4 & 84.8 & 72.7 \\
\hline Sm & 19.2 & 20.5 & 26.1 & 23.9 & 20.5 \\
\hline $\mathbf{E u}$ & 3.49 & 3.95 & 5.81 & 5.27 & 5.16 \\
\hline Gd & 20.3 & 22.2 & 29.8 & 21.7 & 22.6 \\
\hline $\mathbf{T b}$ & 3.05 & 3.46 & 4.77 & 3.34 & 3.08 \\
\hline Dy & 16.7 & 19.0 & 32.1 & 24.4 & 22.7 \\
\hline Ho & 2.71 & 4.05 & 6.67 & 4.69 & 5.21 \\
\hline Er & 11.2 & 11.1 & 16.1 & 12.7 & 12.6 \\
\hline $\mathbf{T m}$ & 0.89 & 1.70 & 1.99 & 1.57 & 1.35 \\
\hline $\mathbf{Y b}$ & 7.86 & 10.4 & 13.7 & 12.6 & 13.0 \\
\hline Lu & 1.20 & 1.41 & 2.29 & 1.37 & 1.31 \\
\hline Hf & 4.41 & 5.33 & 6.17 & 6.56 & 6.55 \\
\hline $\mathbf{T a}$ & 0.966 & 0.621 & 0.646 & 0.743 & 0.337 \\
\hline $\mathbf{P b}$ & 2.13 & 1.85 & 2.98 & 3.70 & 3.16 \\
\hline
\end{tabular}

*Where EMPA analyses were invalid, data from a similar crystal (on the basis of texture and backscatter intensity) were substituted. 
Table A3.4 Trace element concentrations in amphibole crystals analysed by LA-ICP-MS.

Abbreviations same as Table A3.2.

\begin{tabular}{|c|c|c|c|c|c|}
\hline Sample & Inglewood b & Inglewood b & Inglewood b & Inglewood b & Inglewood b \\
\hline ID & A2a & A3 & A8 & A10a & A10b \\
\hline zone & rim & core & core & rim & zone \\
\hline EMPA ID & A2_3 & A3_5 & A8_3 & $\mathrm{A} 1 \_5^{*}$ & A1_ $5^{*}$ \\
\hline $\mathrm{CaO}$ & 11.40 & 11.31 & 11.44 & 11.44 & 11.44 \\
\hline Mg\# & 74.36 & 76.07 & 77.64 & 77.09 & 77.09 \\
\hline $\operatorname{Mn}(w t \%)$ & 0.672 & 0.568 & 0.595 & 0.534 & 0.485 \\
\hline $\mathbf{L i}$ & 5.34 & 5.83 & 5.86 & 3.82 & 5.31 \\
\hline $\mathrm{Sc}$ & 51.3 & 51.0 & 46.9 & 45.6 & 67.4 \\
\hline $\mathbf{T i}$ & 17677 & 15824 & 16011 & 15465 & 19299 \\
\hline $\mathbf{V}$ & 306 & 315 & 300 & 286 & 411 \\
\hline $\mathrm{Cr}$ & 2.11 & $\mathrm{BDL}$ & 11.0 & 3.32 & 9.66 \\
\hline $\mathbf{N i}$ & 9.57 & 2.18 & 3.99 & 11.6 & 31.1 \\
\hline $\mathbf{Z n}$ & 220 & 208 & 194 & 174 & 168 \\
\hline $\mathbf{R b}$ & 3.04 & 2.59 & 2.86 & 1.98 & 2.95 \\
\hline $\mathrm{Sr}$ & 165 & 178 & 155 & 153 & 216 \\
\hline $\mathbf{Y}$ & 148 & 116 & 112 & 106 & 107 \\
\hline $\mathbf{Z r}$ & 147 & 112 & 123 & 101 & 125 \\
\hline $\mathbf{N b}$ & 16.5 & 15.5 & 14.9 & 13.6 & 17.1 \\
\hline $\mathbf{B a}$ & 394 & 342 & 307 & 311 & 371 \\
\hline La & 22.4 & 17.2 & 17.7 & 17.2 & 16.2 \\
\hline $\mathrm{Ce}$ & 95.2 & 73.3 & 70.6 & 73.0 & 67.2 \\
\hline Pr & 16.2 & 13.5 & 13.9 & 13.4 & 11.0 \\
\hline Nd & 94.8 & 68.6 & 68.7 & 76.0 & 72.1 \\
\hline Sm & 24.6 & 17.1 & 21.8 & 21.5 & 21.8 \\
\hline $\mathbf{E u}$ & 6.08 & 4.79 & 4.98 & 5.78 & 4.95 \\
\hline Gd & 24.3 & 17.7 & 24.4 & 24.8 & 24.8 \\
\hline $\mathbf{T b}$ & 4.32 & 3.72 & 3.59 & 3.08 & 3.34 \\
\hline Dy & 27.2 & 22.2 & 22.9 & 24.2 & 24.4 \\
\hline Ho & 5.73 & 5.09 & 4.36 & 3.97 & 4.16 \\
\hline $\mathbf{E r}$ & 16.4 & 13.0 & 13.1 & 13.2 & 11.8 \\
\hline $\mathbf{T m}$ & 2.23 & 1.83 & 1.47 & 1.51 & 1.50 \\
\hline $\mathbf{Y b}$ & 12.3 & 9.99 & 12.5 & 9.92 & 9.58 \\
\hline $\mathbf{L u}$ & 1.96 & 1.27 & 1.57 & 1.70 & 1.15 \\
\hline Hf & 7.28 & 6.30 & 5.02 & 5.81 & 4.39 \\
\hline $\mathbf{T a}$ & 0.524 & 0.581 & 0.516 & 0.737 & 0.550 \\
\hline $\mathbf{P b}$ & 1.89 & 2.40 & 2.59 & 1.64 & 1.95 \\
\hline
\end{tabular}

*Where EMPA analyses were invalid, data from a similar crystal (on the basis of texture and backscatter intensity) were substituted. 
Table A3.4 Trace element concentrations in amphibole crystals analysed by LA-ICP-MS.

Abbreviations same as Table A3.2.

\begin{tabular}{|c|c|c|c|c|c|}
\hline Sample & Inglewood b & Inglewood a & Inglewood a & Inglewood a & Inglewood a \\
\hline ID & A11b & A9a & A9b & A10a & A10b \\
\hline zone & core & core & light core & rim & core \\
\hline EMPA ID & A11_2 & A9_2 & A9_3 & A10_1 & A10_4 \\
\hline $\mathrm{CaO}$ & 11.69 & 11.52 & 11.94 & 11.28 & 11.97 \\
\hline Mg\# & 74.13 & 76.45 & 72.72 & 74.88 & 69.38 \\
\hline $\operatorname{Mn}(w t \%)$ & 0.454 & 0.567 & 0.636 & 0.540 & 0.365 \\
\hline $\mathbf{L i}$ & 5.18 & 5.52 & 6.20 & 4.31 & 4.31 \\
\hline Sc & 42.0 & 51.5 & 59.9 & 53.2 & 59.6 \\
\hline $\mathbf{T i}$ & 14358 & 15625 & 17455 & 16827 & 14290 \\
\hline $\mathbf{V}$ & 308 & 303 & 310 & 302 & 449 \\
\hline $\mathrm{Cr}$ & BDL & 9.20 & BDL & BDL & 2.12 \\
\hline $\mathbf{N i}$ & 3.15 & 4.25 & 2.48 & 9.15 & 15.8 \\
\hline $\mathbf{Z n}$ & 176 & 193 & 213 & 190 & 138 \\
\hline $\mathbf{R b}$ & 3.15 & 3.41 & 2.66 & 2.56 & 3.30 \\
\hline $\mathrm{Sr}$ & 308 & 167 & 159 & 187 & 261 \\
\hline $\mathbf{Y}$ & 59.1 & 123 & 139 & 117 & 51.7 \\
\hline $\mathbf{Z r}$ & 87.2 & 129 & 140 & 135 & 83.0 \\
\hline $\mathbf{N b}$ & 6.62 & 13.9 & 16.9 & 13.6 & 4.39 \\
\hline $\mathbf{B a}$ & 296 & 336 & 351 & 372 & 220 \\
\hline La & 8.11 & 17.2 & 20.8 & 17.5 & 6.72 \\
\hline $\mathrm{Ce}$ & 37.6 & 73.2 & 86.9 & 70.6 & 25.4 \\
\hline Pr & 7.33 & 13.5 & 15.3 & 12.2 & 4.93 \\
\hline Nd & 38.9 & 73.3 & 84.8 & 71.9 & 32.6 \\
\hline Sm & 13.8 & 24.7 & 23.9 & 23.1 & 8.42 \\
\hline $\mathbf{E u}$ & 3.26 & 4.84 & 5.32 & 5.06 & 3.18 \\
\hline Gd & 14.8 & 23.2 & 27.7 & 23.3 & 12.2 \\
\hline $\mathbf{T b}$ & 1.98 & 3.66 & 4.22 & 3.43 & 1.54 \\
\hline Dy & 11.8 & 22.9 & 28.2 & 20.0 & 9.68 \\
\hline Ho & 2.41 & 4.69 & 5.48 & 4.36 & 2.04 \\
\hline Er & 5.83 & 13.9 & 17.0 & 12.7 & 6.21 \\
\hline $\mathbf{T m}$ & 0.74 & 1.71 & 1.43 & 1.79 & 0.542 \\
\hline Yb & 5.34 & 13.0 & 13.5 & 10.5 & 4.53 \\
\hline $\mathbf{L u}$ & 0.81 & 1.47 & 1.81 & 1.42 & 0.629 \\
\hline Hf & 4.29 & 5.80 & 6.21 & 5.41 & 4.27 \\
\hline $\mathbf{T a}$ & 0.327 & 0.578 & 0.833 & 0.746 & 0.174 \\
\hline $\mathbf{P b}$ & 2.05 & 2.31 & 2.33 & 2.17 & 2.12 \\
\hline
\end{tabular}

*Where EMPA analyses were invalid, data from a similar crystal (on the basis of texture and backscatter intensity) were substituted. 
Table A3.4 Trace element concentrations in amphibole crystals analysed by LA-ICP-MS.

Abbreviations same as Table A3.2.

\begin{tabular}{|c|c|c|c|c|c|}
\hline Sample & Inglewood a & Inglewood a & Korito & Korito & Korito \\
\hline ID & A13a & A13b & A3B & A3C & A3D \\
\hline zone & zone & core & zone & zone & zone \\
\hline EMPA ID & A13_5 & A13_7 & A3_2 & A3_7 & A3_11 \\
\hline $\mathrm{CaO}$ & 11.48 & 11.27 & 11.84 & 11.48 & 11.77 \\
\hline Mg\# & 74.90 & 77.54 & 66.42 & 71.17 & 73.40 \\
\hline $\operatorname{Mn}(w t \%)$ & 0.498 & 0.414 & 0.519 & 0.433 & 0.401 \\
\hline $\mathbf{L i}$ & 4.64 & 4.30 & 5.27 & 4.93 & 4.11 \\
\hline Sc & 63.9 & 68.6 & 72.0 & 58.1 & 70.6 \\
\hline $\mathbf{T i}$ & 17962 & 18311 & 19737 & 17279 & 18987 \\
\hline $\mathbf{V}$ & 371 & 400 & 415 & 391 & 401 \\
\hline $\mathrm{Cr}$ & 9.08 & 2.64 & 11.6 & $\mathrm{BDL}$ & 5.97 \\
\hline $\mathbf{N i}$ & 30.1 & 31.3 & 24.7 & 28.5 & 27.6 \\
\hline $\mathbf{Z n}$ & 186 & 152 & 174 & 166 & 139 \\
\hline $\mathbf{R b}$ & 3.10 & 2.94 & 2.71 & 3.43 & 2.46 \\
\hline $\mathbf{S r}$ & 160 & 209 & 192 & 177 & 193 \\
\hline $\mathbf{Y}$ & 108 & 96.8 & 111 & 79.9 & 128 \\
\hline $\mathbf{Z r}$ & 134 & 132 & 126 & 113 & 126 \\
\hline $\mathbf{N b}$ & 15.3 & 13.5 & 14.8 & 12.7 & 16.5 \\
\hline $\mathbf{B a}$ & 361 & 304 & 356 & 285 & 339 \\
\hline $\mathbf{L a}$ & 16.6 & 13.6 & 16.8 & 11.8 & 18.3 \\
\hline $\mathrm{Ce}$ & 68.7 & 54.6 & 62.6 & 48.4 & 70.2 \\
\hline Pr & 12.1 & 10.4 & 11.4 & 9.81 & 12.7 \\
\hline Nd & 67.9 & 58.4 & 63.7 & 48.8 & 77.3 \\
\hline Sm & 21.3 & 19.9 & 19.8 & 15.3 & 22.8 \\
\hline Eu & 4.15 & 4.15 & 4.46 & 3.61 & 5.44 \\
\hline Gd & 23.7 & 21.2 & 21.0 & 12.2 & 22.9 \\
\hline $\mathbf{T b}$ & 3.19 & 3.27 & 3.41 & 2.80 & 3.63 \\
\hline Dy & 19.8 & 19.5 & 21.0 & 15.3 & 22.4 \\
\hline Ho & 3.69 & 3.45 & 4.03 & 3.49 & 4.30 \\
\hline $\mathbf{E r}$ & 12.8 & 11.4 & 10.7 & 8.05 & 13.7 \\
\hline Tm & 1.85 & 1.41 & 1.68 & 0.970 & 1.78 \\
\hline $\mathbf{Y b}$ & 11.3 & 9.49 & 9.29 & 6.87 & 8.74 \\
\hline Lu & 1.17 & 1.31 & 1.22 & 0.955 & 1.34 \\
\hline Hf & 4.99 & 4.31 & 5.90 & 4.69 & 5.90 \\
\hline $\mathbf{T a}$ & 0.514 & 0.809 & 0.547 & 0.427 & 0.557 \\
\hline $\mathbf{P b}$ & 1.89 & 1.51 & 2.54 & 1.43 & 1.52 \\
\hline
\end{tabular}

*Where EMPA analyses were invalid, data from a similar crystal (on the basis of texture and backscatter intensity) were substituted. 
Table A3.4 Trace element concentrations in amphibole crystals analysed by LA-ICP-MS.

Abbreviations same as Table A3.2.

\begin{tabular}{|c|c|c|c|c|c|c|}
\hline Sample & Korito & Korito & Korito & Korito & Korito & Korito \\
\hline ID & A3E & A3F & A3G & A7A & A11a & A12B \\
\hline zone & core & zone & zone & rim & core & zone \\
\hline EMPA ID & A3_13 & A3_6 & A3_10 & A7_2 & A11_2 & A12_3 \\
\hline $\mathrm{CaO}$ & 11.75 & 11.66 & 11.81 & 11.31 & 11.97 & 12.07 \\
\hline Mg\# & 72.48 & 71.00 & 69.07 & 79.30 & 72.87 & 70.34 \\
\hline $\operatorname{Mn}(w t \%)$ & 0.209 & 0.427 & 0.379 & 0.279 & 0.320 & 0.330 \\
\hline $\mathbf{L i}$ & 3.29 & 5.25 & 5.14 & 4.25 & 5.27 & 3.85 \\
\hline Sc & 65.4 & 65.8 & 66.9 & 55.1 & 48.6 & 57.9 \\
\hline $\mathbf{T i}$ & 14652 & 17713 & 16346 & 13176 & 13216 & 13318 \\
\hline $\mathbf{V}$ & 541 & 375 & 462 & 359 & 349 & 337 \\
\hline $\mathrm{Cr}$ & 1.32 & 4.46 & 3.85 & BDL & 11.4 & BDL \\
\hline $\mathbf{N i}$ & 35.1 & 22.6 & 24.8 & BDL & BDL & BDL \\
\hline $\mathbf{Z n}$ & 90.9 & 171 & 155 & 109 & 141 & 144 \\
\hline $\mathbf{R b}$ & 3.17 & 2.32 & 3.65 & 3.89 & 2.66 & 2.79 \\
\hline $\mathbf{S r}$ & 323 & 202 & 288 & 304 & 292 & 333 \\
\hline $\mathbf{Y}$ & 32.1 & 93.5 & 50.7 & 43.0 & 49.0 & 49.6 \\
\hline $\mathbf{Z r}$ & 51.5 & 125 & 102 & 56.2 & 67.2 & 80.1 \\
\hline $\mathrm{Nb}$ & 3.57 & 12.3 & 6.63 & 4.71 & 2.74 & 5.57 \\
\hline $\mathbf{B a}$ & 243 & 318 & 256 & 278 & 247 & 293 \\
\hline La & 4.78 & 13.1 & 6.86 & 5.93 & 6.06 & 6.12 \\
\hline $\mathrm{Ce}$ & 18.6 & 54.8 & 26.6 & 23.3 & 25.3 & 25.9 \\
\hline Pr & 2.68 & 10.6 & 5.55 & 4.32 & 5.19 & 4.98 \\
\hline Nd & 18.1 & 60.5 & 27.6 & 29.7 & 32.5 & 29.3 \\
\hline Sm & 5.76 & 18.2 & 9.90 & 8.00 & 11.3 & 8.71 \\
\hline $\mathbf{E u}$ & 2.20 & 3.71 & 2.82 & 2.03 & 3.05 & 2.92 \\
\hline Gd & 6.85 & 19.8 & 10.6 & 9.27 & 10.1 & 12.8 \\
\hline $\mathbf{T b}$ & 1.03 & 2.84 & 1.50 & 1.49 & 1.38 & 1.74 \\
\hline Dy & 5.77 & 16.8 & 10.3 & 8.31 & 10.0 & 9.54 \\
\hline Но & 1.11 & 3.36 & 2.04 & 1.73 & 1.76 & 1.92 \\
\hline Er & 2.69 & 9.47 & 5.27 & 4.82 & 5.70 & 6.04 \\
\hline $\mathbf{T m}$ & 0.335 & 1.23 & 0.698 & 0.613 & 0.596 & 0.582 \\
\hline Yb & 1.74 & 7.71 & 3.40 & 3.76 & 4.82 & 2.62 \\
\hline $\mathbf{L u}$ & 0.286 & 1.20 & 0.740 & 0.446 & 0.656 & 0.514 \\
\hline Hf & 1.24 & 5.88 & 5.36 & 2.25 & 2.86 & 3.39 \\
\hline $\mathbf{T a}$ & 0.072 & 0.535 & 0.275 & 0.292 & 0.207 & 0.132 \\
\hline $\mathbf{P b}$ & 3.51 & 1.96 & 1.57 & 1.71 & 1.64 & 1.55 \\
\hline
\end{tabular}

*Where EMPA analyses were invalid, data from a similar crystal (on the basis of texture and backscatter intensity) were substituted. 
Table A3.4 Trace element concentrations in amphibole crystals analysed by LA-ICP-MS. Abbreviations same as Table A3.2.

\begin{tabular}{|c|c|c|c|}
\hline Sample & Korito & Korito & Korito \\
\hline ID & A12C & A14A & A14D \\
\hline zone & core & rim & core \\
\hline EMPA ID & A12_4 & A14_1 & A14_5 \\
\hline $\mathrm{CaO}$ & 11.91 & 11.47 & 11.81 \\
\hline Mg\# & 75.02 & 79.09 & 77.28 \\
\hline $\operatorname{Mn}(w t \%)$ & 0.264 & 0.462 & 0.254 \\
\hline $\mathbf{L i}$ & 4.10 & 4.27 & 4.70 \\
\hline Sc & 53.3 & 51.7 & 55.3 \\
\hline $\mathbf{T i}$ & 12093 & 15069 & 12391 \\
\hline $\mathbf{V}$ & 319 & 281 & 343 \\
\hline $\mathrm{Cr}$ & BDL & BDL & BDL \\
\hline $\mathbf{N i}$ & BDL & 4.32 & 3.54 \\
\hline Zn & 109 & 157 & 108 \\
\hline $\mathbf{R b}$ & 2.66 & 2.30 & 2.77 \\
\hline $\mathbf{S r}$ & 315 & 216 & 283 \\
\hline $\mathbf{Y}$ & 37.9 & 101 & 42.9 \\
\hline $\mathbf{Z r}$ & 67.2 & 111 & 62.2 \\
\hline $\mathbf{N b}$ & 3.28 & 9.81 & 2.27 \\
\hline $\mathbf{B a}$ & 237 & 267 & 221 \\
\hline $\mathbf{L a}$ & 4.58 & 12.4 & 4.95 \\
\hline $\mathrm{Ce}$ & 16.8 & 50.3 & 21.3 \\
\hline Pr & 3.58 & 9.81 & 4.24 \\
\hline Nd & 21.8 & 59.1 & 27.9 \\
\hline Sm & 7.65 & 18.9 & 8.66 \\
\hline $\mathbf{E u}$ & 2.29 & 3.85 & 2.83 \\
\hline Gd & 8.23 & 20.4 & 11.9 \\
\hline $\mathbf{T b}$ & 1.09 & 3.14 & 1.46 \\
\hline Dy & 6.75 & 19.1 & 8.74 \\
\hline Нo & 1.48 & 4.01 & 1.88 \\
\hline Er & 3.10 & 10.8 & 4.84 \\
\hline $\mathbf{T m}$ & 0.502 & 1.26 & 0.470 \\
\hline $\mathbf{Y b}$ & 3.34 & 8.17 & 2.34 \\
\hline $\mathbf{L u}$ & 0.607 & 1.05 & 0.420 \\
\hline Hf & 3.93 & 6.33 & 3.23 \\
\hline $\mathbf{T a}$ & 0.172 & 0.503 & 0.138 \\
\hline $\mathbf{P b}$ & 0.72 & 1.77 & 1.15 \\
\hline
\end{tabular}

*Where EMPA analyses were invalid, data from a similar crystal (on the basis of texture and backscatter intensity) were substituted. 


\section{APPENDIX 4: \\ DIFFUSION MODELLING IMAGES AND PROFILES}

Table A4.1 Diffusion ages calculated for each zone in this study

A compilation of the BSE images used for modelling and the profile that was modelled 
Table A4.1 Diffusion ages calculated for each zone used in this study. Errors are based on $\pm 40^{\circ} \mathrm{C}$ error.

\begin{tabular}{|c|c|c|c|}
\hline Kaupokonui & Age & Minimum & Maximum \\
\hline \multicolumn{4}{|l|}{ Rims } \\
\hline $\operatorname{cpx} 2 \mathrm{a} 3$ & 0.30 & 0.08 & 1.20 \\
\hline cpx5a1 & 0.39 & 0.11 & 1.55 \\
\hline cpx17a1 & 0.34 & 0.09 & 1.36 \\
\hline $\operatorname{cpx} 23 \mathrm{a} 1$ & 0.24 & 0.07 & 0.96 \\
\hline сpх24a1 & 0.38 & 0.10 & 1.50 \\
\hline cpx30a1 & 2.25 & 0.62 & 8.90 \\
\hline cpx31a1 & 1.02 & 0.28 & 4.02 \\
\hline $\operatorname{cpx} 32 \mathrm{a} 2$ & 0.70 & 0.19 & 2.78 \\
\hline cpx40a1 & 0.91 & 0.25 & 3.60 \\
\hline \multicolumn{4}{|l|}{ Dark rims } \\
\hline cpx $1 \mathrm{a} 2$ & 0.63 & 0.17 & 2.50 \\
\hline $\operatorname{cpx} 11 \mathrm{a} 2$ & 0.25 & 0.07 & 1.00 \\
\hline $\operatorname{cpx} 21 \mathrm{a} 2$ & 0.71 & 0.20 & 2.81 \\
\hline срх26a1 & 0.22 & 0.06 & 0.86 \\
\hline $\operatorname{cpx} 33 \mathrm{a} 8$ & 0.60 & 0.17 & 2.38 \\
\hline $\operatorname{cpx} 35 \mathrm{a} 2$ & 0.42 & 0.11 & 1.64 \\
\hline cpx46a1 & 0.22 & 0.06 & 0.86 \\
\hline \multicolumn{4}{|c|}{ Outer oscillatory zones } \\
\hline cpx6a1 & 0.12 & 0.03 & 0.49 \\
\hline cpx7a3 & 0.43 & 0.12 & 1.71 \\
\hline $\operatorname{cpx} 21 \mathrm{a} 5$ & 1.40 & 0.39 & 5.53 \\
\hline $\operatorname{cp} \times 22 \mathrm{a} 3$ & 0.17 & 0.05 & 0.69 \\
\hline $\operatorname{cpx} 24 \mathrm{a} 2$ & 0.48 & 0.13 & 1.91 \\
\hline $\mathrm{cpx} 47 \mathrm{a} 1$ & 0.62 & 0.17 & 2.46 \\
\hline $\operatorname{cpx} 52 \mathrm{a} 1$ & 0.52 & 0.14 & 2.06 \\
\hline $\operatorname{cpx} 52 \mathrm{a} 2$ & 0.14 & 0.04 & 0.53 \\
\hline cpx60a1 & 0.25 & 0.07 & 0.98 \\
\hline cpx61a1 & 0.51 & 0.14 & 2.03 \\
\hline \multicolumn{4}{|c|}{ Inner oscillatory zones } \\
\hline cpx10b1 & 0.15 & 0.04 & 0.60 \\
\hline cpx10b3 & 0.58 & 0.16 & 2.30 \\
\hline cpx10b4 & 1.02 & 0.28 & 4.02 \\
\hline cpx24a5 & 0.38 & 0.11 & 1.51 \\
\hline $\operatorname{cpx} 31 \mathrm{a} 3$ & 2.23 & 0.62 & 8.81 \\
\hline cpx36a1 & 1.30 & 0.36 & 5.14 \\
\hline cpx43a2 & 0.62 & 0.17 & 2.47 \\
\hline $\operatorname{cpx} 47 \mathrm{a} 5$ & 0.30 & 0.08 & 1.17 \\
\hline cpx51a2 & 0.57 & 0.16 & 2.27 \\
\hline cpx51a4 & 0.52 & 0.14 & 2.04 \\
\hline cpx 55a4 & 0.58 & 0.16 & 2.31 \\
\hline
\end{tabular}


Table A4.1 Diffusion ages calculated for each zone used in this study. Errors are based on $\pm 40^{\circ} \mathrm{C}$ error.

\begin{tabular}{|c|c|c|c|}
\hline Maketawa & Age & Minimum & Maximum \\
\hline \multicolumn{4}{|l|}{$\overline{\text { Rims }}$} \\
\hline сpx6a1 & 0.45 & 0.11 & 2.05 \\
\hline cpx9b2 & 0.53 & 0.13 & 2.44 \\
\hline cpx14b1 & 1.67 & 0.41 & 7.63 \\
\hline cpx $23 b 1$ & 0.38 & 0.09 & 1.74 \\
\hline cpx26a1 & 1.16 & 0.28 & 5.28 \\
\hline cpx32b1 & 0.74 & 0.18 & 3.37 \\
\hline cpx50a1 & 0.73 & 0.18 & 3.33 \\
\hline $\operatorname{cpx} 51 \mathrm{a} 2$ & 0.53 & 0.13 & 2.40 \\
\hline cpx71b1 & 0.30 & 0.07 & 1.36 \\
\hline \multicolumn{4}{|c|}{ Inner zones } \\
\hline срх6а2 & 0.58 & 0.14 & 2.65 \\
\hline cpx $14 b 2$ & 4.50 & 1.09 & 20.57 \\
\hline cpx $25 b 1$ & 1.22 & 0.30 & 5.57 \\
\hline cpx35b1 & 1.81 & 0.44 & 8.28 \\
\hline cpx46a1 & 1.64 & 0.40 & 7.51 \\
\hline cpx51a1 & 1.71 & 0.42 & 7.81 \\
\hline \multicolumn{4}{|l|}{ Cores } \\
\hline cpx14b3 & 2.84 & 0.69 & 12.96 \\
\hline $\mathrm{cp} \times 32 \mathrm{~b} 2$ & 3.60 & 0.88 & 16.47 \\
\hline cpx $35 b 2$ & 7.55 & 1.83 & 34.51 \\
\hline cpx65a1 & 0.87 & 0.21 & 3.99 \\
\hline
\end{tabular}


Table A4.1 Diffusion ages calculated for each zone used in this study. Errors are based on $\pm 40^{\circ} \mathrm{C}$ error.

\begin{tabular}{lrrr}
\hline Inglewood $b$ & Age & Minimum & Maximum \\
\hline Rims & & & \\
cpx8a2 & 2.91 & 0.64 & 14.75 \\
cpx24b1 & 3.93 & 0.87 & 19.95 \\
cpx29b2 & 1.62 & 0.36 & 8.21 \\
\hline Outer oscillatory zones & & \\
cpx2a1 & 1.45 & 0.32 & 7.33 \\
cpx7b1 & 2.20 & 0.49 & 11.17 \\
cpx9b2 & 3.96 & 0.88 & 20.09 \\
cpx10a5 & 1.74 & 0.39 & 8.84 \\
cpx12b2 & 2.41 & 0.53 & 12.23 \\
cpx13b2 & 2.57 & 0.57 & 13.05 \\
cpx15b2 & 2.18 & 0.48 & 11.06 \\
cpx21a1 & 3.15 & 0.70 & 16.00 \\
cpx24b2 & 3.34 & 0.74 & 16.96 \\
cpx25a1 & 2.32 & 0.51 & 11.77 \\
cpx28b2 & 1.71 & 0.38 & 8.68 \\
cpx34a1 & 1.60 & 0.35 & 8.12 \\
cpx39a1 & 1.83 & 0.40 & 9.29 \\
\hline Inner oscillatory zones & & \\
cpx2a3 & 1.86 & 0.41 & 9.42 \\
cpx8a3 & 11.90 & 2.63 & 60.38 \\
\hline cpx9b3 & 5.18 & 1.15 & 26.29 \\
cpx9b4 & 14.94 & 3.30 & 75.79 \\
cpx10a9 & 2.04 & 0.45 & 10.36 \\
cpx11a1 & 2.83 & 0.63 & 14.34 \\
cpx15b3 & 2.70 & 0.60 & 13.68 \\
cpx21a2 & 7.76 & 1.72 & 39.39 \\
cpx28b3 & 7.05 & 1.56 & 35.75 \\
cpx29b3 & 8.12 & 1.79 & 41.18 \\
cpx33a1 & 2.06 & 0.46 & 10.46 \\
\hline
\end{tabular}


Table A4.1 Diffusion ages calculated for each zone used in this study. Errors are based on $\pm 40^{\circ} \mathrm{C}$ error.

\begin{tabular}{|c|c|c|c|}
\hline Inglewood a & Age & Minimum & Maximum \\
\hline \multicolumn{4}{|l|}{ Rims } \\
\hline cpx 1b3 & 3.42 & 0.79 & 16.40 \\
\hline cpx $5 \mathrm{a} 2$ & 0.68 & 0.16 & 3.25 \\
\hline cpx30b1 & 3.87 & 0.90 & 18.56 \\
\hline cpx39a1 & 1.37 & 0.32 & 6.55 \\
\hline $\mathrm{cpx} 44 \mathrm{a} 1$ & 2.18 & 0.50 & 10.45 \\
\hline cpx 54a1 & 3.93 & 0.91 & 18.86 \\
\hline \multicolumn{4}{|l|}{ Minor zones } \\
\hline cpx5a4 & 0.76 & 0.18 & 3.65 \\
\hline cpx31a3 & 1.62 & 0.38 & 7.78 \\
\hline cpx33b1 & 0.64 & 0.15 & 3.05 \\
\hline cpx58a1 & 1.09 & 0.25 & 5.22 \\
\hline \multicolumn{4}{|c|}{ Second zone from rim } \\
\hline cpx33b2 & 1.43 & 0.33 & 6.85 \\
\hline cpx48a2 & 1.94 & 0.45 & 9.30 \\
\hline cpx56b1 & 1.43 & 0.33 & 6.87 \\
\hline cpx66a1 & 1.93 & 0.45 & 9.29 \\
\hline cpx69b1 & 2.82 & 0.65 & 13.55 \\
\hline \multicolumn{4}{|l|}{ Inner zones } \\
\hline $\operatorname{cpx} 21 \mathrm{a} 1$ & 2.74 & 0.64 & 13.17 \\
\hline cpx30b2 & 2.14 & 0.50 & 10.26 \\
\hline cpx31a4 & 2.17 & 0.50 & 10.42 \\
\hline cpx35b1 & 2.79 & 0.65 & 13.40 \\
\hline cpx63c2 & 3.37 & 0.78 & 16.18 \\
\hline cpx $68 \mathrm{~b} 2$ & 5.90 & 1.37 & 28.32 \\
\hline cpx73a2 & 3.55 & 0.82 & 17.07 \\
\hline cpx74a1 & 3.01 & 0.70 & 14.45 \\
\hline cpx111a1 & 3.03 & 0.70 & 14.55 \\
\hline cpx112a2 & 3.07 & 0.71 & 14.74 \\
\hline
\end{tabular}


Table A4.1 Diffusion ages calculated for each zone used in this study. Errors are based on $\pm 40^{\circ} \mathrm{C}$ error.

\begin{tabular}{lcrr}
\hline Korito & Age & Minimum & Maximum \\
\hline Rims & & & \\
cpx4b3 & 0.82 & 0.20 & 3.70 \\
cpx12a1 & 0.37 & 0.09 & 1.70 \\
cpx18b1 & 0.66 & 0.16 & 2.98 \\
cpx19a1 & 0.61 & 0.15 & 2.77 \\
cpx28b1 & 1.21 & 0.29 & 5.46 \\
cpx30a1b & 0.60 & 0.15 & 2.72 \\
cpx38b1 & 0.46 & 0.11 & 2.07 \\
cpx39b1 & 1.10 & 0.27 & 4.97 \\
cpx44a1 & 2.46 & 0.60 & 11.15 \\
cpx46a1 & 0.57 & 0.14 & 2.60 \\
\hline Second zone from rim & & \\
cpx8a1 & 3.66 & 0.89 & 16.61 \\
cpx14a1 & 2.75 & 0.67 & 12.46 \\
cpx18b4 & 8.87 & 2.16 & 40.20 \\
cpx34a1b & 5.20 & 1.27 & 23.55 \\
\hline Third zone from rim & & \\
cpx7b1 & 0.79 & 0.19 & 3.58 \\
cpx9a1 & 0.36 & 0.09 & 1.65 \\
cpx17a2b & 0.95 & 0.23 & 4.31 \\
cpx18b3 & 3.00 & 0.73 & 13.61 \\
cpx19a4 & 2.04 & 0.50 & 9.26 \\
cpx20b1 & 0.85 & 0.21 & 3.87 \\
\hline Inner zones & & & \\
cpx10a1 & 2.89 & 0.71 & 13.10 \\
\hline cpx17a6 & 2.96 & 0.72 & 13.43 \\
cpx19a3 & 2.23 & 0.54 & 10.12 \\
cpx20b2 & 3.39 & 0.83 & 15.36 \\
cpx28b3 & 2.23 & 0.54 & 10.10 \\
\hline & 2.50 & 0.61 & 11.33 \\
\hline
\end{tabular}




\section{Kaupokonui-Rims}

cpx2a3
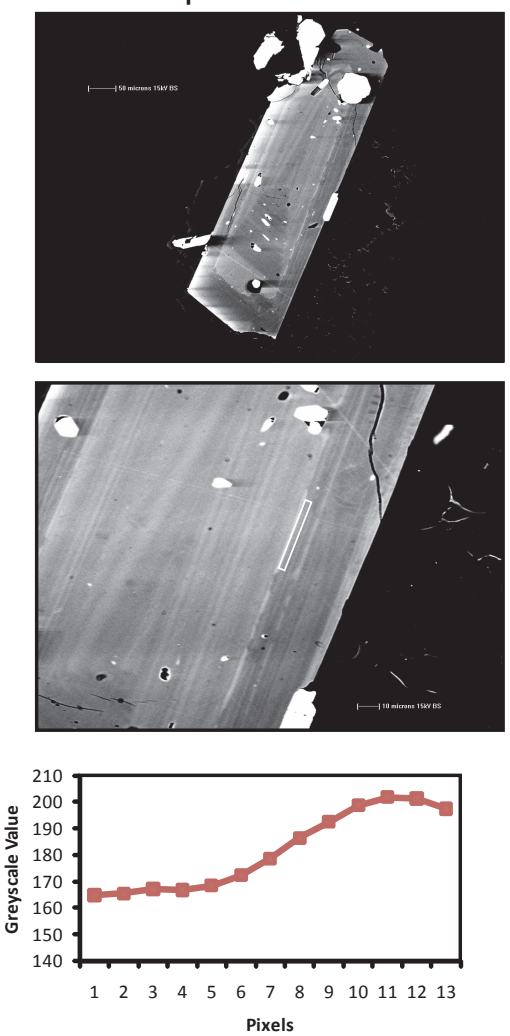

cpx17a1
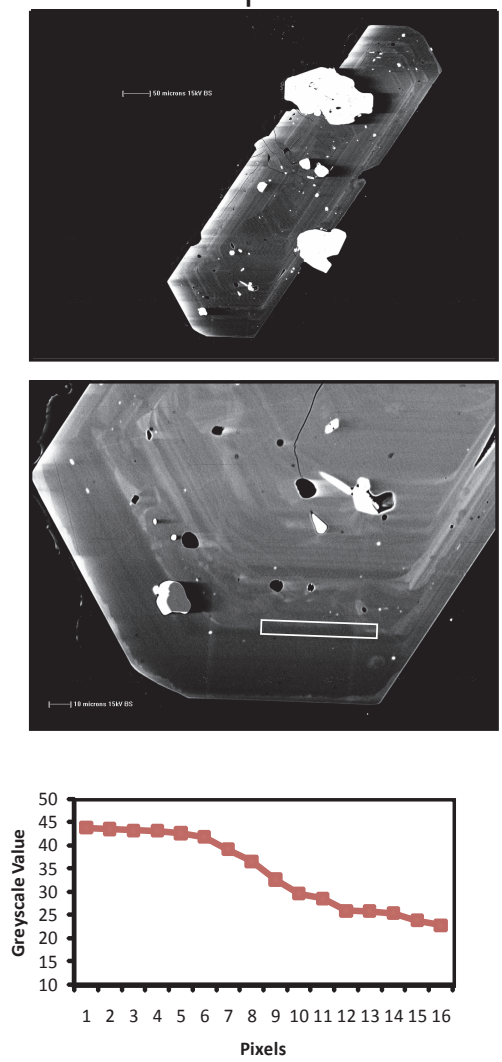

срх5a1
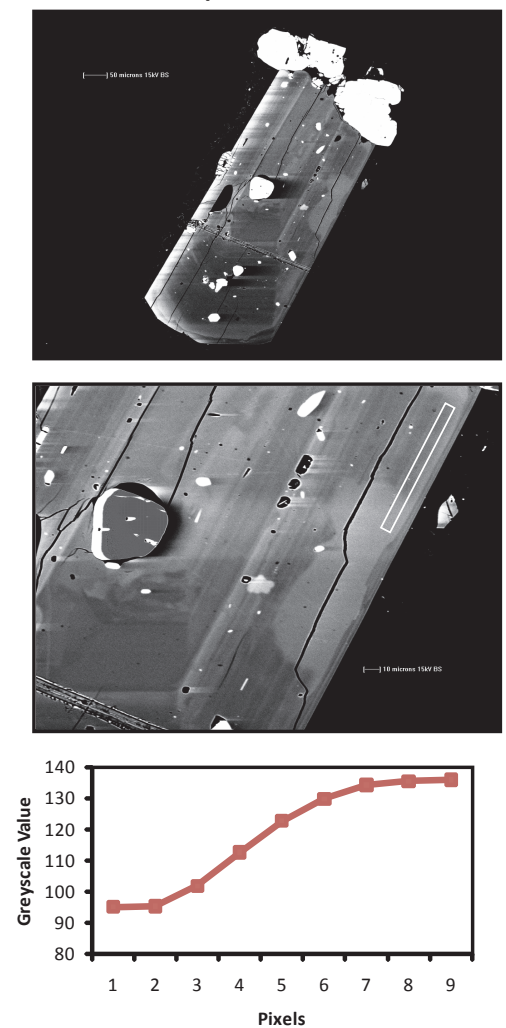

cpx23a1
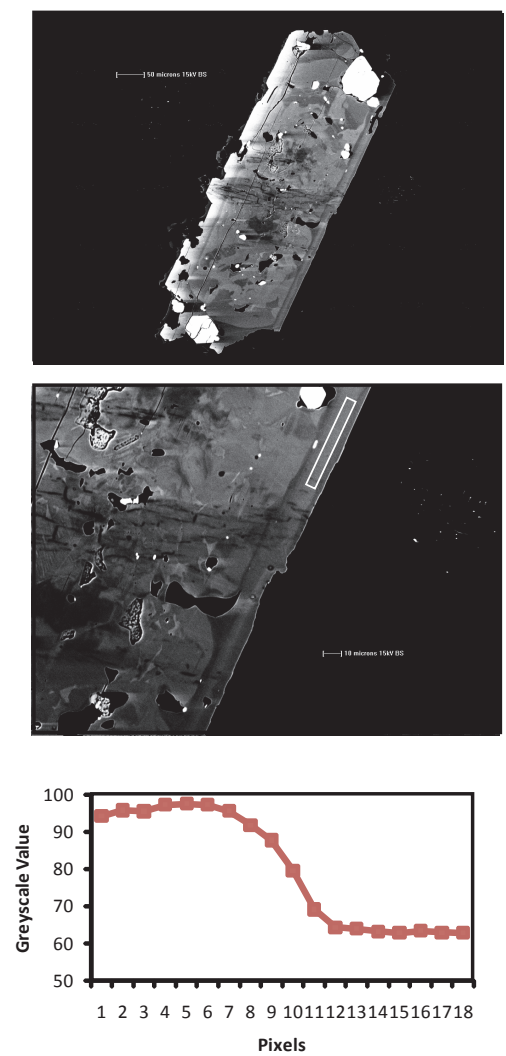


\section{Kaupokonui-Rims}

cpx24a1
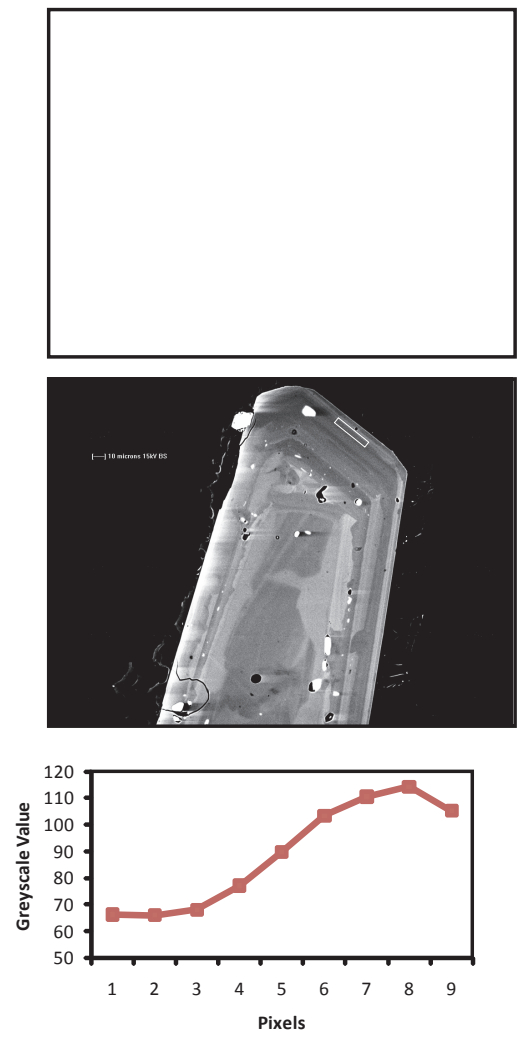

срх31a1
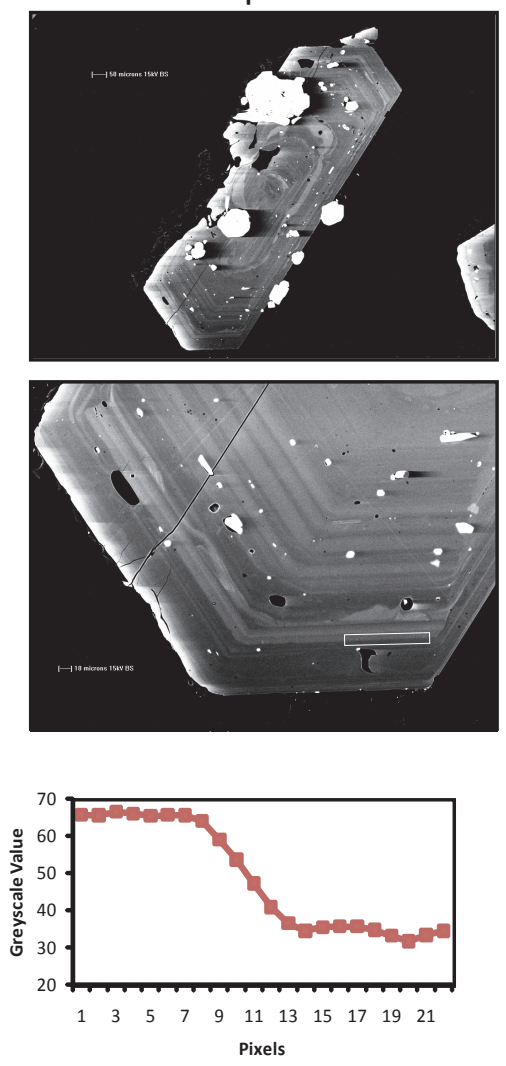

срх30a1
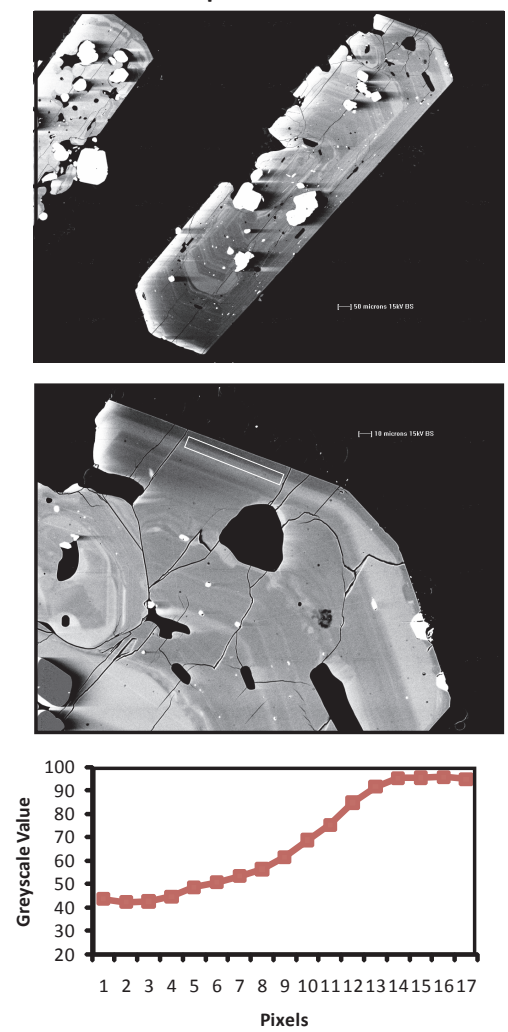

срх32a2
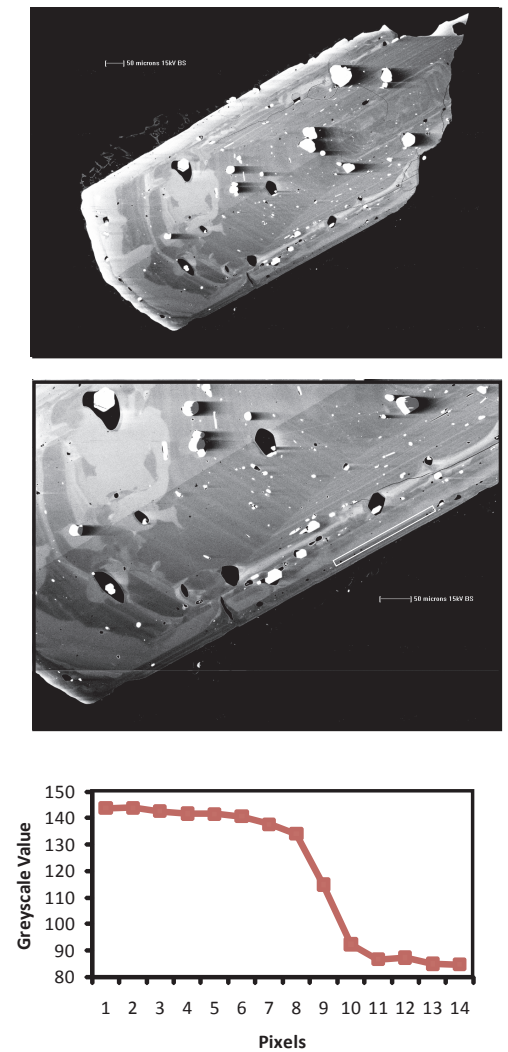
Kaupokonui-Rims

срx40a1
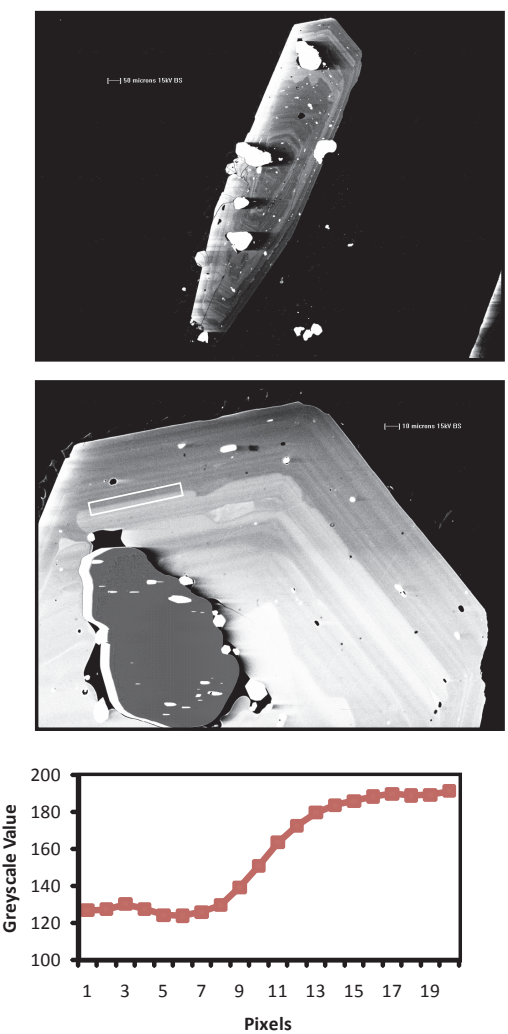

cpx11a2
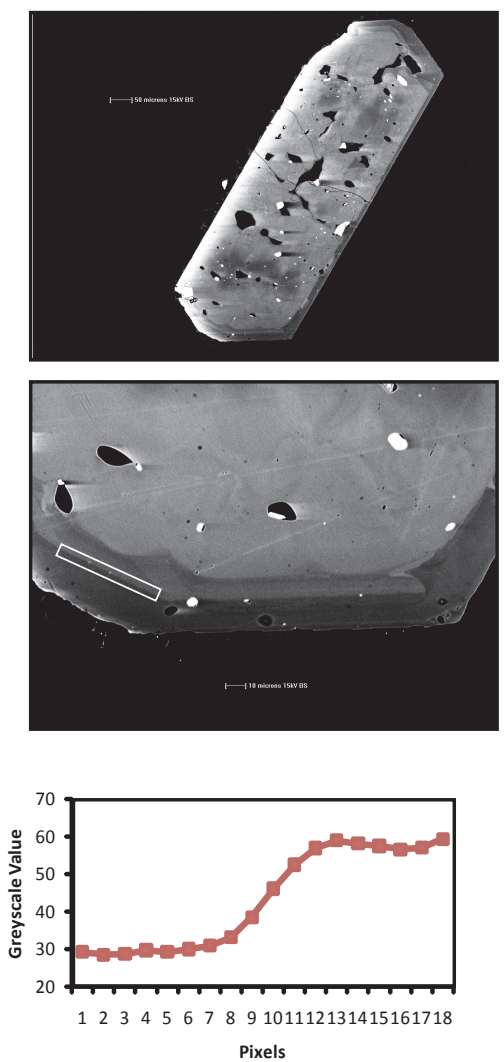

Kaupokonui-Dark rims
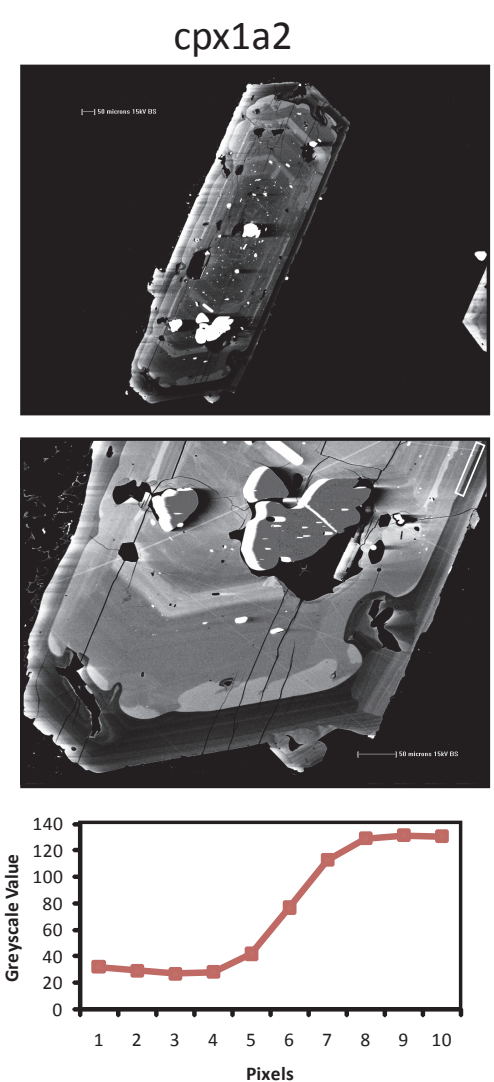

cpx21a2
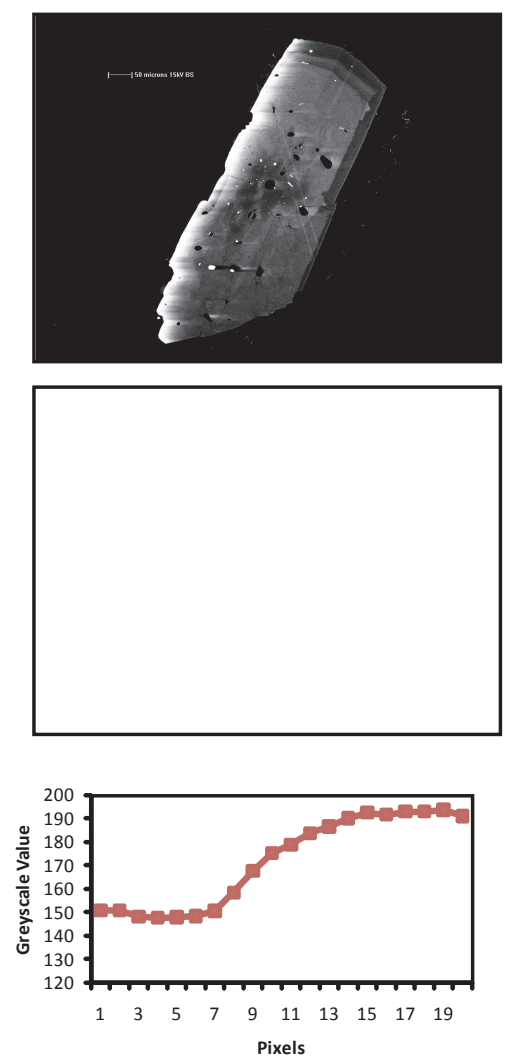


\section{Kaupokonui-Dark rims}

cpx26a1
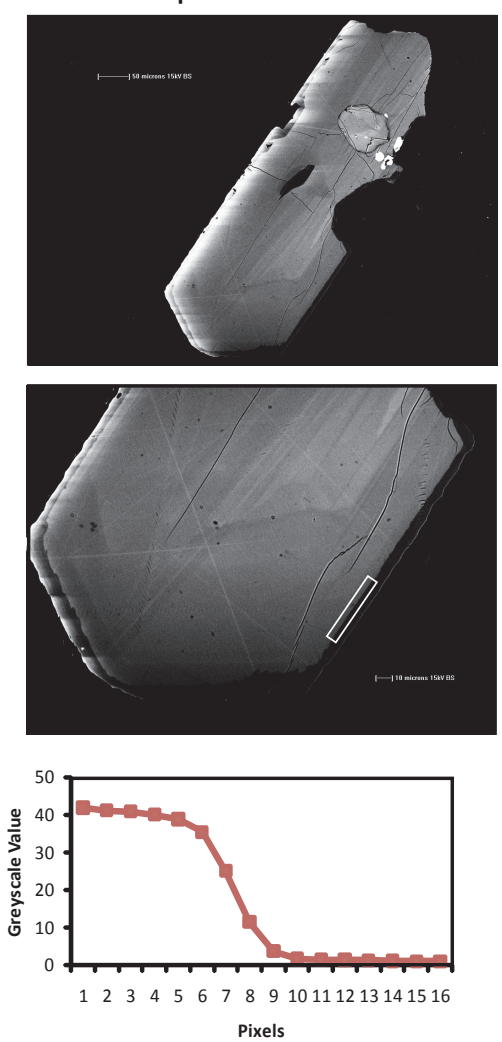

cpx35a2
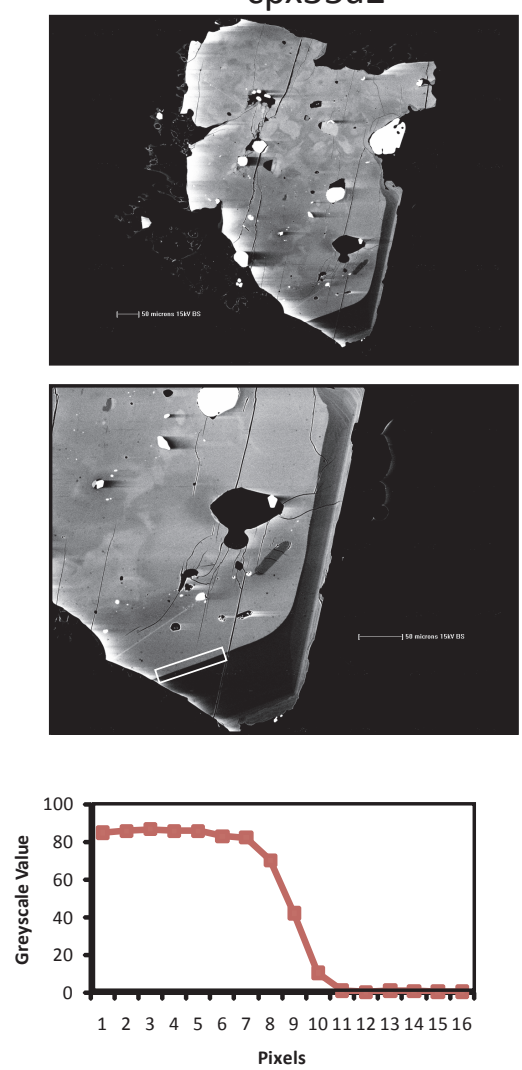

срх33a8
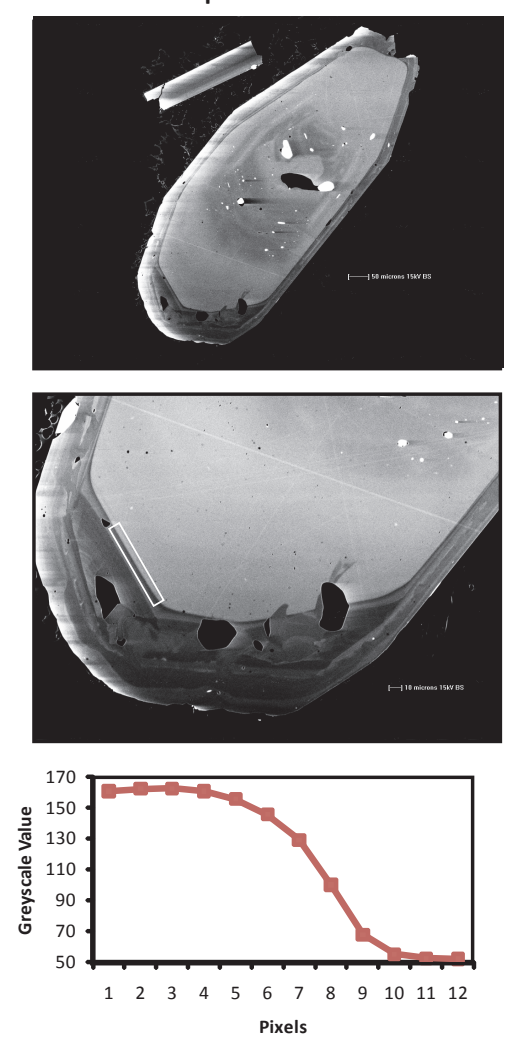

cpx46a1
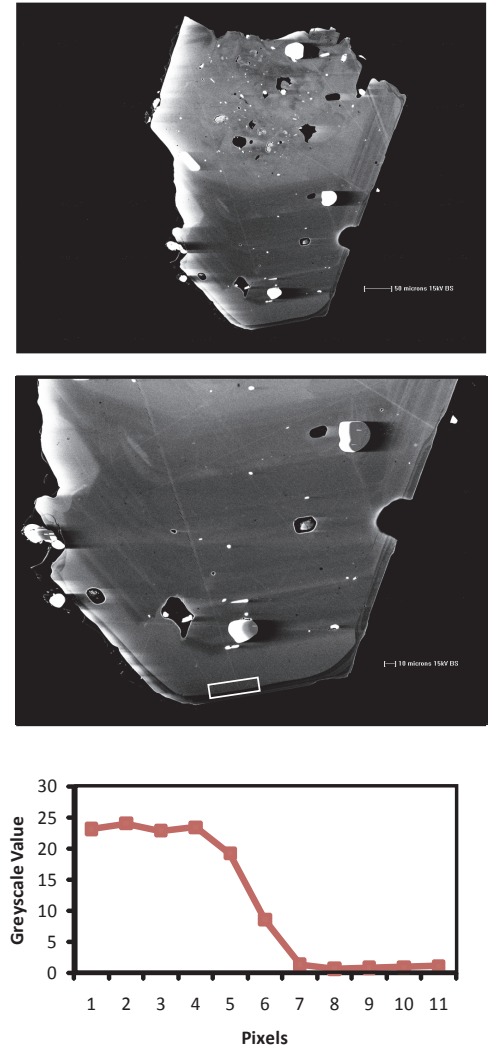


\section{Kaupokonui-Outer oscillatory zones}

срх6а1
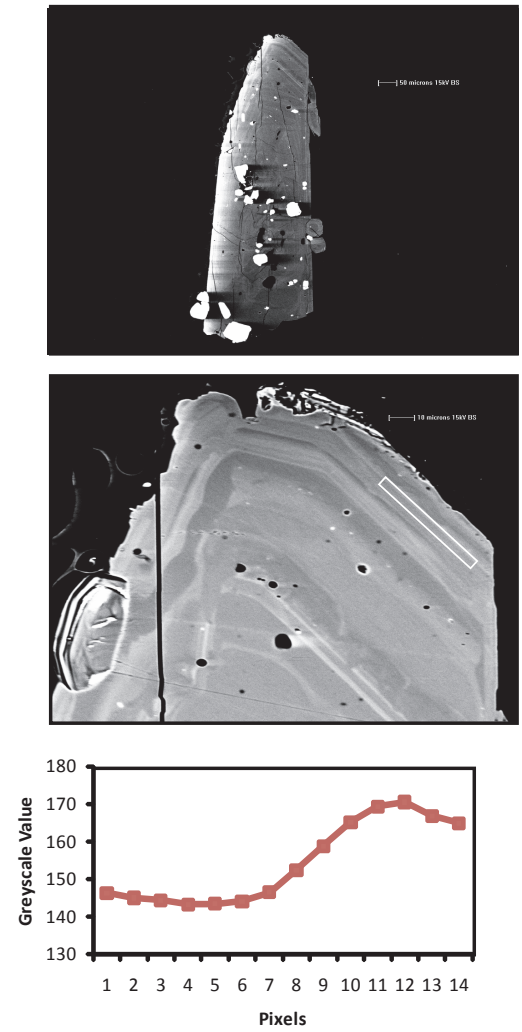

$\mathrm{cpx} 21 \mathrm{a} 5$
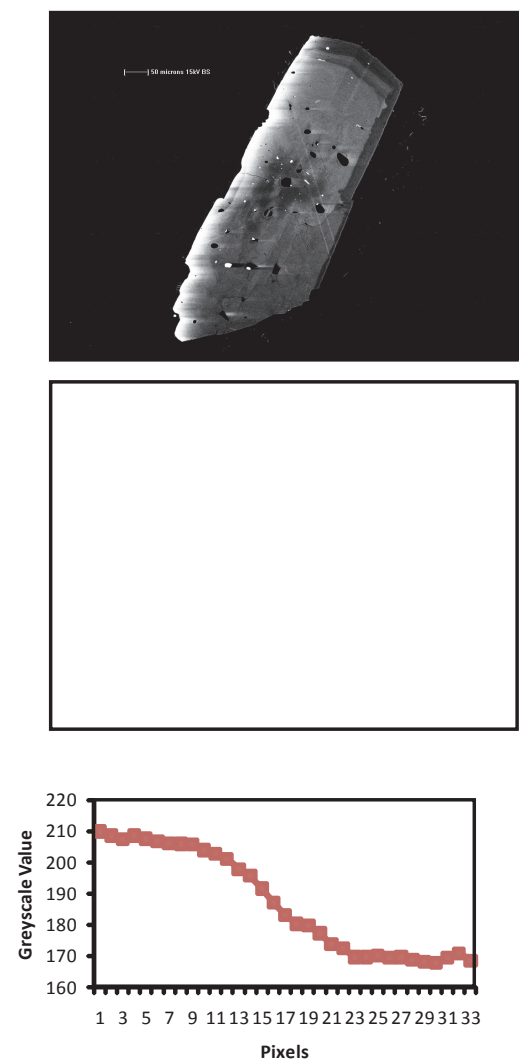

срх7а3
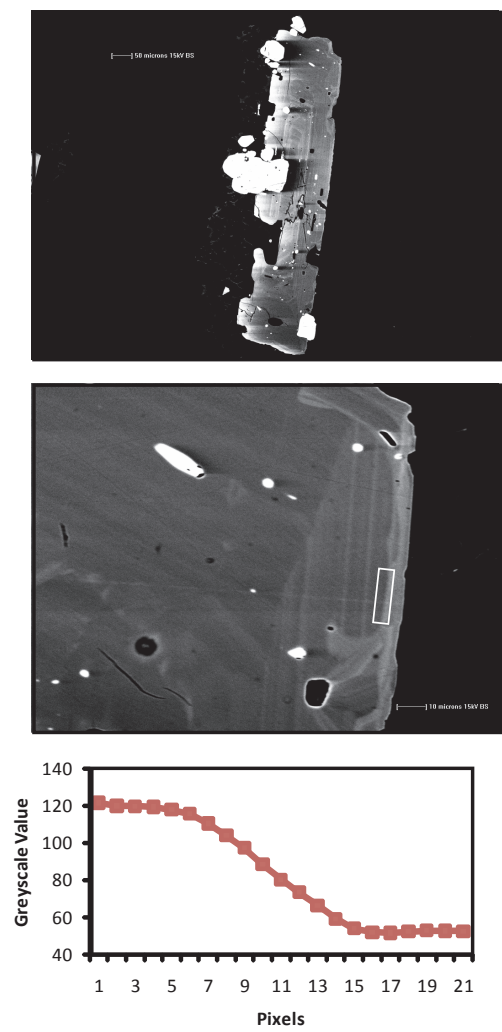

$\mathrm{cp} \times 22 \mathrm{a} 3$
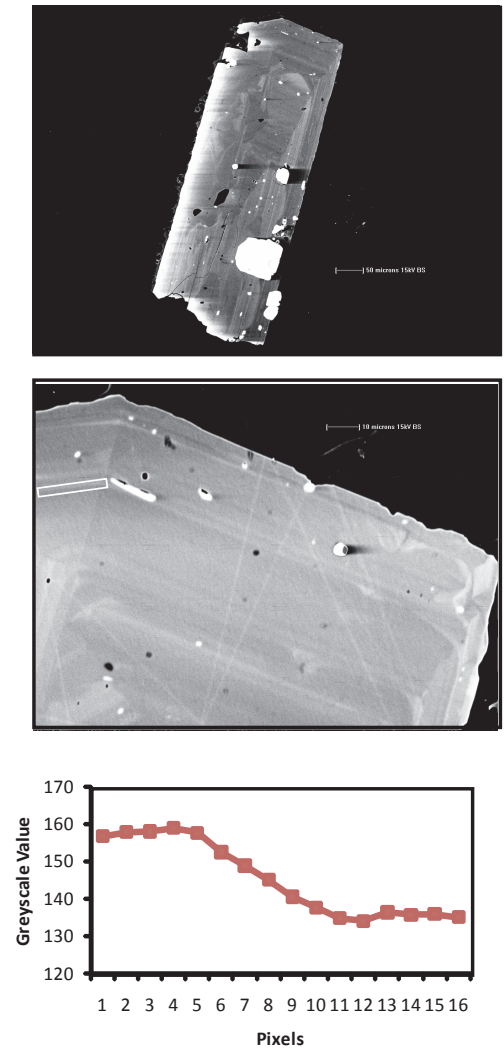


\section{Kaupokonui-Outer oscillatory zones}

cpx24a2
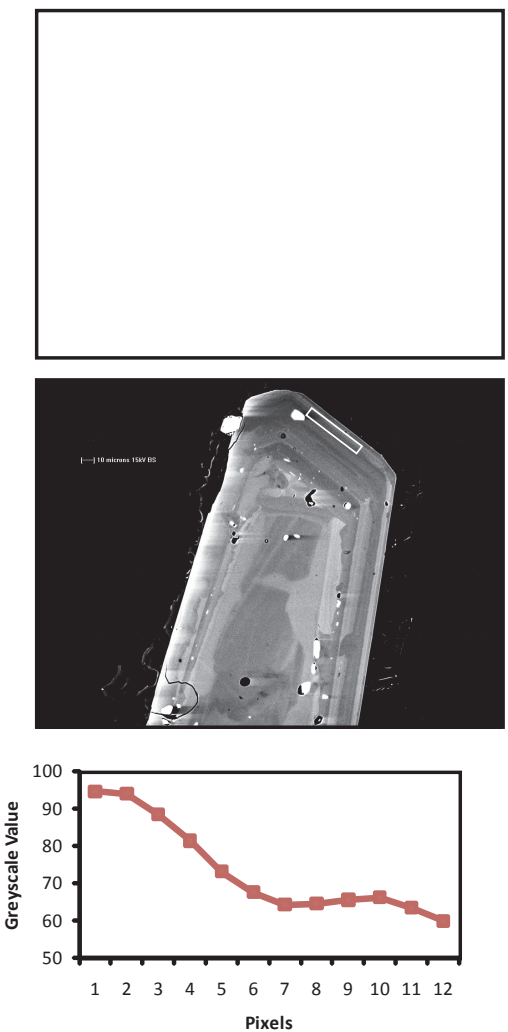

$\operatorname{cp} \times 52 a 1$
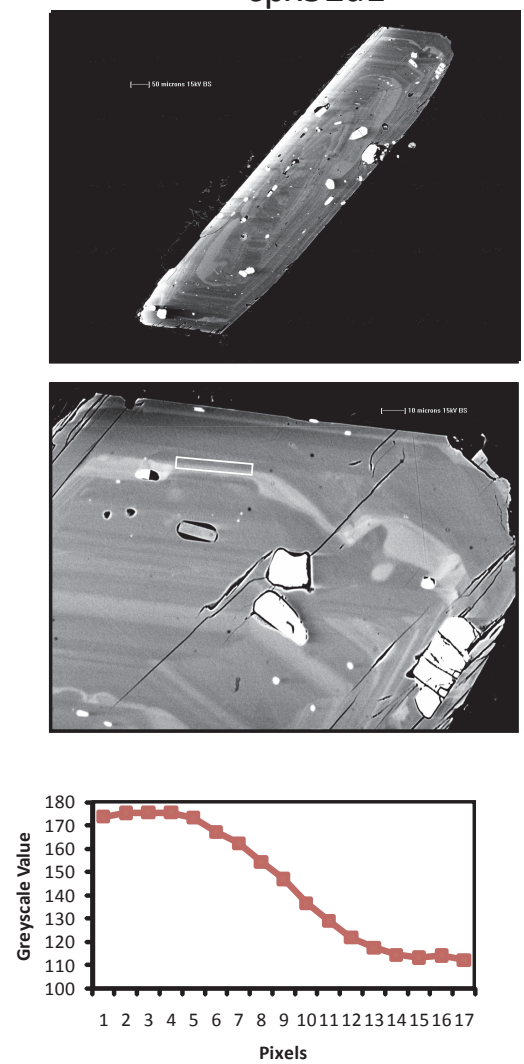

cpx47a1
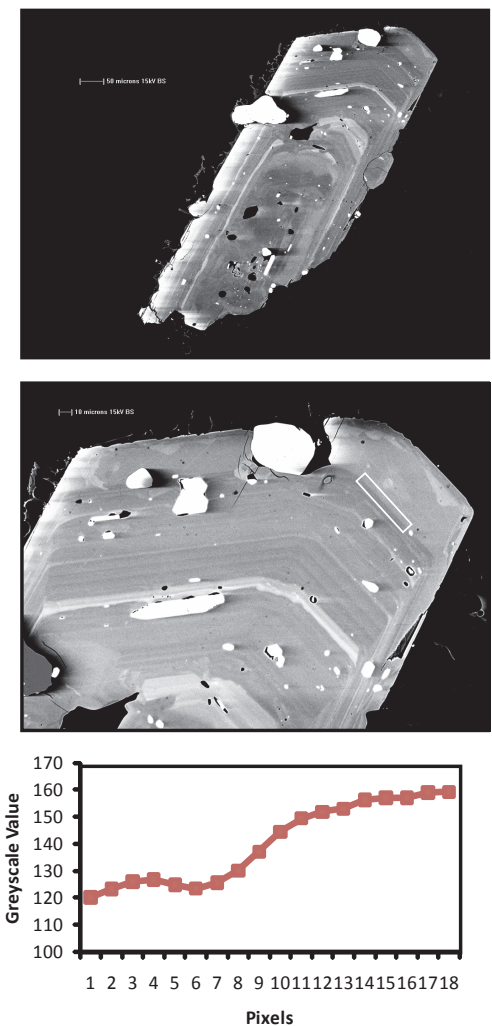

cpx52a2
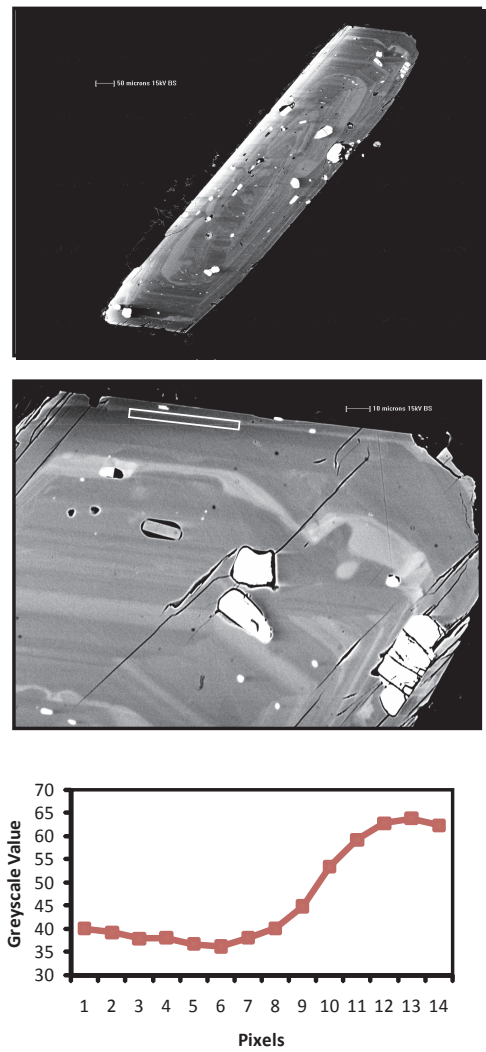


\section{Kaupokonui-Outer oscillatory zones}

cpx60a1
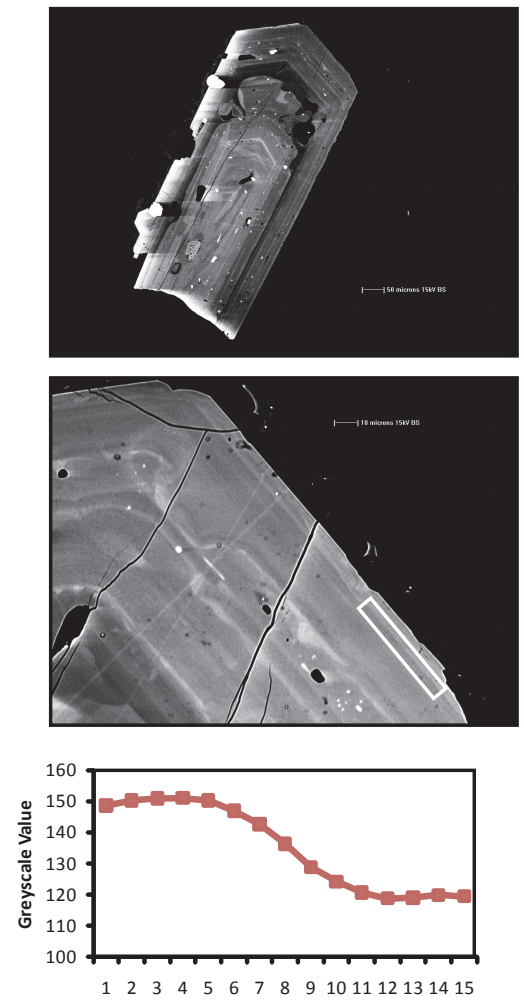

Pixels cpx61a1
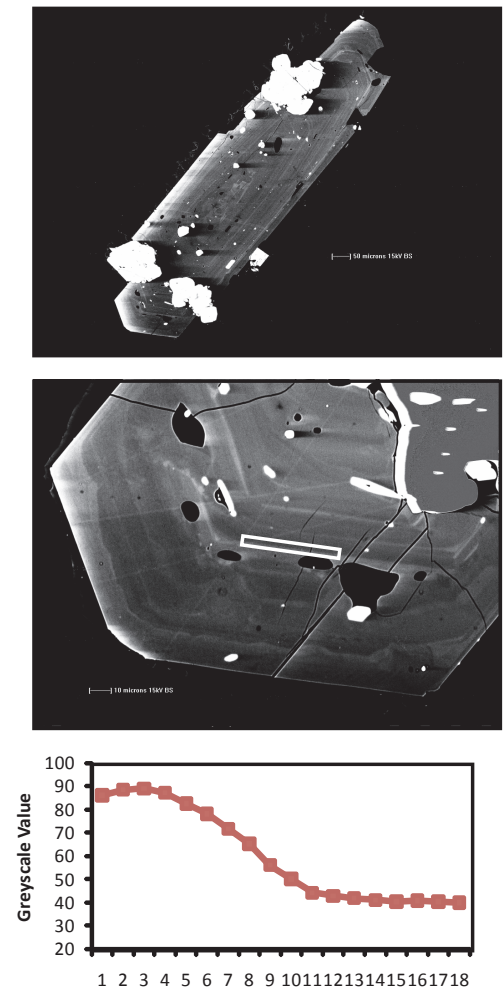

Pixels

Kaupokonui-Inner oscillatory zones

$\mathrm{cpx} 10 \mathrm{~b} 1$
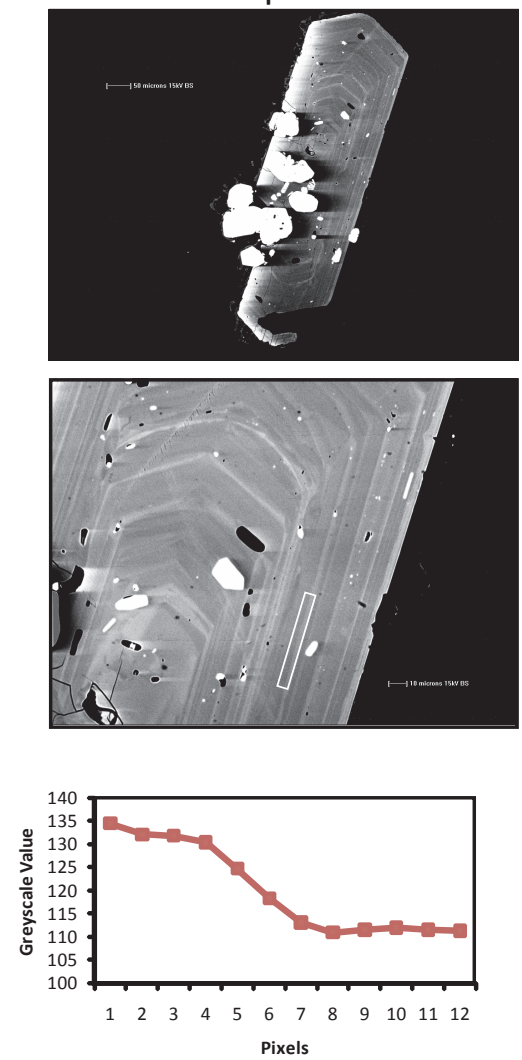

cpx10b3
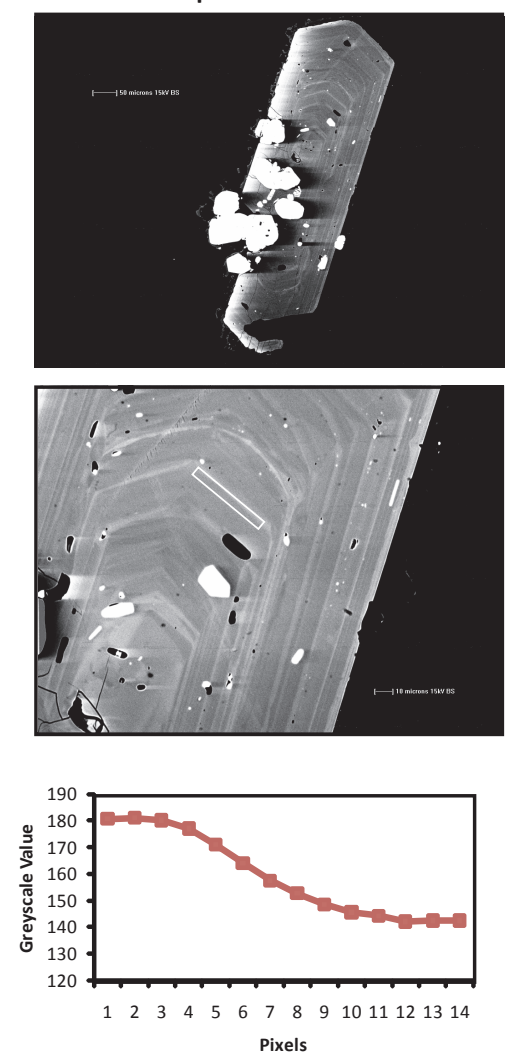


\section{Kaupokonui- Inner oscillatory zones}

cpx10b4
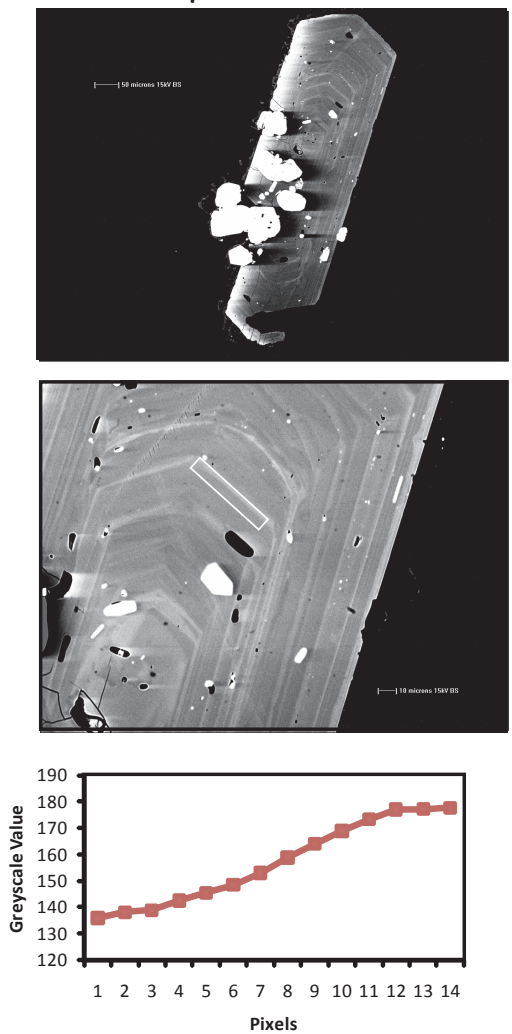

срх31a3
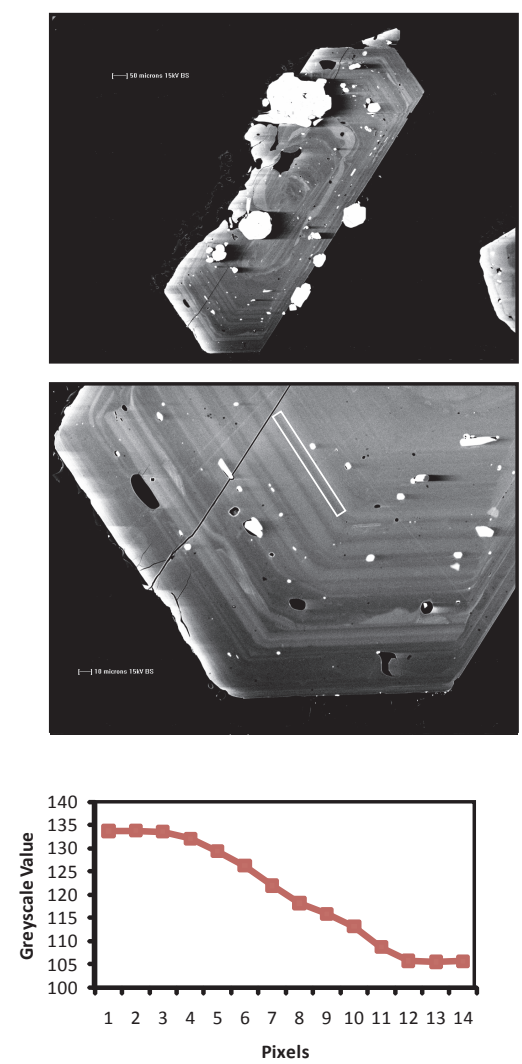

$\mathrm{cp} \times 24 \mathrm{a} 5$
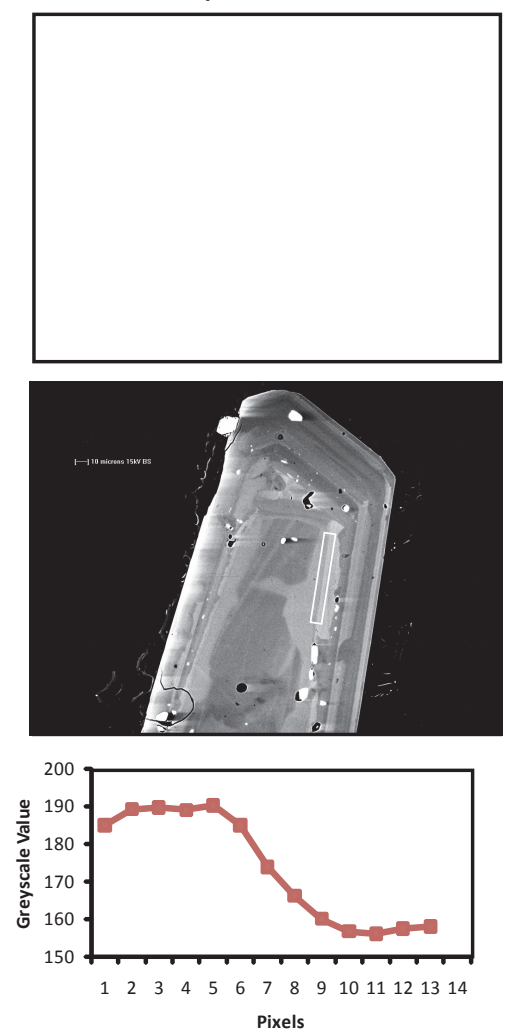

срх36а1
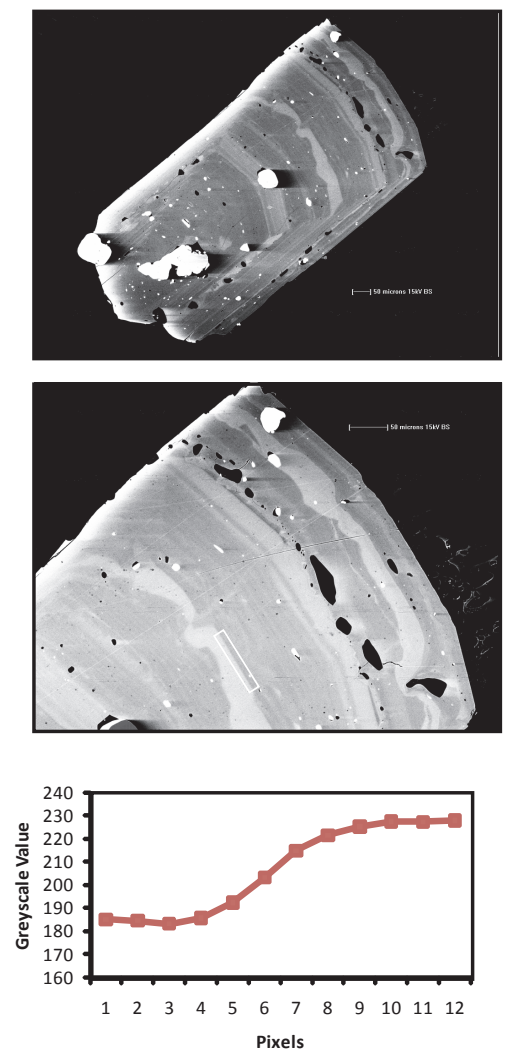


\section{Kaupokonui- Inner oscillatory zones}

$\operatorname{cpx} 43 \mathrm{a} 2$
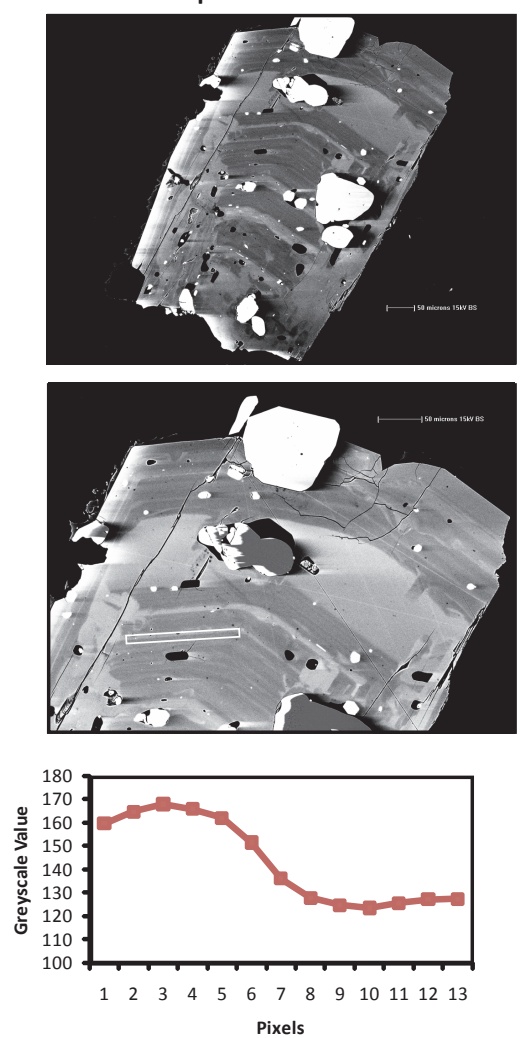

cpx51a2
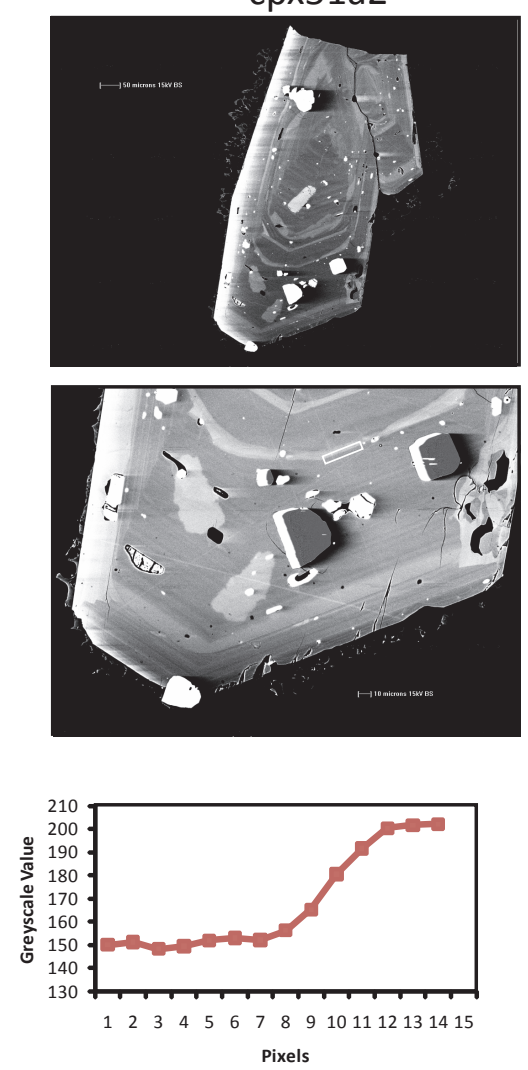

cpx47a5
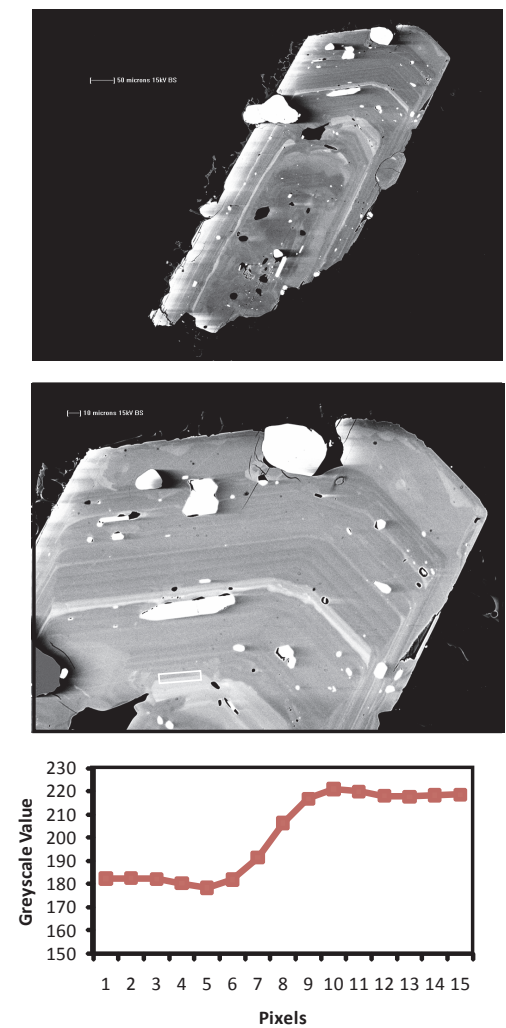

cpx51a4
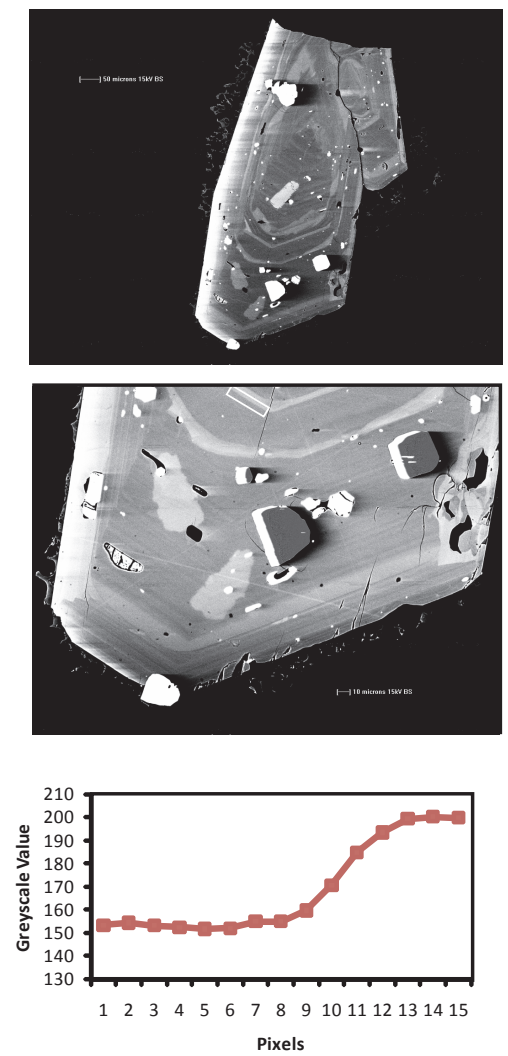
Kaupokonui- Inner oscillatory zones

cpx55a4
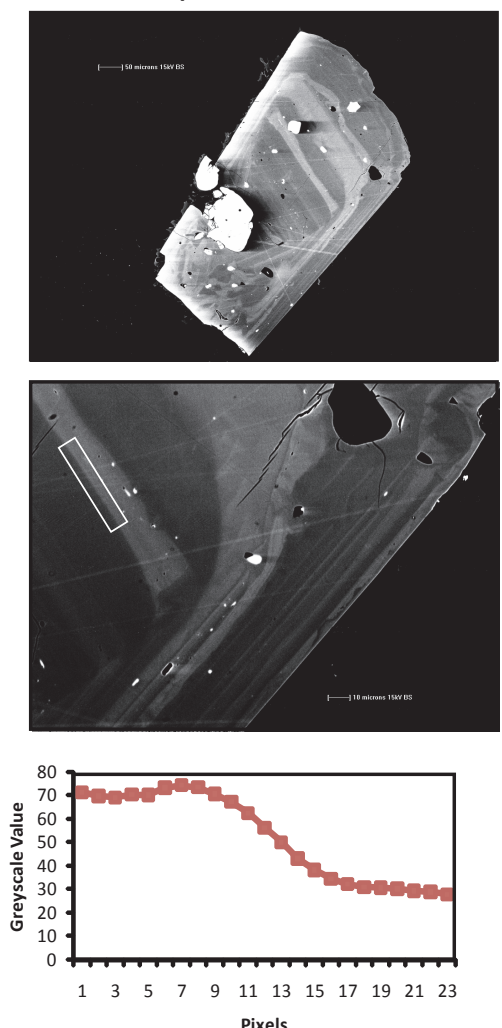

Maketawa-Rims

cpx6a1
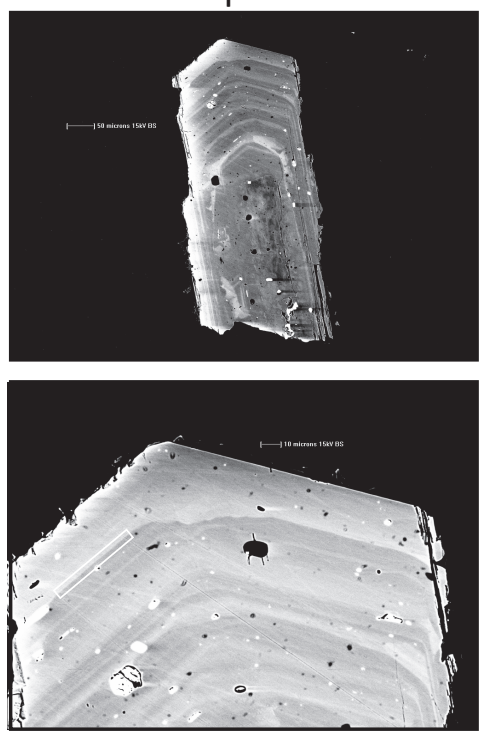

$\mathrm{cpx} 9 \mathrm{~b} 2$
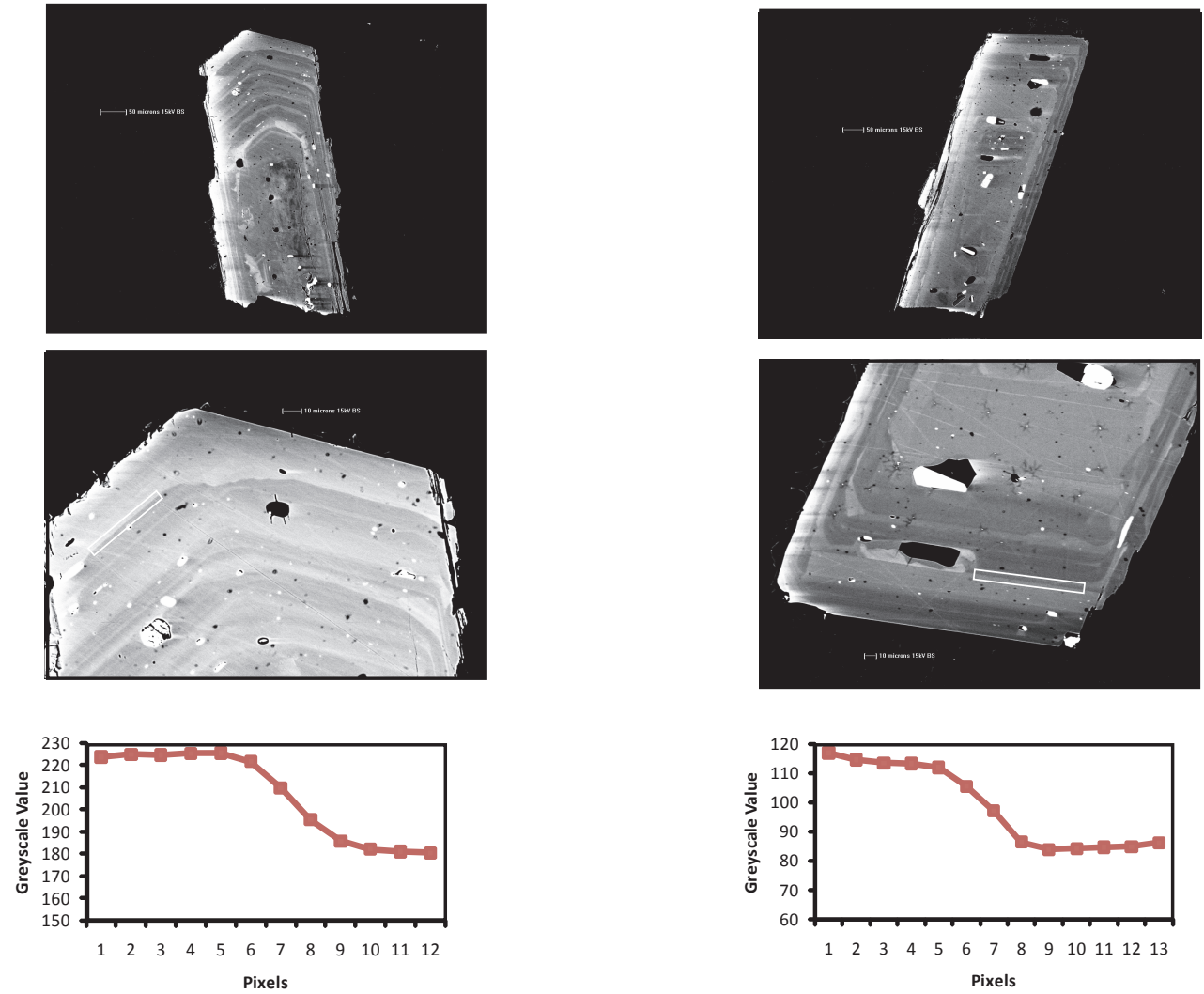


\section{Maketawa-Rims}

cpx14b1
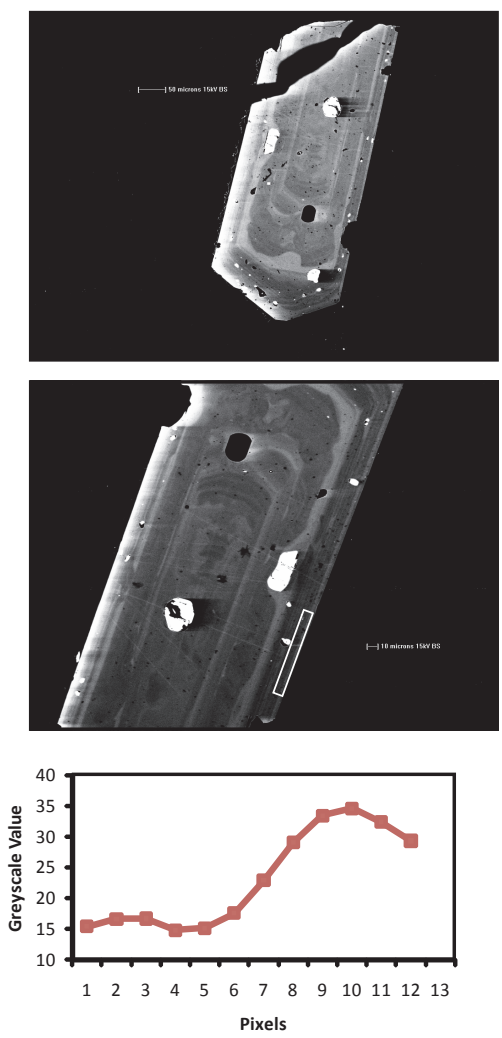

cpx26a1
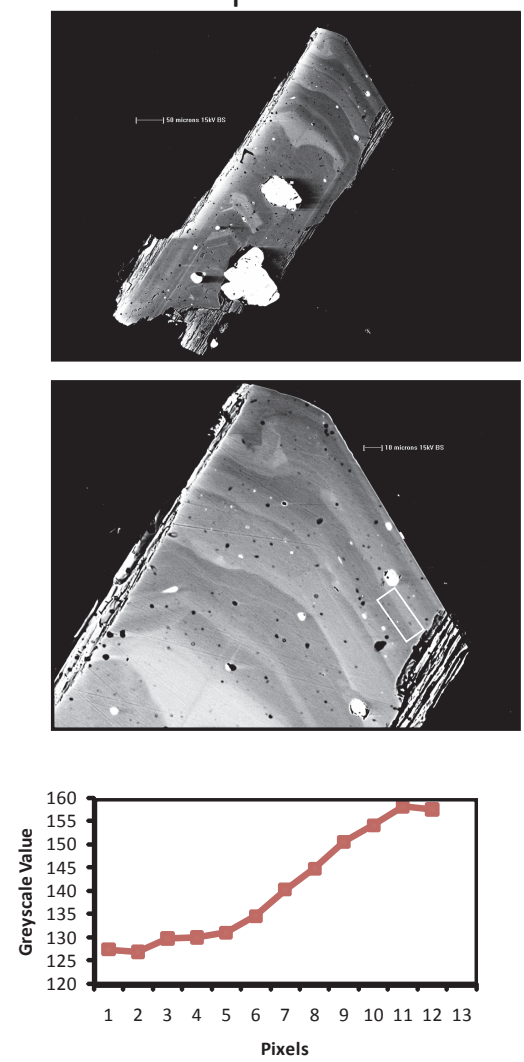

cpx23b1
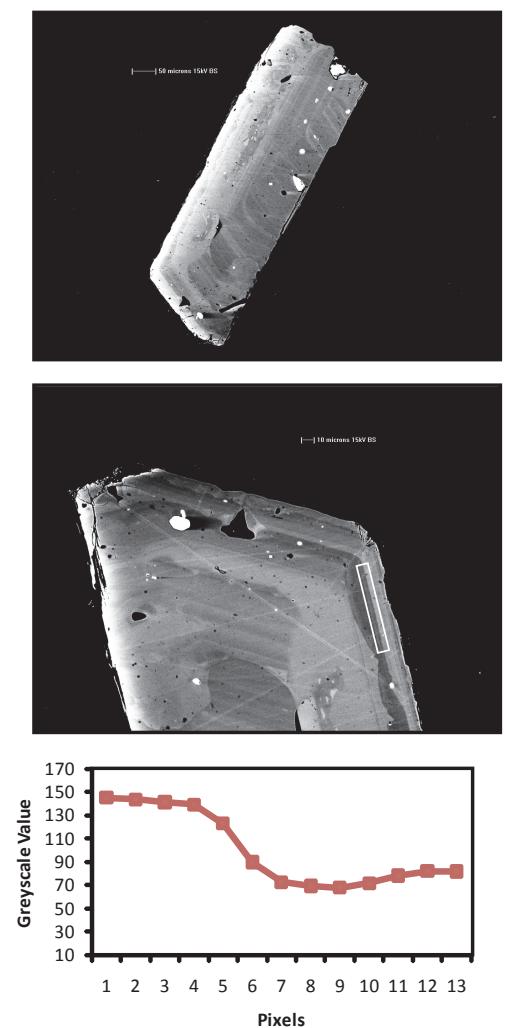

$c p \times 32 b 1$
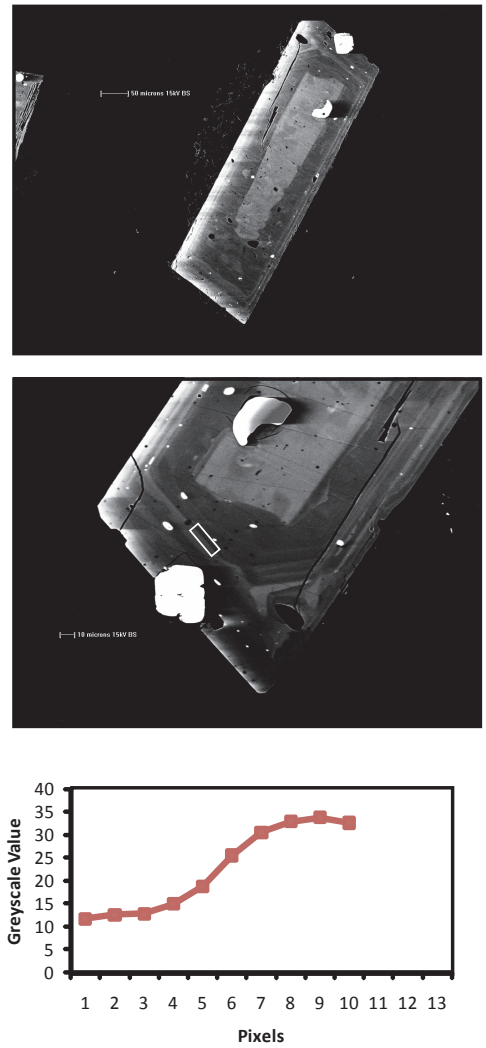


\section{Maketawa-Rims}

cpx50a1
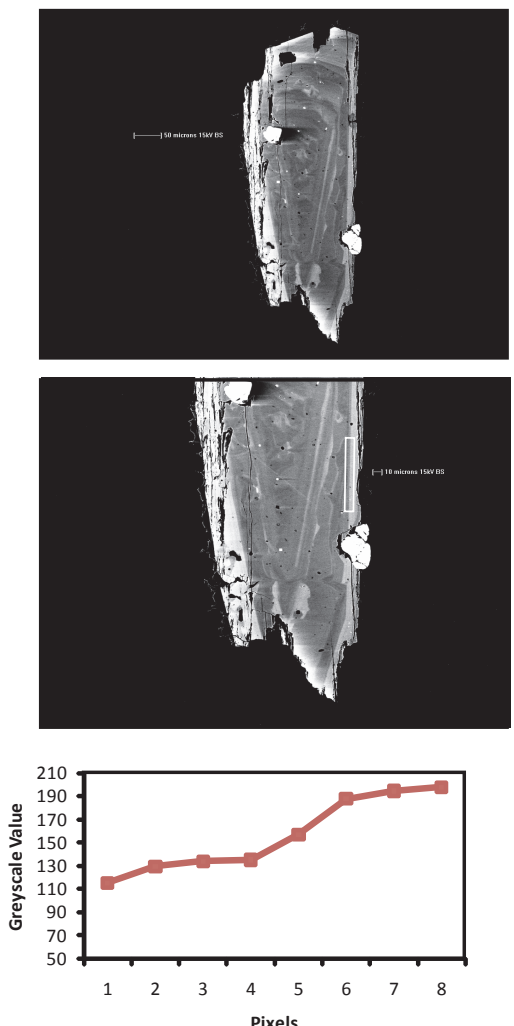

cpx71b1
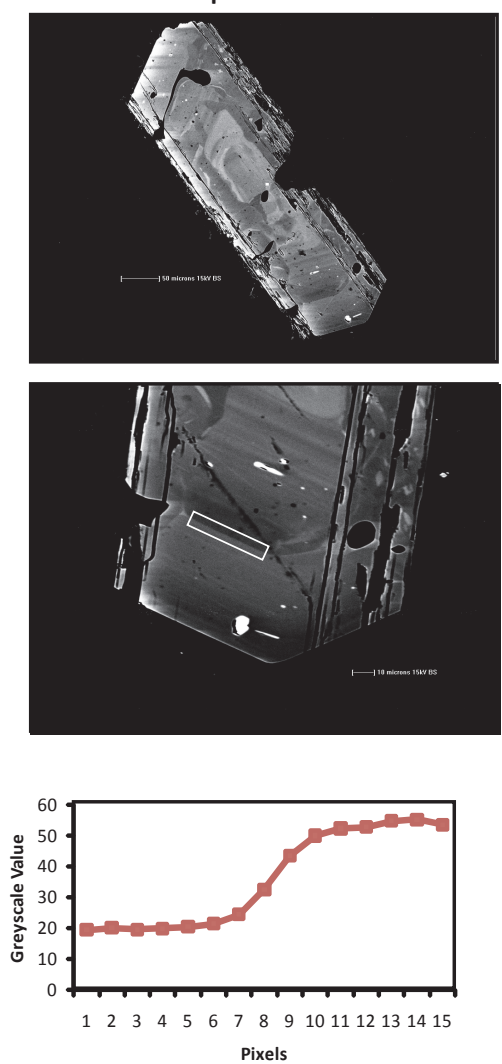

cpx51a2
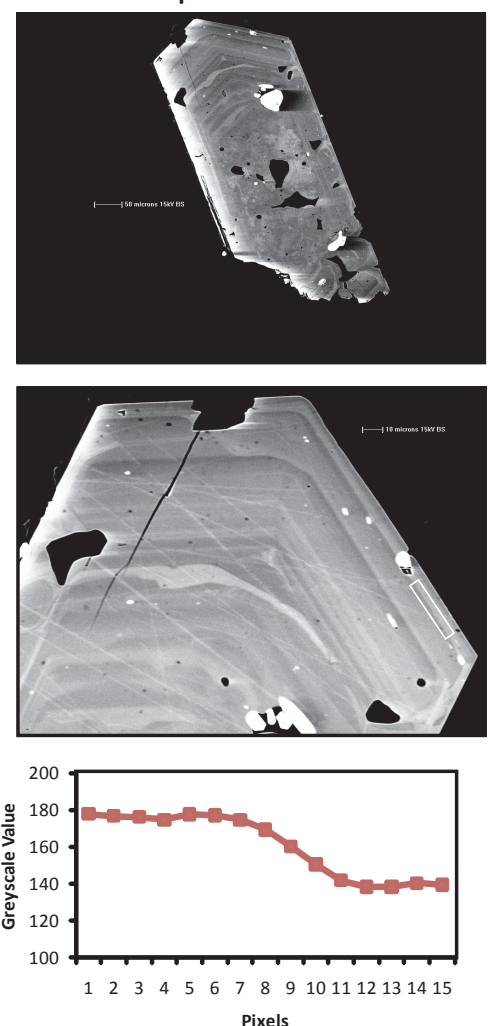

Maketawa-Inner zones срх6а2
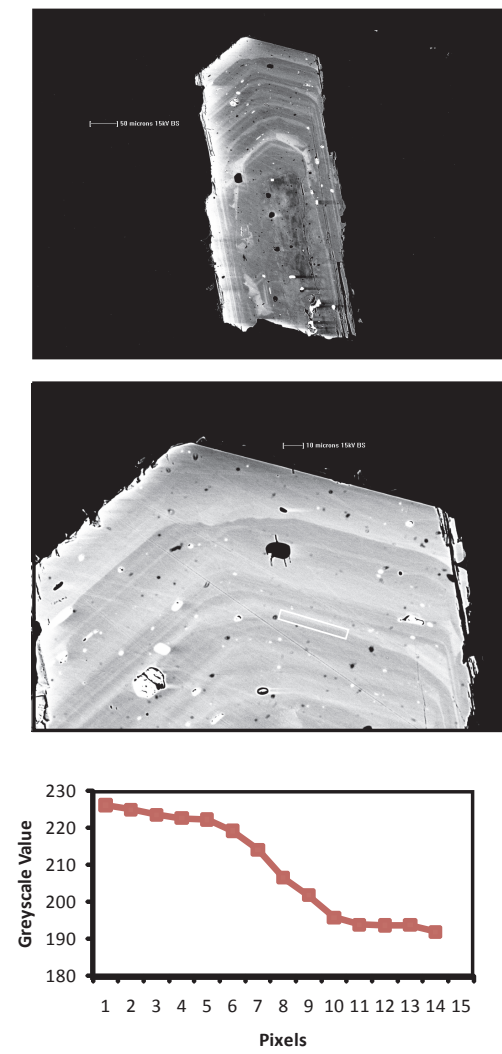


\section{Maketawa-Inner zones}

$\mathrm{cpx} 14 \mathrm{~b} 2$
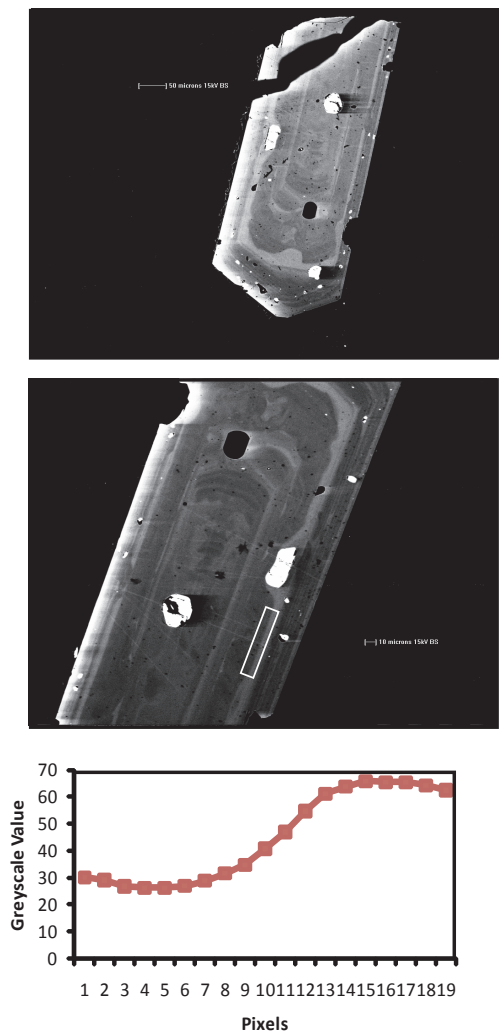

cpx35b1
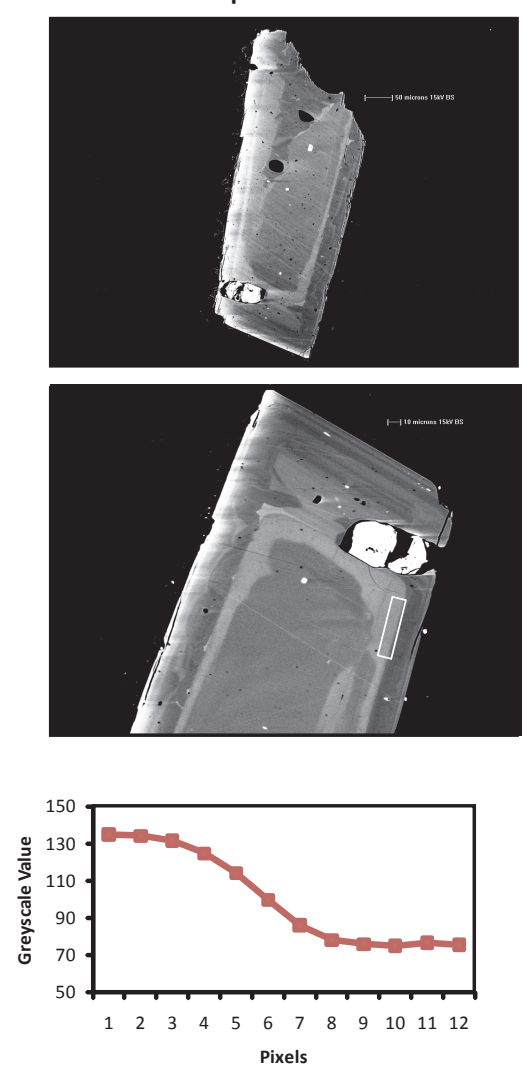

cpx25b1
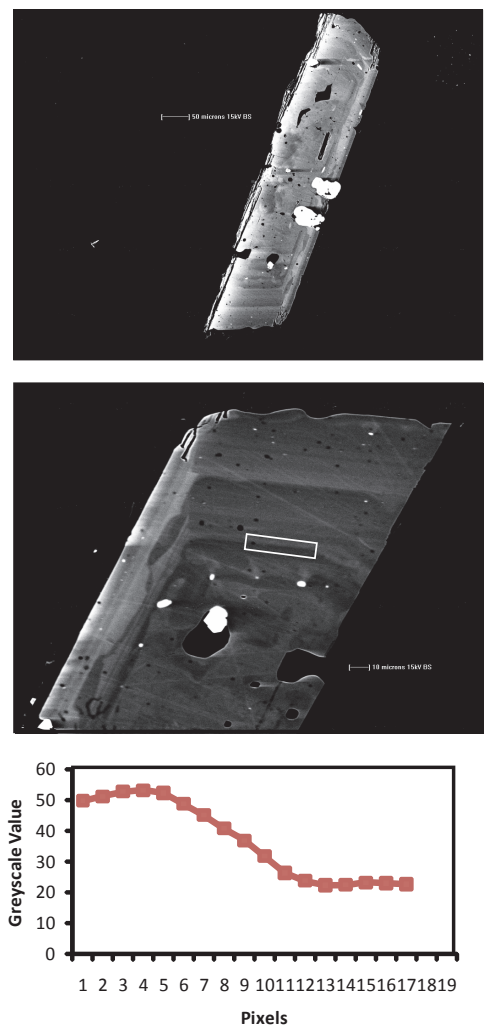

cpx46a1
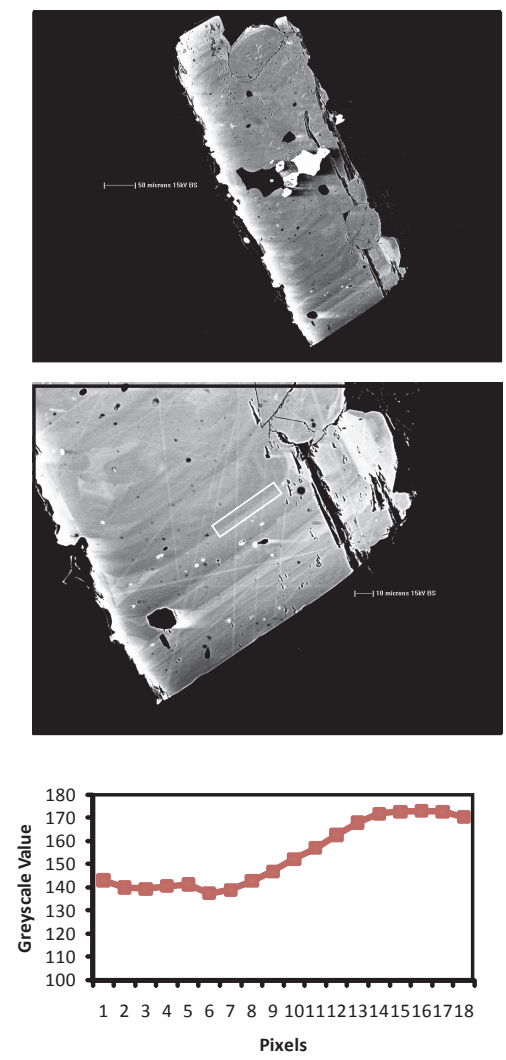
Maketawa-Inner zones

cpx51a1
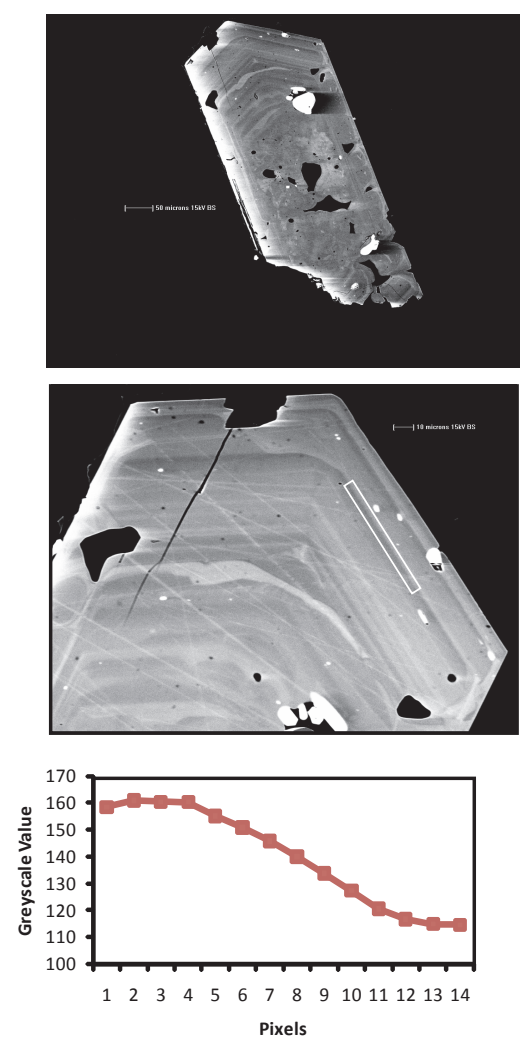

cpx32b2
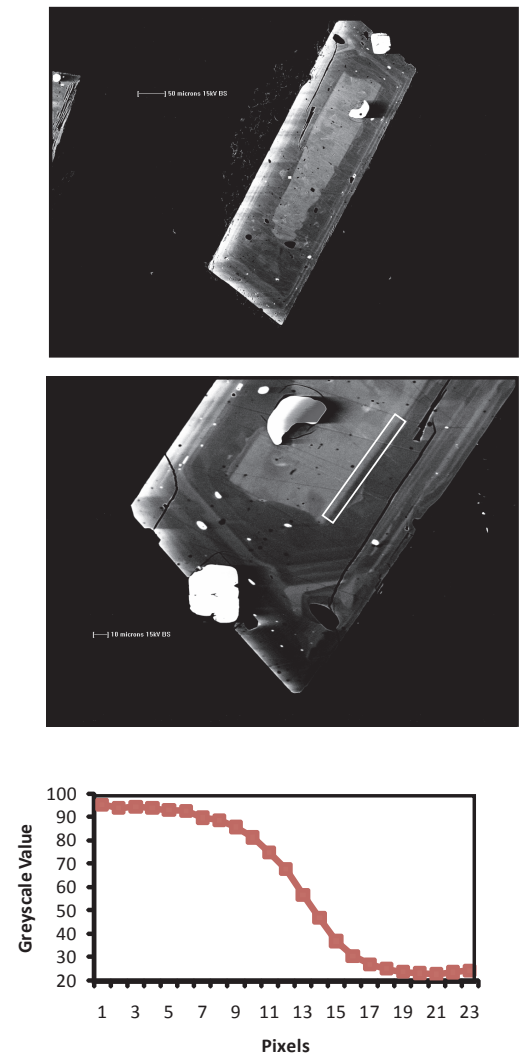

Maketawa-Cores

cpx14b3
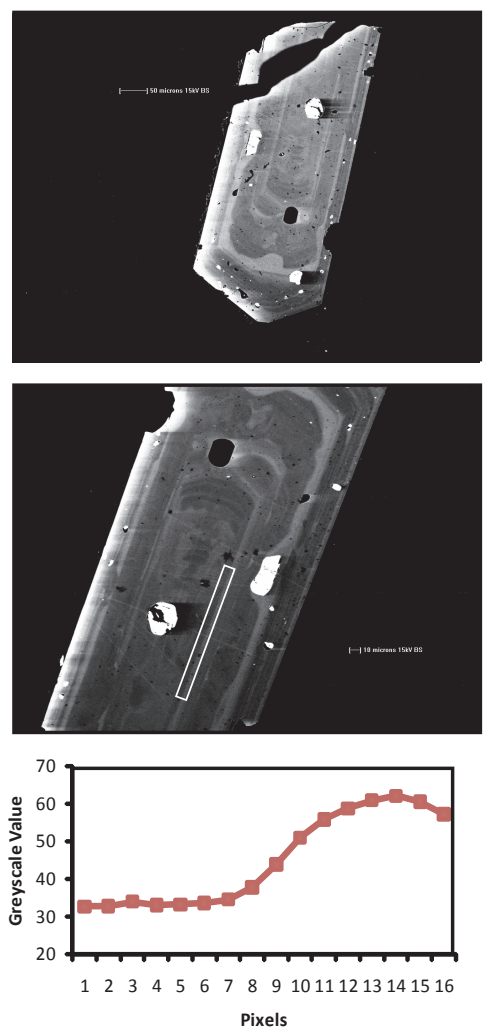

$c p \times 35 b 2$
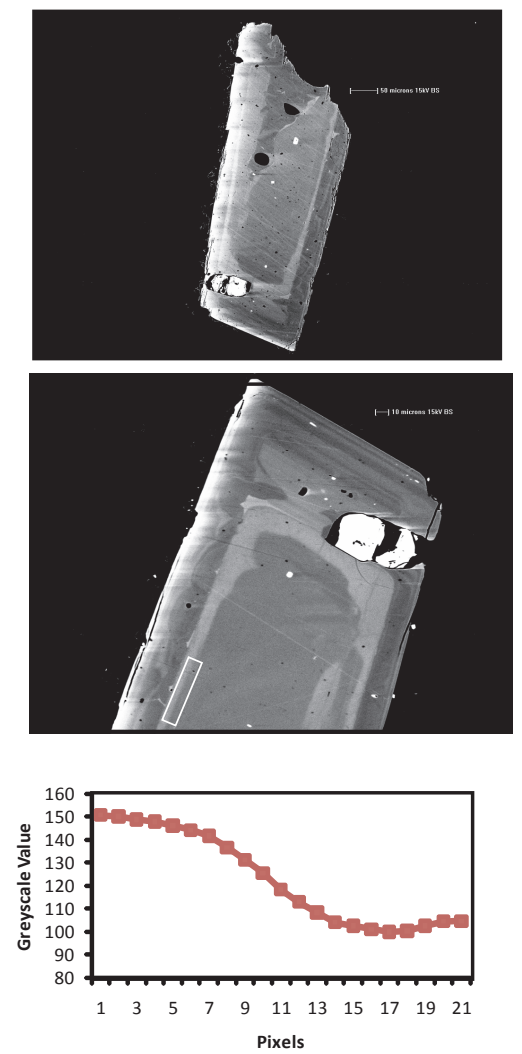


\section{Maketawa-Cores}

срх65a1
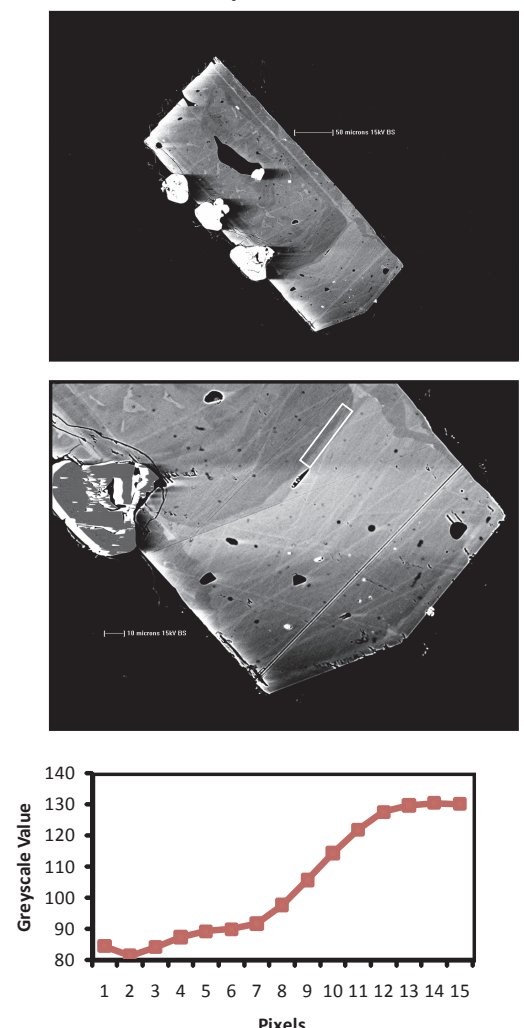

Inglewood b-Rims

cpx8a1
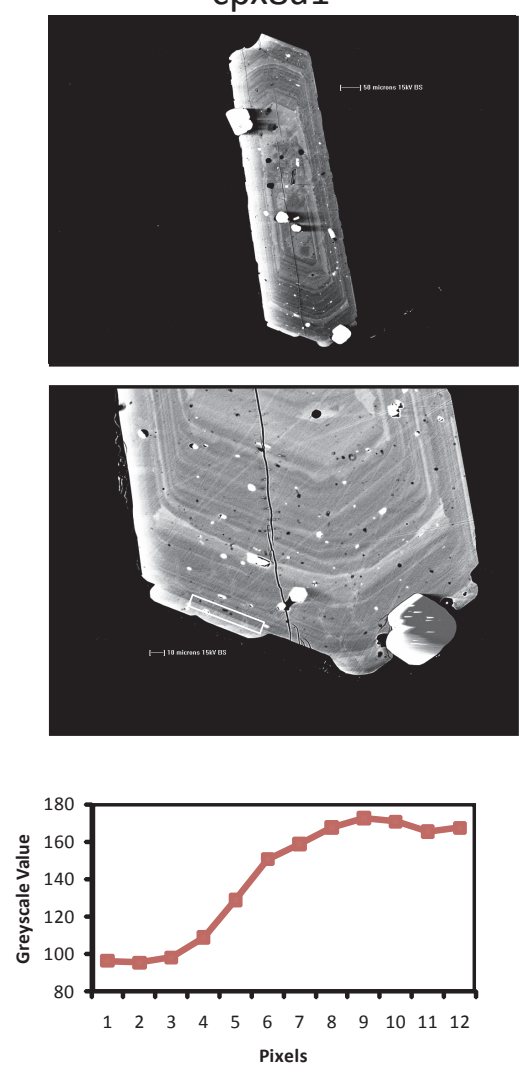

$c p \times 24 b 1$
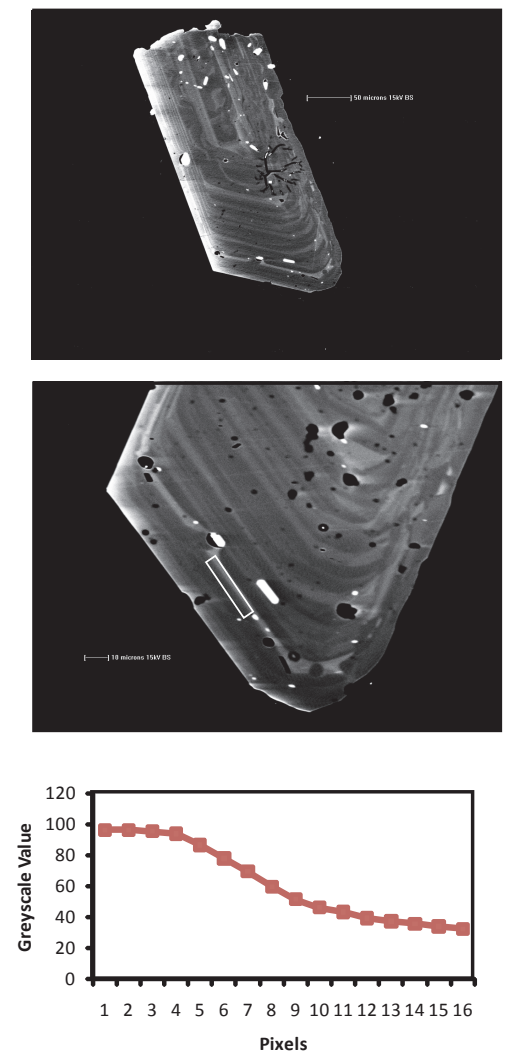


\section{Inglewood b-Rims}
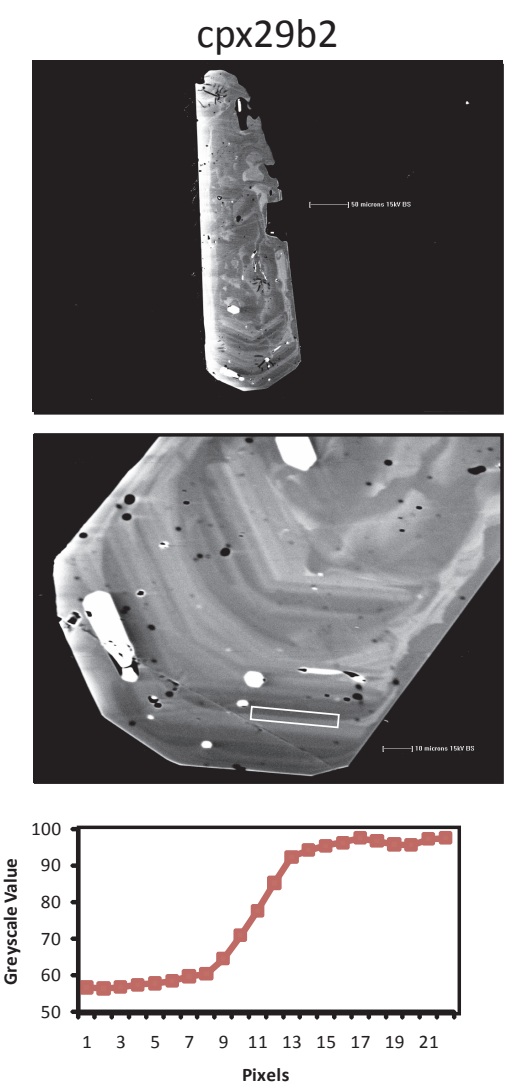

cpx7b1
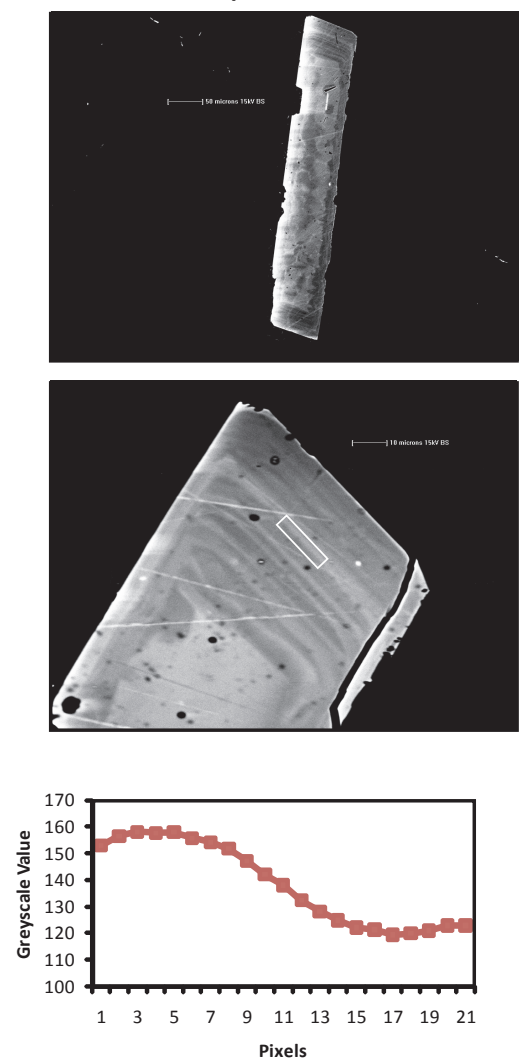

Inglewood b-Outer oscillatory zones

cpx2a1
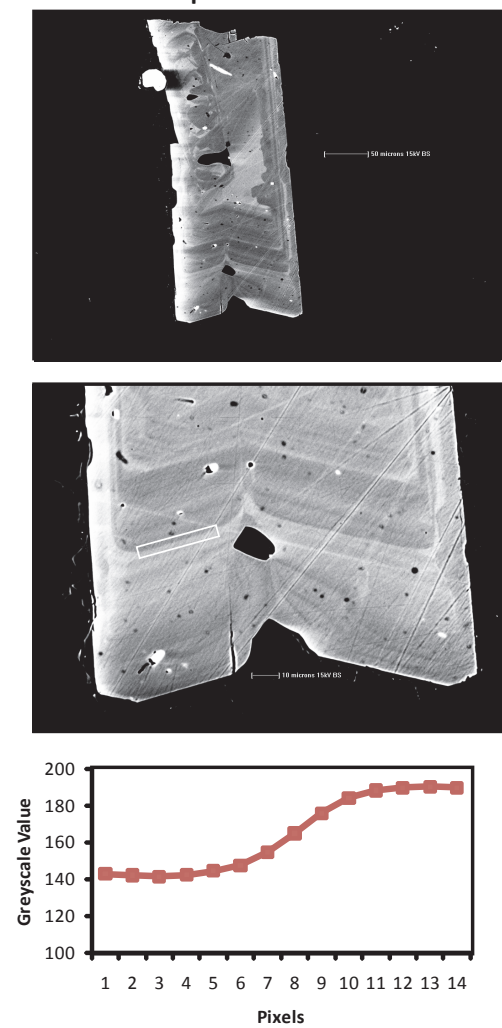

cpx9b2
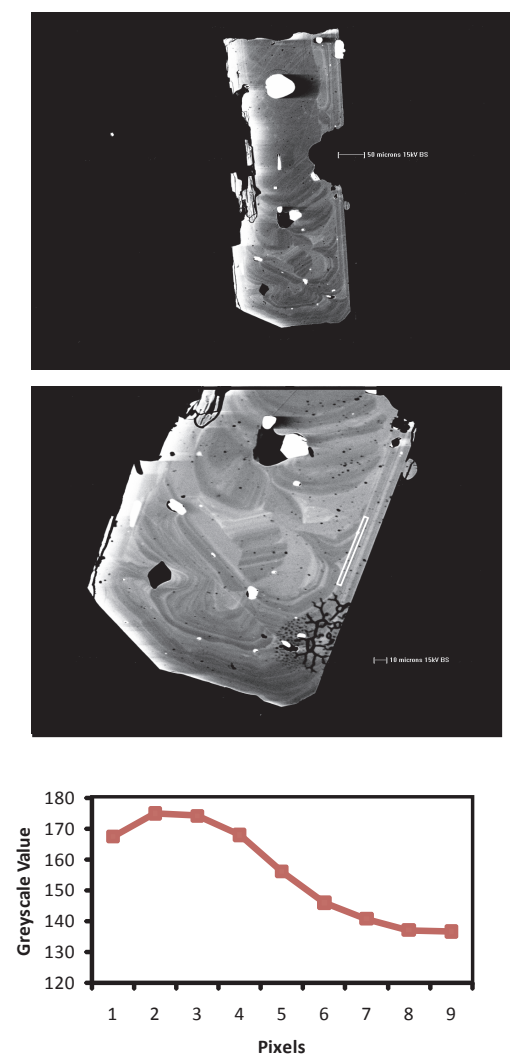


\section{Inglewood b-Outer oscillatory zones}

cpx10a5
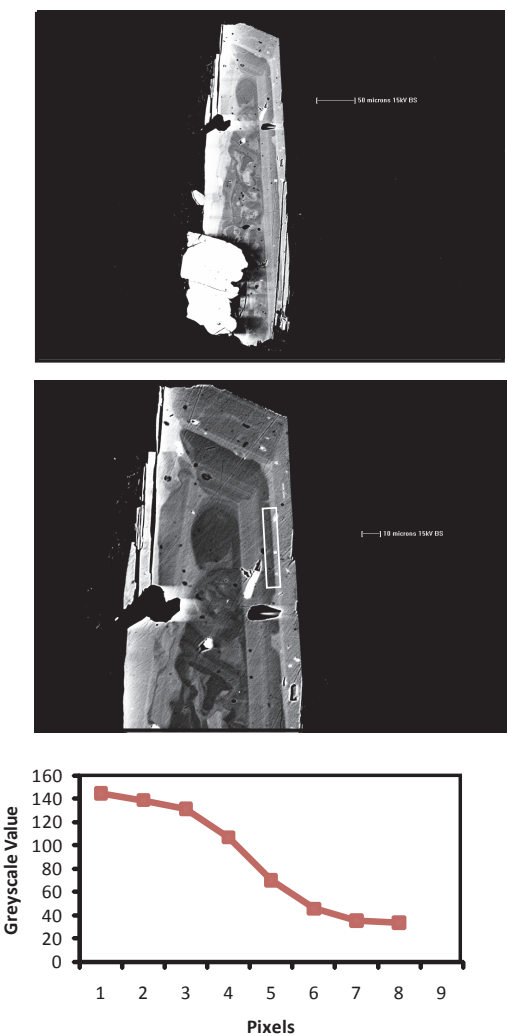

$\mathrm{cpx} 13 \mathrm{~b} 2$
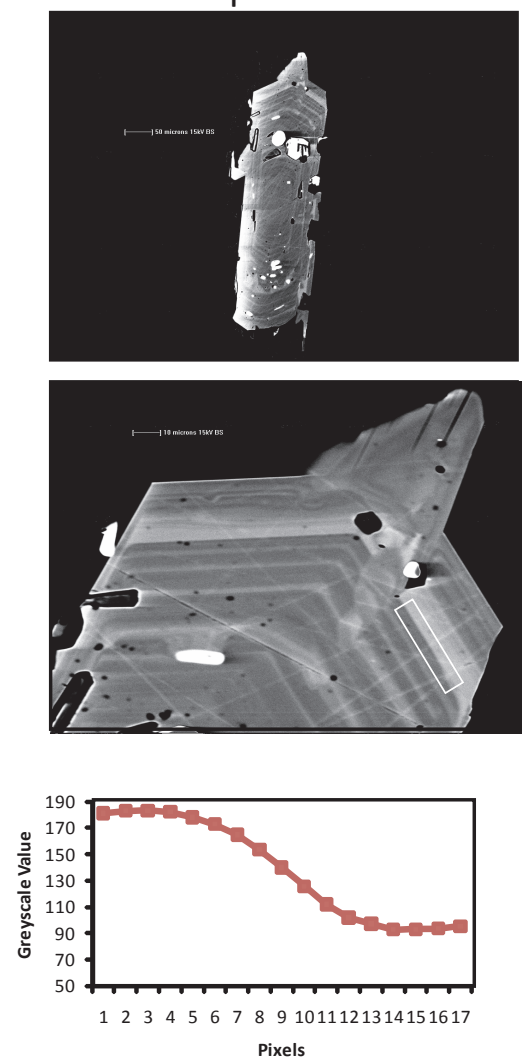

$\mathrm{cpx} 12 \mathrm{~b} 2$
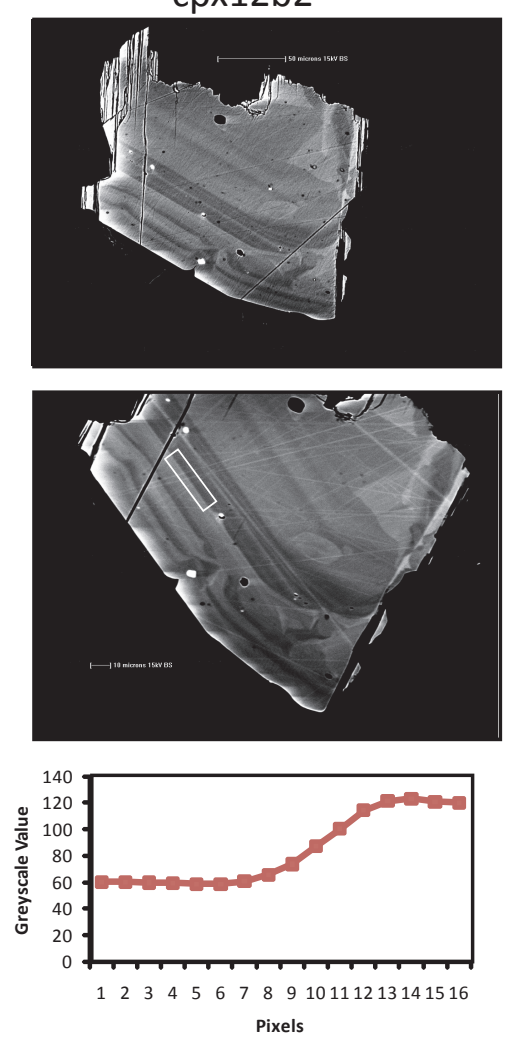

$\mathrm{cp} \times 15 \mathrm{~b} 2$
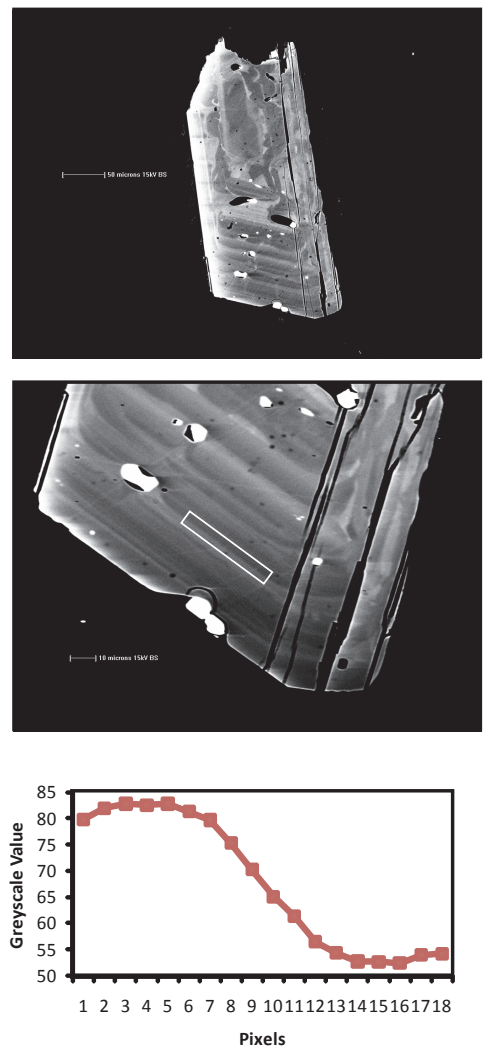


\section{Inglewood b-Outer oscillatory zones}

cpx21a1
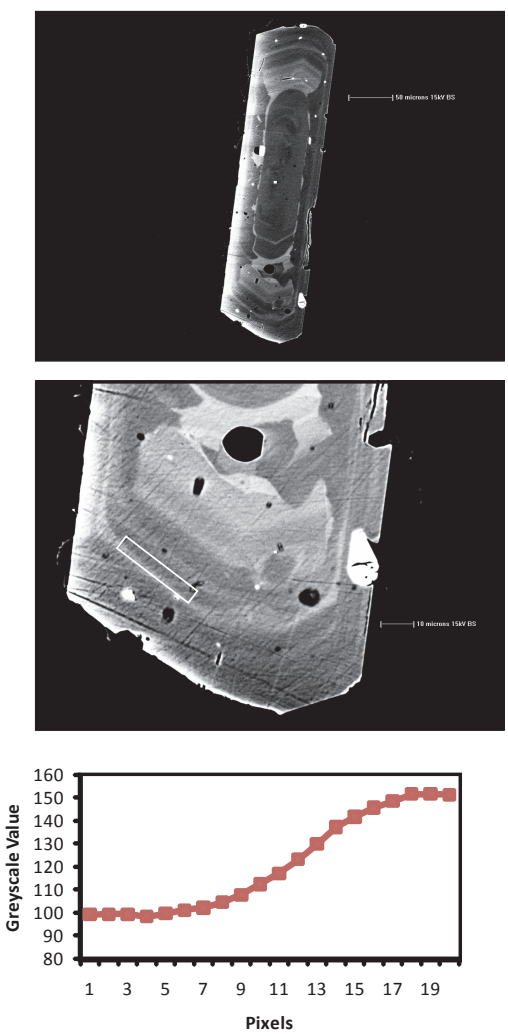

$\mathrm{cpx} 25 \mathrm{a} 1$
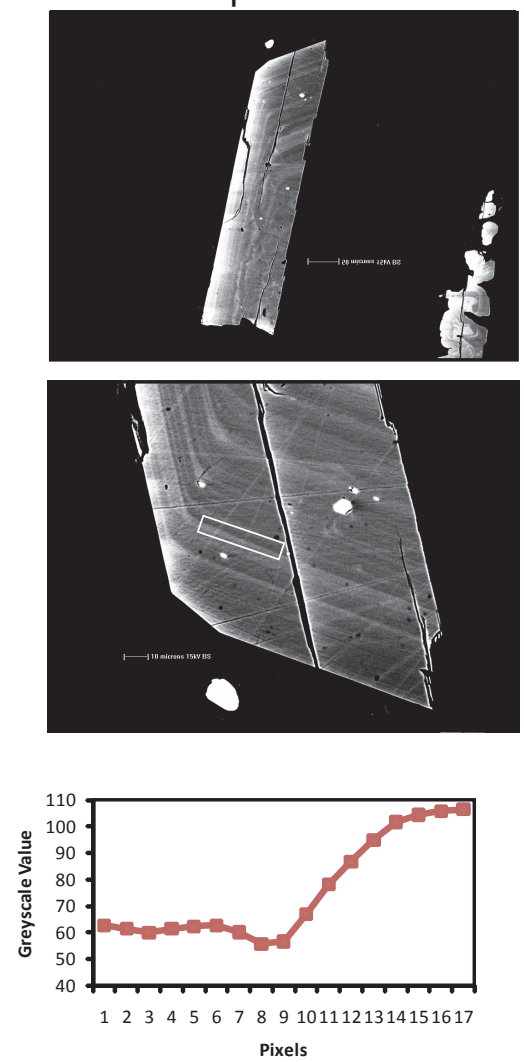

$\mathrm{cp} \times 24 \mathrm{~b} 2$
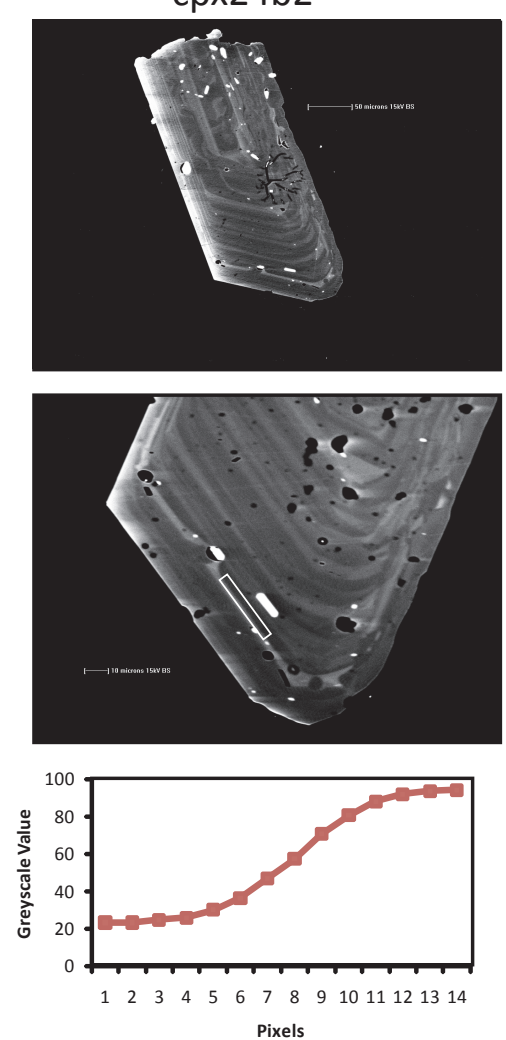

$\mathrm{cp} \times 28 \mathrm{~b} 2$
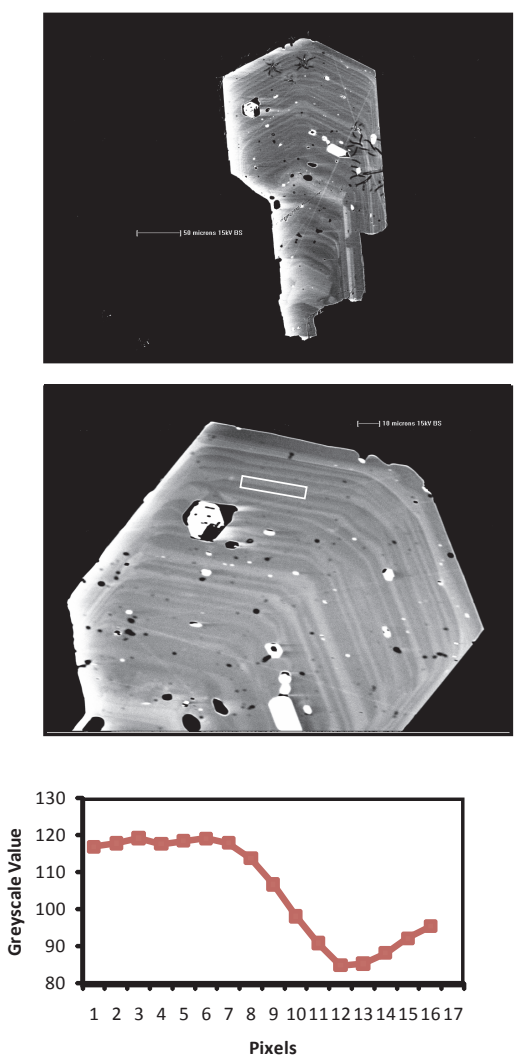


\section{Inglewood b-Outer oscillatory zones}

cpx34a1
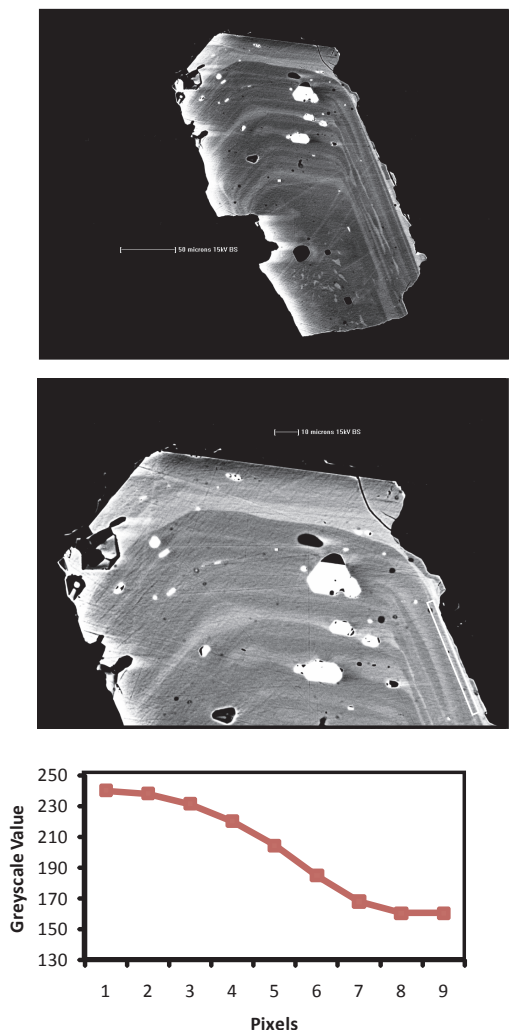

срх39a1
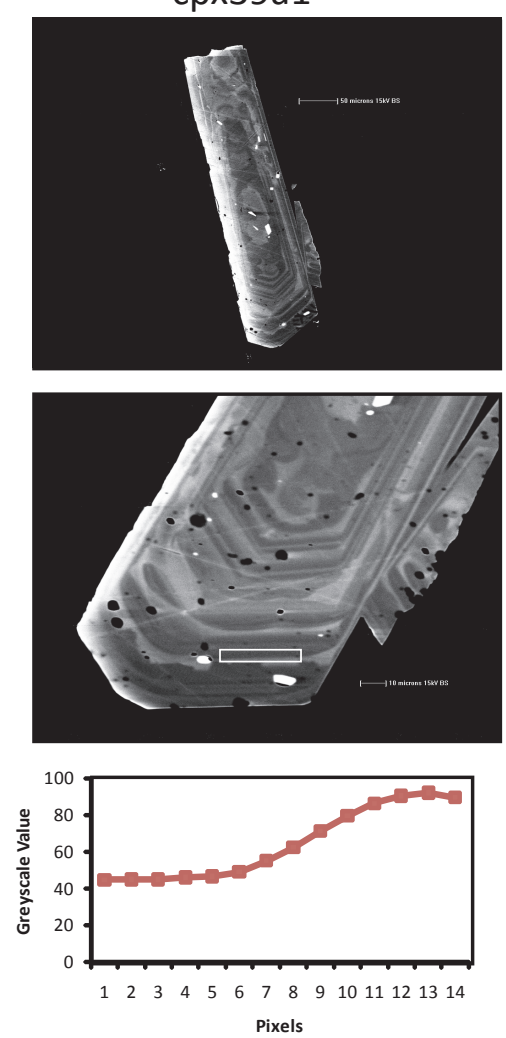

Inglewood b-Inner oscillatory zones

$\mathrm{cp} \times 2 \mathrm{a} 3$
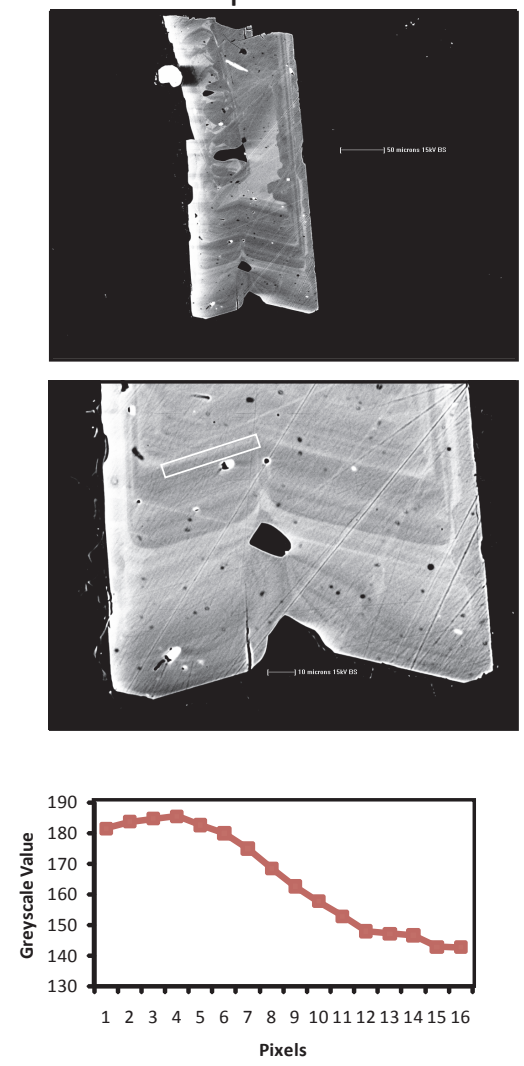

срх8а3
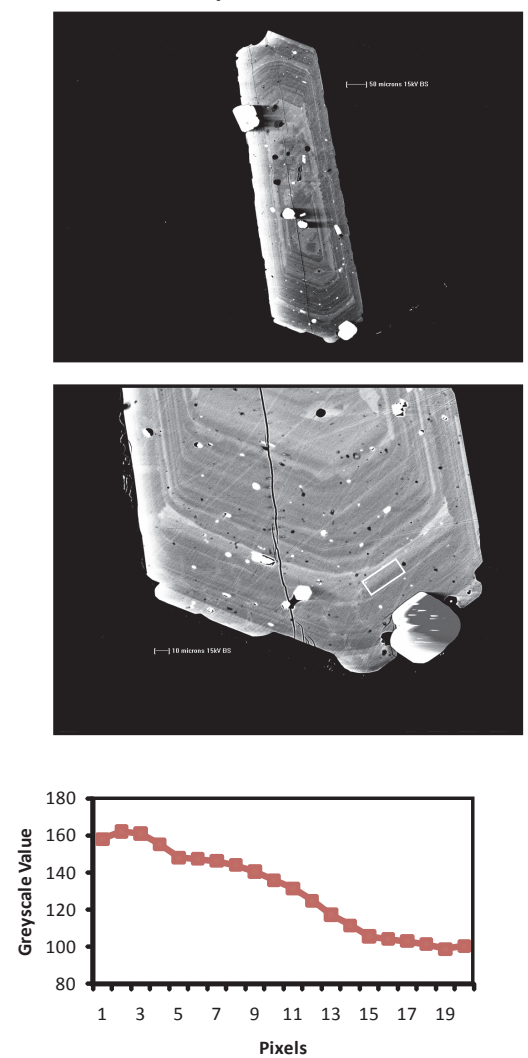
Inglewood b-Inner oscillatory zones

cpx9b3
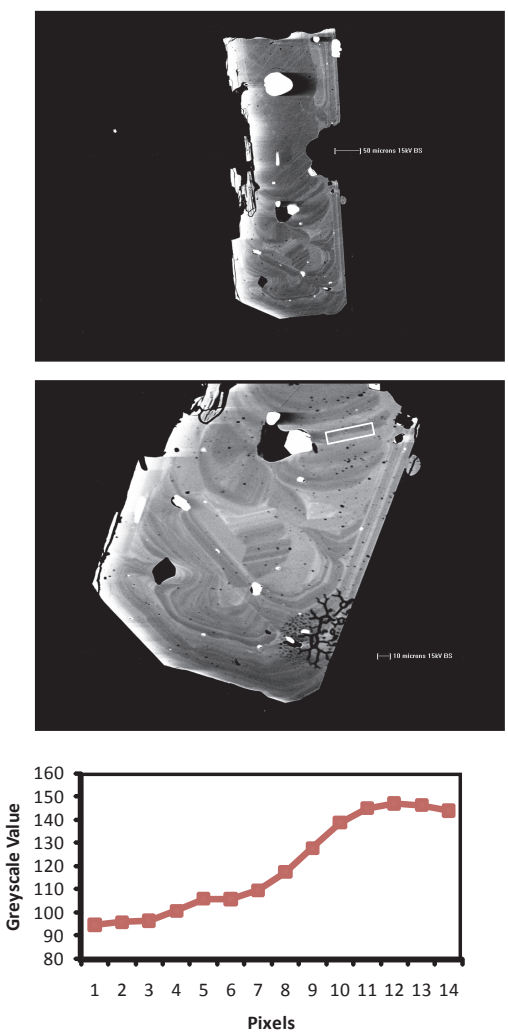

срx10a9
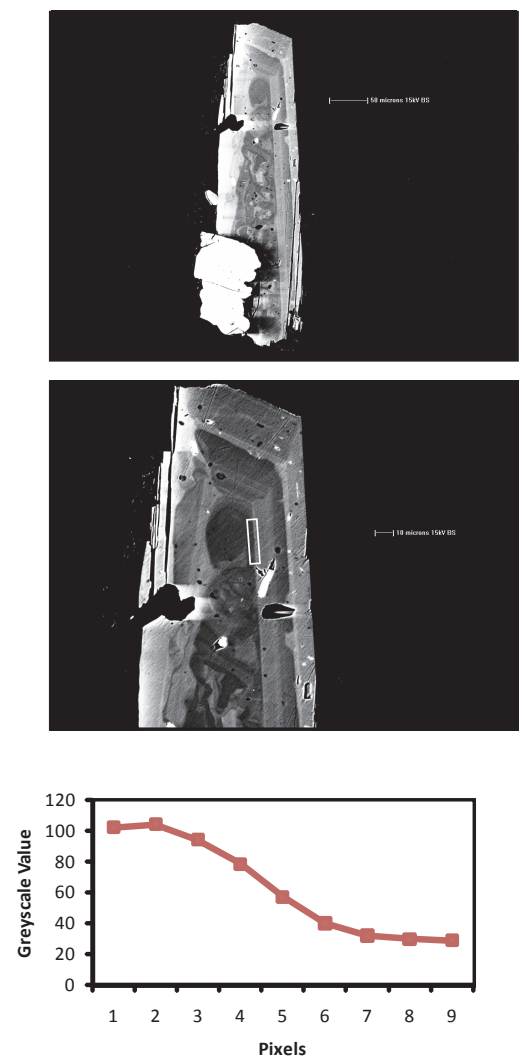

cpx9b4
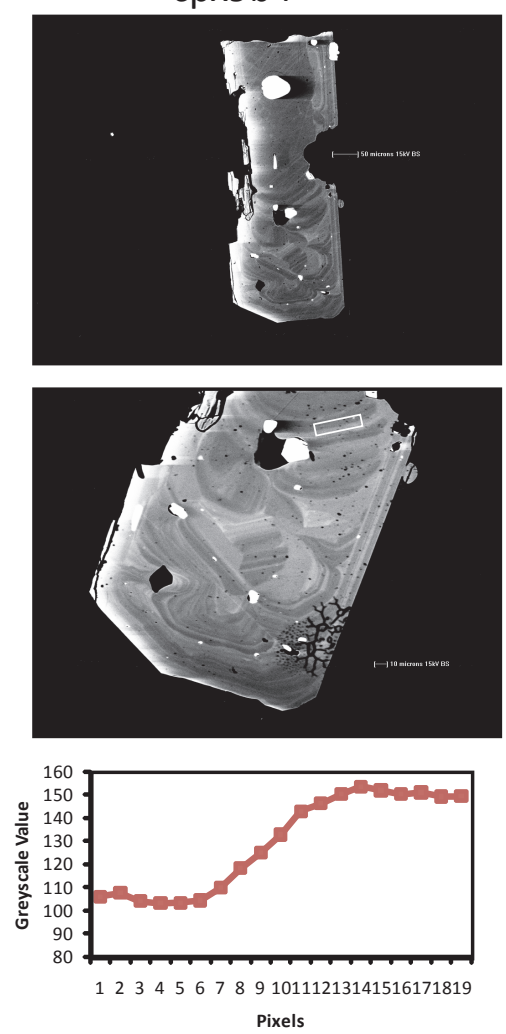

cpx11a1
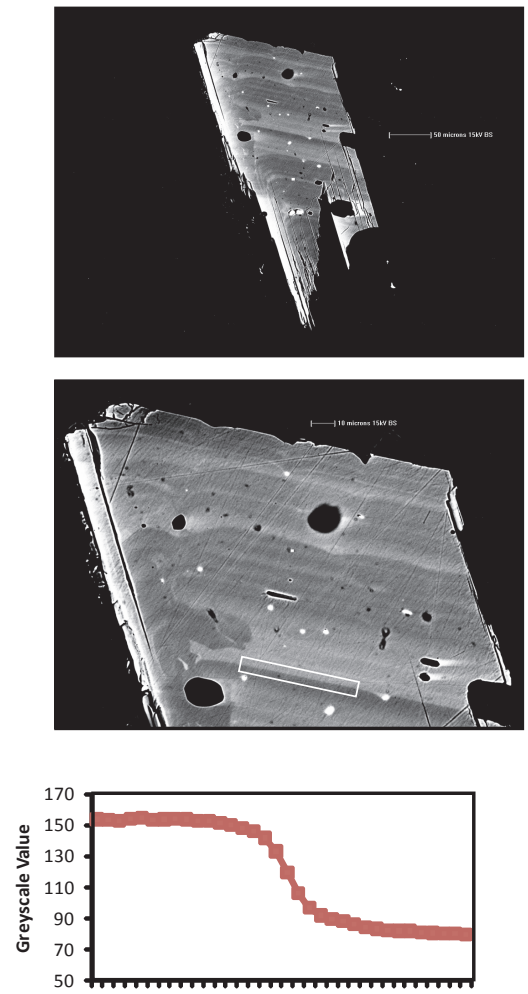

13579111315171921232527293133 Pixels 


\section{Inglewood b-Inner oscillatory zones}

$c p \times 15 b 3$
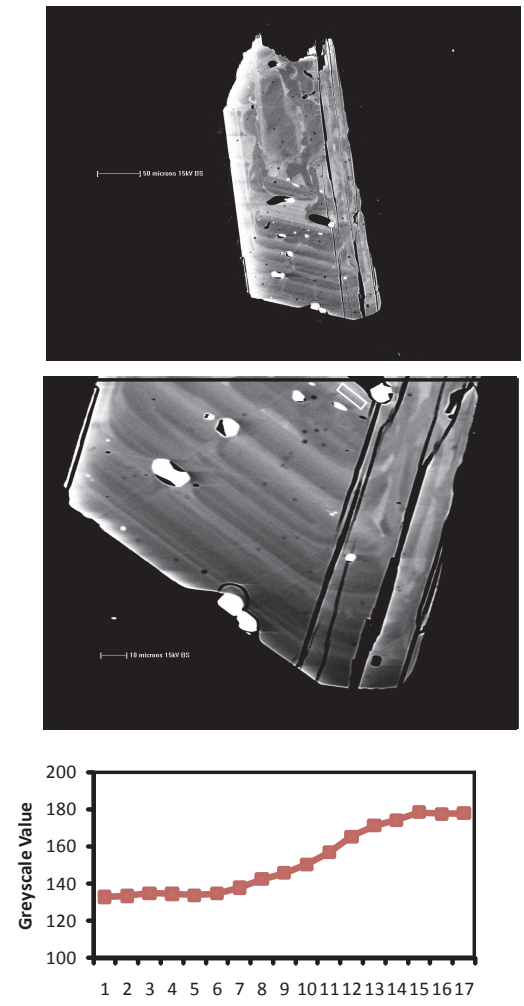

Pixels

cpx28b3
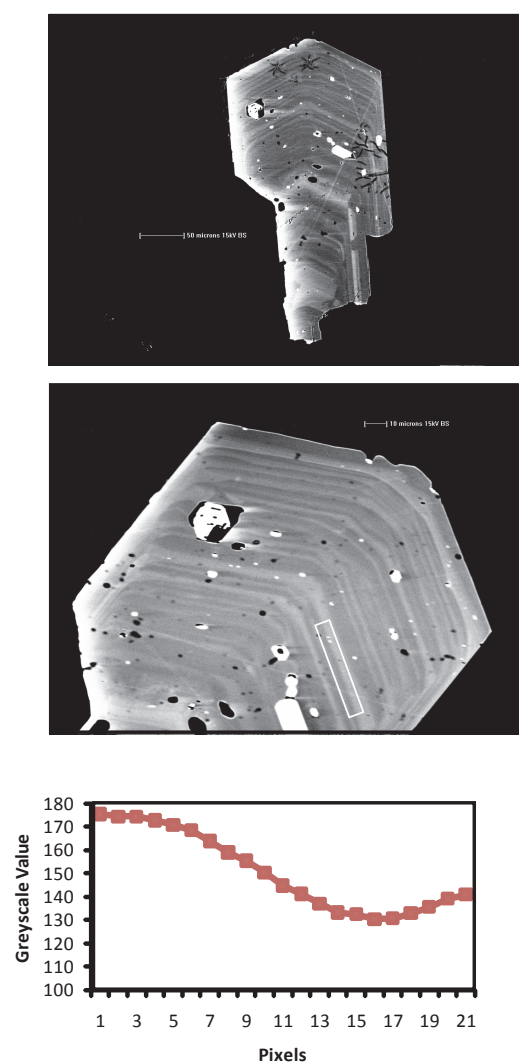

cpx21a2
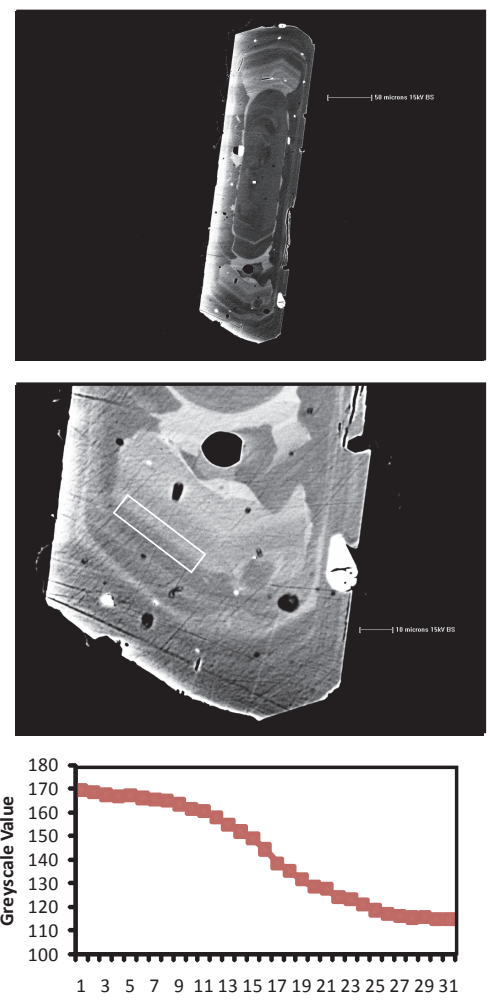

Pixels

cpx29b3
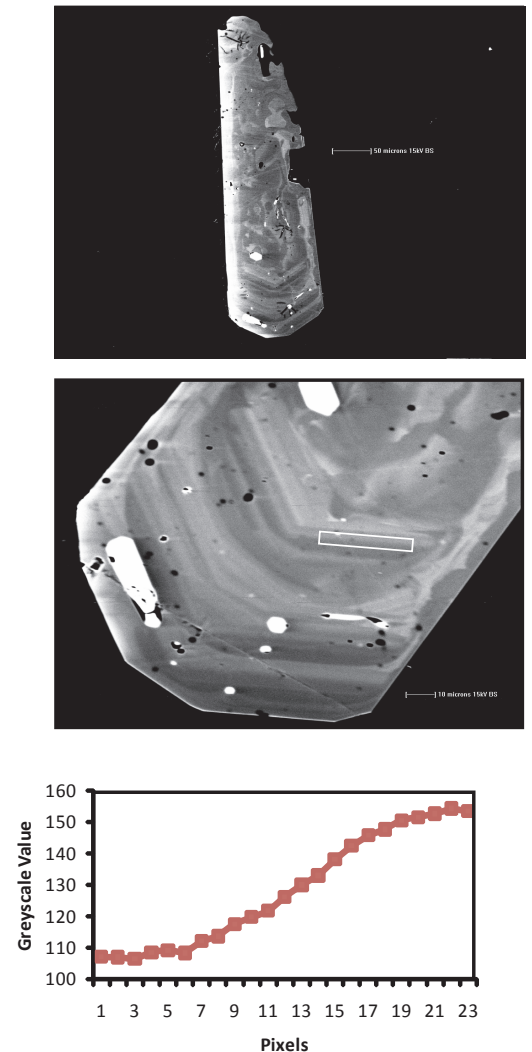
Inglewood b-Inner oscillatory zones

cpx33a1
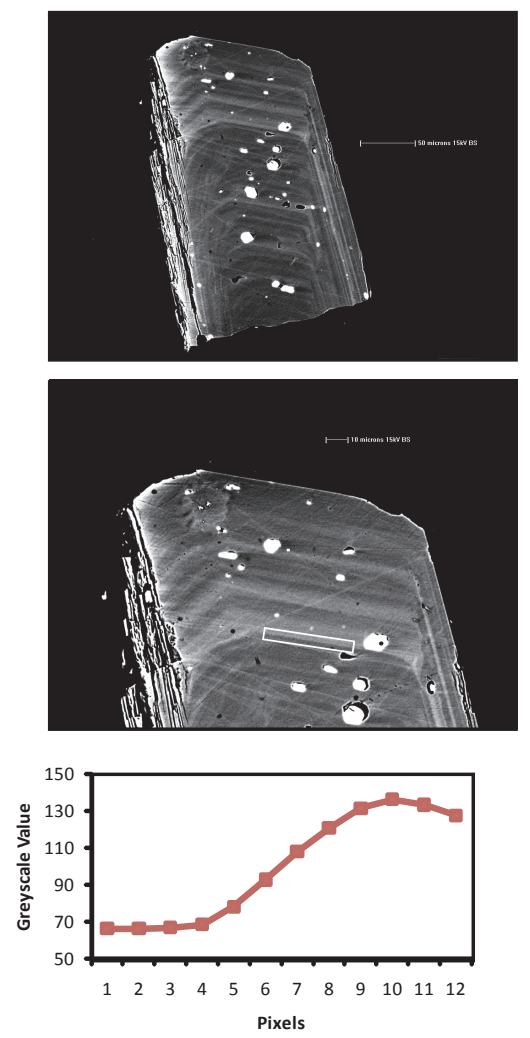

\section{Inglewood a-Rims}
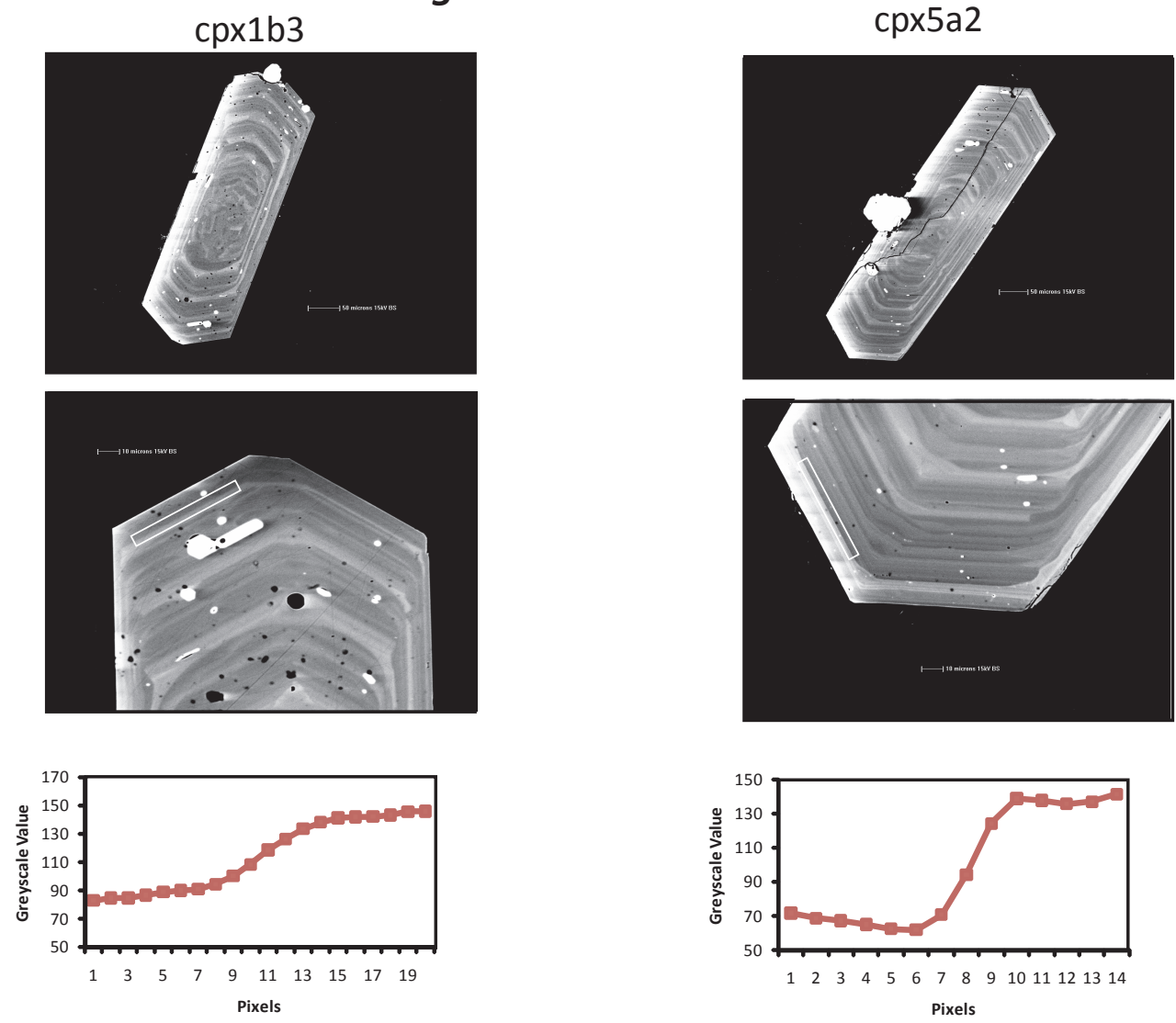


\section{Inglewood a-Rims}
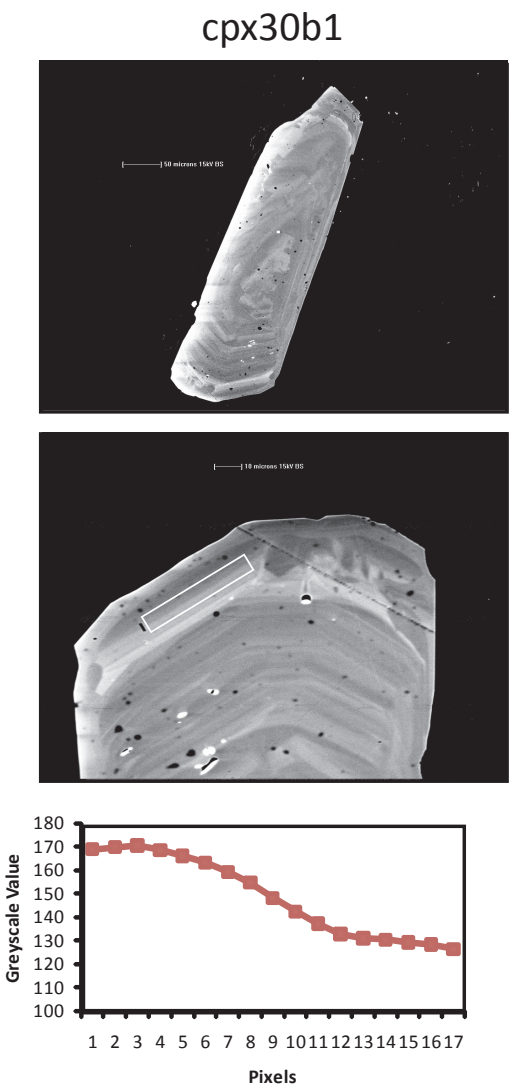

cpx44a1
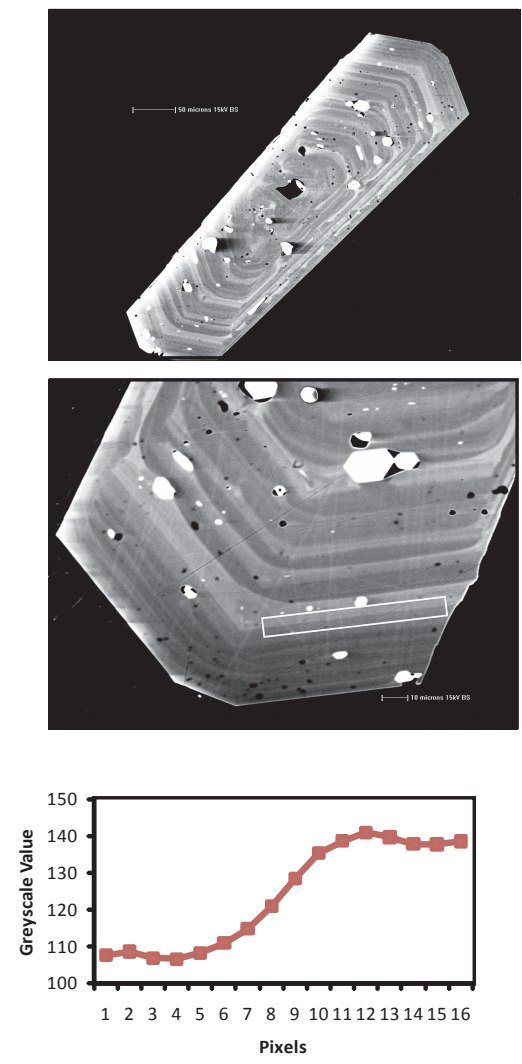

срх39a1
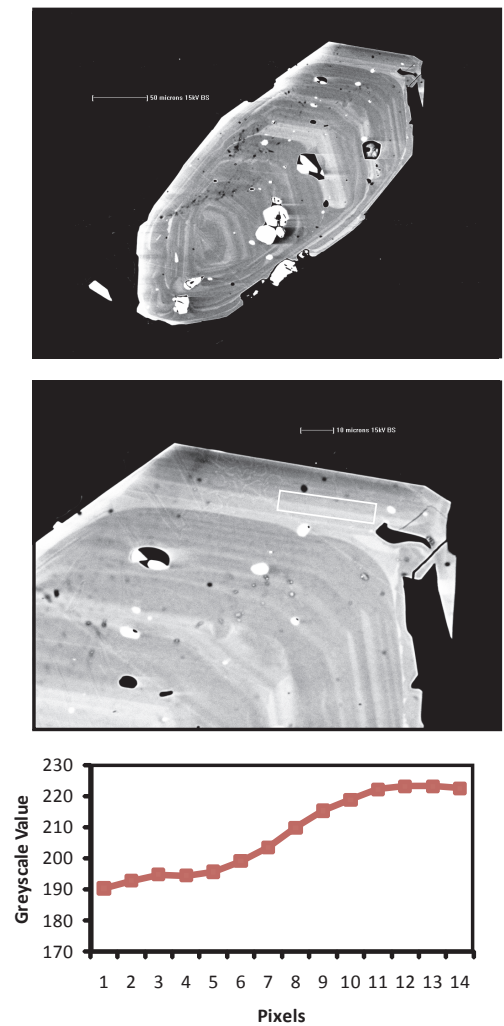

cpx54a1
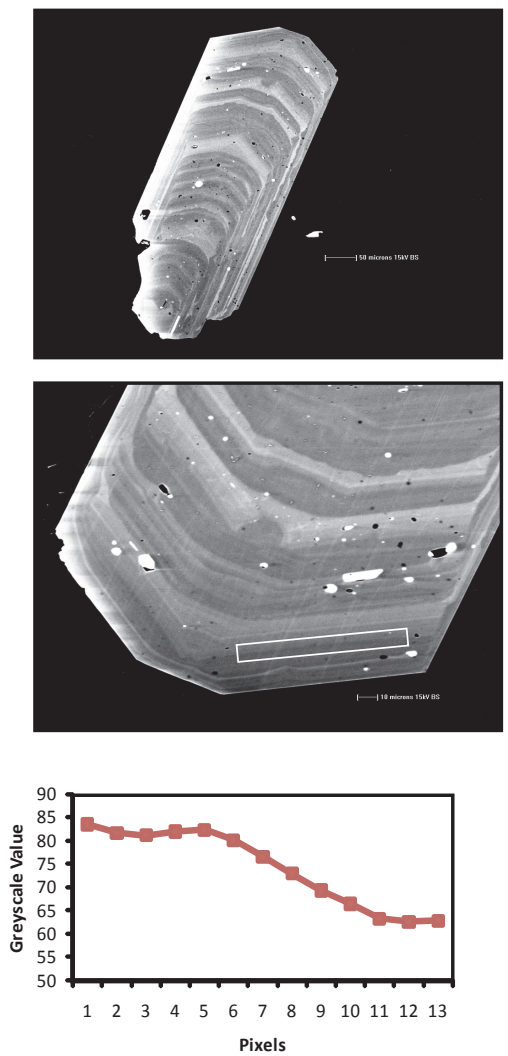


\section{Inglewood a-Minor zones}

$\mathrm{cp} \times 5 \mathrm{a} 4$
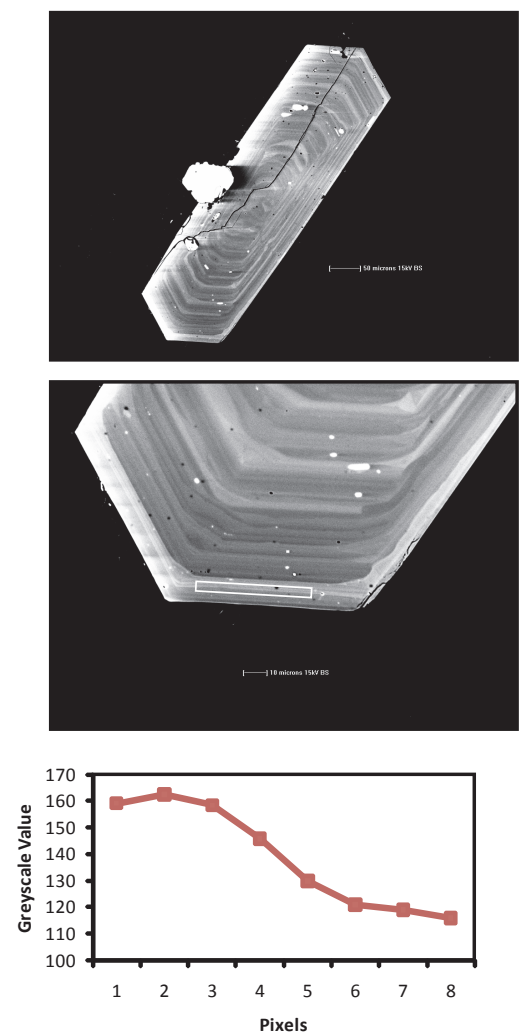

cpx33b1
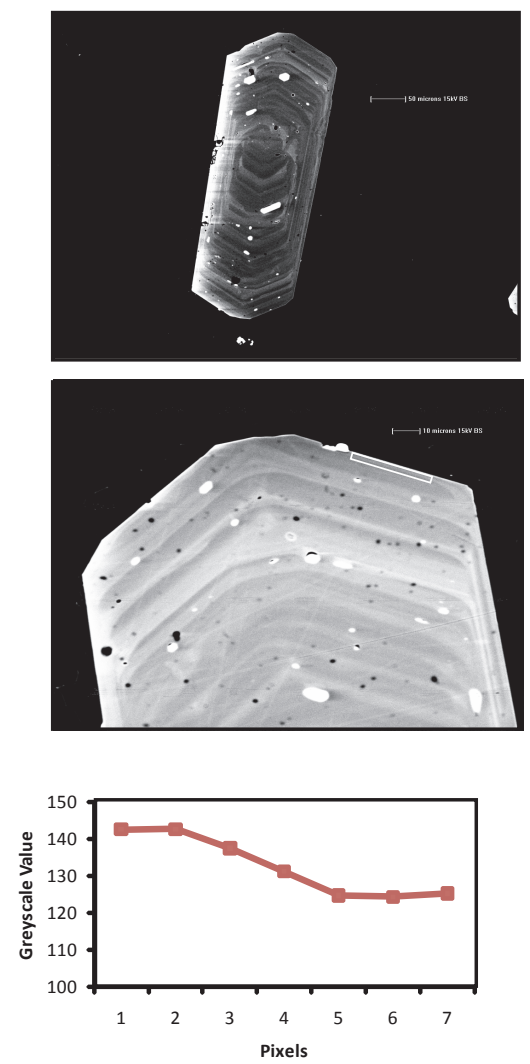

cpx31a3
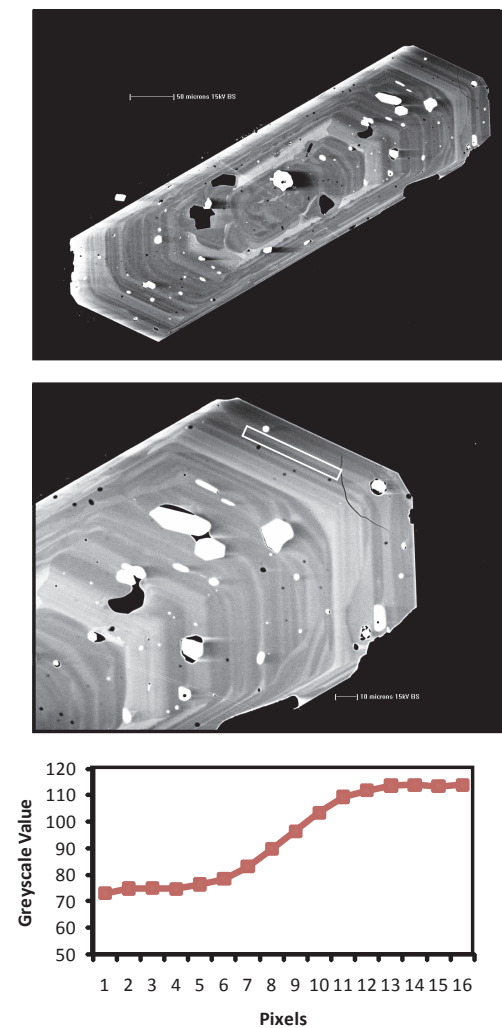

сpx58a1
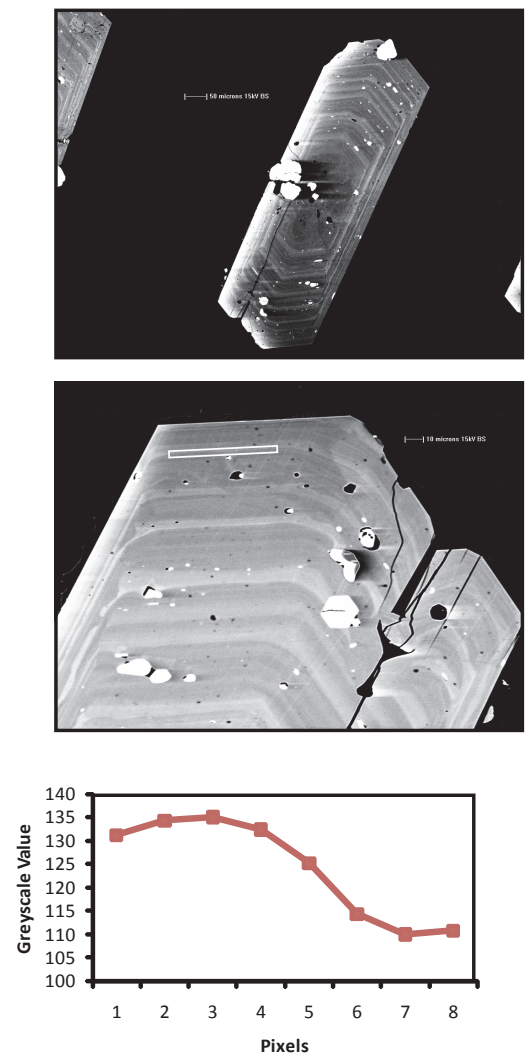


\section{Inglewood a-Second zone from rim}

$\mathrm{cp} \times 33 \mathrm{~b} 2$
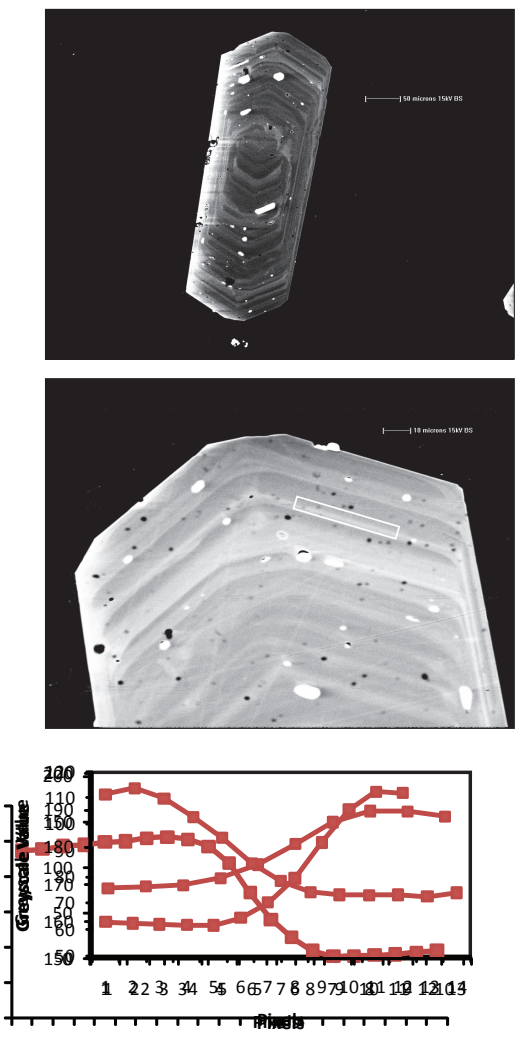

cpx56b1
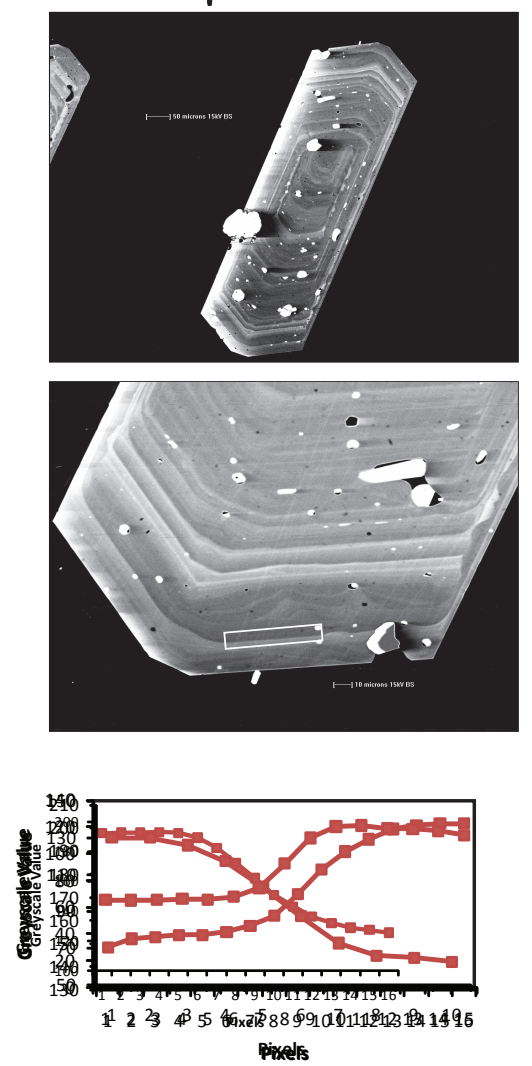

cpx48a2
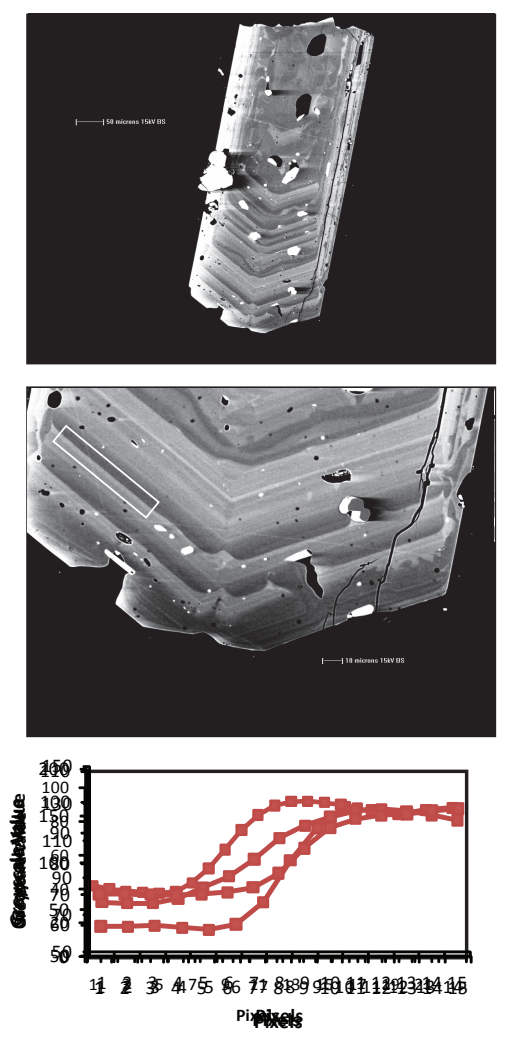

cpx66a1
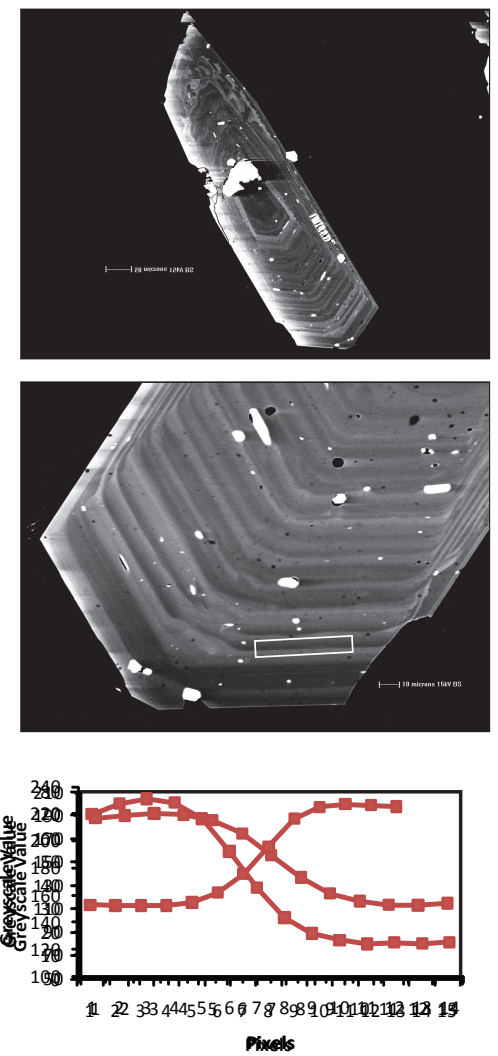
Inglewood a-Second zone from rim cpx69b1
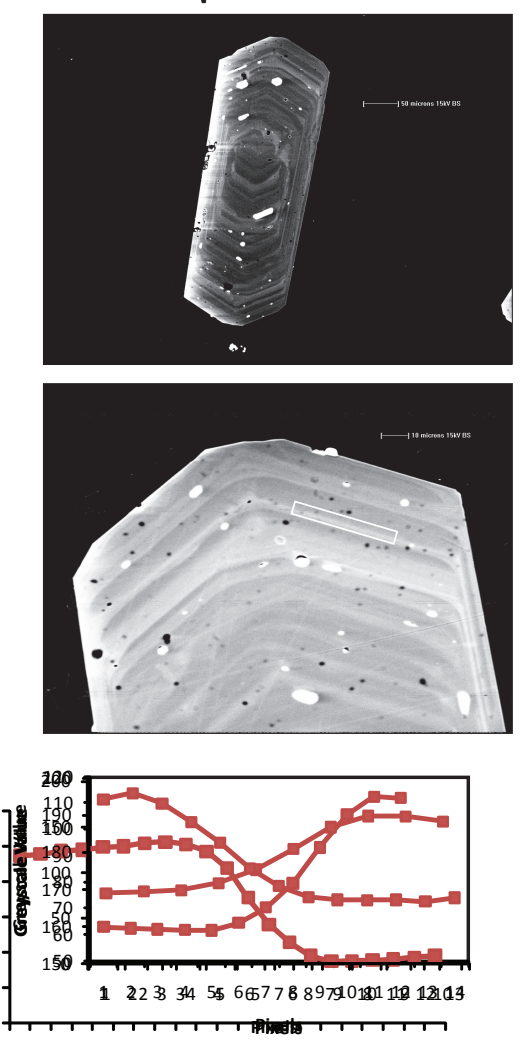

Inner zones

cpx21a1
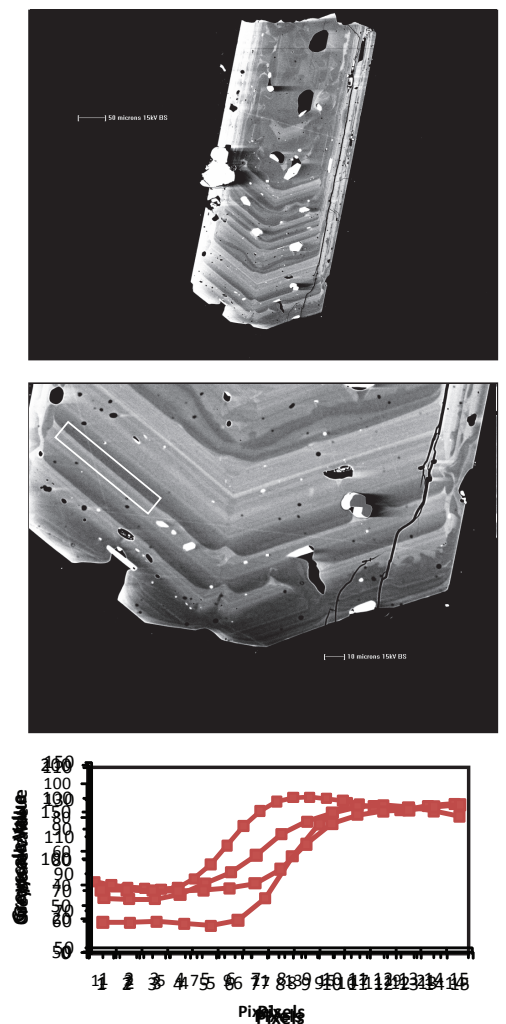

Pixels

Inglewood a-Inner zones

cpx30b2
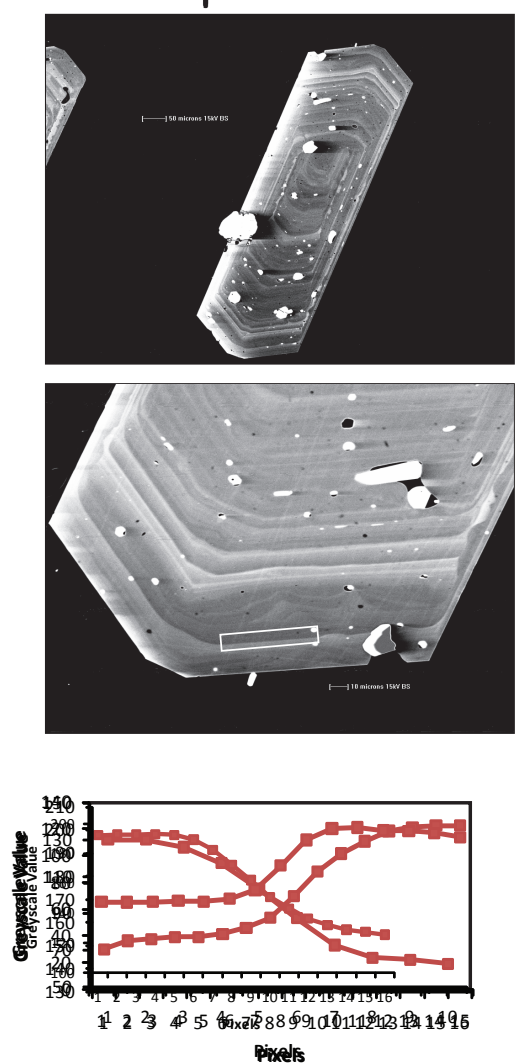

cpx31a4
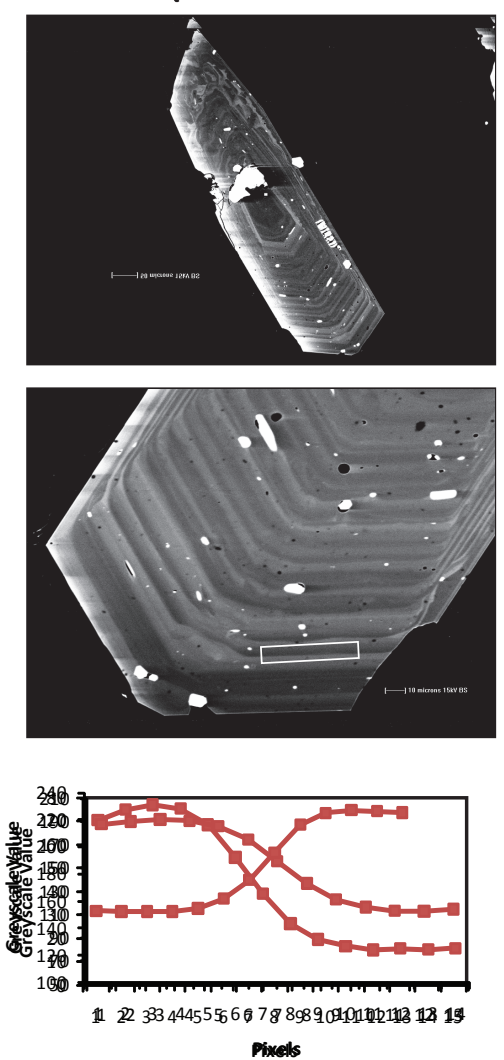


\section{Inglewood a-Inner zone}

cpx35b1
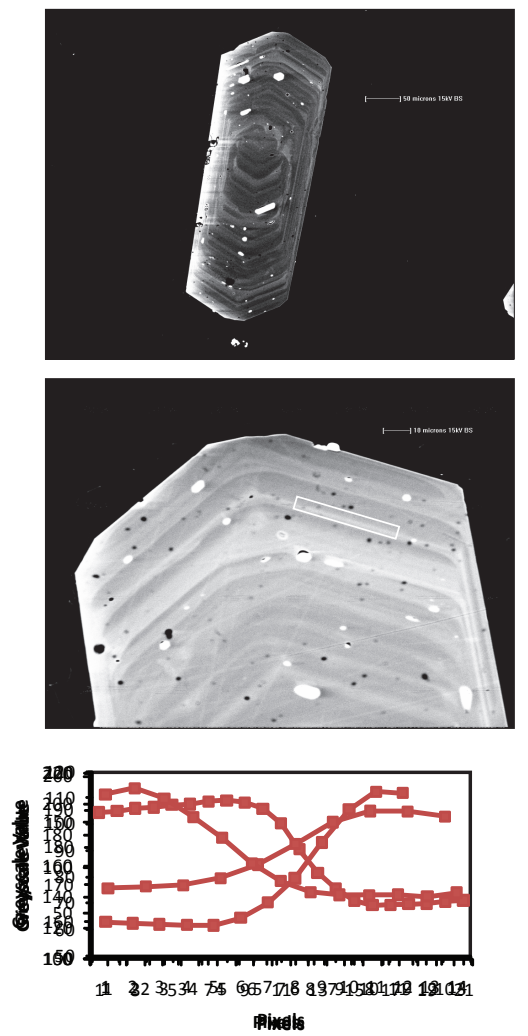

$\mathrm{cp} \times 68 \mathrm{~b} 2$
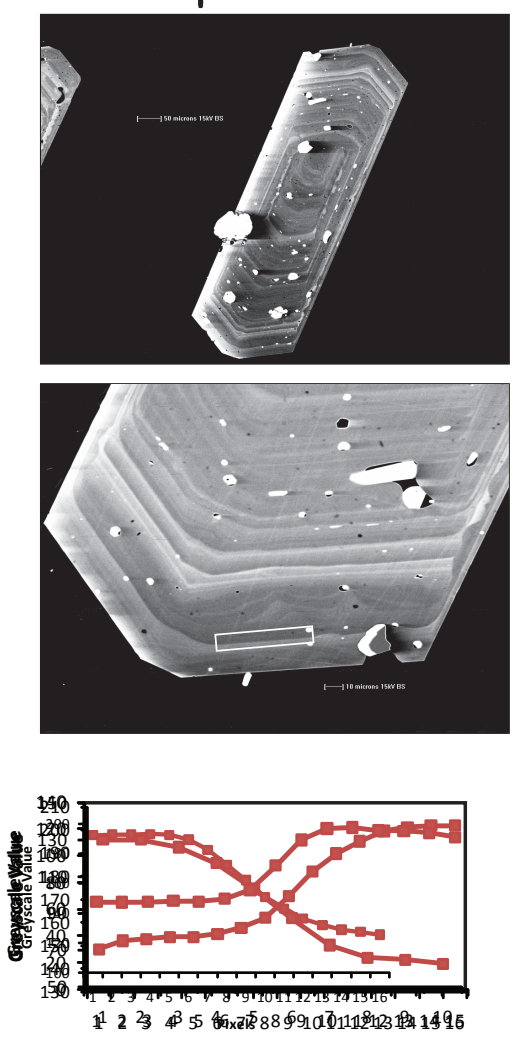

cpx63c2
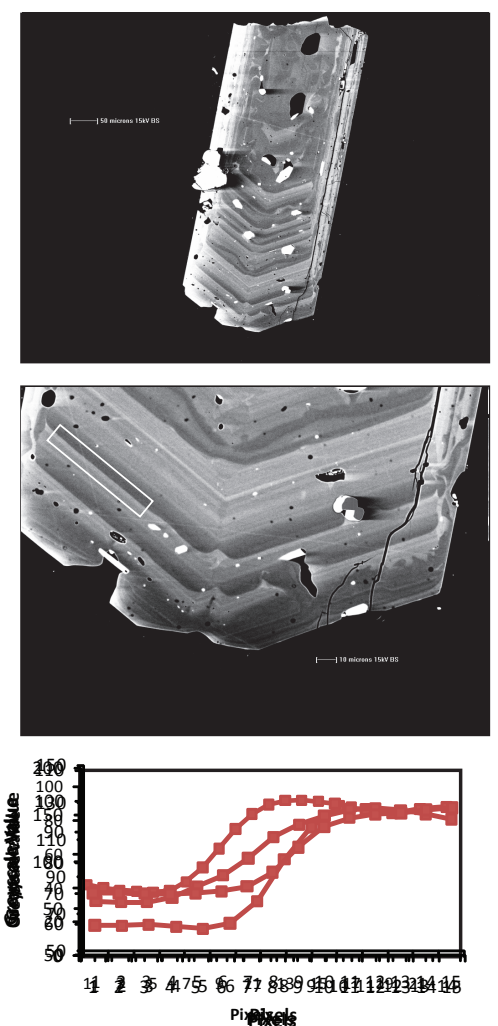

срх73a2
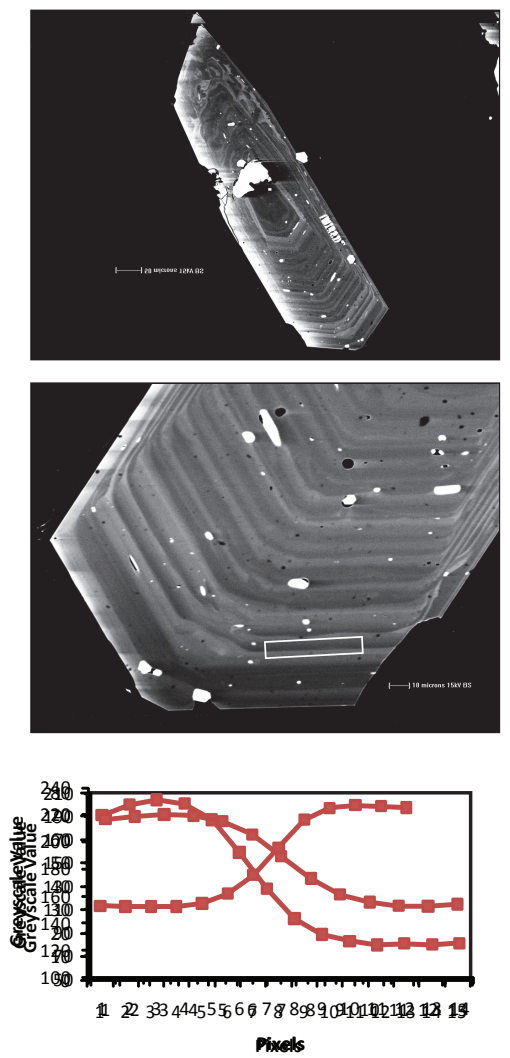


\section{Inglewood a-Inner zones}

cpx74a1
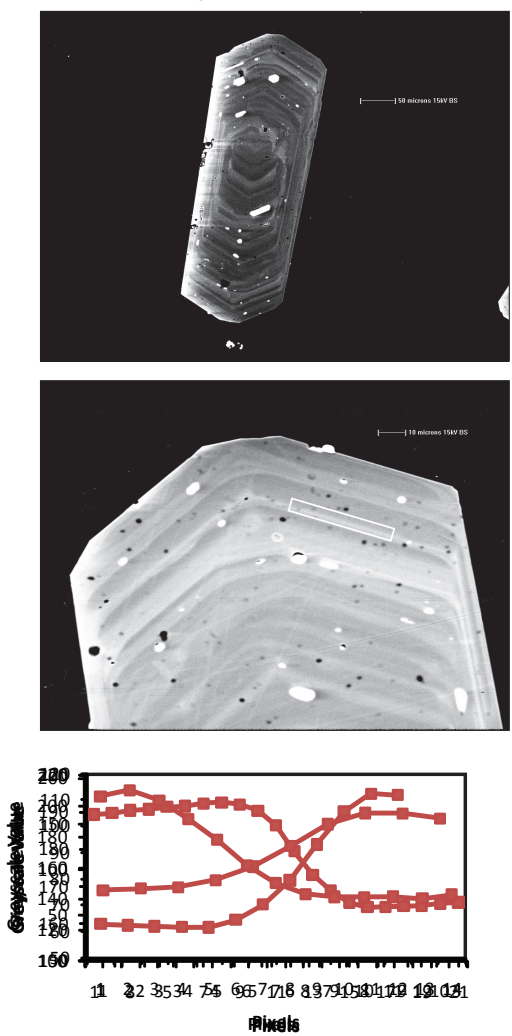

cpx112a2
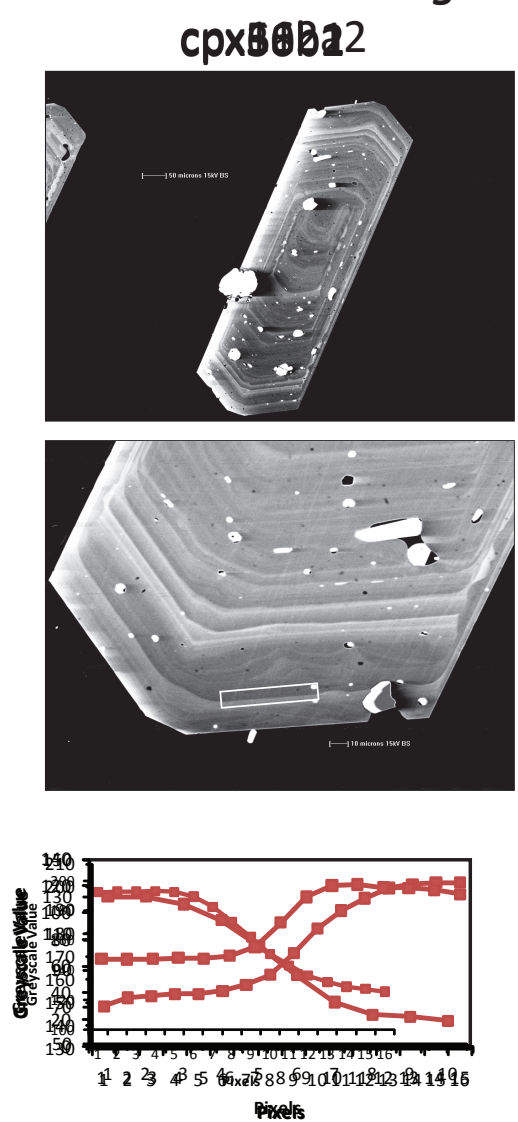

cpx111a1
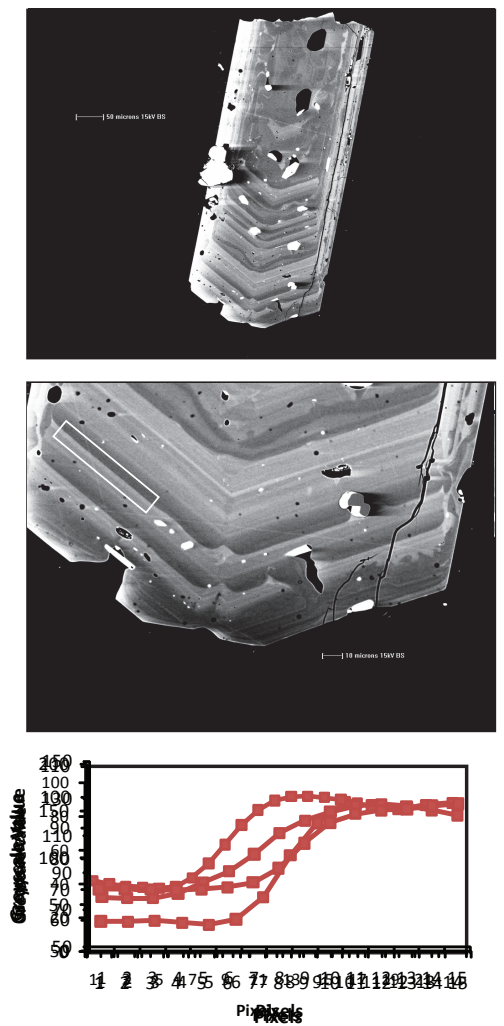
Korito-Rims

cpx4b3
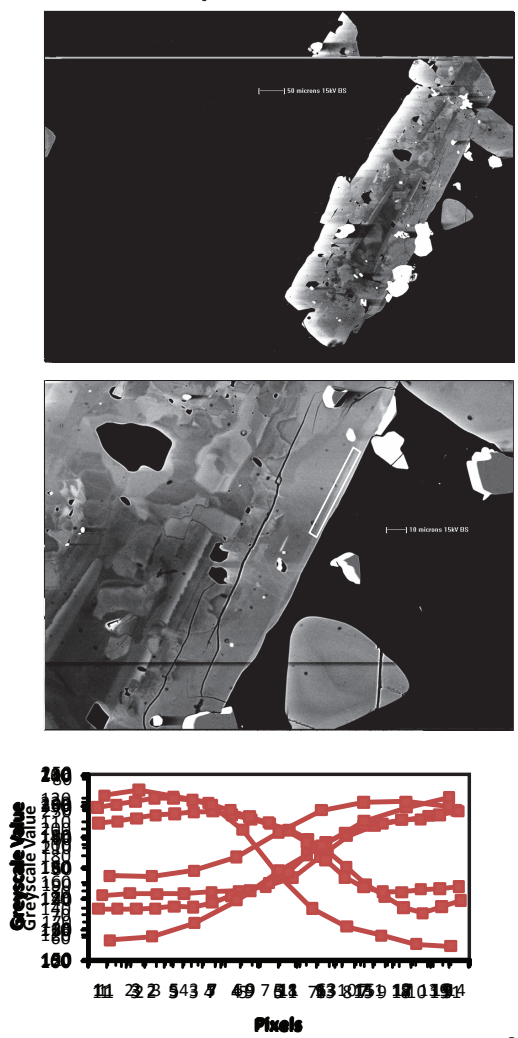

cpx18b1
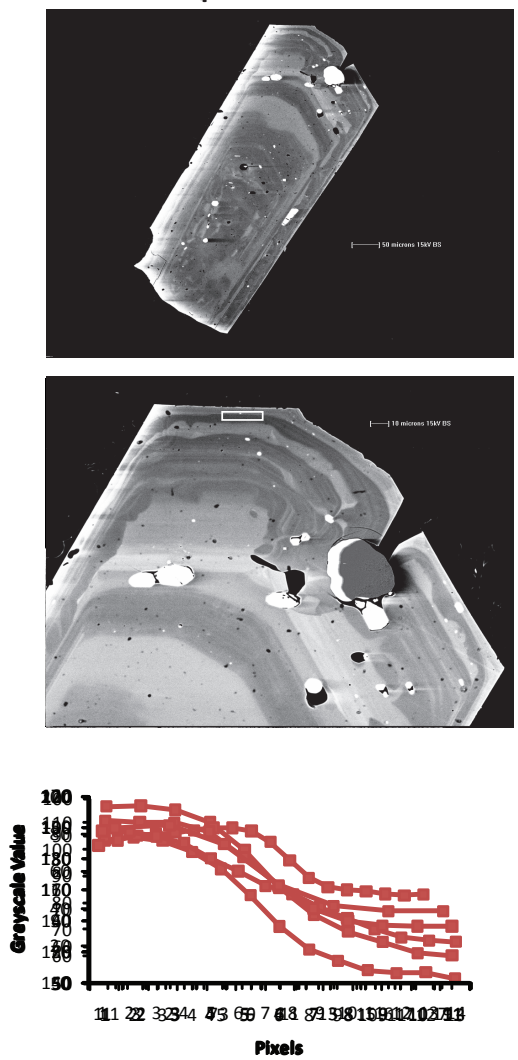

cpx12a1
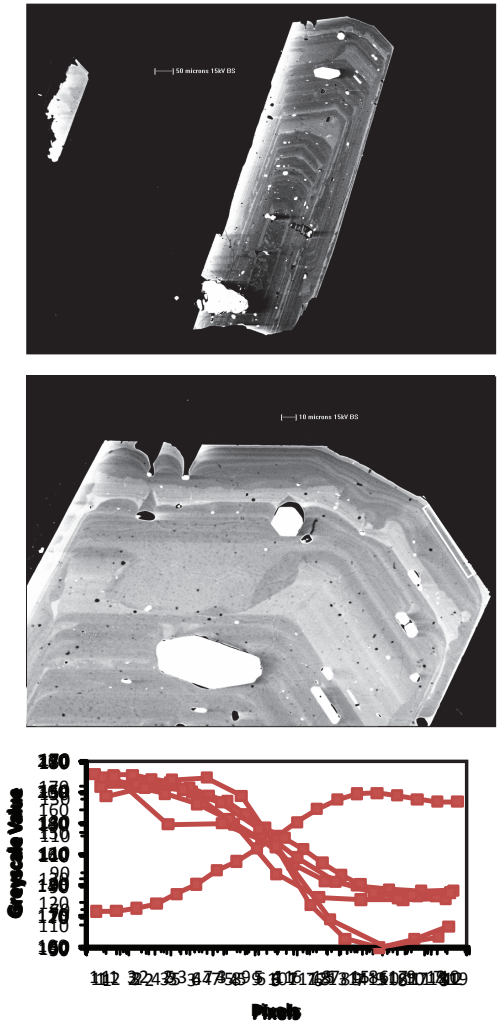

сpx19a1
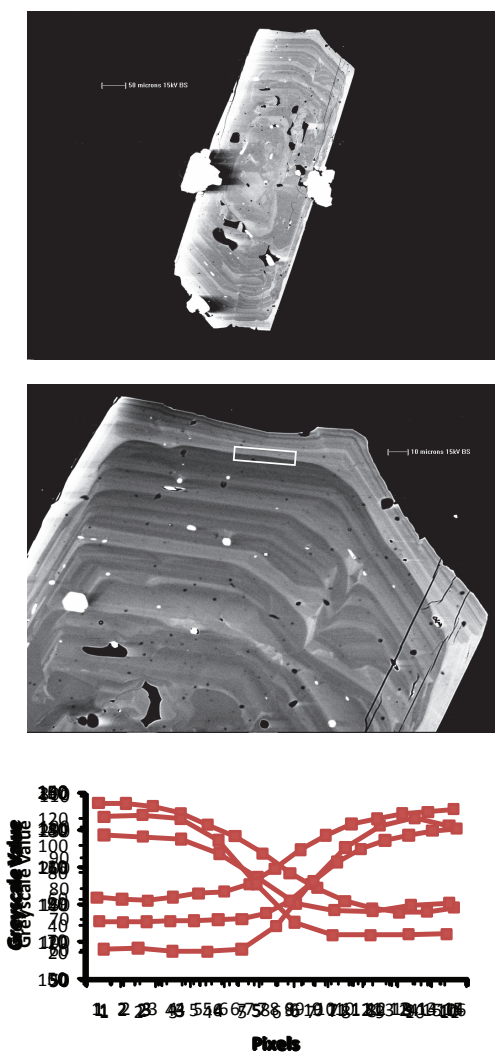


\section{Korito-Rims}
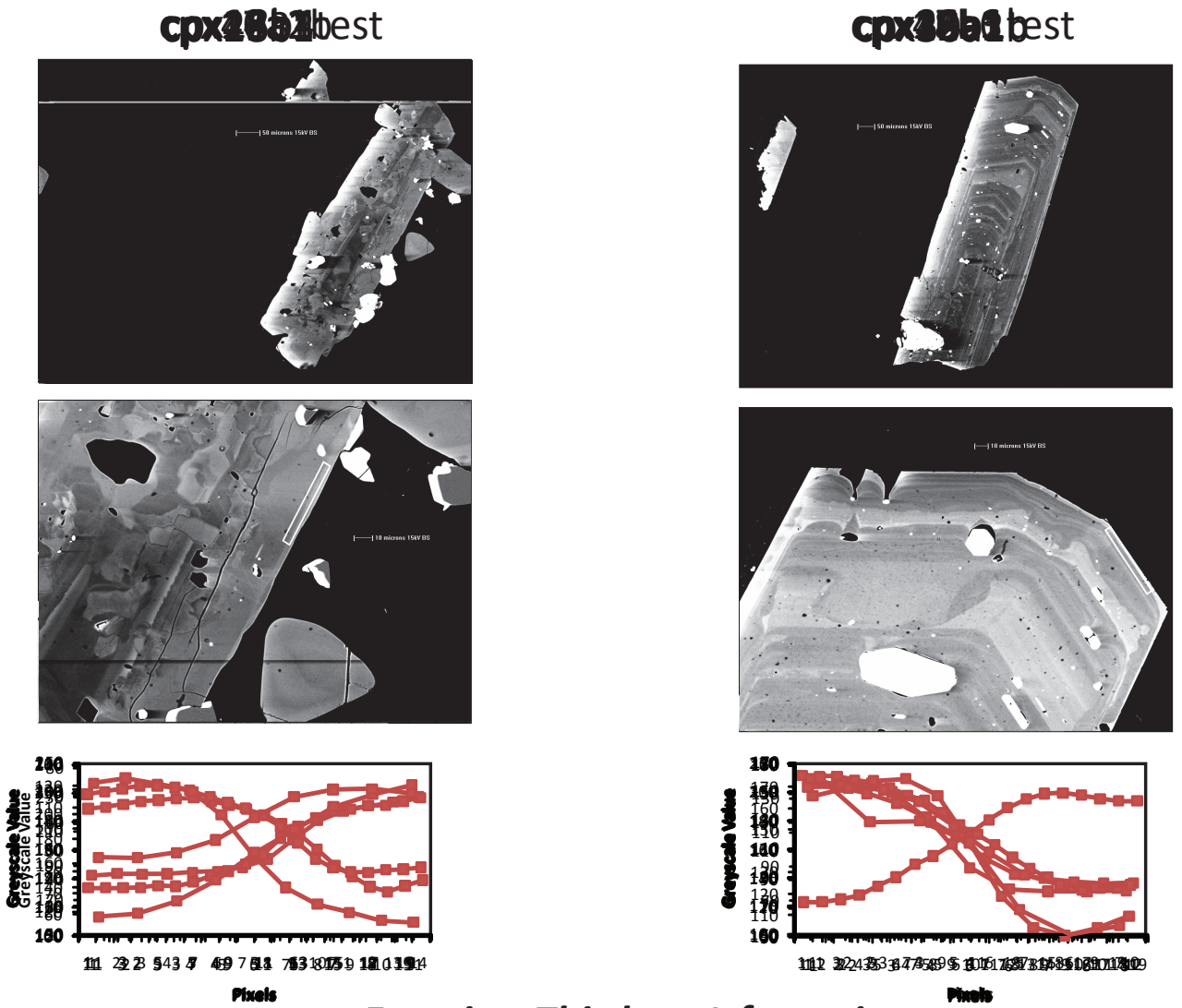

cpx38b1

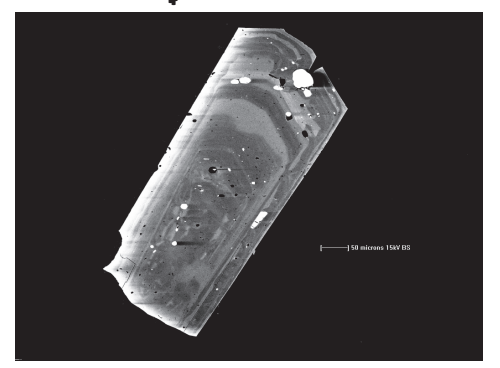

cpx39b1
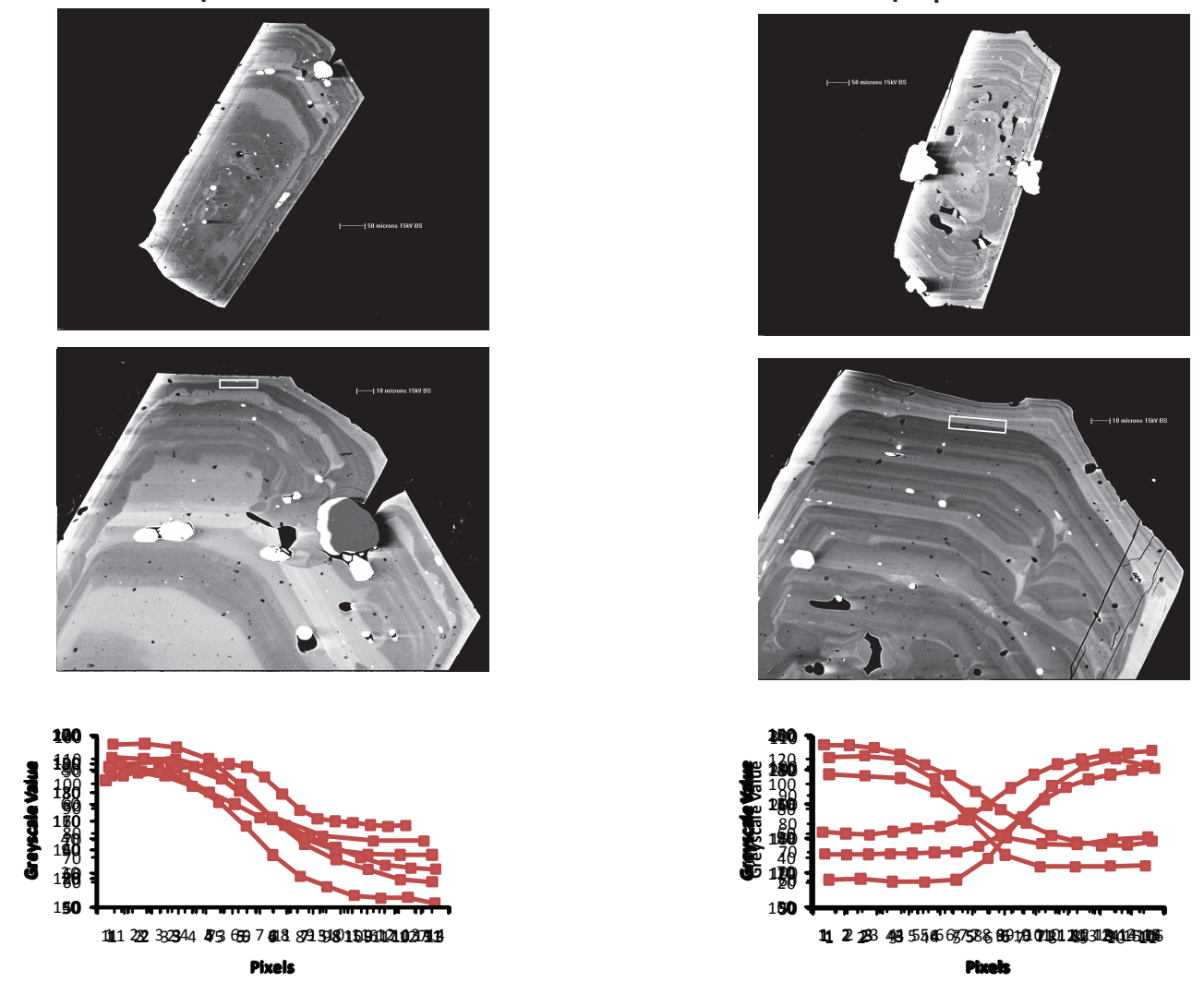


\section{Korito-Rims}

срx44a1
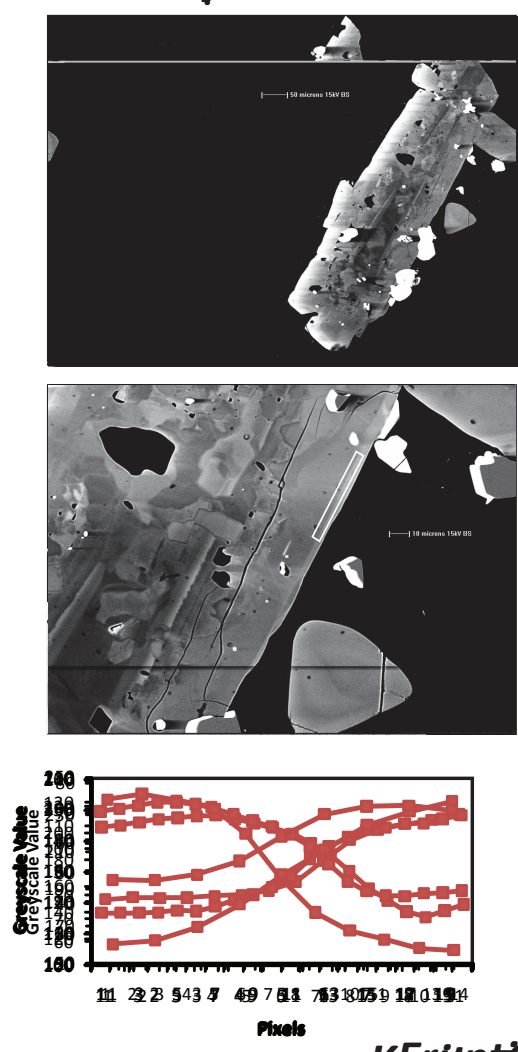

Korito-Second zone from rim cpx46a1
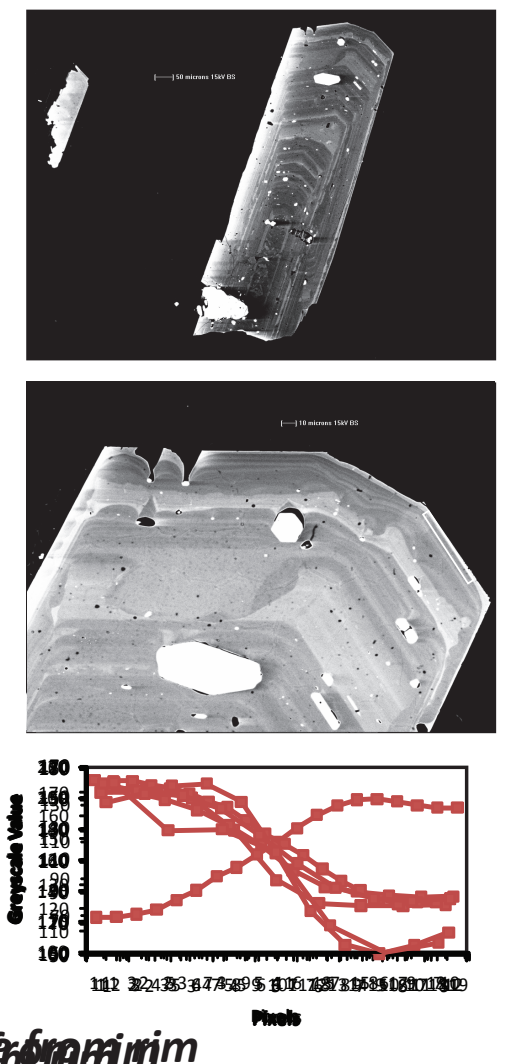

сpx14a1
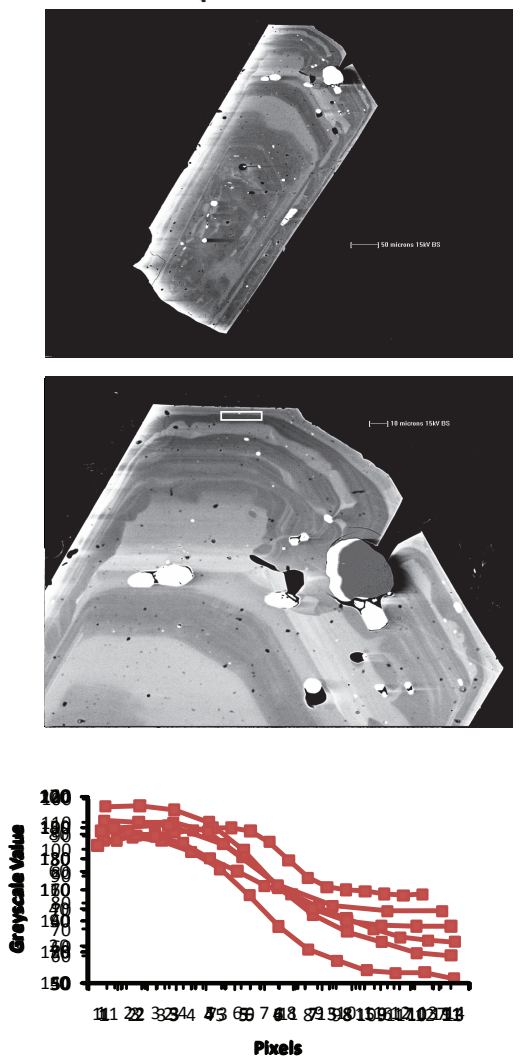
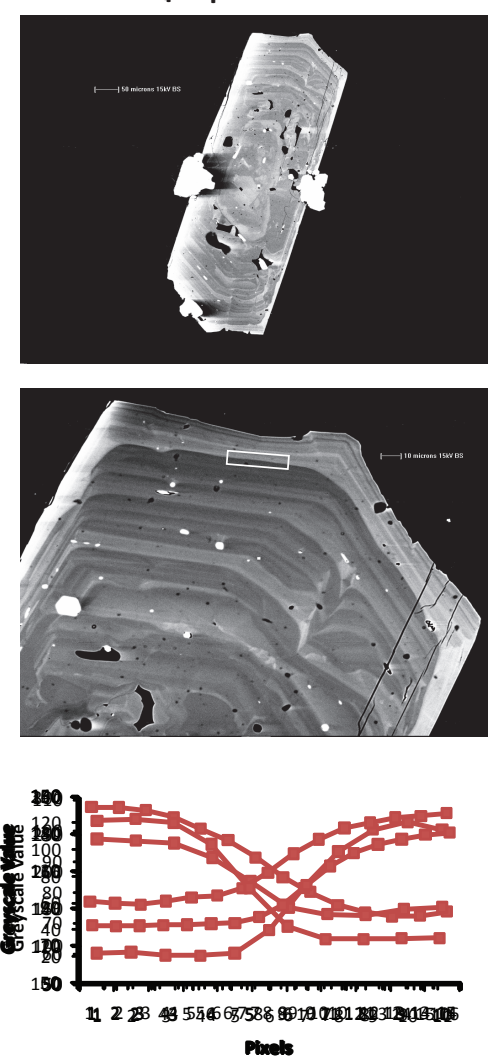


\section{Korito-Second zone from rim}
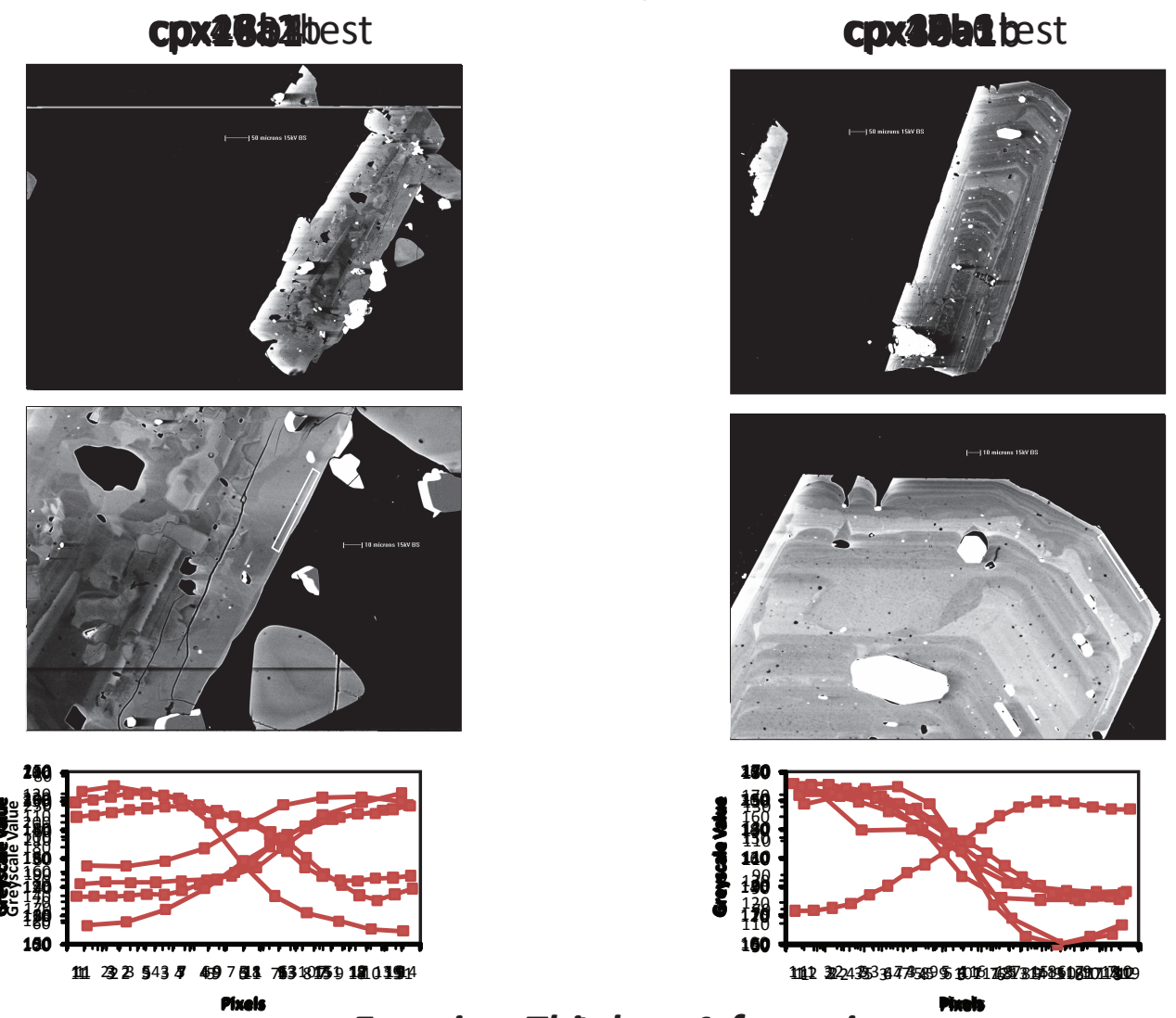

\section{Korito-Thrid zone from rim}

cpx7b1
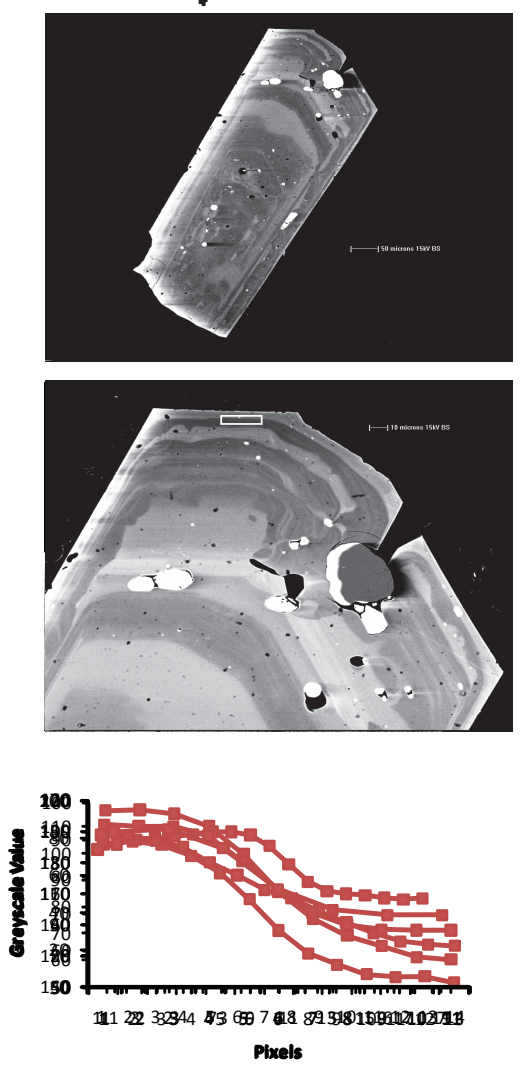

срх9a1
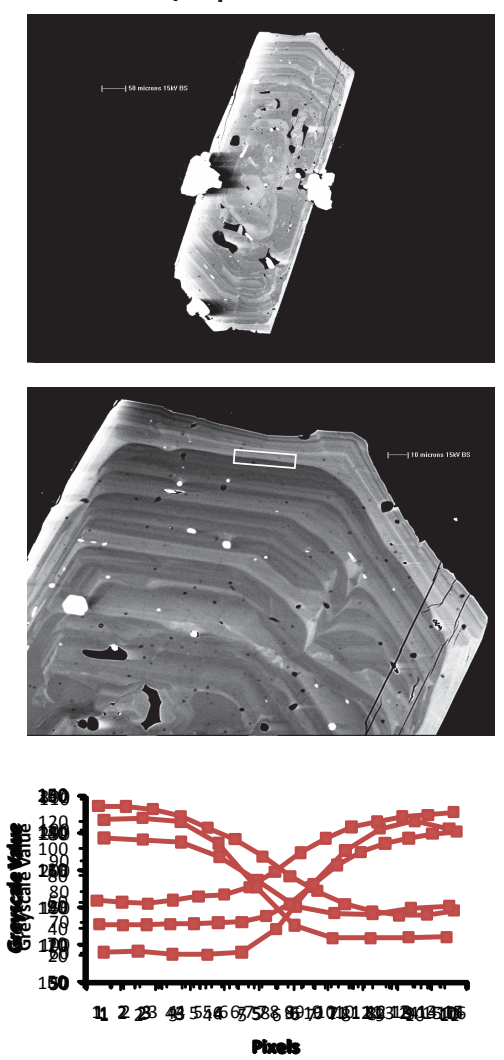


\section{Korito-Third zone from rim}
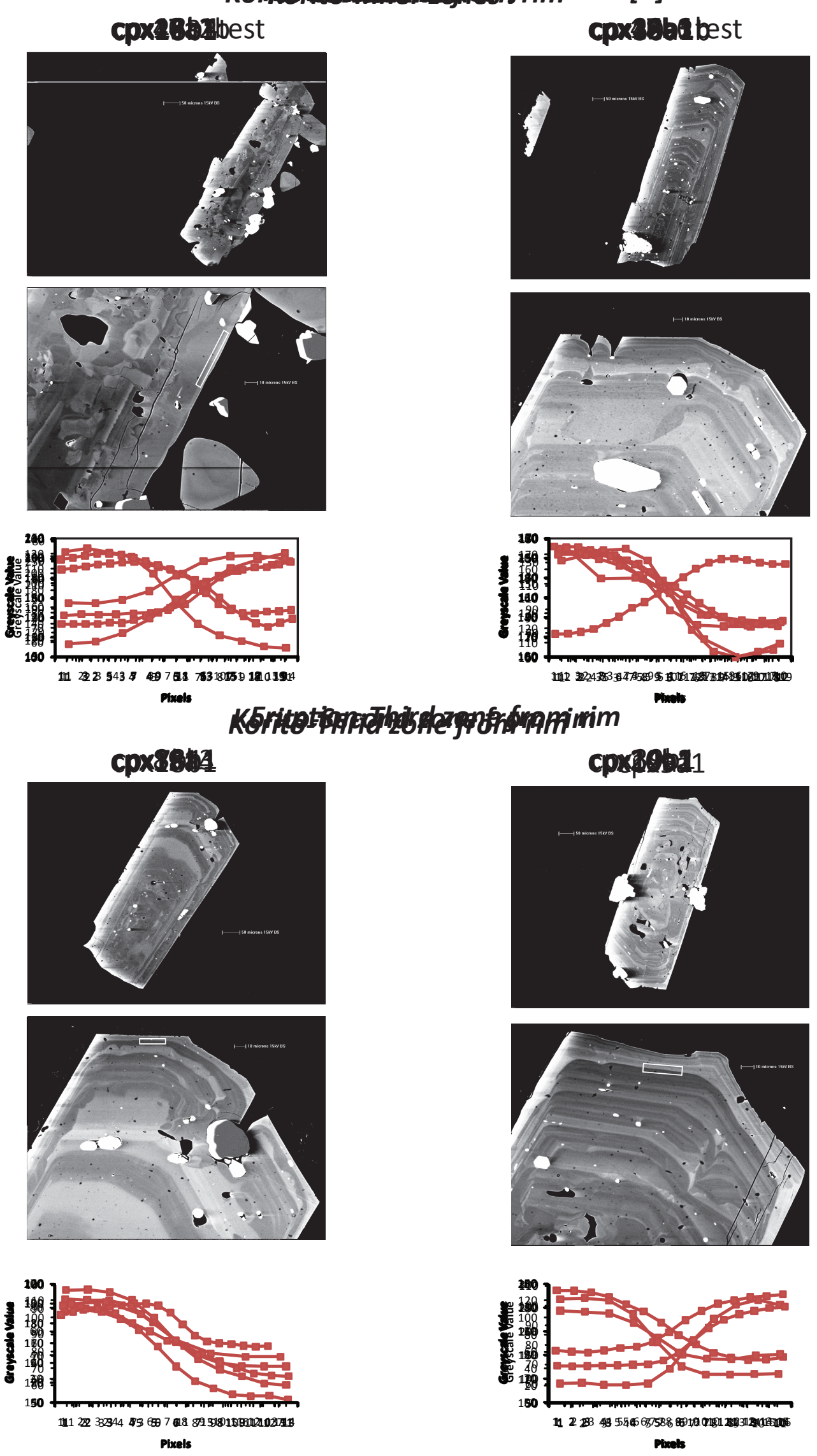


\section{Korito-Inner zones}

cpx10a1
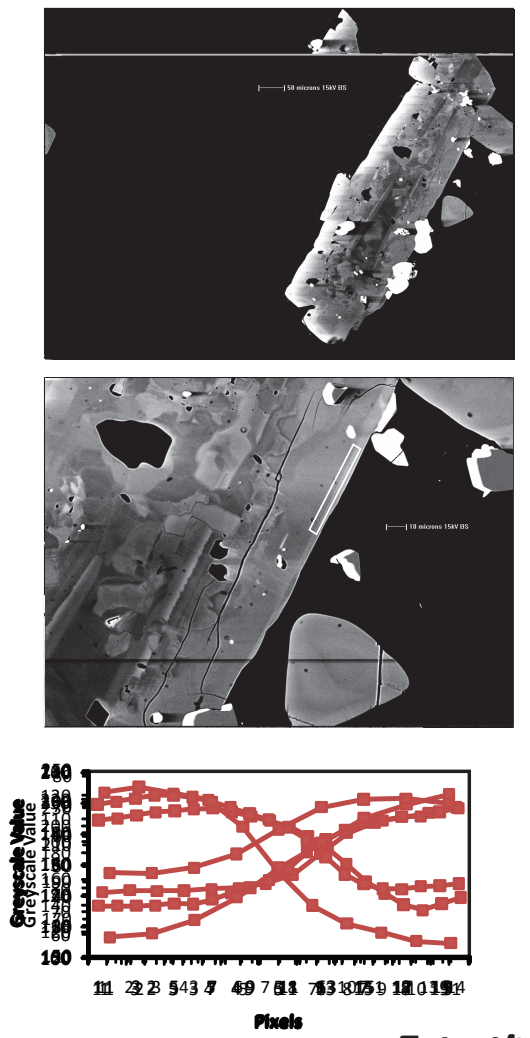

срx19a3
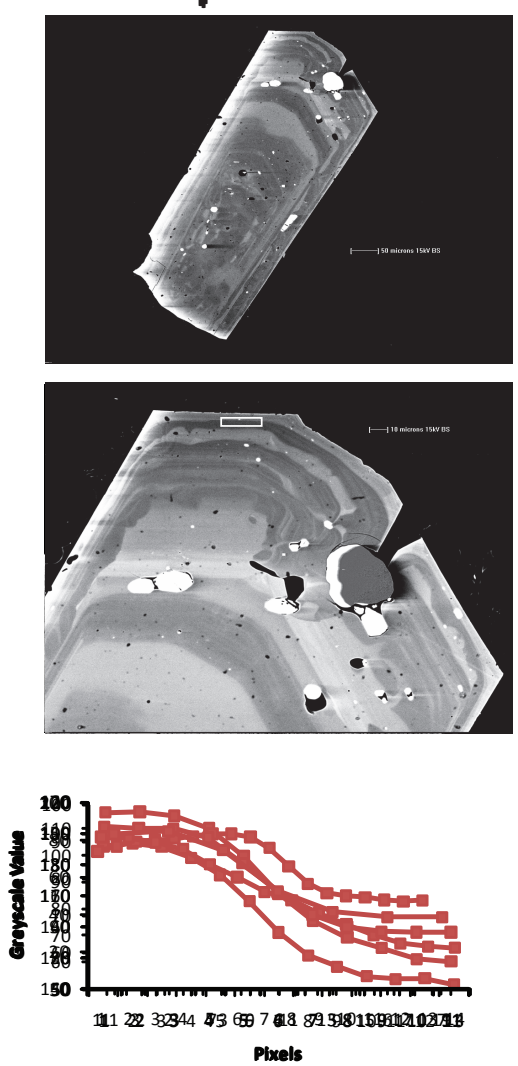

cpx17a6
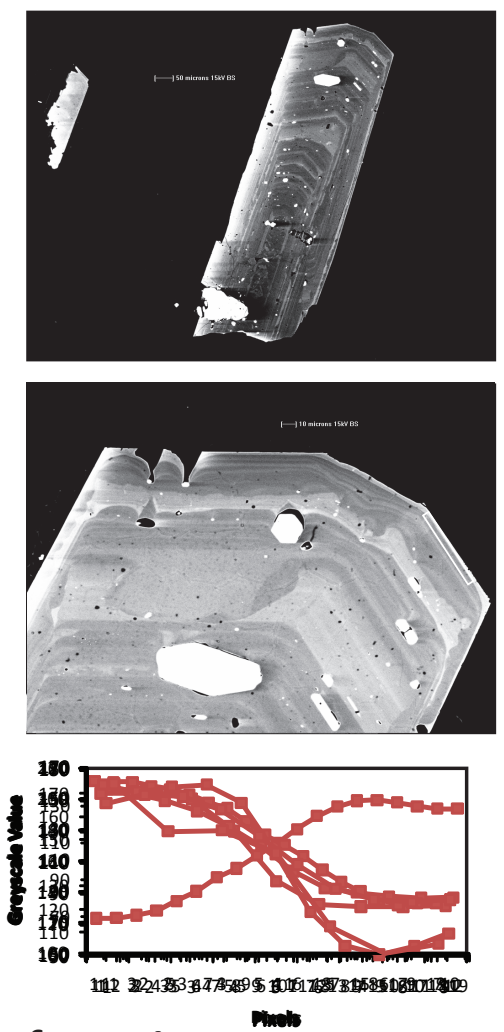

cpx20b2
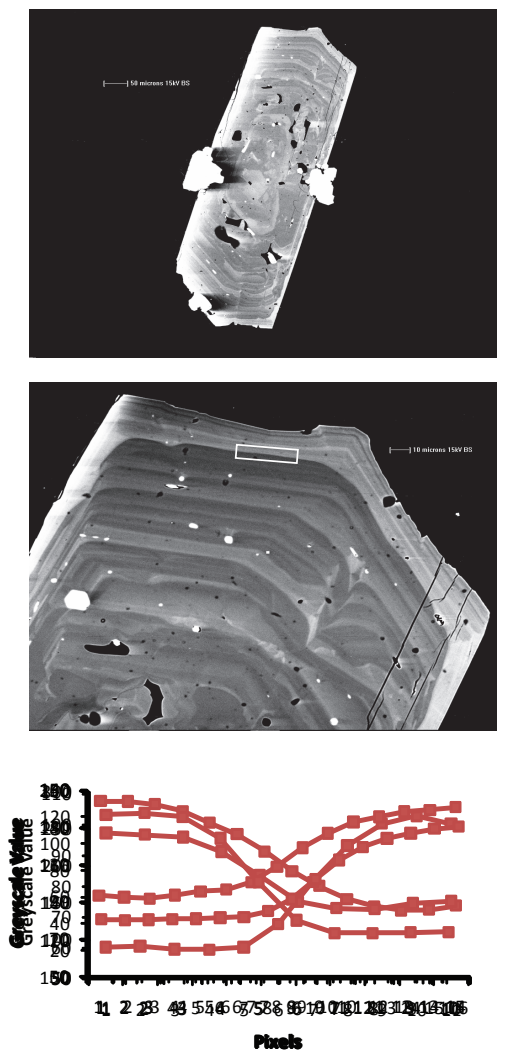


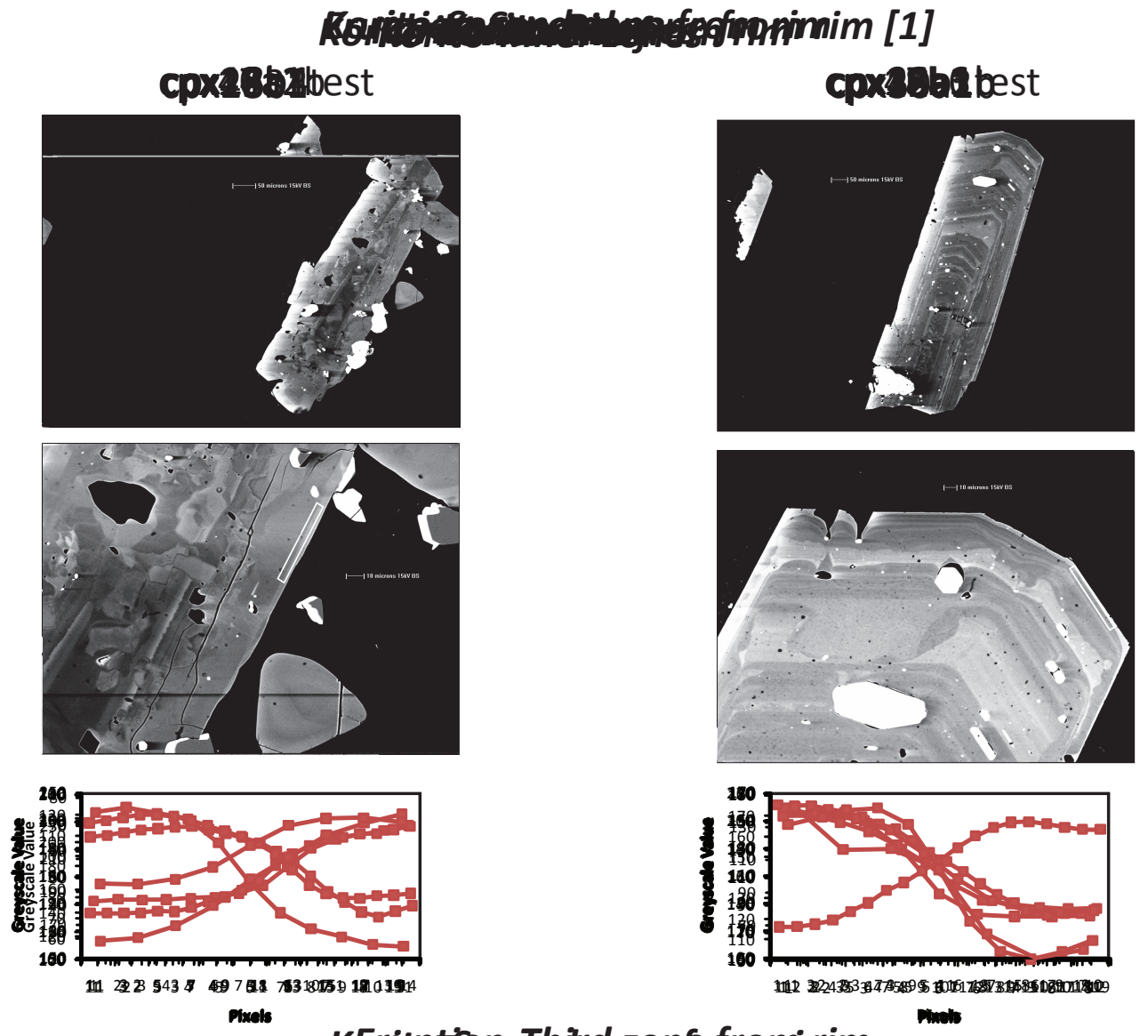

